Recht der Informationsgesellschaft

Günter Barth

\title{
Der Kampf um die Werbung im Internet
}

Online-Werbung, ihre Blockade und Schutzmaßnahmen vor Werbeblockade auf dem Prüfstand des Lauterkeits- und Urheberrechts mit Bezügen zum Datenschutz- und Kartellrecht 
Recht der Informationsgesellschaft

herausgegeben von

Prof. Dr. Jörg Fritzsche, Universität Regensburg, Lehrstuhl für Bürgerliches Recht, Handels- und Wirtschaftsrecht Prof. Dr. Jürgen Kühling, LL.M., Universität Regensburg, Lehrstuhl für Öffentliches Recht, Immobilienrecht, Infrastrukturrecht und Informationsrecht

Prof. Dr. Gerrit Manssen, Universität Regensburg, Lehrstuhl für Öffentliches Recht, insbesondere deutsches und europäisches Verwaltungsrecht

Prof. Dr. Robert Uerpmann-Wittzack, Maître en droit, Universität Regensburg, Lehrstuhl für Öffentliches Recht und Völkerrecht

Band 46 
Günter Barth

\section{Der Kampf um die Werbung im Internet}

Online-Werbung, ihre Blockade und Schutzmaßnahmen vor Werbeblockade auf dem Prüfstand des Lauterkeits- und Urheberrechts mit Bezügen zum Datenschutz- und Kartellrecht 
Die Deutsche Nationalbibliothek verzeichnet diese Publikation in der Deutschen Nationalbibliografie; detaillierte bibliografische Daten sind im Internet über http://dnb.d-nb.de abrufbar.

Zugl.: Regensburg, Univ., Diss., 2020

\section{Auflage 2020 \\ (c) Günter Barth}

Die Bände 1 bis 33 sind im Lit-Verlag erschienen.

Publiziert von

Nomos Verlagsgesellschaft mbH \& Co. KG

Waldseestraße 3-5| 76530 Baden-Baden

www.nomos.de

Gesamtherstellung:

Nomos Verlagsgesellschaft mbH \& Co. KG

Waldseestraße 3-5 | 76530 Baden-Baden

ISBN (Print): 978-3-8487-6750-2

ISBN (ePDF): 978-3-7489-0822-7

DOI: https://doi.org/10.5771/9783748908227

Onlineversion

Nomos elibrary

\section{(c) (1)}

Dieses Werk ist lizensiert unter einer Creative Commons Namensnennung 4.0 International Lizenz. 


\section{Danksagung}

An dieser Stelle möchte ich mich bei allen Menschen bedanken, die mich bei der Anfertigung der Arbeit und auf dem Weg bis zur Promotion begleitet und unterstützt haben.

Mein besonderer Dank gilt Herrn Prof. Dr. Jörg Fritzsche für die hervorragende Betreuung und die Anfertigung des Erstgutachtens. Nicht nur, dass Prof. Fritzsche trotz der Anfertigung der Arbeit durch mich als externer Promovend immer auf meine E-Mails und Anfragen freundlich und ausführlich antwortete, er tat dies auch immer in einer unvergleichbar kurzen Zeit. Ich danke auch für die angenehme Zusammenarbeit bei gemeinsamen Veröffentlichungsprojekten neben dieser Dissertation.

Außerdem gilt mein hervorgehobener Dank Herrn Prof. Dr. Christian Alexander für die außerordentlich zügige Erstellung des Zweitgutachtens. Ich kann mich glücklich schätzen, dass mit Prof. Alexander und Prof. Fritzsche zwei sehr versierte Experten im Themenfeld der Internetwerbeblocker die Begutachtung meiner Arbeit übernommen haben.

Danken möchte ich außerdem der Johanna und Fritz Buch Gedächtnisstiftung für die Gewährung eines großzügigen Druckkostenzuschusses für die Veröffentlichung dieser Arbeit.

Zur größten Dankbarkeit verpflichtet bin ich meiner Ehefrau Julia, die mich immer unterstützt hat und viel zu oft dulden musste, dass neben der Arbeit auch die Anfertigung der Dissertation unsere wertvolle Zeit zu zweit verringert hat. Ohne dich wäre diese Arbeit nicht möglich gewesen.

Ich danke auch herzlich meinen Eltern, die entgegen der Familientradition meine Schulbildung über die frühzeitige Mitarbeit im eigenen Familienbetrieb stellten und somit den Grundstein legten, damit ich studieren und sodann das Promotionsverfahren angehen konnte. Ich danke euch, dass ihr meine Fähigkeiten und Talente immer respektiert und gefördert habt, auch wenn ihr dafür viele eigene Opfer bringen musstet.

Abschließend danke ich Frau Rechtsanwältin Karin Herbert, die mir bereits im Studium die Gelegenheit gegeben hat, juristische Arbeit aus der praktischen Perspektive zu erleben. Ich danke auch dem Team bei CMS Hasche Sigle in Köln um Frau Dr. Heike Blank, Herrn Dr. Pietro Graf Fringuelli und Herrn Dr. Alexander von Bossel, bei dem ich während meines gesamten Referendariats als wissenschaftlicher Mitarbeit nicht nur das Rechtsgebiet des Gewerblichen Rechtsschutzes schätzen lernte, sondern 


\section{Danksagung}

auch die Inspiration für diese Arbeit erlangte. Ich danke zuletzt Frau Dr. Claudia Milbradt und ihrem Team bei Clifford Chance Deutschland in Düsseldorf, die mir den Berufseinstieg als Rechtsanwalt und zugleich die Anfertigung dieser Arbeit ermöglichten. 


\section{Vorwort}

Der Streit um Internetwerbeblocker polarisiert seit mehr als einem halben Jahrzehnt. Der BGH setzte im Jahr 2018 einen vorläufigen Schlusspunkt in einem mehraktigen Justizkrimi. Diese Bearbeitung verfolgt das Ziel, die Entwicklung der Bewertung des Themas Werbeblocker in der juristischen Literatur und der Rechtsprechung nachvollziehbar darzustellen. Auf diese Weise soll das Stück Rechtsgeschichte, zu dem die Rechtsstreitigkeiten zu Internetwerbeblockern in Deutschland zweifelsohne geworden sind, sorgfältig aufgearbeitet und dargestellt werden. Damit mag sich jeder Interessierte in einem einheitlichen Werk über den ausführlichen Streitstand und die Vielzahl von Urteilen verschiedener Gerichte informieren. Doch dies ist nicht der einzige Schwerpunkt dieser Arbeit.

Denn Werbung im Internet ist allgegenwärtig und dynamisch. Sie ist ein erheblicher Wirtschaftsfaktor in Deutschland und auf der gesamten Welt. Dieser wirtschaftlichen Bedeutung wird allerdings die rechtliche Behandlung des Themas nicht gerecht. Es sind nur wenige ausführliche Auseinandersetzungen mit der Zulässigkeit von Werbung im Internet vorhanden. Dieses Werk soll auf der dem Werbeblocken vorgelagerten Stufe zunächst eine ausführliche Darstellung der Sach- und Rechtslage enthalten. Nur auf dieser Grundlage ist eine zutreffende Bewältigung der Blockerproblematik möglich. Werbeblocker sind nur ein Kapitel im Buch der Online Werbung. Deshalb ist es wichtig auch die Einführung zu verstehen. Niemand kann ein Buch in der Mitte beginnen und behaupten, die Handlung voll und ganz zu verstehen.

Deshalb soll auch das Thema Tracking und Targeting nicht ausgespart werden, das eine extrem wichtige Bedeutung für die Internetwerbung einerseits und für die Privatsphäre von Nutzern andererseits hat. Ohne diese Themen kann eine Bewertung der Rechtslage zu Werbung im Internet nicht umfassend sein. Interessant ist dabei, dass der mit Werbefragen verbundene lauterkeitsrechtliche Fokus einem datenschutzrechtlichen Schwerpunkt weicht. Werbung im Internet muss insofern mit Blick auf Rechtsgebiete interdisziplinär bewältigt werden.

Außerdem sind Werbeblocker nur eine Zwischenstation im Kontext der Internetwerbung. Angesichts des enormen Entwicklungstempos von internetbasierten Technologien wird es mit Sicherheit bald neue Streitthemen geben. Deshalb soll die Problematik auch unter der Prämisse untersucht 
werden, inwiefern Geschäftsmodelle im Internet von den WerbeblockerEntscheidungen zukünftig beeinflusst werden. Die Beurteilung der innovativ finanzierten Werbeblocker kann dabei Signalwirkung für die Zukunft haben. Die Frage ist schließlich: Wer kann wie im Netz Geld verdienen? Und ab wann überschreitet man die Grenzen des Zulässigen?

Zuletzt ist interessant, welche Reaktionen den etablierten Unternehmen zur Verfügung stehen. Die vom Werbeblocken betroffenen Webseitenbetreiber wehren sich gegen Werbeblocker - und zwar nicht nur vor Gericht. Hier sind Reaktionen und Gegenreaktionen darzustellen und zu würdigen. Ein Thema, das im Schatten der Frage der Zulässigkeit des Werbeblockens weniger Beachtung gefunden hat.

Nach Ablegung der mündlichen Prüfung am 29.5.2020 wurde die Arbeit angesichts neuer berücksichtigungsfähiger Rechtsprechung angepasst. Stichtag für die Berücksichtigung war der 30.6.2020. 


\section{Inhaltsverzeichnis}

A. Einführung in den Problembereich 23

I. Deutschland, 19. April 2018

II. Internetwerbeblocker - ein Geschäftsmodell vor Gericht 23

III. Zugangssperren für Werbeblockernutzer 26

IV. Whitelisting 29

V. Rechtlicher Prüfungsmaßstab betreffend Werbeblocken und Whitelisting 30

1. UWG 31

2. Urheberrecht 33

3. Kartellrecht 35

VI. Rechtlicher Prüfungsmaßstab betreffend Zugangssperren oder sonstigen Reaktionen $\quad 36$

VII. Rechtlicher Prüfungsmaßstab betreffend Gegenmaßnahmen der Blockeranbieter auf Zugangssperren und Umgehungsmaßnahmen $\quad 37$

VIII.Ziel und Ablauf der Untersuchung 38

B. Grundlage: Werbung im Internet 40

I. Arten von internetbasierter Werbung 42

1. Begriff der Werbung 42

2. Systematik der Werbeformen 44

3. Darstellung der maßgeblichen Werbeformen 46

a) Werbeformen bei PCs 47

aa) E-Mail Werbung 47

bb) Werbung auf Webseiten 48

(i) Klassische Anzeigen $\quad 50$

(ii) Pop-Ups und Layer Ads 57

(iii) Interstitial und Prestitials 58 
(iv) In-Text 59

(v) Video- und Audiowerbung im Stream 61

(vi) Werbender Content 62

(vii) Sonderfall: Suchmaschinenmarketing 63

(viii)Sonderfall: Soziale Netzwerke, v.a. Facebook 66

(ix) Fazit: Klassifizierung der browserbasierten Internetwerbung

cc) Werbung in sonstigen Programmen auf PCs 71

dd) Maßgeblichkeit im Zusammenhang mit Internetwerbeblockern

b) Werbeformen bei mobilen Geräten $\quad 74$

aa) In-App-Werbung 75

bb) Browserbasierte mobile Werbung 79

c) Werbeformen bei Smart TVs 80

d) Werbeformen bei Smart Home Geräten 82

e) Werbung im Internet of Things? 83

4. Methoden der Internetwerbung 84

a) Targeting 85

aa) Technik-Targeting $\quad 86$

bb) Geo-Targeting $\quad 87$

cc) Semantisches Targeting $\quad 87$

dd) Keyword-Targeting $\quad 88$

ee) Kontext-Targeting 88

ff) Soziales Targeting $\quad 89$

gg) Verhalten-Targeting 90

hh) Fazit 91

b) Native Advertising 91

c) Guerilla Marketing 96

d) Influencer-Marketing 96

II. Wirtschaftliche Bedeutung 98

III. Technische Ausgestaltung 104

1. Eine kleine Einführung in die Technik des Internets $\quad 105$

a) Infrastruktur des Internets 105

b) Datenübertragungstechnik 107

aa) Internet Protokoll (IP) 107

bb) Transportschichtprotokolle 108

cc) Darstellungs- bzw. Anwendungsschichtprotokolle 110

2. Webbrowser und Webseiten 114

a) Arbeitsweise des Browsers 114 
b) Programmierelemente von Webseiten

3. Abgrenzung des Internets von anderen Medien 119

4. Online-Werbung Spezifika 120

a) Adserver 120

b) Tracking 123

aa) URL-Tracking 124

bb) Cookie-Tracking 124

cc) Pixel-Tracking 126

dd) Tracking Skripte 126

ee) Session-Tracking 127

ff) Fingerprint-Tracking 128

gg) Datenbank-Tracking 128

hh) Fazit 129

IV. Rechtliche Beurteilung ausgewählter Aspekte 130

1. Gesetzliche Grenzen der Display-Werbung 131

a) Zulässigkeit der Auslieferung von Display-

Werbeanzeigen beim Nutzer 133

aa) Hartnäckige Ansprache, $\mathbb{} 7$ Abs. 2 Nr. 1 UWG 134

bb) Werbung mit einer Nachricht, $\$ 7$ Abs. 2 Nr. 4 UWG

cc) Generalklausel, $\$ 7$ Abs. 1 UWG 139

(i) Fixierte Anzeigen 140

(ii) Dynamische Anzeigen, Pop-Ups \& Co. 141

(1) Ergangene Rechtsprechung 144

(2) Meinungsstand in der Literatur $\quad 146$

(3) Stellungnahme 150

(a) Anzeigen, die aktiv geschlossen werden müssen $\quad 150$

(aa) Gültige

Differenzierungskriterien $\quad 152$

(bb) Ungültige Kriterien $\quad 160$

(b) Sich automatisch schließende

Werbeformen

(aa) Keine Möglichkeit vorzeitiger Beseitigung 164

(bb) Vorzeitige Schließmöglichkeit 165

(c) Pop-Under Werbung 166

(d) Einsatz auf mobilen Endgeräten $\quad 169$

(e) Möglichkeit der Einwilligung durch Nutzer 
(4) Sonderfall: Schließen-Buttons 178

(5) Zusammenfassung 183

(iii) Interstitials und Prestitials 184

(1) Ergangene Rechtsprechung 185

(2) Meinungsstand in der Literatur $\quad 186$

(3) Stellungnahme 188

(iv) Animierte und interaktive Anzeigen 192

(v) Nicht lineare In-Stream Werbung 193

(vi) Suchmaschinenmarketing 194

(vii) Soziale Netzwerke 194

(viii)Fazit: Allgemeine Regeln 198

b) Zulässige Ausgestaltung von Werbeanzeigen 199

aa) Trennungsgebot 199

bb) Irreführungsverbot und Kennzeichnungspflichten 201

2. Zulässigkeit von Tracking und Targeting 201

a) Datenschutzrechtliche Zulässigkeit von Tracking 202

aa) Cookie-Tracking 203

(i) Zulässigkeit nach der E-Privacy-Verordnung (Entwurf) 203

(ii) Zulässigkeit nach der DSGVO 206

bb) Tracking Skripte 208

cc) Fingerprint und Session-Tracking 209

dd) Zulässigkeit der Verbindung von Werbung und

Trackingmethoden 210

ee) Übersicht zum Tracking 212

b) Datenschutzrechtliche Zulässigkeit von Targeting 213

aa) Ein Fall der E-Privacy-Verordnung (Entwurf)? 213

bb) Beurteilung nach DSGVO 215

(i) Techniktargeting 215

(ii) Geotargeting 217

(iii) Semantisches bzw. Keyword Targeting und

Kontext-Targeting 219

(iv) Verhalten-Targeting 219

(1) Meinungsstand in der Literatur 221

(2) Stellungnahme 222

(v) Soziales Targeting 226

(vi) Zusammenfassung zum Targeting 227 
c) Lauterkeitsrechtliche Aspekte von Tracking und Targeting

aa) Rechtsbruch, $\$ 3$ a UWG

(i) Art. 6 DSGVO = Marktverhaltensregelung?

(ii) Art. 8 E-Privacy-Verordnung (Entwurf) = Marktverhaltensregelung?

(iii) Die übrigen Voraussetzungen von $\$ 3$ a UWG

cc) Vergleichende Werbung, \$6 UWG

3. Probleme des modernen Online-Marketing

a) Zulässigkeit des Native Advertising

b) Zulässigkeit von Guerilla-Marketing

c) Zulässigkeit von Influencer-Marketing

V. Zusammenfassende Thesen zum Werbemarkt

C. Aktion: Werbeblocker \& ähnlich invasive Geschäftsmodelle

I. Internetwerbeblocker

1. Geschichte des Werbeblockens

a) Briefkastenwerbung und „Keine Werbung"-Aufkleber

b) TV-Werbung und die „Fernsehfee"

c) Aktuelle Entwicklungen des Werbeblockens außerhalb des Internets

d) Situation bei E-Mail Werbung

e) Erfindung und Lehrjahre der Internetwerbeblocker

f) Die Kommerzialisierung der Adblocker

g) Wie du mir, so ich dir - oder das Wettrüsten 270

h) Letzte Entwicklungen

i) Fazit

2. Wirtschaftliche und technische Hintergründe 275

a) Reine Blacklist-Blocker 276

aa) Technische Grundlagen 276

bb) Wirtschaftliche Bedeutung 280

b) Whitelisting-Blocker 282

aa) Technische Funktionsweise 283

bb) Wirtschaftliche Bedeutung 285

(i) Die Acceptable Ads Initiative von Eyeo 286

(ii) Die „Coalition for Better Ads“ von Google 293

(iii) Stellungnahme zum wirtschaftlichen

Hintergrund des Whitelistings 
(iv) Exkurs: Vergleich der Verbotskataloge mit dem in dieser Arbeit gefundenen Ergebnis zur unzumutbaren Belästigung von Werbeformen

c) Browser mit integrierten Adblockern

d) Software und Einstellungen mit (beiläufiger) Blockierfunktion

e) Abweichende Formen von Internetwerbeblockern $\quad 307$

3. Rechtliche Beurteilung in Rechtsprechung und Literatur

a) Erste Bewertungen in der Literatur

aa) Ausblicke nach der Fernsehfee-Entscheidung des BGH

bb) Lauterkeitsrechtliche Beurteilung durch Hoeren

cc) Lauterkeits- und kartellrechtliche Beurteilung durch Köhler

dd) Lauterkeitsrechtliche Beurteilung durch Herrmann und Lauotoumai

b) Rechtsprechung und Literatur bis zum Urteil des OLG Köln

aa) Erstinstanzliche Entscheidungen

bb) Abzuwägende Interessen der Beteiligten, Betroffenen und der Allgemeinheit

cc) Beiträge in der Literatur

c) Das Urteil des OLG Köln in Sachen Axel Springer./. Eyeo wegen Adblock Plus (inklusive Zwangsvollstreckungsverfahren)

d) Rezeption des Kölner Urteils in der Literatur

e) Instanzrechtsprechung nach dem Urteil des OLG Köln

f) Echo der neueren OLG-Urteile im Schrifttum

g) Dissertationen zum Thema Werbeblocker im Internet

h) Entscheidung des I. Zivilsenats des BGH in Sachen Axel Springer./. Eyeo wegen Adblock Plus

i) Urteile des Kartellsenats des BGH

j) Fazit: Welche Fälle werden aktuell erfasst, welche nicht? 
4. Rechtliche Analyse und Stellungnahme zur Rechtsprechung

a) Stellungnahme zur Rechtslage

aa) Lauterkeitsrecht (einschließlich allgemeines Zivilrecht)

(i) Vorliegen einer geschäftlichen Handlung

(ii) Gezielte individuelle Behinderung eines Mitbewerbers, $₫ 4$ Nr. 4 UWG

(1) Vorliegen eines konkreten

Wettbewerbsverhältnisses

(2) Behinderung

(3) Gezieltheit

(a) Prüfungsmaßstab der Rechtsprechung

(b) Gezielte Behinderung von Webseitenbetreibern

(aa) Verdrängungsabsicht

(bb) Beeinträchtigung der Fähigkeit des Mitbewerbers, eigene Leistungen in angemessener Weise zur Geltung zu bringen

(c) Gezielte Behinderung von Werbenetzwerken

(iii) Allgemeine Marktbehinderung

(iv) Aggressive Geschäftspraktik, $\mathbb{4 a}$ UWG

(1) Festlegung der Betroffenen

(2) Anwendbarkeit von $\$ 4 a$ UWG -

Konkurrenz innerhalb des UWG und zum Kartellrecht

(a) Verhältnis zu $₫ 4$ Nr. 4

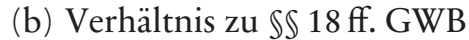

(3) Der Tatbestand des $\$ 4$ a UWG

(a) Geschäftliche Handlung

(b) Geschäftliche Relevanz

(c) Belästigung und Nötigung als Mittel als Aggressionsmittel

(d) Die unzulässige Beeinflussung als Aggressionsmittel

(aa) Machtposition 
(bb) Ausnutzung der Machtposition zur Ausübung von Druck

(cc) Wesentliche Einschränkung der Fähigkeit zu einer informierten Entscheidung

(e) Erhebliche Beeinträchtigung der Entscheidungsfreiheit als Ergebnis der Aggression

(v) Stellungnahme zum Urteil Werbeblocker II des BGH und zu divergierender Instanzrechtsprechung

(1) Konkretes Wettbewerbsverhältnis und geschäftliche Handlung

(2) Gezielte Behinderung

(3) Allgemeine Marktbehinderung

(4) Aggressive geschäftliche Handlung

(5) Verhältnis zu OLG Köln

(vi) Allgemeines Zivilrecht

(i) Schutzfähigkeit von Webseiten

(1) Computerprogramm, $\mathbb{S} 2$ Abs. 1 Nr. 1 , 69a UrhG

(2) Sammel- bzw. Datenbankwerk, $\$ 4$ UrhG

(3) Recht an einer Datenbank, $\$$ 87a UrhG

(4) Multimediawerk, $\$ 2$ UrhG

(5) Schutzrechtsfähigkeit einzelner Teile von Webseiten

(ii) Verletzungshandlungen durch Werbeblocker oder deren Nutzer

(1) Fragen der Täterschaft

(2) Umarbeitung eines

Computerprogramms, $\$ 69 \mathrm{c} \mathrm{Nr} .2$ UrhG

(3) Vervielfältigung eines Werks

(4) Verletzung eines Datenbankrechts, $\$ 87 \mathrm{~b}$ UrhG

(iii) Schranken des Urheberrechts und

Rechtfertigung

(1) Vorübergehende

Vervielfältigungshandlungen, $\mathbb{4 4 a}$ UrhG 
(2) Gesetzlich erlaubte Benutzung eines Datenbankwerkes, $\mathbb{\$} 55$ a UrhG

(3) Notwendigkeit zur bestimmungsgemäßen Benutzung, $\$ 69 \mathrm{~d}$ Nr. 1 UrhG

(4) Schlichte Einwilligung

(5) Konkludente Lizenz

(iv) Fazit

cc) Kartellrecht

dd) Zusammenfassung der Ergebnisse

(i) Lauterkeitsrecht

(ii) Urheberrecht

(iii) Kartellrecht

b) Ausblick nach dem Urteil Werbeblocker II

c) Ausblick nach dem Urteil Werbeblocker III

d) Übersicht und Bewertung von mit Werbeblockern vergleichbaren Phänomenen

e) Leitlinien für zukünftige disruptive Geschäftsmodelle im Internet

5. Beurteilung bislang nicht in der Rechtsprechung behandelter Fälle von Werbeblockern

a) Bereitstellung von Blacklists aller Art 469

b) Browser mit integriertem Werbeblocker 470

c) Sonderfall 1: Coalition for Better Ads 471

d) Sonderfall 2: Ersetzung von Werbeelementen 473

e) Werbeblockade auf Ebene der Internet Service Provider

f) Stichwortbasierte Blocker

g) Reine Trackingblocker

6. Exkurs: „Overblocking“ - Blockieren redaktioneller Drittinhalte

7. Regulierung von Werbeblockern durch den Gesetzgeber?

a) Tendenzen in der 18. Legislaturperiode (2013 bis 2017)

aa) Die Bund-Länder Kommission für Medienkonvergenz

bb) Die Kleine Anfrage der Fraktion DIE LINKE und die Antwort der Bundesregierung

cc) Fachgespräch im Ausschuss für Kultur und Medien 
dd) Antrag der NRW-Landtagsfraktion der PIRATEN und Reaktionen

b) Tendenzen in der 19. Legislaturperiode (ab 2017) 496

c) Meinungstand und Stellungnahme

II. Zwischenergebnis: Parasit oder Symbiont?

D. Reaktion: Maßnahmen zur Verhinderung von Werbeblockern

I. Darlegung von Reaktionen der Webseitenbetreiber und Werbenden

1. Adblocker-Detektoren 503

2. Zugangssperren 504

3. Eingeschränktes Angebot und Bezahlschranken 506

4. Ausspielung nicht blockierbarer Werbung 506

5. Weitere zu beobachtende oder denkbare Reaktionen $\quad 512$

6. Kategorisierung der Reaktionen 513

II. Rechtliche Beurteilung 513

1. Zulässigkeit von Zugangsblockaden zu Webseiten für Werbeblockernutzer

2. Zulässigkeit von Zwangswerbung 518

a) Unzumutbare Belästigung $\quad 519$

b) Gezielte Behinderung 524

c) Aggressive geschäftliche Handlung 526

3. Zulässigkeit wirtschaftlicher Reaktionen 528

E. Konterreaktion: Maßnahmen zur Umgehung der Verhinderung

I. Darlegung von Konterreaktionen der Werbeblockerbetreiber und Nutzer

1. Ergänzung von Werbeblockerfiltern zur Umgehung von Zugangssperren

2. "Adblocker-Detektoren-Blocker“

3. Sonstige Reaktionen

II. Rechtliche Beurteilung

1. Umgehung von Zugangssperren, $\$ 95$ a UrhG

a) Annahme einer Umgehung einer wirksamen technischen Maßnahme durch das LG Hamburg

b) Kritik in der Literatur

c) Stellungnahme

2. Umgehung von Zwangswerbung 
F. Kurzer Blick ins Ausland 549

I. Darstellung der Situation im ausgewählten Ausland 549

1. Situation in den USA 549

2. Situation in China 555

3. Kartellverfahren in Österreich 556

II. Gründe für den Schwerpunkt des Kampfs in Deutschland 557

$\begin{array}{ll}\text { G. Thesen zum Abschluss } & 561\end{array}$

$\begin{array}{ll}\text { Literaturverzeichnis } & 565\end{array}$ 


\section{Abbildungsverzeichnis}

Abbildung 1: Systematik der Werbemedien

Abbildung 2: Übersicht digitaler Werbeformen im Internet des BVDW e.V.

Abbildung 3: Schema browserbasierter Werbeformen

Abbildung 4: einfache schematische Darstellung der üblichen Wertschöpfungskette bei Online-Werbung

Abbildung 5: schematische Darstellung der erweiterten Wertschöpfungskette bei Online-Werbung

Abbildung 6: schematische Darstellung des Datenweges vom Nutzer zum Server

Abbildung 7: Schematische Darstellung der Client-Server Kommunikation beim Abruf einer Webseite mit DNS, TCP und HTTP

Abbildung 8: Schematische Darstellung der hier vorgeschlagenen Lösung für dynamische Anzeigen

Abbildung 9: Funktionsweise von Whitelist-Blockern

Abbildung 10: Schema der unlauteren aggressiven Praktik der Betreiber von kostenpflichtigen Whitelist-Blockern nach Ansicht des OLG Köln 


\section{A. Einführung in den Problembereich}

\section{Deutschland, 19. April 2018}

Es ist ein offener Schlagabtausch. In der roten Ecke: die „Werbeindustrie“, bestehend aus einigen der besucherstärksten Webseiten im deutschsprachigen Internet. Seit Beginn des Internets 2.0 die Champions im Kampf um Gewinne in der digitalen Welt. Ihr Kampfstil ist die Ausspielung der eigenen Dominanz und Reichweitenvorteile.

In der blauen Ecke: die „Adblocker“, also Unternehmen, die mit einer technisch simplen Software die Ausspielung von Werbung auf Webseiten verhindern. Eine kleine Gruppe von Shooting Stars, die mit aggressivem Stil in den Nahkampf drängen und gerade zu Beginn des Kampfes Wirkungstreffer landeten.

Ringrichter, das sind wir alle. Sie, werter Leser, gehören sicher auch dazu. Ringrichter ist nämlich jeder Internetnutzer. Er entscheidet, ob und wie es im Ring abläuft. Kampfrichter - sprich die Entscheider über Sieg und Niederlage - das sind die deutschen Gerichte. Heute muss der oberste Kampfrichter nach Punkten entscheiden.

Die Werbeindustrie unkte schon einige Male, dass Sie K.O. gehen könnte. Dies ist nicht geschehen. Der Champion mag wanken, er fällt aber nicht. Den „Adblockern“ hingegen droht bei einer Niederlage, gleich ob durch K.O. oder nach Punkten, ein jähes Karriereende.

Es läuft alles auf den großen Showdown hinaus - statt Las Vegas, MGM Grand steigt das Event allerdings in Karlsruhe, Erbgroßherzoglicher Palais.

Dieser Kampf wird in die Geschichte eingehen. Ali vs. Foreman, Holyfield vs. Tyson, Klitschko vs. Lewis und jetzt - Bild.de vs. Adblock Plus! Schnappen Sie sich Ihr Popcorn - „are you ready to rumble?“

\section{Internetwerbeblocker - ein Geschäftsmodell vor Gericht}

Ein Geschäftsmodell, das in diversen Verfahren unter gerichtlicher Kontrolle stand, zeigt mit aller Deutlichkeit den ökonomischen Wert von Werbung im Internet. Es geht unter anderem und beispielhaft um das Webbrowser Add-On „Adblock Plus“, welches von einigen namhaften Multimediaunternehmern und Webseitenbetreibern der Bundesrepublik 


\section{A. Einführung in den Problembereich}

mit juristischen Mitteln angegriffen wurde. In einer Reihe erstinstanzlicher Hauptsacheentscheidungen war zunächst die Betreibergesellschaft des Adblockers erfolgreich - so ergingen Klageabweisungen durch das LG München $\mathrm{I}^{1}$, das LG Köln ${ }^{2}$ und das LG Hamburg ${ }^{3}$. Das erste Urteil in der Berufungsinstanz durch das OLG Köln hingegen bedrohte das Geschäftsmodell der Adblocker auf lauterkeitsrechtlicher Grundlage ${ }^{4}$ - eine Totalblockade sei zwar rechtmäßig, die selektive Blockade von bestimmten Werbeanzeigen hingegen sei rechtswidrig. Diese Entscheidung hob der BGH jedoch auf und befand, dass Adblock Plus insgesamt zulässig sei ${ }^{5}$.

Die Berufungsurteile in den Verfahren beim OLG München ${ }^{6}$ bestätigten noch vor der Entscheidung des BGH im Kölner Verfahren die erstinstanzlichen Klageabweisungen und billigten damit das Geschäftsmodell von Adblock Plus auch mit Blick auf eine selektive Blockade. Die Revision ist hinsichtlich der lauterkeitsrechtlichen Problemstellung wegen grundsätzlicher Bedeutung und der Divergenz zur Entscheidung des OLG Köln zugelassen worden ${ }^{7}$. Die Revisionen wurden durch den Kartellsenat des BGH entschieden und es folgten zwei Urteile ${ }^{8}$, die zu einer Rückverweisung an das OLG München wegen Rechtsfehler bei der Anwendung kartellrechtlicher Vorschriften führten?'

Auch die Konkurrenz von Adblock Plus wurde bereits vor den Kadi geschleppt. So wurden in einstweiligen Verfügungsverfahren gegen die Softwares „AdShield“, „AdBlock“, „AdBlock Browser“ und „Blockr“ Entscheidungen erlassen. Die beiden erstgenannten wurden durch das LG

1 Insgesamt drei Verfahren vor dem LG München I, vgl. Urteil vom 27.5.2015 - 37 O 11843/14, WRP 2015, 927; Urteil vom 27.5.2015 - 37 O 11673/14, MMR 2015, 660; Urteil vom 22.3.2016 - 33 O 5017/15, MMR 2016, 406.

2 LG Köln, Urteil vom 29.9.2015 - 33 O 132/14, MMR 2016, 264.

3 LG Hamburg, Urteil vom 21.4.2015 - 416 HKO 159/14, CR 2016, 122, und Urteil vom 25.11.2016, 315 O 293/15, MMR 2017, 351.

4 OLG Köln, Urteil vom 24.6.2016 - 6 U 149/15, GRUR 2016, 1082.

5 BGH, Urteil vom 19.4.2018 - I ZR 154/16, WRP 2018, 1322 - Werbeblocker II.

6 OLG München, Urteil vom 17.8.2017, U 2184/15 Kart, WRP 2017, 1365.; Urteil vom 17.8.2017, U 2225/15 Kart, GRUR 2017, 1147; Urteil vom 17.8.2017, 29 U 1917/16, WRP 2017, 1377.

7 OLG München, Urteil vom 17.8.2017, U 2184/15 Kart, WRP 2017, 1365; Urteil vom 17.8.2017, U 2225/15 Kart, GRUR 2017, 1147.

8 BGH, Urteil vom 8.10.2019, KZR 73/17, WRP 2019, 1572 - Werbeblocker III; Urteil vom 10.12.2019, KZR 57/19, K\&R 2020, 302.

9 Außerdem scheint ein Berufungsverfahren noch beim OLG Hamburg unter Az. 5 U 237/16 anhängig zu sein, vgl. https://dejure.org/dienste/vernetzung/rechtsprechu ng?Text=5\%2520U\%2520237\%2F16\&Suche=olg\%20hamburg\%205\%20U\%20237\% 2F16, zuletzt abgerufen am 11.6.2020. 
Frankfurt vorläufig verboten ${ }^{10}$. Der Vertrieb des Browsers wurde vom LG Berlin $^{11}$ untersagt. Hinsichtlich „Blockr“ wies das LG Stuttgart den Eilantrag hingegen zurück ${ }^{12}$, was vom OLG Stuttgart bestätigt wurde ${ }^{13}$. Einen Adblocker für Safari, den mobilen Browser für Apple-Geräte wie iPhones, verbot das LG Hamburg im Wege der einstweiligen Verfügung ${ }^{14}$.

Es zeichnete sich also schon früh ab, dass das letzte Wort in dieser Angelegenheit erst der Bundesgerichtshof sprechen wird. Dies ist mit dem Urteil vom 19.4.2018 für den Bereich des Lauterkeitsrechts nun vorerst geschehen und der BGH verfolgte eine marktliberale Linie. Wegen der starken Bedeutung der Grundrechte für die zur Entscheidung notwendige Interessenabwägung hatte Axel Springer auch eine Verfassungsbeschwerde zum Bundesverfassungsgericht geführt. Diese wurde allerdings vom Bundesverfassungsgericht durch nicht begründeten Beschluss nicht zur Entscheidung angenommen ${ }^{15}$.

Die Verfahren zeichneten sich dabei durch eine seltene Emotionalität aus, welche einen bemerkenswerten Kontrast zu der ansonsten eher nüchternen deutschen Streitkultur darstellt. Denn auf der einen Seite haben sich die Betreiber von beliebten, werbefinanzierten und damit für den Nutzer kostenlosen Internetseiten nichts weniger als den Fortbestand der Existenz der „Umsonst-Kultur“ im Internet auf die Fahnen geschrieben. Wären die Internetwerbeblocker rechtmäßig, so ein Argument, seien große multimediale Angebote im Internet nicht wirtschaftlich und würden entweder verschwinden oder kostenpflichtig werden.

10 LG Frankfurt, Beschluss vom 6.11.2015 - Aktenzeichen unbekannt, keine Veröffentlichung, Bericht im Internet bei http://www.golem.de/news/werbeblockers perre-auf-bild-de-gericht-bestätigt-verbot-von-umgehungsanleitung-1512-117922-2 .html, zuletzt abgerufen am: 30.5.2019; Beschluss vom 26.11.2015 - 3-6 O 105/15, K\&R 2016, 134.

11 LG Berlin, Urteil vom 8.12.2015 - 16 O 449/15, K\&R 2016, 360.

12 LG Stuttgart, Urteil vom 10.12.2015 - 11 O 238/15, K\&R 2016, 362.

13 http://www.heise.de/newsticker/meldung/Adblocker-Axel-Springer-zieht-Kla ge-gegen-Blockr-zurueck-3240983.html, zuletzt abgerufen am: 30.5.2019, der Verfügungsantrag wurde zurückgenommen.

14 LG Hamburg, Urteil vom 3.5.2016 - 308 O 46/16, CR 2016, 782.

15 So https://www.lto.de/recht/nachrichten/n/bverfg-1bvr921-19-adblocker-verf assungsbeschwerde-nicht-angenommen-axel-springer/, zuletzt abgerufen am 11.6.2020, wonach das Az. beim BVerfG 1 BvR 921/19 lautete und der Beschluss am 22.8.2019 erging. Gleiches berichtet die Eyeo $\mathrm{GmbH}$ per Pressemitteilung, https://eyeo.com/verfassungsgericht_starkt-_adblocking/, zuletzt abgerufen am 11.6.2020. 


\section{A. Einführung in den Problembereich}

Die Betreiber von Adblock Plus hingegen führen zuvörderst die Freiheit und Autonomie jedes einzelnen Internetnutzers ins Feld und sehen sich durch die hohe Nutzerzahl scheinbar quasi-demokratisch legitimiert, das Internet zu „verbessern“ und dabei keine Rücksicht auf große Namen, alte Strukturen oder Traditionen zu nehmen.

Auch die Beschreibungen, welche die jeweiligen Parteien für die Gegenseite verwenden, muten an wie eine Mischung aus „Der Pate“ und „Robin Hood“. Internetseitenbetreiber halten das Geschäftsmodell von Adblock Plus für ein Mafia-Modell, das mit Methoden ähnlich der Wegelagerei oder der Schutzgelderpressung operiere. Für die Betreiber von Adblock Plus ist das Überangebot an Werbung im Internet, insbesondere durch Videos, Animationen oder sonstige den Inhalt überdeckende Motive, nichts anderes als eine Belästigung des hilflosen Internetnutzers. Erst Adblock Plus gebe dem Nutzer ein Werkzeug, mit dem er sich dagegen wehren könne.

Zwischen den Stühlen steht - an entscheidender Stelle - der Internetnutzer mit seiner Entscheidung pro oder contra Werbeblocker. Diese Entscheidung wird selbstverständlich mannigfaltig interpretiert, seziert und für sich beansprucht. So reicht die Einschätzung der Entscheidung des Nutzers von unbeachtlich, da falsch informiert oder desinteressiert, bis hin zu bewusst selbstbestimmt. Es scheint als tobe ein Glaubenskampf im Internet, der durch die Gerichte zwar formell beschieden werden kann. Eine endgültige Beilegung des Streits ist jedoch selbst zum Zeitpunkt des Abschlusses dieser Bearbeitung noch nicht zu erwarten ${ }^{16}$.

\section{Zugangssperren für Werbeblockernutzer}

Denn es bleibt nicht nur bei dem einen großen Kampf um die Werbung im Internet, der eingangs im Stile eines Boxpromoters angepriesen wurde. Es entstanden auch Nebenkriegsschauplätze bei dem Versuch, die eigenen Interessen vor Angriffen der Gegenseite zu verteidigen solange das letzte Wort aus Karlsruhe nicht gesprochen war. So geschehen in einem Verfahren im einstweiligen Rechtsschutz vor dem LG Hamburg ${ }^{17}$. Nach der Niederlage in der Hauptsache „Adblock Plus“ vor dem LG Köln ${ }^{18}$ hat

16 Vgl. https://www.lto.de/recht/nachrichten/n/lg-hamburg-werbeblocker-adblocker -axel-springer-eyeo-urheberrecht-verletzung/, zuletzt abgerufen am 30.5.2019.

17 LG Hamburg, Beschluss vom 22.10.2015 - 308 O 375/15, ZUM 2016, 892.

18 LG Köln, Urteil vom 29.9.2015 - 33 O 132/14, MMR 2016, 264. 
das unterlegene Medienunternehmen den Zugang zu seiner Internetseite für Internetnutzer mit aktiviertem Adblock Plus gesperrt. Die entsprechenden Nutzer konnten statt den Inhalten der Internetseite nur noch einen Sperrbildschirm sehen, welcher einen Hinweis enthielt, warum der Seitenzugriff gesperrt wurde und dass diese Sperrung aufrecht erhalten bleibt, wenn der benutzte Werbeblocker nicht ausgeschaltet werde. Siehe folgenden Screenshot:

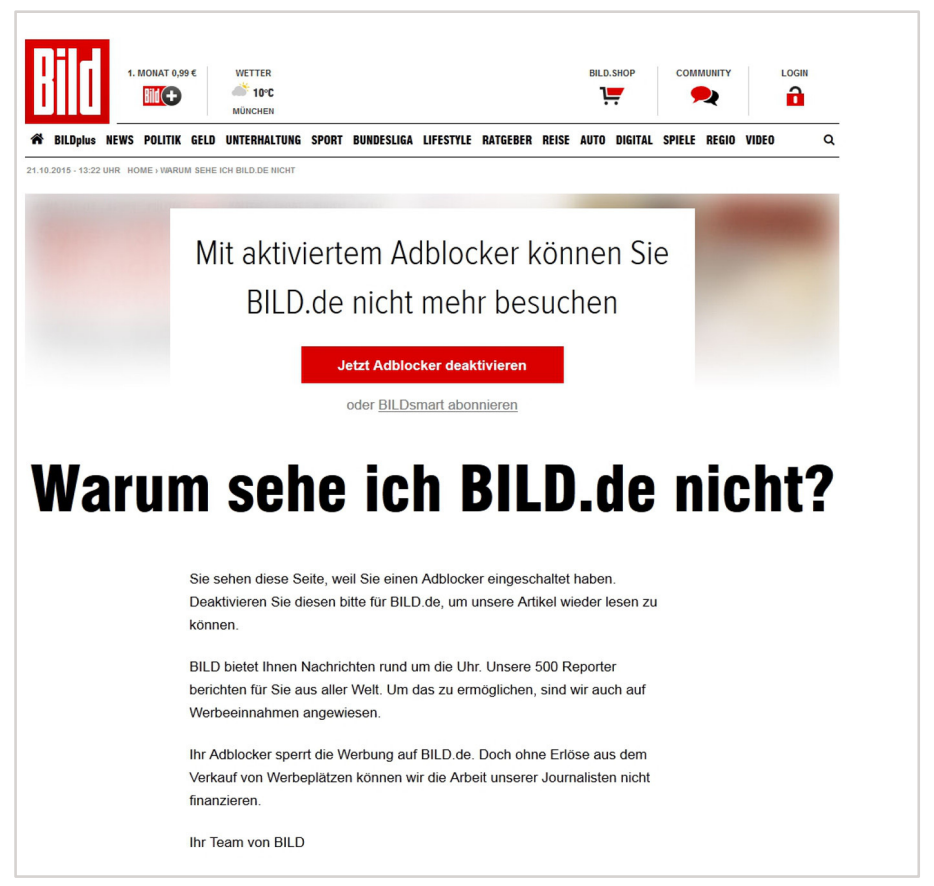

Screenshot ${ }^{19}$ von Bild.de bei Besuch mit Adblocker

Schon schnell nach dieser Barriere fanden sich in einschlägigen Foren im Internet Wege, diese Sperre zu umgehen und trotz eingeschaltetem Adblock Plus die entsprechende Internetseite zu besuchen sowie die Inhalte ohne Werbung zu genießen. Die Krux daran war, dass diese „Tipps“ zwar nicht von der Betreiberin des Werbeblockers stammten, jedoch wohl aus deren „Lager“. Das LG Hamburg untersagte im Wege der einstweiligen

19 Screenshot erstellt am: 20.5.2017; zuletzt abgerufen am 30.5.2019. 


\section{A. Einführung in den Problembereich}

Verfügung solche Umgehungen der Aussperrung von Adblock Plus Nutzern auf urheberrechtlicher Grundlage. Eine weiter begehrte wettbewerbsrechtliche Untersagung des Vorgehens verwarfen sowohl das LG Hamburg im vorgenannten Verfahren als auch das LG Köln sowie das OLG Köln in einem parallel geführten Verfahren des einstweiligen Rechtsschutzes ${ }^{20}$.

Es zeigt sich, dass auf dem Werbemarkt mit harten Bandagen gekämpft wird. Dies hat seinen Grund ohne Frage in der enormen wirtschaftlichen Bedeutung der Werbung für die Internetseitenbetreiber. Die Werbeeinnahmen sind die heilige Kuh der Wirtschaftssparte Internet - gemästet durch Big Data. Es ist kein neues Phänomen, dass dort, wo Geld verdient wird, andere lauern, die ein Stück vom „Kuchen“ abhaben wollen. So ist es nicht verwunderlich, dass Adblock Plus durch ein ausgeklügeltes Geschäftsmodell agiert, um an die gefüllten Topfe der Werbeeinnahmen zu gelangen.

Denn Adblock Plus ist keine rein altruistische Initiative von „Nerds“, die den Nutzern das Aufdrängen von Werbung um seiner selbst willen ersparen will. Vielmehr finanziert sich das Projekt Adblock Plus mehr als kostendeckend ${ }^{21}$ und zwar nicht durch eine Kostenpflichtigkeit der Software oder ein Sponsoring - das wäre ja auch äußerst heuchlerisch -, sondern durch das Freikaufen von Werbeplätzen auf der eigenen Internetseite durch die namhaftesten Anbieter am Markt. Dieses System nennt sich „Whitelisting“. Es funktioniert nach dem Prinzip einer geschlossenen Tür. Durch die Software - welche selbst keine eigene Filter-Funktionalität hat - in Verbindung mit bestimmten Listen, genannt „Blacklists“ - wird zunächst jede Werbung geblockt. Dies erfolgt - an dieser Stelle noch auf das Essentielle beschränkt - dadurch, dass die Server, die Werbung ausspielen, vom Browser erkannt und deren Inhalte nicht geladen werden. Geladen wird nur der Content vom bereitstellenden Server. Diese Art von Werbeblockade ist schon seit langer Zeit am „Werbeblocker-Markt“ zu haben, hat aber den Nachteil, dass hiermit allein kein Geld zu verdienen ist. Denn ist die Tür zu, so kommt rein gar nichts durch. Potentielle Finanzierungen funktionieren nur über eine Kostenpflicht (unwirtschaftlich vor dem Hintergund der „Umsonst-Kultur“ im Internet) oder wiederum über Sponsoring, Werbung oder Ähnliches (womit sich die Katze in den Schwanz beißt).

20 OLG Köln, Beschluss vom 17.12.2015 - 6 W 128/15, (unveröffentlicht).

21 Der im Bundesanzeiger veröffentlichte Jahresabschluss des Eyeo $\mathrm{GmbH}$ über das Geschäftsjahr 2015 weist eine Bilanzsumme von 38.949.345,72 €, für das Geschäftsjahr 2018 sogar 82.718.661,20 € aus. 


\section{Whitelisting}

Über dieses Dilemma des früheren Internetzeitalters setzte sich die Betreiberin von Adblock Plus hinweg, indem sie das "Whitelisting“ erdachte. Denn hierdurch wird die geschlossene Tür sozusagen mit einem Türsteher versehen, der entscheidet, wer durch sie hindurch gehen darf und wer draußen bleiben muss. Wer auf der Whitelist steht, dessen Werbung wird vom Nutzer von Adblock Plus, der die entsprechende (voreingestellte) Option ausgewählt hat, beim Besuch der Internetseite auch gesehen. Wer nicht auf dieser Liste steht, dessen Internetseite zeigt sich beim Nutzer in aufgeräumten, von jeder Werbung gereinigten Zustand bzw. dessen Werbung wird schlicht ausgesperrt. Die Einnahmequelle der nicht auf der Freischaltungsliste geführten Webseite sprudelt aufgrund von zugriffsabhängigen Vergütungen prompt nur noch geringer.

Wer auf diese Whitelist kommt, das entscheidet in einer Art oder der anderen die Betreiberin von Adblock Plus. Dies ist ein äußerst großer Streitpunkt zwischen den jeweiligen Klägerinnen und der Betreiberin von Adblock Plus, auf welchen an dieser Stelle noch nicht vertieft eingegangen werden soll. Denn vornehmlich kommt es an dieser Stelle auf die „Acceptable-Ads-Initiative“ im Rahmen von Adblock Plus an. Den in dieser Initiative aufgestellten Kriterien für akzeptable Werbung muss jede Internetseite entsprechen, welche auf die Whitelist möchte. Sie dient mithin als Anforderungsprofil, Zulässigkeitsvoraussetzung, Scheinargument oder wie man es auch immer bezeichnen möchte. Diese Kriterien sehen vor, dass Werbung in bestimmter Weise platziert, einfach unterscheidbar von Inhalten, nicht übergroß und nicht grafisch übermäßig aufdringlich sein muss ${ }^{22}$.

Nach eigenen Angaben der Betreiberin werden 90\% der Internetseiten, die den „Acceptable Ads“-Kriterien entsprechen, kostenfrei auf einen Antrag hin der Whitelist hinzugefügt. Nur „große Organisationen“ müssen für den Platz auf der Whitelist bezahlen. Eine Organisation gilt als groß, wenn sie, aufgrund der Teilnahme an der Acceptable Ads Initiative, mehr als 10 Millionen zusätzliche Werbeimpressionen pro Monat verzeichnet. In diesem Fall errechnen sich die Kosten für den Whitelistplatz auf $30 \%$ der in Folge der Freigabe akzeptabler Werbeanzeigen zusätzlich generierten Werbeeinnahmen ${ }^{23}$.

22 Vgl. https://adblockplus.org/de/acceptable-ads, zuletzt abgerufen am: 30.5.2019.

23 Vgl. https://adblockplus.org/de/about, zuletzt abgerufen am: 30.5.2019. 


\section{A. Einführung in den Problembereich}

Das Geschäftsmodell basiert also darauf, dass etablierten großen Internetseiten auf einer ersten Stufe für eine erhebliche Anzahl von Nutzern, nämlich Nutzern der Blockiersoftware, die zugriffsabhängigen Werbeeinnahmen gekappt werden, um genau diese Nutzer dann wieder gegen Entgelt freizugeben. Es versteht sich von selbst, dass dieses Modell mit der Anzahl der Nutzer des Werbeblockers attraktiver wird. Die Internetseitenbetreiber stehen vor der Wahl, ob sie diesen - aus ihrer Sicht - Pakt mit dem Teufel eingehen wollen oder aber mit den nicht werbeblockenden Internetnutzern zufrieden sind. Wie die Vielzahl an Verfahren mit gleichem Streitgegenstand zeigen, eifern dabei nicht wenige dem Sheriff von Nottingham nach und bekämpfen das ihre Interessen widerstrebende Add-On, als wäre es der Räuber aus dem Sherwood Forest.

In jüngerer Zeit scheint sich dieses Whitelist-Modell zu verbreiten. So greifen neben dem Betreiber von Adblock Plus auch weitere Werbeblocker, die an sich in Konkurrenz zu Adblock Plus stehen, auf die Finanzierung durch entgeltliche Freischaltung mit der Acceptable-Ads-Whitelist zurück ${ }^{24}$. Deshalb ist auch nicht nur die Frage des Werbeblockens überhaupt, sondern auch die Zulässigkeit des Geschäftsmodells der kostenpflichtigen Whitelist von richtungsweisender Bedeutung.

\section{$V$. Rechtlicher Prüfungsmaßstab betreffend Werbeblocken und Whitelisting}

Wie zudem die Quantität und der Umfang der Verfahren zeigt, ist die Aktion des Werbeblockens mit erheblichen rechtlichen Streitpunkten, insbesondere im Lauterkeits-, Urheber- und Kartellrecht verbunden. Im Bereich des UWG drehen sich die Streitthemen hauptsächlich um das Vorliegen einer geschäftlichen Handlung, im Anschluss daran um eine gezielte Mitbewerberbehinderung, wobei auch ein Wettbewerbsverhältnis zwischen den Betreibern von Webseiten und Betreibern des Adblockers bejaht werden muss, und seit neuestem um die Einschätzung als aggressive Geschäftspraktik gegenüber sonstigen Marktteilnehmern. Urheberrechtlich dreht sich der Streit darum, ob überhaupt eine Verletzungshandlung zu erkennen ist. Im Kartellrecht drehen sich die Auseinandersetzungen schwerpunktmäßig um eine Ausnutzung von Marktmacht. Die rechtlichen Rahmenpunkte werden im Einzelnen in Kürze skizziert:

24 So etwa die Werbeblocker AdBlock und Crystal, vgl. https://www.heise.de/newsti cker/meldung/Acceptable-Ads-Auch-Adblock-laesst-nicht-nervende-Werbung-dur ch-2836888.html, zuletzt abgerufen am: 30.5.2019. 


\section{UWG}

Im Rahmen des Lauterkeitsrechts stützen die Klägerinnen ihr Begehren vornehmlich auf einen Unterlassungsanspruch aus $\$ \int 8$ Abs. 1, 3 Abs. 1, 4 Nr. 10 UWG a.F. (vor Dezember 2015) bzw. $\int \$ 8$ Abs. 1, 3 Abs. 1, 4 Nr. 4 UWG n.F. wegen gezielter Behinderung von Mitbewerbern. Die Streitpunkte beginnen in diesem Rahmen schon dabei, ob das Angebot der Software Adblock Plus eine geschäftliche Handlung eines Mitbewerbers darstellt. Während für die Variante mit Whitelist-Funktion das Vorliegen einer geschäftlichen Handlung gem. $\ 2$ Abs. 1 Nr. 1 UWG bejaht wird ${ }^{25}$, haben die befassten Gerichte unterschiedliche Auffassungen dazu, ob ein konkretes Wettbewerbsverhältnis im Sinne von $\$ 2$ Abs. 1 Nr. 3 UWG besteht. Die 37. Zivilkammer des LG München I lehnte in seinen beiden Verfahren ein solches Wettbewerbsverhältnis $\mathrm{ab}^{26}$, das LG Köln und die 15. Zivilkammer des LG Hamburg ließen diese Frage offen ${ }^{27}$. Die 33. Zivilkammer des LG München I, die 16. Kammer für Handelssachen sowie die 8. Zivilkammer des LG Hamburg, das LG Stuttgart und die OLGe Köln und München hingegen bejahten ein konkretes Wettbewerbsverhältnis ${ }^{28}$.

Eine gezielte Behinderung lehnten jedoch beinahe alle befassten Gerichte mit ähnlichen, aber im einzelnen differierenden Begründungen ab. Einzig das LG Frankfurt, das LG Berlin und die 8. Zivilkammer des LG Hamburg nahmen eine gezielte Behinderung durch werbeblockende Software nach einer summarischen Betrachtung an ${ }^{29}$. Grundlage für die

25 Vgl. LG Hamburg, Urteil vom 21.4.2015 - 416 HKO 159/14 (juris, Rn. 30); LG München I, Urteil vom 27.5.2015 - 37 O 11843/14 (juris, Rn.140ff.); Urteil vom 27.5.2015 - 37 O 11673/14 (juris, Rn. 170ff.); Urteil vom 22.3.2016 - 33 O 5017/15, MMR 2016, 406, 407; OLG Köln, Urteil vom 24.6.2016 - 6 U 149/15, (juris Rn. 51ff.); LG Hamburg, Urteil vom 3.5.2016 - 308 O 46/16, (juris Rn. 38); OLG München, Urteile vom 17.8.2017, U 2184/15 Kart, (juris Rn. 102ff.); 559; U 2225/15 Kart, (juris Rn. 96ff.); 29 U 1917/16, (juris Rn. 37ff.).

26 LG München I, Urteil vom 27.5.2015 - 37 O 11843/14 (juris, Rn. 145ff.); Urteil vom 27.5.2015 - 37 O 11673/14 (juris, Rn. 177ff.).

27 LG Köln, Urteil vom 29.9.2015 - 33 O 132/14, MMR 2016, 264; LG Hamburg, Urteil vom 25.11.2016 - 315 O 293/15, MMR 2017, 351.

28 LG München I, Urteil vom 22.3.2016 - 33 O 5017/15, MMR 2016, 406, 407; LG Hamburg, Urteil vom 21.4.2015 - 416 HKO 159/14 (juris, Rn.31ff.); LG Stuttgart, Urteil vom 10.12.2015 - 11 O 238/15 (juris, Rn. 33f.); OLG Köln, Urteil vom 24.6.2016 - 6 U 149/15 (juris, Rn. 48ff.); LG Hamburg, Urteil vom 3.5.2016 - 308 O 46/16 (juris Rn. 39ff.).

29 LG Frankfurt, Beschluss vom 26.11.2015 - 3-6 O 105/15 (juris, Rn. 7f.); LG Berlin, Urteil vom 8.12.2015 - 16 O 449/15 (juris, Rn. 19ff.); LG Hamburg, Urteil vom 3.5.2016 - $308 \mathrm{O}$ 46/16 (juris, Rn. 42ff.). 


\section{A. Einführung in den Problembereich}

Entscheidungen waren jeweils mehr oder weniger ausführliche Interessenabwägungen.

Prüfungsgegenstand der einzelnen Gerichte war zudem das Vorliegen einer allgemeinen Marktbehinderung als Fallgruppe der Generalklausel in \3 Abs. $1 \mathrm{UWG}^{30}$. Als besonderes Problem wurde in einem Münchener Verfahren die Verleitung der Nutzer durch Adblock Plus zur Verletzung des virtuellen Hausrechts geprüft ${ }^{31}$. Grundlage der ablehnenden Entscheidungen in diesen Aspekten sind ebenfalls ausführliche Interessenabwägungen, die im Endeffekt die Autonomie der Nutzerentscheidung über die übrigen Interessen stellt.

Während eine unlautere Beeinträchtigung im Sinne von $\$ 4$ Nr. 1 UWG a.F. (nach aktueller Gesetzesfassung aggressive Geschäftspraktik gem. $₫ 4 a$ Abs. 1 UWG n.F.) in den erstinstanzlichen Entscheidungen verneint worden ist ${ }^{32}$, wartete das OLG Köln überraschend mit einer Entscheidung auf, die das Whitelisting als gerade solche aggressive Praktik qualifizierte und der Klage insoweit stattgab, dass das kostenpflichtige Angebot zum Whitelisting einer großen Internetseite (gemeint ist Bild.de) verboten wur$\mathrm{de}^{33}$. Entscheidend für diese Einordnung war dabei nicht das unmittelbare Verhältnis zwischen Betreibern von Webseiten und des Adblockers. sondern jenes zwischen Werbeblockerbetreiber und den Werbekunden, welche potentiell Werbung auf Webseiten buchen. Das OLG Köln nahm dabei eine unzulässige Beeinflussung im Sinne von $\mathbb{S} 4 \mathrm{a}$ Abs. 1 S. 2 Nr. 3, S.3 UWG n.F. an. Die dafür erforderliche Machtposition liege in der Schaffung einer technisch wirkenden Schranke - gemeint ist die Blacklist und müsse durch die kostenpflichtige Aufnahme in die Whitelist erst wieder beseitigt werden. Dies stelle also ein „Hindernis nichtvertraglicher Art“ gem. $\int 4 a$ Abs. 2 Nr. 4 UWG n.F. dar, welches die Ausübung vertraglicher Rechte der Werbetreibenden hindere. Der Adblocker sei ein „Gatekeeper“ von dem sich werbewillige Unternehmen freikaufen müssten. Darin sei

30 LG München I, Urteil vom 22.3.2016 - 33 O 5017/15, MMR 2016, 406, 409; LG Hamburg, Urteil vom 21.4.2015 - 416 HKO 159/14 (juris, Rn. 60ff.); Urteil vom 27.5.2015 - 37 O 11673/14 (juris, Rn. 224ff.), OLG Köln, Urteil vom 24.6.2016 6 U 149/15 (juris, Rn. 65); LG Hamburg, Urteil vom 25.11.2016, 315 O 293/15 (juris, Rn. 51); OLG München, Urteil vom 17.8.2017, U 2225/15 Kart (juris, Rn. 95, 183, 230f.).

31 LG München I, Urteil vom 27.5.2015 - 37 O 11673/14 (juris, Rn. 217ff.); OLG München, Urteil vom 17.8.2017, U 2225/15 Kart (juris, Rn. 183, 227f.).

32 LG Hamburg, Urteil vom 21.4.2015 - 416 HKO 159/14 (juris, Rn. 54ff.); LG München I, Urteil vom 27.5.2015 - 37 O 11843/14 (juris, Rn. 254ff.).

33 OLG Köln, Urteil vom 24.6.2016 - 6 U 149/15 (juris, Rn. 66ff.). 
eine erhebliche Beeinträchtigung der Entscheidungsfreiheit werbewilliger Unternehmen zu erblicken. Die anderen Gerichte hätten bei Ihrer Beurteilung (nach $\mathbb{} 4 \mathrm{Nr} .1 \mathrm{UWG}$ a.F.) diese Drittwirkung des Whitelistings komplett verkannt. Auch bestünde keine Sperrwirkung des Kartellrechts für die Anwendung von $\$ 4$ a UWG n.F., wonach diese Norm nur ab dem Vorliegen einer marktbeherrschenden Stellung in Frage komme. Diese Argumentation wurde im Schrifttum kritisiert ${ }^{34}$. Herausragende Bedeutung hat die Entscheidung auch gerade vor dem Hintergrund, dass sie eine der ersten Anwendungen des neuen $₫ 4$ a UWG n.F. darstellt. Nachfolgend lehnte hingegen die 15. Zivilkammer des LG Hamburg das Vorliegen einer Verletzung von $\$ 4$ a UWG n.F. unter Rückgriff auf die Kritik aus der Literatur $\mathrm{ab}^{35}$. Insbesondere sei kein Ausnutzen einer im Einzelfall offengelassenen Machtposition erkennbar. Genauso sah es das OLG München, das ebenfalls das Tatbestandsmerkmal des Ausnutzens einer Machtposition ablehn$\mathrm{te}^{36}$.

Allgemein zivilrechtlich (hier nur kurz genannt, da rechtlich dem Lauterkeitsrecht nahe stehend) wurde im Übrigen das Vorliegen eines Eingriffs in den eingerichteten und ausgeübten Gewerbebetrieb gem. $\mathbb{8} 823$ BGB geprüft und abgelehnt ${ }^{37}$.

\section{Urheberrecht}

In einem Verfahren vor dem LG München I und in einem Verfahren vor der 8. Zivilkammer des LG Hamburg wurde Adblock Plus auch auf den urheberrechtlichen Prüfstand gestellt. Dabei wurde erörtert, ob die klagende Internetseitenbetreiberin einen Unterlassungsanspruch gem. $\$ 97$ Abs. 1 UrhG wegen Verletzung von Rechten an einer Datenbank gem. $\$ 87 b$ UrhG, von Rechten an einem Datenbankwerk gem. $\$ 4$ UrhG, von

34 Vgl. Fritzsche, WRP 2016, 1036; Alexander, GRUR 2016, 1089.

35 LG Hamburg, Urteil vom 25.11.2016, 315 O 293/15 (juris, Rn. 47ff.).

36 OLG München, Urteile vom 17.8.2017, U 2184/15 Kart, (juris Rn. 168ff.); 559; U 2225/15 Kart, (juris Rn. 220ff.); 29 U 1917/16, (juris Rn. 73ff.).

37 LG München I, Urteil vom 27.5.2015 - 37 O 11843/14 (juris, Rn. 196ff., 276ff.); LG Hamburg, Urteil vom 25.11.2016, 315 O 293/15 (juris, Rn. 57); OLG München, Urteil vom 17.8.2017, U 2184/15 Kart, (juris Rn. 120ff.). 


\section{A. Einführung in den Problembereich}

Rechten an einem Multimediawerk gem. $\$ 2$ Abs. 1 UrhG oder von Rechten an einem Computerprogramm gem. \$ 69a Abs. 1 UrhG hat ${ }^{38}$.

Das Vorliegen eines Datenbankwerks wurde in München mangels persönlicher geistiger Schöpfung gem. $\$ 2$ Abs. 2 UrhG abgelehnt. Allein die thematische Gliederung nach Sendungen könne nicht die ausreichende Schöpfungshöhe belegen. Ob ein Multimediawerk vorliege oder die Webseite als Computerprogramm schutzfähig sei, wurde ebenfalls offengelassen. Gleich entschied das LG Hamburg.

Im Übrigen hat die 37. Zivilkammer des Landgerichts München I offengelassen, ob es sich bei der konkret zu untersuchenden Webseite um eine Datenbank handelte. Sie bezweifelte aber, dass die werblichen Inhalte überhaupt als Teil einer Datenbank anzusehen seien, weil sie nicht einzeln mit Hilfe elektronischer Mittel oder auf andere Weise zugänglich sind. Im Ergebnis konnte keine rechtswidrige Verletzungshandlung erkannt werden. Eine solche werde weder durch die Betreiberin von Adblock Plus selbst, noch vermittelt durch die Nutzer begangen. Im Hinblick auf die Datenbank liege auch bei Besuch der Webseite mit aktiviertem Adblock Plus keine einer normalen Auswertung der Datenbank zuwiderlaufende Handlung oder unzumutbare Beeinträchtigung iSv $\ 87$ b Abs. 1 S. 2 UrhG vor. Selbst bei unterstellter Schutzfähigkeit als Datenbank- oder Multimediawerk liege eine rechtmäßige Nutzung der Webseite auch bei Blockieren der Werbung vor, da zum einen keine technischen und rechtlichen Maßnahmen zur Begrenzung des Zugangs getroffen worden seien und zum anderen greife die Schrankenregelung des $\$ 44 a$ Nr. 2 UrhG. Dabei liege auch keine Bearbeitung gem. $\mathbb{\$} 23$ UrhG und keine Entstellung gem. $\mathbb{S} 14$ UrhG vor.

Betreffend ein Computerprogramm liege sowohl nach LG München, als auch nach LG Hamburg keine Umarbeitung nach $\$ 69 \mathrm{c} \mathrm{Nr} .2$ UrhG vor, da kein Eingriff in die Programmsubstanz, sprich den Quellcode, vorliegt. Der Betreiber eines Werbeblockers sei auch kein Teilnehmer einer unerlaubten Vervielfältigung nach $\$ 69$ c Nr. 1 UrhG, da die Kopie im Arbeitsspeicher des Nutzers mit Gestattung der Webseitenbetreiber erfolge.

38 LG München I, Urteil vom 27.5.2015 - 37 O 11673/14 (juris, Rn. 233ff.), nachfolgende Berufung OLG München, Urteil vom 17.8.2017, U 2184/15 Kart (juris, Rn. 115ff.); LG Hamburg, Urteil vom 3.5.2016 - 308 O 46/16 (juris, Rn. 24ff.). 
Diese Ausführungen wurden vom OLG München insgesamt bestätigt und für dieses Rechtsgebiet wurde die Revision zum BGH nicht zugelas$\operatorname{sen}^{39}$.

\section{Kartellrecht}

Kartellrechtliche Fragestellungen waren in den beiden Entscheidungen der 37. Zivilkammer des LG München I, den darauffolgenden Berufungsurteilen sowie im Verfahren vor der 15. Zivilkammer des LG Hamburg streitgegenständlich ${ }^{40}$. Außerdem setzte sich der BGH mit diesem Rechtsgebiet in seinen beiden Urteilen Ende 2019 auseinander ${ }^{41}$. Prüfungsgegenstand waren dabei Unterlassungsansprüche aus $\$ 33$ Abs. 1 GWB iVm $\$ \mathbb{S} 1,18$, 19, 21 GWB bzw. Art. 101, 102 AEUV.

Die Instanzrechtsprechung prüfte dabei wie folgt: eine wettbewerbsbeschränkende Vereinbarung im Sinne von $\$ 1$ GWB bzw. Art. 101 Abs. 1 AEUV wurde mangels Verhaltensabstimmung verneint. Eine solche liege weder horizontal, noch sternförmig - z.B. vermittelt durch einen Dritten - in der Vereinbarung der Werbekriterien, weil kein koordiniertes Verhalten von Webseitenbetreibern vorliege, sondern dies rein wirtschaftlich gesteuert sei. Eine etwaige vertikale Vereinbarung sei freigestellt. Ein Missbrauch einer marktbeherrschenden Stellung gem. $\int \$ 18,19$ GWB bzw. Art. 102 AEUV scheide mangels eben dieser Marktmacht aus. Als sachlich relevanter Markt wurde dabei in München nicht auf den Markt der Werbeblocker generell oder speziell derer mit Whitelist abgestellt, sondern auf den gesamten Internetwerbemarkt in Deutschland. In diesem abgegrenzten Markt erreiche Adblock Plus allerdings nicht die Schwelle von $\$ 18$ Abs. 4 GWB, wonach ab 40 \% Marktanteil eine Vermutung für Marktbe-

39 OLG München, Urteil vom 17.8.2017, U 2225/15 Kart, (juris, Rn. 239): „Hinsichtlich des auf Urheberrecht gestützten Berufungsantrags [...] hat die Rechtssache keine grundsätzliche Bedeutung; auch die Voraussetzungen des $\$ 543$ Abs. 2 Satz 1 Nr. 2 ZPO liegen nicht vor. Die Rechtssache erfordert [...] lediglich die Anwendung gesicherter Rechtsprechungsgrundsätze auf den Einzelfall".

40 LG München I, Urteil vom 27.5.2015 - 37 O 11843/14 (juris, Rn. 204ff., 289ff.); Urteil vom 27.5.2015 - 37 O 11673/14 (juris, Rn.293ff.) sowie nachfolgende Berufungen beim OLG München, Urteile vom 17.8.2017, U 2184/15 Kart, (juris Rn. 149ff.); 559; U 2225/15 Kart, (juris Rn. 126ff.); LG Hamburg, Urteil vom 25.11.2016, 315 O 293/15 (juris, Rn. 52ff.).

41 BGH, Urteil vom 8.10.2019, KZR 73/17, WRP 2019, 1572 - Werbeblocker III; Urteil vom 10.12.2019, KZR 57/19, K\&R 2020, 302. 


\section{A. Einführung in den Problembereich}

herrschung streitet. Es liege auch kein besonderer Fall vor, in welchem auch ein geringerer Marktanteil ausreiche. Ob im Weiteren eine unbillige Behinderung oder eine Diskriminierung vorliege, wurde offengelassen. Das LG Hamburg lehnte ebenfalls im Einzelnen das Vorliegen einer unbilligen Behinderung ( $\mathbb{1} 19$ Abs. 2 Nr. 1 Alt. 1 GWB), einer Diskriminierung ( $\int 19$ Abs. 2 Nr. 1 Alt. 1 GWB), eines Ausbeutungsmissbrauchs ( $\mathbb{1} 19$ Abs. 2 Nr. 2 GWB), einer Veranlassung zur Vorteilsgewährung ( $\int 19$ Abs. 2 Nr. 5 GWB) und ein missbräuchliches Ausnutzen einer marktbeherrschenden

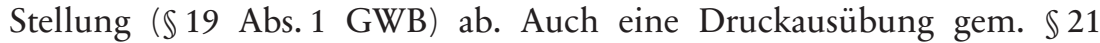
Abs. 2 GWB und Zwangsausübung gem. $\$ 21$ Abs. 3 Nr. 3 GWB wurden vom LG und OLG München verneint.

Der Kartellsenat des BGH monierte jedoch die vom OLG München vorgenommene Marktabgrenzung bei der Beurteilung einer marktbeherrschenden Stellung. Nach dem Bedarfsmarktkonzept könne gerade nicht auf den gesamten Internetwerbemarkt in Deutschland abgestellt werden, sondern es komme allein auf die vom Werbeblockerbetreiber angebotene Dienstleistung an - also die Aufnahme in die kommerzielle Whitelist ${ }^{42}$. Allerdings fehlten dem Kartellsenat tatsächliche Feststellungen, um selbst eine marktbeherrschende Stellung anzunehmen, sodass eine Rückverweisung an das OLG München mitsamt sog. „Segelanweisungen“ erfolgte ${ }^{43}$. Insofern ist der Kampf um die Werbung im Internet noch zum Zeitpunkt der Veröffentlichung dieser Arbeit im Gange.

\section{Rechtlicher Prüfungsmaßstab betreffend Zugangssperren oder sonstigen Reaktionen}

Wie oben dargestellt greifen die durch Werbeblocker betroffenen Webseitenbetreiber teils zu Gegenmaßnahmen. Den Bedarf für diese Reaktionen hat Adblock Plus selbst geschaffen, indem die Betreiber den virtuellen Türsteher namens „Whitelist“ vor der Haustür der Internetseitenbetreiber installiert haben. Wenn der Türsteher dort nun bleibt - weil die Unterlassung des Geschäftsmodells von den Gerichten abgelehnt wird - was können die Internetseitenbetreiber dagegen tun?

42 BGH, Urteil vom 8.10.2019, KZR 73/17, WRP 2019, 1572, Rn. 25 - Werbeblocker III.

43 BGH, Urteil vom 8.10.2019, KZR 73/17, WRP 2019, 1572 - Werbeblocker III; Urteil vom 10.12.2019, KZR 57/19, K\&R 2020, 302. 
Ein Beispiel ist das Vorgehen von Bild.de, welches beim LG Hamburg anhängig war (siehe oben ${ }^{44}$ ), mit dem Adblock Plus Nutzer generell von der Nutzung der Seite ausgeschlossen werden. Diese Zugangssperren an sich wurden bislang nicht angegriffen und es ist keine Rechtsprechung zur Zulässigkeit dieser Sperren vorhanden.

Ein integraler Teil der Gegenmaßnahmen der Webseitenbetreiber sind Adblocker-Detektoren und vergleichbare Schutzsoftware, die auf die eine oder andere Weise der Ausschaltung von Werbeblockern dienen. Doch auch diese Softwareprogramme sind in rechtlicher Hinsicht fragwürdig. Gerade in datenschutzrechtlicher Hinsicht ${ }^{45}$ wurden Bedenken geäußert. So könnte im Rahmen der angekündigten E-Privacy-Verordnung die Zulässigkeit solcher Software bei Wirkung im Endgerät des Nutzers fraglich sein. In jedem Fall ist eine genaue technische Analyse solcher Software notwendig. Daneben könnte auch die europäische Datenschutzgrundverordnung von Bedeutung sein. Diese Aspekte werden in dieser Arbeit untersucht.

Für besondere Software, die trotz eingeschaltetem Werbeblocker beim Nutzer Werbung ausspielt, ist wiederum der Anwendungsbereich des UWG eröffnet. Hier liegt die Anwendung von $₫ 7$ Abs. 1 S. 2 UWG zumindest nicht gänzlich fern ${ }^{46}$.

\section{Rechtlicher Prüfungsmaßstab betreffend Gegenmaßnahmen der Blockeranbieter auf Zugangssperren und Umgehungsmaßnabmen}

Zuletzt kommen die Gegenreaktionen aus dem Lager der Werbeblocker in den Fokus. Wie durch das LG Hamburg ${ }^{47}$ entschieden, kann ein nochmaliges Unterwandern der Internetseiten durch die Betreiber der Werbeblocker rechtlich unzulässig sein. Im speziellen Fall wurde das Verbot auf urheberrechtliche Füße gestellt, da ein Verstoß gegen $\$ 95$ a UrhG, also eine Umgehung einer technischen Maßnahme zum Schutz eines urheberrechtlich geschützten Werkes bzw. eines geschützten Gegenstandes, angenommen worden ist. Diese Einordnung soll ebenfalls analysiert wer-

44 LG Hamburg, Beschluss vom 22.10.2015 - 308 O 375/15, ZUM 2016, 892.

45 Vgl. Bechtolf/Vogt, K\&R 2016, 445.

46 Vgl. Kreutz, MMR 2016, 364.

47 Beschluss vom 22.10.2015 - 308 O 375/15, ZUM 2016, 892; siehe auch das Verfahren gegen einen Nutzer, der bei YouTube ein Tutorial-Video zur Umgehung der Bild.de-Sperre hochgeladen hatte: LG Hamburg, Urteil vom 21.12.2016 - 310 O 129/16, juris. 


\section{A. Einführung in den Problembereich}

den, da es nicht ganz unstreitig ist, ob diese Norm auf den Sachverhalt anzuwenden ist ${ }^{48}$.

Daneben war auch hier eine gezielte Mitbewerberbehinderung nach $\$ 4$ Nr. 4 UWG gerichtlicher Prüfungsgegenstand ${ }^{49}$, sodass sich ein kurzer Blick auf die Bewertung lohnt.

\section{Ziel und Ablauf der Untersuchung}

Ziel dieser Untersuchung ist es einerseits, die rechtlichen Probleme rund um den Einsatz von Internetwerbeblockern systematisch und verständlich darzustellen. Denn aufgrund einer Vielzahl von Gerichtsurteilen und Fachbeiträgen in juristischen Zeitschriften ist die Materie „Adblocker“ innerhalb kürzester Zeit sehr unübersichtlich geworden. Für den nicht vorbefassten Betrachter ist deshalb nicht immer auf die Schnelle erkennbar, auf welcher Ebene das jeweils behandelte Problem anzusiedeln ist. Sprich: betrifft das Problem nun die Zulässigkeit von Werbeblocken generell oder nur die Zulässigkeit des Whitelistings, betrifft es Gegenmaßnahmen der Internetbetreiber oder sogar neuerliche Einwirkungen auf Webseiten wie etwa die Umgehung von Zugangssperren? Insofern verfolgt die Untersuchung das Ziel, als ein Sammelwerk die bereits bekannten und kommentierten Probleme in ein noch nicht vorhandenes Schema zu verorten. Dadurch soll sie idealerweise auch als Nachschlagewerk praktischen Nutzen bringen.

Andererseits ist Ziel dieser Ausarbeitung, solche Probleme näher zu beleuchten, die abseits der Beiträge der prominenten Verfasser etwas weniger Beachtung finden. Dies betrifft etwa eine Betrachtung des Falles, in welcher der Werbeblocker nicht wie geplant arbeitet und zu viele Elemente einer Webseite blockt. Bei solchen Elementen wird es sich dann um redaktionelle Inhalte handeln, die regelmäßig von Drittservern (etwa von sozialen Netzwerken) in den redaktionellen Teil eingebettet werden. Bei diesem „Overblocking" stellt sich genau wie beim Werbeblocken an sich die Zulässigkeitsfrage. Generell ist nicht nur die Frage des „Ob“ von Werbeblockade im Internet zu beleuchten, sondern auch das „Wie“. Auch in diese Richtung geht die Beleuchtung der Schutzmaßnahmen der Webseitenbetreiber und der Konterreaktionen der Werbeblocker, welche bislang

48 Vgl. Kiersch/Kassel, CR 2017, 242; Nink, CR 2017, 103.

49 LG Hamburg, Beschluss vom 22.10.2015 - 308 O 375/15, ZUM 2016, 892; OLG Köln, Beschluss vom 17.12.2015 - 6 W 128/15, (unveröffentlicht). 
nur wenig Beachtung im Schrifttum gefunden haben. Damit verfolgt die Ausarbeitung das Ziel, die Problematik in möglichst ganzheitlicher Weise zu bündeln und Lösungsansätze zu vermitteln.

Ein weiteres Ziel dieser Arbeit ist es, die Rechtsprechung zu Internetwerbeblockern in das bestehende System der Rechtsprechung in Fragen digitalisierter Märkte einzuordnen und daraus eine Leitlinie für existente oder noch zu erdenkende Geschäftsmodelle im Internet zu entwickeln. Denn das Internet als Innovationsmarkt wird voraussichtlich auch in Zukunft neue Geschäftsmodelle hervorbringen, die in bestehende wirtschaftliche Strukturen eingreifen werden und daraus finanziellen Nutzen schlagen wollen. Insofern kann die Rechtsprechung zur Zulässigkeit des Whitelistings eine Blaupause für künftige „Start-Ups“ sein. Diese Arbeit soll damit nicht nur den status quo darstellen, sondern darüber hinaus Maßgaben für die Zukunft herausarbeiten.

Abschließend ist im Rahmen einer rechtsvergleichenden Betrachtung $\mathrm{zu}$ untersuchen, ob die deutsche Diskussion und Beurteilung auch in anderen Ländern und Jurisdiktionen vergleichbar rezipiert werden. Falls Unterschiede bestehen, sollen diese skizziert und analysiert werden. Durch die Ubiquität des Internets ist eine weltweit harmonisierte Beurteilung der Internetwerbeblocker wünschenswert.

Zur Erreichung dieser Ziele wird die Arbeit in fünf Teile gegliedert. Zunächst wird auf die Werbung im Internet als Grundlage der gesamten Auseinandersetzungen eingegangen (siehe Ausführungen unter B.). Im nächsten Teil ist ein ausführlicher Blick auf die Zulässigkeit der Werbeblocker und des Geschäftsmodells des Whitelistings zu richten. An dieser Stelle werden auch ähnliche Geschäftsmodelle der Vergangenheit und Gegenwart thematisiert und Analogien untersucht, um Leitlinien für die Zukunft zu entwickeln (siehe Ausführungen unter C.). Der dritte Teil wird die tatsächlichen und technischen Möglichkeiten des Schutzes der Webseiten vor den Werbeblockern sowie eine rechtliche Bewertung dieser Schutzmaßnahmen beleuchten (siehe Ausführungen unter D.). Im darauf folgenden Teil ist wiederum auf die Konter der Blocker zu blicken (siehe Ausführungen unter E.). In Kürze wird ein Blick auf Auseinandersetzungen mit Internetwerbeblockern im Ausland gewendet (siehe Ausführungen unter F.). Zuletzt werden Thesen zum Abschluss de Arbeit formuliert (siehe dazu Abschnitt G.). 


\section{B. Grundlage: Werbung im Internet}

Internetwerbeblocker bauen auf bestehenden Strukturen auf. Ohne diese Strukturen gäbe es sie überhaupt nicht. Sie wären nie erfunden worden, weil kein Bedürfnis für sie bestünde. Sie sind deshalb in jeder Hinsicht den bestehenden Strukturen nachgelagert. Ein typisches Beispiel einer hoch spezialisierten Gesellschaft und Wirtschaftsordnung.

Diese Strukturen lassen sich schon aus dem Wortlaut gut erkennen. Die Blocker brauchen das Internet und den Werbemarkt - und zwar kumulativ. Fällt eine der beiden Strukturen aus, so ist dies das Ende der Internetwerbeblocker. Andersherum benötigen die Strukturen die Blocker nicht. Der Werbemarkt hat lange Zeit gut ohne das Internet existiert und könnte es auch in Zukunft wieder. Das Internet (nicht im technischen Sinne, sondern als "Content"-transportierendes Medium) hingegen ist zwar praktisch schon immer mit (finanzierender) Werbung verbunden. Es könnte aber theoretisch auch ohne Werbung existieren. Werbung und Internet im vorbeschriebenen Sinne stehen insoweit in einer symbiotischen Beziehung - beide nützen einander und haben das gegenseitige Fortkommen ohne Zweifel begünstigt. Ein treffliches Beispiel aus der Biologie ist die Symbiose im Sinne des Mutualismus zwischen Eiche und Eichelhäher ${ }^{50}$ beide sind nicht lebensnotwendig voneinander abhängig, doch sorgt die Werbung wie der Eichelhäher dafür, dass das Internet wie eine Eiche auch in neuen Gebieten Ableger säen und Wurzeln schlagen konnte. Werbung ist einer der Mulitplikatoren des World Wide Webs und maßgeblich an der Entwicklung zum heutigen Standard beteiligt.

Für die Nutzung des Internets bedarf es im Übrigen notwendigerweise einiger Hard- und Software. Ohne an dieser Stelle auszuschweifen, sind dies zumindest ein internetfähiges Gerät und ein Browser, der den Content wahrnehmbar macht. Man kann die Internetwerbeblocker insoweit als Sekundärsoftware ansehen, weil sie in der Regel an ein primäres Programm (v.a. Browser) angebunden sind. Sie sind regelmäßig als sog. „Add-Ons“ verfügbar ${ }^{51}$. Das heißt, dass diese Programme kleine Erweiterungen von Browsern darstellen. Dies kann freilich auch anders gestaltet

50 Vgl. Smith/Smith, Ökologie, S. 425.

51 Etwa für den Browser Mozilla Firefox, vgl. https://addons.mozilla.org/de/firefox/a ddon/adblock-plus/, zuletzt abgerufen am: 30.5.2019. 
sein. Manche Anwendungen wie Adguard sind etwa eigenständige Apps ${ }^{52}$. Auch gibt es mittlerweile einige Browser mit integriertem Werbeblocker, was im weiteren Verlauf mehrfach behandelt wird. An der Funktionsweise des Werbeblockers ändert sich dabei aber praktisch nichts.

Negativ zugespitzt formuliert: Internetwerbeblocker könnten als „parasitäre Lebensform" angesehen werden, die einen Wirt zum Überleben brauchen. Sie benötigen den Browser als Wirt. Der Browser hingegen ist lediglich Werkzeug zur Rezeption des Internetangebots, welches in der oben genannten Verbindung zur Werbung steht. Um im biologischen Bild zu bleiben: der Browser ist die Eichel, die vom Internetwerbeblocker befallen wird.

Schlussendlich geht es auch um die Frage, ob die Internetwerbeblocker wirklich Parasit oder vielleicht doch (dritter) Teilnehmer der Symbiose sind. Um diese Frage aber zu beantworten, sind zunächst die Strukturen des Werbemarktes und des Internets darzulegen und zu verstehen. Nur bei Betrachtung der Entwicklung und des status quo dieser Strukturen ist verständlich, wieso Internetwerbeblocker entwickelt worden und aktuell überaus erfolgreich sind.

Dabei soll zunächst auf die Arten von Werbung im Internet eingegangen werden (siehe dazu Ausführungen unter Ziffer I.). Sodann ist die wirtschaftliche Bedeutung dieser Werbung sowie die Struktur des Werbemarktes im Internet zu darzustellen (siehe dazu Ausführungen unter Ziffer II.). Auch die technische Ausgestaltung bedarf der ausführlicheren Darlegung. Dabei ist auch ein besonderes Augenmerk auf die mit der Werbung im Internet einhergehende Belastung der Nutzer mit Tracking-Software zu werfen (siehe dazu Ausführungen unter Ziffer III.). Diese tatsächlichen und unjuristischen Feststellungen sind für das korrekte Verständnis der sich anschließenden rechtlichen Fragestellungen unabdingbar.

Zuletzt erfolgt eine ausführliche rechtliche Analyse der gebräuchlichen Werbeformen und Phänomene und wirtschaftlichen Verflechtungen (siehe dazu Ausführungen unter Ziffer IV.). Ziel der Arbeit ist an dieser Stelle eine kohärente Bewertung des Internetwerbemarktes. Abschließend werden zusammenfassende Thesen zum Werbemarkt formuliert (sieh dazu Ziffer V.).

52 Vgl. https://adguard.com/de/welcome.html, zuletzt abgerufen am 30.5.2019. 


\section{Arten von internetbasierter Werbung}

Bevor auf die einzelnen Formen von Werbung im und mit dem Internet eingegangen wird, bedarf der Begriff der Werbung einer Definition. Von dieser Definition ausgehend gilt es, die hier bedeutsamen Werbeformen systematisch abzugrenzen und zu ordnen.

\section{Begriff der Werbung}

Im allgemeinen Wortsinn versteht man unter Werbung die Verbreitung von Informationen in der Öffentlichkeit (= an eine unbestimmte Vielzahl von Adressaten) oder an ausgesuchte Zielgruppen, zwecks Bekanntmachung, Verkaufsförderung oder Imagepflege von Unternehmen bzw. deren Produkten und Dienstleistungen, gleich ob diese entgeltlich sind ${ }^{53}$.

Davon ausgehend sind vier Elemente prägend für eine Werbung:

- ein Werbender,

- mindestens ein Adressat,

- eine Information und

- die werbliche Zwecksetzung dieser Information (d.h. Bekanntmachung, Verkaufsförderung oder Imagepflege).

In spezifisch rechtlicher Hinsicht enthält Art. 2 lit.a) der Richtlinie 2006/114/EG über irreführende und vergleichende Werbung (sog. „Werberichtlinie“) eine Definition des Begriffes der Werbung für den Anwendungsbereich der Richtlinie. Diese Definition lautet:

„Werbung“ (ist) jede Äußerung bei der Ausübung eines Handels, Gewerbes, Handwerks oder freien Berufs mit dem Ziel, den Absatz von Waren oder die Erbringung von Dienstleistungen, einschließlich unbeweglicher Sachen, Rechte und Verpflichtungen, zu fördern.

Anzumerken ist dabei, dass der Anwendungsbereich der vorgenannten Richtlinie sich auf das Verhältnis von Gewerbetreibenden zueinander (B2B-Bereich) beschränkt, weil für das Verhältnis von Gewerbetreibenden zu Verbrauchern (B2C-Bereich) die Richtlinie 2005/29/EG über unlautere Geschäftspraktiken (UGP-Richtlinie) gilt. Die UGP-Richtlinie enthält jedoch keine Definition des Begriffes der Werbung. Auch das deutsche Recht, allen voran das UWG, in welchen die vorgenannten Richtlinien

53 Vgl. die Definition bei Wikipedia, https://e.wikipedia.org/wiki/Werbung, zuletzt abgerufen am: 30.5.2019. 
umgesetzt worden sind, enthält sich einer ausdrücklichen Definition des Begriffs der Werbung ${ }^{54}$.

Dementsprechend obliegt die Begriffsbestimmung im B2C-Bereich der Rechtsprechung. Die ständige Rechtsprechung des BGH zum Begriff der Werbung lautet wie folgt:

„Nach der Rechtsprechung des Senats umfasst der Begriff der Werbung, der weder im Gesetz gegen den unlauteren Wettbewerb noch in der Richtlinie 2002/58/EG über den Datenschutz in der elektronischen Kommunikation definiert ist, schon nach dem allgemeinen Sprachgebrauch alle Maßnahmen eines Unternehmens, die auf die Förderung des Absatzes seiner Produkte oder Dienstleistungen gerichtet sind. Damit ist außer der unmittelbar produktbezogenen Werbung auch die mittelbare Absatzförderung - beispielsweise in Form der Imagewerbung oder des Sponsoring - erfasst. Werbung ist deshalb in Übereinstimmung mit Art. 2 Buchst. a der Richtlinie 2006/114/EG über irreführende und vergleichende Werbung jede Äußerung bei der Ausübung eines Handels, Gewerbes, Handwerks oder freien Berufs mit dem Ziel, den Absatz von Waren oder die Erbringung von Dienstleistungen zu fördern.

Nach der Rechtsprechung des Gerichtshofs der Europäischen Union erfasst die in Art. 2 Buchst. a der Richtlinie 2006/114/EG über irreführende und vergleichende Werbung niedergelegte besonders weite Definition sehr unterschiedliche Formen von Werbung. Der Begriff der Werbung ist daher in keiner Weise auf die Formen klassischer Werbung beschränkt (EuGH, Urteil vom 11. Juli 2013 - C-657/11, GRUR 2013, 1049 Rn. 35 - Belgian Electronic Sorting Technology NV/Peelaers u.a.).“55

Nach dem BGH wird damit die Legaldefinition in Art. 2 lit. a) der Werberichtlinie 2006/114/EG mitsamt der dazu ergangenen, auslegenden Rechtsprechung des EuGH auch für den Begriff der Werbung im B2C-Bereich herangezogen. Widersprüche zwischen der Rechtsprechung des BGH und des EuGH bestehen nicht.

54 Eine Definition ist im Rundfunkstaatsvertrag in $\$ 2$ Abs. 2 Nr. 7 enthalten, diese bezieht sich aber auf die Sendung im Rundfunk und betrifft damit einen speziellen Bereich der Medien.

55 BGH, Urteil vom 14. 012016 - I ZR 65/14, GRUR 2016, 946 - Freunde finden, (juris, Rn. 27f.); BGH, Urteil vom 20.5.2009 - I ZR 218/07, GRUR 2009, 980 E-Mail-Werbung II, (juris, Rn. 27f.); Urteil vom 12.9.2013 - I ZR 208/12, GRUR 2013, 1259 - Empfehlungs-E-Mail (juris, Rn. 17f.). 
Nach dem derart festgelegten rechtlichen Werbungsbegriff sind folgende Elemente für eine Werbung notwendig:

- ein Werbender,

- mindestens ein Adressat,

- eine Äußerung und

- die werbliche Zwecksetzung dieser Äußerung (d.h. Ziel der zumindest mittelbaren Absatzförderung bzw. Förderung der Dienstleistungserbringung).

Abgesehen von kleineren semantischen Feinheiten besteht damit kein relevanter Unterschied zwischen dem Begriff der Werbung im allgemeinen Sprachgebrauch und im rechtlichen Sinne. Die Elemente der Information bzw. der Äußerung können insoweit als Synonyme betrachtet werden. Im Rahmen der Zwecksetzung entspricht der Begriff der mittelbaren Absatzförderung den indirekten Werbeansprachen der Bekanntmachung und der Imagepflege.

Im weiteren Verlauf der Bearbeitung bedarf es insoweit keiner begrifflichen und sinnlogischen Unterscheidung. Der Begriff der Werbung wird damit sowohl im eigentlichen Wortsinne als auch im Sinne eines rechtlichen terminus technicus genutzt.

\section{Systematik der Werbeformen}

Nicht zu den oben herausgearbeiteten Wesenselementen einer Werbung und deshalb für die Qualifikation als solche unerheblich ist hingegen das Verbreitungsmedium. Nach dem genutzten Medium zum Transport der Werbung lassen sich vielmehr die verschiedenen Werbeformen systematisieren.

Als erste Weichenstellung lassen sich dabei analoge und technische Werbemedien abgrenzen. Unter analogen Werbemedien sind dabei vor allem Printmedien, Außenwerbung oder Direktwerbung durch Postsendungen oder Personeneinsatz zu verstehen ${ }^{56}$. Hier sind also alle Werbeträger einzuordnen, bei denen die Werbebotschaft ohne Einsatz eines technischen Gerätes allein mit den menschlichen Sinnen möglich ist. Um solche analoge Werbemedien soll es hier nicht weiter gehen.

56 Vgl. die Aufzählung von Werbeträgern bei Gabler Wirtschaftslexikon, http://wir tschaftslexikon.gabler.de/Definition/werbetraeger.html, zuletzt abgerufen am: 30.5.2019. 
Im Umkehrschluss sind technische Werbemedien im hiesigen Verständnis alle solchen Werbeträger, die unter Einsatz eines technischen Gerätes die werbende Information zum Adressaten transportieren. Dies ist etwa der Fall bei Rundfunk- und Online Werbung. Auch sind hier Werbebotschaften in Computerspielen zu verorten. Ob es sich dabei in technischer Hinsicht um ein analoges Rundfunksignal (etwa das UKW-Radiosignal oder noch vereinzeltes analoges TV-Signal) ist bei dieser Einteilung unerheblich. Es kommt vielmehr auf die Vermittlung der Information durch ein technisches Gerät wie ein Radio- oder TV-Gerät an. Entgegen der umgangssprachlichen Benutzung des Wortes „digital“ als Gegenteil von ana$\log$, wird hier bewusst dieser Begriff vermieden. Der Begriff „digital“ ist bei genauer Betrachtung ambivalent, insbesondere in technischer Hinsicht. Zur Vermeidung von Ungenauigkeiten wird deshalb nur von technischen Werbemedien als Oberbegriff geschrieben.

Um diese technischen Werbemedien wird es in dieser Bearbeitung schwerpunktmäßig gehen. Allerdings nicht um diese technischen Medien in Ihrer Gesamtheit. Denn über den Einsatz eines vermittelnden technischen Gerätes bedarf es mit Blick auf die später zu behandelnden Internetwerbeblocker einer weiteren Abgrenzung. Diese Abgrenzung erfolgt sinnigerweise über das eingesetzte technische Gerät und das sie speisende Signal.

Als wesensverschiedene technische Geräte werden hier angesehen: Radios, Fernseher, Telefone und Computer. Die beiden erstgenannten werden dabei mit den jeweiligen Radio- bzw. TV-Signalen gespeist. Bei Telefonen wird eine Punkt-zu-Punkt Telekommunikationsverbindung hergestellt, bei der die Gespräche selbstverständlich auch werbenden Charakter haben können ${ }^{57}$. Computer hingegen werden beinahe ausnahmslos durch das Internetsignal gespeist. Für die hiesige Betrachtung nicht von Belang sind die Rundfunkmedien, also Radios und Fernseher ${ }^{58}$, und die Telefonie, sodass allein näher auf die internetverbundenen Computer einzugehen sein wird.

Der Begriff des Computers wird dabei für hiesige Zwecke weit aufgefasst. Hierzu zählen nicht nur die im Volksmund „Computer“ genannten Rechner wie Desktop-PCs oder Laptops bzw. Notebooks (im Weiteren: PCs), sondern auch mobile Geräte wie Smartphones oder Tablets. Im

57 Holland, Dialogmarketing, S. 69ff.

58 Zur Problematik von Fernsehwerbeblockern vgl. BGH, Urteil vom 24.6.2004 - I ZR 26/02, GRUR 2004, 877 - Werbeblocker I, sowie Lempe, Der Konflikt zwischen dem Vertrieb von Werbeblockern und der Werbefinanzierung elektronischer Medien. 
Rahmen der jüngeren technischen Evolution sind hier auch Smart-TVs (also Fernsehgeräte mit Internetzugang und der Möglichkeit über Apps Internetangebote zu nutzen) und Smart-Home-Lautsprecher (z.B. Amazon Echo bzw. „Alexa“ oder Google Home) einzuordnen. Im Rahmen der neueren technischen Innovationswelle des „Internet of Things“ („IoT“) sind auch andere internetfähige Haushaltsgeräte hier anzuführen. So können mittlerweile selbst Küchengeräte oder Waschmaschinen mit Internetzugang informationstechnische Funktionen bewältigen. Wirtschaftlich wichtig wird dies zudem bei vernetzten Fahrzeugen, insbesondere wenn die aktuellen Entwicklungen im Bereich des autonomen Fahrens Marktreife erlangen. Alle diese Arten von Computern sind potentiell in der Lage Werbung zu übertragen.

Zusammenfassend ist die vorstehende Systematik dargestellt als Abbildung 1:

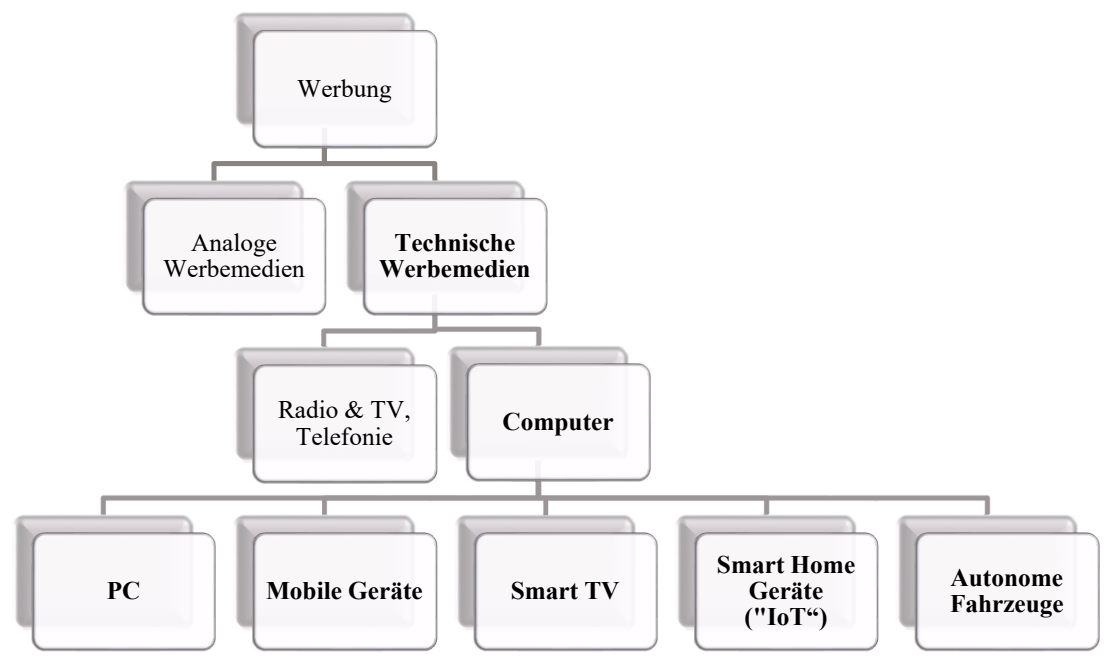

Abbildung 1: Systematik der Werbemedien

3. Darstellung der maßgeblichen Werbeformen

Im Rahmen der für diese Bearbeitung maßgeblichen internetverbundenen Computer bestehen selbstverständlich erhebliche Unterschiede bei der Werbeausspielung. Die Werbeausspielung hängt ganz maßgeblich von der dem Gerät inhärenten Informationsübermittlung ab. Im Weiteren werden 
die gebräuchlichen Werbeformen der verschiedenen Computer, geordnet nach den oben herausgearbeiteten Kategorien dargestellt.

\section{a) Werbeformen bei PCs}

Die Werbeformen bei PCs lassen sich auf einer ersten Ebene in drei Kategorien ordnen: E-Mail-Werbung, Werbung auf Internetseiten und Werbung in sonstigen Programmen. Diese Unterscheidung beruht hauptsächlich auf den unterschiedlichen Softwareanforderungen, die diese Werbeformen stellen. Während bei E-Mails ein einfacher E-Mail-Client (etwa Microsoft Outlook) ausreicht, bedarf es bei Webseitenwerbung eines Internetbrowsers. Bei der letztgenannten sonstigen Werbung bedarf es spezieller Softwareprogramme. Dass hier im Alltag auch Überschneidungen vorkommen, etwa wenn über den Browser auf der Internetseite des Mailanbieters E-Mails abgerufen werden, ändert an der Zweckmäßigkeit dieser Einteilung nichts. Dies kann sogar zur Verknüpfung der Werbeformen führen ${ }^{59}$. Im Einzelnen bestehen maßgebliche Unterschiede zwischen den Werbeformen, die nachfolgend dargestellt werden.

\section{aa) E-Mail Werbung}

Die Werbung mit E-Mails stellt die Übertragung der althergebrachten Postwurfwerbung in den digitalen Bereich dar. Abgesehen von der dahinterstehenden Technik lässt sich der Versand von E-Mails strukturell ohne Weiteres mit der analogen Werbeform des per Post versendeten Anschreibens vergleichen. Vorteile bietet die E-Mail jedoch darin, dass hier keine besonderen Portokosten anfallen, die Übertragungszeit minimal ist und mit Leichtigkeit Informationen an eine Vielzahl von Adressaten verschickt werden können. Die Folgen kennt jeder Internetnutzer nur zu gut - E-Mail-Postfächer werden täglich mit Werbemails überflutet. Der Grat zwischen nützlicher Werbung und Spam ist sehr schmal.

59 Vgl. dazu OLG Nürnberg, Urteil vom 15.1.2019, 3 U 724/18, K\& R 2019, 200, in welchem eine Displaywerbung zwischen E-Mails im Posteingang eine T-OnlineAccounts bewertet worden sind. Das OLG Nürnberg lehnte eine unzumutbare Belästigung der Nutzer nach $\$ 7$ UWG ab. Der BGH hat auf die Revision hin den EuGH auf Grundlage von Art. 267 AEUV angerufen, Beschluss vom 30.1.2020 - I ZR 25/19, GRUR 2020, 420 - Inbox-Werbung. 
Die E-Mail als Werbeform mag einmalig (sog. Stand Alone Mail) oder wiederkehrend in Form eines Newsletters sein. Dazwischen stehen Transaktions-Mails, mit denen eine zuvor abgeschlossene (Internet-)Transaktion - etwa eine Bestellung in einem Online Shop - bestätigt oder ein Kauf abgewickelt wird, sowie Trigger-Mails, die anlassbezogen etwa zum Geburtstag oder anlässlich eines Events werbliche Informationen kundtun ${ }^{60}$.

Im Rahmen der Gestaltung sind nach dem aktuellen Stand der Technik kaum Grenzen gesetzt. Mails können sowohl nur Text enthalten, aber auch aufwändig gestaltet sein wie HTML-Webseiten ${ }^{61}$.

Die Werbeform E-Mail ist dadurch gekennzeichnet, dass sie im Grundsatz ein aktives Abrufen der Nachricht aus dem E-Mail-Postfach erfordert. Wenn der Empfänger seine Mails allerdings nicht liest, kann die Werbeform nicht zum Erfolg führen.

bb) Werbung auf Webseiten

Wie eingangs bereits dargestellt ist es bei PCs notwendig, bestimmte Software zu installieren, um mit Hilfe des Internets wahrnehmbare Informationen zu rezipieren. Dafür werden zur Darstellung von Webseiten im „World Wide Web“ Internetbrowser benötigt ${ }^{62}$. Diese Programme sind jedem Internetnutzer bestens vertraut. Die bekanntesten und verbreitetsten Browser in Deutschland sind Google Chrome, Mozilla Firefox, Apple Safari, Microsoft Internet Explorer und Opera ${ }^{63}$.

Auf den von Nutzern angezielten und im Browser dargestellten Webseiten findet sich standardmäßig Werbung. Als Oberbegriff für solche Werbung wird zum Teil der Begriff des „Display-Marketings“64 oder „Display-Advertisings" ${ }^{65}$ genutzt.

Diese Werbung kann dem Adressaten in vielen verschiedenen Ausgestaltungen entgegen treten. Zur Vereinheitlichung der wiederkehrenden Werbeformen und Standardisierung zwischen Werbemarktteilnehmern existieren von der Wirtschaft formulierte Richtlinien, in denen die Hauptwerbeformen zusammengefasst sind. Eine solche Richtlinie wird etwa

60 Jacob, Integriertes Online-Marketing, S. 201ff..

61 Jacob, Integriertes Online-Marketing, S. 210.

62 Jacob, Integriertes Online-Marketing, S. 29.

63 Vgl. https://www.browser-statistik.de, abgerufen am: 16.8.2017. Der Dienst wurde mittlerweile eingestellt.

64 Jacob, Integriertes Online-Marketing, S. 216f..

65 Kammerzelt/Wimmer, Online Marketing, S. 26f., 78ff.. 
für den deutschen Werbemarkt vom Online-Vermarkterkreis (OVK), einem zentralen Gremium der deutschen Online-Vermarkter unter dem Dach des Bundesverbands Digitale Wirtschaft (BVDW) e.V. ${ }^{66}$, herausgegeben. So gliedert der OVK die Werbeformen auf Internetseiten - wie aus der nachfolgenden Übersicht in Abbildung $2^{67}$ zu erkennen - im Wesentlichen nach den Oberbegriffen „In-Stream“ (betriff Video- und Audio-Werbung), „In-Page“ (betrifft „Anzeigen zum Lesen“) und Kombinationsformen. Innerhalb dieser Kategorien wird noch spezifisch weiter unterteilt, worauf später noch zurückzukommen ist.

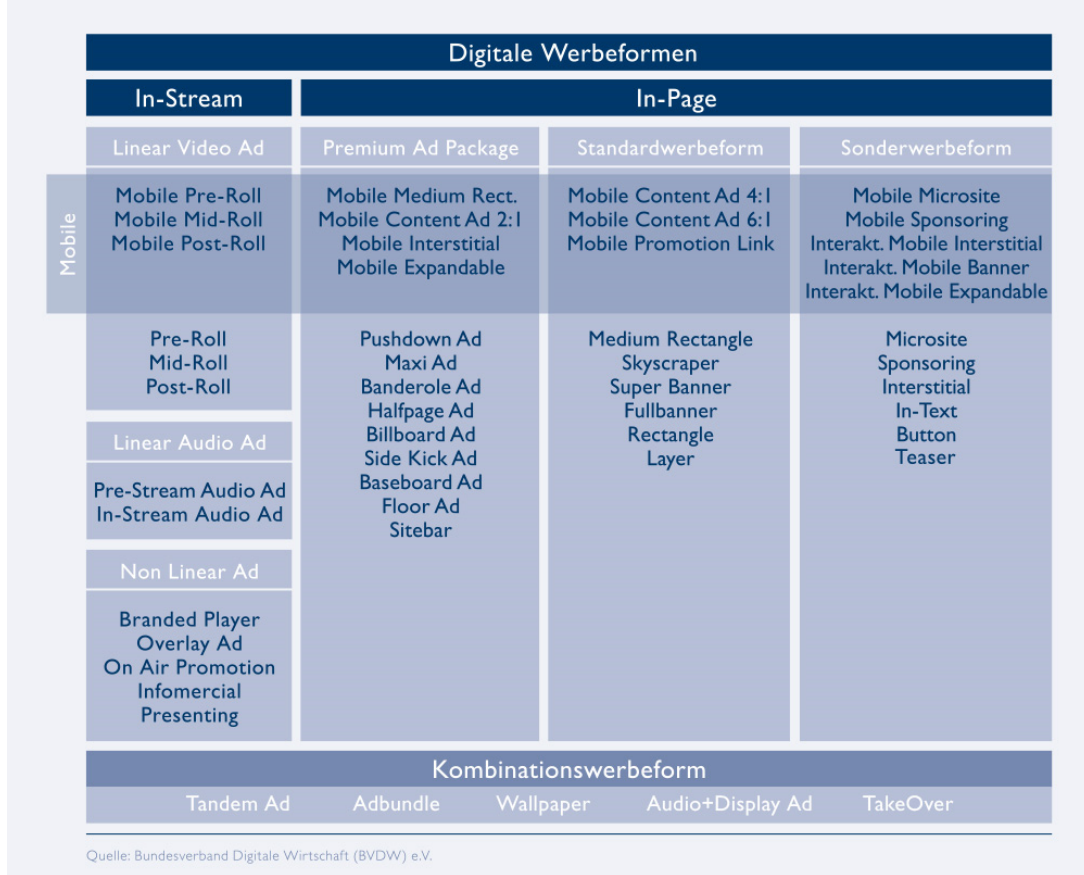

Abbildung 2: Übersicht digitaler Werbeformen im Internet des BVDW e.V.

66 Vgl. http://www.ovk.de/ovk/ovk-de/der-ovk.html, zuletzt abgerufen am: 30.5.2019.

67 Vgl. http://www.ovk.de//fileadmin/medien/ovk/werbeformen2014/digitale_werb eformen_2014.jpg, zuletzt abgerufen am: 30.5.2019. 
Während diese Gliederung sicherlich den Bedürfnissen des Marktes entspricht, wird für die Zwecke dieser Untersuchung hingegen eine schlagwortbasierte Darstellung vorgezogen. Ausgehend von der Standardsituation des Konsums von Internetseiten sollen die Formen näher beleuchtet werden, die dem Nutzer regelmäßig vor die Augen kommen: klassische Anzeigen, Pop-Ups, Interstitials, In-Text, Video \& Audio, Kombinationen und Content-Werbung.

Im Einzelnen:

(i) Klassische Anzeigen

Unter dem Oberbegriff der klassischen Anzeigen (oder „neudeutsch“ Ad$\left.s^{68}\right)$ wird Werbung verstanden, die vergleichbar mit Anzeigen in Printmedien, auf bestimmten, vom redaktionellen Inhalt abgetrennten Flächen einer Webseite geschaltet werden. Sie sind in der Regel optisch auffällig. Bei Klick auf die Anzeige wird der Nutzer regelmäßig auf die Webseite des Werbenden geleitet ${ }^{69}$. Im Volksmund wird die Gesamtheit dieser Werbeformen vereinfachend als Bannerwerbung bezeichnet, was zum Teil auch Wiederhall in juristischen Auseinandersetzungen gefunden hat ${ }^{70}$.

Unter diese Kategorie von Werbung fallen die vom OVK in Abbildung 2 als „In-Page“ klassifizierten Standardwerbeformen: Medium Rectangle, Skyscraper, Super Banner, Fullbanner und Rectangle. Diese Werbeformen sind „Standard“, weil Ihnen eine festgelegte Größe zugewiesen ist, die am Markt akzeptiert ist (so hat etwa ein Medium Rectangle die Größe von 300x250 Pixel, ein Skyscraper 120x600 Pixel ${ }^{71}$ ). Solche Standardwerbeformen lassen sich nach dem Baukastenprinzip ohne Mühe in Internetseiten einfügen.

Banner sind standardisierte Werbeflächen, die oft am oberen Rand einer Webseite positioniert $\operatorname{sind}^{72}$. Sie stehen dann über dem redaktionellen Inhalt der Internetseite und sind typischerweise die Anzeigen, die dem Besucher zuerst ins Auge springen. Sie können aber auch im Content oder am unteren Rand der Webseite positioniert werden. Verwandt damit sind

68 Kurz für Advertisements.

69 Vgl. Solmecke/Kocatepe, Recht im Online-Marketing, S. 403 - dort wird statt Anzeige der Oberbegriff Banner genutzt.

70 Vgl. Eckhardt, in: Auer-Reinsdorff/Conrad, $\$ 25$, Rn. 33.

71 Vgl. die Werbeformenliste des BVDW und OVK, verfügbar unter http://www.we rbeformen.org, zuletzt abgerufen am: 30.5.2019.

72 Jacob, Integriertes Online-Marketing, S. 222. 
Skyscraper, einziger Unterschied ist das Format - Banner sind im Querformat gehalten, Skyscraper im Hochformat. Rectangles sind rechteckige Werbeflächen innerhalb des redaktionellen Bereichs, die regelmäßig an drei Seiten von Text umgeben sind, damit sie im Lesefluss "mitgelesen“ werden ${ }^{73}$.

Daneben gibt es einige besondere Formen: etwa die Maxi Ad, die mit einer Größe von 640x480 Pixeln zentral positioniert ist. Mit dieser Anzeige können vor allem animierte $\mathrm{GIFs}^{74}$ oder Videosequenzen in einer Internetseite eingebunden werden. Durch ihre zentrale Positionierung kann sie vom Nutzer praktisch nicht ignoriert werden. Vergleichbar dazu ist die Halfpage Ad, mit einer Größe von 300x600 Pixeln und Positionierung im redaktionellen Teil. Weiteres Pendant ist die Billboard Ad, die ein überdimensioniertes Banner in der Größe von 800x250 Pixeln darstellt ${ }^{75}$.

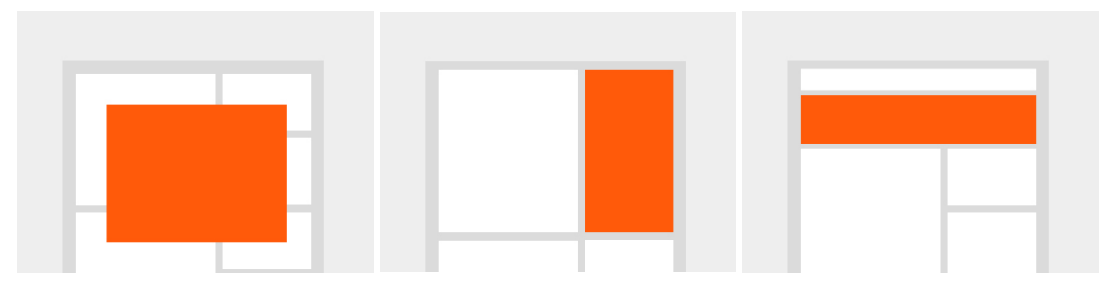

Beispiele von der Internetseite stroeer.de: von links nach rechts - Maxi Ad, Halfpage Ad, Billboard Ad

Anzeigen mit erweiterten Funktionen sind durch eine Dynamik der Webseite gekennzeichnet, die den Content verschiebt oder überlagert. So ist eine Pushdown Ad laut der BVDW Werbeformenliste ${ }^{76}$ eine Anzeige, die den Seitencontent nach unten schiebt. Dies kann durch den Nutzer manuell erfolgen oder optional automatisch Öffnen, wobei dann das Werbemittel nach maximal 7 Sekunden wieder auf seine Ursprungsgröße minimiert wird. Ähnlich ist die Banderole Ad, die sich im Querformat über den Content legt und sich nach maximal 15 Sekunden oder Klick auf den

73 Jacob, Integriertes Online-Marketing, S. 222.

74 GIF = Graphics Interchange Format, mit der animierte Bilderfolgen dargestellt werden können, vgl. https://de.wikipedia.org/wiki/Graphics_Interchange_Format , zuletzt abgerufen am: 30.5.2019.

75 Vgl. die Werbeformenliste des BVDW und OVK, verfügbar unter http://www.we rbeformen.org, zuletzt abgerufen am: 30.5.2019.

76 Vgl. die Werbeformenliste des BVDW und OVK, verfügbar unter http://www.we rbeformen.org, zuletzt abgerufen am: 30.5.2019. 
obligatorischen Schließen Button auf einen „Reminder" reduziert sowie sich nach Klick auf diesen „Reminder" wieder maximiert ${ }^{77}$. Hierhin gehört auch die Sidekick Ad, die im Ausgangspunkt ein herkömmliches Rectangle ist, das nach dem Öffnen durch Klick oder Mouseover ${ }^{78}$ die Webseite verkleinert und nach links verschiebt, während rechts eine großfächige Werbung expandiert.

Eine weitere erweitert funktionale Anzeige ist die Baseboard Ad. Damit ist eine am unteren Rand des angezeigten Ausschnitts fest positionierte, schmale Anzeige gemeint, die den redaktionellen Teil geringfügig überlappt. Diese ist in der Regel „sticky“, d.h. sie bleibt beim Scrollen in voller Größer sichtbar. Deshalb soll ein „Schließen“-Button obligatorisch sein. Damit eng verwandt ist die Floor Ad, die ebenfalls am unteren Rand positioniert und „sticky“ ist, dabei aber entweder per se größer oder expandierend ist, sodass hier Animationen bzw. Videos eingefügt werden können.
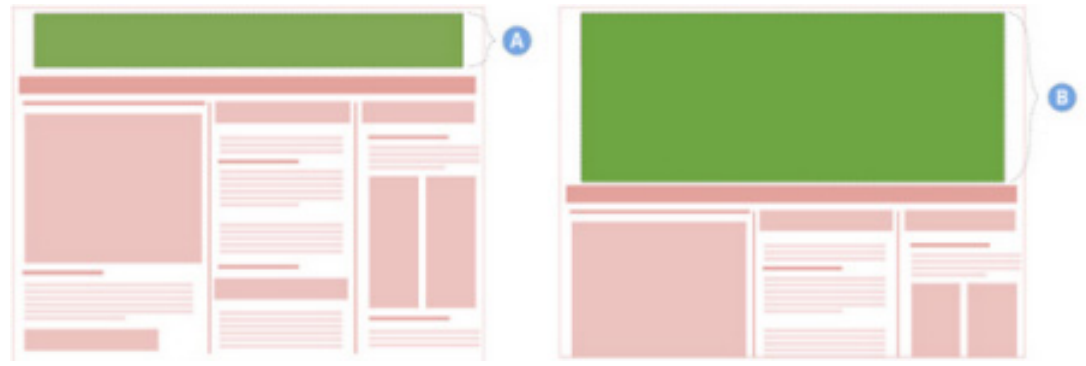

$\underline{\text { Beispiel }}^{79}$ für eine Pushdown Ad in den verschiedenen Anzeigestufen $-A=$ Standardbanner, $B=$ expandiertes Banner

77 Vgl. die Werbeformenliste des BVDW und OVK, verfügbar unter http://www.we rbeformen.org, zuletzt abgerufen am: 30.5.2019.

78 Mouseover (oder auch Rollover) ist ein Gestaltungselement auf Webseiten. Ein in den HTML -Code integriertes JavaScript -Element bewirkt, dass sich ein bestimmtes Element auf einer Webseite (meistens grafisch) verändert, falls der Benutzer mit der Maus über das Objekt fährt, vgl. https://www.e-teaching.org/ma terialien/glossar/mouseover, zuletzt abgerufen am: 30.5.2019.

79 Quelle: https://support.google.com/richmedia/answer/7026299?hl=en, zuletzt abgerufen am: 30.5.2019. 

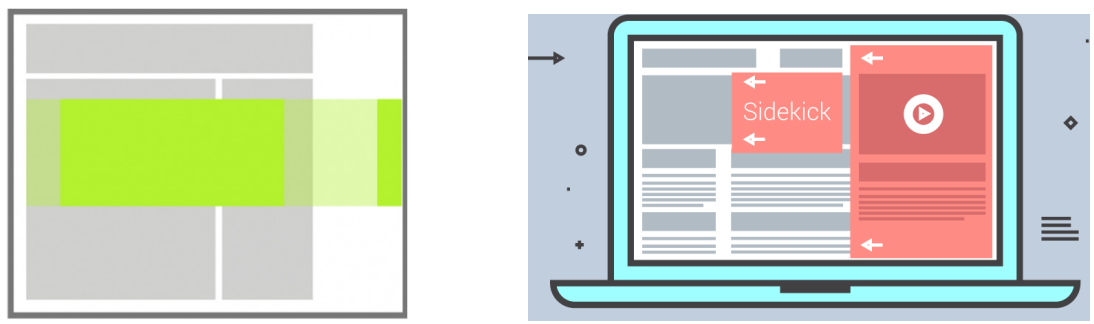

Beispiele für eine Banderole Ad ${ }^{80}$ mit "Reminder" am rechten Rand, linke Abbildung, und für eine Sidekick $A d^{81}$ im expandierten Zustand, rechts
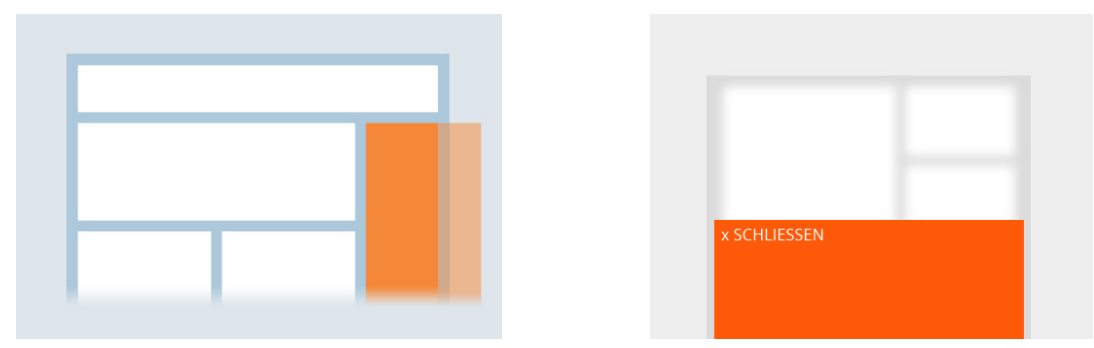

Beispiele für eine Sitebar Ad 82 mit angedeuteter Expansion, links, und eine Floor $A d^{83}$ mit obligatorischem „Schliessen“-Button, rechts

80 Quelle: http://www.urban-media.com/werbemittel/banderole-ad.html, abgerufen am: 16.8.2017.

81 Quelle: https://www.bannersnack.com/blog/iab-display-rising-star-ads/, zuletzt abgerufen am: 30.5.2019.

82 Quelle: http://www.adtargeting.de/formate/, abgerufen am: 16.8.2017.

83 Quelle: https://www.stroeer.de/digitale-werbung/kreation/werbeformen/online/fl oor-ad.html, abgerufen am: 16.8.2017. 


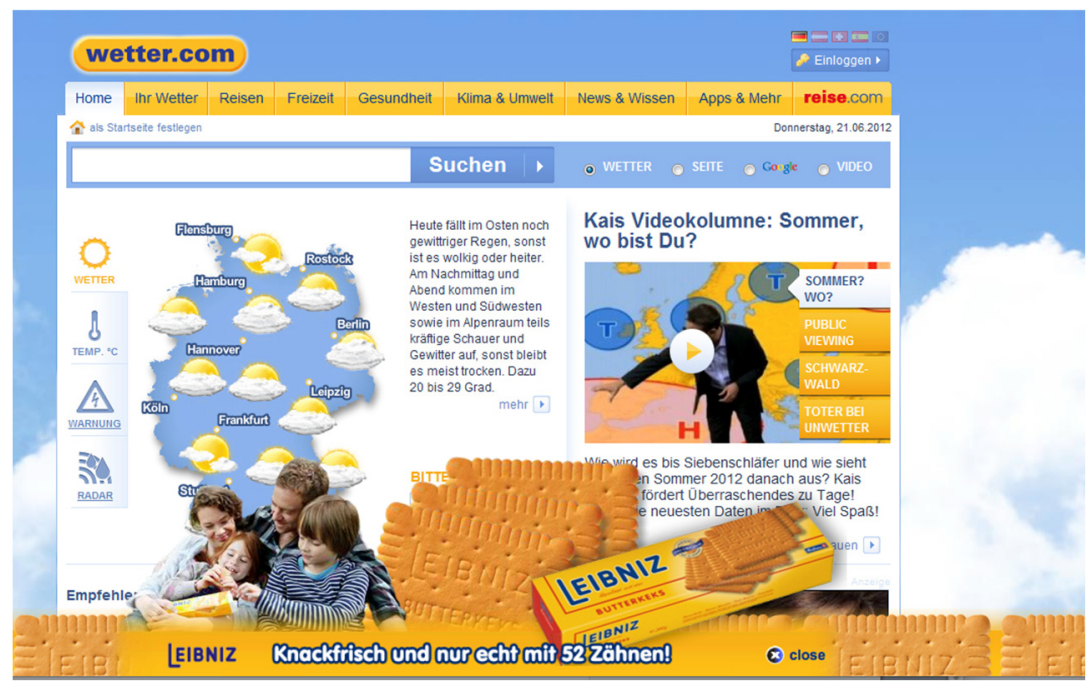

Beispiel einer optisch ausgefallenen Baseboard Ad ${ }^{84}$ für Leibniz Butterkekse auf wetter.com

Es bestehen daneben noch weitere anbieterspezifische Anzeigenformen, die an dieser Stelle mangels Übersichtlichkeit nicht dargestellt werden können. Aufgrund der Multimedialität und Programmierungsmöglichkeiten ist der Fantasie der Webseitengestalter im Grunde genommen keine Grenze gesetzt.

84 Abrufbar unter http://www.markuskroetz.de/portfolio/projects/advertising/baseb oard_bahlsen/, abgerufen am: 16.8.2017. 

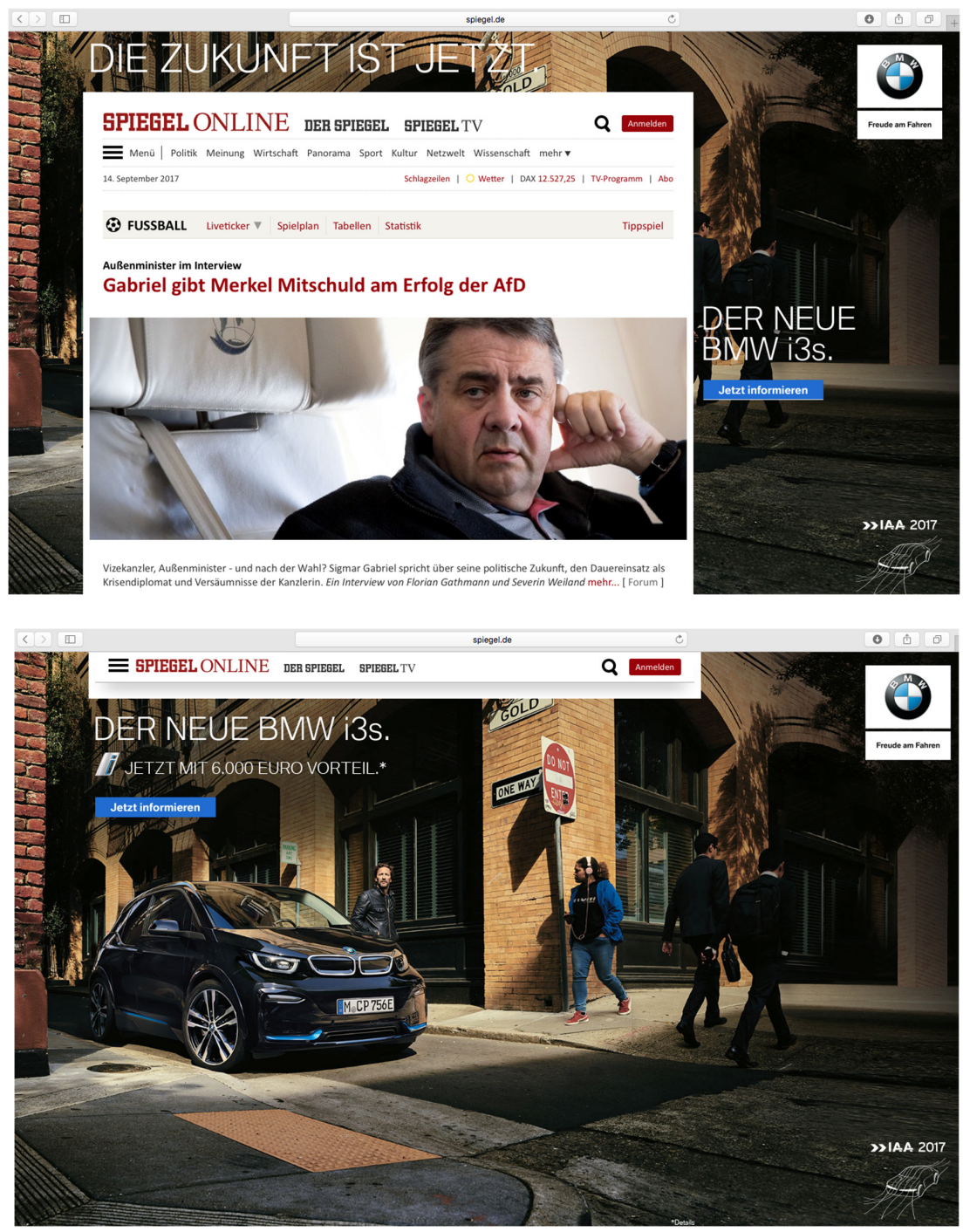

Beispiel einer Werbung ${ }^{85}$ für den BMW i3s bei Spiegel Online bei dem zunächst der gesamte Content in die Anzeige eingebettet ist, siehe oben, und bei Herunterscrollen zeitweise der gesamte Bildschirm für die Werbung genutzt wird, siehe unten

85 Abgerufen am 14.9.2017. 
Im Rahmen der konkreten Ausgestaltung dieser Anzeigenformen lassen sich zuletzt statische, animierte und interaktive Anzeigen unterscheiden. Hierzu lassen sich auch sog. Rich Media Anzeigen und Nanosite Ads zählen ${ }^{86}$. Unter Rich Media versteht man dabei die Einbindung von Video-, Audio- und Animationselementen in ein und derselben Anzeige, die früher regelmäßig durch die Software Adobe Flash ermöglicht wurde ${ }^{87}$. Nanosite Ads sind kleine selbständige Webseiten, die in der Anzeigenform integriert sind - mit dem Vorteil, dass der Nutzer nicht erst durch Anklicken der Anzeige eine neue Internetseite aufrufen muss, sondern in der aktuellen Seite interagieren $\mathrm{kann}^{88}$.
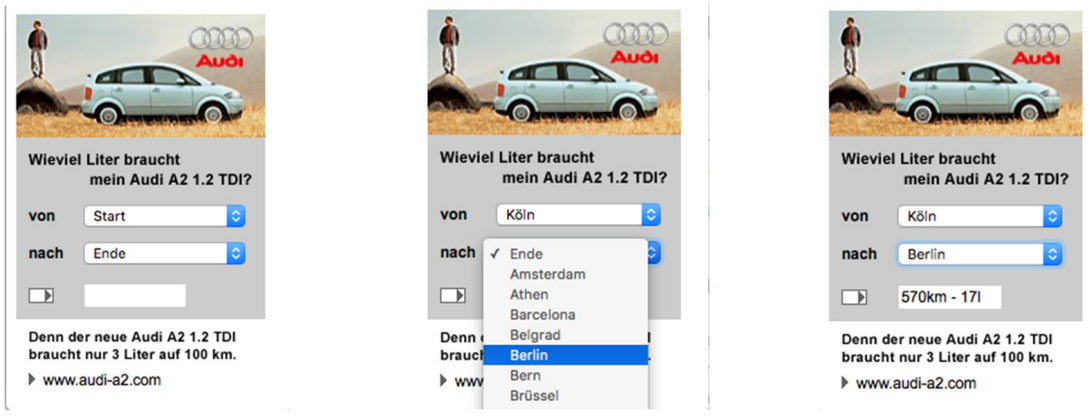

Beispiel für eine Nanosite ${ }^{89}$ zur Verbrauchsberechnung des Audi A2: links die Ausgangsanzeige, in der Mitte die Möglichkeit der Eingabe durch den Nutzer, rechts das interaktive Ergebnis

Allen klassischen Anzeigen ist gemein, dass sie zumindest in minimierter Form bei der vom Webseitenprogrammierer intendierten Fassung ohne weiteres Zutun des Nutzers angezeigt werden. Es bedarf also keiner aktiven Handlung des Nutzers, damit diese Werbung zumindest teilweise in seine Wahrnehmung gelangt. Vielmehr ist es bei vielen, vor allem automatisch expandierenden Anzeigenformen so, dass der Nutzer die invasive Werbeform aktiv schließen oder minimieren muss, wenn er nicht den

86 Vgl. die Aufzählung bei https://www.teialehrbuch.de/Kostenlose-Kurse/Marketin g/15318-Formen-der-Internetwerbung.html, abgerufen am: 16.8.2017.

87 Vgl. https://de.wikipedia.org/wiki/Rich_Media, abgerufen am: 16.8.2017.

88 Vgl. http://www.itwissen.info/Nanosite-nanosite.html, zuletzt abgerufen am: 30.5.2019.

89 Abgerufen von https://www.mediensprache.net/de/werbesprache/internet/forme n/banner.aspx, am: 16.8.2017. 
Ablauf einer bestimmten Zeitspanne abwartet. Diese Formen gehören zu den im weiteren Verlauf als dynamische Werbeformen bezeichneten Werbeanzeigen.

Jedenfalls kann sich der Nutzer nicht ohne aktives Zutun der Werbung ganz entziehen. Ihm bleibt bei „normalem“ Genuss der Webseite nur die eher theoretische Möglichkeit die Werbung nicht anzusehen, sondern den Blick auf andere Elemente zu richten. Jedoch wird eine grafisch auffällige Werbeanzeige immer - mindestens unbewusst ${ }^{90}$ - vom Internetnutzer wahrgenommen. Daraus erklärt sich zum einen eine hohe Effektivität der Anzeigen, gleichsam aber auch eine starke Gefahr, dass sie als belästigend aufgefasst werden.

(ii) Pop-Ups und Layer Ads

Unter Pop-Up Werbung versteht man das automatische Öffnen eines neuen Fensters bei Aufruf einer Internetseite, das den Blick auf die eigentlich angesteuerte Internetseite versperrt und damit die ungeteilte Aufmerksamkeit beansprucht ${ }^{91}$. Diese Fenster waren klassischerweise neue Browserfenster, die sich in den Vordergrund drängten. Mittlerweile können auch innerhalb der geöffneten Webseite überlagernde Fenster geöffnet werden - ähnlich der oben dargestellten Banderole Ad. Dies wird auch als Layer Ad (oder schlicht als Layer) bezeichnet und ist in der oben eingeblendeten OVK-Liste als Standardwerbeform enthalten ${ }^{92}$. Die Pop-Ups oder Layer Ads können dabei in beliebiger Größe ausgeliefert werden - sie können den gesamten Bildschirm einnehmen oder nur einen geringfügigen Seitenbereich.

Eine Abwandlung stellt die Pop-Under Werbung dar. Dabei wird ein neues Browserfenster geöffnet, das allerdings nur im Hintergrund geöffnet wird. Erst bei Schließen des/der Hauptfenster kommt das Pop-Under Fenster in den Blick und muss dann auch geschlossen werden. Ziel dieser Werbung ist es, dass der Nutzer beim eigentlichen Internetkonsum nicht gestört wird, aber im Nachgang die Werbung in sein Bewusstsein tritt und

90 Jacob, Integriertes Online-Marketing, S. 217.

91 Solmecke/Kocatepe, Recht im Online-Marketing, S. 406.

92 Layer werden auch in der BVDW Werbeformenliste beschrieben mit den Worten: „legt sich über den Content, ein Schließen Button ist obligatorisch“. 
er sich dadurch unter Umständen noch die Zeit nimmt, die Werbung mit erhöhter Aufmerksamkeit zu rezipieren ${ }^{93}$.

Der Gestaltung sind auch hier kaum Grenzen gesetzt. Die Pop-Ups \& Co. können auch zur Eigenwerbung eingesetzt werden, indem besondere Produkte oder Seitenbestandteile angepriesen werden. Regelmäßig wird aber Fremdwerbung transportiert ${ }^{94}$. Wollte man einen Vergleich zu den analogen Printmedien ziehen, wären diese Werbeformen am ehesten mit Werbeeinlagen oder Booklets zu vergleichen, die dem Leser beim Blättern in die Hand geraten und so Aufmerksamkeit beanspruchen. Da ein besserer Vergleich nicht erkennbar ist, handelt es sich bei Pop-Up Werbung um ein Spezifikum des Internetwerbemarkts.

Wie bei den klassischen Anzeigen im Internet ist auch bei Pop-Ups und Layern der Nutzer der Werbeausspielung ausgeliefert. Er muss bei Ausspielung dieser Werbeformen oft aktiv werden und diese aktiv schließen, um die Internetseite in Gänze wahrnehmen zu können. Wenn er nicht selbst die Anzeige schließen muss, muss regelmäßig eine gewisse Zeit abgewartet werden, bis die Anzeige verschwindet.

Aufgrund dieser Aggressivität der Aufmerksamkeitserregung werden Pop-Ups und Co. von vielen Internetnutzern als störend empfunden. In einer öffentlich zugänglichen Umfrage aus dem Jahr 2009 empfanden 60\% der Befragten Pop-Ups und Layer als „extrem störend“, 15\% als „sehr

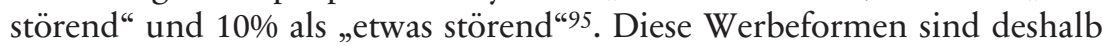
mehrheitlich negativ konnotiert.

\section{(iii) Interstitial und Prestitials}

Unter einem Interstitial versteht man nach der BVDW Werbeformenliste eine vollfl̈̈chige Werbeunterbrechung zwischen zwei Landingpages einer Website ${ }^{96}$. Das bedeutet, dass während des Surfens auf einer Webseite nach Klick auf einen Link zu einer Unterseite eine Werbung zwischengeschaltet wird. Als praktisches Beispiel stelle man sich vor, dass man auf der Startseite eines Nachrichtenportals einen interessanten Beitrag findet und nach

93 Solmecke/Kocatepe, Recht im Online-Marketing, S. 409.

94 Vgl. Solmecke/Kocatepe, Recht im Online-Marketing, S. 405.

95 https:/de.statista.com/statistik/daten/studie/72486/umfrage/akzeptanz-von-pop-u p-werbung-und-layer-werbung-in-2009/, zuletzt abgerufen am: 30.5.2019.

96 Vgl. die Werbeformenliste des BVDW und OVK, verfügbar unter http://www.we rbeformen.org, zuletzt abgerufen am: 30.5.2019. 
Klick auf die Überschrift des Beitrages der gesamte Bildschirm für einige Sekunden von Werbung in Beschlag genommen wird, bevor man endlich zum gewünschten Beitrag weitergeleitet wird. Dies ist im weitesten Sinne vergleichbar mit einer „1-Spot-Werbeeinblendung“ im TV.

Eine ähnliche Werbeform ist das Prestitial. Einziger Unterschied ist die zeitliche Abfolge der Werbung. Beim Prestitial erfolgt die Werbung vor Anzeige der Startseite. Für diese Werbeformen gilt hinsichtlich Gestaltung und Nutzeraktivität dasselbe wie bei den vorgenannten Werbeformen.

(iv) In-Text

Bei In-Text Werbung erfolgt eine Markierung von bestimmten Schlüsselworten im Text einer Webseite. Bei Mouseover öffnet sich dann ein Layer, das sich entweder bei Verlassen des Worts oder Layers mit dem Cursor automatisch schließt oder manuell geschlossen werden muss ${ }^{97}$.

In-Text Werbung gehört deshalb im weitesten Sinne zu den Pop-Up Werbungen, auf die insoweit verwiesen wird. Die Schlüsselworte an sich haben meist noch keine Werbewirkung, sondern sind nur vom Text deutlich gestalterisch abgesetzt.

97 Vgl. die Werbeformenliste des BVDW und OVK, verfügbar unter http://www.we rbeformen.org, zuletzt abgerufen am: 30.5.2019. 
Beispiel für InText-Werbung (von Adiro):

Der Text, den Sie hier lesen, ist ein Beispiel wie InText-Werbung aussehen kann. Wir haben für dieses Beispiel den Anbieter Adiro aus Köln gewählt, der zu den besten InText-Vermarktern zählt. Es folgen nun noch ein paar Beispielsätze zum Thema "Reise und Urlaub". Im besten Fall erkennt dies das System von Adiro und blendet thematisch passende Werbung ein. Los geht's: Wir hatten die Reise bereits ein halbes Jahr vorher gebucht, da der Flug zu diesem Zeitpunkt sehr günstig erschien. Vorher hatten wir die Preise in einer Preissuchmaschine verglichen. Der Weg zum Flughafen war kein Problem, da in unserem Reiseangebot auch ein Ticket für die Bahn inbegriffen war. Und auch das Mietauto hatten wir vorher über unseren Reiseanbieter gebucht, um am Zielort Zeit und Nerven zu sparen. Während sich meine Frau vor allem auf den weißen Sandstrand freute, war ich hingegen voller Vorfreude auf das Tauchen. Unser Platz im Flugzeug war sauber und halbwegs geräumig. Und schon wenige Minuten nach dem Start bestellten wir uns zwei Champagner und stießen auf einen schönen Urlaub am anderen Ende der Welt an.

\begin{abstract}
Artikel oder Beschreibungen aufweisen, können
Beispiel für InText-Werbung (von Adiro):

Der Text, den Sie hier lesen, ist ein Beispiel wi Beispiel den Anbieter Adiro aus Köln gewählt, dı noch ein paar Beispielsätze zum Thema "Reisı von Adiro und blendet thematisch passende W halbes Jahr vorher gebucht, da der Flug zu diє die Preise in einer Preissuchmaschine verglich unserem Reiseangebot auch ein Ticket für die vorher über unseren Reiseanbieter gebucht, ut meine Frau vor allem auf den weißen Sandst Tauchen. Unser Platz im Flugzeug war saube nach dem Start bestellten wir uns zwei Champa Ende der Welt an.
\end{abstract}

Unsere Top 2 - Cash4webmaster empfieh

\section{ADIRO\} WERBUng ? $\mathrm{X}$}

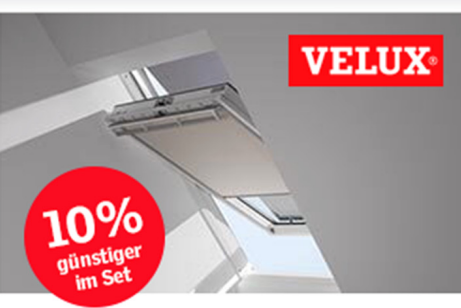

Preisvorteil sichern >

Beispiel für eine In-Text Werbung 98 mit aktivierten Schlüsselworten, oben, und geöffnetem Layer nach Mouseover über eines der Schlüsselworte, unten

Mit dieser Werbeform lässt sich im Idealfall eine kontextbasierte Werbung erreichen, indem man gewisse Schlüsselworte mit dazu passenden Werbeanzeigen verknüpft. Gerade wenn aber - wie im obigen Beispiel - kein automatisches Schließen des Layers vorgesehen ist, hat diese Werbeform eine erhebliche Belästigungstendenz. Dies liegt daran, dass erfahrungemäß viele Nutzer mit dem Cursor „mitlesen“. Dann unterbricht das sich öffnende Layer aber erheblich den Lesefluss, weil es dann regelmäßig den weiteren Text verbirgt.

Die In-Text Werbung unterscheidet sich von den vorgenannten Pop-Ups im engeren Sinne im Grundsatz dadurch, dass hier die Werbung nicht automatisch ausgespielt wird. Hier ist vielmehr eine aktive Handlung des Nutzers notwendig. Wenn er an diese Werbeform gewohnt ist und ein

98 Abgerufen unter http://www.cash4webmaster.de/intext-werbung.php, am: 17.8.2017. 
Mouseover vermeidet, kann er auch bei programmierter Werbung eine Ausspielung verhindern. Damit nimmt die In-Text Werbung eine gewisse Sonderstellung innerhalb der browserbasierten Werbeformen ein.

\section{(v) Video- und Audiowerbung im Stream}

Nicht mehr wegzudenken aus dem Internet ist Werbung durch Videos. Spätestens mit dem Aufstieg von YouTube und der einfachen Integration von Videos in Webseiten sind kurze Clips allgegenwärtig. Videos können Gestaltungsinhalt der oben genannten Werbeformen sein. Der Internetnutzer begegnet beizeiten auch Audio-Sequenzen beim Surfen. Dies kann dann von einigem Erschrecken begleitet sein, wenn diese Sequenz automatisch beginnt und dann ein stiller Raum plötzlich mit einer Werbebotschaft beschallt wird. Dasselbe gilt natürlich für automatisch startende Videos.

An dieser Stelle soll aber nicht auf diese Ausgestaltungen von „In-Page“Werbeformen eingegangen werden, sondern auf die Werbeformen beim Streamen von Videos und Audio-Sequenzen. Der OVK unterscheidet hierbei nach linearer und nicht linearer Werbung. Linearität bedeutet dabei, dass - ausgehend von einer linearen Zeitleiste - die Werbung an bestimmten Stellen anstatt des eigentlich gewollten Inhalts abgespielt wird. Die Linearität fehlt demnach, wenn Werbung parallel zum eigentlichen Content sichtbar ist ${ }^{99}$.

Innerhalb der linearen Werbung unterscheidet der OVK nach Pre-Roll, Mid-Roll und Post-Roll, je nachdem ob die Werbung vor dem Abspielen, in der Mitte oder danach platziert ist. Am geläufigsten ist dabei wohl die Pre-Roll Werbung, bei der regelmäßig vor dem Abspielen des gewünschten Videos ein Werbespot platziert wird. Dieser wird oft nach einer kürzeren Zeit mit der Möglichkeit zum Überspringen versehen. Mid-Roll kann bei mehreren kürzeren Videos ein zwischengeschalteter Werbespot sein oder bei längeren Videos eine Werbeunterbrechung wie beim Fernsehen. Bei einer Post-Roll Werbung dürfte in der Regel davon auszugehen sein, dass hier die Aufmerksamkeit des Nutzers nicht mehr groß ist und er den Stream abbricht. Post-Roll Werbung entspricht also dem Abspann eines Films. Lineare Werbung ist bei YouTube und beinahe allen für den Nutzer kostenfreien Multimediaportalen Standard. Auch bei Musikstreamingdiensten wie Spotify ist dies im Rahmen der kostenfreien

99 Jacob, Integriertes Online-Marketing, S. 220. 
Nutzung üblich. Im Folgenden werden diese Formen auch im Weitesten Sinne mit Pre- und Interstitials gleichgesetzt, weil sie ebenfalls Vorspannbzw. Unterbrechungswerbung darstellen, wenn auch regelmäßig auf den Videoframe begrenzt.

Als nicht lineare Werbung stuft der OVK zuvörderst Branded Player und Overlay Ads ein. Dabei stellt ein Branded Player sozusagen einen Bilderrahmen dar, in den das gestreamte Video eingebettet ist. Praktisch ist dies eine Sonderform der klassischen Anzeige. Eine Overlay Ad hingegen ist ein Banner oder Layer, das im Bereich des Videos positioniert ist.

Als weitere nicht lineare Formen nennt der OVK noch die „On-Air-Promotion“, das „Infomercial“ und das „Presenting“. Bei diesen Formen wird die Werbung in den redaktionellen oder dramaturgischen Ablauf des Video bzw. der Audio-Sequenz eingebaut. Hier bestehen keine Unterschiede zu den entsprechenden Werbeformen im Rundfunk. Als Teil des Contents sind diese Werbeformen in einer besonders festen Beziehung zum Inhalt und sind vor allem statisch, d.h. sie können nicht ausgewechselt werden. Die davor genannten In-Stream Werbeformen hingegen sind dynamisch und können jederzeit geändert oder ausgetauscht werden.

Auch bei dieser In-Stream Werbung mit Videos und Audio-Sequenzen befindet sich der Nutzer in der Situation, dass ihm gegenüber die Werbung ohne sein Zutun ausgespielt wird. Er muss insbesondere lineare Werbung oft zumindest teilweise wahrnehmen, wenn er das Streamingangebot wahrnehmen möchte. Bei nicht linearen Werbeformen kann der Nutzer nur bei Overlay Ads aktiv die Anzeige durch Schließen unterbinden, was er regelmäßig tun wird, um den gesamten Videobereich ohne Einschränkung zu sehen. Die übrigen nicht linearen Werbeformen sind hingegen regelmäßig fester Bestandteil der Streamingangebote.

\section{(vi) Werbender Content}

Eine weitere Werbeform ist die werbliche Ausgestaltung des Contents. Hierhin gehören im Prinzip alle Internetseiten, die ein Unternehmen selbst erstellt oder pflegt, um damit auf die eigenen Produkte und Dienstleistungen hinzuweisen. Auch dazu gehören solche redaktionellen Inhalte, die auf Drittseiten die Produkte eines Unternehmens anpreisen. Dies können Nachrichtenseiten oder Blogs sein, die positiv berichten.

Vor allen Dingen kommen hier Internetportale in Betracht. Bei Bewertungsportalen etwa bestehen einerseits Möglichkeiten besonders herausgehobene Stellungen oder Empfehlungen beim Portalbetreiber gegen Zah- 
lung zu erlangen. Andererseits können Bewertungen manipuliert werden, indem etwa „Fake-Bewertungen“ gefördert werden. Bei sonstigen themengebundenen Portalen kann sich der Werbende zudem als normales Mitglied anmelden und dort unter seinem Unternehmenskennzeichen bzw. seiner Marke Beiträge einpflegen, z.B. das Bereitstellen von Rezeptideen durch einen Nahrungsmittelproduzenten auf Rezeptportalen ${ }^{100}$.

Die Besonderheit an diesem Content-Marketing ist, dass die Werbung zentrales Merkmal des Contents ist. Dies entspricht also in der analogen Welt den klassischen Produktkatalogen oder Marketingmaterialien. Der Internetnutzer weiß genau bei Besuch der eigenen Seiten eines Unternehmens, dass hier eine werbliche Zwecksetzung vorliegt. Andererseits entsprechen die vorgenannten Portale etwa Fachzeitschriften. So ist dem Leser der „Auto Motor und Sport“ bekannt, dass hier über bestimmte Autos berichtet wird und die Automobilhersteller dafür regelmäßig Probewagen zur Verfügung stellen. Bei den Portalen steht auch der Informationscharakter bzw. die Unterhaltungswirkung im Vordergrund, wobei regelmäßig mit der Beeinflussung durch die Anbieter auf die eine oder andere Art zu rechnen ist.

Der Nutzer muss diese Werbeseiten aber wiederum aktiv ansteuern. Das unterscheidet werbenden Content ganz entscheidend von den oben genannten aktiven Werbemitteln.

(vii) Sonderfall: Suchmaschinenmarketing

Suchmaschinen sind außergewöhnliche Webseiten, die sozusagen das Tor zur weiten Welt des Internets darstellen. Selbstredend wird auch auf diesen Webseiten Marketing betrieben. Suchmaschinenmarketing ist dabei der Oberbegriff für die Instrumente Suchmaschinenwerbung (SEA = search engine advertising) und Suchmaschinenoptimierung $(\mathrm{SEO}=$ search engine optimization) ${ }^{101}$. Besondere Bedeutung hat das Suchmaschinenmarketing, weil Suchmaschinen wie Google oder Bing regelmäßig als Startseiten in Browsern vorinstalliert sind und deshalb sowie aus Praktikabilitätsgründen in so gut wie jeder Internetsitzung benutzt werden. Schließlich wird bei der Suche nach Informationen nur äußerst selten die korrekte URL von Webseiten im Browserfeld angegeben. Vielmehr hat

100 Vgl. Beispiel: Hochland auf chefkoch.de bei Solmecke/Kocatepe, Recht im Online-Marketing, S. 45.

101 Kammerzelt/Wimmer, Online-Marketing, S. 97. 
sich das schlagwortartige Durchsuchen des Internets mittels Google o.Ä. praktisch zur Methode des Internetsurfens entwickelt.

Aus dieser enorm wichtigen Bedeutung der Suchmaschinen folgt ein überragend hohes Besucheraufkommen. Deshalb sind zwei Möglichkeiten gegeben, sich diesem breiten Publikum zu präsentieren. Einerseits kann in klassischer Weise Fläche für die Werbung gekauft werden. Dies ist Suchmaschinenwerbung. Andererseits kann das Ziel verfolgt werden, bei der nutzerseitigen Eingabe von bestimmten Begriffen in die Suchmaschine eine möglichst hohe Platzierung in den Ergebnissen zu erreichen. Dafür dient Suchmaschinenoptimierung.

Suchmaschinenwerbung, teils auch Keyword Advertising genannt, stellt die Einblendung bezahlter Ergebnisse in Abhängigkeit eines vom Nutzer eingegebenen Suchbegriffs dar ${ }^{102}$. Für SEA über Google stellt das Unternehmen unter anderem das Werbetool „AdWords“ zur Verfügung.

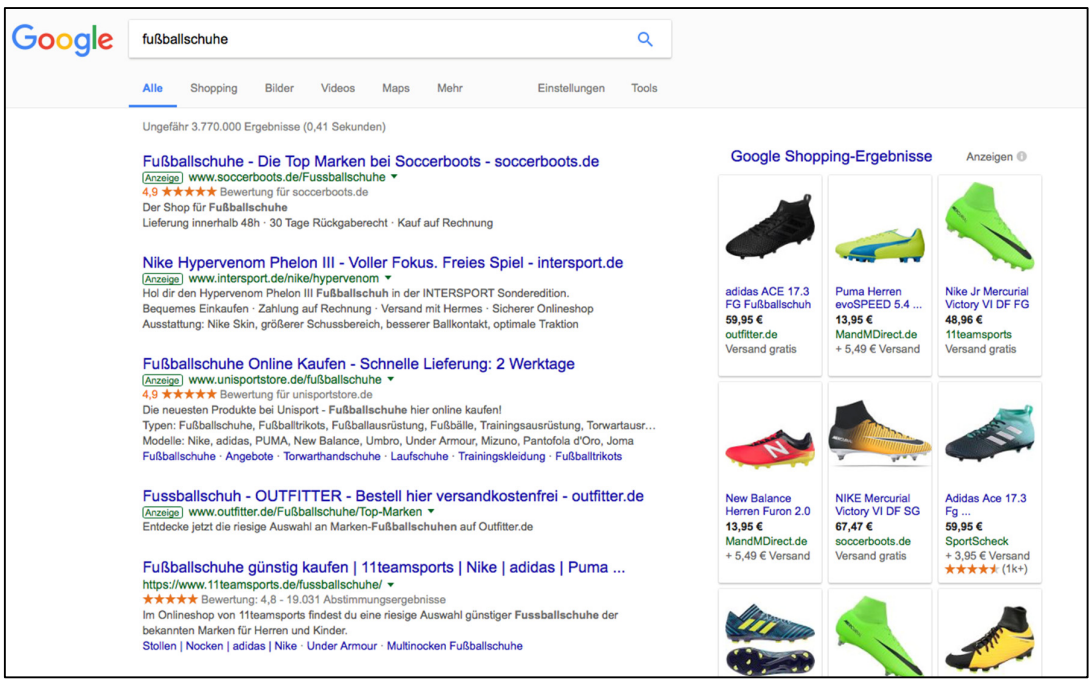

Beispiel einer Google-Suchanfrage ${ }^{103}$ für „Fußballschube“ - die ersten vier Ergebnisse sind Anzeigen, erst an fünfter Stelle erscheint ein Suchergebnis im engeren Sinne; am rechten Rand sind „Google Shopping-Ergebnisse", ebenfalls zum Teil Anzeigen

102 Jacob, Integriertes Online-Marketing, S. 268.

103 Abgerufen am 23.8.2017. 
Solche SEA-Einblendungen werden als „Anzeige“ deklariert, damit der Nutzer diese auch als bezahlte Werbung identifizieren kann. In gestalterischer Hinsicht ist hier allein eine Textwerbung möglich - bestehend aus Überschrift und kurzem Erläuterungstext. Diese Werbung wird dann bestimmten Keywords zugeordnet. Die konkrete Ausspielung der Werbung wird durch einen Algorithmus des Suchmaschinenanbieters gelenkt ${ }^{104}$.

Nach demselben Prinzip funktionieren die „Product-Listing-Ads“, also Text-Bild-Anzeigen mit direkter Verlinkung auf einen Webshop ${ }^{105}$. Weiterhin sind Erweiterungen der Textwerbung um bestimmte Elemente möglich.

Suchmaschinenwerbung stellt damit eine klassische Anzeige dar, die für das Layout von Suchmaschinen angepasst und optimiert wurde. SEA ist damit im Ausgangspunkt mit klassischen Anzeigen auf Webseiten gleichzustellen.

Im Unterschied dazu ist Suchmaschinenoptimierung keine Anzeigenwerbung, sondern vielmehr eine Methode zur Verbesserung des eigenen Contents, sodass er vom Algorithmus der Suchmaschine bei bestimmten Suchwörtern bevorzugt dargestellt wird. Hier wird auch keine Zahlung an Google als Werbeplatzanbieter geleistet. Vielmehr kann jeder Webseitenbetreiber selbst oder durch spezialisierte Dienstleister versuchen, bestimmte Kriterien zu erfüllen, die ein Algorithmus regelmäßig prüft und bei deren Vorliegen eine höhere Platzierung erfolgt. Dafür bilden neben anderen Kriterien ganz maßgeblich „Keywords“ die Grundlage. Hinzu kommen die Domainnamen, Verlinkungen mit anderen Seiten („Backlinks“) und die Besucherzahlen ${ }^{106}$.

SEO stellt somit eine „verlängerte“ Content-Werbung dar, der sich der Nutzer nicht entziehen kann, wenn er nicht auf die Suchmaschine verzichten möchte. Andererseits wird ihm durch die „Keyword“-basierte Optimierung diese Art der Content-Förderung nur selten auffallen, weil er ja gerade nach bestimmten Begriffen sucht. Die Anzeige von suchmaschinenoptimierten Inhalten setzt deshalb wiederum ein aktives Handeln des Nutzers voraus.

104 Jacob, Integriertes Online-Marketing, S. 271.

105 Kammerzelt/Wimmer, Online-Marketing, S. 97; https:/www.ranksider.de/talk /google-shopping-nicht-mehr-kostenlos-doch-noch-immer-effektiv, zuletzt abgerufen am: abgerufen; im oberen zu Fn. 99 dargestellten Screenshot als Google Shopping-Ergebnisse gelistet.

106 Jacob, Integriertes Online-Marketing, S. 273ff.. 
(viii) Sonderfall: Soziale Netzwerke, v.a. Facebook

Soziale Netzwerke wie Facebook, Twitter, Instagram \& Co. sind zum integralen Bestandteil des Internetkonsums von vielen Menschen geworden. Der regelmäßige Besuch von mindestens einem der Social-NetworkChannels ist für viele Menschen eine Selbstverständlichkeit. Obwohl hier eine starke Verbreitung der Nutzung über mobile Geräte und die dazu passenden Apps zu beobachten ist, halten die sozialen Netzwerke ganz überwiegend auch „normale“ Internetseiten vor, die in Browsern geöffnet werden.

Soziale Netzwerke gehören zu dem Überbegriff der sozialen Medien und sind solche, bei denen eine vielseitige Interaktion von einer Vielzahl von Menschen gleichzeitig möglich ist ${ }^{107}$. Das besondere Merkmal von sozialen Netzwerken im hier verstandenen Sinne ist ein Newsfeed oder ein „Stream“, der dem Nutzer aufgrund der eigenen Abonnements oder persönlichen Verbindungen Beiträge anzeigt.

Soziale Medien, die über keinen Newsfeed verfügen, sind dazu in Abgrenzung lediglich als moderne Kommunikationsformen anzusehen. Sie sind sozusagen die aktuellste Evolutionsstufe der menschlichen Punkt-zuPunkt Kommunikation - ausgehend vom klassischen Gespräch, über Telefonie hin zu Messenger Diensten wie WhatsApp oder Snapchat. Diese sozialen Medien werden weitestgehend auf mobilen Endgeräten (wiederum etwa WhatsApp oder Snapchat) oder auf PCs in besonderer Software genutzt (etwa Skype). Deshalb wird an der entsprechenden Stelle näher auf solche soziale Medien eingegangen. Soweit unter die sozialen Medien auch Webseiten wie Blogs, Foren, Wikis oder Bewertungsportale gefasst werden ${ }^{108}$, so ergibt sich kein Unterschied zu den oben dargestellten „normalen"Webseiten.

Beispielhaft wird zunächst auf das soziale Netzwerk Facebook näher eingegangen. Facebook ist als eines der meist frequentierten sozialen Medien ${ }^{109}$ zum Mikrokosmos des Internetwerbemarkts geworden. Auf dieser Plattform ist nämlich einerseits eigenes Content-Marketing über Facebook-Seiten möglich, also sozusagen eine Mini-Homepage im sozialen

107 Jacob, Integriertes Online-Marketing, S. 249f..

108 Jacob, Integriertes Online-Marketing, S. 250f..

109 Laut einer öffentlich zugänglichen Studie hatte Facebook im April 2019 2,375 Mrd. monatlich aktive Nutzer, https://allfacebook.de/toll/state-of-facebook, zuletzt abgerufen am: 30.5.2019; davon 32 Mio. aus Deutschland, https://allfac ebook.de/zahlen_fakten/offiziell-facebook-nutzerzahlen-deutschland, zuletzt abgerufen am: 30.5.2019. 
Netzwerk. Andererseits ist auch aktive Werbung möglich, indem entweder an bestimmten Stellen klassische Anzeigen geschaltet werden oder durch bezahlte Werbung eine Anzeige im Newsfeed des Nutzers positioniert wird. Dabei wird Werbung bei Facebook als „gesponsert“ deklariert.

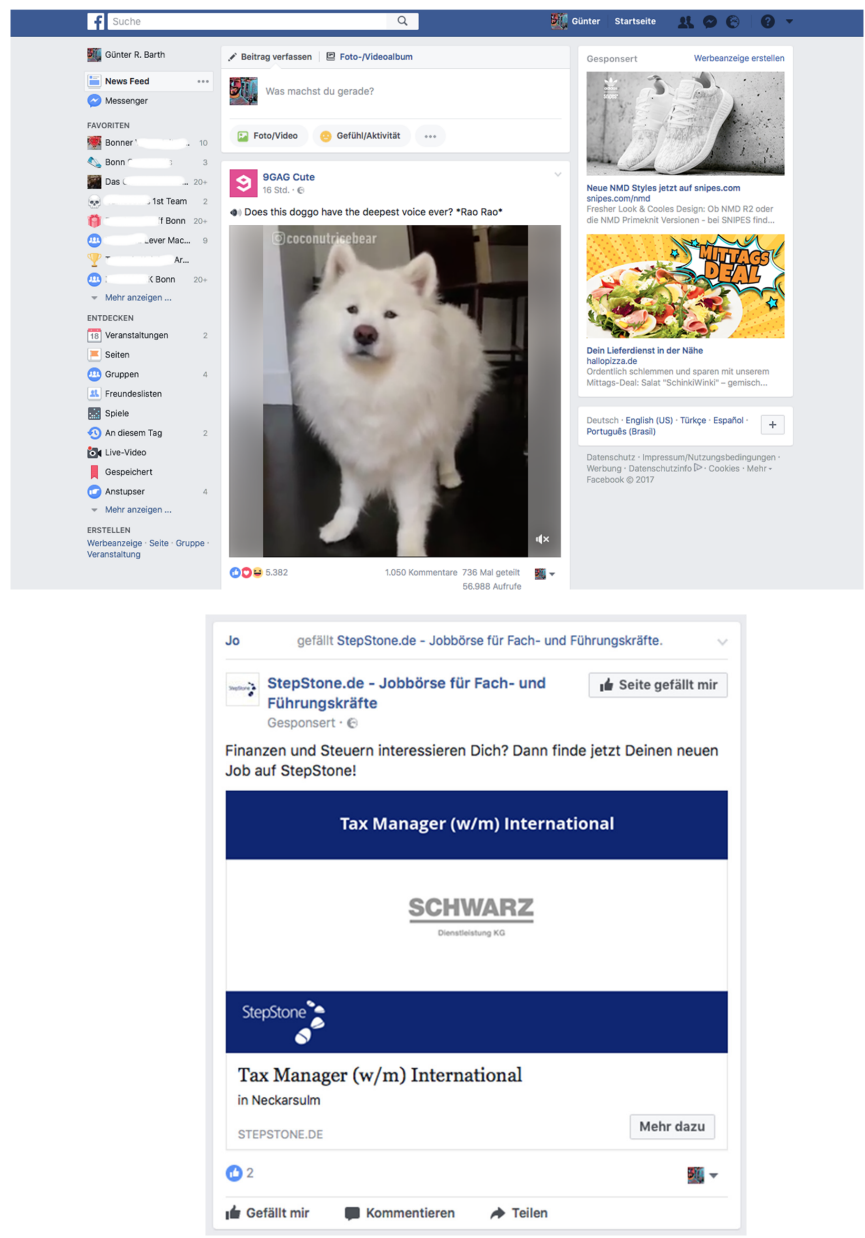

Beispiele aus dem Facebook Feed des Autoren ${ }^{110}$ : "gesponserte" klassische Anzeigen am oberen rechten Rand der Seite, Screenshot oben, und "gesponserter" Content im Newsfeed, Ausschnitt unten

110 Abgerufen am 18.8.2017. 
Für die Werbeformen des Content-Marketings und der klassischen Anzeigen (sog. „rechte Spalte" ${ }^{111}$ ) gelten auf Facebook keine Besonderheiten zum übrigen Werbemarkt im Internet. Während die Konfrontation mit Content von Werbenden auch hier irgendeine aktive Handlung des Nutzers (z.B. Aufrufen von Seiten oder Drücken des „Gefällt mir“-Button mit Abofunktion) bedarf, wird die rechtsseitige Anzeige ohne weiteres Zutun geschaltet.

Eine Besonderheit stellt dagegen Werbung im Newsfeed dar. Der Newsfeed wird durch Content von anderen Mitgliedern oder Facebook-Seiten mit Hilfe eines bestimmten Algorithmus gespeist ${ }^{112}$. Dabei wird regelmäBig ein „gesponserter" Beitrag eingespeist, der nichts anderes als eine Werbeanzeige ist. Diese gesponserten Beiträge kommen in zwei Ausgestaltungen vor: zum einen wird dem Nutzer einleitend mitgeteilt, dass einem „Facebook-Freund“ eine bestimmte Seite gefällt und deshalb dem Nutzer jetzt gerade ein Beitrag von dieser Seite angezeigt wird ${ }^{113}$; zum anderen gibt es Beiträge im Newsfeed, die als „vorgeschlagener Beitrag“ bezeichnet sind - wie die nachfolgend eingeblendete Anzeige.

111 Vgl. Palme, Facebook-Marketing, S. 183.

$112 \mathrm{Zu}$ den Hintergründen des Algorithmus vgl. http://t3n.de/news/facebook-newsf eed-algorithmus-2-577027/, zuletzt abgerufen am: 30.5.2019.

113 Vgl. Screenshot oben, Fn. 106. 


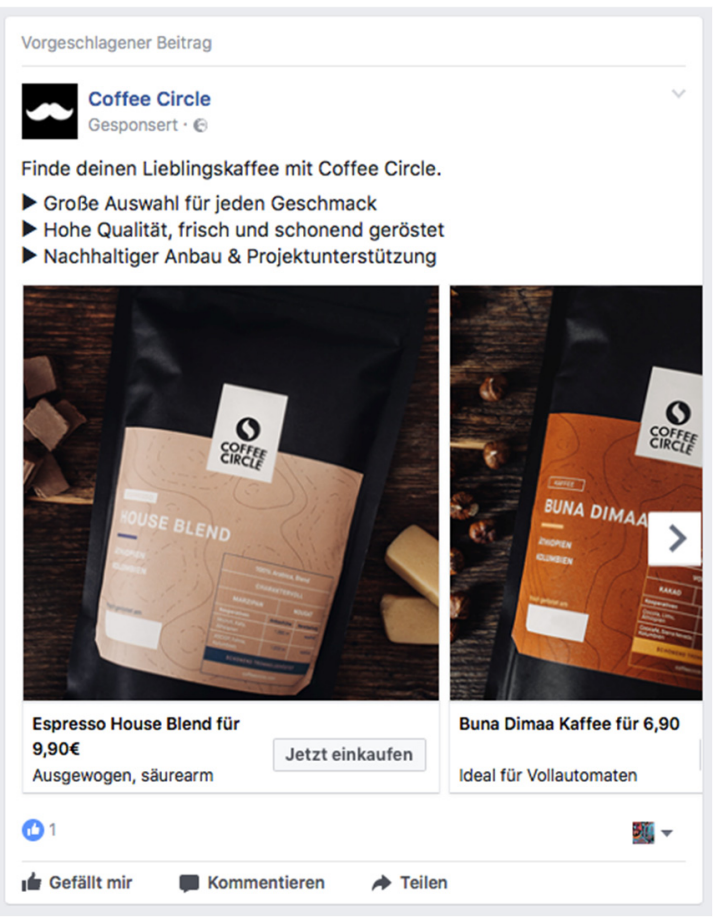

Beispiel aus dem Facebook Feed des Autoren ${ }^{114}$

Die zweite Alternative stellt dabei eine eindeutigere Werbung dar. Bei der erstgenannten Ausgestaltung lehnt sich Facebook hingegen an einen von einem „Facebook-Freund“ geteilten, kommentierten oder ihm gefallenden Beitrag an. Denn regelmäßig werden solche dem sozialen Medium spezifischen Interaktionen im Newsfeed anderer Nutzer angezeigt. Deshalb legt die erste Alternative eine solche Interaktion des Freundes nahe, womit potentiell ein höheres Vertrauen in den Werbenden geweckt wird. Diese Werbeform der "gesponserten Beiträge“ ist eine neue Spielform der klassischen Anzeige, die allerdings als Content-Marketing getarnt ist.

Zuletzt kann Werbung auch durch bei Facebook verbundene Personen oder Seiten (und damit nicht aktiv durch Facebook) in den Newsfeed gespeist werden. Dies ist der Fall wenn die verbundenen Personen bzw. Seiten bestimmte (werbende) Beiträge teilen oder sonstige spezifische In-

114 Abgerufen am 18.8.2017. 
teraktionen vornehmen. Dies stellt dann aber wiederum reines ContentMarketing dar, weil hier der Nutzer durch die Verbindung mit der Seite oder der Person auch eine solche werbliche Interaktion billigt.

Hinsichtlich der Ausgestaltung der Anzeigen bestehen diverse Handlungsmöglichkeiten, die aber durch die Gestaltungsformen von FacebookPosts begrenzt werden. Hinzu kommen von Facebook aufgestellte Werberichtlinien, die vor Freischaltung einer Werbekampagne angewendet werden. Diese enthalten unter anderem thematische Verbote und gestalterische Anforderungen an Text-Bild-Kombinationen ${ }^{115}$.

Weitere in der europäisch und amerikanisch geprägten Kultur stark frequentierte soziale Netzwerke, sind Twitter, LinkedIn, Tumblr, Pinterest und Instagram ${ }^{116}$. Soweit ein solcher Stream verwendet wird, kommen in gleicher Weise wie bei Facebook drei Alternativen für Werbung in Frage: Content, klassische Anzeige und Newsfeed Anzeige.

\section{(ix) Fazit: Klassifizierung der browserbasierten Internetwerbung}

Nach alledem lässt sich Werbung auf Webseiten aller Art in zwei große Gruppen trennen. Einerseits handelt es sich um Content-Werbung, andererseits um Anzeigen.

Content-Werbung zeichnet sich dadurch aus, dass sie auf eigenen oder fremden Webseiten und Kanälen vom Werbenden aktiv eingestellt wird, dem Nutzer aber nur dann entgegentritt, wenn er selbst zuvor auf irgendeine Weise aktiv geworden ist. Der Nutzer muss hier also willentlich eine Webseite oder auf einer Drittseite wie sozialen Netzwerken, Suchmaschinen oder Portalen eine untergeordnete Seite aufrufen, auf der die werbenden Content-Informationen dargestellt werden. Diese zweistufige und doppelpolige Aktivität ist insbesondere für die rechtliche Beurteilung dieser Art von Werbung von Bedeutung (siehe unten Ziffer IV.).

Anzeigenwerbung hingegen zeichnet sich dadurch aus, dass auf eigenen oder fremden Webseiten und Kanälen dem Nutzer andere Inhalte angezeigt werden, die er nicht willentlich und gezielt aufgerufen hat. Dabei ist der Nutzer mit isoliertem Blick auf die Anzeigen passiv, der Werbende hingegen wird (oftmals unter Einbindung Dritter) aktiv. Anzeigen zeichnen sich also durch eine einseitige Aktivität des Werbenden aus. Im Rah-

115 Vgl. Palme, Facebook-Marketing, S. 205f..

116 Siehe https://www.kontor4.de/beitrag/aktuelle-social-media-nutzerzahlen.html, zuletzt abgerufen am 30.5.2019 für Nutzerzahlen in Deutschland. 
men dieser einseitigen Aktivität haben sich diverse wirtschaftliche (siehe unten Ziffer II.) und technische (siehe unten Ziffer III.). Besonderheiten entwickelt. In rechtlicher Hinsicht bestehen Regularien, die je nach Fokus auf das „Ob“ oder das „Wie“ von Werbung unterschiedlich stark differenziert sind (siehe unten Ziffer IV.).

Zusammenfassend werden die Anzeigen in folgender Grafik als Abbildung 3 nochmals dargestellt:

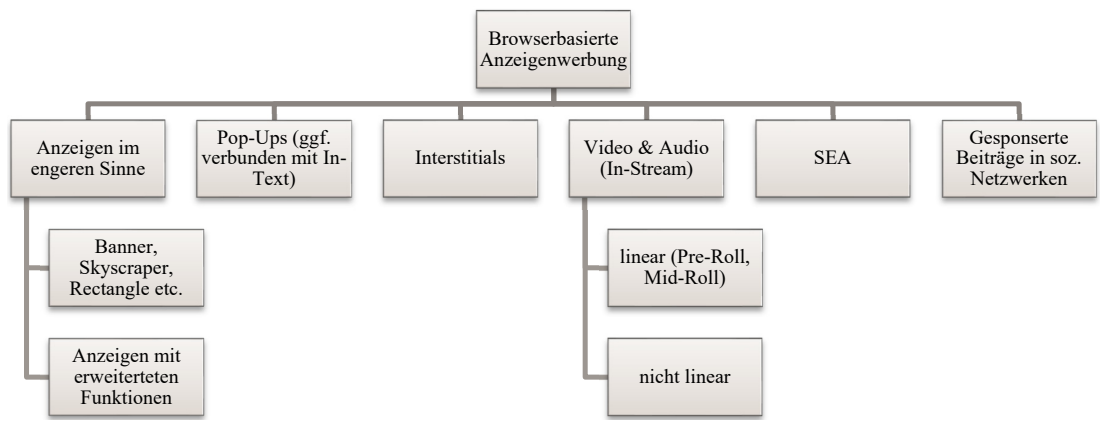

Abbildung 3: Schema browserbasierter Werbeformen

cc) Werbung in sonstigen Programmen auf PCs

Sonstige Programme auf PCs können zu allen denkbaren Zwecken eingesetzt werden. Als häufige Softwareprogramme (außer Internetbrowser und Mailprogramme) kommen dabei in nicht abschließender Aufzählung Textverarbeitungs-, Antiviren-, Kommunikations- ${ }^{117}$, Streaming- ${ }^{118}$ und sonstige Dienstprogramme ${ }^{119}$ sowie Computerspiele in Betracht. Bei allen solchen Programmen ist es möglich, Werbung zu integrieren. Dies kann insbesondere durch die Implementierung von Werbeflächen ähnlich der browserbasierten Anzeigenformate erfolgen. Andererseits können Werbebotschaften auch fest mit dem Programmablauf verbunden werden und damit der Content-Werbung entsprechen.

117 Z.B. Skype.

118 Z.B. Spotify oder sonstige Musikstreamingdienste.

119 Z.B. Adobe Acrobat Reader zur Anzeige von PDF-Dateien oder ähnliche Programme zur Anzeige bestimmter Dateiformate; Bildbearbeitung wie Adobe Photoshop; Musik- oder Fotobibliotheken wie iTunes u.v.m.. 
Aus den vorgenannten Softwaregruppen sollen zur Verdeutlichung zwei Beispiele dienen - zunächst Streamingsoftware und sodann Computerspiele.

Bei kostenlosen Streamingprogrammen, die ohne kostenpflichtiges Abonnement genutzt werden, wird regelmäßig In-Stream-Werbung in Form von Pre-Roll und Mid-Roll Werbeclips eingesetzt. Hinzu kommt die Möglichkeit der Einbindung von Bannern etc. in die Programmoberfläche, die ähnlich wie Webseiten wirken. Es bestehen in diesem Fall keine ersichtlichen Unterschiede zu Werbung auf Webseiten.

Bei Computerspielen dagegen wird Werbung mitunter fest mit der Spielhandlung verbunden. Diese statische In-Game-Werbung entspricht in manchen Fällen einer absichtlichen Produktplatzierung in Spielfilmen, ist teils aber auch schlichte Ausprägung der möglichst realitätsnahen Simulation (etwa bei Sportspielen, die möglichst originalgetreu auch die Werbung von Trikots, Rennwagen etc. nachbilden). In diesen Fällen gehört die Werbung zur Spielidee, sozusagen zum Content des Spiels. Jedoch ist auch bei (Online) Computerspielen mittlerweile eine Inklusion aktueller Werbung möglich ${ }^{120}$. Dies etwa durch Schaltung aktueller Werbung auf im Spielfluss eingeblendeten Werbetafeln.

120 Vgl. https://de.wikipedia.org/wiki/In-Game-Werbung, zuletzt abgerufen am: 30.5.2019. 


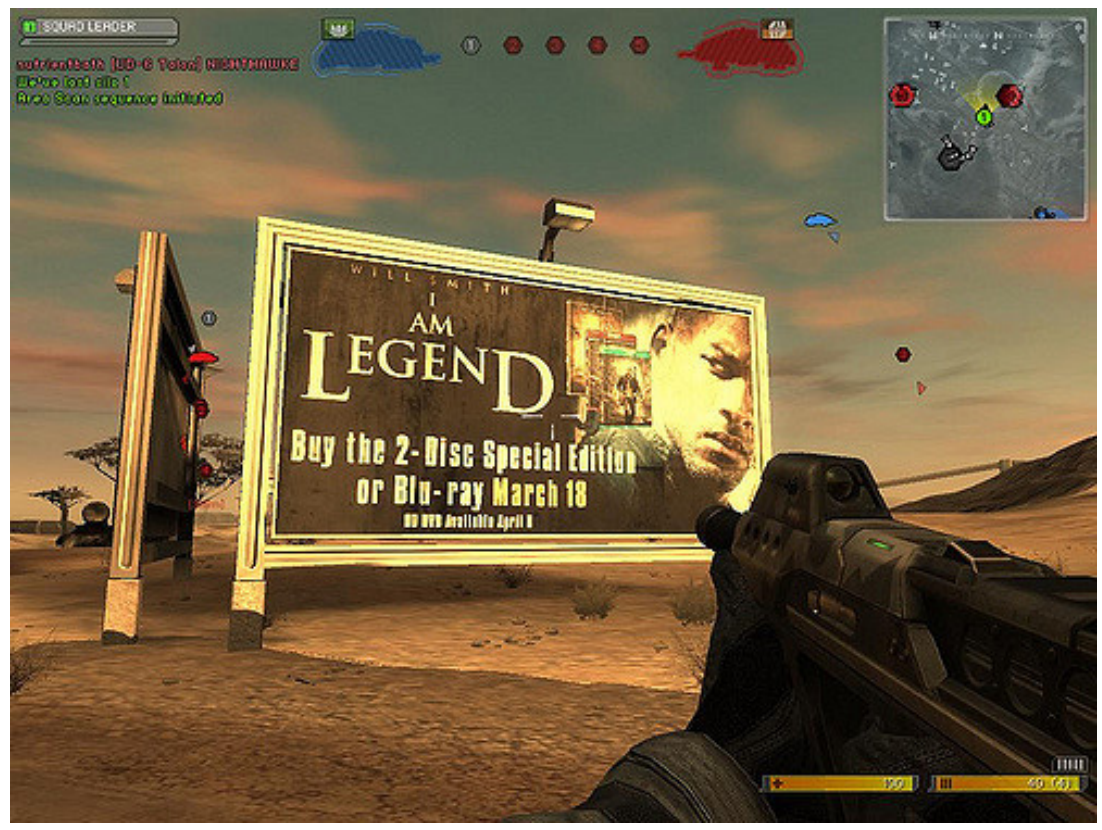

Beispiel $^{121}$ einer aus aktuellem Anlass eingefügten In-Game-Werbung für die Blu-Ray eines Spielfilms innerhalb des Computerspiels „Battlefield 2124“

Diese Werbung entspricht wiederum einer klassischen Anzeige. Sie kann zeitlich und räumlich ausgewechselt werden und ist nicht fest mit der Spielprogrammierung verbunden. Ein Unterschied zu Werbung auf Internetseiten besteht aber darin, dass hier der Nutzer aktiv das Spiel begonnen hat und unter Umständen sogar aktiv die Spielsituation mit der Werbung herbeigeführt hat - unabhängig, ob die Werbung jetzt statisch oder aktuell eingebunden wird. Für Computerspiel-Werbung kann also nicht dieselbe Abgrenzung hinsichtlich der Aktivität von Werbendem und Nutzer gelten wie bei Webseiten.

Eine Unterscheidung zwischen Anzeigen und Programmidee (bzw. Content) muss bei Computerspielen im Konkreten und PC-Software im Generellen deshalb danach vorgenommen werden, ob die konkrete Werbung ursprünglich mit dem vorgesehenen Ablauf verbunden war (also statische Werbung) oder nur die Werbefläche fest programmiert und die Inhalte austauschbar sind (also ein Platzhalter für aktuelle Werbung). Da-

121 http://blog.sponsoo.de/ingameadvertising/, zuletzt abgerufen am: 30.5.2019. 
mit können durchaus Unterschiede in der rechtlichen Beurteilung von Werbung in Softwareprogrammen zu jener auf Webseiten bestehen.

dd) Maßgeblichkeit im Zusammenhang mit Internetwerbeblockern

Bei der PC-basierten Internetwerbung und der Frage des Werbeblockens ist damit vorgreiflich schon jetzt festzustellen, dass nur bestimmte Werbeformen einer Blockade zugänglich sind. Bei E-Mails erfolgt immer ein Zugang im Postfach des Nutzers. Wie sodann innerhalb des Postfachs gefiltert wird ist weniger eine Frage des Blockens, als der Verarbeitung der Werbung durch Sortierung in Listen, z.B. Spam-Listen.

Bei browserbasierter Werbung muss Content-Werbung von der Werbeblockade unberührt bleiben, weil sonst dem Nutzer Informationen vorenthalten werden, die er gerade aufzurufen wünscht ${ }^{122}$. Insoweit muss sich die Werbeblockade innerhalb von Browsern allein auf Anzeigen beziehen.

Zuletzt macht bei sonstigen PC-Programmen nur dort eine Werbeblockade Sinn, wo der gewünschte Inhalt oder Programmablauf nicht gestört wird. Denn eine Leerstelle im Programmablauf oder in der (u.a. bildlichen) Darstellung würde teilweise als störender empfunden als die Werbung selbst. Hinzu kommt, dass Computerprogramme oft zu speziell sind, sodass einheitliche Blockerlösungen, die in einer Vielzahl von Computerprogrammen effektiv wirken, nur schwer vorstellbar sind.

\section{b) Werbeformen bei mobilen Geräten}

Mobile Geräte wie Smartphones, Tablets und Handhelds, aber auch EBook-Reader oder Smartwatches unterscheiden sich von PCs im Wesentlichen durch das Anzeigenformat. Die Anwendungen für solche mobile Geräte werden genau für die Größe des Bildschirms und diese Auflösung optimiert. Dafür werden oft spezielle Apps entwickelt und von den Geräteanwendern genutzt. Diese Apps haben den Vorteil im Vergleich zu im Browser des Geräts angezeigten Webseiten, dass sie benutzerfreundlich sind und die gewünschten Informationen immer in der optimierten Seitengröße ausliefern. Bei klassischen Webseiten kann es bei der Darstellung im Mobilgerät durch eine Umskalierung dazu kommen, dass der Nutzer

122 Vgl. in diesem Kontext auch das Phänomen „Overblocking“ das unter Ziffer C. I. 6. behandelt wird. 
nur Ausschnitte der großen Seite auf dem kleinen Bildschirm sieht und dann „hin- und her wischen“ muss. Hinzu kommt, dass in Browsern immer die ganze Webseite geladen wird. Bei den Apps steht das Grundgerüst der Seite nach einem Download bereits fest zur Verfügung und nur die konkreten Informationen werden geladen. Dies führt zu einer schnelleren Auslieferung der Information und erspart gerade bei Nutzern, die unterwegs sind, meist kostenpflichtiges Datenvolumen.

Aus diesen Gründen sind auf mobilen Geräten Apps oft die bedeutenderen Softwareprogramme als Internetbrowser. Für die Darstellung der Werbung auf diesen Geräten wird demnach unterschieden nach In-AppWerbung (dazu aa.) und browserbasierter Werbung (dazu bb.). E-MailWerbung kann hier vernachlässigt werden, weil sich keine nennenswerten Unterschiede zum Empfang bei PCs ergeben.

\section{aa) In-App-Werbung}

Apps für die beiden meist verbreiteten Betriebssysteme für mobile Endgeräte - iOS von Apple und Android von Google - gibt es für alle denkbaren Anwendungszwecke. Im Januar 2015 gab es in Apples Appstore bzw. Googles Play Store ca. 1,4 Mio. mobile Anwendungen zum kostenfreien oder kostenpflichtigen Download ${ }^{123}$. Zu den beliebtesten und meistgenutzten Apps gehören Kommunikationsdienste, soziale Netzwerke bzw. Medien, Spiele, Online Shops, Streamingdienste, Nachrichten- und übrige Informationsportale sowie sonstige nützliche Anwendungen wie QR Scanner, Foto- und Textbearbeitungsprogramme. Wegen der Mannigfaltigkeit der Ausprägungen lässt sich natürlich nicht auf alle Einzelheiten eingehen ${ }^{124}$.

Soweit die Apps eine Spiegelung der browserbasierten Webseite sind, wie es insbesondere bei den sozialen Netzwerken oder Suchmaschinen der Fall ist, kann hier auf die obigen Ausführungen verwiesen werden. Auch hier sind bei sozialen Netzwerken die gesponserten Posts zu nennen. Hinzu kommt Content-Werbung. Klassische Anzeigen wie die "rechte Spalte“ gibt es aufgrund der Auflösung der Apps regelmäßig nicht, sodass hier die „als Content getarnten“ Anzeigen die einzige klassische Werbung darstel-

123 Keßler/Rabsch/Mandic, Erfolgreiche Websites, S. 851.

124 In diesem Zusammenhang sei auf die Dissertation von Steinmetz, Apps im Lauterkeitsrecht, verwiesen. 
len. Auch bei Suchmaschinen, die eigene Apps anbieten (so etwa Google), gelten die oben dargestellten Möglichkeiten von SEA und SEO.

Bei den übrigen Apps, die einer geräteangepassten Webseite entsprechen oder besondere Dienste erbringen, ist regelmäßig Display-Werbung wie auf Webseiten möglich. Insbesondere Banner sind bei kostenfreien Apps sehr verbreitet. Denkbar sind auch Pop Ups oder Pre-/Interstitials, die vor oder während der Nutzung der App Werbung ausspielen.
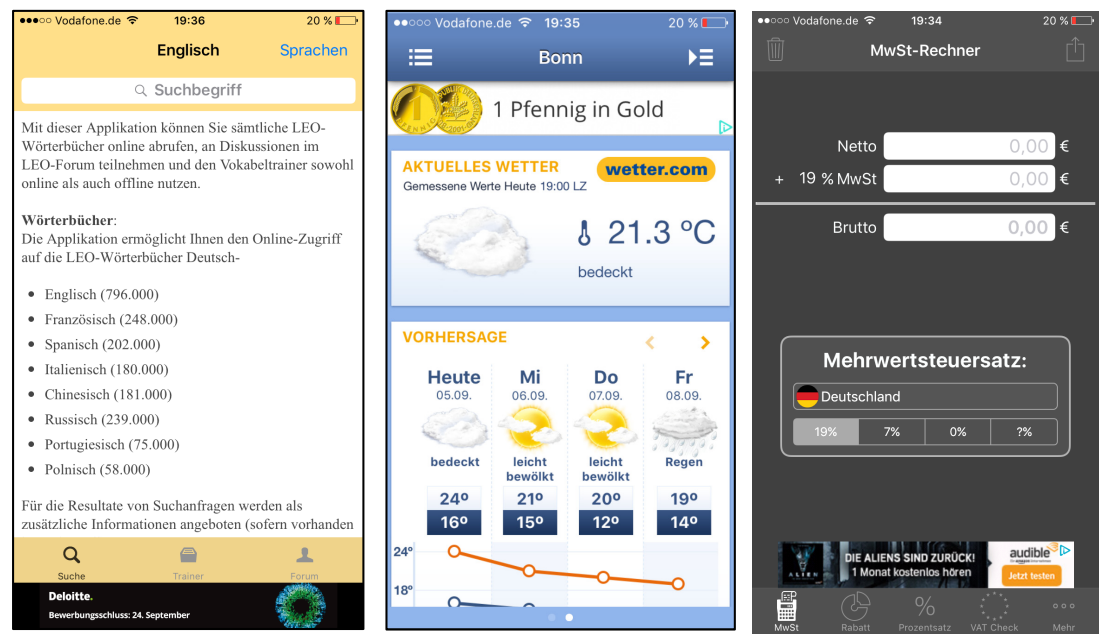

Beispiele für Bannerwerbung in den Apps Leo Wörterbuch, Wetter.com und MwSt.-Rechner, von links nach rechts

Bei Streaming Apps wie YouTube sind ebenfalls lineare Pre- und Mid-Roll Werbespots und die nicht-lineare Overlay Ads üblich. Auch hier bestehen keine Besonderheiten zur browserbasierten Darstellung. Im Großen und Ganzen sind die Unterschiede zu browserbasierten Webseiten und der dortigen Werbung deshalb marginal.

Eine Besonderheit bei den Apps stellen hingegen die Kommunikationsdienste dar. Während die meisten klassischen Chat-Apps wie WhatsApp, Facebook Messenger und Ähnliche eine bloße Vereinfachung der Punktzu-Punkt bzw. Gruppenkommunikation darstellen, zeigen sich in diesem Genre auch innovative Kommunikationsdienste. Besonders hervorzuheben ist dabei Snapchat. Das Prinzip von Snapchat ist, dass die Kommunikationsschnipsel („Snaps“ - also Fotos, Videos oder Texte) nur für eine beschränkte Zeit sichtbar sind. Es werden dabei zwei Modi unterschieden: zum einen die unmittelbare Kommunikation („Chat") und zum anderen 
der „Story“-Modus"125. Beim zweitgenannten Modus wird ein „Snap“ - hier meist ein kurzes Video - mit dem eigenen Konto verbunden und ist für die im Netzwerk verbundenen Freunde 24 Stunden lang sichtbar.

Dieser „Story“-Modus wird dabei als zusätzlicher Social-Media-Kanal von Publishern und Unternehmen genutzt, um so die besondere Zielgruppe der Nutzer von sozialen Medien zu erreichen. Über diesen Weg wird Content verbreitet, der vom Adressaten aktiv aufgerufen wird. Da die meisten Publisher eine Vielzahl von "Snaps“ hinterlegen, durch die sich der Nutzer klicken kann, wird hier zum Teil auch aktive Werbung geschaltet. Diese erfolgt durch werbende „Snaps“ innerhalb der „Stories“.
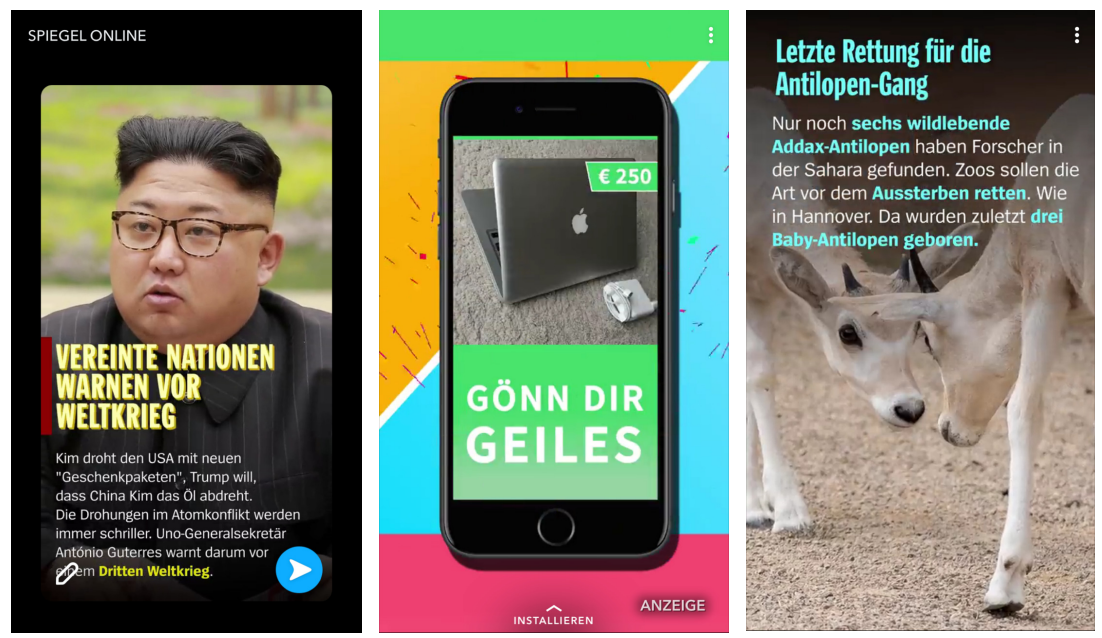

Beispiel aus der Snapchat-Story von Spiegel Online ${ }^{126}$ mit Content links und rechts sowie einer gekennzeichneten Anzeige für eine Smartphone-App in der Mitte

Damit bettet Snapchat, ähnlich wie Facebook, klassische Werbeanzeigen in die natürliches Bedienung der App ein. Ohne die explizite Kennzeichnung der Werbung würden Anzeigen je nach Ausgestaltung sogar überhaupt nicht auffallen. Diese Anzeigen entsprechen einer Mid-Roll Anzeige bzw. einem Interstitial im In-Stream bzw. In-Page-Advertising.

125 Dieser Story-Modus wurde nach dem Erfolg von Snapchat auch bei Instagram und Facebook eingeführt.

126 Abgerufen am 7.9.2017. 
Eine weitere Möglichkeit für Unternehmen mit Snapchat zu werben, ist die Erstellung und Einbindung eines Filters oder sonstigen Foto-/Videoeffekts. Ein Umstand für den Erfolg von Snapchat ist die schier unendliche Gestaltungsmöglichkeit von Fotos und Videos durch Filter, Effekte und Einblendungen. Diese Bild- bzw. Videobearbeitungselemente können dabei rein gestalterischer Natur sein. Hier bietet sich aber auch die Möglichkeit Elemente mit Werbebotschaft zur Verfügung zu stellen und damit eine nutzergenerierte Werbekampagne zu initiieren.

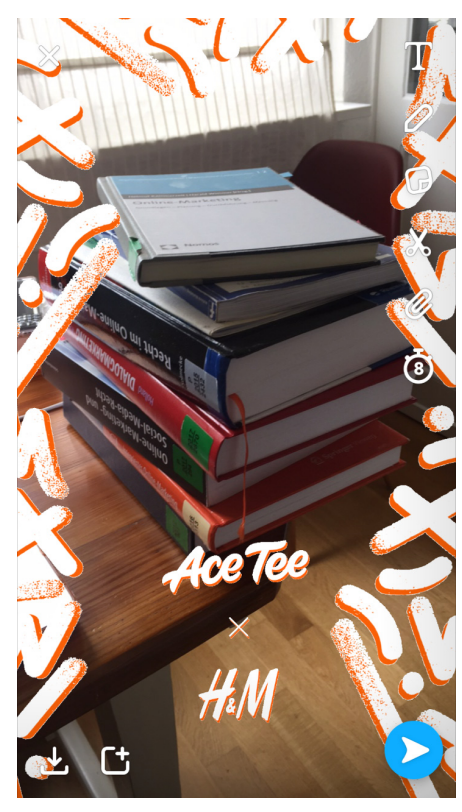

Beispiel eines Snapchat-Filters von H\&M ${ }^{127}$, der vom Autor auf ein beliebiges Foto gesetzt wurde

Hier zeigt sich besonders die Innovation von Snapchat für den Werbemarkt. Diese Werbung erinnert bei rein optischer Betrachtung einer Overlay Ad bei Videostreams. Betrachtet man aber die Ausspielung der Werbung, ist festzustellen, dass hier der "Snapper“ eine eigene Nachricht in die Punkt-zu-Punkt-Kommunikation einbringt, was klassischerweise keine Werbung darstellt oder zumindest als vom Nutzer angeforderte Content-

127 Screenshot angefertigt am 7.9.2017. 
Werbung zu klassifizieren wäre. Der Empfänger der Nachricht wird dann nichtsahnend mit einer Werbebotschaft konfrontiert, die fest mit der Nachricht des „Snappers“ verbunden ist.

Diese Werbeform der Snapchat-Filter ist demnach außergewöhnlich: sie hat zwei zeitlich nacheinander angesprochene Adressaten und wirkt deshalb doppelt. Der erste Adressat ist der „Snapper“ der eine Nachricht kreiert und dabei in der natürlichen Bedienung der App mit Werbung konfrontiert wird. Diese Werbung stellt dabei einerseits Content der App dar, weil sie eine natürliche Bedienungsoption ist. Andererseits stellt sie aber auch eine klassische Anzeige dar, weil sie regelmäßig im Auswahlfeld ungefragt erscheint. Der zweite Adressat ist der Empfänger des „Snaps“, der auf der einen Seite eine Nachricht eines Kontakts erhält und auf der anderen Seite zeitgleich mit einer klassischen Anzeige konfrontiert wird.

Dies zeigt ganz deutlich, dass durch innovative Apps die Grenze zwischen Content und Werbung im Fließen begriffen ist, wenn sie denn gar noch besteht. Aus Marketingsicht dürfte es kaum etwas Positiveres geben, als die Anwendung von Filtern oder Elementen auf eigene Fotos oder Videos (sog. user generated content). Denn hierbei wird der einzelne AppNutzer zum Werbeadressaten und Werbemulitplikator gleichermaßen, der die Werbung dabei sogar wegen seiner Kenntnisse vom Empfänger so verbreitet, dass eine (positive) Wahrnehmung beinahe garantiert ist.

Zur In-App-Werbung bleibt damit abschließend festzuhalten, dass trotz der grundsätzlichen Spiegelung der browserbasierten Internetwerbung hier ein Feld der Innovation für den Werbemarkt besteht, von dem noch nicht abzusehen ist, wie es sich fortentwickelt. Die fortschreitende Marketingarbeit von geschickten Unternehmen kann gerade bei den mobilen Geräten, die zu jeder Zeit und in jeder Lebenslage griffbereit sind, dazu führen, dass sich die Grenze von Werbung und Information immer mehr auflöst.

\section{bb) Browserbasierte mobile Werbung}

Aufgrund der unterschiedlichen Auflösungen der verschiedenen Mobilgeräte werden bei stark frequentierten Internetauftritten besondere Webseiten programmiert, die auf die Bedürfnisse der Mobilgeräte zugeschnitten sind. Insbesondere das Layout und die funktionalen Elemente wie Sucheingabe und Buttons sind dafür regelmäßig im Gegensatz zur PC-optimierten Webseite zu modifizieren. Solche mobile Webseiten werden teilweise auch responsiv programmiert, d.h. die Darstellung passt sich an das jeweils 
verwendete Mobilgerät an. Vorteil dieser mobilen Webseiten ist, dass sie nicht - wie Apps - auf der Grundlage eines bestimmten Betriebssystems programmiert werden müssen ${ }^{128}$.

Auf diesen mobilen Webseiten stehen wie auf den PC-Webseiten regelmäßig Flächen für Werbung bereit. Durch die kleinere Auflösung passen hier selbstredend nicht die standardisierten Größen, die oben ausführlich dargestellt worden sind. Vielmehr wurde auch für die mobile Displaywerbung ein Katalog von Standardwerbeformen erstellt, die vom OVK ebenfalls in der Werbeformenliste aufgenommen worden sind. Dabei stellen die Mobile Content Ads das Pendant zu Bannern dar und sind in verschiedenen Größen implementierbar. Hinzu kommen für die mobile Größe angepasste Rectangles, Interstitials und Expendables (also expandierende Anzeigen, die per Pushdown/Pushup den Content verschieben bzw. als Overlay den Content überdeckt $\left.{ }^{129}\right)$. Selbstverständlich können diese Anzeigen wiederum interaktiv ausgestaltet sein.

\section{c) Werbeformen bei Smart TVs}

Smart TVs sind Fernsehgeräte mit Internetzugang und entsprechender Funktionalität. Dabei entspricht der Smart TV in vielen Belangen einem PC. So ist über einen Browser die Ansicht von Webseiten möglich - womit hier kein Unterschied zu browserbasierten Webseiten besteht. Ebenso können über den Smart TV besondere Apps genutzt werden. Hier kann weitestgehend auf die Ausführungen zu app-basierter Werbung auf Mobilgeräten verwiesen werden. Einziger Unterschied ist wiederum die Größe des Bildschirms, die hier erheblich größere Anzeigen ermöglicht.

Häufig wird der Smart TV jedoch dazu benutzt, bestimmte TV-Programme unabhängig von der Sendezeit abzuspielen, was bei einer Internetverbindung häufig über Mediatheken der bekannten TV-Sender, Streamingdienste wie Netflix und Amazon oder über eine besondere „Time-Shift“Option des Smart TVs erfolgt. Hierbei handelt es sich im Grundsatz jedoch um eine Weiterentwicklung des TV-Angebots, welches in dieser Arbeit nicht behandelt werden soll. Soweit hier ein Internetvideostream erfolgt, gelten die Erwägungen zu In-Stream-Werbung auf browserbasierten Webseiten entsprechend.

128 Vgl. Keßler/Rabsch/Mandic, Erfolgreiche Websites, S. 845.

129 Vgl. die Werbeformenliste des BVDW und OVK, verfügbar unter http://www.w erbeformen.org, zuletzt abgerufen am: 30.5.2019. 
Eine besondere Art von Werbung im Rahmen von Smart TVs kann jedoch über die Menüführung und die Zusatzinformationen zu Werbesendungen ausgespielt werden. So hat etwa Samsung in den USA interaktive Werbung in der Menüleiste ausgespielt, nachdem durch ein Softwareupdate entsprechende Werbeflächen implementiert worden $\operatorname{sind}^{130}$. Diese Werbung stellte sich dabei zunächst als Menüpunkt neben anderen Standardschaltflächen dar, die sich aber bei (notwendigem) Durchklicken vergrößerte ${ }^{131}$. Sie ähnelt dabei In-Text-Werbung auf Webseiten, die bei Mouseover ein Pop-Up öffnen. Berichten zu Folge ist auch für TV-Geräte der Marke Philips eine solche Werbung geplant ${ }^{132}$.

Hinzu kam bei Samsung-Geräten eine über das Betriebssystem des Smart TVs ausgespielte Werbung während auf der Festplatte des Geräts aufgezeichneter Sendungen ${ }^{133}$. Hier wäre denkbar, dass das TV-Betriebssystem die Sendung linear durch eine Pre-Roll-Anzeige verzögert oder durch eine Mid-Roll-Anzeige unterbricht. Zudem wären nicht lineare Werbeanzeige wie Overlay Ads denkbar.

Nach diesem Schema könnten sodann auch Werbeanzeigen in Zusatzinformationen zu (Live-)Sendungen integriert werden. Insbesondere in den EPG (Electronic Program Guide, also der Programmübersicht) oder in mit dem Videotext vergleichbaren Infoboxen könnten vor allem Display Anzeigen eingebettet werden, die damit eine attraktive Werbefläche darstellen. Von solchen Werbeeinblendungen wurde bislang indes noch nicht berichtet.

Die vorbeschriebenen Anzeigen sind potentiell belästigend und könnten auch hier einen Markt für Werbeblocker begründen. Da es sich bislang aber eher um einen Nischenmarkt im Bereich des Internetmarketings handelt, ist noch keine Blockeraktivität zu beobachten. Zudem kontrollieren die Hersteller bislang noch die speziellen Betriebssysteme, was die Programmierung und die Implementierung von neuer Software auf diesen Systemen erschwert.

$130 \mathrm{Vgl.} \mathrm{https://blog.wdr.de/digitalistan/und-ploetzlich-zeigt-der-fernseher-werbung/}$ , abgerufen am: 12.9.2017.

131 Vgl. http://adage.com/article/digital/samsung-smart-tv-update-forces-ads/307246/ , zuletzt abgerufen am: 30.5.2019.

132 Vgl. http://winfuture.de/news,95926.html, zuletzt abgerufen am: 30.5.2019.

133 Vgl. https://blog.wdr.de/digitalistan/und-ploetzlich-zeigt-der-fernseher-werbung/ , abgerufen am: 12.9.2017. 
d) Werbeformen bei Smart Home Geräten

Zuletzt wird auf Smart Home Geräte eingegangen. Damit werden sowohl die zur Zeit der Bearbeitung sich verbreitenden digitalen Assistenten wie Amazon Echo (genannt „Alexa“) oder Google Home gemeint, wie auch internetfähige Haushaltsgeräte.

Während bei den Haushaltsgeräten - soweit sie einen Bildschirm haben - grundsätzlich Display-Werbung möglich ist, zeichnen sich digitale Assistenten durch das Fehlen des Displays aus. Stattdessen erfolgt die Steuerung durch Sprechen. Insoweit ist durchaus anzunehmen, dass in Zukunft auch eine Vielzahl von Haushaltsgeräten oder Steuerungseinrichtungen für Licht, Rollläden, Heizungen oder Ähnliches über eine solche interaktive Sprachsteuerung verfügen werden bzw. mit dem digitalen Assistenten verknüptt sind.

Wie die zeitweise sehr präsente TV- und Videowerbung für Amazon Echo zeigt, stellt der digitale Assistent einen elektronischen Butler dar, der mündliche Befehle ausführt und in Sprache antwortet (so schildert der Assistent auf Befehl die Wettervorhersage oder liest Nachrichten vor ${ }^{134}$ ). Selbsterklärend könnte „Alexa“ auch akustische Werbeanzeigen abspielen oder in ihren Antworten werbliche Aussagen einbauen. Während dies bei den "Grundkenntnissen" des Assistenten unüblich sein wird, können dem Assistenten auch zusätzliche „Fähigkeiten“ (bei Amazon Echo sog. „Skills“) beigebracht werden, die Smartphone Apps entsprechen. Zur Refinanzierung der Entwicklungskosten solcher „Skills“ dürfte durchaus ein Interesse an der Ausspielung von Werbung existieren. Deshalb verwundert es kaum, dass schon früh nach Einführung der Geräte der Versuch gestartet wurde, ein Werbenetzwerk für Amazon Echo zu etablieren. Der Plan war dabei, Botschaften von höchstens 15 Sekunden Länge zu Beginn oder am Ende der durch die Skills bereitgestellten Antworten auszuspielen ${ }^{135}$. Diesen Plan vereitelte jedoch Amazon durch eine Änderung ihrer Entwicklerrichtlinien hinsichtlich der "Skills“ und verbot aktive Werbung im Sinne einer klassischen Anzeige insgesamt. Zulässig ist vielmehr nur Content-Werbung, die entweder Teil eines abgespielten Inhalts ist (etwa eine Mid-Roll Werbung in einem Musikstream) oder Teil eines konkret

134 Vgl. etwa die Werbung auf https://www.youtube.com/watch?v=X2YpMbx1BAo, zuletzt abgerufen am: 30.5.2019.

135 http://www.giga.de/audio/amazon-echo/news/sponsored-messages-in-amazon-ec ho-bombardiert-uns-alexa-bald-mit-werbung/, zuletzt abgerufen am: 30.5.2019. 
werbenden „Skills“ ist (etwa das „Skill“ eines Händlers, bei dem die wöchentlichen Angebote vorgelesen werden) ${ }^{136}$.

Bleibt abzuwarten, ob die Anbieter der digitalen Assistenten bei dieser strengen Maßgabe bleiben oder bei ausreichender Marktverbreitung dieses Werbeverbot lockern werden. Aktuell ist bei Smart Home Geräten deshalb kein Bedarf für Werbeblocker auszumachen.

e) Werbung im Internet of Things?

Zur Zeit der Bearbeitung ein brandaktuelles Thema ${ }^{137}$ ist das Internet of Things bzw. das sog. M2M ${ }^{138}$-Business, also die automatisierte Bewältigung wirtschaftlicher Vorgänge durch Maschinen. Gerade bei automatisierter Kommunikation zwischen Maschinen, die zur Bedarfsdeckung der Maschineneigentümer automatische Bestellungen vornehmen, könnte die „intelligente Maschine“ Adressat von auf diese Maschinen zugeschnittene Werbung sein. Geläufigstes Beispiel für „intelligente Maschinen“ sind im Bereich der „Industrie 4.0" Warenlager, die durch maschinelle Aufzeichnung der Ein- und Ausgänge automatisch Nachbestellungen bei Zulieferern vornehmen können. Im privaten Bereich lässt sich analog das Zukunftsbild eines Kühl- oder Aufbewahrungsschranks anführen, der den Bestand von Lebensmitteln aufzeichnet und überwacht, um bei Bedarf automatisiert Produkte nachzubestellen. Denkbar ist dann auch, dass dieser Kühlschrank Adressat von Werbung wird, zum Beispiel für die Wochenangebote von Lebensmittelhändlern. Auf deren Grundlage könnte die Maschine sodann Einkäufe initiieren.

Natürlich lässt sich eine Maschine, die durch Software gesteuert wird und deshalb die vorher programmierten Programmbefehle abarbeitet, nicht wie ein Mensch zu Impulskäufen oder geschäftlichen Entscheidungen aus irrationalen Gründen hinreißen. Gleichwohl könnten im Programmcode schon Freiräume vorgesehen werden, sodass Informationen, die nicht aktiv von der Maschine gezogen, sondern unter Umständen passiv von Dritten in die Sphäre der Maschine „gepusht“ werden, zur geänderten „Kaufentscheidung“ der Maschine führen. Hier könnte sich also ein

136 https://www.golem.de/news/echo-lautsprecher-amazon-verbietet-fast-alle-werbu ng-in-alexa-skills-1705-127947.html, zuletzt abgerufen am: 30.5.2019.

137 Instruktiv: Grünwald/Nüßing, MMR 2015, 378.

138 Maschine zu Maschine bzw. in englischer Sprache: machine to machine. 
ganz neuer Zweig des Werbemarktes entwickeln, der eher informatischer als gestalterischer Natur ist.

Ob das aktuelle Recht für solche Entwicklungen ausreichende Regelungsmechanismen hat, wird von der Art der Kommunikation der Maschinen abhängen. Die Maschinen sind standardmäßig mit einem Kommunikationsmodul ausgestattet, das per Mobilfunk oder Netzwerk die aggregierten Daten regelmäßig an einen zentralen Rechner (das sog. „M2M-Backend") sendet und im Gegenzug Daten oder Befehle empfängt ${ }^{139}$. Mit weiterer Entwicklung der Technik könnte dieses Backend auch entbehrlich werden, sodass die Geräte für ihren Bereich autark handeln. Insbesondere bei der Mobilfunkalternative stellen sich demnach Probleme aus dem TKG, die hier ausgeklammert werden. Erfolgt die Kommunikation mit der selbsttätigen Maschine analog zur Kommunikation mit einem privaten Rechner bzw. einem mobilen Gerät wie einem Smartphone, kommen zwei Möglichkeiten in Betracht. Entweder wird die Information zum Gerät „gedrückt“, womit eine analoge Betrachtung wie bei E-Mail-Werbung notwendig ist. Oder das Gerät zieht sich die Informationen und initiiert den Informationsvorgang selbst. Dann läge bei Lichte betrachtet nichts anderes als Content-Werbung vor.

Noch nicht deutlich ist, ob eine Maschine zwischen diesen beiden Polen zudem, ähnlich der Display-Werbung, sozusagen beiläufig mit Werbung behelligt werden kann. Da eine Maschine, anders als der Nutzer eines internetfähigen Geräts, keine optische Aufbereitung der Rohinformation bedarf, liegt es eigentlich fern, dass eine der Displaywerbung vergleichbare Situation in der M2M-Kommunikation entstehen wird. Es bleibt abzuwarten, ob sich an dieser Stelle bislang nicht bekannte Entwicklungen durchsetzen können und dem Werbemarkt ein neues Spielfeld eröffnen, das einer rechtlichen Regelung bedarf.

\section{Methoden der Internetwerbung}

Im Rahmen der Internetwerbung begegnen dem unbedarften Beobachter eine Vielzahl von Fachbegriffen, meist Anglizismen, deren Bedeutung naheliegt, aber meist nicht ganz eindeutig ist. Solche Begriffe, die häufig benutzt werden, sollen an dieser Stelle erklärt und die Bedeutung für die Werbung im Internet näher dargelegt werden. Meist handelt es sich dabei um Methoden zur Erreichung einer besonderen Werbewirkung. 
So wird der Leser bestimmt den Begriff Targeting, viellaucht auch die Begriffe Native Advertising, Guerilla Marketing oder Influencer-Marketing schon einmal gehört oder gelesen haben, ohne sich näher damit auseinander gesetzt zu haben. Nicht an dieser Stelle der Bearbeitung wird allerdings das ebenso häufig genannte Tracking behandelt, das erst im Rahmen der technischen Hintergründe (siehe unten Ziffer III.) näher beschrieben wird. Gleiches gilt für den Begriff des Affiliate Marketings, das bei den wirtschaftlichen Hintergründen (siehe unten Ziffer II.) erklärt wird.

\section{a) Targeting}

Targeting wird abgeleitet vom englischen Wort „target“, zu deutsch "Ziel“140, und bezeichnet die gezielte und möglichst zielgenaue Werbeansprache. Targeting ist demnach die Methode zur Bereitstellung zielgruppenspezifischer Werbeinhalte ${ }^{141}$. Durch Targeting sollen Streuverluste minimiert werden und damit die Erfolgswerte verbessert werden. Dies führt zu effektiveren und kosteneffizienteren Werbekampagnen. Auch kann Targeting zu einer höheren Akzeptanz der Adressaten führen, wenn diese eine passgenaue Werbung als sinnvolle Unterstützung des umliegenden Contents auffassen ${ }^{142}$.

Targeting ist im Grundsatz keine neue internetspezifische Erscheinung, weil die Auswahl des richtigen Mediums und Umfelds logischerweise den Erfolg einer Werbekampagne schon immer wesentlich bestimmt hat. Dass eine TV-Werbung für Kinderspielzeug während einer Ausstrahlung des Spielfilms „Der König der Löwen“ erfolgreicher sein wird, als während eines Actionfilms mit Altersbeschränkung ab 18 Jahren bedarf keiner besonderen Kenntnisse des Werbemarkts.

Das Internet mit seiner technischen Besonderheit als vom Nutzer gesteuertes Medium - im Gegensatz zu den redaktionellen Sende- oder Printmedien - bietet aber noch ganz neue Möglichkeiten des Targetings, mit der Zielgruppen sehr viel genauer formuliert und identifiziert werden können. Während bei den klassischen Medien anhand des Mediums, des Kanals und der jeweiligen Sendung nur ein recht grober Zuschnitt von Gemeinsamkeiten möglich ist (was haben etwa alle Bild-Leser, die einen Klatschartikel lesen, oder alle RTL-Zuschauer, die das „Dschungelcamp“

140 Vgl. http://dict.leo.org/englisch-deutsch/target, zuletzt abgerufen am: 30.5.2019.

141 Jacob, Integriertes Online-Marketing, S. 226.

142 Keßler/Rabsch/Mandic, Erfolgreiche Websites, S. 45. 
schauen, gemeinsam?), eröffnet das Internet im Grundsatz die Möglichkeit der Lokalisierung und Benennung gewisser Interessen des Adressaten. Ein solches manuelles Targeting ist eingangs auch bei der Internetwerbung oft nötig, um aus der Vielzahl von Werbeflächen und Anbietern solche zu finden, die für die geplante Werbung erfolgsversprechend sind ${ }^{143}$.

Im Nachgang dazu stehen eine Vielzahl von automatisierten Targetingmethoden zur Verfügung, die im Folgenden näher dargestellt werden sollen:

\section{aa) Technik-Targeting}

Es besteht die Möglichkeit Werbeanzeigen nur an Nutzer bestimmter Hard- und/oder Software auszuspielen. Insbesondere lässt sich differenzieren, ob PCs oder mobile Geräte genutzt werden oder ob ein Windows oder ein Mac-Betriebssystem installiert ist. In diese Kategorie fällt auch das Targeting anhand von verfügbarer Bandbreite oder Internetgeschwindigkeit des Adressaten ${ }^{144}$. Dies ist vor allem sinnvoll, um mobile Adressaten nicht durch aufwändige Anzeigen mit längeren Ladezeiten und Belastung des begrenzten mobilen Internetvolumens zu plagen.

Durch diese Art von Targeting können bereits viele „untaugliche“ Adressaten, vor allem bei techniknaher Werbung, ausgeschlossen werden und so die Streuverluste erheblich minimiert werden. So ist für manche Werbungen wegen der Kompatibilität des beworbenen Produkts für nur bestimmte Betriebssysteme dieses Technik-Targeting ein erster Grobfilter zur Erreichung der gewünschten Zielgruppe.

Im Vergleich zum manuellen Targeting entspricht diese Art der Kundenansprache etwa der Werbung in bestimmten Fachmagazinen, zum Beispiel einer Zeitschrift für Mac-Computer Nutzer wie „MacLife“. Der Vorteil wiederum ist, dass der umgebende Content jedoch ein ganz anderer sein kann und damit nicht nur die Leser der Fachzeitschrift, sondern auch weniger fachinteressierte Personen auf weniger spezialisierten Portalen erreicht werden können.

$143 \mathrm{Keßler} /$ Rabsch/Mandic, Erfolgreiche Websites, S. 46.

144 Jacob, Integriertes Online-Marketing, S. 226. 
bb) Geo-Targeting

Internetnutzer lassen sich durch die technischen Besonderheiten des Internets relativ leicht lokalisieren. Dazu werden im Zusammenspiel zwischen IP-Adresse und Standort des Nutzers besondere regionale Werbeanzeigen ausgespielt. Bei mobilen Geräten kann die Lokalisierung auch durch Einwahl in bestimmte WLAN-Netze oder Hotspots sowie durch GPS-Daten erfolgen ${ }^{145}$.

Durch diese Lokalisierung ist die Schaltung von Anzeigen nur für eine bestimmte Stadt oder Region möglich, was insbesondere für stationäre Gastronomie oder Freizeitangebote sinnvoll ist, für die Kunden regelmäBig keine längeren Wege auf sich nehmen werden.

Dieses Targeting entspricht der Schaltung einer Anzeige bei der klassischen Regionalzeitung, die nur in einem begrenzten Gebiet verfügbar ist. Der Vorteil ist wiederum, dass der umgebende Content gerade nicht regional und allgemein sein muss, sondern auch weltweite und spezialisierte Ausprägung haben kann.

\section{cc) Semantisches Targeting}

Durch semantisches Targeting soll eine thematische Verknüpfung zwischen Content und Anzeigen hergestellt werden. Dazu wird der Text einer Internetseite analysiert und der Schwerpunkt herausgearbeitet. $\mathrm{Zu}$ diesem Schwerpunkt werden dann passende Werbeanzeigen ausgespielt. Ein häufiges Beispiel hierfür sind Reiseberichte als Inhalt einer Webseite mit passenden Werbeeinblendungen zur Buchung einer Reise oder Hotels zu gerade diesem Ort $^{146}$.

Diese Methode stellt die Übersetzung der klassischen Medien- und Kanalauswahl in die Internetumgebung dar. Großer Vorteil ist hier die Automatisierung der Platzierung, sodass kein Austausch mit Redaktionen nötig ist, um die eigene Werbung möglichst nah an bestimmte Inhalte zu binden.

$145 \mathrm{Keßler} /$ Rabsch/Mandic, Erfolgreiche Websites, S. 48; Jacob, Integriertes OnlineMarketing, S. 226.

$146 \mathrm{Keßler/Rabsch/Mandic,} \mathrm{Erfolgreiche} \mathrm{Websites,} \mathrm{S.} \mathrm{49;} \mathrm{Jacob,} \mathrm{Integriertes} \mathrm{Online-}$ Marketing, S. 227. 
dd) Keyword-Targeting

Diese Methode ist ebenfalls ein semantisches Targeting. Der Begriff wird in der multidisziplinären Literatur doppeldeutig benutzt. Einerseits bezeichnet Keyword-Targeting eine weniger komplexe Art des semantisches Targetings, bei dem nicht der ganze Text, sondern nur einzelne Worte auf einer bestimmten Webseite zum Anlass genommen werden, die entsprechende Werbeanzeige einzublenden ${ }^{147}$. Dies wird in der folgenden Bearbeitung als Kontext-Targeting bezeichnet.

Andererseits - und auch im weiteren Verlauf in dieser Bearbeitung wird der Begriff für die spezifische Schaltung von Werbung in Suchmaschinen nach der Eingabe von Suchworten, also „Keywords“, genutzt. Gibt der Nutzer einen bestimmten Werbebegriff ein, können ihm gegenüber bestimmte Anzeigen ausgespielt werden, sofern der Werbende vorab das oder die Suchwörter als „Keywords“ angegeben hat ${ }^{148}$. Bekanntestes Beispiel ist das Werbeprogramm der Suchmaschine Google namens AdWords.

\section{ee) Kontext-Targeting}

Diese gerne auch „contextual targeting“ genannte Methode ist ebenfalls eine Ausprägung des semantischen Targetings. Hier wird aber nicht genau an den Text der Webseite angeknüpft, sondern an bestimmte „Keywords“, die in den Metadaten der Webseite gespeichert werden. Da diese Metadaten oft im Rahmen der Suchmaschinenoptimierung (SEO) gepflegt werden, kann die Werbung im Kontext dieser Schlüsselworte platziert werden. Ein häufiges Beispiel hierfür ist die Schaltung von Werbung für PKW auf einer Motorsportseite ${ }^{149}$. Wie bereits erwähnt ist dies eine weniger gut ausgeprägte Form des semantischen Targetings. Anders als die erschöpfende Analyse von Texten beim semantischen Targeting reichen beim Kontext-Targeting nur einzelne Worte aus. Dies birgt die Gefahr, dass Doppeldeutigkeit oder die vorsätzliche Unterbringung bestimmter

147 Ulmer, in: Ulmer-Eilfort/Obergfell, Verlagsrecht, Kapitel F, Rn. 213; Hass/Willbrandt, Medienwirtschaft 2011, 12, 14.

$148 \mathrm{Keßler} /$ Rabsch/Mandic, Erfolgreiche Websites, S. 49; Jacob, Integriertes OnlineMarketing, S. 226.

149 Jacob, Integriertes Online-Marketing, S. 227; Hass/Willbrandt, Medienwirtschaft 2011, 12, 14 . 
Schlüsselworte im Text trotz fehlender kontextualer Umgebung das Targeting im Ergebnis ins Leere laufen lassen.

\section{ff) Soziales Targeting}

Mit dieser Methode wird aufgrund verfügbarer Information über den Nutzer versucht, möglichst individuelle Werbung zu platzieren. Dies ist regelmäßig bei sozialen Netzwerken möglich, bei denen Nutzer freiwillig unmittelbar ihre Daten wie Geschlecht, Alter und Interessen einpflegen oder mittelbar durch Klicken des „gefällt mir“-Buttons auf bestimmten Seiten preisgeben ${ }^{150}$. Werbekampagnen bei Facebook können etwa so durch Eingabe mehrerer Determinanten extrem zielgenau geschaltet werden. So kann durch kumulative Angabe eines Standorts, des Alters, der Sprache und bestimmter Interessen der Adressaten ein genaues Bild des Wunschkunden gezeichnet werden. Hinzu kommt die Möglichkeit der Beschränkung auf Nutzer, die direkte oder vermittelnde Verbindungen zur eigenen Facebookseite haben, oder eben der Ausschluss dieser Personen, um nur neue Kunden zu gewinnen ${ }^{151}$.

Facebook geht sogar so weit, dass Werbekunden bestehende Kundendatenbanken bestehend aus E-Mail-Adressen oder Telefonnummern einreichen können und daraus dann eine bestimmte fixe Zielgruppe angelegt wird, denen dann bestimmte Werbung ausgespielt wird (sog. Costumer Audience). Ausgehend von einer solchen Liste kann Facebook zudem weitere Nutzer mit ähnlichen Attributen und Interessen finden und dann eine parallele Zielgruppe erstellen (sog. Lookalike Audience) ${ }^{152}$.

Auf die Informationen bei Facebook kann aber auch zur Schaltung von Display Werbung auf anderen Webseiten zurückgegriffen werden. Denn Facebook sammelt und nutzt die Daten der Nutzer auch, wenn sie auf einem Gerät eingeloggt sind und währenddessen andere Seiten als die Netzwerkseite aufrufen. Besucht ein Facebook Nutzer dann eine fremde Webseite, die über das Facebook-Werbenetzwerk „Atlas“ Werbung einpflegt, wird die konkrete Werbung anhand der Informationen aus dem sozialen Netzwerk ausgewählt und damit erheblich personalisiert ${ }^{153}$.

150 Keßler/Rabsch/Mandic, Erfolgreiche Websites, S. 49.

151 Lammenett, Praxiswissen Online Marketing, S. 315.

152 Lammenett, Praxiswissen Online Marketing, S. 319ff..

153 Lammenett, Praxiswissen Online Marketing, S. 321ff.. 


\section{B. Grundlage: Werbung im Internet}

So ist soziales Targeting eine fortschrittliche Form der Kundenansprache, die im klassischen Bereich bei Betrachtung der Individualisierung wohl mit der Empfehlungswerbung durch Bekannte oder Freunde verglichen werden kann. Gleichwohl stellt die Werbung eine eigene Aussage des Werbenden dar und wird nicht wie bei Empfehlungswerbung in der „realen Welt“ nach dem „Stille Post“-Prinzip verfälscht.

\section{gg) Verhalten-Targeting}

Diese häufig mit dem englischen Begriff „(predictive) bahavioral targeting“ bezeichnete Methode zeichnet sich dadurch aus, dass aufgrund von früherem Nutzerverhalten, insbesondere durch den Einsatz und das Auswerten von Cookies sowie anderer Trackingmethoden, ein Nutzerprofil angelegt wird, das die Werbeausspielung steuert ${ }^{154}$. Dadurch soll ähnlich wie bei dem sozialen Targeting eine möglichst zielgenaue Werbeeinblendung bezweckt werden. Auf Grundlage der Informationen aus den Cookies u.a. werden bestimmte Interessen des Nutzers erkannt und mit soziodemografischen Daten aus verschiedenen Quellen abgeglichen. Durch statistische Modelle und Algorithmen wird dann das Verhaltensmuster vorhergesagt und die Zugehörigkeit zu einer bestimmten Zielgruppe definiert ${ }^{155}$.

Diese Art von Targeting kann etwa recht plump erfolgen, wie etwa die Anzeige von Werbung eines bestimmten Online Shops, nachdem dieser besucht worden ist (sog. Re-Targeting) ${ }^{156}$. Dieses Re-Targeting ist sehr häufig und insbesondere dann nicht nur positiv, wenn tatsächlich in dem Shop etwas bestellt worden ist oder eine Bestellung bewusst abgebrochen worden ist. Allerdings kann gerade bei abgeschlossenen Bestellungen auch auf ähnliche Produkte im selben Shop hingewiesen werden und damit ein baldiger nächster Besuch des Online Shops bezweckt werden. Dies insbesondere, wenn das Re-Targeting auf mehrere Tage und Wochen angelegt ist.

Andererseits kann außerhalb des Re-Targetings bei einer geschickten Anlage des Nutzerprofils durch Verhalten-Targeting in subtiler Weise eine passgenaue Werbung ausgespielt werden. So liegt etwa bei wiederholtem Besuch von Sportseiten das Interesse an Live-Sportübertragungen nahe.

154 Jacob, Integriertes Online-Marketing, S. 227.

155 Vgl. Keßler/Rabsch/Mandic, Erfolgreiche Websites, S. 50.

$156 \mathrm{Keßler/Rabsch/Mandic,} \mathrm{Erfolgreiche} \mathrm{Websites,} \mathrm{S.} \mathrm{50f.;} \mathrm{Jacob,} \mathrm{Integriertes} \mathrm{On-}$ line-Marketing, S. 227. 
Dann kann hier passend für Angebote wie Sky oder DAZN geworben werden, selbst wenn der Nutzer aktuell nicht auf Sportseiten surft und auch die Seiten der werbenden Anbieter noch nie aufgerufen hat.

\section{hh) Fazit}

Durch die Vielzahl an vorgenannten Targetingmethoden steht Werbetreibenden im Internet eine nie dagewesene Auswahl an Möglichkeiten zur Ansprache der potentiellen Kunden zur Verfügung. Gleichwohl ist diese Vielzahl an Targetingoptionen ein schmaler Grat. Während einige Nutzer bei zu starker persönlicher Ansprache belästigt werden könnten, sprechen andere Nutzer gerade auf diese Art von Werbung besonders an. Hinzu kommt auch ein Einfluss auf den Ruf des Werbetreibenden. Bei zu stark personalisierter, insbesondere bei auf Cookies beruhender Werbung könnte sich der Nutzer verfolgt und ausspioniert vorkommen, was dann auch negative Rückschlüsse auf den Werbenden zur Folge haben kann.

In technischer Hinsicht ist Targeting, vor allem das Verhalten-Targeting, mit Tracking verbunden. Targeting ist dann der letzte Schritt in einem mehrstufigen Datenverarbeitungsprozess, der mit der Erhebung von Daten beim Nutzer beginnt und nach der Speicherung und Auswertung von Nutzungsprofilen die notwendige Richtung für das Targeting ausgeben $\operatorname{kann}^{157}$.

\section{b) Native Advertising}

Ein weiterer Begriff, der häufig im Kontext von Online-Werbung fällt, ist Native Advertising. Zu deutsch sinngemäß: natürliches Werben. Ziel des Native Advertising ist es, Werbung so zu gestalten, dass sie optisch und thematisch gut in die Content-Umgebung passt. Von den oben dargestellten Werbeformen stellen vor allem die gesponserten Posts in den sozialen Netzwerken und die Suchmaschinenwerbung (SEA) ein Beispiel für natürlich in die Umgebung eingepasste Werbung dar, die bei Aussparung der obligatorischen Kennzeichnung als Anzeige gar nicht als Werbung wahrnehmbar wäre ${ }^{158}$.

157 Vgl. die schematische Darstellung bei Schleipfer, ZD 2017, 460, 462.

158 Vgl. Keßler/Rabsch/Mandic, Erfolgreiche Websites, S. 628. 
Native Advertising ist im Fall von Anzeigenwerbung eine solche, die sich als Content tarnt - sozusagen der Wolf im Schafspelz. Vorteil dieser Gestaltungsart von Werbung ist eine höhere Akzeptanz von Werbung, die zu guten Klickraten und geringer „Bannerblindheit" führen soll159. Deshalb gehen auch klassische Publisher abseits der Suchmaschinen und sozialen Netzwerke nunmehr teils dazu über, auf stark den Inhalt kontrastierende Display-Werbeformen zu verzichten und auf ihren Werbeflächen Anzeigen zu schalten, die dem Layout der Seite insgesamt angepasst sind.

Eines der Kernelemente von Native Advertising ist es, dass der Lesefluss des Nutzers einer Webseite nicht unterbrochen wird ${ }^{160}$. Diese Methode setzt also weniger auf das Prinzip der Störung und stellt ein Gegenkonzept zu Pop-Ups oder Interstitials dar, bei denen gerade auf erzwungene Aufmerksamkeit gesetzt wird. Die Idee des Native Advertising lässt sich auch abseits der Anzeigenwerbung auf Content-Werbung übertragen. Dies betrifft die Gestaltung von Seiteninhalten, die ihren werbenden Charakter nicht durch die äußere Gestaltung bereits eindeutig macht und teils erst am Ende durch Links oder Produktvorschläge den werblichen Zweck offenbart. Als Beispiel für natives Contentmarketing wird vor allem das Portal Buzzfeed genannt ${ }^{161}$, aber auch sonstige thematisch spezialisierte Portale wie die Rezeptdatenbank Chefkoch.de dienen als Beispiel.

159 Keßler/Rabsch/Mandic, Erfolgreiche Websites, S. 628.

160 Vgl. Wiebe/Kreutz, WRP 2015, 1053, 1055.

161 Vgl. Wiebe/Kreutz, WRP 2015, 1053, 1055f.; Hoene, IPRB 2016, 59. 


\section{BuzzFeed Menu}

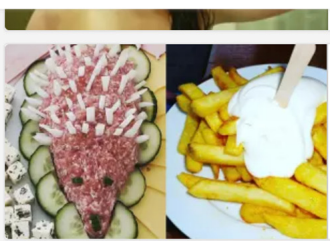

14 German Foods The Rest Of The World Just Doesn't Understand

It's the wurst.

?. Anna Aridzanjan

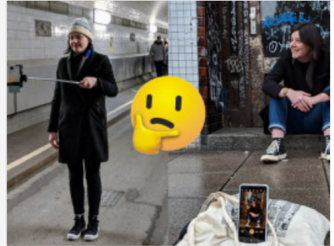

Die schönsten Ecken Hamburgs, um das perfekte Selfie zu schießen

Wir haben das Google Pixel 2 in Deutschlands cooler Stadt im Norden getestet.

C. Promoted von

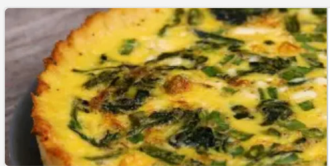

Quiche mit Blumenkohlkruste

Folge Einfach Tasty auf Youtube.

(2) tastyeditor $\cdot$ vor 2 Stunden

Beispiel $^{162}$ eines von Google Deutschland bereitgestellten Beitrages bei Buzzfeed, der auf der Startseite als einer von mehreren Artikeln aufrufbar ist

162 Abgerufen am 27.1.2018. 
BuzzFeed Menu

\section{Die schönsten Ecken Hamburgs, um das perfekte Selfie zu schießen}

Wir haben das Google Pixel 2 in Deutschlands cooler Stadt im Norden getestet.

Gepostet am 22. Januar 2018, 12:26 Uhr

Google DE

Brand Publisher

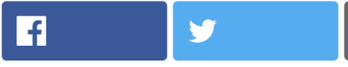

\section{$\nabla$}

(D)

$\mathbf{t}$

e

\section{Hamburg: Das Tor zur Welt und die meistunterschätzte Stadt Europas.}

Hier gibt es nicht nur Docks und Lagerhäuser - die Sehenswürdigkeiten der Hansestadt sind der perfekte Hintergrund für irre Selfies. Was gut für mich ist, weil meine Erfolgsquote bei Selfies normalerweise im Bereich von amateurhaften 1:20 pendelt. Doch mit einem Google

\section{BuzzFeed Menu}

Willkommen im Alten Elbtunnel auf St. Pauli, auch bekannt als der Himmel für AmbienteSelfies. Vielleicht ist es auch die Hölle, da man in einer 106 Jahre alten Röhre steckt, die 24 Meter unterhalb eines enormen Gewässers verläuft? So oder so - leg die Filter drauf und warte auf die Likes. (Ein Selfie-Stick eignet sich hier prima...)

Bring deine Selfies auf ein neues Level - mit dem Google Pixel 2. Probier es noch heute mit deinem Gesicht aus!

Alle Fotos aufgenommen mit dem Google Pixel 2.

Beispiel $^{163}$ des aufbereiteten Beitrages von Google Deutschland auf Buzzfeed mit eindeutiger Werbung für das Produkt "Google Pixel 2" mit Verlinkung zu Beginn und zum Abschluss des Beitrages

163 Abgerufen am 27.1.2018. 


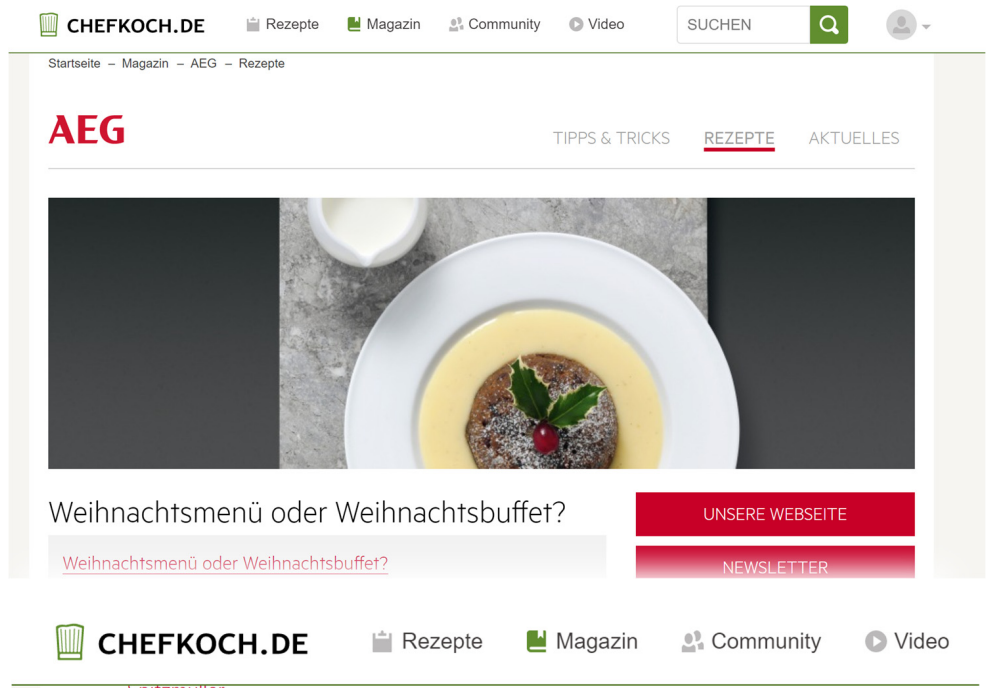

- Geschmorte Schweinebäckchen mit Linsen und gebratener Wassermelone - DampfgarerRezept von Sternekoch Sören Anders

\section{WEIHNACHTLICHE DESSERTS}

- Boskop-Apfel im Strudelblatt mit Vanillesoße - von Foodgenie Christian Mittermeier

- English Christmas Pudding - Dampfgarer-Rezept von Christian Mittermeier

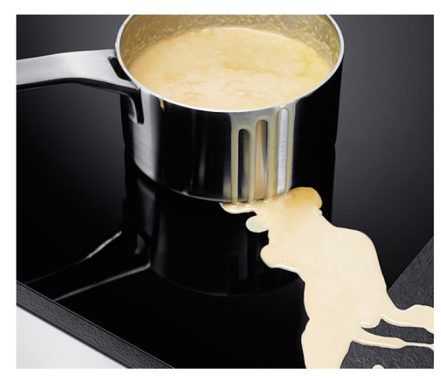

Noch auf der Suche nach einem

Weihnachtsgeschenk - für sich selbst oder einen anderen begeisterten Hobbykoch? Dann entdecken Sie jetzt die edlen Pfannen und Töpfe aus der AEG Gourmet Collection inspiriert und entworfen in Zusammenarbeit mit internationalen Spitzenköchen!

$\underline{W e i t e r e s ~ B e i s p i e l}^{164}$ eines von AEG bei Chefkoch.de platzierten werbenden Beitrages mit Anbringung des Markenzeichens zu Beginn und expliziten Werbeappell zum Abschluss

164 Abgerufen am 27.1.2018. 
Das Native Content Advertising sieht also nach redaktionellen Beiträgen aus und vermittelt auch durchaus Informationen außerhalb der Produktbeschreibung. Dies kann aber nicht davon ablenken, dass es sich um Werbung im eigentlichen Sinne handelt. Die dargestellten Beispiele erinnern an eine Dauerwerbesendung im Fernsehen, die ebenfalls unterhaltend sein kann, jedoch den werbenden Charakter nicht ausschließt.

\section{c) Guerilla Marketing}

Das martialisch klingende Guerilla Marketing ist ein loser Überbegriff für unkonventionelle Werbekampagnen. Andere Begriffe in diesem Kontext sind „Ambush Marketing“ oder virales Marketing. Im Internet sind solche Aktionen denkbar und üblich. Vor allem auf Seiten, die eine Upload- oder Kommentarfunktion haben, wie YouTube, Nachrichtenportale, Foren, Blogs oder soziale Netzwerke, können werbliche Botschaften hinterlassen werden. Damit lässt sich Werbung in fremde Umgebungen platzieren, die aus Nutzersicht streng genommen Content der aufgesuchten Seite darstellt. Sie wirken auf den Nutzer dann aber wie „native Ads“. Als Beispiel sind virale Videoclips zu nennen. Auch denkbar ist, dass sich ein Werbetreibender auf häufig besuchten unspezifischen Seiten wie gutefrage.net oder wer-weiss-was.de als Antwortgeber profiliert. Der Kreativität der Werbenden sind keine Grenzen gesetzt.

Nachteile solcher Aktionen können sein, dass gegen Richtlinien der Seitenbetreiber verstoßen wird und ultimativ ein Ausschluss von der Seite folgt. Auch besteht ein gewisses Risiko, dass Nutzer die Aktionen negativ auffassen ${ }^{165}$.

Hinter dem Begriff des Guerilla Marketing steckt also eine Methode zur unkonventionellen Kundenansprache, die sich aber weniger im Bereich klassischer Anzeigenwerbung abspielt, denn vielmehr im Contentbereich von Internetportalen.

\section{d) Influencer-Marketing}

Zuletzt hat sich auch der Begriff des „Influencers“ verbreitet. Dies ist „jemand, der die Werte und Ziele und damit auch das Kaufverhalten seiner

165 Vgl. Keßler/Rabsch/Mandic, Erfolgreiche Websites, S. 803f.. 
überwiegend jungen Anhängerschaft beeinflussen kann"166. Dies sind in der Regel Prominente, die sich im Internet auf sozialen Medien darstellen, oder sogar Personen, die durch die eigene Darstellung in den sozialen Netzwerken prominent geworden sind. Influencer haben meist „Follower“ im sechs- oder siebenstelligen Bereich. So erreicht die Videobloggerin „Dagi Bee“ mit 4,9 Millionen Instagram-AbonnentInnen, 3.586.418 YouTubeAbonnentInnen und 1.505.098 Personen, denen ihre Facebookseite gefällt (Stand: September 2017) ${ }^{167}$ mit jedem einzelnen Beitrag in den sozialen Netzen mehr Menschen als die Bild-Zeitung mit einer täglichen Ausgabe (1.621.531 verkaufte Exemplare im ersten Quartal 2017168).

Influencer-Marketing funktioniert dabei in der Regel so, dass der Influencer das beworbene Produkt in seinen Beiträgen unterbringt. Es ist also im Grunde nichts anderes als die althergebrachte Produktplatzierung neu aufgelegt im Facebook-Zeitalter. Es hat aber einen grundlegenden Vorteil: das Feedback auf die Produkte kann durch die Kommentare der Internetnutzer in Echtzeit gemessen werden. So kann auf der ersten Stufe schon ermittelt werden, wie viele Personen diese Werbung erreicht hat. Auf der nächsten Stufe kann durch die Bewertungsfunktionen wie „Likes“ gemessen werden, ob der Beitrag gut ankam. Hier spielen auch die Kommentare eine Rolle - wenn die Werbung nicht gut ankommt, kann sich schon einmal der zuletzt sehr häufig anzutreffende "Shitstorm“ zusammenbrauen. Zuletzt kann im Nachgang beobachtet werden, ob sich die Nutzer mit Feedback zu dem Produkt in den Kommentaren an den Influencer oder die anderen Follower wenden. Hiermit erhält der Werbende weitaus mehr Informationen über den Erfolg der Kampagne und kann die tatsächlichen Erfahrungen der Produktnutzer für die zukünftige Produktentwicklung fruchtbar machen.

Influencer kann man mittlerweile über spezialisierte Agenturen buchen, damit sie Produkte in ihre Beiträge einfügen. Damit haben sich die Akteure innerhalb der sozialen Medien zum eigenständigen Werbedienstleister entwickelt. Das Privileg, kostenpflichtige Werbung zu schalten, steht damit nicht mehr nur dem Portalbetreiber zu, sondern auch denjenigen,

166 Dornis/Slavik, Influencer, die neue Marketing-Macht, http://www.sueddeutsch e.de/wirtschaft/influencer-influencer-die-neue-marketing-macht-1.3658317, zuletzt abgerufen am: 30.5.2019.

167 https://www.styleranking.de/galerie/masha-caro-toni-das-sind-die-derzeit-12-wic htigsten-influencer-aus-deutschland/4, zuletzt abgerufen am: 30.5.2019.

168 http://meedia.de/2017/04/24/ivw-blitz-analyse-tages-und-wochenzeitungen-bild -bams-und-wams-verlieren-mehr-als-10-gewinne-fuer-die-junge-freiheit-und-den-f reitag/, zuletzt abgerufen am: 30.5.2019. 
die eigentlich nur Content liefern sollen. Und hier besteht auch die Besonderheit der Influencer-Werbung. Sie ist aus Nutzersicht reiner Content, den sie bewusst aufrufen - ebenso wie Spielfilme oder Serien im TV oder über Streamingportale. Dass im konkreten Beitrag aktiv Werbung für ein Produkt gemacht wird, muss der Nutzer hinnehmen oder das Abonnement beenden. Und kaum ein Nutzer wird bei Werbung innerhalb eines Beitrags sofort die Anhängerschaft aufkündigen. Vielmehr sind solche Werbungen oft erst der Grund für die Popularität von Influencern.

Influencer-Marketing beschäftigte die Rechtsprechung in der Zeit vor Fertigstellung dieser Arbeit regelmäßig. Es ist ein Trend der Werbeausspielung im Internet, der eine differenzierte rechtliche Beurteilung erfordert.

\section{Wirtschaftliche Bedeutung}

Der Internetwerbemarkt hat - parallel zur Etablierung des Internets als fester Bestandteil im Leben vieler Menschen - eine enorme wirtschaftliche Bedeutung erlangt. In Zahlen ausgedrückt bedeutet dies, dass im Jahr 2018 auf dem deutschen Werbemarkt allein für digitale Display-Werbung ein Nettovolumen von 2.065.000.000 $€$ (in Worten: zwei Milliarden fünfundsechzig Millionen) festgestellt worden ist ${ }^{169}$. Damit sind noch nicht die Kosten für Suchmaschinen-, Content-Marketing und andere Internetwerbeformen wie Influencer-Marketing erfasst.

Im Jahr 2016 hatte die Internetwerbung in Deutschland (an dieser Stelle Display- und Suchmaschinenwerbung gemeinsam) erstmals den größten Anteil am medienübergreifenden Werbevolumen insgesamt für sich beanspruchen können und damit das Fernsehen als umsatzstärkstes Medium an der Spitze abgelöst. Mit 29,9\% des Werbevolumens geht beinahe ein Drittel der Werbeausgaben in den Bereich der Online-Werbung ${ }^{170}$. Die Prognosen lauten dabei weiterhin auf Wachstum, sodass von einer Erhö-

169 OVK-Report für digitale Display-Werbung 2019/01, https://www.bvdw.org/fi leadmin/bvdw/upload/publikationen/ovk/bvdw_ovk_report_2019_01_fina 1.pdf0, zuletzt abgerufen am: 30.5.2019. Erfolgreichste Werbeform war dabei die Pre-Roll Werbung mit 417,4 Mio. € Brutto-Werbeinvestition, gefolgt vom „Ad Bundle“ (253,4 Mio. €), der Billboard Ad (218,6 Mio. €), dem Sitebar (132,8 Mio. €) sowie mobiler Pre-Roll Werbung (114,7 Mio. €).

170 OVK-Report für digitale Display-Werbung 2017/02, http://www.bvdw.org/me dien/ovk-report-fuer-digitale-werbung-2017-02? media=8880, abgerufen am: 19.9.2017. 
hung der absoluten Zahlen wie auch des relativen Verhältnisses im Medienvergleich auszugehen ist.

Europaweit betrug 2016 das Volumen des Display-Marketings sogar 16,19 Milliarden $€$ in 27 gemessenen Ländern des Kontinents. Suchmaschinenwerbung kommt zusätzlich dazu auf 19,1 Milliarden. Auch auf europäischer Ebene wurde bei Beachtung aller Online-Marketingaktivitäten das Fernsehen als werbestärkstes Medium überholt ${ }^{171}$.

An dieser Stelle sollen in Kürze die Wirtschaftsakteure, Marktgegebenheiten und Abrechnungsmodelle dargestellt und erklärt werden. Selbstverständlich kann jeder Inhaber einer Internetseite auf seiner eigenen Webseite Eigen- oder Fremdwerbung schalten bzw. veröffentlichen. Die Seitenbetreiber, oft auch Publisher genannt, sind diejenigen Akteure, die Werbeflächen als konkrete Dienstleistung anbieten. In der analogen Welt finden sie ihre Entsprechung in den Eigentümern von Plakatwänden oder Litfaßsäulen.

Die Komplexität des Internets mit seinen Myriaden an Seiten und Unterseiten erlaubt es aber regelmäßig nicht, dass die Vermarktung von Werbeflächen im Internet im direkten „Käufer-Verkäufer-Kontakt" erfolgt. Nur selten wird der Werbetreibende, teils Merchant genannt, unmittelbaren Kontakt zum Seitenbetreiber pflegen. Vielmehr sind regelmäßig Vermittler zwischengeschaltet, die Werbung planmäßig distribuieren und steuern. Als zentrales Glied zwischen Anbietern und Nachfragern von Online-Werbeflächen haben sich deshalb Werbenetzwerke oder Online-Vermarkter etabliert (im Weiteren gemeinsam als [Werbe-]Netzwerke bezeichnet). Diese Netzwerke bündeln einerseits Werbeflächen verschiedenster Seitenbetreiber und sind andererseits Sammelstelle für Anzeigen von einer Vielzahl Werbetreibender. Das Netzwerk nimmt dann die konkrete Platzierung der Anzeigen (u.a. nach Targeting-Präferenzen des Werbenden) auf den Werbeflächen vor ${ }^{172}$.

171 Zahlen laut IAB Europe, https://www.iabeurope.eu/wp-content/uploads/2017/0 5/IAB-Europe-AdEx-Benchmark-2016-Study-FINAL-1.pdf, zuletzt abgerufen am: 30.5.2019.

172 Vgl. Jacob, Integriertes Online-Marketing, S. 233. 

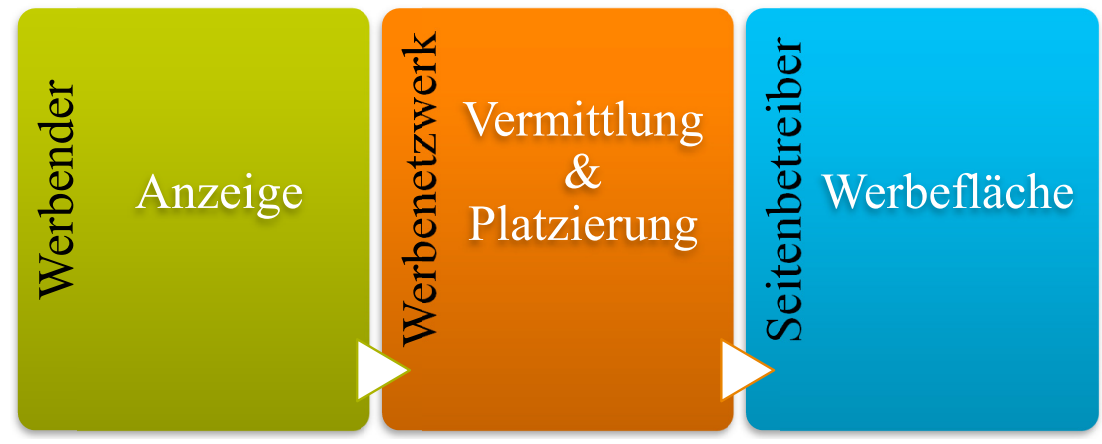

Abbildung 4: einfache schematische Darstellung der üblichen Wertschöpfungskette bei Online-Werbung

Diese Werbenetzwerke können verschiedener Art sein. Sie können wie das Google Display-Netzwerk unternehmensspezifische Online-Vermarkter sein, die alle Seiten eines bestimmten Konzerns (z.B. bei Google: YouTube, GMail etc.) als Werbeflächen bündeln und anbieten sowie für alle Werbetreibenden gegen Vergütung offen stehen ${ }^{173}$. Weitere bekannte Online-Vermarkter sind United Internet Media (gehört zu 1\&1 und betreibt u.a. E-Mail-Hoster wie web.de und gmx.de), SevenOne Media (gehört zum ProSieben und Sat1 Medienkonzern) oder IP Deutschland (gehört zur RTL Gruppe) ${ }^{174}$.

Die Netzwerke können auch als offener Online-Marktplatz konzipiert sein, bei dem Werbeflächen von Seitenbetreibern eingestellt und für Fixpreise oder im Rahmen einer Auktion verkauft werden - so etwa Ströer SSP, vormals AdScale ${ }^{175}$. Abgerechnet wird bei Festpreisen in der Regel nach sog. Ad Impressions, die nach dem Tausender-Kontakt-Preis (TKP) berechnet werden ${ }^{176}$.

Praktisch laufen in diesem Kontext alle Prozesse automatisch und über spezialisierte Software und Computer ab. Man bezeichnet die beteiligten spezialisierten Unternehmen auch als „Adtechs“"177. Den Vorgang der au-

173 Vgl. Keßler/Rabsch/Mandic, Erfolgreiche Websites, S. 291.

174 Lammenett, Praxiswissen Online Marketing, S. 287f.

175 Vgl. https://de.wikipedia.org/wiki/Online-Werbemarktplatz, zuletzt abgerufen am: 30.5.2019; https://www.stroeer.de/konvergenz-konzepte/daten-technologien /stroeer-ssp.html, zuletzt abgerufen am: 30.5.2019.

176 Lammenett, Praxiswissen Online Marketing, S. 282.

177 https:/www.unternehmer.de/lexikon/online-marketing-lexikon/adtech, zuletzt abgerufen am: 30.5.2019. 
tomatischen Werbeausspielung nach bestimmten vorab definierten Kriterien nennt man "Programmatic Advertising "178. Man unterscheidet dabei nach „Demand Side Platforms“ und „Supply Side Platforms“. Die Erstgenannten sind Dienstleister, die Werbetreibenden die Möglichkeit geben an zentraler Steller Werbeplätze auf verschiedensten Webseiten zu erwerben. Die Zweitgenannten sind das Äquivalent auf Seite der Webseitenbetreiber oder Publisher. Diese können bei der "Supply Side Platform“ an einer zentralen Stelle ihre Werbeplätze anbieten und damit eine Vielzahl von potentiellen Kunden erreichen ${ }^{179}$. Auf Grundlage dieser technischen Plattformen ist das sog. „Real Time Bidding“ möglich. Hierbei wird im Moment des Aufrufs einer Webseite durch einen Nutzer in Echtzeit ein Prozess gestartet, an dessen Ende die Ausspielung einer bestimmten Werbeanzeige steht. Dieser Prozess ist bei Darstellung einer durch einen Nutzer aufgerufenen Webseite bereits abgeschlossen. Dafür können Werbekunden bestimmte Höchstgebote oder Targetingeinstellungen bei der „Demand Side Platform" einstellen. Auf Grundlage der von jedem Nutzer im Internet automatisch Preis gegebenen Informationen wird ein „Bid Request“ generiert, der über die "Supply Side Platforms“ die Gebote der „Demand Side Platform" abprüft. Automatisch wird nun nach dem Prinzip von Angebot und Nachfrage das höchste Gebot für den konkreten Aufruf ausgewählt und damit der Preis für die Werbeausspielung festgelegt ${ }^{180}$.

Verbreitet sind aber auch die sogenannten Affiliate-Netzwerke. Affiliates, zu deutsch: (Geschäfts-)Partner ${ }^{181}$, unterstützen sich hier unabhängig von einer übergeordneten gesellschaftsrechtlichen Verbindung. So stellen hier Seitenbetreiber jeglicher Couleur Werbeflächen zur Verfügung. Werbetreibende können ihre Anzeigen dann auf einer Vielzahl von Affiliate-Seiten ausliefern lassen. Wiederum nimmt das Werbenetzwerk die Vermittlung und ggf. die Platzierung vor. Besonderheit bei Affiliate-Netzwerken ist jedoch, dass diese regelmäßig eine "geschlossene Gesellschaft“ darstellen. Ein Beitritt muss oft durch hohe Einrichtungsgebühren erkauft oder durch geeignete Bewerbung erreicht werden ${ }^{182}$. Bekannte und reich-

178 Sahni, The Ultimate Guide To Mobile Programmatic Media Buying, S. 8.

179 Sahni, The Ultimate Guide To Mobile Programmatic Media Buying, S. 10.

180 Sahni, The Ultimate Guide To Mobile Programmatic Media Buying, S. 12 ff.

181 Siehe https://dict.leo.org/german-english/affiliate, zuletzt abgerufen am: 30.5.2019.

182 Jacob, Integriertes Online-Marketing, S. 241. 
weitenstarke Affiliate-Netzwerke sind Awin, vormals zanox ${ }^{183}$, oder affilinet $^{184}$.

Die Vergütung der Seitenbetreiber erfolgt bei solchen Netzwerken in der Regel erfolgsabhängig auf Provisionsbasis. Im Idealfall erfolgt die Schaltung von Werbung dann wie folgt:

- die Anzeige wird auf der freien Werbefläche des Seitenbetreibers eingeblendet,

- der Besucher nimmt die Anzeige wahr und klickt sie an,

- der Besucher wird auf die Seite des Werbetreibenden weitergeleitet und macht dort eine Bestellung oder nimmt Kontakt auf,

- dadurch entsteht ein Anspruch auf Vergütung des Seitenbetreibers gegen den Werbetreibenden (ggf. zuzüglich Provisionen für das Netzwerk) ${ }^{185}$.

Die Vergütung beim erfolgsbasierten Affiliate-Marketing wird regelmäßig nach folgenden anerkannten Abrechnungsmodellen vereinbart:

- Pay-per-Sale (Provision nach Kauf beim Werbenden, abhängig von der Branche des Werbenden ab 2,5\% in der Reisebranche bis zu 22\% bei Softwareherstellern),

- Pay-per-Click (Provision nach Klick auf die Anzeige und Weiterleitung auf die Seite des Werbenden, fixe Geldbeträge zwischen 0,03-0,25 €),

- Pay-per-Lead (Provision nach Kontaktaufnahme mit dem Werbenden, v.a. bei Waren oder Dienstleistungen, die nicht unmittelbar im Internet bestellt werden; fixe Geldbeträge von wenigen $€$-Cent bei Newsletteranmeldung bis zu $240 €$ bei Abschluss eines Telefonvertrages),

- Pay-per-View (Preis für die bloße Ausspielung der Anzeige), regelmäßig nach dem oben schon genannten Tausender-Kontakt-Preis,

- Pay-per-Install (Provision nach Installation einer beworbenen Software des Werbenden),

- Lifetime-Provision (für Dauerschuldverhältnisse oder regelmäßige Folgekäufe) oder

- Mischformen der vorgenannten Modelle ${ }^{186}$.

183 http://www.affiliateblog.de/zanox-heisst-jetzt-awin/, zuletzt abgerufen am: 30.5.2019.

184 Vgl. Lammenett, Praxiswissen Online Marketing, S. 62, $75 \mathrm{ff}$. .

185 Jacob, Integriertes Online-Marketing, S. 234.

186 Jacob, Integriertes Online-Marketing, S. 237f.; Lammenett, Praxiswissen Online Marketing, S. 68ff., 282. 
$\mathrm{Ob}$ eine Provision angefallen ist wird dabei durch Trackingmethoden nachgehalten. Auf das Tracking wird vertieft bei der technischen Ausgestaltung (siehe unten Ziffer B. III. 4. b.) eingegangen.

Innerhalb der Werbenetzwerke und den vorhandenen technischen Möglichkeiten ist zudem eine der Internetwerbung eigentümliche Erfolgskontrolle der geschalteten Anzeigen und Werbekampagnen möglich. Diese Erfolgskontrolle erfolgt regelmäßig nach folgenden Statistiken:

- Page bzw. Ad Impressions (Anzahl der Einblendungen auf der Internetseite des Werbeplatzanbieters bzw. Affiliates),

- Klickrate (Anzahl von Klicks auf eine Anzeige)

- Conversion-Rate (Anzahl von Klicks auf die Anzeige, die tatsächlich zu einem Kauf oder einer Kontaktaufnahme beim Werbenden führen),

- Earnings per click (durchschnittliche Provisionshöhe für jeden Klick auf eine bestimmte Anzeige) ${ }^{187}$.

Unter Umständen drängen sich noch weitere Akteure in die klassische Dreierkette von Werbenden, Werbenetzwerk und Seitenbetreiber. Dies können Meta-Netzwerke sein, die sich zwischen das Werbenetzwerk und den Seitenbetreiber einfügen. Insbesondere in Affiliate-Netzwerken haben sich Meta-Netzwerke eingebürgert, die den Seitenbetreibern die Anmeldung bei einer Vielzahl verschiedener Affiliate-Netzwerke abnimmt. Seitenbetreiber melden sich nur beim Meta-Netzwerk an und können durch doppelte Vermittlung eine noch höhere Anzahl von Werbetreibenden erreichen. Dies erfolgt natürlich zum Preis einer weiteren Provision ${ }^{188}$. Auch häufig anzutreffen sind Mediaagenturen, die vor allem bei fehlender eigener PR-Abteilung beim Werbenden die Gestaltung und Umsetzung, den Kontakt zu Netzwerken sowie das Controlling übernehmen ${ }^{189}$.

187 Jacob, Integriertes Online-Marketing, S. 247, Lammenett, Praxiswissen Online Marketing, S. 284.

188 Lammenett, Praxiswissen Online Marketing, S. 78f..

189 Jacob, Integriertes Online-Marketing, S. 233. 

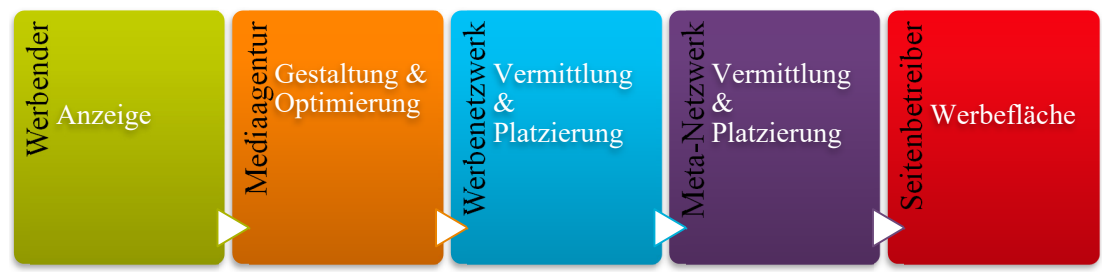

Abbildung 5: schematische Darstellung der erweiterten Wertschöpfungskette bei Online-Werbung

Der Internet-Werbemarkt ist nach alledem im Vergleich zu anderen Medien ein Markt mit einigen Besonderheiten. Statistisch gesehen ist er ein Wachstumsmarkt, der auf absehbare Zeit nicht stagnieren wird.

\section{Technische Ausgestaltung}

Wie bereits festgestellt eröffnet das Internet eine Vielzahl von Möglichkeiten, die auf den technischen Besonderheiten dieses Mediums beruhen. Um die teils sehr spezialisierten Begriffe und Anwendungen richtig zu verstehen, ist es unabdingbar einen Überblick über die Funktionsweise des Internets zu erhalten. Für viele Menschen ist das Internet ein fester Bestandteil im Alltag. Wie genau das Internet funktioniert, ist den meisten "Nicht-IT'lern“ aber unbekannt. Deshalb werden in gebotener Länge die Infrastruktur und die Funktionsweise des Internets dargestellt sowie die Protokolle und Standards des Internets beschrieben (siehe Ziffer 1.). Sodann wird der Blick vom großen Ganzen auf die Kommunikationsteilnehmer im Einzelnen gelenkt. Hier wird erklärt wie beim adressierten Internetnutzer die gewünschte Information als Ergebnis der Datenübertragung im Endgerät angezeigt wird. Dafür wird auf die Funktionsweise von Webbrowsern und anderen Softwareprogrammen, die Daten wahrnehmbar darstellen, eingegangen. Auf der anderen Seite wird die Technik hinter einer Webseite erläutert, mit der Informationen aufbereitet und zur Verfügung gestellt werden. Diese Webseiten bestehen regelmäßig aus vielen verschiedenen Elementen, die dargestellt und erklärt werden sollen (siehe Ziffer 2.). Daraus werden dann Schlussfolgerungen gezogen für die technische Abgrenzung des Internets von anderen Werbemedien (siehe Ziffer 3.). Abschließend wird auf die werbespezifischen Besonderheiten im Internet eingegangen. Hier geht es hauptsächlich um den Einsatz von besonderen Adservern und das für die wirtschaftliche Abwicklung der 
Internetwerbung integrale Tracking (siehe Ziffer 4.). Am Ende dieses Abschnitts soll der Leser das technische Verständnis erlangt haben, um die nachfolgenden rechtlichen Beurteilungen auf Basis hinlänglicher Faktenkenntnis nachvollziehen zu können.

\section{Eine kleine Einführung in die Technik des Internets}

Das Internet ist, wie der Name bei genauem Hinsehen schon verrät, das Netz der Netze. Eine Vielzahl von Einzelnetzwerken wird durch das Internet zu einem großen Netz zusammengeschlossen ${ }^{190}$. Damit in diesem umfassenden Netzwerk Daten übertragen werden können und die uns gewohnte Kommunikation stattfinden kann, bedarf es einer ausreichenden Infrastruktur (siehe dazu a.) und einer zielführenden Datenübertragungstechnik (siehe dazu b.).

\section{a) Infrastruktur des Internets}

Einzelnetzwerke bestehen aus einer Vielzahl von Computern und sind durch Kabel oder über Funksignale verbunden. Dabei kann das Einzelnetzwerk wie bei größeren Arbeitgebern oder Universitäten ein stattliches Ausmaß annehmen und nach außen abgeschlossen sein. Über eine Kabelverbindung oder einen WLAN-Router kann auch die Vielzahl von internetfähigen Geräten, die in einem durchschnittlichen Haushalt regelmäßig anzutreffen sind, ein eigenes abgeschlossenes Netzwerk bilden.

Solche privaten Netze sind wiederum Teil des Netzwerks des Internet Service Providers, der den Internetzugang bereitstellt. $\mathrm{Zu}$ diesem Netzwerk kann auch das große Firmen- oder Universitätsnetzwerk gehören, wenn es beim gleichen Provider einen Internetzugang unterhält. Der Zugang zum Netzwerk des Providers erfolgt jeweils über ein sich einwählendes Modem, das physisch über Glasfaserkabel verbunden ist ${ }^{191}$. Zwischen Heimnetzwerk und Internet existieren also noch ein oder mehrere „Zwischennetzwerke“.

190 Vgl. Lauterschlag, Wie funktioniert das Internet? - http://www.webschmoeker.d e/grundlagen/wie-funktioniert-das-internet/, zuletzt abgerufen am: 30.5.2019.

191 Vgl. Tyson, How Internet Infrastructure Works - http://computer.howstuffw orks.com/internet/basics/internet-infrastructure1.htm, zuletzt abgerufen am: 30.5.2019. 
Dieses Netzwerk des Internet Service Providers wiederum wählt sich per Glasfaserkabel über einen Netzwerkzugangspunkt (bzw. network acces point, NAP) in ein höherrangiges Netz ein ${ }^{192}$. Dieses Netzwerk wird betrieben durch den Netzbetreiber (oder englisch: Carrier), der mit anderen Netzbetreibern über Knotenpunkte verbunden ist ${ }^{193}$.

An den Verbindungsstellen von Carrier-Netzen untereinander sowie an den Netzwerkzugangspunkten der Providernetze befinden sich Router. Diese Infrastruktur-Router sind nicht zu verwechseln mit dem heimischen DSL- bzw. WLAN-Router. Router sind spezielle Computer, die Daten im Netzwerk zum Zielpunkt leiten. Sie haben zwei Aufgaben: sie führen die Information zum intendierten Ziel und halten sie fern von Verbindungen, die nicht zum Transport notwendig sind. Dadurch finden die Daten das richtige Ziel und „verstopfen“ keine Verbindungen, die nicht notwendigerweise gebraucht werden ${ }^{194}$.

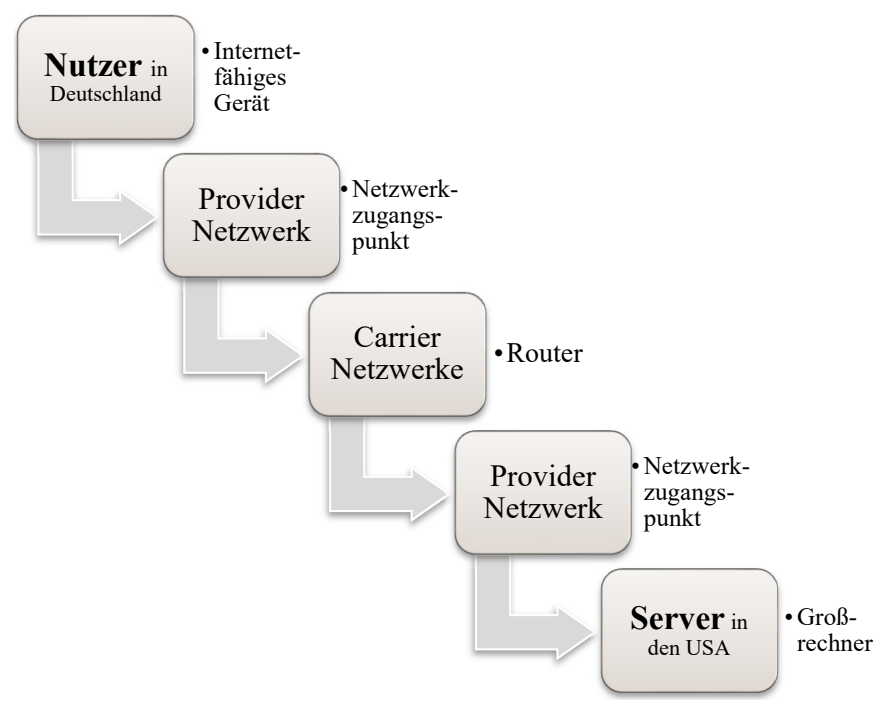

Abbildung 6: schematische Darstellung des Datenweges vom Nutzer zum Server

192 Vgl. http://www.itwissen.info/Netzwerkzugangspunkt-network-access-point-NA P.html, zuletzt abgerufen am: 30.5.2019.

193 http://www.itwissen.info/Netzbetreiber-NB-carrier.html, zuletzt abgerufen am: 30.5.2019.

194 Vgl. Tyson, How Internet Infrastructure Works - http://computer.howstuffw orks.com/internet/basics/internet-infrastructure3.htm, zuletzt abgerufen am: 30.5.2019. 
Die Infrastruktur besteht demzufolge aus diversen Endgeräten, Glasfaserkabeln, die auch durch Satelliten oder Richtfunkstrecken substituiert werden können ${ }^{195}$, und Routern.

\section{b) Datenübertragungstechnik}

Damit diese Geräte miteinander kommunizieren (oder genauer: Daten austauschen) können, bedarf es einer „gemeinsamen Sprache“, also einer einheitlichen Technik, der sich alle Geräte unterordnen. Diese Funktion übernimmt im Wesentlichen das Internetprotokoll (IP) ${ }^{196}$. Alleine das Internetprotokoll würde aber noch nicht das Internet in seiner gewohnten Form ermöglichen, dafür bedarf es weiterer darzustellender Protokolle.

\section{aa) Internet Protokoll (IP)}

Durch das standardisierte Internetprotokoll macht es für die Kommunikation keinen Unterschied welche Hard- oder Software bei den Endgeräten vorhanden ist. Daten werden über das Internet vielmehr plattformunabhängig versendet. Erforderlich für das IP ist eine eindeutige Adresse des Endgeräts, die allseits bekannte IP-Adresse. Sie stellt sozusagen die Postanschrift des Endgerätes dar, an welche die Daten geliefert werden ${ }^{197}$. Sie kann je nach verwendeter Version des IP (IPv4 oder IPv6) unterschiedlich ausgestaltet sein, etwa bei Version 4 die geläufige Vier-Zahlen-Adresse (z.B. 192.0.2.42) oder bei Version 6 eine hexadezimale Adresse (z.B. 2001:0db8:85a3:0000:0000:8a2e:0370:7344). In informatischer Hinsicht wird dieser Code wiederum in eine binäre Zahl, d.h. einem nur aus Nullen und Einsen bestehenden Code, übersetzt ${ }^{198}$.

195 Vgl. Lauterschlag, Wie funktioniert das Internet? - http:/www.webschmoeker.d e/grundlagen/wie-funktioniert-das-internet/, zuletzt abgerufen am: 30.5.2019.

196 Vgl. Lauterschlag, Wie funktioniert das Internet? - http://www.webschmoeker. de/grundlagen/wie-funktioniert-das-internet/, zuletzt abgerufen am: 30.5.2019; Tyson, How Internet Infrastructure Works - http://computer.howstuffworks.co $\mathrm{m} /$ internet/basics/internet-infrastructure1.htm, zuletzt abgerufen am: 30.5.2019.

197 Vgl. Lauterschlag, Wie funktioniert das Internet? - http://www.webschmoeker. de/grundlagen/wie-funktioniert-das-internet/, zuletzt abgerufen am: 30.5.2019; Tyson, How Internet Infrastructure Works - http://computer.howstuffworks.co $\mathrm{m} /$ internet/basics/internet-infrastructure1.htm, zuletzt abgerufen am: 30.5.2019.

198 https://de.wikipedia.org/wiki/IP-Adresse\#IPv6, zuletzt abgerufen am: 30.5.2019. 
Bei einer Datenübertragung im Internet werden die teils sehr großen Datenmengen für eine einzelne Internetaktion aufgeteilt in Datenpakete, die IP-Pakete. Diese Pakete bestehen aus einem Kopf- und einem Nutzdatenbereich. Im Kopfbereich sind hauptsächlich die IP-Adressen des Absenders und des Empfängers enthalten ${ }^{199}$. Hier kommen wieder die Router der Internetinfrastruktur ins Spiel. Die Router lesen allein die Kopfdaten des IP-Datenpakets und vermitteln dieses damit über andere Router zum gewünschten Ziel ${ }^{200}$. Das IP benötigt keine direkte Verbindung zwischen den Kommunikationsteilnehmern und ist deshalb ein sog. verbindungsloses Protokoll.

Nicht durch das IP gewährleistet wird, dass alle fragmentierten Datenpakete tatsächlich beim Adressaten ankommen. Ebenso wenig wird durch das IP gesichert, dass die korrekte Reihenfolge der Datenpakete beibehalten wird. Dies übernehmen andere Protokolle im Rahmen der Nutzda$\operatorname{ten}^{201}$.

In den Nutzdaten sind die gewünschten Inhalte verortet, die ihrerseits in anderen Protokollen verpackt sind. Im Rahmen dieser sog. Datenkapselung verfügt ein IP-Datenpaket über mehrere Schichten von Protokollen. Während das IP an oberster Stelle steht (bzw. nach dem OSI Modell, das noch die physikalische Ebene und die Infrastruktur mitzählt in der Schicht 3), folgen die Transportschicht (Schicht 4) und die Sitzungs-, Darstellungsbzw. Anwendungsschicht (Schichten 5-7) 202.

bb) Transportschichtprotokolle

In der Transportschicht ist das geläufigste Protokoll das Transmission Control Protocol (TCP). Es ist für die Erkennung und Behebung von Datenverlusten, die Sortierung und die Wiederzusammensetzung der per IP

199 Vgl. https:/de.wikipedia.org/wiki/IP-Paket, zuletzt abgerufen am: 30.5.2019.

200 Vgl. Lauterschlag, Wie funktioniert das Internet? - http://www.webschmoeker. de/grundlagen/wie-funktioniert-das-internet/, zuletzt abgerufen am: 30.5.2019; Tyson, How Internet Infrastructure Works - http://computer.howstuffworks.co $\mathrm{m} /$ internet/basics/internet-infrastructure1.htm, zuletzt abgerufen am: 30.5.2019.

201 Vgl. Lauterschlag, Wie funktioniert das Internet? - http://www.webschmoeker.d e/grundlagen/internet-protocol/, zuletzt abgerufen am: 30.5.2019.

202 Vgl. https://de.wikipedia.org/wiki/OSI-Modell, zuletzt abgerufen am: 30.5.2019. 
verschickten Pakete verantwortlich ${ }^{203}$. Beim TCP wird eine direkte Verbindung zwischen zwei Endpunkten aufgebaut, bevor Daten übertragen werden können (sog. Ende-zu-Ende-Verbindung). Eingängigstes Beispiel dafür dürfte der Abruf einer Webseite mit einem PC von einem Webserver sein. In diesem Fall muss zunächst die Verbindung zwischen anfragendem Rechner und auslieferndem Rechner ${ }^{204}$ hergestellt werden. Das TCP hat wiederum einen eigenen Header mit notwendigen Angaben zum Verbindungsaufbau. So arbeiten IP und TCP zusammen und bewerkstelligen sowohl die Verbindung zwischen zwei Rechnern im Internet, als auch den Transport der Daten über eine Vielzahl weiterer Rechner, den Routern.

Im Einzelnen erfolgt der Verbindungsaufbau über TCP dreistufig: zunächst sendet der Client ein TCP-Segment an den Server mit der Bitte um Synchronisation („SYN“-Flag im Header) ohne Nutzdaten. Dann antwortet der Server mit einem TCP-Segment, das den Empfang des „Anfragesegments“ („ACK“-Flag als Abkürzungfür acknowledge) und die Synchronisation (wieder „SYN“-Flag) bestätigt. Im dritten Schritt bestätigt wiederum der Client mit dem „ACK“-Flag, womit die Verbindung aufgebaut ist.

Nun können die Datenpakete mit einer logischen Nummerierung in den TCP Headern und Angabe der IP-Adressen in den IP Headern übertragen werden. Dabei wird wiederum der Erhalt jedes Datenfragments durch den Client bestätigt. Erfolgt keine Bestätigung, wird das Fragment durch den Server erneut verschickt. So wird die Vollständigkeit der Datenübertragung gewährleistet. Durch die Nummerierung kann die Software des Clients die Fragmente wieder in die richtige Reihenfolge setzen. Zum Verbindungsabbau werden wiederum TCP-Segmente ausgetauscht, die auf der einen Seite das Ende anzeigen und auf der anderen Seite bestätigen ${ }^{205}$.

Das TCP ist das „Dachprotokoll“ für die auf den nachfolgenden Schichten weiter genutzten Protokolle HTTP, SMTP und FTP (siehe unten ${ }^{206}$.

203 Vgl. Lauterschlag, Wie funktioniert das Internet? - http://www.webschmoeker. de/grundlagen/internetstandards/\#transmission_control_protocol_tcp, zuletzt abgerufen am: 30.5.2019.

204 Der anfragende Rechner wird im Weiteren TCP-untypisch, aber für das Webseitenbeispiel passend, "Client" genannt, der ausliefernde Rechner wird "Server“ genannt. Diese Begriffe sind eher beim nachgelagerten HTTP im WWW üblich, beim TCP hingegen kommunizieren beide Enden der Verbindung grundsätzlich gleichberechtigt, sodass die Begriffe Client und Server in anderen TCP-Konstellationen unpassend wären.

205 Vgl. Lauterschlag, Wie funktioniert das Internet? - http://www.webschmoek er.de/grundlagen/tcp-transmission-control-protocol/, zuletzt abgerufen am: 30.5.2019.

206 Vgl. https://de.wikipedia.org/wiki/OSI-Modell, zuletzt abgerufen am: 30.5.2019. 
Neben TCP ist auf der Transportschicht noch das User Datagramm Protocol (UDP) verbreitet, das für die Übertragung von Audio- und Videomaterial eingesetzt wird. Bei UDP findet anders als bei TCP keine feste Verbindungskommunikation zwischen den Rechnern und keine Kontrolle statt, ob die Daten korrekt beim Empfänger angekommen sind, sodass Daten verloren gehen, vertauscht oder doppelt ankommen können. Vorteil ist die schnellere Datenübertragung, da keine Bestätigungen abgewartet werden müssen ${ }^{207}$. Ein Protokoll, das durch das Erfordernis einer Verbindung mehr dem TCP ähnelt, aber für Streaming geeigneter ist, ist das Stream Control Transmission Protocol (SCTP) ${ }^{208}$.

cc) Darstellungs- bzw. Anwendungsschichtprotokolle

Für die Übertragung von Webinhalten auf Grundlage von IP und den vorgenannten Transportprotokollen werden im Rahmen der Datenkapselung der Nutzdaten eine Vielzahl weiterer Protokolle genutzt. Zur Wahrung der Übersichtlichkeit sollen im Weiteren nur das Hypertext Transfer Protocol (HTTP) und das File Transfer Protocol (FTP) näher dargestellt werden. Speziell für E-Mails wird oft das Simple Mail Transfer Protocol (SMTP) genutzt, wobei E-Mails regelmäßig auf dem Server des E-Mail-Anbieters gespeichert sind und nur bei Bedarf vom Nutzer über E-Mailprogramme wie Outlook über weitere Protokolle wie IMAP oder POP abgerufen werden ${ }^{209}$. Mangels Bedeutung für die nachfolgende Bearbeitung wird auf eine nähere Erläuterung verzichtet.

Ein weiteres nennenswertes Protokoll ist das Domain Name System (DNS), das zur Namensauflösung, d.h. zur Übersetzung einer sprachlichen Domain (z.B. fc.de) in eine IP-Adresse, benötigt wird. Es stellt sozusagen das Telefonbuch des Internets dar, das erforderlich ist, weil Menschen sich Namen und Wörter besser merken können als Nummern ${ }^{210}$. In hierarchischer Sicht unterliegt DNS dem UDP Transportprotokoll. Der Ablauf der

207 Vgl. Lauterschlag, Wie funktioniert das Internet? - http:/www.webschmoeker .de/grundlagen/udp-user-datagram-protocol/, zuletzt abgerufen am: 30.5.2019; https://www.elektronik-kompendium.de/sites/net/0812281.htm, zuletzt abgerufen am: 30.5.2019.

208 Vgl. https://de.wikipedia.org/wiki/Stream_Control_Transmission_Protocol, zuletzt abgerufen am: 30.5.2019.

209 Vgl. https://de.wikipedia.org/wiki/OSI-Modell, zuletzt abgerufen am: 30.5.2019.

210 Vgl. https://de.wikipedia.org/wiki/OSI-Modell, zuletzt abgerufen am: 30.5.2019. 
Nutzung von DNS wird unten im Zusammenhang mit der Funktionsweise von Browsern näher dargestellt.

Das weitaus wichtigste Protokoll im World Wide Web, also dem weltweiten Fundus von Webseiten, ist hingegen das HTTP. Diese Abkürzung dürfte vielen Internetnutzern bereits begegnet sein, weil in der Adresszeile eines Browsers bei kompletter Anzeige der URL regelmäßig der Anfang auf „http://“ lautet. Heute gebräuchlicher ist dabei HTTPS, das Hypertext Transfer Protocol Secure, das um eine Transportverschlüsselung ergänzt ist $^{211}$.

Bei $\operatorname{HTTP}(S)$ unterscheidet man grundsätzlich den Client und den Server. Der Client begehrt eine Dienstleistung vom Server, indem er eine Anfrage („Request“) stellt. Diese Anfrage wird vom Server beantwortet („Response"). Während eine TCP-Verbindung läuft, die IP-Datenpakete von einem Ende zum anderen Ende austauscht, enthält jedes Datenpaket neben den IP- und TCP-Headern nun wieder HTTP-Header und -Nutzdaten. Dabei übermittelt der Client im Rahmen des Requests im HTTP-Header die URL, was für Uniform Resource Locator steht. Die URL besteht aus dem Protokoll („https:// “), der optionalen Serverbezeichnung („www.“), dem Domainnamen („uni-regensburg“), der Top-Level-Domain (,.de“), des Pfades („/rechtswissenschaft“) und ggf. des Dateinamens („/index.html“). Neben der URL werden die Art der „Request-Methode“ und eine Reihe von weiteren Informationen übermittelt. In den, hier optionalen, HTTPNutzdaten sind bei einem Request etwa Daten eines online ausgefüllten Formulars untergebracht ${ }^{212}$.

Ein Beispiel für einen HTTP-Header eines Requests sähe wie folgt aus:

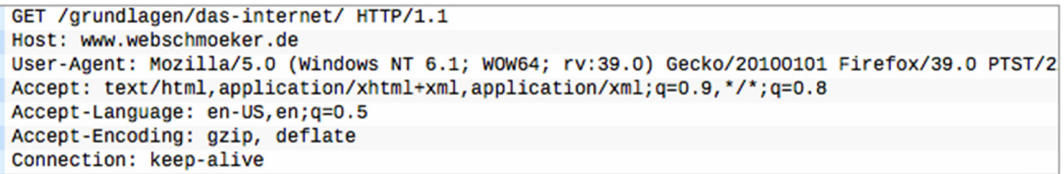

Wobei der Befehl „GET“ in Zeile 1 die Requestmethode zum Abruf einer Datei bedeutet und von dem Pfad sowie der HTTP-Version („HTTP/1.1“)

211 https://de.wikipedia.org/wiki/Hypertext_Transfer_Protocol_Secure, zuletzt abgerufen am: 30.5.2019.

212 Vgl. Lauterschlag, Wie funktioniert das Internet? - http://www.webschmoeker.d e/grundlagen/http-hypertext-transfer-protocol/, zuletzt abgerufen am: 30.5.2019. Die nachfolgenden Beispiele sind ebenfalls dieser Webseite entnommen. 
gefolgt wird. Sodann folgt die Angabe des Webservers durch die Domain. Nach Ziffer 3 folgen Informationen zum Client-Rechner, hier Browser („Mozilla Firefox“), Betriebssystem („Windows NT“) und ggf. weitere Features des Browsers („Gecko“). Die folgenden Zeilen beginnend mit "Accept“ weisen auf Funktionen bzw. Einstellungen des Browsers hin. Abschließend wird eine Aussage zur Verbindung getroffen („keep-alive“) ${ }^{213}$. Es sind neben diesen Beispielen noch viele weitere Eintragungen im Header denkbar, auf die hier nicht näher eingegangen wird ${ }^{214}$.

Die Antwort des Servers ist wiederum in HTTP-Header und -Nutzdaten unterteilt. Ein Beispiel des HTTP-Headers eines Server-Responses sähe beispielhaft wie folgt aus:

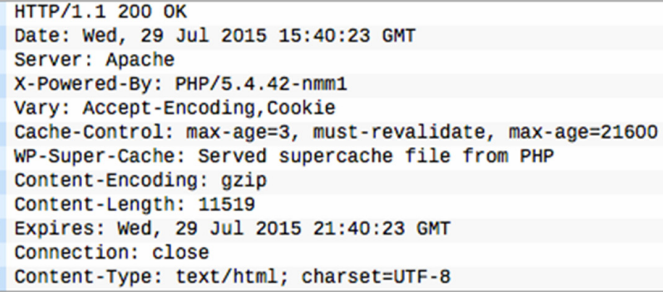

Zeile 1 ist die „Status-Line“, die wiederum die HTTP-Version („HTTP/1.1“) wiederspiegelt, den Status Code („200“) und die textliche Erklärung zu diesem Code („OK“). Die übrigen Header-Informationen bestehen aus Datum der Antwort, Art des Servers („Apache“), Basis der Webapplikation („X-Powered-By: PHP/5.4.42-nmm1“), Anweisungen für folgende Zugriffe („Vary:..."), Einstellungen für den Zwischenspeicher („Cache control:...“), Informationen zur Codierung, Größe und Format des Inhalts („Content-Encoding“, „Content-Length“ \& „Content-Type“), ab wann die Datei als veraltet anzusehen ist („Expires:...“) und einem Befehl zur Verbindung („close“) ${ }^{215}$.

213 Screenshot und Beschreibung nach http:/www.webschmoeker.de/grundlagen/h ttp-hypertext-transfer-protocol/, zuletzt abgerufen am: 30.5.2019.

214 Vgl. https://de.wikipedia.org/wiki/Liste_der_HTTP-Headerfelder, zuletzt abgerufen am: 30.5.2019.

215 Screenshot und ein Teil der Beschreibung nach http://www.webschmoeker.de/g rundlagen/http-hypertext-transfer-protocol/, zuletzt abgerufen am: 30.5.2019. 


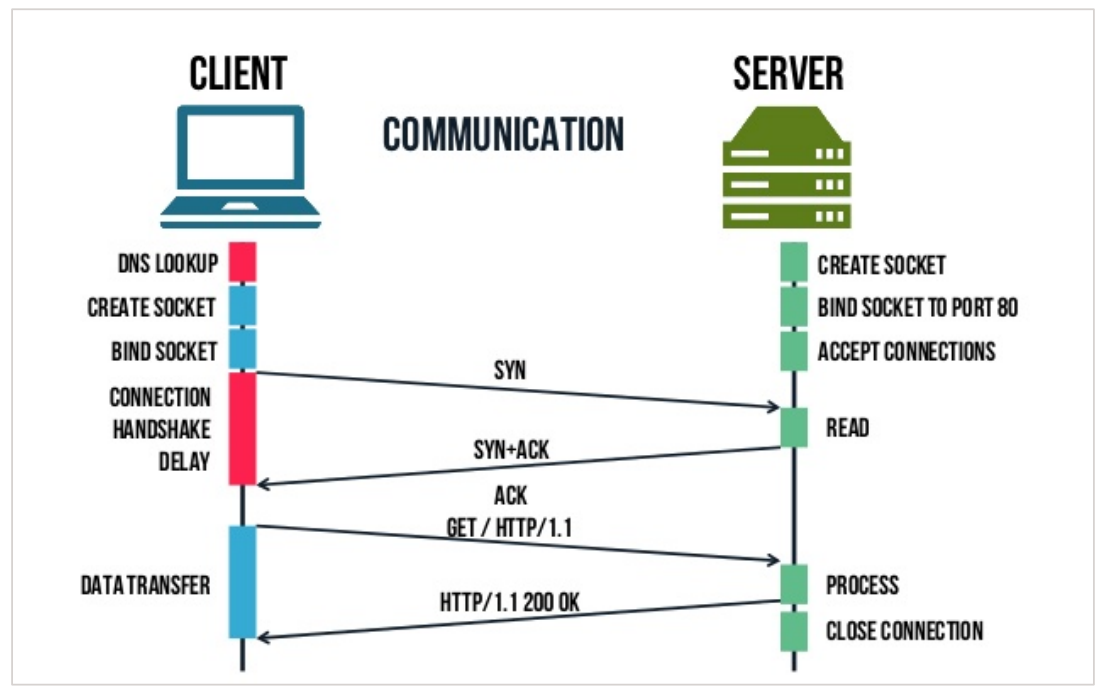

Abbildung 7: ${ }^{216}$ Schematische Darstellung der Client-Server Kommunikation beim Abruf einer Webseite mit DNS, TCP und HTTP

Hinzu kommen die HTTP-Nutzdaten, in diesem Fall die konkrete Webseite. An dieser Stelle werden demzufolge das erste Mal im gesamten IP-Datenfragment die vom Nutzer gewünschten Inhalte transportiert.

In einer stark vereinfachten Allegorie lässt sich der Datentransfer also mit der Kurierzustellung eines Pakets darstellen: das IP ist dabei der Kurier, der Luftwege, Autobahnen und Regionalstraßen - die Internetinfrastruktur - nutzt, um in einem konkreten Transportwagen - dem TCP - eine bestimmte Ware - die HTTP Nutzdaten - zuzustellen. Der HTTP Header stellt dabei eine Mischung aus Zustellinformation und Bedienungsanleitung für die Ware dar.

Während HTTP sozusagen den „Kundenbesuchsverkehr“ auf den Internetseiten betriff, steht das File Transfer Protocol (FTP) für den Upload auf einen Server, den Download von einem Server und ggf. dem Austausch von Dateien zwischen zwei Servern zur Verfügung. Hiermit kann also eine Art „Abwicklung“ komplizierterer Dateien erfolgen, also der Download größerer Dateien, die nicht im Browser dargestellt werden müssen. FTPSoftware ist in den meisten geläufigen Browsern enthalten (zu erkennen

216 Quelle: https://www.slideshare.net/origamiaddict/http-40249449, zuletzt abgerufen am: 30.5.2019. 
an der „Downloadleiste“). Der Weg hin zu FTP kann deshalb auch häufig über optisch einfache Textlinkseiten erfolgen, wobei die Textlinkseite über HTTP übertragen, die verlinkten Dateien aber über FTP217.

\section{Webbrowser und Webseiten}

Auf Grundlage der dargestellten technischen Hintergründe des Internets soll im Weiteren speziell auf die Darstellung von Internetseiten eingegangen werden. Dabei soll zunächst auf die technischen Schritte eingegangen werden, die ein Webbrowser tätigt, um eine Webseite auf dem Gerät des Internetnutzers anzuzeigen (siehe dazu a.). Im Anschluss wird dazu ergänzend auf verschieden programmierte Elemente von Webseiten eingegangen (siehe dazu b.).

\section{a) Arbeitsweise des Browsers}

Browser sind jedem Internetnutzer bekannt. Durch die Eingabe von „Internetadressen", also einer URL, in das Adressfeld des Browsers wird die Anzeige der gewünschten Webseite veranlasst. Auf dieser Webseite kann der Nutzer dann wieder auf eine Vielzahl von Links klicken und damit neue Seiten aufrufen. Dazu kommt der „zurück“- und „vor“-Button, um auf bereits besuchte Seiten zurückzukehren. Mit diesen drei einfachen Elementen kann jeder Nutzer mit Leichtigkeit durch das World Wide Web stöbern, woher auch der Name „Browser“ stammt ${ }^{218}$. Hinter der benutzerfreundlichen Oberfläche laufen jedoch eine Vielzahl technisch komplexer Vorgänge $a b$.

Die Funktionsweise eines Webbrowsers ist stark verknüpft mit der Datenübertragung im Hypertext Transmission Protocol (HTTP), das oben bereits beschrieben worden ist. Der Ablauf nach Eingabe einer URL in die Adresszeile oder Klick auf einen Link einer bereits geöffneten Webseite läuft demnach wie folgt ab:

- Falls eine Seite besucht wird, die der Rechner noch nie oder länger nicht besucht hat und deshalb im internen Speicher keine entsprechende Information hinterlegt ist, führt der Browser eine Anfrage beim

217 Z.B. http://ftp.fernuni-hagen.de/ftp-dir/, zuletzt abgerufen am: 30.5.2019.

218 Aus dem Englischen: to browse = stöbern, durchblättern; vgl. https://dict.leo.org /englisch-deutsch/browse, zuletzt abgerufen am: 30.5.2019. 
DNS-Server durch. Dieser DNS-Server übersetzt die eingegebene oder verlinkte URL in die IP-Adresse des Servers. Deshalb kommt dem DNS-Server die Funktion als Telefonbuch des World Wide Webs zu. Jeder Rechner ist im Grundsatz einem speziellen „Nameserver“ zugeordnet. Hat dieser Server keine Information zur gewünschten URL, konsultiert er wiederum einen übergeordneten „Root-Server“ und bekommt so die aufgelöste IP-Adresse vermittelt und leitet dies dem Client weiter ${ }^{219}$.

- Auf Grundlage dieser Information wird eine TCP-Verbindung zwischen Clientrechner und Server hergestellt. Einzelheiten wurden weiter oben bereits beschrieben.

- Bei einer einfachen Webseite sendet der Server dann an den Clientrechner in den HTTP-Nutzdaten ein HTML-Dokument ${ }^{220}$. HTML steht für Hypertext Markup Language. Dies ist eine Textauszeichnungssprache, die zur Strukturierung digitaler Dokumente dient. Durch HTML wird in codierter Form (sog. "Quellcode“) die Anordnung von Überschriften, Text, Hyperlinks und Bildern festgelegt. Ein HTML-Dokument ist eine bloße Textdatei, die einer gewissen Logik und einem anerkannten Aufbau folgt. Sie kann mit einem normalen Text-Editor oder mit speziellen HTML-Editoren erstellt werden ${ }^{221}$.

- Der Browser speichert dieses HTML-Dokument im Zwischenspeicher („Cache“) des Geräts. Dies hat den Vorteil, dass mehrfach verwendete Seiten nicht ständig neu geladen werden müssen. Dies beschleunigt vor allem das Vor- und Zurückblättern im Browser ${ }^{222}$.

- Das abgespeicherte HTML-Dokument wird sodann vom Browser, genauer von seinem Rendering Modul, ausgelesen und interpretiert (sog. „parsen“223). Diese Interpretation erfolgt von „oben nach unten“, sodass jede Zeile des HTML-Dokuments vom Browser abgearbeitet wird. So wandelt der Browser das HTML-Dokument in einen DOM-Knoten-

219 Vgl. https://de.wikipedia.org/wiki/Domain_Name_System und https:/de.wikipe dia.org/wiki/Root-Nameserver, zuletzt abgerufen am: 30.5.2019.

220 Vgl. http://www.webschmoeker.de/grundlagen/was-ist-ein-browser/, zuletzt abgerufen am: 30.5.2019.

221 https://de.wikipedia.org/wiki/Hypertext_Markup_Language, zuletzt abgerufen am: 30.5.2019.

222 Vgl. Eggeling - Unter der Haube: So funktionieren Browser, https://mobil.pcwe lt.de/ratgeber/Unter_der_Haube_So_funktionieren_Browser-Grundlagen-8536 316.html, zuletzt abgerufen am: 30.5.2019.

223 Aus dem Englischen to parse = analysieren; https://dict.leo.org/englisch-deutsch/ parse, zuletzt abgerufen am: 30.5.2019. 
baum um. DOM steht für Document Object Model und wandelt den Text des HTML-Dokuments in Befehle um, die der Rechner dann schrittweise abarbeitet. Sieht ein HTML-Dokument etwa die Darstellung eines Texts und eines Bildes vor, liegen im DOM-Knotenbaum in der Reihenfolge der späteren Darstellung zwei separate Befehle vor, einer für die Anzeige von Text, einer für die Anzeige des Bildes. Über die DOM-Struktur besteht zudem die Möglichkeit moderne Elemente von Webseiten wie JavaScript einzubinden, weshalb von DOM-Knoten gesprochen wird ${ }^{224}$.

Nicht schon im HTML-Dokument vorhandene Daten wie Bilder oder Videos werden aufgrund der entsprechenden Befehle noch beim Server abgerufen. Diese werden ebenfalls im Cache des Nutzergeräts abgespeichert.

- Ergebnis dieser Interpretation und des weiteren Downloads ist eine weitere Datenstruktur, die der Browser dann visuell umsetzt (sog. „rendern“225). Diese Rendering-Baumstruktur enthält die visuellen Elemente bereits in der Reihenfolge der späteren Anzeige. Hier sind auch geometrische Informationen wie Breite, Höhe und Position der einzelnen Elemente enthalten. Der Unterschied zur DOM-Struktur ist, dass hier nur darstellbare Elemente enthalten sind ${ }^{226}$. Zuletzt wird die Webseite wie vom Programmierer intendiert auf dem Gerät des Nutzers angezeigt $\mathrm{t}^{227}$.

Dieser Ablauf kann zudem durch bestimmte Einstellungen im Browser modifiziert werden. Bekannte Einstellungen sind dabei etwa das Unterbinden der Anzeige von Bildern oder das Blocken von Pop-Up-Fenstern. In solchen Fällen wird beim Parsen der Befehl zum Laden und Anzeigen des Bildes bzw. zur Öffnen eines Pop-Ups nicht ausgeführt. Weiter kann eingestellt werden, ob JavaScript erlaubt wird, was ebenfalls Einfluss auf die DOM-Struktur und das Rendering hat.

224 https://www.html5rocks.com/de/tutorials/internals/howbrowserswork/\#DOM, zuletzt abgerufen am: 30.5.2019.

225 Aus dem Englischen to render = ausführen, wiedergeben; https://dict.leo.org/eng lisch-deutsch/render, zuletzt abgerufen am: 30.5.2019.

226 https://www.html5rocks.com/de/tutorials/internals/howbrowserswork/\#DOM, zuletzt abgerufen am: 30.5.2019.

$227 \mathrm{Vgl}$. http://www.webschmoeker.de/grundlagen/was-ist-ein-browser/, zuletzt abgerufen am: 30.5.2019; Eggeling - Unter der Haube: So funktionieren Browser, https://mobil.pcwelt.de/ratgeber/Unter_der_Haube_So_funktionieren_Browse r-Grundlagen-8536316.html, zuletzt abgerufen am: 30.5.2019. 
Weiteren Einfluss auf die Arbeitsweise des Browsers können auch PlugIns haben. Plug-Ins sind externe Programme und enthalten Funktionen, die ein Browser ursprünglich nicht aufweist. Solche Plug-Ins sind etwa Flash, Java oder Adobe Acrobat Reader ${ }^{228}$.

Durch die Einstellungen von Browsern können Internetnutzer demnach aktiv steuern, wie Webseiten auf ihrem Gerät dargestellt werden. Diese Darstellung kann also der ursprünglichen Intention des Gestalters teilweise widersprechen. Es ist deutlich zu unterscheiden zwischen dem vom Webseitenanbieter entworfenen HTML-Dokument und dem erst im Gerät des Nutzers generierten DOM-Knotenbaum. Die Übersetzung von HTMLDokument in die DOM-Befehle stellt die Grenzüberschreitung von der Sphäre des Webseitengestalters hinein in die Sphäre des Nutzers dar, in welcher der Nutzer Macht über die Darstellung hat. Diese Grenzüberschreitung hat für die rechtliche Bewertung eine überragend wichtige Bedeutung.

\section{b) Programmierelemente von Webseiten}

Wie bereits zuvor bei der Browserfunktionalität dargestellt ist die Grundlage der meisten Webseiten ein HTML-Dokument. Ebenfalls genannt wurde bereits JavaScript. Hinzu kommen noch weitere Elemente.

Das HTML-Dokument stellt den Quellcode der Webseite dar und ist maßgeblich für die logische Struktur der Seite. Ergänzt wird HTML durch Cascading Style Sheets (CSS), die maßgeblich für die Formatierung, die Farben und Positionierung von Text- und Bildelementen ist ${ }^{229}$. CSS sind regelmäßig mit dem HTML-Code verbunden und werden vom Browser geparst. Durch CSS ist auch die Anpassung der Darstellung an verschiedene Gerätetypen mit unterschiedlichem Bildschirmformat möglich ${ }^{230}$.

JavaScript hingegen macht dynamische Anzeigen möglich. So wird vermieden, dass für jeden Klick die gesamte Seite neu dargestellt werden muss. Vielmehr ermöglich JavaScript die Änderung von HTML- und CSS-

228 Eggeling - Unter der Haube: So funktionieren Browser, https://mobil.pcwelt.de /ratgeber/Unter_der_Haube_So_funktionieren_Browser-Grundlagen-8536316. html, zuletzt abgerufen am: 30.5.2019.

229 Eggeling - Unter der Haube: So funktionieren Browser, https://mobil.pcwelt.de /ratgeber/Unter_der_Haube_So_funktionieren_Browser-Grundlagen-8536316. html, zuletzt abgerufen am: 30.5 .2019 .

230 https://de.wikipedia.org/wiki/Cascading_Style_Sheets, zuletzt abgerufen am: 30.5.2019. 


\section{B. Grundlage: Werbung im Internet}

Elementen, nachdem der Browser diese bereits dargestellt hat ${ }^{231}$. JavaScript ist also für die Anzeige vieler moderner Webseiten unerlässlich. Typische Anwendungsgebiete sind Dialogfenster, dynamische Suchbegriffeingaben oder dynamische Werbebanner. JavaScript ist auch für die dynamische Einfügung von „personalisierter“ Werbung zuständig ${ }^{232}$.

Hinzu können noch Java-Applikationen kommen, die in Webseiten eingebunden sind und im Browser dargestellt werden. Ein Beispiel für eine in der Java Programmiersprache entwickelte Webseite ist etwa das soziale Netzwerk Twitter ${ }^{233}$. Bei multimedialen Webseiten kann zudem Adobe Flash zum Einsatz kommen. Flash ermöglicht die Darstellung und Animation von Vektor- und Rastergrafiken sowie Videoclips. Deshalb war es sehr beliebt für animierte und Rich-Media Werbebanner ${ }^{234}$. Allerdings sind die Tage sowohl von Java-Applets ${ }^{235}$ als auch Flash als weit verbreitete Website-Elemente gezählt. Oracle, die Betreiberin des Java-Plug-Ins, hat die Unterstützung des Plug-Ins bereits eingestellt. Adobe hat die Einstellung des Flash-Plug-Ins für 2020 angekündigt ${ }^{236}$. Multimediale und animierte Webseitenelemente werden durch das 2014 eingeführte HTML5, also die fünfte Version der grundlegenden Textauszeichnungssprache, anders als in der Vorversion auch ohne die vorgenannten Plug-Ins darstellbar sein ${ }^{237}$.

Ganz konkret verfügt eine Webseite, die eine Werbefläche - etwa ein Banner - vorsieht, also im HTML-Dokument entweder über eine ganz konkrete Werbung, die auf demselben Server wie die Seiteninhalte gespeichert ist, oder über einen Platzhalter, der durch JavaScript oder HTML5 dynamisch auf Grundlage bestimmter Informationen aus Nutzungsprofilen ausgefüllt wird. Die eingeblendete Werbung selbst kann dann wiede-

231 Eggeling - Unter der Haube: So funktionieren Browser, https://mobil.pcwelt.de /ratgeber/Unter_der_Haube_So_funktionieren_Browser-Grundlagen-8536316. html, zuletzt abgerufen am: $\overline{30} \cdot \overline{5} \cdot \mathbf{2 0 1 9}$.

232 https://de.wikipedia.org/wiki/JavaScript, zuletzt abgerufen am: 30.5.2019.

233 https://de.wikipedia.org/wiki/Java_(Programmiersprache)\#Anwendungsarten, zuletzt abgerufen am: 30.5.2019.

234 https://de.wikipedia.org/wiki/Adobe_Flash\#cite_note-3, zuletzt abgerufen am: 30.5.2019.

235 Das sind dynamische Elemente von Webseiten, die vor allem um die Jahrhundertwende verbreitet waren und heute nicht mehr dem Stand der Technik entsprechen.

236 http://winfuture.de/news,90809.html, zuletzt abgerufen am: 30.5.2019; https://w ww.heise.de/newsticker/meldung/Adobe-verabschiedet-sich-von-Flash-2020-ist-S chluss-3783264.html, zuletzt abgerufen am: 30.5.2019.

237 https:/de.wikipedia.org/wiki/HTML5, zuletzt abgerufen am: 30.5.2019. 
rum von dynamischer Gestaltung sein oder auch während des Besuchs ausgetauscht werden.

\section{Abgrenzung des Internets von anderen Medien}

Diese technischen Gegebenheiten zeigen also vor allem eine grundlegende Besonderheit des Internets im Vergleich zu anderen Medien - der Nutzer hat den Informationsfluss weitgehend in seiner Hand. Schon der Beginn einer Internet-Session ist ohne zielgebende Eingabe einer URL durch den Nutzer nicht denkbar. Denn ein Browser - gesetzt keine besondere Startseite ist eingestellt - sendet keine Informationen wie bei Rundfunkmedien, sondern zieht bestimmte Einzelseiten von Servern. Im weiteren Verlauf erfolgt im Internet auch kein zentral von einer Redaktion gesteuerter linearer Informationsfluss. Solange der Nutzer keine Hyperlinks klickt oder andere URLs eingibt, wird nur der zuvor angeforderte Kommunikationsschnipsel angezeigt.

Aus diesem Grund wird das World Wide Web auch als Pull-Medium bezeichnet, während Rundfunk wie TV und Radio Push-Medien sind ${ }^{238}$. Im ersten Medium zieht der Nutzer aktiv die Information, bei den zweitgenannten Medien werden Information zum Nutzer gedrückt.

Dazwischen sind auch einige Mischformen zu finden. Eine Vermengung von Pull- und Push-Elementen erfolgt etwa bei Smart TVs, die Fernsehen mit Internetfunktionen ergänzt. Andererseits kann die Internetstruktur auch als Push-Medium genutzt werden, etwa bei Online-Radio oder -TV. Auch werbende E-Mails sind durch das Eindrücken von Information in den Bereich des Adressaten als Push-Medium anzusehen.

Der Unterschied zwischen dem World Wide Web und anderen Medien besteht aber nicht nur in der grundsätzlichen Entscheidungsgewalt des Nutzers, welche Seiten aufgerufen werden. Noch größer wird der Unterschied, wenn man die Individualisierungsoptionen innerhalb der Browser hinzuzieht. Durch die Möglichkeit mit bestimmten Einstellungen die intendierte Darstellung der Webseite im eigenen Rechner zu variieren, zeigt sich der Unterschied zwischen den Medien erst wirklich. Denn allein die Funktion „keine Bilder anzeigen“ in einem Browser stellt ein Unikum in der Medienlandschaft dar. Weder beim TV kann man einzelne Elemente

238 https://de.wikipedia.org/wiki/Pull-Medien, zuletzt abgerufen am: 30.5.2019; https://de.wikipedia.org/wiki/Push-Medien, zuletzt abgerufen am: 30.5.2019. 
der Sendung durch Einstellungen im TV-Gerät bzw. Receiver herausfiltern, noch bei einer Zeitung die Anzeige von Bildern abbestellen.

Deshalb ist das World Wide Web im Gegensatz zu anderen Medien nicht hierarchisch oder vertikal, sondern vielmehr horizontal strukturiert. Die Kommunikationsteilnehmer begegnen sich technisch auf Augenhöhe. Das HTML-Dokument einer Webseite ist in technischer Hinsicht weniger eine strikte Regieanweisung als eine unverbindliche Bitte, eine bestimmte Darstellung vorzunehmen. So können Browser theoretisch eine Vielzahl denkbarer Änderungen an der in einem HTML-Dokument vorgesehenen Darstellung vornehmen - etwa können Befehle in den Parsing-Prozess eingepflegt werden, wonach bestimmte Textwörter per se nicht angezeigt werden oder eine bestimmte Farbe immer durch eine andere Farbe ersetzt wird.

Dies führt ohne größere Anstrengung zur Frage, ob eine Integrität eines HTML-Quellcodes besteht. In technischer Hinsicht ist die Frage zu verneinen, weil ein Browser - wie ausführlich aufgezeigt - Änderungen aller Art vornehmen oder Befehle auslassen kann. Die Frage der Integrität ist aber auch eine rechtliche Frage, die eine zentrale Rolle in der weiteren Bearbeitung einnimmt.

\section{Online-Werbung Spezifika}

Vor der rechtlichen Analyse dieser und weiterer Fragen, sollen aber abschließend noch zwei weitere spezifische Besonderheiten des Internets und besonders der Online-Werbung näher erläutert werden. Zum einen der Einsatz besonderer Adserver (siehe dazu a.) und zum anderen das Phänomen namens Tracking (siehe dazu b.).

\section{a) Adserver}

Wie mehrfach herausgearbeitet ist ein besonderer Vorteil von Online-Werbung die effektive Möglichkeit der individuellen Werbeansprache durch diverse Targetingmethoden. Um dies technisch zu bewerkstelligen, werden besondere Adserver eingesetzt. Unter dem Begriff Adserver wird sowohl die Hardware, also ein separater Serverrechner für Werbeelemente, als auch die Software, die für die konkrete Werbungseinspeisung verant- 
wortlich ist, verstanden ${ }^{239}$. Durch den Einsatz von Adservern wird die Ausspielung von Werbung auf Webseiten dynamisiert, sodass nicht bereits im HTML-Dokument eine festgelegte Werbung vorgesehen werden muss. Auch muss bei der Änderung einer Werbeanzeige oder des Werbeplatzes der HTML-Code nicht umgeschrieben werden. Diese Technologie ist damit das Fundament des Programmatic Advertising und des Real Time Bidding.

Während bei den obigen technischen Ausführungen im Grundsatz davon ausgegangen worden ist, dass ein Client bei einem bestimmten Server eine Webseite abruft, ist die praktische Realität eine Andere. Denn bei der Ausspielung einer Webseite kann eine Vielzahl von Servern beteiligt sein. Zur besseren Verständlichkeit wird im Folgenden davon ausgegangen, dass neben dem Content-Server, der die Webseitendaten enthält, nur ein Werbeelement von einem AdServer zusätzlich geladen wird. In diesem Fall wird zunächst nach Eingabe der URL durch den Nutzer wieder das HTML-Dokument der Webseite angefordert, im Cache gespeichert und vom Browser geparst. Bei dieser Interpretation des Quellcodes wird der Browser an einer bestimmten Stelle auf ein „AdTag“ stoßen. Dieses „AdTag" fungiert als Platzhalter für Werbemittel, die von einem AdServer extern angefordert werden. Es ist meist ein Java-Script-Code, kann aber auch ein HTML5-Befehl sein. Durch das Script initiiert der Browser nun neben der bereits bestehenden IP/TCP-Verbindung zum Content-Server auch eine IP/TCP-Verbindung zum im „AdTag“ angegebenen Adserver und schickt einen HTTP-Request (sog. „Ad-Request“). In diesem Request sind, wie bereits oben bei HTTP gezeigt, eine Vielzahl von Informationen über den Empfänger der Webseite enthalten. Auf dieser Grundlage kann die Adserver-Software eine geeignete Werbung auswählen und über HTTP an den Empfänger senden. Diese Daten werden wiederum vom Browser gerendert und schließlich auf dem Gerät des Nutzers angezeigt ${ }^{240}$.

Auf Seiten des Adservers erfolgt gleichzeitig bereits eine Aufzeichnung von wirtschaftlich verwertbaren Informationen. So wird bereits beim AdRequest und der Auslieferung einer bestimmten Werbeanzeige statistisch erfasst, welche Anzeige genau an welchen Empfänger, d.h. an welche (ggf. anonymisierte) IP-Adresse, ausgeliefert wurde. Diese Daten bilden die Grundlage für die Abrechnung nach „AdImpressions“, die regelmäßig

239 Kammerzelt/Wimmer, Online-Marketing, S. 50; Jacob, Integriertes Online-Marketing, S. 227.

240 Vgl. Kammerzelt/Wimmer, Online-Marketing, S. 51ff.; Keßler/Rabsch/Mandic, Erfolgreiche Websites, S. 639. 


\section{B. Grundlage: Werbung im Internet}

nach dem Tausender-Kontakt-Preis (TKP) vergütet werden ${ }^{241}$. Ferner wird der Adserver eingebunden, wenn der Nutzer auf die Anzeige, zum Beispiel ein Werbebanner, klickt. Der Link führt in diesem Fall regelmäßig nicht direkt auf die Webseite des Werbetreibenden, sondern vermittelnd auf eine Zählseite des AdServers, wo eine Protokollierung der Nutzeraktion stattfindet ${ }^{242}$. Diese Protokollierung kann auch ohne Zwischenbesuch einer Zählseite durch ein in der Seite des Werbetreibenden integriertes Zählpixel, ein meist unsichtbares HTML-Element, bewerkstelligt wer$\operatorname{den}^{243}$. Durch diese Daten können der Erfolg eines Werbemittels gemessen und eine leistungsbezogene Abrechnung wie Pay-Per-Click durchgeführt werden.

Bei jedem neuen Aufruf der Webseite, auch innerhalb einer einzigen Session, wird die Werbefläche neu ausgefüllt. Damit wird eine abwechselnde Ausspielung von verschiedenen Werbeanzeigen erreicht, die zudem zu einer Verteilung von AdImpressions auf mehrere Anzeigen führt. Dies ist auch einer von wenigen visuellen Hinweisen für Internetnutzer auf die Einbindung eines AdServers in den Kommunikationsvorgang. Sonst ist für den Nutzer wegen der verzögerungslosen Einspeisung von Werbeelementen die Datenverbindung zu weiteren Servern neben dem Content-Server kaum wahrnehmbar ${ }^{244}$.

Moderne Adserver können im Rahmen der Werbemittelauswahl sehr spezifisch gesteuert werden. Neben den oben bereits skizzierten Targetingmethoden $^{245}$ stehen zum Teil weitere Optionen zur Verfügung wie etwa „Frequency Capping“, womit verhindert werden soll, dass einem Nutzer ein und dieselbe Anzeige $\mathrm{zu}$ oft angezeigt wird ${ }^{246}$. Diese Impressionshöchstgrenze kann negative Gefühle beim Nutzer verhindern. Der Nutzer könnte sich etwa verfolgt fühlen, wenn er im Rahmen des Re-Targeting nach einem unabgeschlossenen Online Shop Besuch den gesamten Tag Werbung des Shops oder zu dem bestimmten Produkt angezeigt erhält. Auch ist durch die statistische Auswertung der Werbung die vorzugsweise Darstellung der erfolgreicheren Elemente möglich.

Spezifisch für Webseiten mit dynamischer Werbung unter Einbindung von Adservern ist also die Kommunikation eines Clients mit mehreren

241 Vgl. Kammerzelt/Wimmer, Online-Marketing, S. 52.

242 Jacob, Integriertes Online-Marketing, S. 227.

243 Vgl. Frosch-Wilke/Raith, Marketing-Kommunikation im Internet, S. 66.

244 Vgl. Keßler/Rabsch/Mandic, Erfolgreiche Websites, S. 639.

245 Siehe Ziffer B. I. 4. a).

246 Vgl. Keßler/Rabsch/Mandic, Erfolgreiche Websites, S. 642. 
Servern. Dadurch ist der Abruf von Webseiten weniger vergleichbar mit einer Kommunikation zwischen zwei Personen. Vielmehr ist er ähnlich einem Gespräch des Internetnutzers auf der einen Seite mit einer Vielzahl von Gesprächspartnern auf der anderen Seite. Diese Gesprächspartner verfolgen einerseits verschiedene Interessen, weisen gleichwohl aber eine wirtschaftliche Verflechtung auf. Durch den Einsatz von AdServern erhält das Surfen im Internet eine erheblich höhere Kommerzialisierung, weil der Nutzer nicht mehr darauf vertrauen kann, dass die Werbung auf einer bestimmten Webseite vom jeweiligen Betreiber willentlich und vertrauensvoll ausgesucht worden ist. Vielmehr erfolgt die Werbeeinspeisung maßgeblich nach dem Willen der Werbenden, während dem Webseitenbetreiber eher die Frage des „Ob“, als des „Wie“ oder „Was" verbleibt. Um beim Bild des Gesprächs zwischen zwei Personen zu bleiben: der Einsatz eines Adservers ist wie eine offenstehende Tür, über die beliebige Werbevertreter sich in das Gespräch einmischen können und der Person, die an sich eine spezifische Information wünscht, sachfremde Informationen unterschieben. Deshalb ist es auch verständlich, wieso Online-Werbevermarkter, die zumeist die Adserver betreiben, ein Interesse daran haben, den Werbevertreter so freundlich und situationsadäquat wie möglich zu gestalten.

Dies gelingt indes nicht immer - manchmal auch zum Nachteil des Werbenden. Ein Beispiel ist etwa die Platzierung einer Werbeanzeige von Daimler-Benz auf YouTube im Kontext eines Propaganda-Videos des „Islamischen Staates"247. Der Einsatz von Adservern ist mit vielen Möglichkeiten verbunden, birgt aber noch immer ein Belästigungspotential an den jeweiligen Enden der Marketingkommunikationskette sowie das Risiko eines Renommeeverlustes der werbevermittelnden Webseite.

\section{b) Tracking}

Verbunden mit dem Einsatz von Adservern ist das Tracking. Durch Medienberichterstattung, insbesondere im Zusammenhang mit Datenerhebung großer Internetkonzerne, ist der Begriff des Trackings vorwiegend negativ gefärbt. Daneben ist Tracking aber auch eine Notwendigkeit des Affiliate-Marketings, um die Entstehung und Abrechnung von Provisionen nachzuhalten. Auch für Werbenetzwerke, die eine Vielzahl von Webseiten

247 Vgl. http://www.zeit.de/2017/14/google-werbung-youtube-extremisten-finanziert -einschraenkung, zuletzt abgerufen am: 30.5.2019. 
bedienen und dafür aus einem reichen Fundus an potentiellen Anzeigen schöpfen, ist Tracking notwendig, um zielgerichtet Werbung auszuliefern.

Zum Tracking stehen diverse technische Möglichkeiten zur Verfügung $^{248}$ :

aa) URL-Tracking

Beim URL-Tracking wird der Nutzer nach Klick auf den Link auf eine Unterseite des Werbenden geleitet, was eindeutig an der URL zu sehen ist. Schematisch erfolgt also eine Weiterleitung von Webseite $\mathrm{x}$ auf die Webseite des Werbenden y, wobei nicht auf die Startseite (z.B. www.y.de), sondern auf eine die Besuche von x zählende Unterseite (z.B. www.y.de/x) geleitet wird.

Diese Art des Trackings ist nur zielführend, wenn die gewünschte und provisionsbewährte Handlung direkt vorgenommen wird. Kommt der Nutzer später erst wieder auf die Webseite y ohne auf den Link von $\mathrm{x}$ zu klicken, wird nicht gezählt und keine Provision ausgelöst. Damit ist diese Art des Trackings für den Nutzer die am wenigsten intensive, weil hier lediglich der Besuch einer bestimmten Webseite protokolliert wird. Für Webseitenbetreiber ist sie hingegen eher uninteressant, da sie eine Provision nur selten verdienen, nämlich nur bei sofortigen Transaktionen. Überlegt der Nutzer erst, wie regelmäßig bei hochpreisigen Gütern zu erwarten, ist die Vermittlung des Webseitenbetreibers wertlos.

\section{bb) Cookie-Tracking}

Cookie-Tracking ist die wohl bekannteste Art des Trackings, nicht zuletzt durch die zur Zeit der Bearbeitung auf nahezu jeder Internetseite vorhandenen Informationsbalken mit Zustimmungsbutton zur Cookie-Nutzung 249 .

In technischer Hinsicht ist ein Cookie eine kleine Textdatei, die beim ersten Besuch einer Webseite vom Server an den Client-Rechner geschickt

248 Alle nachfolgenden Beschreibungen, soweit nicht anders gekennzeichnet, auf Grundlage von: Lammenett, Praxiswissen Online Marketing, S. 58ff.; Jacob, Integriertes Online-Marketing, S. 238ff..

249 Wobei nicht alle Cookies zum Tracking genutzt werden, sondern Cookies auch viele andere Funktionen haben können. 
wird. Bei einem erneuten Besuch der Webseite sendet der Client-Rechner die Informationen aus dem Cookie mit dem Request an den Server und erhält sodann schon eine auf die individuellen Bedürfnisse angepasste Antwort des Servers, etwa im Hinblick auf Sprache, Schriftgröße oder Ähnliches. Die Notwendigkeit von Cookies folgt daraus, dass über HTTP bei jeder Verbindung die Daten von neuem ohne etwaige Einstellungen aus früheren Besuchen lädt. Eine Erinnerungsfunktion sieht das Protokoll nicht vor. Cookies dienen also als das „Gedächtnis von HTTP“ und stellen eine Erweiterung dieses Protokolls dar. Die Cookies haben dabei regelmäßig ein Verfallsdatum, nach welcher sie vom Rechner des Clients gelöscht werden. Nur durch Cookies können etwa bei Online Shops die bei einem Besuch gefüllten Einkaufskörbe auch bei einem späteren Besuch angezeigt werden $^{250}$.

Tracking mit Cookies nutzt diese grundsätzliche Vorteilhaftigkeit der Technologie für die Interessen Dritter. Im Fall von Affiliate-Werbung wird bei Klick auf ein Werbebanner auf Webseite $\mathrm{x}$ und Weiterleitung an eine bestimmte Webseite des Werbenden y ein Cookie auf dem Client-Rechner gespeichert, dass der Nutzer über Webseite $\mathrm{x}$ zu Webseite y geleitet worden ist. Selbst wenn der Nutzer nun nicht direkt kauft, sondern innerhalb der „Lebenszeit“ des Cookies wieder auf die Webseite y zurückkehrt und einen Kauf vollendet, wird dem Betreiber von $\mathrm{x}$ die Vermittlung gutgeschrieben und eine Provision fällt an.

Durch diese Ausgestaltung ist Cookie-Tracking für Webseitenbetreiber äußerst attraktiv. Internetnutzer müssen dafür hinnehmen, dass auf ihrem Rechner eine Datei gespeichert wird, die zwar im Normalfall keinen nennenswerten Speicherplatz auf Festplatte und im Arbeitsspeicher verbraucht und auch für die Schnelligkeit der Datenübertragung nicht ins Gewicht fällt, aber bei zukünftigen Besuchen der Webseite y gewisse Informationen über das eigene Verhalten Preis gibt. So kann über die CookieAuswertung nicht nur analysiert werden, ob der durch seine IP-Adresse bestimmte Nutzer auf die Werbung hin eine gewisse Aktion vorgenommen hat, sondern auch der Zeitraum für diese Entscheidung festgestellt werden.

Trotzdem ist an dieser grundsätzlichen Cookie-Tracking-Gestaltung wohl noch kaum Verwerfliches zu finden, da dies eine gerechte Abrechnung im Verhältnis des Werbenden und des Webseitenbetreibers ermög-

250 Vgl. https://de.wikipedia.org/wiki/HTTP-Cookie, zuletzt abgerufen am: 30.5.2019; https://de.wikipedia.org/wiki/Cookie, zuletzt abgerufen am: 30.5.2019. 
licht. Auch zu beachten ist, dass der Internetnutzer in seinem Browser das Speichern bzw. Senden von Cookies ausschalten kann.

Bedenklich wird Cookie-Tracking erst dort, wo Cookies bereits dann gesetzt werden, wenn der Internetnutzer ein Werbebanner bloß angezeigt bekommt und nicht einmal anklickt. Noch kritischer sind Fälle, in denen Cookies für andere Zwecke als zur Abrechnung von Werbekosten eingesetzt werden, etwa zur grundsätzlichen Verhaltenskontrolle von Internetnutzern. Die Art von Information, die ein Cookie an einen Tracker übertragen kann, ist nicht auf obige Beispiele beschränkt, sondern eröffnet vielfältige Möglichkeiten die Erinnerung des Nutzergeräts anzuzapfen.

\section{cc) Pixel-Tracking}

Stark verbunden mit Cookie-Tracking ist das Pixel-Tracking. Schon im Zusammenhang mit Adservern wurde kurz auf das Zählpixel eingegangen. Dieses Zählpixel stellt den Informationsaustausch zwischen verschiedenen Servern sicher. Denn ein Cookie ist ein Stück Information, das nur zwischen Client-Rechner und konkretem Webserver innerhalb der aktuellen HTTP-Verbindung ausgetauscht wird. Wenn nun mehrere Server bei der Ausspielung von Werbung eingebunden sind bedarf es einer Brücke für den konkret nicht beteiligten Server. Diese Brücke ist regelmäßig das Zählpixel, das bei Online Shops oder Kontaktformularen zumeist auf der „Danke-Seite“ unsichtbar eingebettet ist. Das Zählpixel ist somit das Äquivalent zur Adserver-Werbeanzeige, also ein Inhalt, der von einem Drittserver angefordert wird und diesem im Rahmen der HTTP-Kommunikation Informationen zur Transaktion, etwa den Kaufpreis übermittelt.

Für den Nutzer bedeutet dies, dass ein dritter Server „mitliest“ und die Informationen damit für ihn intransparent an Unternehmen oder Personen gelangen können, mit denen er diese Information nicht unbedingt teilen möchte.

\section{dd) Tracking Skripte}

Neben Cookies und Pixeln bestehen weitere komplexe Methoden zur Datengewinnung auf dem Gerät des Nutzers. Mit Tracking Skripten werden im weiteren Verlauf dieser Bearbeitung kleine selbständige Programme oder Abläufe innerhalb eines übergeordneten Programms wie etwa Browsern gemeint, die in der Übermittlung von Daten des Nutzers an einen 
Tracker münden. Aktuelle Beispiele für solche Tracking Skripte aus der Zeit der Bearbeitung sind etwa das Ausnutzen der Autofill-Funktion von Browsern zur Übermittlung von E-Mail-Adressen und ggf. sogar Passwörtern $^{251}$ oder die Speicherung und Übermittlung von Texteingaben über das sog. "Session-Replay“252. Diese Skripte wirken auf dem Endgerät des Nutzers, indem sie Informationen von dem Gerät abschöpfen. Teils, insbesondere beim oben genannten „Session-Replay“, erfolgt eine Datenübermittlung sogar dann, wenn der Nutzer eigentlich keine Daten abschickt. So konnte nachgewiesen werden, dass über "Session Replay“ sogar nur kurz in entsprechende Felder auf Webseiten eingegebene Texte, die danach ohne Abschicken wieder gelöscht wurden, von Trackern abgegriffen worden sind. Dies zeigt die mögliche Intensität von Tracking Skripten, die also beinah die Ausmaße eines Cyberangriffs annehmen können.

Da solche Skripte im Verborgenen ablaufen, kann sich der Nutzer nur schwer dagegen schützen. Eine Möglichkeit ist die Installation von AntiTracking Programmen, z.B. Ghostery, eine andere Möglichkeit der Einsatz von Werbeblockern, die das Laden von Werbung von Drittservern verhindert. Denn oft nutzen Tracker Werbung als Vehikel auf dem Weg zum Endgerät des Nutzers. Zum Teil lässt sich auch durch die bewusste Option zur Ablehnung von JavaScript ein Schutz vor Trackingskripten erreichen, weil JavaScript die geläufige Programmiersprache für entsprechende Skripte ist.

Auch zu den Trackingskripten lassen sich Adblocker-Detektoren zählen, auf die an späterer Stelle dieser Arbeit eingegangen wird ${ }^{253}$. Mit diesen Detektoren lässt sich ermitteln, ob ein Nutzer einen Werbeblocker oder ähnlich wirkende Funktionen oder Vorrichtungen nutzt.

\section{ee) Session-Tracking}

Session-Tracking ist eine Methode ohne den Einsatz von Cookies, die vielmehr auf die Session Informationen innerhalb des Browsers zugreift. Eine Session endet dabei immer mit dem Schließen des Browsers. Sessi-

251 Vgl. https:/www.heise.de/security/meldung/Tracking-Skripte-klauen-E-Mail-Ad ressen-aus-Web-Browsern-3931772.html, zuletzt abgerufen am: 30.5.2019.

252 Vgl. https://www.heise.de/newsticker/meldung/Session-Replay-Viele-beliebte-W ebseiten-zeichnen-jegliche-Texteingabe-auf-3896475.html, zuletzt abgerufen am: 30.5.2019.

253 Siehe unten Ziffer D. I. 1.. 
on-Tracking erweitert den Zeitraum zur Registrierung einer provisionsfähigen Aktion im Gegensatz zum URL-Tracking, erreicht aber nicht die zeitlichen Möglichkeiten des Cookie-Trackings. Dafür werden hier auch Nutzer erreicht, die Cookies generell nicht akzeptieren. Der Nutzer hingegen kann auch eine solche Informationsübermittlung an Webserver regelmäßig in den Browsereinstellungen verhindern.

\section{ff) Fingerprint-Tracking}

Auch beim Fingerprint werden keine Cookies im Endgerät des Nutzers gesetzt. Bei dieser Methode wertet der Server bestimmte Informationen über das Gerät des Nutzers aus wie unter anderem die Art der Hardware, des Browsers und welche Einstellungen dort genutzt werden, die Installation bestimmter Plug-Ins oder die Unterstützung bestimmter Schriftarten ${ }^{254}$. Durch diese besondere Kombination können bei einem späteren Zugriff desselben Nutzers bzw. mit dessen Gerät, der alte gespeicherte Fingerprint und der beim neuerlichen Besuch erstellte „Fingerabdruck“ verglichen werden. Bei Übereinstimmung kann entsprechend dem Fingerprint zugeordneten Themen eine individualisierte Werbung ausgespielt werden ${ }^{255}$. Vorteil ist, dass der Nutzer nicht allein durch Browsereinstellungen das Tracking verhindern kann. Vielmehr werden gerade solche Browsereinstellungen genutzt, um den Nutzer zu individualisieren. Äußerst bedenklich an dieser Methode ist offensichtlich, dass nicht transparent ist, welche Informationen erhoben werden.

\section{gg) Datenbank-Tracking}

Bei der Methode des Datenbank-Trackings werden Informationen aus den oben beschriebenen, temporären Trackingmethoden in eine Datenbank eingepflegt, aus der sich auch über einen langen Zeitraum eine Zuordnung bestimmter IP-Adressen zu bestimmten Nutzern schließen lässt. Dies stellt im Prinzip eine nachrangige Nutzung der zuvor erlangten Daten dar. Für den Nutzer stellt sich dieselbe Problematik wie oben dar. Für Websei-

254 Unter http://uniquemachine.org/ kann jeder Nutzer seinen eigenen Fingerprint bestimmen lassen und nachvollziehen, welche Informationen ohne weiteres zur Verfügung gestellt werden.

255 Vgl. Schirmbacher, Online Marketing und Social Media Recht, S. 349f.. 
tenbetreiber ist dies interessant, weil so auch späte Entscheidungen oder Folgekäufe zuverlässig provisioniert werden können. Nachteilig ist indes, dass die Datenbank statisch sein kann, also nur der erstmalige Werbende in der Datenbank vermerkt ist und jede Provision einheimst, während spätere Werbeübermittler leer ausgehen.

hh) Fazit

Tracking für Werbezwecke im Internet, gleich über welche der vorstehenden Methoden, ist ein mehrstufiger Vorgang. Mitnichten erschöptt sich das Tracking nur in dem Setzen von Cookies oder Auslesen von Informationen. Dies stellt nur die erste Stufe der Datenerhebung dar. Diese Daten, die auf dem Gerät des Nutzers bzw. während der unmittelbaren Kommunikation zwischen Server und Client erhoben werden, müssen dann zum Tracker übertragen werden. Dort werden sie gespeichert. Dies erfolgt regelmäßig und gerade bei dem Einsatz für Verhalten-Targeting in Nutzungsprofilen, die einem bestimmten Nutzer(-gerät) zugeordnet sind. Diese Nutzungsprofile werden ausgewertet und liefern dann die für das Targeting notwendigen Informationen der ermittelten Vorlieben der Nutzer $^{256}$

Diese gezeigten Methoden des Trackings bergen verständlicherweise eine hohe Gefahr des Missbrauchs. Erschwerend kommt hinzu, dass diese Vorgänge im normalen Surfverhalten des Nutzers unsichtbar sind und dieser erst bestimmte Browserfenster öffnen muss oder sogar Zusatzprogramme installieren muss, um eine Transparenz über Cookies, Skripte, Fingerprints etc. herzustellen. Hinzu kommt ferner, dass gerade bei dem Einsatz von Cookies und Zählpixeln zum einen Informationen auf den Client-Rechnern platziert werden können, die von den meisten Personen nicht entschlüsselt werden, und zum anderen Informationen über eine Vielzahl von Servern weitergegeben werden. Wie das Datenbank-Tracking bzw. die Anlage von Nutzungsprofilen beim Tracker zeigt, ist eine nachrangige Nutzung der so erhobenen Daten verbreitet. Transparenz über die konkrete Nutzung besteht faktisch nicht, was mit Blick auf das Datenschutzrecht und die Persönlichkeitsrechte der Nutzer äußerst problematisch ist.

256 Vgl. Schleipfer, VD 2017, 460, 461f. und die Darstellung zu Targeting oben unter Ziffer B. I. 4. a). 
Daten zur Verbreitung von Tracking wurden im Juli 2017 in der Studie "Tracking the Trackers: Analysing the global tracking landscape with Ghos-

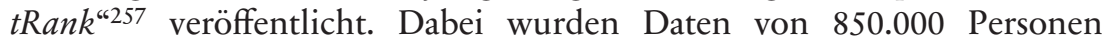
und 440 Millionen Seitenaufrufen ausgewertet, was der bis dato größte Datensatz zu diesem Thema war. Von den beobachteten Seitenaufrufen waren nur 23\% ohne jegliches Tracking. Diese Zahl ist aber vor dem Hintergrund zu lesen, dass von diesem Wert 15\% aller Seitenaufrufe auf Eigenseiten von Google und 6\% auf solche von Facebook führten, bei denen kein Tracking notwendig ist. Auf eigenen Seiten können diese Konzerne schließlich aus erster Hand die Daten erfassen. Die übrigen 77\% der Seitenaufrufe wurden in Kategorien für die Anzahl von Trackinginstrumenten zwischen einem und „mehr als zehn“ eingeordnet. Unter diesen Kategorien war „ein Tracker“ relativ am stärksten vertreten (ca. 17\%), gefolgt von „mehr als zehn Tracker“ (ca. 15\%). Die Unternehmen, die dabei die meisten Trackingaktivitäten verursachten, waren erwartungsgemäß Google und Facebook. Weiterhin kommen noch Twitter und Amazon sowie lokale Anbieter auf beachtliche Werte. Zudem zeigte die Studie, dass in Deutschland verhältnismäßig weniger getrackt wird als etwa in den USA und Russland. Insgesamt zeigen die Werte aber die enorme Bedeutung von Tracking im Internet zur Zeit der Bearbeitung.

Wo dieses Tracking für legale Zwecke genutzt wird, liegt auch eine Nutzung für weniger lautere Ziele leider nahe. Nicht zuletzt Angriffe mit Malware oder Viren über Skripte zeigen die Gefahr für Nutzer. Die Spionageaffäre rund um die NSA und Edward Snowden belegt überdies, dass nicht nur Kriminelle ein Interesse an einer Spionage von Internetnutzern haben können. Dies alles hat zu dem negativen Ruf von Tracking und vor allem Cookies beigetragen und ist zudem ein nicht ganz unwichtiger Grund für den Aufstieg von Internetwerbeblockern.

\section{Rechtliche Beurteilung ausgewählter Aspekte}

Den gesamten Online-Werbemarkt einer intensiven rechtlichen Analyse zu unterziehen, würde den Rahmen dieser Ausarbeitung sprengen. Auch würde dies nicht der Lösung der eingangs herausgearbeiteten Probleme dienen. Insbesondere soll hier nicht auf solche Themen im Kontext

257 https://www.ghostery.com/wp-content/themes/ghostery/images/campaigns/trac ker-study/Ghostery_Study_-_Tracking_the_Trackers.pdf, zuletzt abgerufen am: 30.5.2019. 
mit Online-Werbung wie die Nutzung bestimmter Begriffe als Domains, Keywords oder Meta-Tags eingegangen werden. Diese vorwiegend kennzeichenrechtlichen Themen sind zum einen weitestgehend erschöpfend kommentiert ${ }^{258}$ und zum anderen unbedeutend für das Thema Internetwerbeblocker. Auch nicht näher eingegangen wird auf kollisionsrechtliche Fragestellungen von Internetwerbung, die bereits andernorts ausführlich begutachtet worden sind ${ }^{259}$. Soweit keine Quervergleiche nötig sind, wird auch nicht die Zulässigkeit von E-Mail-Werbung, gleich ob in Form von „Stand-Alone“-Mails oder Newslettern, untersucht. Hierfür bietet vor allem die Kommentarliteratur eine ergiebige Quelle ${ }^{260}$.

Vielmehr sollen nun ausgewählte Aspekte, die im vorangegangenen Teil lediglich in tatsächlicher Hinsicht beschrieben worden sind, aus einem juristischen Blickwinkel näher beleuchtet werden. Von Bedeutung sind dabei zum einen solche Aspekte, die für die weitere Beurteilung der Werbeblocker wesentlich sind. Dies sind insbesondere solche Ausprägungen des Online-Werbemarktes, die den Internetnutzer zum Einsatz von Internetwerbeblockern motivieren können. Insoweit kommen die Art und Weise von Display-Werbung (siehe dazu Ziffer 1.) sowie die Zulässigkeit von Tracking und Targeting (siehe dazu Ziffer 2.) in den Fokus. Außerdem wird ein Blick auf zur Zeit der Bearbeitung aktuelle Probleme des modernen Online-Marketings geworfen, namentlich auf Native Advertising, Guerilla und Influencer Marketing (siehe dazu Ziffer 3.).

\section{Gesetzliche Grenzen der Display-Werbung}

Für die Beurteilung von Display-Werbung im Internet, also vor allem „Bannerwerbung“ in allen denkbaren Ausgestaltungen, existieren im Wesentlichen dieselben gesetzlichen Grenzen wie für jede andere Art der Werbung auch. Zwar sind Webseiten, die Display-Werbung veröffentlichen, als Anwendungsfall der Legaldefinition von „Telemedien“ dem Telemediengesetz (TMG) unterstellt, vgl. $\$ 1$ Abs. 1 TMG. Dieses Gesetz statuiert aber praktisch keine Begrenzungen der Werbung im Internet.

258 Vgl. Weingarten, Werbeformen im Internet; eine wettbewerbsrechtliche Analyse, S. 51ff.; Witte, in: Auer-Reinsdorff/Conrad, $\$ 7$, Rn. 32ff.; Schöttle/Eckhardt, in: Auer-Reinsdorff/Conrad, $\$ 25$, Rn.41ff.; Ingerl/Rohnke, MarkenG, $\$ 15$ Rn. 29ff., 188ff..

259 Vgl. etwa Bettinger/Leistner, Werbung und Vertrieb im Internet, Teil $1 \mathrm{~A}$, Rn. 69ff..

260 Vgl. statt aller: Köhler/Bornkamm/Feddersen, UWG, $\mathbb{7}$, Rn. 196ff.. 
Das TMG ist im breiten Publikum vor allem wegen der Impressumspflicht in $\$ 5$ Abs. 1 bekannt. Dies ist ein beliebter Abmahngrund im Wettbewerb, hat aber für die Beurteilung von Werbung keine Bedeutung. Ebenfalls prominent sind die Vorschriften in $\$ \$$ 7-10 TMG zur Verantwortlichkeit für Inhalte auf Webseiten. Diese können auch bei der Schaltung von Werbung Bedeutung erlangen. Im Normalfall einer nicht rechtsverletzenden Werbeanzeige ergeben sich aus diesen Normen aber auch keine Begrenzungen der Werbemöglichkeiten.

In $\$ 6$ Abs. 1 enthält das TMG jedoch vier Mindestvoraussetzungen für die kommerzielle Kommunikation, die ihrerseits in $\$ 2$ Nr. 5 TMG legaldefiniert wird. Kommerzielle Kommunikation umfasst problemlos jede Werbung, insbesondere Display-Werbung auf Internetseiten, was besonders augenfällig wird, wenn man die Legaldefinition in $\$ 2 \mathrm{Nr} .5$ TMG neben die Definition von Werbung aus Art. 2 lit. a) der Werberichtlinie 2006/114/EG stellt, auf die sich auch der BGH in ständiger Rechtsprechung bezieht ${ }^{261}$. Insbesondere sind in beiden Definitionen sowohl Absatzwerbung als auch Imagewerbung erfasst. Die Besonderheit von $\$ 2$ Nr. 5 TMG besteht allein in der ausdrücklichen Herausnahme bestimmter Elemente aus dem Begriff der kommerziellen Kommunikation und zwar Domainnamen, EMail-Adressen (beide in lit. a.) und Informationsdienste über Drittprodukte, die unabhängig und ohne finanzielle Gegenleistung betrieben werden (lit. b.). Unter die letztgenannten Dienste sind vor allem unabhängige Warentester wie Stiftung Warentest oder Öko-Test zu fassen. Hierher gehören aber auch andere private Bewertungs- und Preisvergleichsportale, solange sie unabhängig und unentgeltlich arbeiten ${ }^{262}$. Dies macht den Begriff der kommerziellen Kommunikation enger als den Begriff der Werbung. Grenzfälle sind demnach Einträge oder Bewertungen in solchen Portalen, die möglicherweise gegen Bezahlung vorgenommen werden. Dies betriff indes allein Content-Werbung und nicht Display-Werbung, die unter keine der Ausnahmen fällt.

Die Mindestvoraussetzungen von $\$ 6$ Abs. 1 TMG sind im Einzelnen die klare Erkennbarkeit der kommerziellen Kommunikation (Nr.1), die klare Identifizierbarkeit des Werbenden (Nr.2), die klare Erkennbarkeit von Verkaufsförderungsangeboten und Gewinnspielen sowie die leichte Zugänglichmachung und klare Angabe der dazugehörigen Bedingungen (Nrn. 3 und 4). Diese Regeln sind indes weitestgehend redundant und

261 Vgl. etwa BGH, Urteil vom 14. 012016 - I ZR 65/14, GRUR 2016, 946 Freunde finden.

262 Vgl. BeckOK InfoMedienR/Martini, TMG, $\$ 2$ Rn. 29. 
ergeben sich grundlegend schon aus dem allgemeinen Wettbewerbsrecht. Das Trennungsgebot aus $\$ 6$ Abs. 1 Nr. 1 TMG ergibt sich etwa bereits aus $\$ 5$ a Abs. 6 UWG und Nr. 11 des Anhangs zu $₫ 3$ Abs. 3 UWG $^{263}$. Die Identität des Werbenden ( $\$ 6$ Abs. 1 Nr. 2 TMG) muss ebenfalls bereits nach $₫ 5$ Abs. 1 Nr. 3 UWG ohne Irreführung angegeben werden. Die weiteren Transparenzpflichten aus $\$ 6$ Abs. 1 Nrn. 3, 4 TMG lassen sich zudem zwanglos aus $\$ \$ 5$, 5a UWG folgern. $\$ 6$ Abs. 1 TMG hat damit vor allem redaktionelle und klarstellende Bedeutung, indem sich Telemedienanbieter auch ohne besondere Kenntnisse des Wettbewerbsrechts schnell mit den Mindestanforderungen vertraut machen können.

Über $\mathbb{S} 1$ Abs. 4 TMG gilt für die Inhalte von Telemedien zudem der Rundfunkstaatsvertrag (RfStV). Dessen $\mathbb{S} 54-61$ befassen sich mit Telemedien. Soweit Werbung betroffen ist, wird wiederum eine klare Erkennbarkeit von Werbung und die eindeutige Trennung vom Inhalt in $₫ 58$ Abs. 1 RfStV zur Pflicht erklärt. Zudem werden in $\$ 58$ Abs. 4 RfStV für Gewinnspiele die gleichen Regeln wie bei Rundfunkanstalten ( $\$ 8 \mathrm{a} R f S t V)$ für anwendbar erklärt, was im Kern jedoch keine Änderung zu den bereits genannten Regelungen bringt. Eine Begrenzung der Werbung im Internet erfolgt demnach auch im Rundfunkstaatsvertrag nicht.

Zuletzt leitet das TMG in $\$ 6$ Abs. 3 auf das allgemeine Wettbewerbsrecht über, indem es die Vorschriften des UWG für unberührt erklärt. Damit hat sich Display-Werbung wie jede andere Werbung auch am Maßstab des UWG zu messen und zwar, soweit es um das „ $\mathrm{Ob}$ “ der Werbung geht, zuvörderst an $\$ 7$ Abs. 1 UWG (siehe dazu lit. a.). Im Rahmen des „Wie“ von Display-Werbung kommen hingegen diverse Tatbestände des UWG ins Spiel, die regelmäßig über $\$ 3$ Abs. 1 UWG zur Unlauterkeit führen können (siehe dazu lit. b.).

a) Zulässigkeit der Auslieferung von Display-Werbeanzeigen beim Nutzer

Die Preisfrage bei der Zulässigkeit der Anzeige von Werbung auf Webseiten ist folglich, ob der Internetnutzer durch diese in unzumutbarer Weise belästigt wird. Wie $\$ 7$ Abs. 1 S. 2 UWG zu entnehmen ist, ist diese unzumutbare Belästigung insbesondere anzunehmen bei Werbung, obwohl erkennbar ist, dass der angesprochene Marktteilnehmer diese Werbung nicht wünscht.

263 Vgl. Schirmbacher, Online Marketing und Social Media Recht, S. 97. 
Neben dieser Generalklausel mit Regelbeispiel in $\$ 7$ Abs. 1 UWG, enthält $\$ 7$ Abs. 2 UWG die Spezialfälle stets unzumutbarer Belästigungen. Dieser Absatz enthält vorrangig anwendbare Per-se-Verbote, die auf europäischen Richtlinien beruhen, Nummer 1 auf der UGP-Richtlinie (2005/29/EG) und Nummern 2-4 auf der E-Privacy-Richtlinie (2002/58/ $E G)^{264}$. Einschlägig für Display-Werbung kann dabei vor allem die Nummer 1 sein. Eine Anwendung bei Nummern 2 und 3 scheidet wegen der eindeutigen Medienbezeichnung schon aus. Nummer 4 hingegen ist offener formuliert und bedarf einer differenzierten Betrachtung.

Im Weiteren werden die einzelnen einschlägigen Fälle von $\$ 7$ UWG näher beleuchtet:

aa) Hartnäckige Ansprache, $\mathbb{} 7$ Abs. 2 Nr. 1 UWG

\7 Abs. 2 Nr. 1 UWG gilt für Display-Werbung, weil das Internet ein für den Fernabsatz geeignetes Mittel der kommerziellen Kommunikation und nicht ein bereits in Nummern 2 und 3 der Norm speziell geregeltes Medium darstellt ${ }^{265}$. Eine unzumutbare Belästigung ist dabei aber nur dann möglich, wenn ein Verbraucher hartnäckig angesprochen wird, obwohl er dies erkennbar nicht wünscht. Hartnäckig bedeutet dabei eine wiederholte, d.h. mindestens zweimalige, Kontaktaufnahme ${ }^{266}$.

Aus dieser Voraussetzung der hartnäckigen Ansprache wird zum Teil gefolgert, dass Telemedien, sprich Webseiten, schon ihrer Natur nach als taugliches Medium von $\mathbb{\$} 7$ Abs. 2 Nr. 1 UWG ausscheiden sollen, weil eine hartnäckige Ansprache überhaupt nicht möglich sei ${ }^{267}$. Dem ist jedoch aus zwei Gründen zu widersprechen. Zum einen werden Fern-

264 Köhler/Bornkamm/Feddersen, UWG, $\mathbb{\$} 7$, Rn. 1-6b. Durch die geplante Einführung der E-Privacy Verordnung ändert sich nichts an der deutschen Rechtslage. Jedoch wird nach Einführung der Verordnung Normenkonkurrenz zum UWG bestehen.

265 Vgl. BGH, Beschluss vom 30.1.2020 - I ZR 25/19, GRUR 2020, 420, Rn. 50ff. Inbox-Werbung.

266 Pahlow, in: Teplitzky/Peifer/Leistner, UWG, $\mathbb{\$} 7$, Rn. 128; OLG Hamm, Beschluss vom 25.11.2014 - I-9 U 225/12 (juris, Rn. 2).

267 Köhler/Bornkamm/Feddersen, UWG, $\$ 7$, Rn. 104; darauf Bezug nehmend: OLG Nürnberg, Urteil vom 15.1.2019, 3 U 724/18, K\& R 2019, 200. Anders sieht dies auch der BGH in seinem Beschluss vom 30.1.2020 - I ZR 25/19, GRUR 2020, 420 - Inbox-Werbung. Der BGH führt insoweit aus, dass die Auslegung denkbar ist, dass ein Verbraucher durch Inbox-Werbung in seiner Privatsphäre betroffen ist und in stärkerem Maße belästigt wird als durch her- 
kommunikationsmittel in $\$ 312$ c Abs. 2 BGB legaldefiniert und erfassen ausdrücklich Telemedien ${ }^{268}$. Zum anderen ist bei technischer Betrachtung der Werbeauslieferung sehr wohl eine wiederholte werbliche Ansprache möglich. Dies ist etwa der Fall, wenn der Internetnutzer seinen Browser - durch Internetwerbeblocker oder durch sonstige Einstellungen - den Abruf der ursprünglich im HTML-Dokument intendierten Werbung nicht durchführen lässt und der Server sodann im Rahmen der Ende-zu-Ende Kommunikation einen Ersatzbefehl schickt, der den Nutzerbefehl umgeht und somit trotzdem die Ausspielung von Werbung bewerkstelligt ${ }^{269}$. In einem solchen Fall erfolgt die erste, nicht zu beanstandende Werbeansprache bereits mit Hinterlegung des Werbeplatzhalters im HTML-Dokument auf dem Server. Durch die Feststellung der Nichtausspielung von Werbung nimmt der Server, sprich der Werbende, faktisch zur Kenntnis, dass der konkrete Internetnutzer keine Werbung wünscht. Die Ausspielung einer Ersatzwerbung kann sodann eine wiederholte, ergo hartnäckige Werbeansprache darstellen, die auch entgegen des zu Tage getretenen Wunsches des Verbrauchers erfolgt. Somit steht die Natur der Telemedien einer hartnäckigen Ansprache gerade nicht entgegen. Die oben geäußerte Ansicht ist wegen der technischen Gegebenheiten nicht zutreffend. Telemedien sind folglich als taugliches Medium im Rahmen von $\$ 7$ Abs. 2 Nr. 1 UWG anzusehen ${ }^{270}$. Ob diese Ersatzwerbeansprache im Ergebnis als unzulässig anzusehen ist, wird an späterer Stelle ausführlich dargestellt ${ }^{271}$.

Aus dem Vorstehenden ergibt sich aber auch, dass der einfache Abruf einer Webseite ohne besondere Einstellungen im Browser des Internetnutzers nie einen Fall von $\$ 7$ Abs. 2 Nr. 1 UWG darstellen kann. Es fehlt dann an der Hartnäckigkeit und an dem erkennbar entgegenstehenden Willen des Nutzers.

Ein Sonderfall sind Webseiten, die einen Log-in bedürfen und bei denen der Nutzer über ein eigenes Nutzerprofil verfügt. Hier liegt der Fall anders als bei üblicher Display-Werbung auf offenen Webseiten mit freiem Publikumsverkehr. Zutrittsgeschützte Webseiten, wie etwa soziale Netzwerke,

kömmliche Bannerwerbung in den dafür normalerweise vorgesehenen, keinen Individualbezug aufweisenden Bereichen einer Internetseite.

268 Schöler, in: Harte-Bavendamm/Henning-Bodewig, UWG, $\mathbb{\$} 7$, Rn. 181.

269 Zur eingehenderen Problematik der Umgehung von Werbeblockern, siehe unten Ziffer D. I..

270 Die Möglichkeit $\$ 7$ Abs. 2 Nr. 1 UWG auch auf Display-Werbung anzuwenden hält sich ohne tiefere Auseinandersetzung auch Schirmbacher offen, siehe K\&R 2019, 229, 230.

271 Siehe unten Ziffer D. II.. 


\section{B. Grundlage: Werbung im Internet}

zeichnen sich durch eine engere Verbindung zwischen Webseitenbetreiber und Nutzer aus. Diese (ggf. vertragliche) Verbindung führt dazu, dass der Webseitenbetreiber den Nutzer zu jeder Zeit durch sein Profil identifizieren kann. Der Webseitenbetreiber kann dabei im Rahmen der Anmeldung durch den Nutzer vertraglich regeln, dass der Nutzer zur Duldung von Werbung verpflichtet ist, was regelmäßig durch Allgemeine Geschäftsbedingungen erfolgen wird. Wird allerdings nichts geregelt, erklärt der Nutzer auch kein ausdrückliches Einverständnis mit der Einblendung von Werbung. Ob in der Anmeldung bei einem Webportal eine konkludente Einwilligung zu erkennen sein mag, kann je nach Einzelfall sehr kontrovers diskutiert werden.

In diesem Zusammenhang ist denkbar, dass der Nutzer dem Webseitenbetreiber gegenüber erklärt, dass er auf der Webseite keine Werbung oder zumindest eine bestimmte Art von Werbung nicht mehr sehen möchte. Damit kann der Nutzer erkennbar machen, dass er Display-Werbung nicht wünscht. Bei strenger Anwendung von $\$ 7$ Abs. 2 Nr. 1 UWG hat der Webseitenbetreiber diesen Wunsch sodann grundsätzlich zu beachten ${ }^{272}$. Spielt er gleichwohl nach der Erklärung des Nutzers die unerwünschte Werbung aus, liegt schon ab der zweiten ausgespielten Werbeanzeige eine per se unzulässige Werbeansprache vor. Raum für eine Interessenabwägung bleibt nicht. Der Nutzer hat demnach bei für ihn günstiger Ausgestaltung der Nutzungsbedingungen einen mächtigen Hebel, um den Webseitenbetreiber in seinem wirtschaftlichen Handeln zu beschränken.

Dieses Ergebnis mag auf den ersten Blick überraschen. Die Anwendung des $₫ 7$ Abs. 2 Nr. 1 UWG auf Telemedien ist aber, wie oben dargestellt, gesetzessystematisch geboten. Hier begeben sich Webseitenbetreiber folglich in ein erhebliches Risiko, wenn sie kein vertragliches Einverständnis in die Ausspielung von Werbung in den Nutzungsbedingungen vorsehen. Wenn dieses Einverständnis auch nicht konkludent hergeleitet werden kann, hat jeder registrierte und angemeldete Nutzer, der seinen fehlenden Willen zur Werbung bekundet hat, einen gesetzlichen Anspruch auf Unterlassung von Display-Werbung.

Dies könnte im Einzelnen zu ernsthaften Problemen bei Webseitenbetreibern führen. Denn sollte eine entsprechende Unterlassungsverpflichtung oder ein solcher Titel bestehen, müssten HTML-Dokumente oder Algorithmen angepasst werden, was mit teils nicht unerheblichem Aufwand und Kosten verbunden sein dürfte. Freilich relativiert sich dieses

272 Vgl. insoweit BGH, Beschluss vom 30.1.2020 - I ZR 25/19, GRUR 2020, 420, Rn. 50ff. - Inbox-Werbung. 
Problem dadurch, dass die betroffenen Webseitenbetreiber ihre Nutzungsbedingungen ändern können. Zumindest für eine Übergangszeit hat das oben dargestellte Ergebnis aber das Potential zu einer „Abmahnwelle“, die ganz unüblich von Nutzern zu Unternehmen schwemmen könnte.

Eine unzumutbare Belästigung durch Display-Werbung nach $₫ 7$ Abs. 2 Nr. 1 UWG ist deshalb ein in der Praxis noch nicht beachtetes Problem. Mangels Anspruchsgeltendmachung gab es auch noch kein Bedürfnis zu einer gerichtlichen Auseinandersetzung. Es bleibt allerdings abzuwarten, ob es bei dieser Untätigkeit der Betroffenen bleibt.

bb) Werbung mit einer Nachricht, $\mathbb{\$} 7$ Abs. 2 Nr. 4 UWG

$\$ 7$ Abs. 2 Nr. 4 UWG betrifft Werbung mit einer Nachricht. Der Begriff der Nachricht ist in $\$ 2$ Abs. 1 Nr. 4 UWG legaldefiniert und fordert als maßgebliche Elemente den Austausch oder die Weiterleitung einer Information zwischen einer endlichen Zahl von Beteiligten innerhalb eines öffentlich zugänglichen elektronischen Kommunikationsdienstes. Rundfunkdienste sind dabei ausgenommen.

Mit dieser Definition ist Display-Werbung nur in bestimmten Fällen in Einklang zu bringen, da es im Normalfall des Besuchs einer öffentlich zugänglichen Webseite an einer endlichen Zahl von Beteiligten fehlt. Mit der Hinterlegung eines HTML-Dokuments mit vorgesehener Werbeanzeige auf einem Server ist gerade der Zugriff durch eine unbegrenzte Anzahl von Internetnutzern möglich und bezweckt. Es mangelt insoweit an einem bestimmbaren Adressatenkreis ${ }^{273}$.

Etwas anderes kann aber auch hier gelten, wenn der Zugriff einer Webseite eine Registrierung erfordert oder passwortgeschützt ist. Dann ist die Webseite nur für eine endliche Zahl von Beteiligten erreichbar ${ }^{274}$. Werbeanzeigen auf zugangsbeschränkten Webseiten erfüllen damit im Grundsatz alle Elemente der Definition. Der Austausch von Information erfolgt durch eine IP/TCP-Verbindung, die einen Informationsaustausch in einem öffentlich zugänglichen und elektronischen Kommunikationsdienst darstellt. Betrachtet man allein den Aspekt der Begrenztheit der Teilnehmer, unterscheidet sich die Übermittlung der Werbeanzeige im geschützten Bereich nicht wesentlich von einer E-Mail im Rahmen eines Newsletters an einen potentiell tausende von Empfängern enthaltenden Verteiler.

273 Vgl. Keller, in: Harte-Bavendamm/Henning-Bodewig, UWG, $\mathbb{2}$ 2, Rn. 161.

274 Bähr, in: MüKo Lauterkeitsrecht, \$2, Rn. 277. 
Allerdings beruht $₫ 7$ Abs. 2 Nr. 4 UWG - wie oben bereits dargestellt und anders als $\$ 7$ Abs. 2 Nr. 1 UWG - auf der E-Privacy-Richtlinie. Die Definition von „Nachricht“ ist dabei wortgleich Art. 2 S. 2 lit. d) der E-Privacy-Richtlinie entnommen. Der Tatbestand von $\mathbb{} 7$ Abs. 2 Nr. 4 UWG beruht auf Art. 13 Abs. 4 der E-Privacy-Richtlinie, der lediglich das „Versenden elektronischer Nachrichten“ regelt. $\$ 7$ Abs. 2 Nr. 4 UWG hingegen betrifft jede Nachricht.

Betreffend die Definition von Nachricht wird auf Grundlage der E-Privacy-Richtlinie zumindest für das Streaming von Rundfunkinhalten eine teleologische Reduktion der Definition der Nachricht erwogen, wonach bei Streams trotz einer direkten Kommunikationsverbindung über IP/TCP oder ähnliche Protokolle (vgl. technische Einzelheiten oben) und der daraus folgenden Erkennbarkeit der IP-Adresse keine Schutzbedürftigkeit bestehe ${ }^{275}$. Für Display-Werbung hat diese Einschränkung keine besondere Bedeutung, weil sie lediglich lineare TV-Werbung betriff, die über das Internet anstatt über klassische TV-Signale gesendet wird.

Außerdem wird eine richtlinienkonforme Auslegung des $₫ 7$ Abs. 2 Nr. 4 UWG auf elektronische Post in Form von E-Mail, SMS und ähnliche Ausprägungen vorgeschlagen ${ }^{276}$. Display-Werbung wäre damit nicht in Einklang zu bringen.

Beide Einschränkungen sind zutreffend und begegnen keinen Bedenken. Die teleologische Reduktion des Nachrichtenbegriffs bei der Verlagerung von Rundfunkangeboten ins Internet ist zutreffend, weil die bloße Technik der Übertragung nichts an dem Charakter der Werbung als Fernsehwerbung ändert. Von dieser Einschränkung sind indes nicht solche Streamingdienste erfasst, die eigene Inhalte auf Abruf und unabhängig von einer linearen TV-Sendung bereitstellen. Dortige Pre-Roll-Werbeclips oder Ähnliches wären gleichwohl Nachrichten, wenn sie im zugangsbeschränkten Bereich erfolgen.

Wichtiger ist die richtlinienkonforme Einschränkung auf elektronische Post. Denn damit fällt Display-Werbung insgesamt aus dem Anwendungsbereich von $₫ 7$ Abs. 2 Nr. 4 UWG heraus. Dies ist angesichts der Wirkweise von Display-Werbung aber auch gerechtfertigt. Betrachtet man näher die drei Fälle in lit. a)-c) von $\$ 7$ Abs. 2 Nr. 4 UWG, die sinngleich in

275 Vgl. Bähr, in: MüKo Lauterkeitsrecht, $\ 2$, Rn. 286; Fezer, in: Fezer/Büscher/Obergfell, UWG $\mathbb{} 2$ E Rn. 8; Erdmann, in: Gloy/Loschelder/Erdmann, $\$ 36, \mathrm{Rn} .14$.

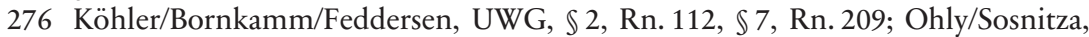

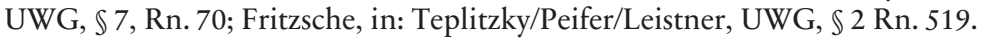


Art. 13 Abs. 4 der E-Privacy-Richtlinie enthalten sind, besteht nämlich kein Bedürfnis Display-Werbung unter diese Norm zu fassen ${ }^{277}$.

An dieser Beurteilung wird mit hoher Wahrscheinlichkeit auch die geplante E-Privacy-Verordnung nichts ändern, die die E-Privacy-Richtlinie ablösen wird. Mit der Verordnung wird in diesem Zusammenhang nicht bloß ein von den Mitgliedsstaaten umzusetzendes, sondern ein mit Gesetzeswirkung versehenes Regelwerk gelten. In Kapitel III des E-Privacy-Verordnungsentwurfs vom 19.10.2019 („EPVO-E“) ${ }^{278}$, also in den Artikeln 12 - 16, sind Regeln für die elektronische Kommunikation enthalten. Die Regelung des $\$ 7$ Abs. 2 Nr. 4 UWG ist dabei in Art. 16 Abs. 6 der EPVOE sinngemäß gespiegelt. Art. 16 Abs. 6 der EPVO-E betrifft dabei nicht eine „Werbung mit einer Nachricht“, sondern „Direktwerbung mittels elektronischer Kommunikationsdienste“. Mit dieser Formulierung wird deutlich, was die Verbotsnorm wirklich betriff. Display-Werbung im Internet gehört wegen der Legaldefinition in Art. 4 Abs. 3 lit.f) sowie der ausdrücklichen Klarstellung in Erwägungsgrund 32 der EPVO-E nicht dazu. Sowohl die deutsche als auch die europäische Norm haben mangels geänderten Willens des europäischen Verordnungsgebers einen parallelen Anwendungsbereich. Demnach wird Display-Werbung in keiner der beiden Normen erfasst.

Demnach scheidet $\$ 7$ Abs. 2 Nr. 4 UWG als Grundlage für eine unzumutbare Belästigung von Internetnutzern durch Display-Werbung aus.

\section{cc) Generalklausel, $\mathbb{} 7$ Abs. 1 UWG}

Die Generalklausel in $\$ 7$ Abs. 1 UWG lässt im Gegensatz zu den Per-seVerboten in Absatz 2 der Vorschrift viel Raum für Einzelfallbetrachtungen und richterliche Rechtsfortbildung. Das einzige Regelbeispiel in $\$ 7$ Abs. 1 S. 2 UWG stellt auf die Erkennbarkeit der Unerwünschtheit von Werbung beim Adressaten ab. Es gilt aber auch bei Feststellung eben dieses Umstandes nicht absolut, sondern muss im Rahmen einer Gesamtabwägung der Interessen aller Beteiligten positiv bejaht werden ${ }^{279}$.

277 Im Ergebnis ebenso, aber ohne tiefergehende Auseinandersetzung: OLG Nürnberg,, Urteil vom 15.1.2019, 3 U 724/18, K\& R 2019, 200.

278 Abrufbar unter: http://data.consilium.europa.eu/doc/document/ST-13256-2018-I NIT/en/pdf, zuletzt abgerufen am 30.5.2019.

279 Köhler/Bornkamm/Feddersen, UWG, $\mathbb{\$} 7$, Rn. 22. 
Die bloße Erwartung eines Werbetreibenden im Internet, der DisplayWerbung auf Webseiten bucht, oder des Webseitenbetreibers, der DisplayWerbung auf seinen Seiten einbettet, der Internetnutzer werde die konkrete Anzeige nicht wünschen, reicht regelmäßig nicht für eine Unzulässigkeit nach $\$ 7$ Abs. 1 UWG aus. Denn das Gesetz verhindert nicht jede einfache Störung von Marktteilnehmern, sondern nur unzumutbare Belästigungen. Maßstab ist der durchschnittlich empfindliche Adressat der Werbung ${ }^{280}$. Kriterium für die Beurteilung der Unzumutbarkeit sind dabei neben dem subjektiven Empfinden des Durchschnittsadressaten auch die Folgen eines Verbots auf den Wettbewerb, die Allgemeinheit und etwaig interessierte Adressaten. Dabei ist auch zu beachten, ob die Belästigung bezweckt und notwendig oder ungewollter und nur gelegentlicher Reflex ist. Auch spielt eine Rolle, welcher Aufwand für den Adressaten erforderlich ist, sich der Werbung zu entziehen ${ }^{281}$.

Deshalb ist kein Pauschalurteil möglich, wann einzelne Display-Werbeformen (un)zumutbar sind. Anhand der oben dargestellten Werbeformen soll im Fortgang die Grenzlinie gezogen werden, ab wann von einer Unzumutbarkeit auszugehen ist.

\section{(i) Fixierte Anzeigen}

Einfache fixierte Anzeigen auf Webseiten wie Werbebanner, Skyscraper und Rectangles sind für sich betrachtet nicht unzumutbar belästigend. Ein durchschnittlich empfindlicher Internetnutzer wird durch die bloße Einblendung solcher Anzeigen auf Webseiten nicht sonderlich gestört. Dies folgt schon daraus, dass Werbebanner etc. die digitalisierte Form der Anzeigen in Zeitungen und Zeitschriften sind und das Publikum daran seit jeher gewöhnt ist. Der Allgemeinheit ist auch regelmäßig bekannt, dass im Print- wie im Onlinebereich Anzeigen zur Finanzierung genutzt werden $^{282}$. Im Internetbereich kommt dabei noch hinzu, dass die meisten Angebote kostenfrei sind und deshalb der Refinanzierungsgedanke umso ausgeprägter ist.

Auf der anderen Seite sind auch die Interessen der Werbenden und Webseitenbetreiber zu beachten. Hier ist zu beachten, dass die zur Refi-

280 Vgl. BGH, Urteil vom 22.4.2010 - I ZR 29/09, GRUR 2010, 1113, Rn. 15 Grabmalwerbung.

281 Köhler/Bornkamm/Feddersen, UWG, $\mathbb{~ 7 , ~ R n . ~} 20$.

282 Vgl. Solmecke/Kocatepe, Recht im Online-Marketing, S. 404. 
nanzierung dienende Werbung für Webseitenbetreiber von der Pressefreiheit nach Art. 5 Abs. 1 S. 2 GG erfasst wird und damit besonderen Rang hat. Für Werbende gehört Werbung für ihre Unternehmen oder Produkte ebenfalls zu den Kommunikationsfreiheiten aus Art. 5 Abs. 1 GG sowie zur freien Berufsausübung im Sinne von Art. 12 Abs. 1 S. 2 GG $^{283}$. Die nachteiligen Folgen für die Werbenden und Webseitenbetreiber bei der Annahme einer unzumutbaren Belästigung einfacher fixierter Anzeigen übersteigen offensichtlich die Vorteile für Internetnutzer. Auch die Allgemeinheit würde durch etwaige Diversitätsverluste im Internetangebot nachteilig beeinflusst. An Werbung interessierte Nutzer würden zudem eine gewohnte Art der Information über neue Produkte einbüßen.

Es spricht also rein gar nichts dafür, fixierte Werbebanner usw. unter $\$ 7$ Abs. 1 UWG zu fassen. Das Regelbeispiel in $\$ 7$ Abs. 1 S. 2 UWG hilft auch nicht weiter. Denn $\mathbb{\$} 7$ Abs. 1 S. 2 UWG gilt nur für Individualwerbung, nicht aber für Allgemeinwerbung wie Display-Anzeigen im Internet ${ }^{284}$. Deshalb kann auch nicht etwa auf Grundlage des Regelbeispiels die Unzumutbarkeit von Werbeanzeigen gefolgert werden, wenn Internetnutzer, die mit installiertem Werbeblocker im Netz surfen, (technisch) erkennbar keine Werbung wünschen. Auf den Einsatz von Werbeblockern kommt es auf dieser Stufe vielmehr nicht an.

Die Grenze des Einsatzes von fixierten Anzeigen zur Unzumutbarkeit kann allenfalls dort gezogen werden, wo ein Webseitenbetreiber derart viele Werbeplätze einsetzt, dass berechtigte Informationsbedürfnisse des Nutzers nicht mehr befriedigt werden. Dieser Fall ist jedoch schon aus Eigeninteresse von Webseitenbetreibern realitätsfern. Im Übrigen gilt bei jedem Fall von (zu) viel Werbung auf einer Webseite, dass der Nutzer sich durch wenige Klicks der Werbeflut entziehen kann, indem er die Webseite verlässt. Da es nur überaus selten sein wird, dass bestimmte Informationen nur auf einer einzigen Webseite zu finden sind, hat der Internetnutzer regelmäßig auch Ausweichmöglichkeiten.

(ii) Dynamische Anzeigen, Pop-Ups \& Co.

Bei dynamischen Anzeigen, die den Content verschieben oder überlagern wie Pushdown Ads, Banderole Ads, Sidekicks und Sitebars, sowie PopUps, die sich im Fenster selbst oder als neues Browserfenster öffnen, gilt

283 Vgl. di Fabio, MMR-Beilage 2016, 1, 7f.; Kuhlmann, AfP 2016, 318, 319.

284 Köhler/Bornkamm/Feddersen, UWG, \$7, Rn. 33. 


\section{B. Grundlage: Werbung im Internet}

für die Bewertung der Interessen im Grundsatz dasselbe wie bei den fixierten Anzeigen. Das Regelbeispiel aus $\$ 7$ Abs. 1 S. 2 UWG kann nicht gelten, weil es sich um Allgemeinwerbung handelt. Im Rahmen der Generalklausel ist wiederum eine Interessenabwägung nötig. Auch hier können sich Werbetreibende und Webseitenbetreiber auf ihre grundgesetzlichen Positionen berufen. Doch auch der Internetnutzer hat die Verfassung auf seiner Seite, da für ihn die allgemeine Handlungsfreiheit, das Recht auf informationelle Selbstbestimmung und das allgemeine Persönlichkeitsrechts aus Art. 2 Abs. 1 (iVm Art. 1 Abs. 1) GG streitet ${ }^{285}$.

Im Gegensatz zu einfachen fixierten Anzeigen, sind dynamische Anzeigen und Pop-Ups jedoch potentiell geeignet, diese Rechte der Internetnutzer in erheblicher Weise zu tangieren. Denn die Dynamik der Anzeigen ist ein Spezifikum des Internets. In Printmedien sind diese nicht möglich. Am ehesten vergleichbar wären sie mit aufklappbaren Seiten in Zeitschriften. Doch besteht dann der Unterschied, dass der Leser die Seiten selbst aufklappen muss. Bei dynamischen Anzeigen und Pop-Ups im Internet geschieht der Aufklappeffekt automatisch und muss zum Teil aktiv vom Nutzer geschlossen werden. In solchen Fällen stellt sich die Interessenlage anders dar als bei fixierten Bannern. Denn hier können sich Werbende und Webseitenbetreiber nicht darauf berufen, gerade diese Art von Anzeige sei nötig, um die Refinanzierung von Inhalten bzw. die Bewerbung von Produkten sicherzustellen. Dies mag auch mit den unbedenklichen fixierten Anzeigen bewerkstelligt werden. Dynamische Anzeigen dienen der Aufmerksamkeitssteigerung beim an fixierte Werbeanzeigen gewöhnten Nutzer. Im Nebeneffekt sind gerade technisch komplexere Werbeformen für Webseitenbetreiber oder Agenturen interessanter, weil sie mehr Kosten produzieren und teuerer verkautt werden können. Sowohl für den Werbeplatz als auch für die Gestaltung und Programmierung werden höhere Entgelte fällig. Die Folgen einer Bejahung der unzumutbaren Belästigung einer dynamischen Anzeigenform wären für Werbende und Webseitenbetreiber nicht so erheblich wie bei den fixierten Bannern, weil die fixierten Banner als Rückfalloption noch zur Verfügung stünden und Werbung damit grundsätzlich möglich bliebe.

Bei diesen dynamischen Anzeigenformen \& Pop-Ups kommt es also im Rahmen der Ermittlung der Unzumutbarkeit mehr auf die subjektive Sicht des Internetnutzers, denn auf die Interessen der Werbenden an. Der durchschnittliche Adressat von Internetwerbung wird dabei von den sich aufdrängenden Werbeinhalten durchaus gestört. $\mathrm{Ob}$ und wann diese

285 Vgl. di Fabio, MMR-Beilage 2016, 1; Kuhlmann, AfP 2016, 318, 321. 
Störung aber zur Belästigung wird, die gar unzumutbar ist, ist jedoch oft nicht eindeutig. Probleme bereitet schon die Ermittlung des durchschnittlichen Adressaten, weil durchaus viele Nutzer die moderne Internetwerbung schätzen. Eine entsprechende Studie weist mit Blick auf die relativ undifferenzierte Frage nach einer "Störung durch Online Werbung“ zustimmende Raten von 68\% auf ${ }^{286}$. Dies bedeutet aber auch, dass 32\% der Nutzer sich von Online Werbung nicht sonderlich gestört fühlen. Dieses Ergebnis würde im Einzelnen je nach zu begutachtender Anzeigenform mit Sicherheit variieren. In diesem Sinne zeigt eine nach Werbeformen differenzierende Studie des Interactive Advertising Bureau („IAB“, ein internationaler Branchenverband der Werbewirtschaft) das erhebliche Störungspotential der sich in den Vordergrund drängenden Werbung. Bei der Studie mit US-Bürgern wurden die hier maßgeblichen dynamischen Anzeigenformen auf einer Skala von 1 (nicht störend) bis 5 (extrem störend) regelmäßig zwischen 4 und 5 bewertet ${ }^{287}$.

Dies sind nur zwei Beispiele aus einer enormen Zahl von Studien über ein kompliziertes Thema, die neben der hier behandelten juristischen Tragweite auch für Sozialwissenschaften und die Betriebswirtschaftslehre wichtige Ergebnisse liefern. Da die Fragen solcher Studien aber oft generell gehalten sind und je nach Formulierung andere Antworten heraufbeschwören können, lassen sich durch Studien nur bedingt verallgemeinerungsfähige Wahrheiten extrahieren. Schlussendlich wird es deshalb im Bereich des Rechts am Ende des Tages immer auf die Ansicht der Richter ankommen, die einen Streitfall zu entscheiden haben.

Im Weiteren soll deshalb die Frage der Unzumutbarkeit auf Grundlage der ergangenen Rechtsprechung und der einschlägigen Meinungen im Schriftum untersucht werden.

286 So eine Studie des Softwareherstellers Adobe aus Oktober 2012, http://www.ado be.com/aboutadobe/pressroom/pdfs/Adobe_State_of_Online_Advertising.pdf, zuletzt abgerufen am: 30.5.2019.

287 https:/www.iab.com/wp-content/uploads/2016/07/IAB-Ad-Blocking-2016-Who -Blocks-Ads-Why-and-How-to-Win-Them-Back.pdf, Seite 25, zuletzt abgerufen am: 30.5.2019. 


\section{(1) Ergangene Rechtsprechung}

Veröffentlichte Rechtsprechung im Kontext von Pop-Ups und dynamischen Werbeformen ist sehr rar. Nur drei Entscheidungen beziehen ausdrücklich Stellung zu solch dynamischer Internetwerbung.

In einem eindeutigen Fall einer unzumutbaren Belästigung ging es um „Exit Pop-Ups“. Dies ist eine Ausprägung des Pop-Ups, das bei Schließen eines bereits geöffneten Pop-Up-Fensters mindestens ein neues PopUp-Fenster öffnet. In einem solchen Fall hat das LG Düsseldorf noch unter Geltung des UWG in der Fassung vor der Reform von 2004 einen Verstoß gegen die guten Sitten nach $\$ 1$ UWG a.F. erkannt, weil der Nutzer gezwungen wird, gegen seinen Willen die Werbung zur Kenntnis zu nehmen. Dies stelle eine nicht hinnehmbare Belästigung des Nutzers dar ${ }^{288}$. Im konkreten Fall kam erschwerend hinzu, dass das Exit-Pop-Up im Kontext pornografischer Internetseiten und Werbung für solche eingesetzt wurde, beim Schließen des ersten Fensters sechs bis acht neue Fenster geöffnet wurden und dieser Vorgang nur durch das Beenden des BrowserProgramms gestoppt werden konnte.

Ein solcher Fall dürfte nach aktueller Gesetzesfassung - auch ohne die erschwerenden Sachverhaltsumstände und bei Öffnen nur eines einzigen neuen Fensters - nicht nur die allgemeine Generalklausel des $₫ 7$ Abs. 1 UWG erfüllen. Sondern er wird auch ohne weiteres die Anwendung des spezielleren Per-se-Verbots von $\$ 7$ Abs. 2 Nr. 1 UWG begründen, weil durch das Schließen des Pop-Up-Fensters erkennbar wird, dass der Nutzer diese Werbung nicht wünscht und jede weitere Ansprache das Merkmal der Hartnäckigkeit erfüllt. Exit Pop-Ups sind folgerichtig aus dem Internet verschwunden.

Die zweite Entscheidung betrifft die dynamische Werbeform der Banderole Ad. Das Kammergericht hatte den Fall zu entscheiden, in dem eine sich von rechts nach links über den Inhalt schiebende Banderole auf einer Internetseite mit kindlicher Zielgruppe eingesetzt worden ist. $\mathrm{Ob}$ die Banderole automatisch wieder aufrollte - und wenn ja - nach welcher Zeit, wurde dabei nicht von der beweisbelasteten klägerischen Partei dargelegt. Das Gericht ging deshalb nach Beweislastgrundsätzen davon aus, dass eine Minimierung der Anzeige „alsbald“ erfolgte. Auf dieser Tatsachengrundlage lehnte das KG - wie zuvor auch das Landgericht Berlin eine unzumutbare Belästigung $\mathrm{ab}^{289}$. Zur Begründung führte das Gericht

288 LG Düsseldorf, Urteil vom 26.3.2003 - 2a O 186/02, MMR 2003, 486.

289 KG, Urteil vom 18.10.2013 - 5 U 138/12, MMR 2014, 44. 
aus, dass zwar eine Belästigung vorliege, aber diese nicht unzumutbar sei. Die Belästigung folge daraus, dass dem Internetnutzer die geschäftliche Handlung der Werbung aufgedrängt werde und er dies als störend empfinde. Unzumutbarkeit sei aber erst dann gegeben, wenn ein großer Teil der durchschnittlichen Verbraucher die Werbung als unerträglich empfinde. Dies war hier nicht der Fall, weil davon auszugehen war, dass die Anzeige innerhalb kurzer Zeit weggeklickt werden konnte bzw. alsbald von selbst verschwand. Als erheblichen Umstand sah das Gericht auch an, dass ein Internetnutzer eine Webseite eigeninitiativ und zum Freizeitvergnügen aufsucht. Dass die Werbung im Endeffekt die aufgesuchten Inhalte finanziere und sie nur deshalb kostenfrei zur Verfügung gestellt werden, zog das Gericht ebenfalls zur Verneinung der Unzumutbarkeit heran. Zuletzt konnte auch die fallspezifische Besonderheit eines kindlichen Publikums nichts an dieser Entscheidung ändern.

In einem dritten Urteil positionierte sich das OLG Nürnberg eindeutig, obwohl es gar nicht über eine dynamische Werbeform zu entscheiden hatte. In einem Fall, in welchem das Gericht über Display-Werbung in einem E-Mail-Postfach zu befinden hatte, äußerte sich der Senat im Stile eines obiter dictums wie folgt: „Dass Werbemittel, die beim Surfen auf dem Bildschirm erscheinen, eine unzumutbare Belästigung darstellen, ist die Ausnabme. Grundsätzlich sind Werbemittel als Informationsquelle und Mittel zur Finanzierung der besuchten Website hinzunehmen. Insbesondere Pop-Ups, Layer-Ads, Video-Ads und Interstitials sind dem Nutzer zumutbar. Dies gilt jedenfalls dann, wenn sich die Werbemittel ohne Weiteres sofort oder nach einer kurzen Zeit, die der Dauer eines Werbespots im Fernsehen entsprechen kann, wegklicken lassen.

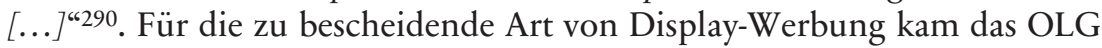
Nürnberg zum Ergebnis, dass keine unzumutbare Belästigung vorliege.

Im Streitfall wird ein Einzelrichter oder ein Kollegialgericht wegen Angehörigkeit zum angesprochenen Adressatenkreis regelmäßig nach eigenem Störungsempfinden entscheiden. Wünschenswert wäre allerdings - trotz der vorgehend angemahnten Vorsicht gegenüber Studien - bei geeigneten Sachverhalten eine gerichtlich angeordnete Beweiserhebung in Form einer demoskopischen Untersuchung, um eine repräsentative Einschätzung für den konkreten Streitgegenstand zu erlangen. Dies gilt umso mehr, wenn man mit dem Kammergericht für die Unzumutbarkeit

290 OLG Nürnberg, Urteil vom 15.1.2019, 3 U 724/18, K\& R 2019, 200 (juris, Rz. 113). Im Revisionsverfahren hat der BGH den EuGH nach Art. 267 AEUV angerufen, siehe Beschluss vom 30.1.2020 - I ZR 25/19, GRUR 2020, 420 Inbox-Werbung. 
fordern möchte, dass ein großer Teil der durchschnittlichen Verbraucher die Werbung als unerträglich empfinde. Ob wirklich ein großer Teil der Internetnutzer wie die Richter empfindet, kann nämlich nicht als reine Rechtsfrage angesehen werden, sondern hat tatsächliche Grundlagen, die durchaus einer sachverständige Aufklärung zugängig ist.

\section{(2) Meinungsstand in der Literatur}

Das Kammergericht stellte in seinem Urteil den Meinungsstand in der lauterkeitsrechtlichen Literatur zur Unzumutbarkeit von dynamischer Internetwerbung bzw. Pop-Up-Werbung dar und schloss sich der „herrschenden Meinung“ an. Nach dieser Ansicht können Werbeanzeigen im Internet, die nach kurzer Zeit weggeklickt oder sich automatisch verkleinern bzw. schließen, keine Unzumutbarkeit begründen ${ }^{291}$. Im Wesentlichen berufen sich die Anhänger dieser Ansicht auf die oben bereits dargestellten Argumente aus dem Urteil des Kammergerichts. Ergänzend wird vorgetragen, dass der Internetnutzer keinen Anspruch auf die kostenfreie Leistung habe $^{292}$ und er zudem eine Ausweichmöglichkeit habe, indem er den Besuch der Webseite beendet ${ }^{293}$.

Dieser „herrschenden Meinung“ stehen indes auch einige widerstreitende Stimmen entgegen. Vor allem Mankowski hat sich der Frage der unzumutbaren Belästigung durch Pop-Ups und ähnliche Internetwerbeformen ausführlich gewidmet ${ }^{294}$. Er kritisiert die vorstehende Entscheidung des Kammergerichts und die Stimmen aus der „herrschenden Meinung“ dezidiert. Im Gegensatz zu den genannten Stimmen hält er nicht nur eine

291 Das KG verwies auf Köhler/Bornkamm/Feddersen, UWG, $\$ 7$, Rn. 93; Ohly/Sosnitza, UWG, $\mathbb{7}$, Rn. 95; Schöler, in: Harte-Bavendamm/Henning-Bodewig, UWG, $\mathbb{7}$ 7, Rn. 131; Schulte-Beckhausen, in: Gloy/Loschelder/Erdmann, $\mathbb{6 2}$, Rn. 50; Koch, in: jurisPK-UWG, $\mathbb{S} 7, \mathrm{Rn} .123$; Bornkamm/Seichter, CR 2005, 747, 752f.Im Übrigen gehören zu diesem „Lager“ Czernik, MMR 2014, 45; Leupold/Bräutigam/Pfeiffer, WRP 2000, 575, 591; Boemke, in: Hoeren/Sieber/Holznagel, Multimedia-Recht, Teil 11, Rn. 80; Micklitz/Schirmbacher, in: Spindler/Schuster, $\mathbb{} 7$ UWG, Rn. 19ff.; Leible, in: MüKo Lauterkeitsrecht, $\mathbb{\$} 7$, Rn. 280; Bettinger/Leistner, Werbung und Vertrieb im Internet, Teil $1 \mathrm{~A}$, Rn. 44; Leible, in FS Köhler, 403, 408f.; Härting, Internetrecht, Rn. 2146; jüngst: Schirmbacher, K\&R 2019, 229, 231; Steinmetz, Apps im Lauterkeitsrecht, S. $266 f f .$.

292 Czernik, MMR 2014, 45.

293 Bornkamm/Seichter, CR 2005, 747, 752f..

294 Mankowski, in: Fezer/Büscher/Obergfell, UWG, S 12, Rn. 149ff.. 
Belästigung, sondern auch eine Unzumutbarkeit eben dieser für gegeben. Speziell für Pop-Ups folge dies schon daraus, dass verdeckt wird, was der Internetnutzer eigentlich sehen wolle. Dynamische Werbeformen, die den Content nicht verdecken, sondern bloß verschieben, verhindern ebenfalls zeitweise den Blick auf die Gesamtheit der eigentlich gewünschten Information oder Unterhaltung. Dies bringe unvermeidlichen Zeitverlust für den Internetnutzer mit sich.

In der Folge versucht Mankowski die Differenzierungskriterien der herrschenden Meinung zu entkräften. So soll die Größe einer Anzeige kein entscheidendes Kriterium sein, weil auch kleine Pop-Ups Informationen verdecken bzw. das Wegklicken Zeit in Anspruch nimmt. Je größer die Anzeige aber sei, desto höher sei auch das Belästigungspotential durch die erhöhte Verdeckung von Information. Die Möglichkeit des Blockens durch Pop-up-Blocker oder Werbeblocker sei hier schon deswegen unbeachtlich, weil es nicht Obliegenheit des Opfers der Belästigung sei, einen Angriff abzuwehren, sondern Sache des Angreifers, den Angriff zu unterlassen. Auch die Dauer der Einblendung sei kein sachgerechtes Kriterium zur Ermittlung der Unzumutbarkeit. Jede ungewollt vertane Zeit sei aber beachtlich, weil der Nutzer seine Zeit tatsächlich anderweitig investieren möchte als in Werbewahrnehmung. Reguläre Möglichkeiten zur Vermeidung der Werbung - wie etwa das Umschalten beim Fernsehen - stünden im Internet nicht zur Verfügung. Den von der „herrschenden Meinung“ angewandten Zeitfaktor kritisiert Mankowski insbesondere vor dem Hintergrund der Beweislastverteilung. Dies führe dazu, dass der Belästigte in der Pflicht sei, die Überschreitung etwaiger Zeitgrenzen nachzuweisen und er die Nachteile fehlender Beweismöglichkeiten zu tragen habe - wie im Fall des Kammergerichts. Im Zusammenhang mit dem Schließen von Pop-Ups oder dem Verkleinern dynamischer Anzeigen weist er auf die Vielzahl verschiedener Buttons hin, die teils an verschiedenen Stellen zu finden sind. Teils muss der Internetnutzer erst nach diesem Button suchen, was ebenfalls Zeit in Anspruch nehmen kann.

Eine Anknüpfung an den Inhalt der Webseite danach, ob der Inhalt essentielle Informationen enthalte oder nur bloß der Unterhaltung diene, sei ebenfalls nicht überzeugend, weil dies nichts am Unwert der Belästigung ändere und der Nutzer hier wie dort eigeninitiativ die Webseite aufsuche.

Besonders kritisiert Mankowski das Refinanzierungsargument. Unbestritten lässt er die Tatsache der Refinanzierungsfunktion von dynamischen Werbemitteln, weil fixierte Anzeigen vergleichsweise geringeren Gewinn generieren. Dass aber ein Internetnutzer aggressive Werbung dulden müsse, weil sonst das angesteuerte Angebot in Zukunft nur noch einge- 
schränkt oder gar nicht mehr zur Verfügung stehen wird, sei eine falsche Verlagerung des Profitabilitätsrisikos von Internetangeboten. Denn Refinanzierung und etwaiger Gewinn seien allein Sache der Werbenden bzw. Webseitenbetreiber. Das Refinanzierungsargument führe sich zudem selbst ad absurdum, wenn es beinhalte, dass der Nutzer, der sich belästigt fühle, die Webseite in Zukunft nicht aufsuchen müsse. Die unzumutbare Belästigung mit dem freiwilligen Besuch der Webseite zu verknüpfen, führe im Endeffekt dazu, dass Werbung aggressiver werde, Nutzer ausbleiben und dann die Attraktivität der Webseite als Werbeplatz schwinde. In diesem Zusammenhang sei auch irrelevant, dass der Internetnutzer keinen Anspruch auf die kostenlose Information oder Unterhaltung habe. Denn so soll das kostenfreie Zurverfügungstellen von Inhalten noch nicht das Recht geben, die Nutzer dieser Inhalte nach eigenem Gutdünken zu belästigen. Die Möglichkeit, das gesamte Angebot zurückzuziehen, könne nicht zu dem Erst-recht-Schluss führen, nach welchem die belästigende Werbung zumutbar und mithin erlaubt sein müsse. Denn das Beenden des Angebots der kostenfreien Inhalte stelle selbst keine Belästigung der Internetnutzer dar. Sie könne deshalb rechtlich auch nicht als höhere Eskalationsstufe zur aggressiven Werbung angesehen werden.

Zuletzt hält Mankowski auch eine Differenzierung nach Inhalt der Werbeanzeige und nach Zeitpunkt des Öffnens der dynamischen Werbeform für nicht gangbar. Er kommt somit konsequenterweise zur Prüfung einer möglichen rechtfertigenden Einwilligung des Internetnutzers. Insoweit vertritt er einen vermittelnden Ansatz. Eine Einwilligung für Werbung wie fixierte Anzeigen bestehe vor dem Hintergrund der Kenntnis der Refinanzierungsbedürfnisse. Nicht aber für aggressive, dynamische Werbeformen, die aktiver Handlung bedürfen, um sie zu beenden oder zu minimieren. Hier komme hinzu, dass der Nutzer vor Besuch der Webseite oder vor Öffnen der dynamischen Werbeform schon gar nicht genau wisse, was auf ihn zukomme. Es mangele insoweit schon an der notwendigen Sachkenntnis zur Einwilligung.

Eine weitere eingehende Auseinandersetzung mit der Problematik, die im Ergebnis für eine unzumutbare Belästigung argumentiert, stammt von Burmeister ${ }^{295}$ aus dem Jahr 2006. Er schlägt vor, Pop-Ups im Grundsatz als unzumutbare Belästigung anzusehen, weil das Interesse des Einzelnen bestimmen zu können, ob und inwieweit er sich mit Werbung auseinandersetzen will oder nicht, beeinträchtigt werde. Zudem werde die Werbung auf Kosten der Internetnutzer betrieben. Folglich werden die von

295 Burmeister, Belästigung als Wettbewerbsverstoß, S. 97ff.. 
\$7 UWG geschützte Individualsphäre und die ebenfalls geschützten Ressourcen der Internetnutzer beeinträchtigt. Allein Bagatellfällen solle die Unzumutbarkeit im Einzelfall abgesprochen werden können.

Burmeister stellt dabei vorwiegend auf eine Summenwirkung mehrerer Pop-Up-Fenster während einer „Internet-Session“ ab, da ein Internetnutzer auf eine Vielzahl von Pop-Ups von diversen Webseitenbetreibern treffen wird. Diese Summenwirkung sei hier ein beachtliches Argument, da es auch in anderen Fällen des $\$ 7$ UWG wie der E-Mail-Werbung ohne vorheriges Einverständnis und der gezielten Werbeansprache von Passanten in der Öffentlichkeit vom BGH genutzt wurde. Hier wie dort werde die Unzumutbarkeit gerade aus der Gefahr hergeleitet, dass sich zahlreiche Anbieter dieser Werbemethode bedienen würden. Eine einzelne Pop-Up-Werbung mag noch wenig belästigend sein, eine ständige Konfrontation hingegen überschreite die Zumutbarkeitsschwelle. Im Zusammenhang mit der Existenz von Pop-Up-Blockern argumentiert Burmeister, dass die Existenz solcher Blocker für die Frage der Unzumutbarkeit der Werbeform unbeachtlich sei. Denn diese Blocker könnten einerseits umgangen werden und andererseits führten sie beim Nutzer teilweise zu Einschränkungen bei regulären Internetfunktionen, bei denen der Browser ein zusätzliches Fenster öffnen muss. Daraus folge auch beim Einsatz von Blockerprogrammen ein zeitlicher Aufwand bzw. ein Störpotential. Im Übrigen sei auch die bewusste Umgehung eines Blockers kein geeignetes Differenzierungskriterium, da zum einen keine Pflicht der Nutzer zum Einsatz bestehe und zum anderen dem Nutzer der Nachweis einer Umgehung kaum möglich sein werde.

Ergänzend stellt Burmeister auf die Beeinträchtigung der Ressourcen der Nutzer ab, namentlich Internetgebühren und Rechnerkapazitäten. Zuletzt stellt er heraus, dass Internetnutzer sich keineswegs freiwillig Pop-Up-Werbung aussetzen, weil diese gerade keine unmittelbare Verknüpfung zur Webseite wie klassische Anzeigen aufweisen. Nutzer hätten keine echte Wahlmöglichkeit, da im Falle flächendeckender Pop-Up-Werbung die Nutzung des Internets insgesamt eingestellt werden müsste.

Der Ansicht von Mankowski und Burmeister trat im Schriftum ohne weitere Vertiefung der Argumentation noch Menebröcker hinzu ${ }^{296}$. Diese drei Stimmen stellen demnach den Gegenpol zur vom KG identifizierten „herrschenden Meinung“ dar.

296 Menebröcker, in: Götting/Nordemann, UWG, \$7, Rn. 181ff. 


\section{(3) Stellungnahme}

Beide Seiten können sich auf gewichtige Argumente stützen. Im Ergebnis verbietet sich aber eine pauschale Lösung für dynamische Werbeformen und Pop-Ups wie sie vor allem Mankowski postuliert. Die denkbaren Ausgestaltungen dieser Werbeformen sind zu mannigfaltig, um sie generell als unzumutbare Belästigung zu qualifizieren. Gleichfalls können diese aggressiven Werbeformen nicht per se als erlaubte, mithin zumutbare Belästigungen oder gar als nicht belästigend angesehen werden. Eine Entscheidung kann, wie bei $\$ 7$ Abs. 1 UWG üblich, nur auf Grundlage des konkreten Einzelfalls unter Berücksichtigung aller Sachverhaltsumstände getroffen werden. Anstatt einer der polarisierenden Meinungen den Vorzug zu geben, ist es zweckmäßiger klare Grenzen abzustecken, wann eine dynamische Werbeform zumutbar ist bzw. wann sie die Schwelle zur Unzumutbarkeit überschreitet. Ein dabei nicht zu vermeidender Graubereich ist ebenfalls zu identifizieren. Wichtig ist vor allem die Differenzierung der verschiedenen, sich in geringfügigen aber erheblichen Umständen unterscheidenden Werbeformen.

(a) Anzeigen, die aktiv geschlossen werden müssen

Auf erster Stufe ist zu differenzieren, ob sich die dynamische Anzeige oder das Pop-Up automatisch schließt oder aber ein aktives Schließen durch den Nutzer notwendig ist. Im Grundsatz kritisch zu hinterfragen sind Werbeanzeigen, die eine aktive Handlung des Internetnutzers erfordern. Dies betrifft also klassische Pop-Ups, die sich in neuen Fenstern öffnen, oder neuartigere Pop-Ups, die sich innerhalb des Fensters über dem Content öffnen, sowie dynamische Anzeigen, die aufklappen oder sonst expandieren, ohne sich wieder automatisch zu minimieren. $\mathrm{Zu}$ solchen Anzeigenformen verhält sich die oben dargestellte Rechtsprechung nicht. Im Fall des LG Düsseldorf ${ }^{297}$ wurde die Unzumutbarkeit (bzw. Sittenwidrigkeit) der dem Schließen eines Fensters nachfolgenden Pop-Ups festgestellt. Eine Aussage zur Zulässigkeit des ersten Pop-Ups ist damit jedoch nicht verbunden. Das Kammergericht hat für seine Zwecke aus Beweislastgründen ein automatisches Schließen angenommen.

Die „herrschende Meinung" stellt in den Fällen des obligatorischen aktiven Schließens durch den Nutzer darauf ab, ob die Anzeige nach

297 LG Düsseldorf, Urteil vom 26.3.2003 - 2a O 186/02, MMR 2003, 486. 
kurzer Zeit weggeklickt werden kann. Erfahrungsgemäß ist dies bei PopUps in der Vielzahl der Fälle von der ersten Sekunde an möglich. Auch dynamische Anzeigen enthalten oft von Beginn an eine Schaltfläche zum Minimieren. Nach allen Ansichten ist deshalb ein Pop-Up oder eine dynamische Anzeige, das bzw. die sich nicht nach kurzer Zeit schließen oder minimieren lässt, eine unzumutbare Belästigung. Als Folgeproblem schließt sich innerhalb der "herrschenden Meinung“ dann jedoch die Frage an, welche Dauer noch als kurz angesehen werden kann. In Abgrenzung zu Interstitials, die weiter unten näher beleuchtet werden und sich dadurch auszeichnen, dass sie eine gewollte Unterbrechung des Surfens bewerkstelligen, muss bei Pop-Ups oder dynamischen Anzeigen, die lediglich während des Surfens einen Teil des Contents verdecken, ein strengerer Maßstab angelegt werden. Zur Wahrnehmung einer sich in den Vordergrund drängenden Anzeige sowie der Erfassung der maßgeblichen Werbebotschaft werden regelmäßig wenige Sekunden ausreichen. Sollte der Button zum Schließen oder Minimieren nicht innerhalb von drei Sekunden zur Verfügung stehen, ist eine unzumutbare Belästigung anzunehmen. Dabei ändert es auch nichts, wenn die zu beurteilende Anzeige multimedial ausgestattet ist und deshalb die Werbebotschaft längere Zeit benötigt, um wahrgenommen zu werden. Dieses Risiko geht der Werbende selbst durch die Wahl des konkreten Werbeinhalts ein.

Umstritten ist hingegen, ob Werbeformen, die zwar aggressiv in den Vordergrund preschen und eine Aktivität des Nutzers erfordern, aber sofort ${ }^{298}$ durch einen Klick geschlossen oder minimiert werden können, eine unzumutbare Belästigung nach $\$ 7$ Abs. 1 UWG begründen können. Im Ergebnis wird auf Grundlage des grundsätzlich marktliberalen UW$\mathrm{G}^{299}$ keine absolute und generelle Unzulässigkeit solcher Werbeformen vertretbar sein. Es sind aber durchaus Fälle denkbar, die trotz sofortiger Schließfunktion den Bereich der Zumutbarkeit überschreiten. Ein solcher Fall kommt etwa bei dem exzessiven Einsatz von dynamischer Werbung auf ein und demselben Webportal in Betracht. Insoweit wird hier eine vermittelnde Ansicht vorgeschlagen, die sich auf die nachfolgenden Differenzierungskriterien stützt.

298 D.h. in Übereinstimmung mit der zuvor genannten „kurzen Dauer“ zwischen 0,1 und 3 Sekunden.

299 Vgl. die Erwägungen zum Wettbewerbsleitbild bei Podszun, in: Harte-Bavendamm/Henning-Bodewig, UWG, $\mathbb{1} 1$, Rn. 76ff.. 
(aa) Gültige Differenzierungskriterien

Gültige Kriterien bei der Beurteilung der Zumutbarkeit von Pop-Up Werbung und dynamischen Werbeformen sind das Zeitmoment, zu einem gewissen Grad der Refinanzierungsgedanke und die Summenwirkung dieser Werbeformen.

Mit Zeitmoment ist jeder durch die Anzeige der Werbeformen im Gerät des Nutzers einhergehende Zeitverlust gemeint. Der „herrschenden Meinung" in Schriftum und Rechtsprechung ist insoweit zuzustimmen, dass die Schließmöglichkeit nach kurzer Zeit das am nächsten liegende Kriterium ist, um eine Belästigung des Nutzers zu kategorisieren. Dies folgt schon daraus, dass Werbung in jedem Medium die Aufmerksamkeit des Adressaten erregt, was mit einem gewissen Zeitaufwand einhergeht - sei es nur der Bruchteil einer Sekunde wie bei einer nur überflogenen Zeitungsanzeige, sei es eine Dauer von mehreren Minuten wie bei TVWerbeblöcken. Anknüpfungspunkt des Zeitmoments ist dabei die Dauer zwischen Beginn der erzwungenen Wahrnehmung der Werbung und erstmaliger Möglichkeit, sich der Werbung zu entziehen. Bei einer Zeitungsanzeige oder einer fixierten Online-Anzeige genügt das Wegschauen oder Fokussieren auf andere Elemente der betrachteten Seite, was nur eine verschwindend kurze Zeit dauert. Beim Extremfall in Printmedien, bei dem eine gesamte Seite oder Doppelseite von Werbung eingenommen ist, bedarf es des Umblätterns, also einer aktiven Handlung, die eine gewisse Zeit beansprucht. Gleichzeitig ist dieser Zeitraum noch sehr gering und kann in Sekundenschnelle bewerkstelligt werden. Es ist keine Stimme ersichtlich, die vertreten würde, eine solche Werbung sei eine unzumutbare Belästigung. Ähnlich stellt sich dies bei TV- oder Radiowerbung dar, der sich der Adressat durch einen Klick auf die Fernbedienung oder das Gerät mit Leichtigkeit und schnell entziehen kann, wenngleich auch dies eine Aktivität fordert. Trotz der gravierenden technischen Unterschiede der Medien passt der aktive Klick auf einen Schließbutton in diese medienevolutionäre Reihe, da er in Sekundenschnelle möglich ist und die Werbung aus der Wahrnehmung verbannt. Rechtlich bedeutsam ist im Rahmen der Bewertung des Zeitmoments, ob der Zeitverlust durch den Werbenden maßgeblich beherrscht wird oder aber der Nutzer die Hoheit über die Dauer dieses Zeitverlustes behält. Im letzteren Fall liegt eine unzumutbare Belästigung fern. Wird dem Adressaten aber die Freiheit zum jederzeitigen Schließen bewusst genommen, wird man von einer unzumutbaren Belästigung ausgehen müssen. 
Wenn Mankowski jede Art von Zeitverlust für den Nutzer für maßgeblich hält und deshalb das Aufscheinen von Pop-Ups bereits für eine unzumutbare Belästigung ausreichen lässt ${ }^{300}$, kann dies nicht überzeugen. Selbstverständlich möchte der Nutzer seine Zeit anders nutzen, als sie mit dem Betrachten von ihn nicht interessierender Werbung zu verschwenden. Gleichwohl ist Werbung fest verankerter Bestandteil der Medienlandschaft und als solcher auch durchaus akzeptiert. Deshalb ist die Möglichkeit, sich der Werbung schnell und effektiv zu entziehen, ein wichtiger Aspekt. Diese Möglichkeit stellt den grundsätzlichen Interessenausgleich zwischen Werbewirtschaft und Nutzerinteressen dar. Dadurch behält der Nutzer jederzeit die Hoheit über seine Werbewahrnehmung. Dass ein Pop-Up oder eine expandierende Anzeige das verdecke, was der Nutzer an sich sehen möchte, ist ebenfalls kein Umstand, der eine Unzumutbarkeit zu tragen vermag. Zwar ist bei diesem Gedanken keine grundlegende Analogie zu Printmedien und Rundfunk möglich, weil diese beiden Mediengattungen durch eine gewisse Linearität gekennzeichnet sind, die eine Überlappung meist ausschließen. Vergleichbar sind aber in TV-Programme eingeblendete Werbeelemente. Solche Werbeformen können nach dem Rundfunkstaatsvertrag ${ }^{301}$ sowohl die Teilbelegung des ausgestrahlten Bildes mit Werbung gemäß $\$ 7$ Abs. 4 als auch die Einfügung virtueller Werbung in Sendungen gemäß $\$ 7$ Abs. 6 sein. Beide Formen sind unter Wahrung der Trennung und Werbekennzeichnung (so in $\$ 7$ Abs. 4 RfStV) bzw. unter dem Vorbehalt des vorherigen Hinweises und der sonst sowieso schon anderweitig bestehenden Werbung am Übertragungsort (so in $\$ 7$ Abs. 6 $\mathrm{RfStV}$ ) erlaubt. Dies zeigt, dass auch das Verdecken gewisser Inhalte dem deutschen Werberecht nicht per se fremd ist. Hier wie dort möchte der Adressat vor allem die Sendung möglichst störungsfrei genießen. Während aber bei paralleler TV-Werbung weitere Voraussetzungen zur Zulässigkeit nötig sind, ist dies bei Pop-Ups und expandierenden Werbeformen im Internet nicht nötig. Grund ist, dass im Internet der Nutzer durch einen Klick die Werbung ausblenden kann. Beim Fernsehen ist dies nicht möglich. Wiederum zeigt sich, dass das Vorhandensein eines Schließbuttons und zwar von Beginn an - unerlässliche Voraussetzung für die Zulässigkeit von Pop-Ups und expandierenden Ads ist.

Verbreitet wird das Zeitmoment jedoch dann als Kriterium für eine Unzumutbarkeit vorgebracht, wenn besonders lange Ladezeiten mit dem

300 Mankowski, in: Fezer/Büscher/Obergfell, UWG, S 12, Rn. 149ff..

301 Staatsvertrag für Rundfunk und Telemedien vom 31.8.1991, zuletzt geändert durch den 20. Rundfunkänderungsstaatsvertrag vom 08. bis 16.12.2016. 
Pop-Up oder der dynamischen Werbeform einhergehen ${ }^{302}$. Unter dem Aspekt des Zeitaufwandes kann dies allerdings nur Bedeutung erlangen, wenn die Möglichkeit zum Schließen oder Minimieren an das vollständige Laden der Anzeige gekoppelt ist. Dies betrifft also nicht den Fall, wenn die Anzeige in einem neuen Fenster geöffnet wird, da dieses Fenster in aller Regel durch die Betriebssystemfunktionalität auch ohne vollständiges Laden der erforderlichen Daten geschlossen werden kann. Wird die Anzeige dynamisch innerhalb des Fensters geöffnet, ergeben sich keine Besonderheiten zum oben Dargestellten, wenn der Schließbutton sofort zur Verfügung steht. In beiden Fällen kann der Nutzer sich sofort der den Content verdeckenden Anzeige durch einen Klick entledigen. Nur wenn der Schließbutton erst bei vollständigem Laden der Anzeige zur Verfügung steht, etwa wenn der Schließbutton den Schlusspunkt des Ladevorgangs darstellt, kann die Ladezeit Bedeutung erlangen. Problematisch ist in diesem Fall aber, dass Ladezeit eine höchst individuelle und von einigen Parametern abhängige Variable ist. Die Ladezeiten hängen vor allem von der Internetverbindung und der Hardware beim Nutzer ab. Deshalb nimmt der Werbende, der die Möglichkeit zum Schließen erst mit vollständiger Ladung der Daten eröffnet, mutwillig in Kauf, dass das Anzeigen von Werbung bei manchen Nutzern eine Dauer von mehreren Sekunden in Anspruch nehmen wird. Damit entzieht er diesem Nutzer die Hoheit über sein Surfverhalten im oben dargestellten Sinne. Eine solche Ausprägung überschreitet deshalb die Grenze zur Unzumutbarkeit. Um Folgeprobleme wie die Bestimmung maßgeblicher Datenmengen oder der Quantität möglicherweise betroffener Internetnutzer zu vermeiden, sind Anzeigen mit Schließmöglichkeit erst nach vollständigem Laden der Daten generell unzulässig, selbst wenn bei einer Vielzahl der Nutzer der Button wegen optimaler Bedingungen sofort angezeigt wird.

Ergänzend sind auch das Refinanzierungsinteresse der Webseitenbetreiber und das Werbeinteresse von Unternehmen heranzuziehen. Diese Interessen sind aber bei aggressiven Werbeformen wie Pop-Ups oder expandierenden Anzeigen nur in vermindertem Maße zu bewerten, weil den Werbenden eine weniger aggressive und zugleich zweifelsfrei zulässige Alternative in Form der klassischen Anzeigen zur Verfügung steht. Allein dieser Umstand kann aber nicht dazu führen, dass Webseitenbetreiber und Werbende nicht mehr ihre grundgesetzlich geschützten Interessen

302 Vgl. Bettinger/Leistner, Werbung und Vertrieb im Internet, Teil 1 A, Rn. 44; Schöler, in: Harte-Bavendamm/Henning-Bodewig, UWG, $\mathbb{7}$, Rn. 131; Ohly/Sosnitza, UWG, \$7, Rn. 95. 
auf möglichst hohe Werbeumsätze und hohe Werbereichweiten verfolgen dürften. Die Werbenden können sich in ihrem Interesse auf Art. 5 und 12 GG stützen. Mangels gesetzlicher Einschränkung ist ein gerechter Ausgleich mit den Individualinteressen der Nutzer aus Art. 2 Abs. 1 GG zu erzielen. Dieser Ausgleich wäre nicht gerecht, wenn den Werbenden absolut die Möglichkeit zum Einsatz von Pop-Ups und dynamischen, expandierenden Werbeformen verwehrt würde. Dies gilt umso mehr vor dem Hintergrund, dass die hier betrachteten Werbeformen erheblich höhere Reichweiten und Folgetransaktionen erreichen ${ }^{303}$.

Besonders virulent wird die Frage der Refinanzierung bei aufwändig gestalteten und dabei kostenfreien Angeboten im Internet. Gerade in diesem Zusammenhang wird teilweise vertreten ${ }^{304}$, dass der Nutzer durch die Duldung von Werbung, die zu Werbeeinnahmen beim Webseitenbetreiber führt, das kostenlose Angebot mittelbar finanziere. Dem zufolge seien die Angebote im Internet zwar kostenfrei, aber nicht umsonst. Dies wird sogar soweit ausgedehnt, dass aufwändigere Werbung zu höheren Einnahmen, ergo zu aufwändigeren Angeboten führe ${ }^{305}$. Dem tritt wiederum Mankowski vehement entgegen, wobei ihm teilweise Recht zu geben ist. Zutreffend verweist er darauf, dass es nicht Sache des Nutzers sein kann, wie ein Unternehmen sein Angebot refinanziert. Ob der Webseitenbetreiber als Unternehmer seine „Ware“ kostenlos zur Verfügung stellt oder ein Entgelt verlangt, ist allein seiner Sphäre zuzuordnen. Mit diesem Sphärenmodell lässt sich auch das teilweise erhobene Argument entkräften, Webseitenbetreiber könnten bei der vorherrschenden „Umsonst-Kultur“ im Internet (vor allem in Deutschland) de facto kein Entgelt fordern, weil kaum Nutzer bereit wären, eine monetäre Gegenleistung zu zahlen ${ }^{306}$. Auch dies ist allein Sache des Unternehmers. Ob ein Absatzmarkt eine ausreichende Finanzierung ermöglicht, ist ureigenes Risiko des Unternehmers in einer Marktwirtschaft. Der Nutzer, seine Aufmerksamkeit und seine Daten dürfen dabei nicht als Ersatzwährung instrumentalisiert werden. Auch zutreffend ist Mankowskis Erwägung, wonach das Faktum, dass ein

303 Vgl. etwa zu Layer Ads https://conversionboosting.com/article/layer-ads-einfach -nur-furchtbar_15413/, zuletzt abgerufen am: 30.5.2019.

304 KG, Urteil vom 18.10.2013 - 5 U 138/12, MMR 2014, 44 mit zustimmender Anmerkung von Czernik; iÜ Leible, in FS Köhler, 403, 408.

305 Bornkamm/Seichter, CR 2005, 747, 753.

306 Vgl. etwa https://www.internetworld.de/onlinemarketing/medien/paid-ansa etze-umsonst-kultur-so-weit-entwickelt-1185089.html, zuletzt abgerufen am: 30.5.2019. Hier wird auch auf die Konkurrenz durch den öffentlich-rechtlichen Rundfunk hingewiesen, was den Markt in Deutschland noch schwerer mache. 
Unternehmen ein kostenloses Angebot im Internet vorhält, keine Rechtfertigung für eine Belästigung des Nutzers nach eigenem Belieben des Anbieters und unabhängig von Recht und Gesetz darstellt. Die Entscheidung, ob eine Werbeform belästigt oder nicht, trifft nicht der Webseitenbetreiber, sondern ein Gericht. Zuletzt überzeugt auch die Überlegung, dass kein Erst-recht-Schluss tunlich ist, wonach Pop-Up Werbung zulässig sein müsse, weil der Unternehmer die Angebote insgesamt zurückziehen oder sperren könne. Vollkommen zu Recht erklärt Mankowski dazu, dass das Beenden des kostenfreien Angebots von Webinhalten keine Belästigung im Rechtssinne darstellt und damit in keiner rechtlichen Beziehung zu belästigender Werbung stehen kann.

Gleichwohl ist die Schlussfolgerung, das Refinanzierungsargument sei insgesamt zu verwerfen, nicht überzeugend. Denn selbst wenn Betreiber kostenloser, werbefinanzierter Webseiten keine Finanzierung im üblichen bipolaren Verhältnis mit dem Nutzer, sondern ein Geschäftsmodell im Dreieck „Werbender - Webseitenbetreiber - Nutzer" vorziehen, ist dies nicht verwerflich oder gar unzulässig. Dieses Geschäftsmodell ist vielmehr von den Grundrechten der Webseitenbetreiber ebenso erfasst wie das Interesse an Profitsteigerung. Ähnlich ist die Lage für Werbende, die aggressiv werben und entsprechende Anzeigen bei den Webseitenbetreibern lancieren. Auch deren Interesse an Profitsteigerung durch Aufmerksamkeit erhaschende Werbung ist grundrechtlich soweit geschützt, bis sie derart in die Freiheitsrechte der Nutzer eingreift, dass von einer unzumutbaren Belästigung auszugehen ist. Eine solche Belästigung folgt aber nicht aus dem bloßen Umstand, dass der Werbende an den Webseitenbetreiber Zahlungen leistet, die schlussendlich die Webseite finanzieren. Diese grundrechtliche Unterfütterung der Interessen von Webseitenbetreibern und Werbenden lässt Mankowski vollkommen außer Acht.

Anders herum darf aber auch das Refinanzierungsargument nicht, wie von Bornkamm und Seichter - wohl mit anderer Intention - beschrieben, derart angewendet werden, dass die Refinanzierung zur Rechtfertigung immer aggressiverer Werbeformen führt, weil diese mehr Profit bringen und damit - vermeintlich - noch mehr oder bessere Angebote ermöglichen. Hier zeigt sich die eingeschränkte Wirkung des Refinanzierungsarguments. Es mag zwar die Existenz von Pop-Ups und neuartigen dynamischen und expandierenden Werbeformen legitimieren. Es kann aber nicht etwa das oben beschriebene Zeitmoment neutralisieren. Wenn dem Nutzer die Hoheit über seine Wahrnehmung entzogen wird, kann dies niemals dadurch gerechtfertigt werden, dass dies notwendig zur Finanzierung der Webseite sei. Denn dem ist zu entgegnen, dass die Profitabilität 
einer Webseite das Risiko des Anbieters ist. Ebenso ist dem denkbaren Argument eines Werbenden, ein Produkt könne anders als durch aggressive, nicht wegklickbare Werbung nicht ausreichend beworben und vermarktet werden, entgegenzuhalten, dass dies niemandes Problem ist außer sein Eigenes.

Schließlich ist das Argument der Summenwirkung in einer bestimmten Spielform erheblich. Und zwar in einer Webseiten-spezifischen, nicht in einer das gesamte Internet betreffenden Betrachtung. Nicht valide ist das von Burmeister vorgebrachte Argument, dass eine Summenwirkung frei nach dem Motto „ein Pop-Up allein ist nicht schlimm, aber wenn es jeder macht, wird es schlimm “ für eine unzumutbare Belästigung spreche. Damit stellt er die Pop-Up-Werbung in eine Reihe mit E-Mail-Werbung und die gezielte werbliche Ansprache in der Öffentlichkeit, bei denen der BGH die Unzumutbarkeit der Belästigung unter anderem mit einer Nachahmungsgefahr und einer Summenwirkung begründet ${ }^{307}$. Der Vergleich zur E-Mail-Werbung ist dabei ohne Weiteres als nicht statthaft zu bewerten, weil dafür $\$ 7$ Abs. 2 Nr. 3 UWG eine Spezialregelung triff, die einer anderen europarechtlichen Grundlage entstammt und daher eine andere Interpretation erfordert als Fälle der Generalklausel ${ }^{308}$. Auch stützt sich Burmeister auf ein BGH-Urteil vor der UWG-Reform von 2004, bei dem die E-Mail-Werbung noch auf der Sittenwidrigkeits-Generalklausel in $\$ 1$ UWG a.F. gestützt wurde. Interessanter ist schon der Vergleich zum Ansprechen in der Öffentlichkeit. Bei dieser Fallgruppe darf aber nicht die Nachahmungsgefahr losgelöst vom eigentlichen Unzumutbarkeitsfaktor betrachtet werden. Schon das Ansprechen in der Öffentlichkeit unter fehlender Erkennbarkeit der Werbeintention stellt eine unzumutbare Belästigung dar, weil diese unerbetene Kontaktaufnahme nicht nur das Bedürfnis des Passanten beeinträchtigt, im öffentlichen Raum möglichst ungestört zu bleiben, sondern auch die übliche Höflichkeit fremden Personen gegenüber zur Erregung von Aufmerksamkeit ausnutze. Die Nachahmungsgefahr kam hier nur erschwerend hinzu ${ }^{309}$. Allein ist die

307 Burmeister, Belästigung als Wettbewerbsverstoß, S.97, 100f. mit Verweis auf BGH, Urteil vom 11.3.2004. I ZR 81/01, GRUR 2004, 517 - E-Mail-Werbung und Urteil vom 9.9.2004 - I ZR 93/02, NJW 2005, 1050 - Ansprechen in der Öffentlichkeit II.

308 Im Ergebnis genauso aber mit anderer Begründung: Bornkamm/Seichter, CR 2005, 747, 752. Dort wird auf die Freiwilligkeit des Besuchs einer Webseite abgestellt, was bei der Zusendung von E-Mails nicht zu erkennen sei.

309 BGH, Urteil vom 9.9.2004 - I ZR 93/02, NJW 2005, 1050 - Ansprechen in der Öffentlichkeit II. 
Nachahmungsgefahr kein Umstand, der eine Unzumutbarkeit im Sinne der Summenwirkung zu begründen vermag. Dies ist auch sinnvoll, weil sonst nach dem Prinzip der Gruppenstrafe immer auch Marktteilnehmer dafür büßen müssten, dass einige wenige Konkurrenten übertriebenen Gebrauch von einer Werbemaßnahme machen. Auf Pop-Ups und Co. bezogen würde also durch die übermäßige Nutzung der Werbeformen auf einigen Webseiten insgesamt ein Verbot folgen, dass anderen Betreibern, die unter Umständen nur bei besonderen Anlässen diese Formen nutzen, die Möglichkeit solcher Werbung entzieht. Dies ist keinesfalls als gerechter Ausgleich der Interessen zwischen der Gesamtheit der Verbraucher und Webseitenbetreiber anzuerkennen. Die Folgen der Maßlosigkeit einzelner müssen diese speziell treffen und nicht die gesamte Branche in Verruf bringen.

Nicht zu verleugnen ist eine Summenwirkung aber, wenn beim Surfen innerhalb einer Webseite im Sinne eines Portals unter einer bestimmten Domain nach jedem Klick und darauf folgenden Öffnen einer Unterseite ein neues Pop-Up oder eine expandierende Anzeige erscheint, die jedes Mal weggeklickt werden muss. In diesem Fall hat es nämlich der Webseitenbetreiber in der Hand, wie oft der Nutzer behelligt wird. Dies kann einerseits darauf gestützt werden, dass durch die Aneinanderreihung der jeweils kurzen Zeitverluste sich schlussendlich ein erheblicher und unzumutbarer Zeitverlust kumuliert. Dann wäre die Summenwirkung nur eine Spielform des oben genannten Zeitmoments. Zum anderen kann dies aber auch auf das natürliche Belästigungsempfinden des Durchschnittsadressaten gestützt werden. Selbst bei hoher Toleranz für Online-Werbung dürfte ab einer gewissen Zahl von Pop-Ups o.Ä. die Grenze erreicht sein, ab denen die aggressiven Anzeigen schlicht „nerven“. Beide Gedanken führen aber wiederum zur Folgefrage, wie viele solcher Anzeigen denn pro Sitzung auf einem bestimmten Portal eingeblendet werden dürfen. Da dies Tatfrage im Einzelfall ist, ließe sich nicht vorhersagen, ob bereits ein zweites Pop-Up ausreicht oder erst ab dem „x-ten“ Pop-up die Grenze zur Unzumutbarkeit überschritten ist ${ }^{310}$.

Deshalb erscheint es für diesen Fall überaus sinnvoll, den Begriff der Hartnäckigkeit aus $\$ 7$ Abs. 2 Nr. 1 UWG zu borgen und für die Zwecke der Generalklausel in $\$ 7$ Abs. 1 UWG zu nutzen. Direkt kann $\$ 7$ Abs. 2

310 Einen ähnlichen Gedanken äußert Steinmetz, der es für unzumutbar belästigend hält, wenn nach Ende einer Anzeige, die der Nutzer beendet hat, unmittelbar eine zweite Anzeige öffnet, siehe Steinmetz, Apps im Lauterkeitsrecht, S. 270. 
Nr. 1 UWG nicht gelten, weil das bloße Wegklicken eines ersten Pop-Ups (außer im Fall des Exit Pop-Ups beim LG Düsseldorf ${ }^{311}$ ) noch nicht die Unerwünschtheit weiterer Werbeansprache mit anderen Anzeigen erkennbar macht. Selbst wenn ein Server - was technisch möglich sein dürfte - die Verweildauer eines Pop-Up-Fensters im Vordergrund bzw. einer integrierten Layer Ad im Vordergrund des Contents oder die Zeit des expandierten Zustandes bei entsprechenden Werbeformen messen und ein sofortiges Schließen erkennen würde, macht dies noch keine generell ablehnende Haltung zweifelsfrei erkennbar. Deshalb sollte die Idee der Hartnäckigkeit zwar in die Generalklausel übertragen werden, aber nicht in der strengen Definition wie in $\$ 7$ Abs. 2 Nr. 1 UWG. Ein bereits zweimaliges Auftreten eines Pop-Ups könnte zwar - etwa beim unmittelbar nächsten Klick nach Schließen des ersten Pop-Ups - schon „nervig“ sein. Insbesondere bei etwas längerem Intervall - etwa bei einem zweiten Pop-Up nach dem Aufruf von mehr als 10 Unterseiten seit Schließen des ersten Pop-Ups - ist die Anwendung der Definition von Hartnäckigkeit aber zu streng, weil die Generalklausel insoweit strenger als der Spezialtatbestand wäre. Deshalb sollte eine Fallgruppe der „hartnäckigen Pop-Up-Werbung“ eine unzumutbare Belästigung begründen bei dem Einblenden von drei PopUps oder vergleichbarer expandierender Werbeformen innerhalb einer Sitzung auf einem bestimmten Webportal.

Ein weiteres Beispiel für diese Fallgruppe sind auch Webseiten, die exzessiven Gebrauch von In-Text-Werbung machen, bei denen der Nutzer durch „Mouse-over“ über bestimmte Links Layer Ads öffnen. Auch hier kann die exzessive Nutzung von mit Werbung verlinkten Begriffen zu einer Summenwirkung führen, die eine ursprünglich noch akzeptable Form der Internetwerbung zu einem unzumutbaren Ärgernis für Internetnutzer macht. Wenn Nutzer nämlich durch unbedachte Bewegungen mit der Maus in ihrem Lesefluss eines Artikels mehrfach gestört werden und sich öffnende Anzeigen beseitigen müssen, nimmt der Webseitenbetreiber eine Belästigung zumindest billigend in Kauf. Dies wiederum hat ab der dritten Unterbrechung während eines Artikels mit hoher Wahrscheinlichkeit zur Folge, dass der Nutzer über den zumutbaren Rahmen hinaus behelligt wird.

311 LG Düsseldorf, Urteil vom 26.3.2003 - 2a O 186/02, MMR 2003, 486. 
(bb) Ungültige Kriterien

Im Übrigen werden in Rechtsprechung und Literatur einige insgesamt ungültige Kriterien zur Bewertung einer unzumutbaren Belästigung durch Pop-Up-Werbung und expandierende Werbeformen vorgebracht.

Nicht von Bedeutung ist, welchen Inhalt die Webseite hat, deren Besuch zum Öffnen des Pop-Ups oder Expandieren der dynamischen Anzeige führt. Eine Abgrenzung, ob essenziell wichtige Informationen oder „nur“ Informationen zur Freizeitbeschäftigung aufgesucht werden, ist im Internet unerheblich ${ }^{312}$. Zur Begründung kann darauf verwiesen werden, dass im Internet keine staatlich garantierte Institution vorgesehen ist wie etwa der öffentlich-rechtliche Rundfunk. Um ein Mindestmaß an essenziell wichtigen, die Allgemeinheit betreffenden Informationen zu erhalten, steht zu jeder Zeit Radio oder TV zur Verfügung. Andere wichtige, nicht mediale Informationen sind regelmäßig über telefonische Ansprache zu erhalten. Es ist auch äußerst schwer zu bestimmen, welche Informationen überhaupt essenziell wichtig sein sollen. Insofern sollte dieser Gedanke schlicht verworfen werden.

Der Inhalt der Anzeige vermag unter Umständen zu einer Unzulässigkeit der Werbung führen. Die grundsätzliche Unzulässigkeit der Werbeform vermag jedoch kein noch so belästigender Inhalt zu begründen ${ }^{313}$.

Auch der Umstand, dass der Nutzer eine Webseite eigeninitiativ aufsucht und er die Webseite jederzeit verlassen und dann fernbleiben könne, ist entgegen der "herrschenden Meinung" unbeachtlich. Insbesondere Bornkamm und Seichter meinen, dass Webseitenbetreiber eine grundsätzliche Gestaltungsfreiheit für ihren virtuellen Bereich haben. Durch den freiwilligen Besuch der Seite durch die Nutzer werde diese Gestaltungsfreiheit nicht eingeschränkt, solange der Nutzer jederzeit die Webseite verlassen kann ${ }^{314}$. Gegen diese Argumentation wird zu Recht heftige Kritik geäußert. Denn richtigerweise ist der Besuch einer Webseite nicht die automatische Erlaubnis jeglicher Belästigung durch Werbung auf oder im $\mathrm{Zu}-$ sammenhang mit der Webseite ${ }^{315}$. Das öffentliche Zugänglichmachen von Inhalten würde dann de facto wie ein Haftungsausschluss für vorsätzliches

312 So aber KG, Urteil vom 18.10.2013 - 5 U 138/12, MMR 2014, 44; gleiche Ansicht aber ohne Begründung bei Mankowski, in: Fezer/Büscher/Obergfell, UWG, S 12, Rn. 149e.

313 Ebenso Mankowski, in: Fezer/Büscher/Obergfell, UWG, S 12, Rn. 156.

314 Bornkamm/Seichter, CR 2005, 747, 752f..

315 Mankowski, in: Fezer/Büscher/Obergfell, UWG, S 12, Rn. 156. 
Verhalten wirken. Abgesehen von schuldrechtlichen Problemen, etwa ob der Besuch einer Webseite einen Vertrag begründen kann, ist ein solcher Haftungserlass schon vor dem Hintergrund von $\$ 276$ Abs. 3 BGB nicht vertretbar. Hierhin passt auch der Gedanke, wonach der Internetnutzer keinen Anspruch auf die Nutzung des Inhalts der angesteuerten Webseite und deshalb schon gar keinen Anspruch auf werbefreie Inhalte hat ${ }^{316}$. Dieser ist ebenfalls zu verwerfen, denn der fehlende rechtliche Anspruch wird jedenfalls durch die faktische Zurverfügungstellung überholt und der Nutzer erhält eine (ggf. werthaltige) Leistung ohne sich einer Kostenpflicht auszusetzen. Hier darf aber wiederum der Webseitenbetreiber dem Nutzer nicht „durch die Hintertür“ eine Gegenleistung abzwingen. Dies stellt dann unter den bereits dargestellten Umständen eine unzumutbare Belästigung dar. In diesem Kontext wird auch der fehlende unmittelbare Zusammenhang zwischen einem neuen Pop-Up-Fenster und der angesteuerten Webseite als Argument für eine unzumutbare Belästigung angeführ$\mathrm{t}^{317}$. Denn bei genauer Betrachtung steuert der Nutzer gerade diese in einem neuen Fenster automatisch geöffnete Webseite nicht eigeninitiativ an. Bei dieser Betrachtung greift das Argument der Eingeninitiative schon gar nicht ein.

Als weiteres Argument wurde die Beeinträchtigung der Ressourcen des Nutzers vor allem in älteren Auseinandersetzungen gerne angeführt ${ }^{318}$. Dieses Kriterium stellt auf die Beanspruchung von Rechnerkapazitäten und die erhöhte Datenmenge ab. Natürlich ist richtig, dass eine dynamische Werbeanzeige beide Ressourcen anzapft. Jedoch ist dieses Kriterium ungeeignet, weil an dieser Stelle sich die Rahmenbedingungen schnell und beständig verändern. Im Gegensatz zu der Situation vor 10 oder 15 Jahren verfügen die meisten Nutzer zur Zeit der Bearbeitung über Datenflatrates, sodass keine Mehrkosten anfallen. Ebenso verfügen die meisten Nutzer über leistungsstarke Computer, die keine Probleme mit der Bewältigung von multimedialen Anzeigen haben. Vor diesem Hintergrund ist schon heute nicht davon auszugehen, dass noch in nennenswertem Umfang Ressourcen des Nutzers beansprucht werden ${ }^{319}$. Da die Digitalisierung mittlerweile den Rang eines Staatsziels erreicht hat, wird die Entwicklung wohl zu noch stärkeren Rechnern und noch günstigeren Internettarifen führen. Anstatt sich also auf unbeständige Faktoren zu stützen, ist das

316 Czernik, MMR 2014, 45.

317 Burmeister, Belästigung als Wettbewerbsverstoß, S. 97, 103.

318 Vgl. nur Burmeister, Belästigung als Wettbewerbsverstoß, S. 97, 102.

319 Ähnlich für In-Game-Werbung: Lober, MMR 2006, 643, 645. 
Zeitmoment vorzugswürdig, da sich dessen Anknüpfungspunkt nicht ändert. Im Rahmen der Ressourcennutzung maßgebliche Gedanken können bei der beachtlichen Summenwirkung verwertet werden. Denn wenn eine exzessive Nutzung von Pop-Ups und Co. etwa zu einer Überforderung der Rechnerkapazitäten führen sollte, geht dies zwingend mit summiertem Zeitverlust einher.

Zuletzt ist auch die Existenz von Werbe- und Pop-Up-Blockern kein Grund, eine absolute Zumutbarkeit von Pop-Ups zu begründen ${ }^{320}$. Mit Pop-Up-Blockern sind hier nur solche Browser Add-Ons oder integrierte Funktionalitäten gemeint, die das Öffnen neuer Browserfenster verhindern. Für integrierte Werbeanzeigen wäre einer der später ausführlich darzustellenden Werbeblocker nötig. Aber weder die Existenz der Pop-Up-, noch der Werbeblocker im engeren Sinne kann zur generellen Zulässigkeit von aggressiven Werbeformen führen. Ganz zutreffend verweist Mankowski darauf, dass es keine Obliegenheit des Nutzers gibt, sich gegen Angriffe zu rüsten, sondern der Angreifer zuvörderst den Angriff auf die Individualsphäre des Nutzers zu unterlassen hat. Wo solche Angriffe aber stattfinden, ist es nur berechtigter präventiver Selbstschutz des Nutzers, Blockerprogramme einzusetzen ${ }^{321}$. Burmeister verweist zudem auf die fehlende Zuverlässigkeit von Blockerprogrammen, die umgangen werden können sowie auf die aus der Nutzung dieser Programme folgenden Funktionseinschränkungen bestimmter Seiten wie etwa beim Öffnen besonderer Online Banking oder Log-In-Fenster. Der Nutzer kann deshalb wohl praktisch nur aus mehreren Alternativen wählen, die Zeit beanspruchen. Entweder er duldet die Werbung mit der Folge, dass er Fenster oder Layer schließen muss oder er muss bei gewissen Funktionen die Wirkung des Blockerprogramms durch andere Klicks für diese spezielle Seite deaktivieren. Der Zeitverlust dürfte im zweiten Fall sogar höher ausfallen, was dem Webseitenbetreiber dann auch mittelbar zuzurechnen ist. Neben diesen zutreffenden Erwägungen ist aber entscheidend für die Ungültigkeit des Arguments der Existenz von Werbeblockern für die Zumutbarkeit von aggressiven Werbeformen, dass schon in logischer Hinsicht eine Verteidigungsmaßnahme niemals den Angriff rechtfertigen oder gar aus der Tatbestandsmäßigkeit führen kann. Überspitzt verglichen würde eine solche Logik im Strafrecht dazu führen, dass der tätliche Angreifer im Falle

320 So auch Mankowski, in: Fezer/Büscher/Obergfell, UWG, S 12, Rn. 149 und Burmeister, Belästigung als Wettbewerbsverstoß, S. 97, 101; a.A. Leible, in FS Köhler, 403, 409.

321 Gomille, GRUR 2017, 241, 245. 
der Notwehr des Angegriffenen keine tatbestandsmäßige Körperverletzung begehen könnte oder er wiederum gerechtfertigt wäre. Dass dies nicht richtig sein kann, ist offensichtlich. Es ist vielmehr anders herum: die Verteidigung zeigt eindeutig, dass der Angriff nicht geduldet wird und damit subjektiv in jedem Fall als unzumutbar belästigend empfunden wird. Sonst wird der Nutzer wohl kaum derart aktiv werden, dass er eine Zusatzfunktionalität installiert, die ihn vor zukünftigen Angriffen schützen soll. Eine Judikatur, die hauptsächlich die Sicht des Adressaten einer Werbemaßnahme in die Interessenabwägung einstellen muss, kann sich dabei dieser faktischen Gewissheit über das Störungsempfinden nicht verwehren.

\section{(b) Sich automatisch schließende Werbeformen}

Ein etwas anderer Fall sind dynamische Werbeformen oder Layer Ads, die sich automatisch schließen oder minimieren. Sie sind von der Funktionsweise her den weiter unten fokussierten Interstitials ähnlich, die grundsätzlich automatisch enden. Sie unterscheiden sich von den oben genannten Werbeformen dadurch, dass nicht unbedingt ein aktives Schließen nötig ist. Die Abgrenzung zu Interstitials lässt sich am ehesten über die Größe erreichen. Während Interstitials als Unterbrecherwerbung den gesamten Content zeitweise verdrängen, überlagern die sich automatisch schließenden dynamischen Werbeformen nur gewisse Teile des Contents.

Dieser Fall war aufgrund der Beweislastentscheidung Gegenstand des oben beschriebenen Urteils des Kammergerichts ${ }^{322}$. Kriterium des Gerichts war dabei das automatische Verschwinden „alsbald“. Der Leitsatz der Redaktion aus der Zeitschriftenfundstelle übersetzt dies nonchalant in „nach wenigen Sekunden“. Pendant dazu ist die oben bereits näher in den Blick genommene Formulierung „innerhalb kurzer Zeit wegklickbar“ für den Fall, dass neben dem automatischem Verschwinden eine zusätzliche Funktionalität vorgesehen ist. Bei den sich automatisch schließenden Werbeformen muss also weiter unterschieden werden zwischen solchen Anzeigen, die nur automatisch schließen und keine Funktion zum Minimieren oder Schließen haben (siehe dazu unten (aa)) und Anzeigen, die bei Ablauf der programmierten Zeit automatisch schließen, aber bereits zuvor eine Option zum Schließen oder Minimieren anbieten (siehe dazu unten (bb)).

322 KG, Urteil vom 18.10.2013 - 5 U 138/12, MMR 2014, 44. 
(aa) Keine Möglichkeit vorzeitiger Beseitigung

Anzeigen mit fester Bindung des Nutzers für eine vom Webseitenbetreiber und/oder Werbenden festgelegte Zeit ohne Abbruchfunktion ${ }^{323}$ begegnen vor dem Hintergrund des oben als Hauptkriterium herausgearbeiteten Zeitmoments erheblichen Bedenken. Denn in einer solchen Ausgestaltung wird dem Nutzer ganz eindeutig die Hoheit über seine Wahrnehmung entzogen. Diese Hoheit liegt dann beim Webseitenbetreiber, was nach oben beschriebener Logik zur unzumutbaren Belästigung führen kann.

Nicht geeignet ist hingegen die vom Kammergericht genutzte zeitliche Komponente „alsbald“. Zwar wendet das Gericht das Zeitmoment im weitesten Sinne an. Die Formulierung „alsbald“ ist jedoch schlicht zu unbestimmt und vieldeutig. „Alsbald“ enthält schon in der Alltagssprache keinerlei hinreichende Bestimmung einer bestimmbaren Dauer, sondern eher einer Abfolge - „alsbald“ als dringlichere Form von „bald“. Ob „alsbald“ aber „nach wenigen Sekunden“ bedeutet - wie es die Redaktion der MMR übersetzt - oder „innerhalb einer halben Minute“ oder „nach wenigen Minuten“, bleibt völlig offen. In anderen Nutzungskonstellationen des Wortes „alsbald“ kann nämlich auch die Bezugshandlung erst nach Tagen erfolgen. Ins Gegenteil verkehrt kann „alsbald“ aber auch mit dem Synonym „sogleich“, „augenblicklich“ oder „unverzüglich“ ausgetauscht werden $^{324}$. Deshalb wäre rein linguistisch auch der Schluss erlaubt, nach welchem die Anzeige sofort wieder schließen muss. Dies macht freilich in logischer Hinsicht keinen Sinn, weil damit die Werbeform zwar Öffnen dürfte, aber sofort wieder schließen müsste. Gerade dies möchte das Kammergericht aber nicht ausdrücken.

Betrachtet man dieses Judiz in Verbindung mit der Beweislastentscheidung, von einem automatischen Schließen innerhalb kurzer Zeit auszugehen, bleibt lediglich zu konstatieren, dass das Kammergericht es sich sehr einfach gemacht hat. Es hat im Prinzip keinen echten Fall entschieden, sondern einen Fall (prozessrechtlich zulässig) konstruiert und eine dazu passende Rechtsmeinung kundgetan. Denn es hat weder in tatsächlicher,

323 Sei es das Schließen oder Minimieren der Anzeige, sei es das Herunterscrollen oder seien es andere Möglichkeiten zum Verbannen der konkreten Werbung aus der Wahrnehmung ohne den gesamten Browser zu schließen bzw. PC zu beenden.

324 Vgl. https://www.duden.de/rechtschreibung/alsbald, zuletzt abgerufen am: 27.11.2017. 
noch in rechtlicher Hinsicht einen belastbaren Zeitraum festgestellt oder genannt, der für die praktische Rechtsanwendung verwertbar wäre.

Deshalb ist das oben ausführlich dargestellte Zeitmoment auch hier konkret mit Blick auf die Hoheit über die Wahrnehmung beim Nutzer auszulegen. Da bei einer fixierten Anzeigedauer die Hoheit de facto nicht beim Nutzer liegt, sind Werbeformen ohne Abbruchfunktion generell als unzumutbare Belästigung anzusehen. Wenn man diese unbedingt zulassen möchte, wäre eine Bagatellgrenze im Rahmen einer Unzumutbarkeitsabwägung allenfalls im Bereich ganz weniger Sekunden vertretbar. Aus Gründen der Konsistenz zum oben genannten Fall der Wegklickbarkeit nach „kurzer Zeit" sollte auch hier die Bagatellgrenze bei drei Sekunden liegen. Nach diesen drei Sekunden müsste die Anzeige automatisch wieder verschwunden sein, um keine unzumutbare Belästigung darzustellen ${ }^{325}$. Alles andere ist eine unzulässige geschäftliche Handlung im Sinne von $\mathbb{} 7$ Abs. 1 UWG.

(bb) Vorzeitige Schließmöglichkeit

Nur unwesentlich anders als die oben behandelten Pop-Ups und expandierenden Werbeformen, sind sodann solche Werbeformen zu beurteilen, die zwar automatisch schließen, aber eine vorzeitige Abbruchfunktion ermöglichen. Hier kann die automatische Schließfunktion - wenn sie erst nach drei Sekunden wirkt, mit anderen Worten bei allen Anzeigen, die länger als drei Sekunden eingeblendet bleiben - schlicht als irrelevant bezeichnet werden. Es kommt nur auf die Verfügbarkeit des Schließbuttons oder der ähnlichen Abbruchfunktion an. Wenn diese nicht sofort ${ }^{326}$ zur Verfügung steht, ist sie genauso eine unzumutbare Übernahme der Hoheit der Wahrnehmungsfreiheit des Nutzers wie eine Anzeige, die aktiv durch Klick geschlossen werden muss.

Interessant bei der Auslegung der Entscheidung des Kammergerichts zur Anwendung in der Praxis wäre allenfalls die zeitliche Abfolge von Schließmöglichkeit nach "kurzer Zeit" und dem automatischen Schließen „alsbald“. Schon logischerweise muss die Schließmöglichkeit nach „kurzer Zeit" früher liegen als das automatische Schließen. Dann kann „alsbald" aber auch mehrere Minuten umfassen. Die Problematik der Zeit,

325 Steinmetz hält 10 Sekunden für die Grenze und alles darunter für zulässig, siehe Steinmetz, Apps im Lauterkeitsrecht, S. 269.

326 Im oben beschriebenen Sinne von 0,1 bis 3 Sekunden. 
ab welcher der Durchschnittsadressat belästigt wird, wird dann schlicht auf das ebenso aussageschwache Attribut „kurze Zeit“ verlagert. Diese Übertragung auf den praktischen Fall zeigt ebenfalls, dass das Urteil des Kammergerichts nicht zu dem Grundsatzurteil taugt, zu dem es in der Kommentarliteratur gemacht wird. Denn solange die Abbruchmöglichkeit besteht, muss sich eine Anzeige schon gar nicht alsbald schließen. Wenn die Abbruchfunktion aber nicht nach kurzer Zeit zur Verfügung steht, macht auch ein automatisches Schließen „alsbald“ die Anzeige nicht zulässig. Zum Beispiel wäre eine Anzeige, die nach zehn Sekunden geschlossen werden kann und nach fünfzehn Sekunden automatisch schließt nach hier vertretener Ansicht unzumutbar belästigend. Mit dem Kammergericht könnte aber argumentiert werden, dass diese Anzeige zulässig sei.

Es sollte also nur eine zeitliche Grenze gelten, die unabhängig davon ist, ob die Anzeige aktiv geschlossen wird oder automatisch schließt, solange der Nutzer es in der Hand hat, dass er nach spätestens drei Sekunden die Anzeige „aus den Augen“ bekommt ${ }^{327}$.

\section{(c) Pop-Under Werbung}

Eine weitere Unterscheidung, die in der Literatur anzutreffen ist, wird zwischen Pop-Up und Pop-Under-Werbung vorgenommen. Dabei wird von Köhler vertreten, dass Pop-Under-Werbung, also das Öffnen eines neuen Browserfensters, das sich im Hintergrund öffnet und erst in die Wahrnehmung gerät, nachdem das Hauptbrowserfenster geschlossen wird, eine unzulässige Belästigung darstellen soll. Dies wird mit den Schwierigkeiten begründet, die ursprünglich angewählte Seite zu verlassen ${ }^{328}$. Eine Differenzierung nimmt Köhler damit anhand des Kriteriums des Wahrnehmungszeitpunkts der Anzeige vor. Pop-Ups werden dabei mit der „herrschenden Meinung“ für zulässig erachtet, wenn sie nach kurzer Zeit geschlossen werden können. Bei Pop-Unders hingegen komme es laut Köhler darauf nicht an, weil der Nutzer ja bereits seinen Willen zum Verlassen der Webseite gezeigt habe. Damit steckt er Pop-Under-Werbung in dieselbe Schublade wie Exit-Pop-Ups.

Dies überzeugt allerdings nicht. Der Fall „Pop-Under“ unterscheidet sich vom Exit-Pop-Up schon dadurch, dass im letzteren Fall ein neues

327 Geringfügig toleranter ist hier Steinmetz, der 5 Sekunden für die Grenze hält, siehe Steinmetz, Apps im Lauterkeitsrecht, S. 269.

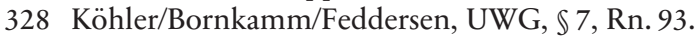


Pop-Up nach dem Schließen eines ersten Pop-Ups geöffnet wird. Das PopUnder öfnet aber wie ein „normales“ Pop-Up schon bei Aufrufen der adressierten Webseite. Gegen eine Vergleichbarkeit mit dem Exit-Pop-Up spricht zudem, dass zwischen Schließen der Hauptseite, etwa durch Anwählen einer anderen Webseite, und Schließen des Browserfensters durchaus eine erhebliche Zeit liegen kann. Das Pop-Under "schlummert“ im Hintergrund und hat insoweit zunächst überhaupt keine belästigende Wirkung. Beim Exit-Pop-Up hingegen folgt auf einen Klick, der das einzige Ziel verfolgt, diese konkrete Werbeform aus der Wahrnehmung zu verbannen, die Einblendung eines formgleichen Werbemittels. Dies zeitigt sofort und entgegen dem Willen des Nutzers eine belästigende Wirkung. Das Pop-Under hingegen erreicht die Wahrnehmung des Nutzers erst, wenn er insgesamt den Beschluss gefasst hat, seine Internet-Session zu beenden. Insoweit kann auch nicht davon ausgegangen werden, dass ein Pop-Under unzulässig sein soll, weil es Schwierigkeiten bereite, die aufgerufene Seite $\mathrm{zu}$ verlassen. Dies ist faktisch unzutreffend, weil das Pop-Under allenfalls Schwierigkeiten bereitet, das Browserprogramm zu schließen. Das Verlassen der Internetseite, die das Pop-Under initiiert, wird überhaupt nicht beeinflusst.

Insgesamt führt das Pop-Under schlicht dazu, dass der Nutzer das Browserprogramm nicht mit einem Klick, sondern mit zwei Klicks - erst das Hauptfenster, dann das Pop-Under-Fenster - beenden muss. Bei Lichte betrachtet erfordert das Pop-Under damit keine andere Reaktion des Nutzers als ein übliches Pop-Up, weil es eines aktiven Schließens eines Fensters bedarf. Bei der Beurteilung muss deshalb auch hier wieder auf das Zeitmoment abgestellt werden. Kann sich der Nutzer dieser Anzeige sofort durch einen Klick entledigen, ist diese Form noch als zumutbar zu werten. Da Pop-Under-Werbung technisch wohl nur sinnvoll durch neue Browserfenster funktioniert ${ }^{329}$, ist eine browserimmanente Schließmöglichkeit immer gegeben. Gegen die Zulässigkeit von einzelnen Pop-Under Anzeigen spricht insoweit nichts ${ }^{330}$.

329 Eine im Fenster geöffnete Werbung, die unter dem Content und von diesem veredeckt liegen würde, ist sinnlos. Eine Werbung, die im Fenster erst beim Verlassen der Webseite erscheinen würde wäre eher im Bereich der Insterstitials zu verordnen, sozusagen ein „Poststitial“. Beide Formen sind allerdings praktisch nicht gebräuchlich.

330 Ebenso Leible, in FS Köhler, 403, 409, der argumentiert, dass allein der Überraschungseffekt beim Schließen des Hauptfensters keine unzumutbare Belästigung begründen könne. Dem ist zuzustimmen und allenfalls hinzuzufügen, 


\section{B. Grundlage: Werbung im Internet}

Freilich wird auch hier wieder die Summenwirkung zu einer Unzulässigkeit führen können ${ }^{331}$. Sollte der Nutzer erst eine Vielzahl von Klicks vornehmen müssen, um das Browserprogramm ganz zu schließen, summiert sich die zeitliche Bindung des Nutzers wieder in den Bereich der unzulässigen Belästigung. Hierbei stellt sich aber im Vergleich zu Pop-Ups ein der Werbeform innewohnendes Problem. Gerade bei längeren Internetsitzungen wird der Nutzer oft keine sichere Zuordnung mehr vornehmen können, von welcher Webseite das Pop-Under stammt ${ }^{332}$. Insoweit ist eine wie bei Pop-Ups vorgeschlagene Betreiberbetrachtung praktisch schwieriger, weil nicht auf den ersten Blick klar wird, welche Internetseite wie viele Pop-Unders initiiert. Gleichwohl gelten auch hier die obigen Erwägungen, wonach ein Webseitenbetreiber nur für eigenes, aber nicht für sonstiges Wettbewerberhandeln einstehen muss. Es ist deshalb wohl auch hier vorzugswürdig, jedem Webseitenbetreiber zumindest ein PopUnder zuzugestehen. Durch die summierende Wirkung am Ende einer Internetsitzung muss aber schon ein theoretisch zweites Pop-Under einer bestimmten Webseite ein unzulässiges Verhalten nach $\$ 7$ Abs. 1 UWG sein. Für diese vermittelnde Lösung spricht, dass zur etwaigen Beweissicherung die Herkunft des Pop-Unders von einem bestimmten Server durchaus ermittelt werden kann und bei einem übermäßigen Gebrauch dieser Werbeform Unterlassungsansprüche geltend gemacht werden könnten. Eine theoretische Anhäufung von Pop-Unders wird zudem von der Länge der Internetsitzung abhängen und liegt damit in der Sphäre des Nutzers. Beim Schalten eines einzigen Pop-Unders greift der einzelne Werbende bzw. Seitenbetreiber noch nicht wesentlich in die Sphäre des Nutzers ein.

Zusammenfassend sind auch Pop-Unders dann zulässig, wenn sie sofort weggeklickt werden können und nicht übermäßig eingesetzt werden.

dass sich der Überraschungseffekt auch abschwächt bei wiederholtem Antreffen durch den Nutzer.

331 Nach Burmeister, Belästigung als Wettbewerbsverstoß, S. 97, 100, soll auch hier die Summenwirkung im Sinne der Nachahmungsgefahr durch die anderen Marktteilnehmer ausreichen.

332 Mankowski, in: Fezer/Büscher/Obergfell, UWG, S 12, Rn. 157, der Pop-Unders als „Exit-Pop-Ups“ bezeichnet, will aus diesem Umstand folgern, dass Webseitenbetreiber geneigt sein könnten, diese Werbeform freizügiger einzusetzen, weil kein direkter Rückschluss des Nutzers auf die schaltende Webseite erfolge. Dies ist jedoch durch nichts belegt und vor allem eine Vermutung, die sich durch den praktischen Einsatz dieser Werbeform bislang nicht bewahrheitet hat. 
(d) Einsatz auf mobilen Endgeräten

Zuletzt ist eine weitere Differenzierung denkbar. Dies betrifft den Einsatz der Pop-Up-Werbung im mobilen Bereich. Da Webseiten oder Apps in der Regel auf das jeweilige Format des Mobilgeräts optimiert sind, haben sich auch die Werbeformen entsprechend spezialisiert. Wie oben technisch beschrieben, werden die Informationen über das benutzte Mobilgerät und dessen Bildschirmgröße in der Kommunikation zwischen Server und Client ausgetauscht und der Server spielt dementsprechend passende Werbung aus. Jedoch ist „passen“ in diesem Kontext doppeldeutig. Denn einerseits mag ein Pop-Up im mobilen Gerät optimiert angezeigt werden. Um eine sinnvolle Werbebotschaft zu überbringen, wird aber regelmäßig gerade bei kleinen Geräten wie Smartphones - ganz zu schweigen von „Wearables“ wie Smart Watches - der gesamte Bildschirm von einem Pop-Up in Beschlag genommen. Insoweit besteht faktisch kein Unterschied zwischen Interstitials und Pop-Ups, weshalb hier die Größe oft kein Kriterium zur unterschiedlichen Einordnung von Werbeformen sein kann und deshalb auch keine differenzierende rechtliche Bewertung möglich ist.

Im Übrigen wird auch im mobilen Bereich das Zeitmoment unterstützt durch den Summeneffekt maßgeblich sein. Auf die obigen Ausführungen wird dabei verwiesen. Einen weiteren Gedanken wert ist im mobilen Bereich mit rein mobilem Datenzugriff über Mobilfunknetze noch das teilweise für erheblich gehaltene Argument der Ressourcennutzung durch die Werbenden. Zum Zeitpunkt der Bearbeitung ist es nämlich üblich, dass mobiler Internetzugriff nur in beschränktem Maße von Mobilfunkverträgen gewährleistet wird. Nach Verbrauch einer definierten Datenmenge wird regelmäßig die Datentransfergeschwindigkeit gedrosselt oder ein weiteres Datenpaket muss gegen Mehrkosten erstanden werden. Vor diesem Hintergrund ist der Gedanke, dass Werbung, die in diese beschränkte Menge durch hohen zur Anzeige benötigten Datenbedarf eingreift, eine unzumutbare, da mittelbar kostenpflichtige Belästigung darstellt, nicht ganz von der Hand zu weisen. Allerdings ist dies eine reine Momentaufnahme. Gerade Deutschland sticht durch relativ hohe Kosten und ungünstige Tarifbedingungen im internationalen Vergleich auf ${ }^{333}$. Es ist wohl zu

333 https://www.welt.de/wirtschaft/webwelt/article141320502/Deutsche-zahlen-gew altig-fuer-winziges-Datenvolumen.html, zuletzt abgerufen am: 30.5.2019. Demnach schnitt Deutschland bei einem EU-weiten Vergleich im Jahr 2017 in der Schlussgruppe ab, im Durchschnitt erhiellt der Nutzer bei einem monatlichen Zahlungsbetrag von $35 €$ lediglich 1GB schnelles Datenvolumen. In anderen 
erwarten, dass sich die Kosten und Tarifbedingungen für mobiles Internet auf lange Sicht soweit verringern, dass schon bald wie beim heimischen DSL-Anschluss die Kosten nur noch ein unwesentlicher Faktor sein werden. Für eine nachhaltige Lösung der Problematik ist also das Kostenund Ressourcenargument eher ungünstig. Die Belästigung durch Verursachung von Zusatzkosten für weitere Datenmengen sollte zudem zweckmäßigerweise im bipolaren Verhältnis zwischen betroffenem Nutzer und Werbenden geklärt werden, in dem der Nutzer auch etwaigen Schadensersatz geltend machen könnte. Für eine prozessuale Gestaltung wie bei $\$ 7$ UWG üblich, bei der ein nach $\$ 8$ Abs. 3 UWG aktivlegitimierter Verband oder ähnliche Stellen Verbraucherrechte quasi in Prozessstandschaft verfolgen, eignet sich dieses Argument, das immer Produkt der aktuellen Tarifinfrastruktur ist, nur sehr eingeschränkt. So könnte ein Judiz auf dieser Grundlage schon innerhalb weniger Jahre überholt sein. Gerade dies dient wenig der Rechtssicherheit, was aber für den Bereich des Internets wünschenswert wäre.

\section{(e) Möglichkeit der Einwilligung durch Nutzer}

Soweit nach dem Vorstehenden durchaus Fälle unzumutbarer Belästigungen auf Tatbestandsebene in Betracht kommen, ist für diese Fälle ein Blick auf die Rechtswidrigkeitsebene zu werfen. In diesem Zusammenhang wird die rechtfertigende Einwilligung durch den Internetnutzer, der eine werbefinanzierte Webseite freiwillig aufsucht, diskutiert ${ }^{334}$.

Unstreitig dürfte eine ausdrücklich erklärte Einwilligung eines einzelnen Nutzers zur Rechtfertigung jeder für den Durchschnittsadressaten unzumutbaren Belästigung taugen. Diese wird freilich so gut wie nie vorliegen. Webseitenbetreiber werden die Werbeauslieferung schon aus Selbstschutz nicht von einem vor dem Besuch positiv erklärten Willen des Nutzers zur Werbewahrnehmung abhängig machen. Ein solcher ausdrücklicher Opt-In ist theoretisch eine Möglichkeit zur absoluten Legitimierung der Anzeigenausspielung. Dies wird aber praktisch niemals Realität, weil Webseitenbetreiber verständlicherweise nicht die Hoheit über die wirtschaftlich wertvollen Seiteninhalte aus der Hand geben wollen.

Ländern wie Finnland, Estland oder Frankreich sind für diesen Betrag zwischen 20 und 50 GB erhältlich.

334 Vor allem Gomille, GRUR 2017, 241, 243f.; iÜ Mankowski, in: Fezer/Büscher/Obergfell, UWG, S 12, Rn. 159f.. 
Interessant ist in diesem Kontext die Frage, wie ein etwaiger Opt-In ausgestaltet sein müsste. Denkbar ist dabei, dass beim (für den Server) erstmaligen Besuch der Seite durch einen durch seine IP-Adresse bestimmten Nutzer ein Informationsfeld eingeblendet wird, in dem eine kurze Information über die Schaltung von Werbung gegeben wird und dann der Nutzer einen Button zur Zustimmung klicken kann. In dieser Art werden in jüngerer Zeit auf beinahe allen Webseiten Cookie-Informationen gegeben und Opt-Ins erlangt. Diese „Cookie-Boxen“ beruhen auf den datenschutzrechtlichen Bestimmungen und sind insbesondere im Vorlauf zum Inkrafttreten der Datenschutzgrundverordnung (DSGVO, VO (EU) 2016/679) vermehrt implementiert worden. Dabei ist diesen Boxen regelmäßig gemein, dass sie keine direkte Wahl ermöglichen, sondern allein den Hinweis und die Möglichkeit zur Zustimmung geben, worauf die Box verschwindet. Allenfalls ist ein Link oder Drop-Down-Menü zu „weiteren Informationen“ erhältlich. Der Nutzer muss also selbst aktiv tätig werden und seine Browsereinstellungen modifizieren oder schlicht die Nutzung der Seite unterlassen, wenn er den Einsatz von Cookies auf seinem Rechner vermeiden will.

Überträgt man diese Informationsboxen auf Displaywerbung im Internet, stellt sich die Frage, ob auf diese Art ein Opt-In mit rechtfertigender Wirkung erreicht werden kann. Im Allgemeinen definiert der BGH in Zivilsachen die Einwilligung im Rahmen von deliktischem Handeln als die „im Augenblick der Tat vorhandene, freiwillige, ernstliche und sittengemäße zustimmende Willensrichtung des betroffenen Rechtsgutträgers zu einer bestimmten Rechtsgutverletzung “335. Daraus folgt, dass die Voraussetzungen einer Einwilligung ein disponibles Rechtsgut, die Kenntnis der konkreten Rechtsgutsverletzung und die Freiwilligkeit des Willensentschlusses umfassen ${ }^{336}$. Die erste dieser Voraussetzungen sowie die noch nicht genannte Voraussetzung der Sittengemäßheit werfen hier keine Probleme auf. Die Unverletzlichkeit der Privatsphäre bzw. genauer das Recht im Internet nicht übermäßig durch Werbung zeitlich eingeschränkt zu werden ist disponibel. Sittenwidrigkeit liegt bei Tatbeständen, die "gerade so" die Unzumutbarkeitsschwelle überschreiten fern. Interessant sind vielmehr die Voraussetzungen der Kenntnis sowie der Freiwilligkeit des Nutzers.

Die Kenntnis des Nutzers von der bevorstehenden Werbeansprache kann durch eine ausreichend transparent formulierte Erklärung in einer

335 BGH, Urteil vom 2.12.1963 - III ZR 222/62, NJW 1964, 1177.

336 Vgl. Förster, in: BeckOK BGB, $\$ 823$, Rn. 33ff.. 
Opt-In-Box bewerkstelligt werden. Dabei wird aber eindeutig zwischen generell zulässiger unaufdringlicher Display-Werbung und den aggressiven Werbeformen mit expandierender Wirkung bzw. Pop-ups unterschieden werden. Die zuletzt genannten müssen dabei in für den Durchschnittsadressaten ausreichend verständlicher Form beschrieben werden. Anders herum, wenn eine solche Aufklärung schon nicht oder nur in pauschaler Form erfolgt, ist die hinreichende Kenntnis wohl zu verneinen, womit die Annahme einer Einwilligung ausscheidet.

Bei der Freiwilligkeit der Einwilligung stellt sich die Frage, was genau freiwillig sein muss. In Betracht kommt naheliegender Weise die Freiwilligkeit mit Blick auf die konkret auszuspielenden Werbeformen. In diesen Prüfungspunkt lässt sich aber auch das regelmäßig vorgebrachte Argument des freiwilligen Besuchs einer Webseite im Gesamten unterbringen. Da der bloße Besuch jedoch schlüssiges Verhalten darstellt, soll dieses Argument weiter unten im Kontext der konkludent geäußerten Einwilligung weitergehend untersucht werden. Im Rahmen einer ausdrücklichen Erklärung durch eine Opt-In-Box stellt sich eine andere Frage: müsste dem Nutzer an dieser Stelle eine echte Wahl ermöglicht werden? Die Cookie-Boxen ermöglichen diese Wahl regelmäßig nicht, sie haben keinen „Nein“-Button, der zum Stopp serverseits gesetzter Cookies führt. Der Nutzer hat die „unechte“ Wahl, die Seite wieder zu verlassen. Bei aggressiver Werbung würde eine solche Ausgestaltung nicht zu einer freiwilligen Einwilligung führen. Denn wie bereits oben im Rahmen der Interessenabwägung im Kontext der Pop-ups vorgebracht, ist der Verweis auf das Verlassen einer Webseite bei Werbung, die der konkrete Adressat als zu aufdringlich einschätzt, kein valides Argument. Auch auf Rechtfertigungsebene gilt dies, denn hier lässt sich genauso hören, dass der Webseitenbetreiber innerhalb seines Redaktionsrechts eben nicht die Freiheit hat, den Nutzer nach eigenem Gutdünken mit Werbung zu behelligen. Ein "Alles-oder-Nichts“ wäre dabei auch keine wirklich freiwillige Entscheidung für die konkret zu betrachtende Tathandlung, nämlich Pop-Ups und expandierende Werbeformen. Diese stellen nämlich nur einen Teil des gesamten Werbepakets dar. Wenn die Grundausstattung der Werbeformen tatbestandsmäßig schon nicht von $\$ 7$ UWG erfasst wird und somit keinerlei Rechtfertigung bedarf, muss sich die freiwillige Entscheidung auch isoliert auf die tatbestandsmäßige und rechtfertigungsbedürftige Handlung beziehen. Folglich müsste eine Opt-In-Box für aggressive Werbung eine echte Wahlmöglichkeit bieten, die neben einer Zustimmung auch ein „Nein“ vorsehen müsste. Diese Entscheidung müsste - was technisch ohne größere Probleme umsetzbar wäre - dazu führen, dass ein Adserver nur die unaufdringliche 
Werbung, nicht aber die aggressiven Anzeigen ausspielt. Wegen dieses Befundes wird diese denkbare Form der Einholung einer Einwilligung wiederum sehr uninteressant für die Werbeindustrie, da auch hier der Nutzer die Hoheit über das „Ob“ von lukrativer Werbung erhielte. Mit einer Implementierung ist deshalb nicht zu rechnen.

Dieses Ergebnis wird ansatzweise gestützt durch eine Passage in einem der Adblocker Urteile des OLG München. Dort enthielt der Footer der Webseite eine Bitte, keine Adblocker zu benutzen. Dies wurde vom Senat im Rahmen der urheberrechtlichen Prüfung einer Verletzung von Rechten der Webseitenbetreiber aus $\$ 69$ c UrhG in die Prüfung eingebracht. Die Angabe im Footer wurde jedoch als lediglich unverbindliche Bitte angesehen, der die Gestattung der Vervielfältigung der Webseite im Arbeitsspeicher des Nutzers nicht derart beschränke, dass keine Werbeblocker eingesetzt werden dürften ${ }^{337}$. Übertragen auf die Einwilligung des Nutzers zu aggressiver Werbung lässt sich deshalb folgern, dass ein bloßer Hinweis auf einer Webseite für die Einwilligung unbeachtlich sein sollte. Generell werden solche einseitigen Hinweise ohne Wahlmöglichkeit und ohne technische Konsequenzen für die Einwilligung in deliktisches Handeln keine besondere Bedeutung erlangen können, sei es zur Erweiterung der Handlungsmöglichkeiten von Webseitenbetreiber oder zur Einschränkung der Abwehrmöglichkeiten der Nutzer.

Im Übrigen stellt sich die praktisch weitaus relevantere Frage, ob trotz fehlender ausdrücklicher Erklärung eine rechtfertigende Wirkung hergeleitet werden kann. Diese mag aus schlüssigem Verhalten oder aus mutmaßlicher Einwilligung folgen ${ }^{338}$.

Eine mutmaßliche Einwilligung ist dabei im Bereich des Internets fernliegend. Zwar ist die mutmaßliche Einwilligung im Rahmen von $\$ 7$ UWG grundsätzlich nicht fremd, weil in Abs. 2 Nr.2 Alt.2, der die Telefonwerbung gegenüber Unternehmen regelt, die mutmaßliche Einwilligung grundsätzlich für ausreichend gehalten wird ${ }^{339}$. Dies ist aber eine aus dem Ausgleich diverser Interessen geborene Sonderkonstellation, die nicht verallgemeinerungsfähig ist. Zudem wird der Unternehmer, der in dieser Eigenschaft einen telefonischen Kommunikationskanal eröffnet, nur in sei-

337 OLG München, Urteil vom 17.8.2017, U 2225/15 Kart, (juris, Rn. 128).

338 Vgl. Gomille, GRUR 2017, 241, 243f..

339 Vgl. Köhler/Bornkamm/Feddersen, UWG, $\mathbb{\$} 7$, Rn. 163ff. mit Verweis auf u.a. BGH, Urteil vom 16.11.2006 - I ZR 191/03, GRUR 2007, 607, Tz. 21 - Telefonwerbung für „Individualverträge“. 
ner Sozialsphäre betroffen ${ }^{340}$. Bei der Internetnutzung hingegen ist, jedenfalls beim Surfen für den privaten Zeitvertreib, die Privatsphäre betroffen. Die unterschiedlichen Schutzbedürfnisse dieser Sphären gebieten eine differenzierte Betrachtung und führen zum Ausschluss der Möglichkeit einer mutmaßlichen Einwilligung im privaten Bereich. Doch auch bei einer Internetnutzung durch natürliche Personen in selbständiger Tätigkeit oder als Arbeitnehmer im Interesse eines unternehmerischen oder öffentlichen Arbeitgebers kann nichts anderes gelten. Insoweit wird schon nur ganz selten eine strikte Trennung zwischen privater und „unternehmerischer" Nutzung des Internets praktiziert. Selbst wenn das zu bejahen sein sollte, nutzt „das Internet“ durch den teils nicht sichtbaren Informationsfluss vom Nutzer zum Server, insbesondere durch die Vielzahl von Trackingmöglichkeiten, eine Vielzahl persönlicher Informationen, die eine Zuordnung einer solchen Werbung zur Sozialsphäre ausschließen. Denn bei der Fallgruppe der Telefonwerbung gegenüber Unternehmern kann der Werbende anders als im Internet nicht allein durch die technische Nutzung des Mediums schon viele Informationen extrahieren - er kann bloß eine Telefonnummer eines Unternehmens wählen und seine Werbebotschaft anbringen. Im Internet kann er entweder so undifferenziert werben, dass keinesfalls von einer an einen Unternehmer adressierte Werbung ausgegangen werden kann. Oder er kann eine durch Tracking besonders an die Bedürfnisse des Unternehmers angepasste Werbeanzeige einblenden lassen, was aber die Nutzung versteckter Informationen bedarf, die nicht - wie in der Sozialsphäre üblich - für jedermann ohne weiteres erkennbar sind. Eine der mutmaßlichen Einwilligung innewohnende gesetzlich vermutete Nützlichkeit der Werbung ist in beiden Alternativen nicht ersichtlich. Deshalb scheidet die mutmaßliche Einwilligung auch praktisch als Rechtfertigungsgrund aus.

Schwieriger zu beurteilen ist eine mögliche Einwilligung durch schlüssiges Verhalten. Maßgebliches schlüssiges Verhalten ist dabei der bewusst freiwillige Aufruf einer werbefinanzierten Webseite. Während dies oben im Rahmen der Interessenabwägung bei $\$ 7$ Abs. 1 UWG als nicht durchgreifendes Argument identifiziert worden ist, stellt sich auf Rechtfertigungsebene die Frage der Erheblichkeit erneut. Auf Tatbestandsebene macht es keinen Unterschied, ob eine Belästigung nur bei freiwilligem Besuch der Webseite stattfindet, weil der Durchschnittsadressat bei einer sozialadäquaten Handlung wie dem Internetsurfen nicht nach Belieben des Betreibers belästigt werden darf und die Frage der Zumutbarkeit nicht

340 Gomille, GRUR 2017, 241, 244. 
zur Frage nach dem Vorliegen eines Haftungsverzichts werden soll. So kann auch die unzumutbare Belästigung beim Ansprechen in der Öffentlichkeit ${ }^{341}$ nicht deshalb in den Bereich der Zumutbarkeit argumentiert werden, weil der Passant auch zu Hause bleiben oder wenig frequentierte Ausweichstraßen nutzen könnte. Im Rahmen der Rechtfertigung ist die Sachlage aber etwas anders, da hier im Einzelfall das schlüssige Verhalten $\mathrm{zu}$ analysieren ist.

Insoweit hält Gomille den freiwilligen Besuch für eine ausreichende Einwilligung durch schlüssiges Verhalten. Er geht dabei davon aus, dass der Internetnutzer eine Webseite in Kenntnis und Bewusstsein der Werbefinanziertheit ansteuere. Der Nutzer treffe für sich selbst die Entscheidung, die ihm lästige Werbung hinzunehmen und gerade nicht auf die kostenlosen Inhalte zu verzichten. Auch verweist Gomille auf den Rechtsgedanken von $\mathbb{1} 151$ BGB. Dies schließe eine Persönlichkeitsrechtsverletzung jedenfalls insoweit aus, wie sich die Werbung im Rahmen des Üblichen bewege und der Nutzer sich ihr „rasch und mühelos wieder entziehen“ könne ${ }^{342}$. Dies erfasst nach seiner Ansicht wohl auch übliche Pop-Ups und aggressive Werbeformen, solange sie wie oben beschrieben sofort weggeklickt werden können.

Anderer Ansicht mit Blick auf Pop-Ups ist wiederum Mankowski ${ }^{343}$, der eine stillschweigende Einwilligung alleine für klassische Anzeigen, nicht aber für aggressive Werbeformen gelten lassen möchte. Denn das Vorstellungsbild des Nutzers bei Aufruf einer Webseite seien solche Seiten, die lediglich klassische und eher unauffällige Werbeformen einsetzen. Pop-Ups \& Co. sollen dieses Vorstellungsbild überschreiten und seien deshalb nicht von einer rechtfertigenden Wirkung erfasst. Da der Nutzer vor Besuch der Seite den Content und nicht die belästigende Werbeform wünsche, könne er auch nicht in die Belästigung einwilligen.

Eine Einwilligung durch schlüssiges Verhalten sollte nach hier vertretener Ansicht nur sehr zurückhaltend bejaht werden. Vor allem sollten Verallgemeinerungen vermieden und der jeweilige Einzelfall in den Blick genommen werden. Durch die erhebliche Vielzahl verschiedener aggressiver Werbeformen kann kein genereller Freibrief erteilt werden wie es Gomille vertritt. Wie bereits oben dargestellt ist auf zwei maßgebliche Voraussetzungen für die Einwilligung abzustellen - die Kenntnis bzw. Erkennbar-

341 BGH, Urteil vom 9.9.2004 - I ZR 93/02, NJW 2005, 1050 - Ansprechen in der Öffentlichkeit II.

342 Gomille, GRUR 2017, 241, 244.

343 Mankowski, in: Fezer/Büscher/Obergfell, UWG, S 12, Rn. 149e, 159f.. 
keit der Belästigung sowie die Freiwilligkeit. Eine abstrakte Erkennbarkeit von aggressiver Werbung mag im Internet immer gegeben sein, reicht aber für eine konkrete Einwilligung nicht aus. Die Kenntnis muss sich insoweit manifestieren, dass der Nutzer die Werbung auch als unzumutbare Belästigung im oben dargestellten Sinne erkennt. Da eine Internetwerbung nur im Ausnahmefall eine unzumutbare Belästigung darstellen wird, sind an die Kenntnis des Nutzers hohe Voraussetzungen zu stellen. Diese Kenntnis kann eigentlich nur beim kurzzeitig aufeinanderfolgenden Besuch einer bestimmten Webseite vorliegen, weil dann der Nutzer im ersten Besuch der betreffenden Werbung bereits ausgesetzt war und ihn dies - im Gegensatz zum Durchnittsadressaten - scheinbar nicht weiter gestört hat. Da Werbungen auf Webseiten regelmäßig nach wenigen Stunden bereits ausgetauscht werden, wäre schon der nächste Besuch nach mehreren Stunden normalerweise nicht mehr in Kenntnis der bevorstehenden Belästigung. Dies könnte nur dann anders gesehen werden, wenn eine bestimmte Seite immer die gleiche belästigende Werbeform einsetzt, was eher selten der Fall ist. Die für die Einwilligung notwendige Kenntnis setzt damit eine vorhergehende vollständige Verwirklichung von $\$ 7$ Abs. 1 UWG voraus, welche an sich schon zur Unzulässigkeit der Werbeform und zu einem Unterlassungsanspruch nach $\mathbb{8} 8$ Abs. 1 UWG bzw. $\$ \$ 1004$ BGB analog iVm $\$ 823$ Abs. 1 BGB führt. Damit ist die Einwilligung durch schlüssiges Verhalten immer nur für die zweite gleichgelagerte unzumutbare Belästigung möglich. Für die erste Belästigung ist eine ausdrückliche Einwilligung nötig.

Im Rahmen eines Urteils könnte deshalb die Frage der Freiwilligkeit der Einwilligung des Nutzers offenbleiben. Dies wäre auch aus dem Grunde möglich, weil die Freiwilligkeit in logischer Verknüpfung zur Kenntnis steht. Denn nur was der Nutzer kennt, kann er freiwillig tolerieren. Bei fehlender Kenntnis ist der Nutzer unfreiwillig mit der Werbung konfrontiert. Zur erschöpfenden Diskussion der Frage, ob der Besuch einer Webseite bereits eine freiwillige Preisgabe des Schutzes der eigenen Privatsphäre darstellt, soll hier gleichwohl ein Beitrag gegeben werden. In diesem Zusammenhang erscheint es befremdlich, den Zeitpunkt der Freiwilligkeit auf den Zeitpunkt des Besuchs der Webseite vorzuverlegen. Denn die Voraussetzungen für die Einwilligung müssen im Zeitpunkt der sie betreffenden Tat vorliegen. Auch im Übrigen deliktischen Bereich würde nur selten eine schlüssig erklärte Einwilligung anzunehmen sein, wenn das Opfer einer Tat sich vorher freiwillig in eine fremde Einflusssphäre begibt. Als Beispiel könnte der Besuch eines Verkaufsraums gesehen werden, der nicht die generelle Einwilligung in die beliebige Verletzung eigener 
Rechtsgüter durch dort tätige Angestellte gibt. Man stelle sich vor, der Verkäufer würde den Besucher direkt bei Besuch und danach wiederkehrend und unterbrechend mit Angeboten Dritter enthaltenden großformatigen Bildern oder mit Werbung aus Lautsprechern oder auf Bildschirmen behelligen. In diesem Fall würde auch niemand argumentieren, dass dies die „Gegenleistung“ des Kunden für den Aufenthalt im Waren ausstellenden Verkaufsraum sei. Der Besuch einer Webseite ist auch nicht mit der

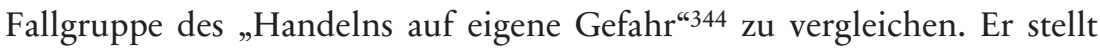
eben nicht ein Äquivalent zum Einsteigen in ein von einem Betrunkenen gesteuerten Pkw dar ${ }^{345}$.

Wenn ein Nutzer freiwillig eine beliebige Webseite ansteuert ist damit noch nicht zwangsläufig die Ausspielung einer aggressiven Werbung verbunden. Auf den freiwilligen Besuch abzustellen, führt hingegen dazu, dass der Nutzer durch jeden Besuch einer Webseite eine generelle Einwilligung in alle denkbaren Belästigungen abgeben würde. Ein solch weitgehender Verzicht auf eigene Abwehrrechte kann aber einem schlüssigen Verhalten nur kaum entnommen werden. Auch ist es schwierig, aus dem konkludenten Verhalten des Besuchs einer Webseite eine Beschränkung auf nur bestimmte Werbeformen zu folgern. So scheint Gomille dem faktischen Besuch einer Webseite im Grundsatz eine rechtfertigende Wirkung beizumessen, es sei denn sie überschreite das übliche Maß. Dies würde dazu führen, dass dem schlüssigen Verhalten ein komplexerer Erklärungsinhalt entnommen wird, als dieser regelmäßig bei ausdrücklichen Erklärungen zu erwarten ist. Dies geht zu weit, zumal kein Anhaltspunkt vorliegt, was das Übliche überschreitet. Die Einwilligung darf nicht zur zweiten Interessenabwägung im Abstrakten werden, sondern muss den konkreten Einzelfall in den Blick nehmen. Der freiwillige erstmalige Besuch einer Webseite ist in erster Linie die Inanspruchnahme einer für den Nutzer kostenfreien Leistung ohne weitere vertragliche Bindung. Demnach lassen sich diesem tatsächlichen Handeln auch keine komplexen „Geschäftsbedingungen" anhängen, die der Nutzer bei wirklicher Wahlmöglichkeit nur selten wählen würde. Auch hier läge erst beim zweiten Besuch derselben Webseite eine deutliche Freiwilligkeit vor.

Die Anwendung einer rechtfertigenden Einwilligung ist deshalb zwar nicht völlig undenkbar. Ihr Anwendungsbereich ist aber sehr einge-

344 Zur dogmatischen Einordnung des BGH des „Handelns auf eigene Gefahr“ vgl. Wagner, in: MüKo/BGB, $\mathbb{8} 823$, Rn. 79ff.Im Ergebnis zwar keine Frage der Einwilligung, aber Erzielung ähnlicher Ergebnisse über $\$ 254$ BGB.

345 Vgl. den Fall bei BGH, Urteil vom 14.3.1961 - VI ZR 189/59, NJW 1961, 655. 
schränkt und praktisch kaum fruchtbar zu machen, es sei denn zur Vermeidung unbilliger Rechtsdurchsetzung.

\section{(4) Sonderfall: Schließen-Buttons}

Auf einer nachgelagerten Stufe stellt sich das Problem der Ausgestaltung von Schließen-Buttons. Erörterungswürdige Fälle liegen vor, wenn der Button zum Schließen oder Minimieren nicht an gewohnten Stellen zu finden ist oder unübliche Gestaltungen aufweist. Dies betrifft nur Werbeformen, die kein separates Browserfenster öffnen, da bei solchen Fenstern der Button immer an der betriebssystemtypischen Stelle zu finden ist (bei Windows Browsern immer rechts oben, beim Mac Browser Safari immer links oben).

Dieser Gewohnheit folgend sollten fensterintegrierte Pop-ups oder expandierende Werbeformen die Schaltfläche zum Schließen oder Minimieren möglichst am oberen rechten oder linken Rand der Anzeige aufweisen. Auch großflächigere Buttons am unteren Rand der Anzeige sind noch hinnehmbar. In solchen Fällen kann der Button kein hinzutretender, eine Unzumutbarkeit begründender Umstand $\operatorname{sein}^{346}$. Befindet sich der Button hingegen außerhalb der im Vordergrund stehenden Anzeige in einem anderen Bereich des Fensters, ist dies anders zu beurteilen. Dann muss der Internetnutzer nämlich regelmäßig erst nach dem Button suchen. Dies stellt einen Umstand dar, der eine ggf. durch die bloße dynamische Werbeform noch nicht vorliegende Unzumutbarkeit die Grenze zur unzumutbaren Belästigung überschreiten lässt. Einerseits wird in einem solchen Fall eine intensivere Form der Aktivität vom Nutzer abverlangt. Er muss die Anzeige nicht nur aktiv schließen, sondern bevor er dies bewerkstelligen kann, muss er zunächst das gesamte geöffnete Fenster visuell erfassen und den maßgeblichen Bereich identifizieren, in dem der Button sich befindet. Insbesondere bei der Verbindung mit multimedialen Inhalten, bewegten Bildern oder Videos läuft die Suche konträr zu der Aufmerksamkeit erhaschenden Anzeige und erfordert eine Unterbindung der natürlichen

346 So auch LG Berlin, Urteil vom 11.9.2012 - Az. 16 O 619/11, zitiert nach Czernik, MMR 2014, 44, 46f.Dies war die Vorinstanz zum Urteil des KG, a.a.O. Das LG hatte sich mit der Frage der Positionierung und Ausgestaltung des Schließen-Buttons für die Banderole Ad zu befassen. Diese Ausführungen begegneten keinen Bedenken durch das KG, weshalb diese rechtliche Frage im Berufungsurteil keinen Wiederklang fand. 
Aufmerksamkeitslenkung auf die Bewegung auf dem Bildschirm und die gewollte Suche eines statischen Elements. Andererseits wird die Dauer der Anzeige der dynamischen Werbung, wenn auch teilweise nur geringfügig, verlängert. Dabei nimmt der Nutzer, vor allem bei mit der Anzeige verbundenen Tonelementen, notwendigerweise mehr Informationen von der ihm ungewollten Werbung auf, als dies im Normalfall des gewohnten Platzes des Buttons geschehen würde. Der Nutzer muss also mehr Zeit aufwenden zur Suche und ihm wird in längerer Dauer in zumindest passiver Wahrnehmung Information verabreicht. Damit wird stärker in seine Individualsphäre eingegriffen als bei üblicher Positionierung der Buttons.

Zur Veranschaulichung sollen die folgenden Beispiele dienen:

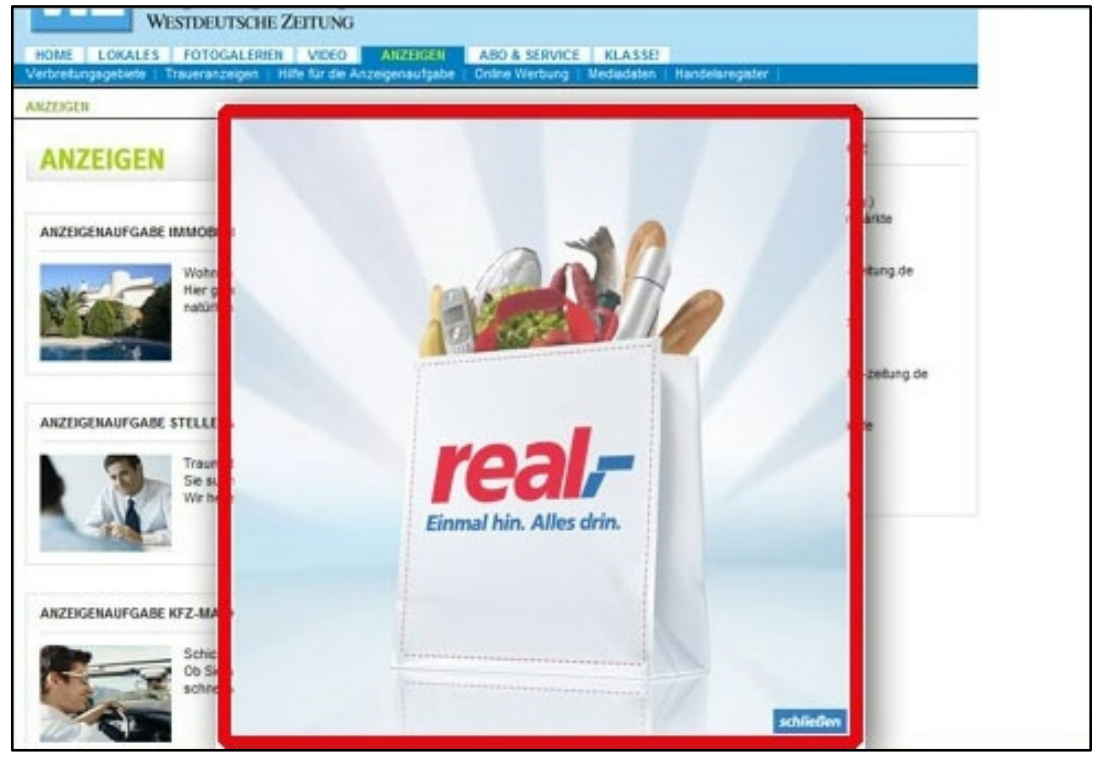

Beispiel ${ }^{347}$ einer Layer Ad von Real mit Schließen-Button an der unteren rechten Seite innerhalb der Anzeige. Dies stellt nach hier vertretener Ansicht keinen besonderen Umstand im Rabmen der Zumutbarkeitsabwägung dar, weil die Schaltfläche leicht erkennbar ist.

347 https:/www.die-zeitungen.de/media/faq/online-werbeformen.html, zuletzt abgerufen am: 30.5.2019. 


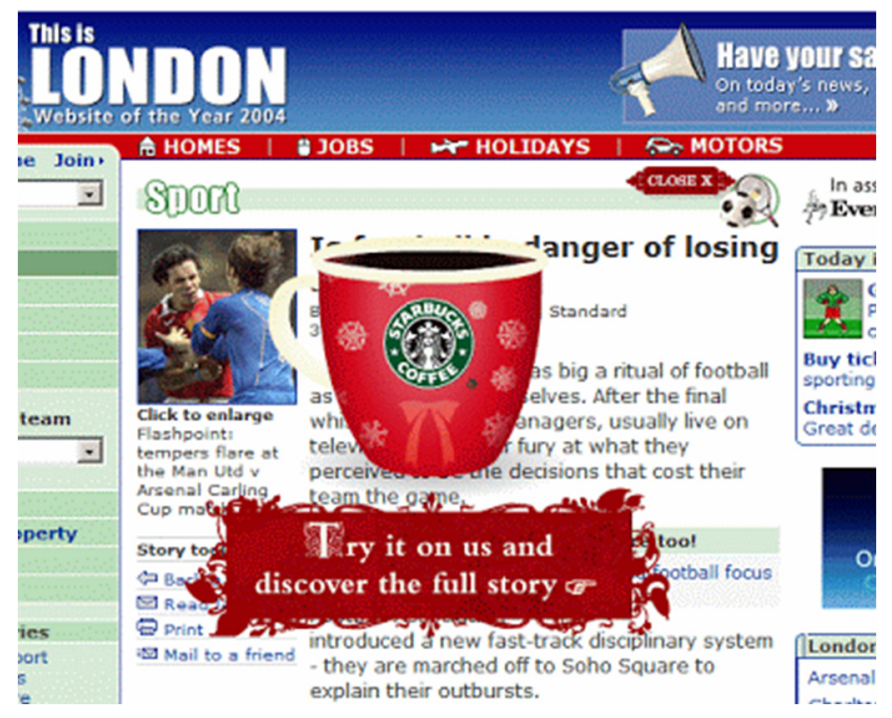

Beispiel $^{348}$ für eine Layer Ad von Starbucks mit "Close"-Button außerbalb der Anzeige, aber an einer gewohnten Stelle am (gedachten) rechten oberen Rand. Dies ist kritischer zu prüfen - im konkreten Einzelfall ist der Button durch die farbliche Gestaltung allerdings relativ leicht zu finden. Eine Unzumutbarkeit liegt eher fern.

348 http://sugarbunnie-ads.blogspot.de/2009/01/ever-since-augmentation-of-technola gy.html, zuletzt abgerufen am: 30.5.2019. 


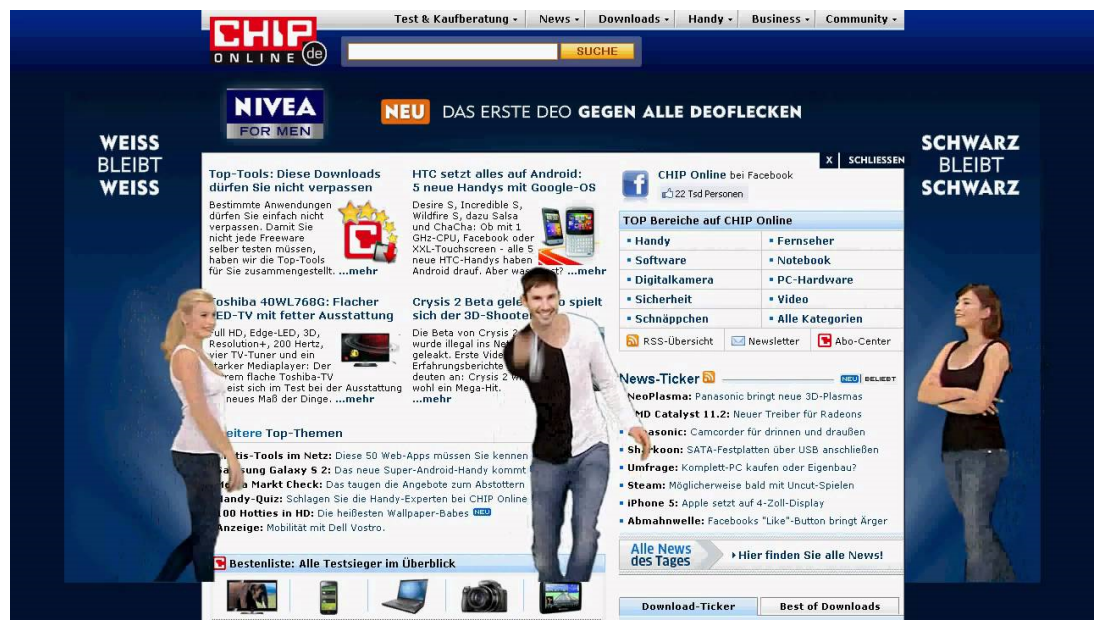

Beispiel ${ }^{349}$ für eine animierte Layer Ad von Nivea mit optisch unauffälligem Schliessen-Button, der zwar am oberen rechten Rand des Contents positioniert ist, aber als eines von vielen Elementen in einem Fenster etwas schwieriger zu finden ist. Solche Werbeformen erfordern die Suche nach dem Button und bleiben dadurch (geringfügig) länger in der zumindest passiven Wabrnehmung des Nutzers. Eine unzumutbare Belästigung nach $\mathbb{} 7$ Abs. 1 UWG ist in diesem Fall zu erwägen.

Die unzumutbare Belästigung durch unübliche Anordnung des SchließenButtons sollte jedoch nur bei Extremfällen angenommen werden. Solche Extremfälle sind erfreulicherweise zur Zeit der Bearbeitung nicht sehr verbreitet.

Neben der Positionierung der Buttons ist auch die Ausgestaltung der Buttons mit Worten oder Symbolen ein näher zu betrachtender Umstand. Insoweit hatte das LG Berlin ${ }^{350}$ im Fall einer Banderole Ad entschieden, dass die Zeichen ",> " bei einer von rechts nach links eingeblendeten Anzeige eine ausreichende Gestaltung des Buttons zum Minimieren darstellt. Dies folge daraus, dass die Zeichen für die Funktion des Buttons selbsterklärend seien. Eines „x“-Symbols entsprechend dem Button bei Windows Fenstern bedürfe es jedenfalls nicht.

349 Screenshot aus einem Video, abrufbar unter https://www.youtube.com/watch?v $=0 \mathrm{kVlHHos} 0 \mathrm{LY}$, zuletzt abgerufen am: 30.5.2019.

350 KG, Urteil vom 18.10.2013 - 5 U 138/12, MMR 2014, 44, 46f.. 
Diese Entscheidung ist vollkommen zutreffend. Insbesondere muss nicht zwangsläufig ein „x“-Symbol genutzt werden, weil ein „x“ schon nicht die einzige gebräuchliche Kennzeichnung von Schließen-Buttons darstellt. So werden solche Buttons bei Mac Fenstern durch einen schwarzen Punkt in einem roten Kreis gekennzeichnet. Für viele Nutzer ist deshalb ein Zeichen wie ein schwarzer Punkt gleichbedeutend mit einem „x“. Folglich können auch andere Symbole genutzt werden, wenn diese selbsterklärend sind. Vor allem bei expandierenden Anzeigen ist die Nutzung von Pfeilen oder „> “-Symbolen selbsterklärend für die Minimierung. Wenn keine Symbole benutzt werden sollen, sind allgemein verständliche Worte zu nutzen wie „schließen“, „verkleinern“ oder auch die geläufigen englischen Worte wie „close“ oder „reduce“ 351.

Ein Umstand, der zur Unzumutbarkeit führen kann, ist dabei nur denkbar, wenn zwar ein Button vorhanden ist, dieser aber so ausgestaltet ist, dass nicht klar ist, dass er zum Schließen oder Minimieren führt. Ein solcher Fall ist schwer denkbar und praktisch nicht existent. Praktische Bedeutung käme diesem Umstand allein zu, wenn überhaupt kein Button existieren würde, sondern der Klick neben eine Anzeige zum Schließen führen würde. Dann könnte der Nutzer sich auf die Suche nach einem Button begeben und mangels Fundes eines solchen längere Zeit verbringen und die Anzeige zumindest passiv wahrnehmen. Ein Pop-Up oder eine expandierende Anzeige ganz ohne Schließen-/Minimieren-Button dürfte ohne Weiteres zur Unzumutbarkeit führen, gleich ob das Verlassen unmöglich ist oder diese Möglichkeit mangels sichtbarer Schaltfläche nicht wahrnehmbar ist. Der erste Fall ist unproblematisch. Im zweiten Fall ist es dem Nutzer nicht zumutbar, erst einen gewöhnlich zu erwartenden Button zu suchen, ihn nicht zu finden und dann auf „gut Glück“ zu klicken $^{352}$.

Insgesamt können Buttons damit den entscheidenden Schritt in die Unzumutbarkeit begründen. Dafür müssen aber schon besondere Fälle vorliegen, die den Nutzer zu einer Suche veranlassen und zumindest eine geringfügig längere Anzeige der Werbung herbeiführen.

351 Ebenso: Steinmetz, Apps im Lauterkeitsrecht, S. 271.

352 Vgl. auch die ergänzenden Gedanken zur einfachen Bedienbarkeit, v.a. bei Touchscreens, bei Steinmetz, Apps im Lauterkeitsrecht, S. 271. 
Nach alledem sind folgende Anzeigenformen nach allen im Schriftum vertretenen Ansichten als unzumutbare Belästigung im Sinne von $\$ 7$ Abs. 1 S. 1 UWG anzusehen:

- Anzeigen, die beim Klicken auf einen Button zum Schließen oder Ähnliches eine neue Anzeige öffnen, die wiederum geschlossen werden muss. Dies stellt die Abstrahierung der „Exit Pop-Up“ Entscheidung des LG Düsseldorf ${ }^{353}$ dar, die allenthalben als zutreffend befürwortet wird. Dieser Fall dürfte sogar unter $\$ 7$ Abs. 2 Nr. 1 UWG zu fassen sein.

- Anzeigen, die nicht automatisch schließen und keinen Button zum Schließen oder Minimieren innerhalb kurzer Zeit zur Verfügung stellen. Als kurze Zeit kann dabei nur der Zeitraum anzusehen sein, der dafür erforderlich ist, dass ein durchschnittlicher Internetnutzer eine durchschnittliche Anzeige erfassen und die Werbebotschaft erkennen kann. Dieser Zeitraum wird nach hier vertretener Ansicht auf drei Sekunden geschätzt. Jede längere Bindung an die Anzeige überschreitet die Schwelle zur Unzumutbarkeit.

- Innerhalb eines Fensters geöffnete Pop-Ups oder dynamische, expandierende Werbeformen, die über keinen Button zum Schließen oder Minimieren verfügen, gleich ob ein Klick neben die Anzeige zum Schließen führt.

Umstritten und nach hier vertretener Ansicht eine unzumutbare Belästigung sind die folgenden Werbeformen:

- Innerhalb eines Fensters geöffnete Pop-Ups oder dynamische, expandierende Werbeformen, die über einen Button zum Schließen oder Minimieren verfügen, der aber erst nach vollständigem Laden der für die Anzeige der Werbung notwendigen Daten eingeblendet wird.

- Das Einblenden von drei oder mehr Pop-Ups oder anderer dynamischer, expandierender Werbeformen während einer Session, d.h. dem Aufruf mehrerer Unterseiten, auf einem verbundenen und unter einer bestimmten Domain verfügbaren Webportal („hartnäckige Pop-UpWerbung").

- Seiten mit exzessivem Gebrauch von In-Text-Werbung, d.h. verlinkter Worte im Fließtext, die bei Mouse-over automatisch Pop-Up Fenster oder Layer Ads öffnet. Exzessiver Gebrauch sollte in Konkordanz mit

353 LG Düsseldorf, Urteil vom 26.3.2003 - 2a O 186/02, MMR 2003, 486. 
dem vorgenannten Fall ab drei verlinkter Worte anzunehmen sein und einen Sonderfall der hartnäckigen Pop-Up-Werbung darstellen.

- Dynamische, in einem Browserfenster integrierte Werbeformen, die sich zwar selbst schließen, dies aber erst nach einer vom Webseitenbetreiber und/oder Werbenden bestimmten Zeit tun, ohne eine Option zum Schließen oder zum sonstigen Wahrnehmungsentzug zu eröffnen. Eine Bagatellgrenze mag bei automatischem Schließen innerhalb von drei Sekunden anzunehmen sein.

- Innerhalb eines Fensters geöffnete Pop-Ups oder dynamische, expandierende Werbeformen, die über einen Button zum Schließen oder Minimieren verfügen, wobei dieser Button an ungewohnter Stelle positioniert wird und den Nutzer deshalb zum Suchen zwingt.

Umstritten, aber nach hier vertretener Ansicht noch im Bereich des Zumutbaren, sind hingegen folgende Phänomene:

- Pop-Ups oder dynamische, expandierende Werbeformen, die sofort, d.h. spätestens nach drei Sekunden weggeklickt werden können.

- Pop-Under Werbung, die sofort weggeklickt werden kann, soweit ein Webseitenbetreiber keinen übermäßigen Gebrauch von dieser Werbeform macht. Übermäßiger Gebrauch kann schon ab dem zweiten PopUnder-Fenster anzunehmen sein.

\section{(iii) Interstitials und Prestitials}

Bei Interstitials, also Werbeunterbrechungen beim Surfen auf einer Webseite zwischen zwei Unterseiten bzw. zwei Seitenelementen, und Prestitials, also Vorschaltwerbung vor Anzeige der aufgerufenen Homepage oder eines bestimmten Seiteninhalts, stellt sich im Großen und Ganzen dieselbe Problematik wie bei dynamischen Anzeigen. Sie unterscheiden sich jedoch darin, dass sie das gesamte Fenster oder bei Elementen wie Videoframes zumindest den gesamten für diesen Inhalt vorgesehenen Bereich beanspruchen (Pre-Roll oder Mid-Roll Werbevideos). Zudem enden sie wesensgemäß automatisch und geben den gewünschten Content wieder frei. Deshalb besteht bei dieser Werbeform nicht das zwingende Erfordernis, dass der Nutzer eine aktive Handlung vornimmt. Regelmäßig ist aber möglich, dass der Nutzer nach einer gewissen Zeit durch aktiven Klick die voreingestellte Anzeigezeit verkürzt und vorzeitig zum eigentlichen Ziel weitergeleitet wird. Insofern kommt auch hier dem Zeitfaktor eine enorm hohe Bedeutung zu. 


\section{(1) Ergangene Rechtsprechung}

Für diese Werbeform stehen zwei Gerichtsentscheidungen zur Verfügung, die die Beurteilung nach $\$ 7$ Abs. 1 UWG betreffen. Zunächst hat das LG Berlin im Jahre 2010 geurteilt, dass ein Interstitial, das sich nach fünf Sekunden durch einen Klick vorzeitig beenden lässt, keine unzumutbare Belästigung im Sinne von $\$ 7$ Abs. 1 UWG darstelle ${ }^{354}$. Der Entscheidung lag ein Interstitial zu Grunde, das nach der Auswahl eines Seiteninhaltes - im konkreten Fall ein Browserspiel auf einer Webseite mit diversen an Kinder adressierten Browserspielen - nach zehn Sekunden automatisch verschwand und nach fünf Sekunden bereits weggeklickt werden konnte. Dies überschreite die Schwelle zur Unzumutbarkeit nicht, da der Nutzer sich der Werbung nach kurzer Zeit entziehen könne. Die Belastungsintensität liege damit „weitgehend in seiner Hand“.

Im selben Urteil urteilte die Kammer des LG Berlin aber auch, dass ein Interstitial ohne Beseitigungsmöglichkeit eine unzumutbare Belästigung im Sinne von $\mathbb{\$} 7$ Abs. 1 UWG darstelle ${ }^{355}$. Dies wurde begründet mit dem den Nutzern auferlegten Zwang, die Werbung abzuwarten. Der Nutzer könne sich der Werbung nur durch Schließen des Browserfensters entziehen, was nicht hinnehmbar sei. In diesem Zusammenhang relativierte das LG Berlin auch ausdrücklich das Refinanzierungsinteresse der Webseitenbetreiber. Dieses Interesse sei zwar gerechtfertigt, da aber auch weniger intensive Werbeformen zur Verfügung stünden und von anderen Webseitenbetreibern eingesetzt würden, ohne dass diese ihren Geschäftsbetrieb einstellen mussten, könne es nur im beschränkten Maße fruchtbar gemacht werden. Etwas aus dem Zusammenhang gerissen wirft das LG Berlin zudem die Frage auf, ob eine so intensiv belästigende Werbeform wie ein nicht vorzeitig wegklickbares Interstitial überhaupt eine effektive Werbung darstellen könne. Es lässt diese Frage dann offen.

Das LG Berlin hat damit erstmals eine Leitlinie für Unterbrechungswerbung im Internet gegeben und zwar für die Werbebranche sehr konkret: Interstitials ohne vorzeitige Beseitigungsmöglichkeit sind per se unzulässig und wenn die Beseitigungsmöglichkeit gegeben ist, sind bis zu fünf Sekunden noch im Bereich des Zumutbaren.

Ein weiterer gleichgelagerter Fall über Werbung auf einer Webseite mit Browserspielen für Kinder wurde vom OLG Köln etwas später im Jahr

354 LG Berlin, Urteil vom 14.9.2010 - 103 O 43/10, GRUR-RR 2011, 332.

355 LG Berlin, Urteil vom 14.9.2010 - 103 O 43/10, GRUR-RR 2011, 332. 
2013 entschieden ${ }^{356}$. Auch hier war die zu bescheidende Werbeform ein Interstitial, das insgesamt zehn Sekunden Laufzeit hatte und bereits nach fünf Sekunden weggeklickt werden konnte. Der Senat in Köln bestätigte die Entscheidung aus Berlin und lehnte eine unzumutbare Belästigung ab. Zwar liege eine Belästigung durch die Werbeeinblendung vor, da sie teils überraschend, jedenfalls aber störend sei. Die Grenze zur Unzumutbarkeit sei aber nicht überschritten. Durch die vorzeitige Beseitigungsmöglichkeit sei der Zeitverlust als gering anzusehen. In diesem Zusammenhang stützt sich das OLG Köln auf „die ganz überwiegende Ansicht“ wonach es für die Zulässigkeit eines Interstitials ausreichend sei, dass es innerhalb kurzer Zeit weggeklickt werden kann oder alsbald von selbst verschwindet. Ergänzend argumentiert der Senat, dass der Besucher eigeninitiativ die Webseite zum Freizeitvergnügen aufsuche. Im Rahmen des Refinanzierungsinteresses widersprechen die Kölner Richter den Kollegen aus Berlin, indem sie es für den Webseitenbetreiber nicht als zumutbar erachten, dass dieser nicht die aggressiven Interstitials, sondern nur weniger attraktive Werbebanner nutzen darf. Denn durch die höhere Refinanzierung erhalte schlussendlich der Nutzer einen Vorteil durch bessere Angebote. Auch die Summenwirkung mehrerer Interstititials auf einem Portal bzw. generell am Markt nennt das OLG Köln als denkbares Argument für eine Unzumutbarkeit. Doch es verwirtt diesen Gedanken ohne tiefergehende Auseinandersetzung.

\section{(2) Meinungsstand in der Literatur}

Diese beiden Urteile wurden in der Zeitschriftenliteratur kommentiert und in der bereits oben im Zusammenhang mit Pop-Ups dargestellten Literatur rezipiert. Das Urteil des LG Berlin wurde insoweit von Rauda dafür kritisiert, dass es ein Interstitial ohne vorzeitige Beseitigungsmöglichkeit als unzumutbare Belästigung angesehen hat ${ }^{357}$. Er sieht darin eine bevormundende Haltung des Gerichts, die den Webseitenbetreibern ein bestimmtes Geschäftsmodell vorschreibe. Dies folgert Rauda aus der Argumentation des Landgerichts, die Finanzierung durch aggressive Werbeformen sei nicht schutzwürdig, weil weniger belastende Werbeformen zur Verfügung stünden. Der Kommentator kritisiert vornehmlich, dass das Gericht nicht für die Beurteilung der Effektivität und die ökonomische

356 OLG Köln, Urteil vom 12.4.2013 - 6 U 132/12, MMR 2014, 51.

357 Rauda, GRUR-RR 2011, 332. 
Sinnhaftigkeit von Internetwerbeformen zuständig sei. Im Übrigen konstatiert Rauda, dass der Nutzer nicht schutzwürdig sei. Denn er sei nicht angewiesen auf eine Freizeitbeschäftigung wie ein Browserspiel. Wer eine Wartezeit von 20 Sekunden nicht aufbringen möchte, solle die Webseite verlassen. Der Erfolg der Webseitenhersteller messe sich daran, ob ihr Angebot ausreichend attraktiv ist, dass es Nutzer zur Tolerierung der Werbung animiere. Dies stelle eine Frage des Markts, nicht des Rechts dar. Mit einem Vergleich zum Exit-Pop-Up-Fall des LG Düsseldorf ${ }^{358}$ möchte Rauda zudem die nur marginale Belästigung des Nutzers herausarbeiten. Insgesamt stellt er also - zuletzt auch unter Vergleich mit Werbeblöcken im TV - das Refinanzierungsinteresse der Medienanbieter über das Zeitmoment der nutzerseitigen Wahrnehmungspflicht. Diese Anmerkung von Rauda hat das OLG Köln ausdrücklich aufgegriffen und sich mit seinem Refinanzierungsargument von der Auffassung der Berliner Richter abgegrenzt $^{359}$.

Ferner übt Lüghausen knappe Kritik an der Entscheidung des LG Berlin über die Unzulässigkeit von Interstitials, indem er auf die Freiwilligkeit des Zugriffs durch den Nutzer und die Einfachheit für ihn, sich der Werbung zu entziehen, verweist ${ }^{360}$.

In der übrigen Literatur wird nur selten wesentlich zwischen Pop-UpWerbung im weiteren Sinne und Interstitials unterschieden. Insbesondere Mankowski, der größte Kritiker der Pop-Ups, differenziert in seinen Ausführungen nicht zwischen verdeckenden Werbeformen und Vorschaltwerbung ${ }^{361}$. Burmeister ${ }^{362}$, Menebröcker ${ }^{363}$ und Leible ${ }^{364}$ wenden auf Interstitials in knappen Ausführungen dieselben Argumentationsmuster an und kommen somit zu übereinstimmenden Ergebnissen bei der Zumutbarkeitsabwägung wie bei Pop-Ups. In der Kommentarliteratur werden beide Werbeformen in der Regel im selben Atemzug miteinander genannt ${ }^{365}$. Weitere Beachtung schenkt allein Leible der Thematik ${ }^{366}$, der Interstitials mit Fernsehwerbung vergleicht und deshalb die Entscheidung des LG

358 LG Düsseldorf, Urteil vom 26.3.2003 - 2a O 186/02, MMR 2003, 486.

359 OLG Köln, Urteil vom 12.4.2013 - 6 U 132/12, MMR 2014, 51.

360 Lüghausen K\&R 2011, 458, 460f..

361 Mankowski, in: Fezer/Büscher/Obergfell, UWG, S 12, Rn. 149ff..

362 Burmeister, Belästigung als Wettbewerbsverstoß, S. 97, 104.

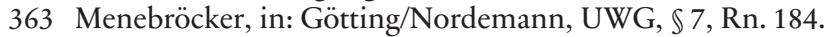

364 Leible, in FS Köhler, 403, 410.

365 Köhler/Bornkamm/Feddersen, UWG, $\mathbb{~ 7 7 , ~ R n . ~ 9 3 ; ~ O h l y / S o s n i t z a , ~ U W G , ~} \mathbb{} 7$, Rn. 95; Schöler, in: Harte-Bavendamm/Henning-Bodewig, UWG, $\mathbb{S}$ 7, Rn. 131.

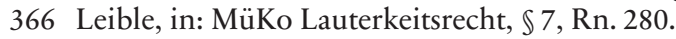


Berlin kritisiert, wonach ein 20-sekündiges Interstitial ohne vorzeitige Beseitigungsfunktion unzulässig sei. Dabei argumentiert auch er mit der Freiwilligkeit des Seitenaufrufs sowie der jederzeitigen Möglichkeit des Nutzers, die Seite zu verlassen, und mit dem Refinanzierungsargument.

\section{(3) Stellungnahme}

Die fehlende Differenzierung zwischen den Werbeformen ist dabei vordergründig nachvollziehbar. Bei genauem Hinsehen sollte aber sehr wohl zwischen Pop-Ups oder dynamischen, expandierenden Werbeformen und Interstitials unterschieden werden. Denn beide Werbeformen weisen tatsächliche Unterschiede bei der Erscheinung im Browser der Nutzer auf. Wenn Pop-Ups entweder ein neues Browserfenster öfnen und damit insgesamt von der Hauptseite isoliert sind, oder als Layer im Fenster über dem Content liegen, stellen sie eine partielle Verdeckung des gewünschten Inhalts dar. Das gleiche gilt für Werbeformen, die über den Content expandieren. Ein Prestitial hingegen ist eine klassische Vorschaltwerbung, ein Interstitial eine klassische Unterbrechungswerbung. Beide Formen können entweder die gesamte Seite betreffen, was praktisch eher selten zu beobachten ist. Regelmäßig sind Prestitials oder Interstitials als In-Stream-Werbung bei Audio- oder Videostreams zu finden (Pre-Roll- oder Mid-Roll-Werbung). Analog zu dieser In-Stream-Werbung sind auch die Interstitials bei Browserspielen wie bei den Fällen des LG Berlin und OLG Köln, weil auch hier ein besonderes Feature einer Werbeseite mit der Vorschaltwerbung verbunden wurde. In all diesen Fällen wird der meist kostenfreie Konsum des gewünschten Mediums sozusagen mit Werbung vinkuliert.

Um einen Vergleich mit den hergebrachten Medien zu wagen, wäre klassische Anzeigenwerbung durch Werbebanner das digitale Pendant zu Printmedien, Pre- und Interstitials jenes zu Radio- und TV-Werbung. Nur Pop-Ups und sonstige dynamische Werbeformen finden kein passendes Gegenstück in den klassischen Medien. Dies legt nahe, dass eine unterschiedliche Beurteilung von Pop-Ups \& Co mit Interstitials durchaus gerechtfertigt ist.

Andererseits ist auch bei Interstitials die technische Ausgangslage internetspezifisch. Denn anders als beim Radio und Fernsehen erfolgt gerade keine lineare Sendung redaktioneller Inhalte. Im Internet als Pull-Medium stellt sich der Nutzer sein „Programm“ selbst zusammen. Deshalb sollte ein Vergleich mit Rundfunkwerbung nur zögerlich angewendet werden. Dies sollte zudem im eigenen Interesse der Werbetreibenden in diesem 
Bereich sein. Denn wer sich auf die gleichen „Werbefreiheiten“ beruft wie sie Rundfunkanbieter haben, der müsste folgerichtig auch Beschränkungen unterliegen wie sie im Rundfunkstaatsvertrag niedergelegt sind. Insbesondere mit Blick auf Gesamtdauer von Werbeeinblendungen gegenüber einem Nutzer während einer Internetsitzung.

Folglich ist auch hier die „Internetbrille“ aufzusetzen, wobei sie eine etwas andere Tönung als bei den vorgenannten Werbeformen haben sollte. Dabei ist innerhalb der Pre- und Interstitials zu unterscheiden zwischen den Fällen, in welchen die ganze Webseite durch Vorschalt- oder Unterbrechungswerbung blockiert wird und solchen, in denen nur einzelne besondere Elemente wie Videoframes oder Browserspiele mit der Werbung versehen werden.

Im ersten Fall wird die gesamte Seite für Werbung genutzt und der Zugang zu Informationen kurzzeitig verhindert. Dies ähnelt einer überdimensionierten Pop-Up-Werbung, die den Blick auf den eigentlich gewollten Content verwehrt. Hier spricht sehr vieles dafür, dass für diese aggressive Anzeigenform dasselbe gilt wie für Pop-Ups und expandierende Anzeigen. Ein ganzseitiges Interstitial ist faktisch die größtmögliche Ausgestaltung der aggressiven Display-Werbeformen. Zwar mag es regelmäßig automatisch verschwinden. Es hält den Nutzer trotzdem gezwungenermaßen an Werbung fest. Hier müssen folglich dieselben Grundsätze wie bei Pop-Ups gelten. Jede erzwungene und die Bagatellgrenze überschreitende Wahrnehmungspflicht ist als unzumutbare Belästigung anzusehen.

Der zweite Fall betrifft Pre-Roll- oder Mid-Roll-Werbung, die besonders bei Videostreams dem Großteil der Nutzer bereits begegnet sein dürften. Hier liegt die Sachlage jedoch etwas anders. Denn bei vielen Multimediaportalen, seien es YouTube oder Mediatheken von Fernsehsendern, werden angesteuerte Videos nicht auf der gesamten Größe des Browserfensters eingeblendet (anders bei Apps im Smartphone-Bereich, wo der ganze Bildschirm beansprucht wird). Die vorgeschalteten oder unterbrechenden Werbungen behindern deshalb im Grundsatz nur die Wahrnehmung des besonderen Videos. Dem Nutzer bleibt es regelmäßig möglich seine Aufmerksamkeit im Laufe der Anzeige anderen Seitenteilen zuzuwenden, vor allem dem Index vergleichbarer Videos oder Seitenrubriken. Die Belastung nur eines abgegrenzten Teils der Webseite ist in diesem Fall keine ohne seiteninterne Alternative erzwungene Wahrnehmungspflicht, sondern eher eine sehr nachdrückliche Bitte zur Wahrnehmung. Der Nutzer kann aber auch anderen Seiteninhalten sein Augenmerk zuwenden und Textbeschreibungen, Kommentare oder andere Rubriken innerhalb derselben geöffneten Webseite rezipieren. Damit ist ein solches „Teil-Interstitial“ 
mit Blick auf die Belästigungsintensität eher mit klassischen Anzeigen vergleichbar, die nur einen Teil der Webseite für Werbung belegen und um Aufmerksamkeit buhlen.

Auch ein nicht ganz von der Hand zu weisender Gedanke ist, dass Preoder Interstitials vor besonders aufwändigen und deshalb sehr attraktiven Inhalten wie Videos oder Browserspielen ein erhöhtes Refinanzierungsbedürfnis haben. Bei redaktionell gestalteten Videos oder Spielen können die Erstellungskosten beträchtlich höher liegen als bei Text- und Bildinhalten oder einer Startseite, die im Grunde ein Inhaltsverzeichnis darstellt. Beim Aufruf solcher Videos dürfte auch so gut wie jeder Nutzer erahnen, dass die Produktion kostspielig gewesen sein dürfte. Deshalb ist eine Vinkulierung mit Werbung eher gerecht als bei günstigeren Inhalten. Weniger stark, aber auch gültig ist dieser Gedanke bei Webseiten, die keine eigenen redaktionellen Inhalte anbieten, sondern wie YouTube eine Plattform für Nutzervideos darstellen. Hier besteht die Kostenbelastung in der Investition von enormen Speicher- und Serverkapazitäten, die der Refinanzierung bedürfen.

Die zu Pop-Ups \& Co herausgearbeiteten Grundsätze können deshalb nicht schablonenhaft übertragen werden. Vielmehr sind das Zeitmoment auf Seiten des Nutzers und das Refinanzierungsargument der Webseitenbetreiber in ein konkret für die Werbeform ermitteltes, gerechtes Verhältnis zu setzen. Wiederum zu beachten ist die Summenwirkung von mehreren Werbungen bei Abruf mehrerer Videos auf einer Plattform. Dabei stellt die oben dargestellte Entscheidung des LG Berlin bereits eine nutzerfreundliche, aber auch für die Medienanbieter gerechte Lösung dar. Ein Pre- oder Interstitial ist grundsätzlich eine zulässige Werbeform. Die Bindung des Nutzers über 20 Sekunden soll nach dem LG Berlin eine unzumutbare Belästigung darstellen, was aus Nutzersicht absolut zutreffend ist. Der erzwungene Zeitverlust von 20 Sekunden überschreitet die Grenze der Zumutbarkeit auch nach hier eingenommenen Standpunkt. Eine sofortige Beseitigungsmöglichkeit fordert das LG Berlin aber nicht, sondern diese kann nach 5 Sekunden eingerichtet werden. Dies ist ein gerechter Ausgleich, weil der Werbende hier einen gewissen Zeitbonus gutgeschrieben erhält. Er hat wenige Sekunden Zeit die freiwillige Aufmerksamkeit zu gewinnen. Schafft er dies nicht, dann hat er auch kein Recht den Nutzer für eine vom Werbenden vorab mutwillig festgesetzte Zeit zu belästigen. Der Zeitraum von 5 Sekunden ist dabei schon großzügig bemessen und durchaus gerecht. Denn in 5 Sekunden erhält der Werbende eine realistische Chance attraktiv seine Werbung einzuführen. Der Nutzer hat genügend Zeit eine eigene Entscheidung zu treffen, ob er die Werbung 
weiter sehen möchte. Nach diesem Zeitpunkt ist die Einschränkung der Wahrnehmungshoheit des Nutzers aber nicht mehr gerechtfertigt.

In diesem Zusammenhang überzeugen weder die Kritik von Rauda, noch die Ausführungen des OLG Köln. Beide halten das Refinanzierungsargument nämlich für erheblich wichtiger als die zeitlich fixierte Aufmerksamkeitsusurpation. Dem ist ausdrücklich zu widersprechen. Denn insbesondere Raudas Kommentar zeigt eine einseitige Sicht aus Perspektive der Werbeindustrie. Wie bereits im Rahmen der Pop-Ups ausführlich dargestellt kann ein Webseitenbetreiber gerade nicht allein vor dem Hintergrund seiner Refinanzierungs- und Gewinninteressen dem Nutzer eine Wahrnehmungspflicht nach eigenem Gutdünken auferlegen. Argumente wie die Freiwilligkeit des Aufrufs, die fehlende Wichtigkeit der Nutzung oder die viel beschworene Handlungsalternative, die Seite insgesamt zu verlassen, greifen hier ebenso wenig wie bei Pop-Ups. Dem Refinanzierungsargument ist tatsächlich ein etwas höherer Stellenwert einzuräumen. Dieser spiegelt sich aber in der zulässigen 5 -Sekunden-Phase bereits wieder. Auf diese Weise lässt sich auch besser erreichen, was Rauda als Frage des Markts bezeichnet. Das Lager der Werbenden erhält bei Interstitials sozusagen einen Freistoß aus guter Feldposition. Wenn die Werbenden diesen nicht sinnvoll nutzen können, müssen sie hinnehmen, dass der Nutzer wieder die Kontrolle übernimmt. Es ist gerade keine Frage des Markts mehr, sondern ein Anwendungsbereich des Lauterkeitsrechts, wenn die Werbenden zunächst äußerst attraktive Inhalte in Aussicht stellen und dann den Nutzer zwingen erhebliche Zeit aufzuwenden. Mangels spezieller Regelungen sind die Interessen beider Lager im Rahmen der Generalklausel des $₫ 7$ Abs. 1 UWG weitestgehend zur Geltung zu bringen.

Der Gegenleistungsgedanke des OLG Köln, wonach der Nutzer für attraktive Inhalte auch seine Aufmerksamkeit schenken müsse, muss ebenso im gemäßigten Rahmen bleiben. Der Nutzer darf nicht mit vordergründig kostenlosen Inhalten gelockt werden und sodann einen an Wucher grenzenden Gegenwert in Form von Aufmerksamkeit „zahlen“. Denn eine erzwungene Werbewahrnehmung von 20 Sekunden, insbesondere im Vergleich zu normalen Wahrnehmungszeiten anderer Werbeformen, entspricht einem erheblichen wirtschaftlichen Wert. Setzt man diesen Wert als Gegenleistung des Nutzers an, so könnte insbesondere für kürzere Videoclips ein erhebliches Missverhältnis von Leistung und Gegenleistung (sprich: Wucher) schon nach wenigen Sekunden bejaht werden. Um aber das Folgeproblem zu vermeiden, dass Gerichte im Einzelfall die Leistungen wertend einordnen müssen, sollte an der für alle Seiten erträglichen 5-Sekunden-Regel festgehalten werden. 
Zuletzt ist noch kurz auf die denkbare Summenwirkung von mehreren Pre- oder Interstitials während eines (längeren) Videos bzw. einer Sitzung mit dem Genuss mehrerer Inhalte auf einem Portal einzugehen. Das OLG Köln lehnte dieses Argument als Grund für eine unzumutbare Belästigung ohne weitere Auseinandersetzung ab. Dem kann in dieser Pauschalität nicht zugestimmt werden. Denn der Einsatz von Vorschalt- oder Unterbrechungswerbung vor oder in jedem Video oder Browserspiel auf einer bestimmten Webseite kann durchaus dazu führen, dass eine im Einzelnen noch zumutbare Belästigung die Grenze zur Unzumutbarkeit überschreitet. Dabei ist das tatsächliche Surfverhalten der Nutzer auf Webseiten, die maßgeblich auf multimediale Inhalte setzen, in den Blick zu nehmen. Es ist keine Seltenheit, dass Nutzer durch Mediatheken oder YouTube stöbern und dabei eine Vielzahl von kürzeren Videoclips konsumieren. Wenn nun bei jedem Clip die oben als zulässig erachtete 5-Sekunden-Regel angewandt wird, könnte der Nutzer insgesamt beim Genuss von einem Dutzend kürzerer Clips von wenigen Minuten schon mit Zwangswerbung von einer Minute konfrontiert sein. Setzt man hier die Zeit der Zwangswerbung in Verhältnis zur Gesamtzeit des eigentlichen Inhalts, ergibt sich eine wohl noch hinnehmbare Relation. Dies änderte sich indes beträchtlich, wenn man mit Rauda auch längere Pre- und Interstitials zulassen wollte. Hier wäre nicht auszuschließen, dass sogar längere Werbeeinspielungen im Verhältnis zum Inhalt als bei Fernsehwerbung vorkommen könnten. Da das Internet durch seine besonderen Möglichkeiten von Targeting aber viel effektiver Werbung verteilen kann, darf die Dauer von Preund Interstitials in keinem Falle die zulässigen Werbezeiten für TV-Sender nach dem Rundfunkstaatsvertrag überschreiten. Diese Rechtsgrundlage ist zwar nicht unmittelbar anwendbar, aber hier zumindest als Argument in die Interessenabwägung einzustellen. Wenn der Konsum kurzer selbst ausgewählter Videoclips die Evolution des Fernsehens darstellt, darf in keinem Fall (noch) mehr Werbung erlaubt sein.

\section{(iv) Animierte und interaktive Anzeigen}

Animationen betreffen grundsätzlich die Ausgestaltung bestimmter Werbeformen. Tritt man einen Schritt zurück und fragt nach der Zulässigkeit des Einsatzes von Animationen und Interaktivität in klassischen Anzeigen, Pop-Ups oder anderen Werbeformen gemäß $\$ 7$ Abs. 1 UWG lässt sich kein triftiger Grund finden, warum dies für einen Nutzer belästigend sein sollte. Der Nutzer ist an Animationen auf Webseiten gewöhnt und 
wird sie mittlerweile auf gewissen Seiten sogar erwarten. Denkbar wären allenfalls zwei Umstände: einerseits die Beanspruchung von Ressourcen des Nutzers, andererseits der Überraschungseffekt etwa bei automatisch mit Klang einsetzender Werbung. Der erste Gedanke ist aber - wie oben bei Pop-Ups ausführlich dargelegt - zu verwerfen. Der Ressourcengedanke ist zu abhängig von sich wandelnder Infrastruktur, Hardware und Datentariflandschaft.

Der Überraschungseffekt hingegen kann durchaus Belästigungscharakter haben. Denn viele Nutzer dürften bereits die unangenehme Situation erlebt haben, dass sie in einem unpassenden Moment - zum Beispiel im Unterricht, in der Vorlesung, im Arbeitsmeeting oder Ähnliches - im Internet gesurft haben und bei Aufruf einer Seite begann kurzerhand eine Tonspur zu laufen. Diese oft peinliche Situation ist aber regelmäßig mehr dem Vorverhalten des Nutzers geschuldet als der Einbindung von Tonspuren in Werbung. So würde den Nutzer dies in seinem normalen privaten Freizeitumfeld regelmäßig nicht stören. Im Rahmen einer einfachen Sphärenauslegung kann den Werbenden diese Art der Werbung nicht wegen selbst verschuldeten Verhaltens einzelner Nutzer generell verboten werden.

Der Einsatz von Animationen und interaktiven Elementen in DisplayWerbeformen ist folglich uneingeschränkt als zulässig zu erachten.

\section{(v) Nicht lineare In-Stream Werbung}

$\mathrm{Zu}$ den linearen In-Stream-Werbeformen der Pre-Roll und Mid-Roll-Videoclips wurde bereits oben im Rahmen der Interstitials ausführlich herausgearbeitet, dass der Einsatz unter Wahrung der 5-Sekunden-Regel des LG Berlin ${ }^{367}$ erlaubt ist. Bei längeren Videos ohne Beseitigungsmöglichkeit hingegen liegt eine unzumutbare Belästigung nach $\$ 7$ Abs. 1 UWG regelmäßig nahe.

Ein näherer Blick soll hier auf nicht lineare Werbeformen geworfen werden. Dies sind nach dem OVK ein Branded Player, Overlay Ads sowie Content-integrierte „Infomercials“. Letztere liegen nicht im Anwendungsbereich von $\$ 7$ UWG, da sie als Content vom Nutzer immer absichtlich aufgerufen werden. Die anderen beiden Werbeformen hingegen lassen sich wie andere Display-Werbeformen beurteilen. So ist der Branded Player, der Bilderrahmen um das eingebettete Videofeld in der Webseite,

367 LG Berlin, Urteil vom 14.9.2010 - 103 O 43/10, GRUR-RR 2011, 332. 
nichts anderes als eine besondere Form der klassischen Anzeige. Hier ist also keine andere Beurteilung statthaft als bei Werbebannern.

Overlay Ads hingegen sind Pop-Ups innerhalb des Videobereichs. Sie können regelmäßig weggeklickt werden. Insoweit kommt keine andere Beurteilung als bei Pop-Ups und vergleichbaren aggressiven Werbeformen in Betracht. Denkbar ist auch, dass eine Overlay Ad an einem bestimmten Bereich im Videofenster fest fixiert ist und sie nicht die maßgeblichen Bereiche verdeckt, vergleichbar etwa mit fest fixierten Senderlogos bei TV-Sendungen. Dann wird sie nicht wie Pop-Ups, sondern ebenfalls wie ein Werbebanner zu beurteilen sein. In jedem Falle ist diese Werbeform grundsätzlich zulässig und kann nur dann die Schwelle zur unzumutbaren Belästigung überschreiten, wenn sie maßgebliche Teile des Videos verdeckt und einen gewissen Zeitaufwand erfordert. Dieser Zeitaufwand kann bei Videos gleich doppelt wirken, weil der Nutzer ggf. sogar das Video zurücksetzen muss, um die gestörte Szene nochmals abzuspielen.

\section{(vi) Suchmaschinenmarketing}

An der Zulässigkeit von Suchmaschinenwerbung durch den Betreiber der Suchmaschine bestehen keine Zweifel. Die „gekauften“ Suchergebnisse in der Suchmaschine sind funktional vergleichbar mit Werbebannern. Deshalb kann für sie auch nichts anderes gelten als für klassische Anzeigen.

Probleme im Zusammenhang mit Suchmaschinen sind allesamt nachgelagert und betreffen etwa auf Seiten des Suchmaschinenanbieters das Trennungsgebot ${ }^{368}$, mithin das „Wie“ der Werbungsdarstellung, oder die Nutzung von Metatags und Keywords durch Webseitenbetreiber, um höhere Platzierungen in der Suchmaschine zu erreichen ${ }^{369}$. Hierauf wird im Rahmen dieser Arbeit nicht weiter eingegangen.

(vii) Soziale Netzwerke

Auch bei sozialen Netzwerken sind Werbeanzeigen, soweit sie einer klassischen Anzeige entsprechen, im Grundsatz unproblematisch. Dies gilt bei

368 Vgl. Micklitz/Schirmbacher, in: Spindler/Schuster, \$ 6 TMG, Rn. 37ff..

369 Vgl. Boemke, in: Hoeren/Sieber/Holznagel, Multimedia-Recht, Teil 11, Rn. 83ff.. 
der Browseransicht von Facebook uneingeschränkt für die Anzeigen in der „rechten Spalte“.

Die Besonderheit bei Facebook, Twitter, Instagram und Co. hingegen stellt die Werbung innerhalb des Newsfeeds dar. Bei dieser Werbeform lohnt sich durchaus eine Prüfung, ob diese Werbeform mit $\$ 7$ UWG vereinbar ist. Eine solche Prüfung ist jedoch nur dann statthaft, wenn der Nutzer mit seiner Anmeldung nicht bereits besonderen Bedingungen des Netzwerkbetreibers zugestimmt hat, die ihn zur Wahrnehmung der Werbung verpflichten. Hierin würde eine vertragliche Gestattung liegen, die regelmäßig als rechtfertigende Einwilligung zu werten sein dürfte. Allerdings sehen die (zur Zeit der Bearbeitung geltenden) allgemeinen Nutzungsbedingungen von Facebook ${ }^{370}$ keine Klauseln vor, in welchen der Nutzer zur Duldung von Werbung verpflichtet würde. Facebook holt sich nur eine Erlaubnis, dass die Namen, Profilbilder, Inhalte und Informationen für Werbung bei anderen genutzt werden dürfen ${ }^{371}$.

Anders Twitter, das in seinen Allgemeinen Geschäftsbedingungen ausdrücklich formuliert:

„Dafür, dass Twitter Ihnen den Zugang zu den Diensten und deren Nutzung gewährt, erklären Sie Ihr Einverständnis, dass Twitter und seine Drittanbieter und Partner im Rahmen der Dienste oder im Zusammenhang mit den Inhalten oder Informationen, die Sie oder andere im Rahmen der Dienste bereitstellen, Werbung platzieren dürfen. ${ }^{\text {" } 372}$

Auch Instagram formulierte in den Nutzungsbedingungen eine vergleichbare Pflicht:

„Ein Teil des Dienstes wird durch Werbeeinnahmen unterstützt und kann Werbeanzeigen und Promotions anzeigen; hiermit erklärst du dich damit einverstanden, dass Instagram solche Werbeanzeigen und Promotions auf dem Dienst bzw. auf, über oder in Zusammenhang mit deinen Inhalten platzieren kann. Die Art und Weise sowie

370 https://www.facebook.com/legal/terms und https://www.facebook.com/terms/pr ovisions/german/index.php, zuletzt abgerufen am: 30.12.2017.

371 Vgl. Ziff. 9 der Nutzungsbedingungen. Beispiele für solche Werbungen, s.o. Ziffer B. I. 3.

372 https://twitter.com/de/tos, zuletzt abgerufen am: 30.5.2019. 
der Umfang solcher Werbeanzeigen und Promotions können jederzeit ohne besondere Mitteilung an dich geändert werden." ${ }^{\text {373 }}$

Soweit die Betreiber also vertragliche Regelungen eingeführt haben, entziehen Sie die Frage der grundsätzlichen Zulässigkeit von Werbung dem Bereich des wettbewerblichen Deliktsrechts. Vorrangig sind hier die vertraglichen Regelungen anwendbar und haben den entsprechenden Regeln zu folgen. Die Bedingungen unterliegen insbesondere der AGB-Kontrolle nach den $\$ \$ 305 f f$. BGB ${ }^{374}$. Vor dem Hintergrund der hohen Verbreitung von Internetwerbung können solche Klauseln nicht als überraschende Klausel im Sinne von $\$ 305 \mathrm{c}$ Abs. 1 BGB angesehen werden. Mangels Einschlägigkeit der besonderen Klauselverbote in den $\$ \$ 308$, 309 BGB, wäre allenfalls eine Kontrolle nach der Generalklausel in $\$ 307$ Abs. 1, 2 BGB möglich. Hier spricht jedoch angesichts der Formulierung der oben dargestellten Klauseln vordergründig nichts dafür, eine unangemessene Benachteiligung anzunehmen. Hier kann uneingeschränkt das Gegenleistungsargument zur Anwendung kommen, wonach die Werbungsduldung durch den Nutzer ein gewisses „Entgelt“ für die kostenfreie Bereitstellung des sozialen Netzwerks darstellt. Einschränkend gilt aber, dass diese Klauseln nicht jede Form belästigender Werbung erfassen können. Es dürften nur übliche Werbeformen erfasst sein, nicht aber solche Anzeigen, die den Nutzer zeitlich übermäßig stark binden oder zum Abbruch der Nutzung drängen, um sich der Werbung zu entziehen. Diese Auslegung wird durch die Zweifelsregelung von $\$ 305$ c Abs. 2 BGB gestützt.

Soweit kein vertragliches Einverständnis vorliegt, ist die Konformität der als Content getarnten Feedwerbung mit $\$ 7$ UWG zu prüfen. Dabei sind zwei Fälle denkbar, in denen $\$ 7$ UWG anwendbar sein könnte. Auf der einen Seite könnte diese Werbeform generell eine unzumutbare Belästigung nach $\$ 7$ Abs. 1 UWG darstellen. Auf der anderen Seite ist der hypothetische Fall denkbar, dass der Nutzer Facebook gegenüber unmissverständlich erklärt, dass er keine bzw. eine bestimmte Art von Werbung nicht wünscht.

Der erste Fall wird zugunsten von Facebook ausgehen. Durch die gekonnte Anpassung an den üblichen Nutzercontent im Newsfeed ist schon

373 So die früheren Nutzungsbedingungen, die unter https:/help.instagram.com/ 478745558852511 abrufbar waren, abgerufen am: 30.12.2017. Die zur Zeit der Abgabe aktuellen Nutzungsbedingungen sehen eine solche Klausel nicht mehr vor.

374 Vgl. Auch die unten gemachten Ausführungen in diesem Kontext unter Ziffer D. II. 3.. 
äußerst fraglich ob für den Durchschnittsadressaten überhaupt eine Belästigung durch die Werbung vorliegt. Im Ergebnis macht es keinen Unterschied, ob der Algorithmus von Facebook einen beliebigen Inhalt von „Facebook-Freunden“ bzw. abonnierten Facebookseiten oder aus nicht verbundenen Seiten mit dem hoch entwickelten Targetingsystem auswählt und dem Nutzer anzeigt. Der einzige sichtbare Unterschied liegt in der Kennzeichnung als "gesponsert“. Einzig einem aufmerksamen Nutzer könnte auffallen, dass er mit dem beworbenen Inhalt keinerlei Kontakt hatte und dies als negativ empfinden. Dies wird aber mit Rücksicht auf den Durchschnittsadressaten von Werbung nicht als Belästigung anzusehen sein. Selbst wenn man diese Einbindung von eigentlich ungewollten Inhalten in den sonst durch selbst gewählte Verästelungen gefüllten Newsfeed als Belästigung ansehen wollte, ist nur schwerlich von einer Unzumutbarkeit auszugehen. Es ist nicht anzunehmen, dass das Interesse des Nutzers, von Werbung verschont zu bleiben, innerhalb einer Plattform wie Facebook dem Refinanzierungs- und Gewinninteresse des Betreibers überwiegt. Da es sich bei Facebook um ein derart hochwertiges und für den Nutzer kostenfreies „Produkt" handelt, lässt sich hier durchaus eine relativ hohe Duldungspflicht für Werbung annehmen - ähnlich wie bei Browserspielen oder Videos ${ }^{375}$. Im Grundsatz ist diese Werbeform also auch eine zulässige Werbeform und nicht anders zu bewerten als eine klassische Anzeige. Gerade dies ist im Übrigen das Ziel des Native Advertising. Es soll nicht belästigen. Dies ist nach hiesiger Ansicht bei Facebook-Werbung gut gelungen.

Anders stellt sich der Fall dar, wenn der Betreiber zuverlässige Kenntnis von der Unerwünschtheit der Werbung hat. Dann könnte ein Fall der hartnäckigen Werbung nach $\$ 7$ Abs. 2 Nr. 1 UWG gegeben sein. Wie oben im Rahmen des $₫ 7$ Abs. 2 Nr. 1 UWG bereits dargelegt, könnte dem Nutzer durch eine erkennbare Äußerung, dass ihm Werbung unerwünscht ist, bei nachfolgender Werbeeinblendung ein Unterlassungsanspruch zustehen $^{376}$.

Wiederum anders zu beurteilen ist Werbung im Story-Modus, wie sie ursprünglich beim sozialen Netzwerk Snapchat eingeführt und seitdem von Konkurrenten übernommen worden ist. Soweit hier im Story-Modus zwischen zwei Inhalten eine Werbeanzeige geschaltet wird, ist dies nichts anderes als ein Interstitial. Ähnlich wie Interstitials bei Videos sind diese Interstitial-Stories als zulässig zu bewerten. Dabei kommt bei Snapchat

375 S.o. zu Interstitials unter C. IV. 1. a) cc) (iii).

376 S.o. unter C. IV. 1. a) aa). 
konkret hinzu, dass die Werbe-Stories regelmäßig sofort weggeklickt bzw. „weggeswiped“ werden können und keine „Zwangsdauer“ vorsehen. Vor diesem Hintergrund sind die Interessen der Nutzer gewahrt. Soweit im Übrigen bei Snapchat werbende Filter angeboten werden, ist dies ebenfalls als zulässige Werbung anzusehen. Der Nutzer, der seine „Snaps“ mit dem Filter bearbeitet, hat die Möglichkeit durch einfaches Wischen einen anderen Filter auszuwählen. Wenn der Nutzer aber den Filter nutzt, zeugt dies davon, dass die Werbung ihm gut gefallen hat. Der Empfänger des „Snaps“ hat zwar nicht eingewilligt, die Nachricht ist für ihn aber eine Individualnachricht des Absenders, der ihm bekannt ist, und nicht des Appbetreibers oder gar des Werbenden. Eine solche Nachricht wirkt im Übrigen nicht anders als würde jemand ein "Selfie“ vor einem Plakat machen und dies versenden. Die Betreiber und Werbenden machen sich lediglich die natürliche Kommunikationsfreudigkeit der Nutzer zu Eigen. Damit ist eine solche Werbung nicht im Anwendungsbereich von $\mathbb{\$} 7$ UWG. Eine Unzulässigkeit der Filter scheidet also aus.

(viii) Fazit: Allgemeine Regeln

Zusammenfassend lassen sich im Rahmen der Generalklausel drei essentielle Regeln herausarbeiten, die für alle aktuell gebräuchlichen Display-Anzeigen eine interessengerechte Lösung bieten. Wie am Beispiel der sozialen Medien Facebook und Snapchat gezeigt können auch neu erdachte Werbeformen im Internet mit diesen Regeln handhabbar gemacht werden. Auch auf den Bereich des mobilen Marketings lassen sich diese Regeln anwenden.

- Regel 1: Einfache Anzeigen, die in die Webseite eingefasst sind und nur einen Teil des Fensters beanspruchen, sind zulässig. Das Interesse des Nutzers, nicht mit Werbung konfrontiert zu werden, wird von den Interessen der Webseitenbetreiber und der Werbenden eindeutig überwogen.

- Regel 2: Werbung, die auf das Prinzip Störung setzt, ist grundsätzlich zulässig. Sie wird aber dann zur unzumutbaren Belästigung, sobald die Freiheit des Nutzers, sich der aufgedrängten Werbung zu entziehen, beschränkt wird. Die Interessen der Nutzer sind vor allem vor dem Hintergrund zeitlicher Bindung an aufgedrängte Inhalte zu schützen. Die an sich berechtigte und notwendige Refinanzierung der kostenfreien Inhalte durch die Webseitenbetreiber darf nicht um den Preis des faktischen Zwangs erreicht werden. Auch ist für einzelne Internetpor- 
tale eine den Nutzer potentiell unzumutbar belästigende Summenwirkung von Zwangswerbung zu beachten.

- Regel 3: Je wertvoller der Content ist, desto höher ist das hehre Refinanzierungsinteresse. Bei der Zurverfügungstellung von Videos, Spielen und besonderen Plattformen ist dem Betreiber spiegelbildlich zu seiner besonderen Leistung, die Schaltung von länger andauernder und im Vordergrund stehender Werbung gestattet. Dies darf aber lediglich dazu führen, dass zeitintensive Werbeformen wie Pre-Roll-Videos nur für eine kurze Zeit verpflichtend sind und dann durch einfachen Klick beendet werden können. In keinem Fall darf der Werbende oder Webseitenbetreiber die zeitliche Bindung einseitig derart festlegen, dass der Nutzer für eine erhebliche Zeit die Werbung rezipieren muss.

\section{b) Zulässige Ausgestaltung von Werbeanzeigen}

Mit Blick auf das „Wie“ der Werbung existiert eine große Menge von Vorschriften, die Werbende einzuhalten haben. Neben einer beträchtlichen Zahl von speziellen Vorschriften zur Werbung für bestimmte Wirtschaftssparten, gelten allgemein vor allem drei Hauptpflichten: das Trennungsgebot von Werbung und Inhalt, das Irreführungsverbot und die Kennzeichnungspflicht.

\section{aa) Trennungsgebot}

Das Trennungsgebot folgt nach der letzten UWG-Novelle nunmehr aus \$5a Abs. 6 UWG, aus Nr. 11 des Anhangs zum UWG sowie aus den beiden gleichlautenden Vorschriften in $₫ 6$ Abs. 1 Nr. 1 TMG und $\$ 58$ Abs. 1 S. 1 Hs. $1 \mathrm{RfStV}^{377}$. Das eindeutig formulierte Verbot verschleierter Werbung aus $₫ 4$ Nr. 3 UWG a.F. wurde durch die letzte UWG-Novelle gestrichen.

Gerichtliche Auseinandersetzungen betreffen Werbung im Internet vor allem dann, wenn sie nicht mit eindeutiger wörtlicher Bezeichnung versehen ist. So haben etwa das LG Berlin ${ }^{378}$ und nachfolgend das Kammergericht $^{379}$ eine nicht wörtlich gekennzeichnete Bannerwerbung auf einer an Kinder adressierte Webseite als ausreichend getrennt angesehen, weil sie

377 Vgl. hierzu auch Fuchs/Hahn, MMR 2016, 503.

378 LG Berlin, Urteil vom 14.9.2010 - 103 O 43/10, GRUR-RR 2011, 332.

379 KG, Beschluss vom 24.1.2012 - 5 W 10/12, MMR 2012, 316. 
optisch ausreichend andersartig gestaltet war und selbst Kinder an die Aufteilung von Webseiten in Inhalt und Werbeflächen gewöhnt seien. Weiterer Streitpunkt im Falle der Kennzeichnung kann die konkrete Wortwahl und Gestaltung sein. So ist die Gestaltung von Adwords-Anzeigen bei Google 380 durch das Wort „Anzeige“ mit blauer Umrandung ausreichen$\mathrm{d}^{381}$. Problematischer sind Gestaltungen mit den Worten „sponsored by“. $\mathrm{Zu}$ dieser Kennzeichnung im Rahmen einer Webseite für Gesundheitsinformationen verhielt sich das LG München I und verbot diese Art der Benennung ${ }^{382}$. Nach Ansicht der Münchener Richter bringe der Hinweis „Sponsored“ für den durchschnittlich aufmerksamen Verbraucher nicht hinreichend deutlich zum Ausdruck, dass es sich nicht mehr um einen redaktionellen Beitrag, sondern um Werbung handele. Im Rahmen der Entscheidung wird auf die im Printbereich erlassene Entscheidung „Good News II"383 des BGH verwiesen. Die Übertragung dieser - auch landespresserechtlich besonderen Konstellation - auf Onlinewerbung begegnet $\mathrm{zu}$ Recht Kritik ${ }^{384}$. Gerade im Internet besteht keine positive Verpflichtung das Wort „Anzeige“ zu benutzen. Zudem ist durch prominente Beispiele wie Facebook, die ihre Anzeigen mit dem Wort „gesponsert“ kennzeichnen von einer ausreichenden Durchsetzung des Worts oder Wortbestandteils „Sponsor" bei den Nutzern auszugehen. Sobald das Wort „Sponsor“ enthalten ist, wird dem Durchschnittsadressaten im Internet auffallen müssen, dass hier zumindest kein rein redaktioneller Inhalt vorliegt. Dies wahrt den Zweck des Trennungsgebotes, eine Irreführung über die unbezahlte Herkunft des Inhalts zu vermeiden. Ein allzu strenger Maßstab sollte deshalb im Internet nicht angesetzt werden.

Aktuell ist dieser thematische Komplex durch das sog. „Influencer-Marketing" wieder etwas mehr in den Fokus geraten. Eine kurze Auseinandersetzung mit diesem Phänomen folgt an späterer Stelle der Bearbeitung unter Ziffer B. IV. 3. c).

380 Vgl. Screenshot oben unter Ziffer B. I. 3. a) bb).

381 Vgl. etwa LG Hamburg, Urteil vom 21.12.2004 - 312 O 950/04, MMR 2005, 629.

382 LG München I, Endurteil vom 31.7.2015 - 4 HK O 21172/14, WRP 2016, 132.

383 BGH, Urteil vom 6.2.2014 - I ZR 2/11, GRUR 2014, 879.

384 Vgl. Fuchs/Hahn, MMR 2016, 503, 506f.. 
bb) Irreführungsverbot und Kennzeichnungspflichten

Das Irreführungsverbot wird maßgeblich durch die $\$ \mathbb{S} 5$, 5a UWG ausgefüllt. Dies stellt für sich betrachtet ein weites Feld dar und wird deshalb in dieser Arbeit nicht weiter vertieft.

Allgemeine Kennzeichnungspflichten folgen vor allem aus der Preisangabenverordnung (PAngV). Darüber hinaus enthält die PAngV spezielle Kennzeichnungspflichten bei Werbung durch bestimmten Sektoren angehörige Unternehmen. Solche speziellen Kennzeichnungspflichten finden sich zudem in Spezialgesetzen wie der allgemeinen Energieverbrauchskennzeichnungsverordnung (EnVKV) und der Pkw-Energieverbrauchskennzeichnungsverordnung (Pkw-EnVKV) oder dem Heilmittelwerbegesetz (HWG). Da diese Materien sehr spezifisch sind, eignen sie sich nicht zur tiefergehenden Auseinandersetzung in dieser Bearbeitung. Festzuhalten ist, dass das "Wie“ der Werbung (im Internet) erheblich gesetzlich reguliert ist.

\section{Zulässigkeit von Tracking und Targeting}

Display-Werbung beruht in hohem Maße auf der Erhebung und Verwertung von Nutzungsdaten der Werbeadressaten. Durch Tracking des Nutzerverhaltens wird eine individualisierte Werbeausspielung möglich, das Targeting. Nachdem die Europäische Union zunächst durch die E-PrivacyRichtlinie (ursprünglich Richtlinie 2002/58/EG, geändert durch die Änderungsrichtlinie 2009/136/EG) eine dezentrale Harmonisierung vornahm, die sich in Regelungen des deutschen Gesetzgebers im BDSG und TMG wiederspiegeln ${ }^{385}$, gelten ab 25.5.2018 nunmehr unmittelbar anwendbare eurpäische Regeln. Die DSGVO (VO (EU) 2016/679) wurde 2016 mit erheblichem zeitlichen Vorlauf beschlossen und verkündet, sodass sich Markt und Rechtswissenschaft zumindest im Prinzip ausreichend auf die neuen Regeln vorbereiten konnten. Hinzu soll die E-Privacy-Verordnung („EPVO-E“) kommen, die die gleichgenannte Richtlinie voraussichtlich ablösen wird. Die EU-Kommission hielt die Übertragung der bisher in einer Richtlinie niedergelegten harmonisierten Vorschriften in eine unmittelbar geltende Verordnung deshalb für notwendig, weil die Richtlinie in

385 Zum mittlerweile obsoleten Streitthema, ob die Richtlinie ausreichend ins deutsche Recht umgesetzt wurde, vgl. Conrad/Hausen, in: Auer-Reinsdorff/Conrad, $\$ 36$, Rn. 10ff.. 
den verschiedenen Mitgliedsstaaten unterschiedlich umgesetzt und angewendet worden sind ${ }^{386}$. Wegen dieser Änderung des Rechtsrahmens wird nur noch auf die zukünftige Rechtslage abgestellt.

Tracking kann auch andere Zwecke verfolgen als die Ermöglichung von Werbung mit wenig Streuverlust, etwa Webanalyse oder Reichweitenmessung ${ }^{387}$. Wenn es aber zur Werbung genutzt wird, dann ist das Tracking mit dem Targeting in einer logischen Abfolge verbunden. Tracking ist die Grundlage modernen Targetings. Targeting ohne vorhergehendes Tracking ist auch über die thematisch verwandte Schaltung von Werbung möglich ${ }^{388}$, etwa die Positionierung von Werbung für Sportartikel auf einer Nachrichtenseite für Sport (eine Art des Kontexttargeting). Dies stellt aber keine internetspezifische Besonderheit dar, sondern ist die ursprüngliche Form strategischer Werbeplatzierung. Sie wird im Printbereich und bei Rundfunkwerbung seit jeher eingesetzt, um die Zielgruppen des Mediums zu erreichen. Diese Art des Targetings ist deshalb rechtlich unbedenklich. Durch den technologischen Fortschritt haben sich aber ausgeklügelte Systeme zur Vermeidung von Streuverlusten der Werbung entwickelt.

Im Fortgang wird darum die datenschutzrechtliche Zulässigkeit des Trackings in seinen häufigsten Erscheinungsformen (siehe dazu a.) sowie der diversen Targetingvarianten (siehe dazu b.) geprüft. Diesen Komplex abschließend werden Tracking und Targeting unter der lauterkeitsrechtlichen Lupe betrachtet (siehe dazu c.).

\section{a) Datenschutzrechtliche Zulässigkeit von Tracking}

In datenschutzrechtlicher Hinsicht ist zu unterscheiden zwischen CookieTracking und Methoden, die ohne Cookies auskommen, wie etwa das Fingerprint-Tracking.

Vor die Klammer zu ziehen ist aber zunächst die Anwendbarkeit der datenschutzrechtlichen Regelungen. Die EPVO-E soll gemäß Art. 8 Abs. 1 für jede Verarbeitung von Daten auf dem Gerät des Nutzers gelten, gleich $\mathrm{ob}$ es sich um personenbezogene oder nichtpersonenbezogene Daten handelt. Damit sind Cookies und andere Verarbeitungsmethoden, die auf dem Gerät der Nutzer ablaufen, erfasst ${ }^{389}$.

386 Vgl. Schleipfer, ZD 2017, 460, 463.

387 Schleipfer, ZD 2017, 460, 461.

388 Vgl. Schirmbacher, Online Marketing und Social Media Recht, S. 384.

389 Schleipfer, ZD 2017, 460, 463f.. 
Anders die Anwendbarkeit der DSGVO. Hier ist das Merkmal des Personenbezugs erforderlich. Nur im Falle von personenbezogenen oder personenbeziehbaren Daten findet das Datenschutzrecht in der DSGVO Anwendung ${ }^{390}$. Im Übrigen ist die Wirkung der DSGVO nicht auf das Gerät des Nutzers beschränkt. Vielmehr regelt die DSGVO gerade die Abläufe außerhalb des Geräts des Nutzers und in den Servern und Datenbanken der Werbenden ${ }^{391}$.

Daraus ergibt sich, dass die Zulässigkeit verschiedener Trackingmethoden isoliert betrachtet werden sollte, da je nachdem beide Verordnungen oder nur die DSGVO alleine Anwendung finden können.

\section{aa) Cookie-Tracking}

Für Cookie-Tracking als mehrstufigem Vorgang werden auf lange Sicht sowohl die E-Privacy-Verordnung als auch die DSGVO gelten. Die E-Privacy-Verordnung wird für die zeitlich zunächst ablaufende Datenerhebung gelten, weil das Cookie auf dem Gerät des Nutzers gesetzt wird und deshalb dort eine erste Verarbeitung erfolgt. Sobald die Daten außerhalb des Geräts beim Webseitenanbieter oder beim sonstigen Tracker verarbeitet werden, gilt die DSGVO. Bis zum Inkrafttreten der E-Privacy-Verordnung wird allerdings nur die DSGVO maßgeblich sein ${ }^{392}$.

(i) Zulässigkeit nach der E-Privacy-Verordnung (Entwurf)

Mit Blick auf das Setzen von Cookies stellt sich die neue Rechtslage wie folgt dar: Art. 8 Abs. 1 der EPVO-E verbietet

390 Schirmbacher, ITRB 2016, 274.

391 Schleipfer, ZD 2017, 460, 464.

392 Aufgrund der Positionsbestimmung der Datenschutzkonferenz (DSK) zur nicht mehr statthaften Anwendbarkeit des TMG nach Inkrafttreten der DSGVO wird in dieser Bearbeitung nicht auf die datenschutzrechtlichen Bestimmungen des TMG abgestellt, sondern die Rechtslage unter der DSGVO und dem zur Zeit der Bearbeitung zur Verfügung stehenden Entwurf der E-Privacy Verordnung geprüft. Vgl. zum Thema der Anwenbarkeit der $\$ \$ 12$ - 15 TMG: Gierschmann, ZD 2018, 297, und Jandt, ZD 2018, 405. Siehe in diesem Zusammenhang auch den Vorlagebeschluss des BGH in Sachen I ZR 7/16, GRUR 2018, 96, sowie das darauffolgende Urteil des EuGH vom 1.10.2019 - C-673/17, NJW 2019, 3433. 
„jede vom betreffenden Endnutzer nicht selbst vorgenommene Nutzung der Verarbeitungs- und Speicherfunktionen von Endeinrichtungen und jede Erhebung von Informationen aus Endeinrichtungen der Endnutzer, auch über deren Software und Hardware",

es sei denn einer der Ausnahmegründe in Art. 8 Abs. 1 lit. a) -f) ist erfüllt. Diese Ausnahmegründe sind im Einzelnen in lit. a) die Notwendigkeit für den Kommunikationsvorgang, in lit. b) die Einwilligung des Nutzers, in lit. c) die Notwendigkeit für die Bereitstellung des vom Nutzer gewünschten Dienstes, in lit.d) die Notwendigkeit für die Messung des Webpublikums, in lit. da) aus Sicherheitsgründen, in lit.e) unter bestimmten Voraussetzungen für automatische Updates oder in lit.f) für Notfallnachrichten.

Für den Fall der Internetwerbung bleibt damit praktisch allein die Einwilligung des Nutzers, weil die Datenerhebung über Cookies zum Zwecke der personalisierten Werbung offensichtlich nicht notwendig ist für die in lit. a), c) -f) genannten Zwecke. Es macht dabei keinen Unterschied, ob die Werbung vom Anbieter selbst herrührt oder über ein Werbenetzwerk geschaltet wird ${ }^{393}$.

Nach Art. 4a Abs. 1 besteht zwischen einer Einwilligung im Sinne der EPVO-E und dem Begriff der Einwilligung in der DSGVO grundsätzlich Gleichlauf, weil dort ausdrücklich auf die entsprechenden Vorschriften in der DSGVO verwiesen wird. Nach der Definition in Art. 4 Nr. 11 DSGVO ist Einwilligung

„jede freiwillig für den bestimmten Fall, in informierter Weise und unmissverständlich abgegebene Willensbekundung in Form einer Erklärung oder einer sonstigen eindeutigen bestätigenden Handlung, mit der die betroffene Person zu verstehen gibt, dass sie mit der Verarbeitung der sie betreffenden personenbezogenen Daten einverstanden ist".

Dies stellt indes einen gewissen Wertungswiderspruch dar, weil die EPVO-E gerade nicht auf personenbezogene Daten beschränkt ist ${ }^{394}$. Ein Gleichlauf ist trotzdem zweckmäßig, um eine künstliche Aufspaltung der Einwilligung für verschiedene technische Stufen eines für den Nutzer als zusammengehörig erscheinenden Vorgangs zu verhindern. Nur so kann verhindert werden, dass Datenschutzerklärungen und Cookiebanner wei- 
ter ausufern und der Durchschnittsnutzer diese faktisch nicht (bzw. noch weniger) versteht.

In Art. 4a Abs. 2, 2a der EPVO-E wird sodann die Möglichkeit eröffnet, die Einwilligung nach Art. 8 Abs. 1 lit. b) der EPVO-E durch Browsereinstellungen zu erteilen bzw. die Dienstebetreiber dürfen eine derart erteilte Einwillung auch bei Unmöglichkeit der Identifizierung eines bestimmten Nutzers verwerten. Ein in diesem Zusammenhang in früheren Entwurfsstadien vorgeschlagener Art. 10 Abs. 2 und 3 der EPVO-E, sah vor, dass bei erstmaliger Installation oder beim nächsten Update des Browsers nach Inkrafttreten der Verordnung die Privatsphäre-Einstellungen ausdrücklich abgefragt werden müssen. Die dazugehörigen, aber ebenfalls gestrichenen Erwägungsgründe 23 und 24 der EPVO-E erläuterten, dass Browser eine differenzierte Einstellung der Annahme von Cookies vorsehen sollen, die von „Cookies niemals annehmen“ über „nur Cookies von Erstanbietern annehmen“ bzw. „Cookies von Drittanbietern zurückweisen“ bis hin zur generellen Erlaubnis von Cookies reicht. Auf diese Optionen sollten die Browser den Nutzer nach der Installation ausdrücklich und verständlich hinweisen. Zudem sollte die Möglichkeit von Black- und Whitelists, sowie scheinbar auch Greylists ${ }^{395}$, gegeben werden, d.h. für jede Seite könnte spezifisch die Annahme von Cookies geregelt werden. Diese Regelung scheint allerdings dem Druck der Kritiker der E-Privacy-Verordnung zum Opfer gefallen zu sein.

Dies ist bedauerlich, denn mit diesem Regelungskomplex hätte die EPVO-E in rechtlich innovativer Weise eine Zwischenform von ausdrücklicher und konkludenter Einwilligung eingeführt. Durch die standardmäßige Abfrage des Nutzerwunsches hinsichtlich der Annahme von Cookies wäre ein originär ausdrücklicher Wille in eine vom Nutzer - nicht wie sonst üblich vom Softwarebetreiber - festgesetzte Standardeinstellung überführt. Diese Standardeinstellung wäre dann für jeden nachfolgenden Webseitenbesuch die Einwilligung. Dies stellt bei genauer Betrachtung zwar keine ausdrückliche Einwilligung dar, weil der Nutzer nicht für jeden Webseitenaufruf erneut eine ausdrückliche Erklärung abgibt. Es ist aber auch mehr als eine rein konkludente Handlung, da der Wille

395 Während Whitelists die vertrauenswürdigen Webseiten und Blacklists solche Seiten enthalten, von denen rein gar nichts akzeptiert werden soll, können Greylists Webseiten für einen Mittelweg enthalten. Dieser Mittelweg kann wie im Erwägungsgrund dargestellt etwa die Beschränkung auf Cookies vom Erstanbieter enthalten. Es sind aber auch andere Einstellungen für diese Listen denkbar. 
ursprünglich einmal geäußert wurde und nun faktisch fortgeführt wird. Bei der klassischen konkludenten Handlung ist gerade nicht bekannt, was der Handelnde tatsächlich denkt oder wünscht, allein aus seinem Verhalten wird auf den wahrscheinlich vorliegenden Willen geschlossen. Mit der ausdrücklichen Standardeinstellungslösung würde jedoch die immer vorhandene Unsicherheit über den wahren Willen bei konkludenten Handlungen erheblich verringert. Zuletzt wäre die Ermöglichung von leichten Browsereinstellungen zur Einordnung von verschiedenen Webseiten in White-, Grey- und Blacklists ein überaus nutzerfreundliches Instrument, um aus dem „Standardeinstellungswillen“ wieder eine konkret aktualisierte und ausdrückliche Willensäußerung zu generieren.

Durch die Streichung steht die Einwilligung durch Standardeinstellungen relativ kontextlos im EPVO-E. Dies könnte im schlimmsten Fall dazu führen, dass dem Nutzer durch betreiberseits vorgenommene Standardeinstellungen ein Wille unterstellt wird, der mit dem wahren Willen nichts zu tun haben kann. Damit droht die Einwilligung zu einer Rechtfertigung durch Nichtstun zu werden. Dies ist extrem bedenklich, vor allem wenn keine ausreichende Information zur Möglichkeit des Opt-outs besteht. Auch dogmatisch ist es sehr kritisch zu bewerten, dass eine nicht vorgenommene Änderung einer Standardeinstellung als Enwilligung gewertet wird, anstatt in diesem Fall eine vermutete Zulässigkeit zu unterstellen, die im Einzelfall widerlegt werden kann.

Im Ergebnis ist die Datenerhebung durch Cookies für personalisierte Werbung möglich, soweit eine Einwilligung vorliegt. Diese Einwilligung mag nicht mehr allein in dem Besuch der Webseite bzw. dem Wegklicken eines meist nicht beachteten Cookiebanners gesehen werden, sondern der Nutzer kann diese auch über Standardeinstellungen festlegen und dadurch seinen Willen bekunden. Allerdings droht auch, dass die Nichtänderung von Standardeinstellungen künftig als Einwilligung angesehen werden muss.

\section{(ii) Zulässigkeit nach der DSGVO}

Wenn demnach eine zulässige Datenerhebung erfolgt ist und die Daten beim Tracker ankommen, stellt sich für die Verarbeitung durch diesen wiederum die Frage, was mit den Daten in legaler Weise angefangen werden und wie dies geschehen darf.

Im Rahmen der Anwendbarkeit der DSGVO stellt sich die Frage des Personenbezugs, Art. 3 Abs. 1 DSGVO. Die in Art. 4 Nr. 1 DSGVO defi- 
nierten personenbezogenen Daten umfassen nach verbreiteter Meinung die IP-Adresse, gleich ob statisch oder dynamisch ${ }^{396}$. Auch Cookies sind nach Erwägungsgrund 30 der DSGVO als Online-Kennung und die dadurch gewonnenen Daten mithin als personenbezogene Daten anzusehen.

Die im Rahmen des Cookie-Trackings regelmäßig verbundene Speicherung in Datenbanken sowie Auswertung dieser Daten kann unter den Begriff des Profilings in Art. 4 Nr. 4 DSGVO gefasst werden. Dieser Begriff findet sich in Art 22 Abs. 1 DSGVO wieder. Allerdings ist Profiling nur dann an strengere Voraussetzungen als üblich geknüpft, wenn dies im Rahmen automatisierter Entscheidungsprozesse mit rechtlicher Wirkung eingesetzt wird bzw. zu einer ähnlichen erheblichen Beeinträchtigung führt. Nach Erwägungsgrund 71 DSGVO hat dies die Fälle von automatisierter Ablehnung von Online-Kreditanträgen oder Online-Einstellungsverfahren im Blick. Die Anzeige von personalisierter Werbung hingegen hat keine solche rechtliche Wirkung und führt auch nicht zu einer vergleichbaren Beeinträchtigung. Eine allein mögliche Belästigung des Nutzers im Sinne des Lauterkeitsrechts genügt hier jedenfalls nicht.

$\mathrm{Da}$ keine Spezialregelungen für die hier betrachteten Vorgänge des Trackings zu Werbezwecken bestehen, sind sie nach der Grundstruktur der DSGVO grundsätzlich verboten. Nach Art. 6 Abs. 1 DSGVO bedarf es deshalb für die Verarbeitung einer der in dieser Norm enumerierten Erlaubnistatbestände. Praktisch in Frage kommen bei der Online-Werbung Art. 6 Abs. 1 lit.a), also die Einwilligung ${ }^{397}$, und lit. f), der die Wahrung berechtigter Interessen nennt.

Für die Einwilligung nach Art. 6 Abs. 1 lit. a) DSGVO genügt konkludentes Handeln. Nach Erwägungsgrund 32 der DSGVO sind vor allem das „Anklicken eines Kästchens beim Besuch einer Internetseite [... und] die Auswabl technischer Einstellungen" ausreichend, sprich Cookiebanner oder Browsereinstellungen. Keine Einwilligung sollen hingegen „Stillschweigen, bereits angekreuzte Kästchen oder Untätigkeit" darstellen. Im Zusammenspiel

396 Zum grundlegenden Streit zwischen den Theorien des absoluten und relativen Personenbezugs, vgl. Schantz/Wolff, Das neue Datenschutzrecht, Rn. 271ff. und Härting, Internetrecht, Rn. 12 m.w.N.; dafür, dass die vom EuGH in Sachen Breyer./.BRD, Urteil vom 19.10.2016, Rs. C-582/14, NJW 2016, 3579, für die Datenschutzrichtlinie (95/46/EG) aufgestellten Grundsätze auch für die DSGVO gelten: u.a. Schirmbacher, ITRB 2016, 274, 275; Schild, in: BeckOK Datenschutzrecht, Art. 4 DSGVO, Rn. 19f.; Schantz/Wolff, Das neue Datenschutzrecht, Rn. 279f.

397 Vgl. zur Vorgängerregelung der DSGVO: EuGH, Urteil vom 1.10.2019 C-673/17, NJW 2019, 3433. 
mit der E-Privacy-Verordnung wird jedenfalls bei Einwilligung zum Setzen von Cookies durch Drittanbieter auch die nachfolgende Verarbeitung als gleichsam miteingewilligt anzusehen sein. Im Übrigen wird offenbar ein Cookiebanner im Zweifel noch ausreichen, um alle Zweifel zu verhindern. Noch eindeutiger ist es, wenn bei Webseiten mit der Pflicht für Nutzer zur Registrierung die Einwilligung ausdrücklich im Anmeldeprozedere abgefragt wird.

Mit mehr Unsicherheit verbunden ist der Rechtfertigungstatbestand der Wahrung berechtigter Interessen nach Art. 6 Abs. 1 lit.f) DSGVO. Dieser mag allerdings mit Rücksicht auf Erwägungsgrund 47 der DSGVO, der die Verarbeitung personenbezogener Daten zum Zwecke der Direktwerbung als potentiell einem berechtigten Interesse dienend bezeichnet, sowie mit dem Umstand, dass Nutzer ein teilanonymes Tracking vernünftigerweise erwarten werden, bejaht werden. Nicht hierauf gestützt werden kann wohl ein Cross-Device-Tracking, d.h. ein Tracking von Nutzern über mehrere Endgeräte wie PC, Smartphone und ggf. weitere Geräte im Haushalt ${ }^{398}$. Spezifisch für Cookie-Tracking wird aber nur äußerst selten auf Art. 6 Abs. 1 lit.f) DSGVO zurückgegriffen werden, weil ohne Einwilligung schon keine Cookies gesetzt werden dürfen. Wie oben bereits beschrieben sollte eine Einwilligung hier den gesamten Trackingvorgang, also Datenerhebung und -nutzung beim Tracker erfassen, um eine Ausuferung von Cookiebannern und Datenschutzerklärungen zu verhindern.

Folglich ist auch nach der DSGVO das Cookie-Tracking möglich. Im Vergleich zur E-Privacy-Verordnung sind die Anforderungen an den Tracker sogar prinzipiell weniger streng. Durch die strengen Anforderungen auf der ersten Stufe strahlen diese allerdings praktisch auf die nachfolgende Stufe aus, sodass die Einwilligung für die Verarbeitung beim Tracker oft im Wege eines „Erst-recht“-Schlusses anzunehmen sein dürfte.

\section{bb) Tracking Skripte}

Im Grunde folgen Tracking Skripte, die auf dem Endgerät des Nutzers ablaufen, denselben Regeln, denen auch Cookies unterstehen. Für diese ist eine Einwilligung nach Art. 8 Abs. 1 lit. b) EPVO-E erforderlich. Freilich ist im Rahmen der Einwilligung zu beachten, dass Tracking Skripten anders wirken als Cookies. Sie initiieren den Ablauf eines bestimmten Programms auf dem Endgerät des Nutzers. Deshalb ist ein erhöhtes Aufklä-

398 Schirmbacher, ITRB 2016, 274, 278. 
rungsniveau zu fordern. Cookies sind den meisten Nutzern durch die Verbreitung seit Jahrzehnten, die Berichterstattung und nicht zuletzt aus den virulenten Cookie-Bannern ein Begriff. Wenn viele Nutzer auch nicht genau wissen, wie Cookies genau funktionieren, ist unter dem Begriff doch bekannt, dass eine Datenweitergabe erfolgt. Bei unbekannteren Tracking Skripten kann von einer solchen Grundkenntnis nicht ausgegangen werden. Der Einsetzende müsste deshalb in den Datenschutzerklärungen im Wesentlichen beschreiben, was die eingesetzten Tracking Skripte auf dem Gerät anstellen. Rein faktisch wird dies bei der Durchleitung von Tracking Skripten durch Dritte eine Hürde darstellen.

Aus diesem Grunde dürfte auch die oben dargestellte Voreinstellungslösung zur Erlangung von Einwilligungen in Art. 4a Abs. 2 EPVO-E für Tracking Skripte aktuell nicht möglich sein. So ist generell bei neuen Trackingmethoden, die auf dem Gerät des Nutzers wirken, ein strenger Maßstab anzulegen, um dem Zweck der E-Privacy-Verordnung gerecht zu werden.

cc) Fingerprint und Session-Tracking

Auch bei Trackingmethoden ohne Cookies sind beide oben genannten Verordnungen auf ihre Anwendbarkeit zu prüfen. Die DSGVO gilt jedenfalls, soweit es sich bei den gesammelten Daten um personenbezogene Daten handelt. Da im Rahmen des Fingerprint-Trackings oder beim Session-Tracking eine Verbindung mit der IP-Adresse im Ausgangspunkt gegeben ist und nur durch ein IP-Masking-Verfahren oder eine gesonderte Speicherung der Fingerprint-Daten ohne IP-Adresse den Bereich der personenbezogenen Daten verlässt, ist die Anwendbarkeit der DSGVO in vielen Fällen gegeben. In diesen Fällen gilt genauso wie beim Cookie-Tracking das Verbotsprinzip von Art. 6 Abs. 1 DSGVO. Wiederum wäre eine Einwilligung nach den oben genannten Bedingungen möglich. Wichtiger könnte bei diesen Methoden aber die Erlaubnis in Art. 6 Abs. 1 lit. f) DSGVO sein. Für die praktisch notwendige Interessenabwägung zwischen Nutzer und Tracker spielt auch hier Erwägungsgrund 47 der DSGVO und dessen intendierte Vorzugswürdigkeit der Interessen der Werbeindustrie an Direktwerbung eine wichtige Rolle. Der Begriff Direktwerbung ist nicht in der DSGVO definiert, erfasst aber mangels unmittelbaren Kontakts zwischen 
Werbenden und Adressaten nicht die Display-Werbung im Internet ${ }^{399}$. A maiore ad minus ließe sich deshalb vertreten, dass für Display-Werbung erst recht die Interessenabwägung zu Gunsten der Werbenden ausfallen muss. Anders herum ist eine pseudonyme oder anonyme Datenspeicherung mit der Folge der Unanwendbarkeit von Datenschutzrecht ohne weiteres möglich und eine ausdrückliche Aussage für Display-Werbung in der DSGVO nicht vorhanden, sodass auch eine Interessenabwägung pro Nutzer gut denkbar ist. Im Einzelfall werden alle Umstände einzubeziehen sein, sodass eine generelle Entscheidung an dieser Stelle nicht zielführend ist.

Jedenfalls sind Trackingmethoden ohne Nutzung von Cookies durchaus gesetzlich zulässig, wenn entsprechende „Trackingbanner“ - ähnlich den verbreiteten Cookiebannern - gesetzt werden. Wird diese einfache Art der Einholung einer Einwilligung vom Webseitenanbieter bzw. Tracker nicht angewendet, begibt er sich mangels ausreichender Entscheidungspraxis auf der neuen Rechtsgrundlage auf dünnes Eis.

Weiter zu prüfen ist allerdings noch die Anwendung der E-Privacy-Verordnung (Entwurf) mit ihrem strengeren Einwilligungserfordernis auf Fingerprints und Session-Tracking. Dabei gilt, dass keine Einwilligung notwendig ist, wenn sowieso im Rahmen der IP-/TCP-/HTTP-Kommunikation übermittelte Daten zur Bildung eines Fingerprints bzw. einer SessionID verwendet werden ${ }^{400}$. In diesem Fall erfolgt keine Datenverarbeitung auf dem Gerät des Nutzers nach Art. 8 Abs. 1 der EPVO-E. Werden aber weitere Informationen vom Gerät des Nutzers abgefragt, die nicht für die Internetkommunikation ohnehin notwendig sind, ist eine Einwilligung nach Art. 8 Abs. 1 lit. b) der EPVO-E notwendig401.

dd) Zulässigkeit der Verbindung von Werbung und Trackingmethoden

Wie bereits dargestellt ist Tracking ein sehr verbreitetes Phänomen im Internet. Werbung ist durch die Einbindung mehrerer Server in die Kom-

399 Vgl. oben Ziffer B. IV. a), bb) sowie Martini, in: Paal/Pauly, DSGVO, Art. 21, Rn. 47ff.; iÜ ist der Begriff in Art. 4 Abs. 3 lit.f) EPVO-E definiert sowie im Erwägungsgrund 32 erläutert und erfasst keine Display-Werbung im Internet.

400 Schleipfer, ZD 2017, 460, 464; in diesem Fall wird auch vom passiven Fingerprinting gesprochen, https://hosting.1und 1.de/digitalguide/online-marketing/w eb-analyse/browser-fingerprinting-tracking-ohne-cookies/, zuletzt abgerufen am: 30.5.2019.

401 So dann beim aktiven Fingerprinting. 
munikation mit dem Client ein Einfalltor für Trackingmaßnahmen. Werbeanzeigen dienen deshalb oft als Vehikel zur Platzierung von Tracking Skripten oder sonstigen Methoden zur Datenübertragung an den Tracker. Bislang wurde nur isoliert die Zulässigkeit von Tracking beurteilt. Durch die in der Praxis verbreitete Verbindung von Werbung und Tracking stellt sich aber die Frage, ob diese Verbindung ein rechtlich relevanter Umstand ist.

Eindeutig ist, dass ein unzulässiges Tracking allein durch die Verknüpfung mit einer zulässigen Werbeanzeige nicht erlaubt sein kann. An die Zulässigkeit des Trackings sind die oben genannten Voraussetzungen zu stellen, gleich ob es offen oder unter dem Deckmantel von oberflächlichen Werbeanzeigen geschieht.

Andersherum ist die entscheidende Frage, ob eine zulässige Werbung durch die Verbindung mit Trackingmaßnahmen, die auf dem Gerät des Nutzers wirken und für die keine Einwilligung vorliegt, zur Unzulässigkeit der Werbung führt. Die E-Privacy-Verordnung (Entwurf) triff zu diesem Fall keine Aussage. Bei strenger Anwendung der datenschutzrechtlichen Vorschriften muss man jedoch zu dem Ergebnis kommen, dass Webseitenanbieter, die Werbung ausspielen, entweder alle nötigen Anforderungen erfüllen oder trackingfreie Werbung anbieten müssen. Das bedeutet konkret, dass die einzuholenden Einwilligungen alle vorgenommenen Trackingmethoden abdecken müssen. Dies wird dann faktisch schwierig, wenn eine Webseite - was nicht ganz unüblich ist - eine Vielzahl von Trackingmaßnahmen von Drittparteien enthält. Liegen nicht für alle Trackingaktionen ausreichende Einwilligungen vor, etwa weil nicht ausreichend über Art des Trackings und Identität des Trackers informiert wird, ist der konkrete Gesamtvorgang als unzulässig anzusehen. Dies bedeutet, dass die Werbeausspielung von der Unzulässigkeit erfasst wird.

Im Ergebnis haben Webseitenanbieter, falls sie nicht nachweisen können, ausreichende Einwilligungen für alle verwendeten Trackingmaßnahmen eingeholt zu haben, dafür Sorge zu tragen, dass sie die Möglichkeit trackingfreier Werbung vorhalten. Dies wird schon im Eigeninteresse notwendig sein, weil die Webseitenbetreiber die naheliegenden Verantwortlichen sind. Durch den gewillkürten Einbau von Werbeplätzen bzw. Platzhaltern für Werbung aus Netzwerken, die mit Trackingmaßnahmen versehen sind, sind diese als Verantwortliche im Sinne von Art. 4 Nr. 7 DSGVO anzusehen.

Die Verbindung von Tracking und Werbeanzeigen kann deshalb dazu führen, dass die Ausspielung von lauterkeitsrechtlich nicht zu beanstandender Werbung durch Missachtung datenschutzrechtlicher Vorschriften 
gesetzwidrig wird. Webseitenanbieter begeben sich also durch den Einsatz von Werbung mit Tracking, das sie nicht kontrollieren oder zumindest nicht transparent darstellen können, unter anderem in die Gefahr von Bußgeldern nach Art. 23 EPVO-E bzw. Art. 83 DSGVO.

ee) Übersicht zum Tracking

Zusammenfassend bleibt festzuhalten, dass das neue Datenschutzrecht jede noch so intensive Trackingmethode in Verbindung mit Internetwerbung erlaubt, soweit entsprechende Einwilligungen bestehen. Ausdrückliche und absolute Verbote sind dem Recht unbekannt.

Strenge Anforderungen bestehen durch das zwingende Einwilligungserfordernis aus Art. 8 Abs. 1 lit.b) EPVO-E für folgende Formen des Trackings:

- Cookie-Tracking,

- Aktives Fingerprinting, d.h. Anforderung von mehr Informationen als durch die Internetkommunikation notwendig, sowie Bildung des Fingerprints auf dem Gerät des Nutzers,

- Session-Tracking unter Abruf des Sessionbrowserverlaufs,

- Trackingpixel und Trackingskripte ${ }^{402}$.

Dies gilt auch, wenn diese Maßnahmen mit zulässigen Werbeanzeigen verbunden sind. Ohne die erforderliche Einwilligung wird die Werbeausspielung unzulässig.

Eine Zulässigkeit durch die milderen Einwilligungsanforderungen im Rahmen von Art. 6 Abs. 1 lit. a) DSGVO bzw. sogar ohne Einwilligung durch Wahrnehmung berechtigter Interessen gemäß Art. 6 Abs. 1 litf) DSGVO kommt für folgende Methoden in Betracht:

- Passives Fingerprinting mit personenbezogenen Daten,

- Session-Tracking mit ausschließlichen personenbezogenen Informationen aus der Session-ID.

Generell erlaubt und keiner gesetzlichen Beschränkung unterliegen die beiden zuvor genannten Trackingmethoden, wenn sie nicht personenbezogene Daten betreffen oder anonyme bzw. pseudonyme Daten verarbeitet werden.

402 Schleipfer, ZD 2017, 460, 464. 
b) Datenschutzrechtliche Zulässigkeit von Targeting

Auch die Zulässigkeit des Targetings ist anhand des neuen datenschutzrechtlichen Rahmens und für die verschiedenen Trackingmethoden gesondert zu prüfen. Mit Targeting ist dabei konkret die letzte Stufe des Datenverarbeitungsprozesses nach Datenerhebung beim Nutzer und ggf. der Speicherung sowie Auswertung von Nutzungsprofilen gemeint ${ }^{403}$.

\section{aa) Ein Fall der E-Privacy-Verordnung (Entwurf)?}

Im Zusammenspiel zwischen der strengen E-Privacy-Verordnung (Entwurf) und der dazu relativ milderen DSGVO stellt sich zunächst die Frage, ob Targeting im Rahmen gezielter Werbeausspielung überhaupt dem Anwendungsbereich der E-Privacy-Verordnung (Entwurf) unterfällt. Anknüpfungspunkt könnte wiederum Art. 8 Abs. 1 der EPVO-E sein, der - wie oben ${ }^{404}$ bereits zitiert - jede nicht vom Endnutzer selbst vorgenommene Nutzung der Verarbeitungs- und Speicherfunktionen seiner Endeinrichtung unter den Vorbehalt eines Rechtfertigungstatbestands stellt. Bei der Einblendung von Werbung während der Anzeige einer Webseite auf dem Gerät des Nutzers liegt der Gedanke nicht fern, dass hier eine Nutzung der Verarbeitungsfunktionen vorliegen könnte. Auch ist eine Speicherung denkbar, weil die Bild- oder Animationsdateien der Werbung im Cache des Browsers, mithin auf der Festplatte oder dem Arbeitsspeicher des Geräts, zumindest vorübergehend gespeichert werden.

Diese Umstände sind aber nicht spezifisch für das Targeting, sondern betreffen jede Art von Display-Werbung. Deshalb ginge eine Einbeziehung jeglicher Display-Werbung unter Art. 8 Abs. 1 der EPVO-E zu weit und ist auch in keiner Weise vom Verordnungszweck oder dem Willen des Verordnungsgebers gedeckt. Weil diese These aber „vom Ergebnis her“ gedacht ist, bedarf es zur Begründung einer Anknüpfung an den Tatbestand der Norm, um Display-Werbung, sei sie durch Targeting individualisiert oder nicht, aus dem Anwendungsbereich von Art. 8 Abs. 1 der EPVO-E zu streichen. Naheliegender Ansatz ist, dass eine Nutzung der Verarbeitungsund Speicherfunktionen des Geräts durch den Endnutzer selbst vorgenommen wird, indem er die Webseite aufruft. Dies wird man uneingeschränkt für solche Werbung vertreten können, die durch den Webseitenbetreiber

403 Siehe auch oben Ziffer B. I. 4. a) und III. 4. b).

404 Ziffer IV. 2. a), aa), (i). 
direkt ausgespielt wird, weil sie Teil des HTML-Codes der Webseite ist. Der Nutzer ruft schließlich die Webseite willentlich und unter Kenntnis von üblicherweise vorhandener Display-Werbung auf.

Kniffliger hingegen ist die Beurteilung von Werbung, die von Werbenetzwerken über Adserver auf der Webseite eingespielt werden. Gerade dies ist das hauptsächliche Anwendungsfeld von Targetingmaßnahmen. Hier hat der Nutzer beim Aufruf der Webseite streng genommen die Nutzung seiner Gerätefunktionen durch den Adserver bzw. das Werbenetzwerk nicht selbst vorgenommen. Der Nutzer hat eine bestimmte Webseite durch Eingabe der Domain oder Klick auf einen Link geöffnet. Er wünscht also den Abruf genau dieser Inhalte von dem durch die Domain gekennzeichneten Server. Dass gleichzeitig dazu von einem ganz anderen Server eine Internetkommunikation aufgebaut wird und somit die Verarbeitung und Speicherung der „fremden“ Werbung initiiert, ist nur den wenigsten Nutzern bewusst. Fraglich ist insoweit, ob diese Nutzung durch das Werbenetzwerk gleichsam noch als im rechtlichen Sinne „vom Nutzer selbst vorgenommen" angesehen werden kann. Anknüpfungspunkt dafür ist, dass der Webseitenbetreiber durch Platzhalter im Quellcode der Webseite die Möglichkeit für das Werbenetzwerk geschaffen hat, um die Werbung einzuspeisen. Diese Frage führt aber konsequent weiter gedacht dazu, generell die Gestaltungsfreiheit von Webseitenbetreibern auf ihren eigenen Webseiten in Frage zu stellen. Soweit soll die Regelungswirkung der EPVO-E indes nicht gehen. Wenn der Nutzer eine Webseite aufruft, initiiert er also auch die etwaige Nutzung der Gerätefunktionen durch Dritte. Dem Webseitenbetreiber steht die Freiheit zu, Werbung durch entsprechende Netzwerke einzuspeisen.

Das abstrakte Tatbestandsmerkmal der „nicht vom Nutzer selbst vorgenommenen Nutzung der Geräte" betriff folglich nicht die Ausspielung von Webseiten oder Teilen davon wie Display-Werbung. Es betrifft vielmehr unerwünschte Verfolgungswerkzeuge wie z. B. Spyware, Webbugs, versteckte Kennungen und Verfolgungs-Cookies (vgl. Erwägungsgrund 20 der EPVO-E). Diese erwartet der Nutzer bei Aufruf einer Webseite gerade nicht und sie werden ganz anders als Display-Werbung versteckt im Gerät untergebracht. Der schon beim Tracking angesprochene Umstand, dass diese Verfolgungswerkzeuge regelmäßig mit Display-Werbeanzeigen über Drittserver erst Einzug auf dem Gerät erhalten, führt nicht dazu, dass Targeting als isolierbarer Endpunkt des Datenverarbeitungsprozesses separat rechtfertigungsbedürftig wird. Vielmehr liegt es an den Werbenden, die Werbung ohne solche Werkzeuge auszuspielen. 
Damit bleibt zunächst festzuhalten, dass Targeting durch die E-PrivacyVerordnung (Entwurf) nicht geregelt wird. Mit Blick auf das vorhergehende Tracking verfolgt die EPVO-E ein „Alles-oder-nichts“-Prinzip, d.h. wenn der Nutzer nicht verhindert, dass seine Daten über Trackingmaßnahmen erhoben werden, gibt er sie unwiderruflich aus der Hand. Eine Speicherung, Verarbeitung und Zusammenführung in Nutzungsprofilen ist deshalb nicht von weiteren Einwilligungen abhängig. Diese Maßnahmen sind zudem nicht nachträglich durch einen Widerruf zu verhindern ${ }^{405}$

\section{bb) Beurteilung nach DSGVO}

Bei der Prüfung, ob Targeting nach den Vorschriften der DSGVO zulässig ist, sind vor allem zwei Fragen von Bedeutung. Erstens muss ein Personenbezug vorliegen, weil sonst das Datenschutzrecht überhaupt nicht eingreift. Zweitens ist bei vorliegendem Personenbezug zu prüfen, auf welche Weise eine Erlaubnis der Datenverarbeitung hergeleitet werden kann. Hierzu stehen praktisch die Einwilligung nach Art. 6 Abs. 1 lit. a) DSGVO und die Wahrnehmung berechtigter Interessen nach Art. 6 Abs. 1 lit.f) DSGVO zur Verfügung ${ }^{406}$. Im Folgenden werden diese beiden Fragen konkret mit Blick auf die einzelnen Targetingmethoden geprüft.

\section{(i) Techniktargeting}

Bei Targeting mit dem Kriterium, welche Hard- oder Software der Nutzer vorhält, handelt es sich um potentiell personenbezogene Daten. Der Umstand, welches Endgerät oder welche Software auf dem jeweiligen Gerät installiert sind, ist ein potentiell schutzfähiges Datum, da die DSGVO keine freien, ungeschützten Daten vorsieht ${ }^{407}$. Ein Teil dieser Information wird bei der Kommunikation zwischen Server und Client sowieso übermittelt. Nur die wenigsten Webseitenbetreiber werden aber über einen Server verfügen, der unmittelbar im Rahmen dieser Punkt-zu-Punkt Kommunikation eine passende Werbung ausspielen könnte. Vielmehr übernimmt diese Aufgabe regelmäßig ein Adserver des Werbenetzwerks. Damit diesem Adserver die notwendigen Infomationen über Hard- und Software

405 Schleipfer, ZD 2017, 460, 465.

406 Vgl. Schirmbacher, ITRB 2016, 274, 279.

407 Vgl. Gola, in: Gola, DSGVO, Art. 4, Rn. 5. 


\section{B. Grundlage: Werbung im Internet}

zukommen, kommt eine Weitergabe der Information über den Server des Webseitenbetreibers als „Intermediär" oder eine direkte Kommunikation zwischen Client des Nutzers und Adserver in Betracht. So oder so liegt regelmäßig eine Verbindung mit der - ggf. dynamischen - IP-Adresse des Nutzers vor, sodass ohne besondere Maßnahmen das Vorliegen personenbezogener Daten nicht ausgeschlossen werden kann. Alleine die Übertragung der Daten, die eine Zuordnung zum Nutzer ermöglicht, ermöglicht auch eine Auswertung dieser Daten zur Nutzung im Rahmen der zielgerichteten Werbung. So kann einem Apple Macbook Nutzer eine passende Werbung für Zubehör, für zum jeweiligen Betriebssystem passende Software oder für spezialisierte Reparaturdienstleister eingeblendet werden. Damit sind klassische Streuverluste vermieden, etwa wenn einem Mac Nutzer Werbung für Windows Rechner und Applikationen eingeblendet werden.

Theoretisch einfachster Weg für die Legitimierung dieser Targetingmethode ist die Einwilligung. Diese kann durch Browser-Opt-in bzw. Abfrage analog zu einem Cookiebanner eingeholt werden, soweit die Einwilligung freiwillig erteilt wird (Art. 7 Abs. 4 DSGVO) und eine ausreichende Information gegeben wird (Art. 13 DSGVO) ${ }^{408}$.

Bei der Prüfung einer Rechtfertigung über die Wahrung berechtigter Interessen im Sinne von Art. 6 Abs. 1 lit. f) DSGVO läuft es auf eine Interessenabwägung zwischen Nutzer und Werbenden hinaus, bei der es auch auf die vernünftigen Erwartungen der Betroffenen ankommt ${ }^{409}$. Berechtigte Interessen sind alle von der Rechtsordnung gebilligten wirtschaftlichen oder ideellen Interessen an der konkreten Datenverarbeitung ${ }^{410}$. Wenn nach Erwägungsgrund 47 der DSGVO Direktwerbung als berechtigtes Interesse angesehen wird, sollte dies ebenso für gezielte Onlinewerbung auf Grundlage rechtmäßig erhobener Informationen über die technische Umgebung beim Adressaten gelten. Unabhängig von nur schwer ermittelbaren Erwartungen der Nutzer hinsichtlich eines Techniktargetings, sind im Rahmen einer Interessenabwägung keine maßgeblichen Gründe erkennbar, die diese Form der Werbeausspielung für Nutzer unzumutbar machen würde. Der durchschnittliche Nutzer wird auch ein Interesse daran haben, Werbung für Dienstleistungen und Waren zu erhalten, die zum persönlichen Bedarf passen. Es dürfte vielmehr negativ auffallen, wenn die Werbung vollends unnütz für den eigenen Bedarf ist. Folglich ist die Wer-

408 Schirmbacher, ITRB 2016, 274, 276, 279.

409 Schirmbacher, ITRB 2016, 274, 276, 279.

410 Härting, DSGVO, Rn. 429f.. 
beausspielung durch Techniktargeting regelmäßig auch ohne Einwilligung rechtmäßig.

\section{(ii) Geotargeting}

Die Information über den aktuellen Ort einer Person, die mit einem internetfähigen Gerät ausgestattet ist, ist in aller Regel ein personenbezogenes Datum. Die geografische Lokalisierung der Nutzer erfolgt über die IPAdresse ihres Geräts. Mit dieser Information ist eine Lokalisierung bis zum nächstgelegenen Einwahlknotenpunkt, meist einige hundert Meter genau, möglich. Bei mobilem Internetzugang erfolgt die Lokalisierung über die nächstgelegene Mobilfunkantenne ${ }^{411}$. Damit erfolgt die Datenerhebung in den vorgenannten Fällen nicht im Gerät des Nutzers und entzieht sich dem Anwendungsbereich der E-Privacy-Verordnung (Entwurf) ${ }^{412}$. Die Verknüpfung von Standort und IP-Adresse stellt aber den Personenbezug her. Deshalb ist die DSGVO anwendbar.

Wiederum ist eine Einwilligung das probate Mittel zur Legitimierung. Auf obige Ausführungen zum Techniktargeting wird verwiesen. Sicherster Weg ist, sowohl die Erhebung der Standortdaten als auch die Nutzung zu standortspezifischer Werbung von der Einwilligung legitimieren zu lassen.

Eine Rechtfertigung nach Art. 6 Abs. 1 lit.f) DSGVO kommt auch beim Geotargeting in Betracht. Im Rahmen einer Interessenabwägung ist hier die Sicht der Nutzer jedoch anders zu bewerten als beim Techniktargeting. Dem durchschnittlichen Nutzer könnte bei stark räumlich wirkender Werbung, vor allem auf Reisen, der Verdacht aufkommen, er werde verfolgt. Wenn etwa auf einer üblicherweise genutzten Webseite plötzlich Anzeigen für Restaurants oder Freizeitangebote für genau die Regionen angezeigt werden, in welcher sich der Nutzer gerade erstmalig aufhält, hinterlässt dies eher ein negatives Gefühl. Natürlich hat diese Form der Werbeadressierung auch Vorteile, da die Anzeigen gezielt sind und wiederum einen theoretisch akuten Bedarf betreffen. Das „Ausspionieren“ des Standorts ist aber im Vergleich zur Analyse, welche Hardware ein Nutzer vorhält, ein weitaus intensiverer Eingriff in die Privatsphäre. Demnach liegt hier eine Abwägung zugunsten der Interessen der Nutzer nahe.

411 Ulmer, in: Ulmer-Eilfort/Obergfell, Verlagsrecht, Kapitel F., Rn. 211f..

412 Soweit Daten im Endgerät des Nutzers erhoben werden, ist unzweifelhaft das Einwilligungserfordernis nach Art. 8 Abs. 1 EPVO-E erfüllt und die entsprechenden Ausführungen gelten. 
Andererseits ist Geotargeting nur schwerlich von der Datenerhebung trennbar. Nach $\$ 28$ Abs. 3 BDSG a.F. war die Nutzung personenbezogener Daten für Zwecke der Werbung einwilligungspflichtig. Dies fällt mit der DSGVO weg, die kein Pendant für diese Norm vorhält. Die E-PrivacyVerordnung (Entwurf) mit ihrem Einwilligungserfordernis wird hingegen nur bei im Gerät des Nutzers erhobenen Daten gelten. Mangels Einwilligungserfordernis für die hier behandelten Geotargetingformen, kommt es maßgeblich auf die vernünftigen Erwartungen der Nutzer an. Diese variieren je nach genutztem Dienst erheblich. Bei der Nutzung einer Suchmaschine wie Google wird der Nutzer, gerade bei der Suche von Dienstleistungen, eine räumliche maßgeschneiderte Antwort erwarten, die auf Grundlage von Standortdaten erfolgt. So auch auf spezialisierten Webseiten wie etwa einer Webseite mit einer Suchfunktion für die nächstgelegene Notfallapotheke ${ }^{413}$. Generell ist Geotargeting also auf Webseiten mit räumlichem Bezug und Suchfunktionen ohne die manuelle Eingabe des Standortes zu erwarten. Dies sollte auf die übrige Display-Werbung auf der Webseite ausstrahlen. Anders liegt der Fall aber bei bundesweit bedeutsamen Webseiten wie Nachrichten- oder Multimediaportalen. Auch bei fremdsprachigen Webseiten mit unter Umständen anderer Top-LevelDomain als „.de“ wird der Nutzer die Abfrage von Standortdaten vernünftigerweise nicht erwarten, sondern die Nutzung solcher Daten als Verfolgung oder gar Spionage auffassen. Gerade im letztgenannten Beispiel käme es einer Vielzahl von Nutzern wohl „spanisch“ vor, wenn auf einer Webseite die über die spanische Fußballiga berichtet, eine Anzeige in deutscher Sprache vom Supermarkt um die Ecke eingeblendet wird.

Das Vorliegen der Gestattung nach Art. 6 Abs. 1 lit.f) DSGVO sollte deshalb einzelfallbezogen und unter Einbeziehung der Datenerhebung beurteilt werden. Hier lauern kaum kalkulierbare Risiken für die Werbenden, sodass die Einwilligung wohl vorzugswürdig ist. Dies gilt umso mehr, weil die DSGVO für die Erlangung von Einwilligungen im Internet eher wirtschaftsfreundlich ausgestaltet ist. Ohne Einwilligung kann Geotargeting möglich sein, der Bereich denkbarer Fälle ist aber überschaubar.

413 Beispiel nach Schirmbacher, ITRB 2016, 274, 276. 
(iii) Semantisches bzw. Keyword Targeting und Kontext-Targeting

Bei den Targetingmethoden, die auf den sprachlichen Bestandteilen einer Webseite basieren, stellen sich keine datenschutzrechtlichen Probleme, weil keine personenbezogenen Daten verarbeitet werden.

Beim semantischen Targeting werden ganze Webseiten automatisch ausgewertet, indem der Text analysiert wird und Algorithmen den Bedeutungszusammenhang aus Wortkombinationen und Worthäufigkeiten unter Zuhilfenahme einer taxonomischen Datenbank ermitteln ${ }^{414}$. Der Text der Webseite besteht bereits bevor der Nutzer die Webseite aufruft und dies ist Anknüpfungspunkt der Werbung. Der Nutzer aktiviert durch seinen Besuch alleine die Ausspielung. Sie würde aber einem anderen Nutzer, der die Seite aufruft gleichermaßen angezeigt. Genauso das Kontext-Targeting, das bei Lichte betrachtet eine primitivere Form des semantischen Targetings darstellt und deshalb datenschutzrechtlich auch genauso zu behandeln ist.

Beim Keyword Targeting erfolgt die Verknüpfung von Werbung durch die Eingabe eines bestimmten Suchbegriffs durch den Nutzer. Hier ist zwar ein personalisierter Anknüpfungspunkt zu erkennen, schließlich muss der Nutzer erst einen bestimmten Begriff eingeben. Es kommt hierbei aber nicht auf den Nutzer in seiner speziellen Person an. Denn würde ein anderer Nutzer nach demselben Keyword suchen, würde auch ihm dieselbe Werbung angezeigt. Auch hier aktiviert der Nutzer die Werbeausspielung erst durch seine Suchanfrage, wobei der Auslöser für die Ausspielung nicht seine privaten Informationen wie Technik oder Standort sind, sondern das eingegebene Suchwort.

\section{(iv) Verhalten-Targeting}

Erhebliche Bedeutung für das Datenschutzrecht hat das Verhalten-Targeting, auch geläufig als „behavioral targeting“. Dies folgt daraus, dass sich diese Form des Targeting nicht damit begnügt, dass der Nutzer gewisse Informationen im Moment des Aufrufs einer Webseite Preis gibt, etwa die technische Ausstattung oder den Standort. Vielmehr ist für das VerhaltenTargeting von Bedeutung, was der Nutzer vor dem Aufruf der Webseite bereits getan hat. Hier wird aus dem Surfverhalten im Internet, also dem Besuch von und der Aktivität auf Webseiten, sowie der Durchführung von

414 Ulmer, in: Ulmer-Eilfort/Obergfell, Verlagsrecht, Kapitel F., Rn. 213. 
Transaktionen, ein Bild des Nutzers gezeichnet, das den Algorithmus des Adservers dazu bewegt, eine bestimmte Werbung auszuspielen. Während andere Targetingmethoden in der Gegenwart operieren, kennt VerhaltenTargeting auch die Vergangenheit des Nutzers.

Bestes Beispiel ist das sog. Retargeting, mit dem ein Internetnutzer, der sich in einem Online Shop einen bestimmten Artikel angesehen oder sogar in seinen Warenkorb gelegt hat, in der Folgezeit mit Werbung zu diesem Artikel konfrontiert wird. Dies ist vor allem bei nicht abgeschlossenen Transaktionen verbreitet, führt aber auch manchmal nach einem abgeschlossenen Kauf eines Artikels zur Werbung gerade mit den gekauften Artikeln. In der Folgezeit sieht der Nutzer sehr oft Display-Anzeigen von den besuchten Webshops und den gesuchten Artikeln.

Dieses Phänomen lässt sich noch überbieten durch das "predictive behavioral targeting“ (im Weiteren abgekürzt als „PBT“). PBT kennt nicht nur den Weg, den der Nutzer bereits hinter sich hat, es bezieht zudem die Vorhersage ein, wo der Nutzer hin möchte. Aus den vorhandenen historischen Daten wird durch Zusammenführung mit anderen Datensätzen zu dem bestimmten Nutzer oder zu vergleichbaren Nutzern bzw. durch Abgleich mit soziologischen Erkenntnissen, eine Vorhersage für Interessen des Nutzers getroffen ${ }^{415}$. Die Ausspielung der Werbung ist also Ergebnis einer Prognose eines Computerprogramms auf Grundlage ihm zur Verfügung stehender Informationen über die Person des Nutzers.

Verhalten-Targeting bzw. PBT sind somit der Arm der Datenkrake namens „Big Data“, der die Internetwerbung im festen Griff hat. Es verwundert nicht, dass gerade an dieser Stelle der datenschutzrechtliche Schuh drückt. Grundlage dieses verhaltensbasierten Targetings sind Nutzungsprofile, in denen allerlei Daten gesammelt werden - also die Vergangenheit des Nutzers. Betrachtet man allein die eigene Aktivität auf alltäglichen Seiten wie Google oder Amazon, verwundert es kaum, dass die Betreiber allein auf Grundlage von Suchbegriffen in der Suchmaschine und aufgesuchten Waren im Online-Kaufhaus ein recht konturiertes Bild der eigenen Person haben. Bei registrierten Nutzern lässt sich dieses Bild direkt mit Klardaten verbinden, im Übrigen ist das Bild allein durch die IP-Adresse verschleiert.

Dieser Befund führt dazu, dass teilweise vertreten wird, dass jedes Datum, das ein Nutzer im Internet hinterlässt, als personenbezogen anzusehen sein soll ${ }^{416}$. Ob dieser radikale Ansatz zutreffend ist, soll an dieser

415 Hass/Willbrandt, Medienwirtschaft 2011, 12, 14ff..

416 Boehme-Neßler, DuD 2016, 419, 420ff.. 
Stelle offenbleiben. Festzuhalten ist, dass der Personenbezug der Daten in einem bereits angelegten Nutzungsprofil in vielen Fällen zu bejahen ist. Für Werbemaßnahmen im Internet war bis Mai $2018 \$ 15$ Abs. 3 TMG zu beachten, wonach die Bildung von Nutzungsprofilen (nur) bei Verwendung von Pseudonymen für Werbung zulässig war. Diese Vorschrift findet allerdings keine Fortsetzung in der $\mathrm{DSGVO}^{417}$. Es gelten die allgemeinen Bestimmungen der DSGVO, das heißt entweder eine Einwilligung nach Art. 6 Abs. 1 lit. a) DSGVO oder die Wahrnehmung berechtigter Interessen gemäß Art. 6 Abs. 1 lit.f) DSGVO können zur Zulässigkeit der Anlegung, Unterhaltung und vor allem der Auswertung von Nutzungsprofilen in Form des Verhalten-Targeting bzw. PBT führen. Die DSGVO stellt hier die gleichen Rechtfertigungsanforderungen für pseudonyme und personenbezogene Nutzungsprofile auf ${ }^{418}$. Ein einwilligungspflichtiges Profiling im Sinne von Art. 22 i.V.m. Art. 4 Nr. 4 DSGVO liegt jedenfalls nicht vor ${ }^{419}$.

Bei der konkreten Prüfung der Rechtfertigung ist wiederum die Einwilligung in das Verhalten-Targeting bzw. PBT möglich. Praktisch dürfte es aber für die Werbenden schwierig sein, den Informationspflichten aus Art. 13 und den Erwägungsgründen 42, 60 DSGVO nachzukommen. Damit wird die Einholung einer Einwilligung, die nach Erwägungsgrund 30 DSGVO unter anderem in informierter Weise erfolgen soll, zur faktischen Hürde.

Deshalb wird es auch bei dieser Targetingmethode oft auf die Interessenabwägung im Rahmen von Art. 6 Abs. 1 lit.f) DSGVO hinauslaufen. Und wieder werden auf der einen Seite das grundsätzlich schutzwürdige Interesse der Wirtschaft an Werbung und auf der anderen Seite die Interessen der Nutzer am Schutz ihrer Privatsphäre abzuwägen sein, wobei auf die vernünftigen Erwartungen der Nutzer abzustellen ist (vgl. Erwägungsgrund 47 DSGVO).

\section{(1) Meinungsstand in der Literatur}

In diesem Zusammenhang werden in der Literatur verschiedene Auffassungen vertreten, ob Verhalten-Targeting bzw. PBT ohne Einwilligung gerechtfertigt sein können. So wird zum Teil eine Rechtfertigung auf

417 Schulz, in: Gola, DSGVO, Art. 6, Rn. 81.

418 Schleipfer, ZD 2017, 460, 463.

419 Siehe oben Ziffer B. IV. 2. a), aa), ii). 
Basis von Art. 6 Abs. 1 lit.f) DSGVO abgelehnt ${ }^{420}$. Anders herum hält Schirmbacher eine Rechtfertigung für möglich, weil insbesondere bei Bannerwerbung seit Jahren in jeder verhaltensbezogen ausgespielten Anzeige eine Aufklärung durch die Werbenetzwerke, etwa durch das Informationsmodul „AdChoices"421, erfolgtt ${ }^{422}$. Vermittelnde Ansichten halten in Festhaltung an die alte nationale Rechtslage, die in $\mathbb{1} 15$ Abs. 3 TMG fixiert war, eine Rechtfertigung dann für möglich, wenn nur pseudonyme Nutzungsprofile genutzt werden, Widerspruchsmöglichkeiten der Betroffenen und technisch-organisatorische Maßnahmen zur Verhinderung einer $\mathrm{Zu}$ sammenführung von Pseudonym und Klardatum bestehen ${ }^{423}$. Allein diese Meinungsvielfalt zeigt, dass diese Frage mit hoher Wahrscheinlichkeit ultimativ erst vom EuGH geklärt werden wird.

\section{(2) Stellungnahme}

Nach hier vertretener Ansicht ist eine Rechtfertigung von Verhalten-Targeting und PBT im engen Rahmen durch die Wahrung berechtigter Interessen im Sinne von Art. 6 Abs. 1 lit.f) DSGVO möglich. Dabei ist, wie von der DSGVO intendiert, ausgehend von den vernünftigen Erwartungen der Nutzer zu argumentieren. Für die Gegenwart der Online-Werbung führt dies dazu, dass eine Prüfung an der Akzeptanz der konkreten Targetingform auf den konkreten Webseiten durch die Nutzer auszurichten ist. Dabei sind maßgeblich zwei Fälle in den Blick zu nehmen. Im ersten Fall erfolgt das Verhalten-Targeting und PBT innerhalb einer Webseite bzw. einer Gruppe offensichtlich verbundener Webseiten. Der zweite Fall betrifft eben solche Targetingmaßnahmen, die Webseiten übergreifend auf diversen Online-Angeboten ohne eindeutig erkennbare organisatorische Verbindung wirken. Während im ersten Fall die Wahrung berechtigter Interessen möglich erscheint, wird der Internetnutzer eine Verfolgung mit gleicher Werbung über viele verschiedene Webseiten vernünftigerweise nicht erwarten und sich zu Recht verfolgt fühlen.

420 Schantz/Wolff, Das neue Datenschutzrecht, Rn. 666ff. unter Berufung auf die Stellungnahme 06/2014 der Art. 29-Gruppe zur Datenschutzrichtlinie, WP 217 vom 9.4.2014, S. 59f. und 86f..

421 Vgl. http://youradchoices.com/, zuletzt abgerufen am: 30.5.2019.

422 Schirmbacher, ITRB 2016, 274, 279.

423 Schulz, in: Gola, DSGVO, Art. 6, Rn. 83f..; Weidert/Klar, BB 2017, 1858, 1862. 
Ein Beispiel für den ersten Fall dürften dabei Online-Dienstleister wie Google sein, die verschiedene Angebote vorhalten. So betreibt Google neben der Suchmaschine auch den Kartendienst „Google Maps“, kostenlose Dienste für E-Mail-Adressen und die Videoplattform YouTube - um nur die berühmtesten Dienste zu nennen. Innerhalb dieses Konglomerats dürfte es für Internetnutzer vernünftigerweise zu erwarten sein, dass Google Nutzerprofile anlegt und diese Erkenntnisse für die Werbeausspielung nutzt. Das Interesse an der Wahrung der eigenen Privatsphäre kann jeder Nutzer dabei auch durch vielfältige Einstellungen wahren ${ }^{424}$. In diesem Rahmen kommt dem berechtigten Interesse an der Ausspielung von Werbung gerade auch vor dem Hintergrund der praktisch wertvollen Dienste der höhere Wert zu und überwiegt das Interesse der Nutzer daran, nicht personalisiert angesprochen zu werden. Das gleiche dürfte auch für Anbieter von einer Vielzahl von Online-Angeboten gelten, seien es Apple, Amazon oder eBay.

Unter der neuen Rechtslage kritischer ist der zweite Fall. Dies betrifft vor allem die zentrale Ausspielung von Werbung über Adserver. Werbeflächen auf Webseiten sind in der Regel nur Platzhalter, die von den Adservern der Werbenetzwerke ausgefüllt werden. Deshalb ist es möglich, dass Informationen aus Nutzungsprofilen, die aus dem Besuch von bestimmten Webseiten gespeist werden, zur Ausfüllung der Leerflächen auf anderen Webseiten genutzt werden. Auch hier kommt wieder Google eine Hauptrolle zu. Das Google-Werbenetzwerk „AdWords“, das zu den größten weltweit gehört, kann auf die von Google im Rahmen ihrer Seiten angelegten Nutzungsprofile, die durch eigenständig gesammelte Daten gespeist werden, zugreifen und Verhalten-Targeting bzw. PBT außerhalb der Google Seiten ausführen. Hinzu kommt, dass durch die enorme Verbreitung von Google als Werbedienstleister ${ }^{425}$ auch Daten aus Myriaden von drittbetriebenen Webseiten zur Fütterung von Nutzungsprofilen genutzt wird. Dies werden durchschnittliche Nutzer regelmäßig nicht erwarten. Die Zusammenhänge der Werbeindustrie sind nicht derart allgemein bekannt, dass Nutzer vernünftigerweise damit rechnen müssen, von Google auf praktisch jeder externen Webseite verfolgt zu werden.

Insbesondere ist überdies das Interesse der Werbetreibenden an Werbung gegen das Interesse der Nutzer, nicht auf einer beliebigen Webseite

424 Vgl. https://privacy.google.com/take-control.html?categories_activeEl=sign-in, zuletzt abgerufen am: 30.5.2019.

$425 \mathrm{Vgl}$. https://t3n.de/news/werbemarkt-online-wachsen-fast-882858/, zuletzt abgerufen am 30.5.2019. 
mit dem Verhalten auf anderen Webseiten konfrontiert zu werden, abzuwägen. Diese Abwägung geht hier zugunsten der Nutzer aus. Die Konfrontation etwa mit Werbung, die zu kürzlich „gegoogleten“ Suchbegriffen oder Produkten passt, auf nicht mit Google unmittelbar verbundenen Webseiten hinterlässt ein Verfolgungsgefühl beim Nutzer. Dies wird umso stärker bei Retargeting von Produkten, die der Nutzer in einem OnlineShop zwar zunächst ausgewählt hat, sich dann aber gegen einen Kauf entschieden hat. Vor allem dann, wenn die Werbung nach Stunden oder Tagen auf Webseiten eingeblendet wird, die offensichtlich thematisch unterschiedlich sind und von anderen Webseitenbetreibern stammen. Man wird diese beiden Arten der Werbeausspielung nicht mit dem Wortlaut von Art. 6 Abs. 1 lit.f) DSGVO in Einklang bringen können. Berechtigte Interessen können die Zulässigkeit der grundsätzlichen Datennutzung zu Werbezwecken als Geschäftsmodell decken. Nicht erfasst ist aber die Hochleistungsdatennutzung zur absoluten Optimierung von Konzerngewinnen auf dem Rücken teils nichtsahnender Nutzer. Die verbreitete Anwendung von Verhalten-Targeting und PBT durch Werbenetzwerke quer durch das World Wide Web, nicht nur durch Google, sondern auch durch andere Werbenetzwerke, ist demnach unter der Geltung der DSGVO nur mit Einwilligung zulässig. Diese Einwilligung muss auf der Webseite etwa durch eine Art Cookiebanner - eingeholt werden und dort muss ausdrücklich auf die Einbindung des Werbenetzwerks hingewiesen werden. Auch ist eine hinreichende Aufklärung über die Zusammenhänge notwendig.

Von diesen beiden Fällen zu unterscheiden ist das Cross-Device-Targeting, bei dem die aus den Nutzungsprofilen gewonnenen Erkenntnisse für Werbung auf mehreren Endgeräten genutzt werden. Genauso wie das Cross-Device-Tracking auf der Ebene der Erhebung kritisch zu bewerten ist, ist die identische Ausspielung von Werbung auf mehreren Geräten wie etwa PC und Smartphone nicht von den vernünftigen Erwartungen der Nutzer gedeckt und erweckt den Verdacht hochgradiger Verfolgung. Der darin zu erkennende Eingriff in die Privatsphäre ist so erheblich, dass das Interesse an der Werbung nicht überwiegen kann. Auch hier ist also eine Rechtfertigung nur über eine Einwilligung möglich.

Der ausdrückliche Verweis der DSGVO auf die vernünftigen Erwartungen der Nutzer wirft eine weitere Frage auf: wie ist die Beurteilung der Wahrung berechtigter Interessen auf Grundlage der Nutzererwartungen mit der Weiterentwicklung von Targetingmaßnahmen und einer Änderung der Nutzererwartungen in Einklang zu bringen? Die vernünftigen Erwartungen können immer nur eine Momentaufnahme darstellen. Wenn 
die DSGVO aber die Beurteilung auf eben diese Momentaufnahme stützt, verwehrt sie in konsequenter Anwendung eine Entwicklung der Erwartungen außerhalb der Einholung von Einwilligungen. Wenn aber sowieso eine Einwilligung eingeholt werden muss, ist der Rückgriff auf die Wahrung berechtigter Interessen uninteressant und läuft auf Dauer leer. Eine Änderung der Nutzererwartungen kann faktisch nur durch transparente Aufklärung der Nutzer erfolgen - wie sie im Rahmen von Einwilligungen sowieso notwendig ist. Erst wenn es der großen Mehrheit der Nutzer bewusst ist, dass ihr Verhalten auf bestimmten Webseiten zu personalisierter Werbung auf beliebigen anderen Seiten führt, könnte eine Rechtfertigung nach Art. 6 Abs. 1 lit.f) DSGVO in Betracht kommen. Folglich kann theoretisch nach längerer Zeit der Einholung von Einwilligungen eine Etablierung der Targetingmaßnahmen eintreten, die sodann eine alternative Anwendung der Wahrung berechtigter Interessen möglich macht. Neue Targetingmethoden, die allerdings noch nicht bekannt sind, müssten immer erst eine Phase der Einwilligungspflicht durchlaufen. Die Regelung in der DSGVO ist demnach nicht sehr innovationsfreundlich.

Mit Blick auf die übrigen Stimmen in der Literatur und deren Ansatzpunkte ist etwa Schirmbacher zu entgegnen, dass die Aufklärung in den Werbebannern bei den meisten Nutzern unbekannt ist und deshalb nicht zu einer Prägung der vernünttigen Erwartungen führt. Die kleinen Symbole in den Werbebannern und ähnlichen Werbeformen werden nur selten als Möglichkeit zur Steuerung der Werbeausspielung oder profunde Aufklärung identifiziert und genutzt. Schulz ist zu entgegnen, dass er die alte deutsche Rechtslage ohne schriftliche Grundlage weiterführen möchte und damit dem Willen des Verordnungsgebers widerspricht, dem die deutsche Regelung im Gesetzgebungsverfahren bekannt war. Der „deutsche Weg“ zu Nutzungsprofilen wurde aber gerade nicht gewählt. Deshalb ist der europäische Weg genuin zu beschreiten, was nicht mit der Devise „weiter so wie gehabt" möglich sein wird. Ein im Übrigen vertretener genereller Ausschluss der Möglichkeit des Eingreifens von Art. 6 Abs. 1 lit. f) DSGVO ist zu pauschal und bei einer Generalklausel nicht vertretbar. Wie aufgezeigt, existieren Situationen, die erlaubt sein sollen. Dies ist auch vom Verordnungsgeber gewollt, sonst wäre keine offene Klausel mit Interessenabwägung in den Rechtfertigungsgrundkatalog von Art. 6 DSGVO eingefügt worden. 
(v) Soziales Targeting

Soziales Targeting stellt sozusagen das „All-Inclusive“-Paket der vorgenannten Targetingmethoden dar. Die Verhaltenskomponente kann durch eindeutige "gefällt mir“-Angaben zweifelsfrei analysiert werden. Hinzu kommt eine Prise Geotargeting, was vor allem bei der Nutzung von mobilen Geräten eine genaue Lokalisation ermöglicht. Zuletzt verfügen Anbieter sozialer Netzwerke noch über genaueste Informationen über Alter, Geschlecht und Herkunft der Nutzer, weil diese bei der Anmeldung angegeben wurden. Demnach stellen sich auch bei dieser Targetingform ähnliche Fragen wie beim PBT.

Soziales Targeting hat aber eine Besonderheit im Vergleich zu den vorgenannten Targetingmethoden auf frei zugänglichen Webseiten: der Nutzer hat sich mit seiner Anmeldung bestimmten Nutzungsbedingungen unterworfen. Im Rahmen der Nutzungsbedingungen ist es möglich, eine datenschutzrechtliche Einwilligung für soziales Targeting festzuschreiben. Dies ist sogar nachträglich möglich durch einseitige Änderung der Nutzungsbedingungen, die durch die bloße Weiternutzung anerkannt werden. Doch selbst wenn die Nutzungsbedingungen nicht ausreichend sein sollten ${ }^{426}$, können sich Anbieter von sozialen Netzwerken im Rahmen ihrer Plattform ebenso gut auf die Wahrung berechtigter Interessen nach Art. 6 Abs. 1 lit.f) DSGVO berufen wie Google im Rahmen ihrer nicht unbedingt von einer Anmeldung abhängigen Plattformen.

Probleme bereitet wiederum ein Targeting außerhalb der eigenen Plattform. Auch Facebook hält etwa ein eigenes Werbenetzwerk vor, dass auf die Informationen aus dem Netzwerk zugreift und auf anderen Webseiten Targeting betreibt ${ }^{427}$. Hier existieren dieselben Probleme wie beim Verhalten-Targeting, weshalb auch hier eine Einwilligung $\mathrm{zu}$ fordern ist und keine Rechtfertigung nach Art. 6 Abs. 1 lit. f) DSGVO in Betracht kommt.

426 Facebook formulierte in den Nutzungsbedingungen vor der Neufassung im Jahr 2018 insoweit eher schwammig: „Unser Ziel ist es, Werbeanzeigen und andere kommerzielle bzw. gesponserte Inhalte, die für unsere Nutzer und Werbetreibende wertvoll sind, zur Verfügung zu stellen.“, vgl. https://www.faceb ook.com/legal/terms, abgerufen am: 20.1.2018. Die zur Zeit des Abschlusses dieser Arbeit aktuelle Fassung enthält keine Einräumung einer ausdrückliche Einwilligung, vgl. https://www.facebook.com/legal/terms, zuletzt abgerufen am: 30.5.2019.

427 Vgl. Lammenett, Praxiswissen Online Marketing, S. 321ff.. 
(vi) Zusammenfassung zum Targeting

Targeting auf Grundlage von personenbezogenen Daten bedarf der Rechtfertigung durch Einwilligung oder durch die Wahrung berechtigter Interessen. Nachfolgend wird zusammengefasst für welche Maßnahmen, welche Rechtfertigungsgründe möglich sind.

Eine Rechtfertigung ohne Einwilligung, sondern nach Art. 6 Abs. 1 lit. f) DSGVO, mithin unter einfacheren faktischen Voraussetzungen kommt in Betracht für:

- Techniktargeting,

- Geotargeting auf Webseiten mit räumlichem Bezug und Suchfunktionen ohne die manuelle Eingabe des Standortes,

- Verhalten-Targeting und "predictive behavioral targeting“ innerhalb von verbundenen Webangeboten, wenn die Daten vom Betreiber selbst gesammelt werden.

Eine Rechtfertigung allein mit Einwilligung ist für folgende Targetingmethoden erforderlich:

- Geotargeting auf Webseiten ohne lokale Bezüge,

- Verhalten-Targeting und „predictive behavioral targeting“ über Werbenetzwerke auf Webseiten, die nicht zur erhebenden Stellen gehören,

- Cross-Device-Targeting.

\section{c) Lauterkeitsrechtliche Aspekte von Tracking und Targeting}

Verbunden mit den datenschutzrechtlichen Problemen, die dem Tracking und Targeting anhaften, sind lauterkeitsrechtliche Aspekte, die beim unrechtmäßigen Gebrauch dieser Technologie zu beachten sind. Bei Nichteinhaltung der lauterkeitsrechtlichen Anforderungen sind somit Unterlassungsansprüche aus $\$ 8$ Abs. 1 UWG möglich. Dadurch könnten Webseitenanbieter beim Einsatz von Tracking und Targeting nicht nur vertikal durch die zuständigen staatlichen Stellen im Datenschutzrecht, sondern auch im horizontalen Verhältnis von Mitbewerbern oder Wettbewerbsund Verbraucherschutzvereinen kontrolliert werden. Die Letztgenannten können sich dabei theoretisch auf drei Tatbestände stützen: Rechtsbruch gemäß $₫ 3 a$ UWG, Irreführung nach $\$ 5$ UWG und vergleichende Werbung gemäß $\$ 6 \mathrm{UWG}$. 
aa) Rechtsbruch, $\mathbb{} 3$ a UWG

Kern der Prüfung eines Rechtsbruchs nach $\mathbb{3} 3 \mathrm{a}$ UWG ist, ob eine gesetzliche Vorschrift vorliegt, die auch dazu bestimmt ist, im Interesse der Marktteilnehmer das Marktverhalten zu regeln (sog. Marktverhaltensregelung). $\mathrm{Ob}$ eine Norm eine Marktverhaltensregelung enthält, ist durch Auslegung zu ermitteln. Die Frage ist zu bejahen, wenn die in Frage stehende Norm zumindest auch den Schutz der Interessen der Marktteilnehmer bezweckt, mag sie auch in erster Linie die Interessen der Allgemeinheit im Auge haben $^{428}$.

Bei der Prüfung, ob Tracking oder Targeting einen lauterkeitsrechtlichen Rechtsbruch darstellen können, ist demnach auf erster Stufe zu prüfen, ob die einschlägigen Normen überhaupt als Marktverhaltensregelungen anzusehen sind. Sowohl für Tracking als auch für Targeting ist Art. 6 DSGVO zu untersuchen. Für Tracking ist dabei speziell Art. 8 der EPVO-E in den Blick zu nehmen.

(i) Art. 6 DSGVO = Marktverhaltensregelung?

Bei der Frage, ob Art. 6 DSGVO eine Marktverhaltensregelung darstellt, ist nicht nur die punktuelle Norm in den Blick zu nehmen, sondern insgesamt das Verhältnis zwischen Datenschutzrecht und Lauterkeitsrecht zu betrachten. Nach alter Rechtslage unter dem BDSG a.F. war umstritten, ob die Vorschriften des Gesetzes den Schutz der Verbraucher als Marktteilnehmer oder lediglich dem grundrechtlichen Schutz der Privatsphäre natürlicher Personen dienen ${ }^{429}$. Unter Geltung der DSGVO ist dieser Streit wieder neu entfacht worden. Die DSGVO sieht nämlich in Art. 77 - 84 ein ausdifferenziertes System von Rechtsbehelfen, Haftungsregeln und Sanktionen vor, das nur an einer Stelle eine Abweichungsmöglichkeit der Mitgliedstaaten enthält. Daraus folgerte Köbler bereits vor Inkrafttreten der DSGVO, dass Verstöße gegen die DSGVO nicht über $\mathbb{\$}$ 3a UWG zu ahnden sind, weil die Vorschriften der DSGVO eine abschließende Regelung darstellen ${ }^{430}$.

428 Vgl. OLG Köln, Urteil vom 28.4.2017 - 6 U 152/16, GRUR 2017, 1048, Rn. 33 mit Verweis auf Köhler/Bornkamm/Feddersen, UWG, $\$ 3 a$, Rn. 1.61, 1.64.

429 Vgl. Podszun/de Toma, NJW 2016, 2987, 2989ff..

430 Köhler/Bornkamm/Feddersen, UWG, $\$ 3$ a, Rn. 1.40a-i, 1.74b. 
In der Zeit unmittelbar vor und nach Inkrafttreten der DSGVO entbrannte sodann ein veritabler Streit in Rechtsprechung und Literatur darüber, ob DSGVO Verstöße über $₫ 3$ a UWG zu ahnden sind und deshalb als rechtliche Grundlage für Abmahnungen im Wettbewerb dienen können. Dies lehnten insbesondere der Bearbeiter ${ }^{431}$ und Köhler ${ }^{432}$ ab. Ebenfalls dieser Ansicht schlossen sich das LG Bochum ${ }^{433}$, das LG Wiesbaden ${ }^{434}$ und Baumgartner/Sitte 435 an. Auf der anderen Seite vertreten Wolff ${ }^{436}$, Laoutoumai/Hoppe ${ }^{437}$, Schreiber ${ }^{438}$ und die OLGe Hamburg ${ }^{439}$ sowie Naumbur$\mathrm{g}^{440}$, dass DSGVO Vorschriften die Eignung zur Marktverhaltensregelung nicht generell abgesprochen werden könne.

Da die Diskussion das Potential hat, eine endgültige Klärung durch den EuGH herauszufordern und die Diskussion außerhalb dieser Arbeit bereits ausführlich geführt wird, soll an dieser Stelle nur kurz darauf hingewiesen werden, dass im Ergebnis der erstgenannten Ansicht der Vorzug einzuräumen ist. Eine Anwendung des $\$ 3$ a UWG in Verbindung mit DSGVO Vorschriften scheidet aus. Das ausdrücklich angeordnete systematisch abgeschlossene Rechtsbehelfssystem ist nicht durch deutsches Wettbewerbsrecht zu erweitern. Es besteht kein zwingender Bedarf dafür, die Normen der DSGVO als Marktverhaltensregelungen im Rahmen des $\$ 3$ a UWG anzusehen. Denn dies würde praktisch vorwiegend dazu führen, dass nach $\$ 8$ Abs. 3 Nr. 1 UWG neben den in $\$ 3$ UKlaG genannten Stellen auch Mitbewerber in die Lage versetzt würden, Verstöße gegen Datenschutzrecht im eigenen Namen und ohne Auftrag des Betroffenen geltend zu machen. Dies widerspricht aber der eindeutigen Anordnung in Art. 79, 80 DSGVO.

Verstöße gegen Art. 6 DSGVO können nicht als Verstöße gegen eine Marktverhaltensregelung im Sinne von $\$ 3$ a UWG angesehen werden. Eine beschränkte horizontale Kontrolle der Webseitenanbieter, die sich Tracking- und Targetingmaßnahmen bedienen, ist ohne Einbindung von

431 WRP 2018, 790.

432 WRP 2018, 1269; ZD 2018, 337.

433 LG Bochum, Urteil vom 7.8.2018 - I-12 O 85/18, ZD 2019, 39.

434 LG Wiesbaden, Urteil vom 5.11.2018 - 5 O 214/18, K\&R 2019, 281.

435 ZD 2018, 555.

436 ZD 2018, 248.

437 K\&R 2018, 533.

438 GRUR-Prax 2018, 371.

439 OLG Hamburg, Urteil vom 25.10.2018 - 3 U 66/17, ZD 2019, 33.

440 OLG Naumburg, Urteil vom 7.11.2019 - 9 U 6/19, WRP 2020, 110; Urteil vom 7.11.2019 - 9 U 39/18, WRP 2020, 114. 
staatlichen Stellen nur durch Organisationen ohne Gewinnerzielungsabsicht über $\mathbb{2}$ Abs. 2 Nr. 11 UKlaG möglich. So können durch $\$ 3$ UKlaG i.V.m. Art. 80 Abs. 2 DSGVO ermächtigte Organisationen Unterlassungsund Beseitigungsansprüche durchsetzen wie es durch $\$ 5$ UKlaG i.V.m. $\$ 12$ UWG klargestellt wird.

\section{(ii) Art. 8 E-Privacy-Verordnung (Entwurf) = Marktverhaltensregelung?}

Die E-Privacy Verordnung (Entwurf) hingegen unterscheidet sich in ihrer Regelung der Rechtsbehelfe von der DSGVO. Eine dem Art. 80 DSGVO vergleichbare Regelung für die Ermächtigung von Verbänden enthält die EPVO-E nicht. Stattdessen regelt Art. 21 EPVO-E, dass jeder Endnutzer Klage erheben bzw. Antrag auf einstweilige Verfügung stellen kann. Dies wird durch den in Art. 21 Abs. 1 EPVO-E enthaltenen Verweis auf Art. 79 DSGVO deutlich. In Art. 21 Abs. 2 EPVO-E wird zudem natürlichen oder juristischen Personen, die nicht als Endnutzer anzusehen sind, ein Recht gewährt, gerichtlich vorzugehen, wenn sie durch Verstöße gegen die EPVO-E beeinträchtigt werden. Als Beispiel („einschließlich“) nennt die Norm die Betreiber elektronischer Kommunikationsdienste, die ihre berechtigten Geschäftsinteressen schützen wollen.

Es stellt sich die Frage, wie Art. 21 Abs. 2 EPVO-E im existierenden deutschen Rechtsschutzsystem einzuordnen ist. Da die Verordnung unmittelbare Wirkung hat, wird man aus Art. 21 Abs. 2 EPVO-E in Verbindung mit den einzelnen Verboten, etwa Art. 8, einen Anspruch von „Nicht-Endnutzern" auf Unterlassung und Beseitigung folgern müssen. Problematisch ist dabei jedoch, dass die EPVO-E sehr vage bleibt und lediglich von einem gerichtlichen Vorgehen spricht. Darin ist keine dem deutschen Rechtssystem entsprechende ausdrückliche Anspruchsgrundlage zu erkennen, die Umfang und Grenzen des Anspruchs deutlich macht. Ein auf Art. 21 Abs. 2 i.V.m. Art. 8 Abs. 1 EPVO-E gestützter Anspruch ist bedenklich unbestimmt.

Eine Möglichkeit zur Aufhebung dieser Unbestimmtheit ist die Anerkennung der Regeln der E-Privacy Verordnung als Marktverhaltensregelungen im Sinne von $₫ 3$ a UWG. Dies wäre auch der deutschen Rechtslage bis Mai 2018 nicht fremd. Denn insbesondere die datenschutzrechtlichen Vorschriften zu Nutzungsprofilen in $\$ \$ \$ 12-15$ TMG wurden von Gerichten 
als Marktverhaltensregelungen eingeordnet ${ }^{441}$. Mit dieser Lösung würde Art. 21 Abs. 2 EPVO-E allerdings nur teilweise verwirklicht. Denn wegen $\$ 8$ Abs. 3 UWG sind für Ansprüche aus $\$ \mathbb{} 8$ Abs. 1, 3 Abs. 1, 3a UWG nur Mitbewerber und bestimmte Verbände aktivlegitimiert. Damit ist nicht gewährleistet, dass alle natürlichen und juristischen Personen, die nicht Endnutzer sind, eine effektive Möglichkeit zur Klage haben. Gleiches gilt für eine Anwendung von $\mathbb{2}$ Abs. $2 \mathrm{Nr} .11 \mathrm{UKlaG}$, weil auch hier nur Verbände Unterlassungs- und Beseitigungsansprüche erhalten.

Nicht alle der von Art. 21 Abs. 2 EPVO-E genannten Personen werden aber die Anforderungen von $\$ 3$ UKlaG bzw. $\$ 8$ Abs. 3 Nr. 2-4 UWG erfüllen oder als Mitbewerber im Sinne von $\$ \$ 8$ Abs. 3 Nr.1, 2 Abs. 1 Nr. 3 UWG anzusehen sein. Die Voraussetzung des berechtigten Interesses laut Art. 21 Abs. 2 EPVO-E wird man insoweit nicht mit einem konkreten Wettbewerbsverhältnis gleichsetzen können. Das berechtigte Interesse kann auch andere, ggf. sogar immaterielle oder populare Interessen, erfassen. Die Fälle, die nicht bereits durch UKlaG und UWG abgedeckt werden, können dann dogmatisch über $\mathbb{\$} 823$ Abs. 1 BGB i.V.m. $\mathbb{\$} 1004$ Abs. 1 BGB analog gelöst werden. Die notwendige Rechtsgutsverletzung als „sonstiges Recht" im Sinne von $\$ 823$ Abs. 1 BGB ergäbe sich dabei potentiell aus dem jeweils einschlägigen Verbot sowie Art. 21 Abs. 2 EPVO-E. Bedenken löst bei dieser Lösung jedoch aus, dass hiermit datenschutzrechtliche Regelungen in den Stand der quasi-absoluten Rechte erhoben würden. Diese lassen sich nur dann auflösen, wenn man einen gedanklichen Umweg über das allgemeine Persönlichkeitsrecht, genauer auf das Recht auf informationelle Selbstbestimmung, nimmt ${ }^{442}$. Die Regelung in der EPVO-E lässt sich dabei als konkrete Ausgestaltung dieser Ausprägung des allgemeinen Persönlichkeitsrechtes qualifizieren und verfügt mithin über ausreichende rechtliche Qualität, die eine Anwendung des Deliktsrechts trägt. Im Übrigen ist eine Anwendung über $\$ 823$ Abs. 2 BGB i.V.m. $\$ 1004$ Abs. 1 BGB analog denkbar. Insoweit wäre Art. 8 EPVO-E ein den Schutz eines anderen bezweckendes Gesetz. Wenn die Norm nämlich bereits als

441 Vgl. OLG Köln, Urteil vom 11.3.2016 - 6 U 121/15, GRUR-RR 2016, 284; LG Düsseldorf, Urteil vom 9.3.2016 - 12 O 151/15, MMR 2016, 328. Das OLG Düsseldorf hat den Fall des LG Düsseldorf dem EuGH mit der Frage vorgelegt, ob auch gemeinnützige Verbände nach der Datenschutzrichtlinie (RL 95/46/EG) klagebefugt sein sollen, vgl. Vorlagebeschluss vom 19.1.2017 - I-20 U 40/16, GRUR 2017, 416. Das Verfahren ist beim EuGH anhängig unter dem Aktenzeichen C-40/17.

442 Mann, in: Spindler/Schuster, $\mathbb{} 823$ BGB, Rn. 40. 
Marktverhaltensregelung anzusehen ist, gilt dies erst recht für die Einordnung als Schutzgesetz im Sinne von $\$ 823$ Abs. 2 BGB.

Demnach sollte Art. 8 EPVO-E, anders als die Vorschriften der DSGVO, als Marktverhaltensregelung angesehen werden, die zu einem Unterlassungs- oder Beseitigungsanspruch nach $\mathbb{S} \$ 8$ Abs.1, 3 Abs. 1, 3a UWG führen kann.

(iii) Die übrigen Voraussetzungen von $₫ 3 a \mathrm{UWG}$

Im Übrigen muss gegen die festgestellte Marktverhaltensregelung verstoßen worden sein, was im Einzelfall Tatfrage sein wird. Letzte Voraussetzung ist die Eignung des Verstoßes zur spürbaren Beeinträchtigung der Interessen von Verbrauchern, sonstigen Marktteilnehmern oder Mitbewerbern. Der Verstoß gegen eine Marktverhaltensregelung indiziert jedoch im Regelfall die Eignung zur spürbaren Beeinträchtigung ${ }^{443}$.

$\mathrm{Zu}$ dem letztgenannten Merkmal ist aus aktuellem Anlass noch ein Gedanke anzuführen. Im Rahmen des $\$ 5$ a UWG, für den nach alter Fassung des UWG bis Dezember 2015 über die Verbindung mit $₫ 3$ UWG a.F. die gleichlautende Spürbarkeitsvoraussetzung galt, hat der BGH für den Bereich der Informationspflichten auf unionsrechtlicher Grundlage kürzlich die Geltung dieser tatsächlichen Vermutung ausdrücklich ausgeschlossen. Jedoch verbleibe eine sekundäre Darlegungslast des Verletzers, eine tatsächliche Grundlage für die fehlende Spürbarkeit vorzubringen ${ }^{444}$. Im Bereich des Rechtsbruchtatbestandes von $\$ 3$ a UWG sollte aber auch weiterhin an der tatsächlichen Vermutung festzuhalten sein. Die Rechtsprechung aus der Komplettküchen-Entscheidung sollte keine Anwendung finden, da $₫ 3$ a UWG anders als $₫ 5$ a UWG nicht auf der UGP-Richtlinie beruht und die Argumente des BGH maßgeblich auf der Umsetzung eben dieser Richtlinie beruhen.

bb) Irreführung, $\$ 5$ UWG

Im Zusammenhang mit Tracking und Targeting ist auch eine Irreführung des durchschnittlichen Internetnutzers möglich. Im Jahr 2016 hat

443 Köhler/Bornkamm/Feddersen, UWG, $\mathbb{3} 3 \mathrm{a}, \mathrm{Rn} .1 .112$.

444 BGH, Urteil vom 2.3.2017 - I ZR 41/16, GRUR 2017, 922, Rn. 31ff. - Komplettküchen. 
der BGH zum Geotargeting entschieden, dass eine Bannerwerbung eines regional tätigen Kabelnetzbetreibers, die auf bundesweit frequentierten Internetportalen ausgespielt wird und über Geotargeting nur Nutzer im Verfügbarkeitsgebiet anzielt, eine unlautere Irreführung nach $₫ 5$ Abs. 1 Nr. 1 UWG darstellt, wenn sie bei Nutzern außerhalb dieses Gebiets angezeigt wird und keinen Hinweis auf die räumliche Begrenzung enthält ${ }^{445}$. Die Täuschung der Verbraucher bezog sich dabei auf die räumliche Verfügbarkeit der Dienstleistung, da das Gericht durch die Werbung den Eindruck gewann, die Dienstleistung sei bundesweit verfügbar.

Neben diesem Befund enthält das Urteil zudem drei bemerkenswerte Aussagen zur Werbung im Internet, die auch für zukünftige, anders gelagerte Fälle Bedeutung erlangen können. Erstens, es bestehe ein Unterschied zwischen dem Vorhalten einer bundesweit aufrufbaren Webseite und einer aktiven Werbung auf fremden Webseiten. Während das passive Bereithalten der Webseite nicht geeignet ist, einen Verbraucher irrezuführen ${ }^{446}$, kann die Trägerwebseite der Werbung einen immanenten Aussagegehalt zuweisen. So etwa im oben gekennzeichneten Fall die bundesweite Verfügbarkeit auf bundesweit tätigen Portalen wie spiegel.de. Zweitens, eine Ungenauigkeit der Targetingmaßnahme, die zu einer Ausspielung der Werbung an nicht angezielte Nutzer führt, ist relevant, d.h. sie ist geeignet, den Verbraucher oder sonstigen Marktteilnehmer zu einer geschäftlichen Handlung zu veranlassen, die er andernfalls nicht getroffen hätte. Im Streitfall konnte das Gericht eine Fehlerquote der Targetingmaßnahme von $5 \%$ annehmen und hielt dies für ausreichend, um die Marktrelevanz zu bejahen. Um die Fehlerquote in ein Verhältnis zur analogen Welt zu setzen, führte der BGH zudem aus, dass eine relevante Irreführung auch dann vorliege, wenn ein beworbenes Produkt eines Filialbetriebs nur in einer von 100 Filialen dieses Unternehmens nicht verfügbar sei. Hinzu komme, dass im Streitfall diese Fehlerquote schon bei Beauftragung der Werbung bekannt und durch den Werbenden bewusst in Kauf genommen worden sei. Drittens und abschließend, stehe das Aufsuchen einer Webseite mit unmittelbarer Bestellmöglichkeit dem Betreten eines stationären Geschäfts gleich. Deshalb ist schon der Klick auf eine Bannerwerbung von dem Begriff der geschäftlichen Entscheidung im Sinne von $\$ 5$ UWG erfasst $^{447}$.

445 BGH, Urteil vom 28.4.2016 - I ZR 23/15, GRUR 2016, 1073 - Geo-Targeting.

446 Vgl. Rehart, MMR 2016, 683, 684.

447 Vgl. EuGH, Urteil vom 19.12.2013, Rs. C-281/12, GRUR 2014, 196 - Trento Sviluppo. 
Das Urteil wurde in der Literatur mit Zustimmung bedacht ${ }^{448}$, wobei eine Auseinandersetzung über den konkreten Fall hinaus nicht erfolgte. Klarzustellen ist, dass die Erhebung von Standortdaten und deren Nutzung zur standortbasierten Werbung als solche nicht unlauter sind. Geotargeting ist vielmehr die Möglichkeit, das Internet auch für räumlich begrenzt verfügbare Waren und Dienstleistungen effektiv werblich zu nutzen. Ohne Geotargeting wäre die Werbung eines rein lokal tätigen Unternehmens auf einer bundesweiten Webseite gegebenenfalls irreführend, weil es den Eindruck bundesweiter Verfügbarkeit erwecken kann. Das Urteil des BGH stellt insoweit jedoch fest, dass der Einsatz von Geotargeting allein nicht einen Hinweis auf die Verfügbarkeit der Dienstleistung in der Werbung selbst entbehrlich macht und zwar wegen der bekannten Ungenauigkeiten und Fehlerquoten. Eine zuverlässigere Ausgestaltung von Geotargeting könnte einen solchen Hinweis zukünftig vielleicht entbehrlich machen. Es lässt sich insgesamt festhalten, dass der Einsatz der (aktuellen) Technik den Werbenden nicht von einer transparenten Anzeigengestaltung befreit. Der Werbende darf sich (noch) nicht allein auf die Technik verlassen.

Interessant ist die Frage, ob aus der Geo-Targeting-Entscheidung ein allgemeines Konzept für Targeting entwickelt werden kann. Aufhänger für den Rechtsstreit war die räumliche Verfügbarkeit der beworbenen Ware, welche ein ausdrücklich genanntes Regelbeispiel in $\$ 5$ Abs. 1 UWG ist. Aus dieser leicht erkennbaren Situation wurde dann festgestellt, dass bewusst in Kauf genommene Streuverluste einer nicht ausreichend aufklärenden Online-Anzeige durchaus zu einer Irreführung führen können. Eine Übertragbarkeit der Rechtsprechung zum Geotargeting ist vor allem auf das Techniktargeting denkbar. Im konstruierten Fall einer gezielt ausgespielten Werbung, die als Targetingkriterium das Bestehen bestimmter Hardware beim Nutzer hat, wären hier die Regelbeispiele der Zwecktauglichkeit oder Verwendungsmöglichkeit aus $₫ 5$ Abs. 1 UWG als Anknüpfungspunkt der Irreführung heranzuziehen. Wird also die Anzeige für ein spezifisches Produkt, das nur zu der angezielten Hardware passt, an Inhaber anderer Hardware ausgespielt und lockt die Anzeigen diesen falsch ausgewählten Nutzer auf einen entsprechenden Online-Shop, ist streng genommen ebenfalls von einer unlauteren Irreführung auszugehen. Der Werbende müsste also den Hinweis auf die Beschränktheit seiner Ware auf bestimmte Hardware in der Anzeige aufnehmen.

448 Rehart, MMR 2016, 683, 684. 
Hingegen ist diese Konstellation bei den Formen des semantischen Targetings nicht einschlägig, weil hier anders als beim Standort oder der Hardware kein individualisiertes Targeting erfolgt, sondern lediglich kontextsensitiv geworben wird. Es ist nicht denkbar, dass durch die Positionierung der Werbung eine ausreichende Spezialisierung des Publikums eintritt, die zum Weglassen gewisser Informationen in einer Anzeige berechtigen.

Beim Verhalten-Targeting bzw. PBT kann an eine Vielzahl von Kriterien angeknüpft werden, je nach früherem Verhalten des Nutzers im Netz. Der Möglichkeit, Streuverluste zu vermeiden, steht aber gleichermaßen die Gefahr gegenüber, dass der Algorithmus Anzeigen von Waren oder Dienstleistungen auswählt, die für den konkreten Nutzer nicht interessant oder überhaupt nicht erhältlich sind. Die Konstellation aus dem Geo-Targeting-Urteil wäre nur dann übertragbar, wenn eine Anzeige ein gewisses verhaltensbasiertes Merkmal verschweigt, dies aber über die gesteuerte Ausspielung auch nicht mitteilen muss, weil der Adressat dies für selbstverständlich hält. Ein Beispiel könnte Werbung für Medien mit FSK-Freigabe ab 18 Jahren sein, die an Nutzer ausgespielt wird, die zuvor etwa Webseiten mit Rezensionen zu dem beworbenen oder ähnlichen Titeln besucht haben. Hat die Anzeige selbst keinen Hinweis auf die FSK-Freigabe und ist dies auch nicht aus dem Titel selbst ersichtlich - wie etwa bei Pornographie - ist die Anzeige unlauter irreführend nach $₫ 5$ UWG, wenn sie auch Nutzer unter 18 Jahren erreicht. Denn ein Nutzungsprofil kann zwar dem auswertenden Algorithmus nahelegen, dass der Nutzer bereits alt genug ist, eine genaue Prüfung ist aber oft nicht möglich. Im derart gezeichneten Fall nähme der Werbende bewusst das Risiko in Kauf, dass die Werbung auch an Minderjährige ausgespielt wird.

Folglich lässt sich die Geo-Targeting-Entscheidung des BGH durchaus verallgemeinern. Targeting führt regelmäßig nicht dazu, dass offenbarungspflichtige Umstände in der Werbung vorenthalten werden dürfen. Dies ist nur dann möglich, wenn die Technik derart zuverlässig ist, dass ein Streuverlust mit Sicherheit ausgeschlossen werden kann. Dies wird nach der strengen Rechtsprechung des BGH praktisch nie erfüllt sein.

Abschließend soll nicht unterschlagen werden, dass auch eine Irreführung durch Unterlassen gem. \$5 a UWG möglich ist. Als wesentliche Information im Sinne von $₫ 5$ a Abs. 2, 4 UWG im Sinne der Norm können die Informationspflichten aus Art. 13, 14 DSGVO oder der E-Privacy Verordnung herangezogen werden. Auf dieser Grundlage können Mitbewerber zumindest im beschränkten Umfang Rechtsschutz gegen Konkurrenten 
wegen Datenschutzverstößen ersuchen, falls schlicht überhaupt keine Informationen gegeben werden.

\section{cc) Vergleichende Werbung, \$6 UWG}

Außerdem wird im Schriftum die Möglichkeit einer unlauteren vergleichenden Werbung angesprochen ${ }^{449}$. Als vergleichende Werbung wird dabei die Einblendung von Werbung eines Unternehmens auf Werbeplätzen einer Webseite angesehen, deren Content die Waren oder Dienstleistungen eines Konkurrenten betrifft. Konkrete Beispiele sind etwa die Einblendung von Werbung in sozialen Netzwerken, vor allem Facebook, im Kontext von Seiten eines Mitbewerbers oder die durch Geotargeting gestützte Anzeige von Werbung, wenn sich der Nutzer in der Nähe von konkurrierenden Geschäften befindet. Ferner wird für Verhalten-Targeting auf die Möglichkeit hingewiesen, dass der Werbende als Targetingparameter den Besuch von Webseiten der Konkurrenten oder die Betrachtung von konkurrierenden Produkten in Online Shops angibt und somit eine Ausspielung auf Grundlage des Interesses an den Konkurrentenprodukten herbeiführt. Diese letzte Konstellation erinnert an die Nutzung markenrechtlich geschützter Keywords bei Suchmaschinenwerbung.

Gleichwohl genügt die bloße Nähe von Werbung und Konkurrenzangeboten im Internet nicht für eine Unlauterkeit. Die Unlauterkeit könnte normativ auf $\$ 6$ Abs. 2 Nr. 3 und 4 UWG gestützt werden. Während eine Verwechslungsgefahr nach Nr. 3 regelmäßig ausscheiden wird, wenn der Werbende sich tatsächlich unter der eigenen Marke von den in Bezug genommenen Konkurrenten abgrenzen will, sind Rufausnutzung oder Rufbeeinträchtigung nach Nr. 4 durchaus denkbar. Jedoch ist gerade für die Rufausnutzung ein sog. Imagetransfer notwendig ${ }^{450}$. Dies wird bei den beschriebenen Situationen oft nicht erfüllt sein, weil es den Werbenden regelmäßig gerade auf die Abgrenzung zum Konkurrenten ankommen wird. Denn wer in einem fremden Bereich wirbt, den der Nutzer freiwillig und aktiv aufgesucht hat, wird regelmäßig werblich herausstellen müssen, warum seine Waren vorzugswürdig sind. Eine Rufausnutzung kommt also praktisch nur in Betracht, wenn sehr ähnliche Waren oder Dienstleistungen unter Angabe von günstigeren Preisen als beim Konkurrenten beworben werden. Also muss der Nutzer, der sich über ein Produkt infor-

449 Micklitz/Namyslowska, in: Spindler/Schuster, $\$ 6$ UWG, Rn. $93 \mathrm{ff}$.

450 Köhler/Bornkamm/Feddersen, UWG, \$6, Rn. 153. 
miert und gleichzeitig in einer Online-Anzeige die konkurrierende Information erhält, einfach erkennen, dass er bei Folgen der Werbung etwas Substituierbares für weniger Geld erhalten kann. Die Rufbeeinträchtigung hingegen verlangt eine Herabsetzung oder Verunglimpfung des konkurrierenden Kennzeichens ${ }^{451}$. Dies ist selbstverständlich denkbar, wird aber praktisch nur selten vorkommen.

Somit ist eine Unlauterkeit nach $₫ 6$ UWG in diversen Konstellationen durchaus möglich. Die Voraussetzungen für eine Bejahung sind allerdings sehr hoch, praktische Relevanz bei rechtlichen Auseinandersetzungen wird dieser Tatbestand deshalb wohl nicht erlangen.

\section{Probleme des modernen Online-Marketing}

Wie bereits oben im Abschnitt B. I. 4. lit. b) - d) beschrieben, finden sich im kontemporären Online-Marketing gewisse Phänomene, die die modernen Möglichkeiten der Online-Kommunikation öffentlichkeitswirksam nutzen. Es handelt sich um die Phänomene des Native Advertising, Guerilla-Marketings und die sog. Influencer.

Allerdings müssen sich diese Phänomene ebenfalls dem geltenden Recht anpassen und genießen keine Sonderrechte. Im Folgenden sollen deshalb in Kürze Hinweise zu rechtlichen Fallstricken des modernen Online-Marketings gegeben werden.

\section{a) Zulässigkeit des Native Advertising}

Sowohl in der Ausprägung als Anzeigenwerbung als auch bei ContentWerbung stellt sich bei Native Advertising vor allem die Frage der zulässigen Ausgestaltung. Mithin geht es nicht um das „Ob“ der natürlichen Werbung, sondern um das „Wie“. Bei Anzeigen ist es gerade Zweck dieser Methode keine unzumutbare Belästigung des Nutzers herbeizuführen. Nach den oben entwickelten Kriterien kann eine zurückhaltende Anzeige ohne zeitliche Bindung des Nutzers auch nicht zu einer Unzulässigkeit nach $\$ 7$ UWG führen. Demnach kreisen sich die rechtlichen Probleme zuvörderst um das Trennungsgebot und die ausreichende Kennzeichnung als Werbung. Die einschlägigen Normen sind also $\mathbb{5} 5$ a Abs. 6 UWG, $\mathbb{} 3$ Abs. 3 UWG i.V.m. Nr.11 des Anhangs zum UWG sowie die beiden

451 Köhler/Bornkamm/Feddersen, UWG, $\$$ 6, Rn. 163. 
gleichlautenden Vorschriften in $₫ 6$ Abs. 1 Nr. 1 TMG und $₫ 58$ Abs. 1 S. 1 Hs. 1 RfStV, die über $\$ 3$ a UWG Bedeutung erlangen können ${ }^{452}$.

Während sich die rechtliche Problematik bei Anzeigenwerbung auf die bereits angesprochene Frage beschränkt, wie die korrekte wörtliche Bezeichnung des Werbehinweises ausgestaltet sein muss, etwa durch Nutzung des Wortes „Anzeige“ oder durch eine Wendung wie „gesponsert“, erfordert die Bewertung von Native Content Advertising einen vertieften Blick. Für die rechtliche Beurteilung soll der vorab bereits mit Screenshots illustrierte Fall zu Grunde gelegt werden, dass auf eigenständigen Webportalen bestimmte Unterseiten durch den Werbenden in der auf dem Portal üblichen Form mit Inhalt bestückt werden. Beispiele hierfür sind bezahlte Beiträge auf den Portalen Buzzfeed oder Chefkoch.de ${ }^{453}$.

Eine Unzulässigkeit dieser Werbemaßnahme nach $\$ 3$ Abs. 3 i.V.m. Nr. 11 des Anhangs UWG wird dabei praktisch nicht vorkommen ${ }^{454}$. Die Finanzierung wird regelmäßig erkennbar sein durch die Abbildung von Markenzeichen der Werbenden, die Verlinkung von Textteilen, in denen die Marken- und Produktnamen hervorgehoben werden und der Angabe einer Wendung wie „promoted von“. Diese Merkmale werden den Durchschnittsadressaten dazu bringen, den Beitrag als zumindest nicht ganz redaktionell und unparteiisch anzusehen. Wo im Einzelfall die Grenze zur Unzulässigkeit verläuft ist, wie so oft im Lauterkeitsrecht, Tatfrage. Konkrete Rechtsprechung zum Native Content Advertising im hier verstandenen Sinne steht nicht zur Verfügung, sodass auf anders gelagerte Sachverhalte ergangene Entscheidungen nur mit Vorsicht heranzuziehen sind. Hinzu kommt, dass sich nach hier vertretener Ansicht beim Durchschnittsadressaten die Sensibilität für Werbung und das Verständnis von Content auf Webportalen im Fluss befinden. Urteile zu anders gelagerten Sachverhalten, die zudem viele Jahre alt sind, beruhen deshalb oft auf einer anderen Verkehrsanschauung ${ }^{455}$.

Die übrigen Tatbestände des $\$ 5$ a Abs. 6 UWG sowie $\$ 3$ a UWG i.V.m. $\$ 6$ Abs. 1 Nr. 1 TMG und 58 Abs. 1 S. 1 Hs. 1 RfStV sind im Ergebnis gleich auszulegen und sollten im Normalfall nicht zu einer Unlauterkeit der hier geprüften Werbeform führen. Bei $\$ 5$ a Abs. 6 UWG sind bei der Betrachtung des kommerziellen Zwecks ausdrücklich auch die Umstände

452 S.o. Ziffer B. IV. 1. b).

453 S.o. Ziffer B. I. 4. b.)

454 Siehe zur sehr ausführlichen Prüfung dieses Tatbestandes Wiebe/Kreutz, WRP 2015, 1053 \& WRP 2015, 1179.

455 Ebenfalls eine marktliberale Ansicht hat Hoene, IPRB 2016, 59. 
in den Blick zu nehmen. Diese Umstände sind wiederum Markennutzung, Verlinkung, Herausstellung einzelner Produkte und ggf. wörtliche Hinweise, die synonym für das Wort „Anzeige“ verstanden werden können. Dasselbe gilt für die klare Erkennbarkeit der kommerziellen Kommunikation bzw. Werbung im Sinne von $\$ 6$ Abs. 1 TMG und $\$ 58$ Abs. 1 RfStV. Hinzu kommt die Spürbarkeitsschwelle in $\$ 3$ a UWG, die die Voraussetzungen für eine Unzulässigkeit relativ hoch setzen.

\section{b) Zulässigkeit von Guerilla-Marketing}

Betrachtet man virales oder Guerilla-Marketing aus der Perspektive des Rechts, stellen sich bekannte Fragen. Auch hier geht es nämlich um das Trennungsgebot und die Kennzeichnung kommerzieller Kommunikation $^{456}$. Ein Fall des OLG Köln betraf etwa die Werbekampagne der Automarke Dacia mit dem Titel „Status Symptome“, bei der mit mehreren Videoclips in satirischer Form deutsche Autogewohnheiten aufs Korn genommen wurden. Diese Clips waren auf der Webseite status-symptome.de ohne Werbekennzeichnung hochgeladen. Dies hat das OLG Köln für einen Verstoß gegen $\$ 4$ Nr. 3 UWG a.F. gehalten ${ }^{457}$, was heute auf $\$ 5$ a Abs. 6 UWG n.F. gestützt werden würde. Das Gericht hat offengelassen, ob zudem ein Verstoß gegen $\$ 3$ Abs. 3 i.V.m. Nr. 11 des Anhangs UWG sowie $\$ 3$ a UWG i.V.m. $\$ 6$ Abs. 1 TMG oder $\$ 58$ Abs. 1 RfStV verwirklicht war - was aber naheliegt. Sobald die Webseite jedoch mit dem Wort „Anzeige“ gekennzeichnet wurde, hat das OLG Köln die Werbung als ausreichend gekennzeichnet angesehen.

Es mag daher für Unternehmen zur Verstärkung des „Guerilla“-Charakters der Werbeaktion ein kalkuliertes Risiko darstellen, keine Kennzeichnung vorzunehmen. Darauf sollte aber nur verzichtet werden, wenn wie im obigen Beispiel von Native Advertising eindeutige Hinweise durch Markenzeichen oder sonstige bekannte Werbeelemente vorhanden sind. Sonst ist eine ausreichende Kennzeichnung bereits zu Beginn zu gewährleisten ${ }^{458}$. Dem ist zuzustimmen, weil - wie das OLG Köln zutreffend ausgeführt hat - gerade beim Teilen in sozialen Netzwerken dem Empfänger der werbliche Charakter nicht immer bekannt sein wird ${ }^{459}$. Es handelt

456 Micklitz/Schirmbacher, in: Spindler/Schuster, \$6 TMG, Rn. 46ff..

457 OLG Köln, Urteil vom 9.8.2014 - 6 U 3/13, NJW 2014, 795.

458 Lichtnecker, GRUR 2013, 135, 139.

459 OLG Köln, NJW 2014, 795, 796. 
sich auch hier regelmäßig um Tatfragen, sodass die Zulässigkeit einer Maßnahme regelmäßig auf Grundlage des Einzelfalls zu beurteilen ist.

\section{c) Zulässigkeit von Influencer-Marketing}

Zur Zeit der Bearbeitung hoch aktuell ist das Thema „Influencer“ auf sozialen Netzwerken, vor allem auf der plastischen und ganz überwiegend auf visuelle Einflüsse abstellenden Plattform Instagram. Das Thema beschäftigte die Zeitschriftenliteratur sowie die Rechtsprechung vor allem ab 2017. In materiell-rechtlicher Hinsicht sind auch hier wieder dieselben Normen einschlägig wie bei den beiden vorbehandelten Phänomenen, vor allem $\$ 5$ a Abs. 6 UWG. Eine Besonderheit beim Influencer-Marketing ist aber, dass hier nicht nur die werbenden Unternehmen in Anspruch genommen werden, sondern auch die Blogger/innen selbst, teilweise sogar ausschließlich. Dies spiegelt die Besonderheit des Influencer-Marketings. Influencer sind in der Regel Privatpersonen, die originär als solche Privatpersonen die sozialen Netzwerke nutzen. Ihre Berühmtheit folgt nicht selten erst aus ihrer Tätigkeit auf dem sozialen Netzwerk, sodass sie aus ihrer privaten Stellung herauswachsen und ihre Kommunikationstätigkeit gewerbliches Ausmaß erreichen kann. Anders als üblicherweise bei werbenden Beiträgen, wo eine Art Redaktion entweder in der Sphäre des Werbenden selbst - so bei klassischer Anzeigenwerbung - oder durch die werbende Plattform - so bei redaktioneller bzw. Content-Werbung oder bei den oben dargestellten Native Ads - erfolgt, ist der/die Influencer/in relativ frei in der Darbietung. Eine Werbung erfolgt also oft in der folgenden Kette: Werbendes Unternehmen - Influencer - Soziales Netzwerk - Adressat. Influencer fungieren sozusagen als ausgelagerte Einheit von Redaktion und Model, die im eigenen Namen für andere wirbt.

Daraus folgt, dass grundsätzlich drei Personen für die Unterlassung rechtsverstoßender Werbung in Frage kommen, nämlich der Werbende, der Influencer und das soziale Netzwerk. Die bis zur Fertigstellung dieser Arbiet veröffentlichten Entscheidungen in diesem Kontext betrafen auf der Passivseite in aller Regel einen Unterlassungsanspruch gegen die Influencer selbst ${ }^{460}$, während eine Entscheidung das werbende Unternehmen

460 LG Hagen, Urteil vom 13.9.2017- 23 O 30/17, GRUR-RR 2017, 510; LG Heilbronn, Urteil vom 8.5.2018 - 21 O 14/18, ZUM-RD 2019, 180; LG Berlin, Urteil vom 24.5.2018 - 52 O 101/18, ZUM-RD 2019, 159; LG Karlsruhe, Urteil vom 21.3.2019 - 13 O 38/18, MMR 2019, 329; LG München I, Endurteil 
als Beklagte auswies ${ }^{461}$. Eine Inanspruchnahme der Plattformen ist indes noch nicht zu beobachten, obschon diese durchaus als Teilnehmer eines fremden Wettbewerbsverstoßes oder als Störer in Betracht kommen könnten.

Alle Gerichte setzten sich mit einem Verstoß gegen $\ 5$ Abs. 6 UWG bei werbenden Posts auf Instagram auseinander. In Influencer-Fällen wird entweder gar keine oder eine unzureichende Kennzeichnung von werblichen Beiträgen verwendet. Eine unzureichende Kennzeichnung stellte etwa die Verwendung von „\#ad“ (gesprochen: „Hashtag ad“) im Textfeld unter dem Foto dar, das zudem noch in einer Vielzahl von Hashtags versteckt war ${ }^{462}$. $\mathrm{Ob}$ \#ad“ überhaupt ausreicht, ließ das OLG Celle offen, jedenfalls war die konkrete Verwendung nicht ausreichend. Auch das KG ließ „\#ad“ nicht ausreichen ${ }^{463}$. Außerdem hielt es "\#sponsoredby“ in Verbindung mit dem Markennamen nicht für eine ausreichende Kennzeichnung, wobei es sich ausdrücklich auf das Good-News II-Urteil des $\mathrm{BGH}^{464}$ berief.

Bei den nicht gekennzeichneten Beiträgen durch „Instagrammer“ selbst, stellt sich als bedeutender Sachverhaltsumstand dar, ob diese für die positive Darstellung der Waren oder Markennamen ein Entgelt oder sonstige Vorteile wie Rabatte oder Zugaben erhalten. Auch die bloße Überlassung von Gegenständen, die für das Werbebild als Modell dienten, soll hierunter fallen. Bei dieser Annahme einer Gegenleistung liegt nämlich eine geschäftliche Handlung vor, die den Anwendungsbereich des UWG eröffnet ${ }^{465}$. Einen anderen Anknüpfungspunkt zur Bejahung der geschäftlichen Handlung wählte das LG Hagen, das die Förderung fremden Wettbewerbs durch die Bloggerin ausreichen lie $\beta^{466}$. Beide Wege sind gangbar, sodass

vom 29.4.2019 - 4 HK O 14312/18, BeckRS 2019, 7496; KG, Beschluss vom 11.10.2017 - 5 W 221/17, WRP 2018, 98; Beschluss vom 17.10.2017 - $5 \mathrm{~W}$ 233/17, WRP 2018, 224; Beschluss vom 27.7.2018 - 5 W 149/18, GRUR-RR 2019, 34; Urteil vom 8.1.2019 - 5 U 83/18, MMR 2019, 175;

461 OLG Celle, Urteil vom 8.6.2017 - 13 U 53/17, MMR 2017, 769.

462 OLG Celle, Urteil vom 8.6.2017 - 13 U 53/17, MMR 2017, 769; ähnlich bei LG Heilbronn, Urteil vom 8.5.2018 - 21 O 14/18, ZUM-RD 2019, 180.

463 KG, Beschluss vom 11.10.2017 - 5 W 221/17 WRP 2018, 98.

464 BGH, GRUR 2014, 879; vgl. auch die obigen Ausführungen unter C. IV. 1. b), aa).

465 KG, Beschluss vom 11.10.2017 - 5 W 221/17 WRP 2018, 58.

466 LG Hagen, Urteil vom 13.9.2017- 23 O 30/17, GRUR-RR 2017, 510; LG Berlin, Urteil vom 24.5.2018 - 52 O 101/18, ZUM-RD 2019; LG München I, Endurteil vom 29.4.2019 - 4 HK O 14312/18, BeckRS 2019, 7496. 
Influencer leicht ins Haifischbecken des Lauterkeitsrechts geraten ${ }^{467}$. Erfolgt keine Werbekennzeichnung ist eine teure Abmahnung mehr als wahrscheinlich.

In der Literatur sorgte das Thema zu einer Flut an Beiträgen. Dabei werden überwiegend das Phänomen beschrieben und die rechtlichen Grundlagen erläutert ${ }^{468}$. Vor dem Hintergrund der erschöpfenden Betrachtung und der bekannten Rechtsgrundlagen wird an dieser Stelle auf eine weitere vertiefte Stellungnahme verzichtet. Allein bleibt anzumerken, dass gerade bei sozialen Netzwerken immer die genaue Ausprägung der Posts zu betrachten ist. Wenn die sich herauskristallisierende herrschende Meinung also auf eine Erkennbarkeit als Werbung auf den ersten Blick abstellt, muss auch in den Blick genommen werden, ob zur Kennzeichnung nutzbare Textfelder über Fotos und Videos (so bei Facebook und Twitter) oder darunter (so bei Instagram) zu finden sind. Bei letzterem Fall ist es freilich aufwändiger, eine ausreichend klare Kennzeichnung auf den ersten Blick zu erreichen. Was in dieser Diskussion ebenfalls nicht aus den Augen verloren werden darf ist, dass die Anforderungen für Influencer nicht höher sein dürfen als für die Betreiber von sozialen Netzwerken selbst. So weist etwa Twitter selbst nicht zu Beginn, sondern erst zum Ende eines werbenden „Tweets“ mit dem Begriff „gesponsert" hin. Facebook und Instagram hingegen haben den "gesponsert“-Hinweis im oberen Bereich eines Posts.

Im Übrigen ist es selbstverständlich, dass sich Influencer, die ihre -wie auch immer erreichte - kommerzialisierbare Position zu ihren finanziellen Gunsten ausnutzen, sich rechtmäßig verhalten müssen. Nur weil viele Influencer jung, unbedarft und - jedenfalls juristisch - oft völlig ohne Problembewusstsein sind, kann dies nicht zu einem Aufweichen werberechtlicher Standards führen. Also muss ein Influencer im Zweifel ebenso wie eine Werbeagentur vor dem Veröffentlichen einer Werbung rechtlichen Rat einholen.

467 Vgl. auch Vonau, GRUR-Prax 2017, 541, vor dem Hintergrund, dass die Beklagte im Fall des LG Hagen auch wegen Verstößen gegen Art. 10 Abs. 1 Health Claims VO, und $\$ 11$ LFGB i.V.m, Art. 7 EU-Lebensmittel-informationsverordnung zur Unterlassung erklärt worden ist.

468 Vgl. Sobottka/Czernik, MMR 2017, 769; Fuchs/Hahn, MMR 2016, 503; Suwelack, MMR 2017, 661; Lehmann, WRP 2017, 772; Reinholz/Schirmbacher, K\&R 2017, 753; Henning-Bodewig, WRP 2017, 1415; Mallick/Weller, WRP 2018, 155; Dahmen/Lauotoumai, K\&R 2017, 29; Gerecke, GRUR 2018, 153; Troge, GRUR-Prax 2018, 87; Lettmann, GRUR 2018, 1206; Ahrens, GRUR 2018, 1211, Peifer, GRUR 2018, 1218; Scherer, WRP 2019, 277. 


\section{Zusammenfassende Thesen zum Werbemarkt}

- Für den rechtlichen Werbungsbegriff sind die folgende vier Elemente prägend: ein Werbender, ein Adressat, eine Äußerung und die werbliche Zwecksetzung dieser Äußerung. Letztgenanntes meint das Ziel der zumindest mittelbaren Absatzförderung bzw. Förderung der Dienstleistungserbringung.

- Werbung im Internet findet hauptsächlich auf PCs und mobilen Endgeräten statt. Hinzu kommen internetbasierte Werbeformen auf Smart TV sowie Smart Home Geräten. Durch das Aufkommen moderner vernetzter Haushaltsgegenstände ist denkbar, dass in Zukunft die Werbung auch den Bereich des Internet of Things erfassen wird. Für die aktuelle Bewertung ist jedoch die Werbung auf Webseiten für PCs die Blaupause, die für die meisten Werbeformen im Internet als Vorbild für die Bewertung dienen sollen.

- Werbung auf Webseiten aller Art lassen sich in zwei Gruppen teilen. Einerseits handelt es sich um Content-Werbung, andererseits um Anzeigen.

Content-Werbung zeichnet sich dadurch aus, dass sie auf eigenen oder fremden Webseiten und Kanälen vom Werbenden aktiv eingestellt wird, dem Nutzer aber nur dann entgegentritt, wenn er selbst zuvor auf irgendeine Weise aktiv geworden ist. Der Nutzer muss hier also willentlich die Wahrnehmung initiieren.

Anzeigenwerbung hingegen zeichnet sich dadurch aus, dass auf eigenen oder fremden Webseiten und Kanälen dem Nutzer Inhalte angezeigt werden, die er nicht willentlich und gezielt aufgerufen hat.

- Der Markt für Werbung im Internet ist in Deutschland und Europa im Vergleich zu anderen Medien der volumenstärkste Werbemarkt. Alleine in Deutschland übersteigt das jährliche Volumen zur Zeit der Bearbeitung die Milliardengrenze deutlich.

- Wichtige Akteure am Werbemarkt sind neben den Werbenden und Webseitenanbietern zudem Online Vermarkter bzw. Werbenetzwerke, die durch enorme technische Kapazitäten die Platzierung von Werbung bis in die Tiefen des Internets bewerkstelligen. Hinzu kommen je nach Komplexität noch weitere Meta-Netzwerke und Mediaagenturen. Zur Abrechnung der Werbekosten wurden ausgeklügelte Systeme entwickelt, die eine punktgenaue Bezahlung der Leistung ermöglichen. Dafür ist ein ausgeprägtes Controlling nötig.

- Bei der Darstellung von Webseiten kommt es entscheidend auf das HTML-Dokument der Webseite an, das vom Anbieter programmiert 
und im Wege der IP-/TCP-/HTTPS-Verbindung an den Nutzerrechner übertragen wird. Dort arbeitet sodann der Browser die Befehle des HTML-Dokuments ab, indem es die Befehle in einen DOM-Knotenbaum übersetzt. In diesem DOM-Knotenbaum werden allerdings neben den Befehlen des Webseitenanbieters auch interne Befehle wie Einstellungen der Nutzer beachtet. Somit kann der Nutzer durch eigene Voreinstellungen eine vom ursprünglichen Willen des Webseitenprogrammierers abweichende Darstellung herbeiführen. Folglich lässt sich festhalten, dass in technischer Hinsicht keine Integrität von Quellcodes einer Webseite besteht.

- Für das „Ob“ der Werbung im Internet ist $\$ 7$ UWG der alleinige Prüfungsmaßstab.

- Entgegen vereinzelter Stimmen im Schriftum ${ }^{469}$ ist eine hartnäckige Ansprache im Sinne von $\$ 7$ Abs. 2 Nr.1 UWG bei Display-Werbung im Internet möglich. Dies kommt in zwei Fallgestaltungen in Betracht: einerseits bei der Ausspielung von Werbung als Umgehungsmaßnahme eines aktivierten Werbeblockers beim Nutzer. Andererseits bei Webseiten, bei denen der Nutzer ein Nutzerprofil hat und sich dafür einloggen muss. Letztgenanntes betrifft auch soziale Netzwerke, insbesondere wenn sie keine Regelung zur Werbeauslieferung in den Nutzungsbedingungen treffen.

- $\$ 7$ Abs. 2 Nr. 4 UWG ist hingegen nicht auf Display-Werbung im Internet anwendbar. Dasselbe gilt für Art. 16 Abs. 6 EPVO-E.

- Im Rahmen der Generalklausel in $\$ 7$ Abs. 1 UWG ist das Regelbeispiel aus Satz 2 nicht bei Display-Werbung anwendbar. Es kommt deshalb immer auf eine Interessenabwägung zwischen den Interessen der Werbenden und Webseitenbetreiber sowie den Interessen der Internetnutzer unter Beachtung deren grundgesetzlichen Gewichtung an. Bei gewissen Standardsituation ergibt die Interessenabwägung jedoch häufig dasselbe Ergebnis. Aufgespalten nach Werbeformen gilt deshalb das Folgende:

- Bei klassischen fixierten Anzeigen auf einer Webseite wie Bannerwerbung geht diese Interessenabwägung zu Gunsten der Werbenden und Webseitenbetreiber.

469 Insbesondere Köhler/Bornkamm/Feddersen, UWG, $\mathbb{7} 7, \mathrm{Rn} .104$; darauf Bezug nehmend: OLG Nürnberg, Urteil vom 15.1.2019, 3 U 724/18, K\& R 2019, 200. Die Frage ist zum Teil Gegenstand eines Vorlageverfahrens zum EuGH, siehe Vorlagefrage 5 bei BGH, Beschluss vom 30.1.2020 - I ZR 25/19, GRUR 2020, 420 - Inbox-Werbung. 
- Bei dynamischen Anzeigen ist die Sachlage zu differenzieren. Einzelheiten sind umstritten. Nach hier vertretener Ansicht ist auf erster Stufe zu differenzieren, ob die Anzeige automatisch schließt oder einen aktiven Klick des Nutzers bedarf. Im Fall des aktiven Schließens ist mit der herrschenden Meinung auf die Möglichkeit des Wegklickens nach kurzer Zeit abzustellen. Die Dauer der „kurzen Zeit" ist dabei auf höchstens drei Sekunden festzusetzen. Eine Unzumutbarkeit bei Wegklickbarkeit innerhalb dieser drei Sekunden kommt nur in Ausnahmefällen in Betracht, wenn die Summenwirkung auf einer Webseite eine an sich nicht zu beanstandende Werbeform exzessiv einsetzt.

Bei sich automatisch schließenden Anzeigen kommt es hingegen darauf an, ob eine vorzeitige Möglichkeit zum Abbruch besteht oder nicht. Ist die vorzeitige Beseitigung nicht möglich, darf die Anzeige im Gleichklang wie im obigen Fall nicht länger als drei Sekunden dauern. Wenn eine vorzeitige Beendigung möglich ist, dann muss die Möglichkeit zum Schließen spätestens nach drei Sekunden zur Verfügung stehen.

Soweit eine unzumutbare Belästigung zu bejahen ist, sollte eine $\mathrm{zu}$ prüfende Einwilligung aus schlüssigem Verhalten nur sehr zurückhaltend angenommen werden. Wegen des Erfordernisses der konkreten Kenntnis der Tat kommt diese nur bei wiederholten Besuchen durch Nutzer auf ein und derselben Webseite innerhalb eines Zeitraums in Frage, in welchem die Anordnung der Werbeelemente nicht geändert wird. 


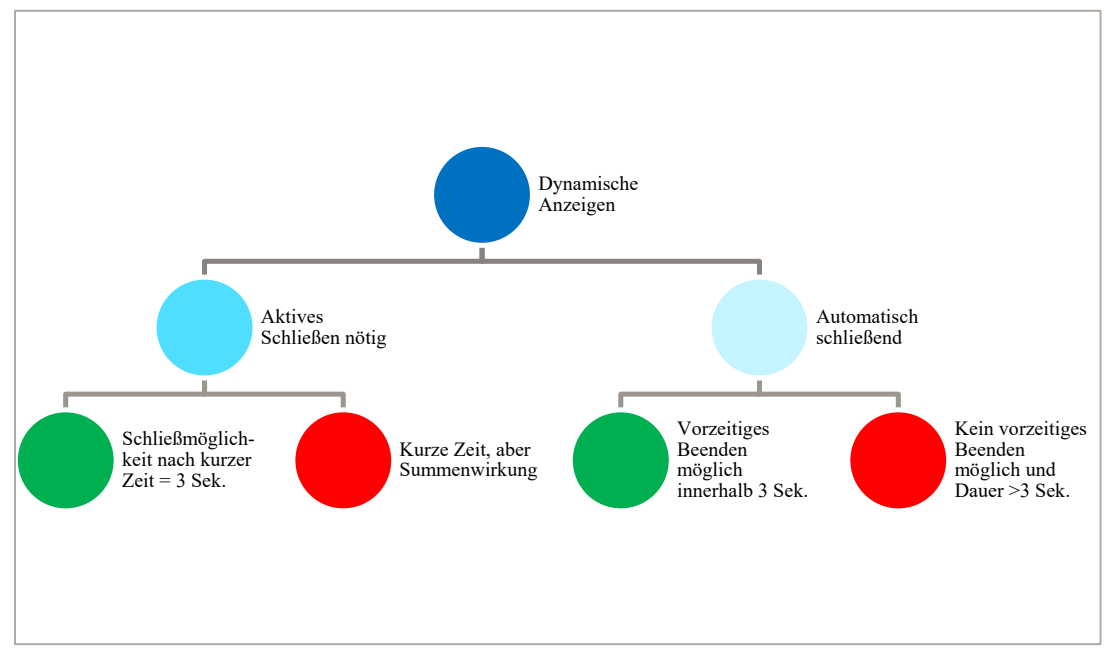

Abbildung 8: Schematische Darstellung der hier vorgeschlagenen Lösung für dynamische Anzeigen

- Buttons zum Schließen von dynamischen Anzeigen sollten deutlich sichtbar und an gewohnten Stellen zu finden sein. Werden die Schaltflächen in optisch aufwändigen Anzeigen „versteckt“, sodass der Nutzer sie suchen muss, kann dies ein Umstand sein, der ultimativ zur Unzumutbarkeit der eigentlich akzeptablen Werbeform führen.

- Bei Pre- oder Interstitials bzw. Pre- oder Mid-Roll Werbung ist zu unterscheiden, ob diese die gesamte Nutzung einer Webseite unterbrechen oder nur ein Teilelement betreffen, etwa einen Videoframe. Im ersten Fall gelten die gleichen Regeln wie bei dynamischen Anzeigen, insbesondere die 3-Sekunden-Regel. Im zweiten Fall ist wegen der Möglichkeit, andere Webseiteninhalte zu rezipieren, und vor allem bei wertvollen Inhalten wie Videos ein geringfügig großzügigerer Maßstab anzusetzen. Die Zeit zumutbar erzwungener Werbebindung kann mit dem LG Berlin auf 5 Sekunden beziffert werden. Danach muss eine Möglichkeit zum Überspringen der Werbung angeboten werden.

- Bei sozialen Netzwerken wird oft in Nutzungsbedingungen eine Pflicht des Nutzers zur Duldung von Werbung fixiert. Dies hält einer AGBKontrolle stand, wenn Werbung nicht exzessiv betrieben wird. Newsfeedwerbung ist jedoch auch außerhalb einer solchen vertraglichen Vereinbarung als grundsätzlich zumutbar anzusehen. Eine scheinbar unbekannte Stolperfalle für soziale Netzwerke, die keine Duldungspflicht in Nutzungsbedingungen vorsehen, ist ein ausdrücklicher Wi- 
derspruch der Nutzer zur Werbeausspielung. Dann könnte eine hartnäckige Ansprache nach $\$ 7$ Abs. 2 Nr. 1 UWG vorliegen.

- Für das „Wie“ der Werbung gilt eine Vielzahl gesetzlicher Vorschriften. Die wichtigsten Regelungen sind das Trennungsgebot, das Irreführungsverbot und allgemeine oder sektorspezifische Kennzeichnungspflichten. Bei den modernen Phänomenen von Online-Werbung wie Native Advertising oder Content-Werbung in Form von Guerilla oder Influencer Marketing ist regelmäßig das Trennungsgebot von überragender Bedeutung.

- Tracking ist vor dem Hintergrund des neuen Datenschutzrechts zu bewerten. Regelmäßig wird wegen der starken Verbreitung von Cookies und aktiven Fingerprinting-Methoden die neue E-Privacy-Verordnung (Entwurf) anwendbar sein, weshalb eine Einwilligung notwendig sein wird. Im Ausnahmefall von passivem Tracking auf Grundlage sowieso übermittelter Kommunikationsdaten ist eine Zulässigkeit aufgrund der milderen DSGVO denkbar.

- Der Einsatz von Werbung, die mit Trackingmaßnahmen verbunden ist, ist unzulässig, wenn für die eingesetzten Trackingaktionen keine ausreichende Einwilligung besteht.

- Targeting als abschließender Teilaspekt des Datenverarbeitungsprozesses, der mit Tracking beginnt, ist als solches nicht isoliert nach der E-Privacy-Verordnung (Entwurf) zu bewerten. Vielmehr richtet sich die Zulässigkeit nach der DSGVO. Dafür muss ein Rechtfertigungsgrund aus Art. 6 DSGVO gegeben sein. Wenn dies nicht eine ausreichende Einwilligung ist, muss im Rahmen der Interessenabwägung bei der Prüfung der Wahrnehmung berechtigter Interessen nach Art. 6 Abs. 1 lit.f) DSGVO auf die einzelnen Targetingformen abgestellt werden. Hier sind insbesondere Geotargeting und Verhalten-Targeting komplizierte Fälle, die eine eingehende Fallanalyse bedürfen. Geotargeting ist etwa über die Wahrnehmung berechtigter Interessen rechtfertigungsfähig, wenn es auf Webseiten eingesetzt wird, die wesensgemäß den Standort nutzen müssen wie Kartendienste oder automatisierte Suchfunktionen für Dienstleistungen. Verhalten-Targeting ist bei einzelnen Webportalen oder offensichtlich verbundenen Konzernwebseiten für Aktivitäten in diesem abgeschlossenen Bereich nach Art. 6 Abs. 1 lit.f) DSGVO zu rechtfertigen, wenn die Daten vom Betreiber selbst gesammelt und ausgewertet werden. Im Übrigen bleibt nur die Einholung einer Einwilligung als Rechtfertigungsgrund.

- Bei lauterkeitsrechtlicher Betrachtung von Tracking und Targeting ist zu beachten, dass Vorschriften der DSGVO nicht als Marktverhaltensnorm im 
Sinne von $₫ 3$ a UWG angesehen werden können. Die Vorschriften der E-Privacy Verordnung (Entwurf) hingegen werden als Marktverhaltensnorm zu qualifizieren sein. Letztere könnten sogar im Rahmen von $\$ 823$ Abs. 1, 2 BGB i.V.m. $\$ 1004$ BGB analog für das allgemeine Zivilrecht herangezogen werden, um die Anordnung der E-Privacy Verordnung erschöpfend im deutschen Recht zu verwirklichen.

Beim Einsatz von Tracking kann zudem eine Irreführung nach $\$ \mathbb{S} 5,5 \mathrm{a}$ UWG vorliegen. Vor allem dann, wenn in der Werbung offenbarungspflichtige Umstände nicht enthalten sind, weil Targeting die Zielgruppe einschränken soll. Nach der Rechtsprechung des BGH sind in Kauf genommene Streuverluste ausreichend für eine relevante Irreführung. 


\section{Aktion: Werbeblocker \& ähnlich invasive Geschäftsmodelle}

Auf Grundlage des oben beschriebenen Werbemarkts im Internet, der zur Frage des „Ob“ von Werbung keine speziellen Rechtsnormen vorsieht und zudem nur selten Gegenstand von Gerichtsentscheidungen war, entwickelten sich Werbeblocker vom Nischenprodukt zu einem der meist verbreiteten kostenlosen Softwareangeboten im Internet. Eine Bewertung von Werbung als unzumutbare Belästigung der Internetnutzer ist für viele Fälle zu verneinen. Nur in Ausnahmefällen kommt die Anwendung von $\$ 7$ UWG in Betracht. Vor dem Hintergrund, dass ein spezialgesetzliches Verbot wegen der Intensität des hoheitlichen Eingriffs und der rechtfertigungsbedürttigen Einschränkung von Grundrechten der Werbenden bzw. Webseitenbetreiber nicht existiert und auch nur die intensivsten Fälle erfassen könnte, bleiben viele "zumutbare“ Belästigungen sowie unter der Schwelle einer Belästigung liegende Störungen oder Unannehmlichkeiten im Bereich des Legalen. Es verwundert deshalb kaum, dass sich einige Nutzer dieser Unannehmlichkeiten erwehren wollten.

Internetwerbeblocker konnten sich im Vakuum fehlender staatlicher Regulierung entwickeln, das zuvor auch die Internetwerbung erst zum oben ausführlich beschriebenen Dickicht aus diversen Werbeformen hat wuchern lassen. Nicht nur die Werbung im Internet war außerhalb des Radars der staatlichen Gewalten, sondern auch die Gegenbewegung dazu. Ganz zu Beginn dieser Bearbeitung wurde bereits eine Anleihe bei der Biologie genommen und die Frage aufgeworfen, ob Werbeblocker Parasit oder Symbiont der Internetwerbung sind. So oder so konnte sich der Markt der Werbeblocker auf dem florierenden Internetwerbemarkt prächtig ausbreiten.

Auch entwickelten sich Werbeblocker parallel zur und abhängig von der technischen Evolution des Werbemarktes. So entwickelten sich gerade aus der Einbindung von Adservern, also dritten Stellen in den Kommunikationsvorgang zum Abruf von Webseiten, neue Möglichkeiten zum Aussperren der so eingefügten Werbung. Auf der anderen Seiten führten die zunächst oft unbekannten Methoden des Trackings dazu, dass Nutzer nach Aufklärung über diese Machenschaften umso mehr nach Schutz vor der Ausspähung ihres Verhaltens suchten. 
Diese Entwicklung führte dazu, dass einige sehr erfolgreiche Wirtschaftsunternehmen nach jahrelangem, beinahe ungebremstem Wachstum ihrer Umsatz- und Gewinnzahlen in der Sparte Internetwerbung durch das Werbeblocken erstmals Rückschläge hinnehmen mussten. Mit dem Aufstieg des Werbeblockens weg vom Spleen einiger „Techies“ zum wirtschaftlich messbaren Faktor begann auch die juristische Mühle zu rattern. Betroffene Unternehmen riefen Gerichte in der gesamten Bundesrepublik an. Die Literatur brachte sich ebenfalls mit einer beachtlichen Anzahl von Auseinandersetzungen in Stellung. Dabei war schon früh klar, dass das letzte Wort in dieser Angelegenheit in Karlsruhe gesprochen wird zivilrechtlich beim BGH und mit Blick auf Grundrechte beim BVerfG.

Neben dem Rechtsweg aktivierten die Betroffenen zudem ihre Kanäle in die Politik. Dies führte dazu, dass ein potentielles Verbot von Werbeblockern im Jahr 2017 zumindest im Ausschuss für Kultur und Medien des Deutschen Bundestags mit Sachverständigen diskutiert wurde. Das Thema Adblocker, das vor allem der sog. Vierten Gewalt ein Ärgernis ist, lag also zumindest bei zwei der drei klassischen staatlichen Gewalten mit dem Ziel eines nachhaltigen Verbots auf dem Tisch.

Diese Zusammenhänge sind Grund genug, das Thema Internetwerbeblocker einer vertieften Analyse zu unterziehen (siehe dazu Ziffer I.). Mit den somit gewonnenen Ergebnissen wird eine Antwort auf die Frage gegeben, ob Werbeblocker als Parasit oder Nützling anzusehen sind (siehe Ziffer II.)

\section{Internetwerbeblocker}

Bei näherer Beobachtung der Rechtsprechung und der sie begleitenden Literatur fällt schnell auf, dass nur ein Teilausschnitt aus dem Gesamtkomplex Internetwerbeblocker behandelt wird. Bei der Rechtsprechung ist dies zwingend, weil wegen des Dispositionsgrundsatzes nur das zu bescheiden ist, was die Parteien zum Gegenstand gemacht haben. Vor dem Hintergrund der Rechtsprechung des I. Zivilsenats des BGH zum Streitgegenstand ${ }^{470}$ stellt die korrekte Formulierung von Unterlassungsanträgen im Gewerblichen Rechtsschutz eine nicht zu unterschätzende Herausforderung dar. Auch ist die Formulierung von abstrahierten Unterlassungsanträgen wegen der Gefahr, auch erlaubtes Verhalten zu erfassen und insoweit

470 Vgl. BGH, Hinweisbeschluss vom 24. 3. 2011 - I ZR 108/09, GRUR 2011, 521 TÜV; Urteil vom 13.9.2012 - I ZR 230/11, GRUR 2013, 401 - Biomineralwasser. 
im Rechtsstreit teilweise zu unterliegen, eine komplexe Angelegenheit. Es wundert deshalb nicht, dass die Parteien in den veröffentlichten Entscheidungen die konkrete Verletzungsform des Werbeblockers Adblock Plus angegriffen haben. Damit kann aus der vorhandenen Rechtsprechung jedoch zwingend nur diese konkrete Verletzungsform beurteilt werden. Verändert sich das Werbeblockerprodukt, können ggf. andere Bewertungen angebracht sein.

Im Rahmen dieser Bearbeitung soll deshalb gerade nicht nur auf eine konkrete Software abgestellt werden, sondern soweit möglich Lösungen für alle am Markt verfügbaren Werbeblocker im Internet gesucht werden. Zunächst soll ein historischer Überblick über das Werbeblocken insgesamt zeigen, wie sich das Thema Werbeblocken über die Jahrzehnte entwickelt hat und wie Adblocker im Internet die aktuelle Prominenz erlangen konnten (siehe dazu Ziffer 1.). Außerdem ist es unerlässlich vor der rechtlichen Bewertung zunächst die Hintergründe des Adblockens in tatsächlicher Hinsicht aufzuklären. Dies beinhaltet sowohl wirtschaftliche als auch technische Umstände im Zusammenhang mit verschiedenen Formen von Werbeblockern im Internet (siehe dazu Ziffer 2.).

Auf dieser Grundlage kann sodann die Literatur und die ergangene Rechtsprechung dargestellt werden (siehe dazu Ziffer 3.), wobei eine Zuordnung zu bestimmten Werbeblockern am Markt möglich ist. Zugleich lässt sich feststellen, welche Fälle die Rechtsprechung konkret erfasst und welche Fälle bislang keine konkrete juristische Beurteilung erhalten haben. Danach wird eine Stellungnahme zur Rechtslage abgegeben und das federführende Urteil des BGH sowie die ergangene Instanzrechtsprechung rechtlich gewürdigt (siehe dazu Ziffer 4.).

Soweit am Markt Werbeblockerformen vertreten sind oder vor dem Markteintritt stehen, die anders als die Filterlisten-Blocker funktionieren, drängt sich die Frage auf, ob die Rechtsprechung auch auf diese nicht konkret entschiedenen Konstellationen übertragbar ist. Dieser Frage wird bei der rechtlichen Beurteilung der besonderen Werbeblockerformen nachgegangen (siehe dazu Ziffer 5.)

In einem Exkurs wird zudem das Phänomen des „Overblocking“ analysiert (siehe dazu Ziffer 6.). Bei diesem "Overblocking" schießt der Werbeblocker sozusagen über sein Ziel hinaus und blockiert mehr als nur Werbung, nämlich auch Teile einer Webseite, die zum Content gehören. Hierzu ist ebenfalls Rechtsprechung verfügbar, sodass eine rechtliche Analyse geboten ist.

Diesen Abschnitt abschließend folgt die Darstellung der Regulierungstendenzen in der deutschen Politik (siehe dazu Ziffer 7.). Ein mögliches 
Verbot von Internetwerbeblockern war bereits soweit gediehen, dass im Ausschuss für Kultur und Medien des Bundestags das Für und Wider diskutiert wurde. $\mathrm{Zu}$ einem Gesetzesvorschlag kam es darauf folgend in der entsprechenden Legislaturperiode nicht. Vor dem Hintergrund von Lobbyarbeit könnte das Thema eines Verbots auch in Zukunft nochmals auf den Tisch der Volksvertreter kommen.

\section{Geschichte des Werbeblockens}

Betrachtet man die Geschichte der Werbung im großen Rahmen so steht dem offensiven Kommunikationsvorgang des Angebots von Waren und Dienstleistungen schon immer die defensive Abwehrhandlung einiger Adressaten entgegen. Einfachstes und von jedem Leser wahrscheinlich schon selbst erlebtes Beispiel ist die Ansprache im öffentlichen Raum. Der Handzettelverteiler in der Fußgängerzone muss auf seine werbenden Aktionen häufig Ablehnung erfahren. Wenn er versucht Blickkontakt aufzunehmen, wenden viele Adressaten den Blick ab. Auf eine direkte Ansprache wird nicht geantwortet oder der Gesprächskontakt sofort beendet. Ein dem Passanten dargereichter Handzettel wird oft gar nicht erst angenommen.

Genauso wie in dieser Werbesituation ohne Zuhilfenahme technischer Mittel, steht der Werbung auf jeder Ebene und in jedem Medium ein Abwehrverhalten entgegen. Deshalb verwundert es auch nicht, dass sich die Geschichte mit jedem neuen technischen Medium, das Werbung ermöglicht, mehr oder weniger wiederholt. Nachfolgend werden zunächst die Vorläufer der Internetwerbeblocker dargestellt, bevor nachfolgend die Entwicklung im Internet näher dargestellt wird.

a) Briefkastenwerbung und „Keine Werbung“-Aufkleber

Klassisches Beispiel für eine Blockade von Werbung in der Fernkommunikation zwischen Werbendem und Adressaten ist der „Keine Werbung“Aufkleber auf dem Briefkasten.

Schon im Jahr 1988 hat der BGH aus dem Eigentums- bzw. Besitzrecht an einer Wohnung sowie dem Allgemeinen Persönlichkeitsrecht gefolgert, dass gegen Postwurfwerbungen, die trotz eines eindeutig erkennbaren werbeverbietenden Aufklebers auf dem Briefkasten eingeworfen werden, 
ein Unterlassungsanspruch nach $\$ \mathbb{S} 1004,903$ und/oder 862 BGB folgt ${ }^{471}$. In diesem Zusammenhang erwähnenswert ist auch die heutzutage nostalgisch anmutende Entscheidung des VG Stuttgart ${ }^{472}$, wonach der damals noch staatlichen Post im Rahmen eines öffentlich-rechtlichen Unterlassungsanspruchs untersagt wurde, Postwurfwerbungen trotz eines eindeutigen Aufklebers einzuwerfen. Diese Entscheidung wurde allerdings vom VGH Mannheim aufgehoben mit dem Argument, ein Empfänger könne nicht durch einen Aufkleber nur einen Teil von Postsendungen durch die Post ausfiltern lassen. Der Empfänger könne nur nach dem „Alles-oderNichts"-Prinzip Postsendungen verweigern ${ }^{473}$. Das BVerwG musste nachgehend im Erledigungsrechtsstreit nur noch über die Kosten entscheiden und hob sie gegeneinander auf, ohne selbst eine ausführliche Entscheidung in der Sache zu treffen ${ }^{474}$.

Hintergrund der verwaltungsrechtlichen Verfahren war, dass es höchst umstritten war, ob nach der damals noch geltenden Postordnung (PostO) die Annahmeverweigerung einer Sendung durch einen Aufkleber möglich sein sollte. Dies führte faktisch dazu, dass beim Einsatz von privaten $\mathrm{Zu}$ stellern die Sperrvermerke zu beachten waren ${ }^{475}$, bei Versendung mit der staatlichen Post die Sperrvermerke jedoch mit hoher Wahrscheinlichkeit nicht beachtet wurden ${ }^{476}$. Damit wurde die Zustellung durch die staatliche Post logischerweise attraktiv für Werbende. Im Laufe der oben genannten verwaltungsgerichtlichen Verfahren wurde die PostO allerdings derart geändert, dass fortan eine selektive Werbeverweigerung gesetzlich möglich wurde.

Interessanterweise ähneln die Entscheidungen von VG Stuttgart und VGH Mannheim den aktuellen Entscheidungen zu Adblock Plus, weil auch sie auf einer ausführlichen Interessenabwägung beruhen. Abzuwägen war damals die Effektivität des Postwesens, damals noch eine Aufgabe der staatlichen Daseinsvorsorge, gegen das allgemeine Persönlichkeitsrecht des Bürgers in seiner speziellen Ausgestaltung als Recht, von Werbung verschont zu bleiben. Allerdings konnte sich insbesondere der VGH Mannheim zuletzt darauf zurückziehen, dass die PostO mit Gesetzesrang ausgestattet war und somit eine verhältnismäßige Beschränkung des Grund-

471 BGH, Urteil vom 20.12.1988 - VI ZR 182/88, NJW 1989, 902.

472 Urteil vom 11.1.1989 - 3 K 795/88, NJW 1989, 1050.

473 Urteil vom 24.4.1990 - 10 S 560/89, NJW 1990, 2145.

474 Beschluss vom 1.8.1991 - 7 C 27/90, NJW 1991, 2920.

475 BGH, Urteil vom 20.12.1988 - VI ZR 182/88, NJW 1989, 902.

476 Kaiser, NJW 1991, 2870. 
rechts aus Art. 2 Abs. 1 GG darstellte, das vor dem Gesetzesvorbehalt der verfassungsmäßigen Ordnung bestehe. Eine Verfassungswidrigkeit der alten Vorschrift der PostO lehnte es ab.

Diese Problematik führte die Briefkastenvignetten zudem vor den I. Zivilsenat des BGH, der die Unlauterkeit des Wettbewerbsverhaltens eines Unternehmens zu bescheiden hatte, das in Kenntnis und Ausnutzung der gerade skizzierten alten gesetzlichen Regelung Postwurfwerbungen veranlasste. Der BGH lehnte die Sittenwidrigkeit nach $\$ 1$ UWG a.F. jedoch $a b^{477}$. Hauptargument war, dass die Vertriebsmethode, Werbung über die Post sozusagen „blockadesicher“ auszuliefern, nicht offensichtlich rechtswidrig gewesen sei. Vor dem Hintergrund der gesetzlichen Regelung sowie der widerstreitenden verwaltungsgerichtlichen Entscheidungen war die Auslieferung von Postwurfwerbungen, die unter Umständen auch vereinzelte Werbeverweigerer erreichten, ein marktkonformes Verhalten. Deshalb konnte eine Interessenabwägung nicht zu Lasten des Unternehmens gehen, das ein geschütztes Interesse an der Werbung für das eigene Unternehmen hat.

Nach der Änderung der PostO entspannte sich diese spezifische Problematik und wurde mit der Privatisierung der Post im Jahr $1995^{478}$ obsolet. $\mathrm{Ab}$ diesem Zeitpunkt war auch die Post ein privater Zusteller, sodass keine Diskrepanz mehr zu anderen privaten Zustellern bestand. Neben den oben dargestellten Verfahren kam es zu einer Vielzahl von Urteilen mit vergleichbarem Streitgegenstand, teils sogar mit dem Ergebnis eines Verbots für werbende Unternehmen ${ }^{479}$.

Deutsche Gerichte hatten sich im Zusammenhang mit Briefkastenwerbung im Übrigen auch mit anderen Streitgegenständen zu befassen. So hat das LG Bonn Ansprüche eines Abonnenten einer Zeitschrift auf Unterlassung von Beilagenwerbung in den Zeitschriften abgelehnt ${ }^{480}$. Das OLG Karlsruhe hat geurteilt, dass ein Aufkleber, der nur Werbung verbietet, nicht auch Anzeigenblätter mit redaktionellem Teil erfasse ${ }^{481}$. Dies alles zeigt, dass das Problem des Werbeblockens deutsche Gerichte schon weit über 30 Jahre beschäftigt.

477 BGH, Urteil vom 5.12.1991 - I ZR 53/90, NJW 1992, 1109.

478 Vgl. https://de.wikipedia.org/wiki/Postordnung, zuletzt abgerufen am 30.5.2019.

479 Vgl. für weitere Nachweise aus der Rechtsprechung: Kaiser, NJW 1991, 2870.

480 LG Bonn, Urteil vom 9.1.1992 - 15 O 341/91, NJW 1992, 1112.

481 OLG Karlsruhe, Urteil vom 30.7.1991, 18a U 46/91, GRUR 1991, 940. Ebenso OLG Stuttgart, Urteil vom 12.11.1993 - 2 U 117/93, NJW-RR 1994, 502. 
b) TV-Werbung und die „Fernsehfee"

Nachdem die Situation bei der Briefkastenwerbung durch Richterspruch und Gesetzesänderung geklärt war, wanderte das Schreckgespenst einige Jahre später zum nächsten Medium über. Nun war TV-Werbung betroffen, die in Konflikt mit der „Fernsehfee“ geriet. Die Fernsehfee war - und ist noch heute in aktualisierter Form - eine Hardware, die jedermann mit seinem Fernsehgerät verbinden kann und automatisch bei Beginn von Werbeblöcken das Programm wechselt sowie zum Ende der Werbeunterbrechung zurückschaltet. Somit muss der Zuschauer keine Werbung sehen und dafür nicht einmal manuell die Sender wechseln.

Die Fernsehfee wurde im Jahr 1994 entwickelt und von den Erfindern patentiert. Auf dem deutschen Markt ist die Fernsehfee seit 1999 vertreten. Ursprünglich war das Gerät funkgesteuert, sodass im Studio der Betreiberfirma Mitarbeiter anwesend waren und manuell die Funksignale absetzten ${ }^{482}$. Zur Zeit der Entwicklung war dies bei der überschaubaren Anzahl der TV-Sender noch praktikabel, zumal neben dem Anschaffungspreis für damals 299,- bis 399,- DM noch ein Abonnementpreis von 48 DM jährlich kam, um diese Mitarbeiter zu finanzieren ${ }^{483}$. Die aktuellen Geräte hingegen sind vollautomatisch und verfügen über eine Vielzahl ergänzender Funktionen ${ }^{484}$.

Vor dem Hintergrund der ursprünglich manuellen Steuerung erinnert eine Anekdote beinahe an einen Spielfilm: im Frühjahr 1999 wurde im Koblenzer Studio der Betreiberfirma eingebrochen. Dabei wurden rund 30 TV-Geräte demoliert und die Antennenkabel zerschnitten. Zudem wurden der Chefin des Unternehmens die Reifen an ihrem Sportwagen aufgeschlitzt. Die Polizei konnte die Täter niemals ermitteln. Nach dem Vorfall wurde das Studio an einen geheim gehaltenen Ort verlegt ${ }^{485}$.

In den Gerichtssälen der Republik wurde kurz nach Markteintritt der Fernsehfee ebenfalls, jedoch mit Argumenten, gekämptt. Im einstweiligen Verfügungsverfahren verfolgten namhafte TV-Sendeanstalten ein Verbot der Fernsehfee. Während dieses Begehren bei den befassten Richtern des

482 Vgl. http://www.spiegel.de/wirtschaft/stichwort-fernsehfee-a-48917.html sowie https://www.focus.de/kultur/medien/fernsehen-zoff-um-die-zapping-kiste_aid_1 79179.html, beide zuletzt abgerufen am 30.5.2019.

483 Vgl. die Ausführungen im Tatbestand des LG Berlin, Urteil vom 7.12.1999, 15 O 352/99, ZUM-RD 2000, 144.

484 Vgl. http://www.fernsehfee.de/, zuletzt abgerufen am 30.5.2019.

485 https://www.focus.de/kultur/medien/fernsehen-zoff-um-die-zapping-kiste_aid_1 79179.html, zuletzt abgerufen am 30.5.2019. 
LG Frankfurt sowie des OLG Frankfurt auf taube Ohren stieß ${ }^{486}$, konnte am Landgericht Berlin zunächst ein Erfolg für die TV-Sender errungen werden. Laut Leitsatz des Urteils im Verfügungsverfahren sollte der Hersteller der Fernsehfee mit der Funktion, Werbung automatisch auszublenden, in die Rundfunkfreiheit eines Fernsehsenders gem. Art. 5 GG eingreifen, da dessen wirtschaftliche Lebensgrundlage gefährdet werde. Dies widerspräche dem Leitbild des Leistungswettbewerbs, indem das eigene wirtschaftliche Fortkommen des Herstellers durch den Eingriff in Grundrechte Dritter erreicht werde ${ }^{487}$. Diese Einschätzung teilte das Kammergericht allerdings nicht und hob die einstweilige Verfügung sowie das Urteil des Landgerichts auf. Unter Verweis auf das OLG Frankfurt fällte das KG eine Interessenabwägung zu Gunsten der Fernsehfee, da es die eigene freie Entscheidung der Zuschauer sei, das Wegschalten bei Werbung nicht manuell vorzunehmen, sondern automatisch bewerkstelligen zu lassen. Auch der Eingriff in die Rundfunkfreiheit sei nicht schädlich, da keine greifbaren Nachteile durch den antragstellenden TV-Sender glaubhaft gemacht worden $\operatorname{sind}^{488}$.

Im Rahmen des Hauptsacheverfahrens zeigte sich das Landgericht Berlin renitent und verurteilte die Betreiber der Fernsehfee erneut zur Unterlassung. Der Vertrieb eines Zusatzgeräts für Fernsehapparate, das die automatische Ausblendung von Werbung aus dem Programm ermöglicht und die Werbung hierfür sollten nach Ansicht der Berliner Richter gegen $\mathbb{S} 1$ UWG a.F. verstoßen. Bejaht wurden ein unmittelbarer Eingriff in das Grundrecht der privaten Fernsehveranstalter auf Rundfunkfreiheit und eine daraus folgende sittenwidrige Behinderung. Außerdem sollte das Angebot der Fernsehfee einen rechtswidrigen Eingriff in den eingerichteten und ausgeübten Gewerbebetrieb gemäß $\int 823$ Abs. 1 Abs. 1 BGB darstellen ${ }^{489}$. Wieder kassierte das Kammergericht die Entscheidung und attestierte der Fernsehfee Legalität. Der TV-Werbeblocker sei weder wettbewerbsrechtlich noch urheberrechtlich zu beanstanden ${ }^{490}$.

Diese Ansicht fand sodann auch Zustimmung des BGH im noch heute oft zitierten Grundsatzurteil „Werbeblocker"491. Grund für die verbreitete Zitierung ist dabei in erster Linie, dass der BGH die Grenzen für das kon-

486 LG Frankfurt a. M., Urteil vom 8.4.1999 - 2/03 O 97/99, MMR 1999, 613 und OLG Frankfurt a. M., Urteil vom 23.09.199 - 6 U 74/99, NJW 2000, 2029.

487 LG Berlin, Urteil vom 28.5.1999 - 15 O 123/99, MMR 1999, 640.

488 KG, Urteil vom 22.10.1999 - 5 U 5806/99, ZUM-RD 2000, 17.

489 LG Berlin, Urteil vom 7.12.1999, 15 O 352/99, ZUM-RD 2000, 144.

$490 \mathrm{KG}$, Urteil vom 24.07.201 - 5 U 1112/00, MMR 2002, 483.

491 BGH, Urteil vom 24.6.2004 - I ZR 26/02, GRUR 2004, 877 - Werbeblocker I. 
krete Wettbewerbsverhältnis sehr weit gezogen hat. So sind auch solche Unternehmen als Mitbewerber anzusehen, die sich „wenn auch mit umgekehrter Zielrichtung" an dieselben Abnehmerkreise wenden. Im konkreten Fall waren dies die Fernsehsender, die mit ihrer Werbung genauso wie der Anbieter der Fernsehfee die Fernsehkonsumenten ansprechen. Der Umstand, dass die Fernsehfee mit ihrem Erfolg unmittelbar die Attraktivität der Werbeplätze bei den Fernsehsendern beeinflusse, genügte deshalb für die Mitbewerbereigenschaft.

Im Rahmen der Generalklausel von $\$ 1$ UWG a.F. lehnte der BGH eine individuelle Behinderung sowie eine allgemeine Marktbehinderung. Hauptargument im Rahmen der individuellen Interessenabwägung war, dass die geringere Verbreitung der Werbung nur diejenigen Fernsehzuschauer betriff, die sich bewusst dafür entschieden haben, keine Werbung sehen zu wollen. Im Übrigen hat der BGH den TV-Sendern und Werbenden aufgegeben, „sich den Herausforderungen des Marktes stellen, der von der Freiheit der wirtschaftlichen Betätigung und von der Kraft der Innovation lebt“. Ganz konkret meint das höchste Zivilgericht damit, dass die TV-Sender sich nicht auf die Rundfunkfreiheit im Sinne einer Bestandsgarantie berufen können. Vielmehr sollen sie in Zusammenarbeit mit der werbetreibenden Wirtschaft das Interesse des Zuschauers am Werbeprogramm wecken und wach halten. Bei der allgemeinen Marktbehinderung reichte es aus, dass die TV-Sender nicht existentiell bedroht waren.

Die zweite Welle der Werbeblocker in der Rechtsprechung war demnach ein voller Triumph für die Blocker - und ein Sieg für die TV-Zuschauer. Die Blocker durften sich freuen, dass ihr Geschäftsmodell höchstrichterlich als legal eingestuft worden ist. Zu Gunsten der Zuschauer wurde festgestellt, was eigentlich selbstverständlich ist. Sie sind frei, die Werbeinseln im TV nicht zu rezipieren - und für die eigene Bequemlichkeit technische Hilfsmittel einzusetzen.

Am Ende haben sich aber die Horrorszenarien der TV-Sender bekanntlich nicht realisiert. Die Fernsehfee ist vor allem Wettbewerbsrechtlern, nicht aber Verbrauchern ein Begriff. Fernsehwerbung existiert nach wie vor und wirft Gewinne ab. Ironischerweise war nicht der TV-Werbeblocker der Grund für den relativen Rückschritt der Werbeeinnahmen im Rundfunk im Vergleich zum übrigen Werbemarkt, sondern der Aufstieg und Siegeszug des Internets, das das Fernsehen als beliebtestes (Werbe-)Medium verdrängt hat. Denn den Appell des BGH, für das Publikum ansprechende Werbung zu senden, haben einige TV-Sender nicht nur ignoriert, sondern noch ins Gegenteil verkehrt. Bedauerlicherweise nahm oft auch die Qualität des Programms an sich ab. Dies zeigt wiederum, dass 
es im Wettbewerb regelmäßig wichtiger ist, die eigene Leistung am Markt zu optimieren, als externe Angriffe auf das eigene Geschäftsmodell mit zu viel Eifer zu verfolgen.

\section{c) Aktuelle Entwicklungen des Werbeblockens außerhalb des Internets}

Bei den beiden vorgenannten Medien, die nicht vom Internet abhängig sind und deshalb gemeinsam mit anderen analogen Werbemethoden wie Telefon- und physischer Außenwerbung auch „Nonline-Werbung“ genannt werden könnten, haben sich also die Blockmethoden juristisch behauptet. Bei Betrachtung der tatsächlichen Verbreitung hat sich der TVWerbeblocker nicht durchsetzen können. Die „Keine Werbung“-Aufkleber hingegen sind durchaus weit verbreitet. Dies wahrscheinlich auch schlicht vor dem Hintergrund, dass diese Sticker leicht und günstig zu beziehen und anzubringen sind.

Die beiden vorgenannten Rechtsprechungswellen ergingen allesamt zur alten Fassung des UWG, das noch die „große“ Generalklausel in $\$ 1$ UWG enthielt. Kurz nach der BGH-Entscheidung in Sachen „Werbeblocker“ im Jahr 2004 wurde das UWG reformiert und erhielt eine Kodifizierung verschiedener Fallgruppen, die zuvor über die Generalklausel gelöst wurden. Dabei wurde im Zuge der Umsetzung europäischer Richtlinien $\$ 7$ UWG, weitestgehend in seiner zur Zeit der Bearbeitung noch gültigen Struktur, inkorporiert. Im Rahmen der Prüfung der unzumutbaren Belästigung war und ist zwischen den Fallgruppen zu unterscheiden, die eine aktive Einwilligung („Opt-in“) benötigen, und solchen, die einen Widerspruch ermöglichen bzw. sogar auf die Erkennbarkeit des Wunsches, nicht angesprochen zu werden, abstellen. Bei den letztgenannten Fallgruppen ist folglich die Möglichkeit, Werbung zu blocken integraler Bestandteil der gesetzlichen Regelung. Die Äußerung des „Nichtwunsches“, Werbung zu erhalten, begründet regelmäßig eine unzumutbare Belästigung. Da die Art und Weise dieser Äußerung nicht festgelegt ist, ist eine Vielzahl technischer wie untechnischer Werbeblockmaßnahmen denkbar.

Durch diese Systematik haben sich gewisse Institute herausgearbeitet, die aktuell eine werbeblockende Wirkung haben. Zuvörderst ist hier auf zentral geführte Listen zu verweisen. Berühmtestes Beispiel ist die Robinson Liste, eine seit 1971 vom Deutschen Dialogmarketing Verband (DDV) 
geführte Liste, auf der sich jedermann eintragen kann ${ }^{492}$. Ihren Namen verdankt die Liste übrigens der geläufigen Romanfigur Robinson Crusoe ${ }^{493}$. Trotz der Suggestion, dass sich der Eintragende damit auf eine einsame Insel begibt, umfasste die Liste des DDV im Juni 2016 rund 899.000 Einträge ${ }^{494}$. Daneben bestehen weitere zentral oder bei einzelnen Unternehmen geführte Robinson Listen, die die Werbenden vor den Risiken von Abmahnungen durch Verbraucher schützen sollen.

Die Relevanz der allgemeinen Robinson Listen beim Prüfungspunkt der Erkennbarkeit des entgegenstehenden Willens eines Verbrauchers, Werbung zu erhalten, wird in der Literatur überwiegend bejaht. Wegen der leichten Verfügbarkeit der Listen, im Fall der DDV-Liste auch für Nichtmitglieder des Verbands wird gefolgert, dass die Listen mit zumutbarem Aufwand beschafft und konsultiert werden und damit die Erkennbarkeit der Werbeablehnung für den Werbenden begründen könnten ${ }^{495}$. Nicht ausreichend ist eine Eintragung jedoch für die Annahme eines ausdrücklichen Widerspruchs bzw. Opt-outs, weil ein solcher als rechtsgeschäftsähnliche Handlung beim Empfänger zugehen muss ${ }^{496}$.

Der Versuch, die Idee der Robinson Liste zu einem Geschäftsmodell zu entwickeln, sorgte im Jahr 2017 zu mehreren Rechtsstreitigkeiten. Stein des Anstoßes war dabei das Portal „werbestopper.de“, auf dem sich Verbraucher in eine Art Robinson Liste einschreiben konnten. Jedoch ging der Betreiber des Portals noch einen Schritt weiter und leitete die Information über den Werbewiderspruch aktiv an ausgewählte werbende Unternehmen - nach eigener Ansicht als Erklärungsbote - weiter ${ }^{497}$. Als weiteren Service bot das Portal an, bei Erhalt von Werbung durch die betroffenen Unternehmen u.a. über eine Smartphone App eine „Verstoßmeldung“ ans Portal absetzen können. Das Portal vermittelte dann den Kontakt zu

492 Vgl. Leible, in: MüKo Lauterkeitsrecht, $\mathbb{\$} 7$, Rn. 90. Siehe auch www.ichhabediewahl.de, zuletzt abgerufen am 30.5.2019.

493 https:/de.wikipedia.org/wiki/Robinsonliste, zuletzt abgerufen am 30.5.2019.

494 www.ichhabediewahl.de, zuletzt abgerufen am 30.5.2019.

495 Leible, in: MüKo Lauterkeitsrecht, $\mathbb{7}$, Rn. 90; Köhler/Bornkamm/Feddersen,

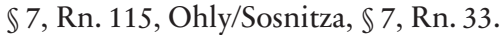

496 Köhler/Bornkamm/Feddersen, $\mathbb{8} 7$, Rn. 206.

$497 \mathrm{Vgl}$. die AGB des Portals in Ziff. 2.d., https:/werbestopper.de/landing-pages/ homepage/css/ws/landing-mobile/legal/agb.html?data-goto=1, abgerufen am 24.3.2018. 
einem Rechtsanwalt, der eine Abmahnung veranlassen kann. Zur Zeit der Abgabe dieser Ausarbeitung war der Dienst nicht mehr aktiv ${ }^{498}$.

Das Geschäftsmodell war dabei scheinbar primär auf die Generierung von Anwaltskosten gerichtet ${ }^{499}$, zumal der regelmäßig beauftragte Rechtsanwalt selbst Teilhaber der Betreibergesellschaft war ${ }^{500}$. Wie jeder gewerbliche Herausforderer der Werbewirtschaft hat auch dieses Geschäftsmodell zu gerichtlicher Überprüfung an mehreren Fronten geführt. Zunächst hat die Betreibergesellschaft von „werbestopper.de“ in ersten Testverfahren die vermeintlichen Ansprüche eigener Mitarbeiter, die auf den an die Beklagte versandten Abmahnlisten standen, aus abgetretenem Recht durch Klage verfolgt. In einem dieser Musterverfahren hat das AG Nürnberg die Klage abgewiesen und Unterlassungsansprüche wegen Rechtsmissbrauchs abgelehnt ${ }^{501}$. Es hat zudem den Standpunkt des Portals entkräftet, wonach dieses nur Erklärungsbote für die Verbraucher sei. Vielmehr handele es sich um eine Stellvertretung gegen die beim (regelmäßigen) Fehlen einer Vollmacht die sofortige Zurückweisung nach $₫ 174$ S. 1 BGB statthaft sei. Im Übrigen sah sich das Portal auch mehreren Abmahnungen und Verfahren wegen Irreführung nach $\$ \$ 5$, 5a UWG ausgesetzt, weil der konkrete Internetauftritt zu viel versprach und Kostenrisiken für die Teilnehmer nicht ausreichend erklärte ${ }^{502}$.

Die Episode „werbestopper.de“ zeigt wiederum, dass selbst der eigentlich schon längst höchstgerichtlich abgesteckte Rahmen für Briefkastenwerbung noch Potential für Streit birgt. Die Rechtsstreitigkeiten wurden in diesen Fällen jedoch nicht durch die um Umsätze fürchtende Werbewirtschaft, sondern durch das aggressive und fragwürdige Verhalten der Portalbetreiber und des beteiligten Rechtsanwalts selbst heraufbeschworen.

498 Der Dienst wurde gerichtlich als unzulässige Anwaltswerbung bewertet: erstinstanzlich LG Köln, Urteil vom 7.11.2017 - 31 O 76/17, und in der Berufung OLG Köln, Urteil vom 29.6.2018 - 6 U 179/17, WRP 2018, 1119.

499 So ausdrücklich AG Nürnberg, Urteil vom 30.6.2017 - 22 C 235/17, juris, Rn. 44.

500 Vgl. LG Köln, Urteil vom 7.11.2017 - 31 O 76/17 und zum Hintergrund: https:/ /www.juve.de/nachrichten/verfahren/2017/11/streit-unter-kanzleien-jonas-erzi elt-vor-lg-koeln-erfolg-gegen-duesseldorfer-rechtsanwalt, zuletzt abgerufen am 30.5.2019.

501 AG Nürnberg, Urteil vom 30.6.2017 - 22 C 235/17; noch anhängig: LG Nürnberg-Fürth, Az. 19 O 1765/17, zum Hintergrund: https:/www.wettbewerbszentr ale.de/de/_pressemitteilungen/?id=299, zuletzt abgerufen am 16.5.2019.

$502 \mathrm{Vgl}$. https://www.haerting.de/de/neuigkeit/werbewidersprueche-ueber-werbe stopperde-faq-fuer-betroffene-unternehmen, mit weiteren unveröffentlichten Rechtsprechungsnachweisen, zuletzt abgerufen am 30.5.2019. 
Dass das Geschäftsmodell im konkreten Fall Angriffsfläche bot, heißt indes nicht, dass sich bei ausgeklügelter Modellierung der Prozesse nicht neuartige Werbeblockervorgänge am Markt etablieren können. Die Werbemärkte bleiben deshalb auch langfristig ein potentielles Ziel, um auf dieser Grundlage eigenes Geschäft zu generieren.

\section{d) Situation bei E-Mail Werbung}

Bevor auf die Internetwerbeblocker, die auf Webseiten wirken, eingegangen wird, soll zur Vollständigkeit noch kurz die Lage bei E-Mail Werbung skizziert werden. Bei E-Mail Werbung gelten im Grundsatz ähnliche Regeln wie bei Briefkastenwerbung.

Während einerseits die gesetzlichen Regelungen in $\$ 7$ UWG geeignete Mechanismen zur grundsätzlichen Verhinderung von Werbemails enthalten, haben die meisten E-Mail Nutzer automatische Spamfilter, die werbende Mails im Bereich des Empfängers aussortieren. Mit den Mitteln des Werbewiderspruchs sowie der Registrierung auf Robinson Listen für E-Mail Adressen kann bei Missachtung eine unzumutbare Belästigung begründet werden.

Der Spamfilter hingegen entspricht seiner Funktion nach einem „Keine Werbung"-Aufkleber. Zwar geht die unerwünschte Werbemail im Postfach zu - anders als bei Briefkastenwerbung. Durch die Sortierung in einer separaten Spamliste muss der Nutzer diese Mail aber nicht zur Kenntnis nehmen. Je nach Einstellung wird die Spammail auch sofort gelöscht. Im Ergebnis wird der Empfänger also nicht von der Mail belästigt, da er sie nicht zur Kenntnis nimmt. Die Zulässigkeit der Spamfilterung durch den Nutzer selbst wird nicht angezweifelt. Probleme können sich allenfalls ergeben, wenn die Spamfilter oder Löschung von Spammails durch Provider oder Netzwerkbetreiber ohne Einwilligung der Nutzer erfolgen ${ }^{503}$. Dies betrifft indes nicht die grundsätzliche Erlaubnis für Nutzer, sich vor unerwünschten Werbemails zu schützen bzw. diese aus der eigenen Wahrnehmung zu verbannen. Bei der Blockade von E-Mail Werbung durch Spamfilter kam es dementsprechend nie zu einer Klagewelle wie bei den anderen Medien.

503 Vgl. Hoeren, NJW 2004, 3513. 
e) Erfindung und Lehrjahre der Internetwerbeblocker

Die Geschichte der Internetwerbeblocker für Display Werbung ist eng verbunden mit den Programmierern des Quellcodes der Programme. Sie ist auch recht gut dokumentiert im World Wide Web, zum Teil durch die Protagonisten selbst ${ }^{504}$. Laut den verfügbaren Quellen hat das, was seinen vorläufigen Höhepunkt 2018 beim BGH in Karlsruhe gefunden hat, im Jahre 2002 begonnen. Ein Informatikstudent aus Kopenhagen namens Henrik Aasted Sørensen hat nach einhelligen Angaben den Quellcode für Adblock geschrieben ${ }^{505}$.

Seinen eigenen Angaben zufolge war dies das Ergebnis von kreativer Prokrastination. Statt für eine Klausur zu lernen, entwickelte Sørensen eine Erweiterung für den Vorgänger des Firefox-Browsers, um Werbeanzeigen von den Webseiten zu verbannen. Es bestand zu diesem Zeitpunkt bereits ein Vorläufer, der zum Werbeblocken eingesetzt werden konnte. Dieser beruhte jedoch auf der Detektion großer Bilddateien, wie sie für Banner oft benutzt wurden. Dies war nachvollziehbarer Weise nicht sehr zuverlässig. Sørensens neuer Ansatz beruhte auf der Filterung von Werbung, die von bestimmten Adressen stammen. Damit war die Idee des Blacklist-Werbeblockers geboren. Den Code veröffentlichte Sørensen ohne Gewinnerzielungsabsicht in der Open Source Community. An der weiteren Entwicklung von Adblock beteiligte er sich allerdings nicht ${ }^{506}$.

Zur Zeit dieser Erfindung war „das Internet“ noch ein ganz anderer virtueller Ort als im Jahr 2018. Die Szene wurde maßgeblich von den Providern wie AOL, MSN oder in Deutschland durch T-Online beherrsch$\mathrm{t}^{507}$, die den ca. 569 Mio. Internetnutzern über 56k-Modems den Zugang zum Netz der Netze vermittelten. Mit 95\% Verbreitung war Microsofts Internet Explorer quasi Monopolist unter den Browsern mit dem ca. 3 Mio. Webseiten angesteuert werden konnten. Zum Vergleich: zehn Jahre später im Jahr 2012 waren 2,27 Milliarden Menschen online und konnten auf

504 Vgl. etwa einen Beitrag auf der Webseite von Adblock Plus von Wladimir Palant, https://adblockplus.org/blog/the-semi-authoritative-semi-complete-histor y-of-the-adblock-plus-project, zuletzt abgerufen am 30.5.2019.

$505 \mathrm{Vgl}$. http://web.archive.org/web/20100822080628/http:/adblockplus.org/en/histo ry und http://www.businessinsider.com/interview-with-the-inventor-of-the-ad-bl ocker-henrik-aasted-srensen-2015-7? IR=T, zuletzt abgerufen am 30.5.2019.

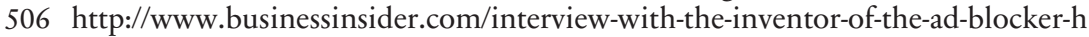
enrik-aasted-srensen-2015-7? IR=T, zuletzt abgerufen am 30.5.2019.

507 Vgl. http://www.spiegel.de/netzwelt/web/online-werbung-der-harmlose-kreuzzu g-der-pop-up-hasser-a-210293.html, zuletzt abgerufen am 30.5.2019. 
ca. 555 Mio. Webseiten surfen ${ }^{508}$. Nach einer Hochphase in den Jahren 2000/2001 musste sich Napster 2002 nach dem Verlust von Rechtsstreiten in den USA bankrott erklären ${ }^{509}$, was aber nicht zum Ende der Peer-toPeer-Tauschbörsen führte ${ }^{510}$. Google war noch ein junger Aufsteiger, das 1998 gegründet wurde, und bei den Klickzahlen noch relativ weit hinter Yahoo und MSN zurücklag ${ }^{511}$. Facebook existierte noch nicht einmal. Das Projekt startete an der Harvard University erst $2004^{512}$.

Mit Blick auf Internetwerbung erreichte die Verbreitung klassischer Pop-Ups in 2002 ihren Höhepunkt, der dazu führte, dass Provider wie die heute weitestgehend vergessenen Earth Link oder MSN die Einfügung von standardmäßigen Pop-Up Blockern in ihren Zugangssoftwares vornahmen $^{513}$. Selbst der Marktführer AOL zog kurz darauf nach, kündigte eine Reduzierung von Pop-Up Werbung auf eigenen Seiten an und bot eine entsprechende Software für die Nutzer an ${ }^{514}$. Während sich der Mainstream allein auf Pop-Ups konzentrierte, betraf Adblock bereits zu diesem Zeitpunkt weitaus mehr Werbeformen. Es setzte ganz grundlegend an der Wurzel an und war damit seiner Zeit weit voraus.

Ein Jahr später im Jahr 2003 stieg ein weiterer Programmierer ein, der bis heute eine Schlüsselrolle spielt: Wladimir Palant, der Gründer und Geschäftsführer der Eyeo $\mathrm{GmbH}$, der Betreibergesellschaft von Adblock Plus. Die auf Sørensens Entwicklung basierende Browsererweiterung Adblock war zu diesem Zeitpunkt in Version 0.3 und führte dazu, dass Werbeanzeigen auf Webseiten nicht angezeigt worden sind, ohne dabei den Downlaod der Daten für die Anzeigen zu unterbinden. An dieser Stelle setzte Palant an und programmierte eine Anwendung, die auch die „requests“ zur Übertragung der Werbedatenpakete unterband. Im Austausch mit dem pseudonymen Team von Adblock, dem Sørensen zu dieser Zeit schon nicht mehr angehörte, konnte sich Palant allerdings nicht ent-

508 Vgl. https:/venturebeat.com/2012/08/14/the-internet-2002-2012-infographic/, zuletzt abgerufen am 30.5.2019.

509 https://en.wikipedia.org/wiki/Napster\#History, zuletzt abgerufen am 30.5.2019.

510 Vgl. nur BGH, Urteil vom 8.1.2014 - I ZR 169/12, GRUR 2014, 657 - BearShare, dessen Verletzung aus dem Jahr 2007 datierte.

$511 \mathrm{Vgl}$. https://searchengineland.com/yes-steve-scalise-google-2002-211892, zuletzt abgerufen am 30.5.2019.

512 Vgl. https://en.wikipedia.org/wiki/Facebook, zuletzt abgerufen am 30.5.2019.

$513 \mathrm{Vgl}$. http://www.spiegel.de/netzwelt/web/online-werbung-der-harmlose-kreuzzu g-der-pop-up-hasser-a-210293.html, zuletzt abgerufen am 30.5.2019.

514 https:/www.geek.com/news/aol-unveils-pop-up-ad-blocker-553247/, zuletzt abgerufen am 30.5.2019. 
scheidend durchsetzen und entschied sich dazu seine Entwicklung selbst zu veröffentlichen - unter einem anderen Namen: Adblock Plus. Dies geschah im Januar 2006 und blockte nunmehr auf Basis einer Blacklist den gesamten Vorgang des Abrufs der Werbeanzeigen. Im November 2006 wurde Adblock Plus das meist heruntergeladene Add-on für den Mozilla Firefox Browser. Das Ausgangsprojekt Adblock hingegen wurde von Mozilla wegen technischer Probleme von ihrer Webseite entfernt ${ }^{515}$.

Auf der einen Seite stand die Software Adblock Plus an sich, auf der anderen Seite die Filterlisten. Ohne Filterlisten war und ist Adblock Plus wertlos. Die Filterlisten wurden seit jeher von der „Adblock Community“ gepflegt. Mit steigenden Downloadzahlen benötigten die Filterlisten ebenfalls ein Zuhause. Wieder stieg Palant ein, dieses Mal als Host für das „EasyList“-Projekt, die schnell die beliebtesten Filterlisten im Internet zur Verfügung stellten. Alle beliebten Filterlistenhosts hatten jedoch das Problem, dass sie selbst Gast waren und über kurz oder lang große Teile des Traffics bei Ihren Serverhosts beanspruchten. Letztendlich benötigte das gesamte Projekt eine professionelle Organisation.

Neben dem Erfolg bei technikaffinen Nutzern erlebte Adblock Plus einen ersten Schritt in Richtung Mainstream im Sommer 2007. Ein USamerikanischer Blogger namens Danny Carlton begab sich auf Kriegsfuß mit dem zu dieser Zeit stark in den Vordergrund preschenden Browser Mozilla Firefox. Er sperrte den Zugang zu seinem Blog für Firefox Nutzer und leitete sie stattdessen auf eine andere Seite weiter. Auf dieser Informationsseite mit der Domain „whyfirefoxisblocked.com", die heute nicht mehr erreichtbar ist, wurden die Hintergründe des Protests erläutert: Werbeblocken sei Diebstahl; wahrer Grund des Protests sei die Weigerung von Mozilla, den Webseitenbetreibern die Möglichkeit zu geben, Adblock Plus Nutzer auszusperren ${ }^{516}$. Grund für diesen radikalen Schritt war, dass Mozilla zu dieser Zeit der maßgebliche Browser war, auf dem werbeblockende Erweiterungen ohne größeren Programmieraufwand zu installieren waren. Der Blogger fürchtete um seine Refinanzierungsgrundlage, die Adblock Plus zu zerstören drohte. Da weder Palant noch die Verantwortlichen bei Mozilla Einsicht mit seiner Situation zeigten, baute er seine

515 https://adblockplus.org/blog/the-semi-authoritative-semi-complete-history-of-the -adblock-plus-project, zuletzt abgerufen am 30.5.2019.

516 Zitiert nach https://www.theguardian.com/technology/blog/2007/aug/19/adbloc kingis, zuletzt abgerufen am 30.5.2019. 
Sperre auf ${ }^{517}$. Der Ausschluss aller Firefox Nutzer hatte dabei wohl zwei Gründe: einerseits war dies medienwirksamer, da Adblock Plus noch nicht bekannt genug war, um die Medien aufzuwecken. Mozilla als Shooting Star unter den Browsern war bekannt genug und taugte als Sündenbock, der die „bösen“ Add-ons tolerierte. Andererseits war es wegen des Informationsaustauschs bei der HTTP-Verbindung zwischen Server und Client einfach möglich den Nutzer eines Browsers zu identifizieren. Die Möglichkeit nur die Nutzung eines Add-ons innerhalb eines Browsers zu identifizieren hätte stattdessen besonderer Detektionsmaßnahmen bedurft, die Carlton wohl kaum bewerkstelligen konnte.

Jedenfalls erreichte Carlton sein Ziel der Medienwirksamkeit, weil unter anderem die New York Times ${ }^{518}$, das britische Portal der Zeitung „The Guardian"519 und der Stern ${ }^{520}$ über den Zwist und damit auch erstmals im größeren Forum über den Programmierer Palant aus Köln und sein Adblock Plus berichteten. Die New York Times berichtete auch über die Ignoranz der Internetriesen des Jahres 2007 und deren Unwillen, gegen Adblock Plus vorzugehen. Dabei sah insbesondere Palant das Projekt Adblock Plus in dieser Zeit noch nicht gewappnet, einem Rechtsstreit gleich ob berechtigt oder unberechtigt - Stand zu halten ${ }^{521}$. Ergebnis des PR-Stunts war eine kostenlose Kampagne für Adblock Plus, die ironischerweise im Content eben jener Online-Medien verbreitet wurde, an deren Geschäftsmodell der Werbebblocker die Axt ansetzte.

Gleichsam war die Episode um Carlton, dem kleinen Blogger, der für seine Schreibleistungen nun nur noch sehr viel weniger Werbeeinnahmen generieren konnte, vielleicht einer von vielen Umständen, die Palant zu dem Gedanken brachten, dass der Weg des absoluten Blockens nicht zukunftsverträglich für die Vielfalt im Internet abseits der Mainstreammedien sein könnte. Im Mai 2009 veröffentlichte Palant jedenfalls ein Pamphlet

517 Vgl. https://techcrunch.com/2007/08/23/why-darwin-beats-danny-carlton/, zuletzt abgerufen am 30.5.2019.

518 https://www.nytimes.com/2007/09/03/technology/03link.html, zuletzt abgerufen am 30.5.2019.

519 https://www.theguardian.com/technology/blog/2007/aug/19/adblockingis, zuletzt abgerufen am 30.5.2019.

520 https:/www.stern.de/digital/online/onlinewerbung-blocken-oder-nicht-blocken -3264652.html, zuletzt abgerufen am 30.5.2019.

521 https://adblockplus.org/blog/the-semi-authoritative-semi-complete-history-of-the -adblock-plus-project, zuletzt abgerufen am 30.5.2019. 
zu seinem Konzept für faires Adblocken ${ }^{522}$. Dies mündete sodann in die Acceptable Ads Kriterien und das Whitelisting-Konzept, die im nachfolgenden Abschnitt näher beschrieben werden.

Abseits von Palants Adblock Plus gab der Markt der Werbeblocker im Internet in der zweiten Hälfte des ersten Jahrzehnts im 21. Jahrhundert praktisch keine Alternativen. Erst im Dezember 2009 wurde in Anknüpfung an Sørensens Adblock die auch heute noch verfügbare Alternative namens AdBlock veröffentlicht. Diese Veröffentlichung stand im engen Zusammenhang mit der Öffnung des Google Chrome Browsers für Addons wie es bei Firefox schon lange möglich war und einer der Hauptgründe für den Aufstieg des Browsers an die Spitze der Nutzerzahlen war. Adblock Plus war zunächst nicht für Google Chrome verfügbar, sodass neue Programmierer das Vakuum füllten. Neben AdBlock war auch ein Add-on namens Adthwart eine in diesem Zeitraum erfolgreiche Erweiterung für den Chrome Browser, die allerdings zur Zeit der Bearbeitung schon nicht mehr verfügbar war. Beide Programme funktionierten weitestgehend gleich und stammten von US-amerikanischen Programmierern ${ }^{523}$. Erst Ende Dezember 2010 entschloss sich Palant auch Adblock Plus für Chrome anzubieten ${ }^{524}$. Mit Einstieg in diesem Browser errang sich Adblock Plus auch für diesen Browser schnell eine führende Stellung bei den Downloadzahlen.

\section{f) Die Kommerzialisierung der Adblocker}

Etwa zeitgleich mit den Gedanken an faires Adblocken begann zudem die Kommerzialisierung der Adblocker. Während sie zuvor als extrem schnell gewachsene Open Source Projekte mit Filterlisten angesehen werden konnten, die absolut von der sie pflegenden Community abhängig waren, stand das zweite Jahrzehnt des aktuellen Jahrtausends unter dem Stern der Kapitalisierung. Palant bekam in dieser Zeit nämlich Hilfe von außerhalb durch Tim Schumacher und Till Faida, die beide einen wirtschaftlichen Hintergrund in Online Marketing und Internetgeschäftsmo-

522 https://adblockplus.org/blog/an-approach-to-fair-ad-blocking, zuletzt abgerufen am 30.5.2019.

$523 \mathrm{Vgl}$. https://www.nytimes.com/2010/01/04/business/media/04link.html, zuletzt abgerufen am 30.5.2019.

524 https://adblockplus.org/blog/adblock-plus-for-google-chrome-to-be-released-soo n, zuletzt abgerufen am 30.5.2019. 
dellen hatten ${ }^{525}$. Durch diese Allianz wurde die Eyeo GmbH gegründet, die fortan das Projekt Adblock Plus weitestgehend im Rahmen eines Unternehmens führt. Palant konnte sich dadurch voll und ganz auf die Programmierung und Weiterentwicklung konzentrieren, während sein neues Unternehmen das Rückgrat für einen rasanten wirtschaftlichen Aufstieg schaffte ${ }^{526}$.

Unter der Ägide der Eyeo GmbH wurde im Dezember 2011 das Acceptable Ads Programm gestartet. Dies beinhaltete die Einführung der Whitelist-Funktion als Standardeinstellung bei Neuinstallation des Add-ons. Zugleich wurden die Kriterien für Werbeanzeigen festgelegt, die nach Ansicht von Palant, Eyeo und einiger Nutzer von Adblock Plus vorliegen müssen, damit die Anzeigen nicht unbedingt geblockt werden müssen. Nur Webseiten, die ausschließlich solche Werbung implementieren, die diesen Kriterien entsprechen, haben die Chance auf die Whitelist zu kommen. Die Whitelist ist sozusagen der Passierschein, der den Weg durch die Adblock Schleuse ermöglicht. Nach Palants eigener Beschreibung war die erste Zeit des Acceptable Ads Programms nicht ganz optimal wegen unvorhergesehener Probleme und einiger Kritik von Nutzern und Publishern ${ }^{527}$.

Dieser Kritik zum Trotze wuchs Eyeo bzw. Adblock Plus weiter. Zum einen im eigenen Unternehmen, das neben den Gründern mehr und mehr Entwickler, Programmierer aber auch Marketingspezialisten und sonstige Mitarbeiter für die Aufgaben eines millionenschweren Unternehmens einstellte. Zur Zeit der Bearbeitung zählt das Team von Eyeo GmbH weit über 100 Personen ${ }^{528}$. Zum anderen in der Akzeptanz der Internetnutzer. Zwischen dem 17.1.2006 und dem 13.2.2008 zählte Mozilla für Firefox insgesamt etwas unter 14 Mio. Downloads von Adblock Plus mit durchschnittlichen täglichen Downloadzahlen von ca. 60.000. Unter dem Zählpunkt „Active Daily Users“ zählte Mozilla am 13.2.2008 3.033.440 Nutzer $^{529}$. In den Jahren 2016 und 2017 zählte Mozilla hingegen regelmäßig über 23 Mio. tägliche Benutzer von Adblock Plus. Bis März 2018 konnten

525 Schumacher war u.a. Mitgründer von sedo.com, einem Marktplatz für Domains, vgl. https://www.schumacher.me/, zuletzt abgerufen am 30.5.2019.

526 S.o. Fn. 20; https://adblockplus.org/blog/the-semi-authoritative-semi-complete-h istory-of-the-adblock-plus-project, zuletzt abgerufen am 30.5.2019.

527 https://adblockplus.org/blog/the-semi-authoritative-semi-complete-history-of-the -adblock-plus-project, zuletzt abgerufen am 30.5.2019.

$528 \mathrm{Vgl}$. https://eyeo.com/en/team, zuletzt abgerufen am 30.5.2019.

529 https://adblockplus.org/blog/statistics-statistics-statistics, zuletzt abgerufen am 30.5.2019. 
insgesamt alleine für Firefox über 474 Mio. Downloads der Erweiterung registriert werden ${ }^{530}$. Für die übrigen Browser stehen keine öffentlich zugänglichen, belastbaren Zahlen zur Verfügung. Gleichsam zeigen die Entwicklungen der Zahlen der Downloads sowie der täglichen Nutzer den enormen Sprung, den Adblock Plus nach Gründung von Eyeo gemacht hat.

Ein Grund für den Anstieg der „Performance“-Werte waren auch immer wieder Geschehnisse mit hohem Medienecho. Dies war schon 2007 bei der wirkungslos gebliebenen Firefox Blockade durch Danny Carlton der Fall. Eine vergleichbare Episode ereignete sich 2013 als der Techblogger Sascha Pallenberg mit mehreren Beiträgen in der Serie "\#adblockgate“ Enthüllungen über die Hintergünde von Adblock Plus postulierte. Pallenberg äußerte harsche Kritik an den Personen und dem Geschätfsmodell, berichtete von Vetternwirtschaft, geheimen Geldgebern und Ignoranz gegenüber der „Community“. Das Acceptable Ads-Programm titulierte er als Mafiamethode, das Schutzgeld erpresse ${ }^{531}$. Die Medien griffen die emotional geprägte und teils auf persönlicher Ebene geführte Diskussion auf ${ }^{532}$, die es sogar bis zur ARD ins TV schaffe ${ }^{533}$. Wie die Nutzerzahlen für Mozilla Firefox zeigen, haben die Enthüllungen am Ende jedoch mehr zur Bekanntheit der Werbeblockersoftware beigetragen, denn deren Ruf bei den Nutzern zu beeinträchtigen.

Auch die im Laufe der Jahre 2014 und 2015 eingereichten Klagen durch Medienhäuser konnten dem Erfolg von Adblock Plus nicht schaden. Dass der Großteil der Verfahren in den Instanzgerichten zudem ein Erfolg für Eyeo war, stellte dabei zudem eine ausnahmsweise sehr positive Berichterstattung für das Unternehmen und die Software dar. Insgesamt lässt sich beobachten, dass jede neue Berichterstattung über Adblock Plus in den nicht technikspezifischen Medien nichts an den sowieso schon verhärteten Fronten geändert hat. Adblock-Gegner brauchten keine weiteren Beweise für ihre ablehnende Haltung, Befürworter ließen sich nur kaum durch

530 https://addons.mozilla.org/DE/firefox/addon/adblock-plus/statistics/?last=365, abgerufen am 27.3.2018.

531 https://www.mobilegeeks.de/adblock-plus-undercover-einblicke-in-ein-mafioeses -werbenetzwerk/, zuletzt abgerufen am 30.5.2019.

532 Eine gute Zusammenfassung des Streits mit weiteren Nachweisen findet sich unter https://www.gruenderszene.de/allgemein/adblock-plus-kritik, sowie unter https://www.mobilegeeks.de/adblock-plus-adblockgate-eyo-gmbh/, zuletzt abgerufen am 30.5.2019.

533 https://www.youtube.com/watch?v=5RGKy34K3xE, zuletzt abgerufen am 30.5.2019. 
schlechte Presse zur Abkehr vom im Alltag gut funktionierenden Adblock Plus bewegen. Bislang unbedarfte Beobachter konnten aber durch die Berichterstattung potentiell als neue Nutzer von Werbeblockern gewonnen werden, die ohne die Berichterstattung wohl nicht von sich aus auf die Existenz der Werbeblockersoftware aufmerksam geworden wären.

Ein neuer Meilenstein in dem kontroversen Kommerzialisierungsprozess von Eyeo wurde 2016 erreicht. Da das System des Whitelisting nicht nur zu Protesten von Webseitenbetreibern (siehe \#adblockgate) und gut ein halbes Dutzend Gerichtsverfahren geführt hat, sondern offensichtlich auch bei den Nutzern der Whitelisting-Freischaltung als intransparent und aufwändig angesehen wurde, hat Eyeo eine vollautomatische Ad-tech Plattform zum Whitelisting eingeführt. Diese Plattform wurde aus naheliegenden Gründen „Acceptable Ads Platform“ getauft. Innerhalb dieser Plattform soll nach Angaben von Eyeo zudem ein Nutzer-Feedback basiertes „Real-Time-Bidding“ stattfinden, d.h. eine Auktion der Werbeplätze erfolgt nicht auf Grundlage trackingbasierter Algorithmen. Wenn Nutzer "gewhitelistete“ Anzeigen aus welchen Gründen auch immer monieren, haben die Anbieter bei der nächsten Auktion schlechte bis gar keine Chancen $^{534}$. Die Medien indes nennen im Zusammenhang mit dieser Neueinführung das Kind beim Namen: Adblock Plus verkauft selbst Werbung. Die Acceptable Ads Platform ist im Ergebnis nichts anderes als ein Werbenetzwerk, jedoch ein spezielles Netzwerk für Adblock Plus Nutzer ${ }^{535}$.

Dieses neueste Projekt wird mit Hilfe des Unternehmens Combotag, einem Anbieter von Tools zur Werbeoptimierung im Internet, gestemmt. Diese verteidigen das paradoxe Verkaufen von Werbeplätzen durch Werbeblocker als Fortschritt, weil auf massives Tracking und Targeting zum Wohle der Nutzer verzichtet werde ${ }^{536}$. Interessant in diesem Zusammenhang ist auch, dass diese Werbeausspielung allein bei Nutzern mit aktiviertem Adblocker und Whitelistingfunktion abläuft. Bei Nutzern ohne Adblock Plus werden die üblichen Werbungen ausgespielt ${ }^{537}$. Faktisch entstehen also zwei getrennte Werbemärkte: auf der einen Seite das ungeblockte Netz, auf der anderen Seite das Netz der Werbeblockernutzer.

534 https://adblockplus.org/blog/new-acceptable-ads-platform-launches-bringing-fee dback-to-rtb-and-help-to-small-websites, zuletzt abgerufen am 30.5.2019.

$535 \mathrm{Vgl}$. https://www.forbes.com/sites/johnkoetsier/2016/09/13/adblock-plus-is-now -an-ad-network/\#fd2a0ba5db08, zuletzt abgerufen am 30.5.2019.

536 Vgl. https://www.brandeins.de/magazine/brand-eins-wirtschaftsmagazin/2017/m arketing/sehnsucht-nach-dem-paradies, zuletzt abgerufen am 30.5.2019.

$537 \mathrm{Vgl}$. https://www.golem.de/news/neue-plattform-gestartet-adblock-plus-verkauft -selbst-werbeanzeigen-1609-123238.html, zuletzt abgerufen am 30.5.2019. 


\section{Aktion: Werbeblocker \& ähnlich invasive Geschäftsmodelle}

Auch bei dem bis dato einzigen anderen namhaften Werbeblocker auf Basis von Filterlisten zeigte sich der Trend zur Kommerzialisierung. Das ursprünglich für Chrome entwickelte AdBlock wurde vom Entwickler Michael Gundlach 2015 an einen anonymen Käufer verkauft. Im Zuge des Verkaufs trat diese eigentliche Konkurrenzsoftware von Adblock Plus dem Acceptable Ads-Programm bei ${ }^{538}$, das eigentlich die Besonderheit des Marktführers war. Die gesamten Hintergründe des Verkaufs und der Einfügung der Whitelist-Funktion wurden nicht veröffentlicht. Es steht nur fest, dass der Käufer nicht Eyeo war. Es gilt allerdings zu erwarten, dass vor dem Hintergrund des Kaufs von AdBlock sowie der Refinanzierung dieser Transaktion finanzielle Gründe nicht ganz bedeutungslos waren. Faktisch unterscheiden sich demnach Adblock Plus und AdBlock nur noch in Nuancen.

Im Übrigen entwickelte sich eine weitere Alternative zu den WhitelistBlockern, die weiterhin allein auf Blacklisting setzt, d.h. Werbung absolut blockiert. Dabei handelt es sich um die zur Zeit der Bearbeitung unter „uBlock“ und „uBlock origin“ firmierenden Browser-Add-ons. Zunächst wurde 2014, „BBlock“ veröffentlicht, das technisch auf der Software HTTP Switchboard basiert. Auf dieser Grundlage spalteten sich 2015 die zwei Wege „uBlock origin“, das vom ursprünglichen Programmierer von „, Block“ weiterentwickelt wurde, sowie „uBlock“ das von einem anderen Programmierer gepflegt wird ab. Beide Browsererweiterungen stellen durch den Verzicht auf Whitelisting als Kommerzialisierungsinstrument das Gegenkonzept zu Adblock Plus und AdBlock dar. Beide Projekte finanzieren sich maßgeblich durch Spenden ${ }^{539}$. Diese Erweiterungen stellen also eine nicht kommerzialisierte Alternative zu Adblock Plus dar.

g) Wie du mir, so ich dir - oder das Wettrüsten

Der Aufstieg der Internetwerbeblocker erfuhr nicht nur medialen Gegenwind. Da Worte im Kampf gegen Adblock Plus \& Co nie nachhaltig fruchteten, entwickelte sich auf Seiten den Webseitenbetreiber und Werbenden ein neuer Plan. Den technischen Eingriffe in das eigene Geschäftsmodell sollte ebenfalls mit technischen Mitteln begegnet werden. Ein frühes Beispiel für eine solche Gegenmaßnahme war die Firefox-Blockade

538 https://www.pcwelt.de/news/Adblock-wurde-verkauft-und-setzt-auf-Akzeptable

-Werbung-Safari-Extension-9821882.html, zuletzt abgerufen am 30.5.2019.

539 https://en.wikipedia.org/wiki/UBlock_Origin, zuletzt abgerufen am 30.5.2019. 
der Blogger um Danny Carlton im Jahr 2007. Diese haben, weil sie noch nicht über die Möglichkeiten verfügten, spezifisch Nutzer mit aktiviertem Adblocker zu erkennen, nur solche Nutzer ausgesperrt, die den Browser Firefox nutzen ${ }^{540}$. Die Nutzung eines bestimmten Browsers war problemlos erkennbar, weil in der HTTP-Verbindung diese Information sowieso übertragen wird. Auf einen entsprechenden Request konnte der Server, durch leichte Programmbefehle gesteuert, die eigentlich angeforderten Daten nicht senden, sondern stattdessen andere Daten ausliefern. Die erste Adblockersperre existierte also schon weit bevor Bild.de im Jahre $2015 \mathrm{zu}$ diesem drastischen Schritt überging ${ }^{541}$.

Die Gegenbewegung zum Blocken von Display-Werbung ist das AntiAdblocking. Als eines der hauptsächlichen Gegengewichte zu Adblock Plus tat sich dabei das 2002 gegründete irische Unternehmen PageFair hervor. Während PageFair zunächst vor allem die Auswirkungen des Adblockens im Internet maß und visualisierte ${ }^{542}$, bot das Unternehmen schon schnell technische Maßnahmen zur Erkennung von Adblockern, zur blockersicheren Ausspielung von Werbung sowie ein eigenes Werbenetzwerk an $^{543}$. Bekannt ist das Unternehmen zudem durch die jährlichen Reports mit denen das Unternehmen zur Bewerbung der eigenen Dienste die Verbreitungszahlen von Adblockern und deren ökonomische Folgen veröffentlicht.

Ein weiterer prominenter Gegenspieler ist das Hamburger Unternehmen AdDefend, das 2015 gegründet worden ist. Es verspricht so gut wie jeden Adblocker umgehen zu können und damit die Reichweite für Webseitenbetreiber wiederherzustellen ${ }^{544}$. Weitere namhafte Anbieter sind

540 Vgl. https://techcrunch.com/2007/08/23/why-darwin-beats-danny-carlton/, zuletzt abgerufen am 30.5.2019.; https://www.nytimes.com/2007/09/03/technol ogy/03link.html, zuletzt abgerufen am 30.5.2019.; https://www.theguardian.co $\mathrm{m} /$ technology/blog/2007/aug/19/adblockingis, zuletzt abgerufen am 30.5.2019.; https://www.stern.de/digital/online/onlinewerbung-blocken-oder-nicht-blocken --3264652.html, zuletzt abge-rufen am 30.5.2019.

541 S.o. den Screenshot unter Ziffer A. III..

542 Vgl. https:/www.theguardian.com/technology/2014/mar/27/page-fair-anti-adblo ck-startup-funding, zuletzt abgerufen am 30.5.2019.

543 https://pagefair.com/about-us/, zuletzt abgerufen am 30.5.2019.

544 https://www.addefend.com/de/about/, zuletzt abgerufen am 30.5.2019. 
Ooyala $^{545}$, Sourcepoint ${ }^{546}$, Secret Media ${ }^{547}$ oder Admiral ${ }^{548}$. Allein diese Auswahl zeigt, dass am Markt der Anti-Adblock Maßnahmen eine Vielzahl verschiedener Angebote erhältlich sind. Dies ist auch naheliegend. Potentielle Kunden gibt es zuhauf, da Internetwerbeblocker praktische jede Webseite betreffen.

Mit spezialisierten Programmierern und finanzkräftigen Partnern auf beiden Seiten hat sich also ein Wettrüsten entwickelt. Auf Blocker folgen Anti-Blockmaßnahmen. Daraufhin ziehen Blocker wieder nach und versuchen diese Maßnahmen zu umgehen, was wiederum eine Reaktion bezweckt. Am Ende stellen sich großen Webseitenbetreibern drei Optionen, die allesamt mit nicht unerheblichen Kosten verbunden sind: erstens, sie ignorieren Werbeblocker und nehmen geringere Werbeausspielungsraten hin. Zweitens, sie zahlen die Whitelisting-Gebühr von Adblock Plus. Drittens, sie nehmen die Dienste der Anti-Adblocker in Anspruch. So oder so werden Webseitenbetreiber nie mehr die ungestörte Einnahmesituation ohne gegenüberstehende Ausgaben vorfinden wie sie in den frühen Internetjahren herrschte.

\section{h) Letzte Entwicklungen}

Der Markt entwickelt sich weiter. Während der Browser Opera schon seit 2016 mit einem eingebauten Adblocker aufwartet ${ }^{549}$ und auch Eyeo auf dem mobilen Markt mit einem Adblock Browser versucht Marktanteile zu gewinnen, verkündete Google, seinen Browser Chrome ab Februar 2018 mit einem integrierten Adblocker auszurüsten ${ }^{550}$. Google macht damit den manuellen Download einer Browsererweiterung wie Adblock Plus überflüssig. Dies kann wegen der Verbreitung von Chrome auf dem Markt als direkter Angriff auf die Erweiterungsanbieter angesehen werden, da potentiell „Noch-nicht- Werbeblocker“-Nutzer oder Nutzer, die neue Geräte einrichten, vom Neudownload der Add-ons abgehalten werden. Außerdem

545 http://community.ooyala.com/t5/Ooyala-Player-Knowledge-Base/Adblock-is-Blo cking-the-Ooyala-Player/ta-p/8533, zuletzt abgerufen am 30.5.2019.

546 https://www.sourcepoint.com/, zuletzt abgerufen am 30.5.2019.

547 http://www.secretmedia.com/, zuletzt abgerufen am 30.5.2019.

548 https://getadmiral.com/, zuletzt abgerufen am 30.5.2019.

549 https://blogs.opera.com/news/2016/05/ad-blocker-integrated-opera-for-android -windows-mac-opera-mini/, zuletzt abgerufen am 30.5.2019.

550 http://www.sueddeutsche.de/digital/google-chrome-adblocker-1.3868742, zuletzt abgerufen am 30.5.2019. 
verfolgt auch Google eine Art Acceptable Ads-Initiative. Google nennt dies "Coalition for Better Ads" und mimt die aus der Programmiererund Tech-Szene entsprungende Acceptable Ads Initiative von Wladimir Palant, Eyeo und Co. Google koaliert dabei unter anderem mit Facebook, Microsoft oder Axel Springer, also mit den Schwergewichten am Markt. Entwickelt hat sich dadurch eine Blacklist, die Google zunächst mit einer Aufforderung zur Änderung der Werbung an Webseitenbetreiber und ultimativ mit Blockade durchsetzt. Großer Unterschied dieser Blacklists ist aber, dass Google und seine Koalitionäre gewisse Werbeformen wie Pre-Roll bzw. Interstitials als akzeptabel ansehen, was bei den klassischen Blacklistblockern undenkbar ist ${ }^{551}$.

Wiederum andere Akteure erdenken und entwickeln neue Formen des Werbeblockens. Forscher der Universitäten Princeton und Stanford haben etwa einen „wahrnehmenden" Werbeblocker entwickelt, der sich die Werbekennzeichnung zu Nutze macht und auf Grundlage der Signalworte wie "Anzeige“ oder „gesponsert“ an den üblichen Stellen Anzeigen erkennt und damit blockbar macht ${ }^{552}$.

Weiterhin machen sich Werbeblockerbetreiber neueste Technologien zunutze, um im Wettrüsten am Online-Werbemarkt weiterhin mitmischen zu können. So wurde berichtet, dass Eyeo auf künstliche Intelligenz setzen möchte, um das Werbeblocken zu verbessern. Diese Lösung soll nach dem Prinzip des zuvor dargestellten „wahrnehmenden“ Werbeblockers auf visueller Grundlage beruhen und durch die Vorzüge von „Machine Learning“ zuverlässig funktionieren ${ }^{553}$. Es verwundert jedoch kaum, dass auch auf Seiten der Anti-Adblocker Methoden der sog. künstlichen Intelligenz eingesetzt werden können, um Werbung dynamisch zu verschleiern und damit die Effektivität der neuesten Art des Werbeblockers zu untergraben 554 .

Die Entwicklung auf dem Markt der Internetwerbung sowie der abhängig nachgelagerten Märkte der Adblocker und der Anti-Adblocker ist mithin noch immer im Fluss und mäandriert gewaltig. Wohin diese Reise am

551 http://www.sueddeutsche.de/digital/google-chrome-adblocker-1.3868742, zuletzt abgerufen am 30.5.2019.

552 https://motherboard.vice.com/en_us/article/9a4yny/princetons-ad-blocking-su perweapon-may-put-an-end-to-the-ad-blocking-arms-race, zuletzt abgerufen am 30.5.2019.

553 https://t3n.de/news/werbeblocker-vs-facebook-ki-1091758/, zuletzt abgerufen am 30.5.2019.

554 https://floriantramer.com/docs/slides/pan19adblock.pdf, zuletzt abgerufen am 30.5.2019. 
Ende geht, ist schlicht nicht prognostizierbar. Vielleicht sind die aktuell großen Werbeblocker bis zum Jahr 2030 vergessen. Vielleicht sind aber auch die großen Werbenetzwerke bis zu diesem Zeitpunkt nicht mehr so einflussreich wie zur Zeit der Bearbeitung. Die Wahl treffen schlussendlich die Nutzer, deren Aufmerksamkeit, Daten und potentielles Konsumverhalten Grundlage der wirtschaftlichen Entwicklung ist.

\section{i) Fazit}

Die Beispiele in den verschiedenen Medien zeigen deutlich, dass Werbeblocken ein integraler Teil des Kommunikationsvorgangs Werbung ist. Der aktive Werbevorgang fordert regelmäßig eine ablehnende Reaktion heraus. Die neuere Geschichte der Werbung zeichnet sich durch die starke Technisierung aus. Aktueller Stand der Technik ist die im Internet durch Tracking und Targeting geprägte gezielte Werbeausspielung. Dass auch die Reaktionen der Nutzer eine entsprechende technische Evolution durchliefen, ist deshalb kaum verwunderlich.

Maßgeblich verändert hat sich indes, dass der durchschnittliche Werbeadressat mit zunehmender Technisierung Werbung nicht mehr allein durch eigenes Tun aus seiner Wahrnehmung verbannen kann. Bis zum Aufkommen der Internet-Adtechs konnte der Adressat abwimmeln, auflegen, umblättern, entsorgen oder umschalten. Auf Webseiten ist dies je nach Werbeform nicht möglich.

Während die erste Welle von Rechtsstreiten rund um Werbeblocker, die die Briefkästen betraf, von den Adressaten ausging, die ihre Persönlichkeitsrechte schützen wollten, rollte die zweite Welle von TV-Sendern auf den Anbieter der Fernsehfee zu. Die Fernsehfee war aber in erster Linie ein Werkzeug zur Erleichterung eines Vorgangs, den der Nutzer selbst auch bewerkstelligen konnte.

Die Internetwerbeblockerwelle geht ebenfalls von den Medienanbietern aus und attackiert Anbieter von Werbeblockerinstrumenten. Diese Werbeblocker ermöglichen dem Nutzer aber praktisch etwas, was er alleine nur bei enormen Sonderkenntnissen bewerkstelligen könnte: Das Entfernen von Werbeanzeigen aus Webseiten. Hier erlangt der Nutzer also im Gegensatz zu den früheren Werbeblockermethoden ein „Mehr“. Beim Blocken des Empfangs von Postwurfsendungen oder dem automatischen Umschalten eines TV-Programms erhält der Adressat anders als bei Internetwerbeblockern kein von Werbung bereinigtes Ergebnis. Adblock Plus und Co. können einzelne Teile einer Webseite ausschneiden und damit 
ein anderes Produkt herstellen, dass sich von der intendierten Form des Herausgebers unterscheidet.

Internetwerbeblocker unterscheiden sich also maßgeblich in zweierlei Hinsicht von anderen geblockten Medien: der Nutzer braucht die Expertise von Dritten und erhält dadurch ein „Aliud“ zum eigentlichen Medienangebot.

Eine zweite Folgerung aus der Werbeblockergeschichte ist, dass ein radikales Blocken, das den Werbevorgang derart verhindert, dass er gar nicht erst initiiert wird, nur durch gesetzliche Regelungen möglich ist. Nur wo ein Opt-in notwendig oder ein Opt-out möglich ist, wird eine Werbeansprache vor dem Druck von rechtlich angeordneten Konsequenzen unterbleiben. Alle anderen Methoden sind vor allem Filter, die einen bereits begonnenen Werbevorgang in der Sphäre des Adressaten abfangen und diesem eine Wahrnehmung ersparen. Hier gleichen sich sowohl „Keine-Werbung“-Aufkleber, die Fernsehfee und Adblock Plus.

2. Wirtschaftliche und technische Hintergründe

In diesem Abschnitt werden die wirtschaftlichen Zusammenhänge und technischen Grundlagen geordnet nach den verschiedenen Werbeblockerformen dargestellt. Die nachfolgend näher zu beschreibenden Formen von Werbeblockern sind zunächst undifferenziert wirkende Werbeblocker, die über einen beim Nutzer installierten Filter jede als solche erkennbare Werbung ausblenden (hier genannt: „Reine Blacklist-Blocker“, siehe dazu lit. a.). Eine Weiterentwicklung dazu sind die differenzierenden Werbeblocker, die zunächst über den oben beschriebenen Blacklist-Filter Werbung erkennen und diese dann über eine zweite Freigabeliste, die Whitelist, unter Umständen wieder freigeben (im Weiteren als „Whitelist-Blocker“ bezeichnet, siehe dazu lit. b.). Kurz wird auch auf Browser mit integrierten Werbeblockern eingegangen, siehe dazu lit c.). Daneben haben auch andere Softwares oder Browsererweiterungen als beiläufige Folge des Hauptzwecks eine werbeblockierende Wirkung. Dies kann zum Teil auch durch im Browser verfügbare Einstellungen oder Einstellungen am Betriebssystem bewerkstelligt werden (siehe dazu lit d.). Sodann ist auf neue Entwicklungen auf dem Markt der Internetwerbeblocker einzugehen, die Werbung unabhängig von Filterlisten oder Browsereinstellungen zu blockieren vermögen (siehe dazu lit. e.). 
a) Reine Blacklist-Blocker

Bei den reinen Blacklist-Blockern handelt es sich um die bereits in der historischen Beschreibung genannten Browsererweiterungen, die auf dem 2002 entwickelten ursprünglichen Adblock beruhen. Aktuell sind unter diese Kategorie Adblock Plus und AdBlock zu fassen, wenn dort die Whitelisting-Funktion ausgeschaltet wird, sowie uBlock und uBlock origin. Hinzu kommt eine Vielzahl von kleineren Werbeblocker Anbietern, die zum Browser oder auf ein mobiles Gerät geladen werden können. Eine Aufzählung ist wegen der Unübersichtlichkeit nicht möglich, zumal viele Angebote kommen und gehen. Deshalb konzentriert sich die nachfolgende Beschreibung auf die im deutschen Markt konstant vertretenen Anbieter.

\section{aa) Technische Grundlagen}

Das Konzept dieser Blocker ist simpel und das wirtschaftliche Ausmaß der Folgen enorm. Auf Grundlage einer selbst erstellten oder aus dem Netz geladenen Filterliste, der Blacklist, erkennt die Blockersoftware die Werbeelemente, verhindert deren Download und veranlasst den Browser, die Webseite ohne die Anzeigen aber trotzdem stimmig anzuzeigen. Auf diese Weise werden keine Anzeigen ausgespielt, sodass weder eine Abrechnung auf Grundlage der „Views“, noch weitergehende abrechnungsrelevante Transaktionen oder Kontaktaufnahmen erfolgen. Diese Form des Werbeblockens entzieht den jeweiligen Nutzer komplett aus dem wirtschaftlichen Geflecht der Internetwerbung, das aber auf Downloads und Klicks durch Nutzer beruht.

Konkret funktioniert Werbeblocken über eine Blacklist über die Modifizierung des üblichen Programmablaufs des Browsers. Beim Parsen des HTML-Dokuments, das zur Erstellung des DOM-Knotenbaums führt ${ }^{555}$, wird jedes zu ladende Element der Webseite auf einen Eintrag in der verknüpften Blacklist kontrolliert. Jedes Element durchgeht also eine Ja/ Nein-Abfrage des Browsers ${ }^{556}$. Bei Eintrag auf der Blacklist lautet der Befehl an den Browser, das Element nicht zu laden. Andernfalls wird das Element geladen und gerendert.

Laut der eigenen Beschreibung von Adblock Plus setzt die Blockersoftware beim Browser Mozilla Firefox an dessen Rendering Modul namens 
„Gecko“ an. Gecko liest die geparsten HTML-Dateien, Style Sheets sowie weitere Ressourcen wie Mediadaten ein und sorgt für die Darstellung im Nutzergerät ${ }^{557}$. Bei Gecko wird durch die Installation von Adblock Plus eine "Content Policy“ eingefügt. Also wird der eigentliche Code von Gecko derart geändert, dass neben originären Content Policies, etwa einer möglichen Standardeinstellung im Browser, wonach dieser keine Bilddateien laden soll, zusätzlich die Adblock Plus Content Policy ablaufen lässt. Dies ist dann der Abgleich mit der Filterliste bevor ein Element geladen wird. Adblock Plus nennt dies „shouldLoad"558. Auf der ersten Stufe ist Adblock Plus also vor allem die bloße Einfügung eines Befehls im Rendering Modul des Browsers. Deshalb erklärt sich auch der Umstand, dass Adblock Plus alleine, d.h. ohne eine Filterliste, keine Wirkung entfaltet. Der Browser prüft ohne verknüptte Liste trotzdem die Content Policy ab, d.h. er fragt: darf ich das Element laden? Die Antwort auf diese Frage ist mangels Angaben von zu blockenden Elementen allerdings logischerweise immer Ja.

Also löst erst die Kombination zwischen Blockersoftware und Filterliste Wirkungen aus. Auch die Filterliste allein kann keine Werbeblockade erzielen. Denn diese ist konzeptionell eine reine Textliste. Diese Liste wird bei der shouldLoad-Anfrage ausgelesen. Hier lauert bei zu langen oder zu vielen Listen natürlich die Gefahr, dass der Browser zu langsam arbeitet. Man vergleiche nur einmal wie lange es dauert, in einem umfangreichen PDF-Dokument im Adobe Acrobat Reader einen Begriff über das Textsuche-Tool zu suchen. Diese Möglichkeit der Verlangsamung des Internetsurfens führt also dazu, dass es in der Regel keine absoluten Filterlisten für das gesamte Internet gibt, sondern regelmäßig auf bestimmte Länder oder Sprachen optimierte Listen ${ }^{559}$.

Ein einfacher Filter in der Blacklist kann zum Beispiel lauten: /http:// ad.". In diesem Fall werden Elemente, die diese Adresse enthalten, blockiert. Die Kunst eines gut funktionierenden Adblockers ist folglich die möglichst schnelle Abgleichung mit den Filterregeln. Hierzu bedient sich etwa Adblock Plus besonderer Techniken, die die Filter effizient finden und anwenden ${ }^{560}$.

557 https://de.wikipedia.org/wiki/Gecko_(Software), zuletzt abgerufen am 30.5.2019.

558 https://adblockplus.org/de/faq_internal, zuletzt abgerufen am 30.5.2019.

559 Vgl. https://easylist.to/index.html und https://forums.lanik.us/, zuletzt abgerufen am 30.5.2019.

560 https://adblockplus.org/de/faq_internal, zuletzt abgerufen am 30.5.2019. 
Das ursprüngliche Konkurrenzprodukt AdBlock funktioniert zum größten Teil gleich. Wesentlicher Unterschied zwischen Adblock Plus und AdBlock ist an sich ein historischer. Adblock Plus wurde ursprünglich für Mozilla Firefox entwickelt und später für andere Browser „flott gemacht“. Bei AdBlock war die Grundlage Google Chrome und wurde von dort auf andere Browsercodes portiert. Alle Filterlisten sind für beide Blocker nutzbar, da beide dieselbe Filtersyntax nutzen ${ }^{561}$. Durch das Herrühren von einem anderen Browser musste AdBlock an einem anderen Rendering Engine anknüpfen - bei Google Chrome war dies zunächst „Webkit“ und später „Blink“, eine Eigenentwicklung von Google ${ }^{562}$. Durch einzelne Unterschiede in der Programmierung bei den Browsern und deren Rendering Modulen muss auch eine Werbeblockererweiterung für jeden Browser besonders programmiert werden, was kleinere technische Besonderheiten erfordert. In der Nutzung durch den Nutzer ergeben sich aber regelmäßig keine spürbaren Unterschiede.

Da diese Filterung aufgrund von vordefinierten Adressen und Merkmalen allein regelmäßig nicht ausreicht, um eine erschöpfende Werbeblockade zu erreichen, wird eine zweite Stufe durch die Werbeblocker gezündet: das sog. Element Hiding. Hier werden durch den Filter gerutschte Inhalte, die trotzdem von der Software als Werbung erkannt werden, nach dem Laden versteckt. Dadurch wird erreicht, dass der Nutzer die Werbung nicht angezeigt erhält ${ }^{563}$. Element Hiding beruht technisch auf Cascading Style Sheets (CSS) ${ }^{564}$. Diese sind - wie bereits weiter oben ${ }^{565}$ beschrieben - für die Formatierung, die Farben und Positionierung von Text- und Bildelementen zuständig. Praktisch werden CSS-Anweisungen oft als externes Stylesheet neben der HTML-Datei heruntergeladen, um so Inhalt und Darstellung von Webseiten zu trennen ${ }^{566}$. Der Browser setzt dann während des Renderns die Webseite in der für den Nutzer günstigsten Form zusammen. Adblock Plus benutzt eigene CSS-Anweisungen, um eine lückenhafte Darstellung nach Nichtladen von Elementen zu verhindern. Hinzu kommen auch CSS-Anweisungen, um die durch die Blacklists gerutschten Elemente, die aber trotzdem geblockt werden sollen auszublenden.

561 Vgl. https://en.wikipedia.org/wiki/AdBlock, zuletzt abgerufen am 30.5.2019.

562 https:/www.golem.de/news/blink-statt-webkit-google-entwickelt-eigene-renderi ng-engine-fuer-chrome-1304-98514.html, zuletzt abgerufen am 30.5.2019.

563 Nink, CR 2017, 103, 104.

564 https://adblockplus.org/de/faq_internal, zuletzt abgerufen am 30.5.2019.

565 S.o. Ziffer B. II. 2. b).

566 https://de.wikipedia.org/wiki/Cascading_Style_Sheets, zuletzt abgerufen am 30.5.2019. 
Geringfügig anders funktionieren die „uBlocker“. Diese basieren auf der Software HTTP Switchboard ${ }^{567}$, welche einen eigenen Matrixfilter beinhaltet. Dieser Matrixfilter beruht auf eigenen Filterregeln des Programmierers und unter Umständen des Nutzers, mit der bestimmte Arten von Elementen ausgeschlossen werden können. Erst nach dieser Matrix erfolgt eine Filtrierung aufgrund der allgemein verfügbaren Blacklist, z.B. der Easylist $^{568}$. Hier zeigen sich dann wenige Unterschiede zu Adblock Plus. Wegen der vorangestellten Matrix bezeichnet etwa der Programmierer von uBlock Origin die Software als „Weitspektrumblocker“, der beiläufigerweise auch Werbung blocken kann ${ }^{569}$. Ein weiterer Unterschied zu AdBlock Plus liegt zum Beispiel darin, dass uBlock Origin die Blockade ganzer Webseiten, also die Primärressource, zulässt (sog. „strict blocking“). Adblock Plus hingegen blockiert lediglich Sekundärressourcen, also niemals die angesteuerte Webseite selbst. Dies hat den Sicherheitsvorteil, dass Webseiten, die selbst wegen Risiken in ihren eigenen Ressourcen auf einer Filterliste aufgenommen worden sind, erst gar nicht geladen werden ${ }^{570}$. Was bei Adblock Plus als Element Hiding bezeichnet wird, ist bei uBlock (Origin) ein „kosmetischer Filter“. Kosmetische Filter verhindern nicht das Laden der Elemente, sondern streichen sie schlicht beim Rendern aus dem Document Object Model (DOM). Hier unterscheidet sich uBlock (Origin) dadurch, dass nur spezifische kosmetische Filter eingesetzt werden, was zu einer schnelleren Anzeige führt ${ }^{571}$. Technisch basieren aber beide Methoden auf CSS-Anweisungen.

Diese technische Funktionsweise zeigt, dass im Gerät des Nutzers durch den Browser und dessen Erweiterungen nach Download des ursprünglichen HTML-Dokuments vom Server der Webseitenbetreiber eine Vielzahl an Vorgängen abläuft. Praktisch bietet der Webseitenbetreiber durch seine HTML-Dokumente nur einen Vorschlag an, wie er seine Webseite gerne angezeigt haben möchte. Was zum Schluss der Internetkommunikation auf dem Gerät des Nutzers angezeigt wird kann jedoch sehr anders sein. Dies ist der enormen technischen Komplexität der Internetkommunikati-

567 https://en.wikipedia.org/wiki/UBlock_Origin, zuletzt abgerufen am 30.5.2019.

568 https:/github.com/gorhill/httpswitchboard/wiki/Net-request-filtering:-overview , zuletzt abgerufen am 30.5.2019..

569 https://github.com/gorhill/uBlock/wiki/Blocking-mode, zuletzt abgerufen am 30.5.2019.

570 https://github.com/gorhill/uBlock/wiki/Strict-blocking, zuletzt abgerufen am 30.5.2019.

571 https:/github.com/gorhill/uBlock/wiki/Does-uBlock-block-ads-or-just-hide-them $\% 3 \mathrm{~F}$, zuletzt abgerufen am 30.5.2019. 
on geschuldet. Mit vielen neuen technischen Raffinessen auf Seiten der Webseitenbetreiber, öffneten sich Tore für Nutzer, deren Browser die Anweisungen notgedrungen ausführen müssen, eigene Befehle einzufügen. Dies zeigt sich deutlich an zwei Beispielen. Erstens bei der Einbindung von Sekundärressourcen, die durch Filterlisten regelmäßig und verhältnismäßig einfach blockiert werden können. Zweitens bei dynamischen Gestaltungen durch CSS, die Adblockern nicht nur die Möglichkeit geben, Werbung auszuschneiden, sondern danach auch ein ansehnliches Bild der Webseite abzuliefern. Im Umkehrschluss sind Werbeblocker in ihrer Standardeinstellungen oft gerade dort wenig effektiv, wo Elemente von der primären Ressource, also dem Webseitenserver selbst, und in einer starren Darstellung ausgeliefert werden sollen.

Der Prozess der Selbstoptimierung der Webseiten mit immer aufwendigeren Gestaltungen hat demnach zu zwei Folgen geführt: auf der einen Seite haben Sie viele Nutzer verdrossen, auf der anderen Seite haben sie ihr Geschäftsmodell durch technische Gegenmaßnahmen wie Werbeblocker anfällig gemacht.

\section{bb) Wirtschaftliche Bedeutung}

In wirtschaftlicher Hinsicht sorgt Werbeblocken auf Grundlage von Blacklists für einen einschneidenden Eingriff in die Abrechnungsmodelle der modernen Online-Werbung. Die beiden maßgeblichen Abrechnungsparameter sind Pay-Per-View (oder besser: pro Download vom Server) und Bezahlung pro Klick, Lead oder sonstige (Trans-) Aktionen. Werden die Werbeelemente erst gar nicht geladen, weil sie über Blacklists schlicht ignoriert werden, fallen jedenfalls keine Umsätze nach Pay-Per-View an. Schafft es die Werbung durch die Blacklist, kann sie aber immer noch durch Element Hiding oder kosmetische Filter ausgeblendet sein. Dann mag zwar ein Download zählbar sein, erfolgsabhängige Vergütungen für Klicks, Leads, Käufe oder Ähnliches jedoch unmöglich. Infolge dieses Umstandes wird außerdem der Wert der Pay-Per-View Umsätze erheblich geschmälert, weil der Werbekunde schlussendlich nicht sicher sein kann, dass die gezählten Downloads auch tatsächlich angezeigt worden sind. Soweit die abstrakte Logik hinter den disruptiven Werbeblockern.

Konkret nennt PageFair, der Anbieter von Anti-Adblock-Maßnahmen, regelmäßig Zahlen im Zusammenhang mit dem Einsatz von Werbeblockern auf dem Online-Werbemarkt. Im Jahr 2015 bezifferte der „Ad Blocking Report" die Kosten der Adblocker auf Umsatzausfälle in den USA für das 
Jahr 2014 in Höhe von geschätzten 5,8 Milliarden US-Dollar. Dies wurde in Verhältnis gesetzt zum gesamten Volumen des Online-Werbemarktes in den USA von 49,5 Milliarden US-Dollar. Für den weltweiten Online-Werbemarkt wurden die Umsatzausfälle auf 11,7 Milliarden US-Dollar geschätzt ${ }^{572}$. Zahlen speziell für Deutschland waren dabei nicht enthalten.

Ein anderer Bericht von PageFair berichtet über die Ergebnisse einer dreijährigen Beobachtung von Traffic auf Webseiten. Dabei wurde beobachtet, dass gerade kleinere und mittlere Webseiten unter Adblockern leiden. Zunächst erhöhte sich zwar oft der Traffic. Durch ausbleibende Werbeeinnahmen stagnierte der Traffic sodann und fiel später. Als Grund wurde ausgemacht, dass ohne Werbeeinnahmen auf Dauer kein interessanter Content mehr ausgeliefert werden konnte. Große Portale indes seien von diesem Phänomen verschont geblieben ${ }^{573}$. Diese Informationen sind durch die Stellung von PageFair am Markt natürlich immer mit Vorsicht zu genießen. Sie machen die Effekte der Werbeblocker jedoch teilweise greifbar. Insbesondere zeigen sie, dass Werbeblocker einen ganz enormen Einfluss auf einen etablierten Wirtschaftszweig haben.

Für den deutschen Werbemarkt sind keine solchen „Schadensschätzungen" verfügbar, allerdings erhebt der OVK im BVDW regelmäßig die Adblockerrate, sprich die Verbreitung von Adblockern auf Endgeräten der deutschen Nutzer. Diese bewegte sich zwischen 2015 und 2017 konstant in einem Korridor zwischen 17 und 22 Prozent $^{574}$. Im Jahr 2018 bewegte sie sich zwischen 23,4 und 24,45\% $\%$. Nach der Logik von PageFair ließe sich aus dieser Verbreitungsrate in Verbindung mit dem Gesamtumsatz des Onlinewerbemarktes, etwa im Jahr 2018 2.065.000.000 $€^{576}$, ein Schaden von ca. 500 Mio. $€$ errechnen. Dies geht natürlich von der optimistischen Prognose aus, dass jeder Adblockernutzer dann abrechenbare Views und Aktionen getätigt hätte wie ein durchschnittlicher Nutzer, der

572 https://pagefair.com/downloads/2016/05/2015_report-the_cost_of_ad_blocking. pdf, zuletzt abgerufen am 30.5.2019.

573 https://pagefair.com/downloads/2017/04/White-paper-on-the-hidden-cost-of-adbl ock.pdf, zuletzt abgerufen am 30.5.2019.

$574 \mathrm{https} / / / \mathrm{www}$. bvdw.org/presse/detail/artikel/bvdw-messung-adblocker-rate-bleibt -stabil/, zuletzt abgerufen am 30.5.2019.

575 https:/www.bvdw.org/der-bvdw/news/detail/kein-signifikanter-anstieg-abblocke r-rate-steigt-um-024-prozentpunkte/, zuletzt abgerufen am 30.5.2019.

576 OVK-Report für digitale Display-Werbung 2019/01, https:/www.bvdw.org/filea $\mathrm{dmin} / \mathrm{bvdw} / \mathrm{upload} /$ publikationen/ovk/bvdw_ovk_report_2019_01_final.pdf0, zuletzt abgerufen am: 30.5.2019. 
keinen Adblocker einsetzt. Ob dies faktisch zutreffend ist, mag man mit guten Gründen anzweifeln. Gleichsam zeigt sich, dass Adblocker alleine in Deutschland mit hoher Wahrscheinlichkeit einen Umsatzverlust für den Werbemarkt im dreistelligen Millionenbereich begründen.

Vor diesem wirtschaftlichen Hintergrund wundert es kaum, dass die Größen in diesem Markt den Kampf aufgenommen haben, sowohl vor Gerichten als auch durch Lobbyarbeit. Ob aber die vom Interessenverband OVK herausgegebene und von beinahe jedem Publisher nachgebetete Warnung zutriff, dass die Nutzung von Adblockern die Finanzierung kostenfrei zugänglicher Inhalte im Internet sowie den Zugang aller Bevölkerungsschichten zu hochwertigen journalistischen Inhalten gefährde, ist in dieser Ultimativität zweifelhaft. Auch die weiter befürchteten Konsequenzen wie Verlust von Meinungsvielfalt bis hin zur Möglichkeit der Gefährdung von Arbeitsplätzen, ist dramatisch überspitzt ${ }^{577}$. Denn gerade PageFair zeigt mit ihrer Beobachtung, dass kleine und mittlere Webseitenbetreiber unter Adblockern leiden. Diese hingegen sind selten große Arbeitgeber. Bei dem heiklen Thema Arbeitsplätze sei trotz der tragischen sozialen Folgen eines Jobverlustes mit Blick aufs große Ganze der Gedanke erlaubt, dass durch die rasanten Anstiege der Werbeeinnahmen im Internet teilweise Jobs geschaffen wurden, die auf dieser „Blase“ beruhten. Wenn solche Jobs nunmehr wegfallen ist dies eine nicht ausschließbare Folge des Wettbewerbs. Mit Blick auf die Meinungsvielfalt darf nicht vergessen werden, dass Publisher nicht unbedingt auf eigene Webseiten angewiesen sind, sondern auch die sozialen Medien mit geringerer Kostenbelastung nutzen können. Die Meinungsvielfalt wird nach hier vertretener Ansicht auch durch ein weniger an Webseiten nicht gefährdet, da seit dem Aufkommen von Facebook, Twitter \& Co. sogar jede Einzelperson ihre Meinung spürbar kundgeben kann. Die These, Meinungsvielfalt beruhe auf Werbeeinnahmen, ist deshalb eine äußerst Streitbare.

\section{b) Whitelisting-Blocker}

Die nächste Evolutionsstufe des Werbeblockens im Internet ist das Blocken mit Whitelists. Während die Möglichkeit, vom Nutzer selbst definierte Ausnahmen zur Blacklist zu speichern, soweit ersichtlich in jedem am Markt erfolgreichen Blacklist-Blocker enthalten ist, gehen

577 https://www.bvdw.org/presse/detail/artikel/bvdw-messung-adblocker-rate-bleibt -stabil/, zuletzt abgerufen am 30.5.2019. 
die hier als "Whitelisting-Blocker" bezeichneten Softwares noch einen Schritt weiter. Diese Blocker sind standardmäßig mit einer Whitelist verknüpft, die von einem darauf spezialisierten Unternehmen - teils in Personaleinheit mit dem Softwareanbieter des Werbeblockers - gepflegt wird. Dabei bestimmen diese pflegenden Unternehmen nach eigenen Kriterien, welche Webseiten und/oder Werbeelemente trotz aktivierter Adblockersoftware in die Wahrnehmungssphäre des Nutzers durchgeleitet werden. Berühmtestes Beispiel ist Adblock Plus bzw. die Eyeo GmbH und ihre Acceptable Ads-Kampagne, auf welche bereits in der Darstellung der historischen Entwicklung eigegangen wurde. Diesem Konzept sind auch die Konkurrenzangebote AdBlock ${ }^{578}$ und Crystal ${ }^{179}$ gefolgt, die standardmäßig Eyeos Whitelist verknüpfen. Auch Google stützt sich nach Einführung eines Werbeblockers in seinen Browser Chrome mit ihrer „Coalition for Better Ads" auf dieses Prinzip ${ }^{580}$.

Während bei der undifferenzierten, möglichst undurchlässigen Blockade über Blacklists die Interessenlage eindeutig und nicht interpretationsbedürttig ist, scheiden sich am Whitelisting die Geister. Wie die \#adblockgate-Saga ${ }^{581}$ und die Rechtsstreite in Deutschland anschaulich zeigen, verschwimmt die Grenze zwischen Gut und Böse auf beiden Seiten der Auseinandersetzung.

Nachfolgend wird auch hier zunächst der technische Rahmen und sodann die wirtschaftliche Bedeutung dieser Werbeblockerform dargestellt.

aa) Technische Funktionsweise

In technischer Hinsicht funktioniert ein Werbeblocker mit Whitelist von der Grundidee her gleich wie ein Blacklist-Blocker. Während der Browser das HTML-Dokument parst, gleicht er für jedes Element die mit der Software verknüpften Listen ab. Ist ein Eintrag auf der Whitelist enthalten, dann wird das Element geladen. In technischer Hinsicht macht es dabei

578 https://www.pcwelt.de/news/Adblock-wurde-verkauft-und-setzt-auf-Akzeptable -Werbung-Safari-Extension-9821882.html, zuletzt abgerufen am 30.5.2019.

579 Crystal ist Add-on für die Browser auf mobilen Apple- und Samsung-Geräte wie Smartphones und Tablets; es nutzt ebenfalls Whitelisting auf Grundlage von Eyeos Whitelists, vgl. http://crystalapp.co/faq/, zuletzt abgerufen am 30.5.2019.

580 http://www.sueddeutsche.de/digital/google-chrome-adblocker-1.3868742, zuletzt abgerufen am 30.5.2019.

581 https://www.mobilegeeks.de/adblock-plus-undercover-einblicke-in-ein-mafioeses -werbenetzwerk/, zuletzt abgerufen am 30.5.2019. 
Sinn, dass die Whitelist hierarchisch vor der Blacklist geprüft wird. Denn somit kann der Browser positiv nach einer Erlaubnis suchen, statt zunächst nach einem Verbot des Downloads und dann nach einer Rückausnahme zu suchen ${ }^{582}$. Die umgekehrte Reihenfolge, also erst Black- dann Whitelist würde zu langsamerem Laden von Webseiten und der höheren Inanspruchnahme von Arbeitsspeicher führen, was die Werbeblockersoftware zu einem gewissen Grade unattraktiv machen würde. Wie beim Blacklisting fragt der Browser die über den Werbeblocker verknüpften Filterlisten auf eine Ja/Nein-Entscheidung ab. In logischer Hinsicht stellt sich der Ablauf eines abgelehnten oder zugelassenen Requests für ein Webseitenelement wie ein Banner schematisch wie folgt in Abbildung 9 dar:

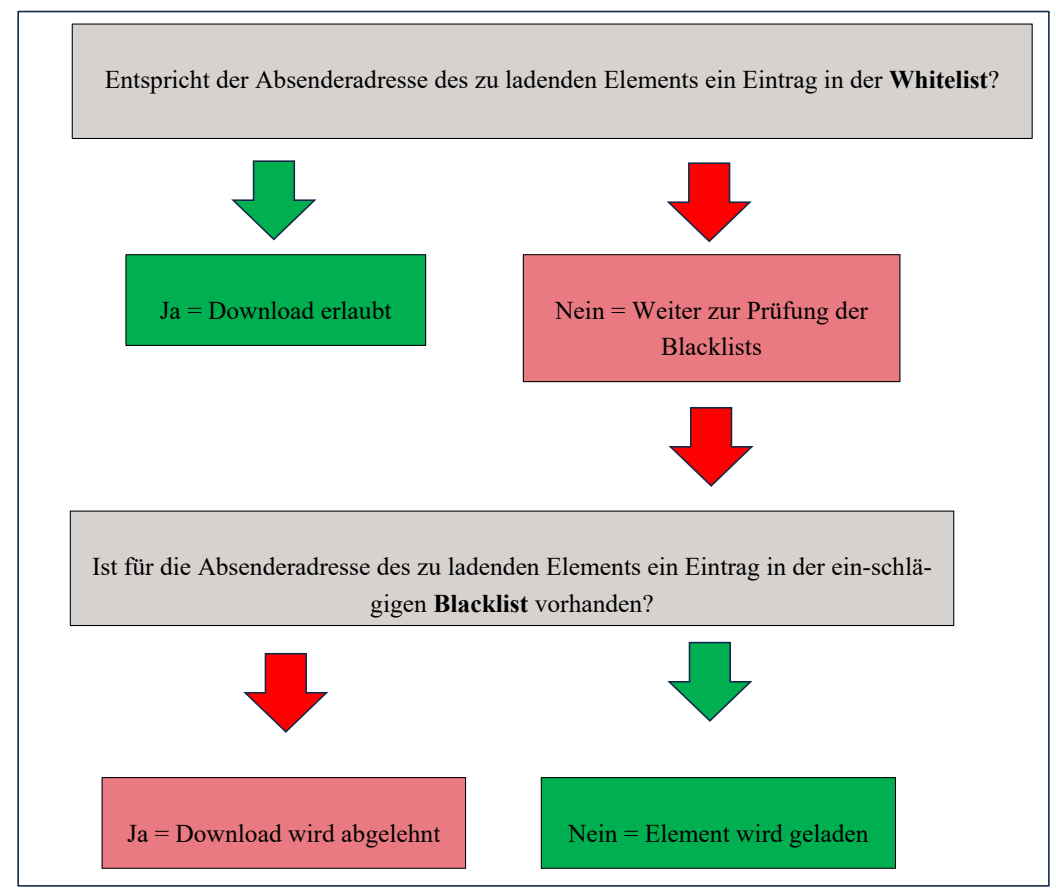

\section{Abbildung 9: Funktionsweise von Whitelist-Blockern}

582 So funktioniert jedenfalls uBlock, in deren Matrixfilter ebenfalls nutzereigene Ausnahmen zu einer Art Whitelist gesammelt werden können, https://github.c om/gorhill/uBlock/wiki/Does-uBlock-block-ads-or-just-hide-them\%3F, zuletzt abgerufen am 30.5.2019.; an dieser Stelle finden sich von Adblock Plus selbst keine Informationen zur Funktionsweise. 
Die Whitelist-Blocker sehen durchgehend die Möglichkeit vor, vom Nutzer zu einem Blacklist-Blocker umgewandelt zu werden. Die Whitelist ist als Standardeinstellung, vor allem nach erstem Download, vorgesehen. Durch einfache Menüführung bereitet es aber den durchschnittlich begabten Nutzern aber keine Schwierigkeiten, diese Einstellung zu ändern. Betrachtet man die technische Wirkweise, die bei beiden Arten von Blockern durch die Abarbeitung von Listen geprägt ist, unterscheiden sie sich praktisch nicht. Die Funktionalität der Blockersoftware wird durch die Erlaubnis- und Blockierlisten gewährleistet. Insoweit sind auch verschiedene Ausführungen denkbar. So muss eine Whitelist nicht zwingend separat erstellt und vorangestellt werden. Wenn die entsprechenden „gewhitelisteten" Ausnahmen schlicht aus der Blacklist gestrichen würden, würde auch ein reiner Blacklist-Blocker zu identischen Ergebnissen wie ein WhitelistBlocker führen. Einen praktischen Unterschied würde der Nutzer nicht bemerken.

Aus technischer Sicht findet sich, wenn man allein die Funktionsweise der Blockersoftware betrachtet, kein Unterschied zwischen einem Blacklist- und einem Whitelist-Blocker. Erst die Verknüpfung der Software mit verschiedenen Zwecken dienenden Listen führt zu andersartigen Wirkungen.

bb) Wirtschaftliche Bedeutung

In wirtschaftlicher Hinsicht ist die Hierarchie der Listen allerdings umgekehrt. Erst durch Existenz und Effektivität der Blacklist entfaltet die Whitelist ihr ökonomisches Potential. Die Blacklist führt erst die Lage herbei, dass sich Webseitenbetreiber oder Werbeanbieter ernstlich mit dem Angebot des Werbeblockeranbieters bzw. des Whitelistpflegers auseinandersetzen, gegen Einhaltung bestimmter Bedingungen auf die weiße Liste aufgenommen zu werden. Aus diesem Umstand folgen deshalb die zahlreichen Vergleiche, nach denen Adblock Plus Wegelagerei betreibe. Diese Vergleiche gehen indes ebenfalls von einer technisch nicht haltbaren Vorstellung aus. Wegelagerei impliziert, dass der Weg für Werbung für jedermann frei sein muss. Technisch stellt sich die Sachlage aber vielmehr so dar, dass der Weg für die Werbung derart blockiert wird, dass sie an der Haustür abgewiesen wird. Denn es ist der Browser im Nutzergerät, der die Anzeige von Werbung verhindert. Wegelagerei läge höchstens vor, wenn die Internetinfrastruktur für Werbeelemente blockiert würde. Dies können Filterblocker wie Adblock Plus aber nicht bewerkstelligen. 
Zur Zeit der Bearbeitung sind zwei wirtschaftliche Konzepte des Whitelisting erkennbar. Auf der einen Seite steht Adblock Plus mit der Acceptable Ads Initiative. Das andere Konzept ist Googles „Coalition for Better Ads“. Beide sollen nachfolgend in ihrer ökonomischen Wirkweise näher vorgestellt werden:

(i) Die Acceptable Ads Initiative von Eyeo

Die „Mutter aller Whitelists“ wurde von Eyeo in Adblock Plus zur Standardeinstellung gemacht und begründete damit den Beginn der Kommerzialisierung der Werbeblocker. Die Acceptable Ads Initiative zeichnet sich durch zwei Aspekte aus: erstens die Formulierung von Kriterien, die akzeptable Werbung erfüllen müssen, und zweitens der Abschluss eines in bestimmten Fällen kostenpllichtigen Whitelisting-Vertrags. Eben dieses Konzept stand in den deutschen Gerichtsverfahren auf dem Prüfstand, weil sich Betroffene der Kostenpflicht gegen dieses Verhalten der Whitelist-Pflegerin Eyeo GmbH wehrten. Aus den den unstreitigen Sachverhaltsdarstellungen in den Tatbeständen der Urteile lässt sich der Ablauf und die Abwicklung des Whitelistings durch Eyeo bzw. Adblock Plus sehr gut nachvollziehen.

Zunächst bilden die Acceptable Ads Kriterien die Stütze des Geschäftsmodells. Bereits ganz zu Beginn dieser Bearbeitung wurden diese Kriterien bereits angerissen ${ }^{583}$. Ganz konkret forderte Eyeo zur Zeit der Klageerhebung von Werbung, die als akzeptabel angesehen wird, folgendes Anforderungsprofil:

- Sie dürfen nicht nerven,

- Sie dürfen nicht den Seiteninhalt unterbrechen oder deformieren, der vom Nutzer gerade gelesen wird,

- Sie müssen transparent gekennzeichnet sein,

- Sie müssen effektiv sein, ohne Nutzer „anzuschreien“ und

- Sie müssen für die jeweiligen Seite, auf der sie erscheinen, angemessen $\operatorname{sein}^{584}$.

Diese weitestgehend als Maximen zu bezeichnenden Generalformulierungen taugen jedoch nur schlecht zur konkreten Bewertung, da abgesehen von Kennzeichnungsanforderungen und dem Verbot der Content-Unter-

583 https://adblockplus.org/de/acceptable-ads, zuletzt abgerufen am 30.5.2019.

584 https://acceptableads.com/en/about/, zuletzt abgerufen am 30.5.2019. 
brechung nur wenige objektive Kriterien genannt sind. In Konkretisierung gelten die folgenden Regeln ${ }^{585}$ :

- Platzierung: Werbeelemente dürfen nur am oberen, unteren oder seitlichen Rand positioniert werden. Verboten sind Elemente wie Banner oder Billboard Ads, die zwischen Contentbestandteilen angeordnet sind. Zum Beispiel ist demnach eine rechteckige Anzeige zwischen zwei Textabsätzen eines journalistischen Artikels im Internet inakzeptabel platziert.

- Kennzeichnung: Die Nutzung anderer Kennzeichnungsbegriffe als „Advertisment“" bzw. „Anzeige“ oder deren Äquivalente ist nicht akzeptabel. Hiermit wiederholen die Kriterien praktisch nur das in Deutschland und vielen anderen Jurisdiktionen geltende Recht.

- Größe: Hinsichtlich der Größe bestehen prozentuale und absolute Anforderungen. So sehen die Kriterien in relativer Hinsicht eine Höchstgrenze von 15\% bzw. 25\% Raum im sichtbaren Bereich einer Webseite für Werbeelemente insgesamt vor. Der geringere Prozentsatz gilt für den Bereich der Webseite, der beim Aufruf der Seite sofort sichtbar ist („above the fold“). Im Bereich der Webseite, der nach Herunterscrollen durch den Nutzer sichtbar wird, sind die Kriterien etwas großzügiger und erlauben ein Viertel Werberaum.

Soweit absolute Größen angegeben sind, hängen diese von der Position des Werbeelements ab. Sind die Anzeigen über dem Content beträgt die maximale Höhe 200 Pixel, sind sie darunter maximal 400 Pixel. Bei Positionierung an der Seite ist die maximale Breite auf 350 Pixel festgelegt.

- Textanzeigen: Grundsätzlich sind Textanzeigen erlaubt. Reine Textanzeigen dürfen aber keinen exzessiven Gebrauch von Farben und/oder anderen Elementen machen, die die Aufmerksamkeit der Nutzer an sich ziehen.

- Bildanzeigen: Grundsätzlich sind Bildanzeigen kritisch. Sie können als akzeptabel gelten, wenn es sich um statische Bilder handelt und sie ohne besonders aufzufallen in die Seite integriert sind.

- Newsfeed-Anzeigen: sind erlaubt, wenn sie sich im Rahmen der anderen Elemente im Newsfeed bewegen.

- Suchmaschinen-Anzeigen: An dieser Stelle sind die Kriterien nicht ganz eindeutig. Diese Anzeigen dürfen „größer sein und zusätzlichen Raum auf dem Bildschirm einnehmen“. Unklar bleibt, woran dieser Komparativ anknüpft - dürfen sie größer als die übrigen Suchergebnisse sein? Oder dürfen sie größer als übliche Anzeigen sein?

585 https://acceptableads.com/en/about/criteria, zuletzt abgerufen am 30.5.2019. 
- Schwarze Liste der Werbeformate: Jedenfalls als inakzeptabel angesehen werden hingegen gut ein Dutzend Anzeigenformate. So fallen darunter Anzeigen, die erkennbar neu laden, obwohl die Webseite an sich nicht geändert wird. Zudem „schwebende“ Anzeigen („hovering ads“), die nicht vom Nutzer geöffnet wurden. Hinzu kommen animierte Anzeigen, automatisch startende Video-/Audioanzeigen, expandierende Anzeigen sowie übergroße Bildanzeigen. Kein Pardon gibt es zudem für Pop-Ups, Pop-Unders sowie Layer Ads. Dasselbe gilt für Pre-Rolls und Interstitials, vor allem in Videos. Zuletzt sind Rich Media Anzeigen unerwünscht.

Praktisch verbieten die Kriterien alle Arten von Anzeigen, die mit der höheren Leistungsfähigkeit der Endgeräte beim Nutzer Einzug gehalten haben, insbesondere also Animationen, Interaktionen und Videos. Die Kriterien stellen die Uhr sozusagen zurück auf Anfang der 2000er Jahre. Werbung darf demnach nur ein statischer Teil einer Webseite sein, der nicht im Vordergrund, sondern im Hintergrund zu sein hat. Selbsterklärend ist dabei, dass gerade die „verbotenen“ Anzeigen für die Werbenden besonders interessant sind, weil diese durch die höhere Aufmerksamkeitserregung regelmäßig bessere Klickzahlen aufweisen. So fühlen sich vor allem Webseitenanbieter ungerecht behandelt, die kaum die Möglichkeit haben, native Werbung auszuspielen. Während Google und Facebook durch ihre Suchmaschinen- und Newsfeedanzeigen regelmäßig zur Whitelist zugelassen werden, werden Nachrichtenportale mit den auf ihren Seiten verbreiteten großen, animierten und effektreichen Anzeigen ausgeschlossen. Auch Portale, die auf Pre-Roll oder Interstitials angewiesen sind, haben keine Chance zur Whitelist aufgenommen zu werden.

Den Bedarf für eine Werbeblockerlösung, die nicht undifferenziert blockiert, sondern bestimmte, nicht störende Inhalte zulässt, folgerte der Entwickler von Adblock Plus, Wladimir Palant, bereits im Jahr 2009586, ca. zwei Jahre bevor mit der Gründung der Eyeo GmbH die WhitelistFunktion im großen Stil ausgerollt wurde. Weiter beruft sich Eyeo für das „Ob“ des Whitelistings auf Nutzerbefragungen, die ergaben, dass die wenigsten Nutzer jede Art von Werbung ablehnen. Auf die Frage, ob sich die befragten Nutzer vorstellen könnten, einige unauffällige Werbung zu erlauben, um kostenfreie Webseiten zu unterstützen, stimmten 32,5\% uneingeschränkt und weitere 38,4\% eingeschränkt zu. Nur 21\% lehnten dies kategorisch ab. Dies deckte sich auch weitestgehend mit der Gegenfra-

586 https://adblockplus.org/blog/an-approach-to-fair-ad-blocking, zuletzt abgerufen am 30.5.2019. 
ge, ob alle Webseiten ihre Inhalte umsonst und ohne Werbung anbieten sollen. Hier antworteten nur 23,5\% uneingeschränkt mit Ja. 33,2\% hingegen lehnten dies ab. Zu dieser Nutzerbefragung durch Adblock Plus ist allerdings hinzuzufügen, dass sie nur auf 1559 Antworten beruht ${ }^{587}$. Von einer flächendeckenden Befragung kann hier selbstverständlich keine Rede sein. Sie entspricht auch keiner gerichtsfesten demografischen Befragung. Zudem lässt sich hierauf wohl kaum eine quasi-demokratische Legitimation der Whitelist-Funktion stützen. Gleichwohl ist der Kreis der Befragten groß genug, um hieraus gewisse Trends in der Meinung der Nutzer zu erkennen. Sie zeigt jedenfalls, dass es nur eine Minderheit unter den Nutzern gibt, die Werbung im Internet radikal ablehnen und die Mehrheit für gewisse, maßvolle Werbung offen sind.

Auch der Umstand, dass trotz den in der Software vorhandenen Hinweisen zur Abschaltung der standardmäßigen Whitelist-Funktion, die Mehrheit aller Nutzer bei der Grundeinstellung blieben, spreche laut Eyeo für die Akzeptanz der Nutzer ${ }^{588}$. In einem der Gerichtsverfahren war es unstreitig geblieben, dass ca. 75\% der Nutzer von Adblock Plus die Whitelist-Funktion beibehalten ${ }^{589}$.

Während die Whitelist-Aspiranten, d.h. Webseitenbetreiber oder Werbende mit ihren konkreten Werbeformen, ursprünglich vor Eintragung in ein öffentlich zugängliches Forum eingestellt worden sind und dort aktive Nutzer des Forums ihre Meinung dazu abgeben konnte ${ }^{590}$, existiert seit 2017 ein Komitee zur Wahrung und Weiterentwicklung der Kriterien. Dieses Komitee besteht aus elf Mitgliedern aus drei Bereichen: Vertreter der Nutzer, der Werbenden und Webseitenbetreiber gemeinsam sowie Experten $^{591}$. Konkrete Mitglieder des Komitees waren bei der ersten Besetzung als Werbetreibender das Computer-Unternehmen Dell, diverse Adtech-Dienstleister, etwa das Affiliate- und Display-Werbenetzwerk Rakuten Marketing, Werbeagenturen sowie Publisher wie der renommierte Condé Nast Verlag 592 .

587 https://adblockplus.org/blog/adblock-plus-user-survey-results-part-3, zuletzt abgerufen am 30.5.2019.

588 https://acceptableads.com/en/users, zuletzt abgerufen am 30.5.2019.

589 LG Hamburg, Urteil vom 25.11.2016 - 315 O 293/15, MMR 2017, 351.

590 Vgl. u.a. LG München I, Urteil vom 27.5.2015 - 37 O 11673/14, MMR 2015, 660.

591 https://acceptableads.com/en/committee/, zuletzt abgerufen am 30.5.2019.

592 https://www.adzine.de/2017/03/eyeo-gibt-acceptable-ads-committee-bekannt/, zuletzt abgerufen am 30.5.2019. 


\section{Aktion: Werbeblocker \& ähnlich invasive Geschäftsmodelle}

Um die Kriterien auch effektiv durchzusetzen, bedarf es eines wirkungsvollen Hebels. In tatsächlicher Hinsicht ist dies zunächst die Existenz der Blacklist und deren Effektivität. Denn so eröffnet die Whitelist für Werbende einen Weg, ansonsten verlorene Nutzer zumindest teilweise wieder mit Werbung zu erreichen. Im Verhältnis zwischen Werbendem bzw. Webseitenbetreiber und Whitelistpfleger bedarf es zudem eines rechtlichen Hebels, der die dauerhafte Einhaltung der Kriterien sichert. Dazu verlangt Eyeo den Abschluss eines Whitelist-Vertrages, in denen gegenseitige Rechte und Pflichten geregelt werden. Unter Umständen gehört dazu auch eine Gegenleistung. Im Einzelnen stellte sich das Zustandekommen eines Whitelist-Dauerschuldverhältnisses im maßgeblichen Zeitraum der konkreten Verletzungsformen der deutschen Gerichtsverfahren, d.h. zwischen 2014 und 2015, wie folgt dar:

- Entscheidet sich ein Webseitenbetreiber oder ein Werbenetzwerk (nicht aber ein Werbetreibender) ${ }^{593}$ dazu, seine Webseite bzw. die auszuliefernden Werbeelemente auf die Whitelist eintragen zu lassen, nimmt der Whitelist-Aspirant Kontakt zur Eyeo GmbH auf. RegelmäBig wird dazu ein Formular im Internet ausgefüllt ${ }^{594}$.

- Daraufhin prüft Eyeo im konkreten Fall, ob die Aceeptable Ads Kriterien eingehalten werden ${ }^{595}$. Außerdem wird ein Testlauf durchgeführt, um einzuschätzen, welche finanziellen Auswirkungen die Freischaltung der zuvor blockierten Werbeelemente über die Whitelist für das Unternehmen hat ${ }^{596}$. Konkret werden sog. „Ad Impressions“ gezählt, die ausschließlich bei Adblock Plus Nutzern mit aktivierter WhitelistFunktion erscheinen. Auf dieser Grundlage wird das Anfallen und die Höhe der Vergütung bemessen.

- Besteht demnach weiterhin das Einverständnis der Parteien, eine Vereinbarung abzuschließen, folgt eine Veröffentlichung exemplarischer Werbebeispiele in einem öffentlich zugänglichen Forum der Eyeo $\mathrm{GmbH}$. Dort werden sie für einen Zeitraum von einer Woche zur Diskussion gestellt und Nutzer können durchgreifende Bedenken vorbringen $^{597}$. Eine Abstimmung über die Vorschläge findet hingegen

593 OLG München, Urteil vom 17.8.2017, U 2225/15 Kart, GRUR 2017, 1147.

594 LG Hamburg, Urteil vom 25.11.2016 - 315 O 293/15, MMR 2017, 351; vgl. auch das Formular unter https://acceptableads.com/en/get-whitelisted/, zuletzt abgerufen am 30.5.2019.

595 LG Hamburg, Urteil vom 25.11.2016 - 315 O 293/15, MMR 2017, 351.

596 OLG Köln, Urteil vom 24.6.2016 - 6 U 149/15, GRUR 2016, 1082.

597 OLG Köln, Urteil vom 24.6.2016 - 6 U 149/15, GRUR 2016, 1082. 
nicht statt ${ }^{598}$. Auch muss die im Forum aktive "Community“ nicht ausdrücklich zustimmen ${ }^{599}$.

- Sind keine durchgreifenden Bedenken aus dem Forum vorgebracht worden, die Eyeo zum Widerruf der Freischaltung drängen, wird die Whitelist-Vereinbarung verbindlich. Wann genau die Whitelist-Vereinbarung geschlossen wird, also erst nach der Veröffentlichung im Forum oder bereits davor (dann jedoch mit einer Loslösungsmöglichkeit für Eyeo bei berechtigten Bedenken der Nutzer) unterlag im maßgeblichen Zeitraum Änderungen ${ }^{600}$. Fest steht aber, dass ein schriftlicher Vertrag geschlossen wird. Diese sieht auf Seiten von Eyeo die Hauptpflicht vor, während der Laufzeit des Vertrages Ausnahme-Filterregeln in ihre Whitelist aufzunehmen. Diese Filterregeln betreffen URLs oder sonstige Pfadnamen, die durch Adblock Plus nicht blockiert werden. Eine weitere Pflicht von Eyeo in diesen Vereinbarungen ist, dass die Software so ausgeliefert wird, dass die Whitelist-Funktion als Standardeinstellung beim Nutzer vorgesehen ist ${ }^{601}$.

- Hauptpflicht der Whitelist-Nachfrager ist unter Umständen die Zahlung einer Gegenleistung. Diese wird nicht von kleinen oder mittleren Webseiten erhoben, weil in diesen Fällen der Verwaltungsaufwand für Monitoring und Rechnungsstellung in keinem Verhältnis zu den Einnahmen stünde ${ }^{602}$. Bei größeren Webseiten wird regelmäßig ein erfolgsbezogenes Vergütungsmodell eingesetzt, indem Eyeo an den Mehreinnahmen durch die Whitelist beteiligt wird. Eine Webseite gilt als groß, wenn durch das Whitelisting 10 Mio. zusätzliche Ad Impressions pro Monat generiert werden. Ob dies der Fall ist wurde in der oben skizzierten Testphase bereits vorab festgestellt. Eyeo verlangt bei solch großen Webseiten dann ein Entgelt in Höhe von 30\% der durch die Freischaltung generierten Werbeumsätze. Dies beinhaltet nicht Werbeeinnahmen, die durch Nutzer ohne aktivierten Werbeblocker bzw. bei Nutzung selbst konfigurierter Ausnahmefilter anfallen ${ }^{603}$.

Dies zeigt, dass Werbeblocker mit Whitelist-Funktion zudem über ausgeklügelte Zählinstrumente verfügen müssen, um bei Nutzern mit aktivierter Whitelist-Funktion und Verknüpfung mit Eyeos Whitelist jede ausge-

598 LG München, Urteil vom 27.5.2015 - 37 O 11673/14, MMR 2015, 660.

599 LG Hamburg, Urteil vom 25.11.2016 - 315 O 293/15, MMR 2017, 351.

600 OLG Köln, Urteil vom 24.6.2016 - 6 U 149/15, GRUR 2016, 1082.

601 OLG Köln, Urteil vom 24.6.2016 - 6 U 149/15, GRUR 2016, 1082.

602 LG München, Urteil vom 27.5.2015 - 37 O 11843/14, WRP 2015, 927.

603 LG Hamburg, Urteil vom 25.11.2016 - 315 O 293/15, MMR 2017, 351. 
spielte Werbung aufzuzeichnen und die Information an Eyeo zu senden. Dort muss dann aufgrund der gesammelten Daten und der vom WhitelistKunden anzugebenen Einnahmen die Vergütung berechnet werden.

Füllt man die oben genannte Formel mit Zahlen zeigt sich, dass die Einnahmen der Eyeo GmbH nicht in jedem Fall horrende Summen erreichen. So ist bei einem Tausender-Kontakt-Preis (TKP) für Ad Impression zu zwei Euro ${ }^{604}$ beim Schwellenwert der Kostenpflicht von 10 Mio. Ad Impressions von einem Werbeumsatz von $20.000 €$ auszugehen. Davon berechnet Eyeo 30\%, sprich $6.000 €$ pro Monat. Die übrigen $14.000 €$ stellen aber einen Mehrwert für den Whitelisting-Kunden dar, weil er bei reiner Blacklist keinen dieser Adressaten erreicht hätte.

Teilweise rechnet Eyeo auch pauschal ab. Die insoweit in den Tatbeständen der Urteile unstreitig gebliebenen Pauschalzahlungen von Internetriesen wie Google ${ }^{605}$ stellen scheinbar jedoch Ausreißer dar, die kaum repräsentativ zu sein scheinen. Einerseits ist Google durch seine schiere Größe nicht mit einem großen nationalen Webseitenbetreiber vergleichbar. Andererseits dürfte bei Google die Anknüpfung an Werbeumsätze schwierig sein, weil Google selbst sowohl als Provider der Suchmaschine oder vieler weiterer Dienste als auch als Werbenetzwerk tätig ist.

- Zuletzt finden sich in den Tatbeständen der Urteile weitere Inhalte der Whitelisting-Verträge, die eine Erwähnung verdienen. So verlangt Eyeo von den Whitelist-Kunden nicht, in Zukunft immer und auf allen Wegen akzeptable Werbung auszuspielen ${ }^{606}$. Sondern das Unternehmen fordert dies nur für seinen eigenen Einflussbereich, also für die Nutzer von Adblock Plus bzw. mittlerweile auch anderen Whitelist-Blockern. Man kann also vom „geblockten Netz“ sprechen. Was außerhalb dessen, sozusagen im „ungeblockten Netz“ geschieht, bleibt von der Whitelisting Vereinbarung unberührt.

Dies äußert sich auch in der „Fall-back“-Lösung. Dies ermöglicht es den Webseitenbetreibern zwischen Besuchern mit und ohne aktiviertem Adblock Plus zu unterscheiden. Wer Adblock Plus mit Whitelist aktiviert hat,

604 Vgl. für den TKP und die Variablen die dabei mit einspielen https://www.intern etworld.de/onlinemarketing/online-werbung/kosten-online-werbung-teure-tech nische-helferlein-1062268.html, zuletzt abgerufen am 30.5.2019.

605 OLG München, Urteil vom 17.8.2017, U 2225/15 Kart, GRUR 2017, 1147, nennt Google namentlich. LG München, Urteil vom 27.5.2015 - 37 O 11843/14, WRP 2015, 927, beziffert den Pauschalbetrag auf 25 Mio US Dollar, wobei unklar bleibt für welchen Zeitraum diese Zahlung gilt.

606 OLG Köln, Urteil vom 24.6.2016 - 6 U 149/15, GRUR 2016, 1082. 
der erhält eine akzeptable Werbeform; wer keinen Werbeblocker einsetzt, erhält hingegen eine herkömmliche Werbeanzeige ausgespielt ${ }^{607}$.

- Im Jahr 2016 waren ca. 3.500 Webseiten durch die Whitelist freigeschaltet ${ }^{608}$. Das Geschäftsmodell hat sich folglich am Markt etabliert.

Sind Webseitenbetreiber oder Werbenetzwerke nicht bereit, einen Whitelisting-Vertrag mit Eyeo abzuschließen, werden sie von den Whitelist-Blockern blockiert, selbst wenn sie die Acceptable Ads Kriterien erfüllen ${ }^{609}$. Demnach bilden Einhaltung der Kriterien und Abschluss einer Vereinbarung eine Einheit, die kumulativ vorliegen muss. Dies führt gleichwohl dazu, dass Werbetreibende mit einer nach Eyeos Kriterien akzeptablen Werbeform nicht über jede Webseite bzw. jedes Werbenetzwerk den Adressaten erreichen. Im Konkurrenzverhältnis von Webseiten bzw. Werbenetzwerken untereinander ist der Umstand, auf der Whitelist zu sein, ein maßgeblicher Umstand.

Wie unter anderem die Einführung der „Acceptable Ads Platform“, dem eigenen Werbenetzwerk von Eyeo ${ }^{610}$, zeigt, ist die weitgehende Sicherheit, die werbeblockenden Nutzer mit Werbung zu erreichen durchaus marktfähig. Die Existenz dieser Plattform zeigt aber vor allem auch eine Weiterentwicklung des oben dargestellten zähen und aufwändigen Prozesses. Durch die Einfügung bereits freigeschalteter Element stellen sich für Webseitenbetreiber keine eigenen Anforderungen mehr, sich selbst der Freischaltungsprozedur zu unterziehen. Der vormals teils händische Vorgang wird so ebenfalls weitestgehend rationalisiert und automatisiert.

(ii) Die „Coalition for Better Ads“ von Google

Das andere Konzept auf dem Whitelisting-Markt ist die „Coalition for Better Ads“ (im Weiteren teilweise abgekürzt als „CBA“) unter Federführung von Google. In dieser Koalition hat der Internetriese knapp vierzig Mitglieder vereint, darunter Hochkaräter aus dem Internetsektor wie Facebook und Microsoft, große Publisher wie Axel Springer, Thomson Reuters und The Washington Post sowie Schwergewichte der Werbetreibenden wie Unilever und Procter \& Gamble. Hinzu kommen noch diverse Werbenetzwerke und Adtech-Dienstleister. Komplettiert wird die Koalition durch

607 LG München, Urteil vom 27.5.2015 - 37 O 11843/14, WRP 2015, 927.

608 LG Hamburg, Urteil vom 25.11.2016 - 315 O 293/15, MMR 2017, 351.

609 LG München, Urteil vom 27.5.2015 - 37 O 11673/14, MMR 2015, 660.

610 S.o. Ziffer C. I. 1.f). 
Branchenverbände wie die bereits in dieser Bearbeitung genannten BVDW und $\mathrm{IAB}^{611}$.

Die Koalition definiert ebenfalls feste Regeln für bessere Werbung im Internet. Nach eigenen Angaben beruhen diese Regeln auf einer Umfrage unter 25.000 Verbrauchern in Nordamerika und Europa. Ergebnis dieser Umfragen war, dass die folgenden Werbeformen in der Akzeptanz bei den Nutzern unter einem gewissen Schwellenwert liegen ${ }^{612}$ :

- Pop-Ups (sowohl auf Desktop Computern als auch auf mobilen Geräten),

- Automatisch abspielende Videoanzeigen mit Ton (sowohl auf Desktop Computern als auch auf mobilen Geräten),

- Prestitials mit Countdown bis zum möglichen Überspringen (auf Desktop Computern), wobei damit nicht Pre-Roll-Werbespots etwa bei YouTube gemeint sind,

- Große „sticky“ Anzeigen ${ }^{613}$ (sowohl auf Desktop Computern als auch auf mobilen Geräten),

- Jegliches Prestitial im mobilen Bereich, wiederum jedoch nicht PreRoll-Werbespots,

- Poststital mit Countdown (im mobilen Bereich),

- Gesamtvolumen einzelner Anzeigen auf einem mobilen Screen von über 30\%,

- "Full Screen Scrollover Ads“ auf mobilen Geräten, d.h. Anzeigen, die auf dem Bildschirm erscheinen und durch Weiterscrollen erst aus dem Sichtfeld verschwinden (entsprechen praktisch einem Pre- oder Interstitial),

- Aufblitzende, animierte Anzeigen auf mobilen Geräten.

Ein wichtiger Schritt hin zur Durchsetzung dieser Regeln im unregulierten World Wide Web war die Einführung eines integrierten Werbeblockers in den Browser Google Chrome in Nordamerika und Europa zum 15.2.2018. Dieser Blocker musste also nicht durch den Nutzer erst aktiv installiert werden, sondern wurde durch automatisches Softwareupdate ohne Zutun des Nutzers installiert und standardmäßig scharf gestellt. In technischer Hinsicht beruht auch dieser Blocker auf Filterlisten und nutzt

611 https://www.betterads.org/members/, zuletzt abgerufen am 30.5.2019.

612 https://www.betterads.org/standards/, zuletzt abgerufen am 30.5.2019.

613 Vgl. etwa Beispiele oben unter Ziffer B. I. 3. a), bb) unter dem Schlagwort „klassische Anzeigen". 
die Filtersyntax der öffentlichen Easylist ${ }^{614}$. Zur Zeit dieser Änderung am Browser verfügte Google Chrome über ca. 40\% Marktanteil bei Browser auf Desktop-PCs $s^{615}$ sowie von ca. 50\% auf mobilen Endgeräten ${ }^{616}$. Google hat somit auf einen Schlag etwa doppelt so viele Personen in Deutschland zum Nutzer eines Whitelist-Blockers gemacht, als es alle erfolgreichen Erweiterungsblocker gemeinsam durch eigene Anstrengungen in ca. 15 Jahren bewerkstelligen konnten.

Nach eigenen Angaben verfolgt die Koalition zur konkreten Durchsetzung ihrer Standards ihr sog. „Better Ads Experience Program“. Mission sei es, die Nutzererfahrungen mit Online-Werbung zu verbessern und die Durchsetzung der „Better Ads“-Kriterien zu fördern. Als ersten Schritt erlaube die Koalition freiwillig teilnehmenden Webseitenbetreibern, sich auf die Einhaltung der Kriterien zu verpflichten. Dazu hat sich der Webseitenbetreiber zu registrieren und ausreichende Informationen zur Kontrolle durch die Koalition preiszugeben. Diese Registrierung ist zunächst kostenfrei, eine zukünftige jährliche Zahlungspflicht wird allerdings explizit in Aussicht gestellt ${ }^{617}$. Auf welcher Grundlage diese Zahlungspflicht beruht, also pauschale Zahlung als Mitgliedsbeitrag oder erfolgsabhängige Abrechnung ist nicht genau bekannt. Einer Meldung zufolge zahlen Mitglieder pauschale Summen zwischen 20.000 und 100.000 USD $^{618}$.

Den zur Zeit der Bearbeitung öffentlich verfügbaren Informationen zu Folge fordert Google praktisch die Mitgliedschaft in der Koalition, um nicht der Blacklist anheim zu fallen. So wird das Prozedere rund um die Einführung des integrierten Werbeblockers wie folgt beschrieben: Google informiert Webseitenbetreiber über „schlechte Werbung“ in ihrem Einflussbereich und setzt eine Frist zur Beendigung dieser Werbung innerhalb von 30 Tagen. Läuft die Frist fruchtlos ab, wird der entsprechende Webseitenbetreiber mit dem Status „nicht bestanden“ gekennzeichnet und

614 https://blog.chromium.org/2018/02/how-chromes-ad-filtering-works.html, zuletzt abgerufen am 30.5.2019. Ab Juli 2019 soll der Chrome Werbeblocker auch in allen anderen Ländern der Welt ausgerollt werden, https://www.express .co.uk/life-style/science-technology/1070863/Google-Chrome-update-browser-ch ange-2019, zuletzt abgerufen am 30.5.2019.

615 http:/gs.statcounter.com/browser-market-share/desktop/germany/\#monthly-201 801-201803-bar, abgerufen am 23.4.2018.

616 http://gs.statcounter.com/browser-market-share/mobile/germany/\#monthly-201 801-201803-bar, abgerufen am 23.4.2018.

617 https://www.betterads.org/program/, zuletzt abgerufen am 30.5.2019.

618 https://digiday.com/mobile/coalition-better-ads-experiences-european-growing-p ains/, zuletzt abgerufen am 30.5.2019. 
der Blacklist zugeordnet. In diesem Fall werden aber nicht nur die „bad ads" blockiert, sondern alle Werbemittel. Genau wie bei Eyeo/Adblock Plus und deren Forderung zum Abschluss einer Vereinbarung wird also ein gewisser Druck zur Kollaboration aufgebaut. Dies hat scheinbar bereits Wirkung gezeigt, da wenige Tage vor Scharfstellung des Adblockers in Chrome von 100.000 durch Google untersuchten Webseiten nur noch $0,8 \%$ mit „schlechter“ Werbung versehen waren ${ }^{619}$. Von den ermahnten Webseitenbetreibern sollen $42 \%$ die „schlechte“ Werbung abgestellt haben ${ }^{620}$.

Optisch macht sich der Chrome-Werbeblocker ebenfalls erkennbar, indem ein Informationsfeld öffnet, das über den Block informiert:
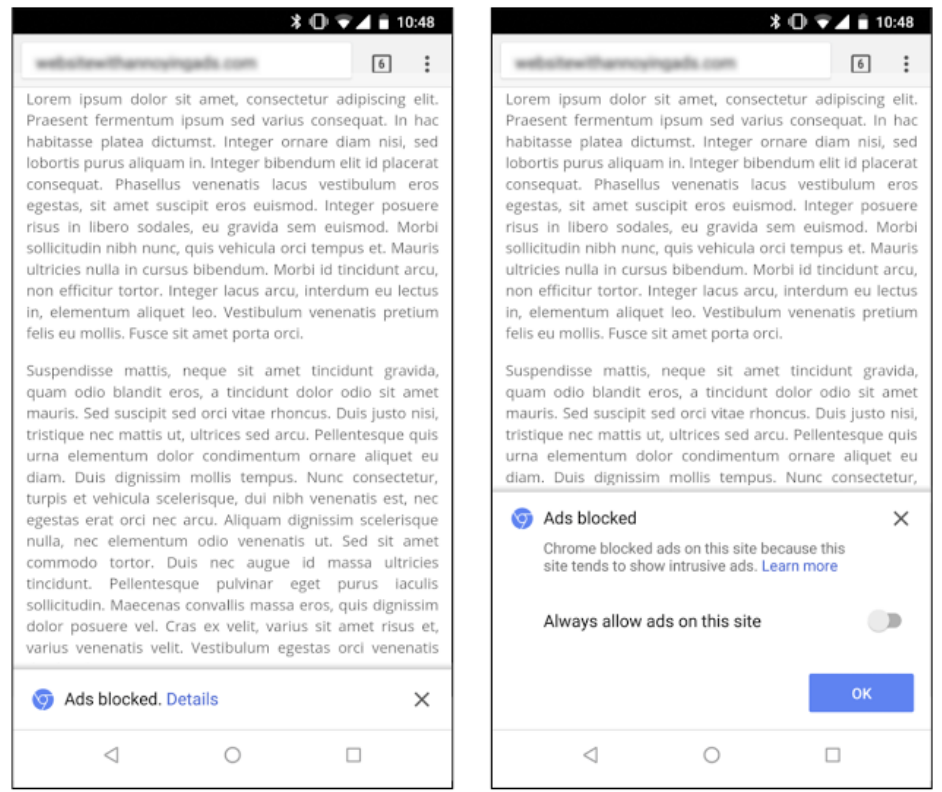

Screenshot ${ }^{621}$ des Chrome Blockers in Aktion

619 https:/www.adzine.de/2018/02/coalition-for-better-ads-google-chrome-filtert-ner vige-werbemittel-raus/ und https://support.google.com/webtools/answer/730803 3 , zuletzt abgerufen am 30.5.2019.

620 https://betanews.com/2018/02/14/google-chrome-ad-filtering/, zuletzt abgerufen am 30.5.2019.

621 https://mashable.com/2018/02/14/chrome-ad-blocking/\#E54ntQ673aqz, zuletzt abgerufen am 30.5.2019. 
Nicht ganz zu Unrecht wurde deshalb bereits angemerkt, dass Google praktisch anstatt einer aufdringlichen Werbung eine Art Pop-Up anzeigt. Dies muss wiederum durch Klick geschlossen werden, was einen ähnlichen Effekt wie eine entsprechende Werbung hat ${ }^{622}$.

Wie der Screenshot zudem zeigt, erlaubt Chrome dem Nutzer den integrierten Werbeblocker auszuschalten und Werbung zu erlauben. Auch verhindert Google nicht die hergebrachten Browsererweiterungen zu nutzen oder gar neu zu installieren. Als Plattform verhält sich Google demnach liberal und schließt die nunmehr als Konkurrenz zu bezeichnenden Erweiterungen nicht aus.

Wenig erstaunlich ist, dass Kritik an Googles Vorgehen laut wurde. So wurde öffentlich in Frage gestellt, ob Google noch glaubwürdig sein könne in seiner Rolle als Richter, Jury und Vollstreckungsorgan der Online-Werbung. Dies umso mehr, als Google selbst über diese Wirtschaftssparte Umsätze in Höhe von ca. 40 Milliarden US-Dollar generiert und neben der bedenkliche „Ämterkonzentration“ zudem noch befangen im Rechtssinne sein dürfte. Erste Beispiele für fehlende Parteilichkeit sind etwa die Zulassung von Pre-Roll-Werbung zu den „Better Ads“, eine Ausnahme hauptsächlich zugunsten von YouTube oder Facebook, die selbst startende Videowerbung zeigen dürfen ${ }^{623}$. $\mathrm{Zu}$ den Hintergründen dieses Vorgehens von Google wurde dem entsprechend gemutmaßt, dass die Einführung eines groben Filters, der nur die gröbsten Schmutzpartikel des Werbemarktes ausfiltert, den Bedarf für feinere Filtersoftware wie Adblock Plus oder reine Blacklist-Blocker wie uBlock origin abschwächt und somit den Werbemarkt strukturell stärkt ${ }^{624}$.

Harschere Kritik kommt von Nutzerseite. So wird bemängelt, dass in der Coalition for Better Ads keine Sitze für Nutzer und Gruppierungen, die digitale Rechte verfechten, vorgesehen sind. Die Koalition sei also praktisch ein Lobbyistentreff. Zudem sorge der Chrome-Blocker für keinerlei Besserstellung der Nutzer in Fragen des Datenschutzes, des Schutzes vor Malware und der Einsparung von Bandbreite oder Datenvolumen ${ }^{625}$.

622 http://www.gq.com.au/entertainment/tech/googlers+new+ad+blocker+changed+ the+web,53829, zuletzt abgerufen am 30.5.2019.

$623 \mathrm{Vgl}$. https://www.theguardian.com/technology/2018/feb/15/google-chrome-adbl ocking-online-ads, zuletzt abgerufen am 30.5.2019.

624 Vgl. https:/www.nytimes.com/2018/02/18/business/media/google-chrome-ad-bl ock.html, zuletzt abgerufen am 30.5.2019.

625 https://www.eff.org/deeplinks/2018/02/chromes-ad-filter-much-ado-about-nothi ng, zuletzt abgerufen am 30.5.2019. 
Das zweite Whitelisting-Konzept steckt also noch in den Kinderschuhen. Unter Aufsicht der mächtigsten Unternehmen des kontemporären Internets ist die Prognose für das „Better Ads“-Programm jedoch positiv, sodass es wahrscheinlich in nächster Zeit nicht beendet wird.

(iii) Stellungnahme zum wirtschaftlichen Hintergrund des Whitelistings

Die Einführung der Whitelist in Adblock Plus, zumal einhergehend mit einer Zahlungspflicht für einige potente Webseitenbeteiber und Werbenetzwerke, sorgte für mannigfaltige Anfeindungen. Vor allem aus dem Bereich der Webseitenbetreiber war diese Kritik harsch und teils unsachlich. Dies gilt nicht nur, aber vornehmlich für die zur Zahlung verpflichteten Unternehmen.

Auf der anderen Seite ist die Acceptable Ads-Whitelist nicht das reine Samariterwerk, wie es von der Betreibergesellschaft teilweise angepriesen wird. Mit diesem Instrument wird am Markt, allen herausgestellten Vorteilen für kleinere und mittlere Webseitenbetreiber zum Trotz, harte Kante gefahren. Denn alleine die Einhaltung der Acceptable Ads-Kriterien hilft den Webseitenbetreibern nicht weiter. Sie müssen als kumulative Voraussetzung der Aufnahme in die Whitelist einen ggf. kostenpflichtigen Vertrag mit Eyeo abschließen.

Betrachtet man dieses Geschäftsmodell aus einer objektiven Sicht, erscheint das kommerzielle Whitelisting als ein weiteres Beispiel erfolgreicher Internetgeschäftsmodelle. Dabei darf nicht vergessen werden, dass Werbeblocker als für den Nutzer kostenloses Produkt strikt von der Akzeptanz bei eben diesen Nutzern abhängig ist. Hier ähnelt es Angeboten wie Facebook, tausenden kostenloser Apps für Smartphones oder diversen kostenlosen Angeboten von Google. Solche Produkte müssen im Ausgangspunkt nicht besonders überzeugen, weil sie gerade keine Anschaffungskosten beim Nutzer entstehen lassen. Auf der anderen Seite ist ein Nutzer bei einem kostenlosen Angebot auch schneller bereit, sich von ihm zu verabschieden und es zu deinstallieren. Im digitalen Zeitalter bedarf dies zudem nur weniger Klicks. Der Markt für kostenfreie digitale Angebote ist also generell durch eine hohe Dynamik und Schnelllebigkeit geprägt.

Auch bei Adblock Plus lässt sich außerdem in gewisser Weise das „Metcalfe'sche Gesetz" beobachten. Nach dieser Faustregel steigt der Nutzen eines Kommunikationssystems proportional zur Anzahl der möglichen 
Verbindungen zwischen den Teilnehmern ${ }^{626}$. Ein klassisches Beispiel zur Veranschaulichung ist die Verbreitung von Telefonen. Das erste Telefon hatte noch keinen Wert, weil man damit niemanden anrufen konnte. Mit zwei Telefonen konnten nur zwei Personen miteinander kommunizieren. Haben aber zehn Personen Telefone können alle zehn Personen sich gegenseitig anrufen. In den letzten Jahren hat sich die Wirkung des „Metcalfe'schen Gesetzes“ vor allem bei Facebook gezeigt. Am Anfang nur eines von vielen sozialen Netzwerken hat es sich durch die weltweit starke Verbreitung zum quasi-Monopolisten entwickelt ${ }^{627}$. Diese starke Verbreitung hat das Netzwerk attraktiv für noch mehr Neuzugänge gemacht, denn irgendwann ist eine Person ausgeschlossen, die sich nicht beteiligt. Auf dieser Grundlage konnte Facebook zu einem der wertvollsten Werbeplattformen werden. Und auch hier ist darauf hinzuweisen, dass Facebook in der frühen Zeit kostenlos und werbefrei war. Planmäßige Werbung wurde erst 2007 in die Plattform integriert ${ }^{628}$.

Ähnlich die Lage bei Adblock Plus, bei dem es sich jedoch nicht um einen Kommunikationsdienst im engeren Sinne handelt. Hier wirkt das „Metcalfe'sche Gesetz“ sozusagen umgekehrt. Je mehr Nutzer den Werbeblocker verwenden, desto höher ist der Schaden für die Werbewirtschaft. Bei einem einzigen Werbeblockernutzer ist der Schaden mikroskopisch, bei 1.000 Werbeblockernutzern ist er immer noch kaum merklich. Wenn aber 100 Mio. Nutzer Werbeblocker einsetzen, sind die Folgen drastisch. Auf der anderen Seite hat diese Verbreitung einen neuen Werbeplatz hervorgebracht: das geblockte Netz. Wie viele Umfragen sowie die Akzeptanz der Nutzer für die Whitelist-Funktion zeigen ist auch hier im beschränkten Umfang Werbung möglich. Dieses künstliche und wahrscheinlich ursprünglich nicht einmal geplante Forum wird durch Whitelisting genauso kommerzialisiert wie Facebook es mit ihrem sozialen Netzwerk getan hat. Dies stellt eine nachvollziehbare kommerzielle Nutzung einer als vermarktbar erkannten Plattform dar. Wer also Eyeo für das Whitelisting verteufelt, muss dieselbe Ablehnung auch Facebook entgegen bringen,

626 https://de.wikipedia.org/wiki/Metcalfesches_Gesetz, zuletzt abgerufen am 30.5.2019.

627 Vgl. Baumgärtel, http://www.zeit.de/digital/2018-04/soziale-netzwerke-facebo ok-mark-zuckerberg-algorithmus-metcalfesches-gesetz, zuletzt abgerufen am 30.5.2019.

628 https://en.wikipedia.org/wiki/Timeline_of_Facebook, zuletzt abgerufen am 30.5.2019. 
das ihre Macht über eine Plattform mit ca. zwei Milliarden Nutzern weltweit $^{629}$ zur profanen Umsatzgenerierung ausnutzt.

Kostenpflichtiges Whitelisting sollte also nicht generell als Teufelswerk angesehen werden. Ein Teil der Kritik an dem Geschäftsmodell rührt wohl auch aus enttäuschtem Idealismus her. Denn Adblocker verkörpern ein im Grundsatz rebellisches Weltbild, nach welchem die von „oben“ vorgegebene Struktur nicht befolgt zu werden braucht. Sie stehen auch für den Widerstand der Nutzer dagegen, als bloßes Abrechnungssubstrat der Werbeindustrie angesehen zu werden, dieimmer mehr und immer aufdringlichere Werbung schaltet. Für solche Nutzer muss die Erkenntnis, dass der Helfer zur Befreiung solcher „kapitalistischer“ Bevormundung, selbst kapitalistische Motive verfolgt, eine herbe Enttäuschung darstellen. Dahingegen ist die Kritik aus dem Lager der Webseitenbetreiber, Werbenetzwerke und Werbetreibenden vornehmlich auf Sorge um die eigenen Umsätze getrieben.

Dabei ist das Argument von Eyeo durchaus valide, dass das Angebot zum kostenpflichtigen Whitelisting schlussendlich niemanden schadet, sondern vielmehr auf beiden Seiten des Whitelisting-Vertrags zu Umsätzen führt. Denn den Webseitenbetreibern wird eben nicht durch Adblocker zunächst etwas weggenommen und dies dann gegen Schutzgeld wieder herausgegeben. Praktisch ist es so, dass selbst bei einem Verbot oder einer Aufgabe der Whitelisting-Funktion das geblockte Netz weiterhin bestehen wird. Dies bedeutet, dass die Einnahmenverluste durch Blacklist-Blocker sowieso bestehen. Vor dieser Prämisse stellt das Whitelisting-Angebot, bestimmte Werbung gegen 30\% der Mehreinnahmen freizuschalten, ein für Webseitenbetreiber risikoloses Vorgehen dar. Im schlimmsten Fall fällt keine erfolgsbezogene Vergütung an. Dagegen sind potentiell hohe Zusatzeinnahmen möglich.

Schlussendlich wird der Nutzer wiederum zum Abrechnungssubstrat von Unternehmen. Wer aber dies nicht hinnehmen möchte, kann sich jederzeit der reinen Blacklist-Funktion bedienen. Schlussendlich entwickeln sich so drei verschiedene Werbemärkte im Internet: das ungeblockte Netz, das strikt geblockte Netz und in der Mitte das Netz der akzeptablen Werbung. Der Nutzer hat jederzeit die Wahl, welchem dieser Märkte er sich anschließt.

Whitelisting in der konkreten Form bei Adblock Plus ist nach alledem ein ordentlicher Kompromiss für alle Beteiligten.

629 https://allfacebook.de/toll/state-of-facebook, zuletzt abgerufen am 30.5.2019. 
Hingegen erscheint die Coalition for Better Ads mit ihrem weitaus wirtschaftsfreundlicheren Konkurrenzprogramm wie der Preußische Monarch, der dem untertänigen Volk durch stückweises Entgegenkommen und dem Aufoktroyieren einer obrigkeitsfreundlichen Verfassung das Gefühl gibt, dem Zeitgeist zu entsprechen ${ }^{630}$. Berechtigt ist die Kritik an diesem Programm vor allem aus einem Grund. So stellt es eine bedenkliche Machtdemonstration von Google dar, wenn Nutzer des Browsers ohne eigenen Antrieb zu Werbeblockern werden. Dies erscheint im Vergleich zum oft stark kritisierten Standardeinstellungsmodell von Adblock Plus sogar noch gravierender. Wird bei Adblock Plus zumindest der Grundentschluss pro Werbeblocken gefordert, sieht Chrome nur noch einen Opt-out vor.

Als positiv ist hingegen zu bewerten, dass gewissen Werbeformen praktisch der Garaus gemacht wurde. Auch wenn es mehr eine Selbstregulierung der mächtigen Marktteilnehmer darstellt, handelt es sich aus Nutzersicht um Fortschritt. Die Kritik an fehlender Datenschutzfunktionalität des Chrome-Blockers ist hingegen verfehlt, weil der Browser dafür sonstige isoliert steuerbare Einstellungen vorhält, was zuletzt auch durch den neuen europäischen Rechtsrahmen erforderlich ist.

Schlussendlich beackert die Koalition aber nicht das geblockte Netz, sondern widmet sich dem ungeblockten Netz. Durch das faktische Verbot einiger weniger Werbeformen wird das ungeblockte Netz aufgehübscht und flott gemacht, um den heute noch in ihm verweilenden Nutzer zu binden. Erstmals besteht also eine Art Konkurrenzsituation zwischen dem Internet, wie es Werbeblockeranbieter geschaffen haben, und dem Internet, das dem Wechselspiel des Marktes frei ausgesetzt ist. Diese Konkurrenz, die für die Werbenden enorme wirtschaftliche Bedeutung hat, kann schlussendlich also dem Nutzer eher nutzen, denn schaden.

(iv) Exkurs: Vergleich der Verbotskataloge mit dem in dieser Arbeit gefundenen Ergebnis zur unzumutbaren Belästigung von Werbeformen

Die beiden vorgenannten Werberegelwerke der Acceptable Ads Initiative und der Coalition for Better Ads nennen konkret Werbeformen, die die Verantwortlichen aus dem Web tilgen wollen. Beide Regelwerke berufen

630 Vgl. zum geschichtlichen Hintergrund im 19. Jahrhundert https://de.wikipedi a.org/wiki/Preu\%C3\%9Fische_Verfassung_(1848/1850), zuletzt abgerufen am 30.5.2019. 
sich dabei auf die sich unterscheidende Nutzerakzeptanz bei diversen Werbeformen. Die weiter oben vorgenommene Prüfung verschiedener Werbeformen auf ihre Konformität mit $\$ 7$ UWG hat hingegen einen anderen Maßstab. Dabei kommt es auf eine unzumutbare Belästigung an. Schon rein semantisch ist die fehlende Akzeptanz eine erheblich geringere Eskalationsstufe als die gesetzlich verbotene unzumutbare Belästigung. Es ist deshalb logisch, dass mehr Werbeformen die Schwelle zur fehlenden Akzeptanz überschreiten, denn jene zur unzumutbaren Belästigung. Im Jargon der deutschen Juristen betreffen die Verbotskataloge der WhitelistPfleger demnach Belästigungen, gleich ob diese (un-)zumutbar sind. Die Frage der Zumutbarkeit ist eine Rechtsfrage, die im Rahmen der gesetzlichen Zuständigkeiten durch einen Richter zu beurteilen ist.

Gleichwohl hat die aus dem Markt entwickelte Klassifizierung von Werbeformen als inakzeptabel erheblich schwerere praktische Folgen. Wie bereits aufgezeigt führte unter anderem der massenhafte Einsatz der als inakzeptabel identifizierten Werbeformen zum Erstarken von Werbeblockersoftware. Wenn die Betreiber von weit verbreiteten Werbeblockern dann aber nicht nur undifferenziert blocken, sondern über Whitelists die Tür zum Nutzer wieder einen Spalt weit öffnen, werden sinnigerweise nur solche Anzeigen erlaubt, die den Nutzer minimal invasiv begegnen. Würde die Whitelist hier auf den Maßstab der unzumutbaren Belästigung abstellen, hätte die Blockersoftware oder zumindest die Whitelist-Funktion keine Zukunft. Die Whitelist - ohne Bewertung einer etwaigen Kostenpflicht im Verhältnis der Whitelisting-Partner - ist demnach ein guter Kompromiss zwischen den Interessen den Nutzern und der werbenden Seite.

Vergleicht man nun die Whitelist-Kriterien von Eyeo und Google mit dem weiter oben ${ }^{631}$ gefundenen Ergebnis zur Unzumutbarkeit bestimmter Werbeformen, zeigen sich folgende Unterschiede:

- Klassische Anzeigen sind unter $\$ 7$ UWG als zulässig anzusehen, gleich wie viel Platz sie einnehmen. Wenn sie Content überdecken handelt es sich nicht mehr um eine klassische Anzeige, sondern um ein Pop-Up oder Interstitial und unterliegt anderen Abwägungsregeln. Denn wenn neben klassischen Anzeigen der Content in der üblichen Größe zur Verfügung steht, kann der Nutzer sich dem Content zuwenden und muss nicht aktiv werden, um Content aufzudecken. Die Whitelist-Kataloge sind hier strenger. Während die CBA eine zu hohe Werbedichte nur im mobilen Bereich ausschließt, sind die ursprünglichen Accepta-

631 S.o. Ziffer B. IV. 1. a), cc). 
ble Ads sehr streng und erlauben nur 15-25\% des sichtbaren Bereichs für Werbung.

- Ob innerhalb einer klassischen Anzeige, Elemente animiert bzw. besonders auffällig sind oder automatisch Audio- bzw. Videosequenzen starten, kann nach hier vertretener Ansicht nicht zu einer unzumutbaren Belästigung im Sinne von $\$ 7$ UWG führen. Die Whitelist-Kataloge sind hier hingegen sehr streng. Die nicht zu verleugnende und von einer nicht unerheblichen Anzahl von Nutzern empfundene Überraschungswirkung solcher Anzeigen genügt den jeweiligen WhitelistPflegern, um sie als inakzeptabel zu klassifizieren. Die Acceptable Ads Kriterien sind hier wiederum rigoroser als die Kriterien der CBA, weil bei ersteren schon der exzessive Gebrauch von Farben oder der Einsatz von Rich Media ausreicht, um auf dem „Index“ zu landen.

- Pop-Ups sind bei beiden Whitelist-Katalogen strikt ausgeschlossen. Unter dem Regime von $\$ 7$ UWG sind sie nicht generell verboten, sondern nur, wenn sie nicht sofort geschlossen werden können. Für Pre- und Interstitials als Anzeige gilt dasselbe.

- Bei Pre-Roll-Werbung stellt sich die Sachlage ähnlich wie bei klassischen Anzeigen dar. Eyeo verbietet sie strikt, die CBA erlauben sie jedoch. Von einer unzumutbaren Belästigung im Sinne von $\$ 7$ UWG kann nur dann in Betracht kommen, wenn die Pre-Roll-Werbung einen Nutzer mehr als fünf Sekunden zwangsweise festhält und danach keine Möglichkeit zum Überspringen bietet ${ }^{632}$. In diesem Fall sind erstaunlicherweise die CBA die liberalste Regelung und würden Werbung erlauben, wo der Nutzer unter Umständen ein Abwehrrecht aus dem Gesetz hat.

Zusammenfassend lässt sich feststellen, dass die aus dem Werbeblockermarkt stammenden Acceptable Ads Kriterien, die maßgeblich aus dem Bereich technikaffiner Personen herrühren, die strengste Regelung darstellen. Die Kriterien der CBA, die aus dem Lager der Werbewirtschaft stammt, sind in vielen Bereichen offener und verbieten weniger Werbeformen. Nicht unerwartet ist das Gesetz der am wenigesten strenge Maßstab. Dies gilt nur in einer bestimmten Ausnahme nicht, nämlich bei Pre-Roll-Werbung. Hier sind potentiell als unzumutbare Belästigung anzusehene Werbungen Teil der zugelassenen Werbeformen.

632 Vgl. LG Berlin, Urteil vom 14.9.2010 - 103 O 43/10, GRUR-RR 2011, 332. 
c) Browser mit integrierten Adblockern

Neben dem oben bereits dargestellten Werbefilter in Google Chrome haben auch andere Browser integrierte Werbeblocker. Dies zeigt sich überwiegend im nicht europäischen Ausland und im mobilen Bereich.

Das Konzept der Browser mit integrierten Adblockern ist schlicht. Die Werbeblockerfunktion ist eine von vielen vorprogrammierten Einstellungen und eine zusätzliche Installation einer Erweiterung ist nicht erforderlich. Die Angebote unterscheiden sich im Außenauftritt danach, ob sich der Browser hauptsächlich über die Adblock-Funktion definiert, so etwa beim Adblock Browser der Eyeo $\mathrm{GmbH}^{633}$, oder aber diese Funktion nur ein Charakteristikum von mehreren ist, so etwa beim Opera Browser ${ }^{634}$. Ein Beispiel für einen ausgesprochen erfolgreichen Browser mit integriertem Werbeblocker ist der UC Browser, der zum chinesischen Internetgiganten Alibaba Group gehört. Dieser Browser ist vor allem auf Mobilgeräten in China, Indien, Vietnam, Russland und Indonesien stark verbreitet, im Jahr 2016 errechnet PageFair alleine auf diesen Märkten insgesamt 237,8 Mio. Nutzer von Adblocker-Browsern. In Nordamerika und Westeuropa hingegen war die Verbreitung solcher Browser zu diesem Zeitpunkt mit unter $2 \%$ jedoch sehr gering 635 .

Zum Teil sind diese Browser bereits auf dem Gerät vorinstalliert. Dies ist insbesondere bei Smartphones der Fall, die das Android Betriebssystem haben. Hier ist in der Regel Google Chrome vorinstalliert. Schon länger sehen andere Hersteller wie etwa ASUS in den vorinstallierten Browsern integrierte Werbeblocker vor ${ }^{636}$. Abgesehen davon wird aber in der Regel ein aktiver Download durch den Nutzer erforderlich sein, bei dem eine etwaig vorhandene Werbeblockerfunktion des Browsers Entscheidungskriterium sein kann.

633 https://adblockbrowser.org/de/, zuletzt abgerufen am 30.5.2019.

$634 \mathrm{https}: / / \mathrm{www}$. opera.com/de/computer/features/ad-blocker, zuletzt abgerufen am 30.5.2019.

635 https://pagefair.com/downloads/2016/05/Adblocking-Goes-Mobile.pdf, zuletzt abgerufen am 30.5.2019.

636 https:/www.heise.de/newsticker/meldung/Asus-Android-Browser-mit-vorinstalli ertem-AdBlock-Plus-3056167.html, zuletzt abgerufen am 30.5.2019. 
d) Software und Einstellungen mit (beiläufiger) Blockierfunktion

Neben den Werbeblockerprogrammen, deren Hauptzweck in der Verhinderung bzw. differenzierten Filterung von Display-Werbung liegt, gibt es auch andere Möglichkeiten Werbeelemente faktisch zu blockieren. Nachfolgend werden drei Beispiele vorgestellt, die stellvertretend für drei Möglichkeiten stehen sollen, mit denen die Anzeige von Werbeelementen im Browser des Nutzers beschränkt werden kann. Dabei handelt es sich zum einen um Browsererweiterungen, die eigentlich einen anderen Zweck haben, als Werbung zu blocken. Weiter sehen manche Browser besondere Anzeigenmodi vor, um Werbung auszublenden. Zuletzt kann auch das Betriebssystem des Nutzer-PCs dahingehend eingestellt werden, dass von bestimmten Quellen keine Daten heruntergeladen werden.

Im ersten Komplex sind hauptsächlich Tracking- oder Scriptblocker gemeint. Dies sind ebenso wie Werbeblocker Browsererweiterungen, die vom Nutzer aktiv installiert werden müssen. Ähnlich wie Werbeblocker modifizieren auch diese Erweiterungen die Kommunikation zwischen Clientrechner und Server und zwar mit dem Hauptzweck, keine Trackingskripte ablaufen zu lassen und Fingerprinting zu vermeiden ${ }^{637}$. Entsprechende Angebote sind unter anderem Ghostery, No Script für Firefox, Disconnect oder Scriptsafe. Auch die meisten Werbeblocker wie Adblock Plus und uBlock origin bieten Trackingschutz. Praktisch bestehen erhebliche Überschneidungen zwischen Tracking- und Werbeblockern. So bietet Ghostery auch eine Funktion zum Blocken von Anzeigen an.

Wird bei einem Trackingblocker allerdings eine etwaig vorhandene Werbeblockerfunktion ausgeschaltet oder ist diese gar nicht vorhanden, kann es trotzdem dazu kommen, dass Werbeelemente blockiert werden. Dies beruht auf der starken Verknüpfung von Werbung mit den genutzten Trackingmethoden. Teils führt die Blockade des zugrunde liegenden Trackingvorgangs dazu, dass ebenfalls der Download des Werbeelements unterbleibt. Diese Verknüpfung von Tracking und Werbung macht aus Werbesicht viel Sinn, denn der Trackingblocker verhindert regelmäßig die Zählung des Abrufs, der aber für die Abrechnung wichtig ist. Während ein reiner Werbeblocker bei Ausfilterung den Download verhindert und damit weder eine Anzeige noch eine zählbare Abrechnung erlaubt, kann es bei reinen Trackingblockern zu einem noch unerwünschteren Ergebnis kommen. Die Werbung wird ausgeliefert, aber jegliches abrechnungsrele-

637 Vgl. etwa https://www.ghostery.com/de/blog/ghostery-news/cookies-fingerprinti ng-co-tracking-methods-clearly-explained/, zuletzt abgerufen am 30.5.2019. 
vante Tracking wird unterbunden. Der Webseitenbetreiber bzw. das Werbenetzwerk „arbeitet“ sozusagen umsonst. Für den Werbekunden ist diese Gestaltung vorteilhaft. Für Nutzer, die nichts gegen die Anzeige von Werbung, sehr wohl aber gegen die unsichtbaren Trackingvorgänge haben, ist diese Ausgestaltung ebenfalls hinnehmbar.

Für die zweite Gruppe lässt sich als Beispiel der „Reading Modus“ im mobilen Safari-Browser von Apple nennen. Dieser sorgt dafür, dass bei Webseiten nur noch der Textinhalt angezeigt wird, dieser aber dann optimiert für den kleinen iPhone-Bildschirm.

Der Reading Modus ist technisch eine anders gerenderte Ansicht einer Webseite. Er wirkt technisch also gleich wie das „Element Hiding“ bei Adblock Plus. Der wesentliche Unterschied zu den Werbeblockern liegt aber darin, dass kein Download der Werbeelemente unterbunden wird. Das HTML-Dokument wird insgesamt abgearbeitet und dann in zwei verschiedenen Möglichkeiten gerendert. Dies führt zu dem Ergebnis, dass der abrechnungsrelevante Download des Werbeelements erfolgt und getrackt werden kann. Ob das Element schlussendlich angezeigt wird oder lediglich im Verborgenen bleibt ist für die Abrechnung egal. Die Webseitenbetreiber und Werbenetzwerke kann diese Option freudig stimmen, für die Werbetreibenden ist dieser Modus hingegen ungünstig. Sie zahlen für nicht wahrgenommene Werbung. Der Nutzer muss in diesem Modus auch die Bandbreite bzw. das Datenvolumen für den Download der Werbeelemente aufbringen. Der Reading Modus ist für ihn lediglich eine optische Verbesserung.

Zuletzt ist auch ohne jegliche Zusatzsoftware oder besondere Funktion Werbeblocken möglich. Dafür müssen Einstellungen an der Host-Datei im Betriebssystem, etwa Windows, vorgenommen werden. In der Host-Datei kann explizit festgelegt werden, welcher Domainname auf welche IPAdresse im Netz zugreift. Es hat also denselben Zweck wie der DNS-Server und stellt sozusagen ein eigenes Adressbuch des Nutzer-PCs dar. Als der DNS-Service im Internet noch nicht verbreitet war, wurde die Auflösung der Internetadressen standardmäßig von der Host-Datei erledigt. Diese Datei arbeitet, im Gegensatz zum Domain Name System, nicht von einem Server aus, sondern liegt lokal auf jedem Computer. Diese Host-Datei kann der Nutzer bei ausreichenden Computerkenntnissen selbst modifizieren, indem er bestimmte IP-Adressen sowie die dazugehörigen Domainnamen in Textform listet und damit die Kommunikation mit dem entsprechenden Server unterbindet. Der Client sucht im Ergebnis die Webseite bzw. das bestimmte Element an einer Stelle, wo sie nicht hinterlegt ist. Logischerweise führt dies zur nicht ausführbaren Kommunikation, sprich 
die Webseite oder ein einzelnes Element wird nicht geladen. Entsprechende Host-Dateien sind schon für das Werbeblocken fertig gelistet im Internet verfügbar und können sozusagen als Blacklist genutzt werden ${ }^{638}$. In diesem Fall wird schlicht das Betriebssystem als Werbeblocker genutzt. Im Gegensatz zu spezieller Werbeblockersoftware wirkt die Blockade über Host-Dateien dann undifferenziert in allen Browsern, weil sich alle Browser an die hierarchisch höher stehende Host-Datei halten. Nicht erfasst ist jedoch das Rendering im Browser, sodass bei dieser Alternative sichtbare Lücken bleiben. Gleichsam ist die Blockade über die Host-Datei für puristische Nutzer eine Möglichkeit selbst Adblockersperren oder Ersatzmeldungen an Stelle der ausgefilterten Werbung zu verhindern.

Zuletzt kann eine Blacklist auch auf heimischen Netzwerkroutern hinterlegt werden. In diesem Fall wird sogar der Router als Werbeblocker genutzt. Einige heimische Netzwerkrouter, etwa eine Fritzbox, sehen die Anlage einer Blacklist durch Einfügung von Domainnamen vor. Somit kann ein Heimnetzwerk bereits am Knotenpunkt zum Internet vor Werbung und Tracking abgeschirmt werden ${ }^{639}$.

Dies alles zeigt, dass die Komplexität der Internetkommunikation an vielen Stellen die Möglichkeit bietet, Werbung zu blockieren. Dies hat vor allem dann eine Bedeutung, wenn über die Reichweite der bislang ergangenen Entscheidungen oder ein mögliches gesetzliches Verbot von Werbeblockern diskutiert wird. Die konkrete Ausgestaltung von Adblock Plus stellt also nur eine - sehr elaborierte - Lösung zur Werbeblockade dar. Der Themenkomplex betrifft hingegen noch sehr viele andere Ausgestaltungen, die ebenfalls bedacht werden müssen.

\section{e) Abweichende Formen von Internetwerbeblockern}

Abschließend soll noch auf gänzlich andere Internetwerbeblocker eingegangen werden. Die vorstehend behandelten weit verbreiten Werbeblocker beruhen allesamt auf Filterlisten, die in den Browserablauf integriert werden. Es sind allerdings auch andere Formen von zweckmäßigen Werbeblockern zu beobachten. So kann einerseits bereits auf Infrastrukturebe-

638 https://blog.botfrei.de/2013/02/wie-kann-ich-bose-webseiten-blockieren/ und http://www.pcgameshardware.de/Internet-Thema-34041/Tipps/Webseiten-mit-d er-Hosts-Datei-sperren-1077336/, zuletzt abgerufen am 30.5.2019.

639 http://cpu.de/werbung-blocken-im-ganzen-netzwerk-anleitung-am-beispiel-der-fr itzbox, zuletzt abgerufen am 25.4.2018. 
ne durch die Netzbetreiber bzw. Service Provider Werbeblockade betrieben werden. Andererseits lässt sich beobachten, dass auch Werbeblocker ohne Filterlisten auskommen können, wenn sie anhand besonderer Stichworte Werbung erkennen und ausblenden können.

Eine Lösung zur Werbeblockade auf Netzwerkebene wurde zwischen 2015 und 2017 unter dem Namen „Shine“ angeboten. Adressat waren hier nicht die Endnutzer, sondern die Netzwerkbetreiber von mobilen Netzen, etwa Unternehmen wie die deutsche Telekom. Das potentielle Interesse solcher Unternehmen an Werbeblockade ließe sich vor dem Hintergrund erklären, dass viele Unternehmen enorme Umsätze mit Werbung über das Internet erzielen, die Inhaber der grundlegenden Infrastruktur davon aber keinen Anteil erhalten. Mit der Werbeblockade wäre ein wirtschaftlicher Hebel der Netzwerkbetreiber vorhanden und eine monetäre Beteiligung an den Umsätzen durchsetzbar. Mit so durchgesetzten Zahlungen hätte ein Teil der Investitionen in neue Infrastruktur wie etwa für die 5G-Technologie refinanziert werden können ${ }^{640}$. Probleme hatte dieser Ansatz jedoch vor allem mit dem Prinzip der Netzneutralität ${ }^{641}$. Auch würde bei der Blockade auf Netzwerkebene aus technischer Sicht das gegen Adblock Plus vorgebrachte Argument der Wegelagerei und Schutzgelderpressung zutreffen. Die rechtliche Bewertung zu Filterwerbeblockern ist also nicht ohne weiteres übertragbar. Dies führte wohl dazu, dass mit Ausnahme eines jamaikanischen Netzbetreibers kein einziger Kunde von Shine öffentlich bekannt wurde. Im Jahr 2017 benannte sich Shine dann in „Rainbow" um und verfolgte fortan ein neues Geschäftsmodell. Weiterhin auf Netzwerkebene unterwegs soll nunmehr eine differenzierte Blockade a la kommerzielles Whitelisting zum Erfolg verhelfen. Filter auf Netzwerkebene sollen dann nur überwunden werden, wenn die Webseitenbetreiber sich kostenlos bei Rainbow zertifizieren lassen ${ }^{642}$. Als Kriterien werden die LEAN-Richtlinien des IAB herangezogen ${ }^{643}$. Ob dieses Konzept vor den weiterhin fortbestehenden Bedenken Erfolg haben wird, ist eher unwahrscheinlich.

Ein anderes Konzept verfolgt eine browserbasierte Werbeblocker-Technologie, die allerdings noch nicht als Werbeblocker-Software in Konkur-

640 https://omr.com/de/shine-adblocker-interview/, zuletzt abgerufen am 30.5.2019.

641 https:/www.bvdw.org/der-bvdw/news/detail/artikel/bvdw-stellungnahme-netzn eutralitaet-sichert-freien-informationszugang-3/, zuletzt abgerufen am 30.5.2019.

642 https://www.heise.de/newsticker/meldung/Adblocker-Shine-Vom-Werbefeind-z um-Werbefreund-3634344.html, zuletzt abgerufen am 30.5.2019.

643 Vgl. https://www.iab.com/iab-tech-lab-solutions/, zuletzt abgerufen am 30.5.2019. 
renz zu den durchgesetzten Anbietern tritt. Verfügbar ist hingegen bislang nur eine Browsererweiterung, die deutlich macht, was alles geblockt werden könnte ${ }^{644}$. Diese Technologie, die von Informatikern der Universitäten Princeton und Stanford entwickelt worden ist, basiert auf einer stichwortbasierten Aufspürung von Werbeelementen. Dies macht sich die gesetzlichen Vorschriften zum Transparenzgebot zu Nutze. Verfügt eine Anzeige über die zwingend vorgesehene Kennzeichnung mit Worten wie „Anzeige“, „gesponsert“ oder „Ad“ erkennt die Software dies und kann eine Blockade herbeiführen. Diese Lösung ist nicht auf pflegebedürftige Listen angewiesen und kann auch nicht durch technische Schutzmaßnahmen der Webseitenbetreiber wie den ständigen Wechsel von URLs der Werbeelemente oder Anti-Adblocksoftware beeinträchtigt werden. Hinzu kommt, dass zur Ausschaltung von Anti-Adblockern Skripten in die Software implementiert wurden, die die Aufspürung durch Adblock-Detektoren verhindern. Dadurch soll diese Lösung „unblockbar“ sein ${ }^{645}$.

Nach dem aktuellen Stand dieser Technologie wird die Werbung zunächst komplett geladen und dann in Sekundenbruchteilen als Anzeige gekennzeichnet. Es erfolgt also grundsätzlich ein Download des Elements. Demnach beeinträchtigt diese Technik nicht die abrechnungsrelevanten Downloads, was zum Nachteil der Werbenden ginge, die für den erfolgten Download zahlen müssten. Für die Nutzer negativ ist, dass durch den Download kein Anfall von Datenvolumen und kein Tracking verhindert sowie kein Schutz vor etwaig verbundener Malware bewerkstelligt wird. „Perceptual Ad Blocking“ hat also nur visuelle Effekte und entspricht damit im Wesentlichen dem „Element Hiding“ in Adblock Plus. Es bleibt abzuwarten, ob diese Technologie weiter entwickelt und letztendlich „scharf gestellt" wird.

\section{Rechtliche Beurteilung in Rechtsprechung und Literatur}

Die juristische Literatur beschäftigen Internetwerbeblocker seit 2013, die ersten Gerichte wurden wenig später angerufen. Nachfolgend soll in

644 Siehe die Erweiterung für den Browser Chrome namens „Perceptual Ad Highlighter“, zuletzt im Chrome Store aufgesucht am 25.4.2018.

645 https://motherboard.vice.com/en_us/article/9a4yny/princetons-ad-blocking-su perweapon-may-put-an-end-to-the-ad-blocking-arms-race, zuletzt abgerufen am 30.5.2019. 
weitestgehend chronologischer Reihenfolge die rechtliche Auseinandersetzung mit dem Thema Internetwerbeblocker dargestellt werden.

\section{a) Erste Bewertungen in der Literatur}

Schon nach dem Urteil des BGH zum TV-Werbeblocker „Fernsehfee“ wurde auf die bereits damals existenten Internetwerbeblocker geblickt und ein Ausblick über die rechtliche Zulässigkeit gegeben. Die konkrete Ausgestaltung, vor allem mit Blick auf Whitelisting, wurde allerdings erst ab 2013 durch Beiträge renommierter Kommentatoren wie Hoeren und Köhler bewertet. An dieser Stelle werden die Stellungnahmen zur rechtlichen Zulässigkeit von Internetwerbeblockern vor Erscheinen der ersten Gerichtsurteile skizziert.

\section{aa) Ausblicke nach der Fernsehfee-Entscheidung des BGH}

Bereits nach der Entscheidung des BGH zur „Fernsehfee“, dem TV-Werbeblocker, im Jahr 2004 waren Stimmen im Schrifttum erkennbar, die auf Grundlage des Urteils auch eine Zulässigkeit von Internetwerbeblockern vorhersagten. Fritzsche wies insoweit auf die Bedeutung der Entscheidung weit über den konkreten Fall hin und nannte auch Werbeblocker-Programme für Internetbrowser als zulässiges Wettbewerbshandeln. Dies folgerte er daraus, dass wegen der Nutzerhoheit über das Ein- und Ausschalten sowie einzelner Konfigurationen der Werbeblocker die Möglichkeit einer individuellen Behinderung noch unwahrscheinlicher sei als bei der ferngesteuerten Wirksweise der Fernsehfee. Auch eine allgemeine Marktbehinderung sah er nicht, da bereits zur Zeit der Stellungnahme ein Trend hin zu immer mehr Internetwerbung zu beobachten war, den Werbeblocker nicht maßgeblich umdrehen konnten ${ }^{646}$. Kurz und knapp setzte auch Hoeren Internetwerbeblocker - in seinem Beitrag als „Webwasher" bezeichnet - auf dieselbe Stufe wie TV-Werbeblocker und hielt diese für zulässig ${ }^{647}$.

646 Fritzsche, LMK 2004, Heft 10, 192, 193f..

647 Hoeren, EWiR 2004, 1193, 1194. 
bb) Lauterkeitsrechtliche Beurteilung durch Hoeren

Der Aufsatz von Hoeren ${ }^{648}$ beruht auf einem Rechtsgutachten, welches für die Betreibergesellschaft von Adblock Plus erstellt wurde, bevor die Klageverfahren anhängig gemacht worden sind. Es stellt die erste veröffentlichte Beurteilung im deutschen juristischen Schrifttum dar. Inhaltlich beschränkt sich der Beitrag auf die lauterkeitsrechtliche Beurteilung einer gezielten Behinderung von Mitbewerbern nach $\$ 4$ Nr. 10 UWG a.F. im Verhältnis der Betreiber von Internetseiten und des Werbeblockers. Zur Frage des Vorliegens eines Wettbewerbsverhältnisses zwischen diesen beiden Parteien kommt Hoeren unter Rückgriff auf die TV-Werbeblocker Entscheidung des BGH zu einem klaren Ergebnis - da keine hohen Anforderungen zu stellen sind, liege regelmäßig, so auch hier, ein konkretes Wettbewerbsverhältnis vor.

Im Rahmen der Prüfung einer gezielten Behinderung wird zunächst eine produktbezogene Behinderung geprüft bevor auf die Fallgruppe der Werbebehinderung eingegangen wird. Eine produktbezogene Beeinträchtigung in unmittelbarer Hinsicht liege schon deshalb nicht vor, weil die Werbeblocker-Software nicht in die Webseite an sich eingreife, sondern lediglich den Download der Werbeelemente unterbinde. Dies geschehe auf Wunsch des Nutzers, der die Software installiert habe. Eine mittelbare produktbezogene Behinderung scheide ebenfalls aus, weil kein wettbewerbsfremdes Mittel eingesetzt werde. Das Angebot der eigenen Software sei ein wettbewerbsimmanentes Verhalten. Daran ändere auch die besondere Finanzierung durch das Whitelisting nichts.

Die in der Rechtsprechung anerkannte Fallgruppe der Werbebehinderung hält Hoeren ebenfalls nicht für einschlägig. Dabei wird unterschieden zwischen einem absoluten Werbeblocker (hier als reiner Blacklist-Blocker bezeichnet) und dem differenzierenden Whitelist-Blocker. Die reine Blacklist-Blockersoftware sei dabei keine Werbebehinderung, weil die Entfernung der Werbung aus der Wahrnehmung des Internetnutzers gerade auf dessen willentlichen Entschluss fußt, den Werbeblocker zu installieren und zu benutzen. Im Rahmen des differenzierenden Werbeblockers stelle sich die Frage, ob der Nutzer immer noch die Entscheidungshoheit habe. Aufgrund der verschiedenen Wahlmöglichkeiten der Nutzer innerhalb von Adblock Plus sei dies nach Hoeren immer noch der Fall, womit auch diese Form des Werbeblockers keine unlautere Werbebehinde-rung darstelle.

648 Hoeren, K\&R 2013, 757. 
Im Weiteren werden noch eine Irreführung nach $\iint 5$ Abs. 1 S. 2 Nr. 1, 5a Abs. 2 UWG und eine allgemeine Marktbehinderung als Ausprägung der Generalklausel in $\$ 3$ UWG a.F. geprüf, jedoch im Ergebnis ebenfalls abgelehnt. Es liege nämlich ausreichende Information über die Funktionsweise der Software vor. Auch eine spürbare Auswirkung auf den Werbemarkt sei anhand der positiven finanziellen Ergebnisse der Internetwerbebranche nicht zu erkennen.

cc) Lauterkeits- und kartellrechtliche Beurteilung durch Köhler

Der Aufsatz von Köhler ${ }^{649}$ ebnete sodann den Weg zu den ersten Gerichtsentscheidungen $\mathrm{zu}$ den Internetwerbeblockern. In rechtlicher Hinsicht differenziert er Werbeblocker mit Filterfunktionalität, die eine kostenlose Freischaltung anbieten, und solche, die die Freischaltung von einem Entgelt abhängig machen.

Bei der erstgenannten Alternative, also einer kostenlosen Freischaltung, kommt Köhler zu dem Ergebnis, dass eine Rechtsverletzung auf Grundlage des UWG schon am Fehlen einer geschäftlichen Handlung scheitere. Im Übrigen sollen auch keine Verstöße gegen Urheberrecht, bürgerliches Deliktsrecht (v.a. \$S 823, 826 BGB) oder Kartellrecht bestehen.

Anders stelle sich die Rechtslage jedoch bei der entgeltlichen Freischaltung dar, wie sie etwa bei Adblock Plus eingesetzt wird. Hier nahm Köhler das Vorliegen einer geschäftlichen Handlung an. Dies jedoch mit der Einschränkung, dass die geschäftliche Handlung gegenüber sonstigen Marktteilnehmern erfolge. Eine geschäftliche Handlung gegen Mitbewerber liege nicht vor, weil kein konkretes Wettbewerbsverhältnis zwischen den Betreibern von Webseiten und Werbeblocker bestehe. Dies folge daraus, dass weder ein Substitutions- noch ein Behinderungswettbewerb vorliege. Vielmehr gehe es dem Betreiber des Werbeblockers mit dem Angebot der Freischaltung um die Ermöglichung des Absatzes einer bestimmten Werbedienstleistung. Webseitenbetreiber sind Nachfrager dieser besonderen Werbedienstleistung. Daran ändere auch nichts, dass der Bedarf durch eine vorherige Blockade erst geschaffen werde.

Mangels Vorliegens eines konkreten Wettbewerbsverhältnisses ist nach Auffassung Köhlers bereits zwangsläufig kein Raum für die Prüfung einer gezielten Behinderung im Sinne von $₫ 4$ Nr. 4 UWG n.F. Gleichwohl vertritt Köhler die Auffassung, dass eine gezielte Behinderung schon allein

649 WRP 2014, 1017. 
aufgrund fehlender technischer Schutzmaßnahmen durch die Webseitenbetreiber ausscheiden müsse. Eine Interessenabwägung gehe zu Lasten der Webseitenbetreiber. Sie seien zudem bei Möglichkeit der Freischaltung besser gestellt als bei (zulässiger) vollständiger Blockade ohne Freischaltungsoption.

Ein Verstoß gegen $₫ 4$ Nr. 1 UWG a.F. (nunmehr $\ 4$ a Abs. 1 UWG n.F.) scheide wegen des Vorrangs des Kartellrechts aus. Für eine Irreführung sah Köhler keine Hinweise. Ebenso wenig liege ein Verstoß gegen allgemeines bürgerliches Recht vor.

Bei seiner kartellrechtlichen Würdigung vertritt Köhler, dass zur Marktabgrenzung im Rahmen der Ermittlung einer marktbeherrschenden Stellung auf alle Internetnutzer abgestellt werden müsse, die von Werbung angesprochen werden können. Also sei ein Abstellen allein auf den Markt der Werbeblocker fehlerhaft. Einen Missbrauch einer etwaig bestehenden marktbeherrschenden Stellung gemäß $₫ 20$ Abs. 1 S. 1 GWB hält Köhler für denkbar, je nachdem wie die Tatsachenfeststellungen im Einzelfall ausfallen.

dd) Lauterkeitsrechtliche Beurteilung durch Herrmann und Lauotoumai

Ebenfalls vor einer ersten Entscheidung durch die Instanzgerichte haben sich Herrmann und Lauotoumai 650 mit dem Problem der Internetwerbeblocker beschäftigt. Ihr Beitrag fokussiert sich auf die Darlegung der Interessen der Beteiligten, welche im Rahmen einer Abwägung bei $\$ 4$ Nr. 10 UWG a.F. bzw. $\$ 4$ Nr. 4 UWG n.F. zu ermitteln und zu gewichten sind. Dabei werden die allgemeinen Nutzerinteressen besonders hervorgehoben. Dazu gehöre zuvörderst das Interesse, beim Internetkonsum nicht durch störende Werbung beeinträchtigt zu werden. Hinzu komme noch das Interesse an der Sicherung des eigenen Computers vor mit Werbung ggf. einhergehender Schadsoftware und das Interesse an einer Kontrolle des kindlichen Internetkonsums. Gerade Kinder, die noch nicht über eine ausgeprägte Erfahrung beim Surfen im Internet und mit den Aufmerksamkeit erhaschenden Werbeformen haben, könnten bei Nutzung eines Werbeblockers behutsam an die verantwortliche Mediennutzung herangeführt werden. Im Ergebnis halten die Autoren diese Interessen auch für höherwertig gegenüber den Interessen von Webseitenbetreibern und Werbetreibenden. Hauptargument ist dabei die selbständige Entscheidung der

650 IPRB 2014, 272. 
Nutzer pro Werbeblocker. Eine gezielte Behinderung scheide demnach aus.

In einer eher oberflächlichen Auseinandersetzung mit $\$ 4$ Nr. 1 UWG a.F. kommen die Autoren zudem zum Ergebnis, dass keine unangemessene unsachliche Beeinflussung der Nutzer festzustellen sei.

b) Rechtsprechung und Literatur bis zum Urteil des OLG Köln

Nach diesen ersten Stimmen im Schriftum, die - vorbehaltlich kartellrechtlicher Marktmacht - die Konformität mit geltendem Recht befürworteten, ergingen zwischen April 2015 und Mai 2016 mehrere erstinstanzliche Urteile. Die Urteile betrafen zum Teil die konkrete Verletzungsform durch Adblock Plus, zum Teil aber auch andere Blockersoftware. Die Entscheidungen, ob das jeweilige Angebot erlaubt sei oder aber durch einen Unterlassungsanspruch verhindert werden könne, variierten im Ergebnis. In der gebotenen Kürze sollen deshalb die ergangenen Entscheidungen kurz nach betroffenem Werbeblockerangebot und maßgeblicher rechtlicher Begründung beschrieben werden. Sodann erfolgt eine zusammenfassende Darstellung der in den Urteilen angeführten Interessen, die bei den im Ergebnis entscheidenden Abwägungen angeführt worden sind. Im Anschluss erfolgt eine Darstellung der Stimmen in der Literatur in dem vorgenannten Zeitraum.

\section{aa) Erstinstanzliche Entscheidungen}

Das erste veröffentlichte Urteil erging im April 2015 durch das LG Hamburg ${ }^{651}$ und betraf ein Verfahren zwischen den Betreibern von Zeit Online sowie der Onlinepräsenz des Handelsblatts als Kläger und Eyeo mit ihrem

651 Urteil vom 21.4.2015, 416 HKO 159/14, CR 2016, 122; noch vor diesem Urteil war ein anderer Spruchkörper des LG Hamburg bereits in einem einstweiligen Verfügungsverfahren (Az. 312 O 341/13) mit dem Streitgegenstand befasst, als die ProSieben Sat1 Media Gruppe versuchte im Eilrechtsschutz Adblock Plus untersagen zu lassen. Nach geäußerten Bedenken in der mündlichen Verhandlung nahm die Antragstellerin ihren Antrag jedoch zurück, vgl. https://www.cm shs-bloggt.de/cms/prosiebensat1-nimmt-verfuegungsantrag-gegen-adblock-plus-z urueck/, zuletzt abgerufen am 30.5.2019. 
Angebot Adblock Plus als Beklagte ${ }^{652}$. Der Streitgegenstand umfasste im Hauptantrag das abstrakte Verbot eines reinen Blacklist-Blockers, war also auf das generelle Verbot von Adblocken im Internet gerichtet. Im Hilfsantrag war die Klage in abstrakter Weise darauf gerichtet, dass das Gericht untersage, einen Werbeblocker mit Whitelist-Funktion anzubieten, die mit einer kostenpflichtigen Aufnahme auf die Whitelist verknüptt ist. Die Klage wurde in beiden Anträgen abgewiesen. In diesem Verfahren wurden alleine Vorschriften des UWG geprüft. Den Hauptantrag lehnte die befasste Kammer für Handelssachen am LG Hamburg dabei bereits mit dem Argument ab, es liege keine geschäftliche Handlung gem. $\$ 2$ Abs. 1 Nr. 1 UWG vor, weil die Software Adblock Plus unentgeltlich zur Verfügung gestellt werde. Im Hilfsantrag prüfte das Gericht eine gezielte Mitbewerberbehinderung nach $\$ 4 \mathrm{Nr}$. 10 UWG a.F., lehnte sie jedoch nach einer ausführlichen Interessenabwägung ab (siehe für die Einzelheiten nachfolgenden Abschnitt in lit. bb.). Die weiterhin geprüfte unlautere Beeinträchtigung der Kläger nach $\$ 4$ Nr. 1 UWG a.F. wurde unter Hinweis auf eine echte Wahlmöglichkeit der Webseitenbetreiber zwischen kostenpflichtiger Aufnahme in die Whitelist und anderen Optionen wie Errichtung einer Zugangssperre, einer Paywall oder technischer Schutzmaßnahmen abgelehnt. Die zuletzt angeprüfte allgemeine Marktbehinderung wurde mangels tatsächlicher Hinweise auf die Gefahr des Ausscheidens der Kläger aus dem Markt abgelehnt.

Etwa einen Monat später im Mai 2015 folgte ein Doppelschlag durch das LG München I, das in zwei Verfahren urteilte ${ }^{653}$. In beiden Verfahren war die Beklagte die Eyeo GmbH als Betreiberin von Adblock Plus. Kläger waren in einem Verfahren ein Unternehmen der ProSieben Sat1 Media Gruppe, im anderen Verfahren ein Unternehmen aus der RTL Mediengruppe $^{654}$. Während die Streitgegenstände durch Anknüpfung an die konkrete Verletzungsform der Software Adblock Plus gekennzeichnet war, unterschieden sich die Anträge, sodass teilweise verschiedene rechtliche Gesichtspunkte geprüft wurden. Allen verschiedenen Angriffspunkten zum Trotz wurden beide Klagen vollumfänglich abgewiesen. Beide Urteile waren durch eine Vielzahl von Haupt- und Hilfsanträgen gekennzeichnet, die

652 http://www.faz.net/aktuell/feuilleton/medien/gerichtsurteil-adblock-plus-weiter -erlaubt-13552676.html, zuletzt abgerufen am 30.5.2019.

653 Urteil vom 27.5.2015 - 37 O 11843/14, WRP 2015, 927; Urteil vom 27.5.2015 37 O 11673/14, MMR 2015, 660.

654 http://www.faz.net/aktuell/feuilleton/medien/adblock-plus-gewinnt-gegen-prosi ebensat-1-rtl-vor-gericht-13616367.html, zuletzt abgerufen am 30.5.2019. 
zu einem enormen Umfang geführt haben. Deshalb wird an dieser Stelle nur grob skizziert, womit sich die 37. Zivilkammer des LG München I befasst war. Im Verfahren mit dem Aktenzeichen 37 O 11673/14 waren sowohl Ansprüche aus dem UWG, dem allgemeinen Deliktsrecht, nach dem Urheberrechtsgesetz sowie aus dem Kartellrecht gegenständlich (siehe für die einzelnen Anspruchsgrundlagen die diesem Abschnitt angefügte tabellarische Auflistung). Das andere Verfahren mit dem Aktenzeichen 37 O 11843/14 betraf Ansprüche nach dem UWG, dem allgemeinen Deliktsrecht und dem Kartellrecht. Hierbei wurden sogar Anträge gestellt, die das Gericht zur Prüfung einer unzumutbaren Belästigung ( $\$ 7$ UWG) und einer Irreführung von Internetnutzern ( $\$ 5$ UWG) durch Adblock Plus veranlassten. Im Rahmen der lauterkeitsrechtlichen Ansprüche beruhten die Entscheidungen maßgeblich auf einer sehr umfassenden Interessenabwägung. Im Rahmen des Kartellrechts erkannte die Kammer weder eine marktbeherrschende Stellung von Adblock Plus noch eine wettbewerbsbeschränkende Vereinbarung durch die Whitelist-Vereinbarungen. Urheberrechtliche Ansprüche scheiterten am Fehlen einer Verletzung durch den Adblocker-Betreiber, die weder selbst unmittelbar noch als Gehilfe der Nutzer handelten, da die Nutzer ihrerseits keine Verletzungshandlung begingen.

Im September 2015 legte sodann das LG Köln ${ }^{655}$ sein Urteil im Rechtsstreit zwischen der Axel Springer Gruppe und Eyeo wegen Adblock Plus vor ${ }^{656}$. Dieses Urteil beschränkt sich wie bereits das erste Urteil aus Hamburg auf die Prüfung von Ansprüchen aus dem UWG. Bemerkenswert ist dieses Urteil vor allem aus zwei Gründen. Zunächst machte das Landgericht im Laufe des Verfahrens zunächst in einem Hinweisbeschluss deutlich, es wolle eine gezielte Behinderung nach $\$ 4$ Nr.10 UWG a.F. bejahen, weil die Whitelisting-Funktion für Webseitenbetreiber „keinen irgendwie gearteten Mehrwert" darstelle, sondern diese allein dafür zahlen sollten, dass sie sich weiterhin an Nutzer wenden könnten ${ }^{657}$. Im Urteil hingegen positionierte sich das Landgericht Köln anders und nahm in seinen Entscheidungsgründen schlicht Bezug auf die Entscheidungen des LG München. Ohne eigene ausformulierte Entscheidungsgründe wies es die Klage ab und zwar im Hauptantrag, der auf das Verbot von Adblock

655 Urteil vom 29.9.2015 - 33 O 132/14, MMR 2016, 264.

656 https://www.heise.de/newsticker/meldung/Adblock-Plus-gewinnt-vor-Landgeric ht-Koeln-gegen-Axel-Springer-2833813.html, zuletzt abgerufen am 30.5.2019.

657 So die Zitierung aus dem Hinweisbeschluss des LG Köln im Urteil des LG München I, Urteil vom 27.5.2015 - 37 O 11843/14, WRP 2015, 927. 
Plus insgesamt als Verbindung von Black- und Whitelist gerichtet war, sowie im Hilfsantrag, der nur auf ein Verbot des kostenpflichtigen Whitelist-Geschäftsmodells hinauslief.

Während Adblock Plus demnach in vier Verfahren unbesiegt geblieben ist, folgten in den Monaten November und Dezember 2015 insgesamt vier Verfahren gegen andere Werbeblocker mit teils anderem Ausgang. Den Beginn machte dabei eine Beschlussverfügung, die Axel Springer bzw. Welt.de beim LG Frankfurt a.M. erwirken konnte. Antragsgegnerin war die Betreiberin des Werbeblockers „AdShield“, die öffentlicher Berichterstattung zu Folge die einstweilige Verfügung hat rechtskräftig werden lassen und ihr Angebot sodann eingestellt hat ${ }^{658}$. Da Beschlussverfügungen wegen $\$ \$ \$ 936,922$ Abs. 1 S. 2 ZPO nicht begründet werden müssen ${ }^{659}$, liegt keine Begründung vor, sodass die rechtliche Würdigung des LG Frankfurt nicht überprüft werden kann. Die Software „AdShield“ ist jedenfalls nach hiesigen Recherchen nicht mehr in den jeweiligen Stores der gängigen Browser verfügbar.

In einem weiteren Verfahren beim LG Frankfurt erwirkte Axel Springer bzw. Welt.de am 26.11.2015 wiederum eine einstweilige Verfügung, dieses Mal gegen das Unternehmen Betafish wegen der Software „AdBlock“660, einem damaligen Konkurrenten von Adblock Plus, der ab Oktober 2015 ebenfalls nach den Acceptable Ads-Kriterein eine Whitelist-Funktion einführte. In dieser Angelegenheit ist ein knapp begründeter Beschluss veröffentlicht worden ${ }^{661}$. Demnach liege eine gezielte Behinderung des Webseitenbetreibers durch die Adblock-Software vor, was mit der gezielten Ausschaltung fremder Werbung begründet worden ist. In der Verhinderung des Anzeigens von Werbung, die zum medialen Gesamtprodukt eines Webportals gehöre, liege eine gezielte, unmittelbare Vereitelung der Werbung. Eine Interessenabwägung im Übrigen erfolgte nicht. Scheinbar wurde diese einstweilige Verfügung jedoch nie vollzogen oder der Antrag wurde seitens der Antragstellerin im weiteren Verlauf des Verfahrens zurückgenommen, weil der Werbeblocker AdBlock bis zum Abschluss dieser Arbeit noch verfügbar ist und auch im Übrigen nie von den Down-

658 LG Frankfurt a.M., Beschluss vom 26.11.2015 - 3-6 O 105/15, K\&R 2016, 134 sowie https://www.mobilegeeks.de/news/axelspringer-juristische-erfolge-gegen -werbeblocker/, zuletzt abgerufen am 30.5.2019.

659 Musielak/Voit, ZPO, $\$ 922$, Rn. 4.

660 LG Frankfurt a.M., Beschluss vom 26.11.2015 - 3-6 O 105/15, K\&R 2016, 134; https://www.heise.de/newsticker/meldung/Adblock-Plus-gewinnt-vor-Landgeric ht-Koeln-gegen-Axel-Springer-2833813.html, zuletzt abgerufen am 30.5.2019.

661 LG Frankfurt a.M., Beschluss vom 26.11.2015 - 3-6 O 105/15, K\&R 2016, 134. 
loadplattformen zurückgezogen worden ist. Auch ist weder ein Urteil durch das LG Frankfurt nach einem etwaigen Widerspruch gegen die Beschlussverfügung, noch ein Urteil in einem bei Vollziehung dann wohl unausweichlichen Hauptverfahren ergangen. Vor dem Hintergrund der weitaus ausführlicheren Urteile aus Hamburg und München konnte auch nur kaum davon ausgegangen werden, dass die knappe Begründung nach ausführlichem schriftsätzlichen Vortrag durch die Antragsgegnerin vom Gericht bestätigt worden wäre.

Kurze Zeit später wurde ein Urteil des LG Berlin in einem einstweiligen Verfügungsverfahren veröffentlicht, mit dem ein Unterlassungsanspruch gegen eine Adblocker-Software stattgegeben worden ist ${ }^{662}$. Als Parteien des Verfahrens war auf Aktivseite wiederum Axel Springer über Welt.de vertreten sowie auf Passivseite die Betreiber des „Adblock Browsers“663. Bei diesem Adblock-Browser handelte es sich laut Tatbestand des Urteils um einen für Apple Mobilgeräte verfügbaren Browser mit integriertem Werbeblocker, der zum Preis von 3,99€ im AppStore verfügbar war. Von einer Whitelist-Funktion berichtet der Tatbestand nicht, sodass es sich bei diesem Browser nicht um den gleichgenannten mobilen Browser der Adblock Plus Betreiberin Eyeo handelte. Auch das LG Berlin erkannte eine gezielte Behinderung nach $₫ 4$ Nr. 10 UWG a.F. durch die Software. Zur Begründung führte es aus, dass durch den Werbeblocker ein unmittelbarer Substanzeingriff in das Produkt des Webseitenbetreibers erfolge. Es führt zunächst aus, dass in der Verbindung von redaktionellem Inhalt und Werbeelementen eine tatsächliche und wirtschaftliche Einheit bestehe. Dies mag zwar technisch nicht der Fall sein, was aber vor dem wirtschaftlichen Hintergrund der Refinanzierung des kostenlosen Angebots durch Werbung zurückzutreten habe. Ein weiteres Argument war, dass der Nutzer anders als etwa beim TV-Werbeblocker „Fernsehfee“ - die Werbeblockade nicht durch eigene Handlungen ohne Weiteres bewerkstelligen könne. Die Programmierung eines Internetwerbeblockers, der einzelne Teile herausfiltert, sei etwas maßgeblich anderes als ein bloßes Umschalten am Fernseher. Deshalb sei eine Abweichung von der BGH-Entscheidung zum TV-Werbeblocker gerechtfertigt. Werbeblocker beschädigten nur fremde Produkte, ohne zugleich etwas Eigenes zu schaffen. Zumutbare Mittel, den Werbeblocker entgegen zu wirken, stünden dem Webseitenbetreiber ebenfalls nicht zur Verfügung. Dieses Judiz des LG Berlin stellt die einzige

662 LG Berlin, Urteil vom 8.12.2015 - 16 O 449/15, K\&R 2016, 360.

$663 \mathrm{http}: / /$ meedia.de/2015/12/15/doppelte-attacke-springers-zwei-fronten-strategie-i m-kampf-gegen-ad-blocker/, zuletzt abgerufen am 30.5.2019. 
ausführlich begründete Entscheidung zu Ungunsten eines Werbeblockerbetreibers dar. Berufung gegen dieses Urteil wurde nicht eingelegt. Ebenso wenig wurde ein Hauptsacheverfahren durchgeführt.

Wiederum nur wenige Tage später erging ein Urteil durch das LG Stuttgart in einem einstweiligen Verfügungsverfahren ${ }^{664}$. Antragstellerin war auch hier die Axel Springer Gruppe durch Welt.de, die in diesem Fall gegen die für mobile Apple-Geräte aufgelegte Werbeblocker-Software „Blockr" vorging ${ }^{665}$. Die Richter aus dem Südwesten der Bundesrepublik prüften eine gezielte Mitbewerberbehinderung nach $\$ 4$ Nr. 10 UWG a.F., lehnten diese jedoch nach einer Interessenabwägung ab. Wie bereits die Landgerichte in München und Hamburg stellte die Kammer aus Stuttgart auf die eigenständige Entscheidung des Nutzers zur Installation der Werbeblockersoftware ab. Eine Einheit des Angebots des Webseitenbetreibers konnte die Kammer vor dem technischen Hintergrund der Einspeisung von Werbeelementen durch Adserver ebenfalls nicht erkennen. Im Ergebnis gleicht dieses Urteil den Fällen, in welchen Adblock Plus Beklagte war. Axel Springer legte gegen diese Entscheidung zunächst Berufung ein, nahm diese aber nach Hinweis des OLG Stuttgart auf die fehlende Erfolgsaussicht der Berufung zurück ${ }^{666}$. Das Blatt, das sich durch die Entscheidungen aus Frankfurt und Berlin kurze Zeit in Richtung Verbot von Werbeblockern zu drehen schien, war nun wieder in der alten Position.

In den nächsten drei veröffentlichten Gerichtsentscheidungen divergierten erneut die Ansichten verschiedener Spruchkörper. So schlossen sich in den letzten beiden erstinstanzlichen Hauptsacheentscheidungen zu Internetwerbeblockern die Landgerichte München und Hamburg (allerdings jeweils durch andere Spruchkörper als in den oben genannten Urteilen) der herrschenden Rechtsprechung an. Ein dazwischen ergangenes Urteil des LG Hamburg im einstweiligen Verfügungsverfahren erkannte indes eine unlautere gezielte Behinderung.

Der Reihe nach: Im März 2016 legte das LG München I sein Urteil im Rechtsstreit zwischen der Süddeutschen Zeitung und Adblock Plus-Betrei-

664 LG Stuttgart, Urteil vom 10.12.2015 - 11 O 238/15, K\&R 2016, 362.

665 https://www.mobilegeeks.de/news/axelspringer-juristische-erfolge-gegen-werbeb locker/, zuletzt abgerufen am 30.5.2019.

666 http://www.heise.de/newsticker/meldung/Adblocker-Axel-Springer-zieht-Kla ge-gegen-Blockr-zurueck-3240983.html, zuletzt abgerufen am: 30.5.2019, der Verfügungsantrag wurde zurückgenommen. 
berin Eyeo vor ${ }^{667}$. Anders als in den ersten beiden Münchener Urteilen war in diesem Verfahren wiederum nur ein Unterlassungsanspruch aus dem UWG streitgegenständlich. Geprüft wurde eine gezielte Mitbewerberbehinderung nunmehr nach $\$ 4 \mathrm{Nr} .4$ UWG n.F. und eine allgemeine Marktbehinderung. Beide Aspekte wurden jedoch abgelehnt. Einen Fokus setzte die 33. Zivilkammer dabei auf den verfassungsrechtlichen Schutz der Webseitenbetreiber aus Art. 5 und 12 GG. Dieser rechtfertige aber keine überwiegende Schutzwürdigkeit der Webseitenbetreiber gegen Werbeblocker, die ein Verbot zu tragen vermag.

Im Mai 2016 erging durch die 8. Zivilkammer des LG Hamburg ein sehr ausführlich begründetes Urteil in einem einstweiligen Verfügungsverfahren der Axel Springer Gruppe gegen den für Apple Mobilgeräte im AppStore vertriebenen Werbeblocker „Admop“668. Bei Admop handelte es sich laut Tatbestand des Urteils um einen kostenpflichtigen Whitelist-Blocker, dessen Whitelist allerdings vom Nutzer erst proaktiv scharf gestellt werden musste. In diesem Verfahren stützte sich Axel Springer primär auf einen urheberrechtlichen Unterlassungsanspruch, welchem das LG Hamburg jedoch nicht stattgab. Stattdessen stelle das Angebot der Werbeblockersoftware eine gezielte Behinderung gemäß $₫ 4$ Nr. 4 UWG dar. Im urheberrechtlichen Teil erkannte die Kammer keinen Substanzeingriff in ein Computerprogramm, weshalb keine Umarbeitung im Sinne von $\$ 69 c$ Nr. 2 UrhG vorliege. Eine Teilnahme des Werbeblocker-Betreibers an einer unerlaubten Vervielfältigung des Computerprogramms der Webseitenbetreiber scheide aus, da Letztere die Vervielfältigung durch kosten- und einschränkungslose Zurverfügungstellung im Netz gestatten. Im Übrigen verneinte die Kammer die Schutzfähigkeit der konkreten Webseiten als Datenbank- oder Multimediawerk. Im lauterkeitsrechtlichen Teil hielt das LG Hamburg eine produktbezogene Absatzbehinderung für verwirklicht, was zu Unterlassungsansprüchen gemäß $\$ \$ 8,3,4$ Nr. 4 UWG führte. Es sah keinen Unterscheid zu physischen Presseprodukten und sprach Webseitenbetreibern eine „Verfügungsmacht“ über die bereitgestellten Werbeflächen zu. Als Anzeichen für die Unlauterkeit zog es zudem heran, dass auch Eigenwerbung der Webseitenbetreiber blockiert werde. Es bestehe

667 Urteil vom 22.3.2016 - 33 O 5017/15, MMR 2016, 406; https:/www.golem.de/n ews/adblock-plus-sueddeutsche-zeitung-verliert-klage-gegen-eyeo-1603-120031.ht $\mathrm{ml}$, zuletzt abgerufen am 30.5.2019.

668 Urteil vom 3.5.2016 - 308 O 46/16, CR 2016, 782; https://www.heise.de/newstic ker/meldung/Adblocker-Admop-geht-vor-Axel-Springer-in-die-Knie-3946476.ht $\mathrm{ml}$, zuletzt abgerufen am 30.5.2019. 
insoweit eine Integrität des Produktes „werbefinanzierte Webseite“. Die Kammer meinte auch, dass der Werbeblockerbetreiber eine Verdrängungsabsicht mit Blick auf das Angebot der werbefinanzierten Verbreitung redaktioneller Inhalte im Internet objektiv zeige. Der Werbeblocker sei gerade dazu bestimmt, die Integrität der Webseiten zu beeinträchtigen. In einer weiterhin noch vorgenommenen Interessenabwägung wog das LG Hamburg das aus der Pressefreiheit folgende Interesse der Webseitenbetreiber an der Integrität ihrer Produkte höher als die Interessen der Betreiber und Nutzer von Werbeblockersoftware. Sehr ausführlich begründet die Kammer die besondere Bedeutung der Pressefreiheit gemäß Art. 5 Abs. 1 S. 2 GG. Die negative Informationsfreiheit der werbeblockenden Nutzer hielt sie hingegen für geringwertiger, weil bei den in Streit stehenden Webseiten keine aufgedrängte Form von Werbung zu erkennen sei. Auch könne der Nutzer nicht einerseits die Inhalte rezipieren, andererseits aber die das Angebot finanzierende Werbung ausblenden. Bezahlmodelle seien kurzfristig gesehen keine tragbare Alternative zur Finanzierung und deshalb den Webseitenbetreibern nicht zumutbar.

Im November 2016 urteilte dann die 15. Zivilkammer des LG Hamburg im Rechtsstreit zwischen Spiegel Online und Eyeo und wies die Klage gegen den Vertrieb von Adblock Plus ab ${ }^{669}$. Da dieses Urteil erst nach dem nachfolgend näher darzustellenden Urteil des OLG Köln erging, wird hierauf nicht an dieser Stelle, sondern erst in Ziffer C. I. 3. lit. e) eingegangen. Mit diesem letzten erstinstanzlichen Urteil konnte Eyeo in den Eingangsinstanzen eine weiße Weste bewahren und blieb insgesamt in sechs Hauptsacheverfahren unbesiegt.

Zur Veranschaulichung der Reichweite der gerichtlichen Überprüfung der Zulässigkeit von Werbeblockern in Form von reinen Blacklist-Blockern sowie als Whitelist-Blocker wird nachfolgend eine Übersicht über die von den erstinstanzlichen Gerichten im Einzelnen geprüften Anspruchsgründe eingeblendet:

669 Urteil vom 25.11.2016, 315 O 293/15, MMR 2017, 351; https:/www.heise.de/ne wsticker/meldung/Landgericht-Hamburg-Adblock-Plus-gewinnt-gegen-Spiegel -Online-3538870.html, zuletzt abgerufen am 30.5.2019. 


\begin{tabular}{|c|c|c|c|c|}
\hline Gericht & $\begin{array}{l}\text { Aktenzei- } \\
\text { chen \& Par- } \\
\text { teien }\end{array}$ & $\begin{array}{l}\text { UWG (inkl. BGB- } \\
\text { Deliktsrecht) }\end{array}$ & Urheberrecht & Kartellrecht \\
\hline $\begin{array}{l}\text { LG } \\
\text { Hamburg }\end{array}$ & $\begin{array}{l}416 \text { HKO } \\
159 / 14 \\
\text { (Zeit Online/ } \\
\text { Handelsblatt } \\
\text { vs. Adblock } \\
\text { Plus) }\end{array}$ & $\begin{array}{l}\text { Gezielte Be- } \\
\text { hinderung } \\
\text { } 4 \text { Nr. } 10 \text { a.F. } \\
\text { - abgelehnt } \\
\text { \$ } \$ 4 \text { Nr. } 1 \text { a.F. - } \\
\text { abgelehnt } \\
\text { Allg. Marktbe- } \\
\text { hinderung - } \\
\text { abgelehnt }\end{array}$ & $\begin{array}{l}\text { Nicht streitgegenständ- } \\
\text { lich }\end{array}$ & $\begin{array}{l}\text { Nicht streitgegen- } \\
\text { ständlich }\end{array}$ \\
\hline $\begin{array}{l}\text { LG } \\
\text { München I }\end{array}$ & $\begin{array}{l}37 \mathrm{O} \\
11673 / 14 \\
\text { (ProSieben } \\
\text { Sat1 Media } \\
\text { vs. Adblock } \\
\text { Plus) }\end{array}$ & $\begin{array}{l}\text { Gezielte Be- } \\
\text { hinderung } \\
\$ 4 \text { Nr. } 10 \text { a.F. } \\
\text { - abgelehnt } \\
\text { Verleiten zur } \\
\text { Verletzung des } \\
\text { virtuellen } \\
\text { Hausrechts - } \\
\text { abgelehnt } \\
\text { Unlauterer } \\
\text { Boykottaufruf } \\
\text { - abgelehnt } \\
\text { Allg. Marktbe- } \\
\text { hinderung - } \\
\text { abgelehnt } \\
\text { Recht am ein- } \\
\text { gerichteten } \\
\text { und ausgeüb- } \\
\text { ten Gewerbe- } \\
\text { betrieb } ₫ 823 \\
\text { Abs. } 1 \text { BGB - } \\
\text { abgelehnt }\end{array}$ & $\begin{array}{l}\text { Verletzung von Rech- } \\
\text { ten an einer/m } \\
\text { - Datenbank ( } \$ 87 \mathrm{~b}) \\
\text { - abgelehnt } \\
\text { - } \text { Datenbankwerk - } \\
\text { abgelehnt } \\
\text { - Multimediawerk - } \\
\text { abgelehnt } \\
\text { - Computerpro- } \\
\text { gramm - abge- } \\
\text { lehnt }\end{array}$ & 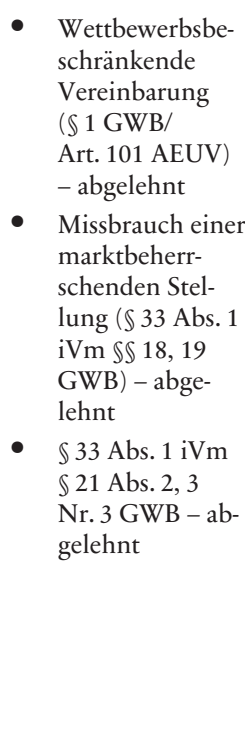 \\
\hline
\end{tabular}




\begin{tabular}{|c|c|c|c|c|}
\hline Gericht & $\begin{array}{l}\text { Aktenzei- } \\
\text { chen \& Par- } \\
\text { teien }\end{array}$ & $\begin{array}{l}\text { UWG (inkl. BGB- } \\
\text { Deliktsrecht) }\end{array}$ & Urheberrecht & Kartellrecht \\
\hline $\begin{array}{l}\text { LG } \\
\text { München I }\end{array}$ & $\begin{array}{l}37 \text { O } \\
\text { 11843/14 } \\
\text { (RTL Gruppe } \\
\text { vs. Adblock } \\
\text { Plus) }\end{array}$ & $\begin{array}{l}\text { Gezielte Be- } \\
\text { hinderung } \\
\text { \$4 Nr. } 10 \text { a.F. } \\
\text { - abgelehnt } \\
\text { Recht am ein- } \\
\text { gerichteten } \\
\text { und ausgeüb- } \\
\text { ten Gewerbe- } \\
\text { betrieb } ₫ 823 \\
\text { Abs. } 1 \text { BGB - } \\
\text { abgelehnt } \\
\text { \$ } 4 \text { Nr. } 1 \text { a.F. - } \\
\text { abgelehnt } \\
\text { Unlauterer } \\
\text { Boykottaufruf } \\
\text { oder „parasitä- } \\
\text { res Ausnutzen“ } \\
\text { - abgelehnt } \\
\text { \$7 Abs. } 1 \text { - ab- } \\
\text { gelehnt } \\
\text { \$5 Abs. } 1 \text { Nr. } 1 \\
\text { - abgelehnt }\end{array}$ & $\begin{array}{l}\text { Nicht streitgegenständ- } \\
\text { lich }\end{array}$ & $\begin{array}{l}\text { Missbrauch einer } \\
\text { marktbeherr- } \\
\text { schenden Stel- } \\
\text { lung }(\$ 33 \text { Abs. } 1 \\
\text { iVm } \$ \$ 18,19 \\
\text { GWB) - abge- } \\
\text { lehnt } \\
\text { Wettbewerbsbe- } \\
\text { schränkende } \\
\text { Vereinbarung } \\
\text { ( } ₫ 1 \text { GWB/ } \\
\text { Art. } 101 \text { AEUV) } \\
\text { - abgelehnt } \\
\text { - }\end{array}$ \\
\hline LG Köln & $\begin{array}{l}33 \text { O 132/14 } \\
\text { (Axel Sprin- } \\
\text { ger vs. Ad- } \\
\text { block Plus) }\end{array}$ & $\begin{array}{l}\text { Gezielte Be- } \\
\text { hinderung } \\
\$ 4 \text { Nr. } 10 \text { a.F. } \\
\text { - abgelehnt } \\
\text { Allg. Marktbe- } \\
\text { hinderung - } \\
\text { abgelehnt }\end{array}$ & $\begin{array}{l}\text { Nicht streitgegenständ- } \\
\text { lich }\end{array}$ & $\begin{array}{l}\text { Nicht streitgegen- } \\
\text { ständlich }\end{array}$ \\
\hline $\begin{array}{l}\text { LG } \\
\text { Frankfurt }\end{array}$ & $\begin{array}{l}\text { 3-6O 105/15 } \\
\text { (Axel Sprin- } \\
\text { ger vs. Ad- } \\
\text { Block) }\end{array}$ & $\begin{array}{l}\text { Gezielte Behinde- } \\
\text { rung } \\
\$ 4 \mathrm{Nr} .10 \text { a.F. - } \\
\text { stattgegeben }\end{array}$ & $\begin{array}{l}\text { Nicht streitgegenständ- } \\
\text { lich }\end{array}$ & $\begin{array}{l}\text { Nicht streitgegen- } \\
\text { ständlich }\end{array}$ \\
\hline LG Berlin & $\begin{array}{l}16 \text { O 449/15 } \\
\text { (Axel Sprin- } \\
\text { ger vs. Ad- } \\
\text { block Brow- } \\
\text { ser) }\end{array}$ & $\begin{array}{l}\text { Gezielte Behinde- } \\
\text { rung } \\
\$ 4 \mathrm{Nr} .10 \text { a.F. - } \\
\text { stattgegeben }\end{array}$ & $\begin{array}{l}\text { Nicht streitgegenständ- } \\
\text { lich }\end{array}$ & $\begin{array}{l}\text { Nicht streitgegen- } \\
\text { ständlich }\end{array}$ \\
\hline $\begin{array}{l}\text { LG } \\
\text { Stuttgart }\end{array}$ & $\begin{array}{l}11 \text { O 238/15 } \\
\text { (Axel Sprin- } \\
\text { ger vs. } \\
\text { Blockr) }\end{array}$ & $\begin{array}{l}\text { Gezielte Behinde- } \\
\text { rung } \\
\$ 4 \mathrm{Nr} .10 \text { a.F. - ab- } \\
\text { gelehnt }\end{array}$ & $\begin{array}{l}\text { Nicht streitgegenständ- } \\
\text { lich }\end{array}$ & $\begin{array}{l}\text { Nicht streitgegen- } \\
\text { ständlich }\end{array}$ \\
\hline
\end{tabular}




\begin{tabular}{|c|c|c|c|c|}
\hline Gericht & $\begin{array}{l}\text { Aktenzei- } \\
\text { chen \& Par- } \\
\text { teien }\end{array}$ & $\begin{array}{l}\text { UWG (inkl. BGB- } \\
\text { Deliktsrecht) }\end{array}$ & Urheberrecht & Kartellrecht \\
\hline $\begin{array}{l}\text { LG } \\
\text { München I }\end{array}$ & $\begin{array}{l}33 \text { O 5017/15 } \\
\text { (Süddeutsche } \\
\text { Zeitung vs. } \\
\text { Adblock } \\
\text { Plus) }\end{array}$ & $\begin{array}{l}\text { Gezielte Be- } \\
\text { hinderung } \\
\text { } 4 \text { Nr. } 4 \text { n.F. - } \\
\text { abgelehnt } \\
\text { Allg. Marktbe- } \\
\text { hinderung - } \\
\text { abgelehnt }\end{array}$ & $\begin{array}{l}\text { Nicht streitgegenständ- } \\
\text { lich }\end{array}$ & $\begin{array}{l}\text { Nicht streitgegen- } \\
\text { ständlich }\end{array}$ \\
\hline $\begin{array}{l}\text { LG } \\
\text { Hamburg }\end{array}$ & $\begin{array}{l}308 \text { O 46/16 } \\
\text { (Axel Sprin- } \\
\text { ger vs. Ad- } \\
\text { mop) }\end{array}$ & $\begin{array}{l}\text { Gezielte Behinde- } \\
\text { rung } \\
\$ 4 \mathrm{Nr} .4 \text { n.F. - } \\
\text { stattgegeben }\end{array}$ & $\begin{array}{l}\text { Verletzung von Rech- } \\
\text { ten an einem } \\
\text { - Computerpro- } \\
\text { gramm - abge- } \\
\text { lehnt } \\
\text { - Datenbankwerk - } \\
\text { abgelehnt } \\
\text { - Multimediawerk - } \\
\text { abgelehnt }\end{array}$ & $\begin{array}{l}\text { Nicht streitgegen- } \\
\text { ständlich }\end{array}$ \\
\hline $\begin{array}{l}\text { LG } \\
\text { Hamburg }\end{array}$ & $\begin{array}{l}315 \text { O 293/15 } \\
\text { (Spiegel On- } \\
\text { line vs. Ad- } \\
\text { block Plus) }\end{array}$ & $\begin{array}{l}\text { Gezielte Be- } \\
\text { hinderung } \\
\text { } 44 \text { Nr. } 4 \text { n.F. - } \\
\text { abgelehnt } \\
\text { } \$ 4 \text { a n.F. -ab- } \\
\text { gelehnt } \\
\text { Allg. Marktbe- } \\
\text { hinderung - } \\
\text { abgelehnt } \\
\text { Recht am ein- } \\
\text { gerichteten } \\
\text { und ausgeüb- } \\
\text { ten Gewerbe- } \\
\text { betrieb } \$ 823 \\
\text { Abs. } 1 \text { BGB - } \\
\text { abgelehnt }\end{array}$ & $\begin{array}{l}\text { Nicht streitgegenständ- } \\
\text { lich }\end{array}$ & 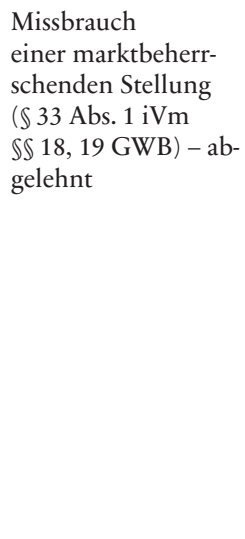 \\
\hline
\end{tabular}

bb) Abzuwägende Interessen der Beteiligten, Betroffenen und der Allgemeinheit

Wie die vorstehende Übersicht zeigt wurde in jedem einzelnen Verfahren das Vorliegen einer gezielten Mitbewerberbehinderung nach $\$ 4 \mathrm{Nr} .10$ UWG a.F. bzw. $\$ 4$ Nr. 4 UWG n.F. geprüft. Nahezu jedes dieser Urteile beruht im Rahmen der Prüfung dieses lauterkeitsrechtlichen Tatbestands auf einer Interessenabwägung. Diese Abwägung nimmt nicht nur die Interessen der konkreten Streitparteien, sondern auch die Interessen der konkret betroffenen Internetnutzer sowie der Allgemeinheit in den Blick. 
Die Interessenlage all dieser Personen(-gruppen) ähnelt sich durch die Gleichförmigkeit der Streitgegenstände in allen Verfahren. Nachfolgend wird zusammengefasst dargestellt, welche Interessen die Gerichte für die verschiedenen Lager herangezogen haben.

Mit Blick auf die Streitparteien ist die Interessenlage bei der eigentlich im Mittelpunkt stehenden Beklagten, also der jeweiligen Betreiberin eines Werbeblockerprogramms, recht überschaubar. Den Betreibern von Adblock-Software wird schlicht die Berufsfreiheit aus Art. 12 GG zugebilligt, wonach sie ein schutzwürdiges Interesse an ihrem Geschäftsmodell haben ${ }^{670}$. Den Klägern, die durchweg Webseitenbetreiber von stark frequentierten Nachrichten- oder Entertainmentportalen waren, billigten die Gerichte dagegen das spiegelbildliche Interesse an der Erzielung von Werbeeinnahmen auf ihren Webseiten aus Art. 12 GG zu${ }^{671}$. Auch die Webseitenbetreiber haben ein schutzwürdiges Interesse an ihren Geschäftsmodellen, konkret der Refinanzierung kostenfreier Inhalte durch von dritter Seite bezahlter Werbung. Hinzu kommt bei den Webseitenbetreibern allerdings noch die weitere grundrechtliche Position der Pressefreiheit aus Art. 5 Abs. 1 S. 2 GG $^{672}$. In der Gemengelage dieser Positionen erkannten befasste Gerichte den Webseitenbetreibern auch ein schutzwürdiges Interesse an der Schaltung aufmerksamkeitserregender Werbung, da insoweit eine Umsatzsteigerung möglich ist ${ }^{673}$. Singulär wurde dabei auch ein Interesse an der wirtschaftlichen Einheit von redaktionellem und werbendem Inhalt erkannt ${ }^{674}$.

Außerhalb dieser bipolaren Verbindung wurden mehrfach auch die Interessen der Internetnutzer, der Werbetreibenden und der Allgemeinheit in die Abwägung eingestellt. Interessen von Intermediären auf der Werbeseite wie etwa Werbenetzwerke spielten in dieser Phase noch keine erkennbare Rolle. Auch bei den Werbetreibenden erschöpfte sich die ein-

670 So etwa bei LG Hamburg, Urteil vom 21.4.2015 - 416 HKO 159/14, CR 2016, 122; Urteil vom 3.5.2016 - 308 O 46/16, CR 2016, 782, und LG München I, Urteil vom 27.5.2015 - 37 O 11843/14, WRP 2015, 927; Urteil vom 27.5.2015 37 O 11673/14, MMR 2015, 660.

671 LG München I, Urteil vom 27.5.2015 - 37 O 11843/14, WRP 2015, 927; Urteil vom 27.5.2015 - 37 O 11673/14, MMR 2015, 660.

672 LG Hamburg, Urteil vom 21.4.2015 - 416 HKO 159/14, CR 2016, 122; Urteil vom 3.5.2016 - 308 O 46/16, CR 2016, 782, und LG München I, Urteil vom 22.3.2016 - 33 O 5017/15, MMR 2016, 406.

673 LG München I, Urteil vom 27.5.2015 - 37 O 11843/14, WRP 2015, 927; Urteil vom 27.5.2015 - 37 O 11673/14, MMR 2015, 660.

674 LG Berlin, Urteil vom 8.12.2015 - 16 O 449/15, K\&R 2016, 360. 
zige ausdrückliche Nennung darin, dass sie ein Interesse an der Schaltung aufmerksamkeitserregender Werbung haben ${ }^{675}$.

Sehr ausführlich wurde in mehreren Urteilen jedoch die Interessenlage bei den Internetnutzern, insbesondere den Nutzern von Werbeblockersoftware, dargestellt und abgewogen. Schon in der ersten Entscheidung sah das LG Hamburg in der Nutzung eines Werbeblockers die Möglichkeit, personalisierte Werbung zu unterdrücken, Tracking zu verhindern und durch den Download von Werbeanzeigen die Übertragung von Malware zu verhindern. Dies stelle unter Geltung der freien Entscheidung darüber, welche eigene Daten Nutzer beim Internetsurfen preisgeben wollen, eine Ausprägung des grundrechtlich geschützten informationellen Selbstbestimmungsrechts dar und sei in die Gesamtabwägung einzustellen ${ }^{676}$. Dieses Recht auf Selbstbestimmung als Teil des allgemeinen Persönlichkeitsrechts nach Art. 2 Abs. 1 GG wurde zudem mit der negativen Informationsfreiheit aus Art. 5 Abs. 1 S. 1 GG verknüpft, wonach es die schutzwürdige eigenständige Entscheidung Nutzers einer Werbeblocker-Software sei, ob und in welchem Ausmaß Werbung sichtbar ist ${ }^{677}$. Insbesondere bei aufdringlichen oder sogar datenschutzrechtlich problematischen Werbeformen sei ein anerkennenswertes Interesse des Internetnutzers, von Werbung verschont zu bleiben, anzunehmen ${ }^{678}$. Zudem sind positive Aspekte wie Jugendschutz und Schutz vor Bandbreitenverlust angeführt worden ${ }^{679}$.

Die Interessen der Internetnutzer, die keinen Gebrauch von Werbeblocker-Software machen, finden sich nur selten, da regelmäßig allein die Sicht der Nutzer von Werbeblockern angeführt wurde. An einzelner Stelle klang an, dass nicht werbeblockende Nutzer jedoch auch ein Interesse daran haben, weiterhin kostenfreie Inhalte bereitgestellt zu erhalten ${ }^{680}$. Sozusagen ist dies ein Interesse daran, dass alles so bleibt wie es vor dem starken Zuwachs der Adblockerraten war. Diese Sicht entspricht den im Übrigen als Interesse der Allgemeinheit genannten Umstand, dass die

675 LG München I, Urteil vom 27.5.2015 - 37 O 11843/14, WRP 2015, 927; Urteil vom 27.5.2015 - 37 O 11673/14, MMR 2015, 660.

676 LG Hamburg, Urteil vom 21.4.2015 - 416 HKO 159/14, CR 2016, 122.

677 LG München I, Urteil vom 27.5.2015 - 37 O 11843/14, WRP 2015, 927; Urteil vom 27.5.2015 - 37 O 11673/14, MMR 2015, 660; dies relativierend LG Hamburg, Urteil vom 3.5.2016 - 308 O 46/16 (juris, Rn. 50f.).

678 LG Stuttgart, Urteil vom 10.12.2015 - 11 O 238/15, K\&R 2016, 362.

679 LG München I, Urteil vom 27.5.2015 - 37 O 11843/14, WRP 2015, 927; Urteil vom 27.5.2015 - 37 O 11673/14, MMR 2015, 660.

680 LG München I, Urteil vom 27.5.2015 - 37 O 11843/14, WRP 2015, 927; Urteil vom 27.5.2015 - 37 O 11673/14, MMR 2015, 660. 
Existenz von Internetwerbeblockern die Gefahr der Verminderung oder des Verschwindens kostenfreier Inhalte im Web begründe. Zu dieser Allgemeinheit gehören wiederum auch die Nutzer von Werbeblockern, weil auch diese von einem Verschwinden des „kostenlosen Internets“ tangiert wären.

Als Argument der vereinzelt gebliebenen Gerichtsentscheidungen, die einen Unterlassungsanspruch bejahten oder zumindest in Erwägung zogen, sticht Folgendes heraus: Für den Markt bestehe kein Mehrwert durch Werbeblocken. Das Geschäftsmodell sei vielmehr allein auf Zerstörung gerichtet ${ }^{681}$. Das Geschäftsmodell der Webseitenbetreiber sei hingegen vor dem Hintergrund von Art. 5 Abs. 1 S. 2 GG besonders schutzwürdig ${ }^{682}$.

Abgesehen davon entpuppten sich aus der oben dargestellten Interessenlage jedoch vor allem drei Argumente, die die meisten Gericht pro Zulässigkeit von Werbeblockern entscheiden ließen. Zum ersten bestehe kein Bestandsschutz für Geschäftsmodelle wie dem im Internet stark verbreiteten Modell, kostenlose Inhalte gegen den Preis der Rezeption von Werbung anzubieten, zumal dieses Modell nicht vertragsrechtlich fixiert wird $^{683}$. Zum zweiten stehen den Webseitenbetreibern Handlungsalternativen zur Verfügung, die von technischen Schutzmaßnahmen verbunden mit der Aussperrung von Werbeblocker-Nutzern oder der Einschränkung des Angebots an diese Nutzer hin zu Einführung von Bezahlschranken oder Registrierungserfordernissen reichen ${ }^{64}$. Zum dritten und ganz maßgeblich für die meisten Urteile ist das Argument, dass die Installation einer Werbeblocker-Software auf der freiwilligen und bewussten Entscheidung der Nutzer basiert. Kein Nutzer werde gezwungen, einen Werbeblocker zu installieren und zu nutzen, sondern dies bedarf bei Browsererweiterungen oder besonderen Browsern eines aktiven Handelns. Wegen dieser Nutzer-

681 Vor allem LG Berlin, Urteil vom 8.12.2015 - 16 O 449/15, K\&R 2016, 360; als Randnotiz in LG München I, Urteil vom 27.5.2015 - 37 O 11843/14, WRP 2015, 927.

682 LG Hamburg, Urteil vom 3.5.2016 - 308 O 46/16, CR 2016, 782.

683 LG Hamburg, Urteil vom 21.4.2015 - 416 HKO 159/14, CR 2016, 122 und LG Stuttgart, Urteil vom 10.12.2015 - 11 O 238/15, K\&R 2016, 362.

684 LG Hamburg, Urteil vom 21.4.2015 - 416 HKO 159/14, CR 2016, 122 und LG München I, Urteil vom 27.5.2015 - 37 O 11843/14, WRP 2015, 927; Urteil vom 27.5.2015 - 37 O 11673/14, MMR 2015, 660; LG Stuttgart, Urteil vom 10.12.2015 - 11 O 238/15, K\&R 2016, 362. 
autonomie verdienen die Interessen eben der Nutzer, die Werbeblocker willentlich nutzen, ein besonders hohes Gewicht in der Abwägung ${ }^{685}$.

cc) Beiträge in der Literatur

Diese Salve an erstinstanzlichen Entscheidungen führte reflexartig zu einer gleichsam hohen Menge an Beiträgen in der Literatur. Einige dieser Beiträge erschöpfen sich in der Aufbereitung zum schnellen Verständnis ohne eigene Stellungnahme ${ }^{686}$. Die im Gegenteil dazu die Sachlage bewertenden Stimmen werden nachfolgend so dargestellt, dass erkennbar wird, wer die herrschende Meinung der Gerichte befürwortet, also pro Zulässigkeit von Internetwerbeblockern argumentiert, und wer im Gegenteil für ein Verbot solcher Software plädiert. Differenzierende oder neue Gedanken einbringende Beiträge werden sodann mit besonderem Augenmerk behandelt.

$\mathrm{Zu}$ den Befürwortern der Zulässigkeit von Werbeblockern, selbst in Form der Whitelist-Blocker, gesellte sich Luckhaus, der in zwei Beiträgen die Linie der Landgerichte Hamburg, München und Stuttgart befürwortete und das Urteil aus Berlin kritisierte ${ }^{687}$. Seine maßgeblichen Kritikpunkte an der Berliner Entscheidung sind, dass verkannt worden sei, dass ein Internetwerbeblocker nur die Anzeige von Elementen von dritten Adservern verhindere und damit keine Substanzverletzung der Webseite an sich erfolge. Auch die vom LG Berlin vertretene Annahme einer wirtschaftlichen Einheit von Werbung und Inhalt sei nicht ausreichend, weil gerade eine rechtliche Einheit für ein Verbot der Werbeblocker erforderlich wäre. Die Ansicht des LG Berlin, technische Gegenmaßnahmen seien den Webseitenbetreibern nicht zumutbar, überzeugt den Autor ebenfalls nicht. Die andere Linie in der Rechtsprechung hält Luckhaus hingegen für zutreffend. Hier sei der technische Hintergrund der Wirkweise eines Werbeblockers korrekt erfasst worden. Auch sei die Einschätzung richtig, dass eine unmittelbare Werbebehinderung nicht vorliege und deshalb eine Interessenabwägung notwendig ist. Hierbei sei auch zutreffend davon ausgegangen

685 LG Hamburg, Urteil vom 21.4.2015 - 416 HKO 159/14, CR 2016, 122 und LG München I, Urteil vom 27.5.2015 - 37 O 11843/14, WRP 2015, 927; Urteil vom 27.5.2015 - 37 O 11673/14, MMR 2015, 660; Urteil vom 22.3.2016 - 33 O 5017/15, MMR 2016, 406; LG Stuttgart, Urteil vom 10.12.2015 - 11 O 238/15, K\&R 2016, 362.

686 Herrmann/Schwarz K\&R 2015, 622; Ullmann, jurisPR-WettbR 11/2015 Anm. 4; Müllejans GWR 2015, 281; Zenker GWR 2016, 81.

687 IPRB 2016, 103; K\&R 2016, 313. 
worden, dass Gegenmaßnahmen der Webseitenbetreiber gegen die Wirkweise von Werbeblockern möglich seien.

Mit diesen Ausführungen reiht sich Luckhaus in die schon vor Erlass der erstinstanzlichen Urteile publizierten Stellungnahmen von Hoeren und Köhler ein. Gemeinsam mit der Vielzahl von Werbeblocker billigenden Urteilen ist diese Ansicht als herrschende Meinung zu bezeichnen.

Die Gegenansicht wurde neben den Entscheidungen der Landgerichte aus Frankfurt und Berlin insbesondere von zwei Beiträgen in der Literatur vertreten. Zum einen kritisieren Hoche und Polly die herrschende Meinung ${ }^{688}$. Insbesondere die Ablehnung einer gezielten Mitbewerberbehinderung halten sie für nicht überzeugend. Sie sind der Auffassung, dass die Nutzerautonomie nur ein vorgeschobenes Argument sei. Dies folge aus einer Intransparenz für die Nutzer. Der Nutzer könne nicht wirklich beurteilen, wie sich die Sachlage darstellt, weil die genauen Konditionen für die großen, zur Kasse gebetenen Seitenbetreiber unbekannt seien und generell dem Umstand der Zahlungspflicht zu wenig Aufmerksamkeit zukomme. Auch könne der Nutzer in Wahrheit nicht in vollem Umfang selbständig über das Blocken von Werbung entscheiden. Denn der Umstand, dass nicht zahlungswillige Seitenbetreiber auch bei Einhaltung der Acceptable-Ads-Kriterien von einer möglichen Kenntnisnahme durch den Nutzer abgeschnitten werden, stelle eine erhebliche Einschränkung der Autonomie der Nutzer dar. Auch ziehen die Autorinnen den Schluss, dass sich mit der einseitigen Herausstellung der Nutzerautonomie sich bei konsequenter Fortführung dieser Rechtsprechung jede behindernde Software mit dem Argument der freien Nutzerentscheidung rechtfertigen lasse. Zuletzt nehmen die Autorinnen Anstoß an dem Umstand, dass die verlangte Vergütung des Werbeblockers sich nicht an der eigenen Leistung, sondern an der Höhe des Werbeumsatzes der Webseite bemisst.

Einen weiteren kritischen Beitrag fügte Engels der Diskussion bei ${ }^{689}$. Dieser Beitrag ist allerdings vor dem Hintergrund der Mandatierung des Verfassers durch die ProSieben Sat 1 Media Gruppe und die Vertretung dieser Mandantin im Rechtstreit gegen Eyeo vor dem LG München I zu bewerten. Bekanntlich unterlag ProSieben Sat1 in diesem Verfahren. Der Beitrag ist insoweit eine Art Veröffentlichung der schriftsätzlich vorgebrachten Argumente, die das Gericht nicht überzeugen konnten. Konkret vertritt Engels, dass eine gezielte Behinderung von Webseitenbetreibern beim Whitelisting vorliege, weil diese sich von einer gezielten Blockade

688 IPRB 2015, 231.

689 GRURPrax 2015, 338. 
freikaufen müssten. Zudem sieht er in der bloßen Verhinderung bzw. Unterdrückung von Elementen aus dem Quellcode (gemeint ist wohl das HTML-Dokument) einen Eingriff in den technischen Ablauf, der eine Substanzbeeinträchtigung begründe. Auch hierin sei ein Grund für die Bejahung von $₫ 4$ Nr. 10 UWG a.F. zu sehen. Als weiteres Argument wird genannt, dass Werbeblocker den freien Zugang zu einer in Wahrheit nicht kostenlosen Leistung ermöglichen. Der Umstand, dass der Nutzer zwar nicht monetär zahlen müsse, mache die Zurverfügungstellung nicht kostenlos. Vielmehr sei die Gegenleistung die Duldung von Werbung. Zuletzt liege in diesem Zusammenhang eine gezielte Ausschaltung fremder Werbung vor. Die zwischengelagerte Entscheidung des Nutzers will Engels nicht gelten lassen, weil dieser bewusst vom Werbeblocker-Anbieter dazu verleitet werde, das „Austauschverhältnis“ mit dem Webseitenbetreiber zu brechen. Im Weiteren befürwortet der Verfasser des Beitrags auch urheberund kartellrechtliche Ansprüche, ohne hier über die bloße Negierung der Argumentation des LG München I hinauszugehen.

Zuletzt äußerte sich Deutsch vorsichtig kritisch gegenüber den Urteilen der Landgerichte Hamburg und München ${ }^{690}$. Er hält es für bemerkenswert, dass die Gerichte sich vielmehr mit technischen Alternativen denn mit den Bedingungen und der Kostenpflicht für die Aufnahme in die Whitelist auseinander gesetzt haben. Er hält die Ansicht, dass die Grenze zur Unlauterkeit überschritten sein könnte, zumindest für denkbar.

Zwischen diesen beiden Extremen findet sich mit dem Beitrag von Becker und Becker eine differenzierende Ansicht ${ }^{691}$. Isoliert von lauterkeitsrechtlichen Tatbeständen vertreten die Autoren zunächst, dass der Einfluss der Pressefreiheit (Art. 5 Abs. 1 GG) bei einem absoluten Blacklist-Blocker höher sei, als dies bei differenzierenden Whitelist-Blockern der Fall ist. Denn durch die gesamte Blockade wird die Finanzierungsgrundlage der Presse stärker eingeschränkt als bei differenzierenden Blockern, die zumindest einen Teil von Werbung mitsamt Umsatzchancen erlaubt. Eine urheberrechtliche Schutzfähigkeit der Verbindung von Display-Werbeelementen mit dem Inhalt der Webseite halten die Autoren aufgrund der Individualisierung der Werbung durch Tracking und der damit einhergehenden Austauschbarkeit für ausgeschlossen. Im Rahmen des UWG wird eine gezielte Behinderung für reine Blacklist-Blocker als fernliegend angesehen, weil es den Nutzern nicht auf die Schädigung der Webseitenbetreiber, sondern auf die Erhöhung des eigenen Nutzungskomforts an-

690 GRURPrax 2015, 357.

691 GRURPrax 2015, 245. 
komme. Bei Whitelist-Blockern wird eine gezielte Behinderung wegen der nur „akzidentellen Behinderung" der Webseitenbetreiber verneint. Der drohende oder erpresserische Charakter der kostenpflichtigen Whitelist sei nicht unter die Mitbewerberbehinderung, sondern andere Tatbestände zu fassen. Im Rahmen der Prüfung der anderen Tatbestände scheide aber eine Anwendung des $₫ 4$ Nr. 1 UWG a.F. ebenfalls aus, weil die Webseitenbetreiber Mitbewerber seien und der Anwendungsbereich mithin gesperrt sei. Wegen eines offensichtlich bei den Verfassern bestehenden Störgefühls durch das „erpresserische Element“ bei der kostenpflichtigen Whitelist sehen sie jedoch einen ungeregelten Fall unlauteren Verhaltens auf Grundlage der Generalklausel von $\$ 3$ Abs. 1 UWG als gegeben an. Der Unwert liege in der Instrumentalisierung der Blockade durch die Blacklist zur Erzielung von Gewinnen durch den Verkauf von Whitelistplätzen. Die Autoren folgern daraus jedoch kein zwingendes Verbot von Werbeblockersoftware, sondern lediglich die Pflicht zur kostenfreien Aufnahme in die Whitelist. Bei reinen Blacklist-Blockern wird überdies vor dem bereits angesprochene Einfluss der Rundfunkfreiheit ein Verstoß gegen den eingerichteten und ausgeübten Gewerbebetrieb für möglich gehalten, womit den betroffenen Webseitenbetreibern Ansprüche aus $\mathbb{8} 823$ Abs. 1 BGB (ggf. iVm $\ 1004$ BGB analog) zustehen würden. Auch hier sei ein Totalverbot jeglicher Werbeblocker jedoch unverhältnismäßig. Zusammenfassend plädieren Becker und Becker also für eine Restriktion des Adblocker-Markts auf Whitelist-Blocker, wobei jeder Webseitenbetreiber, der die entsprechenden Kriterien einhält, kostenfrei auf die Whitelist aufzunehmen sein soll.

Eine neue Wendung erhielt die Auseinandersetzung um die Adblocker zu Beginn des Jahres 2016 durch einen Beitrag von Peifer ${ }^{692}$. Bei der Frage der gezielten Behinderung geht er grundsätzlich konform mit den bis dato ergangenen Urteilen der Landgerichte München, Hamburg und Köln. Neu ist allerdings, dass Peifer erstmals $₫ 4$ a Abs. 1 UWG n.F. für die Fallgestaltung ins Spiel bringt. Zwar war die Vorgängervorschrift des $\$ 4$ Nr. 1 UWG a.F. in richtlinienkonformer Auslegung bereits Prüfungsgegenstand beim LG Hamburg und dem LG München und wurde mit knappen Begründungen abgelehnt. Die im Rahmen der letzten UWG-Reform aus 2015 nunmehr der UGP-Richtlinie erschöpfend angepasste Nachfolgevorschrift des $\$ 4 \mathrm{Nr} .1 \mathrm{UWG}$ a.F. stellt nicht mehr auf eine unangemessene unsachliche Beeinflussung $\mathrm{ab}$, sondern auf eine aggressive geschäftliche Handlung, die gemäß $₫ 4$ a Abs. 1 S. 2 Nr. 3 UWG n.F. insbesondere dann

692 AfP 2016, 5. 
aggressiv ist, wenn eine unzulässige Beeinflussung vorliegt. Diese ist sodann in $\$ 4$ a Abs. 1 S. 3 UWG n.F. definiert als Ausnutzung einer Machtposition zur Ausübung von Druck. Peifer meint deshalb, dass sich die Argumentation in diesem Tatbestand noch ändern könne. Dieser unscheinbare Hinweis, der nicht durch eine konkrete Prüfung der Norm gestützt wird, stellt sich im Nachhinein als erster Fingerzeig zum kontroversen Urteil des OLG Köln dar, das im nachgehenden Abschnitt schwerpunktmäßig erläutert wird. Peifer war nämlich zur Zeit der Befassung Mitglied des 6. Zivilsenats des OLG Köln, dem die Berufung im Verfahren zwischen Axel Springer und Eyeo zur Entscheidung vorlag693.

\section{c) Das Urteil des OLG Köln in Sachen Axel Springer./. Eyeo wegen Adblock Plus (inklusive Zwangsvollstreckungsverfahren)}

Besondere Bedeutung für die Entwicklung des Streitstandes zum Thema Adblocker kommt dem Urteil des OLG Köln vom 24.6.2016 ${ }^{694}$ nicht nur deshalb zu, weil es das erste Berufungsurteil war. Die besondere Bedeutung rührt vor allem daher, dass es das erste (und einzige) Urteil war, das Adblock Plus in seiner konkreten Gestaltung zumindest teilweise untersagte.

Ausgehend vom Streitgegenstand in der Vorinstanz waren lediglich Ansprüche nach dem UWG zu prüfen, wobei die Antragstellung der Klägerin eine gerichtliche Prüfung zunächst des Adblockers als Blacklist-Blocker und sodann hilfsweise der reinen Whitelist-Funktion erzwang.

Im Hauptantrag, d.h. dem Verbotsantrag bezogen auf das Angebot eines auf Filterlisten beruhenden Werbeblockers im Allgemeinen, erkannte der 6. Zivilsenat des OLG Köln keine Grundlage für einen Unterlassungsanspruch. Die Erfordernisse einer Mitbewerberstellung sowie einer geschäftlichen Handlung bejahte das Gericht knapp. Mitbewerber seien die Parteien, weil Adblock Plus das Absatz- und Werbeverhalten von Webseitenbetreibern beeinträchtige und dies ein konkurrentenbezogenes Handeln darstelle. Die Kostenfreiheit für den Nutzer schließe im Übrigen nicht das Vorliegen einer geschäftlichen Handlung aus, weil es sich bei Adblock Plus um ein einheitliches Geschäftsmodell handele, das nicht künstlich in Blacklist- und Whitelist-Funktionen getrennt werden dürfe. Der Um-

693 Vgl. https://de.wikipedia.org/wiki/Karl-Nikolaus_Peifer, zuletzt abgerufen am 31.5.2019.

694 OLG Köln, Urteil vom 24.6.2016 - 6 U 149/15, GRUR 2016, 1082. 
stand, dass durch Whitelist-Vereinbarungen Umsätze generiert werden, schlage also auch auf die reine Blacklist-Funktion durch. Eine gezielte Behinderung nach $\$ 4$ Nr. 10 UWG a.F. scheide hingegen aus, weil weder eine Schädigungsabsicht vorliege, noch das Angebot der Software geeignet sei, die wettbewerbliche Entfaltung von Webseitenbetreibern übermäßig zu beeinträchtigen. Die Einwirkung auf Werbeumsätze genüge dafür jedenfalls nicht. Der durch Adblock Plus generierte Konkurrenzdruck sei vielmehr wettbewerbsimmanent. Ferner erkennt der Senat in technischer Hinsicht zutreffend, dass der Datenstrom nicht von einem einheitlichen Server stammt. Korrekterweise stammt Werbung von Adservern, die in der Regel nicht mit den Content-Servern der Webseitenbetreiber identisch sind. Selbst bei Eigenwerbung auf dem eigenen Server könne jedoch nicht von einer Integrität der Webseite ausgegangen werden, weil auch hier Daten von erkennbar verschiedenen Adressen geladen werden. Ein Eingriff in die Kommunikation erfolgt technisch also erst im Bereich des Endgeräts des Nutzers, was keinem unlauteren physischen Eingriff in das Angebot oder die Werbung von Webseitenbetreibern gleichstehe. Zudem stellt das OLG Köln auch darauf ab, dass es der Nutzer sei, der sich aktiv für die Installation eines Adblockers entscheidet. Dieses Ergebnis hält laut OLG Köln auch einer Gegenprüfung vor dem Hintergrund des besonderen Schutzes von Webseitenbetreibern durch die Pressefreiheit nach Art. 5 Abs. 1 S. 2 GG stand. Denn die Pressefreiheit dürfe nicht im Ergebnis dazu führen, dass dem Nutzer gewisse Inhalte aufgedrängt werden, die er nicht wünsche. Dies gebiete schon die negative Informationsfreiheit aus Art. 5 Abs. $1 \mathrm{~S} 1 \mathrm{GG}$.

Eine allgemeine Marktbehinderung als Fallgruppe der Generalklausel in $\$ 3$ Abs. 1 UWG sei ebenfalls nicht verwirklicht. Diese Fallgruppe erforderte nämlich, dass bestimmte Angebotsformen vom Markt verdrängt werden. Dies sei vor dem Hintergrund von Reaktionsmöglichkeiten der Webseitenbetreiber, etwa der Aussperrung von Adblocker-Nutzern, nicht ersichtlich.

Allerdings gab der Senat dem Hilfsantrag statt. Zwar liege hier aus denselben Gründen wie im Hauptantrag keine gezielte Behinderung des Webseitenbetreibers vor, jedoch sei eine aggressive Geschäftspraktik im Sinne von $₫ 4$ a UWG n.F. verwirklicht. Besonderheit im Vergleich zu den erstinstanzlichen Auseinandersetzungen mit $\$ 4 \mathrm{Nr} .1 \mathrm{UWG}$ a.F. ist, dass laut OLG Köln Adressat der aggressiven geschäftlichen Handlung nicht nur die Webseitenbetreiber sein sollen, sondern auch die „Abnehmer, die auch von der Klägerin (sprich: Axel Springer) potentiell Werbeleistungen entgegennehmen“. Der Senat nimmt also Werbekunden als Opfer des 
Werbeblockens in den Blick, die als sonstige Marktteilnehmer ebenfalls im Schutzbereich des $\$ 4$ a UWG n.F. liegen. Diesen Weg zur Bewertung des Sachverhaltes hatte bis dato weder ein Gericht, noch ein Kommentator in der Literatur gewählt. Bis zum Urteil des OLG Köln wurden die lauterkeitsrechtlichen Ansprüche lediglich auf das direkte Verhältnis zwischen klagenden Webseitenbetreibern als Verletzten und Adblocker-Anbietern als Täter gestützt, wobei in der Interessenabwägung die Wirkung auf die Internetnutzer entscheidend war. Das OLG Köln hingegen fasst die Wirkungen der Software auf Dritte als anspruchsbegründend auf und betrachtet den Fall in einem Dreiecksverhältnis, wie es sonst regelmäßig in Irreführungsfällen nach $\$ 5$ UWG erfolgt. Der klagende Webseitenbetreiber macht demnach nicht als unmittelbar verletzter Wettbewerber Ansprüche gegen den Adblocker-Anbieter geltend, sondern als nach $₫ 8$ Abs. 1 Nr. 1 UWG aktivlegitimierte Stelle, die die nicht aktivlegitimierten sonstigen Marktteilnehmer als unmittelbar Verletzte sozusagen „vertritt“.

Diese Änderung der Perspektive führte dazu, dass nicht die Wirkungen auf die Webseitenbetreiber in den Blick genommen wurden, sondern die Konsequenzen für die Werbekunden. Problematisch ist bei diesem Vorgehen jedoch, dass die tatsächlichen Feststellungen sowohl des vorbefassten Landgerichts als auch des OLG Köln praktisch keine Hinweise auf die Wirkung bei den Werbekunden aufwiesen.

In der konkreten Prüfung von $\$ 4$ a UWG n.F. nahm das OLG Köln dann eine unzulässige Beeinflussung nach Absatz 1 Satz 2 Nr. 3 an. Dieser wiederum in $₫ 4$ a Abs. 1 S. 3 UWG n.F. legaldefinierte Begriff setzt voraus, dass eine Machtposition gegenüber dem Verbraucher oder sonstigen Marktteilnehmer zur Ausübung von Druck in einer Weise ausgenutzt wird, die die Fähigkeit des Betroffenen zu einer informierten Entscheidung wesentlich einschränkt. Im Rahmen der Voraussetzung der Machtposition vertritt der Senat die Ansicht, dass diese Machtposition nicht dasselbe meint wie die Marktbeherrschung im Sinne des kartellrechtlichen Missbrauchsverbot aus $\mathbb{\$} \$ 18 \mathrm{ff}$. GWB. Eine Machtposition könne auch strukturell oder situationsbedingt begründet sein. Als diese Machtposition sieht das OLG Köln dabei die durch die Blacklist hervorgerufene Stellung des Adblocker-Betreibers, entscheiden zu können, welche Werbeelemente trotz der Blacklist-Blockade ausgeliefert werden. Konkret bezeichnet das Kölner Urteil die Blacklist als eine technisch wirkende Schranke, die auf technischem Wege durch die Whitelist wieder beseitigt wird. In dieser Situation scheint der Senat zudem die erforderliche Druckausübung zu erkennen. Die Aggressivität dieses Vorgangs wird unter Rückgriff auf die in $\$ 4$ a Abs. 2 UWG n.F. genannten Auslegungskriterien hergeleitet, weil ein 
Hindernis nichtvertraglicher Art sowie ein Hindernis für die Ausübung von vertraglichen Regeln nach Nr. 4 vorliege. Der Adblocker-Betreiber hindere nämlich die vertragsgemäße Auslieferung von Werbung, die ein Werbekunde bei einem Webseitenbetreiber gebucht hat, indem er sich in diesen Prozess hineinbegebe und dort die vertragsgemäße Ausspielung von der eigenen technischen Freischaltung abhängig mache.

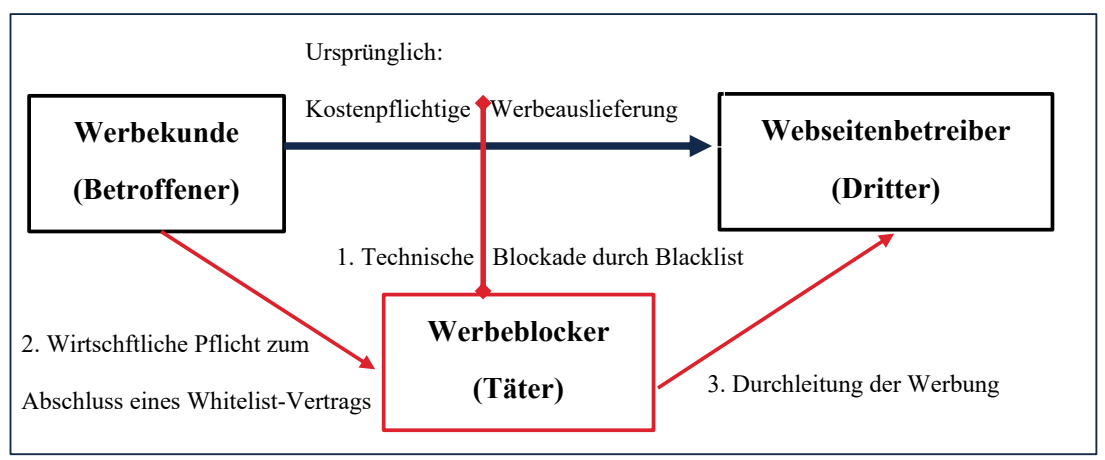

Abbildung 10: Schema der unlauteren aggressiven Praktik der Betreiber von kostenpflichtigen Whitelist-Blockern nach Ansicht des OLG Köln

Die Handlungsalternativen sowie die Nutzerautonomie über den Einsatz von Werbeblockern sah das OLG Köln in dieser Konstellation nicht als erheblich an. Denn für die Werbekunden bestünden solche Alternativen gerade nicht. Auf die Nutzer komme es bei dieser Betrachtung auch nicht an, weil bei Gesamtbetrachtung der Wirkweise eines Whitelist-Blockers die vorgehende Blockade durch den Betreiber der Software unlauter ausgenutzt werde. Bei $\$ 4$ a Abs. 1 S. 2 Nr 3 UWG komme es gerade nicht auf eine Interessenabwägung an, sondern auf das Vorliegen freier Marktentscheidungen bzw. wirtschaftlicher Entscheidungsfreiheit. Im Fall von Adblock Plus sei die Sachlage jedoch so, dass werbewillige Unternehmen sich aus einer Blockadesituation herauskaufen müssten.

Dies wiederum führe zu einer erheblichen Beeinträchtigung der Entscheidungsfreiheit der Werbekunden. Sie würden dazu gezwungen eine Dienstleistung - gemeint ist die kostenpflichtige Freischaltung zur Whitelist - in Anspruch zu nehmen, die sie ohne Blockade gar nicht benötigen würden. Als Beispiele solch zahlender Unternehmen nennt der Senat große Internetunternehmen, etwa Google.

Das OLG Köln untersagte der Eyeo GmbH mit dieser Begründung das Angebot von Adblock Plus „wenn und soweit Werbung nur nach von den 
Beklagten vorgegebenen Kriterien und gegen Zahlung eines Entgelts der Klägerin nicht unterdrückt wird“. Dieser Tenor führte in der Folge dazu, dass sich die Parteien im Rahmen der Zwangsvollstreckung des vorläufig vollstreckbaren Urteils darüber stritten, ob die kostenfreie Aufnahme auf die Whitelist ausreiche, um dem Verbot nachzukommen. Diesen nachgelagerten Streit um die tatsächlichen Folgen des Urteils entschied wiederum das OLG Köln durch Beschluss vom 21.12.2017, indem es eine sofortige Beschwerde von Axel Springer zurückwies ${ }^{695}$. Zuvor hatte das LG Köln einen Ordnungsmittelantrag gegen Eyeo bereits zurückgewiesen. Was war geschehen? Nach dem Urteil des OLG Köln hatte Eyeo an Axel Springer ein Angebot geschickt, kostenfrei auf der Whitelist aufgenommen zu werden. Jedoch baten sie in diesem Angebot um die Mitwirkung von Axel Springer durch die Beantwortung dreier Fragen, nämlich welche Webseiten der Gruppe alle aufgenommen werden sollen, wer genauer Domaininhaber sei und welche Werbemittel genau freigeschaltet werden sollen, was für die Prüfung der Acceptable Ads Kriterien notwendig sei. Axel Springer hat dieses Angebot nicht angenommen, sondern stattdessen einen Antrag nach $\$ 890$ Abs. 1 ZPO gestellt.

Unter Rückgriff auf den eindeutigen Tenor konnte Axel Springer hiermit aber keinen Erfolg haben. Der Tenor des Urteils des OLG Köln, der wortgleich mit dem von der Klägerin gestellten Hilfsantrag übereinstimmt, fordert das kumulative Vorliegen von Anwendung der WhitelistKriterien und Zahlungspflicht des Webseitenbetreibers. Eyeo verzichtete auf die Zahlungspflicht, was das Verhalten des Werbeblockeranbieters aus dem Kernbereich der Unterlassungsverpflichtung führte. Der Senat erläuterte, dass sich aus der Begründung eindeutig ergebe, dass die Whitelist-Funktion alleine keine Unlauterkeit begründet habe, sondern erst die hinzukommende Zahlungspflicht die Unlauterkeit begründe. Weiterhein habe Axel Springer keine "und/oder" Verknüpfung von Kriterien und Zahlungspflicht im Antrag gewählt, sondern selbst die Voraussetzung des kumulativen Vorliegens beider Umstände heraufbeschworen. Dass Axel Springer trotz des zugesprochenen Unterlassungsanspruchs mitwirken müsse, indem es sich dem Whitelisting-Prozess bei Eyeo unterwerfe, sei ihr nach dem Grundsatz von Treu und Glauben zumutbar.

Die Weigerung von Axel Springer das kostenfreie Whitelisting-Angebot anzunehmen, führte im Ergebnis dazu, dass das an sich „verlorene“ Verfahren vor dem OLG Köln für Eyeo niemals zu einer praktischen Einschränkung des eigenen Betriebs geführt hat. So mag das Urteil des

695 OLG Köln, Beschluss vom 21.12.2017, 6 W 28/17, BeckRS 2017, 143862. 
OLG Köln zwar eine herausragende Bedeutung im Gesamtbild der Rechtsstreitigkeiten haben, praktische Auswirkungen hat es jedoch nicht hervorgebracht.

\section{d) Rezeption des Kölner Urteils in der Literatur}

Das Urteil des OLG Köln wurde in diversen Beiträgen mehr oder weniger ${ }^{696}$ ausführlich kommentiert.

Zuerst hat Fritzsche das Urteil besprochen und dabei die Entscheidung kritisiert, soweit sie auf $\$ 4$ a UWG beruht ${ }^{697}$. Er hält insbesondere die Ausführungen des Kölner Wettbewerbssenats zum Vorliegen der „Machtposition “ für unzutreffend. Bei den vom Senat hervorgehobenen Werbekunden bleibe schon unklar, welche Unternehmen hier genau gemeint sein sollen. Soweit Werbenetzwerke gemeint sein sollen, seien diese selbst Mitbewerber und nicht von $\$ 4$ a UWG geschützt. Dasselbe gelte, wenn ein werbendes Unternehmen Werbeelemente auf eigenen Servern bereithalte und bei Webseitenbetreibern einstelle.

Im Weiteren sei eine Ausnutzung dieser Machtposition durch das Gericht nicht begründet worden, womit ein Tatbestandsmerkmal des $\$ 4 \mathrm{a}$ Abs. 1 S. 3 UWG insgesamt unbeachtet geblieben sei. Der Senat setze vielmehr die Existenz einer Machtposition mit deren Ausnutzung gleich, was angesichts des Wortlauts der Norm nur schwer vertretbar sei. Die Ausübung von Druck auf Grund der Machtposition könne aber in der bloßen Einräumung der Möglichkeit die Blacklist-Blockade zu lockern gesehen werden. Hier hätte sodann aber genauer geprüft werden müssen, warum eine solche Druckausübung unzulässig sei. Dies liege im Streitfall umso ferner, da der Senat die Blacklist-Blockade zuvor als zulässig bezeichnet habe.

\4a Abs. 2 S. 1 Nr. 4 UWG, der hier zur Begründung der nun doch unzulässigen Blacklist-Blockade herangezogen wurde, genauer das vom OLG Köln aus dieser Norm extrahierte „Hindernis nichtvertraglicher Art“, passe überdies nicht zur vorhergehenden Prüfung. Denn dieses Hindernis betreffe vertragliche Rechte des Betroffenen zum Aggressor, sprich Werbeblocker-Anbieter, und nicht zu Dritten, also die Webseitenbetreiber.

696 Stellungnahmen ohne eigene Stellungnahme oder mit nur knapper eigener Meinungskundgabe sind Hansen, GRUR-Prax 2016, 338, und Schippel, AfP 2017, 185.

697 WRP 2016, 1036. 
Zudem schlössen im Tatbestandsmerkmal der „wesentlichen Einschränkung der Fähigkeit zu einer informierten Entscheidung " - hier der Werbekunden - existierende Handlungsoptionen der Betroffenen die Annahme einer notwendigen praktischen Alternativlosigkeit aus. Hier sei nämlich auf den Durchschnittsadressaten, d.h. eines durchschnittlichen sonstigen Marktteilnehmers ( $\$ 3$ Abs. 4 UWG analog) abzustellen. Bei den betroffenen Unternehmen als Handelsunternehmen sei abstrakt von einer starken Entscheidungsfähigkeit auszugehen. Hinzu komme, dass konkret durch die Whitelist-Option eine weitere Handlungsoption eröffnet werde und damit die Einschränkung der Entscheidungsfähigkeit erst recht ausscheide - die Werbekunden würden gerade deshalb umso mehr zu einer informierten Entscheidung gezwungen. Zuletzt arbeitet Fritzsche im Merkmal der Eignung der aggressiven Handlung zur Beeinflussung des Geschäftsverhaltens heraus, dass es nicht nachvollziehbar sei, wenn zunächst die reine Blacklist-Funktion für zulässig erachtet wird, um sie sodann als Grund anzuführen, der die Whitelist-Funktion unzulässig mache.

Neben dieser harschen Kritik hat außerdem Alexander eine Anmerkung zum Urteil verfasst ${ }^{698}$. Auch er kritisiert die Entscheidung, soweit das OLG Köln $₫ 4$ a UWG angewendet hat. Neben der Kritik an der Aussage, dass sich durch die UWG-Novelle keine Unterschiede zwischen $\$ 4$ Nr. 1 UWG a.F. und $\$ 4$ a UWG n.F. ergäben, zweifelt er die gerichtliche Auslegung der Tatbestandsmerkmale „Machtposition“ und „Ausnutzung zur wesentlichen Einschränkung der Fähigkeit zu einer informierten Entscheidung“ an. Zum Erstgenannten mahnt er die fehlende Abstimmung zu kartellrechtlichen Wertungen an, die unterlaufen zu werden drohen. Die vom Gericht propagierte Koexistenz von kartellrechtlichem Missbrauchsverbot und unzulässiger Beeinflussung lässt er mit der abgegebenen knappen Begründung nicht gelten. Das zweitgenannte Merkmal liege mit Rücksicht auf den Beurteilungsmaßstab - gemeint ist ein geschäftserfahrener Durchschnittsmarktteilnehmer - nach der einschlägigen BGH-Rechtsprechung nicht vor, da die Rationalität seiner Entscheidung im konkreten Fall nicht vollständig in den Hintergrund trete. Im Übrigen habe das OLG Köln $\$ 4$ a Abs. 2 S. 1 Nr. 4 UWG trotz fehlender Anwendungsvoraussetzungen herangezogen, denn dafür müssten Vertragspartner der Beklagten, sprich des Werbeblocker-Betreibers, behindert werden. Zuletzt sei nicht nachzuvollziehen, warum im Rahmen des $₫ 4$ a UWG vom Gericht keine umfassende Interessenabwägung vorgenommen worden sei, obschon das Gesetz eine Beurteilung im konkreten Fall unter Berücksichtigung aller Umstän-

698 GRUR 2016, 1089. 
de verlange. An dieser Stelle hätte wiederum das Interesse der Nutzer angeführt werden müssen, die vollkommene Ausblendung an dieser Stelle sei angesichts der überragenden Bedeutung im Rahmen der gezielten Mitbewerberbehinderung nicht nachvollziehbar.

Weitere Kritik an der Entscheidung folgte in einem Beitrag von Nink ${ }^{699}$. Während sie die Entscheidung im Rahmen von $\$ 4$ Nr. 4 UWG noch befürwortet, hält sie die Annahme einer aggressiven Praktik gemäß $\$ 4 a$ UWG für abwegig. Das Angebot des Whitelistings anstelle der sonst durchgeführten Komplettblockade durch die Blacklist stelle einen wirtschaftlichen Anreiz für Webseitenbetreiber dar. Darin könne keine unzulässige Ausübung von Druck zu erkennen sein, zumal das Blacklisting zuvor als zulässig bezeichnet worden sei. Dies wiederum stehe im Widerspruch zu $\$ 4 \mathrm{a}$ Abs. 2 Nr. 5 UWG, der eine aggressive Handlung nahelegt, wenn Drohungen mit rechtlich unzulässigen Handlungen erfolgen. Nink möchte scheinbar im Umkehrschluss die fehlende Aggressivität herleiten, da bei Adblock Plus mit einer rechtlich zulässigen Handlung operiert werde. In diesem Zusammenhang weist sie zudem daraufhin, dass die Ausnutzung einer Machtposition stets eine Verschlechterung der Lage für den Betroffenen darstellen müsse. Dies sei indes durch das Whitelisting nicht der Fall, da im Gegenteil ein Mehr an Einnahmen im Vergleich zur Blacklist-Blockade erzielbar sei. Mithin verbessere die Whitelist-Funktion die wirtschaftliche Lage. Zuletzt stellt sie auf die zur Verfügung stehenden Ausweichmöglichkeiten der Webseitenbetreiber hin. Auffällig ist bei diesem Kommentar jedoch, dass die Verfasserin nicht wie das OLG Köln im Verhältnis Werbeblocker-Anbieter zum Werbekunden, sondern im Verhältnis zum Webseitenbetreiber argumentiert. Dies trifft zwar nicht die Entscheidung des OLG Köln, ist jedoch in sich konsequent, da ihrer Ansicht nach kein konkretes Wettbewerbsverhältnis zwischen Webseitenund Werbeblocker-Betreibern bestehe.

In einem weiteren Beitrag nimmt Krüger Stellung zum Urteil des OLG Köln ${ }^{700}$. Er findet Gefallen an der Idee der allgemeinen Marktbehinderung durch Adblock Plus und hält die Begründung des OLG Köln an dieser Stelle für sehr knapp. Für ihn stellt ein Werbeblocker eine Parallele zum massenhaften Verschenken von Ware dar, der den Bestand des Wettbewerbs gefährde. Zum Themenkomplex der unzulässigen Beeinflussung

699 CR 2017, 103. Die Autorin war zur Zeit der Veröffentlichung des Beitrags Syndikusrechtsanwältin und Datenschutzbeauftragte bei der Eyeo GmbH.

700 GRUR-Prax 2016, 322. 
nach $₫ 4$ a UWG enthält er sich eines Kommentars, worin sich die relativ oberflächliche Betrachtung des Urteils verdeutlicht.

Des Weiteren referenziert Gomille das Urteil des OLG Köln ${ }^{701}$, prüft aber im eigenen Gedankengang die lauterkeitsrechtliche Rechtslage für Werbeblockersoftware. Eine gezielte Mitbewerberbehinderung verneint er sowohl vor dem Hintergrund der Störung fremder Vertragsbeziehungen, als auch in der Fallgruppe der unlauteren Werbebehinderung. Den ersten Gedanken lehnt er ab, da nach deutschem Recht allein die Veröffentlichung der Werbung, nicht aber die Kenntnisnahme beim Nutzer geschuldet ist. Mangels von außen provozierter Leistungsstörungen könne keine Behinderung erkannt werden. Bei der Werbebehinderung arbeitet der Verfasser heraus, dass bei mittelbarer Werbeausschaltung strengere Maßstäbe gelten, so auch bei Internetwerbeblockern. Hier sei es der Nutzer, der unmittelbar blockiere. Die Software sei nur sein Werkzeug. Durch die Zwischenschaltung des Nutzers seien aber dessen Interessen im besonderen Maße zu berücksichtigen, insbesondere seine negative Informationsfreiheit. Will der Webseitenbetreiber dies nicht hinnehmen, müsse er die Werbeblocker-Nutzer eben ausschließen. Dieses Ergebnis möchte Gomille aber nur für reine Blacklist-Blocker gelten lassen. Er befürwortet die Entscheidung des OLG Köln, soweit es sie auf $₫ 4$ a UWG stützt. Eine vertiefte Auseinandersetzung mit dem Tatbestand bleibt er indes schuldig. Als eigenen Gedanken in diesem Zusammenhang nennt der Verfasser noch, dass ein Werbeblocker seine Funktion als Selbsthilfewerkzeug des Nutzers einbüße, wenn die Whitelist seine Wirkung für fremde Zwecke kommerzialisiere. Darüber hinaus sieht Gomille beim Whitelisting auch $\$ 4 \mathrm{Nr} .4$ UWG als erfüllt an, da dies eine Parallele zum Verteilen von „Bitte keine Werbung"-Aufklebern in der analogen Welt sei, die die Werbematerialien des die Aufkleber verteilenden Unternehmers von dieser Bitte ausnehmen.

Ein Beitrag von Beater ${ }^{702}$ bezeichnet die Entscheidung des OLG Köln zu $\$ 4$ a UWG sogar als ,auf einem Auge blind“, da es die Interessen der Verbraucher vollkommen außer Acht lasse. Das Störgefühl der Entgeltpflicht für die Aufnahme von umsatzstarken Webseiten auf die Whitelist versucht Beater dabei wie folgt aufzulösen: der Nutzer könne seine Aufmerksamkeit für Werbung theoretisch gegen Entgelt an Webseitenbetreiber „verkaufen“, freilich wird er dies nicht durchsetzen können. Der Whitelist-Anbieter nehme dem Nutzer diese Durchsetzung ab und fordere ein Entgelt für die Aufnahme in die Whitelist von den Webseitenbetreibern. Dieses

701 GRUR 2017, 241.

702 AfP 2017, 277, 281. 
Entgelt müsse an sich an die Nutzer ausgezahlt werden. Da aber auch der Whitelist-Anbieter seine Dienste nicht kostenfrei erbringen müsse, finde eine Verrechnung des theoretischen Anspruchs auf Auszahlung des „Aufmerksamkeitsentgelts" mit dem theoretischen Anspruch auf Vergütung für die differenzierende Werbeblockersoftware statt. Beater hält demnach die Finanzierung von Adblock Plus für äquivalent zur Finanzierung von kostenfreien Webseiten, weil in beiden Fällen ein Dritter für die Leistung an den Nutzer aufkomme. Beide Modelle seien deshalb nicht wettbewerbswidrig.

Nach der Entscheidung des OLG Köln erschien zudem die erste Monographie zum Thema Werbeblocker im Internet von Stephanie Raithe ${ }^{703}$. Die Verfasserin kommt dabei an diversen Stellen zu anderen Ergebnissen als die herrschende Rechtsprechung. So bejaht sie vor allem das Vorliegen einer gezielten Behinderung von Webseitenbetreibern sowie eine allgemeine Marktstörung durch Werbeblocker ${ }^{704}$. Das Vorliegen einer aggressiven Geschäftspraktik nach $₫ 4$ a UWG lehnt sie gemeinsam mit einer kartellrechtlichen Behinderung ab, wobei sie in beiden Komplexen die Machtposition kongruent prüft ${ }^{705}$. Abschließend hält sie bei dem Angebot eines Werbeblockers eine Anstiftung zu einer Verletzung des Rechts am eingerichteten und ausgeübten Gewerbebetrieb und zu einer vorsätzlichen, sittenwidrigen Schädigung gem. $\mathbb{S} 823$ Abs. 1, 826, 830 Abs. 1 S. 1, Abs. 2, 1. Alt. BGB für erfüllt ${ }^{706}$.

Die Vielzahl von Meinungen im Schrifttum, gemeinsam mit den teils divergierenden Rechtsprechungsfundstellen, führte dazu, dass der Streitstand im Detail sehr unübersichtlich wurde. Diese Unübersichtlichkeit gepaart mit dem technisch enorm komplizierten Sachverhalt stellte für eine gewisse Zeit eine starke Unsicherheit über die Zukunft von Werbeblockern im Internet her. Allenthalben war jedoch eindeutig, dass eine verbindliche Entscheidung erst durch den BGH erfolgen würde. Durch den zeitlichen Vorsprung des in Köln eingeleiteten Verfahrens Axel Springer versus Eyeo, das bereits im Jahr 2016 durch Einlegung der Revision nach Karlsruhe gelangte, gerieten die übrigen Verfahren dadurch etwas in den Hintergrund. Denn jede lauterkeitsrechtliche Entscheidung eines Oberlandesgerichts konnte nur als vorläufig anzusehen sein, bis der BGH sein Urteil zu Internetwerbeblockern fällen sollte.

703 Diese Monographie beruht auf der Masterarbeit der Verfasserin.

704 Raithel, Werbeblocker im Internet, S. 172, 186.

705 Raithel, Werbeblocker im Internet, S. 192, 201f.

706 Raithel, Werbeblocker im Internet, S. 210. 
e) Instanzrechtsprechung nach dem Urteil des OLG Köln

Gleichwohl ist die Instanzrechtsprechung nach dem Urteil des OLG Köln keineswegs als uninteressant zu bezeichnen. Denn Eyeo hatte vor allem Argumentationsbedarf, um die weiterhin befassten Gericht davon abzuhalten, ebenfalls $₫ 4 \mathrm{a}$ UWG anzuwenden und damit das Whitelisting-Geschäftsmodell zu gefährden. Und tatsächlich hatte Eyeo in allen weiteren Verfahren Erfolg.

Die erste gerichtliche Entscheidung nach dem OLG Köln stammt vom LG Hamburg und stellt damit noch eine erstinstanzliche Entscheidung dar. Im November 2016 urteilte das LG Hamburg im Rechtsstreit zwischen Spiegel Online und Eyeo und wies die Klage gegen den Vertrieb von Adblock Plus ab ${ }^{707}$. Mit der herrschenden Rechtsprechung und in Abgrenzung zum Urteil einer anderen Kammer des LG Hamburg im Mai 2016 lehnte die 15. Zivilkammer das Vorliegen einer gezielten Behinderung nach $\$ 4$ Nr. 4 UWG ab. Insoweit liege weder eine erkennbare Verdrängungsabsicht vor, noch könne von einer produktbezogenen Behinderung ausgegangen werden. Letzteres scheide schon mangels körperlicher Einwirkung auf ein fremdes Produkt aus. Aufgrund der Eigenheiten der Internetkommunikation wirke der Werbeblocker nur in der Sphäre des Nutzers, indem bestimmte Befehle zum Laden von Seitenelemente unterblieben. Daraus folge, dass eine aus redaktionellem Inhalt und Werbeelementen bestehende Webseite keine integrale Datei sei. Der klagende Webseitenbetreiber ergreife keine technischen Schutzmaßnahmen, die umgangen würden. Hinzu komme, dass es die eigenständige Entscheidung des Nutzers sei, einen Adblocker zu installieren und damit eigene schutzwürdige Interessen an der Abwehr unerwünschter Werbung, Schutz vor Malware und Kontrolle der eigenen Daten durchzusetzen. Die durch die Pressefreiheit gestützten Interessen der Webseitenbetreiber müssten dahinter zurücktreten.

Im Übrigen grenzte sich das LG Hamburg gegenüber dem OLG Köln ab und lehnte die Anwendung von $\$ 4$ a UWG auf den Fall Adblock Plus ab. Die Kammer ließ dabei im Rahmen der Prüfung einer unzulässigen Beeinflussung nach $\mathbb{S} 4 \mathrm{a}$ Abs. 1 Nr. 3 UWG offen, ob eine Machtposition der Betreiber von Adblock Plus bestehe. Es betrachtete bei der Prüfung nicht das Verhältnis zwischen Werbeblocker-Betreiber und Werbetreibenden, sondern prüfte die Ausnutzung einer Machtposition mit Blick auf den klagenden Webseitenbetreiber. Dies lehnte das LG Hamburg aber

707 LG Hamburg, Urteil vom 25.11.2016, 315 O 293/15, MMR 2017, 351. 
$\mathrm{ab}$, weil durch das Whitelisting-Angebot der Webseitenbetreiber weder zu einem irrationalen Verhalten verleitet, noch in seinem Urteilsvermögen beeinträchtigt werde. Die Nichtannahme des Angebots mache dies deutlich. Zudem stünden dem Webseitenbetreiber Reaktionsmöglichkeiten wie der Ausschluss der werbeblockenden Nutzer zu. Im Endeffekt stelle der Werbeblocker-Betreiber den Webseitenbetreibern eine weitere Möglichkeit zur Verbreitung von Werbung mit der Möglichkeit zur Erzielung von Mehreinnahmen zur Verfügung, was eine unzulässige Beeinflussung ausschließe.

Abschließend lehnte das LG Hamburg eine allgemeine Marktstörung nach $₫ 3$ Abs. 1 UWG und einen Missbrauch einer marktbeherrschenden Stellung nach $₫ \$ 33,18,19$ GWB ab. Im letzteren enthielt sich die Kammer einer Marktabgrenzung und lehnte auf nächster Stufe das Vorliegen eines missbräuchlichen Verhaltens ab.

Nach einer Dauer von ca. einem dreiviertel Jahr, in der keine neuen Gerichtsentscheidungen im Themenkomplex Internetwerbeblocker öffentlich bekannt wurden, verkündete das OLG München im August 2017 auf einen Schlag drei Berufungsurteile ${ }^{708}$ für alle anhängigen Münchener Verfahren, die allesamt als Beklagte die Eyeo $\mathrm{GmbH}$ auswiesen. Wie bereits in erster Instanz unterschied sich das Prüfungsprogramm in allen drei Verfahren, sodass in einem Verfahren lediglich UWG-Ansprüche ${ }^{709}$, in einem weiteren Verfahren UWG- und kartellrechtlichen Ansprüche ${ }^{710}$ und im letzten Verfahren neben den beiden vorgenannten Anspruchsnormen noch eine urheberrechtliche Prüfung hinzukam ${ }^{711}$.

In lauterkeitsrechtlicher Hinsicht lehnte das OLG München in allen drei Verfahren mit gleicher Begründung das Vorliegen einer gezielten Mitbewerberbehinderung und einer aggressiven Geschäftspraktik ab. Eine Besonderheit bei der Bewertung der gezielten Behinderung stellt dar, dass das OLG München die Anträge teils als zu weit gefasst ansah, weil die jeweiligen Kläger eine Untersagung jeglicher Art des Whitelistings begehrten. Dies hingegen könnten sie unter keinem Umstand fordern, da ein rein kostenpflichtiges Whitelisting schon keine geschäftliche Handlung gemäß $\ 2$ Abs. 1 Nr. 1 UWG darstelle. Ein kostenloses Whitelisting hin-

708 OLG München, Urteil vom 17.8.2017, U 2184/15 Kart, WRP 2017, 1365; Urteil vom 17.8.2017, U 2225/15 Kart, GRUR 2017, 1147; Urteil vom 17.8.2017, 29 U 1917/16, WRP 2017, 1377.

709 Im Fall Süddeutsche./. Eyeo, Az. 29 U 1917/16, WRP 2017, 1377.

710 Im Fall RTL./. Eyeo, Az. U 2184/15 Kart, WRP 2017, 1365.

711 Im Fall ProSieben Sat1./. Eyeo, Az. U 2225/15 Kart, GRUR 2017, 1147. 
gegen stelle keine gezielte Behinderung dar. Das OLG München lehnte das Vorliegen einer Verdrängungsabsicht ab, da die Existenz der Werbeblocker die Existenz der Online-Werbung voraussetze. Im Rahmen der Interessenabwägung war wiederum die Nutzerautonomie das entscheidende Argument für die Zulässigkeit der Software. Die Pressefreiheit der Webseitenbetreiber sah auch der Münchener Kartellsenat nicht als durchgreifendes Argument an, Werbeblocker zu verbieten. Schließlich müssten sich auch Presseunternehmen den Herausforderungen des Marktes stellen. In diesem Zusammenhang wurden außerdem wieder die technischen Schutzmaßnahmen als Alternativen der Webseitenbetreiber aufgezählt.

Im Rahmen des $\$ 4$ a UWG lehnte auch das OLG München den Kölner Sonderweg ab und verneinte eine unzulässige Beeinflussung gemäß $\mathbb{4} 4 \mathrm{a}$ Abs. 1 Nr. 3 UWG. Dabei wurde auf eine Auseinandersetzung mit dem Merkmal der Machtposition verzichtet, da jedenfalls keine Ausnutzung dieser erkennbar sei. Dies sei schon dem simplen Umstand geschuldet, dass bei fehlender Whitelisting-Funktion nur die noch einschneidender wirkende, aber lauterkeitsrechtlich nicht zu beanstandende Blacklist-Funktion verbliebe. Auch das OLG München stellte dabei - anders als das OLG Köln - im Vertikalverhältnis auf die Webseitenbetreiber, nicht auf Werbekunden, $a b$.

Die kartellrechtliche Prüfung endete beim Kartellsenat des OLG München an früher Stelle. Die vom LG München bereits vorgenommene Marktabgrenzung, wonach nicht auf den isolierten Markt der Werbeblocker, sondern auf den gesamten Internetwerbemarkt abzustellen sei, wurde bestätigt. Es komme also auf die Verbreitung von Adblock Plus unter allen deutschen Internetnutzern an. Selbst eine Verbreitung unter den Werbeblockerprogrammen von 90\% verhelfe Adblock Plus bei einer Adblockerrate von ca. 20\% nicht zur marktbeherrschenden Stellung. Das OLG München wählte dabei eine Analogie zu einem Lebensmitteldiscounter, der bestimmte Stammkunden haben mag, aber alleine aufgrund der treuen Stammkunden noch lange keine marktbeherrschende Stellung auf dem Gesamtmarkt der Lebensmittelhändler habe. Zudem erkannte der Senat keine kartellrechtswidrigen Vereinbarungen nach $\$ 33$ Abs. 1 GWB iVm $₫ 1$ GWB, Art. 101 AEUV.

Schließlich hatten auch urheberrechtliche Ansprüche keinen Erfolg. Bei der Prüfung eines Eingriffs in das ausschließliche Recht an einem Computerprogramm nach $\$ \mathbb{S} 69 \mathrm{a}$, 69c UrhG ließ der Senat die Schutzfähigkeit der Webseite offen, da es weder einen rechtswidrigen Eingriff des Werbeblocker-Betreibers selbst noch der Internetnutzer erkannte. Für letzteres führte das OLG München eine Einwilligung zur Vervielfältigung im Ar- 
beitsspeicher der Nutzer durch den Webseitenbetreiber an. Argument an dieser Stelle war die fehlende Einrichtung technischer Schutzmaßnahmen. Nach demselben Muster schloss es eine Verletzung eines Datenbankrechts gem. $\$ 87 \mathrm{~b}$ UrhG aus, auch hier mangele es an einer rechtswidrigen Tat. Hier führt der Senat als Argument an, dass eine einzelne aufgerufene Unterseite eines Webportals kein wesentlicher Teil einer Datenbank darstelle. Ergänzend wurde erneut angeführt, dass die freie Zurverfügungstellung ohne technische Barrieren dem klägerischen Unterlassungsbegehren im Wege stehe. Zuletzt liege auch keine unerlaubte Bearbeitung oder Umgestaltung eines Datenbankwerks vor, da auch hier die obigen Ausführungen zur Einwilligung der Webseitenbetreiber Geltung beanspruchten.

Auf Zurückweisung der Berufung erkannte auch das OLG Hamburg ca. ein halbes Jahr später, das allein über lauterkeitsrechtliche Ansprüche zu befinden hatte ${ }^{712}$. Einen ungeschickt formulierten Hauptantrag, der allumfassend Blacklisting-Blocker verbieten sollte, hat das OLG Hamburg bereits am Fehlen einer geschäftlichen Handlung gemäß $\mathbb{2}$ Abs. 1 Nr. 1 UWG scheitern lassen, da eine dann kostenlose Software ohne Refinanzierung durch eine Whitelist schon kein taugliches Makrtverhalten darstelle. Zum Hilfsantrag, der die konkrete Gestaltung von Adblock Plus betraf, wurde wiederum zunächst die gezielte Mitbewerberbehinderung nach $\$ 4$ Nr. 4 UWG geprüft. Mit den altbekannten Argumenten der zumutbaren Alternativen für Webseitenbetreiber zum kostenfreien und werbefinanzierten Angebot ihrer Leistungen im Netz, der fehlenden Schutzvorkehrungen sowie der in einer Abwägung nicht überwiegenden Pressefreiheit lehnte der Senat diesen Vorwurf ab. Im Rahmen des $\mathbb{S} 4 \mathrm{a}$ UWG riss das OLG Hamburg zunächst die Frage der Anwendbarkeit an, ohne sie aber im Ergebnis zu entscheiden. Das Gericht liebäugelte mit der Ansicht nach Köhler, die Mitbewerber als Adressaten einer aggressiven Handlung ausschließen ${ }^{713}$. Eine Prüfung der Werbetreibenden als Adressaten wie beim OLG Köln komme mangels Klägervortrags nicht in Betracht. Selbst wenn man aber Webseitenbetreiber als Adressaten ansehe, läge kein Verstoß gegen $\ 4 \mathrm{a}$ UWG vor. Hauptargument war, dass letztlich eine Drohung mit einem zulässigen Handeln vorliege. Das zulässige Handeln sei demnach die Nichtaufnahme in die Whitelist, wenn keine Zahlung geleistet wird. Nach $₫ 4$ Abs. 2 S. 1 Nr. 5 UWG sei aber nur eine Drohung mit einem unzulässigen Handeln als Nötigung oder unzulässige Beeinflussung anzusehen. Dafür lagen jedoch laut OLG Hamburg keine Hinweise vor.

712 OLG Hamburg, Urteil vom 15.3.2018 - 5 U 152/15, WRP 2018, 604.

713 Vgl. Köhler/Bornkamm/Feddersen, \$4a Rn.1.27. 
Abschließend setzte sich der Senat noch in unüblicher Ausführlichkeit mit dem Tatbestand der allgemeinen Marktstörung auseinander, konnte jedoch auch hier keinen Grund für ein Verbot von Adblock Plus finden. Hauptargument des Gerichts war dabei die besondere Dynamik der Geschäftsmodelle im Internet, die ein Ausruhen auf dem status quo nicht erlaubten.

\section{f) Echo der neueren OLG-Urteile im Schrifttum}

Auch die zuvor dargestellten Urteile haben zu Reaktionen in der juristischen Literatur geführt. Diverse Autoren kommentierten die Urteile des OLG München. Wie bereits nach dem Urteil des OLG Köln kommentierte zunächst Alexander die Adblocker-Urteile ${ }^{714}$. Er begrüßte die lauterkeitsrechtlichen Wertungen, insbesondere die Ablehnung einer aggressiven Geschäftspraktik gemäß $\$ 4$ a UWG. Dadurch werde der Gesetzeskonkurrenz zwischen Kartell- und Lauterkeitsrecht Rechnung getragen und ersteres drohe nicht durch eine allzu weite Anwendung von $\$ 4$ a UWG unterlaufen zu werden. Bei der Beurteilung einer Machtposition komme es demgemäß auf $\mathbb{\$} 18 \mathrm{GWB}$ an. Für $\mathbb{4} 4 \mathrm{a}$ UWG bedürfe es eines besonderen Unlauterkeitsvorwurfs. Auch die kartellrechtliche Entscheidung befürwortete Alexander uneingeschränkt. Vor allem die Marktabgrenzung des OLG München hält er für zutreffend.

In einer weiteren Anmerkung stimmt Luckhaus den Münchener Urteilen $\mathrm{zu}^{715}$. Er geht mit den Ausführungen des Gerichts konform, bemängelt allein im Kontext von $₫ 4$ a UWG, dass die Entscheidung an dieser Stelle etwas knapp begründet sei. Dies vor allem vor dem Hintergrund, dass das OLG Köln zuvor an dieser Stelle den Hebel ansetzte, um einen Unterlassungsanspruch auszuurteilen. In einem Ausblick auf die Revision im Kölner und den Münchener Verfahren prognostiziert er eine Fortführung der BGH-Rechtsprechung aus der „Fernsehfee“-Entscheidung. Zudem ging er von einer Befassung des BVerfG aus, da die grundrechtlichen Fragen im Ergebnis streitentscheidend sein dürtten.

Ähnlich positioniert sich Ziegelmayer, der die Ansätze der Prüfung des $§ 4 a$ UWG der OLGe Köln und München gegenüberstellt ${ }^{716}$. Dabei stimmt

714 GRUR 2017, 1156.

715 MMR 2017, 765.

716 CR 2017, 668. 
er der Lösung des OLG München und dessen Argument der fehlenden Beeinträchtigung der Entscheidungsfreiheit der Webseitenbetreiber zu.

Weiterhin stimmt Raue dem OLG München in weiten Teilen $\mathrm{zu}^{717}$. Insbesondere im Bereich der UWG-Prüfung identifiziert er jedoch noch einige offene Fragen, die vor allem in der knappen Begründung der Ablehnung von $\mathbb{4} 4 \mathrm{a}$ UWG nicht deutlich wurden. Dabei handelt es sich zunächst um die systematische Anwendbarkeit von $\$ 4$ a UWG neben kartellrechtlichen Normen. Auch sei umstritten, ob Mitbewerber überhaupt in den Schutzbereich von $\$ 4$ a UWG fallen. Raue bejaht dies im Ergebnis. Im Übrigen vollzieht er die Entscheidung des OLG München zum Ausnutzen einer Machtposition nach, merkt jedoch an, dass der Whitelist-Anbieter nach Vertragsschluss tatsächlich keine aufdringliche Werbung mehr zulassen dürfe. Denn sonst würde sich der Anbieter widersprüchlich verhalten und gerade nur dem eigenen Gewinnstreben und nicht der Verbesserung des Internets für Nutzer dienen. In seinem abschließenden Ausblick begrüßt er es, dass durch die Einführung von technischen Zugriffsbeschränkungen für Adblocker-Nutzer zuletzt der Markt - und nicht etwa die Gerichte - entscheidet, was Bestand haben wird.

Im größeren Kontext kommentierte zudem Thomale die Urteile aus München ${ }^{718}$. Dieser Kommentator war zur Zeit seiner Beitragsverfassung Syndikus bei Axel Springer und damit Beteiligter in einer Vielzahl der vorgenannten Gerichtsentscheidungen, insbesondere den Kölner Verfahren sowie der Vielzahl von einstweiligen Verfügungsverfahren, die zum Teil zu Unterlassungsansprüchen gegen Werbeblocker-Betreiber führten. Erwartungsgemäß kritisierte er die Münchener Urteile, wobei er lediglich den lauterkeitsrechtlichen Tatbestand der gezielten Behinderung anspricht. Dabei bedauert er eine grundlegende Verkennung der BGH-Entscheidung im Fall des TV-Werbeblocker „Fernsehfee“. Er proklamiert ein grundsätzliches Recht der Webseitenbetreiber, ihr Produkt unbeeinträchtigt so anzubieten, wie sie es selbst anbieten wollen. Einen gezielten Eingriff folgert er zudem aus dem Vorliegen eines massiven Eingriffs in die Webseiten-Programmierung, der urheberrechtlich verboten sei. Damit verkennt er jedoch die ausführliche Prüfung des OLG München, das einen Urheberrechtsverstoß gerade nicht erkannte. Abschließend betont er noch die seiner Ansicht nach alles überragende Bedeutung der Pressefreiheit.

717 WRP 2017, 1363.

718 MMR 2017, 789. 
Einen Kommentar zum Urteil des OLG Hamburg lieferte $\mathrm{Kreutz}^{719}$. Er stimmte der Entscheidung vollumfänglich zu, insbesondere bei der Begründung der Ablehnung der gezielten Behinderung sowie einer allgemeinen Marktbehinderung. Im Rahmen von $\$ 4$ a UWG, bei dessen Prüfung das OLG Hamburg einen eigenen Lösungsweg entwickelte, zweifelt Kreutz an, dass die Fallgruppen der Nötigung und der unzulässigen Beeinflussung deckungsgleich seien. Er hält eine isolierte und ausdrückliche Prüfung der unzulässigen Beeinflussung für notwendig, weil in diesem Rahmen unter Umständen nicht auf $\$ 4$ Abs. 2 S. 1 Nr. 5 UWG hätte abgestellt werden können. Auch sei dann eine konkrete Auseinandersetzung mit den in den bisherigen Urteilen strittigen Tatbestandsmerkmalen der Machtposition, deren Ausnutzung und der wesentlichen Einschränkung der Fähigkeit des Betroffenen zu einer informierten Entscheidung nötig gewesen. Im Ergebnis sieht aber auch Kreutz $\mathbb{4}$ a UWG nicht als verwirklicht an.

Nach dem Urteil des OLG Hamburg im März 2018 und noch vor dem Urteil des BGH stellte sich der Meinungsstand folglich so dar, dass nur ganz wenige Stimmen eine gezielte Behinderung nach $\$ 4$ Nr. 4 UWG durch totale oder differenzierende Werbeblockade im Internet ernsthaft befürworteten. Dasselbe gilt für die allgemeine Marktbehinderung. Bei der Betrachtung des $\$ 4$ a UWG neigte die herrschende Meinung ebenfalls dazu, den Fall Internetwerbeblocker nicht als Verwirklichung des Verbots anzusehen. Dabei blieb lediglich die korrekte Anwendung der Norm noch umstritten. Neben dem OLG Köln ist keine Fundstelle ersichtlich, die das Vorliegen einer aggressiven Geschäftspraktik annahm. Im urheber- und kartellrechtlichen Bereich stellte sich das Meinungsbild vergleichbar dar, sodass auch hier keine durchgreifenden Bedenken an den Entscheidungen des OLG München erkennbar sind.

\section{g) Dissertationen zum Thema Werbeblocker im Internet}

In der Zeit vor Erlass des BGH-Urteils in Sachen Axel Springer gegen Eyeo erschien zudem die erste juristische Dissertation zum Thema Internetwerbeblocker von Oliver Kreutz unter dem Titel „Online-Angebote und Werbeblockersoftware“. Diese stellt eine lauterkeits- und zivilrechtliche Untersuchung des Themas dar. Sie verzichtet demnach auf eine Prüfung der urheberrechtlichen und kartellrechtlichen Problematik von Internetwerbeblockern. Im Rahmen der Prüfung der lauterkeitsrechtlichen Zulässigkeit

719 WRP 2018, 621. 
von Internetwerbeblockern widmet sich Kreutz intensiv dem Tatbestand der gezielten Behinderung gemäß $₫ 4$ Nr. 4 UWG. Nachdem er für differenzierende Werbeblocker im Wege einer einheitlichen Betrachtung das Vorliegen einer geschäftlichen Handlung bejaht ${ }^{720}$, votiert er nach ausführlicher Darstellung von Schriftum und Rechtssprechung auch für das Vorliegen eines konkreten Wettbewerbsverhältnis mit Webseitenbetreibern ${ }^{721}$. Die Prüfung der gezielten Behinderung erfolgt zunächst streng an den von der Rechtsprechung aufgezeigten Fallgruppen der kundenbezogenen, produktbezogenen und vertriebsbezogenen Behinderung, welche Kreutz aber alle ablehnt ${ }^{722}$. Sodann lehnt er auch die Fallgruppe der Werbebehinderung $\mathrm{ab}^{723}$, bevor er ausführlich eine gezielte Behinderung aufgrund einer Gesamtabwägung prüft. Seine Gesamtabwägung fällt dabei zugunsten der Zulässigkeit der (differenzierenden) Werbeblocker aus ${ }^{724}$. Die Prüfung des $\$ 4$ a UWG hingegen erfolgt nicht in selbiger Tiefe. Im Rahmen dieser Prüfung lehnt Kreutz das Bestehen einer Machtposition der Werbeblockerbetreiber $a b^{725}$. Zudem lehnt er die erhebliche Beeinträchtigung der Entscheidungsfreiheit der Webseitenbetreiber $\mathrm{ab}^{726}$. Dasselbe gilt für Werbenetzwerke und Werbetreibende, sodass er insgesamt keine Verletzung von $₫ 4$ a UWG annimmt ${ }^{727}$. Mangels besonderer Gefahr für die OnlineMedienlandschaft komme auch keine allgemeine Marktbehinderung nach $\$ 3$ Abs. 1 UWG in Betracht ${ }^{728}$. Bei der allgemein zivilrechtlichen Beurteilung prüft Kreutz nicht nur Deliktsrecht, sondern auch die Möglichkeit eines Vertragsschlusses über die Nutzung einer Webseite. Er erkennt zwar an, dass regelmäßig der Rechtsbindungswille der Nutzer fehlen wird ${ }^{729}$, prüft gleichwohl in Frage kommende Vertragstypen, insbesondere für den Fall einer Registrierung durch den Nutzer. Im Ergebnis geht Kreutz von einem typengemischten Vertrag mit miet-, dienst- und werkvertraglichen

720 Kreutz, Online-Angebote und Werbeblockersoftware, S. 134. Keine geschäftliche Handlung nimmt er bei rein unentgeltlichen Blacklist-Blockern an, S. 135.

721 Kreutz, Online-Angebote und Werbeblockersoftware, S. 173.

722 Kreutz, Online-Angebote und Werbeblockersoftware, S. 191, 210, 222.

723 Kreutz, Online-Angebote und Werbeblockersoftware, S. 227. Weitere geprüfte Fallgruppen sind Boykott, Betriebsstörung, Diskriminierung und Missbrauch von Nachfragemacht, die aber allesamt abgelehnt werden, S. 227-234.

724 Kreutz, Online-Angebote und Werbeblockersoftware, S. 267.

725 Kreutz, Online-Angebote und Werbeblockersoftware, S. 289f..

726 Kreutz, Online-Angebote und Werbeblockersoftware, S. 297.

727 Kreutz, Online-Angebote und Werbeblockersoftware, S. 298.

728 Kreutz, Online-Angebote und Werbeblockersoftware, S. 312.

729 Kreutz, Online-Angebote und Werbeblockersoftware, S. 350. 
Elementen aus ${ }^{730}$. Eine AGB-Klausel, die den Einsatz von Werbeblockern in einem solchen Vertrag verbieten würde, hält Kreutz für eine unangemessene Benachteiligung gemäß $₫ 307$ Abs. 1 BGB $^{731}$. Insgesamt ist die sehr ausführliche Dissertation von Kreutz ein gelungenes Werk, welche das Thema gut und überzeugend aufbereitet.

Eine weitere Dissertation mit dem Titel „Adblocking im Internet und seine lauterkeitsrechtliche Bewertung" legte Philipp Kiersch vor. Wie der Titel schon erahnen lässt beschränkt sich auch diese Bearbeitung auf die Rechtsfragen aus dem UWG. Die Dissertation wurde ebenfalls vor der BGH Entscheidung fertiggestellt. Den Schwerpunkt der Bearbeitung stellt ebenfalls die Prüfung der gezielten Behinderung gemäß $₫ 4$ Nr. 4 UWG dar. Kiersch lehnt eine gezielte Behinderung im Allgemeinen ab und hält diese nur in zwei Fallkonstellationen für möglich. Einerseits bei nicht ausreichender Aufklärung über die Wirkweise der Blockade, andererseits bei der Umgehung durch von Webseitenbetreibern eingerichteter Schutzmaßnahmen ${ }^{732}$. Nachgelagert prüft Kiersch die aggressive geschäftliche Handlung im Sinne von $₫ 4$ a UWG. Hier kommt er zum Ergebnis, dass eine Verwirklichung des Tatbestands in den bislang gerichtlich entschiedenen Fällen nicht anzunehmen sei, da durchschnittliche Gewerbetreibende dem ausgeübten Druck standzuhalten haben ${ }^{733}$. Diese Dissertation ist von erheblich geringererem Umfang als die Bearbeitung von Kreutz, beschränkt sich dafür auf die brisanten Prüfungen von $₫ 4 \mathrm{Nr} .4$ und $\$ 4$ a UWG.

Zuletzt legte Christina Julia Brüggemann eine Dissertation mit dem Titel „Die rechtliche Zulässigkeit von Online Werbeblockern unter besonderer Berücksichtigung der Pressefreiheit" vor. Die Arbeit beschränkt sich ebenfalls auf die Prüfung der lauterkeitsrechtlichen Ansprüche, insbesondere $\$ 4$ Nr. 4 UWG und $\$ 4$ a UWG. Bei der Prüfung der gezielten Behinderung kommt sie ebenfalls zum Ergebnis, dass Werbeblocker weder als Blacklistnoch als Whitelist-Blocker unzulässig sind ${ }^{734}$. Bei $\$ 4$ a UWG hält sie die Norm mangels geeigneten Schutzsubjekts für nicht anwendbar ${ }^{735}$. Gleichsam prüft sie die übrigen Merkmale der Norm und lehnt insbesondere im Rahmen der Prüfung der unzulässigen Beeinflussung die Machtposition

730 Kreutz, Online-Angebote und Werbeblockersoftware, S. 368f..

731 Kreutz, Online-Angebote und Werbeblockersoftware, S. 388.

732 Kiersch, S. 148.

733 Kiersch, S. 174.

734 Brüggemann, S. 228f..

735 Brüggemann, S. 235. 
des Werbeblockeranbieters $a^{736}$. Im Ergebnis lehnt sie auch eine Unzulässigkeit von Werbeblockern nach $₫ 4$ a UWG ab ${ }^{737}$.

h) Entscheidung des I. Zivilsenats des BGH in Sachen Axel Springer./. Eyeo wegen Adblock Plus

Das lang ersehnte Urteil des Bundesgerichtshofs in der Revision des Kölner Urteils erging am 19.4.2018, unmittelbar im Anschluss an die mündliche Verhandlung und zunächst in mündlicher Form. Im Ergebnis bestätigte der BGH die Entscheidung des OLG Köln und die Ansicht der herrschenden Meinung, wonach weder eine gezielte Behinderung nach $\$ 4$ Nr. 4 UWG noch eine allgemeine Marktbehinderung nach $\$ 3$ Abs. 1 UWG vorliege. In der vom OLG Köln kreativ gelösten Frage der aggressiven Praktik gemäß $₫ 4$ a UWG hingegen hob der BGH das Berufungsurteil auf. Im Ergebnis bestätigte der I. Zivilsenat damit die volle lauterkeitsrechtliche Zulässigkeit der streitgegenständlichen Software Adblock Plus. Über andere Rechtsgebiete hatte der BGH in diesem Fall nicht zu entscheiden.

Als Randnotiz ist zu bemerken, dass diese mündliche Urteilsverkündung als das erste Urteil des BGH überhaupt von den Medien gefilmt worden ist und danach zumindest in Teilen ausgestrahlt sowie in gesamter Länge im Internet verfügbar gemacht wurde. Möglich machte es eine Änderung des $\$ 169$ GVG, der durch das Gesetz über die Erweiterung der Medienöffentlichkeit in Gerichtsverfahren vom 8.10.2017, das am 18.4.2018 in Kraft getreten ist ${ }^{738}$. Der I. Zivilsenat hat die Möglichkeit genutzt und Videoaufnahmen der Urteilverkündung auf Grundlage von $\$ 169$ Abs. 3 S. 1 GVG erlaubt. Die gesamte mündliche Begründung kann - als YouTube-Clip im Internet nachvollzogen werden ${ }^{739}$.

Aus der mündlichen Begründung ließ sich bereits der grundsätzliche Gedankengang des BGH entnehmen. Im Rahmen der gezielten Mitbewerberbehinderung bejahte der I. Zivilsenat ohne viel Aufhebens die Mitbewerbereigenschaft zwischen Webseitenbetreiber und Werbeblockeranbie-

736 Brüggemann, S. 242.

737 Brüggemann, S. 253f..

738 BGBl. I S. 3546.

739 https://www.youtube.com/watch?v=yry3084J87M, zuletzt abgerufen am 31.5.2019. Von dem politisch fragwürdigen Account und den Kommentaren auf der Seite möchte sich der Verfasser ausdrücklich distanzieren, es ist allerdings die einzige dauerhaft zugängliche Quelle für die Videoaufnahmen. 
ter mit der eigenen Entscheidung in Sachen „Fernsehfee“ aus 2004. Bei der Bejahung der geschäftlichen Handlung stützte sich der Senat auf ein einheitliches, nicht in kostenfreies Blacklisting und Umsatz generierendes Whitelisting aufspaltbares Geschäftsmodell, das Adblock Plus zu Grunde liege. Im Tatbestand der gezielten Behinderung an sich verneinte er eine Verdrängungsabsicht des Werbeblockeranbieters, denn die Software sei abhängig von der Existenz des Internetwerbemarktes. Der BGH konnte auch keine unangemessene Beeinträchtigung der wettbewerblichen Entfaltung des Mitbewerbers, sprich des Webeseitenbetreibers, feststellen. Insbesondere sei keine unmittelbare produktbezogene Behinderung gegeben, weil die Änderung der Seitendarstellung nur im Gerät des Nutzers erfolge. Bei einer mittelbaren Produktbehinderung kam es sodann wieder zur Interessenabwägung. Der I. Zivilsenat nannte als entscheidendes Argument gegen die Webseitenbetreiber schlussendlich, dass es den Webseitenbetreibern zumutbar sei, erforderliche technische oder sonstige Schutzmaßnahmen gegen die Nutzung der eigenen Seiten mit Werbeblockern zu ergreifen. Die allgemeine Marktbehinderung lehnte der BGH knapp mit dem Fehlen entsprechender Feststellungen im Tatbestand des OLG Köln ab.

Die Ablehnung einer aggressiven Geschäftspraktik nach $₫ 4$ a UWG begründete der Senat damit, dass eine Machtposition nicht ausgenutzt werde sowie die Fähigkeit der vom OLG Köln in den Mittelpunkt gerückten Werbekunden zu einer informierten Entscheidung nicht wesentlich eingeschränkt sei. Hierbei war das Hauptargument, dass es bei den Werbekunden als zumeist erfahrenen Kaufleuten bzw. großen Handelsbetrieben fern liege, dass diese durch das Whitelisting-Angebot zu irrationalen Entscheidungen verleitet würden.

Die schriftlichen Entscheidungsgründe wurden sodann im Oktober 2018 vorgelegt und gaben tieferen Einblick in die Argumentation des Senats. Die Besprechung der schriftlichen Urteilsgründe erfolgt an späterer Stelle im Zusammenhang mit der rechtlichen Stellungnahme des Verfassers $^{740}$.

i) Urteile des Kartellsenats des BGH

Im Oktober 2019 erging dann im Revisionsverfahren zu einem der Urteile des OLG München das Urteil „Werbeblocker III“ durch den Kartellsenat

740 Ziffer C. I. 4. b). 
des $\mathrm{BGH}^{741}$. Die Entscheidung betrifft schwerpunktmäßig die kartellrechtlichen Probleme der Thematik.

Nur kurz ging der Kartellsenat auch auf lauterkeitsrechtliche Aspekte ein, zu denen der I. Zivilsenat zuvor noch nicht erschöpfend entschieden hatte: so hatte der Kartellsenat zu entscheiden, ob in dem Angebot von Adblock Plus ein unlauterer „Boykottauftruf“ als Fallgruppe des $\$ 4$ Nr. 4 UWG oder eine Irreführung der Nutzer nach $\$ \$ 5$, 5a UWG liege. Beides lehnte der Kartellsenat allerdings ab. Beim Boykottaufruf beruhte diese Entscheidung auf rechtlichen Gründen, weil die einzelnen Webseitenbetreiber als angeblich Verrufene aus der Whitelist nicht erkennbar sind. Die Entscheidung zur Irreführung beruhte auf den tatsächlichen Feststellungen der Instanzgerichte, welche eine Irreführung nach $\$ \$ 5$, 5a UWG nicht tragen. Insoweit hatten die Münchener Gerichte festgestellt, dass die konkrete Aufmachung von Adblock Plus die interessierten Nutzer hinreichend über das dahinter liegende Geschäftsmodell aufklärt.

Im Bereich des Kartellrechts hingegen hob der Kartellsenat des BGH das Urteil des OLG München (Az. U 2184/15 Kart) wegen Rechtsfehlern auf. Das OLG München hatte kartellrechtliche Ansprüche schon wegen der fehlenden Marktmacht abgelehnt, welche es auf Grundlage einer vom BGH als unvertretbar eingeschätzten Marktabgrenzung feststellte. Nach dem Urteil „Werbeblocker III“ habe das Berufungsgericht allerdings nicht das in ständiger Rechtsprechung angewendete Bedarfsmarktkonzept beachtet. Laut Kartellsenat kann es nicht darauf ankommen, welche Verbreitung der Werbeblocker im gesamten Internetwerbemarkt in Deutschland hat, sondern es muss auf die entgeltliche Dienstleistung der Aufnahme in die Whitelist abgestellt werden. Wegen dieser grundsätzlich anderen Ausrichtung schon zu Beginn der kartellrechtlichen Prüfung haben die Münchener Instanzgerichte in tatsächlicher Hinsicht den Sachverhalt nicht ausreichend aufgeklärt. Über diesen Umstand konnte der BGH auch nicht hinwegsehen und selbst entscheiden, weil er einen Missbrauch im Sinne von $\$ 19$ Abs. 2 GWB nicht mit Sicherheit ausschließen wollte. Im Ergebnis fehlten dem Kartellsenat auch an dieser Stelle tatsächliche Feststellungen, weil die Münchener Berufungsurteile stark von der lauterkeitsrechtliche Interessenabwägung geprägt sind. Die nach $\mathbb{1} 19$ Abs. 2 Nr. 1 GWB gebotene Interessenabwägung hätte aber speziell die kartellrechtliche Zielsetzung und besondere Verhaltenspflichten eines marktbeherrschenden Unternehmens mit einbeziehen müssen, was im Rahmen der tatsächlich vorgenommenen Interessenabwägung nach $\$ 4 \mathrm{Nr} .4$ UWG unterblieben

741 BGH, Urteil vom 8.10.2019, KZR 73/17, WRP 2019, 1572 - Werbeblocker III. 
ist. Der Kartellsenat hat die Sache deshalb an das OLG München zurückverwiesen.

Der BGH hat dabei auch „Segelanweisungen“ für die Beurteilung der kartellrechtlichen Prüfung gegeben. Im Rahmen der Frage der Marktbeherrschung durch Adblock Plus sowie einer etwaigen unbilligen Behinderung gemäß $₫ 19$ Abs. 2 Nr. 1 GWB müsse aufgeklärt werden, ob eine ausreichende marktimmanente Kontrolle des Preissetzungsspielraums des Werbeblockerbetreibers aus für Werbseitenebetreibern effektiven Alternativmaßnahmen existiert. Hier kommt es also auf die Durchsetzung von Zugangssperren und Anti-Adblocklösungen an, wobei aber eine Einführung einer reinen Bezahlschranke keine geeignete Alternativmaßnahme ist, weil sie einen Wechsel des Geschäftsmodells von kostenfreien „Content-Providern" darstellen würde. Entscheidend ist also, ob ein We bseitenbetreiber nicht nur die Wahl zwischen Annahme und Ablehnung des Whitelistangebots habe, sondern daneben weitere Handlungsoptionen gegeben sind. Zudem erhält das OLG München den Auftrag, aufzuklären, ob der Werbeblockerbetreiber bloß Gewinne des Werbemarktes abschöpft oder sich neben der Finanzierung der eigenen Produktenwticklung und -pflege einen angemessenen und risikoadäquaten Gewinn zurückhält. Die neuerliche Tatsachenfeststellung wird auch die konkrete Ausgestaltung der Whitelistverträge, die gleichbleibende Anwendung bei allen Kunden des Werbeblockerbetreibers sowie eine Angemessenheitsprüfung der Freischaltungskriterien erfassen.

Nach dem Urteil „Werbeblocker III“ wiederholte der Kartellsenat in der anderen anhängigen Revision nach dem OLG München (Az. 2225/15 Kart) seine Ausführungen zum Kartellrecht in seinem Urteil vom 10.12.2019742. Neben der bereits oben skizzierten Kritik an der Entscheidung des OLG München ergänzt der Kartellsenat in seinem Urteil vom 10.12.2019 jedoch, dass neben der möglichen Verwirklichung von $\mathbb{1} 19$ Abs. 2 Nr. 1 GWB andere kartellrechtliche Verbote zu Recht vom OLG München verworfen worden sind. So ist nicht von einer horizontalen Wettbewerbsbeschränkung und insbesondere nicht von einem koordinierten Bündel vertikaler Verträge im Sinne eines "Sternvertrags" auszugehen. Es fehlt auch an einer vertikalen Wettbewerbsbeschränkung. Auch das Vorliegen von $\$ 21$ Abs. 2 sowie Abs. 3 Nr. 3 GWB lehnt der Kartellsenat ab.

Abseits von kartellrechtlichen Ansprüchen führt der Kartellsenat in seinem Urteil vom 10.12.2020 außerdem noch kurz zum von der dortigen Klägerin behaupteten Verstoß gegen ihr „virtuelles Hausrecht“ aus. Ohne

742 BGH, Urteil vom 10.12.2019 - KZR 57/19, K\&R 2020, 302. 
in der Sache zu entscheiden, ob es ein solches Recht überhaupt gebe, lehnt der BGH es unter Hinweis darauf ab, dass die Webseitenbetreiberin jedenfalls nicht erkennbar ein Verbot des Einsatzes von Werbeblockern ausgesprochen oder den Zugang zu ihren Internetseiten technisch oder vertraglich begrenzt hat.

Nach den Urteilen des Kartellsenats des BGH ist der Kampf um die Werbung im Internet noch immer nicht beendet. Gleichwohl werden die kartellrechtlichen Scharmützel aller Voraussicht nicht dazu führen, dass Adblock Plus vom Markt verschwindet. Vielmehr ist zu erwarten, dass Einzelheiten des Geschäftsmodells und des Marktverhaltens auf Seiten des Betreibers der Blockersoftware angepasst werden. Denn die Urteile des Kartellsenats enthalten keine Aussagen, die ein Totalverbot von Werbeblockern begründen können, insoweit lässt der Kartellsenat keinen Zweifel an der Richtigkeit der Entscheidung des I. Zivilsenats in "Werbeblocker II“ aufkommen ${ }^{743}$.

\section{j) Fazit: Welche Fälle werden aktuell erfasst, welche nicht?}

Tritt man nun einen Schritt zurück von den konkreten Streitgegenständen der oben dargestellten Gerichtsverfahren und der dazu ergangenen Literatur, stellt sich die Frage, was nun konkret von der Rechtsprechung erfasst wird - und welche Fälle nicht unmittelbar entschieden worden sind.

Mit Blick auf die Seite der Werbeblocker betreffen die Urteile, insbesondere alle obergerichtlichen Urteile sowie eingangsinstanzliche Urteile in Hauptsacheverfahren die konkrete Verletzungsform durch Adblock Plus. Damit wird in erster Linie das Angebot eines kombinierten Filterwerbeblockers betroffen, also eine Blockersoftware, die sowohl Blacklists einbezieht als auch eine Whitelist-Funktion zu Öffnung der Sperre enthält. Dabei ist zu beachten, dass in allen Verfahren die wirtschaftliche Komponente der Kostenpflicht der Aufnahme in die Whitelist für große Webseiten hinzukommt. Gegenstand war also immer ein kommerzielles, aber indirekt finanziertes Werbeblocker-Geschäftsmodell. Weiterhin von Bedeutung ist, dass die „Adblock Plus-Urteile“ eine Browsererweiterung betreffen, die vom Nutzer aktiv installiert werden muss. Innerhalb dieser Erweiterung hat der Nutzer zudem Entscheidungsmöglichkeiten hinsichtlich der Art der Werbeblockade. Er kann also die reine Blacklist-Blockade,

743 Vgl. insoweit auch die Anmerkung des Verfassers zum Urteil „Werbeblocker III“ in WRP 2019, 1578. 
die nach den Kriterien der Acceptable Ads Initiative differenzierende Whitelist-Blockade oder eine individualisierte Whitelist-Blockade ggf. mit situativer Abschaltung der Blockadefunktionen wählen und ständig ändern.

Die übrigen von Axel Springer angestrengten einstweiligen Verfügungsverfahren betreffen Adblock Plus ähnliche Filterblocker, die jedoch teilweise leichte Unterschiede aufweisen. So waren das dem LG Stuttgart zur Entscheidung vorliegende Programm „Blockr"744 und das beim LG Hamburg im Eilverfahren behandelte Programm „Admop"745 Add-ons für das mobile Betriebssystem von Apples Smartphones und Tablets, die im AppStore kostenpflichtig heruntergeladen werden mussten. Im Gegensatz zu Adblock Plus wurde hier also der Nutzer zur Zahlung eines einmaligen Betrags verpflichtet. Beide Softwares waren in technischer Hinsicht jedoch auch Filterblocker, die standardmäßig als Blacklist-Blocker ausgestaltet waren und bei denen durch den Nutzer Whitelists aktiviert werden konnten, wobei sie nicht mit der Acceptable Ads Initiative verbunden waren. Gegenstand der Rechtsprechung waren folglich auch direkt durch Nutzer finanzierte Werbeblockerprogramme.

Beim LG Berlin war hingegen ein Browser für mobile Geräte mit inkludiertem Adblocker Gegenstand der Entscheidung ${ }^{746}$, also nicht lediglich ein Browser-Add-on. Auch dieser Browser war für das mobile Apple Betriebssystem konzipiert und kostete den Nutzer bei Download einen einmaligen Kaufpreis. Auch der hier schon inkludierte Werbeblocker beruhte auf der Filtertechnologie. Über die Möglichkeit einer Whitelist lässt sich dem Tatbestand des Urteils nichts entnehmen. Auch der Umstand eines fest in einem Browser integrierten Werbeblockers war also bereits Gegenstand der Rechtsprechung.

Trotz der nicht unerheblichen Zahl von Gerichtsurteilen ist nicht jede Art von Internetwerbeblocker von der Rechtsprechung explizit behandelt worden. So betreffen die Urteile allesamt die Filtertechnologie im Endgerät des Nutzers. Nicht hingegen entschieden ist der Fall, dass ein Internet Service Provider eine Filtertechnologie einsetzt und Datenpakete in der Internetinfrastruktur blockiert. Bei dieser Konstellation dürften auch kaum Argumente aus den Urteilen übertragbar sein, da es in diesem Fall keinen vermittelnden Nutzer gibt, dessen Interessen zu beachten wären, und auch keine sich spontan aufdrängenden Schutzmechanismen für Webseitenbetreiber erkennbar sind.

744 LG Stuttgart, Urteil vom 10.12.2015 - 11 O 238/15, K\&R 2016, 362.

745 LG Hamburg, Urteil vom 3.5.2016 - 308 O 46/16, CR 2016, 782.

746 LG Berlin, Urteil vom 8.12.2015 - 16 O 449/15, K\&R 2016, 360. 
Ein weiterer nicht behandelter Fall ist das „Perceptual Adblocking", das nicht auf Filterlisten beruht, sondern den Inhalt von Werbeanzeigen in Sekundenbruchteilen scannt und dann ausblendet. Hier wiederum zeigen sich erhebliche Parallelen zu den Filterblockern, weil die Blockade auch hier im Endgerät des Nutzers erfolgt. Ähnliches gilt bei reinen Trackingblockern, die mehr beiläufig Werbung blockieren.

Ein letzter denkbarer und nicht unmittelbar erfasster Fall ist die Bereitstellung von blockenden Host-Dateien, Blacklists für Router oder sonstige außerhalb des Browsers, sondern an Betriebssystem oder Netzwerkroutern ansetzende Blockiermethoden. Da hier keine besondere Software installiert wird, sondern lediglich die Funktionalität sowieso bestehender Softoder Hardware genutzt wird, kann nur auf die Bereitstellung entsprechender Listen abgestellt werden. Bei dieser Überlegung schließt sich sodann d er Kreis zu den Filterblockern wie Adblock Plus. Denn kein einziges U rteil musste sich mit der Frage auseinandersetzen, ob die Bereitstellung v on (Black-) Filterlisten an sich ein rechtlich zulässiges Verhalten ist. Dies w urde, wenn überhaupt, nur am Rande behandelt, da es dem Streitgegenstand folgend nur um das Angebot der gesamten Blockiersoftware ging.

Eine Stellungnahme zur Erstreckung der ergangenen Rechtsprechung auf diese Fälle wird unten unter Ziffer C. I. 5 abgegeben.

Mit Blick auf die klagenden Betreiber der Webseiten zeigt sich ebenfalls, dass vornehmlich nur eine bestimmte Art von Webseiten zur Bewertung stand: Online Portale von Zeitungen oder Fernsehsendern. Der Fokus lag damit durchweg auf Webseiten des Online-Journalismus und auf Multimediaplattformen. Nicht konkret geprüft wurde hingegen die Sachlage bei regelmäßig mit Werbung versehenen und gleichsam stark frequentierten Webseiten wie Suchmaschinen oder sozialen Netzwerken. Insgesamt gehen alle Entscheidungen von betroffenen Webseiten ohne Registrierungspflicht oder Notwendigkeit eines Log-ins aus. Wenn man jedoch von solchen Webseiten ausgeht könnte die Argumentation ebenfalls abweichen, insbesondere bei der Frage der Pressefreiheit. Auch hier soll in Ziffer C. I. 6. geprüft werden, ob sich die Rechtslage an dieser Stelle anders darstellt.

\section{Rechtliche Analyse und Stellungnahme zur Rechtsprechung}

In diesem Abschnitt erfolgt zunächst die rechtliche Analyse der Werbeblocker-Problematik auf Grundlage des „Standardfalls“ Adblock Plus (siehe dazu lit. a.). Diese Analyse betrifft schwerpunktmäßig das Lauterkeits- und Urheberrecht. Die kartellrechtliche Befassung erfolgt im Nachgang. Nach 
der Analyse und rechtlichen Bewertung durch den Verfasser wird Stellung zum Urteil Werbeblocker II des BGH genommen (siehe dazu lit.b.). Es folgt ein Ausblick auf die Folgen des vorgenannten BGH-Urteils (siehe dazu lit. c.). Sodann werden Phänomene bewertet, die mit Internetwerbeblockern im weiteren Sinne vergleichbar sind (siehe dazu lit.d.)

\section{a) Stellungnahme zur Rechtslage}

Der nachfolgenden Stellungnahme liegt - in Kürze zusammenfasst - der Fall zu Grunde, der auch den meisten Gerichten zur Entscheidung vorlag. Dabei handelt es sich um eine multifunktionale Werbeblocker-Software, die vom Nutzer aktiv installiert werden muss und durch einfach verständliche Steuerung oder als reiner Blacklist-Blocker, als Whitelist-Blocker genutzt werden kann. Bei der Whitelist-Funktion kann auf eine vom Anbieter gestellte und der Refinanzierung der Software dienende Freischaltungsliste zurückgegriffen werden oder eine individuell einstellbare Whitelist erstellt werden. In der reinen Blacklist-Funktion blockt die Software jede Werbung, wobei hier außer Betracht bleiben soll, dass die Blacklists an sich ständiger Pflege bedürfen, um die effektive Werbeblockade zu bewerkstelligen. Bei der Whitelist-Funktion ist - wie bei Adblock Plus - die Kooperation mit dem Whitelist-Pfleger notwendig und kann bei Erreichen einer gewissen, vorab formulierten Schwelle kostenpflichtig sein. Wird nicht kooperiert, erfolgt keine Freischaltung durch die Whitelist, selbst wenn alle anderen zur Aufnahme in die Whitelist erforderlichen Kriterien erfüllt sind. Auf die dritte Funktion der individuell modifizierten Whitelist-Regeln kommt es wegen der weitgehenden Nutzerautonomie nicht an, da die Erwägungen zu den anderen Funktionen erst recht bei dieser Variante gelten. Andere Formen von Werbeblockern werden in Ziffer C. I. 5. behandelt.

\section{aa) Lauterkeitsrecht (einschließlich allgemeines Zivilrecht)}

Im Rahmen des Lauterkeitsrechts besteht eine Schwierigkeit der Bewertung darin, dass es sich bei Werbeblockersoftware wie Adblock Plus um ein kombiniertes Produkt aus Blacklist- und Whitelist-Blocker handelt. Deshalb lässt sich bei Betrachtung des konkreten Angebots eine Trennung zwischen reinem Blacklist-Blocker und der Whitelisting-Funktion nicht ohne logische Brüche vornehmen. Die von den Klägern teils durch An- 
tragsstellung vorgenommene Trennung zwischen beiden Ausprägungen in einigen Rechtsstreiten beruhte scheinbar auf der Erwägung, dass die absolute Blockade auf Grundlage einer Blacklist als intensivster Eingriff in den gesamten Online-Werbemarkt angesehen wurde. Whitelisting führt hingegen zu einem Weniger an blockierten Werbeelementen. Gleichsam hat diese potentiell geringere Blockierintensität keinen Einfluss auf eine Webseite, deren Betreiber keine Aufnahme auf die Whitelist angefragt hat oder dessen Anfrage mangels Erfüllung sachlicher Werbekriterien abgelehnt worden ist. Für diese Seite wirkt Adblock Plus in beiden Funktionen gleich. Aus der Sicht eines derart vom Adblocking betroffenen Webseitenbetreibers mag das Blacklisting ein allgemeines Phänomen sein, wobei das Whitelisting eine individuelle Behinderung und nach dieser Logik die intensivere Eingriffsstufe darstellt.

Trotz der unterschiedlichen Wirkung der verschiedenen Funktionen ist die Werbeblocker-Software aber als Ganzes zu beurteilen, was vor allem bei Merkmalen wie dem Vorliegen einer geschäftlichen Handlung gemäß $\$ 2$ Abs. 1 Nr. 1 UWG sowie eines konkreten Wettbewerbsverhältnis gemäß $\mathbb{2}$ Abs. 1 Nr. 3 UWG Bedeutung gewinnt. Die nachfolgende rechtliche Analyse erfolgt demnach nicht getrennt nach reinen Blacklistund differenzierenden Whitelist-Blockern. Im Rahmen der eingleisigen Prüfung wird jedoch explizit darauf hingewiesen, sollten andere Angebote auf dem Markt der Filterblocker, die unter Umständen ein anderes Geschäftsmodell als Adblock Plus verfolgen, anders zu beurteilen sein.

Die lauterkeitsrechtliche Prüfung beginnt mit einem vorgelagerten Teil, der sich mit dem für alle Verbotstatbestände des UWG notwendigen Vorliegen einer geschäftlichen Handlung befasst (siehe dazu Ziffer (i)). Sodann wird entsprechend der Rechtsprechung das Vorliegen einer gezielten Mitbewerberbehinderung nach $\ 4$ Nr. 4 UWG geprüft (siehe dazu Ziffer ii)), eine Stellungnahme zur allgemeinen Marktbehinderung nach \3 Abs. 1 UWG abgegeben (siehe Ziffer (iii)) und eine Prüfung einer aggressiven Geschäftspraktik im Sinne von $\$ 4$ a UWG vorgenommen (siehe Ziffer (iv)).

\section{(i) Vorliegen einer geschäftlichen Handlung}

Ausgehend von der Legaldefinition der geschäftlichen Handlung in $\mathbb{} 2$ Abs. 1 Nr. 1 UWG ergeben sich bei der zu bewertenden Software auf den ersten Blick keine Probleme. Nach der Legaldefinition ist jedes Verhalten einer Person zugunsten des eigenen oder eines fremden Unternehmens 
vor, bei oder nach einem Geschäftsabschluss erfasst, das mit der Förderung des Absatzes oder des Bezugs von Waren oder Dienstleistungen oder mit dem Abschluss oder der Durchführung eines Vertrags über Waren oder Dienstleistungen objektiv zusammenhängt.

Das Angebot einer für den Nutzer kostenfreien Software wie Adblock Plus, ist nur vordergründig ein Indiz für das Fehlen einer geschäftlichen Handlung. In dem Anbieten eines kommerziellen Produkts, das dem Endnutzer wegen indirekter Finanzierung durch Dritte kostenfrei angeboten werden kann, ist recht deutlich eine geschäftliche Handlung zu erblicken. Insofern ist das Angebot der Software ein Verhalten des Anbieters zugunsten des eigenen Unternehmens, da im Endeffekt Gewinne erzielt werden sollen. Mit Blick auf die finanzierenden Whitelisting-Verträge ist das Angebot auch ein Verhalten vor einem Geschäftsabschluss - und zwar mit den potentiellen Kunden der Whitelist. Die Förderung des Absatzes der kostenpflichtigen Freischaltungsdienstleistung steht auch unschwer erkennbar im objektiven Zusammenhang mit dem kostenfreien Angebot der Software. Ohne Werbeblocker-Software ist die Freischaltung für den erst durch die Software geschaffenen Markt des „geblockten Netzes“ wertlos.

Eine künstliche Aufspaltung eines kombinierten Produkts wie Adblock Plus ist nicht statthaft. Man darf sich also nicht auf den Standpunkt stellen, dass ein Teil der Software unter Umständen isoliert betrachtet keine geschäftliche Handlung darstellen würde. Der Umstand, dass es möglich ist, Adblock Plus und ähnliche Angebote kostenlos herunterzuladen und sodann in der reinen Blacklist-Funktion oder einer nur individuellen Whitelist zu nutzen, kann nicht zu einer geteilten Bewertung führen. Die Erweiterung des Blacklist-Blockers um die Option, mit der Nutzer die kommerzielle Whitelist verwenden können, führt zur „Alles-oder-Nichts“Bewertung. Wollte ein Werbeblocker-Anbieter also das Angebot so ausgestallten, dass es nicht als geschäftliche Handlung im Sinne des UWG verstanden wird, müsste er theoretisch eine eigenständige Software ohne die kommerzielle Whitelist-Option anbieten - sozusagen ein „Adblock Light“.

Jedoch bedarf es auch bei reinen Blacklist-Blockern, die ggf. durch individuelle Freischaltbefehle ergänzt werden können, eines genaueren Blicks auf das Vorliegen einer geschäftlichen Handlung. Das bloße Abstellen auf die fehlende Refinanzierung im Sinne monetärer Leistungen durch Nutzer oder Dritte führt nicht zwingend zum Ausschluss der geschäftlichen Handlung. Zu Recht weist Alexander darauf hin, dass auch die Hingabe von Daten durch Nutzer als eine Art Gegenleistung qualifiziert werden könn- 
te $^{747}$. Soweit das Verhalten der Nutzer eines kostenfreien Werbeblockers nämlich von dessen Anbieter getrackt, analysiert und nutzbar gemacht werden, kann bei kommerzieller Nutzung dieser Datensätze ebenfalls eine geschäftliche Handlung vorliegen. Nach demselben Argumentationsmuster wie beim indirekt kostenpflichtigen Whitelisting wäre die Software dann nämlich ein Verhalten vor einem Geschäftsabschluss und in objektivem Zusammenhang mit der Absatzförderung von Dienstleistungen. Diese Dienstleistungen können im datengetriebenen Wirtschaftsumfeld zur Zeit der Bearbeitung mannigfaltig sein, etwa eine Beratung auf Grundlage von Erkenntnissen über Nutzerverhalten oder Bereitstellung von Daten zur Speisung und Verbesserung von Algorithmen. Die pauschale Schlussfolgerung einer fehlenden geschäftlichen Handlung bei Fehlen von monetärer Kompensation durch Nutzer oder Whitelisting-Kunden verkennt, dass in der Internetwirtschaft oft eine „Metaebene“ der Finanzierung möglich ist. Daten sind insoweit der Rohstoff für Big Data, die durch Data Mining Prozesse „raffiniert“ werden und schlussendlich kommerziellen Wert erhalten. Das Fehlen einer geschäftlichen Handlung kommt einzig dann in Betracht, wenn in altruistischer Weise eine Software angeboten und gepflegt wird, ohne dabei jegliches kommerzielle Interesse zu verfolgen.

Dies wiederum führt dazu, dass ein Unternehmen als Anbieter von Werbeblockern sich praktisch nie auf das Fehlen einer geschäftlichen Handlung berufen können wird. Denn selbst beim oben genannten Beispiel eines „Adblock Light“ wird ein Wirtschaftsunternehmen irgendeine Art von Geschäftsförderung bezwecken, sei dies allein ein Hinweis auf ein „Upgrade“ zur voll funktionalen, kommerziellen Software. Überall wo eine kostenlose Software Teil eines Geschäftsmodells im Wortsinne ist, ist der Anwendungsbereich des UWG eröffnet. Heraus fallen einzig private Entwickler, wie in den Anfangsjahren der Adblocker noch anzutreffen waren. Im Zuge der Kommerzialisierung sind solche praktisch jedoch nicht mehr anzutreffen.

Unkompliziert ist zuletzt der Fall, dass eine Werbeblocker-Software für den Nutzer gegen Entgelt angeboten wird. Dann ist eine geschäftliche Handlung ohne weiteres anzunehmen. 
(ii) Gezielte individuelle Behinderung eines Mitbewerbers, $\mathbb{4}$ Nr. 4 UWG

Angesichts der in der herrschenden Rechtsprechung durchgängig abgelehnten Unlauterkeit auf Grundlage von $\$ 4$ Nr. 4 UWG und der sehr ausführlichen Auseinandersetzung mit diesem Thema durch Kreutz ${ }^{748}$ beschränkt sich die Prüfung dieses Tatbestands auf die grundlegenden Merkmale und punktuelle nennenswerte Aspekte. Durch den ausreichenden Fundus an Interessenabwägungen im Schriftum und Rechtsprechung ist eine weitere ausufernde Stellungnahme an dieser Stelle schlicht überflüssig. Deshalb wird im gebotenen Umfang eine eigene Bewertung der drei maßgeblichen Tatbestandsmerkmale gegeben.

\section{(1) Vorliegen eines konkreten Wettbewerbsverhältnisses}

Anders als beim Merkmal der geschäftlichen Handlung reicht die Legaldefinition der Mitbewerber in $\$ 2$ Abs. 1 Nr. 3 UWG nicht aus, um den Fall der Werbeblocker angemessen zu lösen. Dies liegt nicht zuletzt an der offenen Formulierung, wonach jeder Unternehmer, der mit einem oder mehreren Unternehmern als Anbieter oder Nachfrager von Waren oder Dienstleistungen in einem konkreten Wettbewerbsverhältnis steht, als Mitbewerber anzusehen ist. Ohne Zuhilfenahme der Rechtsprechung kann nicht abgesehen werden, ob ein notwendiges konkretes Wettbewerbsverhältnis vorliegt.

Da die Mitbewerberstellung im konkreten Verhältnis zwischen Anspruchsteller und Anspruchsgegner vorliegen muss, wird zunächst ein Webseitenbetreiber als Anspruchsteller herangezogen. Im weiteren Verlauf wird auch auf die Mitbewerberstellung von Werbenetzwerken eingegangen.

Die Rechtsprechung wendet bei der Auslegung des konkreten Wettbewerbsverhältnisses einen weiten Maßstab an. Dies wird mit dem grundsätzlichen Interesse an einem wirksamen lauterkeitsrechtlichen Individualschutz begründet ${ }^{749}$. Der BGH wendet bei der Prüfung der Mitbewerberstellung folgende essentiell komprimierte Definition an: Ein konkretes Wettbewerbsverhältnis besteht nicht nur dann, wenn zwei Parteien gleichartige Waren oder Dienstleistungen innerhalb desselben Endverbraucher-

748 Kreutz, Online-Angebote und Werbeblockersoftware, S. 173ff.

749 Ständige Rechtsprechung des $\mathrm{BGH}$, aus der jüngeren Rechtsprechung etwa WRP 2017, 1085 - Wettbewerbsbezug. 
kreises abzusetzen suchen. Es besteht vielmehr auch dann, wenn zwischen den Vorteilen, die eine Partei durch eine Maßnahme für ihr Unternehmen oder das eines Dritten zu erreichen sucht, und den Nachteilen, die die andere Partei dadurch erleidet, eine Wechselwirkung in dem Sinne besteht, dass der eigene Wettbewerb gefördert und der fremde Wettbewerb beeinträchtigt werden kann ${ }^{750}$. Daraus lassen sich die zwei Fälle des Substitutions- und des Behinderungswettbewerbs entnehmen ${ }^{751}$.

Um einen Fall des Substitutionswettbewerbs handelt es sich offensichtlich nicht. Das Angebot eines Werbeblockers oder auch einer Freischaltungsdienstleistung für eine Whitelist ist weder eine gleiche, noch eine gleichartige Dienstleistung zum Bereitstellen von Werbeplätzen gegen Entgelt (bei Webseitenbetreibern) oder der Zurverfügungstellung von werbenahen Dienstleistungen (bei Werbenetzwerken).

Ein Behinderungswettbewerb ist hingegen zu bejahen. Denn der Vorteil des Werbeblocker-Anbieters durch seine Software liegt in der Schaffung eines Marktes, zu welchem nur der Anbieter selbst einen Zugang einrichten kann. Die Nachteile der Webseitenbetreiber liegen in den nicht nur potentiellen, sondern greifbaren Einschränkungen bei der Vermarktung der eigenen Werbeflächen. Der erhöhte Einsatz von Werbeblockern führt zu geringeren Download-, Klick- und sonstigen „Conversion“-Zahlen, die wiederum zur Abrechnung gegenüber den Werbenden üblich sind. Daraus ergibt sich auch ohne Schwierigkeiten das Vorliegen der geforderten Wechselwirkung der Wettbewerbsförderung der Werbeblocker-Anbieter mit der Beeinträchtigung der Webseitenbetreiber. Ein Einsatz der Software führt zwangsläufig zur Beeinträchtigung der Werbeausspielung und -abrechnung. Auf der Ebene der Subsumtion des geltenden Gesetzeswortlauts einschließlich der durch die Rechtsprechung geformten Definition muss ein konkretes Wettbewerbsverhältnis demnach bei konsequenter Anwendung bejaht werden. Der Werbeblockeranbieter ist damit als Mitbewerber der Webseitenbetreiber anzusehen.

Hinzu kommt, dass der BGH im „Fernsehfee“-Urteil ${ }^{752}$ bereits einen im Prüfungspunkt des Wettbewerbsverhältnisses ähnlich gelagerten Fall zu entscheiden hatte - und eine Mitbewerberstellung bejahte. Die wenig technisch, sondern vor allen Dingen wirtschaftlich geprägte Prüfung des konkreten Wettbewerbsverhältnisses beim TV-Werbeblocker weist auch erhebliche Ähnlichkeiten zum aktuellen Online-Werbeblocker auf. In bei-

750 BGH, Urteil vom 10.4.2014 - I ZR 43/13, WRP 2014, 1307 - nickelfrei.

751 Köhler/Bornkamm/Feddersen, UWG, $\mathbb{~} 2$, Rn. 108a, 109b.

752 BGH, Urteil vom 24.6.2004 - I ZR 26/02, GRUR 2004, 877 - Werbeblocker I. 
den Fällen steht auf Seiten des Medienanbieters ein werbefinanziertes, für den Nutzer kostenloses Angebot. Ebenso ist in beiden Fällen ein Produkt ersichtlich, das dem Nutzer Hilfe leistet, Werbeelemente aus seiner Wahrnehmung zu bannen. Ein Unterschied liegt jedoch darin, dass der TV-Werbeblocker gegen Entgelt und monatliche Abonnementkosten finanziert worden ist, während ein kombinierter Whitelist-Blocker ein indirektes Finanzierungsmodell anwendet.

Der BGH argumentierte im Fall „Fernsehfee“ wie folgt: Der Werbeblocker-Anbieter wandte sich mit seinem Angebot genau wie der Medienanbieter an Konsumenten - wenn auch mit umgekehrter Zielrichtung. Während ein Medienanbieter möglichst viele Zuschauer zu erreichen versucht, um sein Angebot lukrativ zu machen, wendet sich der Anbieter des Blockers an Zuschauer, die statt der Werbung lieber Sendebeiträge eines zu dieser Zeit werbefreien Senders sehen wollten. Schon eine geringere Anzahl von Werbezuschauern mindere laut BGH aus der Sicht der Werbekunden die Attraktivität der vom Medienanbieter angebotenen Werbesendeplätze und könne daher den Absatz eben jener Plätze behindern.

Überträgt man dieses Judiz auf Internetwerbeblocker zeigt sich eine hohe Schnittmenge. Auch hier wird von beiden Seiten um Konsumenten gebuhlt, die entweder die Webseiten mit Werbung betrachten oder umgekehrt die Software nutzen. Ebenfalls mindert eine geringere Anzahl von Besuchern einer Webseite, welche die dort ohne Software an sich ausgelieferten Werbeanzeigen wegen des Einsatzes eines Werbeblockers nicht mehr wahrnehmen, die Attraktivität der Werbeplätze für die Werbekunden. Dass der Vorteil des TV-Werbeblockeranbieters in einem unmittelbaren Entgelt vom Nutzer liegt, der Vorteil beim kommerziellen Whitelisting dagegen in der Schaffung eines erst nachfolgend zur indirekten Finanzierung genutzten Marktzugangs liegt, rechtfertigt keine andere Bewertung. In beiden Fällen ist der Vorteil im Endeffekt geldwert. Wann dieser monetäre Erfolg eintritt, ist weniger entscheidend, als der Umstand, dass die Attraktivität der Werbeplätze unmittelbar gemindert wird. Eine Mitbewerberstellung zwischen Webseitenbetreiber und Werbeblockeranbieter ist demnach anzunehmen.

Eine Besonderheit wohnt allerdings dem Fall „Adblock Plus“ inne, die mit Recht thematisiert worden ist: zur Finanzierung des Werbeblockers wird pikanterweise der Webseitenbetreiber herangezogen. Webseitenbetreiber sind folglich potentielle Abnehmer der Freischaltungsdienst- 
leistung, womit sie auch als sonstige Marktteilnehmer anzusehen $\operatorname{sind}^{753}$. Die gleichzeitige Qualifizierung ein und derselben Person als Mitbewerber wie auch als sonstiger Marktteilnehmer bereitete der 37. Zivilkammer des Landgerichts München I wie auch Köhler scheinbar ein unüberbrückbares Störgefühl. Den durch die Werbeblockersoftware herbeigeführten Bedarf für die Freischaltungsdienstleistungen sehen beide als kartellrechtlich zu klärende Frage an und entziehen ihn daher dem lauterkeitsrechtlichen Tatbestand der Mitbewerberbehinderung. Die Beeinträchtigung der Webseitenbetreiber müsste dann im Vertikalverhältnis nach $\$ 4$ Nr.1 UWG a.F. bzw. $\$ 4 a$ UWG n.F. geprüft werden. Diese Ansicht geht mit einer hier nicht befürworteten Aufspaltung des Geschäftsmodells des kommerziellen Whitelisting in das Angebot der Software auf erster Stufe und der Freischaltung auf zweiter Stufe einher. Wenn man jedoch eine solche Aufspaltung vornehmen möchte, steht die Qualifikation als Mitbewerber und als sonstiger Marktteilnehmer nicht in einem logischen Konflikt. Denn auf der ersten Stufe - dem isolierten Angebot der Software - kann eine Mitbewerberstellung angenommen werden, ohne dass Webseitenbetreiber sonstige Marktteilnehmer wären. Für eine rein kartellrechtliche Bewertung dieser Frage sprechen keine triftigen Gründe und widersprechen gar dem Grundsatz der Doppelkontrolle ${ }^{754}$. Auf der zweiten Stufe - dem isolierten Freischaltungsangebot an die Webseitenbetreiber - kommt dann aber mangels Substitution oder Behinderung kein konkretes Wettbewerbsverhältnis in Betracht, sondern nur eine Stellung als sonstiger Marktteilnehmer.

Soweit in verwandten Fällen eine Werbeblockersoftware an Nutzer nur gegen Entgelt vertrieben wird, liegt ein konkretes Wettbewerbsverhältnis nach den obigen Erwägungen erst recht vor. Der im Rahmen der Prüfung der geschäftlichen Handlung angerissene Fall, in welchem ein Werbeblockeranbieter eine Gegenleistung in Form der Datenhingabe begehrt, um diese nachfolgend zu monetarisieren, führt ebenfalls zu einer Mitbewerberstellung. Hier gelten dieselben Regeln wie beim kommerziellen Whitelisting. Es kann nämlich im Sinne eines effektiven Schutzes vor Behinderung keinen Unterschied machen, auf welche Weise ein Behinderungswettbewerb zuletzt in Gewinn gemünzt wird. Ob hierfür der Nutzer direkt, der Webseitenbetreiber indirekt oder gar ein Vierter als Nutznießer zahlt, ändert die Qualität der Beeinträchtigung der Webseitenbetreiber

753 Vgl. LG München I, Urteil vom 27.5.2015 - 37 O 11843/14, WRP 2015, 927; Köhler, WRP 2014, 1017, 1021.

754 Vgl. Köhler/Bornkamm/Feddersen, UWG, $\$$ 4, Rn. 4.18. 
durch die Beeinflussung der Werbeausspielung und -abrechnung nicht. Ein Fall, in welchem das Angebot einer Werbeblockersoftware zwar eine geschäftliche Handlung darstellt, jedoch kein konkretes Wettbewerbsverhältnis begründet wird, ist nach hiesigem Verständnis nicht möglich.

Stellt man hingegen auf Seiten der Anspruchsteller nicht auf einen Webseitenbetreiber, sondern auf ein Werbenetzwerk ab, verändert sich die Lage. Denn ein Werbenetzwerk wird nicht in originär eigenen Positionen beeinträchtigt. Ein Werbenetzwerk ist ein Intermediär zwischen Webseitenbetreiber und Werbenden, der beiden Enden der Wertschöpfungskette einen Dienst zur Vereinfachung des Werbeprozesses erbringen kann. Es verfügt hingegen nicht über eigene Werbeplätze, die gemäß der BGH-Argumentation im „Fernsehfee“-Fall durch den Werbeblocker in ihrer Attraktivität beeinträchtigt werden können. Das Werbenetzwerk muss den Markt folglich so hinnehmen, wie er sich zu einem gewissen Zeitpunkt präsentiert. Durch die Bündelung von fremden Werbeplätzen und der Schaffung einer bequemen Plattform für Werbende verdient sich ein Werbenetzwerk eine Provision. Ob ein Werbeplatz hingegen einen Abnehmer findet oder besser, ob ein Werbeplatz durch die Nutzung von Werbeblockersoftware nicht mehr vermittelt werden kann, stellt eine mittelbare Folge dar. Im Rahmen des Behinderungswettbewerbs stellt sich hier also die Frage, ob es sich noch um ein wechselwirkendes Verhältnis handelt oder schon eine nicht ausreichende rein reflexartige Beeinträchtigung ${ }^{755}$ der Werbenetzwerke vorliegt.

Dies könnte man zugunsten des konkreten Wettbewerbsverhältnisses entscheiden, wenn man als Faktum heranzieht, dass Werbeblocker im ganz maßgeblichen Umfang Filterbefehle für von Adservern bezogene Werbeelemente ausführen und damit in der Sphäre des Werbenetzwerks wirken. Praktisch sind es auch die Werbenetzwerke, die maßgeblichen Einfluss auf die Standardisierung von Werbemitteln haben und für die Ausspielung von „inakzeptabler“ Werbung mitverantwortlich sind. Der weitere Umstand, dass sich Werbenetzwerke wie Webseitenbetreiber über die Whitelist freischalten lassen können und es wohl denkbar ist, dass Adserver-URLs von nicht gewhitelisteten Werbenetzwerken blockiert werden, obschon ein Webseitenbetreiber sich selbst hat freischalten lassen, sprechen für ein Wettbewerbsverhältnis. So ist bei Lichte betrachtet auch davon auszugehen, dass das kommerzielle Whitelisting durch seine Wirkungen dazu geeignet ist, ein bestimmtes Werbenetzwerk aus seiner Mittelposition in der Werbeausspielungskette zu verdrängen. Dies alles stellt

755 Vgl. Köhler/Bornkamm/Feddersen, UWG, $\$ 2$, Rn. 109a. 
mehr dar als eine bloß reflexartige Beeinträchtigung. Auch Werbenetzwerke sind folglich als Mitbewerber der Werbeblockeranbieter anzusehen.

Dieses Ergebnis kann vor dem Hintergrund neuester Entwicklungen bei der Eyeo $\mathrm{GmbH}$, die über die Acceptable Ads Platform ${ }^{756}$ eine Art eigenes Werbenetzwerk aufbaut, mittlerweile sogar über das Argument des Substitutionswettbewerbs gelöst werden. Denn durch diese neue Plattform können adressierte Werbende mittlerweile wählen, ob sie ein klassisches oder eben das Whitelist-Werbenetzwerk mit der Werbeplatzierung beauftragen.

\section{(2) Behinderung}

Da bereits im Großteil aller Fallkonstellationen das konkrete Wettbewerbsverhältnis aus dem Gesichtspunkt des Behinderungswettbewerbs gefolgert worden ist, ist es logisch zwingend auch das Merkmal der Behinderung anzunehmen. Unter Behinderung wird nach herrschender Meinung die Beeinträchtigung der wettbewerblichen Entfaltungsmöglichkeiten eines Mitbewerbers verstanden ${ }^{757}$. Die Behinderung kann sich dabei auf alle Wettbewerbsparameter des Mitbewerbers wie beispielsweise Absatz, Bezug, Werbung oder Finanzierung beziehen ${ }^{758}$. Die Eignung der geschäftlichen Handlung zur Behinderung genügt, eine solche muss also nicht tatsächlich eingetreten $\operatorname{sein}^{759}$.

Diese Behinderung ist mit Blick auf Webseitenbetreiber insbesondere mit Blick auf den Absatz ihrer Dienstleistung der Zurverfügungstellung von Werbeplätzen, auf die Platzierung von Eigenwerbung und auf die generelle Finanzierung des eigenen Angebots greifbar. Ähnliches gilt im Verhältnis zu Werbenetzwerken, wobei auch hier auf die bereits beim Wettbewerbsverhältnis angeführten Umstände zu verweisen ist. Als Intermediär sind diese wohl nicht durch die Entwertung eigener Werbeplätzen und im Refinanzierungsinteresse von kostenlosen Angeboten betroffen. Gleichsam ist die teils direkt auf Werbenetzwerke, insbesondere deren Adservern, abstellende Wirkung eine Beeinträchtigung der Entfaltungsmöglichkeiten der Netzwerke. So kann die Blockade aller von einem Adserver ausgelieferten Werbeelemente den Absatz der Vermittlungs- und Abwick-

756 S.o. Ziffer C. I. 1.f).

757 Vgl. etwa BGH, Urteil vom 11.10.2017, I ZR 210/16, GRUR 2018, 317 - Portierungsauftrag.

758 BGH, Urteil vom 24.6.2004 - I ZR 26/02, GRUR 2004, 877 - Werbeblocker I.

759 Köhler/Bornkamm/Feddersen, UWG, $\$ 4$, Rn. 4.6. 
lungsdienstleistungen intensiv stören. Daran ändert sich im Übrigen auch nichts, wenn man Werbenetzwerke und konkret Eyeo als Mitbewerber qua Substituierbarkeit ansieht. Die Behinderungsthematik wird dadurch nicht ausgeschlossen oder abgemildert.

\section{(3) Gezieltheit}

Das Merkmal der Behinderung alleine kann jedoch nicht zu einem Verbot einer geschäftlichen Handlung führen. Vielmehr erfordert $₫ 4$ Nr. 4 UWG durch das Erfordernis, dass die Behinderung gezielt sein muss, besondere unlautere Merkmale der Behinderung. Ohne auf die dogmatischen Einzelheiten einzugehen, soll an dieser Stelle das grundsätzliche Prüfungsprogramm des BGH kurz skizziert werden, um sodann ein Einschätzung mit Blick auf Webseitenbetreiber und Werbenetzwerke abzugeben.

(a) Prüfungsmaßstab der Rechtsprechung

Nach ständiger Rechtsprechung des BGH prüft der I. Zivilsenat mit folgendem Definitionssatz ${ }^{760}$ :

"Eine unlautere Behinderung von Mitbewerbern setzt eine Beeinträchtigung der wettbewerblichen Entfaltungsmöglichkeiten der Mitbewerber voraus, die über die mit jedem Wettbewerb verbundene Beeinträchtigung hinausgeht und bestimmte Unlauterkeitsmerkmale aufweist. Unlauter ist die Beeinträchtigung im Allgemeinen dann, wenn gezielt der Zweck verfolgt wird, Mitbewerber an ihrer Entfaltung zu hindern und sie dadurch zu verdrängen, oder wenn die Behinderung dazu führt, dass die beeinträchtigten Mitbewerber ihre Leistung am Markt durch eigene Anstrengung nicht mehr in angemessener Weise zur Geltung bringen können. Ob diese Voraussetzungen erfüllt sind, lässt sich nur aufgrund einer Gesamtwürdigung der Umstände des Einzelfalls unter Berücksichtigung der Interessen der Mitbewerber, Verbraucher und sonstiger Marktteilnehmer sowie der Allgemeinheit beurteilen"

760 Zitiert nach BGH, Urteil vom 12.1.2017, I ZR 253/14, GRUR 2017, 397 - World of Warcraft II. 
Die erste zu prüfende Frage ist, ob gezielt der Zweck verfolgt wird, Mitbewerber in ihrer Entfaltung zu hindern und sie damit zu verdrängen. Diese Alternative wird regelmäßig als Verdrängungsabsicht bezeichnet, erschöpft sich jedoch nicht in der subjektiven Zielsetzung, sondern bedarf eine konkrete objektive Verwirklichung ${ }^{761}$.

Entsprechende Fälle in diesem Kontext sind rar und soweit ersichtlich wurde noch in keiner obergerichtlichen Entscheidung die Verdrängungsabsicht angenommen. Möglich wäre eine Verdrängungsabsicht vor allem im Preiswettbewerb, in welchem ein Mitbewerber ökonomisch schlicht unsinnig günstige Preise aufruft, um Mitbewerber vom Markt zu verdrängen. Hingegen reicht hier keine rein abstrakte Gefahr aus ${ }^{762}$. Der Verdrängung wohnt eine Absolutheit inne, die eine Verdrängung vom konkreten Markt insgesamt erfordert. Liegen lediglich Einschränkungen in gewissen Teilaspekten der wettbewerblichen Entfaltung auf einem bestimmten Markt vor, kann nicht von einer Verdrängung gesprochen werden. Es bedarf also ähnlich dem Kartellrecht einer Marktabgrenzung, um eine Verdrängung von eben diesem Markt feststellen zu können. Beruhen neue Geschäftsmodelle hingegen auf dem (Fort-)Bestehen aktuell vorhandener Angebote am Markt, kann schon logischerweise nicht von einer Verdrängung gesprochen werden ${ }^{763}$. Solche abhängigen oder abgeleiteten Geschäftsmodelle stehen und fallen mit dem „Mutterangebot“, sodass kein Interesse an einer Verdrängung bestehen kann.

Die zweite zu prüfende Frage ist, ob die Behinderung dazu führt, dass die beeinträchtigten Mitbewerber ihre Leistung am Markt durch eigene Anstrengung nicht mehr in angemessener Weise zur Geltung bringen können. Die Auflösung des unbestimmten Gesetzeswortlauts der gezielten Behinderung mit einer weiteren offenen Formulierung führt zum Erfordernis einer Interessenabwägung. Im Rahmen einer dann vorzunehmenden Gesamtwürdigung der Umstände des Einzelfalls unter Berücksichtigung der Interessen der Mitbewerber, Verbraucher und sonstiger Marktteilnehmer sowie der Allgemeinheit haben die befassten Gerichte verständlicherweise eine hohe Einschätzungsfreiheit. Abstrakte Regeln zur Vornahme der Interessenabwägung bestehen nicht, vielmehr versucht die Kommen-

761 Vgl. Köhler/Bornkamm/Feddersen, UWG, $\mathbb{\$}$ 4, Rn. 4.9; Büscher, GRUR 2018, 1, 7.

762 BGH, Urteil vom 30.3.2006, I ZR 144/03, GRUR 2006, 596 - 10\% billiger; Urteil vom 2.10.2008, I ZR 48/06, GRUR 2009, 416 - Küchentiefstpreis-Garantie.

763 So in den Fallgestaltungen bei BGH, Urteil vom 22.6.2011, WRP 2011, 1469 Automobil-Onlinebörse; Urteil vom 30.4.2014, WRP 2014, 839 - Flugvermittlung im Internet. 
tarliteratur an dieser Stelle eine Bildung von Fallgruppen. Die gezielte Behinderung ist damit eine deutsche Ausprägung des an sich systemfremden „Caselaws“. Mangels zwingender Bindungswirkung früherer Entscheidungen kann eine Fallgruppe jedoch immer nur Anhaltspunkte für die Bewertung zukünftiger Fälle geben. Fallgruppen helfen insoweit auch vor allem dort, wo ein Standardfall zu beurteilen ist. Neuartige Fälle, die zwischen diesen weitestgehend anerkannten Fallgruppen liegen, müssen jedoch aufgrund konkreter und sorgfältiger Ermittlung und Abwägung der Interessen entschieden werden.

(b) Gezielte Behinderung von Webseitenbetreibern

Der zweistufigen Prüfung des BGH folgend gilt für die gezielte Behinderung eines Webseitenbetreibers Folgendes.

(aa) Verdrängungsabsicht

Bei der Frage nach der Verdrängungsabsicht muss beachtet werden, dass ein Internetwerbeblocker ein abhängiges Produkt ist. Egal welche kommerzielle Strategie der Werbeblockerbetreiber beim Vertrieb der Software verfolgt, die Software ist nur dann für den Nutzer interessant, wenn die Medienumgebung Anlass zur Blockade bietet. Im Extremfall eines werbefreien Mediums könnte ein Werbeblocker logischerweise nicht existieren. Im Übrigen gilt: je mehr Werbung dem Nutzer ausgespielt wird, desto eher wird er sich gestört fühlen und ein Bedürfnis für einen Werbeblocker haben. Werbeblocker bedienen unter anderem das Bedürfnis nach Eindämmung fremdbestimmter Kommunikationsaufforderung. Sie geben dem Adressaten ein Werkzeug zur Vermeidung von unerwünschter Werbung mitsamt allen daran hängenden Prozessen wie Tracking oder Virengefahr. Bei der Frage der Verdrängung macht es aber im Ergebnis keinen Unterscheid, ob die Software dem Nutzer gegen Entgelt überlassen wird oder aber indirekt finanziert wird. In beiden Fällen liegt keine Verdrängungsabsicht vor, weil weder objektive Hinweise auf die absolute Verdrängung vorliegen, noch nachvollziehbare Motive für eine Absicht der Verdrängung im Rechtssinne erkennbar sind.

Bei einer für den Nutzer kostenpflichtigen Software kann nicht darauf geschlossen werden, dass es dem Anbieter nur auf den eigenen Absatz ankommt. Die Argumentation, dass der Anbieter bei Forderung einer 
einmaligen Zahlung nur im Hier und Jetzt agiert und die absolute Verdrängung von kostenfreien Medien im Internet bezweckt, greift zu kurz. Denn ein Anbieter einer Software hat selbst ein Interesse möglichst lange am Markt verfügbar zu sein und damit immer neue zahlende Kundschaft zu generieren. Eine Verdrängungsabsicht wäre nur dann denkbar, wenn in einem Schwung nahezu jeder Internetnutzer die Software „kaufen“ würde und dann das werbefinanzierte Internet einen raschen Todeskampf verliert. Der Softwareanbieter hätte seinen einmaligen Umsatz gemacht und müsste sodann seinen Betrieb einstellen, weil es kein Bedürfnis mehr für das Produkt gibt. Ein solches Szenario ist jedoch nicht realistisch, weil ein kostenpflichtiges Angebot im konkreten Markt nicht ausreichend attraktiv ist.

Im Internet kann die oben genannte Fallgruppe der unlauteren Preisunterbietung wegen der oft zitierten „Umsonst-Kultur“ (jedenfalls aktuell) generell nicht funktionieren. Eine Preisüberbietung kann aber schon logischerweise nicht zur Verdrängungsabsicht führen. Preise können zudem im Verhältnis der hier maßgeblichen Mitbewerber kein wichtiger Umstand sein, weil die Leistungen nicht substituierbar sind und kein Preisvergleich möglich ist. Der strategische Ansatz eines einmaligen Kaufpreises zeugt insgesamt aber mehr davon, dass nicht die Masse der Internetnutzer angesprochen wird, sondern ein bewusst agierender und zahlungsbereiter Nutzer. Dies ist eine Nische, die faktisch keine Verdrängung herbeiführt. Jeder Rückschluss auf eine Verdrängungsabsicht ist deshalb verfehlt.

Doch auch bei einem indirekten Finanzierungsmodell a la Adblock Plus kann keine absolute Verdrängung erkannt werden. Konkret fordert Eyeo etwa eine erfolgsabhängige Vergütung von Webseitenbetreibern oder Werbenetzwerken. Das bedeutet gleichzeitig, dass ohne Erfolg gar keine Vergütung anfällt. Allein deshalb ist das Geschäftsmodell von dem Fortbestehen des aktuellen status quo abhängig und eine Verdrängung der werbefinanzierten Medien aus dem Web widersinnig. Der Erfolg des Geschäftsmodells erfordert eine besondere Balance an Verbreitung der Software. Denn eine zu hohe Verbreitung der Werbeblockersoftware würde den Bedarf für die Software beim Nutzer auf lange Sicht negieren. Bei einer nahezu allumfassenden Ausstattung von Nutzern mit Werbeblockern würden werbefinanzierte Webseiten nicht mehr existieren können. Wenn aber das etablierte Modell der Werbefinanzierung aufhören würde zu existieren, gäbe es weder einen Bedarf für Werbeblocker, noch für die finanzierende Freischaltung von Werbung. Der Betreiber eines Whitelist-Geschäftsmodells wird also ein Interesse daran haben, dass ein beachtlicher Teil der Nutzer noch als „Nährgrundlage“ des werbefinanzierten Internets existiert. 
Im Rahmen strategischen Vorgehens könnte dies sogar soweit führen, dass $\mathrm{ab}$ einer gewissen Verbreitung eine Art Downloadstopp vorgenommen werden sollte, um ein gewisses Maß der Verbreitung nicht zu überschreiten. Auf der anderen Seite ist eine zu geringe Verbreitung der Software hinderlich, weil dadurch die Freischaltungsdienstleistung nicht attraktiv ist. Die Adblockerrate sollte deshalb (schätzungsweise) nicht höher als 50\% betragen.

Ein weiteres Argument gegen die Annahme einer Verdrängungsabsicht ist die technische Wirkweise von Filterblockern. Diese können nur gewisse Arten von Werbung blockieren, die durch die URL oder besondere Merkmale erkannt werden. Daraus folgt im Umkehrschluss eine gewisse Zahl von Werbeelementen, die unblockierbar sind oder auf diese Weise ausgestaltet werden. Demnach betrifft die Verdrängung nur einen gewissen Teil der Markttätigkeit und eben nicht die absolute Verdrängung von werbefinanzierten Webseitenbetreibern.

(bb) Beeinträchtigung der Fähigkeit des Mitbewerbers, eigene Leistungen in angemessener Weise zur Geltung zu bringen

Auf der zweiten Stufe der Lauterkeitsprüfung geht es darum, ob Webseitenbetreiber ihre Leistung am Markt durch eigene Anstrengung noch in angemessener Weise zur Geltung bringen können. Hier ist die im Ergebnis alles entscheidende Interessenabwägung vorzunehmen. Diese fällt nach hier vertretener Ansicht - in Übereinstimmung mit der herrschenden Meinung in Rechtsprechung und Literatur - im Ergebnis zugunsten der Werbeblockerbetreiber aus. Webseitenbetreiber, auch (Qualitäts-) Medienanbieter, sind nicht derart in der eigenen Marktentfaltung beschränkt, dass das technische und gesellschaftliche Phänomen des Werbeblockens verboten werden könnte.

Aufgrund der vielen ausführlichen Auseinandersetzungen in Rechtsprechung und Literatur beschränkt sich diese Bearbeitung auf die folgenden grundlegenden Argumente, die den Ausschlag zugunsten der Werbeblocker geben:

\section{(aaa) Nutzerautonomie}

Das überragende Argument für die Zulässigkeit von Internetwerbeblockern ist nach hiesigem Dafürhalten die Nutzerautonomie beim Einsatz 
der Blocker. Diese Autonomie besteht von Beginn an und bleibt auch zu jeder Zeit der Nutzung der Blockersoftware vorhanden. Es liegt jederzeit am Nutzer, ob er sich dem werbefinanzierten Web als „Substrat" zur Verfügung stellt oder aber er sich dieser Monetarisierung seiner Aufmerksamkeit entzieht. Schon der Download erfolgt eigenverantwortlich. Gerade bei den Browsererweiterungen wie Adblock Plus ist der Download eine aktive Tat. Auch bleibt zu jeder Zeit die Blockersoftware derart programmierbar, dass sie insgesamt oder partiell für einzelne Seiten deaktiviert werden kann. Die Möglichkeit zur Erstellung persönlicher Filterlisten bildet ebenfalls die individuellen Wünsche des Nutzers ab. Vollfunktionale Filterlistenblocker ermöglichen dem Nutzer also eigenen Willen im Netz durchzusetzen und nicht bloß Empfänger von Daten und Informationen zu sein. Werbeblocker sind technisch fundamental in die Internetkommunikation eingebunden, welche eine mehrpolige Interaktion und keine Einbahnstraße ist. Der Werbeblocker übersetzt sozusagen den Nutzerwillen zu keiner oder weniger Werbung im Web in die Sprache des HTTP-/ TCP-/IP-Protokolls.

Alle Versuche, diese Nutzerautonomie zu widerlegen, setzen an der unbestreitbar hohen Beteiligung des Werbeblockerbetreibers bzw. mit ihm verbundener Personen an. So wird versucht herbei zu argumentieren, dass der Nutzer praktisch gar nicht die Macht über den Blockiervorgang habe. Es ist zwar richtig, dass ohne gut gepflegte Blacklists keine effektive Blockade von Display-Werbung möglich ist. Da diese Blacklists aber nicht von den Nutzern selbst stammen, so könnte argumentiert werden, stellen sie nicht den vorbehaltlosen Willen der Nutzer dar. Dieser Gedanke ist falsch. Denn ein Werbeblockernutzer wünscht im Ausgangspunkt eine effektive Blockade von Werbeelementen. Welche Elemente genau in einer Blacklist enthalten sind, ist ihm egal. Wenn die effektive Blockade errichtet ist, liegt es wiederum am Nutzer eigene Ausnahmefilter zu setzen. Etwas anders liegt der Fall bei vorgefertigten Whitelists. Aber auch hier kann man nicht maßgeblich in Zweifel ziehen, dass der Nutzer die Einbindung der fremden Liste jederzeit modifizieren oder beenden kann. Zur Freiheit der Nutzer gehört insoweit nun mal auch, dass man sich die Mühen von anderen zu Eigen machen darf.

Um die alles überragende Nutzerautonomie führt auch nicht der Gedanke herum, dass Anknüpfungspunkt der Unlauterkeit die Zurverfügungstellung eines Werkzeugs für den Nutzer ist, sodass sich der Anbieter nicht hinter dem Endnutzer verstecken könne. Denn natürlich dürfen keine Werkzeuge zu eindeutig verbotenen Tätigkeiten vertrieben werden. Aber ob das Ausblenden von Werbung für sich gesehen ein verbotenes Tun 
darstellt, ist gerade nicht eindeutig, sondern höchst kompliziert und von mannigfaltigen Interessen abhängig, auf die im Weiteren noch eingegangen wird. Ein Werbeblocker kann allein deshalb nicht mit dem Vertrieb von offensichtlich rechtswidrigen „Piraten“-Karten für Pay-TV Dekoder verglichen werden ${ }^{764}$. Hinzu kommt, dass diese „Piraten“-Karten einen $\mathrm{Zu}$ gang durch eine „Paywall“ hindurch ermöglichen. Webangebote sind aber gerade kostenlos im monetären Sinne, sodass hier keine Bezahlschranke umgangen wird.

(bbb) Selbstschutz des Nutzers

Beim Nutzer ist ein erhebliches Interesse zum Selbstschutz vor Werbung und ihren verborgenen Begleitprozessen anzuerkennen. Der Medienmarkt im Internet, der von den 1990er Jahren an durch einige alteingesessene Unternehmen aus den klassischen Medien wie Print und Rundfunk mitgeprägt worden ist, zeigte eine für Nutzer spürbare Entwicklung hin zu intensiveren Werbeformen. Aus dem eigenen Internetkonsum wird der Leser sicherlich kennen, dass Pop-Ups oder Prestitials faktisch zur Wahrnehmung zwingen. Die Implementierung solcher Werbeformen folgte scheinbar dem Selbstbild der Medienanbieter, die auf „ihren“ Seiten ausspielen dürfen, was sie wünschen - nicht was der Nutzer wünscht. Denn es liegt ja auch bei den hergebrachten Medien allein in der Hand der Anbieter, welche Werbung in „ihrer“ Zeitung oder in „ihrem“ Programm erscheint. Ein Selbstschutz des Adressaten vor Werbung war bei einer Print Ausgabe nur im Umblättern oder gesamten Fernbleiben der Ausgabe möglich. Beim TV/Radio konnte der Nutzer umschalten, was dann auch legaler Weise ein „Werbeblocker“, besser ein „Umschaltassistent“, bewerkstelligen konnte. Feedback an die Anbieter konnte nur über Verkaufszahlen oder Einschaltquoten erreicht werden, die andererseits auslegungsbedürftig waren, weil die Rezipienten schließlich auch bloß das Programm nicht gutheißen könnten. Im Internet hingegen besteht durch die dargestellte Funktionsweise zum ersten Mal eine konkrete Handhabe gegen ausgespielte Werbung. Der Nutzer muss technisch nicht alles laden, was der Anbieter im wörtlichen Sinne anbietet. Er kann in seinem Bereich bestimmen, was er angezeigt erhalten möchte.

Selbstschutz bedeutet in diesem Zusammenhang jedoch nicht Schutz gegen illegale Einwirkungen, die der Nutzer rechtlich nicht zu dulden

764 Dahingehend Engels, GRURPrax 2015, 338. 
hätte. Denn die meiste geläufige Display-Werbung ist auch nach hier vertretener Ansicht nicht lauterkeitsrechtlich unzulässig765. Gleichsam kann nicht aus der Legalität eines Verhaltens auf eine korrespondierende Pflicht zur Duldung dieses Verhaltens im interpersonellen Kontakt geschlossen werden. Nur weil es legal ist, fremde Menschen in der Öffentlichkeit anzusprechen und ihnen Werbebotschaften zu vermitteln, folgt noch keine Pflicht des Passanten die werbliche Ansprache zu dulden. Selbstschutz, etwa durch das Wechseln der Straßenseite, abwehrende Gesten und schlichter Ignoranz, ist selbstredend erlaubt. Nichts anderes darf aber in der Internetkommunikation gelten, die anders als Print und Rundfunk, aber parallel zur artikulierten Ansprache beide Teilnehmer der Interaktion befähigt die Kommunikation zu prägen. Die Einstellung des Nutzers in seinem Browser, wonach Werbung nicht zu laden ist, entspricht insoweit im Internetkommunikationsvorgang dem Wechsel der Straßenseite, mithin der Selbstentzug aus der Reichweite der Werbung. Dieses Vorgehen des Einzelnen muss respektiert werden.

Dies umso mehr, als nach der Rechtsprechung des Bundesverfassungsgerichts dem Individuum im Zeitalter der Informationstechnologie unantastbare Rechte verbleiben ${ }^{766}$. Ob das Interesse des Einzelnen von störender (nicht: unzumutbar belästigender) Werbung innerhalb von Medienangeboten betroffen zu werden in den Kanon des Allgemeinen Persönlichkeitsrechts, des Rechts auf informationelle Selbstbestimmung und das Grundrecht auf Gewährleistung der Vertraulichkeit und Integrität informationstechnischer Systeme passt, bedarf zwar noch einer Klärung durch das BVerfG, steht aber nicht der Heranziehung in einer Interessenabwägung entgegen.

Denn der Selbstschutzgedanke ist nicht nur auf den sichtbaren Teil der Werbung zu beschränken. Es ist nicht nur die Spitze des Eisberges, die Nutzer zur Blockade von Werbung motiviert, sondern auch die Vorgänge unter der (grafischen Benutzer-) Oberfläche sind bedeutsam. Tracking und Targeting, die mit moderner Ad-Technologie zwingend verknüpft sind, sind datenschutzrechtlich kritisch zu betrachten. An dieser Stelle ist der Selbstschutzgedanke werthaltig, weil ein Werbeblocker (oder auch ein besonderer Trackingblocker) oftmals die einzige effektive Abwehr der entsprechenden Vorgänge bewerkstelligen $\mathrm{kann}^{767}$. Ähnliches gilt für die

765 Vgl. oben Ziffer B. IV. 1. a).

766 Vgl. BVerfG, Urteil vom 27.2.2008, 1 BvR 370, 595/07, BVerfGE 120, 274.

767 Insbesondere wenn sich der Anbieter auf die Wahrnehmung berechtigter Interessen aus Art. 6 lit.f) DSGVO beruft und der Nutzer praktisch kein sofortiges 
latente Gefahr von Malware oder Viren, die durch die Einbindung von einer Vielzahl von Servern in den Kommunikationsvorgang begründet wird. An dieser Stelle vermag das Interesse auf Selbstschutz wohl ohne große Hürdensprünge unter die „IT-Grundrechte“ und das allgemeine Persönlichkeitsrecht der Nutzer subsumiert werden.

\section{(ccc) Handlungsalternativen der Webseitenbetreiber}

Wendet man weiterhin den Blick weg vom Nutzer und hin zu Medienanbietern im Internet wiegt ebenfalls schwer, dass sowohl in technischer als auch wirtschaftlicher Sicht Alternativen zur Verfügung stehen. Ein sehr starkes Argument ist, dass Werbeanzeigen im Netz für Filterblocker unblockierbar ausgestaltet werden kann. Dies kann auf verschiedene Arten bewerkstelligt werden, etwa die nicht spaltbare Verbindung von Anzeige mit Content auf dem Anbieterserver oder den Einsatz von Verschleierungstaktiken ${ }^{768}$. In wirtschaftlicher Hinsicht lässt sich auch ohne die allseits unbeliebte Bezahlschranke ein Registrierungsmodell wählen, das im Rahmen von Allgemeinen Nutzungsbedingungen die Wahrnehmung von Werbung als Pflicht der Nutzer ausgestaltet.

Insoweit gilt schlicht: wer sich selbst nicht vor der Wirkweise von innovativen Anwendungen im Internet schützt, der ist selbst nicht schutzwürdig.

In diesem Kontext ist das Verhalten klagender Medienanbieter vielfach auch mit der Verteidigung der aufgebauten Prozesse der Einbindung von Adservern und automatisierten Prozessen in den Werbeprozess zu erklären. Das Werbesystem im Internet zeichnet sich durch eine starke Dezentralisierung aus, das durch die Einbindung verschiedener Intermediäre in den Ausspielungsprozess für Webseitenbetreiber interessant ist, weil kaum eigene technische und organisatorische Kapazitäten notwendig sind. Die Umsetzung von technischen Alternativen erfordert entweder die Bildung eigener Kapazitäten, um Werbung selbst und auf eigenen Servern abzuwickeln, oder den Einsatz weiterer zu vergütender Dienstleister, die Werbung unblockierbar machen. So oder so sinkt die Marge der Webseitenbetreiber.

Durchsetzungsmittel seines Widerspruchsrechts aus Art. 21 Abs. 1 DSGVO hat, weil gerichtliche oder behördliche Sanktionen nicht zeitnah und effektiv greifen.

768 Zur rechtlichen Bewertung solcher Taktiken, siehe Ziffer D. II.. 
Allerdings sind solche Preisfragen kein Grund ein anderes Geschäftsmodell zu verbieten. Vielmehr muss sich derjenige, der Vorteile von dezentralisierten Prozessen genießt, auch damit abfinden, wenn diese Vorteile in Nachteile umschwenken. Im Falle der Adserver eröffnet die Einbindung von dritten Servern in den Werbevorgang eine Flanke, die Werbeblocker nutzen, um Werbung zu erkennen und deren Download zu unterbinden. Da diese Unterbindung auf Grundlage der technischen Rahmenbedingungen geschieht und zudem auf dem Willen des Nutzers beruht, ist nicht nachvollziehbar, wieso Webseitenbetreiber an dieser Stelle überwiegende Interessen zugestanden werden sollen.

\section{(ddd) Medienfreiheit}

Das Ass im Ärmel der medialen Content bereitstellenden Webseitenbetreiber war zuletzt die grundgesetzlich geschützte Medienfreiheit aus Art. 5 Abs. 1 S. 2 GG. Allerdings entpuppt sich das Ass bei näherem Hinsehen als Bube und dieser sticht nicht. Denn die Medienfreiheit kann nicht - wie von den klagenden Medienanbietern propagiert - dahingehend ausgelegt werden, dass sie einen Wahrnehmungszwang von Werbung beim Nutzer und folglich einen Schutz eines willkürlich gewählten Geschäftsmodells zementiert. Dies lässt sich weder aus einer Institutionsgarantie der freien "Online-Presse" noch aus einer Einbeziehung von Werbeelementen in den Schutzbereich der Freiheiten folgern. Denn wie bereits im Rahmen der Verdrängungsabsicht angesprochen, sind Medienanbieter nicht gehindert weiterhin ihr bisheriges Modell der werbefinanzierten Inhalte zu verfolgen. Einzig ihr Publikum schwindet. Ein Verbot von Werbeblockern würde deshalb nicht zur Festigung der Freiheit, sondern zur Festigung der wirtschaftlichen Wertigkeit des Produkts der Webseitenanbieter führen. Dies ist aber nicht die Aufgabe von Grund- und Freiheitsrechten.

(eee) Spiegelbildliche Freiheiten

Ein offenbar noch nicht genannter Gedanke in diesem Zusammenhang ist, dass die Werbebranche bei der Frage des „Ob“ von Werbung nur sehr wenigen zwingenden Regeln unterliegt. Wie oben herausgearbeitet ist eine gesetzliche Schranke der Möglichkeiten von Werbung im Internet praktisch nur in dem offenen Tatbestand des $\$ 7$ UWG zu erblicken. Bei Anwendung dieser Norm kann aber nur im Ausnahmefall eine unzumut- 
bare Belästigung bejaht werden. Nun lässt sich argumentieren, dass die Kehrseite dieser Freiheit beim aktiven Werbevorgang eine erhöhte Duldungspflicht von Reaktionen der Adressaten sein muss. Denn wenn Webseitenbetreiber und Werbende auf der einen Seite kaum Restriktionen unterliegen, ist es schlicht ungerecht dem Adressaten eine Beschränkung der (technischen) Freiheit für Abwehrmaßnahmen aufzuerlegen. Die liberale Ausgestaltung der Werbemöglichkeiten führt demnach logisch zwingend zu einer liberalen Betrachtung der Reaktionen.

Wollte man den Nutzern diese Freiheit zur Reaktion auf unerwünschte und störende Werbung absprechen, müsste der Gesetzgeber umgekehrt zum Schutz der Nutzer schärfere Regeln zur Zulässigkeit und technischen Ausgestaltung von Werbung im Internet verabschieden. Denn der Kommunikationsvorgang im Internet erfordert eine Balance, die entweder durch beidseitige Freiheit oder gleichsam geltende Beschränkungen hergestellt werden kann. Allerdings ist die aktuelle Lage mit einer offenen Betrachtung auf Grundlage von technologieneutralen Generalklauseln vorzugswürdig. Es ist kaum vorstellbar, dass der Gesetzgeber mit dem technischen Fortschritt mithalten könnte.

(fff) Intensität des Eingriffs in den Werbemarkt

Zuletzt ist speziell mit Blick auf die Whitelist zu konstatieren, dass gleich welche Meinung man zum Geschäftsgebaren der Whitelistanbieter haben mag - die selektive Blockade auf transparenten Kriterien ein weniger einschneidender Engriff in den Werbemarkt darstellt als die Komplettblockade. Das treffendste Beispiel hierfür ist wohl die geschlossene Tür, die ein Stück weit geöffnet wird. Während die Blacklist die geschlossene Tür darstellt, öffnet die Whitelist diese Tür wieder ein Stück breit. Die geöffnete Tür stellt wiederum eine Option für Webseitenbetreiber dar. Der Umstand, dass sich gewisse Anbieter nicht derart schlank machen wollen, sodass sie durch die Tür passen, kann aber im Endeffekt nur zu Lasten eben dieser Anbieter führen.

(ggg) Fallgruppen der gezielten Mitbewerberbehinderung

Traditionell werden bei der Prüfung der lauterkeitsrechtlichen Mitbewerberbehinderung Fallgruppen herangezogen. Nach Ansicht des Verfassers benötigt man diese Fallgruppen nicht unbedingt zur Lösung von Fällen 
der gezielten Mitbewerberbehinderung. Aus diesem Grunde wurde in dieser Arbeit - wie im Übrigen auch in dem Urteil Werbeblocker II des $\mathrm{BGH}^{769}$ - auf die Prüfung anhand von mehr oder minder gefestigten Fallgruppen verzichtet. Gleichwohl werden in der Rechtsprechung und Literatur immer wieder gewissen Fallgruppen erwähnt.

Der Vollständigkeit halber soll nachfolgend kurz auf eine häufig genannte Fallgruppe eingegangen werden: der Boykottaufruf. Dieser Rechtsgedanke kann allerdings nicht zu einem Verbot von Werbeblockern herangezogen werden. Eine gezielte Behinderung durch Boykott erfordert (i) eine entsprechende Aufforderung eines Marktteilnehmers, (ii) die Bestimmtheit der Adressaten und der vom Boykott betroffenen Personen sowie (iii) die Zwecksetzung eine Liefer- oder Bezugssperre herbeizuführen $^{770}$. Insofern ist unter einer Aufforderung zum Boykott der Versuch zu verstehen, einen anderen dahin zu beeinflussen, bestimmte Liefer- oder Bezugsbeziehungen nicht einzugehen oder nicht aufrechtzuerhalten ${ }^{771}$. Es fällt bereits schwer, in dem Angebot eines Werbeblockers eine solche Aufforderung zu erkennen. Denn der Werbeblocker fordert ja gerade nicht dazu auf, den Besuch bestimmter Webseiten zu boykottieren. Er ist vielmehr ein Mittel, um einzelne Bestandteile von Webseiten optisch zu entfernen. Somit wäre der Boykottaufruf jedenfalls nur isoliert auf die Werbeelemente gerichtet. Wenn dies ausreichen würde, müsste spiegelbildlich der Bezug von Werbeelementen durch Internetnutzer für sich alleine gesehen eine für die Webseitenbetreiber schützenswerte Lieferbeziehung sein. Dies liegt bei praktischer Betrachtung der Interessenlage indes fern. Folglich scheitert die Fallgruppe des Boykottaufrufs bereits am Fehlen einer entsprechenden Aufforderung. Hinzu kommt, dass die vom Boykott betroffenen Unternehmen nicht hinreichend bestimmt sind. Denn der Boykott betrifft bei der Totalblockade via Blacklist alle Webseiten mit Werbung gleichermaßen. Ein Boykott gegen „jedermann“ ist aber nicht unter $\$ 4$ Nr. 4 UWG zu fassen, weil die Norm ihrem Zweck nach nur Individualbeziehungen betrifft72. Bei der Whitelist beträfe ein Boykott alle Unternehmen, die nicht auf diese Liste aufgenommen worden sind. Auch hier ist zu beachten, dass damit im Ausgangspunkt eine Vielzahl von Unternehmen „boykottiert“ werden. Durch die Beschränkung auf sozusagen unwillige Mitbewerber, ist hier aber abstrakt eine Eingrenzung möglich und eine

769 BGH, Urteil vom 19.4.2018 - I ZR 154/16, WRP 2018, 1322 - Werbeblocker II.

770 Köhler/Bornkamm/Feddersen, UWG, $\$ 4$, Rn. $4.119 \mathrm{ff} .$.

771 BGH GRUR 1999, 1031, 1033 - Sitzender Krankentransport.

772 Köhler/Bornkamm/Feddersen, UWG, $\$ 4$, Rn. 4.2. 
Individualisierbarkeit denkbar. Diese ist aber in der praktischen Ausgestaltung der Whitelist nicht gegeben. Denn diese Liste ist zuvörderst eine technische Anweisung für das Computerprogramm und enthält textliche Filterbefehle ${ }^{773}$. Hieraus lässt sich also nicht positiv ein Name eines Unternehmens entnehmen, das „boykottiert“ werden soll. Folglich sind die vom angeblichen Boykott betroffenen Unternehmen nicht bestimmbar ${ }^{774}$.

\section{(c) Gezielte Behinderung von Werbenetzwerken}

An dieser Stelle soll auch ein kurzer Blick auf die Behinderung von Werbenetzwerken geworfen werden, die in den Gerichtsverfahren nicht bewertet worden sind. Die Sach- und Interessenlage unterscheidet sich in beachtlichem Maße, sodass eine Prüfung geboten ist.

Auch hier ist der zweistufige Maßstab der Rechtsprechung anzuwenden. Im Rahmen der primär zu prüfenden Verdrängungsabsicht kommt es deshalb wiederum darauf an, ob Werbeblocker eine Verdrängung von Werbenetzwerken bezwecken. Werbenetzwerke unterscheiden sich von Webseitenbetreibern dadurch, dass sie als Intermediär zwischen Werbendem und Werbeplatzanbieter fungieren und damit absolut vom Bestehen der Internetwerbung abhängig sind. Während Webseiten andere Finanzierungswege suchen können, sind Werbenetzwerke bei Wegfall von Display-Werbung weitestgehend obsolet. Dies wiederum stellt eine Ähnlichkeit zum Werbeblocker selbst dar. Wenn also den Werbeblockern eine Verdrängungsabsicht mit Blick auf die Online-Werbung insgesamt nicht zugesprochen wird, weil sie sich damit selbst den Ast absägen würden, auf dem sie sitzen, schlägt dies auch auf die Werbenetzwerke durch. Vielmehr profitieren Werbeblocker gerade von der Existenz der Werbenetzwerke und ihrer Adserver. Denn würden alle Webseitenbetreiber auf Eigenvermarktung setzen, wäre die technische und wirtschaftliche Funktionsweise von kommerziellen Werbeblockern sehr eingeschränkt.

Auf der anderen Seite sind Werbenetzwerke nicht insgesamt im Visier der Werbeblocker, sondern vielmehr deren technische Hilfestellung mit Adservern und der Einbindung von Tracking und Targeting. Dass Werbenetzwerke ihre Vermittlungsdienstleistung auch innerhalb der technischen Kapazitäten der Webseitenbetreiber erbringen könnten, dürfte nicht aus-

773 Siehe dazu oben Ziffer C. I. 2. a) und b).

774 So im Ergebnis auch: BGH, Urteil vom 8.10.2019, KZR 73/17, WRP 2019, 1572 - Werbeblocker III. 
zuschließen sein. Demnach liegt auch hier lediglich eine Einschränkung der wettbewerblichen Entfaltung in einem Teilaspekt vor. Es ist hingegen nicht ersichtlich, dass Werbeblocker insgesamt Maklertätigkeiten oder ähnliche Dienste mit Bezug zu Internetwerbung vom Markt auslöschen wollen.

Im Rahmen der Prüfung, ob Webseitenbetreiber ihre Leistung am Markt durch eigene Anstrengung noch in angemessener Weise zur Geltung bringen können, sind wiederum Interessen abzuwägen. In dieser Konstellation besonders zu beachten ist, dass Werbenetzwerke selbst abhängig von einem dynamischen Markt sind. Da sie selbst keinen originären Beitrag zur Werbung beitragen, sondern vielmehr die Abwicklung optimieren, haben sie auch keinen gesicherten Stand am Markt. Vor diesem Hintergrund bereitet es schon Probleme eine gefestigte und schutzwürdige Stellung der Werbenetzwerke am Markt zu erkennen. Ihre Tätigkeit am Markt kann durch viele Faktoren beeinflusst werden, etwa durch das Verhalten der Werbenden, der Webseitenbetreiber oder eben der Nutzer. Vorliegend schlägt die autonome Entscheidung der Nutzer für einen Werbeblocker wiederum durch und zwingt Werbenetzwerke zum Angebot angepasster Lösungen. Eine Unlauterkeit könnte allenfalls angenommen werden, wenn man der Leistung von Werbenetzwerken, über Adserver und mit bestimmten technischen Vorgängen eine optimierte Werbeausspielung zu bewerkstelligen, einen über die reine Abwicklung hinausgehenden Wert zuerkennen möchte. Dies fällt jedoch schwer, da die Technologie derart spezialisiert ist, dass eine anderweitige Nutzung nicht denkbar ist. Eine Dienstleistung läuft indes immer Gefahr durch geänderte Marktumstände obsolet zu werden. Dass das Marktverhalten der Werbeblocker maßgeblich zu diesen geänderten Verhältnissen geführt hat, ist unbedenklich. Beide Seiten, also Werbeblocker und Werbenetzwerke bieten Dienste in einem sekundären Werbemarkt an und sind somit gleichrangig und gleichwertig. Die gegenseitige Verzahnung im komplexen Internetwerbeprozess ist lauterkeitsrechtlich als erwünschter Wettbewerb anzusehen. Im Übrigen gelten auch hier die oben bereits genannten Argumente der Nutzerhoheit und des Selbschutzes.

Insgesamt wäre also auch eine Klage eines Werbenetzwerks auf Grundlage von $\$ 4$ Nr. 4 UWG nicht aussichtsreich. Das Angebot kommerzialisierter Werbeblocker stellt auch in diesem Verhältnis keine gezielte Behinderung dar. 
(iii) Allgemeine Marktbehinderung

Eine in den lauterkeitsrechtlichen Urteilen durchgehend angesprochene Fallgruppe ist die Allgemeine Marktbehinderung als weitere Eskalationsstufe zur Individualbehinderung. Nach der Rechtsprechung des BGH ist eine allgemeine Marktbehinderung anzunehmen, wenn ein für sich genommen noch nicht unlauteres, aber doch „bedenkliches“ Wettbewerbsverhalten allein oder in Verbindung mit gleichartigen Maßnahmen von Mitbewerbern die „ernstliche“ Gefahr begründet, den auf der unternehmerischen Leistung beruhenden Wettbewerb in erheblichem Maße einzuschränken ${ }^{775}$. Im Ergebnis ist dieser ungeschriebene Unlauterkeitstatbestand zu Recht abgelehnt worden. Neben dogmatischen Zweifeln an der Notwendigkeit dieser Fallgruppe ist sie insbesondere im Streitfall „Adblock Plus" nicht verwirklicht.

In jüngster Zeit mehren sich die Stimmen, die die Fallgruppe der allgemeinen Marktstörung für obsolet halten ${ }^{776}$. Dieser Ansicht stimmt der Bearbeiter vollumfänglich zu. Die allgemeine Marktbehinderung passt nicht in das System des Lauterkeits- und Kartellrechts und ist zudem nicht notwendig, um das mit ihr zum Ausdruck gebrachte Unwertsurteil zu erreichen. Denn allgemeine Einflüsse auf den Markt, die Wettbewerb beschränken, sind über das Kartellrecht zu lösen. Die Schwelle der im Kartellrecht regelmäßig notwendigen Marktmacht sowie die kartellrechtlichen Sondertatbestände dürfen nicht unterlaufen werden, indem jeder Mitbewerber eine Marktstrukturkontrolle in die Hände von nicht unbedingt mit Kartellsachen vertrauten Gerichte legen darf. Unterhalb der Marktmachtsgrenze ist eine allgemeine Marktstörung überdies nur selten widerspruchsfrei begründbar. Denn es bedarf einiger Überlegung einen Fall zu konstruieren, in welchem ein „kleiner Fisch“, der in seinem abgegrenzten Markt keine beherrschende Stellung hat, ohne das Vorliegen einer Individualbehinderung seinen Markt derart unlauter in seinen Grundfesten erschüttert, dass eine allgemeine Marktbehinderung zu bejahen wäre. Dieses Potential kann höchstens eine bahnbrechende Innovation in einem bestimmten Markt haben. Dann wiederum ist weder das Wettbewerbsrecht im Sinne von Lauterkeits- noch von Kartellrecht anwendbar.

Neben diesen vom Fall losgelösten Erwägungen bereitet die Anwendung auch im konkreten Fall unauflösbare Probleme. Zunächst müsste

775 BGH, Urteil vom 20.11.2003, GRUR 2004, 602, 606 - 20 Minuten Köln; Urteil vom 29.10.2009, GRUR 2010, 455 - Stumme Verkäufer II.

776 Sosnitza GRUR 2018, 255, 261, m.w.N. in der dortigen Fn. 84. 
der einschlägige Markt abgegrenzt werden. Es ist aber sehr fraglich, welcher Markt hier überhaupt durch Werbeblocker gestört wird. Der „gesamte Werbemarkt im Internet" ist zu undifferenziert, um eine qualifizierte Aussage über den für die Marktstörung notwendigen außerordentlich drastischen Eingriff zu treffen. Jede Argumentation in diese Richtung würde auf eine Festschreibung von nicht existierenden Regeln der Internetwirtschaft hinauslaufen, die einem aktuellen status quo Bestandsschutz verleihen würden. Stellte man auf das Angebot kostenloser Inhalte im Internet ab, muss man wie im Rahmen der Individualbehinderung konstatieren, dass diese Marktbetätigung noch möglich ist, wenn auch unter Anwendung von Schutzvorkehrungen. Ähnlich verhält es sich, wenn man generell darauf abstellt, dass Werbung im Internet ausgespielt werden darf. Dies ist zum einen bei Anwendung verschiedener blocksicherer Methoden noch möglich. Zum anderen kann der Markt nicht dadurch in lauterkeitsrechtlich relevanter Weise tangiert sein, wenn die Adressaten von Werbung freiwillig die Wahrnehmung eben jener verweigern. Insofern ist der Ansicht von Krüger zu widersprechen, der eine allgemeine Marktbehinderung mit dem Argument vertritt, dass Werbeblocker der massenhaften Verteilung von Gratisware gleich stehe, die den jeweiligen Markt gefährde $^{777}$. Denn grundsätzlich trifft der Vorwurf, Gratisware zu verteilen, die Webseitenbetreiber. Dass nun Nutzer diese Gratisware nicht so annehmen wollen, wie es der Schenkende wünscht, kann nur schwerlich ein Grund zum Verbot sein.

Deshalb bleibt konkret nur das Abstellen auf die Ausspielung von Werbung, die an kostenlose Inhalte gekoppelt ist. Dies stellt aber nur eine Refinanzierungsmethode auf dem Markt und keinen eigenen Markt dar. Dies kann nicht durch einen ungeschriebenen und auf der Generalklausel beruhenden Tatbestand geschützt werden.

Demnach ist gleichgültig, ob man die allgemeine Marktstörung aus dogmatischen Gründen oder im konkreten Fall ablehnt. So oder so kann ein Verbot von Werbeblockern nicht auf diese Grundlage gestellt werden.

(iv) Aggressive Geschäftspraktik, $\mathbb{4} 4 \mathrm{a}$ UWG

Die bislang ergangene Rechtsprechung und erschienene Literatur zum Tatbestand des $\$ 4$ a UWG zeigt, dass die Handhabung dieser - für das Lauterkeitsrecht eigentlich unüblichen - sehr ausführlich kodifizierten

777 Krüger, GRUR-Prax 2016, 322. 
und gleichsam sehr sperrigen Vorschrift noch in Entwicklung begriffen ist. Deshalb soll dieser Tatbestand ein Schwerpunkt der vorliegenden Auseinandersetzung sein.

Eine Besonderheit des $₫ 4$ a UWG ist, dass er eine europäische Regelung mit Grundlage in Art. 8, 9 UGP-Richtlinie darstellt und somit von seiner Entstehungsgeschichte und Formulierung her auf den Schutz von Verbrauchern zugeschnitten ist. Die Entscheidung des deutschen Gesetzgebers, auch sonstige Marktteilnehmer in den Schutzbereich des Verbots aggressiver Geschätfspraktiken einzubeziehen, stellt dabei einen nationalen Sonderweg dar. Dieser Weg erschließt wiederum einen Bereich, der nicht zwingend richtlinienkonform auszulegen ist ${ }^{778}$ und folglich keiner Kontrolle durch den EuGH unterliegt. Stattdessen ist der Schutz sonstiger Marktteilnehmer einer freien Rechtsfortbildung nach hergebrachten deutschen Auslegungsmethoden zugänglich und steht unter der exklusiven Aufsicht des BGH.

Im Rahmen dieser rein nationalen Ausgestaltung ist denkbar, den Schutz von sonstigen Marktteilnehmern streng parallel zum Verbraucherschutz auszugestalten oder eine abweichende Auslegung bestimmter Tatbestandsmerkmale vorzunehmen, womit $₫ 4$ a UWG praktisch zweigeteilt würde. Innerhalb dieses Spektrums liegt es an der deutschen Rechtsprechung die Anwendung der Norm im Bereich des Schutzes sonstiger Marktteilnehmer zu gestalten. Insoweit stellen die Adblock Plus-Fälle den ersten Themenkomplex nach der UWG Reform von Dezember 2015 dar, der unter die „neue“ Tatbestandsfassung zu subsumieren war. Mangels vorhandener früherer Fundstellen in der Instanzrechtsprechung, geschweige denn des BGH, betrat insbesondere das OLG Köln in seiner Entscheidung rechtliches Neuland. Zwar war zuvor schon der $\$ 4 \mathrm{Nr} .1 \mathrm{UWG}$ a.F. in richtlinienkonformer Auslegung anhand der Art. 8, 9 UGP-Richtlinie auszulegen, dies betraf indes nur den Bereich des Verbraucherschutzes zwingend. Der Schutz von sonstigen Marktteilnehmern über $\$ 4$ Nr. 1 UWG a.F. erforderte nach dem Gesetzeswortlaut die Beeinträchtigung ihrer Entscheidungsfreiheit durch Ausübung von Druck, in menschenverachtender Weise oder - praktisch relevanter - durch sonstigen unangemessenen unsachlichen Einfluss. Dabei kam die Norm ohne die Nennung spezieller Definitionen oder Beurteilungskriterien - wie nunmehr in $\$ 4$ a Abs. 1 S. 3, Abs. 2 UWG enthalten - aus. Die bereits in Art. 8, 9 UGP-Richtlinie enthaltenen Definitionen und Kriterien wurden im B2B-Bereich auch nicht herangezogen.

778 Vgl. Scherer, WRP 2015, 148, 152, Rn. 30 mit der treffenden Bezeichnung als „richtlinienfrei". 
So hat der BGH in seiner Entscheidung Brillenversorgung $I I^{779}$ gerade nicht Art. 8, 9 UGP-Richtlinie referenziert, sondern autonom einen unangemessenen unsachlichen Einfluss geprüft. Insofern gebieten die Unterschiede zwischen dem „sonstigen unangemessenen unsachlichen Einfluss“ und der unzulässigen Beeinflussung gem. $\$ 4$ a Abs. 1 S. 3 UWG eine kritische Betrachtung alter Fallgruppen des $\$ 4$ Nr. 1 UWG a.F. unter der neuen Rechtslage ${ }^{780}$ sowie eine originäre Beurteilung neuer Fallkonstellationen.

Doch ist der Tatbestand des $\mathbb{4} 4 \mathrm{a}$ UWG vom Gesetzgeber einheitlich zum Schutz für die gesamte Marktgegenseite ausgestaltet worden, sodass eine einheitliche Auslegung der Norm naheliegt, um grundlegende und schwer begründbare Unterscheidungen in der Anwendung der Norm zu vermeiden. Dies bedeutet jedoch nicht, dass die Beurteilung aggressiver geschäftlicher Handlungen gegenüber Verbrauchern und Unternehmern im Einzelfall stets gleich ausfallen muss. Es folgt aus $\$ 3$ Abs. 4 UWG, aus dem sich für Verbraucher unmittelbar und für sonstige Marktteilnehmer analog ergibt, dass stets der Durchschnittsadressat maßgeblich ist. Daraus können sich Unterschiede im Bewertungsmaßstab ergeben. Bei Maßnahmen nur gegenüber Unternehmern, wie im hiesigen Fall, kommt es nur auf die Sicht des durchschnittlichen Marktteilnehmers an.

Die Anwendung des $₫ 4$ a UWG im hier maßgeblichen Fall des Angebots von Werbeblockern hat deshalb besondere Bedeutung und ist eine Blaupause für zukünftige Fälle des Schutzes von sonstigen Marktteilnehmern vor aggressiven geschäftlichen Handlungen im B2B-Vertikalverhältnis. Im Folgenden wird deshalb ein Beitrag zur vorzugswürdigen Anwendung von $\$ 4$ a UWG in diesem B2B-Verhältnis gegeben.

\section{(1) Festlegung der Betroffenen}

Vor Anwendung der rechtlichen Norm muss allerdings zunächst geklärt werden, welche Unternehmen überhaupt von der potentiell aggressiven geschäftlichen Handlung des Werbeblockens betroffen werden. Dies ist insbesondere deshalb bedeutsam, weil das OLG Köln sowie der BGH in der darauffolgenden Revision die „Werbekunden“ als Betroffene identifiziert und geprüft haben, während beim OLG München und OLG Hamburg nur die klagenden Webseitenbetreiber als potentielle Opfer geprüft worden sind.

779 BGH, Urteil vom 24.6.2010 - I ZR 182/08, GRUR 2010, 850, Rn. 14 ff..

780 Vgl. Fritzsche, WRP 2016, 1, 4, Rn. 30. 
Lässt man Fragen der persönlichen Anwendbarkeit der Norm zunächst außer Acht, kommt als Betroffener potentiell jedes Unternehmen im Prozess der Online-Werbung in Betracht. Begonnen von einem Werbenden, der eine Anzeige schalten möchte ${ }^{781}$, über die diversen Intermediäre wie unter anderem Werbenetzwerke, hin zu den Webseitenbetreibern. Denn es ist bei allen diesen Unternehmen, die versuchen über Online-Werbung Vorteile zu erreichen, zumindest denkbar, dass sie durch die Werbeblockade in ihrer nach $\$ 4$ a UWG maßgeblichen Entscheidungsfreiheit beeinträchtigt werden.

Allerdings unterscheiden sich die Umstände bei jedem dieser potentiell betroffenen Unternehmen beachtlich. Eine pauschale Antwort, die für alle drei genannten Gruppen von Betroffenen zutreffen würde, ist nicht möglich. Deshalb ist auf einer ersten Stufe zu prüfen, wer von diesen Betroffenen überhaupt dem Anwendungsbereich der Norm unterfällt. Soweit diese Hürde genommen ist, wird in der folgenden Stellungnahme zwischen den Betroffenen unterschieden.

(2) Anwendbarkeit von $\$ 4 a$ UWG - Konkurrenz innerhalb des UWG und zum Kartellrecht

Ein vorrangig zu klärender Aspekt ist, ob der Anwendung des $₫ 4$ a UWG im konkreten Fall aus systematischen Gründen eine Sperrwirkung durch vorrangige Rechtsnormen entgegen steht.

In diesem Zusammenhang ist vor allem das Verhältnis zu zwei Normen bzw. Normenkomplexen klärungsbedürftig. Innerhalb des UWG ist das Verhältnis zu $\$ 4$ Nr. 4 UWG erörterungswürdig, insbesondere wenn der Betroffene zugleich Mitbewerber des Werbeblockeranbieters ist. Wie bereits Köhler in seiner frühen Bewertung zu Internetwerbeblockern andeutete $^{782}$, ist die zeitgleiche Bewertung ein und derselben (juristischen) Person als Mitbewerber und sonstiger Marktteilnehmer bei Betrachtung derselben geschäftlichen Handlung gewissermaßen schizophren und sollte kritisch hinterfragt werden. Im Verhältnis zu Normen außerhalb des UWG sind die kartellrechtlichen Normen der $\mathbb{S} 18 \mathrm{ff}$. GWB zu beachten, wo bei unabgestimmter Anwendung der Normen Wertungswidersprüche drohen ${ }^{783}$.

781 Oder im Wortlaut des OLG Köln der „Werbekunde".

782 Köhler, WRP 2014 1017, 1021.

783 Scherer, GRUR 2016 233, $235 \mathrm{f}$. . 
(a) Verhältnis zu $₫ 4 \mathrm{Nr} .4$

Zunächst soll auf die „intra-UWG“-Konkurrenz eingegangen werden. Im Grundsatz ist zu konstatieren, dass die Verbote der gezielten Mitbewerberbehinderung nach $\$ 4 \mathrm{Nr}$. 4 UWG und der aggressiven Geschäftspraxis in $\$ 4$ a UWG unterschiedliche Schutzzwecke verfolgen und deshalb nebeneinander anzuwenden sind ${ }^{784}$. Der $\$ 4 \mathrm{Nr} .4 \mathrm{UWG}$ schützt nämlich nicht die Entscheidungsfreiheit von Marktteilnehmern im Vertikalverhältnis, sondern allein Mitbewerber im Horizontalverhältnis ${ }^{785}$.

Kein Bedarf zu einer Auseinandersetzung besteht, wenn der Betroffene der potentiell aggressiven geschäftlichen Handlung kein Mitbewerber ist, weil in diesem Fall nur $\mathbb{\$} 4$ a UWG anzuwenden ist. $\$ 4$ Nr. 4 UWG hingegen ist mangels konkreten Wettbewerbsverhältnisses mit Leichtigkeit bei einer der Eingangsvoraussetzungen der Prüfung abzulehnen. Auf den hier maßgeblichen konkreten Fall bezogen ist dies der Fall, wenn „Werbekunden" in ihrer geschäftlichen Entscheidung, auf welcher Plattform sie Werbung schalten möchten, betroffen sind. Diese Werbenden sind nämlich keine Mitbewerber des Werbeblockeranbieters. Dieser Abgrenzung folgend hat das OLG Köln die gezielte Mitbewerberbehinderung im Verhältnis Webseitenbetreiber zum Werbeblockeranbieter und die aggressive Geschäftspraxis im Verhältnis der Werbekunden zum Werbeblockeranbieter geprüft.

Bei Webseitenbetreibern und Werbenetzwerken stellt sich die Lage jedoch anders dar. Wie oben ausführlich dargelegt bejaht die herrschende Meinung zu Recht ein konkretes Wettbewerbsverhältnis zwischen diesen Akteuren und dem Anbieter eines Werbeblockers. Jedoch stehen diese Mitbewerber nicht ausschließlich im Horizontalverhältnis zum Werbeblockeranbieter, sondern sie sind auch zur Handlung animierte Betroffene des Werbeblockens und potentielle Abnehmer von Freischaltungsdienstleistungen im Vertikalverhältnis. Damit sind sie zugleich sonstige Marktteilnehmer. Dieses Phänomen ist im Grundsystem des UWG nicht vorgesehen und bedarf einer argumentativen Bewältigung, möchte man den Akteur vor einer einheitlichen geschäftlichen Handlung sowohl nach $₫ 4$ Nr. 4 UWG als auch über $\$ 4$ a UWG schützen.

Insoweit ist zu klären, ob der Wortlaut des $₫ 4$ a UWG, der auf Verbraucher oder sonstige Marktteilnehmer als Betroffene abstellt, in der Weise

784 Scherer, GRUR 2016 233, 235; Scherer, in: Fezer/Büscher/Obergfell, UWG, $\mathbb{S}$ 4a, Rn. 68; apodiktisch Köhler/Bornkamm/Feddersen, $\$ 4 a$, Rn. 1.12.

785 Ohly/Sosnitza, UWG, $\mathbb{\$} 4$, Rn. 1. 
auszulegen ist, dass letztere nicht zugleich Mitbewerber sein dürfen ${ }^{786}$ - oder ob die gleichzeitige Einordnung als Mitbewerber und sonstiger Marktteilnehmer unschädlich ist ${ }^{787}$. Dabei kommen drei Argumente in Betracht, um eine parallele Anwendung beider Normen bei Betroffenheit nur einer einzigen Person als sonstiger Marktteilnehmer und Mitbewerber zu begründen.

Erstens, ließe sich die Rechtsfigur der doppelrelevanten Handlung bemühen ${ }^{788}$. In dieser Konstellation wäre eine doppelrelevante Handlung dann gegeben, wenn durch ein und dieselbe geschäftliche Handlung Interessen von Mitbewerbern und sonstigen Marktteilnehmern unmittelbar geschädigt werden. In diesen Fällen gilt das Prinzip der Doppelkontrolle, also der gleichzeitigen Anwendung von Mitbewerber und sonstige Marktteilnehmer schützenden Normen ${ }^{789}$. Im Allgemeinen setzt eine doppelrelevante Handlung aber Personenverschiedenheit zwischen den betroffenen Mitbewerbern und sonstigen Marktteilnehmern (bzw. Verbrauchern) voraus. Als Beispiel für eine doppelrelevante Handlung wird insoweit regelmäßig das Verleiten zum Vertragsbruch eines (gewerblichen) Abnehmers eines Mitbewerbers angeführt, das zugleich eine Verwirklichung von $\mathbb{} 4$ Nr. 4 UWG im Verhältnis zum Mitbewerber als auch von $\$ 4$ a UWG im Verhältnis zum Abnehmer darstelle ${ }^{790}$. Dass aber gerade der behinderte Mitbewerber zeitgleich auch der aggressiv behandelte Abnehmer ist, ist unüblich. Eine Erweiterung der Doppelrelevanz auf die Personalunion des betroffenen Marktteilnehmers und Mitbewerbers liegt zudem nicht derart nahe, dass sie als Anwendungsbegründung herangezogen werden könnte. Denn bei genauem Hinsehen handelt es sich tatsächlich um keine Doppelrelevanz, sondern eine Singularrelevanz für eine Person, die allein zwei rechtliche Konzepte verwirklicht. Dies sollte nicht ausreichen. Demnach lässt sich das hergebrachte Prinzip der Doppelkontrolle von doppelrelevanten Handlungen nicht auf die hier behandelte Sachlage übertragen.

Zweitens, ließe sich eine gleichzeitige Anwendung der Normen durch die Aufspaltung der geschäftlichen Handlung des Werbeblockens in zwei

786 In diese Richtung lässt sich Köhler/Bornkamm/Feddersen, UWG, $\mathbb{S} 4 a$, Rn. 1.27 verstehen. Ebenfalls diesem Ergebnis zuneigend OLG Hamburg, Urteil vom 15.3.2018 - 5 U 152/15, WRP 2018, 604.

787 Vgl. Raue, WRP 2017, 1363, 1364, Rn. 12.

788 Vgl. zur doppelrelevanten Handlung im UWG: Köhler WRP 2015, 275, 280; Scherer, in: Fezer/Büscher/Obergfell, UWG, $\mathbb{\$} 4 a$, Rn. 69.

789 Vgl. Köhler/Bornkamm/Feddersen, UWG, $\$ 4$, Rn. 0.5.

790 Köhler WRP 2015, 275, 280; Scherer, in: Fezer/Büscher/Obergfell, UWG, $\mathbb{\$}$ 4a, Rn. 69. 
getrennt zu betrachtende Handlungen begründen. Bei der einen Handlung müsste der Betroffene allein als Mitbewerber betroffen sein, bei der anderen hingegen nur als sonstiger Mitbewerber. Genau dies wurde oben bereits bei der Stellungnahme im Rahmen der Prüfung des konkreten Wettbewerbsverhältnisses innerhalb von $\$ 4$ Nr. 4 UWG angedeutet. Auf der ersten Stufe des isolierten Angebots der Software kommt keine Qualifizierung der Webseitenbetreiber oder Werbenetzwerke als sonstige Marktteilnehmer in Betracht, weil diese allein behindert werden, nicht aber als Abnehmer in Betracht kommen. Auf der zweiten Stufe des isolierten Freischaltungsangebots an die Webseitenbetreiber und Werbenetzwerke kommt dann aber ein konkretes Wettbewerbsverhältnis weder wegen Substitution noch Behinderung in Betracht, sehr wohl aber eine Stellung als sonstiger Marktteilnehmer. Diese Aufspaltung der geschäftlichen Handlung führt dann zwangsläufig dazu, dass nur das (ggf. kostenpflichtige) Angebot auf Freischaltung nach $\$ 4$ a UWG zu bewerten ist, nicht aber das vorgelagerte Faktum der Blockade. Dieser Befund ist für Betroffene unbefriedigend, weil das Angebot der Freischaltung stark mit der Blockade verknüptt ist, aber über $\$ 4$ a UWG nur das Angebot selbst untersagt werden könnte. Eine Aufspaltung des Geschäftsmodells „Whitelisting“ ist demnach praktisch nicht tauglich, um unter Anwendung von $\mathbb{\$} 4$ a UWG einen effektiven Rechtsschutz gegen kommerzielles Werbeblocken zu etablieren. Es wurde im Übrigen bereits weiter oben abgelent, weil eine einheitliche Software wie Adblock Plus nicht zur genehmeren rechtlichen Handhabung künstlich zerteilt werden darf.

Drittens, lässt sich die Anwendung für $\$ 4$ a UWG auf im Vertikalverhältnis betroffene Mitbewerber darauf stützen, dass dies eine "Spätfolge“ aus der Erweiterung des Mitbewerberbegriffs auf den Behinderungswettbewerb ist. Denn wenn sich das konkrete Wettbewerbsverhältnis nur auf den Substitutionswettbewerb beschränken würde, könnte die geschäftliche Handlung des Werbeblockens nicht nach $\$ 4 \mathrm{Nr} .4$ UWG überprüft werden. In diesem hypothetischen Fall würde $\mathbb{\$} 4 \mathrm{a}$ UWG anwendbar sein, jedenfalls um effektiven Rechtsschutz zu gewährleisten. Wenn nun aber der Anwendungsbereich des $₫ 4$ Nr. 4 UWG in extensiver Weise ausgeweitet wird, sollte darunter nicht der Anwendungsbereich des $₫ 4$ a UWG spiegelbildlich eingeschränkt werden. Die Situation, dass ein Marktakteur durch dieselbe geschäftliche Handlung als Mitbewerber und sonstiger Marktteilnehmer betroffen ist, mag zwar im ursprünglichen System des UWG nicht vorgesehen sein, wird aber durch die aktuell anwendbare Definition des konkreten Wettbewerbs laut der Rechtsprechung sowie neue invasive Geschäftsmodelle in Zukunft erneut auftreten können. Die Anwendung 
beider Normenkomplexe mit ihren verschiedenen Tatbestandsvoraussetzungen gewährleistet eine möglichst umfassende lauterkeitsrechtliche Prüfung solcher Geschäftsmodelle. Außerdem würde eine Beschränkung der Anwendung von $\$ 4$ a UWG auf „auch-Mitbewerber“ einen nicht im Gesetz vorgesehenen Vorrang des Mitbewerberschutzes vor dem Schutz sonstiger Marktteilnehmer etablieren.

Mithin sind die Tatbestände des $\$ 4$ a UWG und $\$ 4$ Nr. 4 UWG auch in der vorliegenden Konstellation nebeneinander anzuwenden. Der $\mathbb{4} 4 \mathrm{a}$ UWG bedarf keine seinen Anwendungsbereich einschränkende Auslegung in dem Sinne, dass nur "reine“ sonstige Marktteilnehmer erfasst wären. Trotz allem ist bei der Anwendung zu beachten, dass ein logisch konsequenter Gleichlauf in gewissen Tatbestandsmerkmal notwendig ist. So darf insbesondere nicht das Beurteilungskriterium für die Aggressivität einer Handlung in $\$ 4$ a Abs. 2 S. 1 Nr. 5 UWG, wonach Drohungen mit rechtlich unzulässigen Handlungen für eine Aggressivität sprechen, mit einer lauterkeitsrechtlichen Unzulässigkeit bejaht werden, wenn weder $₫ 4 \mathrm{Nr} .4$ UWG noch andere UWG Tatbestände eine solche Unzulässigkeit ergeben.

\section{(b) Verhältnis zu $\$ \mathbb{S} 18 \mathrm{ff}$. GWB}

Die Aufnahme von sonstigen Marktteilnehmern in den Schutzbereich des $\mathbb{4} 4$ a UWG macht die Norm zu einer Art „Kartellrecht light“, die zwingend unter Beachtung der einschlägigen kartellrechtlichen Normen zu bewerten ist. Denn durch die semantische Ähnlichkeit der Tatbestände in $\$ 4$ a UWG („Ausnutzen einer Machtposition“) und $\$ 19$ Abs. 1 GWB („Ausnutzung einer marktbeherrschenden Stellung“) bzw. Art. 102 AEUV („Ausnutzung einer beherrschenden Stellung auf dem Binnenmarkt") stellt sich die Frage, ob Verbote auf Grundlage von $\$ 4$ a UWG nicht das bestehende Schutzkonzept des Kartellrechts im Kontext von Marktmacht aushebeln und damit im Gesamtkomplex zu widersprüchlichen Ergebnissen führen können. So könnte gerade im Fall eines Handelnden, der nicht die Voraussetzungen von $\$ 18$ GWB erfüllt, eine Unterlassung gegen kartellrechtlich erlaubtes Verhalten begehrt werden - und zwar mit ähnlichen Argumenten, die an sich nur gegen marktbeherrschende Unternehmen statthaft wären. Aus diesem Grunde bedarf es einer Prüfung, ob die Verbotsnormen der $\mathbb{S} \mathbb{S} 19,20 \mathrm{GWB} /$ Art. 102 AEUV nicht als leges speciales die Anwendung des $\mathbb{S} 4 \mathrm{a}$ UWG in der vorliegenden Konstellation insge- 
samt ausschließen ${ }^{791}$. Andererseits könnten die Normen nebeneinander angewendet werden, aber das Tatbestandsmerkmal der Ausnutzung einer Machtposition in $\$ 4$ a UWG in Konkordanz mit den kartellrechtlichen Vorschriften ausgelegt werden ${ }^{792}$.

Die zunächst genannte Ansicht, die kartellrechtlichen Normen seien vorrangige Sonderregeln, befürwortet vor allem Scherer. Sie schränkt den Anwendungsvorrang des Kartellrechts aber insoweit ein, dass im Falle fehlender Marktmacht eine Unlauterkeit nach $₫ 4$ a UWG bejaht werden könne, wenn sonstige - also nicht in den $\$ \mathbb{S} 19-21$ GWB enthaltene unlauterkeitsbegründende Umstände hinzutreten ${ }^{793}$. Gleichermaßen argumentiert Köhler für eine Sperrwirkung der kartellrechtlichen Normen, wenn vom Marktpartner eine geschäftliche Entscheidung im Sinne des $\$ 2$ Abs. 1 Nr.9 UWG verlangt wird ${ }^{794}$. Im Adblock Plus Fall wären demnach alle Umstände, die auf eine generelle Ungleichbehandlung des Betroffenen ( $\mathbb{S} 18$ Abs. 2 Nr. 1 GWB), eine ungleiche Entgeltgestaltung gegenüber dem Betroffenen ( $\mathbb{\$} 18$ Abs. 2 Nr. 3 GWB), den verweigerten Zugang des Betroffenen zum "geblockten Netz“ ( $\mathbb{1} 18$ Abs. 2 Nr. 4 GWB) und das Fordern von Zahlungen für den Zugang zum „geblockten Netz“ ( $\$ 18$ Abs. 2 Nr. 5 GWB) gesperrt. Dies gilt sowohl für Webseitenbetreiber als auch für Werbetreibende, soweit Letztgenannte überhaupt Adressat des Angebots der Werbeblocker sind. Was dann allerdings übrig bliebe wäre schlicht die isolierte Prüfung der Werbeblockade, die bereits als nicht unzulässig behindernd im Sinne von $\$ 4 \mathrm{Nr} .4 \mathrm{UWG}$ festgestellt wurde und bei der mangels Angebots durch den Betreiber keine Qualifizierung der Betroffenen als sonstiger Marktteilnehmer möglich ist. Die Ansicht Scherers würde folglich dazu führen, dass $₫ 4$ a UWG keinen verbleibenden Anwendungsspielraum mehr im Fall der Werbeblocker (sowie in einer Vielzahl von sonstigen B2B-Fällen) hätte. Bei strenger Anwendung dürfte somit erst gar nicht mit der Prüfung der einzelnen Tatbestandsmerkmale des $₫ 4$ a UWG begonnen werden.

Solch eine weitgehende Sperrwirkung hat insbesondere das OLG Köln in seinem Urteil nicht anerkannt und $\$ 4$ a UWG ohne Auseinandersetzung mit der systematischen Anwendbarkeit der Norm herangezogen und

791 So angedacht durch Fritzsche in WRP 2014, 1392, 1396, Rn 38 und vorgeschlagen durch Scherer in WRP 2015, 148, 152, Rn. 33.

792 So wiederum alternativ vorgeschlagen durch Scherer in WRP 2015, 148, 152, Rn. 34.

793 GRUR 2016, 233, 236.

794 Köhler/Bornkamm/Feddersen, UWG, $₫ 4 a$, Rn. 1.16. 
im Ergebnis auch bejaht. Eine denkbar kurze Auseinandersetzung mit der Konkurrenz zum Kartellrecht erfolgte am Tatbestandsmerkmal der „Machtposition"795. Im Umkehrschluss lässt sich hieraus folgern, dass keine systematische Sperrwirkung des Kartellrechts angenommen wurde. Ähnlich sind auch Beiträge von Fritzsche und Alexander zu verstehen. Fritzsche behandelt die Konkurrenz zum Kartellrecht in seinem Aufsatz nach Inkrafttreten des $₫ 4$ a UWG nicht als Anwendbarkeitsproblem, sondern als Problem bei der Auslegung des Merkmals der Ausnutzung einer Machtposition. Dies insbesondere, weil neben $₫ 20 \mathrm{GWB}$ Schutzlücken durch $₫ 4 \mathrm{a}$ UWG geschlossen werden könnten. Gleichfalls seien die Wertungen von $\$ 18$ GWB zu beachten ${ }^{796}$. Alexander erklärte in seiner Anmerkung zum Urteil des OLG München in Sachen Adblock Plus, dass die speziellen Tatbestände des Kartellrechts als Beurteilungsmaßstäbe bei der Interpretation der Machtposition heranzuziehen seien ${ }^{797}$.

In der Literatur besteht insoweit Einigkeit darin, dass die $\mathbb{S} 18 \mathrm{ff}$. GWB jedenfalls nicht ignoriert werden dürfen, wie es das OLG Köln bei seiner rein lauterkeitsrechtlichen Beurteilung getan hat. Ob hieraus nun eine systematische Sperrwirkung oder eine restriktive Auslegung des Tatbestandsmerkmals der Machtposition zu erkennen ist, ist eine dogmatische Feinheit, die praktisch keinen Unterschied macht, denn so oder so würde ein Unterlassungsanspruch nach $\mathbb{\$} 4$ a UWG daran scheitern, dass das Verhalten in den kartellrechtlichen Normen ausdrücklich angelegt ist.

Nach hier vertretener Ansicht ist jedoch keine systematische Sperrwirkung durch die $\mathbb{S} 18 \mathrm{ff}$. GWB, sondern eine kartellrechtsfreundliche Auslegung der „Machtposition“ im Sinne von $\mathbb{4} 4 \mathrm{a}$ UWG vorzugswürdig. Eine die Prüfung der einzelnen Tatbestandsmerkmale ausschließende Sperrwirkung der kartellrechtlichen Vorschriften birgt das Risiko, dass sich die Praxis allzu pauschal auf diese Sperrwirkung beruft und die Besonderheiten des Einzelfalles nicht weiter berücksichtigt. Da es sich bei $\$ 4$ a UWG im Verhältnis von Unternehmen zueinander um „richtlinienfreien Raum" handelt, ist hier durchaus eine Rechtsfortbildung denkbar, die neben den kartellrechtlichen Marktbeherrschungskriterien einen Bereich unlauter ausnutzbarer Machtpositionen zu Tage fördert. Diese Rechtsentwicklung sollte nicht durch pauschale Anwendbarkeitssperren ausgehebelt werden. Vielmehr sind auf Sachverhaltsebene die konkreten geschäftlichen Handlungen genau zu analysieren und inzident mit den $\mathbb{S} 18 \mathrm{ff}$. GWB

795 OLG Köln, Urteil vom 24.6.2016 - 6 U 149/15, GRUR 2016, 1082.

796 Fritzsche, WRP 2016, 1, 4.

797 Alexander, GRUR 2017, 1147, 1157. 
abzugleichen. Sind demnach Umstände wie Ungleichbehandlung oder Zugangsbeschränkungen das vom Betroffenen angegriffene Unlauterkeitsmerkmal, sperrt das Kartellrecht. In Fällen von Autoritätsausnutzung 798 hingegen ist das Kartellrecht nicht anwendbar und entfaltet keine Sperrwirkung. Gerade beim Zusammentreffen von kartellrechtlich relevanten Umständen und weiteren Umständen, die allein über das Lauterkeitsrecht zu lösen sind, würde eine pauschale Annahme einer Sperrwirkung hemmend für die Rechtsfortbildung wirken.

Demnach ist auch im hier beurteilten Fall keine Sperrung des $₫ 4$ a UWG anzunehmen. Die einzelnen Tatbestandsmerkmale sind demnach sorgsam zu prüfen.

\section{(3) Der Tatbestand des $\$ 4$ a UWG}

Da die Anwendbarkeit der Norm somit geklärt ist, ist der konkrete Tatbestand des $\$ 4$ a UWG in den Blick zu nehmen. Wäre der $\$ 4$ a UWG nur auf seinen ersten Satz im ersten Absatz beschränkt, würde die Vorschrift trefflich in das tradierte System des deutschen UWG passen. Die Norm weist (neben dem personellen Anwendungsbereich) im Wesentlichen drei Tatbestandsmerkmale auf und zwar erstens das Erfordernis einer geschäftlichen Handlung, zweitens die Eignung zur Beeinträchtigung der geschäftlichen Entscheidungsfreiheit des Betroffenen (die sog. „geschäftliche Relevanz"${ }^{1799}$ ) und drittens die Aggressivität der Handlung.

Traditionell läge es von dieser Warte aus an der Rechtsprechung die beiden letztgenannten Merkmale mit Leben zu füllen. Allerdings setzt insbesondere beim letzten Merkmal - der Aggressivität - der europarechtliche Einschlag der Norm an. So wird in Satz 2 des ersten Absatzes eine Legaldefinition gegeben, wonach die Aggressivität aus einer Belästigung, Nötigung oder unzulässigen Beeinflussung folgt. Satz 3 wiederum definiert die unzulässige Beeinflussung.

Absatz 2 der Norm liefert sodann eine Art „Bedienungsanleitung“ zur Bewertung der Aggresivität, indem bestimmte Umstände zu bedenken sind. Zum größten Teil erfolgt an dieser Stelle bereits eine intendierte Auslegung. Mit Ausnahme von $\mathbb{4} 4 \mathrm{a}$ Abs. 2 S. 1 Nr. 1 UWG spricht die Feststellung der aufgezählten Umstände sehr stark für eine Aggressivität, so

798 Vgl. Hintergrund und Fallmaterial bei Köhler/Bornkamm/Feddersen, UWG, \4a, Rn. 1.67ff..

799 Vgl. Köhler/Bornkamm/Feddersen, UWG, $\$ 2$, Rn. 148. 
bei drohenden oder beleidigenden Formulierungen und Verhaltensweisen gem. Nr. 2, Ausnutzen von Unglückssituationen gem. Nr. 3, belastenden oder unverhältnismäßigen Hindernissen nichtvertralicher Art gem. Nr. 4 und rechtlich unzulässigen Handlungen gem. Nr. 5. Es ist zwar nur schwer denkbar wie beim Vorliegen dieser Umstände noch eine Aggressivität ausgeschlossen werden soll. $\$ 4$ a Abs. 2 UWG nennt sie aber nur als zu berücksichtigende Kriterien. Dies bedeutet, dass sich der Handelnde trotz Verwirklichung dieser Umstände weiterhin auf eine fehlende Aggression berufen kann. Freilich wird er hierfür dann in besonderer tatsächlicher Darlegungs- und rechtlicher Argumentationsnot sein.

Bemerkenswert ist bei diesem Aufbau, dass nahezu in jedem Tatbestandsmerkmal und auch innerhalb dieser Merkmale in den einzelnen Definitionen unbestimmte Rechtsbegriffe und relativierende Erheblichkeitsschwellen eingebaut sind, die bei strenger Anwendung an beinahe jeder Stelle eine Differenzierung erfordern. Somit erweist sich die ausführliche Kodifizierung zuletzt als gedanklicher Umweg, der zuletzt wieder den Gerichten den Ball zuspielt. So muss sowohl in $\$ 4$ a Abs. 1 S. 1 als auch in $\mathbb{4} 4 \mathrm{a}$ Abs. 1 S. 2 UWG die Eignung der Handlung zur Beeinflussung der Entscheidungsfindung bzw. zur Beeinträchtigung der Entscheidungsfreiheit festgestellt werden. Beim letzteren sogar ,im konkreten Fall unter Berücksichtigung aller Umstände“. Bei der Definition der unzulässigen Beeinflussung in $\$ 4$ a Abs. 1 S. 3 UWG ist zudem die Wesentlichkeit des Eingriffs in die Fähigkeit zur informierten Entscheidung zu prüfen.

Bei dieser Komplexität der Norm, die neben den Erheblichkeitsschwellen auch zwischen der Veranlassung zu einer geschäflichen Entscheidung in Abs. 1 S. 1, der Entscheidungsfreiheit in Abs. 1 S. 2 und der Fähigkeit zu einer informierten Entscheidung in Abs. 1 S. 3 unterscheidet ohne dabei dasselbe zu meinen, verwundert es kaum, dass bei dem wenigen einschlägigen Fallmaterial noch viele Fragen in der Anwendung offen bleiben. Diese Stellungnahme soll einen Beitrag zur Etablierung einer konsistenten Anwendung des $₫ 4$ a UWG geben.

\section{(a) Geschäftliche Handlung}

Keine Probleme bereitet das erste Tatbestandsmerkmal der geschäftlichen Handlung. Hier gilt die allgemeine Definition aus $\$ 2$ Abs. 1 Nr. 1 UWG. Für das Angebot von Werbeblockern gilt hier das bereits oben im Kontext 
der gezielten Behinderung Ausgeführte entsprechend ${ }^{800}$. Das Angebot eines Werbeblockers ist demnach als einheitliche geschäftliche Handlung anzusehen.

Vorsicht ist allein geboten, dass das simple Merkmal der geschäftlichen Handlung nicht mit der geschäftlichen Entscheidung verwechselt wird, auf die es im Weiteren an entscheidender Stelle ankommen wird.

\section{(b) Geschäftliche Relevanz}

Zentrales Schutzsubstrat des $\mathbb{4} 4 \mathrm{a}$ UWG ist die geschäfliche Entscheidungsfreiheit des - für hiesigen Fall allein maßgeblichen - sonstigen Marktteilnehmers. Der Begriff der geschäftlichen Entscheidung ist ebenfalls im Definitionsparagrafen des UWG enthalten. Gemäß $\$ 2$ Abs. 1 Nr. 9 UWG beinhaltet er jede Entscheidung eines sonstigen Marktteilnehmers darüber, ob, wie und unter welchen Bedingungen er ein Geschäft abschließen, eine Zahlung leisten, eine Ware oder Dienstleistung behalten oder abgeben oder ein vertragliches Recht im Zusammenhang mit einer Ware oder Dienstleistung ausüben will, unabhängig davon, ob der sonstige Marktteilnehmer sich entschließt, tätig zu werden.

Die Eignung zur Entscheidungsveranlassung wird dabei auf Grundlage einer objektiven Wahrscheinlichkeit der Reaktion eines durchschnittlichen sonstigen Marktteilnehmers geprüf ${ }^{801}$. Diese Wahrscheinlichkeit ist durch eine ex ante-Betrachtung zu bewerten ${ }^{802}$. Im Rahmen des Werbeblockens ist es nicht fernliegend anzunehmen, dass ein durchschnittlicher Webseitenbetreiber durch die schiere Existenz einer Werbeblockersoftware und dem generellen Angebot deren Betreibers, dafür zu sorgen, einen Teil der blockenden Nutzer gleichwohl zu erreichen, den Abschluss eines Vertrags erwägt. Damit ist die geschäftliche Relevanz bei Erfüllung der sonstigen Tatbestandsmerkmale kein ernsthaftes Problem.

800 Vgl. oben Ziffer C. I. 4. a) aa) (1).

801 Köhler/Bornkamm/Feddersen, UWG, $\mathbb{S} 4 a$, Rn. 1.32.

802 Scherer, in: Fezer/Büscher/Obergfell, UWG, $\mathbb{S}$ 4a, Rn. 102. 
(c) Belästigung und Nötigung als Mittel als Aggressionsmittel

Eine geschäftliche Handlung ist nach $₫ 4$ a Abs. 1 S. 2 Nrn. 1 und 2 UWG u.a. dann aggressiv, wenn die Entscheidungsfreiheit des sonstigen Marktteilnehmers durch Belästigung oder Nötigung beeinträchtigt $\mathrm{t}^{803}$.

Diese beiden Varianten der Aggressionsmittel werden zum Teil als zur unzulässigen Beeinflussung nach $₫ 4$ a Abs. 1 S. 2 Nr. 3 UWG spezielle und vorrangig anwendbare Ausprägungen qualifiziert ${ }^{804}$. So soll immer wenn eine Belästigung oder Nötigung vorliegt, auch eine unzulässige Beeinflussung gegeben sein, weil bei der Belästigung Druck aufgebaut und bei der Nötigung ein solcher Druck ausgeübt werde.

Diese Ansicht überzeugt nicht vollends, da vor allem eine Belästigung auch ohne die für eine unzulässige Beeinflussung notwendige Machtposition möglich ist. So ist gut denkbar, dass auch ein untergeordneter Marktteilnehmer durch Belästigungen eine geschäftliche Entscheidung des Adressaten herbeiführt. Insbesondere bei hartnäckigem Verhalten, dem der Adressat irgendwann schlicht zur Entledigung der Belästigung stattgibt, mag $\mathbb{S} 4 \mathrm{a} U W G$ erfüllt sein ${ }^{805}$.

Hingegen ähneln sich Nötigung und unzulässige Beeinflussung schon eher. Aber auch im Rahmen der Nötigung ist gerade im B2B-Verhältnis nicht zwingend eine Machtposition notwendig ${ }^{806}$. In diesem Verhältnis kommt praktisch allein die Anwendung psychischen Zwangs in Frage. Dies mag am ehesten durch Drohungen allgemein oder mit rechtlich unzulässigen Handlungen im Sinne von $\$ 4$ a Abs. 2 S. 1 Nrn. 2 und 5 UWG bewerkstelligt werden. Drohungen können hingegen auch ohne übergordente Machtposition etwa aufgrund von Wissen um geheime Umstände zur gewünschten geschäftlichen Entscheidung führen.

Insgesamt stehen die Aggressionsmittel in $\$ 4$ a Abs. 1 S. 2 UWG deshalb in keinem besonderen Rangverhältnis ${ }^{807}$. In dieser Bearbeitung werden die

803 Laut Gesetz einschließlich der Anwendung körperlicher Gewalt, was allerdings für die hiesige Fallkonstellation außer Acht bleiben kann. Jegliche Einwirkungen finden allein auf virtueller Ebene statt.

804 Scherer, GRUR 2016, 233, 236.

805 Überschneidungen zu $\$ 7$ UWG sind dabei nicht ausgeschlossen, wobei die Begriffe in beiden Normen nicht kongruent sind. Für eine tiefere Auseinandersetzung mit den verschiedenen Bedeutungen der Belästigung im UWG, vgl. Scherer, WRP 2017, 891.

806 Vgl. Köhler/Bornkamm/Feddersen, UWG, $\$ 4 a$, Rn. 1.49.

807 So auch Köhler/Bornkamm/Feddersen, UWG, $\mathbb{4} 4 a$, Rn. 1.29. 
beiden Mittel allein deshalb gemeinsam dargestellt, weil ihre Bedeutung für den Werbeblocker-Fall beschränkt ist.

So wird zum einen von keiner Stimme in Rechtsprechung oder Literatur das Vorliegen einer Belästigung durch die Werbeblockade angenommen oder nur erwogen. Zum anderen fehlt dem allgemein wirkenden Verhalten der Werbeblockeranbieter ein adressatenspezifisches Belästigungsmoment. So wird Belästigung im Ausgangspunkt definiert als eine geschäftliche Handlung, die dem Adressaten aufgedrängt wird und die bereits wegen ihrer Art und Weise als störend empfunden wird ${ }^{808}$. Ferner soll der Handlung ein „Bedrängungspotential“ innewohnen ${ }^{809}$. Dies kann bei der undifferenzierten Errichtung einer Blacklist-Werbeblockade hingegen weder gegenüber Webseitenbetreibern, Werbenetzwerken noch Werbenden angenommen werden. Keiner dieser Marktteilnehmer wird spezifisch bedrängt, vielmehr müssen sie alle gleichsam die Blockade zunächst hinnehmen. Auch die generelle Eröffnung der Möglichkeit einer Aufnahme in die Whitelist hat kein Bedrängungspotential in dem Sinne, dass hier belästigt würde. Dies könnte anders zu betrachten sein, wenn die Werbeblockeranbieter in regelmäßigen Abständen aktiv einem Marktteilnehmer die Freischaltung unter Hinweis auf die Nachteile der Blockade anbieten würden. Die Belästigung ist demnach vor allen Dingen durch ein direktes kommunikatives Element geprägt, das bei generell wirkenden Vorgängen wie der Werbeblockade nicht passt. Die unzulässige Beeinflussung ist geeigneter um solche Vorgänge zu erfassen.

Die Nötigung wurde bislang nur durch das OLG Hamburg in Erwägung gezogen. Das OLG Hamburg vertrat dabei aber die Ansicht, dass die Nötigung nach $₫ 4$ a Abs. 1 S. 2 Nr. 2 UWG wegen der Fixierung auf die Druckausübung im Ergebnis deckungsgleich mit der unzulässigen Beeinflussung nach $₫ 4$ a Abs. 1 S. 2 Nr. 3 UWG sei ${ }^{810}$. Dementsprechend differenzierte der Senat auch nicht weiter zwischen beiden Merkmalen. Im Wege der Auslegung ließ das OLG Hamburg im Übrigen verlauten, dass der Begriff der Nötigung aus $\$ 240$ StGB hier nicht anwendbar sei, da $\$ 4$ a UWG richtlinienkonform auszulegen sei. Vielmehr sei der Begriff der Nötigung anhand des $\$ 4$ a Abs. 2 S. 1 UWG mit Leben zu füllen. In diesem Katalog sah der Senat zudem mangels einer „insbesondere“-Einschränkung eine abschließende enumerative Aufzählung von möglichen Anhaltspunkten. Daraus folgert er sodann, dass nicht alle Drohungen

808 Ohly/Sosnitza, UWG, $\mathbb{\$} 4 a$, Rn. 11.

809 Scherer, WRP 2017, 891, 894.

810 OLG Hamburg, Urteil vom 15.3.2018 - 5 U 152/15, WRP 2018, 604. 
nach $₫ 4$ a UWG verboten seien, sondern allein solche mit rechtlich unzulässigen Handlungen. Gerade eine solche rechtlich unzulässige Handlung konnte das OLG Hamburg aber in der Nichtaufnahme in die Whitelist ohne Zahlung durch den klagenden Webseitenbetreiber nicht erkennen. Wettbewerbsrechtliche Gründe mochte es per se nicht gelten lassen, weil sonst ein Zirkelschluss drohe. Dies gelte insbesondere für die Intensität des Drucks durch die Werbeblockade. Als mögliche rechtlich unzulässige Handlung nannte es die Umgehung von technischen Schutzvorkehrungen gem. $\mathbb{S} 95$ a UrhG, die aber im Streitfall nicht vorlag.

Obschon dem Ergebnis des OLG Hamburg beizupflichten ist, dass keine Nötigung der Webseitenbetreiber durch die kostenpflichtige Freischaltungsmöglichkeit seitens der Werbeblockeranbieter vorliegt, mag die Herleitung nicht insgesamt zu überzeugen. Die Gleichstellung von Nötigung und unzulässiger Beeinflussung ist jedenfalls sehr kühn. Wenn man dies schon entgegen dem eindeutig differenzierenden Gesetzeswortlaut vertreten möchte, dann müssten aber jedenfalls die besonderen Tatbestandsmerkmale der unzulässigen Beeinflussung in $\$ 4$ a Abs. 1 S. 3 UWG herangezogen werden. Insbesondere müsste dann eine Machtposition sowie die Ausnutzung eben dieser im Rahmen der Nötigung positiv festgestellt werden. Zu derlei Problemen enthält sich das OLG Hamburg voll und ganz.

Ebenfalls problematisch ist die Annahme des Hamburger Senats, dass die Kriterien in $\$ 4$ a Abs. 2 S. 1 UWG eine abschließende Aufzählung relevanter Umstände für eine Nötigung darstellen sollen ${ }^{811}$. Diese Interpretation ist durchaus vom Wortlaut der Norm („Bei der Feststellung, ob eine geschäftiche Handlung aggressiv [...] ist, ist abzustellen auf [... “') gedeckt, mag aber bei historischer und systematisch-teleologischer Auslegung auch anders bewertet werden. Denn wie Köhler unter Verweis auf die fremdsprachigen Fassungen der UGP-Richtlinie herausarbeitet, ist der deutsche Wortlaut historisch betrachtet eher unglücklich geraten. Eine Interpretation des Begriffes des Abstellens hin zur Bedeutung, dass die Kriterien lediglich zu berücksichtigen seien, würde dazu führen, dass in $\$ 4$ a Abs. 2 S. 1 UWG keine abschließende Aufzählung zu erkennen wäre ${ }^{812}$. Dem wiederum ließe sich entgegnen, dass im hier maßgeblichen B2B-Verhältnis gerade nicht zwingend auf die UGP-Richtlinie rekurriert werden muss. Betrachtet man im Übrigen systematische und teleologische Gründe innerhalb des $\$ 4$ a UWG insgesamt, so ist auch die Nötigung wegen der

811 Ebenfalls eine abschließende Aufzählung befürwortet Scherer, GRUR 2016, 233, 239.

812 Köhler/Bornkamm/Feddersen, UWG, $₫ 4 a$, Rn. 1.83. 
ausdrücklichen Anordnung in $\ 4$ a Abs. 1 S. 2 UWG „im konkreten Fall unter Berücksichtigung aller Umstände" zu ermitteln. Ersichtlich steht die Wendung „alle Umstände“ im nicht auflösbaren logischen Konflikt mit einer abschließenden Wirkung von $₫ 4$ a Abs. 2 S. 1 UWG. Hinzu kommt die enorm offene Formulierung der Kriterien in $\mathbb{S} 4 \mathrm{a}$ Abs. 2 S. 1 Nrn. 1 und 2 UWG, die einen Bereich ungeschriebener Kriterien und Verhaltensweisen geradezu erzwingt.

Demnach ist der Begriff der Nötigung entgegen der Ansicht des OLG Hamburg gerade nicht im Umkehrschluss zu $\mathbb{\int} 4 \mathrm{a}$ Abs. 2 S. 1 Nr. 5 UWG auf einen Bereich der Drohungen mit rechtlich unzulässigen Handlungen zu fixieren. Der Begriff geht darüber hinaus. Er kann indes nicht dasselbe meinen wie die Nötigung im Sinne von $\mathbb{} 240$ StGB - da ist dem OLG Hamburg beizupflichten. Denn es besteht kein Bedarf in $\$ 4 \mathrm{a}$ UWG einen deckungsgleichen Nötigungsbegriff einzufügen, insoweit ist die Durchsetzung des $\$ 240$ StGB durch einen Betroffenen im Zivilrecht mit den allgemeinen systematischen Mitteln de iure ausreichend sichergestellt. Die Schwierigkeit bei der Auslegung des Nötigungsbegriffs liegt also darin, einen eigenen Anwendungsbereich zu finden, der spezifisch den Schutzgegenstand des $\mathbb{\$} 4 \mathrm{a}$ UWG betrifft. Dies kann nach hier vertretener Ansicht allerdings nur darin liegen, dass ein sonstiger Marktteilnehmer durch vorsätzlichen bilateralen psychischen Zwang ${ }^{813} \mathrm{zu}$ geschäftlichen Entscheidungen genötigt wird, die er sonst nicht hätte treffen wollen.

So liegt allerdings der Fall bei Werbeblockern nicht. Hier agiert der Werbeblockeranbieter multilateral. Wenn er also durch die Werbeblockade implizit droht, bestehende Geschäftsmodelle zu beeinträchtigen und zugleich der Allgemeinheit der Betroffenen einen Weg durch die Blockade weist, fehlt diesem Handeln der nötige bewusst und konkret auf eine bestimmte juristische Person gerichtete psychische Zwang. Eine Drohung an die Allgemeinheit als Nötigung im Sinne von $\mathbb{S} 4 \mathrm{a} U \mathrm{UW}$ anzunehmen, verlässt die natürliche Bedeutung des Begriffs der Nötigung und würde uferlos wirken.

Demnach sind weder eine Belästigung noch eine Nötigung durch den Werbeblockeranbieter anzunehmen. Dies gilt im Verhältnis zu allen potentiell betroffenen Marktteilnehmern, also Webseitenbetreibern, Werbenetzwerken und Werbenden.

813 Körperlich wirkender Zwang ist im Verhältnis zweier Unternehmen zueinander nur schwer vorstellbar und wird deshalb ausgeklammert. 
(d) Die unzulässige Beeinflussung als Aggressionsmittel

Das gemeinhin erörterte Aggressionsmittel im Kontext der Werbeblocker ist die unzulässige Beeinflussung gemäß $\ 4$ a Abs. 1 S. 2 Nr. 3 UWG. Dies liegt nicht zuletzt daran, dass das OLG Köln eben jene unzulässige Beeinflussung bejahte und damit einen Unterlassungsanspruch gegen das kostenpflichtige Anbieten der Freischaltungsdienstleistungen durch den Adblock Plus Betreiber annahm.

Bei der Prüfung der unzulässigen Beeinflussung ist zum einen die Legaldefinition in $\ 4$ a Abs. 1 S. 3 UWG korrekt anzuwenden und zum anderen sind die Beurteilungskriterien in $\ 4$ a Abs. 2 UWG, soweit für die unzulässige Beeinflussung einschlägig ${ }^{814}$, zu beachten.

Aus der Legaldefinition ergeben sich maßgeblich drei Tatbestandsmerkmale. Zunächst ist das Vorliegen einer Machtposition das zentrale Merkmal der unzulässigen Beeinflussung (siehe dazu (aaa)). Diese Machtposition muss zudem ausgenutzt werden. Doch reicht nicht jedes Ausnutzen aus, sondern erforderlich ist ein Ausnutzen zur Ausübung von Druck (siehe dazu (bbb)). Aus alledem muss eine wesentliche Einschränkung der Fähigkeit des Adressaten zu einer geschäftlichen Entscheidung folgen (siehe dazu (ccc)).

\section{(aa) Machtposition}

Wie bereits zuvor angedeutet sind bei der Auslegung des Tatbestandsmerkmals der Machtposition im horizontalen Verhältnis von Unternehmen die Wertungen des Kartellrechts zu beachten, um Widersprüche in der Gesetzesanwendung zu vermeiden. Was allerdings abstrakt unter einer Machtposition $\mathrm{zu}$ verstehen und wie dieser Begriff $\mathrm{zu}$ definieren ist, bleibt bis zum Zeitpunkt dieser Bearbeitung weitestgehend unklar. Nach dem Wortsinne erforderlich ist jedenfalls eine Überlegenheit der einen Partei, die mit einer Unterlegenheit der anderen Partei korrespondiert ${ }^{815}$. Daneben gibt der Wortsinn keine weiteren Anhaltspunkte zur Auslegung, sodass diese vornehmlich nach systematischen und teleologischen Gesichtspunkten zu erfolgen hat.

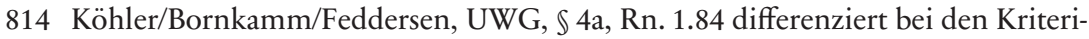
en und hält nur $₫ 4$ a Abs. 2 S. 1 Nrn. 1, 3 und 4 für anwendbar bei der Prüfung der unzulässigen Beeinflussung.

815 Scherer, in: Fezer/Büscher/Obergfell, UWG, $\$ 4 a$, Rn. 130. 
Aus Literatur und Rechtsprechung lassen sich nur ansatzweise Hinweise auf die Bedeutung des Begriffs der Machtposition folgern. Insbesondere vor dem Hintergrund der Konkurrenz mit den kartellrechtlichen Begriffen der Marktbeherrschung und Marktmacht wird versucht, den Begriff negativ abzugrenzen. Insoweit wird regelmäßig behauptet, dass die Machtposition im Sinne des $₫ 4$ a UWG nicht dasselbe meint wie die hergebrachten Begriffe aus dem GWB. Insbesondere seien nicht die im Kartellrecht gefordertern Kriterien und Schwellenwerte maßgeblich ${ }^{816}$. In diesem Sinne umschiffte das OLG Köln in seinem Adblock Plus Urteil die Konkurrenz mit dem Kartellrecht eher non-chalant, indem es aus der relativen Neuheit des $₫ 4$ a UWG und dem bis dato nicht bekannten Begriff der Machtposition folgert, dass mit diesem Merkmal eben keine kartellrechtliche Marktbeherrschung oder Marktmacht gemeint sein könne. Die Machtposition könne sich stattdessen auch aus strukturellen oder situationsbedingten Umständen ergeben ${ }^{817}$. Darin erschöpfen sich allerdings auch die abstrakten Ausführungen des OLG Köln zum Begriff der Machtposition. Was mit der angesprochenen strukturellen oder situationsbedingten Machtposition gemeint sein soll, bleibt trotz Bejahung durch das Gericht offen. Denn das Vorliegen der unzulässigen Beeinflussung begründet der Senat in freier Argumentation abseits einzelner Markmale der Legaldefinition durch Annahme eines „Gesamtverhalten[s], das über die Blacklist die Whitelist mit Durchsetzungskraft verbindet und hernach auf technischem Wege dafür sorgt, dass allein der Anbieter dieser Whitelist die Bedingungen für den Zugang zu den Inhalteangeboten wieder herstellen kann"818.

Der vom OLG Köln geäußerte Gedanke der strukturellen oder situationsbedingten Machtposition klingt auch an anderen Stellen in der Literatur an. Er findet sich bei Scherer ${ }^{819}$ und Köhler ${ }^{820}$. Scherer bleibt jedoch - ähnlich wie das OLG Köln - recht vage in ihren Ausführungen. Die strukturelle oder situationsbedingte Machtposition stellt sie als „sonstige Überlegenheit" neben wirtschaftlicher Überlegenheit dar, enthält sich aber genauerer Beschreibungen. Tiefer dringt Köhler in die potentielle Bedeutung der strukturellen oder situationsbedingten Machtposition ein, ohne allerdings diese Machtposition explizit auf den B2B-Bereich anzuwenden.

816 Vgl. Seichter, in: jurisPK-UWG, $\mathbb{4} 4 \mathrm{a}, \mathrm{Rn} .38 .1$ unter Verweis auf OLG Köln, Urteil vom 24.6.2016 - 6 U 149/15, GRUR 2016, 1082.

817 OLG Köln, Urteil vom 24.6.2016 - 6 U 149/15, GRUR 2016, 1082.

818 OLG Köln, Urteil vom 24.6.2016 - 6 U 149/15, GRUR 2016, 1082, 1088, Rn. 58.

819 Scherer, GRUR 2016, 233, 238.

820 Köhler/Bornkamm/Feddersen, UWG, $₫ 4 a$, Rn. 1.58. 
Denn Köhler vertritt - wie oben bereits dargestellt - die Vorrangthese, wonach das Kartellrecht als lex specialis die Anwendung für weite Teile des B2B-Verhältnisses sperrt. Eine strukturelle Überlegenheit könne im nicht gesperrten persönlichen Anwendungsbereich demnach rechtlich, wirtschaftlich, sozial, beruflich, intellektuell, religiös, weltanschaulich oder psychisch bedingt sein. Eine situationsbedingte Überlegenheit komme bei konkreten Unglückssituationen und in den Fällen des Ansprechens am Unfallort oder des Ansprechens von trauernden Angehörigen kurz nach einem Todesfall in Betracht. Ersichtlich sind die meisten dieser Kriterien auf das B2C-Verhältnis bzw. das Verhältnis großer Unternehmen zu Kleinunternehmern zugeschnitten. Im hiesigen Fall, wo sich auf beiden Seiten wirtschaftlich starke, rechtlich beratene und intellektuell ebenbürtige Parteien gegenüberstehen, kommt es auf Kriterien wie soziale, religiöse, weltanschauliche oder psychische Gründe jedoch nicht an. Ebenso sind die aufgezählten situativen Machtpositionen nicht einschlägig, weil sie auf Ausnahmesitutionen beruhen, die nur natürliche Personen betreffen können.

Neben diesen Erwägungen bleibt auch bei näherer Betrachtung kein Raum für die Anwendung einer strukturellen oder situationsbedingten Machtposition zwischen Werbeblockeranbietern und Betroffenen der Blockade. Bei der situationsbedingten Machtposition ist dies auch abseits der oben genannten Fallbeispiele abstrakt zu begründen. Denn eine situationsbedingte Machtposition muss nach hier vertretener Ansicht spontan und temporär sein. Sobald sich die Situation ändert, löst sich die konkrete Überlegenheit auf. Da Werbeblocker allerdings über die Blacklist eine dauerhafte Blockade errichten und aufrechterhalten, ist die Situation keineswegs spontan oder temporär, sondern andauernd.

Bei der strukturellen Machtposition ist zu beachten, dass das Verhältnis von organisierten Unternehmen zueinander nur dann eine ausreichend korrespondierende Über- bzw. Unterlegenheit zeitigt, wenn diese in der Marktstruktur begründet ist. Denn im Ausgangspunkt stehen sich Unternehmen am Markt ebenbürtig gegenüber. Mit „strukturell“ darf hingegen nicht abseits von konkreten Märkten die Struktur von Unternehmen betrachtet werden, sodass etwa international tätige "mega corporations“ durch ihre enormen Mitarbeiterzahlen und finanziellen Möglichkeiten immer überlegen wären zu in dieser Hinsicht strukturell weniger gut ausgestatteten national tätigen Unternehmen. Eine solche marktunabhängige Strukturbetrachtung wäre uferlos und würde das Merkmal der Machtposition entwerten. 
Eine strukturelle Machtposition kann also nur daraus folgern, dass ein Unternehmen auf seinem konkreten Markt eine Schlüsselrolle innehat. Damit ist jedoch zugleich der thematische Anwendungsbereich des GWB eröffnet. Denn überlegene Unternehmen können ihre starke Position zu Wettbewerbsbeschränkungen ausnutzen, was (nur) in den im GWB und dem AEUV bestimmten gesetzlich geregelten Fällen verboten ist. Damit ist aber entgegen der oben geschilderten, pauschalen Negativabgrenzung zum Kartellrecht sehr wohl der Begriff der Marktbeherrschung aus $\$ 18$ GWB bedeutsam. Die von der Literatur und dem OLG Köln postulierte Existenz einer strukturellen Machtposition ist bei genauem Hinsehen kein Fall, der eine vom Kartellrecht abweichende, spezifisch lauterkeitsrechtliche Beurteilung erfordert. Nähme man insoweit eine rein lauterkeitsrechtlich begründete strukturelle Machtposition eines Unternehmens an ${ }^{821}$, das jedoch nicht die Anforderungen des $\mathbb{1} 18 \mathrm{GWB}$ erfüllt, könnte kartellrechtlich erlaubtes Verhalten untersagt werden. Dieses Verbot könnte sogar unter Meidung der spezialisierten Kartellkammern und -senate bei den angerufenen Gerichten erwirkt werden, womit auch das hergebrachte funktionale Zuständigkeitssystem in der deutschen Zivilgerichtsbarkeit tangiert wäre. Maßgeblich ist jedoch, dass eine lauterkeitsrechtliche Annahme einer Machtposition zu dem grotesken Ergebnis führen würde, dass marktmächtigen Unternehmen im Sinne des Kartellrechts weitgehendere Freiheiten zu wettbewerbsbeeinträchtigen Handlungen zustehen würden als jungen, innovativen Unternehmen oder Start-ups, die durch Technologie oder sonstige innovative Ideen eine Schlüsselrolle einnehmen. Eine solche Auslegung würde folglich ein konkretes Innovationshindernis bedeuten und reaktionäres Verhalten durch bestehende Eliten heraufbeschwören, mit dem junge Unternehmen durch Unterlassungsansprüche schon im Aufbau gehindert werden könnten. Es darf deshalb strukturelle Machtpositionen im B2B-Verhältnis nur dort geben, wo eine dem B2C-Verhältnis ähnliche Sachlage besteht, also vor allem dort wo großen Unternehmen kleine Gewerbetreibende ohne ernsthafte Struktur gegenüberstehen. Dies dürfte also vorranging bei Einzelunternehmen im Gewerbe und bei kleineren Handwerks- und Familienbetrieben in Betracht kommen.

Eine bloße wirtschaftliche Überlegenheit, die regelmäßig mit einer strukturellen Überlegenheit zusammenfällt, jedoch theoretisch auch unabhängig davon vorliegen könnte, taugt ebenfalls nicht zu einer Machtposition im Sinne von $\mathbb{\$}$ a a Abs. 1 S. 3 UWG. Der bloße Umstand, dass gewisse

821 Diese Machtposition würde dann maßgeblich auf gesetzlich nicht in bestimmte Bahnen geleiteten Billigkeitserwägungen beruhen. 
wirtschaftlich starke Unternehmen - man denke an Apple, Amazon oder Google - hart verhandeln und für sich möglichst positive Konditionen erreichen wollen, genügt nicht für eine rechtlich maßgebliche Überlegenheit ${ }^{822}$. Wenn der vermeintlich unterlegene Marktteilnehmer gerne einen Branchenriesen als Referenzkunden gewinnen oder im Verhältnis zu solchen Kunden selbst Know-how generieren möchte und deshalb zu starken Kompromissen bereit ist, sind dies für das Lauterkeitsrecht unbeachtliche Motive. Solange an dieser Stelle die kartellrechtlichen Vorschriften nicht einschlägig sind, bedarf es auch keines weiteren lauterkeitsrechtlichen Schutzes.

Es lässt sich somit festhalten, dass der Begriff der Machtposition eines Unternehmens gegenüber sonstigen Marktteilnehmern in weiten Teilen schnittgleich zur Marktbeherrschung bzw. Marktmacht im Sinne der $\mathbb{S} 18 \mathrm{ff}$. GWB ist. Insbesondere kann im Verhältnis von strukturierten Unternehmen untereinander keine lauterkeitsrechtlich isoliert zu betrachtende strukturelle oder wirtschaftliche Überlegenheit ausreichen ohne die Wirkung der kartellrechtlichen Vorschriften zu untergraben. Eine situationsbedingte Machtposition mag konstruierbar sein, wenn etwa ein Unternehmen in akuten Notsituationen ist. Insoweit könnte man an Cyberangriffe, Datenleaks oder Streiks durch die Belegschaft denken. Diese Fälle dürften aber praktisch nur begrenzte Relevanz haben und sind für den hier maßgeblichen Fall schlicht irrelevant.

Zuletzt bleibt noch zu prüfen, inwieweit der vom OLG Köln herangezogene Umstand der technischen Überlegenheit geeignet ist, eine Machtposition zu begründen, die neben dem Kartellrecht Bestand haben kann. Hier ist zum einen bereits fraglich, ob im konkreten Fall überhaupt von einer technischen Überlegenheit der Werbeblocker gesprochen werden kann. Denn die Blockade durch die Blacklist nutzt bei genauem Hinsehen schlicht die grundsätzliche Funktionsweise der Internetkommunikation aus und könnte durch technische Schutzmaßnahmen der Webseitenbetreiber umgangen werden. Insoweit ist die Werbeblockade schon deshalb nur schlecht als Überlegenheit oder Machtposition geeignet, weil sie von einem Teil der angeblich Unterlegenen - den Webseitenbetreibern - zugelassen und aktiv geduldet wird. Auch die anderen betroffenen Marktteilnehmer - Werbenetzwerke und Werbende - haben es zumindest mittelbar in der Hand, sich der Werbeblockade zu entziehen, indem sie ausschließlich unblockbare Werbung bei den Webseitenbetreibern nachfragen oder durch Vertrags- und Vergütungsgestaltung zu einer vor der Wirkung von

822 Vgl. Fritzsche, WRP 2016, 1, 4. 
Werbeblockern sicheren Ausspielung auffordern. Von einer mit der „Überlegenheit" der Werbeblocker korrespondierenden Unterlegenheit dieser Marktteilnehmer kann deshalb nicht gesprochen werden. In Wirklichkeit bewegen sich alle Betroffenen auf Augenhöhe mit den Werbeblockeranbietern.

Doch selbst wenn man von einer technischen Überlegenheit ausgehen würde, wäre diese wiederum strukturell bedingt und müsste sich der Konkurrenz zum Kartellrecht stellen. Wenn technische Überlegenheit in einem Unternehmen konzentriert wäre, ließe sich regelmäßig auch eine Marktbeherrschung nach $\mathbb{1 8}$ GWB oder relative Marktmacht nach $\$ 20$ GWB annehmen. Unterhalb dieser Schwelle muss es Unternehmen erlaubt sein, einen technischen Vorsprung oder eine technische Schlüsselstellung auch zum eigenen Vorteil auszunutzen. Gerade dies macht den freien Wettbewerb aus.

Nach alledem sollte eine abstrakte Definition der Machtposition im B2B-Verhältnis wie folgt lauten: Machtposition ist die Überlegenheit eines Unternehmens gegenüber einem oder mehreren sonstigen Marktteilnehmer, die mit einer nicht ohne Weiteres behebbaren Unterlegenheit korrespondiert, wobei diese Unterlegenheit darauf beruht, dass (i) der sonstige Marktteilnehmer ein Kleingewerbetreibender oder ähnlicher Betrieb ohne markttypische Struktur ist oder (ii) ein ausreichend strukturierter Marktteilnehmer in einer für das Gesamtunternehmen außergewöhnlichen und besonders fordernden Situationen angetroffen wird. Eine Machtposition kann nicht dort angenommen werden, wo sich strukturell (annähernd) ebenbürtige Unternehmen gegenüberstehen, weil in diesem Verhältnis die Vorschriften des Kartellrechts Vorrang genießen.

Auf dieser abstrakten Grundlage ist für eine Machtposition im (Filter-)Werbeblockerfall regelmäßig kein Raum und zwar weder gegenüber größeren Webseitenbetreibern, noch gegenüber Werbenetzwerken, noch gegenüber Werbetreibenden. Bezüglich der beiden Erstgenannten ist nämlich von einer ausreichenden Struktur der betroffenen Unternehmen auszugehen. Kleinere Webseitenbetreiber, insbesondere Blogger oder kleine Publisher mit eigenen Webseiten, können bei Adblock Plus zwar kostenfrei zur Whitelist zugelassen werden, eine Machtposition der Werbeblockeranbieter ließe sich jedoch darauf gründen, dass der Werbeblockeranbieter die Begrenzung auf bestimmte Acceptable Ads zur Bedingung macht. Dadurch könnten von kleinen Webseitenbetreibern nur noch geringere Werbeumsätze generiert werden, weil erfahrungsgemäß besonders Aufmerksamkeit erhaschende Werbeanzeigen zu mehr abrechenbaren Klicks führen. Hier wird man eine strukturelle Machtposition anneh- 
men können, die auch unterhalb der Marktbeherrschungs- bzw. relativen Marktmachtsschwelle eine Existenzberechtigung hat. Denn einzelne Blogger oder Publisher stehen Verbrauchern in vielen Fällen gleich, obwohl allein der Einsatz von Display-Werbung zur Generierung von Einnahmen sie bereits aus der Verbrauchereigenschaft heraus führen dürfte. Eine ausreichende unternehmerische Struktur liegt jedoch in der Regel nicht vor. In diesem Fall ist eine Unterlegenheit dieser Publisher anzunehmen, wenn der überlegene Werbeblocker mit dem Angebot auf Freischaltung aufwartet.

Im Verhältnis zu Werbetreibenden kommt allerdings keine Machtposition in Betracht. Denn der Werbeblocker bietet den Werbenden überhaupt keine Leistungen an. Einzelne Werbende können sich nicht freischalten lassen, es sei denn sie sind zugleich Webseitenbetreiber oder Werbenetzwerke und haben damit eigene Server oder Webseiten, auf denen sie ihre Werbung platzieren. Die bloße mittelbare Betroffenheit der Webseitenbetreiber in dem Sinne, dass sich die Marktgegebenheiten geändert haben, führt zu keiner Unterlegenheit der Werbenden gegenüber dem Werbeblockeranbieter. Werbende müssen vielmehr den Markt, der sich aus den freien Kräften von Angebot und Nachfrage und Resonanz beim Publikum ergibt, so annehmen, wie er sich zur jeweiligen Zeit darstellt. Dazu gehört auch die Beschränkung auf bestimmte Werbeformen und gewisse Preise für die Erreichung verschiedener Adressaten. Das OLG Köln stellte also zu Unrecht die Betroffenheit von Werbekunden von einer Machtposition des Werbeblockeranbieters fest.

Da insoweit eine Machtposition - zwar nur - für einen sehr beschränkten Personenbereich festgestellt worden ist, ist die Prüfung der weiteren Tatbestandsmerkmale geboten. Dies ist trotz Ablehnung der Machtposition in den meisten Fällen des Online-Werbemarktes auch deshalb interessant, um für zukünftiges Fallmaterial Denkanstöße zu geben, falls eine Machtposition aus hier nicht vorhergesehenen Gründen zu bejahen ist.

\section{(bb) Ausnutzung der Machtposition zur Ausübung von Druck}

Die Machtposition allein führt noch nicht zur unzulässigen Beeinflussung. Vielmehr muss die Machposition ausgenutzt werden und zwar zur Ausübung von Druck auf den Adressaten. Diesem Erfordernis kann entnommen werden, dass die Machtposition im Zeitpunkt des Ausnutzens zur Druckausübung schon bestehen muss und nicht etwa erst durch 
die Druckausübung entsteht ${ }^{823}$. Jedoch besteht kein Erfordernis, dass die Machtposition schon für längere Zeit for der Druckausübung besteht, weil sonst keine situativen Machtpositionen zu einer unzulässigen Beeinflussung führen könnten. Die Machtposition muss demnach nur für einen logischen Moment vorbestehen, damit der Aggressor den Betroffenen sodann unter Druck setzen kann. Zirkelschlüssig wäre allerdings eine durch eigene Druckausübung erschaffene Machtposition, die dann weiterhin zur Druckausübung ausgenutzt wird. Für einen solchen Fall müssen andere Tatbestandsvarianten des $\$ 4$ a UWG, vor allem die Nötigung, oder andere Normen des Zivilrechts Vorrang haben.

Im Merkmal des Ausnutzens stellt sich zudem die Frage, ob mit diesem Erfordernis ein subjektives Tatbestandsmerkmal etabliert wird ${ }^{824}$. Scherer lehnt dies ab, weil es potentiell den Schutz der Betroffenen erheblich reduzieren könnte ${ }^{825}$. Köhler vertritt an dieser Stelle, dass sich der Aggressor der Ausnutzung der Machtposition und der damit verbundenen Druckausübung bewusst sein muss, eine Absicht sei aber nicht erforderlich ${ }^{826}$. Abseits der für den harmonisierten B2C-Bereich aus dem Wortlaut der UGP-Richtlinie gefolgerten Argumente, spricht für die Annahme eines Bewusstseins beim Aggressor der Wortsinn des auch im deutschen Gesetzeswortlaut genutzten Begriffs des „Ausnutzens“. Die Ausnutzung einer Situation ist nur dann möglich, wenn die Sachlage bekannt ist. Erfolgt etwa das Verhalten eines „Aggressors“ am Markt über eine gewisse Dauer unverändert und wird erst im Laufe dieser unveränderten Verhaltensweise die Qualifikation einer Machtposition rechtlich möglich, kann nicht von einem Ausnutzen gesprochen werden. Auch hier wird die zeitliche Komponente der vorbestehenden Machtposition deutlich. Eine Schutzverringerung für von einer Druckausübung betroffene sonstige Marktteilnehmer ist entgegen Scherers Argumentation jedoch nicht zu befürchten. Denn dort wo eine Machtposition schon vorbesteht und der Aggressor sein Verhalten hin zu einer Druckausübung der Betroffenen ändert, wird wohl eine tatsächliche Vermutung zugunsten des Ausnutzens anzunehmen sein. Dann muss nämlich der Aggressor darlegen und beweisen, warum seine Verhaltensweise gerade kein Ausnutzen der Machtposition sein soll.

823 Fritzsche, WRP 2016, 1, 4.

824 Scherer, GRUR 2016, 233, 239.

825 Scherer, GRUR 2016, 233, 239; Scherer, in: Fezer/Büscher/Obergfell, UWG, $\$ 4 a$, Rn. 143ff..

826 Köhler/Bornkamm/Feddersen, UWG, $₫ 4 a$, Rn. 1.59. 
Ein weiterer Aspekt, der am Tatbestandsmerkmal der Druckausübung herausgestellt wird, ist die Notwendigkeit einer Verschlechterung der Sach- und Rechtslage für den Betroffenen, sollte er dem Druck nicht nachgeben. Dies bedeutet zugleich, dass eine Verbesserung der Sach- oder Rechtslage für den Adressaten der potentiell aggressiven Handlung niemals einen notwendigen Druck begründet. Ein solches dem Adressaten sozusagen "dienendes" Verhalten ist nicht von der Schutzkonzeption des $\$ 4$ a UWG umfasst, das vor einer Verschlechterung schützen soll ${ }^{827}$.

Überträgt man diese abstrakten Erwägungen auf den noch verbleibenden Bereich, in welchem eine Machtposition anzunehmen ist - also im Verhältnis des Werbeblockerbetreibers zu kleinen Publishern bzw. Webseitenbetreibern - lässt sich zunächst festhalten, dass die Machtposition des Adblockers schon vor dem Angebot der Freischaltung besteht. Das Angebot zur Freischaltung ist sodann eine bewusste Handlung zum Ausnutzen der Machtposition. Somit lässt sich das Bewusstsein für die Ausnutzung der Machtposition ebenfalls bejahen. Maßgebliche Gründe, mit denen sich der Werbeblockeranbieter hier „exkulpieren“ könnte, sind nicht ersichtlich.

Allerdings stellt sich die Frage, ob überhaupt von einer Druckausübung gesprochen werden kann, weil die Freischaltung den Webseitenbetreibern überwiegend Vorteile bringen könnte. Denn durch die Freischaltung erreicht der Publisher auf den ersten Blick Internetnutzer, die ohne Freischaltung für seine Werbung unerreichbar wären. Dann würde er mit diesen Nutzern keinen Werbeumsatz realisieren können und allein im Bereich des ungeblockten Netzes eine Refinanzierungsmöglichkeit haben. Die Freischaltung erweitert also den Adressatenkreis für die Werbung. Gegenleistung dieser Freischaltung ist bei kleineren Webseitenbetreibern, die keine Provisionszahlungen an den Whitelist-pflegenden Werbeblockeranbieter leisten müssen, allein die Einhaltung der Acceptable Ads-Kriterien. Aus dieser objektiven Perspektive ist kein durchgreifender Nachteil für den kleinen Publisher ersichtlich, sondern vor allem ein ökonomisch greifbarer Vorteil. Diese Betrachtung nimmt allerdings die vor dem Freischaltungsangebot liegende Werbeblockade aus der Beurteilung insgesamt aus.

Nimmt man die Perspektive der Webseitenbetreiber an und sieht die Freischaltung untrennbar mit dem Angebot der Werbeblockersoftware und der dadurch bewerkstelligten Blackade mittels Blacklist, könnte sich

827 Scherer, GRUR 2016, 233, 238f.; Köhler/Bornkamm/Feddersen, UWG, $\mathbb{4}$ 4a, Rn. 1.60; Nink, CR 2017, 103, 109. 
dies anders darstellen. So könnte man annehmen, dass implizit in Aussicht gestellt wird, dass die Werbeblockade aufrechterhalten und der Adressat nicht mit seiner „inakzeptablen“ Werbung durchgelassen wird. Der Vorteil der Erreichung von Nutzern, die sich von Werbung an sich abgewendet hatten, wäre demnach nur ein Minus dazu, dass nur durch die aufrechterhaltene Blockade diese Nutzer erst gar nicht erreicht werden. Bei dieser Sichtweise zeigt sich jedoch die Überschneidung zu $\$ 4$ Nr. 4 UWG. Denn es muss hier wertungsmäßig ein Einklang gebracht werden, dass die Werbeblockade keine unzulässige Mitbewerberbehinderung ist und auch im Übrigen nicht als rechtswidrig anzusehen ist. Mit der vorgenannten Betrachtungsweise des impliziten Nachteils würde diese Wertung konterkariert und durch die Hintertür eine Unlauterkeit der Werbeblockade errichtet. Dies ist so nicht statthaft. Vielmehr muss davon ausgegangen werden, dass die Werbeblockade zulässig ist und im Rahmen des $\$ 4$ a UWG nur die Druckausübung durch die Freischaltungsangebote einen eigenen Unlauterkeitsgehalt aufweisen können. Mangels objektiv zu erkennender Nachteile für die Webseitenbetreiber, besteht jedoch keine Druckausübung.

Dieser Gedankengang lässt sich auch auf größere Webseitenbetreiber übertragen, wenn man doch von einer Machtposition in deren Verhältnis zum Werbeblockeranbieter ausgehen wollte. Denn auch bei der im konkreten Fall angeboteten Kostenregelung, wonach die Publisher nicht pauschale Summen zur Freischaltung zahlen sollen, sondern ein gewisser Prozentsatz an Provision für im Rahmen der Freischaltung erfolgter Werbeauslieferung anfällt, kommt objektiv nur ein Vorteil in Betracht. Die Werbeblockade als solche ist kein Nachteil, der an dieser Stelle zu beachten wäre.

Es lässt sich folglich festhalten, dass kein Ausnutzen einer Machtposition zur Druckausübung erkennbar ist. Und zwar gegenüber keinem der potentiell Betroffenen. Spätestens an dieser Stelle müsste somit schon jede Prüfung des $\$ 4$ a UWG im Werbeblockerfall enden.

(cc) Wesentliche Einschränkung der Fähigkeit zu einer informierten Entscheidung

Gleichwohl wird aus Gründen der gesamtheitlichen Betrachtung noch kurz auf das weitere Merkmal der wesentlichen Einschränkung der informierten Entscheidungsfreiheit eingegangen.

Die Fähigkeit zu einer informierten Entscheidung wird laut Köhler dann eingeschränkt, wenn das Verhalten des Unternehmers die Möglichkeiten 
des sonstigen Marktteilnehmers, entscheidungsrelevante Informationen zu erlangen und/oder zu nutzen und damit seine Entscheidung auf rationalkritische Erwägungen zu stützen, einschränkt. In wesentlichem Maße ist diese Fähigkeit eingeschränkt, wenn die geschäftliche Handlung das Urteilsvermögen des sonstigen Marktteilnehmers, also seine Fähigkeit, die Vor- und Nachteile einer geschäftlichen Entscheidung zu erkennen und gegeneinander abzuwägen, beeinträchtigt ${ }^{828}$.

Im Fall Adblock Plus kann schon die bloße Einschränkung der Fähigkeit zu einer informierten Entscheidung nicht erkannt werden. Denn das Angebot einer Freischaltung auf der Whitelist mit Folge der Durchbrechung der Werbeblockade erlaubt es den Adressaten durchaus, die Annahme kritisch zu hinterfragen. Dies gilt dabei für große Webseitenbetreiber, die unter Umständen auch Provisionszahlungen leisten müssten, noch mehr als für kleinere Publisher. Denn alle potentiellen Leistungsnehmer der Freischaltung können zu jederzeit anhand öffentlich zugänglicher Quellen analysieren, ob das „ungeblockte“ Netz noch eine ausreichende Adressatenschaft für die eigenen Werbebemühungen und Refinanzierungshoffnungen darstellt. In keinem der Streitfälle wurde laut den Tatbeständen der Urteile aktenkundig, dass der Werbeblockeranbieter entscheidungsrelevante Informationen zurückhält oder unterdrückt. Das Angebot zur Freischaltung erfolgt vielmehr ausreichend transparent, sodass größere Werbeseitenbetreiber betriebswirtschaftlich kalkulieren können, ob die Freischaltung unter Provisionszahlung noch profitabel sein kann. Ähnlich zeigt sich die Sachlage bei Werbenetzwerken, die ebenfalls eine ökonomische Entscheidung treffen können. Kleinere Publisher ohne Provisionspflicht können zudem kritisch hinterfragen, ob sie die Einschränkung ihrer Gestaltungsfreiheit in Werbeformen auf der eigenen Seite hinnehmen wollen oder nicht. Alle diese Betroffenen können vor dem Hintergrund der Dauerhaftigkeit der Blockade und der fehlenden zeitlichen Befristung des Freischaltungsangebots informiert entscheiden. Sie können von einem Vertragsschluss mit dem Werbeblockeranbieter absehen oder sogar Werbeblockergegenmaßnahmen ergreifen, der ihnen den Zugang zur Wahrnehmung der Nutzer eröffnen kann ${ }^{829}$.

Da schon auf erster Stufe keine Einschränkung feststellbar ist, muss nicht mehr weiter auf die Wesentlichkeit eingegangen werden. Dass hier allerdings die Urteilsfähigkeit der Adressaten angegriffen würde, ließe sich (bei gedachter Bejahung aller vorhergehenden Tatbestandsmerkmale) nur

828 Köhler/Bornkamm/Feddersen, UWG, $\$ 4$ a, Rn. 1.65f..

829 Vgl. auch Fritzsche, WRP 2016, 1, 5. 
mit Blick auf den „Angriff“ durch die vorgehende Blacklist-Blockade bejahen. Diese darf aber - wie oben bereits dargestellt - wegen der Wahrung der Wertung aus $\$ 4$ Nr. 4 UWG hier nicht als rechtswidriges oder auch nur bedenkliches Handeln in die Bewertung einfließen.

(e) Erhebliche Beeinträchtigung der Entscheidungsfreiheit als Ergebnis der Aggression

Zuletzt sind noch abschließende Worte zum Merkmal der Beeinträchtigung der Entscheidungsfreiheit abzugeben. Da bereits keine Aggression festgestellt werden konnte, ist offensichtlich, dass im Ergebnis keine Eignung zur Beeinträchtigung der Entscheidungsfreiheit feststellbar ist.

Die vorhandene Rechtsprechung mit Blick auf Verbraucher zeigt bereits, dass der BGH relativ zurückhaltend in der Bejahung einer erheblichen Beeinträchtigung der Entscheidungsfreiheit ist ${ }^{830}$. Diese Schwelle wird bei sonstigen Marktteilnehmern generell noch erhöht sein, wobei große Unternehmen nur in äußerst extremen Situationen erheblich beeinträchtigt sein können. Ein solcher Fall ist nur schwer denkbar. Deshalb wird die Anwendung des $\$ 4$ a UWG im B2B-Verhältnis wohl auch in Zukunft keine größere Relevanz erhalten.

(v) Stellungnahme zum Urteil Werbeblocker II des BGH und zu divergierender Instanzrechtsprechung

Ausgehend von der obigen Stellungnahme des Rechtslage soll nun das Urteil Werbeblocker II ${ }^{831}$ des BGH bewertet werden. Das Revisionsurteil zum Kölner Rechtsstreit beschränkt sich auf Ansprüche aus dem Lauterkeitsrecht. Ausführlich setzte sich der I. Zivilsenat mit der Mitbewerberbehinderung nach $₫ 4$ Nr. 4 UWG auseinander. Etwas weniger Aufmerksamkeit erhalten die allgemeine Marktbehinderung sowie die Prüfung des $\$ 4 \mathrm{a}$ UWG.

830 BGH, Urteil vom 29.10.2009 - I ZR 180/07, GRUR 2010, 455 - Stumme Verkäufer II; Urteil vom 24.6.2010 - I ZR 182/08, GRUR 2010, 850 - Brillenversorgung II; Urteil vom 3.3.2011 - I ZR 167/09, GRUR 2011, 747 - Kreditkartenübersendung.

831 BGH, Urteil vom 19.4.2018 - I ZR 154/16, WRP 2018, 1322 - Werbeblocker II. 
Im Rahmen der Prüfung des $₫ 4$ Nr. 4 UWG bestätigt der BGH die bislang von allen mit der Software Adblock Plus befassten Gerichten eingenommene Ansicht, dass der Internetwerbeblocker keine gezielte Behinderung eines Mitbewerbers darstelle. Die Instanzgerichte hatten sich dabei unter anderem auf die erste Werbeblocker-Entscheidung des BGH gestützt $^{832}$. In Fortführung dessen enthält das Urteil Werbeblocker II die folgenden bemerkenswerten Aussagen.

\section{(1) Konkretes Wettbewerbsverhältnis und geschäfliche Handlung}

Bei der Frage des konkreten Wettbewerbsverhältnisses gemäß $\ 2$ Abs. 1 Nr. 3 UWG stellt der I. Zivilsenat auf den für ausreichend angesehenen Behinderungswettbewerb ab. Dies entspricht der ständigen Rechtsprechung. Im Rahmen der Mitbewerbereigenschaft erklärt der Senat ausdrücklich, dass die gleichzeitige Qualifizierung eines Unternehmens als Mitbewerber und sonstiger Marktteilnehmer jedenfalls im Rahmen des $₫ 4$ Nr. 4 UWG unschädlich ist (vgl. Rn.18 des Urteils). In ausdrücklicher Abgrenzung einer von Köhler ${ }^{833}$ geäußerten Ansicht soll die Qualifizierung als sonstiger Marktteilnehmer die Mitbewerberstellung nicht „aufheben“. Dies wirkt wie eine konsequente Fortführung der Rechtsprechung zum konkreten Wettbewerbsverhältnis durch Behinderungswettbewerb. Weiterhin stellt der BGH klar, dass das Geschäftsmodell von Adblock Plus einheitlich bewertet werden müsse und nicht zergliedert werden dürfe in eine erste Behinderungsstufe und eine zweite Angebotsstufe. Das ist nach hier vertretener Ansicht richtig ${ }^{834}$ : Wenn man auf der Behinderungsebene - Werbeblockierung - die Mitbewerberstellung qua Beeinträchtigung annimmt, knüpft die „Nachfragerstellung“ der Medienunternehmen hinsichtlich des „Freikaufs“ in das Whitelisting gerade an die Behinderung an. Auch wenn die Medienunternehmen also keine Mitbewerber des Adblock-Anbieters beim „Angebot zum Freikauf“ sind, sind sie es auf der notwendigen vorgelagerten Stufe ${ }^{835}$.

832 BGH, Urteil vom 24.6.2004, I ZR 26/02 - Werbeblocker I.

833 Köhler/Bornkamm/Feddersen, (36. Auflage!), UWG, $\mathbb{2}$ 2, Rn. 111 - in der 37. Auflage wurde diese Ansicht fallengelassen; näher Köhler, WRP 2014, 1017 Rn. 28 ff., 32.

834 Vgl. oben Ziffer C. I. 4. a) aa) (1).

835 Vgl. auch die obigen Ausführungen zur Aufspaltung des Geschäftsmodells und den (fehlenden) Auswirkungen auf die Bewertung des konkreten Wettbewerbsverhältnisses, Ziffer C. I. 4. a) aa) (2) (i). 
Auf Grundlage der zuvor geschilderten einheitlichen Betrachtung des Geschäftsmodells nimmt der BGH eine geschäftliche Handlung im Sinne von $\$ 2$ Abs. 1 Nr. 1 UWG an (vgl. Rn. 21 des Urteils). Da das streitgegenständliche Whitelisting entgeltlich erfolgt, kann der BGH der Frage ausweichen, ob eine geschäftliche Handlung eine Entgeltlichkeit voraussetzt, und diese offenlassen ${ }^{836}$.

\section{(2) Gezielte Behinderung}

Bei der gezielten Behinderung zeigt sich der BGH marktliberal. Im Rahmen der Einzelfallabwägung unter Berücksichtigung der Interessen aller Beteiligten gibt der I. Zivilsenat dem Interesse des Werbeblockerbetreibers am Vertrieb der Software den Vorzug. Dies vor allem unter Heranziehung der Interessen der Werbeblockersoftware, inklusive der negativen Informationsfreiheit der Nutzer. Im Detail unterscheidet das Urteil zwischen dem Interesse der Nutzer, von aufgedrängter Werbung - sprich Werbung entgegen $\$ 7$ UWG - verschont zu bleiben, und dem Interesse, nicht mit aufdringlicher (aber erlaubter) Werbung konfrontiert zu werden. Nur das erstgenannte Interesse unterfalle der grundrechtlich geschützten negativen Informationsfreiheit. Aufgedrängte Werbung im Sinne einer unzumutbaren Belästigung erkennt der Senat im Streitfall jedoch nicht ${ }^{837}$. Gleichsam stellt er auch das (nicht grundrechtlich geschützte) Interesse der Internetnutzer in seine Abwägung ein ${ }^{838}$. Dem „reaktionären“ Ansinnen der Verlage, neue Technologien vor dem Hintergrund der Bewahrung alter Strukturen zu verbieten, wird insgesamt eine Absage erteilt. Auch Medi-

836 Vgl. zur Bewertung der geschäftlichen Handlung durch unentgeltliche Werbeblocker oben Ziffer C. I. 4. a) aa) (1).

837 Vgl. zu Fällen, in welchen Displaywerbung durchaus eine aufgedrängte Werbung sein kann oben Ziffer B. IV. 1. a).

838 Im Kontext der grundrechtlichen Bewertung der verschiedenen Interessen erhob die Klägerin im Nachgang zum Urteil eine Anhörungsrüge zum BGH, die allerdings zurückgewiesen worden ist - BGH, Beschluss vom 21.11.2018 - I ZR $154 / 16$, juris. Die Klägerin rügte demnach u.a. vergeblich, dass der Senat sich mit dem Vortrag der Klägerin zum Schutzbereich des Art. 5 Abs. 1 Satz 2 GG nicht auseinandergesetzt habe. Dieses letzte zivilprozessuale Mittel zeigt, dass alle Mittel ausgeschöpft werden, damit der Weg der Verfassungsbeschwerde zum BVerfG zulässig wird. Vgl. dazu auch https://www.lto.de/recht/nachrichten /n/lg-hamburg-werbeblocker-adblocker-axel-springer-eyeo-urheberrecht-verletzu ng/, zuletzt abgerufen am 30.5.2019. 
enunternehmen müssen sich den Herausforderungen des Marktes stellen (vgl. Rn. 24 ff. des Urteils).

Dem von den Webseitenbetreibern vorgebrachten Argument, es liege eine Einwirkung auf fremde Werbung vor, schiebt der I. Zivilsenat einen Riegel vor. Jedenfalls bei der Abwägung in $\$ 4 \mathrm{Nr} .4$ UWG sei zu berücksichtigen, dass hier ein Dritter eine autonome Entscheidung treffe, ohne die der Behindernde den Mitbewerber nicht in seiner Entfaltung beeinträchtigen könnte ${ }^{839}$. Dieses aus der analogen Welt bewährte Judiz reichert der Senat sodann mit einem sehr technologiefreundlichen Argument an. Selbst wenn das vom Werbeblocker herbeigeführte Ergebnis über das hinausgeht, was der Nutzer ohne besondere Fähigkeiten selbst bewerkstelligen könnte, ändere dies nichts an der Autonomie der Nutzerentscheidung. Auch „technisch anspruchsvolle Produkte" müssen erst vom Nutzer eingesetzt werden, um ihre Wirkung zu entfalten (vgl. Rn. 30 des Urteils).

Ferner verweist der Senat auf einen weiteren Ansatz in seiner Rechtsprechung zu $₫ 4$ Nr. 4 UWG, der nun endgültig als gefestigte Rechtsprechung anzusehen ist. Unter Hinweis auf die Entscheidungen Automobilbörse Online $e^{840}$, Flugvermittlung im Internet ${ }^{841}$ und World of Warcraft II $^{842}$ betont das oberste Zivilgericht erneut, dass eine unlautere Einwirkung auf fremde digitale Produkte nur vorliegt, wenn eine Schutzvorkehrung unterlaufen werde (vgl. Rn. 31 des Urteils). Wer seine Angebote schutzlos am Markt platziert, wird durch externe Einwirkungen nicht gezielt behindert. Ein Schutz gegen Einwirkungen anderer Marktteilnehmer, insbesondere Mitbewerber, setzt voraus, dass die Leistung durch vertragliche oder technische Schutzmaßnahmen sozusagen mit einem „Burggraben“ versehen wird. Daran fehlte es im Streitfall.

Diese Ausführungen des BGH sind insgesamt zu begrüßen ${ }^{843}$. Es fällt jedoch auf, dass der BGH nicht auf die Frage eingeht, ob in der Beurteilung zwischen dem zulässigen allgemeinen Blacklisting und dem darauf aufbauenden kommerziellen Whitelisting unterschieden werden könnte. Natürlich kann man die beiden Aspekte nicht trennen, weil beides eine

839 Unter Verweis auf BGH, Urteil vom 23.06.16 - I ZR 137/15, WRP 2017, 46 Fremdcoupon-Einlösung.

840 BGH, Urteil vom 22.06.11 - I ZR 159/10, WRP 2011, 1469 - Automobil-Onlinebörse.

841 BGH, Urteil vom 30.04.14 - I ZR 224/12, WRP 2014, 839 - Flugvermittlung im Internet.

842 BGH, Urteil vom 12.01.17 - I ZR 253/14, WRP 2017, 434 - World of Warcraft II.

843 Vgl. insoweit die hiesigen Ausführungen zur gezielten Behinderung in Ziffer C. I. 4. a) aa) (3). 
einheitliche geschäftliche Handlung darstellt. Aber auch wenn man davon ausgeht, dass ein (insbesondere für den Nutzer unentgeltliches) Blacklisting zulässig ist, muss damit nicht zwingend einhergehen, dass ein Whitelisting gegen Entgelt zulässig sein muss. Denn man könnte durchaus in Erwägung ziehen, dass die Behinderung durch die Werbeblockierung an sich nach Abwägung der Interessen der behinderten Medien- und Werbeindustrie einerseits und des Adblock Plus-Herstellers andererseits nicht zuletzt wegen der Interessen der Nutzer, die Werbung in legitimer Weise vermeiden wollen, zulässig ist. Daraus muss nicht unbedingt folgen, dass die Etablierung eines abhängigen Geschäftsmodells auf dieser Grundlage auch noch zulässig sein muss. Allerdings bietet dieses Geschäftsmodell den behinderten Unternehmen immerhin die Möglichkeit, der Werbeblockade in gewissen Grenzen zu entkommen, sofern der Nutzer dies nicht durch Änderung der Einstellung verhindert. Vor diesem Hintergrund wäre für die Medien- und Werbeindustrie durch ein Verbot des Whitelistings nichts gewonnen ${ }^{844}$.

\section{(3) Allgemeine Marktbehinderung}

Eine allgemeine Marktbehinderung auf Grundlage der Generalklausel in $\$ 3$ UWG lehnt der BGH klar und deutlich ab. Es sei nämlich nicht die „Aufgabe des Behinderungstatbestands oder des Lauterkeitsrechts allgemein, bestehende wettbewerbliche Strukturen zu bewahren und wirtschaftichen Entwicklungen entgegenzusteuern, in denen die bisherigen Marktteilnehmer eine Bedrohung ibres Kundenstammes erblicken" 845 .

Unabhängig davon, dass der BGH an dem dogmatisch fragwürdigen Tatbestand ${ }^{846}$ wie selbstverständlich festhält, ist dieser zutreffenden Aussage nichts hinzuzufügen.

844 Vgl. dazu auch das Beispiel einer geschlossenen Tür, die ein Stück weit geöffnet wird. Während die Blacklist die geschlossene Tür darstellt, öffnet die Whitelist diese Tür wieder ein Stück breit. S.o. Ziffer C. I. 4. a) aa) (3) (b) a.E..

845 BGH, Urteil vom 19.4.2018 - I ZR 154/16, WRP 2018, 1322, Rn. 45 - Werbeblocker II.

846 Vgl. insoweit obige Ausführungen in Ziffer C. I. 4. a) aa) (3). 
(4) Aggressive geschäftliche Handlung

Bleibt noch das Verbot einer aggressiven geschäftlichen Handlung nach $\mathbb{\$} 4 \mathrm{a}$ UWG. Hier postuliert der I. Zivilsenat, dass es keine gespaltene Auslegung des $\$ 4$ a UWG mit Blick auf die Schutzsubjekte der Norm, also einerseits Verbraucher und andererseits sonstige Marktteilnehmer, geben dürfe (vgl. Rn. 54 des Urteils). Dies ist keine völlige Selbstverständlichkeit, weil im B2B-Verhältnis zumindest theoretisch ein Bereich gegeben ist, der nicht richtlinienkonform auszulegen ist ${ }^{847}$.

Die Prüfung konzentrierte sich auf die vom OLG Köln festgestellte unzulässige Beeinflussung der Werbekunden gemäß $\$ 4 a$ Abs. 1 S. 2 Nr. 3, S. 3 UWG. Leider hatte der BGH dabei keine direkte Veranlassung, die im B2B-Verhältnis noch ungeklärte Konkurrenz zum Kartellrecht auszuloten $^{848}$, weil es den Anspruch über den Prüfungspunkt der „Ausnutzung der Machtposition zur Einschränkung der Fähigkeit zu einer informierten Entscheidung" ausscheiden ließ. Insoweit stellte der I. Zivilsenat maßgeblich darauf $a b$, dass ein werbewilliges Unternehmen seine kommerzielle Entscheidungsfähigkeit nicht generell einbüße und nicht zu irrationalen Handlungen verleitet werde (vgl. Rn. 67 ff. des Urteils).

Hier ist dem BGH uneingeschränkt zuzustimmen, wenn er ausführt, dass ein Unternehmen die zur Verfügung stehenden Optionen kaufmännisch betrachten und abwägen werde. Bei der Schaltung von Werbung wird das werbewillige Unternehmen überlegen, welches Medium, welches Werbeformat, welche Zielgruppe etc. zu wählen sind. Dass ein bestimmtes Medium und Werbeformat dabei durch die Existenz von Werbeblockern nur eine geringere Zielgruppe erreicht, ist ein berechenbarer Faktor, der in der Praxis Berücksichtigung finden wird. Entwertet die Existenz der Werbeblocker die gewünschte Werbung allzu sehr, wird das Unternehmen eine kaufmännische Entscheidung zu treffen haben. Sie wird allerdings wegen der überragenden Bedeutung des Internets auch in seiner mobilen Variante bzw. in dem Sonderbereich der sozialen Netzwerke kaum dahingehen, auf diesen Werbekanal ganz zu verzichten, sondern eher zur Folge haben, dass das Entgelt, dass man zu zahlen bereit ist, sinkt. Ferner könnte man in Erwägung ziehen, auf die Dienste leicht blockierbarer Adserver zu verzichten ${ }^{849}$.

847 Vgl. oben Ziffer C. I. 4. a) aa) (4).

848 Siehe für die hier vertretene Ansicht zur Abgrenzung oben Ziffer C. I. 4. a) aa) (4) (ii) (b).

849 Vgl. auch oben Ziffer C. I. 4. a) aa) (4) (c) (dd) (ccc). 
In aller Deutlichkeit weist der BGH zudem daraufhin, dass die Annahme des OLG Köln, dass im vorliegenden Sachverhalt $₫ 4$ a Abs. 2 Nr. 4 UWG die Aggressivität belege, nicht zutrifft. Denn die aggressive Handlung muss nach dieser Norm in derselben Rechtsbeziehung erfolgen wie die Hindernisbereitung (vgl. Rn. 63 ff. des Urteils). Das OLG Köln nahm hingegen eine Aggressivität im Verhältnis Werbeblocker zu Werbekunde an, die Hindernisbereitung aber im Verhältnis Werbekunde zu Webseitenbetreiber. Diese Anwendung entsprach nicht der gesetzlichen Regelung des $\$ 4$ a UWG. Andere Auslegungskriterien des $\$ 4$ a Abs. 2 UWG waren nicht einschlägig und konnten demnach keinen Hinweis für eine Aggression geben.

Nicht vollends überzeugen die Ausführungen zum Prüfungspunkt der Machtposition (vgl. Rn. 59 ff. des Urteils). Die Definition der Machtposition bezieht sich auf eine situativ oder strukturell begründete überlegene Stellung. Im B2B-Verhältnis ist diese Definition allerdings relativ schwach $^{850}$. Eine situative Machtposition ist denkbar, müsste aber spontan und temporär sein. Die Werbeblockerproblematik ist hingegen dauerhaft und nicht nur Ausdruck einer besonderen Situation. Demnach wäre nur eine strukturelle Machtposition möglich. Woraus sich laut BGH aber im konkreten Fall eine strukturelle Überlegenheit ergeben soll, bleibt leider unklar.

Die Ausführungen zu $₫ 4 a$ UWG sind vor dem Hintergrund der überraschenderweise an dieser Stelle stattgebenden Entscheidung des OLG Köln ziemlich knapp geraten, sodass dem Urteil über den konkreten Fall hinaus kaum allgemeingültige Thesen zu entnehmen sind.

\section{(5) Verhältnis zu OLG Köln}

Der BGH hob mit seinem Urteil das vom OLG Köln tenorierte Verbot auf, den Betreiber von Webseiten wie unter anderem Bild.de nur unter Einhaltung der Acceptable Ads Kriterien und gegen Entgelt auf die Whitelist aufzunehmen ${ }^{851}$. Diese Aufhebung war im Streitfall zwingend geboten und faktisch wie rechtlich zutreffend. Denn es fehlten im Tatbestand des Urteils maßgebliche Feststellungen, um im Vertikalverhältnis zwischen dem Werbeblockerbetreiber und einem Werbekunden eine aggressive geschäftliche Handlung anzunehmen.

850 Siehe dazu oben Ziffer C. I. 4. a) aa) (4) (c) (dd) (aaa).

851 Siehe oben D. I. 3. c). 
Dabei war der Ansatz des Kölner Senats, den Streitfall aus etwas mehr Abstand und unter Heranziehung der Folgen für andere Marktteilnehmer als den Webseitenbetreibern, dem Werbeblockeranbieter und deren Nutzern zu betrachten, durchaus spitzfindig. Allerdings ist die konkrete Annahme in den Entscheidungsgründen, dass „werbewillige Unternehmen [...], die zunächst in eine Blockadesituation geraten, aus der sie sich sodann freikaufen" 852 müssen, faktisch nicht tragbar. Denn es sind in der klassischen Dreierkette der Werbeausspielung „Werbekunde-Webseitenbe-

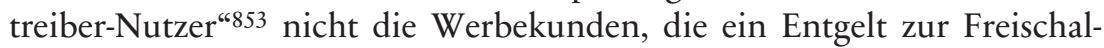
tung zahlen müssten. Dies sind vielmehr die Webseitenbetreiber. Das „Freikauf“-Argument wäre nur dann denkbar, wenn höhere Werbepreise für die Ausspielung von Werbeanzeigen festgestellt worden wären. Dazu verhält sich der Tatbestand allerdings nicht. Es ist auch nicht offenkundig, dass es zu einem solchen Anstieg gekommen ist.

In diesem Fall einer mittelbaren Belastung durch höhere Werbepreise für gewöhnliche Displayanzeigen, z.B. Banner oder In-Stream Videos, kann sodann aber auch nicht per se eine unzulässige Beeinflussung gem. \4a Abs. 1 S. 2 Nr. 3 UWG erkannt werden. Wie der BGH richtigerweise erkannte, können Werbekunden immer noch frei und kaufmännisch entscheiden, ob Sie weiterhin Werbung schalten wollen oder nicht. Auch wird man nicht auf hohe Kosten für solche Werbung abstellen, die als Acceptable Ads über die Whitelist an Werbeblockernutzer durchgeleitet wird. Denn diese Werbung gibt gerade die Möglichkeit einen neuen Markt zu erreichen - und zwar „das geblockte Netz“. Dass dieser Markt erst neu entstanden ist, und früher Teil des allgemeinen Onlinewerbemarkts war, schadet nicht. Denn wie der BGH ebenfalls zurecht urteilte, ist zu beachten, dass sich Märkte ändern können. Ein Schutz vor diesen Veränderungen des Markts kann nicht über das UWG erreicht werden.

Anders könnte die Sachlage höchstens bei Hybriden wie Google, Facebook oder Amazon sein. Diese Unternehmen betreiben insofern selbst die Webseiten, sind aber auch als Werbenetzwerk oder sogar als Werbender selbst betroffen. Ohne hier formal auf verschiedene Rechtspersonen innerhalb der Multikonzerne abzustellen, würde der Werbeblocker stark in die konzerninternen Prozesse wie Eigenwerbung eingreifen. Hier wird man aber in der Mitbewerberbehinderung wie auch in der aggressiven geschäftlichen Handlung den Ausweg aus einer potentiellen Unlauterkeit

852 OLG Köln, Urteil vom 24.6.2016 - 6 U 149/15, GRUR 2016, 1082.

853 Praktisch oft mindestens als Viererkette mit einem Werbenetzwerk zwischen Werbekunden und Webseitenbetreiber. 
über das Erfordernis der technischen oder rechtlichen Schutzmaßnahmen finden. Diese führen zur Interessenabwägung zugunsten der Werbeblocker in $₫ 4$ Nr. 4 UWG und zum Ausschluss einer Machtposition der Werbeblocker in $\$ 4$ a Abs. 1 S. 2 Nr. 3, S. 3 UWG. Interessanterweise waren es aber gerade nicht die Tech-Riesen, die den Rechtsweg gegen Adblock Plus suchten. Diese wählten vielmehr den Weg der Kooperation mit dem Werbeblockerbetreiber. Der Bearbeiter vermutet, dass dies wohl weniger einer extensiven rechtlichen Prüfung als einer generellen Philosophie in der digitalisierten Welt geschuldet ist.

\section{(vi) Allgemeines Zivilrecht}

Soweit man nach der Ablehnung der speziellen Tatbestände im UWG noch auf Grundlage des Rechtes am eingerichteten und ausgeübten Gewerbebetrieb auf $\$ 823$ Abs. 1 BGB eingehen möchte, lässt sich die Prüfung sehr kurz halten. Denn alle oben genannten Erwägungen sind im Rahmen der Interessenabwägung zu übertragen. Demnach besteht kein Raum für Unterlassungsansprüche auf Grundlage von $₫ 823$ Abs. 1 BGB in Verbindung mit $₫ 1004$ BGB.

\section{bb) Urheberrecht}

Neben dem Lauterkeitsrecht ist zudem denkbar, Werbeblockersoftware auf urheberrechtlicher Grundlage zu bekämpfen. Das Urheberrecht kennt insoweit gleich effektive Unterlassungsansprüche bei Verletzungen schutzwürdiger Rechtspositionen wie das Lauterkeitsrecht. Als solche schutzwürdige Rechtsposition sind für Webseitenbetreiber ein Urheberrecht oder Leistungsschutzrecht an der "Webseite in ihrer Gesamtheit“ denkbar. Die Entfernung von Werbelementen aus dieser Gesamtheit müsste bei nachfolgend zu überprüfender - Schutzfähigkeit eine ausreichende Verletzungshandlung sein. Hier darf wiederum nicht außer Acht bleiben, dass der Nutzer einen Werbeblocker in seinem Endgerät bewusst installiert und anwendet. Zuletzt dürfen auch keine Schranken oder Rechtfertigungsgründe einschlägig sein, die bei der Internetkommunikation regelmäßig Bedeutung erlangen.

Wegen dieser komplexen rechtlichen Ausgangslage widem sich nur wenige Abhandlungen über das Thema Werbeblocker der urheberrechtlichen 
Bewertung der Thematik ${ }^{854}$. In der Rechtsprechung waren bislang nur das LG München $I^{855}$, das LG Hamburg ${ }^{856}$ sowie das OLG München ${ }^{857}$ mit Unterlassungsansprüchen aus dem UrhG befasst. Die Urteile fielen dabei dadurch auf, dass an vielen Stellen die eher komplizierten Fragen nach der Schutzfähigkeit offengelassen worden sind, weil die Verletzungshandlung mit weniger Begründungsaufwand abgelehnt werden konnte.

An dieser Stelle soll deshalb eine für möglicherweise zukünftige Fälle im Kontext von Webseiten und dort platzierter Werbung interessante Prüfung der Schutzfähigkeit erfolgen ${ }^{858}$. Im Weiteren erfolgt eine knappe Beleuchtung der Entscheidung zu Verletzungshandlungen durch die Betreiber von Werbeblockern als Täter oder Teilnehmer. Zuletzt soll auf Schranken des Urheberrechts und einschlägige Rechtfertigungsgründe eingegangen werden.

\section{(i) Schutzfähigkeit von Webseiten}

Die Schutzfähigkeit von komplexen Webseiten, die nicht bloß aus banalen HTML-Befehlen bestehen und als einfache Textseiten beim Nutzer erscheinen, sondern mit optisch aufbereiteter und bewusst gegliederter Darbietung von Inhalten aufwarten, wurde bislang hauptsächlich auf die folgenden Werktypen und Leistungsschutzrechte gestützt: Computerprogramm, Datenbankwerk, Recht an einer Datenbank und Multmediawerk. In dieser Reihenfolge wird nachfolgend die Schutzfähigkeit von Webseiten wie jene der klagenden Medienhäuser - etwa bild.de, zeit.de oder prosieben.de - bewertet. Zudem wird im Anschluss betrachtet, ob diese Webseiten oder Elemente davon noch vor dem Hintergrund anderer Werktypen oder Leistungsschutzrechte gesetzliche Schutzfähigkeit beanspruchen kann, die gegenüber Werbeblockern Wirkung entfalten könnte.

854 Engels, GRURPrax 2015, 338; Kreutzer, MMR 2018, 639.

855 LG München I, Urteil vom 27.5.2015 - 37 O 11673/14, MMR 2015, 660.

856 LG Hamburg, Urteil vom 3.5.2016 - 308 O 46/16, CR 2016, 782.

857 OLG München, Urteil vom 17.8.2017, U 2225/15 Kart, GRUR 2017, 1147.

$858 \mathrm{Vgl}$. https://www.lto.de/recht/nachrichten/n/lg-hamburg-werbeblocker-adblocke r-axel-springer-eyeo-urheberrecht-verletzung/, zuletzt abgerufen am 30.5.2019. 
Vor dem Hintergrund der technischen Vorgänge die mit dem Abruf von Webseiten durch den Nutzer verbunden sind, liegt es nahe vornehmlich einen Schutz der Webseiten als Computerprogramm zu prüfen. Nach den unionsrechtlich geprägten Vorschriften über Computerprogramme in den $\$ 69$ a ff. UrhG sind Programme in jeder Gestalt geschützt. Der gewährte Schutz gilt für alle Ausdrucksformen eines Computerprogramms, jedoch sind Ideen und Grundsätze nicht schutzfähig ( $\$$ 69a Abs. 2 UrhG). Auch Computerprogramme müssen personliche geistige Schöpfungen ihrer Urheber sein ( $\$ 69$ a Abs. 3 UrhG).

Mit diesen gesetzlichen Formulierungen sind allerdings nur ganz grob die Eckpunkte abgesteckt. Einer handhabbaren Definition des Computerprogramms enthält sich der Gesetzgeber bewusst und überlässt dies der Rechtsprechung ${ }^{859}$. Eine frühe Definition des BGH aus dem Jahr 1985 lautet etwa: „Das fertige Computerprogramm wird als eine Folge von Befehlen definiert, die nach Aufnahme in einen maschinenlesbaren Träger fähig sind $z u$ bewirken, daß eine Maschine mit informationsverarbeitenden Fähigkeiten eine bestimmte Funktion oder Aufgabe oder ein bestimmtes Ergebnis anzeigt, ausführt oder erzielt" 860 .

Der EuGH enthält sich bislang einer konkreten Definition des Begriffs des Computerprogramms, der in der alten Richtlinie 91/250/EWG sowie der aktuellen Richtlinie 2009/24/EG („Software-Richtlinie“) verwendet wird. Im Urteil SAS Institute hat der Gerichtshof vielmehr eine negative Abgrenzung vorgenommen und dargestellt, was nicht zum Schutzgegenstand eines Computerprogramms gehöre: weder die Funktionalität eines Computerprogramms, noch die Programmiersprache, noch das Dateiformat, die im Rahmen eines Computerprogramms verwendet werden ${ }^{861}$. Daraus wurde gefolgert, dass das Computerprogramm als solches keine reine Datenbeschreibung sein dürfe, sondern eine Datenverarbeitung im eigentlichen Sinne ermöglicht werden müsse ${ }^{862}$. Vorab hatte der EuGH

859 Vgl. Kotthoff in: Dreyer/Kotthoff/Meckel/Hentsch, UrhG, \$69a, Rn. 4f.; Marly, GRUR 2012, 773, 774.

860 BGH, Urteil vom 9.5.1985, I ZR 52/83, GRUR 1985, 1041, unter Rückgriff auf die Definition, die in $\mathbb{1} 1$ (i) der WIPO-Mustervorschriften aus 1977 enthalten ist.

861 EuGH, Urteil vom 2.5.2012 - C-406/10, GRUR 2012, 814, Rn. 39.

862 Grützmacher, in: Wandtke/Bullinger, UrhG, $\$ 69$ a, Rn. 3. 
bereits entschieden, dass die grafische Benutzeroberfläche eines Computerprogramms nicht am Schutz eines eben solchen teilhabe ${ }^{863}$.

In diesem Spannungsfeld von Schutz des Quell- und Objektcodes von Computerprogrammen, aber der Nichterfassung von freihaltebedürftigen Funktionalitäten, Programmsprachen und Dateiformaten sowie bloßem Output wie Benutzeroberflächen ist eine Einordnung von Webseiten vorzunehmen. Eine solche Beurteilung kann freilich nicht ohne technische Beurteilung erfolgen. Vor dieser anspruchsvollen technischen Beurteilung bewahrten sich die mit urheberrechtlichen Fragen befassten Gerichte weitestgehend. Allein das LG Hamburg führte insoweit aus:

"Es dürfte es sich bei der von der Antragstellerin für den Aufbau ihrer Webseite verwendeten Software um ein Computerprogramm im Sinne des $\$ 69$ a UrhG handeln. [...] Es liegt nahe, dass es sich bei der dynamischen html-Programmierung unter Verwendung von JavaScripts, die den bei jedem Abruf individuell erstellten Aufbau der Webseite der Antragstellerin bestimmen, um ablauffähige und interpretierbare Steuerbefehle handelt, die auch hinreichend komplex sind und insofern die nach $\$ 69$ a Abs. 3 UrhG erforderliche Individualität erreichen (BGH GRUR 2013, 509 Rn. 24 - UniBasic-IDOS). Dies kann jedoch vorliegend dahinstehen." 864

Mit dem Verweis auf die HTML-Programmierung der im Streitfall maßgeblichen Webseite stellen sich bei genauem Hinsehen jedoch eine Reihe komplexer Fragen, die das LG Hamburg nicht beantwortet.

Das LG Hamburg nennt die Begriffe „dynamische HTML-Programmierung" und „JavaScripts“, sodass zunächst in einem ersten Schritt kurz erläutert werden muss, was hier überhaupt Gegenstand der Diskussion ist. Hierbei ist auf HTML-Programmierungen, deren Erscheinungsformen als statisch oder dynamisch und JavaScript sowie weiteren Skriptsprachen bzw. Hilfsmitteln beim Webseitendesign einzugehen.

$\mathrm{Zu}$ HTML, der standardisierten Auszeichnungssprache für das World Wide Web, enthält diese Arbeit bereits weiter oben Erklärungen zum technischen Hintergrund ${ }^{865}$. Der HTML-Code einer Webseite ist - stark

863 EuGH, Urteil vom 22.12.2010 - C-393/09, GRUR 2011, 220 - BSA/Kulturministerium.

864 LG Hamburg, Urteil vom 3.5.2016 - 308 O 46/16, CR 2016, 782. Ähnlich Engels, GRURPrax 2015, 338, der aus der Komplexität der Befehlskette im HTML-Dokument einen Schutz als Computerprogramm folgert.

865 Siehe vor allem Abschnitt C. III.. 
vereinfacht ausgedrückt - die Arbeitsanweisung an den Browser, wo und wie bestimmte Inhalte zu laden, anzuordnen und visuell darzustellen sind. Traditionell sieht die allgemeine Ansicht im urheberrechtlichen Schrifttum und der Rechtsprechung in „HTML-Programmierungen“ kein Computerprogramm. Zur Begründung wird ausgeführt, dass es sich bei HTML sowie anderen „markup languages" 866 um Beschreibungssprachen handelt, die keine Steuerung eines Programmablaufs bewirken, sondern stattdessen nur bewirken, dass die enthaltenen multimedialen Elemente angezeigt werden $^{867}$. Der HTML-Code an sich bewirkt keine Datenverarbeitung ${ }^{868}$.

Dies alles gilt uneingeschänkt für das statische Webdesign, bei dem der Nutzer als Client vom Server eine starre Anleitung von Inhalten erhält, die der Browser in eine sichtbare Webseite verwandelt. Jedoch ist zur Zeit der Bearbeitung das dynamische Webdesign sehr viel verbreiteter, da auf diese Weise in Echtzeit auf aktuelle Informationen zugegriffen werden kann. Bei dieser Art von Webseite werden zwischen Anfrage des Client beim Server und der endgültigen Anzeige noch diverse Zwischenschritte durchlaufen, etwa der Abruf von Daten aus einer Datenbank oder die Einblendung von für den Nutzer besonders relevanten Inhalten. Hier wird das HTML-Dokument, das der Server an das Nutzergerät sendet dynamisch und computerbasiert generiert ${ }^{869}$. So erklärt sich auch, warum beim mehrfachen Aufruf einer Webseite innerhalb kurzer Zeit häufig unterschiedliche Werbeanzeigen oder auch Contentinhalte angezeigt werden. In der Regel ist dabei die grundsätzliche Formatierung der Webseite statisch gehalten und nur die Inhalte werden dynamisch bei Abruf eingefügt. Dies ist v.a. bei Webseiten wie Google oder auch Facebook leicht zu beobachten ${ }^{870}$.

Innerhalb der dynamischen Webseiten ist zudem noch zu unterscheiden, ob die Dynamik auf Seiten des Servers oder des Clients bewerkstelligt wird. Beim oben beschriebenen Abruf von Daten aus einer Datenbank

866 Beispiele sind XML, XHTML oder HTML5.

867 OLG Rostock, Beschluss vom 27.6.2007 - 2 W 12/07, GRUR-RR 2008, 1; OLG Frankfurt a.M., Urteil vom 22.3.2005, 11 U 64/04, GRUR-RR 2005, 299; Wiebe, in: Spindler/Schuster, $\mathbb{5} 69$ a UrhG, Rn. 6 mit weiteren Nachweisen aus Rechtsprechung und Literatur; Schöttle, in: Auer-Reinsdorff/Conrad, $\$ 25$, Rn. 11.

868 Grützmacher, in: Wandtke/Bullinger, UrhG, $\mathbb{6} 69$ a, Rn. 18.

$869 \mathrm{Vgl}$. https://webanwendungen.at/webdesign/statische-dynamische-websites.html , zuletzt abgerufen am 30.5.2019.

$870 \mathrm{Vgl}$. https://www.netgenerator.de/de/webdesign-begriffslexikon/webdesign-begr iffe-dynamische-webseiten.html, zuletzt abgerufen am 30.5.2019. 
handelt es sich in der Regel um serverseitige dynamische Webseiten ${ }^{871}$. Aus Sicht des Clients wird hier praktisch wie beim statischen Webdesign ein fertiges, ausführbares HTML-Dokument geladen. Bei clientseitigen dynamischen Webseiten werden in der Regel JavaScript-Programme verwendet, die im HTML-Dokument integriert sind. Das in diesem Dokument enthaltene Programm wird dann vom Browser ablaufen gelassen ${ }^{872}$. JavaScript-Progamme dienen zum Beispiel zur Validierung von Nutzereingaben in entsprechende Eingabefelder vor einem Datenaustausch mit dem Server. Sie werden zudem eingesetzt für die auf der Webseite selbst ohne neues Laden durchzuführende Handlungen wie ein-/ausklappbare Texte oder Abschnitte, Kalender zum Auswählen von Daten für Eingabefelder und für Layer Ads, die „modernen Pop-Ups"873.

Nach diesen technischen Hintergünden lässt sich die Aussage des LG Hamburg also so verstehen, dass es bei einer clientseitigen dynamischen Webseite davon ausgeht, dass es sich um ein Computerprogramm handele. Auf der anderen Seite beschreibt das LG Hamburg einen „bei jedem Abruf individuell erstellten Aufbau der Webseite“. Dies spricht für eine zudem serverseitig dynamische Webseite. Jedenfalls erkennt die Kammer „ablauffäbige und interpretierbare Steuerbefehle handelt, die auch hinreichend komplex sind“. Diese Aussage stimmt im Kern zu, die gezogene Konsequenz allerdings nicht.

Denn aus dem Vorliegen von einzelnen ablauffähigen Steuerbefehlen, die bei der vom LG Hamburg betrachteten Seite sowohl serverseitig als auch cleintseitig existieren, kann nicht gefolgert werden, dass die gesamte Webseite ein Computerprogramm darstellt, geschweige denn, dass die Anzeige der Webseite auf dem Gerät des Nutzers an dem Schutz eines etwaigen Computerprogramms Teil hat. So kann der HTML-Code in Teilen als Computerprogramm geschützt sein, wenn er solche Computerprogramme enthält ${ }^{874}$. Der Schutz des Computerprogramms erstreckt sich also nur auf die konkreten JavaScript-Programme im HTML-Code. Jedoch kann das Integrieren einzelner Computerprogrammfragmente in einen zusammengesetzten HTML-Code diesen nicht mit der Schutzfähigkeit als Computerprogramm insgesamt „infizieren“. Soweit der HTML-Code weiterhin

871 Dies ist in der Regel dadurch zu erkennen, dass die Programmiersprachen PHP, Ruby oder Perl sowie das Datenbankprogramm MySQL verwendet werden.

872 Vgl. http://www.jgiesen.de/javascript/JavaScript/JSBeispiele/start.htm, zuletzt abgerufen am 30.5.2019.

$873 \mathrm{Vgl}$. Beispiele in https://www.youtube.com/watch? $\mathrm{v}=\mathrm{hN} 1 \mathrm{gW}$ 8xayLM, zuletzt abgerufen am 30.5.2019.

874 Grützmacher, in: Wandtke/Bullinger, UrhG, $\$ 69$ a, Rn. 18. 
bloße Information zur Auszeichnung und Anordnung der Inhalte ist, gilt der allgemeine Grundsatz, dass kein Computerprogramm vorliegen kann. Daran ändert auch der Umstand nicht, dass das HTML-Dokument auf dem Server durch ein Computerprogramm dynamisch generiert worden ist. Denn der Schutz als Computerprogramm bezieht sich hier nur auf das auf dem Server ablaufende Computerprogramm, nicht aber auf das Arbeitsergebnis dieses Computerprogramms ${ }^{875}$.

Insgesamt sind die meisten Publikumswebseiten zur Zeit der Bearbeitung ein Konglomerat von verschiedenen Elementen, die für sich gesehen urheberrechtlich geschützt sind (z.B. Bilder, Texte oder eben kleine Computerprogramme), und somit als „hybrides Produkt“ einzuordnen sind. Bei dieser komplexen Sammlung von an sich schutzfähigen Werken, kann ein übergeordneter Schutz nach dem Urheberrecht aus dem Gesichtspunkt des Sammel- oder Multimediawerks folgen. Ein Schutz als Computerprogramm scheidet aber wegen der zuvor dargestellten rechtlichen Umstände zwingend aus ${ }^{876}$.

Somit kann dem LG Hamburg nicht zugestimmt werden. Vielmehr verbietet es sich, für die urheberrechtliche Betrachtung des Eingriffs durch Werbeblocker in die Anzeige einer Webseite auf den Schutz für Computerprogramme abzustellen.

\section{(2) Sammel- bzw. Datenbankwerk, $\mathbb{} 4$ UrhG}

Sammelwerke vermitteln Schutz für eine Auswahl und besondere Anordnung von einzelnen Werken, wenn gerade die Sammlung eine persönliche geistige Schöpfung darstellt ${ }^{877}$. Ein Unterfall des Sammelwerks ist dabei das Datenbankwerk, bei welchem nach $\$ 4$ Abs. 2 UrhG die Elemente systematisch oder methodisch angeordnet und einzeln mit Hilfe elektronischer Mittel oder auf andere Weise zugänglich sein müssen.

875 Vgl. in diesem Zusammenhang auch LG Köln, MMR 2009, 640 zu einem behaupteten Urheberrechtsverstoß betreffend einen PHP-Quellcode, der allein auf dem Server der Antragstellerin, nicht aber öffentlich verfügbar war. Eine ähnliche Webseitengestaltung wurde deshalb nicht als Urheberrechtsverletzung erkannt.

876 Vgl. auch Kreutzer, MMR 2018, 639, 640, unter Verweis auf BGH, Beschluss vom 6.2.2013, MMR 2013, 671 - Videospiel-Konsolen und EuGH, Urteil vom 23.1.2014, MMR 2014, 401 - Nintendo.

877 Dreier/Schulze, UrhG, $\mathbb{\$} 4$, Rn. 1. 
Eine Webseite, vor allem die besucherstarken Publikumswebseiten der Zeitungen oder sonstigen Medienunternehmen, sind in jedem Falle eine Sammlung diverser Einzelwerke. Allerdings ist genau zu überprüfen, ob die Schutzvoraussetzung der persönlichen geistigen Schöpfung im Sinne von $\$ 2$ Abs. 2 UrhG erfüllt ist. In diesem Zusammenhang existiert Rechtsprechung, die die Grenzen abstecken, wann die Schwelle zur Schutzfähigkeit in diesem Kontext überschritten ist. Das OLG Düsseldorf führte bereits 1999 aus, dass Datenbankwerke ein gewisses, aus der Alltäglichkeit herausragendes $\mathrm{Ma}$ an Individualität und Originalität aufweisen müssen, damit ihnen Werkqualität zukommen kann. Qualitative oder ästhetische Anforderungen seien jedoch nicht zu fordern. Die individuell-schöpferische Auswahl der aufzunehmenden Daten, etwa durch eine konkrete Entscheidung welche Elemente aufzunehmen sind, kann dabei die ausreichende Schöpfungshöhe statuieren. Diese sei aber nicht gegeben, wenn die Webseite eine Zusammenstellung von Elementen oder Daten ist, die allein zu Informations- oder Werbezwecken dienen und bei denen die Auswahl diesen Zwecken zwingend folgt ${ }^{878}$. Obschon bei Sammel- und Datenbankwerken die „kleine Münze“ geschützt ist ${ }^{879}$, werden viele auf Aktualität getrimmte Webseiten diese Schutzvoraussetzung nicht erfüllen. Denn bei Pressewebseiten ist die Themenauswahl und deren Gliederung maßgeblich vom aktuellen Zeitgeschehen oder von tradierten Ressorts abhängig ${ }^{880}$. Die Schutzfähigkeit kann hier eher bei spezialisierten Webseiten anzunehmen sein, bei denen die Inhalte besonders thematisch ausgesucht und aufbereitet werden ${ }^{881}$. Das LG München I hat in seiner Entscheidung zu Adblock Plus gegen einen der Fernseh- und Multimediaunternehmen ebenfalls den Schutz als Datenbankwerk am Feheln der Schutzhöhe scheitern lassen. In diesem Fall sollte allein die thematische Gliederung nach Sendungen nicht die ausreichende Schöpfungshöhe belegen ${ }^{882}$. Auch bei sozialen Netzwerken wie Facebook oder Twitter und weiteren Webseiten, die Newsfeeds oder Streams verwenden, wird es an der persönlich-geistigen Schöpfung fehlen, wenn die Auswahl der einzelnen Elemente Ergeb-

878 OLG Düsseldorf, Urteil vom 29.6.1999, 20 U 85/98, MMR 1999, 729; ebenfalls in diese Richtung argumentiert OLG Frankfurt a.M., Urteil vom 22.3.2005, 11 U 64/04, GRUR-RR 2005, 299.

879 Marquardt, in: Wandtke/Bullinger, UrhG, $\$$ 4, Rn. 5.

880 Vgl. Kreutzer, MMR 2018, 639, 641.

881 So beispielsweise bei einer Webseite mit einer Sammlung von Rezepten für spezielle Küchenutensilien, vgl. LG Frankfurt a.M., Urteil vom 28.3.2012, 2-06 O 387/11, ZUM 2013, 151.

882 LG München I, Urteil vom 27.5.2015 - 37 O 11673/14, MMR 2015, 660. 
nis eines Algorhitmus ist. Denn hier fehlt es bei der rein computerbasierten Ausführung von Steuerbefehlen an der menschlichen Schöpfung.

Insgesamt ist der Bereich an Webseiten, die einen Schutz als Sammelbzw. Datenbankwerk nach $\$ 4$ UrhG beanspruchen können, beschränkt ${ }^{883}$. Der Großteil der populären und stark frequentierten Webseiten wird auf dieser Grundlage keine Ausschließlichkeitsrechte herleiten können.

\section{(3) Recht an einer Datenbank, $₫ 87$ a UrhG}

Jedoch wird vielen Betreibern dieser populären Webseiten im Grundsatz ein sui generis-Recht an einer Datenbank zustehen. Im Schriftum werden maßgeblich zwei Meinungen zum Datenbankschutzrecht an Webseiten vertreten ${ }^{884}$. Auf der einen Seite wird vertreten, dass die in HTML-Dokumenten enthaltenen Strukturinformationen eine systematische Sammlung von unabhängigen Elementen im Sinne des $₫ 87$ a UrhG darstellen soll ${ }^{885}$. Auf der anderen Seite sollen Webseiten mangels Unabhängigkeit der Elemente und aufgrund der fehlenden Indexierungs- und Katalogisierungsfunktion des HTML-Codes nicht als Datenbank qualifiziert werden ${ }^{886}$. Ohne an dieser Stelle zu tief in diese spezielle Materie einzudringen, ist der erstgenannten Ansicht zu folgen, da wegen der zugrundeliegenden europäischen Richtlinie eine weite Auslegung des Datenbankbegriffs notwendig ist ${ }^{887}$. Daneben ist bei der Auslegung des Begriffs der Datenbank auch teleologisch keine Einschränkung notwendig. Eine solche Einschränkung folgt beim sui-generis Recht über das Investitionskriterium und wird beim zuvor genannten Datenbankwerk über die Schöpfungshöhe wirksam.

Bei den oben genannten Ansichten fällt auf, dass allein auf das zur Darstellung der Webseite dienende HTML-Dokument abgestellt wird. Allerdings wurde oben bereits dargestellt, dass kontemporäre Webseiten in der Regel dynamisch gestaltet sind. Bei der serverseitigen HTML-Dokumentengenerierung zur Einfügung aktueller oder nutzerrelevanter Beiträge wird also in der Regel eine von der einzelnen anzuzeigenden Webseite zu unterscheidende Datenbank konsultiert. Bei manchen Webseiten wür-

883 So im Ergebnis auch Grünig, S. 63.

884 Vgl. die Zusammenfassung bei Thum/Hermes, in: Wandtke/Bullinger, UrhG, $\$ 87 a$, Rn. 94.

885 Im Ergebnis offenlassend: OLG Frankfurt a.M., Urteil vom 22.3.2005, $11 \mathrm{U}$ 64/04, GRUR-RR 2005, 299 mit Verweis auf Köhler, ZUM 1999, 548, 551.

886 Kotthoff in: Dreyer/Kotthoff/Meckel/Hentsch, UrhG, $\mathbb{\$} 87 \mathrm{a}$, Rn. 18.

887 Eingehend dazu Köhler, ZUM 1999, 548, 551. 
de ohne diese Datenbankabfrage im Nutzergerät nur ein leeres Gerüst ohne Inhalte angezeigt ${ }^{888}$. Insoweit ist bei geordneten Sammlungen unabhängiger Elemente im Internet, die durch den Nutzer über ein Eingabefeld durchsucht werden können, das Vorliegen einer Datenbank zu bejahen ${ }^{889}$. Allerdings betrifft diese Datenbank nicht das konkrete HTML-Dokument (wie es beim Nutzer durch den Browser zu einer sichtbaren Webseite verarbeitet wird), sondern nur die abgefragte Datenbank an sich. So ist zum Beispiel die Internetenzyklopädie Wikipedia eine Datenbank von Millionen verschiedener Erklärungstexte, die von Nutzern einzeln abrufbar sind. Eine konkret dargestellte Webseite von Wikipedia mit einem Erklärungstext ist aber eine Ausdrucksform des HTML-Codes, jedoch maßgeblich bestimmt durch die Datenbank, die andernfalls nicht wahrnehmbar wäre. Bei der gebotenen weiten Auslegung des Datenbankbegriffs stellt deshalb auch diese Webseite bzw. das HTML-Dokument einen Teil der Datenbank im Sinne von $\$ 87$ a UrhG dar, die aus einer Mehrzahl von einzelnen Daten besteht.

Somit kommt es bei der Prüfung der Schutzfähigkeiten von Webseiten im Einzelnen und einer zugrundeliegenden Datenbank auf die Vornahme wesentlicher Investitionen durch den Webseitenbetreiber an ${ }^{890}$. Diese Investition wird bei den Content-Datenbanken in der selbst vorgenommenen Schaffung und Ordnung der Daten liegen oder bei „user-generated content" (wie bei Wikipedia oder Facebook) in dem Zurverfügungstellen der Plattform und Ausspielen von Inhalten. Denn diese Plattformgestaltung geht regelmäßig mit erheblichen Programmierungs- oder Lizenzierungskosten sowie erheblichen Erhaltungskosten, z.B. für die notwendigen Server und für deren Betrieb notwendiger Software, einher ${ }^{891}$.

Nicht ganz so eindeutig ist die Bewertung der wesentlichen Investition für eine einzelne Webseite bzw. das vom Server ausgelieferte HTML-Dokument. Hier wird man im Einzelfall zwischen einfachen Webseiten, die mit wenig personellem oder finanziellem Aufwand geschaffen werden, und komplexen Webseiten unterscheiden müssen. Wenn etwa ein Webseitenbetreiber einen günstigen Dienstleister von Homepage-Baukästen ${ }^{892}$ für einen geringen jährlichen Betrag nutzt, um seine Webseiten auszuspielen,

888 Man denke etwa an einen Facebook-Newsfeed ohne Nutzerbeiträge.

889 BGH, Urteil vom 22.6.2011, WRP 2011, 1469 - Automobil-Onlinebörse; Beispiele gibt Thum/Hermes, in: Wandtke/Bullinger, UrhG, $\mathbb{\$} 87 \mathrm{a}, \mathrm{Rn} .95$.

890 Vgl. Auch Grünig, S. 63, 82f..

891 Vgl. Thum/Hermes, in: Wandtke/Bullinger, UrhG, $\mathbb{8} 87 \mathrm{a}$, Rn. 95.

892 Etwa die Anbieter Jimdo oder 1\&1. 
wird er keine schützenswerte Investition getätigt haben. Wird jedoch, wie bei großen Webseitenbetreibern üblich, ein komplexes Content Management System eingesetzt, das zur Integration und Pflege erhebliche Kosten auslöst, kann auch bei einzelnen HTML-Dokumenten von einer wesentlichen Investition ausgegangen werden.

Neben diesen grundsätzlichen Erwägungen stellte das LG München I in einem seiner Adblock-Plus Urteile bei der Behandlung der Schutzfähigkeit von Webseiten als Datenbank eine ergänzende Frage: Gehören Werbeelemente überhaupt zur Datenbank des Webseitenbetreibers? ${ }^{893}$ Obwohl es diese Frage letztendlich offen ließ, äußerte die Kammer ihre Meinung, dass dies wohl nicht der Fall sei. Grund dafür sei, dass Werbeelemente nicht einzeln mit Hilfe elektronischer Mittel oder auf andere Weise zugänglich sind. Weiterhin machte die Kammer deutlich, dass Werbeelemente, v.a. Vorschaltwerbung, nicht einzeln oder getrennt vom nachfolgenden Video bzw. Inhalt abrufbar sei. Diese Begründung ist auf den ersten Blick sinnvoll. Bei einem genaueren Blick auf die technischen und rechtlichen Grundlagen, stellt sich die Lage abseits von durchsuchbaren Contentdatenbanken jedoch komplexer dar. Stellt man nämlich bei der Prüfung der Schutzfähigkeit einer einzelnen Webseite als Datenbank - wie nach den oben skizzierten Ansichten im Schrifttum - allein auf das HTML-Dokument ab, wird man die Werbeelemente zur Datenbank hinzuzählen müssen. Denn bei statischen und serverseitig dynamisch generierten Webseiten enthält das vom Browser auszuführende HTML-Dokument auch das Werbeelement bzw. zumindest einen entsprechenden Platzhalter in Verbindung mit enem Skript zur Auswahl des Werbeelements. Bei clientseitig dynamischen Webseiten werden nach hiesigem Verständnis bereits im HTML-Code vorgesehene Elemente visuell angepasst oder auf Ressourcen des Clients zugegriffen, nicht aber neue Werbeanzeigen von Servern geladen ${ }^{894}$. Somit sind die Werbeelemente als Datei oder als URL im HTML-Dokument vorgesehen und müssen wegen der oben beschriebenen weiten Auslegung zur Datenbank hinzugerechnet werden.

Allerdings stellt sich wiederum die Frage nach der schutzbegründenden Investition durch den Webseitenbetreiber. Denn die Einfügung von Werbeelementen - gleich ob Eigen- oder Fremdwerbung - wird nur selten einen solch hohen Aufwand bereiten, dass hierfür eine schutzwürdige Investition notwendig ist. In vielen Fällen werden hier Platzhalter

893 LG München I, Urteil vom 27.5.2015 - 37 O 11673/14, MMR 2015, 660.

$894 \mathrm{Vgl}$. insoweit https:/www.edv-lehrgang.de/serverseitige-clientseitige-programmi erung/, zuletzt abgerufen am 30.5.2019. 
für Adserver der Werbenetzwerke im Webdesign vorgesehen, die dann beim Zugriff durch den Nutzer serverseitig ausgefüllt werden. Hierfür ist keine Investition des Webseitenbetreibers notwendig. Vielmehr nutzt er in der Regel kommerzielle Angebote und erhält die ihm zustehende Entlohnung für das Zurverfügungstellen des Werbeplatzes abzüglich der Vermittlungskosten der Werbeintermediäre. Nur unwesentlich anders ist die Lage bei Eigenwerbung. Auch wenn hier eine gewisse Eigenleistung für Gestaltung und Upload der Anzeigen auf dem Server bzw. Integration in die Webseitengestaltung anfällt, ist hier bei einer Gesamtbetrachtung der Kosten für eine Webpräsenz kaum ein erheblicher personeller oder finanzieller Aufwand zu erkennen. Die Verknüpfung von Werbeelementen mit HTML-Dokumenten erfordert mithin keine wesentliche Investition im Sinne von $\ 87 \mathrm{a}$ UrhG. Jedoch würde eine getrennte Betrachtung von Inhalten und Werbung zur Zergliederung eines einheitlichen HTML-Dokuments in zwei Teile führen. Dies wäre eine rechtliche Bewertung, die dem technischen Sachverhalt nicht entspricht. Ein HTML-Dokument ist deshalb einheitlich zu behandeln.

Folge dieses Befunds ist zum einen, dass eine ohnehin nicht als Datenbank schutzfähige Webseite nicht durch Beifügung von Werbeelementen Schutz erlangen kann. Wenn aber zum anderen eine Webseite bzw. das entsprechende HTML-Dokument als Datenbank bereits schutzfähig ist, ändert die Verknüpfung mit Werbeelementen nichts an der Schutzfähigkeit. Im letzteren Fall stellt sich dann die vom LG München I aufgeworfene Frage, ob die Werbeelemente dann vom Schutz einer an sich schutzfähigen Datenbank ausgenommen werden können. Das Argument der Kammer, dass die Werbeelemente nicht einzeln zugänglich bzw. abrufbar seien, ist bei technischer Betrachtung kritisch, weil die Elemente im HTML-Quellcode durchaus einzeln identifizierbar und zugänglich sind - schließlich schafft es ein Internetwerbeblocker gerade die Werbeelemente zu erkennen und zu blockieren. Der Ansicht des LG München I kann also nicht gefolgt werden. Soweit das Investitionserfordernis mit Blick auf einzelne HTML-Webseiten also bejaht werden kann, genießt das gesamte Dokument (mit Ausnahme der wegen $₫ 4$ Abs. 2 S. 2 UrhG nicht erfassten Computerprogramme ${ }^{895}$ ) Schutz. Eine Herausnahme der werblichen Elemente aus dem Schutzbereich einer nach $\$ 87$ a UrhG geschützten HTML-Datenbank ist nicht angezeigt.

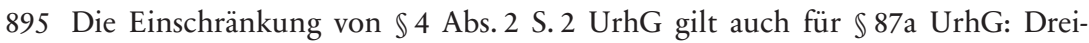
er/Schulze, UrhG, $\mathbb{\$} 87 \mathrm{a}, \mathrm{Rn} .5$. 
(4) Multimediawerk, $\$ 2$ UrhG

Ein weiterer Aspekt, unter dem Webseitenbetreiber versucht haben, eine urheberrechtlich schutzfähige Rechtsposition herbei zu argumentieren, ist das Multimediawerk ${ }^{896}$. Ähnlich wie beim Sammel- und Datenbankwerk ergibt sich die Schutzfähigkeit des Multimediawerks daraus, dass eigenständig schutzfähige Elemente zu einer Einheit verschmolzen werden. Jedoch muss die Bearbeitung, Anordnung, Abfolge und Zusammenstellung der einzelnen Elemente eine persönliche geistige Schöpfung nach $₫ 2$ Abs. 2 UrhG darstellen ${ }^{897}$.

Im Streitfall des LG Hamburg konnte die erkennende Kammer keine solche Schöpfungshöhe bei der Webseite „welt.de“ erkennen. Die Kammer konnte insoweit der Webseite keine „über [eine] handwerklich gut aufbereitete Art der Informationsvermittlung hinaus gehende schöpferische Gestaltung entnehmen"898. Dem ist zuzustimmen. Die meisten multimedial gestalteten Webseiten, die aus Bildern, Videos, Text und ggf. Computerprogrammen bestehen, haben einen bestimmten zweckmäßigen Aufbau. Dieser Aufbau besteht aus einem Header, einer Navigationsleiste, dem Bereich des eigentlichen Contents und standardisierten Werbeflächen. Für schöpferische Gestaltungen bleibt dabei selten Raum ${ }^{899}$. Abgesehen von außergewöhnlich individuell gestalteten - und damit wohl nicht vornehmlich kommerziellen Interessen dienenden - Webseiten, kommt keine Schutzfähigkeit als Multimediawerk in Betracht.

\section{(5) Schutzrechtsfähigkeit einzelner Teile von Webseiten}

Da der urheberrechtliche Schutz demnach in der Regel nur einzelne Elemente von Webseiten betriff, soll nun kurz überprüft werden, ob einzelne schutzfähige Elemente unmittelbar bei der Werbeausspielung involviert und von der Werbeblockade betroffen sind. Dies gilt insbesondere für Computerprogramme, die bei dynamischen Webseiten im HTML-Dokument vorgesehen sind.

896 LG Hamburg, Urteil vom 3.5.2016 - 308 O 46/16, CR 2016, 782.

897 Bullinger, in: Wandtke/Bullinger, UrhG, $\$ 2$, Rn. 152.

898 LG Hamburg, Urteil vom 3.5.2016 - 308 O 46/16, CR 2016, 782.

899 Vgl. im Ergebnis auch Kreutzer, MMR 2018, 639, 641, und OLG Frankfurt a.M., Urteil vom 29.2.2012 - 5 U 10/10, MMR 2012, 832. 
Bei Computerprogrammen kann nach $\$ 69 \mathrm{c}$ Nr. 1 UrhG schon die bloß vorübergehende Vervielfältigung eine zustimmungspflichtige Handlung darstellen. Deshalb wird an dieser Stelle kurz überprüft, welche Rechte Webseitenbetreibern an den üblicherweise bei dynamischen Webseiten eingesetzten Computerprogrammen zustehen.

Bei serverseitig dynamischen Webseiten werden Computerprogramme zur Konsultation von Datenbanken eingesetzt. Diese sind also in einem Schritt vor Generierung des konkreten zur Seitendarstellung notwendigen HTML-Dokuments involviert. Die dynamisch generierten Inhalte der Webseite sind mithin Arbeitsergebnis des Computerprogramms, nicht aber das Programm an sich. Damit haben diese Arbeitsergebnisse ebenso wie die folgende Darstellung der Webseite bzw. deren Elemente im Nutzergerät wegen der EuGH Rechtsprechung in SAS Institute ${ }^{900}$ nicht Teil am Schutz des Computerprogramms. Mit dem Ablauf des Computerprogramms auf dem Server hat der im Clientrechner installierte Werbeblocker indes nichts zu tun. Insoweit kommt selbst beim Einsatz einer selbst entwickelten Serversoftware zur Generierung von Werbeelementen kein Schutz für Webseitenbetreiber in Betracht, in dessen Umfang die Funktionsweise des Werbeblocker eingreifen würde.

Bei clientseitig dynamischen Webseiten sind im HTML-Dokument Computerprogramme vorgesehen, die vom Browser sodann nur auf dem Nutzergerät ausgeführt werden. Hier kommen JavaScript-Programme in Betracht. Zum Beispiel kann somit bei Mouseover über bestimmte Bereiche der Webseite ein Layer Ad geöffnet werden. In diesem Fall ist es denkbar, dass ein Computerprogramm durch den Werbeblocker betroffen ist. Allerdings ist hier zu beachten, dass die entsprechenden Anzeigen mit den dazugehörigen JavaScript-Befehlen ohne Werbeblockereinsatz bereits beim Zugriff durch den Client mitgeladen werden. Das JavaScript-Programm führt dann je nach eingestelltem Befehl zur Ausspielung der Werbeanzeige, z.B. bei Mouseover, nach Klick auf bestimmte Links oder nach einer gewissen Verweildauer auf einer Webseite. Wird ein Werbeblocker eingesetzt, werden in der Regel die Werbeanzeigen und das dazugehörende JavaScript-Programm nicht geladen. Wird nur die Werbeanzeige blockiert, das JavaScript aber geladen, dann wird das JavaScript nicht vom Browser ausgeführt, da die verknüpfte Anzeige nicht verfügbar ist. Es ergeben sich also zwei für Werbeblocker relevante Alternativen: das Computerprogramm wird gar nicht geladen oder es wird ohne Ausführungssubstrat geladen. Der erste Fall ist nicht vom Schutzumfang erfasst. Das Nichtladen

900 EuGH, Urteil vom 2.5.2012 - C-406/10, GRUR 2012, 814. 
eines Werks ist rechtlich nicht zu beanstanden. Beim zweiten Fall stellt sich die Frage, ob die verknüpfte Anzeige zum Schutzumfang des Computerprogramms gehören kann. Dies muss aber wiederum verneint werden, weil die Anzeige gerade nicht an der Abfolge von Steuerbefehlen beteiligt ist, sondern sich die Steuerbefehle vielmehr darin erschöpfen mit der Anzeige visuelle Effekte herbeizuführen. Demnach kann der Schutz eines im HTML-Dokument vorgesehenen Scriptprogramms nicht auch die Anzeige umfassen ${ }^{901}$. Folglich lässt sich auch aus dem urheberrechtlichen Schutz einzelner Webseitenelemente kein überschießender Schutz von Werbung vor Blockade folgern.

\section{(ii) Verletzungshandlungen durch Werbeblocker oder deren Nutzer}

Durch das zuvor gefundene Ergebnis zur Schutzfähigkeit für Webseiten und einzelner Elemente bedarf es für diese Bearbeitung keiner ausufernden Prüfung der Verletzungshandlungen mehr. Da die Webseiten weder als Computerprogramme, noch als Sammel-, Datenbank- oder Multimediawerk anzusehen sind, erübrigt sich in diesem Zusammenhang streng genommen die Verletzungsfrage. Allein mit Blick auf das sui generis Recht an einer Datenbank muss die Verletzung durch Werbeblockersoftware noch geklärt werden.

Da die Rechtsprechung, die sich mit urheberrechtlichen Fragen bei Adblocker-Fällen auseinanderzusetzen hatte, sich jedoch nicht in die Tiefen der Prüfung der Schutzrechtsfähigkeit begeben wollte, löste sie die Fälle über die Verletzungshandlungen. Insoweit sollen die Hauptthesen der Rechtsprechung an dieser Stelle kurz wiedergegeben und bewertet werden.

\section{(1) Fragen der Täterschaft}

Vorab muss dabei klargestellt werden, dass es nicht der beklagte Anbieter des Werbeblockers war, der eine Verletzungshandlung selbst vorgenommen hatte. Das Bereitstellen der Software bzw. von Filterlisten führt für

901 Dieses Ergebnis lässt sich auch mit einer Analogie begründen: Ein Programm zum Abspielen von Musikdateien, z.B. MP3-Dateien, schützt nur den Vorgang der Musikwiedergabe, nicht aber das wiedergegebene Musikstück oder die entsprechende Datei. 
sich gesehen noch nicht zu einer Verletzungshandlung. Vielmehr muss bei der Prüfung der Täterschaft beachtet werden, dass es der einzelne Nutzer ist, der die Werbeblockersoftware einsetzt und damit zum unmittelbaren Täter würde, wenn eines Verletzungshandlng anzunehmen wäre. Eine mittelbare Täterschaft scheidet ebenfalls aus, da einerseits keine Kontrolle des Softwareanbieters über die Nutzer besteht und andererseits die Nutzer selbst unmittelbare Täter wären. Der Werbeblockeranbieter haftet allenfalls als Teilnehmer oder Störer. Auf die Prüfung, ob die Voraussetzung der Teilnehmer- oder Störerhaftung vorliegen, verzichteten die befassten Gericht, da sie schon keinen rechtswidrige Haupttat des einzelnen Nutzers feststellten ${ }^{902}$. Ohne auf die Frage näher eingehen zu wollen, liegt eine Teilnehmerhaftung nahe, weil Werbeblockersoftware das Werkzeug für eine potentielle Urheberrechtsverletzung darstellt. Da gerade beim kommerziellen Whitelisting auch ein eigenes Interesse des Softwareanbieters erkennbar ist, scheint die Teilnehmerhaftung vorzugswürdig zur Störerhaftung. Letztere scheint jedoch auch nicht ausgeschlossen zu sein, wollte man die Qualfikation als Teilnehmer ablehnen.

\section{(2) Umarbeitung eines Computerprogramms, $\$ 69$ c Nr. 2 UrhG}

Bei der Prüfung der Verletzung eines (gedachten) Rechts an einem Computerprogramm wurde maßgeblich geprüft, ob durch den Werbeblocker eine Umarbeitung im Sinne von $\$ 69$ c Nr. 2 UrhG erfolgt. Das LG München I und das LG Hamburg prüften in diesem Zusammenhang ausführlich, ob eine Änderung des Ablaufs einer (unterstellt) geschützten Software dadurch vorliege, dass für die Ausspielung von Werbeanzeigen verantwortliche Programmcodes durch die Adblock-Software unterdrückt werden. Dabei ging die Münchener Kammer auch auf den Streit in der Literatur ein, ob ein Substanzeingriff in den Programmcode vorliegen müsse. Unter Ablehnung der Ansicht, wonach ein solcher Substanzeingriff entbehrlich sei und jeglicher Eingriff in den Programmablauf durch externe Befehle ausreiche ${ }^{903}$, folgt die Kammer der strengeren, eine Quellcodeveränderung

902 Vgl. stellvertretend für alle befassten Gerichte: OLG München, Urteil vom 17.8.2017, U 2225/15 Kart, GRUR 2017, 1147.

903 Zitiert wurde insoweit OLG Hamburg, Urteil vom 13.4.2012, 5 U 11/11, GRUR-RR 2013, 13 - Replay PSP. 
fordernden Meinung in Schrifttum und Rechtsprechung904. Als Grund führt sie an, dass der gesetzlich vorgesehene, weitgehende Schutz, der bereits die Herstellung einer Umarbeitung erfasst, nur bei einem solchen Substanzeingriff Sinn mache. Auch die Hamburger Kammer kommt zu diesem Ergebnis. Sie stellt darauf ab, dass die bloße Funktion eines Programms als Idee nach dem Wortlaut des $\$ 69$ a Abs. 2 UrhG außerhalb des Urheberrechtsschutzes stehe. Weiter begründet das LG Hamburg, dass bei strenger Anwendung der „Mindermeinung“ die Weiterentwicklung von Programmen auf der Grundlage von offenen Schnittstellen, die keinen Eingriff in die Programmsubstanz erfordern, unmöglich würde, was dem in der Software-Richtlinie niedergelegten Ziel der Interoperabilität widerspräche ${ }^{905}$.

Dem ist voll und ganz zuzustimmen, insbesondere mit Blick auf die Entscheidung des Meinungsstreits. In vielen Fällen, v.a. bei serverseitig dynamisch generierten Webseiten, scheidet eine Umarbeitung zudem deshalb aus, weil auf das geschützte Computerprogramm (also nicht die Webseite als solche, sondern Inhalte generierende Programme) gar kein Zugriff auf den Quellcode mit dem Nutzergerät möglich ist. Dann ist schon faktisch kein Substanzeingriff möglich.

Für Computerprogramme, die auf dem Nutzergerät zur Verfügung stehen, wobei damit nicht die Webseite als solche gemeint ist, sondern allenfalls einzelne Computerprogramm-Elemente gilt ergänzend: Wenn ein Computerprogramm in einer Umgebung abläuft, die grundsätzlich Einstellungen im Nutzergerät zulässt, kann nicht die Ausübung der Freiheit zu eben diesen Einstellungen ein zustimmungspflichtiges Handeln darstellen. Webseiten wären dafür ein gutes Beispiel - wenn sie denn Computerprogramme darstellten. Denn es ist jedem Webdesigner bekannt, dass im standardisierten Web Modifikationsmöglichkeiten durch Browser gegeben sind. Sich in diesem Wissen auf eine Exklusivität zu berufen, die auch die Vornahme von seit jeher möglichen Nutzereinstellungen mit umfasst, ist rechtlich nicht erklärbar. Es handelt sich bloß um einseitige Erwartungen oder Wünsche, dass sich das Programm wie intendiert visuell manifestiert.

904 LG München I, Urteil vom 27.5.2015 - 37 O 11673/14, MMR 2015, 660 mit Verweis auf Grützmacher, in: Wandtke/Bullinger, UrhG, $\mathbb{\$} 69$ c, Rn. 20, und KG, Urteil vom 6.9.2010, 24 U 71/10, ZUM-RD 2011, 544.

905 LG Hamburg, Urteil vom 3.5.2016 - 308 O 46/16, CR 2016, 782. Die Kammer lässt die Verletzung dann aufgrund fehlender Glaubhaftmachung scheitern, schließt die grundsätzliche Möglichkeit eines Substanzeingriffs durch Werbeblocker jedoch nicht aus. Dem kann aus den oben zur Schutzfähigkeit getätigten Erklärungen nicht gefolgt werden. 
Erst wenn der Programmcode durch aktiven Eingriff geändert wird, der nicht durch die Umgebung ohne Weiteres möglich ist, kann ein Verbietungsrecht des Rechteinhabers eingreifen. Dies wird indes praktisch nie der Fall sein, weil Computerprogramm-Elemente entweder gar nicht erst geladen werden, deren Ablauf unterbunden wird oder der Ablauf mangels verknüpftem Element nicht funktioniert. Alle drei Varianten haben nichts mit einer Urheberrechtsverletzung zu tun.

\section{(3) Vervielfältigung eines Werks}

Bei der Frage der Verletzung durch Vervielfältigung eines Computerprogramms, eines Datenbank- oder Multimediawerks im Zwischenspeicher des Nutzers verweisen die befassten Gerichte beinahe ausschließlich auf die nachfolgend noch darzustellenden Schranken und Rechtfertigungsgründe. Dies ist auch zutreffend, weil eine zumindest vorübergehende Vervielfältigung des HTML-Dokuments sowie darin enthaltener oder wegen darin vorgesehener Nachladebefehle nachfolgend geladener Elemente im Arbeitsspeicher des Nutzergeräts technisch zwingend nötig ist.

Allein das LG München I prüfte einen Gedanken im Rahmen der Verletzungshandlung von Datenbankwerken: Die Vervielfältigung einer Webseite ohne die Werbeelemente könnte eine einwilligungspflichtige Bearbeitung im Sinne von $\$ 23$ S. 2 UrhG sein. Denn bei Datenbankwerken bedarf qua gesetzlicher Anordnung bereits das Herstellen - und nicht erst das Veröffentlichen oder Verwerten - der Bearbeitung oder Umgestaltung eine Einwilligung. Zutreffend erkennt das LG München I hierbei, dass sich diese Bearbeitung auf die Struktur eines Datenbankwerks beziehen muss, der Inhalt der Datenbank hingegen frei veränderlich ist ${ }^{906}$. Die Wirkweise des Werbeblockers führt aber gerade nicht zu einer Bearbeitung der Struktur, sondern lediglich zum Nichtladen bzw. Ausblenden bestimmter Inhalte.

906 LG München I, Urteil vom 27.5.2015 - 37 O 11673/14, MMR 2015, 660. Die Kammer lehnte außerdem in Kürze eine Entstellung nach $₫ 14$ UrhG ab, da bei Werbung keine urheberpersönlichkeitsrechtlichen, sondern finanzielle Interessen im Vordergrund stünden. Dem ist beizupflichten. 
(4) Verletzung eines Datenbankrechts, $\mathbb{S} 87 \mathrm{~b}$ UrhG

Bei der Prüfung der Verletzung eines denkbaren Datenbankrechts muss der eingeschränkte Schutzumfang des $\$ 87 \mathrm{~b}$ UrhG beachtet werden. Denn das ausschließliche Recht des Datenbankherstellers beschränkt sich nach Satz 1 darauf, die Datenbank insgesamt oder einen nach Art oder Umfang wesentlichen Teil der Datenbank zu vervielfältigen, zu verbreiten und öffentlich wiederzugeben, sowie nach Satz 2 die wiederholte und systematische Vervielfältigung, Verbreitung oder öffentliche Wiedergabe von nach Art und Umfang unwesentlichen Teilen der Datenbank, sofern diese Handlungen einer normalen Auswertung der Datenbank zuwiderlaufen oder die berechtigten Interessen des Datenbankherstellers unzumutbar beeinträchtigen.

Mit Blick auf $\$ 87 \mathrm{~b}$ S. 1 UrhG können anhand des Wortlauts bereits einige Varianten verworfen werden. Die Verbreitung und öffentliche Wiedergabe durch einen Internetnutzer liegen im normalen Betrieb eines Webbrowsers mit installiertem Werbeblocker nicht vor. Bleibt folglich nur noch die Vervielfältigung als Tathandlung. Bezugsobjekt dazu ist die Datenbank insgesamt oder zumindest ein wesentlicher Teil davon. Unter Rückgriff auf die notwendige Unterscheidung zwischen der der Webseite zugrunde liegenden Datenbank (vgl. das Beispiel Wikipedia) und dem einzelnen HTML-Dokument, das zur Darstellung einer Webseite führt, ist zu differenzieren. Im Verhältnis zur gesamten Content-Datenbank kann eine einzelne Webseite weder die gesamte, noch einen wesentlichen Teil der Datenbank ausmachen ${ }^{907}$. Auf ein HTML-Dokument bezogen erfolgt eine Zwischenspeicherung des gesamten HTML-Dokuments und nach Wirkung des Werbeblockers jedenfalls eines wesentlichen Teils der darin vorgesehenen Elemente im Gerät des Nutzers. Mithin ist eine Vervielfältigung einer Datenbank (soweit schutzfähig) zu bejahen. Für diese Vervielfältigung wird auf einen später noch zu besprechenden Rechtfertigungsgrund zurückzugreifen sein.

Bei den ferner zu prüfenden Varianten des $\$ 87 b$ S. 2 UrhG können wiederum die Verbreitung und die öffentliche Wiedergabe außer Acht gelassen werden. Die wiederholte und systematische Vervielfältigung von unwesentlichen Teilen der Datenbank, die einer normalen Auswertung zuwiderlaufen oder die berechtigten Interessen des Datenbankherstellers

907 So auch OLG München, Urteil vom 17.8.2017, U 2225/15 Kart, GRUR 2017, 1147, unter dem Oberbegriff „quantitative Wesentlichkeit“ und LG München I, Urteil vom 27.5.2015 - 37 O 11673/14, MMR 2015, 660. 
unzumutbar beeinträchtigen, kommt hingegen nur im Verhältnis zur Content-Datenbank in Betracht. Die Zwischenspeicherung einer einzelnen HTML-Webseite ist nicht hierunter zu fassen, da sie unter $\$ 87 \mathrm{~b} \mathrm{S.} 1$ UrhG fällt und das Merkmal der Widerholtheit und Systematik in diesem Kontext schlicht nicht passt. Mit Blick auf die Content-Datenbank stellt selbst das regelmäßige Besuchen von Webseiten durch Internetnutzer keine Verletzung dar. Das OLG München beschrieb insoweit auf Grundlage der europäischen Richtlinie, dass verboten sei, dass durch die kumulative Wirkung der wiederholten Entnahme aus der Datenbank die Investition des Datenbankherstellers schwerwiegend beeinträchtigt wird. Durch die vielen Entnahmen unwesentlicher Teile erwächst sozusagen eine wesentliche Entnahme. Dies könne allerdings nicht durch den Besuch von Webseiten mit Werbeblockern geschehen, weil der Besuch nicht auf eine Erstellung einer wesentlich gleichen Datenbank gerichtet sei ${ }^{908}$. Dieser Ansicht ist zuzustimmen. Der Besuch einer Webseite - mit oder ohne Werbeblocker ist auf den Konsum der Inhalte gerichtet. Die entsprechenden Daten werden zudem nur zwischengespeichert und nicht archiviert. Der intendierte Schutz wird also nicht tangiert.

Deshalb kommt es erst gar nicht auf die nachgelagerten Voraussetzungen des Zuwiderlaufens gegen eine normale Auswertung oder die unzumutbare Beeinträchtigung der Interessen der Datenbankhersteller an. Soweit man hierauf eingehen möchte, lässt sich jedoch für die allgemeinklauselartigen Formulierungen eine Lösung parallel zum Lauterkeitsrecht finden. Die (technisch und rechlich) schutzlose Zurverfügunstellung von Inhalten kann demnach weder einer „normalen“ Auswertung entgegenstehen, noch die Webseitenbetreiber unzumutbar beeinträchtigen. Denn andernfalls hätten sie gar nicht erst die Situation entstehen lassen, dass ihre Inhalte ohne Werbung rezipiert werden können ${ }^{909}$. Effektive Gegenmaßnahmen gibt es insoweit bereits seit Beginn der ersten Rechtsstreitigkeiten in Deutschland ${ }^{910}$.

908 OLG München, Urteil vom 17.8.2017, U 2225/15 Kart, GRUR 2017, 1147, das mit „Webseite“ die Gesamtheit der Webseiten der Betreiber meint. Dies entspricht der hier als Content-Datenbank bezeichneten Datenbank.

909 Ähnlich OLG München, Urteil vom 17.8.2017, U 2225/15 Kart, GRUR 2017, 1147.

910 Vgl. dazu unten Teil D. 
(iii) Schranken des Urheberrechts und Rechtfertigung

Die Funktion von Computern und die Internetkommunikation bauen auf dem Zwischenspeichern von Daten auf. Dieses Zwischenspeichern stellt bei Computerprogrammen, Datenbank- und Multimediawerken sowie Datenbanken tatbestandlich eine Vervielfältigung dar. Deshalb ist noch zu prüfen, ob diese Vervielfältigungen wegen des Eingreifens von urheberrechtlichen Schrankenregelungen oder wegen Rechtfertigungsgründen erlaubt sind.

\section{(1) Vorübergehende Vervielfältigungshandlungen, $\$ 44 a$ UrhG}

Zulässig sind vorübergehende, d.h. flüchtige oder begleitende Vervielfältigungshandlungen. Sie müssen einen integralen und wesentlichen Teil eines technischen Verfahrens darstellen. Außerdem muss der alleinige Zweck sein, dass entweder eine Übertragung in einem Netz zwischen Dritten durch einen Vermittler oder eine rechtmäßige Nutzung eines Werkes oder sonstigen Schutzgegenstands ermöglicht wird. Zuletzt darf die vorübergehende Vervielfältigung keine eigenständige wirtschaftliche Bedeutung haben. Dies sind die Voraussetzungen der gesetzlichen Schranke des $₫ 44$ a UrhG.

Einen Hauptanwendungsbereich hat $\$ 44 a$ UrhG in internetbasierten Fallgestaltungen, dabei vor allem bei Webseiten, die in den Arbeitsspeicher (RAM) des Nutzergeräts gespeichert werden ${ }^{911}$. Diese Zwischenspeicherung im "Cache“ ist notwendig, um die Daten im nächsten Schritt auf dem Gerät sichtbar zu machen. Eine Speicherung im Hauptspeicher des Nutzergeräts erfolgt im Grundsatz nicht. Für das Zwischenspeichern von Daten durch Browser zur Anzeige von Webseiten gilt $\mathbb{\$} 44 \mathrm{a}$ UrhG standardmäßig ${ }^{912}$. Die Streaming-Problematik ${ }^{913}$ soll an dieser Stelle nicht weiter behandelt werden, weil beim Streamen von Videos oder Sendungen ein linearer und zusammenhängender Datenfluss stattfindet, der vom digitalen Werbeblocken unangetastet bleibt.

Von den mit Adblocker-Rechtsstreiten befassten Gerichten bestätigten das LG München I und das LG Hamburg die Anwendung von $\$ 44 a$ UrhG

911 Vgl. v. Welser, in: Wandtke/Bullinger, UrhG, $\$ 44 a$, Rn. 2 f.

912 Vgl. zur europäischen Grundlage EuGH, Urteil vom 5.6.2014 - C-360/13, GRUR 2014, 654.

913 Vgl. die Zusammenfassung bei Dreier/Schulze, UrhG, $\mathbb{\$} 44 a$, Rn. 4ff. 
auf die Darstellung von Webseiten. Die Münchener Kammer bejahte dabei die Voraussetzung der rechtmäßigen Nutzung mit dem Argument, dass durch das Zwischenspeichern der private Werkgenuss ermöglicht werden. Dieser wiederum sei nach den Grundsätzen des Urheberrechts stets zulässig914. Die Hamburger Kammer grenzte die Schranke des $\$ 44 a$ UrhG noch gegen $₫ 62$ Abs. 1 UrhG ab, der ein Änderungsverbot für allein über Schrankenregelungen gestatteter Nutzung statuiert. Sie lehnte dabei eine Änderung mit dem Argument ab, dass Werbung nicht am Schutz eines etwaigen Sammelwerkes teilhabe, weil die Werbung in den überwiegenden Fällen von dritten Stellen bezogen würde ${ }^{915}$.

Diesen Ausführungen ist zuzustimmen. Es ist unbestritten, dass $\$ 44 a$ UrhG bei der Server-Client-Internetkommunikation eingreift. Der einzige aus dem Wortlaut folgende Anhaltspunkt für ein Nichteingreifen der Schranke, wäre es, wenn die Zwischenspeicherung eine unrechtmäßige Nutzung bezwecken würde. Zu Recht wird an dieser Stelle an den rechtmäßigen Werkgenuss angeknüpft ${ }^{916}$. Allein das technisch notwendige Zwischenspeichern im Rahmen des technischen Fortschritts hin zu digitalisierten Daten ändert daran nichts. Dies gilt umso mehr, als durch das digitalisierte Umfeld auch ganz neue Möglichkeiten der Verhinderung einer Werkrezeption durch ungewollte Personen ergeben, insbesondere durch Zugangsbeschränkungen. Auch zu beachten ist, dass die Rechtmäßigkeit sich bei privaten Nutzern zudem aus $₫ 53$ Abs. 1 UrhG, d.h. dem Recht zur Privatkopie, ergeben kann ${ }^{917}$.

Das vom LG Hamburg systematisch zu Recht genannte Änderungsverbot in $\$ 62$ UrhG ist nicht anwendbar. Anders als bei $\$ 44$ a UrhG muss dabei nicht auf die Gestalt des angezeigten Werks, sondern auf das Vervielfältigungsstück abgestellt werden. Dieses Vervielfältigungsstück, etwa das einer Webseite zugrunde liegende HTML-Dokument, liegt aber regelmäBig unverändert im Zwischenspeicher. Die Änderungen an der Anzeige der Webseite sind vielmehr daran anknüpfenden Befehlen des Browsers geschuldet. Das Nichtausführen von HTML-Befehlen ist jedoch keine Änderung des Werks.

914 LG München I, Urteil vom 27.5.2015 - 37 O 11673/14, MMR 2015, 660.

915 LG Hamburg, Urteil vom 3.5.2016 - 308 O 46/16, CR 2016, 782.

916 Vgl. auch Marly, EuZW 2014, 616: Beispiele des reinen Werkgenusses sind etwa das Benutzen eines Computerprogramms, des Lesen eines Buchs, des Anhören einer Musik-CD oder Schallplatte oder des Betrachtens eines Kunstwerks oder eines Videofilms. Im Werbeblocker Zusammenhang passend ist das Lesen einer Zeitung oder eines Magazins.

917 Schulz, in: BeckOK UrhR, $\$ 44 a$, Rn. 13. 
Wollte man dies anders sehen, stünde im Übrigen $\$ 62$ Abs. 1 UrhG unter dem Vorbehalt des $\$ 39$ UrhG. Nach $\$ 39$ Abs. 2 UrhG wären dann aber Änderungen möglich, wenn der Urheber seine Einwilligung in die Änderung des Werks nach Treu und Glauben nicht versagen kann. Die insoweit notwendige Interessenabwägung könnte wegen der auf finanzielle Interessen beschränkten Lage der Webseitenbetreiber durchaus parallel zu den lauterkeitsrechtlichen Abwägungen ausfallen. Der Nutzerautonomie wäre dann in Abwesenheit technischer und rechtlicher Schutzmaßnahmen der Vorzug einzuräumen.

Dort wo also ein schutzfähiges Werk vorliegen sollte und auch eine Verletzungshandlung nicht schon ausscheidet, führt $\mathbb{4} 44$ a UrhG zur Ablehnung einer Urheberrechtsverletzung durch den Nutzer. Dies gilt jedoch nur innerhalb der Anwendbarkeit von $\$ 44 a$ UrhG. Die Norm wird als lex generalis zu spezielleren Schrankenregelungen aus der Software-Richtlinie und der Datenbankrichtlinie angesehen ${ }^{918}$. Diese Richtlinien führten zu den leges speciales in $\$ \mathbb{S 5} 5 \mathrm{a}$ und $69 \mathrm{~d}$ UrhG. Problematisch ist jedoch die Anwendung des $\$ 44$ a UrhG auf das Datenbankrecht gem. $\$ 87$ a UrhG. Auch $\$ 87 \mathrm{c}$ UrhG sieht Schrankenregelungen als lex specialis zu $\mathbb{\$} 44 \mathrm{a}$ UrhG vor, enthält allerdings keinen Passus zu vorübergehenden Vervielfältigungshandlungen. Deshalb ist im Grundsatz auch die nur vorübergehende Vervielfältigung einer geschützten Datenbank bei Vorliegen der Voraussetzungen von $₫ 87 \mathrm{~b}$ UrhG dem Datenbankhersteller vorbehalten. Eine analoge Anwendung von $\$ \$ \$ 44 a, 55 a$ und $69 \mathrm{~d}$ UrhG soll insoweit ausscheiden. Der Nutzer ist vielmehr auf das Vorliegen einer Rechtfertigung zur entsprechenden Nutzung der wesentlichen Datenbankteile, etwa durch schlichte Einwilligung oder konkludente Lizenz angewiesen ${ }^{919}$.

\section{(2) Gesetzlich erlaubte Benutzung eines Datenbankwerkes, $₫ 55$ a UrhG}

Würde man entgegen dem oben gefundenen Ergebnis in Webseiten ein schutzfähiges Datenbankwerk erkennen, würde $\$ 55$ a UrhG im Regelfall als gesetzliche Schranke in den Blick geraten. Zulässig ist nach dieser Vorschrift u.a. die Vervielfältigung eines Datenbankwerkes durch denjenigen, dem ein Datenbankwerk aufgrund eines mit dem Urheber oder eines mit dessen Zustimmung mit einem Dritten geschlossenen Vertrags zugänglich

918 v. Welser, in: Wandtke/Bullinger, UrhG, $\$ 44 a$, Rn. 23.

919 Vogel, in: Schricker/Loewenheim, UrhG, $\mathbb{8} 87 \mathrm{~b}$, Rn. 40f.; Thum/Hermes, in: Wandtke/Bullinger, UrhG, $\mathbb{\$} 87 \mathrm{c}$, Rn. 42. 
gemacht wird, wenn und soweit die Bearbeitung oder Vervielfältigung für den Zugang zu den Elementen des Datenbankwerkes und für dessen übliche Benutzung erforderlich ist.

Der Wortlaut scheint nicht unmittelbar zu passen, da gerade bei einer Webseite kein Vertrag mit dem Urheber oder einem von diesem autorisierten Dritten geschlossen wird. Soweit das Datenbankwerk im Internet aber zum freien Download bereitgestellt wird, ist von einer konkludent erteilten vertraglichen Berechtigung auszugehen ${ }^{920}$. Demnach würde die kurzfristige Zwischenspeicherung beim Browsing einer kostenlosen Webseite gesetzlich erlaubt sein. Dieses Ergebnis der konkludenten Lizenz ist vor dem Hintergrund des Übertragungszweckgedankens in $\$ 31$ Abs. 5 UrhG jedoch sehr zweifelhaft. Tendenziell passt $\$ 55$ a UrhG deshalb nicht auf die Zwischenspeicherung von Webseiten. Für diesen Fall sollte besser auf Rechtfertigungsgründe zurückgegriffen werden.

(3) Notwendigkeit zur bestimmungsgemäßen Benutzung, $\$ 69 \mathrm{~d} \mathrm{Nr} .1$ UrhG

Anders ist die Lage, wenn die Schutzfähigkeit einer Webseite als Computerprogramm anzunehmen wäre. $\$ 69 \mathrm{~d}$ Abs. 1 UrhG nimmt die vorübergehende Vervielfältigung gemäß $\$ 69 \mathrm{c}$ Nr. 1 UrhG ausdrücklich vom Umfang des Ausschließlichkeitsrechts aus, wenn sie für eine bestimmungsgemäße Benutzung notwendig ist. Wozu ein Programm benutzt werden soll, ergibt sich aus der Art des Programms und seiner Ausgestaltung 921. Unterstellt man, eine Webseite wäre ein Computerprogramm, so würde die Benutzung bestimmungsgemäß zum bloßen Werkgenuss führen. Die Zwischenspeicherung wäre dafür technisch notwendig. Die gesetzliche Schranke würde eingreifen.

\section{(4) Schlichte Einwilligung}

Wenn trotz Prüfung der gesetzlichen Schranken noch immer eine Urheberrechts- bzw. Leistungsschutzrechtsverletzung möglich ist, muss diese Verletzung zudem rechtswidrig sein. Dies ist sie nicht, wenn ein Rechtfer-

920 Lüft, in: Wandtke/Bullinger, UrhG, $\mathbb{\$} 55 \mathrm{a}, \mathrm{Rn} .4$; Dreier/Schulze, UrhG, $\mathbb{\$} 55 \mathrm{a}$, Rn. 5.

921 Loewenheim/Spindler, in: Schricker/Loewenheim, UrhG, $\mathbb{6} 69 \mathrm{~d}, \mathrm{Rn} .7$. 
tigungsgrund eingreift. Als solcher Rechtfertigunggrund wird in Internetsachverhalten häufig die schlichte Einwilligung herangezogen. Eine solche schlichte Einwilligung setzt - anders als eine Lizenz - keine rechtsgeschäftliche Willenserklärung voraus. Hierfür reicht es aus, wenn dem schlüssigen Verhalten des Berechtigten die objektive Erklärung entnommen werden kann, er sei mit der Nutzung seiner Werke einverstanden. Davon ist nach der herrschenden Rechtsprechung auszuegehen, wenn geschützte Inhalte ohne technische Beschränkungen öffentlich zugänglich sind ${ }^{922}$.

Genauso hat es das OLG München auch für den Fall gesehen, in welchem ein Nutzer mit aktiviertem Adblock Plus eine Webseite aufsucht. Der Verzicht auf eine vorherige Anmeldung, Registrierung und Bezahlschranken führt laut dem Senat zur objektiv erkennbaren Einwilligung der Nutzung der Webseite. Damit rechtfertigt der Senat sodann (unter Aussparung aller an sich vorher anstehender Prüfungspunkten) die Vervielfältigung und Umarbeitung eines Computerprogramms gemäß $\$ 69 \mathrm{c}$ Nrn. $1 \& 2$ UrhG. An diesem Ergebnis änderte auch der in den Nutzungsbedingungen befindliche Passus der streitgegenständlichen Webseite nichts, wonach die Webseiten ohne Zustimmung der Klägerin nicht verändert werden dürften. Die unstreitig einseitig gebliebenen Nutzungsbedingungen entfalteten laut OLG München keine Wirkung. Auch eine im Footer der Webseite geäußerte Bitte, keinen Werbeblocker zu nutzen, sah der Senat als unverbindlich an. Denn die Bitte könne vor dem Hintergrund des weiterhin gewährten Zugriffs auch für Werbeblockernutzer nichts an der Einwilligung ändern. Die Wirkung der schlichten Einwilligung könne also erst durch das Scharfstellen technischer Zugriffshindernisse bekämpft werden ${ }^{923}$.

Diese Lösung verdient Zustimmung. Die vom BGH in seinen Vorschaubilder-Urteilen erarbeitete Lösung der schlichten Einwilligung beim bewussten Verzicht auch technisches Schutzmaßnahmen für eigenen Content ist zweckmäßig und führt zu gerechten Ergebnissen. Es ist auch richtig, dass einseitige kommunikative Handlungen ohne wirksame technische oder rechtliche Konsequenzen diese Einwilligungswirkung nicht ausräumen. Wenn ein Contentanbieter also seinen (nach eigener Ansicht rechtlich oder wirtschaftlich) schutzwürdigen Content vor dem beliebigen Zugriff im Web schützen will, muss er selbst dafür die Grundlage legen. Ein freies Anbieten des Contents unter rein plakativen Hinweisen, dass

922 OLG München, Urteil vom 17.8.2017, U 2225/15 Kart, GRUR 2017, 1147; BGH, Urteil vom 19.10.2011 - I ZR 140/10, GRUR 2012, 602 - Vorschaubilder II.

923 Vgl. OLG München, Urteil vom 17.8.2017, U 2225/15 Kart, GRUR 2017, 1147. 
keine Werbeblocker genutzt werden sollen, ist demnach eine rechtlich nicht relevante moralische Ansprache oder sogar ein venire contra factum proprium. Dies gilt umso mehr, weil technische oder rechtliche Schutzmaßnahmen bei Betroffenen bekannt sind und mit nicht unzumutbarem Aufwand implementiert werden können.

Nach dieser Argumentation muss auch die in hiesiger Prüfung allein noch mögliche Verletzung eines Datenbankrechts aus $\$ 87 \mathrm{~b}$ UrhG durch Vervielfältigung des HTML-Dokuments gerechtfertigt sein, wenn keine technischen oder rechtlichen Schutzmaßnahmen auf der Webseite erkennbar sind. Wenn hingegen solche Maßnahmen existieren, wird bei technischem Zugriffsschutz bereits die Verletzungshandlung unterbunden.

\section{(5) Konkludente Lizenz}

Neben der schlichten Einwilligung könnte zudem noch an eine konkludente Lizenzgewährung gedacht werden. Auf diese wird es angesichts der einfacheren Möglichkeit der schlichten Einwilligung jedoch kaum noch ankommen. Dies auch vor dem Hintergrund, dass bei der konkludenten Lizenzgewährung der strenge Übertragungszweckgedanke des $₫ 31 \mathrm{Abs} .5$ UrhG gilt und nur im geringsten Maße Rechte eingeräumt werden sollen ${ }^{924}$. Eine konkludente Lizenzgewährung sollte deshalb nur sehr vorsichtig angenommen werden. Dies gilt auch vor dem Hintergrund, dass beim Abruf einer Webseite durch einen Nutzer gerade kein Vertragsverhältnis entstehen soll. Es wäre dann nicht erklärbar, bei urheberrechtlicher Betrachtung eine rechtsgeschäftliche Nutzungserlaubnis anzunehmen.

\section{(iv) Fazit}

Für die Nutzung von Webseiten, die frei und ohne technische Schutzvorkehrungen im Web erreichbar sind, besteht kein Grund für die Annahme einer Urheberrechtsverletzung. Mit Ausnahme eines potentiellen Schutzes als sui generis Datenbank besteht schon keine Schutzfähigkeit für Webseiten an sich. Spätestens durch die Anwendung von Schrankenregelungen oder des Rechtfertigungsgrundes der schlichten Einwilligung endet die Prüfung einer Urheberrechtsverletzung.

\footnotetext{
924 BGH, Urteil vom 29.4.2010 - I ZR 69/08, GRUR 2010, 628 - Vorschaubilder I.
} 
cc) Kartellrecht

Als drittes und verbleibendes Rechtsgebiet ist das Kartellrecht in den Blick zu nehmen. Über kartellrechtliche Ansprüche entschieden das LG München I, das LG Hamburg sowie das OLG München - und lehnten alle in Frage kommenden Anprüch ab ${ }^{925}$. Erst der Kartellsenat des BGH hielt eine unbillige Behinderung durch den Betreiber von Adblock Plus für möglich, sah sich aber mangels Tatsachenfeststellungen nicht zu einer eigenen Entscheidung in der Lage ${ }^{926}$.

Maßgeblich prüften die Gericht dabei einen Unterlassungsanspruch gemäß $\$ 33$ Abs. 1 GWB iVm $\mathbb{S} 18,19$ GWB wegen des Missbrauchs einer marktbeherrschenden Stellung. Die Münchener Gerichte ließen den Anpruch dabei bereits am Fehlen einer marktbeherrschenden Stellung der Werbeblockerbetreiberin scheitern ${ }^{927}$. Das LG Hamburg ließ seinerseits dieses Merkmal offen und lehnte das Vorliegen der verschiedenen in $\$ 19$ GWB genannten Missbrauchsvarianten $\mathrm{ab}^{928}$. Der BGH wiederum hält eine marktbeherrschende Stellung für möglich, da es den Markt anders als das OLG München abgrenzte ${ }^{929}$.

Die Münchener Rechtsprechung grenzte zunächst den sachlichen und räumlichen Markt nach $\$ 18$ Abs. 1 GWB ab und zog dafür „den Markt des Zugangs zu Internetnutzern in Deutschland" heran. Dies erfolgte in Ablehnung der Heranziehung eines von Klagerseite befürworteten engeren Marktes der Werbeblocker oder Marktes der Freischaltung von Onlinewerbung. Dem Begehren der Klägerinnen und dem Bedarfsmarktkonzept folgend lehnt die Rechtsprechung den Markt der Werbeblocker als sachlich relevanten Markt ab, weil die klagenden Webseitenbetreiber jedenfalls kein Interesse an der Vermittlung der Nutzung von Werbeblockern habe. Da im konkreten Fall auch kein Klagenatrag gestellt wurde - noch die Bereitschaft gezeigt wurde - die klägerischen Webseiten bei der Werbeblo-

925 LG München I, Urteil vom 27.5.2015 - 37 O 11843/14 (juris, Rn. 204ff., 289ff.); Urteil vom 27.5.2015 - 37 O 11673/14 (juris, Rn. 293ff.) sowie nachfolgende Berufungen beim OLG München, Urteile vom 17.8.2017, U 2184/15 Kart, (juris Rn.149ff.); 559; U 2225/15 Kart, (juris Rn. 126ff.); LG Hamburg, Urteil vom 25.11.2016, 315 O 293/15 (juris, Rn. 52ff.).

926 BGH, Urteil vom 8.10.2019, KZR 73/17, WRP 2019, 1572 - Werbeblocker III.

927 Exemplarisch OLG München, Urteil vom 17.8.2017, U 2225/15 Kart, GRUR 2017, 1147.

928 LG Hamburg, Urteil vom 25.11.2016, 315 O 293/15.

929 BGH, Urteil vom 8.10.2019, KZR 73/17, WRP 2019, 1572 - Werbeblocker III. 
ckerbetreiberin zu „whitelisten"930, konnte es aus demselben Grund nicht auf den Markt der Werbefreischaltung oder des „kommerziellen Whitelistings" ankommen. Die Klägerinnen begehrten vielmehr ihre Inhalte mitsamt Werbung möglichst vielen Internetnutzern bereitzustellen und dabei nicht durch die Wirkweise von Adblock Plus beeinträchtigt zu werden. Als maßgeblich sah das OLG München deshalb an, welchen Anteil die Kunden des Werbeblockerbetreiber an der Gesamtheit der Internetnutzer in Deutschland darstellen ${ }^{931}$.

Die fehlende Beherrschung dieses Marktes folgerten die Münchener Gerichte dann aus den unstreitigen Werbeblockerraten von 20\% (+/- weniger Prozentile), die auf OVK-Messungen aus den Jahren 2015 und 2016 beruhten. Damit wurde nicht die in $\$ 18$ Abs. 4 GWB genannte Quote von $40 \%$ erreicht, ab welcher eine Marktbeherrschung zu vermuten ist. Eine Marktbeherrschung folgerten die Gerichte auch nicht aus anderen in $\mathbb{1} 18$ Abs. 3, 3a GWB niedergelegten Umständen ${ }^{932}$.

Dem ist der Kartellsenat des BGH entgegen getreten und machte klar, dass bei korrekter Anwendung des Bedarfsmarktkonzepts auf den Markt der entgeltlichen Werbefreischaltung für Werbeblocker abzustellen ist ${ }^{933}$.

Die Missbrauchsvarianten des $₫ 19$ Abs. 2 GWB lehnte das LG Hamburg sodann ab, da es keine unbilligen Verhaltensweisen der Werbeblockerbetreiber im „kommerziellen Whitelisting“ durch die gelebte Praxis der „Acceptable Ads-Kriterien"934 erkannte. Wegen des grundsätzlich rechtlich zulässigen Vertriebs eines Werbeblockers, nahm die Hamburger Kammer keine unbillige Behinderung im Sinne des $\$ 19$ Abs. 2 Nr. 1 Alt. 1 GWB an. Weder die variable Vergütung des Whitelistings noch die Privilegierung von Betreibern kleinerer Webseiten stelle eine Diskriminierung im Sinne

930 Was bei entsprechender Anfrage der klagenden Webseitenbetreiber von Eyeo wohl auch nicht verweigert worden wäre, soweit die Acceptable Ads Kriterien und die Zahlungspflicht akzeptiert worden wären.

931 Exemplarisch OLG München, Urteil vom 17.8.2017, U 2225/15 Kart, GRUR 2017, 1147.

932 OLG München, Urteil vom 17.8.2017, U 2225/15 Kart, GRUR 2017, 1147: der Senat setzte sich nicht tiefergehend mit anderen Umständen als dem Marktanteil auseinander. LG München I, Urteil vom 27.5.2015 - 37 O 11673/14, MMR 2015, 660: die Kammer prüfte zumindest eine Marktbeherrschung durch besondere Finanzkraft, Zersplitterung des Marktes und Ausweichmöglichkeiten der Marktgegenseite an.

933 BGH, Urteil vom 8.10.2019, KZR 73/17, WRP 2019, 1572 - Werbeblocker III; siehe die Zusammenfassung unter Ziffer C. I. 3. i).

934 Vgl. die Beschreibung der wirtschaftlichen Grundlagen unter Ziffer. C. I. 2. b) bb) (i). 
des $₫ 19$ Abs. 2 Nr. 1 Alt. 2 GWB dar. Insoweit liege keine Gleichartigkeit zwischen den Betreibern von Deutschlands erfolgreichsten Webseiten und kleiner Anbieter. Außerdem wäre eine unterschiedliche Behandlung durch den unterschiedlichen Aufwand der Freischaltungs und den unterschiedlichen Ertrag der kommerziellen Werbeblockeranbieters gerechtfertigt. Zudem lehnte es einen Ausbeutungsmissbrauch im Sinne des $\mathbb{} 19$ Abs. 2 Nr. 2 GWB ab, da die erfolgsbasierte Zahlung von 30\% der Mehreinnahmen nicht objektiv überhöht sei ${ }^{935}$.

Ferner prüfte die Münchener Rechtsprechung das Vorliegen einer kartellrechtswidrig wettbewerbsbeschränkenden Vereinbarung iSv $\mathbb{} 1 \mathrm{GWB}$ bzw. Art. 101 AEUV. Einen Unterlassungsanspruch nach $\ 33$ Abs. 1 GWB lehnten aber alle Gerichte ab. Die Zulassung von Onlinewerbung nach Abschluss von Whitelistverträgen und auf Grundlage der Acceptable Ads Kriterien sei zwar eine Wettbewerbsbeschränkung, da hierdurch eine Einschränkung und Kontrolle des Absatzes von Onlinewerbung bewirkt werde. Die Freischaltungsverträge seien jedoch als Vertikalvereinbarung gemäß $\mathbb{2}$ Abs. 2 GWB iVm Art. 2 Abs. 1 Satz 1 und 2 der Verordnung (EU) Nr. 330/2010 („VertikalGVO“) freigestellt. Im Rahmen der Frage nach einer horizontalen oder sternförmigen Vereinbarung, wurde weder von einem Eigeninteresse der Webseitenbetreiber an der Beschränkung auf bestimmte „akzeptable“ Werbeformen, noch von einer Koordinierung der Webseitenbetreiber untereinander ausgegangen. Vielmehr beugten sich die kooperierenden Webseitenbetreiber den einseitig bestimmten Acceptable Ads Kriterien, um zumindest einen Teil der erhofften Werbeeinnahmen mit „Werbeverweigerern“ zu erzielen und so die wirtschaftlichen Einbußen zu verringern. Es bleibe also bei der Freistellung der Vereinbarungen $^{936}$.

Zuletzt wurden in den Münchener Urteilen Unterlassungsansprüche nach $₫ 33$ Abs. 1 GWB iVm $\$ 21$ Abs. 2, Abs. 3 Nr. 3 GWB abgelehnt. Das Verbot der Druckausübung aus $\mathbb{} 21$ Abs. 2 GWB sei schon nicht tangiert, da der Abschluss einer Whitelisting-Vereinbarung - wie gerade dargestellt - nicht kartellrechtswidrig sei. Einen in $\$ 21$ Abs. 3 Nr. 3 GWB verbotenen Druck auf andere Unternehmen, sich im Markt gleichförmig zu verhal-

935 LG Hamburg, Urteil vom 25.11.2016, 315 O 293/15. Das LG München I ließ es sich trotz Ablehnung der marktbeherrschenden Stellung und unter ausdrücklicher Offenlassung nicht nehmen, einige wenige Gedanken zur unbilligen Behinderung in ihre Urteile zu schreiben, vgl. Urteil vom 27.5.2015 - $37 \mathrm{O}$ 11673/14, MMR 2015, 660. Dieses „obiter dictum“ legt nahe, dass das LG München I auch hier den Unterlassungsanspruch hätte scheitern lassen.

936 OLG München, Urteil vom 17.8.2017, U 2225/15 Kart, GRUR 2017, 1147. 
ten, sahen die Münchener Richter ebenfalls nicht, da hinreichende und zumutbare Handlungsalternativen der betroffenen Webseitenbetreiber zur Verfügung stünden ${ }^{937}$.

Der Kartellsenat des BGH hält eine unbillige Behinderung nach $\mathbb{} 19$ Abs. 2 Nr. 1 Alt. 1 GWB für möglich ${ }^{938}$. Die übrigen von der Münchener Instanzrechtsprechung geprüften kartellrechtlichen Verbote lehnte der Kartellsenat des BGH allerdings ab ${ }^{939}$.

Den Ergebnissen der Instanzrechtsprechung ist entgegen der Zweifel des Kartellsenats des BGH zuzustimmen ${ }^{940}$. Insbesondere den ausführlich auf beinahe jedes klägerische Argument eingehenden Urteilen des LG München I lässt sich entnehmen, mit welcher Salve an Argumenten die Webseitenbetreiber gegen das Geschäftsmodell des kommerziellen Whitelistings geschossen haben. So scheinte es, dass wegen der durchaus bestehenden Beherrschung des Marktes der Werbeblocker (belegt durch die beeindruckenden Downloadzahlen) und des Marktes der Werbefreischaltung (als logische Konsequenz der Beherrschung des vorgelagerten Werbeblockermarkts) im Einklang mit den einseitig gesetzten, wettbewerbsbeschränkenden Freischaltungsbedingungen sowie der nur selektiven Kostenpflicht, doch „irgendein“ kartellrechtliches Verbot getroffen werden musste. Es ist hier ebenso wie in den anderen beiden Rechtsgebieten ein Verdienst der (Instanz-) Gerichte - und der rechtlichen Vertreter der Werbeblocker - das Augemerk auf die tatsächlichen Strukturen gelenkt zu haben. Dies zeigt die Marktabgrenzung der Münchener Kartellrechtsprechung eindringlich. Während das LG Hamburg sich gar nicht erst an die "heikle“ Marktabgrenzung wagte, entlarvten die Münchener Richter den Knackpunkt der klägerischen Argumentation. Das eigene Begehren führte zur zwingenden Annahme des sachlichen Markts. Aber schon nach eigenem Vortrag konnte keine höhere Werbeblockerrate in Deutschland als ca. 20\% dargelegt werden. Das bedeutet, dass potentiell immer noch ca. $80 \%$ der deutschen Internetnutzer auf die mit Werbung versehenen Webseiten deutscher Publisher zugreifen. Es blieben also trotz aller Hysterie noch genügend Adressaten, die Werbung rezipierten. Zwar neigen technikaffine Nutzer zum Einsatz von Werbeblockern, diese Nutzer machen aber in Deutschland seit geraumer Zeit eine eher konstante Anzahl

937 OLG München, Urteil vom 17.8.2017, U 2225/15 Kart, GRUR 2017, 1147.

938 BGH, Urteil vom 8.10.2019, KZR 73/17, WRP 2019, 1572 - Werbeblocker III; siehe die Zusammenfassung unter Ziffer C. I. 3. i).

939 BGH, Urteil vom 10.12.2019, KZR 57/19, K\&R 2020, 302.

940 Ebenso: Alexander, GRUR 2017, 1147, 1157. 
aus. Dies entspricht auch statistischen Zahlen, die für Onlinewerbung generell und Displaywerbung speziell von den Jahren 2013 an Wachstumsraten ausweisen ${ }^{941}$. Bei Lichte betrachtet nimmt „kommerzielles Whitelisting“ dem Onlinewerbemarkt also kein Geschäft weg, sondern hemmt allenfalls das Wachstum. Vor dem Hintergrund der klaren gesetzlichen Formulierung der 40\%-Grenze in $\$ 18$ Abs. $4 \mathrm{GWB}^{942}$ hätte es daher oblegen, klare Umstände für eine Marktbeherrschung unterhalb dieser Marktanteilsschwelle vorzubringen. Einzig, diese Hinweise gab der Fall nicht her. Weder ist der Werbeblockerbetreiber auf dem gesamten deutschen Onlinemarkt beherrschend finanzkrättig ( $\$ 18$ Abs. 3 Nr. 2 GWB), noch sind bedenkliche Verflechtungen mit anderen Unternehmen ( $\$ 18$ Abs. 3 Nr. 4 GWB) erkennbar. Auf letzteres schien, unter anderem, die mehrfach geäußerte Kritik der Webseitenbetreiber an der Kooperation mit Google hinauszulaufen. Den Zugang zu einem Markt ( $\$ 18$ Abs. 3 Nr. 3 GWB) kontrolliert Adblock Plus nur mit Blick auf den nachgelagerten Markt der Ausspielung von Werbung an Werbeblockernutzer. Eine notwendige Gesamtschau der Merkmale in $\mathbb{\$} 18$ Abs. 3 GWB $^{943}$ führt also in keinem Fall zu einer marktbeherrschenden Stellung auf dem gesamten deutschen Onlinewerbemarkt.

Die Entscheidung des BGH in seinem Urteil „Werbeblocker III“ hingegen verdient nur eingeschränkte Unterstützung. Das soll natürlich in keiner Weise bedeuten, dass die Auslegung des Kartellsenats auf Grundlage des in ständiger Rechtsprechung angewendeten Bedarfsmarktkonzeptes rechtlich falsch wäre. Der BGH und die übrigen Gerichte verweisen durchgehend darauf, dass Adblock Plus als differenzierender kommerzieller Whitelistblocker einen zweiseitigen Markt bedient, der auf der einen Seite die Internetnutzer als Abnehmer der Software und auf der anderen Seite Webseitenbetreiber als Kunden für die Freischaltung anspricht. Während die Münchener Rechtsprechung scheinbar im Wege eines „entwederoder"-Schlusses für die Marktabgrenzung nur die eine Seite der Medaille, d.h. über die Nutzerperspektive den gesamten Werbemarkt in Deutschland in den Blick nahm, zieht der BGH auch die andere Seite beachtliches

941 Vgl. die Zahlen von PwC, Ovum und BVDK, vlg. https://www.pwc.de/de/tec hnologie-medien-und-telekommunikation/gemo-2018.pdf\#page=136, zuletzt abgerufen am 30.5.2019.

942 Zur Rechtsnatur der Vermutung vgl. Fuchs/Möschel, in: Immenga/Mestmäcker,

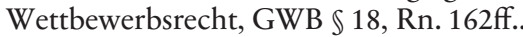

943 Vgl. Bechtold/Bosch, GWB, $\mathbb{1} 18$, Rn. 56. 
Kriterium heran. Auf dem somit beachtlichen Markt der Whitelist-Freischaltung ist die Eyeo $\mathrm{GmbH}$ faktisch Monopolist.

Diesem Judiz kann rechtlich nichts Substanzielles entgegnet werden, bei Betrachtung der faktischen Umstände ist diese Entscheidung aber bedenklich. Denn die Kläger der entsprechenden Verfahren haben den öffentlichen Quellen und gerichtlichen Feststellungen zufolge nie eine Freischaltung bei Adblock Plus ernsthaft gewünscht - sie begehrten vielmehr das Totalverbot des Internetwerbeblockers. Der BGH eröffnet mit seiner Marktabgrenzung nun eine Detailprüfung des Whitelist-Geschäftsmodells, welches die Kläger an sich nicht wollten.

Das Urteil „Werbeblocker III“ fördert die Auseinandersetzung um die Internetwerbeblocker jedoch enorm, weil der Kartellsenat für die neue Verhandlung beim OLG München bereits ausführliche „Segelanweisungen“ gab. So wird das OLG München Feststellungen zur Existenz und Effektivität von Ausweichmöglichkeiten gegen Werbeblocker treffen müssen. Außerdem erwartet der BGH Feststellungen zur tatsächlichen Geschäfts- und Vertragspraxis im Zusammenhang mit dem kommerziellen Whitelisting durch Eyeo. Bislang war hier das Verhältnis des Werbeblockerbetreibers zu zahlenden Kunden praktisch als Geschäftsgeheimnis behandelt worden. Außerdem wird es eine gerichtliche Einschätzung zur Angemessenheit der Acceptable Ads-Kriterien und zur Angemessenheit der 30\%igen Beteiligung an Werbeerlösen geben.

Die Marktabgrenzung entsprechend dem Urteil „Werbeblocker III“ des BGH und die maßgeblich vom Marktanteil bestimmte Marktmacht auf dem relevanten Markt führt dazu, dass die Fälle aus Sicht der Instanzrechtsprechung kartellrechtlich neu zu bewerten sind - nicht nur, aber vor allem sobald eine Werbeblockerrate von $40 \%$ (bzw. $30 \%$ wegen $\$ 3$ VertikalGVO) dauerhaft überschritten wird ${ }^{944}$. Zwingende Gründe für eine Ablehnung der Missbrauchsvarianten des $\mathbb{1 9}$ GWB liefert insbesondere das LG Hamburg in seinem Urteil nicht. An dieser Stelle besteht wohl das größte Risiko für eine fortdauernde Zulässigkeit des Angebots von Werbeblockern mit dem Geschäftsmodell des kommerziellen Whitelisting. Im Rahmen der unbilligen Behinderung ( $\$ 19$ Abs. 2 S. 1 Alt. 1 GWB) wird man jedoch im Einklang mit $\mathbb{4} 4 \mathrm{Nr} .4$ auf Grundlage einer weitestgehend gleichlaufenden Interessenabwägung ebenfalls zum Ergebnis der Zulässigkeit sowohl der Black- als auch der Whitelistblocker kommen

944 Dies wäre auch bei der Marktabgrenzung entsprechend den Urteilen des OLG München bei entsprechender Verbreitung unter den Nutzern möglich. 
müssen $^{945}$. Für eine ungerechtfertigte Ungleichbehandlung gleichartiger Unternehmen ( $\mathbb{1} 19$ Abs. 2 S. 1 Alt. 2 GWB) mögen bis zum Zeitpunkt der Beurteilung keine Hinweise vorliegen. Denkbar wären jedoch Fallgestaltungen, in welchen diese Art des Missbrauchs zu bejahen wäre. In Zeiten großer digitaler Plattformen könnte Whitelisting ein Wettbewerbsvorteil sein und so zum Beispiel die Ablehnung gleichartiger freischaltungswilliger Plattformbetreiber wegen bestehender Exklusivitätsvereinbarungen einen Marktmissbrauch darstellen.

\19 Abs. 2 GWB lag als Anknüpfungspunkt eines Angriffes besonders nahe, weil Adblock Plus mit seiner Whitelist als „first mover" sozusagen einziger Anbieter des kommerziellen Whitelistings war und seine Preise selbst bestimmte. Mittlerweile scheint sich jedoch Wettbewerb auch auf dem Markt der Freischaltung zu entwickeln. Eine Änderung von Entgelten oder Kriterien für die Freischaltung könnte bei Erreichung von Marktmacht jedoch kartellrechtlich kritisch sein. Das LG Hamburg sah die geforderten 30\% der Mehreinnahmen durch das Whitelisting als nicht überhöht an. Dies kann man aus der Perspektive der Webseitenbetreiber natürlich anders sehen. Dies ist schließlich das altbekannte „Freikauf“-Argument der Verlagshäuser. Bei nüchterner Betrachtung sollte auch hier nicht von einem Freikauf „weggenommener“ Werbeaufmerksamkeit, sondern von einer Hemmung des Wachstums des Onlinewerbemarkts ausgegangen werden. Denn eine Position, die man noch nicht inne hat (hier: Aufmerksamkeit von „Werbehassern“), kann man nicht freikaufen. Betrachtet man das Whitelisting-Angebot als Angebot zur Generierung von Wachstum ist eine 30\%ige Beteiligung an diesem Wachstum auch nach hier vertretener Ansicht nicht zu hoch angesetzt. Dies gilt auch vor dem Hintergrund, dass tatsächlich ein gewisser technischer Aufwand für den kommerziellen Werbeblockerbetreiber zu bewältigen ist. Der erneute Einwand, dieser technische Aufwand entstehe ja erst durch die vorangegangene Blockade, muss dann damit entkräftet werden, dass diese Blockade von einer breiten Masse der Internetnutzer gewollt ist. Anders wäre die Frage des Ausbeutungswettbewerbs wohl zu bewerten, wenn der Werbeblockerbetreiber nicht am neu generierten Geschäft mit der Werberezeption partizipieren

945 Dass der Kartellsenat des BGH in „Werbeblocker III“ diesen Gleichlauf von lauterkeits- und kartellrechtlicher Interessenabwägung ausdrücklich moniert hat, dürfte eher eine Formulierungsfrage, denn ein wahres Hindernis sein. Denn auch bei Beachtung kartellrechtlicher Besonderheiten sind die Interessen der Internetnutzer an der Existenz von Werbeblockern die Hochwertigsten. Wie die Abwägung mit Blick auf die Details des Geschäftsmodells ausfällt, ist hingegen eine andere Frage, die hier nicht im Einzelnen behandelt wird. 
würde, sondern Anteile am sonstigen Geschäft oder überhöhte pauschale Aufwandsentschädigungen forderte.

Wenn kommerzielles Whitelisting nicht nur zur Marktbeherrschung aufsteigen würde, sondern sogar zum absoluten Standard im Web würde, könnte die Sachlage mit den zur Zeit der Bearbeitung im Patentrecht virulenten „SEP“946 und „FRAND“947 Streitigkeiten vergleichbar werden. Aktuell ist die Interessenlage freilich eine andere. Die Webseitenbetreiber denken nicht daran, sich über die Whitelist freischalten zu lassen. Und der Werbeblockerbetreiber lässt jeden zu, der sich freischalten lassen will. Auch mittelfristig ist die Interessenlage immer noch nicht vergleichbar. Webseitenbetreiber können sich selbst mit technischen Schutzmaßnahmen behelfen. Vergleichbar würde es erst, wenn die Nutzer sich in absoluter Mehrheit zur Nutzung von Werbeblockern à la Adblock Plus entschließen und gleichsam Werbeblockersperren zum ausnahmslosen Nichtbesuch der entsprechend zugangsgeschützten Webseiten führte. Zeitgleich müsste der - vom OLG Köln sogenannte - „Gatekeeper“ das Tor zur Freischaltung schließen und nur noch wohlgesonnene Unternehmen durchlassen. Etwa solche, die in der Vergangenheit nicht gegen ihn geklagt hatten. In dieser eher fernliegenden Zukunftsvision würde die Stellung des kommerziellen Whitelistblockers durchaus an die Stellung der technologischen Marktzutrittskontrolleure etwa im Mobilfunksektor heranreichen. Dann könnte auch hier ein kartellrechtlicher Kontrahierungszwang eingreifen. Die heutigen Whitelist-Voraussetzungen der Einhaltung von Acceptable Ads und Zahlung einer Beteiligung am generierten Geschäft scheinen jedoch bereits gerecht, vernünftig und nicht diskriminierend zu sein, sodass sich ein Kontrahierungszwang am aktuellen status quo orientieren könnte.

In einer Pressemitteilung des Bundeskartellamt, in welcher über die Einstellung eines anhängiges Kartellverwaltungsverfahren gegen Google und Eyeo wegen vertraglicher Beschränkungen im Zusammenhang mit einer Whitelisting-Vereinbarung informiert wurde, ließ sich Andreas Mundt, Präsident des Bundeskartellamtes wie folgt zitieren: „Adblocker sind legale

946 SEP ist das durchgesetzte Akronym für standardessentielle Patente, also solche, die durch Standardisierungsstellen oder durch Marktdurchsetzung der Standard für gewisse Technologien darstellen und praktisch genutzt werden müssen, vgl. Hauck, NJW 2015, 2767.

947 FRAND ist die Abkürzung für „fair, reasonable and non-discriminatory“ und betrifft die Lizenzbedingungen für SEPs. Diese Einordnung ist vor allem bei der Bewältigung des kartellrechtichen Zwangslizenzeinwands von nutzungswilligen Unternehmen entscheidend. Für die Anwendung im Patentprozess vgl. Kellenter/Verhauwen, GRUR 2018, 761. 
Instrumente, wie auch der Bundesgerichtshof kürzlich festgestellt hat. Es ist nachvollziehbar, dass Verbraucher ein Interesse daran haben, die Art und die Menge der Online-Werbung zu kontrollieren, die sie zu sehen bekommen. Die Verbreitung von Adblockern ist Teil des Wettbewerbsprozesses bei Dienstleistungen der Online-Werbung. Vertragsregelungen, die auf die Beschränkung der Verbreitung von Adblockern zielen, können daher wettbewerblich nicht hingenommen werden"948. Der Umstand, dass sich das Bundeskartellamt also bereits offiziell mit dem Thema „kommerzielles Whitelisting“ auseinandergesetzt hat, und kein Verfahren gegen Eyeo wegen dieses Verhaltens eröffnet hat, scheint das oben gefundende Ergebnis zu bekräftigen.

Nach alledem gilt: Kartellrechtliche Ansprüche sind zur Zeit der Bearbeitung und mittelfristig danach nicht erfolgsversprechend, um ein Totalbverbot der Werbeblocker zu erreichen. Nach den Urteilen des Kartellsenat könnte es aber durchaus Aspekte des Geschäftsmodells des kommerziellen Whitelistings geben, die kartellrechtlich verboten sind. Ein Totalverbot von Werbeblockern oder des kommerziellen Whitelistings generell wird nach hiesigem Verständnis allerdings auch dann nicht im Raum stehen.

dd) Zusammenfassung der Ergebnisse

Zusammenfassend lassen sich also folgende Ergebnisse festhalten:

(i) Lauterkeitsrecht

- Im Rahmen der geschäftlichen Handlung ( $\$ 2 \mathrm{Nr} .1 \mathrm{UWG}$ ) ist zu beachten, dass keine Aufspaltung von multifunktionalen Blockern in eine Blacklist- und eine Whitelist-Funktion zulässig ist. Die Kostenfreiheit für Nutzer ist unbeachtlich. Bei Adblock Plus ist dies etwa nur eine Vorbereitung für das Whitelist-Geschäft. Bei reinen Blacklist-Blockern reicht schon eine Nutzung von Daten im Rahmen sekundärer Geschäftsmodelle für die Annahme einer geschäftlichen Handlung. Demnach ist praktisch jedes Angebot einer Adblocker Software, die von profitorientierten Unternehmen betrieben wird, eine geschäftliche Handlung. Eine Ausnahme kann allenfalls beim Angebot durch Privatpersonen eingreifen, was aber praktisch nicht zu beobachten ist.

948 https://www.bundeskartellamt.de/SharedDocs/Meldung/DE/Pressemitteilungen /2019/21_01_2019_Eyeo_Google.html, zuletzt abgerufen am 30.5.2019. 
- Bei der Prüfung von $\$ 4$ Nr. 4 UWG ist ein konkretes Wettbewerbsverhältnis auf Grundlage der ständigen Rechtsprechung des BGH zum Behinderungswettbewerb zu bejahen. Die Werbeblockade blockiert in praktisch jedem Fall abrechnungsrelevante Parameter im Verhältnis zu Werbekunden bzw. Intermediären. Damit ist eine Wechselwirkung zwischen den Vorteilen der Werbeblockade für den Anbieter und den Nachteilen der Blockade für die Betroffenen zu bejahen. Dies gilt für die Webseitebentreiber als unmittelbar Betroffene wie auch für Werbenetzwerke oder sonstige Intermediäre.

- Herzstück der Prüfung von $\$ 4$ Nr. 4 UWG ist die Abwägung der Interessen der Parteien, der sonstigen Betroffenen und der Allgemeinheit. Da Werbeblocker vom Bestehen des Werbemarkts abhängig sind, kann keine Verdrängungsabsicht angenommen werden. Bei der Bewertung der Frage, ob Webseitenbetreiber ihre eigene Leistung am Markt nicht mehr durch eigene Anstrengung frei vermarkten können und deshalb gezielt behindert werden, führen folgende Umstände zum Ergebnis der Zulässigkeit der Werbeblocker. Die Hoheit über den Einsatz von Werbeblockern haben in aller Regel die Nutzer. Wenn sich der Nutzer zum Einsatz eines Add-ons oder eines bestimmten Blockers mit Werbeblockerfunktion bedient, ist das in den meisten Fällen eine autonome Entscheidung ${ }^{949}$. Diese Nutzerautonomie ist das überragende Argument für die Zulässigkeit von Werbeblockern. Flankiert wird dies durch das erhebliche Interesse der Nutzer an einem Schutz vor mit Werbung verbundenen Begleitprozessen wie Tracking oder Risiken der Infizierung mit Schadsoftware. Hinzu kommt außerdem, dass Webseitenbetreibern Handlungsalternativen zur Verfügung stehen, die die Wirksweise von Werbeblockern ausschließen, insbesondere die Zugangsblockade für Adblocker-Nutzer. Daran ändern auch die Grundrechte der Webseitenbetreiber, insbesondere die Medienfreiheit bei redaktionellen Angeboten, nichts. Diese können nicht zu einem Wahrnehmungszwang der Nutzer führen. Außerdem ist es nicht Aufgabe von Grundrechte altgediente Geschäftsmodelle zu zementieren. Mit besonderem Blick auf kommerzielles Whitelisting ist zu beachten, dass diese Methode der Blockade abstrakt weniger einschneidend für den Werbemarkt ist als eine Komplettblockade via Blacklist. Zum selben Ergebnis kommt man, wenn man Werbenetzwerke als Betroffene des Werbeblockens

949 Dies ist wohl nicht bei Google Chrome der Fall, der nunmehr standardmäßig eine Werbeblockerfunktion enthält. Hier besteht die Entscheidungshoheit über den Einsatz wohl beim Anbieter des bereits weit verbreiteten Browsers. 
heranzieht. Neben den zuvor genannten Argumenten der Nutzerautonomie und des Selbstschutzes, sind die Intermediäre des Adtech-Zeitalters nicht gleichermaßen schutzbedürftig wie Webseitenbetreiber und müssen sich dem dynamischen Wettbewerb deshalb umso mehr stellen.

- Eine Allgemeine Marktbehinderung ist nach hier vertretener Ansicht aus dogmatischen Gründen bereits als Fallgruppe der Generalklausel abzulehnen. Wenn man diese Fallgruppe anwenden möchte, würde sie gleichwohl kein Verbot rechtfertigen, weil hier der betroffene Markt wie man ihn auch konkret definieren möchte - nicht grundlegend in seinem Bestand gefährdet wird.

- Bei der Prüfung des $₫ 4 a$ UWG sind mehrere Aspekte besonders herauszustellen:

- Zunächst ist zu bedenken, dass die Streitigkeiten zwischen Betroffenen der Werbeblockade und den Anbietern der entsprechenden Software das B2B-Vertikalverhältnis betreffen und damit zumindest im Ausgangspunkt keine richtlinienkonforme Auslegung des $\$ 4 \mathrm{a}$ UWG zwingend ist.

- Zudem ist eine Besonderheit, dass eine Webseitenbetreiber im Verhältnis zu einem Anbieter eines kommerziellen Whitelisting-Blocker (z.B. Adblock Plus) sowohl als Mitbewerber als auch als sonstiger Marktteilnehmer betroffen ist. Gleichwohl sind $\$ 4$ Nr. 4 UWG und $\sqrt{4}$ a UWG nebeneinander anzuwenden. Dies kann man als Folge der extensiven Auslegung des Mitbewerberbegriffs durch den BGH begreifen, der den Anwendungsbereich des $\$ 4$ a UWG nicht beschneiden kann.

- Im Verhältnis zwischen $₫ 4 a$ UWG und den kartellrechtlichen Vorschriften der $\mathbb{S} 18 \mathrm{ff}$. GWB gilt nach hier vertretener Ansicht, dass keine generelle Sperrwirkung des Kartellrechts eingreift. Vielmehr ist eine kartellrechtsfreundliche Auslegung des Begriffs der Machtposition in $\$ 4$ a Abs. 1 S. 3 UWG geboten.

- Im Rahmen der Prüfung der enumerierten Aggressionsmittel in $\$ 4$ a Abs. 1 S. 2 UWG gilt, dass die in Nummer 1 genannte Belästigung und die in Nummer 2 genannte Nötigung in beschiedenen und naheliegenden Fallgestaltungen im Zusammenhang mit Internetwerbeblockern ausscheiden müssen.

- Bei der Prüfung der regelmäßig streitentscheidenden unzulässigen Beeinflussung gemäß $₫ 4$ a Abs. 1 S. 2 Nr. 3, S. 3 UWG sind zwei Aspekte kritisch. Zum einen das Vorliegen einer Machtposition und 
zum anderen die Ausnutzung dieser Machtposition zur Ausübung von Druck.

Bei der Machtposition ist zu beachten, dass es noch keine gefestigte Auslegung dieses Begriffs im B2B-Verhältnis gibt. Regelmäßig werden im B2C-Verhältnis situationsbedingte oder strukturelle Machtpositionen für ausreichend gehalten. Dies darf allerdings nur mit Bedacht auf das B2B-Verhältnis übertragen werden. Denn in diesem Verhältnis sind situationsbedingte Machtpositionen nur in Ausnahmefällen denkbar. Bei Werbeblockern sind sie mangels spontaner, lediglich temporärer Situation ausgeschlossen. Bei strukturellen Machtpositionen ist ein Gleichlauf mit kartellrechtlichen Vorschriften herzustellen. Sonst würde das Lauterkeitsrecht potentiell strengere Anforderungen stellen als das Kartellrecht. Dies würde v.a. Unternehmen unterhalb der Marktmachtschwelle von $\mathbb{S} 18$ GWB beeinträchtigen. Eine rein lauterkeitsrechtlich begründete strukturelle Machtposition kommt im B2B-Verhältnis nur dort in Betracht, wo einer der Marktteilnehmer sich in einer mit einem Verbraucher vergleichbare Lage befindet, also z.B. wenn ein Kleinunternehmen in Gewerbe oder Handwerk von einem Großkonzern beeinflusst wird. Dies ist bei den in den deutschen Rechtsstreiten aktiven Webseitenbetreibern, bei spezialisierten Werbenetzwerken oder professionell aufgestellten Werbekunden indes nicht der Fall. Eine strukturelle Machtposition von Anbietern des kommerziellen Whitelisting (z.B. Eyeo mit Adblock Plus) könnte allenfalls zu "kleinen“ Webseitenbetreibern wie etwa plattformunabhängigen Bloggern bejaht werden, weil diese nicht über eine ausreichende Struktur verfügen, um es mit gut organisierten Unternehmen aufzunehmen. Auch kann es im Streitfall der Filterwerbeblocker keine technische Machtposition geben, weil Betroffene des Werbeblockens unmittelbar oder mittelbar die blockiersichere Ausspielung von Werbung anwenden oder fördern können. Filterwerbeblocker sind insoweit nicht unumgehbar, was eine Machtposition praktisch ausschließt.

Beim Merkmal der Ausnutzung zur Ausübung von Druck ist zu beachten, dass das Freischaltungsangebot im kommerziellen Whitelisting keine Druckausübung darstellt. Denn bei objektiver Betrachtng werden hier Vorteile angeboten. Weil die Werbeblockade als solche zulässig ist, kann nicht argumentiert werden, dass die Aufrechterhaltung der Blockade ein rechtswidrige Druckausübung. Vielmehr weist der Anbieter einen Weg zur (beschränkten) Erreichung von 
Werbeblockerkunden mit Werbeanzeigen, was eine wirtschaftlich betrachtet bessere Situation als die Gesamtblockade darstellt.

Auch das zuletzt in $₫ 4 \mathrm{a}$ Abs. 1 S. 3 UWG enthaltene Merkmal der wesentlichen Einschränkung der Fähigkeit des sonstigen Marktteilnehmers zu einer informierten Entscheidung ist regelmäßig nicht erfüllt. Unternehmen können das Angebot zur Freischaltung ausreichend prüfen, das Für und Wider abwägen und demnach das Angebot ablehnen.

Aus diesen Gründen scheidet eine unzulässige Beeinflussung beim kommerziellen Whitelistung aus.

- Zuletzt wird im B2B-Verhältnis praktisch nie das Merkmal der erheblichen Beeinträchtigung der Entscheidungsfreiheit als Ergebnis der Aggression erfüllt sein. Nur in äußerst extremen Situation ist eine solche Beeinträchtigung von markterfahrenen und ausreichend organisierten Unternehmen denkbar, die dazu führt, dass keine vernünftige Entscheidung mehr möglich ist. Das Angebot der Freischaltung zur Whitelist ist in jedem Falle nicjt eine solche Extremsituation.

- Im Ergebnis scheidet also ein Verbot von kommerziellem Whitelisting auf Grundlage von $\$ 4$ a UWG aus. Das isolierte Blacklisting bedarf schon gar keiner Auseinandersetzung unter $\$ 4$ a UWG, weil die Betroffenen nicht zu geschäftlichen Entscheidungen aufgefordert werden.

(ii) Urheberrecht

- Das Urheberrecht war bislang ein weniger beachtetes Thema im Zusammenhang mit Internetwerbeblockern. Allerdings stellen sich klärungsbedürftige Fragen im Rahmen der Schutzfähigkeit von Webseiten, bei Verletzungshandlungen, Schranken und Rechtfertigungsgründen.

- Im Rahmen der Schutzfähigkeit von Webseiten ist zunächst festzustellen, dass diese kein Computerprogramm im Sinne von $\$ 69$ a UrhG darstellen. HTML-Code kann solche Computerprogramme enthalten, v.a. bei dynamisch serverseitig generierten Webseiten, bei denen JavaScript-Programme für allerlei nützliche Funktionen sorgen. Dies führt aber in keinem Fall dazu, dass eine Webseite insgesamt als Computerprogramm zu qualifizieren wäre. Eine Webseite stellt auch in aller Regel weder ein Sammel- oder Datenbankwerk gemäß $\$ 4$ UrhG noch ein Multimediawerk gemäß $\$ 2$ UrhG dar, weil sie nicht die notwendige Schöpfungshöhe aufweist. Die Anordnung einzelner Werke folgt 
regelmäßig Informationszwecken oder Zweckmäßigkeitserwägungen, nicht aber aus schöpferischer Betätigung. Bei rein computergenerierter Auswahl von Inhalten liegt schon keine menschliche Schöpfung vor. Ein Datenbankschutz nach $\mathbb{8} 87$ a UrhG ist denkbar, wenn das Investitionsefordernis im Einzelfall zu bejahen ist. Hier stellt sich aber die Folgefrage, ob Werbeelemente an einem solchen Schutz Teil haben. Dies mag zu bejahen sein, wenn eine schutzwürdige Investition gerade in der Erstellung des Werbeinhalte umfassenden HTML-Dokuments zu erblicken ist.

- Abgesehen davon sind einzelne Elemente einer Webseite wie Fotos, Texte oder Videos für sich gesehen natürlich schutzfähig. Differenzierend zu betrachten ist die Einbindung von Computerprogrammen in HTML-Dokumenten. Wenn es sich um Anwendungen wie Browserspiele handelt, die ein Element der Webseite darstellen, ist auch hier ohne Zweifel Schutz gegeben. Andererseits führen Programme zur Konsultation von Datenbanken bei serverseitig dynamisch generierten Webseiten, die auf Servern ablaufen, nicht dazu, dass HTML-Dokumente oder gar die daraus abgeleiteten Webseitendarstellungen nicht Teil am Schutz dieses Computerprogramms. Diese sind vielmehr Arbeitsergebnis (oder Output) des Computerprogramms und müssen isoliert rechtlich bewertet werden. Bei Computerprogrammen in HTMLDokumenten, die bei clientseitig dynamisch generierten Webseiten ohne Werbeblockernutzung derart wirken, dass gewisse verknüpfte Elemente nachgeladen werden, haben diese verknüpften Elemente nicht Teil am Schutz des Computerprogramms.

- Im Rahmen der Verletzungshandlungen ist zu beachten, dass Täter einer potentiellen Urheberrechtsverletzung der Nutzer der Werbeblockersoftware ist. Der Anbieter dieser Software ist allenfalls Teilnehmer oder Störer. Selbst wenn man eine Schutzfähigkeit als Computerprogramm annehmen wollte, läge keine Umarbeitung vor, weil keine Quellcodeveränderung durch Werbeblockersoftware vorgenommen wird. Eine Vervielfältigung des HTML-Dokuments und diverser darin vorgesehener Elemente im Arbeitsspeicher des Nutzergeräts ist auf Verletzungsebene zu erkennen. Hier kommen aber Schranken und Rechtfertigungsgründe in Betracht.

- Innerhalb dieser Schrankenregelungen kommt $\$ 44 a$ UrhG Bedeutung zu, weil damit technisch notwendige vorübergehende Vervielfältigungen erlaubt sind. Diese Norm gilt aber aus systematischen Gründen nicht für Computerprogramme, Datenbankwerke und sui-generis Datenbankrechte. Während bei einer (hier gedanklich unterstell- 
ten) Schutzfähigkeit von Datenbankwerken die Spezialnorm des $₫ 55 \mathrm{a}$ UrhG nicht auf das Zwischenspeichern angewandt werden könnte, wäre dies beim (ebenfalls gedanklich unterstellten) Schutz als Computerprogramm durch $\$ 69 \mathrm{~d}$ Nr. 1 UWG legitmiert. Für den sui-generis Datenbankschutz steht keine entsprechende Schranke zur Verfügung und eine analoge Anwendung der vorgenannten Regeln scheidet aus. Insoweit muss also auf Rechtfertigungsgründe zurückgegriffen werden.

- Als wichtigster Rechtfertigungsgrund kommt die schlichte Einwilligung in den Fokus. Dieser Grund rechtfertigt jede urheberrechtlich relevante Nutzungshandlung, wenn die Webseite ohne technische Schutzmaßnahmen frei erreichbar und nutzbar ist.

- Eine Urheberrechtsverletzung durch Einsatz von Werbeblockersoftware scheidet also spätestens deshalb aus, dass durch Webseitenbetreiber keine technische Schutzmaßnahmen ergriffen werden, sondern der Zugang unbegrenzt ist.

(iii) Kartellrecht

Es kommen nach hier vertrener Ansicht keine kartellrechtlichen Unterlassungsansprüche in Betracht, weil kein Werbeblockeranbieter eine marktbeherrschende Stellung inne hat. Der relevante Markt ist der gesamte deutsche Onlinemarkt oder anders formuliert, die Gesamtheit deutscher Internetnutzer. Dort ist aktuell kein ausreichender Anteil der Nutzer auch zugleich aktiver Adblocker-Nutzer ${ }^{950}$. Der Kartellsenat des BGH hält hingegen den Markt der kommerziellen Werbefreischaltung auf einer Whitelist für maßgeblich und deutet an, dass der Betreiber von Adblock Plus eine marktbeherrschende Stellung haben könnte, wenn keine ausreichend effektiven Ausweichmöglichkeiten für Webseitenbetreiber existieren. Wenn die Marktbeherrschung eines Werbeblockerbetreibers festgestellt wird, ist eine tiefere Auseinandersetzung mit den Varianten des Marktmissbrauchs in $\$ 19$ GWB angezeigt. Hieraus könnten sich Unterlassungsansprüche ergeben.

950 Dies gilt nicht für die Werbeblockerfunktionalität in Google Chrome, sondern nur für Anbieter von Add-ons oder speziellen Browsern zum Werbeblocken. 
b) Ausblick nach dem Urteil Werbeblocker II

Übrig bleibt nun die Frage, welche Auswirkungen das Urteil Werbeblocker II auf das Lauterkeitsrecht speziell sowie auf Recht und Wirtschaft generell haben wird.

Insgesamt ist die liberale und fortschrittsorientierte Grundeinstellung des I. Zivilsenat des BGH sehr zu begrüßen. Im Kontext weiterer, zukünftig zu erwartender „disruptiver Technologien“ wird das UWG anscheinend keinen Innovationshemmer darstellen, solange die durch die Rechtsprechung aufgestellten Regeln beachtet werden.

Bei der Frage der geschäftlichen Handlung im Sinne des $₫ 2$ Abs. 1 Nr. 1 UWG gilt, dass das Urteil richtungsweisend für die gerichtliche Kontrolle zukünftiger „disruptiver“ Technologien sein dürfte. Das Verhältnis von Behinderungswettbewerb und zeitgleichem Angebot von Diensten an die dadurch behinderten Unternehmen ist nunmehr soweit geklärt ist, dass jedenfalls eine Prüfung nach $\$ 4$ Nr. 4 UWG möglich ist. Andernfalls könnten sich Anbieter neuer Technologien einer lauterkeitsrechtlichen Kontrolle durch ein „Freikaufangebot" an den Behinderten leicht der lauterkeitsrechtlichen Kontrolle entziehen. Im Einklang mit der Bewertung des konkreten Wettbewerbsverhältnisses auch im Fall gleichzeitiger Bewertung als sonstiger Marktteilnehmer führt dies dazu, dass die Rechtsprechung praktisch jeden Fall "disruptiver Technologieanbieter" über eine Interessenabwägung lösen wird. Dies führt aber nur auf den ersten Blick zum Risiko divergierender Entscheidungen in ähnlichen Fällen. Denn die ständige Rechtsprechung, wonach eine unlautere Einwirkung auf fremde digitale Produkte nur vorliegt, wenn eine Schutzvorkehrung unterlaufen wird $^{951}$, bildet eine zuverlässige Trennlinie erlaubten und verbotenen Handelns. Weitere Argumente wie die Nutzerautonomie können das Pendel dabei noch mehr in die eine oder andere Richtung schlagen.

Eine besonders positive Aussage im Urteil Werbeblocker II ist, dass bei technisch komplexen Werkzeugen wie Werbeblockern, deren Wirkung der durchschnittliche Nutzer ohne dieses Werkzeug nicht hätte herbeiführen können, keine Sonderbetrachtung geboten ist. Denn selbst wenn das vom Werbeblocker herbeigeführte Ergebnis über das hinausgeht, was der Nutzer ohne besondere Fähigkeiten selbst bewerkstelligen könnte, ändert

951 Vgl. BGH, Urteil vom 22.06.11 - I ZR 159/10, WRP 2011, 1469 - Automobil-Onlinebörse; Urteil vom 30.04.14 - I ZR 224/12, WRP 2014, 839 - Flugvermittlung im Internet; Urteil vom 12.01.17 - I ZR 253/14, WRP 2017, 434 - World of Warcraft II. 
dies nichts an der Autonomie der Nutzerentscheidung. Auch „technisch anspruchsvolle Produkte" wirken erst, wenn der Nutzer sie einsetzt. Dies zeigt, dass nicht der Nutzer das Werkzeug der Software ist, sondern andersherum. Beachtlich wird diese Passage insbesondere dann, wenn man sie in ihr Gegenteil verkehrt. Wenn sich der Nutzer nur leichteste Prozesse von einer Software abnehmen lassen dürfte - zum Beispiel den Vorgang des Programmwechsels bei der Fernsehfee -, würde der Einsatz leistungsstarker Computerprogramme zur Lösung neuer Probleme potentiell leichter lauterkeitsrechtlich zu untersagen. Denn wenn die Nutzerautonomie wegfiele, fiele ein starkes Argument in der Interessenabwägung zugunsten der Zulässigkeit einer solchen Software weg. Beeinträchtigende Features wären dann wohl als unmittelbare Behinderung durch den Softwareanbieter anzusehen, womit man argumentativ leichter zu einer Verdrängungsabsicht gelangen könnte. Die Zulässigkeit von Anwendungen auf Grundlage von künstlicher Intelligenz würde damit ernsthaft gefährdet. Denn die angepriesenen Möglichkeiten künstlicher Intelligenz ${ }^{952}$ stellen die Disruptivität der Internetwerbeblocker weit in den Schatten. Insoweit ist es gerade Sinn und Zweck von Computerprogrammen und Automation die Handlungsmöglichkeiten von Menschen zu erweitern. Werbeblocker II wird zum Glück keine technologiefeindliche Fundstelle, die später einmal zum Kampf gegen Disruptoren aller Art angeführt wird.

Mit Blick auf $\$ 4$ a UWG ist dem Urteil allerdings mangels Ausführungen zum Verhältnis zu den $\$ \$ 18 \mathrm{f}$. GWB sowie mangels überzeugender abstrakter Beschreibung des Merkmals der Machtposition kein Mehrwert zu entnehmen. Dies kann man, unter Ausblendung der prozessualen Belange, aus akademischer Sicht als vertane Chance bezeichnen, dem immer noch recht neuen $\$ 4$ a UWG im „richtlinienfreien“ B2B-Verhältnis Konturen zu geben.

Da das Urteil keine Aussage zu urheberrechtlichen und kartellrechtlichen Ansprüchen enthält, bleibt in dieser Hinsicht noch ein Fünkchen Hoffnung für die Webseitenbetreiber. Wie in dieser Stellungnahme allerdings ausgeführt, werden auch die Versuche Unterlassungsansprüche mit

952 Vgl. etwa https://www.cmswire.com/information-management/11-industrie s-being-disrupted-by-ai/, zuletzt abgerufen am 30.5.2019.Man stelle sich nur medizinische Diagnoseroboter vor, die auf das gesamte medizinische Wissen und Millionen von Erfahrungsberichten gleichgelagerter Krankheitssymptome in Sekundenschnelle zugreifen könnten. Dies könnte erhebliche Teile des medizinischen Sektors umwälzen. 
dem Ziel eines Totalverbots von Werbeblockers aus dem UrhG oder GWB durchzusetzen, zum Scheitern verurteilt sein.

Abseits der rein rechtlichen Sphäre ändert sich nach dem Urteil Werbeblocker II auf dem hart umkämpften Werbemarkt zunächst nichts. Die Fronten bleiben verhärtet. Werbeblocker dürfen weiterhin ihre Software vertreiben und ihre Refinanzierung durch kommerzielles Whitelisting sicherstellen. Jeder Webseitenbetreiber kann also das grundsätzlich an die Allgemeinheit abgegebene Whitelisting-Angebot annehmen. Webseitenbetreiber, die es sich leisten können (oder wohl eher wollen), werden wahrscheinlich weiterhin ihre Aussperrungstaktik gegenüber den Nutzern fortführen - wie bei der eingangs erwähnten Bild.de Sperre. Weiterhin werden Lösungen von Anti-Adblocksoftware am Markt gefragt bleiben, dies umso mehr vor dem Hintergrund, dass erst die Umgehung von Schutzmaßnahmen eine Unlauterkeit oder eine Urheberrechtsverletzung begründen kann.

Die Entscheidung fand in der Literatur durchgehend Zustimmung953. Einzig Köhler kritisiert die Ausführungen zum konkreten Wettbewerbsverhältnis im konkreten Fall und auf dogmatischer Ebene. Er mahnt dabei die Gefahr der Überdehnung dieses Tatbestandsmerkmals an und hätte es vorgezogen, dieses im Streitfall abzulehnen ${ }^{954}$. Diese Kritik richtet sich aber zugleich gegen die ständige Rechtsprechung des I. Zivilsenats des $\mathrm{BGH}$, sodass diese Kritik weniger fallspezifisch als grundlegend dogmatisch zu bezeichnen ist.

\section{c) Ausblick nach dem Urteil Werbeblocker III}

Da der Kartellsenat des BGH durch seine Urteile noch einmal Schwung in die an sich beendet geglaubte Diskussion um die Internetwerbeblocker brachte, ist auch hier nach den Folgen der Urteile für Recht und Wirtschaft zu fragen.

Deutlich ist bei Werbeblocker III, dass die Entscheidung schon gar nicht mehr das Totalverbot von Werbeblockern thematisiert, sondern spezifisch das Geschäftsmodell des entgeltlichen Whitelistings beleuchtet. Falls im weiteren Verlauf des Verfahrens das Angebot von Adblock Plus in der angegrif-

953 Alexander, NJW 2018, 3620; Kiersch, GRUR-Prax 2018, 487; Glöckner, ZUM 2018, 844; Scherer, WRP 2019, 1; Hoeren/Brandenburg, MMR 2018, 821; Köhler, GRUR 2019, 123.

954 Köhler, GRUR 2019, 123, 126f.. 
fenen Form verboten wird, wird dies allenfalls Details betreffen. Allerdings ist ein Prozessverlust für den Werbeblockerbetreiber keineswegs eindeutig. So könnte das OLG München angesichts der Segelanweisungen aus Karlsruhe auch zu dem Ergebnis kommen, dass der Markt bereits ausreichend über effektive Zugangsbeschränkungen und Anti-Adblocker-Lösungen verfügt, sodass Webseitenbetreiber bei der Erreichung von Werbeblockernutzern als Adressaten ihrer Werbeanzeigen tatsächlich die Wahl aus einer Vielzahl von Angeboten haben. Nur wenn es gerichtlich festgestellt wird, dass diese Alternativmaßnahmen faktisch untauglich sein sollten, kommt eine marktbeherrschende Stellung des Werbeblockerbetreibers in Betracht. So oder so werden die zu erwartenden Urteile nur das konkret angegriffene Werbeblockergeschäftsmodell betreffen und demnach bei Abweichungen im Geschäftsmodell nicht unbedingt übertragbar sein.

Auch bei der sich ggf. anschließenden Prüfung der unbilligen Behinderung nach $₫ 19$ Abs. 2 Nr. 1 GWB und der vom BGH geforderten kartellrechtsspezifischen Interessenabwägung ist keinesfalls eindeutig, dass die Interessen des klagenden Webseitenbetreibers bzw. des Wettbewerbs als höherwertig einzuschätzen sind. So dürften die Acceptable Ads Kriterien bei Adblock Plus durchaus von einem Nutzerwunsch gedeckt und die verlangte Vergütung für die Freischaltung nicht bloß als Bereicherung aus der selbst geschaffenen Blockade anzusehen sein. Die Vergütung scheint bei Beachtung der komplexen und dynamischen technischen Materie auch zur Deckung der Kosten für die Produktpflege notwendig zu sein.

Im größeren Kontext ist Werbeblocker III als Indiz dafür zu sehen, dass der Kartellsenat des BGH neben dem Bundeskartellamt den Bereich der Digitalwirtschaft mit Argusaugen betrachtet. Während die großen TechPlattformen wie Google, Facebook und Amazon jedoch eine mehrere Fachbereiche umfassende Marktmacht für sich beanspruchen können (z.B. Google bei Suchmaschinen, Betriebssystemen für Smartphones, OnlineWerbung, Kartendiensten und als Videoplattform) und deshalb zu Recht unter strenger Beobachtung stehen, handelt es sich beim Betreiber von Adblock Plus bei Lichte betrachtet um eine Beherrscher einer Nische. Dass sich der Kartellsenat an dieser Stelle sehr streng zeigt, verkehrt die allgemein wirtschaftliche Bedeutung der Streitparteien in ihr Gegenteil. Denn der Werbeblockerbetreiber ist im Verhältnis zum Axel Springer Konzern, zur RTL Gruppe oder zur ProSiebenSat1-Gruppe eher als „kleiner Fisch“ anzusehen. Zugleich nimmt der erst 2019 neu gegründete Kartellsenat ${ }^{955}$

955 Siehe https:/www.bmjv.de/SharedDocs/Pressemitteilungen/DE/2019/090219_Z ivilsenat_BGH.html, zuletzt abgerufen am 27.6.2020. 
seine Pflicht als richterlicher Wettbewerbshüter sehr ernst wie etwa eine Entscheidung zu einer missbräuchlichen Ausnutzung einer marktbeherrschenden Stellung durch Facebook im Bereich des Datenschutzrechtes zeigt $^{956}$. Es wird spannend sein, zu beobachten, ob dieser Kampf gegen Marktmissbrauch im Bereich der Digitalwirtschaft langfristig Erfolge für die Verbraucher und den Markt erzielt.

\section{d) Übersicht und Bewertung von mit Werbeblockern vergleichbaren Phänomenen}

Bevor der BGH nunmehr Internetwerbeblocker sowohl in Form reiner Blacklistblocker als auch in Form kommerzieller Whitelistblocker als zulässig ansah, attestierte er schon dem Screen Scraping die lauterkeitsrechtliche Zulässigkeit ${ }^{957}$. Screen Scraping stellt sozusagen die Basis der bekannten Vergleichsportale für Hotels, Flüge und allerlei sonstige Waren und Dienstleistungen dar. Es beruht auf der Auslesung öffentlich verfügbarer (Preis-)Informationen und dient der sich anschließenden besonderen Aufbereitung für den Nutzer. Während der BGH im Lauterkeitsrecht wegen der Zuordnung zum B2B-Bereich die Auslegungshoheit hat, stellen sich im Rahmen des Urheberrechts, insbesondere beim Datenbankerstellerrecht, durchaus Auslegungskonflikte mit der Rechtsprechung des $\mathrm{EuGH}^{958}$. Da nach dem Urteil Flugvermittlung im Internet jedoch erkennbar keine neuen Versuche von Betroffenen des Screen Scraping in Deutschland unternommen worden sind, die Vergleichsportale gerichtlich zu bekämpfen, besteht wohl keine Zuversicht, dass die deutsche Rechtsprechung sich den EuGH-Urteilen in Innoweb/Wegener ${ }^{959}$ oder Ryanair ${ }^{960}$ anschließen wird. Ökonomisch betrachtet ist die Implementierung von CAPTCHAs ${ }^{961}$, den wohl jedem Leser bekannten verfremdeten Zeichen-

956 Vgl. BGH Beschluss vom 23.6.2020, KVR 69/19.

957 Vgl. BGH, Urteil vom 22.06.11 - I ZR 159/10, WRP 2011, 1469 - Automobil-Onlinebörse; Urteil vom 30.04.14 - I ZR 224/12, WRP 2014, 839 - Flugvermittlung im Internet.

958 Vgl. Schapiro/Żdanowiecki, MMR 2015, 497.

959 EuGH, Urteil vom 19.12.2013 - C-202/12, GRUR 2014, 166.

960 EuGH, Urteil vom 15.1.2015 - C-30/14, GRUR 2015, 253.

961 Abkürzung für „completely automated public Turing test to tell computers and humans apart", vgl. https://de.wikipedia.org/wiki/Captcha, zuletzt abgerufen am 30.5.2019. 
folgen oder den Bilderrätseln, durchaus sinnvoller, als Prozesse über drei Instanzen zu führen und zu finanzieren.

Auch die urheberrechtlichen Urteile des BGH in Vorschaubilder I962 und $I I^{963}$ lassen sich in die Riege liberaler Entscheidungen in invasiven Internetsachverhalten einreihen. Die Gewährung einer schlichten Einwilligung zugunsten der Nutzer und zulasten der Rechteinhaber beim Fehlen technischer Schutzmaßnahmen trägt ebenfalls die These, dass das Immaterialgüter- und Lauterkeitsrecht nicht der taugliche Weg zur Begrenzung von Geschäftsmodellen im Internet ist, sondern nur in ausnahmsweise vorliegenden Umgehungssachverhalten eingreifen soll. So geschehen etwa in World of Warcraft II, wo Botprogramme für das Computerspiel nur unter Verstoß gegen wirksame AGB eingesetzt werden können ${ }^{964}$. Ähnlich ist die Argumentation auch beim urheberrechtlichen Urteil Session $I D^{965}$. In diesem Fall bestand die technische Absicherung eines Onlinekartendienstes darin, bei Zugriff auf die Startseite eine zeitlich befristete Session-ID zu speichern. Die Beklagte nutzte auf ihrer externen Webseite ein Skript, das einen an sich nicht vorgesehenen Direktlink zu dem Kartendienst herstellte. Unter Umgehung der Startseite ermöglichte dies dann den Aufruf eines bestimmten Orts im Kartendienst. Der BGH stellt dabei ausdrücklich klar, dass eine technische Schutzmaßnahme nicht wirksam im Sinne von $\$ 95$ a UrhG sein müsse. Jede Schutzmaßnahme, die im Normalfall funktioniert, ist also ausreichend. Demnach kann der Einsatz bestimmter Skripte in der Internetkommunikation zu einer Täterschaft bzw. Störereigenschaft für eine rechtswidrige öffentliche Zugänglichmachung gem. $\mathbb{\$} 19$ a UrhG führen.

Zur Zeit der Bearbeitung sind zudem weitere digitalen Phänomene verbreitet, die sich an der „Schutzmaßnahmendoktrin“ des BGH messen lassen müssen. Eines dieser Phänomene sind Social Bots ${ }^{966}$. Social Bots sind

962 BGH, Urteil vom 29.4.2010 - I ZR 69/08, GRUR 2010, 628 - Vorschaubilder I.

963 BGH, Urteil vom 19.10.2011 - I ZR 140/10, GRUR 2012, 602 - Vorschaubilder II.

964 BGH, Urteil vom 12.1.2017 - I ZR 253/14, WRP 2017, 434 - World of Warcraft II. Die Verwendung von Bots, die im Streitfall automatisiert Quests erfüllen und Items sammeln und somit den Nutzeraccount verbessern können, war in den Spielregeln ausdrücklich untersagt. Das BGH sah ein schützenswertes wirtschaftliches Interesse des Spieleherstellers, dass sich alle Spieler an die Spielregeln halten, und hielt die rechtliche Absicherung des Verbots für ausreichend.

965 BGH, Urteil vom 29.4.2010 - I ZR 39/08, GRUR 2011, 56 - Session ID.

966 Vgl. zur politischen Debatte um Social Bots, http://www.spiegel.de/netzwelt/w eb/social-bots-die-elektronische-sau-im-dorf-a-1244141.html, zuletzt abgerufen am 30.5.2019. 
von Menschen programmierte Computerprogramme, die eine menschliche Identität vortäuschen und zu manipulativen Zwecken eingesetzt werden, indem sie wie Menschen im Internet kommunizieren ${ }^{967}$. Unternehmen, die Social Bots in sozialen Netzwerken benutzen wollen, müssen zunächst prüfen, ob die Nutzungsbedingungen der Dienste, einen solchen Einsatz erlauben. Twitter untersagt etwa den Zugriff auf die Dienste mit automatisierten Mitteln, die nicht von Twitter verfügbar gemacht oder veröffentlicht worden sind. Zudem dürfen keine veränderten oder irreführenden Informationen unter Angabe falscher Quellen versendet werden. Interessant ist auch das Verbot, durch Skripting Inhalte zu erstellen, die die Dienste ungebührlich beeinträchtigen oder belasten ${ }^{968}$. Damit könnten Bots zumindest in einem gewissen Teil ihres denkbaren Wirkspektrums auf Twitter nicht lauter eingesetzt werden. Bei Facebook darf nicht mittels automatisierter Methoden auf Daten der Facebook Produkte zugegriffen und solche Daten dürfen nicht erfasst werden ${ }^{969}$. Dies steht einer Nutzung von „freundlichen“ Social Bots im Grundsatz nicht entgegen. Allerdings sind die Nutzungsbedingung von Facebook ihrem gesamten Duktus nach auf menschliche Nutzer angelegt, sodass die Anlegung und der Betrieb eines reinen Bot-Accounts (etwa für eine Art automatisierten Influencer), hinter dem keine natürliche Person bzw. ein Unternehmen steht, rechtlich kritisch zu bewerten ist. Neben diesen rechtlichen Schutzmaßnahmen sind keine technischen Schutzmaßnahmen gegen Social Bots erkennbar. Ein lauterkeitsrechtlich zulässiger Einsatz von Social Bots zur Unterstützung des eigenen Werbeauftritts in sozialen Medien durch „bot-generated Content" ist also nicht ausgeschlossen.

Ein weitere Software, die lauterkeitsrechtlich relevant werden könnte, ist das im Nachgang des Cambridge Analytica Skandals ${ }^{970}$ von Mozilla veröffentlichte Add-On namens „Facebook Container“. Mozilla erklärt die Idee dieser Browsererweiterung wie folgt:

967 Libertus, ZUM 2018, 20.

968 https://twitter.com/de/tos, abgerufen am: 9.1.2019.

969 https://de-de.facebook.com/legal/terms/, abgerufen am 9.1.2019. Interessanterweise war in der Vorgängerversion der Nutzerbedingungen noch ein Passus enthalten, wonach der Zugriff auf Facebook mithilfe automatisierter Methoden (wie Bots, Roboter, Spider oder Scraper) nur mit vorheriger Genehmigung erlaubt war.

970 Vgl. https://netzpolitik.org/2018/cambridge-analytica-was-wir-ueber-das-groe sste-datenleck-in-der-geschichte-von-facebook-wissen/, zuletzt abgerufen am 30.5.2019. 
„[...] Facebook verfügt daher über ein Netzwerk von Tracking-Tools auf verschiedenen Webseiten. Deren Code verfolgt Sie unsichtbar und es ist dadurch fast unmöglich, nachzuvollziehen, wann die so gesammelten Daten mit anderen geteilt werden.

Der Facebook Container isoliert Ihre Facebook-Identität vom Rest Ihrer Internetaktivitäten. Nach der Installation können Sie Facebook weiterhin ganz normal nutzen und auch Facebook kann umgekehrt seine Dienste wie gewohnt für Sie bereitstellen und Ihnen Werbung anzeigen. Der wesentliche Unterschied besteht darin, dass es für Facebook deutlich schwieriger wird, Ihre gesammelten Aktivitäten außerhalb von Facebook zu nutzen, um Ihnen Anzeigen und andere personalisierte Nachrichten zu senden.

Das Add-On bietet eine Lösung, die nicht einfach darin besteht, Nutzern grundsätzlich von einem Service abzuraten, der ihnen einen Mehrwert bietet. Stattdessen gibt es den Usern ein Werkzeug an die Hand, um sich proaktiv vor unerwünschten Nebenwirkungen eben dieser Nutzung zu schützen." ${ }^{\text {991 }}$

Dies führt zu einer ähnlichen Interessenlage wie bei den Internetwerbeblockerfällen. Wie die Webseitenbetreiber ein Interesse an der Ausspielung von Werbung haben, hat Facebook ein Interesse daran, möglichst viele Daten zu erlangen. Beweis dafür sind die vielfältigen Möglichkeiten des Verhalten-Targeting für Werbung auf Facebook ${ }^{972}$. Wenn der Nutzer nun über eine Browsererweiterung dieses Sammeln von Daten einseitig beendet und diese Erweiterung auf einen bestimmten Dienst beschränkt ist, liegt die Möglichkeit einer unlauteren Behinderung nicht ganz fern. In einer Interessenabwägung würde auch hier die Umgehung von technischen und rechtlichen Schutzmaßnahmen durch den Facebook Container - hier mit Blick auf die Datensammlung - zu prüfen sein. Soweit die Nutzungsbedingungen nicht ausdrücklich und rechtlich wirksam die Berechtigung zum Sammeln von Daten, etwa als Gegenleistung für die Nutzung der Dienste, beinhalten, läge keine rechtliche Schutzmaßnahme vor. Mangels genauer technischer Beschreibung der Wirkweise der Software kann die Betroffenheit technischer Schutzmaßnahmen nicht verlässlich beurteilt werden. Es liegt allerdings fern, dass das Tracking von Nutzern, das selbst außerhalb der eigenen Plattform über Social Media Buttons und

971 https://blog.mozilla.org/press-de/2018/03/27/mit-unserem-neuen-add-on-faceb ook-container-surfen-sie-offen-und-vernetzt-nach-ihren-eigenen-regeln/, zuletzt abgerufen am 30.5.2019.

972 Siehe oben Ziffer B. I. 4. a). 
sonstige Skripten funktioniert, über den Akt der Datengenerierung hinaus einen Schutzmechanismus aufweist. Angereichert mit dem Argument der Nutzerautonomie wird man wohl auch bei Facebook Container zu einer lauterkeitsrechtlichen Zulässigkeit gelangen.

Zuletzt ist noch denkbar, dass sich lauterkeitsrechtliche Streitigkeiten im Zusammenhang mit cloudbasierten Lösungen, im Bereich des Software-as-a-service („SaaS“) und des Application Service Providing („ASP“) entwickeln können. Denn bei all diesen Arten von modernen, digitalen Dienstleistungen steht im Vordergrund, dass fremde Server genutzt werden, auf welchem Computerprogramme oder Speicherungsvorgänge ablaufen. Die Nutzer geben also Anfragen und erhalten Arbeitsergebnisse über die Internetkommunikation. Dies eröffnet theoretisch wie beim digitalen Werbeblocken Spielräume zur Modifikation der eigentlich vom Anbieter intendierten Leistung. Die Frage in diesem Bereich ist, ob der Nutzer einer Saas-Lösung auf seinem Clientrechner die vorprogrammierten Abläufe hinnehmen muss oder er bei technischer Möglichkeit filtern, modifizieren oder hinzufügen darf. Dies wird wiederum stark von den vertraglichen Regelungen abhängig sein. Doch das potentielle Hineinbegeben eines Dritten in die Verbindung zwischen Anbieter und Nutzer birgt erhebliches Streitpotential.

e) Leitlinien für zukünftige disruptive Geschäftsmodelle im Internet

Zusammenfassend lassen sich aus dem Urteil Werbeblocker II und den einschlägigen Vorgängerurteilen des BGH für den Bereich des Lauterkeitsrechts maßgeblich die folgenden Leitlinien für zukünftige disruptive Geschäftsmodelle im Internet folgern:

- Vertragliche Bedingungen im Verhältnis Nutzer und Leistungsanbieter dürfen durch eigene Leistungen, Anwendungen oder Produkte nicht unterwandert werden. Das Interesse der Unverfälschtheit der primären Leistung wiegt schwer, wenn es Gegenstand einer Vereinbarung ist.

- Technische Schutzmaßnahmen, selbst wenn sie leicht zu umgehen sind, müssen respektiert werden. Die Umgehung von technischen Schutzmaßnahmen, etwa die Ausschaltung von CAPTCHAs bei Screen Scraping durch Skripte, führt wohl im Regelfall zur Annahme einer gezielten Behinderung. Das Interesse des Leistungsanbieters an der Übertragung der Leistung in einer bestimmten Art und Weise wiegt bei Anwendung von Schutzmaßnahmen schwer. 
- Wenn Leistungen hingegen schutzlos angeboten werden und für jedermann frei verfügbar sind, sind eigene darauf aufbauende wettbewerbliche Leistungen regelmäßig nicht zu beanstanden.

- In Dreipersonenverhältnissen wie bei Werbeblockern kommt der Nutzerautonomie eine herausragende Stellung zu, da ohne den Einsatz durch den Nutzer keine Verletzung eintreten würde. Die Nutzerautonomie wird hingegen nicht die Umgehung von technischen oder vertraglichen Schutzmechanismen rechtfertigen.

- Grundrechte schützen Leistungsanbieter nicht vor innovativem Wettbewerb. Insbesondere können sie nicht den Schutz eines zuvor praktizierten Geschäftsmodells bewirken, wenn keinerlei Anstrengung zum Schutz des Geschäftsmodells durch bekannte technische oder vertragliche Schutzmaßnahmen zu erkennen ist.

Innerhalb dieser Grenzen ist ein gesunder Wettbewerb im Internet gewährleistet. Flankiert werden diese lauterkeitsrechtlichen Grenzen durch das Urheberrecht und das Kartellrecht, in welchen insbesondere auch die Nichtvornahme von Schutzmaßnahmen Bedeutung erlangt.

5. Beurteilung bislang nicht in der Rechtsprechung behandelter Fälle von Werbeblockern

Im Laufe der Darstellung ${ }^{973}$ wurden einzelne Fälle von Werbeblockern oder gleichwirkenden Handlungen idnetifiziert. Diese sollen nun vor dem Hintergrund des zu Filterwerbeblockern heraugearbeiteten Ergebnisses bewertet werden.

\section{a) Bereitstellung von Blacklists aller Art}

Die Urteile beziehen sich allesamt auf das Angebot der Blockiersoftware. Zumeist wird jedoch im Tatbestand klargestellt, dass Filterwerbeblocker ohne die entsprechenden Filter keine Funktionalität haben. Deshalb liegt es nahe, kurz über die Zulässigkeit der Anfertigung und Pflege von Filterlisten nachzudenken.

Die Filterlisten sind maßgeblicher Teil der Funktionalität der Filterwerbeblocker. Sie sind sozusagen die Munition für die „Waffe Werbeblocker“. Aus diesem Grund wird man das Angebot von Filterlisten lauterkeitsrecht-

973 Siehe oben Ziffer C. I. 3. i). 
lich genauso wie die Werbeblockersoftware bewerten müssen. Da das Angebot von Filterwerbeblocker aus den oben dargestellten Gründen zulässig ist, gilt dies auch für das Angebot der Blacklists.

Nichts anderes kann für die Bereitstellung von Blacklists für Netzwerkrouter wie einen heimischen W-Lan Router gelten. Es kommt nicht darauf an, ob die Blockade von einer Software im Clientrechner oder von einem in den IP-Kommunikationsvorgang eingebundenen, durch den Nutzer kontrollierten Gerät bewerkstelligt wird. Aus diesem Grund ist auch die Bereitstellung von Host-Dateien für ein Betriebssystem, das derart modifziert ist, dass bestimmte Werbung per se blockiert wird, nicht $\mathrm{zu}$ beanstanden. Wiederum kommt es nicht an, ob das Betriebssystem oder eine Applikationssoftware für den Blockiervorgang verantwortlich ist. Eine funktionale Betrachtung ist notwendig und führt zur Gleichbehandlung dieser Fälle.

\section{b) Browser mit integriertem Werbeblocker}

Das Angebot von Browsern mit integriertem Werbeblocker ist grundsätzlich nicht anders zu bewerten als das Angebot bloßer Browsererweiterungen. Dies stellt im Ausgangspunkt ein erlaubtes rechtliches Handeln dar. Ein tatsächlicher Unterschied liegt allerdings darin, dass eine Browsererweiterung aktiv installiert werden muss. Beim Browser mit integriertem Blocker ist dieser willentliche Akt des Nutzers nicht so eindeutig. Er kann leicht angenommen werden, wenn ein eigens mit dieser Funktion beworbener Browser gewählt wird. So etwa beim Adblock Browser von Eyeo für mobile Geräte ${ }^{974}$ oder den Opera Webbrowser ${ }^{975}$, die diese Funktion im Namen nutzt oder eindeutig bewirbt.

Anders könnte sich der Fall aber darstellen, wenn der integrierte Werbeblocker nicht besonders beschrieben oder beworben, sondern eher beiläufig als Funktion des Browsers enthalten ist. Hier verliert das Argument der Nutzerautonomie bedeutend an Gewicht. In diesem Kontext sind durchaus Einzelfälle denkbar, in welchen die Nutzerautonomie gar durch eine Irreführung in ihr Umteil verkehrt werden könnte. Abgesehen von Ansprüchen aus $\$ \$ 5$, 5a UWG könnte dies auch im Rahmen der Interessenabwägung in der gezielten Behinderung bedeutsam werden. Die komplexe

974 https://adblockbrowser.org/de/, zuletzt abgerufen am 30.5.2019.

975 https://www.opera.com/de/computer/features/ad-blocker, zuletzt abgerufen am 30.5.2019. 
Interessenlage aus grundrechtlich geschützten Interessen, insbesondere der Medienfreiheiten, würde erheblich anders zu beurteilen sein, wenn die Nutzer nicht bewusst pro Werbeblockade entschieden, sondern diese mehr oder minder bloß akzeptieren würden. Hieran änderte auch nichts, wenn bei dem Browser ebenso wie in den oben skizzierten Fallgestaltungen keine technischen oder rechtlichen Schutzmaßnahmen unterlaufen werden.

Des weiteren dürfte es wohl entscheidend sein, ob mit dem werbeblockenden Browser allein eine Blacklist oder ein kommerzielles Whitelisting verfolgt würde. Ersteres wäre wohl noch eher zu hinzunehmen als ein verstecktes kommerzielles Whitelisting.

\section{c) Sonderfall 1: Coalition for Better Ads}

Und dann ist da noch die Coalition for Better Ads. Diese von Google und Facebook federführend regierte Koalition machte mit der Einfügung eines Werbeblockers in den weit verbreiteten Browser Google Chrome auf sich aufmerksam. Dieser Blocker wurde durch automatisches Softwareupdate im Februar 2018 ohne Zutun des Nutzers installiert und standardmäßig scharf gestellt. In technischer Hinsicht ist der Blocker ein Filterwerbeblocker, sodass der Fall sich technisch nur unwesentlich von den Adblock Plus Fällen unterscheidet. Die wirtschaftlichen Rahmenumstände sind aber erheblich verschieden: Zur Zeit der Einführung am Browser verfügte Google Chrome über ca. 40\% Marktanteil bei Browser auf Desktop-PCs sowie von ca. 50\% auf mobilen Endgeräten. Die Markteinführung wurde von einer Aufforderung an vorab ermittelte Webseitenbetreiber mit „bad ads" begleitet, die „Better Ads“-Kriterien anzuwenden und somit die Totalblockade zu vermeiden. Wenn nur eine einzige nicht den Kriterien entsprechende Werbeanzeige auf der Webseite erkannt wird, erfolgt ein Blockade jeglicher, auch konformer Werbeelemente ${ }^{976}$.

Diese wirtschaftlichen Rahmenbedingungen könnten zu einer anderen Beurteilung der lauterkeitsrechtlichen Zulässigkeit nach $\$ 4$ Nr. 4 UWG und $\mathbb{\$} 4 \mathrm{a}$ UWG sowie der kartellrechtlichen Zulässigkeit nach $\mathbb{S} \mathbb{S} 18 \mathrm{ff}$. GWB haben.

Bei der Interessenabwägung in der Prüfung einer gezielten Behinderung nach $₫ 4$ Nr. 4 UWG wird hier der zuvor genannte Umstand virulent, dass keine nutzerautonome Entscheidung für den Werbeblocker erkennbar ist. Durch das standardmäßige Update und die automatische Scharfstellung

976 Siehe oben Ziffer C. I. 2. b) bb) (ii). 
des Werbeblockers müsste der Nutzer aktiv den Werbeblocker ausschalten, um seine Wirkung zu verhindern. Nun ist es freilich schwierig zu bewerten, ob ein unterlassener Opt-out auf Nutzerseite eine autonome Entscheidung oder eher Ausdruck von Unkenntnis oder Ignoranz ist. Das in den Adblock Plus Rechtsstreiten jedoch als sehr stark gewertete Argument der autonomen Nutzerentscheidung pro Werbeblocker tritt an dieser Stelle allerdings stark in den Hintergrund, wenn es nicht sogar gesamt zu verwerfen ist. Allerdings ist auf der anderen Seite zu beachten, dass der Kriterienkatalog der Coalition for Better Ads erheblich liberaler ist und deshalb erheblich weniger auf die Einnahmensituation für Webseitenbetreiber einwirkt. So ist beispielsweise Bild.de mit aktiviertem Google Chrome Werbeblocker problemlos aufzurufen und dort findet keine Werbeblockade statt. Das weniger an Nutzerautonomie wird demnach durch den geringer invasiven Einschnitt in die Finanzierungsverflechtungen der Online-Werbung wettgemacht. Technische oder rechtliche Schutzmaßnahmen werden ebenfalls nicht unterlaufen. Da der Chrome-Blocker mithin nur beim Vorliegen enorm unbeliebter Werbeelemente eingreift, ist das Behinderungspotential als gering anzusehen. Allein der Umstand, dass bei Einfügung nur einer einzigen inakzeptablen Werbeform auf einer Webseite eine Totalblockade wirksam wird, ist kritisch zu betrachten. Hier wird man aber den Webseitenbetreibern, die unbedingt solche Werbeanzeigen ausspielen wollen, wie bei den Adblock Plus Fällen zur Selbsthilfe durch technische oder rechtliche Schutzmaßnahmen raten müssen. Dies ist auch in dieser Fallgestaltung zumutbar.

Bei der Prüfung der aggressiven Geschäftspraktik im Vertikalverhältnis von Google zu von einer Totalblockade betroffenen Webseitenbetreibern gelten ebenfalls die gleichen Maßstäbe wie bei Adblock Plus. Bei der Prüfung der unzulässigen Beeinflussung kommt es im Ergebnis wieder darauf an, ob der betroffene Webseitenbetreiber noch informiert und frei entscheiden kann. Es ist nicht ersichtlich, dass dies in dieser Fallgestaltung anders zu bewerten wäre.

Allerdings ist bei der kartellrechtlichen Bewertung ein Unterschied zu erkennen ${ }^{977}$. Denn Google wird durch seinen Browser Chrome und die enorme Marktdurchsetzung von mehr als 40\% wohl als marktbeherrschendes Unternehmen im Sinne von $\mathbb{1} 18$ Abs. 1, 4 GWB anzusehen sein. Damit sind die in $\$ 19$ GWB genannten Verhaltensweisen verboten. Während eine Behinderung nach $\mathbb{\$} 19$ Abs. 2 Nr.1 Alt. 1 GWB im Einklang mit

977 Kiersch, GRUR-Prax 2018, 487, deutet ebenfalls kurz in diese Richtung ohne weitergehende Aussagen zu treffen. 
der Bewertung nach $₫ 4$ Nr. 4 UWG wohl noch abzulehnen ist, könnte eine ungerechtfertigte Ungleichbehandlung gemäß $₫ 19$ Abs. 2 Nr. 1 Alt. 1 GWB vorliegen. Allerdings greift die Blockade nach aktuellem Kenntnisstand nur bei Einsatz von Werbeelementen, die gegen die Freigabekriterien verstoßen. Da die Kriterien für alle Webseitenbetreiber gleich gelten, wird wohl nicht diskriminiert. Eine solche Diskriminierung wäre somit allenfalls über die geforderten monetären Entgelte denkbar. An dieser Stelle wird auch $\mathbb{1 9}$ Abs. 2 Nr. 2 GWB bedeutsam. Denn die Coalition for Better Ads schafft anders Adblock Plus mit seinem kommerziellen Whitelisting keinen neuen Markt. Vielmehr hält sie den bestehenden Markt „sauber" und blockiert nur Störer dieser Ordnung. Damit lässt sich die Forderung von Entgelten für die Nichtblockade nicht damit rechtfertigen, dass eine messbare Leistung erbracht wird. Deshalb scheint die Koalition Mitgliedsbeiträge zu fordern ${ }^{978}$. Es ist nicht ersichtlich, dass die Mitgliedschaft in der Koalition zur Abwendung von Werbeblockaden notwendig ist. Sollte dies allerdings der Fall sein oder werden, wird $\$ 19$ Abs. 2 S. 2 GWB wohl zumindest diskutabel sein.

Alles in allem ist jedoch von einer Zulässigkeit der Werbeblockeraktionen der Coalition for Better Ads bzw. von Google Chrome auszugehen. Durch die wohl anzunehmende marktbeherrschende Stellung bewegt sich die Koalition jedoch auf erheblich dünnerem Eis als etwa der Betreiber von Adblock Plus.

\section{d) Sonderfall 2: Ersetzung von Werbeelementen}

Einen radikalen Sonderweg schlägt der Webbrowser „Brave“ ein. Brave wirbt damit, dass der Browser alle Arten von Werbung und Trackern weitestmöglich blockiert. Der Browser tut sich zudem damit hervor, dass er mit einer eigenen Kryptowährung - dem Basic Attention Token („BAT“) - ein Micropayment System für Webseitenbetreiber etablieren möchte ${ }^{979}$. Neu ist, dass Brave anstelle der blockierten Werbung andere Werbeelemente aus einem eigenen Netzwerk mit Werbekunden anzeigen möchte. Eine entsprechende Testphase begann im Juni 2018 mit Freiwilligen. Das

978 Zwischen 20.000 und 100.000 USD, vgl. https://digiday.com/mobile/coalition-b etter-ads-experiences-european-growing-pains/, zuletzt abgerufen am 30.5.2019.

979 https://brave.com/, zuletzt abgerufen am 30.5.2019. 
System soll gemeinsam mit der BAT Kryptowährung einen neuen Schritt in der Vergütung von kleineren Publishern darstellen ${ }^{980}$.

Dieses System stellt eine ähnliche Art der Kommerzialisierung wie das kommerzielle Whitelisting bei Adblock Plus dar. Allerdings könnte die Ersetzung von Werbeplätzen mit anderen Werbeelementen rechtlich anders zu beurteilen sein. Im konkreten Fall von Brave scheint die Ersetzung von Werbeelementen streng an der Zustimmung der Nutzer ausgerichtet zu sein, was mit einer transparenten Erklärung einhergeht. In diesem Fall wird der Fall im Ergebnis nicht anders zu bewerten sein wie das kommerzielle Whitelisting. Denn hier wie dort erfolgt jegliche Anpassung der Webseiten im Nutzergerät. Ob der Nutzer in seiner Sphäre nun aber gar keine Werbung, nur Acceptable Ads oder eben nur Werbelemente aus dem Pool eines von ihm ausgewählten Dritten (hier: Brave) angezeigt erhalten möchte, ändert nach hier vertretener Ansicht nichts an der lauterkeitsrechtlichen Bewertung ${ }^{981}$.

Etwas anderes sind die sogenannten „Ad Injections"982, bei denen im Bereich der Intermediäre in der Echtzeitwerbeausspielung manipuliert wird. Durch den mehrstufigen und hoch automatisierten Vorgang der Ausfüllung von Werbeplätzen auf einer Webseite existiert ein hohes Betrugspotential. So können Werbeplätze durch bestimmte Computerprogramme gekapert werden. Diese Computerprogramme können als unerkannte Malware auf den Rechner des Nutzers gelangen und dann neben der Ad Injection auch erhebliche Cybersicherheitsrisiken darstellen ${ }^{983}$.

$\mathrm{Zu}$ Recht werden Ad Injections als gezielte Behinderung von Webseitenbetreibern angesehen, wenn die Installation des Ad Injectors nicht ausdrücklich auf dem Willen der Nutzer basiert ${ }^{984}$. Dasselbe wird man auch für Werbenetzwerke als Betroffene annehmen müssen. Webseitenbetreiber können durch Ad Injections auch gezielt behindert werden und zwar insbesondere dann, wenn sie trotz der Ersetzung im Nutzergerät im Abrechnungsprozedere der Ausspielung für tatsächlich nicht rezipierte Werbung zahlen müssen.

980 https://brave.com/brave-launches-user-trials-for-opt-in-ads/, zuletzt abgerufen am 30.5.2019.

981 Urheberrechtliche Probleme sind ebenfalls wie bei Adblock Plus zu bewältigen. Kartellrechtliche Ansprüche liegen wegen der geringen Marktverbreitung von Brave fern.

982 Zimprich/Jeschke, MMR 2016, 300.

983 Zum Beispiel die Malware „Superfish“, https://en.wikipedia.org/wiki/Superfish, zuletzt abgerufen am 30.5.2019.

984 Zimprich/Jeschke, MMR 2016, 300. 
e) Werbeblockade auf Ebene der Internet Service Provider

Im Weiteren ist auf die Zulässigkeit der Werbeblockade auf der Infrastrukturebene durch Internet Service Provider einzugehen ${ }^{985}$. Abgesehen von den wiederkehrenden Problemen lauterkeitsrechtlicher, urheberrechtlicher und kartellrechtlicher Art ist hier der Grundsatz der Netzneutralität betroffen. Es lohnt insoweit eine kurze rechtliche Betrachtung dieses Stichworts und ob dies im deutschen Recht ein Verbot von Werbeblockade auf der Infrastrukturebene stützen kann.

Der Grundsatz der Netzneutralität manifestiert sich durch die europäische Verordnung 2015/2120 über Maßnahmen zum Zugang zum offenen Internet. Der Begriff der Netzneutralität lässt sich weiter in übermittlungsbezogene und zugangsbezogene Netzneutralität trennen. Mit übermittlungsbezogener Netzneutralität ist die Gleichbehandlung aller Datenpakete bei der Einspeisung in das Netz und der Leitung durch das Netz gemeint. Der Begriff der zugangsbezogenen Netzneutralität meint dagegen die den Nutzern gleichermaßen offenstehende Möglichkeit, das Netz für ihre Zwecke zum Empfang und Versenden von Daten ihrer Wahl zu nutzen ${ }^{986}$. Für die Betrachtung einer Werbeblockade durch Internet Service Provider ist die übermittlungsbezogener Netzneutralität von Belang. Die damit einhergehenden Pflichten und erlaubten Verhaltensweisen der Provider werden maßgeblich durch Art. 3 Abs. 3 der VO (EU) 2015/2120 festgelegt. Demnach haben Anbieter von Internetzugangsdiensten den gesamten Verkehr bei der Erbringung von Internetzugangsdiensten gleich zu behandeln, insbesondere frei von Diskriminierungen persönlicher, inhaltlicher oder technischer Art. Erlaubt sind angemessene Verkehrsmanagementmaßnahmen. Diese müssen aber transparent, nichtdiskriminierend sowie verhältnismäßig sein und dürfen nicht auf kommerziellen Erwägungen beruhen. Insbesondere dürfen sie nicht bestimmte Inhalte, Anwendungen oder Dienste - oder bestimmte Kategorien von diesen - blockieren, wenn keiner der restriktiven Erlaubnisgründe in Art. 3 Abs. 3 Uabs. 3 lit. a) - c) vorliegt.

Eine Werbeblockade, die wirkungsäquivalent zu Adblock Plus wäre, würde mit hoher Wahrscheinlichkeit eine Diskriminierung darstellen und nicht als angemessene Verkehrsmanagementmaßnahme einzustufen sein. Dies vor allem, wenn die Blockade zur Durchsetzung von kommerziellen

985 Siehe oben Ziffer C. I. 2. e).

986 Klement, in: Scheurle/Mayen, TKG, EU-NNVO, Rn. 21. 
Interessen dienen sollte. Die Erlaubnisgründe würden jedenfalls nicht zur dauerhaften Legitimierung einer Werbeblockade taugen.

Die vorgenannten Regeln werden in Deutschland von der Bundesnetzagentur überwacht ${ }^{987}$. Daneben ist es nicht ganz ausgeschlossen, dass Art. 3 Abs. 3 VO (EU) 2015/2120 als Marktverhaltensregelung im Sinne von $\$ 3 a$ UWG anzusehen wäre. Auf eine ausführliche Prüfung wird an dieser Stelle allerdings verzichtet. Denn so oder so wäre eine Werbeblockade durch einen der deutschen Internet Service Provider nicht lange aufrechtzuerhalten. Aus diesem Grunde ist auch eine ausführliche Prüfung der Lauterkeit nach $\$ 4$ Nr. 4 UWG nicht notwendig. Es spricht allerdings an dieser Stelle mangels der Nutzerentscheidung pro Werbeblockade und der wohl erheblich geringeren Möglichkeit von Selbstschutzmaßnahmen der Webseitenbetreiber und Werbedienstleister einiges für eine gezielte Behinderung durch einen werbeblockenden Internet Service Provider. Je nach Marktanteil des Providers spiegelt sich dies auf kartellrechtlicher Ebene.

Eine Werbeblockade durch Internet Service Provider ist demnach in der Europäischen Union nicht legal. Das Angebot entsprechender Software könnte ebenfalls verboten werden.

\section{f) Stichwortbasierte Blocker}

Neben der Filterblockertechnologie gibt es auch Werbeblocker, die rein stichwortbasiert und auf visuellen Kriterien beruhend Werbung identifizieren und blockieren können ${ }^{988}$. Da auch hier lediglich im Bereich des Nutzers die Blockade herbeigeführt wird, ändert sich an der in den Adblock Plus Fällen dargestellten rechtlichen Beurteilung auf den ersten Blick nichts. Die nutzerautonome Entscheidung pro Werbeblockade ist grundsätzlich hinzunehmen.

Allerdings könnten sich Unterschiede in der rechtlichen Bewertung daraus ergeben, dass mit dieser Art der Blockertechnologie auch Webseitensperren umgangen werden könnten. Denn wenn die Nichtdarstellung der Werbung nicht durch den Nichtabruf bestimmter Elemente herbeigeführt wird, kann die Sperre oftmals nicht wirksam werden. Die Sperren beruhen regelmäßig darauf, dass nicht ordnungegmäß durchgeführte Requests in der HTTP-Kommunikation erkannt werden. Der stichwortbasierte Blocker würde in den Abruf nicht eingreifen, sondern allein bei der Darstellung

987 Klement, in: Scheurle/Mayen, TKG, EU-NNVO, Rn. 111.

988 Siehe oben Ziffer C. I. 2. e). 
der Webseite - während des Rendering-Prozesses des Browsers ${ }^{989}$. Auch die Ausspielung unblockierbarer Werbung würde durch diese Technologie stark eingeschränkt. Nicht zuletzt deshalb wird diese Lösung als letzte Eskalationsstufe im Kampf zwischen Werbeindustrie und Werbeblockern bezeichnet ${ }^{990}$.

Mangels bisher erkennbarer Nutzung in Verbindung mit Refinanzierungsmodellen wie einer kostenpflichtigen Freischaltung oder einer Werbeersetzung kommt es in rechtlicher Hinsicht vorrangig auf das Vorliegen einer gezielten Behinderung nach $\$ 4$ Nr. 4 UWG an. Hier ist freilich $\mathrm{zu}$ beachten, dass eine rein kostenfreie, also auch nicht drittfinanzierte oder über Nutzerdatenverwertung kommerzialisiertes Angebot keine geschäftliche Handlung gemäß $\ 2$ Abs. 1 Nr. 1 UWG darstellt. Soweit eine geschäftliche Handlung bejaht werden kann, sind wiederum die Interessen der Nutzer und der Werbeblockerbetreiber mit den Interessen der Webseitenbetreibern und weiterer Akteure in der Werbeindustrie sowie der Allgemeinheit abzuwägen. Mit der „Schutzmaßnahmendoktrin“ des BGH aus Werbeblocker II und den anderen vorgenannten Grundsatzentscheidungen lässt sich dieser Fall aber nicht alleine lösen. Denn der stichwortbasierte Blocker kann zwar technische Schutzmaßnahmen gegen die gängigeren Filterwerbeblocker umgehen. Dies ist aber wohl nicht der alleinige Zweck der Software, da hiermit im Ausgangspunkt eine ganzheitliche Ausblendung von Werbung beim Nutzer gewollt ist. Dass Schutzmaßnahmen für andere Werbeblocker gegen diese Technologie nicht wirken, macht diese nicht per se unlauter. Vielmehr wäre zu betrachten, ob es auch gegen diese Technologie wirksame Schutzmaßnahmen gibt. Dies ist in technischer Hinsicht noch nicht erkennbar. In jedem Fall bleibt den Webseitenbetreibern allerdings eine Auswegmöglichkeit zur Refinanzierung ihrer Leistungen - die ungeliebte Zahlschranke. Während in Werbeblocker II noch die Zumutbarkeit zum Selbstschutz der Webseitenbetreibern zu prüfen war, indem ihnen zur Abwendung der ganz kostenlosen Hingabe ihrer Inhalte eine Vielzahl von technischen und rechtlichen Auswegmöglichkeiten zur Auswahl standen, reduziert sich diese im hiesigen Fall wohl praktisch auf die Zahlschranke. Deshalb käme es bei der Bewertung dieser Fallgestaltung zum Schwur: Kann das Interesse der Nutzer von Werbung verschont

989 Ähnlich wie das Element Hiding bei Adblock Plus, vgl. oben Ziffer D. I. 2. a) aa).

990 https://motherboard.vice.com/en_us/article/9a4yny/princetons-ad-blocking-su perweapon-may-put-an-end-to-the-ad-blocking-arms-race, zuletzt abgerufen am 30.5.2019. 
bleiben so weit gehen, dass es für Webseitenbetreiber zumutbar ist, Zahlschranken einzuführen? Und würde dies die Interessen der Allgemeinheit, insbesondere der Nutzer, die keinen Werbeblocker nutzen, nicht allzu sehr tangieren?

Ohne Frage stehen die Chancen für ein Verbot unter diesen Vorzeichen höher als bei Adblock Plus. Wenn es eine weitere Befassung von Gerichten mit Internetwerbeblockern geben sollte, könnte dies durchaus in der Nutzung dieser Technologie begründet sein. Allerdings ist nach hier vertretener Ansicht auch an dieser Stelle das Interesse des einzelnen Nutzers, der sich freiverantwortlich und für seinen eigenen Bereich für den Einsatz eines stichwortbasierten Werbeblockers entscheidet, als überragend schützenswert anzusehen. Auf Seiten der Webseitenbetreiber ist zudem die Argumentation aus Werbeblocker II weiterhin anwendbar, wonach die kostenfreie Zugänglichmachung von Content im Internet keineswegs Bestandsschutz genießt. Wenn die Publisher ihre Inhalte kostenfrei vorhalten, tragen sie das alleinige Risiko für ihre anderweitige Refinanzierung. Eine Garantie des werbefinanzierten Modells gibt es jedenfalls nicht. Der einfachste und sicherste Weg zur Refinanzierung wäre also eine Zahlung für den Zugang zum Inhalt durch den jeweiligen Nutzer. Würde daraus eine Einschränkung der Medienvielfalt oder des freien Zugang zu Medien folgen, der eine nicht zu tragende Beeinträchtigung der Interessen der Allgemeinheit darstellen würde? Nicht unbedingt. Denn der noch höhere Marktdruck könnte insgesamt sogar zu einer Verbesserung des Niveuas der Medien führen. Wie das? Wenn Medienanbieter, Verlage und sonstige Schöpfer von Inhalten im Web sich übergreifend vereinen würden und gemeinsame Vergütungsplattformen schaffen würden, könnte dies sogar ein Gewinn für die Allgemeinheit sein. So ist es nicht undenkbar, dass eine Art Spotify oder Netflix für Presseerzeugnisse oder sonstigen Content nicht zu einer nachhaltigen Finanzierung führen könnte. Das Problem der Zahlschranke ist nämlich vor allem dann schwerwiegend, wenn jede größere Webseite eine eigene Zahlschranke fordert und sich für Nutzer, die sich aus mehreren Quellen informieren wollen, damit Kosten addieren würden, die nicht mehr attraktiv sind. Das Gegenteil ist bei den vorgenannten Streamingangeboten zu beobachten. Die hohe Zahl der Nutzer von Spotify, Netflix und Co. zeigt, dass ein monatlicher Geldbetrag, den sich der Großteil der Allgemeinheit leisten kann, durchaus am Markt angenommen wird und zudem die Qualität der Medien verbessert. So ist seit dem Erfolg der Musikstreamingplattformen praktisch das Problem der illegalen Downloads von Musik ausgestorben. Netflix hat durch ihren Fokus auf beliebte, teils selbstfinanzierte Serienformate nach hier vertretener 
Ansicht erheblich zu einer Qualitätssteigerung im Bewegtbildsegment im Vergleich zu verbreiteten TV-Formaten, z.B. Reality-TV, beigetragen. Freilich gibt es Verlierer dieser Entwicklung, etwa die früher sehr starken privaten Fernsehsender oder Plattenfirmen. Diese Entwicklungen sind dem freien Wettbewerb geschuldet, den das Lauterkeitsrecht ausweislich der klaren liberalen Aussagen des BGH in Werbeblocker II nicht einschränken soll. Insgesamt werden die Interessen der Allgemeinheit nach hier vertretener Ansicht also nicht derart durch stichwortbasierte Werbeblocker beeinträchtigt, dass sie den Ausschlag für eine Unlauterkeit geben könnten.

Stichwortbasierte Werbeblocker sind demnach ebenfalls lauterkeitsrechtlich zulässig. Mangels ausreichender Verbreitung erübrigen sich vorerst Ausführungen zu kartellrechtlichen Ansprüche. In urheberrechtlicher Hinsicht unterscheidet sich der Fall nur unwesentlich von Adblock Plus. Dies liegt vor allem an den oben aufgezeigten Schwierigkeiten bei der Schutzfähigkeit von Webseiten sowie bei der Verletzungsfrage, die unabhängig von der Blockadewirkung durch Nichtladen oder bloßem Nichtanzeigen von Werbeelementen sind.

\section{g) Reine Trackingblocker}

Nur kurz soll abschließend noch auf reine Trackingblocker eingegangen werden. Diese sind nicht anders als reine Blacklistblocker zu bewerten. Skripten zum Tracking von Nutzern kann man der Sache nach als Teil des Onlinewerbeprozesses ansehen. Somit kann man deren Zulässigkeit bereits aus dem Urteil Werbeblocker II folgern. Wenn die vollständige Blockade von Werbung zulässig ist, muss dies auch für damit verknüpfte Vorfeldhandlungen gelten. Ein Trackingskript zur Sammlung von Daten für Nutzungsprofile zur Ausspielung personalisierter Werbung ist eine solche Vorfeldhandlung.

Auch andere Trackingskripte oder -methoden, die nicht unmittelbar mit Werbung verbunden sind, dürfen indes geblockt werden. Da es sich hier wohl immer um personenbezogene Daten handelt ${ }^{991}$, ist der Einsatz spätestens als Selbsthilfe des Nutzers gerechtfertigt, der einen Verstoß gegen Handlungen entgegen Art. 6 DSGVO abwehren möchte. Ein schützenswertes Interesse zur Vornahme nicht nach Art. 6 Abs. 2 DSGVO gerecht-

991 EuGH in Sachen Breyer./.BRD, Urteil vom 19.10.2016, Rs. C-582/14, NJW 2016, 3579 . 
fertigter Handlungen besteht in keinem Fall, sodass der Handelnde nicht unlauter behindert werden kann.

\section{Exkurs: „Overblocking“-Blockieren redaktioneller Drittinhalte}

Die Funktionsweise von Filterwerbeblockern und der modulare Aufbau von modernen Webseiten, der Elemente von verschiedenen Servern bezieht, beschwören geradezu herauf, dass der Werbeblocker über sein eigentliches Ziel hinausschießt. Insbesondere wenn Webseiten Techniken wie Frames benutzen, um Videos von außerhalb der unmittelbaren ServerClient Verbindung anzuzeigen, können Filterbefehle dazu führen, dass Inhalte, die zum redaktionellen Content der Webseiten zu zählen sind, nicht korrekt angezeigt werden. Dies ist insbesondere bei in Berichterstattung eingebettten Youtube-Vidoes oder Twitter-Beiträgen denkbar.

Dieses Phänomen, bei dem nicht nur Werbeelemente, sondern auch einzelne redaktionelle Inhalte blockiert werden, kann man mit dem Begriff „Overblocking“ bezeichnen. Dieses „Zuvielblocken“ wurde in der Literatur bislang nicht ausführlich behandelt ${ }^{992}$. In der Rechtsprechung findet sich in diesem Kontext ein Urteil, das genau diesen Fall betrift ${ }^{993}$. Ein zum Axel Springer Konzern gehörendes Unternehmen hat dabei gegen die Betreiberin von Adblock Plus zunächst eine einstweilige Verfügung erwirkt, welche sodann bestätigt worden ist. Der Sachverhalt berichtet dabei von einem generellen Filterbefehl in der Blacklist „Easylist Germany“, der dazu geführt hat, dass in fünf Fällen auf der Webseite der Klägerin redaktionelle Inhalte beim Besuch mit aktiviertem Adblock Plus nicht ordnungsgemäß abrufbar waren. Bei den blockierten Inhalten handelte es sich um in Frames eingeblendete Youtube-Videos, Memes ${ }^{994}$, Quizzes oder Liveticker. Also in allen Fällen Inhalte, die nicht unmittelbar und fest mit dem reinen Text des Beitrags verbunden waren, sondern von anderen Quellen geladen und vom Browser in die fertige Webseite integriert werden.

Das LG Hamburg gab dem Unterlassungsanspruch der Klägerin, diese Blockade von redaktionellen Beiträgen zu unterlassen, auf Grundlage

992 Allein bei Witte, ITRB 2018, 34, findet sich ein Satz zum potentiellen Fall, dass redaktionelle Inhalte blockiert werden.

993 LG Hamburg, Urteil vom 26.9.2016, 308 O 244/16 (unveröffentlicht).

994 Dies sind Bilder von berühmten oder in sozialen Medien berühmt gewordenen Film- oder TV-Szenen oder sonstige Fotos, die mit einem Schrifteil zu einem Witz kombiniert werden. 
von $\$ 4$ Nr. 4 UWG statt. Einen weiterhin geltend gemachten Anspruch wegen Urheberrechtsverletzung lehnte es insgesamt bereits vor Erlass der einstweiligen Verfügung ab. Zur Begründung des lauterkeitsrechtlichen Unterlassungsanspruchs bejahte die Kammer zunächst, dass auch das nicht intendierte - sozusagen „versehentliche“ - Blocken von redaktionellen Inhalten an der geschäftlichen Handlung des Geschäftsmodells von Adblock Plus einen Teil der geschäftlichen Handlung darstellt. In diesem Kontext grenzte das LG Hamburg den Fall von der Konstellation in den BGH Urteilen „Änderung der Voreinstellung I und II“995 ab. Dort wurde eine versehentliche Vertragsverletzung nicht als Wettbewerbshandlung im Sinne der früher geltenden Terminologie angesehen ${ }^{996}$, wenn denn tatsächlich feststellbar war, dass ein Versehen vorlag997. Im Fall eines absolut wirkenden Filterbefehls ließ das LG Hamburg die Verteidigung, es liege nur ein Versehen vor, aber nicht gelten. Denn insoweit sei dem Werbeblockerbetreiber die Gefahr, dass auch redaktionelle Inhalte erfasst werden können, bewusst und sie sei der Funktionsweise inhärent. Wenn sich bei einem solchen "gefahrgeneigten Werkzeug" die an sich nicht gewünschte Unterdrückung redaktioneller Inhalte einstellt, könne nicht von einem ungewollten Versehen ausgegangen werden. Eine geschäftliche Handlung nach $₫ 2$ Abs. 1 Nr. 1 UWG bejahte die Kammer folglich ${ }^{998}$. Die weiterhin notwendige Mitbewerberstellung folgerte das LG Hamburg aus dem Grundsatz des Behinderungswettbewerbs.

Bei der Prüfung der gezielten Behinderung nahm das LG Hamburg vorliegend eine produktbezogene Behinderung an, weil in die Integrität des Produkts „Webseite“ eingegriffen werde. Ein solcher Eingriff könne auch bei nichtkörperlichen Veränderungen von digitalen Produkten angenommen werden. Da die überschießende Blockade von redaktionellen Beiträgen nicht von den Nutzern gewünscht sei, müsse auch nicht geprüft werden, ob hier das Vorliegen einer produktbezogenen Behinderung ausscheide - wie es kurz vor der Bescheidung erst das OLG Köln gesehen

995 BGH, Urteil vom 29.3.2007, I ZR 164/04, GRUR 2007, 987 - Änderung der Voreinstellung I; Urteil vom 5.2.2009, I ZR 119/06, GRUR 2009, 876 - Änderung der Voreinstellung II.

996 BGH, Urteil vom 29.3.2007, I ZR 164/04, GRUR 2007, 987 - Änderung der Voreinstellung I.

997 Kein Versehen, sondern bewusstes Handeln wurde in BGH, Urteil vom 5.2.2009, I ZR 119/06, GRUR 2009, 876 - Änderung der Voreinstellung II, angenommen.

998 LG Hamburg, Urteil vom 26.9.2016, 308 O 244/16 (unveröffentlicht). 
hatte ${ }^{999}$. Die behindernde Wirkung folgerte das LG Hamburg aus dem Umstand, dass Nutzer die Fehlfunktion der Webseite - und nicht etwa dem installierten und aktivierten Werbeblocker - zuschreibe. Folglich drohten Reichweitenverluste im Sinne weniger Page Impressions. Bei der nötigen Interessenabwägung sah das LG Hamburg dann die von Art. 5 Abs. 1 S. 2 GG geschützte Pressefreiheit als überwiegend an, weil der Kern der Pressefreiheit durch Eingriff in das redaktionelle Kernprodukt betroffen sei. Auch könne sich der Werbeblockerbetreiber hier nicht auf die Interessen der Nutzer berufen. Dass das „Overblocking“ als mögliche Nebenfolge in Kauf genommen werde, konnte die Kammer nicht erkennen. Das oben bereits verworfene Argument der "versehentlichen Blockade“ konnte auch an dieser Stelle nicht für den Werbeblockerbetreiber streiten, da die Kammer es nicht als schützenswertes Interesse ansah, dass bewusst Kollateralschäden am redaktionellen Inhalt von Webseiten hingenommen würden. Schließlich ergebe eine Folgenabwägung, dass die Kontrolle der Filterbefehle durch den Werbeblockerbetreiber weniger einschneidend sei, als die Duldung des Eingriffs in das redaktionelle Angebot der Webseitenbetreiber.

Diese Entscheidung überzeugt in der Bewertung der geschäftlichen Handlung, nicht aber in der Annahme einer gezielten Behinderung. Bei ersterem nimmt die Hamburger Kammer zu Recht an, dass Adblock Plus ein einheitliches Geschäfts- und Wirkungsmodell ist. Nur durch die allgemeine Wirkung der Filterregeln kann die Software so zuverlässig arbeiten, wie von der hohen Nutzerschaft geschätzt. Wenn die Filterregeln aber zu weitgehend sind, ist dies vielleicht eine nicht unmittelbar intendierte Folge. Es handelt sich aber in jedem Fall um eine in Kauf genommene Folge, sodass die Annahme eines Versehens ausfällt. Im Übrigen ist auch sehr unwahrscheinlich, dass die Annahme des BGH in „Änderung der Voreinstellung I", wonach versehentliche Vertragsverletzungen nicht in den Regelungsbereich des Lauterkeitsrechts fallen, in dieser Konstellation außerhalb des Vertragsrechts eingreifen kann. Im hier anwendbaren gesetzlichen bzw. deliktischen Schuldverhältnis ist kein Platz für eine Privilegierung von Versehen. Dies gilt umso mehr für den Bereich der verschuldensunabhängigen Unterlassungshaftung. Schließlich ist auch zu konstatieren, dass auch versehentliches oder unerkannt fehlerhaftes Handeln dem eigenen Unternehmen nützen kann. Damit sind die Voraussetzungen des Wortlauts von $\$ 2$ Abs. 1 Nr. 1 UWG erfüllt.

999 OLG Köln, Urteil vom 24.6.2016 - 6 U 149/15, GRUR 2016, 1082. 
Bei der Bewertung der gezielten Behinderung muss dem Urteil jedoch widersprochen werden. Die Argumentation erscheint sehr einseitig zugunsten der Webseitenbetreiber und verkennt die wirtschaftlichen Zusammenhänge. Insbesondere die Annahme, der Werbeblockernutzer würde bei Fehlfunktionen der Webseite, dieses Ärgernis der Webseite zumessen und dadurch zur Verringerung von Page Impressions führen, überzeugt nicht. Denn zum einen sind Werbeblockernutzer gerade keine lukrativen Gäste. Durch die Verhinderung der zugriffsbasierten Werbefinanzierungsauslöser macht es praktisch für einen kommerziellen, werbefinanzierten Webseitenbetreiber keinen Unterschied, ob der Nutzer gar nicht auf seiner Seite surft oder mit Werbeblockern. Dies ist die Logik der Zugangssperre der Seitengenuss mit aktiviertem Werbeblocker dürfte dabei gar noch ungewollter sein, weil hier die Leistung des Seitenbetreibers gerade ohne die erhoffte Gegenleistung der Werbewahrnehmung konsumiert wird. Zum anderen liegt es bei Abstellen auf einen durchschnittlichen Verbraucher und nicht auf einen technisch absolut unbedarften Nutzer - eher fern, dass Fehlfunktionen bei aktiviertem Werbeblocker auf die Webseite geschoben würden. Es dürfte dem Nutzer, der sich bewusst für den Einsatz eines spürbar wirkenden Tools wie Adblock Plus entscheidet, klar sein, dass auch Elemente, die ähnlich wie Werbung nur auf einer Seite eingebettet sind, nicht immer richtig funktionieren werden. Dies ist auch nicht beispiellos. So führt etwa das Löschen oder Ablehnen von Cookies zu Funktionsproblemen von Elementen im Web. Auch das Fehlen oder die Nutzung bestimmter Tools sowie die Vornahme bestimmter Einstellungen im Browser kann zu Fehlfunktionen führen. Zumal bei Adblock Plus die Abschaltung nur weniger Klicks bedarf und somit die Fehlfunktion nach kurzer Überprüfung unschwer dem Werbeblocker zugeordnet werden kann. Fehlfunktionen werden deshalb wohl eher zu einem Vertrauensverlust in den Blocker führen.

Die Bewertung, dass auch nicht körperliche Veränderungen von digitalen Produkten $\mathrm{zu}$ einem Eingriff in die Integrität der Leistung führen können, überzeugt ebenfalls nicht. Bei den falsch blockierten Inhalten handelte es sich ausschließlich um solche Elemente, die auf der Webseite durch Frames eingebunden und von unterschiedlichen Servern geladen worden sind. Dies zeigt bereits, dass sich die Autoren der Webseiten einer besonderen Technik bedient hatten, die gerade keine Integrität der Webseite dergestalt bezweckte, dass alle Elemente von einem Server geladen werden. So ist die Einbettung von Videos von YouTube oder von Tweets, die von den jeweiligen Drittservern angefordert werden, Ausdruck einer dezentralen Kommunikation. Die Fehlfunktion kann in diesem Verhältnis 
auch dadurch folgen, dass die "eingeframten" Inhalte auf den jeweiligen Plattformen gelöscht werden. Auch dann würde eine Fehlfunktion der Webseite eintreten. Auch nicht ganz von der Hand zu weisen ist an dieser Stelle ein geraumes Missbrauchspotential in der Hand der Webseitenbetreiber, denn diese könnten vorsätzlich solche Drittinhalte in das HTML-Dokument einbetten, die von Filterbefehlen erfasst werden. Somit könnten auf der ersten Stufe Verletzungsfälle provoziert werden, die zu Unterlasungsansprüchen führen, und auf der zweiten Stufe weitere Fälle, die eine Vertragsstrafe verwirken oder eine Ordnungsmittel nach $\$ 890$ ZPO nach sich ziehen.

Zuletzt verkennt das LG Hamburg eklatant die Reichweite der durch "Overblocking" herbeigeführten Wirkung der als Eingriff in den Kernbereich der Pressefreiheit qualifizierten Behinderung. Zwar erkennt es ausweislich des Urteils, dass die Fehlfunktion nur in den Geräten der Werbeblockernutzer zur Nichtdarstellung redaktioneller Inhalte führt. Es zieht daraus aber nicht den folgerichtigen Schluss. Denn die Funktion bleibt bei jedem Nutzer, der die Webseite ohne Werbeblocker besucht, unangetastet ${ }^{1000}$. Sie zeigt sich bei einer nicht unerheblichen Anzahl von Nutzern. Diese Nutzer haben sich aber für den Werbeblocker entschieden - mit all seinen Vor- und Nachteilen. Der Werbeblocker greift aber außerhalb seiner Nutzerschaft nicht in das redaktionelle Angebot der Webseitenbetreiber ein. Deshalb passt auch das Argument des Eingriffs in den Kernbereichs der Pressefreihit nicht. Wenn der Nutzer in seiner Sphäre ihm technisch mögliche - und nicht durch technische oder rechtliche Schutzmaßnahmen abgeschnittene - Veränderungen an Webseiten vornimmt, ist dies sein gutes Recht. Genauso wenig wie er eine rechtliche Pflicht hat, eine Webseite mit Werbung zu sehen, hat er die Pflicht Webseiten mit allen redaktionellen Inhalten zu sehen. Man denke nur daran, ein Nutzer stellte die Anzeige von Bildern in seinem Browser aus. Dann würden auch erhebliche Teile der redaktionellen Berichterstattung vieler Webseiten nicht angezeigt. Dies kann aber in keinem Fall ein Verhalten sein, dass die Pressefreiheit tangiert oder gar lauterkeitsrechtlich relevant ist.

Nach alledem ist das „Overblocking“ also nicht anders zu bewerten als das „normale“ Blacklisting. Das Urteil des LG Hamburg stellt - gemeinsam mit einem weiteren Urteil derselben Hamburger Kammer im Kontext der generellen Zulässigkeit einer Werbeblockersoftware ${ }^{1001}$ - ein Beispiel

1000 In diese Richtung argumentiert auch Witte, ITRB 2018, 34.

1001 LG Hamburg, Urteil vom 3.5.2016 - 308 O 46/16, CR 2016, 782. 
für die kurze Zeit in der Rechtsprechung aufflammende Mindermeinung dar, die durch das BGH Urteil Werbeblocker II nunmehr zu Recht als überholt anzusehen ist.

\section{Regulierung von Werbeblockern durch den Gesetzgeber?}

Nachdem sich schon nach den ersten Urteilen in den Rechtsstreiten um Adblock Plus zeigte, dass der Weg zu einem Verbot von Werbeblockern unter geltendem Recht und auf dem Weg der Judikative schwierig sein würde, lag es für die Feinde des Werbeblockens nahe, eine gesetzliche Regulierung von Werbeblockern zu forcieren. Und tatsächlich sind in der deutschen Politik Versuche gestartet worden, über die Legislative ein Verbot von Werbeblockern herbeizuführen. Auch wenn diese Versuche bis zur Zeit der Fertigstellung dieser Arbeit nicht zum Ziel geführt haben, soll ein kurzer Überblick über die politischen Bestrebungen im Themenfeld Werbeblocker gegeben werden. Außerdem wird eine Stellungnahme zu einem kolportierten Werbeblockerverbot de lege ferenda abgegeben.

a) Tendenzen in der 18. Legislaturperiode (2013 bis 2017)

Der Großteil der Instanzrechtsprechung in Werbeblockerfällen erging im Zeitraum von 2013 bis 2017. Dies war die 18. Legislaturperiode des Bundestags, in welchem eine Mehrheit der CDU/CSU und der SPD eine große Koalition bildeten ${ }^{1002}$.

In diesem politischen Milieu gab es insbesondere drei nennenswerte Vorgänge im Kontext einer gesetzlichen Regulierung von Werbeblockern. Im Juni 2016 legte die Bund-Länder Kommission für Medienkonvergenz ihren Bericht vor, in welchem sie sich zu diesem Thema äußerte. Im Oktober 2016 erfolgte eine Kleine Anfrage von Abegeordneten der Fraktion DIE LINKE, die noch im selben Monat durch die Bundesregierung beantwortet wurde. Außerdem wurde im Ausschuss für Kultur und Medien im Bundestag am 30.11.2016 ein Fachgespräch mit Experten aus Recht, Wirtschaft und NGOs geführt. Diese Vorgänge erzeugten zudem ein interessantes mediales Echo. Im Einzelnen:

1002 https://de.wikipedia.org/wiki/18._Deutscher_Bundestag, zuletzt abgerufen am 31.5.2019. 
aa) Die Bund-Länder Kommission für Medienkonvergenz

Laut ihrem Bericht vom Juni $2016^{1003}$ entstand die Bund-Länder Kommission für Medienkonvergenz durch einen Beschluss der Bundeskanzlerin sowie der Regierungschefinnen und Regierungschefs der Länder am 11.12.2014. Demzufolge sollte eine "gemeinsame Steuerungsgruppe auf politischer Ebene“ eingesetzt werden, die Vorschläge für eine der Medienkonvergenz angemessene Medienordnung auf nationaler und internationaler Ebene erarbeiten. Teilnehmer waren Beauftragte der Bundesregierung für Kultur und Medien, der Bundesministeriem für Wirtschaft und Energie, des Innern, für Verkehr und digitale Infrastruktur und für Familie, Senioren, Frauen und Jugend für den Bund. Auf Länderseite führte den Vorsitz das in der Rundfunkkommission vorsitzende Bundesland Rheinland-Pfalz sowie die Staats- und Senatskanzleien der Länder Berlin, Bayern, Hessen, Hamburg, Nordrhein-Westfalen, Sachsen und Baden-Württemberg. Zwischen Mai 2015 und April 2016 fanden dabei mehrere Sitzungen verschiedener Arbeitsgruppen statt. Die Teilnahme an den entsprechenden Sitzungen stand grundsätzlich Vertretungen aus allen Ländern und Bundesressorts offen, wobei auch Sachverständige, Verbände, Institutionen und Unternehmen durch Workshops oder schriftliche Stellungnahmen einbezogen worden sind.

In ihrem Bericht im Juni 2016 legte die Kommission ihre bisherigen Abstimmungen für eine konvergente Medienordnung vor. Dabei hat sich die Arbeitsgruppe Kartellrecht/Vielfaltsicherung unter anderem mit dem Thema Werbeblocker befasst. Ausweislich des Berichts wudes das Thema Werbeblocker erst im Dezember 2015 nach Vorlage eines Zwischenberichts auf die Agenda genommen. Als Begründung zur Aufnahme des Themas wurde ausgeführt, dass das Geschäftsmodell der Werbeblocker als ein unzulässiger Eingriff in eigene werbefinanzierte Geschäftsmodelle der Medienunternehmen angesehen werde. Deshalb würden teilweise, auch unter Hinweis auf längerfristig mögliche Beeinträchtigungen der Medienvielfalt, gesetzgeberische Maßnahmen gefordert.

Bei einem Workshop im März 2016 haben ausweislich des Berichts teilgenommen: Vertretungen der Organisation der Mediaagenturen (OMG e.V.), der Omnicom Media Group Germany GmbH, des Bundesverbands Deutscher Zeitungsverleger (BDZV), des Verbandes Deutscher Zeitschrif-

1003 Abrufbar unter https://www.bundesregierung.de/resource/blob/997532/473870 /07ba875e860ada4556526641bd9151b6/2016-06-14-medienkonvergenz-bericht -blk-data.pdf?download=1, zuletzt abgerufen am 31.5.2019. 
tenverleger (VDZ), des Zentralverbandes der deutschen Werbewirtschaft (ZAW), des Verbands Privater Rundfunk und Telemedien e.V. (VPRT), der ARD, der Geschäftsführer der ZDF Werbefernsehen GmbH, der AG Privater Rundfunk (APR) sowie der Anzeigenchef eines weiteren Verlags. Diese Gespräche sind weitestgehend vertraulich geführten worden.

Die Problematik beschreibt der Bericht wie folgt:

„Ad-Blocker sind Programme, welche dafür sorgen, dass auf Webseiten enthaltene Werbung dem Betrachter nicht dargestellt wird. Nach Angaben der betroffenen Kreise, greifen sie unmittelbar in die Software der Webseiten der Medienanbieter ein und blockieren die Werbung. Nach Auffassung der Medienanbieter stellen diese ein Gesamtprodukt zur Verfügung, zu welchem bei kostenlosen Angeboten auch Werbung gehöre, um das journalistische Angebot zu refinanzieren. Dieses Gesamtangebot werde durch den Ad-Blocker faktisch entbündelt. Es bestünde aber kein Anspruch auf unentgeltliche Information, weshalb entweder für ein Medienprodukt gezahlt oder die Werbung geduldet werden müsse. Ad-Blocker wurden als existentielle Bedrohung der wirtschaftlichen Basis insbesondere für die digitalen Angebote der Zeitungs- und Zeitschriftenverleger bezeichnet, da derzeit bereits ca. 30 Prozent der Internetnutzerinnen und -nutzer Ad-Blocker verwenden würden, bei technikaffinen Titeln liege die Blockerrate sogar bei über 50 Prozent. Für das Jahr 2016 werde ein hierdurch entstehender Schaden von weltweit ca. $40 \mathrm{Mrd}$. Euro prognostiziert. Die Medienunternehmen forderten vor diesem Hintergrund ein generelles gesetzliches Verbot von Ad-Blockern. Das Abwarten höchstrichterlicher Rechtsprechung zu den insbesondere lauterkeitsrechtlichen Rechtsfragen, die von verschiedenen Gerichten bisher unterschiedlich beurteilt worden seien, wurde von ihnen als nicht zumutbar betrachtet. Sie halten die bisherige Rechtsprechung des Bundesgerichtshofs, die Werbeblocker im Fernsehen für zulässig ansah, als nicht übertragbar. Das Umstellen auf Bezahlangebote oder ein technisches Wettrüsten sei für sie ebenfalls keine tragfähige Alternative."1004

Daraus fasste die Kommission folgende Handlungsempfehlung:

„In der Anhörung wurden Ad-Blocker als rechtswidrig angesehen. Die vertretenen Stakeholder sahen einen rechts- und medienpolitischen Bedarf für ein gesetzliches Verbot von Ad-Blockern. Eine mögliche

1004 S. 20 des Berichts, siehe Link in Fn. 979. 
Regelungsoption könnte ein Integritätsschutz für journalistisch-redaktionelle digitale Produkte vergleichbar dem Gedanken des Signalschutzes im Rundfunkrecht sein. Die AG sieht das Geschäftsmodell von Ad-Blockern als rechtlich und mit Blick auf die Refinanzierung journalistisch-redaktioneller Angebote auch medienpolitisch als problematisch an. Sie hält daher die Prüfung gesetzlicher Regelungen für erforderlich.“1005

Als weiteres Verfahren sah der Bericht vor:

„Bei der Thematik Ad-Blocker ist eine zeitnahe Prüfung durch den Bund und die Länder erforderlich, ob im Hinblick auf die wirtschaftlichen Auswirkungen und damit verbundenen medienpolitischen Risiken ggf. eine gesetzliche Flankierung geboten ist. "1006

Was bei diesem Bericht sofort auffallt, ist die enorm einseitige Herangehensweise an das Thema. Bei der Sachverhaltsaufklärung wurden nur Vertreter aus dem Lager der Medienanbieter und Medienintermediäre eingeladen und gehört. Dies spiegelt sich klar in der Problembeschreibung und der Handlungsempfehlung wider. Ein Austausch verschiedener Meinungen fand in diesem Rahmen jedenfalls nicht statt.

Gerade in Anbetracht der ausdifferenzierten Rechtsprechung zum Zeitpunkt der Berichterstattung kann der Bericht als nichts anderes als Ergebnis funktionierender Lobbyarbeit bezeichnet werden. Dieser Vorwurf trifft dabei vor allem die politischen Funktionäre, die es versäumt haben ihre Sachverhaltsaufklärung auf eine pluralistische Grundlage zu stellen und die ökonomisch geprägten Sorgen der Medienanbieter unter dem nichtssagenden Begriff der Medienkonvergenz als gesellschaftliches Problem darzustellen.

Im Nachgang zur Berichtveröffentlichung konnten Journalisten der Webseite netzpolitik.org über eine Anfrage nach dem Informationsfreiheitsgesetz Einsicht in nicht veröffentlichte Dokumente im Zusammenhang mit der Bund-Länder Kommission für Medienkonvergenz erhalten. Diese teilweise stark geschwärzten Dokumente hat die Webseite öffentlich zugänglich gemacht ${ }^{1007}$. Die dort enthaltenen Protokolle und schriftlichen Stellungnahmen der Workshop-Teilnehmer sind überwiegend einseitige Beschwerden über Werbeblocker und entsprechen praktisch dem Kläger-

1005 S. 21 des Berichts, siehe Link in Fn. 979.

1006 S. 22 des Berichts, siehe Link in Fn. 979.

1007 https://cdn.netzpolitik.org/wp-upload/2016/08/IFG-Adblocker-Medienkonverg enzkommission.pdf, zuletzt abgerufen am 31.5.2019. 
vortrag in den Klageverfahren. So wird vom Verband Deutscher Zeitschriftenverleger gefordert den „Schutz der Integrität redaktionell-journalistischer Produkte in ibrer Einheit aus redaktionellen und werblichen Inhalten mit Wirkung gegenüber jedermann (auch außerhalb von Kartellsachverhalten und Wettbewerbsverhältnissen) gesetzlich klarzustellen"1008.

Die in dem Bericht der Kommission geäußerte Ansicht, dass ein gesetzgeberisches Handeln gegen digitale Werbeblocker notwendig sei, teilten allerdings nicht alle Beteiligten. Das Medienreferat der Bayerischen Staatskanzlei äußerte, dass aus bayerischer Sicht aktuell kein konkreter gesetzgeberischer Handlungsbedarf gesehen werde und der Ausgang der Rechtsstreitigkeiten abzuwarten sei ${ }^{1009}$.

bb) Die Kleine Anfrage der Fraktion DIE LINKE und die Antwort der Bundesregierung

Unter Berufung auf den Bericht der Bund-Länder Kommission für Medienkonvergenz stellten Abgeordnete der Fraktion DIE LINKE eine Kleine Anfrage an die Bundesregierung mit 23 Fragen in diesem Kontext ${ }^{1010}$. Interessante Fragen sind dabei vor allem:

„1. Ist die kritische Sichtweise, die im Bericht der BLKM zu Ad-Blockern zum Ausdruck kommt, auch offizielle Sichtweise der Bundesregierung, und wenn ja, aus welchen Gründen änderte sich die Position der Bundesregierung bezüglich eines Ad-Blocker-Verbotes (s. Vorbemerkung)?

2. Aus welchen Gründen erachtet die Bundesregierung ein Ad-BlockerVerbot als prüfenswert?

[...]

8. Welche Bundesministerien oder Bundesbehörden außer den oben genannten beschäftigen sich aktuell oder haben sich in den letzten zwei Jahren mit dem Thema Ad-Blocker beschäftigt?

1008 S. 46 und 49 der Dokumentensammlung, https://cdn.netzpolitik.org/wp-up load/2016/08/IFG-Adblocker-Medienkonvergenzkommission.pdf, zuletzt abgerufen am 31.5.2019.

1009 S. 114 der Dokumentensammlung, https://cdn.netzpolitik.org/wp-upload/2016 /08/IFG-Adblocker-Medienkonvergenzkommission.pdf, zuletzt abgerufen am 31.5.2019.

1010 BT-Drs. 18/9922, abrufbar unter https://dip21.bundestag.de/dip21/btd/18/099/1 809922.pdf, zuletzt abgerufen am 31.5.2019. 
9. Unterscheidet die Bundesregierung zwischen von Unternehmen (z. B. EYEO $\mathrm{GmbH}$ ) angebotenen Ad-Blockern und nicht kommerziell betriebenen AdBlockern, und wenn ja, ist die Unterscheidung in dem Angebot von kommerziellen Whitelists oder anderweitig begründet (bitte ausführen)?

10. Auf welcher rechtlichen Grundlage könnte ein mögliches Ad-Blocker-Verbot fußen (bitte detailliert aufzeigen)?

11. Gibt es infolge oder im Zuge des Ad-Blocker-Verbotes auch Planungen, den Werbeanteil von Webseiten auf ein „maßvolles Gehalt“ zu limitieren, um die Anwendung von Ad-Blockern zu minimieren? $[\ldots]$

15. Wie bewertet die Bundesregierung den Einsatz von Ad-Blockern aus datenschutzrechtlicher Perspektive insbesondere vor dem Hintergrund, dass diese es erlauben, Tracking-Anfragen von Webseiten zu blockieren, und die Onlineangebote der Presseanbieter - wie beispielsweise von Trackography.org visualisiert - intensive Tracking-Praktiken zur Ausforschung der Nutzerinnen und Nutzer ihrer Webseiten betreiben?

$[\ldots]$

18. Ist der Bundesregierung bekannt, dass durch DNS-Filtering auf Nutzerseiten ein mögliches Ad-Blocker-Verbot umgangen werden kann, und wenn ja, welche Schlussfolgerungen zieht die Bundesregierung daraus für ein mögliches Ad-Blocker-Verbot?

19. Wie schätzt die Bundesregierung Ad-Blocker-Detektoren ein, die von Verlagswebseiten (z. B. bild.de) eingesetzt werden, um Nutzer mit Ad-Blockern auszusperren, und sieht die Bundesregierung darin eine Verletzung der europäischen ePrivacy-Richtlinie (bitte begründen)?"

Im Übrigen beziehen sich die Fragen auf die Ansicht verschiedener Ministerien oder Bundesbehörden zu diesem Thema, auf Kenntnisse zu tatsächlichen und technischen Hintergründen sowie auf die Hintergründe der Auswahl der Teilnehmer an dem Workshop der Kommission.

Die Antwort der Bundesregierung ${ }^{1011}$ fiel in weiten Teilen kurz aus. Vorwiegend verwies sie auf laufende Prüfungen, zu denen noch kein abschließendes Ergebnis vorliege. Hervorzuheben sind allenfalls die folgenden Aussagen: In Beantwortung der oben zitierten Frage in Ziffer 15. verweist die Bundesregierung auf die seinerzeit geltenden datenschutzrechtlichen Regelungen im TMG sowie auf Grundlage der E-Privacy-Richtlinie. Au- 
Berdem kommentiert sie die Sachlage mit dem Hinweis: „Ob vor diesem Hintergrund Ad-Blocker einen Mehrwert haben, erscheint fraglich"1012.

Auf die Frage in Ziffer 18. im Kontext der möglichen Umgehung eines Verbots, teilte die Bundesregierung mit, dass dies im Rahmen der Erforderlichkeit eines Gesetzes geprüft werde. Bei den in Ziffer 19. angesprochenen Adblocker-Detektoren sah die Bundesregierung kein datenschutzrechtliches Problem, da nicht notwendigerweise personenbezogene Daten verarbeitet würden.

Die zurückhaltende Antwort der Bundesregierung war vor dem Hintergrund des für die Politik recht neuen Themas nachvollziehbar. Die Kleine Anfrage aus der Mitte des Bundestags lieferte sozusagen die in dem Bericht der Bund-Länder Kommission fehlende kritische Beleuchtung der Sicht der Medienunternehmen nach. Ob diese aber praktisch ein Gesetzesvorhaben aufgehalten haben, mag doch sehr bezweifelt werden. Die in Fragen verpackten Argumente gegen ein Gesetz ließen sich auch der außerparlamentarischen Diskussion leicht entnehmen.

Die Antwort der Bundesregierung und auch die Herangehensweise der Bund-Länder Kommission wurden öffentlich als nutzerfeindlich und das Problem des Malvertising verkennend kritisiert ${ }^{1013}$.

cc) Fachgespräch im Ausschuss für Kultur und Medien

Den scheinbaren Höhepunkt der Verbotsbestrebungen auf Bundesebene stellt wohl das Fachgespräch im Ausschuss für Kultur und Medien am 30.11.2016 dar ${ }^{1014}$. Der Ausschuss lud - anders als die Bund-Länder Kommission zuvor - Gesprächsteilnehmer aus verschiedensten Lagern ein. Die sechs Experten waren Vertreter aus der Rechtswissenschaft, von der Verbraucherzentrale, vom Verband Privater Rundfunk und Telemedien e.V., vom Bundesverband Deutscher Zeitungsverleger e.V., dem Zentralverband der deutschen Werbewirtschaft e.V. und vom Chaos Computer Club. Alle Teilnehmer kamen zu Wort und konnten ihre Sicht auf die Werbeblocker Problematik schildern.

1012 BT-Drs. 18/10115, S. 3.

1013 https://netzpolitik.org/2016/moegliches-ad-blocker-verbot-verbraucherperspe ktive-fuer-bundesregierung-nicht-so-wichtig/\#spendenleiste, zuletzt abgerufen am 31.5.2019.

1014 Das Protokoll ist nicht veröffentlich worden. Der Bearbeiter erhielt wegen seines akademischen Interesses eine Kopie zur Verfügung gestellt. Deshalb wird anonymisiert über die Aussagen der Teilnehmer berichtet. 
Von Seiten der Werbewirtschaft wurde dabei argumentiert, dass ein grober Eingriff in die Computerprogramme hinter der Ausspielung von Webseiten, inklusive der Werbelemente, vorliege. Dies gebiete ein gesetzliches Verbot. Dem hielt der Vertreter der Rechtswissenschaft entgegen, dass dies der herrschenden rechtlichen Bewertung des Sachverhalts widerspreche. Insbesondere erfolge der Eingriff allein im Nutzergerät. Daraufhin schilderte der Vertreter der Verbraucherzentrale die Sicht vieler Verbraucher auf das Thema. Werbeblocker würden heruntergeladen und eingesetzt, weil die jeweiligen Nutzer sich von aufdringlicher Werbung belästigt fühlten. Hinzu komme, dass ein Werbeblocker ein probates Mittel zur Erhöhung des Datenschutzes und des Schutzes gegen Tracking darstelle. Weitere Gründe seien eine Hilfe beim Jugendschutz und Verringerung von Datenverbrauch.

Auf Seiten der Rundfunkvertreter wurde sodann wieder auf die finanziellen Gefahren hingewiesen, insbesondere beim kommerziellen Whitelisting. Diese Einschränkung der Refinanzierung gefährde die Medienund Meinungsvielfalt. Außerdem sei das Argument der Nutzerautonomie ein Trugschluss, weil der Nutzer nicht genau wisse, was auf den eingesetzten Listen der Filterwerbeblocker stehe. Außerdem seien die von der Rechtsprechung herausgestellten Gegenmaßnahmen kostenintensiv oder würden, vor allem bei Bezahlschranken, nicht vom Publikum angenommen. Der sodann gehörte Vertreter der Zeitungsverleger bekrättigte diesen Vortrag und wies erneut auf einen urheberrechtlich relevanten Eingriff in die Webseitenausspielung. Auch stellte er auf den Einfluss der Pressefreiheit und den auf die Anzeigenwerbung ausstrahlenden Schutz ab. In Konsequenz dieser Umstände zeichnet er ein Bild, in welchem das Internet wie wir es kennen nicht mehr existieren werde. Schließlich liege die Kostenfreiheit der Inhalte an einer Werbefinanzierung.

Dem widersprach der Vertreter des Chaos Computer Club und beschrieb die Anzahl der Zwischenvermarkter, Tracker und sonstigen unbekannten Intermediären, die in der Ausspielung einer Webseite involviert sind. Deshalb habe eine Webseitenbetreiber selbst praktisch keinen Einfluss auf die eingespielte Werbung. Ausnahmen seien allein grobe Einschränkungen, z.B. Verbote hinsichtlich pornographischer oder Glücksspielwerbung. Deshalb könne bei einer Webseite gerade nicht von einer urheberrechtlich schutzwürdigen Leistung ausgegangen werden. Hinzu komme das Problem von Schadsoftware. Internetwerbung sei dabei nach E-Mail Anhängen die zweithäufigste Ursache für die Infektion von Rechnern. Werbeblocker seien in dieser Hinsicht ein Mittel zur digitalen Selbst- 
verteidigung. Trotz dessen äußerte er seine Meinung, dass kommerzielles Whitelisting unethisch sei.

In der Folge konnten die Ausschussmitglieder Fragen stellen, die die Experten beantworteten. Dabei wurde unter anderem aufgeworfen, dass ein Verbot von Werbeblockern auch allerlei andere Phänomene verbieten müsste - etwa reine Lesefunktionen in Browsern oder die Möglichkeit, gewisse Skripte nicht auszuführen. Im Übrigen argumentierten die Interessenvertreter weithin in Vertiefung ihrer oben dargestellten Argumente. Bemerkenswert war indes noch der Abschluss der Sitzung. Der Vertreter des Chaos Computer Club äußerte dabei seine Ansicht, dass ein Verbot von Werbeblockern von den Nutzern nicht akzeptiert würde. Der Download der Software und die Pflege von Filterlisten würde weitergehen. Ein Verbot von Werbeblockern wäre ein „weiteres Gesetz an das sich keiner hält“.

Der Ausschussvorsitzende musste zum Abschluss also feststellen, dass das Thema eine besondere Dimension aufweise und nicht mit einem „Keine Werbung"-Aufkleber am Briefkasten zu vergleichen sei. Es handele sich um eine zentrale medien- und kulturpolitische Frage.

Im Nachgang zu diesem Fachgespräch kam es offenbar nicht zu weiteren gesetzgeberischen Schritten. Insbesondere ist nicht ersichtlich, dass je ein Gesetzesvorschlag eingebracht worden sei. Das Gespräch zeigte in jedem Fall die Unversöhnlichkeit der Lager der Publisher- und der Nutzervertreter, die sich an allerlei Detailfragen zeigte. Die Freiheit, zu bestimmen, was auf dem Nutzerbildschirm angezeigt wird, reklamieren beide Lager für sich. Der Gesetzgeber hat sich zu Recht auf keine der beiden Seiten geschlagen und die Entscheidung weiterhin der Rechtsprechung überlassen. Die Rechtsprechung hat diese Entscheidung, wie oben aufgezeigt, dem Markt überlassen. Der Markt scheint gut genug zu funktionieren, sodass sowohl die Meinungsvielfalt im Internet als auch die Existenz von Werbeblockern koexistieren können.

dd) Antrag der NRW-Landtagsfraktion der PIRATEN und Reaktionen

Schließlich gab es eine weitere Episode im Streit um ein gesetzliches Vorgehen gegen Werbeblocker im nordrhein-westfälischen Landtag. Am 6.12.2016 stellt die Fraktion der PIRATEN einen Antrag, nach welchem der Landtag gewisse Thesen im Kontext von Werbeblocker feststellen und die Landesregierung auffordern soll, weitere Verbotsbemühungen zu un- 
terlassen ${ }^{1015}$. Konket fordert der Antrag zur Feststellung der folgenden Thesen auf:

„1. Ein Verbot von Software, die aus dem Internet übertragene Inhalte nach Wunsch des Nutzenden darstellt, wäre eine Maßnahme gegen die prinzipielle Konzeption und den fundamentalen Aufbau der WebTechnologie, die wir heute zur Mediennutzung anwenden.

2. Mediennutzende sollen nicht entgegen ihrem Willen ungewünschter Werbung ausgesetzt werden. Internetnutzende dürfen selbst entscheiden, was in ihren Browsern dargestellt wird und was nicht.

3. Mediennutzende sollen nicht unüberschaubaren Risiken durch Schadsoftware ausgesetzt werden, daher ist der Einsatz von Software, die vor mögliche Infizierung durch Schadsoftware schützt, zu begrüßen.

4. Nutzerautonomie und das Recht auf informationelle Selbstbestimmung sind auch bei der Mediennutzung zu wahren.

5. Es ist besser, Innovationen und Neuentwicklungen zu fördern um jenseits des Streits um alte Geschäftsmodelle neue Vertriebswege und Werbekommunikation zu ermöglichen, statt überholte Geschäftsmodelle zu schützen."

Außerdem lauten die Aufforderungen an die Landesregierung wie folgt:

„1. auf allen politischen Ebenen darauf hinzuwirken, dass die laufenden Prüfungen und Bemühungen, Ad-Blocker-Software zu verbieten, schnellstmöglich eingestellt werden.

2. zu prüfen, inwieweit innovative Entwicklungen im Bereich Onlinewerbung gezielt gefördert und unterstützt werden können."

Zur Begründung verweist der Antrag auf den Bericht der Bund-Länder Kommission sowie auf den Bericht der Landesregierung NRW vom 1.9.2016 zum Abschlussbericht der Kommission. In diesem Bericht heißt es, dass die gemeinsam getroffen Vereinbarungen der Kommission hinter dem Wunsch der Länder zurück geblieben seien. Im Übrigen nennt er die weithin für die Zulässigkeit von Werbeblockern angeführten Argumente wie Nutzerautonomie und Schutz vor Tracking. Außerdem nennt der Antrag eine potentielle gesetzliche Regulierung eine sehr einseitige Bevorzugung von Interessen von Medienkonzernen und der Werbeindustrie.

1015 Drucksache 16/13682, abrufbar unter https:/www.landtag.nrw.de/portal/WW W/dokumentenarchiv/Dokument/MMD16-13682.pdf, zuletzt abgerufen am 31.5.2019. 
Dieser Antrag führte zur Behandlung des Themas im Ausschuss für Kultur und Medien des Landtags NRW. Hier wurde insbesondere am 7.3.2017 eine vergleichbare Diskussion wie im entsprechenden Ausschuss des Bundes geführt ${ }^{1016}$. Bereits im Vorfeld wurden schriftliche Stellungnahmen der verschiedenen Interessenvertreter eingereicht. Besonders ist hierbei die Stellungnahme des Zeitungsverleger Verband Nordrhein Westfalen ${ }^{1017}$. Neben den bekannten Argumenten der Verlage enthält diese Stellungnahme sogar einen Vorschlag für den Wortlaut eines Verbotsgesetzes. Dieses Gesetz unterfalle als Gesetz zur Ausgestaltung der Medienordnung der konkurrierenden Gesetzgebung gem. Art. 74 GG. Konkret schlägt die Stellungnahme eine Ergänzung des VI. Abschnitt (Telemedien) des Rundfunkstaatsvertrages vor.

Der Vorschlag lautet wie folgt:

„Schutz der Integrität von journalistisch-redaktionellen Telemedienangeboten

Die Herstellung, Verbreitung, Bewerbung sowie die Verwendung von Vorrichtungen, Computerprogrammen oder Dienstleistungen, die die Integrität eines Telemedienangebots mit journalistisch-redaktionellen Inhalten einschließlich Rubrikenanzeigen beeinträchtigen, indem bestimmte Seiteninhalte beim Nutzer nicht geladen oder nicht angezeigt werden, sind ohne Zustimmung des Anbieters unzulässig. Dies gilt nicht für Vorrichtungen, Computerprogramme oder Dienstleistungen, die es einem Nutzer ermöglichen, bestimmte Seiteninhalte auszublenden, nachdem sie geladen wurden und die Möglichkeit zur Kenntnisnahme bestand. Der Verzicht auf technische Maßnahmen im Sinne des $\$ 95$ a UrhG gilt nicht als Zustimmung des Anbieters."

Der Entwurfstext erfasst durch die Handlung der Verwendung ausdrücklich das Nutzerverhalten. Der Begriff der Integrität eines Telemedienangebots würde gerade jenes Konzept schützen, das nach der herrschenden Rechtsprechung nicht schutzfähig sein soll. Die Ausnahme gälte zuvörderst für reine Lesefunktionen in Browsern. Nach hiesigem Verständnis würde allerdings auch das von den Verlagen ebenfalls als rechtswidrig angesehene „Element Hiding“ von Adblock Plus wohl hierunter fallen.

1016 Das Ausschussprotokoll ist abrufbar unter https://www.landtag.nrw.de/portal /WWW/dokumentenarchiv/Dokument/MMA16-1620.pdf, zuletzt abgerufen am 31.5.2019..

1017 https:/www.landtag.nrw.de/portal/WWW/dokumentenarchiv/Dokument/M MST16-4625.pdf, zuletzt abgerufen am 31.5.2019. 
Ebenso würden textbasierte Blocker wohl nicht vom Verbot erfasst. Der Entwurf würde praktisch wohl viele existierende Programme neben Adblock Plus erfassen, so etwa reine Trackingblocker. Das wahre Problem der effektiven Blockade von Werbung würde es aber wegen der Ausnahmen wohl nicht lösen. Zuletzt enthält der Entwurf eine gesetzliche Fiktion, dass der Verzicht auf technische Gegenmaßnahmen gegen das Blockieren nicht als schlichte Einwilligung zu werten sein soll.

Gegen diese Stellungnahme wurde recht harsche Kritik in der IT-Fachpresse laut. Vor allen wurde kritisiert, dass die Zeitungsverleger Werbeblockern die Schuld für in Deutschland weithin unbeliebte und kontroverse Entscheidungen wie die Wahl von Donal Trump zum US-Präsidenten oder für den Austritt Großbritanniens aus der EU. Auch wird zu Recht darauf hingewiesen, dass der Gesetzestext und die dazugehörende Begründung daruf abzielt, dass der bloße Abruf bereits die Vergütung für die Webseitenbetreiber auslöst. Dass die entsprechende Werbung dann aber nicht angezeigt werden muss, würde den finanziellen Schaden praktisch auf die Werbekunden verlagern. Ob dies eine langfristige Lösung sei, wird zu Recht bezweifelt ${ }^{1018}$. Zudem wird kritisiert, dass durch den Gesetzesentwurf Nutzer kriminalisiert würden. Praktisch könnten dann Webseitenbetreiber Nutzer abmahnen, wofür sie davor zudem erst ihre Identität ermitteln müssten ${ }^{1019}$.

Der Antrag der PIRATEN wurde übrigens am 21.3.2017 mit den Stimmen der rot-grünen Mehrheit im Ausschuss für Kultur und Medien abgelehnt ${ }^{1020}$. Der Gesetzesentwurf der Zeitungsverleger schaffte es jedoch nicht zur Aufnahme in gesetzgeberische Prozesse.

b) Tendenzen in der 19. Legislaturperiode (ab 2017)

In der sich darauf anschließenden Legislaturperiode des Bundestags mussten die parlamentarischen Anläufe zu einem Verbot von Werbeblockern wegen des Diskontinuitätsgrundsatzes fallengelassen werden. Allerdings konnte nicht beobachtet werden, dass die Atktivitäten aus der 18. Legis-

1018 https:/www.golem.de/news/verbot-gefordert-verleger-geben-adblockern-mitsc huld-an-trumps-wahlsieg-1703-126579.html, zuletzt abgerufen am 31.5.2019.

1019 https://www.golem.de/news/gesetzliches-verbot-die-schlechte-adblocker-satire -der-verleger-1703-126607.html, zuletzt abgerufen am 31.5.2019.

1020 Siehe S. 15 der Drucksache 16/14678, https://www.landtag.nrw.de/portal/WW W/dokumentenarchiv/Dokument/MMD16-14678.pdf, zuletzt abgerufen am 31.5.2019. 
laturperiode wieder aufgenommen worden sind. Es bleibt abzuwarten, ob die Niederlage beim Bundesgerichtshof zu einem neuen Anlauf der Verbotsbefürworter führen wird.

\section{c) Meinungstand und Stellungnahme}

Die aufgezeigten parlamentarischen Vorstöße sind vor allem Ausdruck von Verzweiflung auf Seiten der Medienanbieter. Während sie natürlich ein legitimes Mittel zur Interessenverfolgung waren, konnten sie zu Recht keinen Erfolg haben. Es ist auch zu begrüßen, dass es niemals zu einem förmlichen Gesetzgebungsverfahren gekommen ist. Tatsächlich sind die Bestrebungen niemals über die Schwelle der Sachverhalts- und Interessenaufklärung in Fachausschüssen hinaus gekommen.

Was dabei freilich nicht oder nur am Rande diskutiert worden ist, ist die Frage der verfassungsrechtlichen Zulässigkeit eines Verbotsgesetzes für Werbeblocker. Diese Frage war zum Teil Gegenstand des Auftragsgutachtens von di Fabio ${ }^{1021}$. Eine konkrete Frage im Begutachtungsauftrag war es dabei perspektivisch zu beurteilen, „welche verfassungsrechtlichen Vorgaben der Gesetzgeber zu beachten hat, wenn er die Verwendung oder das Inverkehrbringen von Werbeblockern untersagen oder einschränken wollte" 1022 .

In seiner Begutachtung stellte di Fabio einige Thesen ${ }^{1023}$ heraus. So wäre angesichts der Globalität des Netzes eine Regelung sinnvollerweise international, zumindest aber auf der Ebene der EU, angezeigt. Ein generelles Verbot des Geschätsmodells selektiver Werbefilter (sprich: kommerzielles Whitelisting) scheide aus, weil die grundrechtlichen Interessenlagen multipolar und gleichwertig seien. Zudem bestehe keine gesetzliche Schutzpflicht des Gesetzgebers zugunsten von Presseunternehmen, da die Substanz der Pressefreiheit zur Zeit der Gutachtenerstellung nicht bedroht sei. Eine verfassungsrechtliche Grenze einer gesetzlichen Regulierung von Werbeblockern bestehe indes in der Formulierung eines allgemeinen Gesetzes und in der Erforderlichkeit eines solchen Gesetzes. Ein spezielles Verbot für bestimmte Werbeblockerformen, z.B. kommerzielles Whitelisting, würde diese Voraussetzungen wahrscheinlich nicht erfüllen.

1021 MMR-Beilage 2016, 1. Das Gutachten wurde von der Eyeo GmbH beauftragt, vgl. https://www.golem.de/news/gutachten-verbot-von-adblockern-verfassungsr echtlich-bedenklich-1610-123634.html, zuletzt abgerufen am 31.5.2019.

1022 di Fabio, MMR-Beilage 2016, 1, 5.

1023 di Fabio, MMR-Beilage 2016, 1, $12 \mathrm{f}$. . 
Ähnlich argumentiert Kublmann in einem ähnlich gelagerten Beitra$\mathrm{g}^{1024}$. Der Einsatz von Werbeblockern, insbesondere im Fall Adblock Plus, sei kein hinreichend relevanter Eingriff in die Presse-, Rundfunk- und Meinungsfreiheit, der ein Handeln des Gesetzgebers im Hinblick auf die Beeinträchtigung der Vermittlung werblicher Inhalte verfassungsrechtlich gebiete. Mit Blick auf einen gesetzlichen Schutz der Refinanzierung von Webangeboten durch Werbung sieht Kuhlmann ein legitimes Ziel für eine Regulierung. Der Gesetzgeber könne im Rahmen seines Normsetzungsermessens die Absicherung dieser Finanzierungsform schützen, wenn er sie zur Erhaltung der Existenz der Presse im Internet für notwendig erachte. Aus dieser Möglichkeit folge jedoch keine Handlungspflicht, da keine gesicherten Erkenntnisse vorliegen, dass Vorkehrungen zur Erhaltung der Funktionsfähigkeit der Presse notwendig sind. Aktuell bestehe allenfalls eine Beobachtungspflicht des Gesetzgebers. Zuletzt stelle auch das Risiko verminderter Medienvielfalt im Onlinebereich keinen Grund für eine Regulierung dar, da keine Anzeichen für eine maßgebliche Gefährdung des Meinungspluralismus vorlägen. Zuletzt sei ein gesetzliches Verbot von Werbeblockern im Gegenteil sogar verfassungsrechtlich bedenklich, weil damit Einschränkungen für die Nutzer im Hinblick auf das verfassungsrechtlich abgesicherte Interesse am Fortbestand von Abwehrmöglichkeiten gegen unerwünschte Werbung einhergingen.

Den Ausführungen von di Fabio und Kublmann ist ganz überwiegend zuzustimmen. Insbesondere liegen beide Autoren richtig mit der Ansicht, dass Werbeblocker keine dermaßen bedrohliche Lage für Refinanzierung von Medienangeboten und damit für die Medienvielfalt insgesamt schaffen, dass der Gesetzgeber gezwungen wäre zu handeln.

Im Übrigen stellte sich die Frage, in welchem Gesetz ein Verbot gegen Werbeblocker überhaupt unterzubringen wäre. Durch die starke lauterkeitsrechtliche Prägung der Diskussion böte sich das UWG an. Allerdings würde ein solches Spezialverbot schwerlich mit der gesetzlichen Konstellation des UWG als „Gesetz der Generalklauseln“ vereinbar sein. Eine Öffnung des UWG für ein spezielles Verbot wäre ein unerwünschter Präzedenzfall, dem praktisch viele weitere Spezialverbote folgen könnten. Denn wenn die Presse einen besonderen Schutz erhält, werden auch viele weitere Wirtschaftsbereich nach gesetzlichem Schutz im Wettbewerbsrecht rufen. Eine Unterbringung im Urheberrecht scheidet maßgeblich aus zwei Gründen aus: Zum einen müsste der Gesetzgeber in einem Vorschritt die „Integrität von Inhalt und Werbung“ unter urheberrechtlichen Schutz

1024 Kuhlmann, AfP 2016, 318. 
oder zumindest unter ein neues Leistungsschutzrecht stellen. Zum anderen ist es sehr fragwürdig, ob im stark unionsrechtlich geprägten Urheberrecht ${ }^{1025}$ ein solches einseitig in einem Mitgliedsstaat geltendes Verbot zulässig sein kann. Hier wäre es nicht unwahrscheinlich, wenn der EuGH eingreifen würde. Das Kartellrecht verfügt ebenfalls bereits über ausgeklügelte Regeln, in welchen im Rahmen der letzten (9.) GWB-Novelle erst Neuerungen mit Blick auf die Internetökonomie vorgenommen worden sind $^{1026}$.

Eine Regulierung im vom Zeitungsverleger Verband Nordrhein Westfalen vorgeschlagenen Rundfunkstaatsvertrag erscheint sehr unglücklich. Hier sind zwar Regeln für Telemedien enthalten, diese binden aber eher die Diensteanbier. Ein an Nutzer und Softwarehersteller gerichtetes Verbot passt aber systematisch nicht so recht in dieses Regelwerk. Es ist zudem offen, ob ein Verbot von Werbeblockern wegen der allgemeinen Wirkung für Bürger und Gewerbetreibende im Bundesgebiet in der für Staatsverträge notwendigen Gesetzgebungskompetenz des Bundesländer liegt. Ein solches Verbot scheint wohl eher dem bürgerlichen Recht nach Art. 74 Abs. 1 Nr. 1 GG bzw. des Recht der Wirtschaft nach Art. 74 Abs. 1 Nr.11 GG zuzuordnen zu sein, die der konkurrierenden Gesetzgebungskompetenz unterliegen. Der Bund hat in diesen Bereich bereits ausreichende Regeln erlassen, sodass die Bundesländer hier nicht ihrerseits ergänzende Spezialverbote in einem Staatsvertrag erlassen könnten.

Zuletzt stünde noch das TMG zur Verfügung. Auch das TMG stellt aber regelungstechnisch eine Regulierung der Telemediendienstleister dar. Ein sie begünstigendes Verbot, das die Handlungsfreiheit einer Vielzahl von Bürgern beschränken würde, wirkte deplatziert.

Somit fehlt es schon an einem passenden Ort für ein Verbotsgesetz gegen Werbeblocker. Ein neues Spezialgesetz nur für ein Werbeblockerverbot - soweit es das verfassungsrechtliche Verbot von Einzelfallgesetzen nicht tangieren würde - wäre wohl kaum politisch tragfähig. Nur allzu deutlich würde die Bevorteilung der Pressewirtschaft gegenüber den Bürgern als Internetnutzern zu Tage treten.

1025 Vgl. auch die Richtlinie (EU) 2019/790 des Europäischen Parlaments und des Rates vom 17. April 2019 über das Urheberrecht und die verwandten Schutzrechte im digitalen Binnenmarkt und zur Änderung der Richtlinien 96/9/EG und 2001/29/EG, die am 17.5.2019 im Amtsblatt der Europäischen Union veröffentlicht worden ist. Dieses Ergebnis der im Jahr 2019 heftig umstrittenen Urheberrechtsreform verfügt über keinerlei Hinweise darauf, dass Werbeblocker ein urheberrechtlich zu regelndes Thema sind.

1026 Vgl. Podszun/Schwalbe, NZKart 2017, 98. 
Damit ist auch der weitere und maßgeblich entscheidende Punkt gegen ein gesetzliches Verbot von Werbeblockern angerissen. Denn wie die zivilrechtlichen Urteile zeigen, handelt es sich um eine komplexe Interessenlage mit vielen Betroffenen. Es geht nicht nur um die Presse, die Webseitenbetreiber, die Werbetreibenden und Werbeblockersoftwarehersteller. Es geht auch um die Allgemeinheit und die Nutzer von Werbeblockern. Es wurde im Rahmen dieser Arbeit auch bereits hinlänglich aufgezeigt, dass sich im Groben zwei Lager bilden lassen, deren Interessen konträr sind. Der Gesetzgeber tut gut daran, diesen Grabenkampf nicht einseitig zugunsten der „Werbeindustrie“ zu entscheiden. Denn aktuell wird die Entscheidung über die Werbung im Internet dem Markt überlassen und beide Lager existieren erkennbar fort. Eine Entscheidung würde die Entwicklungen des Marktes künstlich lenken und unnötiges Lenken führt nur selten zum Erfolg.

Erschwerend kommt hinzu, dass die Durchsetzbarkeit eines Werbeblockerverbots ein Schreckensszenario darstellt. Nimmt man ein Verbot wie im obigen "Gesetzesentwurf“ der Zeitungsverleger aus NRW, so müsste das Gesetz durch Verweisung oder durch ausdrückliche Regelung flankierende Berechtigungen zur Ermittlung von Nutzern von Werbeblockern sowie zum Schadensersatz vorsehen. Webseitenbetreiber würden also vergleichbar mit den Filesharing-Fällen von Anfang dieses Jahrtausends - Nutzer identifizieren und gerichtlich verfolgen können mit enormen finanziellen Folgen für Nutzer. Die Folge wäre eine Abmahnwelle gegen „Nichtabschalter“, die sich seinerseits zum Geschäftsmodell entwickeln könnte. Doch auch Nutzer, die Werbeblockern abschwören, würden durch ein entsprechendes Gesetz einer weiteren Überwachung neben dem sowieso bestehenden Tracking ausgesetzt.

Es spricht nach hiesiger Ansicht demnach rein gar nichts für ein gesetzliches Verbot von Werbeblockern ${ }^{1027}$. Dies wäre im Gegenteil ein äußerst undemokratisches Einknicken vor einer Lobby, das rechtspolitisch und ethisch nicht akzeptabel ist.

\section{Zwischenergebnis: Parasit oder Symbiont?}

Nach alledem lässt sich an dieser Stelle ein Zwischenfazit ziehen und eine Antwort auf die eingangs gestellte Frage geben, ob die Internetwer-

1027 Im Ergebnis ähnlich: Kreutz, Online-Angebote und Werbeblocker, S. 407, 410. 
beblocker wirklich Parasit oder vielleicht doch (dritter) Teilnehmer der Symbiose sind. ${ }^{1028}$

Im zumindest bei der Frage des „Ob“ von Werbung relativ ungeregelten Milieu mögen die Werbeblocker zwar ein Nachzügler sein, die nicht ursprünglich in die Wertschöpfung eingebunden waren. Allerdings sind Werbeblocker eine Ausprägung genau dieses Milieus. Geschaffen wurden sie von Werbeadressaten, ebenso haben diese die Werbeblocker erst zu einem ernstzunehmenden Phänomen gemacht. Der oben dargestellten rechtlichen Analyse zu Folge sind die Werbeblocker demnach auch nicht Parasit, sondern Symbiont. Dieser Ansicht war wohl auch die Politik, die auf Verbotsbestrebungen keinen förmlichen Versuch eines solchen Verbots startete.

Werbeblocker sind deshalb ein nicht mehr wegzudenkender Teilnehmer im Rahmen der Kommunikation im World Wide Web. Dies müssen Webseitenbetreiber und Werbetreibende hinnehmen. Die sie zweifellos treffenden Auswirkungen können sie mit wettbewerbsimmanenten Mitteln abfedern. Seien diese Mittel der Verzicht auf Werbung, die die Adressaten vergrämt, oder Maßnahmen, die die Wirkung von Werbeblockern verhindert. Letzteren widmet sich diese Arbeit sogleich im Anschluss.

1028 Siehe oben die Eingangserwägungen in Abschnitt B. 


\section{Reaktion: Maßnahmen zur Verhinderung von Werbeblockern}

In seinem Urteil Werbeblocker II führte der BGH im Kontext der möglichen Reaktionen durch von Werbeblockern betroffenen Webseitenbetreibern wie folgt aus:

„Bei der Gewichtung der von der Klägerin beanstandeten Beeinträchtigung ihrer Geschäftstätigkeit ist zunächst zu beachten, dass sich auch Unternehmen des Medienbereichs den Herausforderungen des Marktes stellen müssen, der von der Freiheit der wirtschaftlichen Betätigung und von der Kraft der Innovation lebt (vgl. BGH, GRUR 2004, 877, 880 [juris Rn. 33] - Werbeblocker I). Zu diesen Herausforderungen zählt auch die Entwicklung von Maßnahmen, mit deren Hilfe Medienunternehmen den negativen Auswirkungen der Handlungen eines Wettbewerbers entgegenwirken können (vgl. BGH, GRUR 2004, 877, 880 [juris Rn. 33] - Werbeblocker I). Hierzu hat das Berufungsgericht festgestellt, dass die Klägerin über eine technische Funktion verfügt, mit deren Hilfe Nutzer, die Werbeblocker einsetzen, von der Wahrnehmung kostenloser redaktioneller Inhalte ausgeschlossen werden können. Das Berufungsgericht hat weiter festgestellt, dass Anbietern von redaktionellen Inhalten im Internet die Möglichkeit offensteht, durch die Einführung von Bezahlangeboten für Einnahmen zu sorgen. Auf der Grundlage dieser Feststellungen, die die Revision der Klägerin nicht wirksam angreift, kann keine Rede davon sein, dass die Klägerin gezwungen wäre, auf das Angebot der kostenpflichtigen Whitelisting-Funktion einzugehen."1029

Dieses Zitat gilt für die Betroffenen als Grundlage für ihre Bemühungen gegen Werbeblocker. Der BGH hat bereits den sich aufdrängenden Weg skizziert: technischer Ausschluss von Werbeblockernutzern und Einführung von Bezahlangeboten. Beide Lösungen können alternativ oder kumulativ verbunden werden.

Nicht zuletzt weil beide Lösungen bereits vor Abschluss des Revisionsverfahrens beim BGH in der Praxis angewendet worden sind, lohnt sich

1029 BGH, Urteil vom 19.4.2018 - I ZR 154/16, WRP 2018, 1322, 1326, Rn. 39 Werbeblocker II. Hervorhebung nur hier. 
an dieser Stelle ein vertiefter Blick auf die tatsächlichen und rechtlichen Hintergründe der Reaktionen der Online-Werbewirtschaft.

\section{Darlegung von Reaktionen der Webseitenbetreiber und Werbenden}

Zunächst sollen dazu die tatsächlich zu beobachtenden oder denkbaren Reaktionen auf Seiten des werbenden Lagers skizziert werden. Die Reaktionen sind in der Regel technisch komplexe Lösungen, sodass das Verständnis der genauen Wirkweise für die sich anschließende rechtliche Beurteilung unerlässlich ist.

Nicht näher eingegangen werden soll auf rein kommunikative Maßnahmen wie Aufklärung von Nutzern oder Appelle aller Art, auf Werbeblocker zu verzichten ${ }^{1030}$. Es ist eindeutig, dass diese Reaktionen erlaubt sein müssen. Ebenso ist die denkbare Reaktion einer Verbesserung von Online Werbung, d.h. der Verzicht auf aufdringliche Werbeformen oder -inhalte, nicht näher zu untersuchen. Auch dies ist ohne Zweifel ein erlaubtes Verhalten. Im Gegensatz dazu sind die meisten technischen und wirtschaftlichen Maßnahmen nicht darauf gerichtet, den Nutzer zu überzeugen, auf Werbeblocker zu verzichten. Sie sind darauf gerichtet, den Einsatz von Werbeblockern unmittelbar mit spürbaren Folgen für den Nutzer zu verbinden und den Einsatz damit uninteressant zu machen.

\section{Adblocker-Detektoren}

Die Grundlage für technische Lösungen zum Gegenschlag gegen Adblockernutzer stellen Adblocker-Detektoren dar. Diese Detektoren dienen der Ermittlung, ob ein Besucher einer Webseite einen aktivierten Werbeblocker nutzt ${ }^{1031}$. Dies ist der logische erste Schritt, um für diesen unerwünschten Zugriff auf den Webseitencontent eine Reaktion zu aktivieren.

Wie funktionieren diese Adblocker-Detektoren? Dazu muss nochmals die grundsätzliche Funktion der HTTP-Kommunikation und der Werbeblocker ins Gedächtnis gerufen werden ${ }^{1032}$. Der Detektor macht sich diese Wirkweise zu Nutze, indem er einen oder mehrere Köder in den HTML-

1030 Vgl. etwa https://winfuture.de/videos/Werbespots/Stromberg-macht-Werbung -gegen-Adblocker-11928.html, zuletzt abgerufen am 31.5.2019.

1031 Vgl. auch Bechtolf/Vogt, K\&R 2016, 445, 446.

1032 Siehe oben Ziffern B. III. 1. b) cc) und C. I. 2. a) aa). 
Code integriert. Dieser Köder ist in der Regel ein sehr kleines Element und für Nutzer unsichtbar, aber fällt unter einen Blacklist-Filterbefehl. Folglich wird der Köder nicht vom Browser geladen - paradoxerweise „beißt“ der Werbeblocker also nicht an. Der „Köder“ wirkt aber gerade deshalb, denn im HTML-Code ist neben dem speziell benannten Köderelement außerdem ein Skript vorgesehen, dass nach dem Ladevorgang der Seite prüft, ob das Element angezeigt wird. Das Ergebnis dieser Prüfung wird an den Server zurückgesendet ${ }^{1033}$.

Diese Methode funktioniert auch bei Element Hiding oder sonstigen Blockern, die das Element zwar laden, aber deren Anzeige unterdrücken. Denn hier wird der Köder geladen, unterfällt aber den bekannten Regeln des Element Hidings und wird deshalb nicht angezeigt. Dieser Umstand wird danach wiederum von einem Skript überprüft und an den Server als Information zurückgesendet ${ }^{1034}$.

All diese Vorgänge laufen in den Sekunden des Ladevorgangs der Webseite ab. Wenn der Adblocker-Detektor demnach einen aktivierten Werbeblocker feststellt, werden die nachfolgend dargestellten Maßnahmen ausgelöst.

Adblock-Detektoren sind demnach eine Verbindung aus einem Köderelement im HTML-Code einer Webseite sowie eines Skripts, zumeist JavaScript, d.h. einem kleinen Computerprogramm. Es versteht sich, dass diese Methode bei komplexen Webseiten mit einer Vielzahl von Ködern einhergeht, um die Effektivität des Detektors zu verstärken. Denn als Antwort auf bekannte Köder könnten die Filterlisten angepasst werden, indem ein einzelner Köder von der Blockade ausgenommen und damit wirkungslos gemacht werden.

\section{Zugangssperren}

Erkennt der Adblocker-Detektor den aktivierten Werbeblocker wird bei einigen Webseiten eine Zugangssperre ausgelöst. Das bekannteste Beispiel dafür dürfte in Deutschland die Webseite Bild.de $\operatorname{sein}^{1035}$. Die Bild.de-

1033 Vgl. die Beschreibung bei https://www.quora.com/How-do-AdBlock-detectors -work, oder https://clearcode.cc/blog/detect-ad-blockers/, zuletzt abgerufen am 31.5.2019.

1034 Vgl. https://www.techotopia.com/index.php/Ad_Blocker_Detection_Techniqu es, zuletzt abgerufen am 31.5.2019.

1035 Siehe eingangs unter Ziffer A. III.. 
Sperre wurde im Tatbestand eines Urteils des LG Hamburgs wie folgt beschrieben:

„Besucht ein Nutzer die Webseite, lädt sein Browser zunächst das auf einer HTML-Datei basierende Grundgerüst der Seite, das für den Abruf und die Darstellung der eigentlichen Inhalte benötigt wird. An diesem Punkt greift die Maßnahme ein. Diese besteht aus verschiedenen auf JavaScript basierenden Komponenten, die parallel vom Browser des Nutzers geladen und ausgeführt würden. Mit Hilfe der Komponenten wird geprüft, ob der Browser des Seitenbesuchers auch Werbeinhalte aufrufe. Stellt die Software fest, dass das Laden von Werbung blockiert wird, bricht sie den Ladevorgang der Webseite ab und leitet den Nutzer auf eine Sperrseite um.“1036

Ebenfalls diesem Modell folgen zum Zeitpunkt der Bearbeitung dieser Arbeit die Frankfurter Allgemeine Zeitung (faz.net), die Süddeutsche Zeitung (sz.de) sowie die Rheinische Post Düsseldorf (rp-online.de). Das Handelsblatt (handelsblatt.de) und der Spiegel (spiegel-online.de) haben die Zugangssperre als Pop-Up ausgestaltet, dass zwar den Inhalt in der Schicht darunter erkennen lässt, jedoch kein Lesen ganzer Absätze möglich macht.

Dieser drastische Schritt wird durch das Einblenden einer Sperrseite vollzogen, auf der Informationen zum Abschalten des Werbeblocker oder alternativ zum Abschluss eines kostenpflichtigen Abonnements gegeben werden. Diese Webseiten verfolgen also streng die Maßgabe, dass es keinen kostenlosen Content für Nutzer gibt. Entweder man zahlt einen gewissen Geldbetrag oder man akzeptiert die Werbung.

Bei den Zugangssperren lässt sich in manchen Fällen die Wirkweise des Adblocker-Detektors beobachten. Wenn man bei gewissen Seiten erstmals eine Webseite besucht, wird nämlich bei entsprechend schneller Internetverbindung häufig für einen kurzen Augenblick die Webseite noch „normal“ angezeigt. Erst wenn der Adblocker-Detektor die Information des aktivierten Werbeblockers zurück an den Server gesendet hat, wird von dort aus der Befehl zum Einblenden des Sperrbildschirms gesendet. Die Zugangssperre ist demnach der Folgebefehl nach Ablauf des DetektorSkripts.

Eine alternative Gestltung würde darauf hinauslaufen, dass in der usrpünglich übersandten HTML-Datei noch keinerlei Daten für die später zu ladende Webseite enthalten sind, sondern lediglich ein Kontrollskript.

1036 LG Hamburg, Urteil vom 21.12.2016 - 310 O 129/16, juris. 
Erst nach dem Prüfergebnis dieses Skripts würde dann die eigentliche Vervielfältigung der Webseitenelemente initiiert ${ }^{1037}$.

\section{Eingeschränktes Angebot und Bezahlschranken}

Als anderer Folgebefehl nach der erfolgreichen Adblocker-Detektion käme in Betracht, das Angebot enorm einzuschränken, also nur noch Vorschauen oder Ausschnitte zuzulassen. Eine solche eingeschränkte Sperre ist allerdings nach hiesigen Beobachtungen im Bereich der deutschen Medien nicht zu beobachten. Die Einschränkung von freien Angeboten bzw. die Herausnahme gewisser Inhalte aus dem kostenlosen Bereich und deren Verlagerung in einen kostenpflichtigen Abonnementbereich richtet sich generell an alle potentiellen Nutzer, nicht nur solche mit aktiviertem Werbeblocker. So zum Beispiel das „F+“ Angebot bei faz.net ${ }^{1038}$.

Ebensowenig sind reine Bezahlschranken außerhalb der klassischen PayAngebote im Bereich von TV- oder Streamingangeboten in der deutschen Medienlandschaft zu erkennen. Im Übrigen ist auch nicht ersichtlich, dass Contentanbieter wegen der Verbreitung von Werbeblockern vom rein kostenlosen Angebot zu einem reinen Bezahlangebot gewechselt wären.

Damit können diese Reaktionsmöglichkeiten aus dem Bereich der „Werbeblocker Kampfmaßnahmen“ gestrichen werden. Soweit entsprechende Reaktionen zu beobachten sind, sind sie eher der Marktentwicklung insgesamt geschuldet. Dass Werbeblocker hierbei wohl mittelbar auf die Umsätze des früheren rein kostenlosen Angebots eingewirkt haben, fällt dabei für diese Bearbeitung nicht weiter ins Gewicht.

\section{Ausspielung nicht blockierbarer Werbung}

Statt den Zugang zum Inhalt zu versperren, anzupassen oder nur gegen Zahlung freizugeben, lässt sich auch ein gegenteiliges Vorgehen beobachten. Bei dieser Strategie wird versucht, den Werbeblocker in seiner Funktionalität auszuschalten. Das Ergebnis ist eine nicht blockierbare Werbung, die auch bei Nutzern mit aktiviertem Werbeblocker angezeigt wird.

1037 Vgl. Kiersch/Kassel, CR 2017 242, 243.

1038 https://abo.faz.net/angebote/digital/komplett/, zuletzt abgerufen am 31.5.2019. 
Diese Strategie verfolgen zur Zeit der Bearbeitung etwa stark frequentierte Webseiten wie, welt.de, kicker.de, zeitweise bei spiegel-online.de ${ }^{1039}$ oder die insbesondere für IT-Nachrichten spezialisierte Webseite golem.de. Auch müssen Nutzer von Adblock Plus beim Abspielen von Videos auf prosieben.de trotz aktiviertem Werbeblocker Pre-Roll Werbung sehen.

Dieser Effekt lässt sich nur damit erklären, dass die jeweiligen Anbieter die Werbeausspielung „adblocksicher" geamcht haben. Dabei lassen sich bei grober Betrachtung zwei Methoden unterscheiden: Werbung wird generell unblockierbar programmiert oder sie wird nach der Wirkung eines Adblocker-Detektors ersatzweise ausgespielt ${ }^{1040}$.

Bei der generell unblockierbaren Werbung sind unter Ausnutzung der Funktionsweise von Filterwerbeblockern mehrere technische Möglichkeiten gegeben. Zunächst ist die Einbindung und Auslieferung von Werbeelementen durch eigenen Server ein Mittel zur Erschwerung der Blockade durch die Blockersoftware ${ }^{1041}$. Wenn die Werbeblockaden nämlich wie Contentelemente erscheinen - und zwar insbesondere in der Art und Weise der Einbindung im HTML-Code - kommen Filterwerbeblocker an Ihre Funktionsgrenze. Die Werbeblocker als Publikumsinstrument haben schließlich kein Interesse daran, dass sie im großen Umfang Bildelemente, die zum Content gehören, blocken. Eine solche Unzuverlässigkeit würde bei wiederholtem Auftreten wohl zu einer Abkehr des Nutzers vom speziellen Werbeblocker führen. Außerdem werden bei der Auslieferung über denselben Server, über den auch der übrige Content abgerufen wird, die Drittserververbindungen vermieden. Diese sind über Filterlisten relativ leicht $\mathrm{zu}$ unterbinden. Eine integrale Verbindung zwischen Server und Client hingegen verhindert in manchen Fällen das Eingreifen bekannter Filterwerbeblocker.

Zudem lässt sich der HTML-Code so programmieren, dass gezielt die Filterbefehle der üblichen Filterlisten, z.B. der Easylist Germany, umgangen werden ${ }^{1042}$. Gleichwirkend wäre wohl auch die Hinterlegung der Werbeelemente unter statischen URLs, die die Filterlisten nicht als Werbung erkennen. Die Easylist Germany ist öffentlich zugänglich, sodass Programmierer Bezeichnungen für die Werbeelemente nutzen können, die der

1039 Hier lässt der Betreiber ein Pop-Up mit der Bitte um Ausschalten des Werbeblockers einblenden und bei Ablehnung Zwangswerbung ausspielen.

1040 Vgl. Kreutz, MMR 2016, 364; Online-Angebote und Werbeblockersoftware, S. $415 \mathrm{ff.}$.

1041 Kreutz, MMR 2016, 364; LG Hamburg, Urteil vom 21.4.2015 - 416 HKO 159/14, CR 2016, 122.

1042 Vgl. Kreutz, MMR 2016, 364. 
Browser mit Werbeblocker im Ladevorgang nicht als „verbotene“ Requests erkennt. Diese Methode ist freilich aufwändig und kurzweilig, weil die neuen Bezeichnungen und URLs der Filterliste hinzugefügt werden können. Damit verwandt, jedoch dauerhaft effektiver ist die Verwendung von dynamischen URLs für Werbeelemente ${ }^{1043}$. Bei dieser dynamischen Generierung von URLs werden immer neue Quellpfade erstellt, die naturgemäß nicht in einer statischen Filterliste vorab aufgenommen werden können.

Bei der reaktiven Ausspielung von „adblocksicherer“ Werbung steht im Ausgangspunkt wieder die Erkennung des Nutzers mit aktiviertem Werbeblocker. Anstatt jedoch wie bei der Zugangssperre nun die Sicht auf die Inhalte zu verdecken und zum Abschalten aufzufordern oder auf Zahlangebote hinzuweisen, lautet der Programmbefehl hier auf Nachladen von Ersatzwerbung ${ }^{1044}$. Bei der technischen Ausgestaltung bestehen scheinbar diverse Methoden, die sich im Detail unterscheiden können. Ihnen ist aber der oben beschriebene Vorgang gemein: Adblock-Nutzung wird erkannt und Werbeplätze werden durch alternative Quellen nachgeladen.

Der Dienstleister „AdDefend“ beschreibt seine Leistungen mit einem Schaubild wie folgt ${ }^{1045}$ :

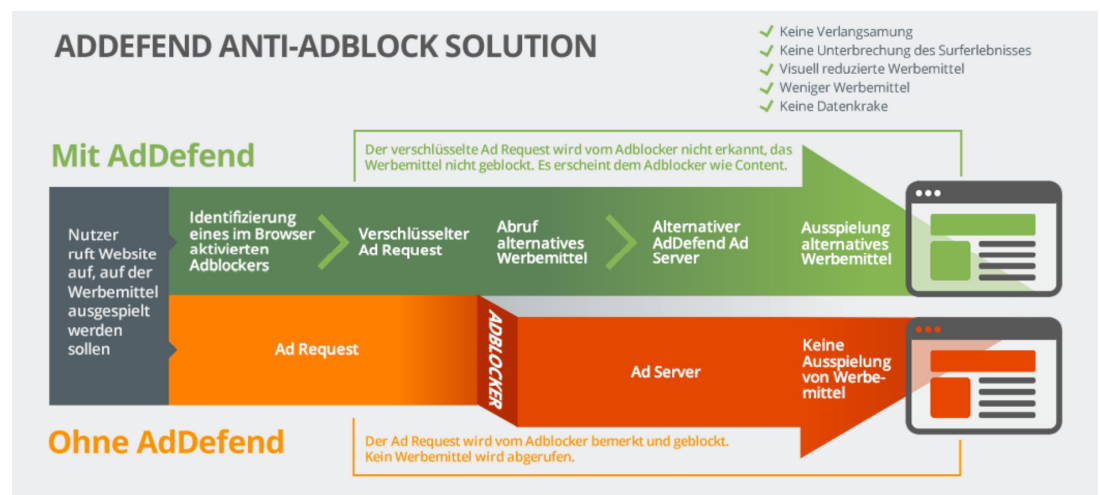

Ein aufmerksamer Nutzer mit aktiviertem Werbeblocker wird diesen Vorgang zumindest in zeitlicher Hinsicht nachvollziehen können. Denn bei den meisten der vorgenannten Webseiten vergehen wenige Sekunden bis die alternativen Werbemittel eingeblendet werden. Auch die Qualität der

1043 Kreutz, MMR 2016, 364.

1044 Vgl. Kreutz, MMR 2016, 364.

1045 https:/www.addefend.com/de/platform/, zuletzt abgerufen am 31.5.2019. 
alternativen Werbemittel ist teils fragwürdig wie der nachfolgende Vergleich der Webseite kicker.de ${ }^{1046}$ zunächst ohne und dann mit aktiviertem Adblock Plus zeigt:

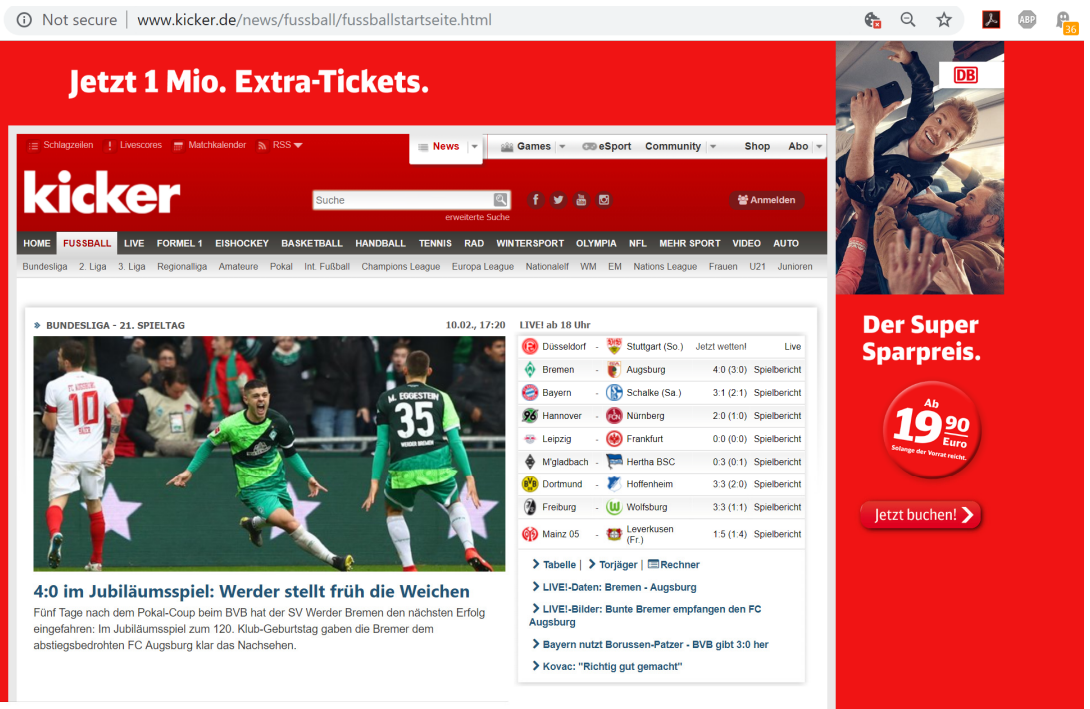

Anzeige der Webseite ohne Werbeblocker

1046 Die nachfolgenden Screenshots wurden gefertigt am 10.2.2019. Es ist nicht bekannt, ob diese Ersatzwerbung über einen bestimmten Dienstleister wie Addefend abläuft. 


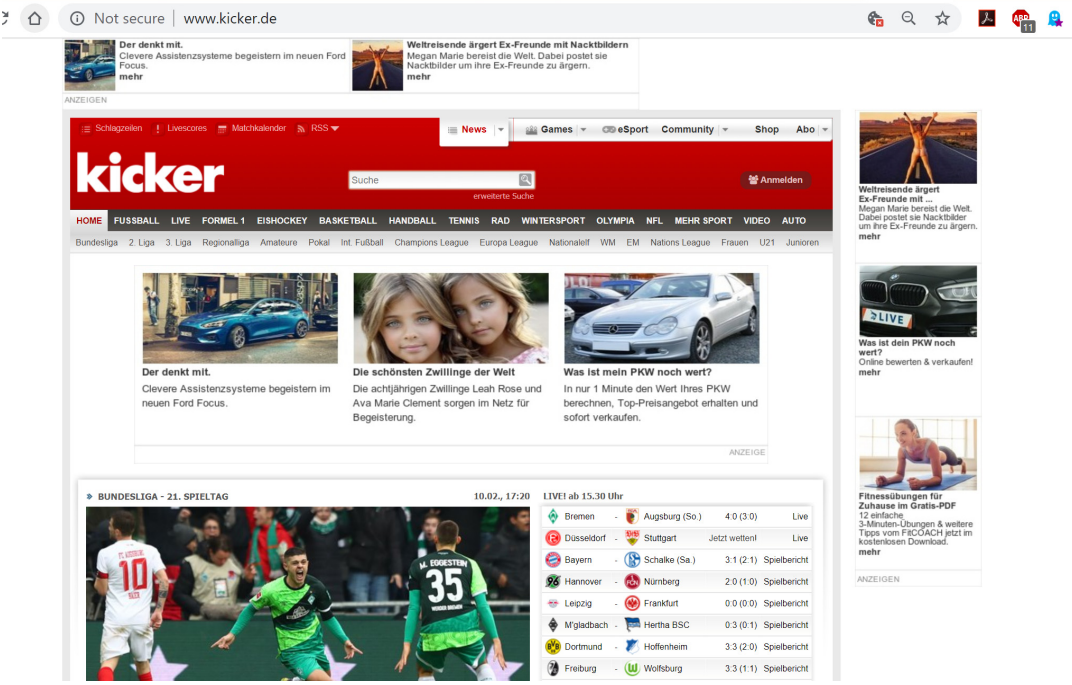

Anzeige der Webseite mit Werbeblocker

In technischer Hinsicht lässt sich bei den zuvor dargestellten Webseiten und den Werbeelementen zudem beobachten, dass diese von verschieden Quellen stammen. Während die aufwändige Standardwerbung vom Server eines Werbenetzwerks stammt, liegen die Ersatzwerbemittel auf dem Contentserver der Webseite:

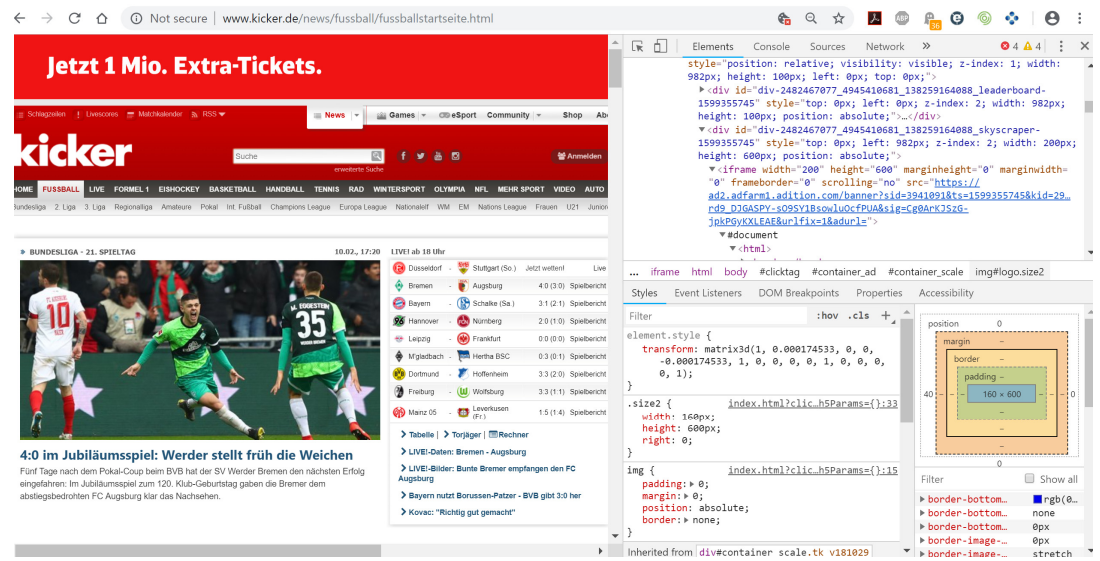

Anzeige der Webseite ohne Werbeblocker - in der Developer Tools Ansicht 

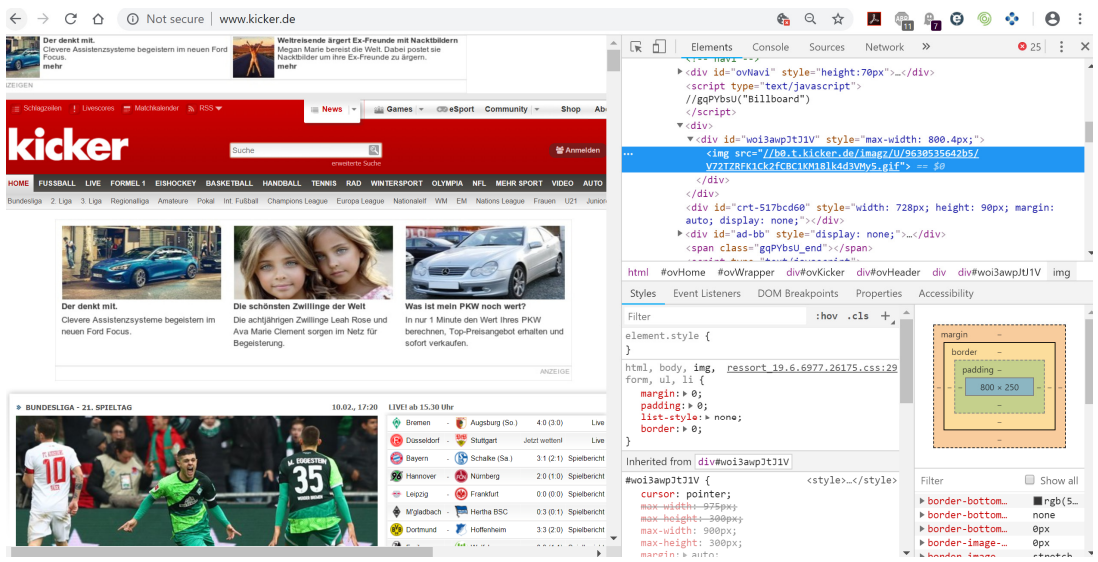

Anzeige der Webseite mit Werbeblocker - in der Developer Tools Ansicht

Der Werbeblocker hält die hier nachträglich eingesetzten Werbeelemente demnach für Content - wie von AdDefend beschrieben.

In wirtschaftlicher Hinsicht erscheint die Ausspielung von unblockbarer Ersatzwerbung lukrativ. In der öffentlichen Berichterstattung wird von Reichweitenzugewinnen von $25-30 \%$ berichtet $^{1047}$. Abzuziehen sind die nicht näher bekannten Kosten für die Dienstleistung. Die relativ hohe Verbreitung von AdDefend und vergleichbaren Dienstleistern ${ }^{1048}$ zeigt, dass scheinbar ein wirtschaftlicher Nutzen dieser Lösungen existiert.

Mit Blick auf den Nutzer ist der Einsatz dieser Lösungen jedoch die ultimative Eskalation. Während hinter der Zugangssperre noch ein ethisch nachzuvollziehender Gedanke steht, nämlich die technische Manifestierung der Werbefinanziertheit bei Achtung der Nutzerentscheidung pro Werbeblocker, ist die Ersatzwerbung eine Art „Zwangswerbung“. Sie marginalisiert die Nutzerentscheidung für den Werbeblocker zu einem Umstand, der dem Contentanbieter schlicht egal zu sein scheint. Sie verfestigt zudem den „Meine Webseite - meine Regeln“ Gedanken in fragwürdiger Weise. Es liegt insofern bei untechnischer Betrachtung nicht fern, diese Fallgestaltung mit dem Einwurf von Printwerbung in Briefkästen mit dies verbietenden Aufklebern zu vergleichen.

1047 https:/www.horizont.net/tech/nachrichten/Anti-Adblocker-Tool-So-funktionie rt-Adblock-Advertising-bei-AdDefend-165268, zuletzt abgerufen am 31.5.2019.

1048 Siehe oben Ziffer C. I. 1. g). 


\section{Weitere zu beobachtende oder denkbare Reaktionen}

Im Übrigen lassen sich weitere Reaktionen aus dem Bereich der Webseitenbetreiber und Online-Werbemarktteilnehmern beobachten. Eine solche Reaktion ist etwa die generelle Registrierungspflicht auf Webseiten mit wertvollem Content. So fordert etwa die Streamingplattform der RTL-Sender (tvnow.de) eine generelle Registrierungspflicht. Diese geht dort zwar nicht mit einer Regelung in den Nutzungsbedingungen einher, die zur Rezeption von Werbung zwingt oder den Einsatz von Werbeblockern verbietet. Gleichsam verfügt die Plattform trotz Anmeldung über einen die Rezeption des gewünschten Videos verhindernden Adblocker Hinweis, wenn die Pre-Roll Werbung nicht abgespielt werden kann ${ }^{1049}$. Wie das Beispiel Twitter zeigt, ist eine Regelung zur Ausspielung von Werbung in Nutzungsbedingungen jedoch nicht undenkbar ${ }^{1050}$.

Eine ganz andere (potentielle) Strategie lässt sich an einem Beispiel von Google erahnen. Google sortierte im Jahre 2014 den Android-Adblocker Disconnect aus den USA aus seinem Play Store aus. Die entsprechende App war nicht mehr für Smartphone Nutzer mit Android verfügbar ${ }^{1051}$. Da gerade auf dem Markt der großen Plattformen ein denkbarer Flaschenhals zum Zugang von Werbeblockersoftware zu erkennen ist, besteht hier das Risiko einer Reaktion von auch im Werbegeschäft engagierten Unternehmen. Dies ist bei Google schlechthin am wahrscheinlichsten, da das Unternehmen nicht nur ein mächtiges Werbeunternehmen, sondern eben auch Plattformanbieter ist. Wie das langezeit aufrechterhaltene Verbot für Werbeblocker in Apples AppStore ${ }^{1052}$ und die neuerdings ersichtliche Entfernung bestimmter Blockertechniken im mobilen Bereich ${ }^{1053}$ zeigen, liegt in der Hinderung von Werbeblockern zur freien Verbreitung auf iOSGeräten ein wirksames Instrument. Apple selbst scheint zwar keine unmittelbar eigenen Interessen auf dem AdTech Sektor zu verfolgen, nachdem

1049 https:/hilfe.tvnow.de/hc/de/articles/207633575-Adblocker-deaktivieren-, zuletzt abgerufen am 31.5.2019.

1050 https://twitter.com/de/tos, abgerufen am: 30.12.2017; vgl. auch obige Ausführungen unter Ziffer C. IV. 1. a) (cc) (vii).

1051 Vgl. https://www.brandeins.de/magazine/brand-eins-wirtschaftsmagazin/2017/ marketing/sehnsucht-nach-dem-paradies, zuletzt abgerufen am 30.5.2019.

1052 https://www.heise.de/mac-and-i/meldung/Werbeblocker-fuer-iOS-Safari-kuenft ig-moeglich-2687525.html, zuletzt abgerufen am 31.5.2019.

1053 https://www.heise.de/mac-and-i/meldung/iOS-App-Store-VPN-Werbeblocker-v erboten-3772471.html, zuletzt abgerufen am 31.5.2019. 
der Versuch eines eigenen Werbenetzwerks („iAds“) scheiterte ${ }^{1054}$. Die Vernetzung mit anderen Werbeunternehmen könnte hier jedoch bei der Entscheidungsfindung pro und contra Werbeblocker im AppStore nicht ganz unwesentlich sein.

\section{Kategorisierung der Reaktionen}

Nach Beschreibung der vorstehenden, nicht abschließenden Reaktionsmöglichkeiten von Webseitenbetreibern und Werbenden lässt sich eine abstrakte Kategorisierung der Reaktionen wagen. $\mathrm{Zu}$ Unterscheiden ist demnach zwischen technischen Reaktionen und wirtschaftlichen Reaktionen.

Unter die technischen Reaktionen lassen sich jedenfalls der Einsatz von Adblocker-Detektoren sowie sich daran anschließende Folgen wie Zugangssperren oder Austauschwerbung fassen. Auch generell unblockierbar ausgestaltete Werbung fällt unter diese Kategorie.

Bei den wirtschaftlichen Reaktionen lassen sich weiter solche unterscheiden, die primär zulasten der Nutzer und solche, die zulasten der Betreiber von Werbeblockern. Primär zulasten der Nutzer gehen demnach Paywalls, Registrierungspflichten auf Webseiten und Nutzungsbedingungen, die die Rezeption von Werbung verbindlich machen wollen. Gegen die Betreiber richten sich hingegen Maßnahmen hinsichtlich des Vertriebs wie etwa der oben beschriebene Ausschluss aus Appstores.

\section{Rechtliche Beurteilung}

Anhand der zuvor skizzierten Kategorisierung soll nachfolgend eine rechtliche Beurteilung erfolgen.

1. Zulässigkeit von Zugangsblockaden zu Webseiten für Werbeblockernutzer

Zunächst wird die Zulässigkeit der Zugangssperren für Nutzer von aktivierten Werbeblockern erörtert. Dabei ist die technische Zweiteilung

1054 https://www.heise.de/mac-and-i/meldung/iAd-Apple-schliesst-App-Werbeplattf orm-endgueltig-3210644.html, zuletzt abgerufen am 31.5.2019. 
der Zugangsblockade zu beachten - im ersten Schritt muss über eine Adblocker-Detektion ermittelt werden, dass der Nutzer einen Werbeblocker oder eine aquivälente Einstellung verwendet, bevor im zweiten Schritt der Sperrbildschirm angezeigt wird.

Aus rechtlicher Sicht ist es bemerkenswert, dass die Rechtsprechung in den Werbeblocker-Fällen maßgeblich auf dem Argument beruht, dass Webseitenbetreibern technische Abwehrmöglichkeiten gegen Werbeblockernutzer zustehen. Nicht zuletzt der I. Zivilsenat des BGH hat in seinem Werbeblocker II Urteil aus der Existenz von technischen Ausschlussmöglichkeiten bezüglich solcher Nutzer einen erhebliches Argument für die Zulässigkeit von Werbeblockern gefolgert. ${ }^{1055}$ Für die betroffenen Webseitenbetreiber lässt sich dies als bedeutendes Präjudiz für die rechtliche $\mathrm{Zu}$ lässigkeit von Zugangsblockaden heranziehen. Es stellt sich aber die Frage, ob der BGH und die übrige Rechtsprechung in den Werbeblockerfällen an diesem Punkt nicht unbewusst vorgreiflich war und sorglos formuliert hat. Denn diese Ausführungen beruhen darauf, dass technische Reaktionen der Webseitenbetreiber zulässig sind. Eine eingehende Prüfung dazu ist aber in keinem Urteil zu finden.

Bei genauer Betrachtung der technischen Wirkweise von Adblocker-Detektoren kommt man jedoch nicht umhin, nach der Zulässigkeit der Informationserhebung betreffend den Einsatz eines Werbeblockers beim Nutzer zu fragen. Das automatisierte Abprüfen, ob bestimmte Webseitenelemente auf dem Nutzergerät dargestellt werden, muss vor dem Hintergrund des geltenden Datenschutzrechts geprüft werden ${ }^{1056}$. Grundlage dieser Überlegung ist, dass die Detektion des Einsatzes eines Werbeblockers praktisch eine weitere Facette des Nutzertrackings darstellt. Insoweit wird durch die Programmierung eines Skripts eine Information über einen Nutzer erhoben und zur Durchführung einer unmittelbaren Reaktion ver-

1055 BGH, Urteil vom 19.4.2018 - I ZR 154/16, WRP 2018, 1322, 1326, Rn. 39 Werbeblocker II.

1056 Vgl. Bechtolf/Vogt, K\&R 2016, 445, die vor Inkrafttreten der DSGVO die Rechtslage unter der E-Privacy Richtlinie und unter $\mathbb{S} \mathbb{S} 12,15$ TMG prüfen. Siehe auch Ziebarth, VuR 2018, 257, der ebenfalls auf Grundlage der $\$ \$ \$ 12-$ 15 TMG prüft. Aufgrund der Positionsbestimmung der Datenschutzkonferenz („DSK“) zur nicht mehr statthaften Anwendbarkeit des TMG nach Inkrafttreten der DSGVO wird in dieser Bearbeitung jedoch nicht auf die datenschutzrechtlichen Bestimmungen des TMG abgestellt, sondern die Rechtslage unter der DSGVO und dem zur Zeit der Bearbeitung zur Verfügung stehenden Entwurf der E-Privacy Verordnung geprüft. Vgl. zum Thema der Anwenbarkeit der $\int \mathbb{S} 12$ - 15 TMG: Gierschmann, ZD 2018, 297, und Jandt, ZD 2018, 405. 
arbeitet. Da IP-Adressen und in deren Zusammenhang erhobene Daten nach der EuGH Rechtsprechung als personenbezogene Daten anzusehen sind, ist auch die hier beachtliche Information, ob ein Nutzer einen Werbeblocker nutzt, ein personenbezogenes Datum ${ }^{1057}$. Die dafür notwendige Verbindung mit der Erhebung der IP-Adresse ist durch die standardmäßige Informationsübertragung über HTTP gegeben. Die Datenverarbeitung hat sich folglich bis zum Inkraftreten der E-Privacy Verordnung an den geltenden Regeln der DSGVO zu messen.

Die Rechtfertigung der Verarbeitung wird praktisch über Art. 6 Abs. 1 S. 1 lit.f) DSGVO erfolgen müssen. Auf eine Einwilligung nach Art. 6 Abs. 1 S. 1 lit. a) DSGVO können sich Webseitenbetreiber in den zur Zeit der Bearbeitung zu beobachtenden Fällen nicht stützen. Insbesondere werden solche Einwilligungen in der Praxis nämlich nicht vor dem Besuch der Seite abgefragt ${ }^{1058}$. Die Notwendigkeit zur Erfüllung vertraglicher oder sonstiger rechtlicher Pflichten nach Art. 6 Abs. 1 S. 1 lit. b) und c) DSGVO liegen ebenfalls fern. Im Rahmen der berechtigten Interessen nach Art. 6 Abs. 1 S. 1 lit. f) DSGVO werden sich Webseitenbetreiber mit guten Gründen auf den Einsatz von Adblocker-Detektoren berufen können und zwar zur Sicherung der Finanzierung und zur Aussperrung von Nutzern, die diese Finanzierung unterlaufen. Diese berechtigten, wirtschaftlichen Interessen dürften die Interessen oder Grundrechte der Werbeblockernutzer nach hier vertretener Ansicht auch überwiegen. Nach Diktion des BGH in Werbeblocker II ist durch die Ausspielung von bloß „nerviger Werbung“, aber nicht unter $\$ 7$ UWG fallender Werbeansprache sowieso kein grundrechtlich geschütztes Recht betroffen ${ }^{1059}$. Das verbleibende Interesse der Nutzer, werbefreien Content zu beziehen und bei diesem Vorgang auch nicht auf den Einsatz von Werbeblockern hin überprüft zu werden, wäre allenfalls gleichwertig mit den rechtlichen Interessen der Webseitenbetreiber. Der Einsatz von Adblocker-Detektoren ist demnach unter der DSGVO wohl zu rechtfertigen. Freilich steht dies unter der Voraussetzung transparenter Information gemäß Art. 12 DSGVO. Allerdings enthalten zur Zeit der Bearbeitung die Datenschutzerklärungen der Webseiten, die Zugangsperren für Werbeblockernutzer einsetzen, praktisch keine Information

1057 Siehe dazu oben Ziffer B. IV. 2. a) aa) (ii) mit weiteren Nachweisen; vgl. im Übrigen EuGH, Urteil vom 19.10.2016, Rs. C-582/14, NJW 2016, 3579. Zustimmend Ziebarth, VuR 2018, 257; a.A. Bechtolf/Vogt, K\&R 2016, 445, 446.

1058 Vgl. in diesem Zusammenhang die Beschreibung einer denkbaren, aber praxisfernen Einwilligungsabfrage bei Bechtolf/Vogt, K\&R 2016, 445, 449.

1059 BGH, Urteil vom 19.4.2018 - I ZR 154/16, WRP 2018, 1322 - Werbeblocker II. 
über den Einsatz von Adblocker-Detektoren ${ }^{1060}$. Damit liegt wohl in vielen Fällen ein Verstoß gegen die Informationspflicht nach Art. 13 DSGVO vor. Ein weiteres praktisches Problem beim Einsatz von Adblocker-Detektoren und bei einer Rechtfertigung über Art. 6 Abs. 1 S. 1 lit. f) DSGVO liegt in dem Widerspruchsrecht der Nutzer gemäß Art. 21 Abs. 1 DSGVO. Nach Satz 2 dieser Vorschrift wäre nach Widerspruch die Verarbeitung nur noch bei „zwingenden schutzwürdigen Gründen“ zugunsten der Webseitenbetreiber erlaubt. Ob die wirtschaftlichen Belange jedoch diese hohe Schwelle überschreiten ist sehr fraglich. Von einer detaillierten Stellungnahme zu dieser Frage soll an dieser Stelle jedoch abgesehen werden.

Denn praktisch wird in absehbarer Zukunft die Rechtmäßigkeit der Adblocker-Detektoren nach der neuen E-Privacy-Verordnung (Entwurf) zu bewerten sein. Wie weiter oben bereits für diverse Trackingmaßnahmen skizziert ${ }^{1061}$ wird die Rechtmäßigkeit von Adblocker-Detektoren nach Art. 8 EPVO-E zu messen sein. Bei bloßer Betrachtung des Verordnungsartikeln bleibt praktisch nur die Einwilligung der Nutzer als Rechtfertigungsgrund (Art. 8 Abs. 1 lit. b) EPVO-E). Es ist dabei leicht prognostizierbar, dass ein Nutzer eines Werbeblockers in keinem Fall eine ausdrückliche und bewusste Einwilligung zur Prüfung seines Rechners erteilen wird, wenn dies zur Folge haben wird, dass er die gewünschten Inhalte nicht mehr sehen kann. Dem entsprechend sieht der EPVO-E in den Erwägungsgründen ergänzende Beschreibungen vor, ob bei gewissen Vorgängen ein Zugriff auf ein Gerät oder ein Nutzung der Verarbeitungsfunktionen des Geräts anzunehmen sein soll. Soweit dies nämlich verneint wird, bedarf es keiner Einwilligung. Nach Erwägungsgrund 21a EPVO-E sollen aber „Konfigurationsprüfungen, die Anbieter von Diensten der Informationsgesellschaft vornehmen, um ibren Dienst entsprechend den Einstellungen des Endnutzers bereitstellen zu können, wie auch das bloße Feststellen der Tatsache, dass das Gerät des Endnutzers die vom Endnutzer angeforderten Inhalte nicht empfangen kann" keinen Zugriff darstellen.

Daraus und aus einer Pressemitteilung der EU Kommission ${ }^{1062}$ folgert Nink eine ausdrückliche Zulässigkeit von Adblocker-Detektoren. Sie kriti-

1060 Vgl. https:/www.bild.de/corporate-site/datenschutz/datenschutz/artikel-datens chutz-54485502.bild.html, zuletzt abgerufen am 31.5.2019; https://www.faz.ne t/datenschutzerklaerung-11228151.html, zuletzt abgerufen am 31.5.2019.

1061 Siehe oben Ziffer B. IV. 2. a).

1062 http://europa.eu/rapid/press-release_MEMO-17-17_de.htm, zuletzt abgerufen am 31.5.2019. Auf die Frage „Können Nutzer weiterhin Werbeblocker benutzen?“ heißt es dort „Die Verwendung von Werbeblockern ist in dem Vorschlag nicht explizit geregelt. Den Nutzern steht es frei, auf ihren Geräten Software zu installieren, die 
siert diese Ausnahme wegen des Eingriffs in das Recht auf informationelle Selbstbestimmung des Nutzers ${ }^{1063}$. Die Sorge, dass hier die besondere Fallgestaltung der Adblocker-Detektoren begünstigt werden soll ist berechtigt. Ebenso berechtigt sind die Bedenken, dass durch die abstrakte Formulierung in Erwägungsgrund 21a EPVO-E auch „Kollateralschäden“ eintreten können ${ }^{1064}$. Auf der anderen Seite ist der Wortlaut im Erwägungsgrund 21a EPVO-E recht offen formuliert. Denn das „Feststellen der Tatsache, dass das Gerät des Endnutzers die vom Endnutzer angeforderten Inhalte nicht empfangen kann" könnte in zwei verschiedene Richtungen ausgelegt werden: Zum einen ist eine Betrachtung mit Fokus auf die genutzte Hardware möglich, z.B. Anzeige einer Videowerbung auf einem E-Book-Reader. Zum anderen lässt sich auf die Softwaregestaltung in einem an sich empfangsgeeigneten Gerät abstellen, also z.B. die Nutzung von Werbeblockersoftware. Die (noch nicht abgeschlossene) Gesetzgebungshistorie mag für die letztgenannte Auslegung sprechen. Allerdings könnte der EuGH im Streitfall hier auch eine systematische und teleologische Auslegung vornehmen, die im Zusammenhang mit datenschutzrechtlichen Normen in der DSGVO dem Schutz der informationellen Selbstbestimmung der Nutzer den Vorrang einräumt.

Vorbehaltlich weiterer Änderungen am EPVO-E ist die Zukunft der Adblocker-Detektoren demnach auf lange Sicht unklar. Wenn die oben genannte Ausnahmeregelung in Erwägungsgrund 21a EPVO-E nicht derart wirken sollte, dass die Detektoren erlaubt sind, wären sie nicht mehr wie unter der DSGVO durch berechtigte Interessen zu rechtfertigen. Dies würde voraussichtlich das Ende der Adblocker-Detektoren und mithin auch der aktuell genutzten Zugangssperren sein. Denn sowohl Nutzer würden effektive Ansprüche auf Unterlassung gegen Webseitenbetreiber geltend

die Anzeige von Werbung unterbindet. Die Kommission ist sich jedoch auch der Tatsache bewusst, dass „kostenlose" Inhalte im Internet häufig durch Werbeeinnahmen finanziert werden. Deshalb können Website-Betreiber nach dem Verordnungsentwurf auch obne die Einwilligung des Nutzers prüfen, ob das Gerät des Nutzers in der Lage ist, ihren Inhalt, einschließlich Werbung, zu empfangen. Stellt ein Website-Betreiber fest, dass nicht alle Inhalte beim Endnutzer ankommen, steht es ihm frei, entsprechend darauf zu reagieren, indem er $z$. B. beim Endnutzer anfragt, ob dieser einen Werbeblocker verwendet und bereit wäre, ihn für die betreffende Website abzuschalten".

1063 Nink, CR 2017, 103, 111.

1064 Nink, CR 2017, 103, 111, weist insoweit daraufhin, dass allerlei Browsererweiterungen legal getracked werden dürfen, z.B. Tools für Sehbehinderte. Die derart legal erhobenen sensiblen Daten könnten dann mit allerlei anderen Informationen verknüpft werden. 
machen können, als auch - nach hier vertretener Ansicht - Wettbewerber, wie u.a. Werbeblockerbetreiber, da die Vorschriften der E-Privacy Verordnung Marktverhaltensregeln im Sinne des $\$ 3$ a UWG darstellen werden.

Zusammenfassend kann man dem BGH also durchaus eine etwas sorglose Formulierung mit Blick auf mögliche technische Reaktionen durch Webseitenbetreiber vorwerfen. Denn nach der DSGVO sind AdblockerDetektoren zwar theoretisch zu rechtfertigen. Hierfür sind aber praktische Vorkehrungen zu treffen, insbesondere die transparente Information der Nutzer. Ungeklärt ist allerdings, ob ein Webseitenbetreiber auch nach Widerspruch eines Nutzers weiterhin Detektoren einsetzen darf. Die Tendenz scheint hier eher negativ zu sein, da der Einsatz von Adblocker-Detektoren wohl nicht zwingend ist. Nach Wirksamwerden der E-Privacy-Verordnung könnte sich die Rechtslage für Webseitenbetreiber nochmals erheblich verschärfen, sodass Webseitenbetreiber gut beraten sind, schon frühzeitig neue technische Reaktionsmöglichkeiten zu erforschen, die nicht mit uneingewilligter Informationserhebung auf dem Nutzergerät einhergehen.

\section{Zulässigkeit von Zwangswerbung}

Auch die Zulässigkeit von Zwangswerbung für Werbeblockernutzer verdient eine rechtliche Prüfung. Unterteilt man die Zwangswerbung in generell unblockierbare Werbung und „reaktive“ Zwangswerbung nach Adblocker-Detektion, stellen sich bei der letztgenannten Methode zunächst dieselben Probleme wie im vorstehenden Absatz. Die Adblocker-Detektoren mögen unter Geltung der DSGVO zu rechtfertigen sein. Das abzusehende Ende dieser technischen Lösung wegen der E-Privacy-Verordnung ist allerdings möglich

Jedoch stellen sich auch außerhalb bzw. gerade aufgrund der AdblockerDetektion maßgebliche rechtliche Fragen. So ist für Zwangswerbung zu prüfen, ob diese nicht für Werbeblocker Nutzer eine unzumutbare Belästigung nach $\$ 7$ UWG darstellt. Zudem stellt sich wegen des Effekts, dass Werbeblocker ihre Wirkung nicht mehr zeitigen können, die Frage, ob der Einsatz von unblockierbarer Werbung nicht eine gezielte Behinderung von Werbeblockern im Sinne von $\$ 4 \mathrm{Nr} .4 \mathrm{UWG}$ darstellt. Wiederum mit Blick auf die Nutzer könnte die Zwangswerbung auch eine aggressive geschäftliche Handlung gemäß $\$ 4$ a UWG darstellen. 


\section{a) Unzumutbare Belästigung}

Die Frage einer unzumutbaren Belästigung von Werbeblockernutzern wurde bislang nicht von der Rechtsprechung entschieden, jedoch vereinzelt im Schriftum geprüft. Eine dieser Stellungnahmen stellte dabei nicht auf besondere Austauschwerbung ab, sondern auf ein Pop-up-Layer einer Zugangssperre. Bereits dies wurde für eine ausreichende Werbeanzeige gehalten, weil hierin eine werbliche Botschaft enthalten sei ${ }^{1065}$. Zwar wird man in den Sperrbilschirmen tatsächlich eine geschäftliche Handlung der Webseitenbetreiber erkennen können, die zum einen für den Zugang zur Webseite mit Werbeelementen wirbt und zum anderen oft auch für Bezahlangebote wirbt. Allerdings spielt dieser Werbezweck eine untergeordnete Rolle. Wichtiger ist die Mitteilung über die Sperre an sich. Die Sperre hingegen ist nach BGH Werbeblocker II aber grundsätzlich eine anerkannte Wehrmaßnahme ${ }^{1066}$. Es ist deshalb nicht zu erwarten, dass die Rechtsprechung im Rahmen einer Interessenabwägung bereits in diesen Sperrbildschirmen in Verbindung mit der Information über Möglichkeiten für den Nutzer, eine Aufhebung der Sperre zu erreichen, eine unzumutbare Belästigung im Sinne von $\$ 7$ UWG annehmen würde. Die Gedanken lassen sich aber auf Zwangswerbung, also wahren Anzeigen, die trotz aktiviertem Werbeblocker angezeigt werden, übertragen.

Zweckmäßiger ist die Aufteilung, die Kreutz vornimmt. Er unterscheidet die rechtliche Bewertung zwischen generell unblockierbarer Werbung einerseits und spezieller Austauschwerbung für Werbeblockernutzer andererseits ${ }^{1067}$. Bei der Prüfung der generell unblockierbaren Werbung, also solchen Anzeigen, die ohne Ansehung des Einsatzes von Werbeblockern beim Nutzer gleich ausgespielt wird und bei beiden Arten von Nutzern auch tatsächlich angezeigt werden, lehnt Kreutz eine hartnäckige Ansprache gemäß $₫ 7$ Abs. 2 Nr. 1 UWG mangels wiederholter Ansprache ab. Im Rahmen des $\$ 7$ Abs. 1 UWG positioniert sich Kreutz nicht eindeutig. $\mathrm{Da}$ in der Konsequenz der Anwendung von $\$ 7$ Abs. 1 S. 2 UWG Webseitenbetreiber verpflichtet wären, Empangseinrichtungen für die Werbeablehnung (sprich: der Nutzung von Werbeblockern) vorzuhalten und

1065 Ziebarth, VuR 2018, 257, der in der Aufforderung den Werbeblocker auszuschalten und damit für andere Werbung empfänglich zu werden eine maßgebliche geschäftliche Handlung und Werbemaßnahme sieht.

1066 BGH, Urteil vom 19.4.2018 - I ZR 154/16, WRP 2018, 1322 - Werbeblocker II.

1067 Kreutz, MMR 2016, 364; Online-Angebote und Werbeblockersoftware, S. 422ff.. 
sogar Werbung „wieder blockierbar“ zu machen, tendiert er scheinbar dazu, eine unzumutbare Belästigung mangels klarer Erkennbarkeit für den Webseitenbetreiber abzulehnen ${ }^{1068}$. Bei spezieller Austauschwerbung bejaht Kreutz jedoch einen Fall der unerwünschten Werbung im Sinne von $\mathbb{5} 7$ Abs. 1 S. 2 UWG und hält eine hartnäckige Ansprache gemäß $\$ 7$ Abs. 2 Nr. 1 UWG bei wiederholter Ansprache beim Besuch mehrerer Unterseiten für einschlägig ${ }^{1069}$.

Dieses Ergebnis soll nachfolgend überprüft werden. Auch hier soll zunächst auf die generell unblockierbare Werbung eingegangen werden. Es stellen sich dabei zwei grundlegende Fragen: Erstens, darf ein Webseitenbetreiber im Vorhinein darüber bestimmen, ob Werbung beim Nutzer angezeigt wird und damit vorsorglich Werbeblocker unterwandern? Und zweitens, kann ein Webseitenbetreiber den Umstand der Werbeblockernutzung ohne Einsatz von Adblocker-Detektoren erkennen bzw. ist er dazu verpflichtet?

Beide Fragen sind dabei sowohl für die hartnäckige Ansprache gemäß $\$ 7$ Abs. 2 Nr. 1 UWG ${ }^{1070}$ als auch für die unerwünschte Werbung gemäß $\$ 7$ Abs. 1 S. 2 UWG von entscheidender Bedeutung. Denn die Erkennbarkeit ist in beiden Tatbeständen ausdrücklich genanntes Merkmal. Ob bereits die erste Ausspielung von unblockierbaren Werbeanzeigen oder erst die wiederholte Ausspielung, etwa durch Besuch mehrerer Unterseiten oder auch durch Anordnung mehrerer Werbeelemente auf einer Webseite, vorliegt, entscheidet nur über die Anwendbarkeit von $₫ 7$ Abs. 1 S. 2 oder Abs. 2 Nr. 1 UWG und ist nachrangig zu prüfen ${ }^{1071}$. Deshalb wird zunächst für beide Tatbestände gemeinsam geprüft, ob erkennbar ist, dass ein Nutzer Werbung nicht wünscht.

Maßgeblich beim Merkmal der Erkennbarkeit, dass Werbung nicht gewünscht wird, ist nicht der innere Wille des Adressaten, sondern der für den Werbenden erkennbare Wille ${ }^{1072}$. Dieser Wille wird regelmäßig

1068 Kreutz, MMR 2016, 364, 367; Online-Angebote und Werbeblockersoftware, S. $425,428 f f ., 435$.

1069 Kreutz, MMR 2016, 364, 369; Online-Angebote und Werbeblockersoftware, S. 430ff..

1070 Siehe zur Anwendbarkeit des $\$ 7$ Abs. 2 S. 1 UWG auf Telemedien oben Ziffer B. IV. 1. a) aa).

1071 A.A. ist hier scheinbar Kreutz, MMR 2015, 364, 367, 369, der im Rahmen von \$ 7 Abs. 2 S. 1 UWG ausführt, Werbung werde grundsätzlich nur einmal pro Abruf geladen, aber an späterer Stelle das Surfen auf mehreren Unterseiten für ausreichend hält, um eine Hartnäckigkeit zu begründen.

1072 Schöler, in: Harte-Bavendamm/Henning-Bodewig, UWG, $\mathbb{~ 7 , ~ R n . ~} 53$. 
durch Maßnahmen im eigenen Bereich des Empfängers geäußert, wobei das Musterbeispiel der Aufkleber „Bitte keine Werbung einwerfen“ am Briefkasten ist ${ }^{1073}$. Jedenfalls muss dieser Wille in einer Weise geäußert worden sein, dass gerade der Werbende oder für ihn tätige Personen bei Anwendung der gebotenen unternehmerischen Sorgfalt im Sinne von $\ 2$ Abs. 1 Nr. 7 UWG diesen Willen erkennen können. Erkennbarkeit bedeutet dabei nicht positive Kenntnis ${ }^{1074}$.

Auf dieser Grundlage kommt es auch im Fall der generell unblockierbaren Werbung auf Webseiten auf die Erkennbarkeit des Einsatzes von Werbeblockern an. Die Erkennbarkeit ist nicht schon dadurch ausgeschlossen, weil sich ein Webseitenbetreiber in diesem Fall einer potentiell möglichen Kenntnisnahme verschließt, weil er gerade keinen Adblocker-Detektor einsetzt. Es bedarf deshalb einer Entscheidung der Frage, ob der Einsatz eines Werbeblockers während der Internetkommunikation im Grundsatz erkennbar ist. Dies wiederum führt laut Kreutz zur Frage der Zumutbarkeit von Empfangseinrichtungen beim Werbenden, die im Fall von Adblocker-Detektoren durchaus mit erheblichen Kosten verbunden sein können $^{1075}$. Laut Mankowski müssen sich Werbende generell so organisieren, dass sie Empfangseinrichtungen vorhalten, die die „ablehnenden Signale auffangen, entsprechend verarbeiten und umsetzen“. Die Werbenden trügen dann das Risiko, dass sie erkennbare Signale des Adressaten tatsächlich nicht erkennen, wobei sie "Ignoranz und Indolenz" nicht schützen sollen ${ }^{1076}$.

Diese Ansicht ist im digitalen Bereich jedoch problematisch, weil für hier einschlägige Empfangseinrichtungen die datenschutzrechtliche Problematik rund um Adblocker-Detektoren Bedeutung gewinnt. Schon jetzt sind diese nicht per se erlaubt und in Zukunft könnten sie gar insgesamt verboten sein. Den Webseitenbetreibern kann jedoch nicht zugemutet werden, besondere Lösungen einzusetzen, die aktuell unter Umständen und in Zukunft wahrscheinlich nicht legal sind. Deshalb kann sich die Erkennbarkeit nicht durch das Unterlassen einer möglichen technischen Aufklärung des Umstands, ob Nutzer einen Werbeblocker einsetzen, ergeben.

1073 Mankowski, in: Fezer/Büscher/Obergfell, UWG, $\mathbb{8}$ 7, Rn. 92.

1074 Köhler/Bornkamm/Feddersen, UWG, $\mathbb{7} 7$, Rn. 37.

1075 Kreutz, MMR 2016, 364, 368; Online-Angebote und Werbeblockersoftware, S. $428 f f .$.

1076 Mankowski, in: Fezer/Büscher/Obergfell, UWG, $\mathbb{\$} 7$, Rn. 94. 
Stattdessen ist die Lösung des Problems der Erkennbarkeit auf einem anderen Weg zu suchen. Hier kommt ein Vergleich mit einer anderen (analogen) Werbeform in Betracht - und zwar der "guten alten" Scheibenwischerwerbung. Diese Art der unorthodoxen und die Interessen der Adressaten generell ignorierenden Werbung wird gemeinhin als Fall des $\$ 7$ Abs. 1 S. 2 UWG angesehen ${ }^{1077}$. Sie lässt sich mit der Schaltung generell unblockierbarer Werbung vergleichen. Denn in beiden Fällen unterscheidet sie sich von dem Normalfall der Auslieferung (im analogen Bereich: Einwurf in Briefkästen; im digitalen Bereich: erkennbare Ausgestaltung der Daten als Werbung), die dazu führt, dass die Möglichkeit der Kenntnisnahme eines der Werbung entgegenstehenden Willens mutwillig nicht wahrgenommen werden kann (im analogen Bereich: Umgehung eines möglicherweise bestehenden „Keine Werbung“ Aufkleber am Briefkasten in Kenntnis, dass niemand einen solchen Sticker an der Windschutzscheibe seines Pkws anbringt; im digitalen Bereich: Umgehung eines möglicherweise bestehenden Werbeblockers, der technische Befehle zur Vermeidung von Werbung ausführt, in Kenntnis, dass die Befehle diese Art der Werbung nicht erfassen können).

Denn bei Lichte betrachtet ist die Furcht vor Werbeblockade der einzige stichhaltige Grund die generell unblockierbare Werbung in die Webseiten „einzuprogrammieren“. Demgemäß ist bei Werbung im Internet, gerade auch unter Beachtung der in der Werbewirtschaft allgegenwärtigen Verbreitungsraten von Werbeblockernutzern von ca. 20\%1078, bekannt, dass viele Nutzer Werbeblocker nutzen. Die Schaltung einer nicht blockierbaren Werbung, die notwendigerweise zur fehlenden positiven Kenntniserlangung der Werbeblockernutzung im Rahmen der HTTP-Kommunikation führt ${ }^{1079}$, schließt folglich nicht die Erkennbarkeit des Nutzerwunsches, von Werbung verschont zu bleiben, aus. In diesem Zusammenhang lässt sich auch die oben angesprochene unternehmerische Sorgfalt heranziehen. Legt man diesen „Standard an Fachkenntnissen und Sorgfalt, von dem billigerweise angenommen werden kann, dass ein Unternehmer ibn in seinem Tätigkeitsbereich gegenüber Verbrauchern nach Treu und Glauben unter Berücksichtigung der anständigen Marktgepflogenheiten einbält" an, wird deutlich,

1077 Köhler/Bornkamm/Feddersen, UWG, $\mathbb{~ 7 , ~ R n . ~ 3 7 , ~ 1 1 7 ; ~ O h l y / S o s n i t z a , ~ U W G , ~}$ $\$ 7$, Rn. 32 .

1078 Siehe oben mit Nachweisen Ziffer C. I. 2. a) bb).

1079 Dies muss nämlich nicht durch Adblocker-Detektoren geschehen, sondern wird in der Regel schon durch fehlgeschlagene oder unterbliebene Requests von Elementen im HTML-Dokument zumindest auf Serverebene erkennbar. 
dass die mutwillige Umgehung von Selbsthilfemaßnahmen von Nutzern gegen Displaywerbung nicht rechtmäßig sein kann. Dies gilt jedenfalls, wenn die Werbung über spezialisierte Dienste und Server unblockierbar gemacht wird. Die bloße Ausspielung von eigenen Servern, die ggf. dazu führt, dass der Werbeblocker die Werbung nicht als solche erkennt, ist nicht hierunter zu fassen.

Folglich ist für Webseitenbetreiber, die mutwillig generell unblockierbar gemachte Werbung einsetzen, aus Rechtsgründen erkennbar, dass Nutzer mit aktiviertem Werbeblocker keine Werbung wünschen. $\$ 7$ Abs. 1 S. 2 UWG und $\$ 7$ Abs. 2 Nr. 1 UWG sind demnach anwendbar. Durch die enorme Belästigungswirkung einer Werbeausspielung trotz eigens dagegen ergriffener Maßnahmen wird auch eine bei $\$ 7$ Abs. 1 S. 2 UWG vorzunehmende Interessenabwägung die Werbetreibenden nicht retten, wenn sie spezielle Umgehungsdienste nutzen. Denn es gibt im konkreten Fall kein schützenswertes Interesse, dass die intendierte Unzumutbarkeit in Fällen des Beispielstatbestands umkehren könnte. Wenn eine Vielzahl von Werbeanzeigen zwangsweise ausgespielt wird, entweder durch Ansammlung auf einer Webseite oder durch Surfen auf mehreren Unterseiten, ist auch ein hartnäckiges Ansprechen im Sinne des $\$ 7$ Abs. 2 Nr. 1 UWG gegeben, das laut gesetzlicher Anordnung stets verboten ist.

Noch eindeutiger ist der Fall bei Schaltung von Austauschwerbung nach erfolgreicher Detektion der Werbeblockernutzung. Hier ist innerhalb der Systeme der Webseitenbetreiber also sogar positiv bekannt, dass keine Werbung gewünscht wird ${ }^{1080}$. Die Schaltung der Ersatzwerbung ist eine unmittelbare Reaktion auf den durch den Nutzer geäußerten und vom Webseitenbetreiber erkannten Willen, keine Werbung zu erhalten. Da hier absichtlich der Wille des Nutzers ignoriert wird, bedarf es schon keiner ergänzenden Interessenabwägung im Fall des $\mathbb{} 7$ Abs. 1 S. 2 UWG mehr. Auch hier ist im Übrigen die hartnäckige Ansprache nach $₫ 7$ Abs. 2 S. 2 UWG denkbar.

Zusammenfassend ist demnach jede Zwangswerbung, die vorsätzlich dazu eingesetzt wird, um die Funktionalität von Werbeblockern auszuhebeln, eine unzumutbare Belästigung des Empfängers.

1080 Vgl. Ziebarth, VuR 2018, 259; Kreutz, MMR 2016, 364, 369. 


\section{b) Gezielte Behinderung}

Darüberhinaus liegt es nicht fern, dass der Eingriff durch Zwangswerbung aus Sicht der Werbeblockerbetreiber ebenfalls als unlauteres Handeln anzusehen ist. Auch das Angebot besonderer Software und Dienstleistungen zum effektiven Einsatz von Zwangswerbung durch Anbieter wie AdDefend könnte insoweit eine gezielte Behinderung der Werbeblockeranbieter darstellen.

Grundlage der Überlegung ist, dass der BGH die geschäftliche Handlung des Angebots einer Werbeblockersoftware insgesamt als zulässig bewertete $^{1081}$. Das Angebot von Werbeblockern ist demnach genauso schutzwürdig vor gezielten Behinderungen wie die Schaltung von Werbung auf Webseiten. Wenn nun aber das reaktive Verhalten von Webseitenbetreibern zielgerichtet auf die Ausschaltung eben jener zulässigen Software beruht, stellt dies nach den Kriterien des BGH ohne weiteres eine geschäftliche Handlung im konkreten Wettbewerbsverhältnis dar. Dies gilt gleichermaßen für einen Dienstleister wie AdDefend. Auch eine Behinderung der Werbeblockeranbieter lässt sich leicht bejahen, da die Zwangswerbung gerade dazu dient, die Wirkweise der Software zu stören und damit die Software für den Nutzer unattraktiv zu machen.

Entscheidend kommt es deshalb auf die Interessenabwägung an, mit der geklärt werden muss, ob diese Behinderung auch gezielt bzw. unlauter ist. Es ist demnach zu prüfen, ob eine Beeinträchtigung der wettbewerblichen Entfaltungsmöglichkeiten des Werbeblockeranbieters vorliegt, die über die mit jedem Wettbewerb verbundene Beeinträchtigung hinausgeht und bestimmte Unlauterkeitsmerkmale aufweist. Dies ist dann der Fall, wenn gezielt der Zweck verfolgt wird, den Mitbewerber an seiner Entfaltung zu hindern und ihn dadurch zu verdrängen. Oder, in Ermangelung einer solchen Verdrängungsabsicht, wenn die Behinderung dazu führt, dass der beeinträchtigte Mitbewerber seine Leistung am Markt durch eigene Anstrengung nicht mehr in angemessener Weise zur Geltung bringen kann ${ }^{1082}$.

Nicht ganz fernliegend erscheint dabei das Vorliegen einer Verdrängungsabsicht. Bei einem spezialisierten Dienstleister wie AdDefend wird dies spiegelbildlich zur Argumentation bei Adblock Plus zu verwerfen sein. Denn genauso wie ein Werbeblocker davon lebt, dass es (viel) zu blo-

1081 BGH, Urteil vom 19.4.2018 - I ZR 154/16, WRP 2018, 1322 - Werbeblocker II.

1082 Ständige Rechtsprechung des BGH, vgl. nur Urteil vom 19.4.2018 - I ZR 154/16, WRP 2018, 1322 - Werbeblocker II. 
ckende Werbung gibt, lebt ein „Werbeblocker-Blocker“ von der Existenz und starken Verbreitung von Werbeblockern. Dies Verdrängung würde zwangsläufig auch die eigene Verdrängung beinhalten ${ }^{1083}$.

Anders hingegen erscheint die Interessenlage, wenn man als Täter auf den Webseitenbetreiber abstellt. Dieser hat kein eigenes Interesse am Fortbestand der Werbeblocker. Damit scheint dieses "Verhalten in erster Linie auf die Beeinträchtigung der wettbewerblichen Entfaltung des Mitbewerbers und nicht auf die Förderung des eigenen Wettbewerbs gerichtet" $1084 \mathrm{zu}$ sein. Es bedarf insoweit der Entscheidung, ob der mutwillige Einsatz von Zwangswerbung noch zu einem ausreichenden Maße auf die Förderung des eigenen Wettbewerbs der Webseitenbetreiber gerichtet ist. Hierbei wird zu beachten sein, dass die Webseitenbetreiber versuchen, die eigenen Werbeumsätze zu steigern. Mithin ist eine Förderung des eigenen Wettbewerbs durchaus erkennbar. Allerdings ist eine Gesamtwürdigung der Umstände des Einzelfalls unter Berücksichtigung der Interessen der Mitbewerber, Verbraucher, sonstiger Marktteilnehmer und der Allgemeinheit vorzunehmen ${ }^{1085}$. Hier spielen also unter anderem die oben bereits geprüften Interessen der Werbeblockernutzer hinein. Aus deren Sicht stellt sich die Umgehung der Werbeblocker durchaus als Versuch dar, Werbeblocker zu verdrängen. Dasselbe gilt für den betroffenen Werbeblockeranbieter selbst. Aus dessen Sicht liegt ein unmittelbarer Angriff auf sein Angebot ohne Auswegmöglichkeit vor. Insbesondere sehen die Zwangswerbungsmaßnahmen keine Möglichkeit zur (ggf. eingeschränkten) Koexistenz vor, wie es das kostenpflichtige Whitelisting eröffnet. Vor allem die spezielle Austauschwerbung ist ein konkreter Aggressionsakt gegen Werbeblocker, gegen den sich dessen Betreiber auch nicht durch technische Reaktionen behelfen kann. Auf der anderen Seite muss sich der Webseitenbetreiber jedoch vorhalten lassen, dass ihm mildere Mittel als Wehrung gegen Werbeblocker zur Verfügung stehen. So ist die oben genannte Aussperrung von Werbeblockernutzern - soweit datenschutzrechtlich zulässig - ein Mittel, um die Umgehung des eigenen Geschäftsmodells der werbefinanzierten Inhalte zu schützen. Auch wird man hier wieder alternative Refinanzierungswege der Webseitenbetreiber beachten müssen. Ironischer-

1083 Vgl. die Argumentation des OLG München, Urteil vom 17.8.2017, U 2184/15 Kart, WRP 2017, 1365; Urteil vom 17.8.2017, U 2225/15 Kart, GRUR 2017, 1147; Urteil vom 17.8.2017, 29 U 1917/16, WRP 2017, 1377.

1084 BGH, Urteil vom 19.4.2018 - I ZR 154/16, WRP 2018, 1322 - Werbeblocker II.

1085 Ständige Rechtsprechung des BGH, vgl. nur Urteil vom 19.4.2018 - I ZR 154/16, WRP 2018, 1322 - Werbeblocker II. 
weise könnte hier sogar das kostenpflichtige Whitelistingangebot von Adblock Plus als solches mildere Mittel angesehen werden. Denn hierdurch würde unter Einsparung der Kosten für die Einrichtung effektiver Umgehungswerbung ein Weg zu Nutzern eröffnet, die Werbung in einem bestimmten Rahmen dulden. Da nur eine erfolgsabhängige Vergütung anfiele, würden Webseitenbetreiber auf diese Weise ebenfalls Werbung trotz Werbeblockernutzung ausspielen und Umsätze generieren können.

Insgesamt fällt die Interessenabwägung also gegen die Webseitenbetreiber, die Zwangswerbung schalten, aus. Dies mag man durchaus als Schädigungs- oder Verdrängungsabsicht bezeichnen. Doch selbst, wenn man diese Schädigungsabsicht nicht annehmen möchte, wird die Zwangswerbung doch als unmittelbar produktbezogene Behinderung zu bewerten sein - dies insbesondere bei der Bewertung von Dienstleistern wie AdDefend. Die Zwangswerbung führt nämlich dazu, dass der Werbeblockeranbieter seine Leistung am Markt durch eigene Anstrengung nicht mehr in angemessener Weise zur Geltung bringen kann. Die Zwangswerbung zielt darauf ab, die Wirkweise der Software so zu unterwandern, dass die Verbreitungszahlen dauerhaft sinken und der "gute“ Ruf der Werbeblockersoftware bei ihren Nutzern beschädigt wird. Man stelle sich nur vor, Zwangswerbung würde von jedem Webseitenbetreiber eingesetzt: Werbeblocker mit Filterlistentechnologie würden vollständig obsolet.

Demnach ist die Schaltung von Zwangswerbung auch als gezielte Behinderung gemäß $\$ 4$ Nr. 4 UWG anzusehen.

\section{c) Aggressive geschäftliche Handlung}

Sodann könnte die Schaltung der Zwangswerbung zudem als aggressive geschäftliche Handlung gemäß $₫ 4 a$ UWG anzusehen sein. Diese geschäftliche Handlung ist im Ausgangspunkt mit Wirkung auf die Nutzer als Verbraucher oder auf die Werbeblockerbetreiber als sonstige Marktteilnehmer denkbar.

Allerdings lässt sich die Anwendbarkeit von $\$ 4$ a Abs. 1 UWG im Verhältnis zum Werbeblockerbetreiber schon damit verwerfen, dass die Werbeblockerbetreiber gar nicht zu einer geschäftlichen Entscheidung veranlasst werden. Denn die Zwangswerbung ist nicht darauf gerichtet, die Werbeblockerbetreiber zur Einstellung ihrer Geschäftstätigkeit zu bewegen. Sie ist vielmehr darauf gerichtet, die Software effektiv zu unterwandern. Deshalb liegt in dieser geschäftlichen Handlung der Fokus auf der Behinderung. 
Anders könnte der Fall mit Blick auf die Nutzer von Werbeblockern zu bewerten sein. Die hier bezweckte geschäftliche Entscheidung der Nutzer könnte darin liegen, den weiteren Einsatz von Werbeblockern zu unterlassen. Dies steht im Einklang mit der Legaldefinition der geschäftlichen Handlung in $\$ 2$ Abs. 1 Nr. 9 UWG, wonach auch die Entscheidung darüber, ob eine Ware oder Dienstleistung behalten oder abgegeben werden soll erfasst ist. Ein weiterer denkbarer Anknüpfungspunkt für die geschäftliche Entscheidung ist der Konsum der durch die Werbung vorgeschlagenen Dienstleistung. Die bloße Entscheidung, ob Werbung rezipiert werden soll oder nicht, lässt sich indes nicht mit dem Wortlaut von $\$ 2$ Abs. 1 Nr. 9 UWG in Einklang bringen.

In jedem Fall muss eines der in $\mathbb{4} 4$ a Abs. 1 S. 2 UWG genannten Aggressionsmittel erfüllt sein. Die Belästigung kommt insoweit vor dem Hintergrund in Betracht, als dass Zwangswerbung oben als unzumutbare Belästigung im Sinne des $\$ 7$ UWG eingeordnet worden ist. Über das Verhältnis und die Bedeutung der Belästigungsbegriffe in $₫ 4$ a Abs. 1 S. 2 Nr. 1 UWG und in $\$ 7$ UWG herrscht aber ein erheblicher Streit im Schrifttum $^{1086}$. Mit Blick auf die unterschiedlichen Zwecke der $\$ 4$ a und $\$ 7$ UWG indiziert die oben festgestellte unzumutbare Belästigung also nicht das Vorliegen der hier unabhängig und vor dem Hintergrund des Schutzes der wirtschaftlichen Interessen der Nutzer vorzunehmenden Prüfung der Belästigung ${ }^{1087}$. Eine aufgedrängte Werbung kann dabei jedoch durchaus eine Belästigung im Sinne von $\$ 4$ a Abs. 1 S. 2 Nr. 1 UWG darstellen, was sich bei richtlinienkonformer Auslegung aus Nr. 26 Anh. I UGP-Richtlinie folgern lässt ${ }^{1088}$. Demnach ist es eine aggressive Geschäftspraktik, wenn Kunden durch hartnäckiges und unerwünschtes Ansprechen über Telefon, Fax, E-Mail oder sonstige für den Fernabsatz geeignete Medien geworben werden. Die Schaltung von Zwangswerbung ist ein solches hartnäckiges und unerwünschtes Ansprechen mit Werbung. Eine Belästigung von Verbrauchern kann demnach angenommen werden.

Abgesehen davon liegt keine Nötigung im Sinne von $\$ 4$ a Abs. 1 S. 2 Nr. 2 UWG vor. Eine unzulässige Beeinflussung im Sinne von $₫ 4$ a Abs. 1 S. 2 Nr. 3, S. 3 UWG scheitert wohl daran, dass ein Webseitenbetreiber keine Machtposition ausnutzt, die die Fähigkeit der Nutzer zur informierten Entscheidung wesentlich einschränkt. So mag der Webseitenbetreiber

1086 Vgl. die ausführliche Darstellung des Streitstands bei Scherer, WRP 2017, 891.

1087 Köhler/Bornkamm/Feddersen, UWG, $\mathbb{S} 4 a$, Rn. 1.38.

1088 Köhler/Bornkamm/Feddersen, UWG, $\$ 4$ a, Rn. 1.44; Scherer, WRP 2017, 891, 896. 
zwar die Macht besitzen, Werbung trotz aktiviertem Werbeblocker im Nutzergerät zu platzieren. Diese Macht wird aber zur bloßen Werbeausspielung ausgenutzt, also zur Generierung eigenen Umsatzes. Nicht wird dadurch der Nutzer derart in seiner Entscheidungsfreiheit bedrängt, Werbeblocker weiterhin zu nutzen. Mit Blick auf die beworbenenen Waren und Dienstleistungen liegt dies ohnehin fern, da diese schlicht wie normale Werbung Appelle vermittelt, aber keinen Zwang ausübt.

Soweit jedoch eine Belästigung angenommen wird, ist nach $\ 4 \mathrm{a}$ Abs. 1 S. 1 UWG noch die Eignung der Veranlassung zu einer geschäftlichen Entscheidung, die der Nutzer andernfalls nicht getroffen hätte, zu prüfen. Es geht also um die Frage, ob ein durchschnittlicher Nutzer durch die Ausspielung von Werbung trotz aktiviertem Werbeblocker entgegen seinen eigentlichen Plänen den Werbeblocker abschwört oder beworbene Produkte nachfragt. Beides liegt jedoch eher fern. So wird die Entscheidung über die fortwährende Nutzung von Werbeblockern durch die Zwangswerbung unangetastet bleiben, weil auch der Verzicht auf Werbeblocker nichts an der Werbeausspielung ändert. Anders wäre dies etwa bei der Zugangssperre, wo die Deaktivierung des Werbeblockers einen direkten Vorteil bring$\mathrm{t}^{1089}$. Die Möglichkeit, dass sich ein Nutzer von aufgedrängter Werbung angesprochen fühlt und das beworbene Produkt sodann nachfragt, stellt eine besondere Leistung der Werbenden dar, die keine aggressive geschäftliche Handlung sein darf. Insgesamt scheidet deshalb eine Anwendung von $\$ 4$ a UWG auf Zwangswerbung aus.

\section{Zulässigkeit wirtschaftlicher Reaktionen}

Auf der anderen Seite stehen wirtschaftliche Reaktionen der Webseitenbetreiber und Inhalteanbieter auf Werbeblocker.

Soweit diese Reaktionen in der Errichtung von „Paywalls“, d.h. des Wechsels von kostenfreiem und werbefinanziertem auf kostenpflichtiges Angebot, besteht, kann dies rechtlich nicht verboten sein. Es bestehen für private Unternehmen keine rechtlichen Pflichten zur kostenfreien $\mathrm{Zu}$ gänglichmachung von Inhalten im Web. Demnach obliegt es der Freiheit von Unternehmen, monetäre Gegenleistungen zu fordern. Dasselbe gilt

1089 Die Zugangssperre stellt jedoch keine Belästigung und keine unzulässige Beeinflussung, mithin keine aggressive Geschäftspraktik dar. Dies ist bei wertender Betrachtung allein deshalb zwingend, weil den Webseitenbetreibern ein effektives Wehrmittel gegen Werbeblocker zustehen muss. 
für Registrierungspflichten von Nutzern. Es steht privaten Unternehmen vorbehaltlich der datenschutzgerechten Ausgestaltung frei, eine vertragliche Verbindung zu den Nutzern zu fordern, bevor Inhalte weitergegeben werden.

Rechtliche Prüfungen werden erst dort möglich, wo im Rahmen der Registrierung Nutzungsbedingungen oder sonstige Regelwerke von Nutzern anerkannt werden müssen. In diesem Fall ist die AGB-Prüfung eröffnet. Die Bedingungen müssen sich dann an den Voraussetzungen der $\$ \$ 305 \mathrm{ff}$. BGB messen lassen. Denkbarer Konflikt ist in diesem Zusammenhang eine in AGB niedergelegte Werberezeptionspflicht oder - umgekehrt ein Verbot des Einsatzes von Werbeblockern. Eine solche Klausel könnte schon als überraschende Klausel gemäß $\$ 305$ c Abs. 1 BGB nicht Vertragsbestandteil werden. Dies wird natürlich nur auf einer Einzelfallbasis zu beurteilen sein. Ein redlicher Kunde von durchschnittlicher Geschäftserfahrung, Aufmerksamkeit und Umsicht ${ }^{1090}$ könnte durchaus bei der Registrierung auf der Webseite eines Medienanbieters durch eine solche Klausel überrumpelt werden, wenn die Webseite an keiner Stelle auf die generelle Ablehnung von Werbeblockern hinweist und die Klausel auch in den Nutzungsbedingungen nicht deutlich und transparent angelegt ist ${ }^{1091}$.

Eine Klauselkontrolle nach $\$ \$ 307$ - 309 BGB wird indes allein durch Anwendung der Generalklausel in $\$ 307$ Abs. 1 BGB erfolgen. Keine der spezielleren Regelungen ist für eine Werberezeptionspflicht oder ein Werbeblockerverbot einschlägig. Es kommt also darauf an, ob ein Internetnutzer entgegen den Geboten von Treu und Glauben unangemessen benachteiligt wird. Dies wird bei kostenlosen Angeboten wie etwa sozialen Netzwerken weniger anzunehmen sein als bei kostenpflichtigen Angeboten, die zudem ergänzende Werbeeinnahmen erzielen wollen. Auch hier kommt es stark auf den Einzelfall an, d.h. auf die Art der Plattform, Umstände der Registrierung und konkreter Ausgestaltung der Klausel. Tendenziell sollte eine unangemessene Benachteiligung bei kostenlosen oder sehr kostengünstigen ${ }^{1092}$ Angeboten ausscheiden. In diesen Fällen wird dem Nutzer bekannt sein, dass der Anbieter auf Werbeeinahmen zur Refinanzierung angewiesen ist. Wenn allerdings eher hochpreisige Abonnementpreise gefordert werden, wird die weitergehende vertragliche

1090 Basedow, in: MüKo/BGB, $\$ 305$ c, Rn. 7.

1091 Ähnlich: Kreutz, Online Angebote und Werbeblockersoftware, S. 380, der auf die zurückhaltende Anwendung von $\$ 305$ c BGB in der Rechtsprechung hinweist.

1092 Etwa bei Zugriff auf weite Inhaltsdatenbanken für unter $5 €$ pro Monat. 
Verpflichtung des Nutzers zudem als Werberezipient zur Verfügung zu stehen, eine Unwirksamkeit der Klausel durchaus begründen können ${ }^{1093}$.

Maßnahmen wirtschaftlicher Art, die sich anstatt an Nutzer an Werbeblockerbetreiber richten, müssen sich an Lauterkeits- und Kartellrecht messen lassen. Insbesondere die Ausnutzung von Plattformmacht, wie dem Ausschluss von Werbeblockern aus Appstores ${ }^{1094}$, kann dabei eine gezielte Behinderung der Werbeblockerbetreiber nach $\$ 4$ Nr. 4 UWG oder verbotenes marktbeherrschendes Verhalten nach $\mathbb{\$} \mathbb{1 8 f f .}$ GWB darstellen.

1093 Kreutz, Online Angebote und Werbeblockersoftware, S. 387f., geht an dieser Stelle weiter und hält diese Klauseln generell für einen Anwendungsfall von $\$ 307$ Abs. 1 BGB.

1094 https://www.heise.de/newsticker/meldung/Google-wirft-Werbeblocker-aus-de m-Android-Play-Store-1822706.html, zuletzt abgerufen am 31.5.2019. 


\section{E. Konterreaktion: Maßnahmen zur Umgehung der Verhinderung}

Es verwundert kaum, dass die im vorigen Abschnitt beschriebenen Reaktionen der Webseitenbetreiber ihrerseits Konterreaktionen heraufbeschwören. Denn Nutzer, die sich von der verbreiteten Werbung im Internet bereits belästigt fühlen und aus freier Entscheidung, ein technisches Mittel zur Ausschaltung dieser Werbung einsetzen, werden tendenziell auch andere technische Wege zur Beibehaltung einer effektiven Werbeblockade beschreiten. Wo allerdings technisch unblockierbare Werbung ausgespielt wird und Zugangssperren oder „Paywalls“ errichtet werden, erreichen die Konterreaktionen tatsächliche und rechtliche Grenzen, die in diesem Abschnitt aufgezeigt werden sollen.

\section{Darlegung von Konterreaktionen der Werbeblockerbetreiber und Nutzer}

Gewisse technische Reaktionen der Webseitenbetreiber setzen sozusagen einen Schlusspunkt und können nicht gekontert werden. Dies ist der Fall bei generell unblockierbarer Werbung, die durch eine effektive dynamische Generierung von URLs von Filterwerbeblockern schlicht nicht mehr blockiert werden kann. Dies ist ebenso der Fall bei fest mit dem Content verwobener Werbung, die technisch nicht blockierbar ist. Dies mag einer von vielen Gründen sein, warum sich Werbende im modernen Internet gerne den Formen des Native Advertising oder Influencern bedienen ${ }^{1095}$.

Daneben gibt es aber auch Maßnahmen der Webseitenbetreiber, die ihrerseits eine offene Flanke für Gegenangriffe bieten. Bekannte Phänomene werden nachstehend beschrieben. Im Nachgang erfolgt die rechtliche Bewertung der Konterreaktionen.

1095 Vgl. obige Beschreibungen unter B. I. 4. b) und d). 
1. Ergänzung von Werbeblockerfiltern zur Umgehung von Zugangssperren

Unmittelbar nachdem Axel Springer auf Bild.de ihre Zugangssperre installierte, die Nutzern von Werbeblockern den Zugang verweigert, waren in spezialisierten Foren im Web Filterbefehle für Werbeblockersoftware verfügbar, die diese Zugangssperre aushebelten. Diese Umgehung der Zugangssperre führte zu einstweiligen Verfügungsverfahren zwischen Axel Springer und dem AdBlock Plus Betreiber Eyeo GmbH beim LG Hambur$\mathrm{g}^{1096}$ sowie beim LG und OLG Köln ${ }^{1097}$. Den Verfahren lag laut ihren Tatbeständen der Fall zu Grunde, dass AdBlock Plus im eigenen Forum sowie in dem auf Filterlisten spezialisierten Forum "forums.lanik.us" zunächst zwei Filterbefehle und später ein „12-zeiliger Code“ zur Einfügung in die Blacklist von AdBlock Plus zur Verfügung stellte. Nach entsprechender Abmahnung waren jedenfalls im eigenen Forum von AdBlock Plus die Filterbefehle noch verfügbar, sodass Axel Springer eine einstweilige Verfügung beantragte und vom LG Hamburg auch erhielt. Eyeo darf dem Beschluss entsprechend weder Programmcodes noch Links zu Programmcodes, noch ganze Filterlisten mit Befehlen verbreiten, die eine Umgehung der Bild.de-Zugangssperre ermöglichen.

Ein ähnliches Vorgehen galt einer Privatperson, die auf YouTube eine Videoanleitung zur Einbindung der Programmcodes zur Umgehung der Zugangssperre auf Bild.de veröffentlicht hat. In einem Hauptsacheverfahren entschied hier das LG Hamburg zu Gunsten von Axel Springer ${ }^{1098}$. Laut Tatbestand des Urteils war folgendes Vorgehen notwendig, um die Bild.de-Sperre mit AdBlock Plus zu umgehen:

"- das ABP Icon anklicken und Filtereinstellungen aufrufen,

- die Easylist (+ Easylist Germany) deaktivieren,

- unter https:// e.a.org/en die Liste "E. without element hiding from" laden, - danach entweder die Liste "Easylist Germany" hinzufügen (wobei darauf $z u$ achten war, dass man nicht die "E. + e. Germany", die man hier findet https:// e.a..org/en/, hinzufügt) oder in ABP als Filterprofil hinzufügen;

- sodann musste man noch eine eigene Liste erstellen

- und sodann diesen Code einfügen mit z.B. STRG+V: @@/|sascdn.com^\$domain=b..de@@@|smartadserver.com^ ${ }^{\wedge} \$$ domain=b..de. $“$

1096 LG Hamburg, Beschluss vom 22.10.2015 und Urteil vom 3.12.2015 - $308 \mathrm{O}$ 375/15, ZUM 2016, 892.

1097 OLG Köln, Beschluss vom 17.12.2015 - 6 W 128/15, (unveröffentlicht).

1098 LG Hamburg, Urteil vom 21.12.2016 - 310 O 129/16, juris. 
In der hier maßgeblichen tatsächlichen Betrachtung der Konterreaktion war also die für Adblock Plus notwendige Filterliste um gewisse Sonderbefehle zu ergänzen. Die Programmierung der Sonderbefehle bedurfte wohl besondere Kenntnisse der anwendbaren Programmier- bzw. Auszeichnungssprachen. Sobald diese aber im Internet verbreitet worden sind, war die Einbindung durch den Nutzer leicht zu bewerkstelligen. Deshalb war es auch nicht verwunderlich, dass Axel Springer Rechtsschutz gegen einige prozessual leicht erreichbare Quellen der Verbreitung ersuchten, um die Effektivität der Zugangssperre nicht unmittelbar nach Installation einzubüßen.

\section{2. „Adblocker-Detektoren-Blocker“}

Neben den oben genannten und für das Verhältnis AdBlock Plus und Bild.de spezifischen Befehlen sind im Netz zudem besondere Add-ons verfügbar, mit denen sich der Ablauf der Adblocker-Detektoren verhindern lässt. Entsprechende Programme sind zum Beispiel Tampermonkey oder Greasemonkey. Dies sind Userscript-Manager Tools, die die Installation von Skripten ermöglicht, die ihrerseits Inhalte von aufgerufenen Webseiten ändern. Konkret ermöglichen sie es dem Benutzer, die Ausführung von JavaScript-Dateien im Browser zu unterbinden, die die angezeigte Webseite mittels DOM-Schnittstelle manipulieren können ${ }^{1099}$. Im Rahmen dieses Add-ons kann dann ein für das spezielle Problem der Adblocker-Detektoren, und folglich auch für Zugangssperren oder Austauschwerbung, ein Skript hinzugefügt werden, etwa der „Anti-Adblock Killer“1100. Dieser „Killer“ besteht aus einem JavaScript-Programm und einer speziellen Filterliste, um eine Vielzahl von Webseiten mit Adblock-Detektoren freizuschalten.

\section{Sonstige Reaktionen}

Außerhalb dieser technischen Reaktionen sind auf tatsächlicher Ebene kaum weitere Reaktionen erkennbar. Ein Phänomen, das sich mit dem Erfolg kostenpflichtiger Abo-Modelle wie Netflix und Spotify verbreitet hat,

1099 https://de.wikipedia.org/wiki/Greasemonkey, zuletzt abgerufen am 31.5.2019.

1100 https://openuserjs.org/scripts/reek/Anti-Adblock_Killer_Reek, zuletzt abgerufen am 31.5.2019. 
ist das Teilen von Zugangsdaten zur Überwindung von Bezahlschranken. So ist es nicht selten, dass sich mehrere Personen einen Account bei Netflix oder Spotify teilen, obwohl dies nicht mit den Vertragsbedingungen übereinstimmt - etwa weil diese Bedingungen für die gemeinsame Nutzung vorschreiben, dass alle Nutzer im selben Haushalt leben ${ }^{1101}$. Historisch könnte man dieses Verhalten als eine Art Fortführung der „Piratenkarten" im Pay-TV Bereich verstehen, wenngleich das Teilen von Zugangsdaten offensichtlich weniger praktischen Aufwand und krimineller Energie bedarf. Dass der Verstoß gegen Vertragsbedingungen negative Rechtsfolgen haben kann, bedarf keiner weiteren Vertiefung. Dasselbe gilt für eine potentielle strafrechtliche Bedeutung des „Passwort-Sharing“.

Eine andere naheliegende Reaktion auf die Wehrreaktionen der Webseitenbetreiber wird allerdings offenbar nicht genutzt: die rechtliche Wehr der Nutzer oder Werbeblockerbetreiber gegen die Anti-Werbeblocker Maßnahmen der Werbeindustrie. Es bleibt abzuwarten, ob im Fortgang der rechtlichen Diskussion eine neue Generation der Werbeblockerfälle auf die Justiz zukommt. Ein gerichtliches Verbot von werbeblockerabhängiger Zwangswerbung würde zum Beispiel eine effektive Konterreaktion darstellen.

\section{Rechtliche Beurteilung}

Auf Grundlage der zuvor dargestellten Reaktionen soll nachfolgend die rechtliche Zulässigkeit der Umgehung von Zugangssperren und der Umgehung von Zwangswerbung untersucht werden.

\section{Umgehung von Zugangssperren, \$95a UrhG}

Wie oben bereits beschrieben ist Rechtsprechung verfügbar, die die konkrete Umgehung der Bild.de-Sperre betrifft. Das LG Hamburg hat dabei in zwei Urteilen einen Unterlassungsanspruch aus $₫ 823 \mathrm{Abs.} 2 \mathrm{BGB} \mathrm{iVm}$ $\$ 95$ a III Nr. 3 UrhG und $\$ 1004$ BGB erkannt ${ }^{1102}$. Rechtlich entscheidend

1101 https://www.chip.de/news/Illegales-Netflix-Streaming-Passwort-Trick-wird-zur -Bedrohung-fuer-den-Streaming-Dienst_118683472.html, zuletzt abgerufen am 31.5.2019.

1102 LG Hamburg, Urteil vom 3.12.2015 - 308 O 375/15, ZUM 2016, 892; Urteil vom 21.12.2016 - 310 O 129/16, juris. 
war demnach die Rechtsfrage, ob die Zugangssperre eine wirksame technische Maßnahme gemäß $\$ 95 a$ UrhG ist ${ }^{1103}$. Dies wurde von zwei Kammern des LG Hamburg mit den nachfolgenden darzustellenden Argumenten bejaht, allerdings im Schrifttum angezweifelt. Dieser Abschnitt endet mit einer kurzen Stellungnahme zur Streitfrage.

a) Annahme einer Umgehung einer wirksamen technischen Maßnahme durch das LG Hamburg

Nachdem die 8. Zivilkammer des LG Hamburg bereits am 22.10.2015 mit einem knapp begründeten Beschluss dem Begehren der Betreiber von Bild.de entsprachen und Eyeo per einstweiliger Verfügung untersagte, die Umgehung der Bild.de-Sperre zu fördern, äußerte sich die Kammer in ihrem Urteil vom 3.12.2015 ausführlich zur rechtlichen Beurteilung der Umgehung der Zugangssperre.

Im hier untersuchten Punkt des Vorliegens und der Umgehung einer wirksamen technischen Maßnahme iSv $\$ 95 a$ Abs. 1 UrhG begründete die Kammer ihre Entscheidung wie folgt. Zunächst untersuchte sie die Wirksamkeit der Zugangssperre. Unter Verweis auf die herrschende Rechtsprechung zu dieser Frage prüfte das LG Hamburg, wie schwierig es für einen durchschnittlichen Internetnutzer sei, die hinter der Sperre liegenden Inhalte zu erreichen, wenn er nicht auf den Einsatz von Werbeblockern verzichten wolle. An dieser Stelle könne es jedenfalls nicht auf die Schwierigkeit für einen „Hacker“ ankommen. Es kam zum Ergebnis, dass eine Umgehung für einen Durchschnittsnutzer nicht möglich sei, da hierfür jedenfalls die Fähigkeit gehöre, den JavaScript-Code im Quellcode der Webseite zu verstehen. Mangels einer allgemeinen Verbreitung der Fähigkeit, den Code der für Webseiten geläufigen Auszeichnungs- und Programmiersprachen (HTML, CSS und JavaScript) lesen und verstehen zu können, sei dies also schon ausreichend für das Merkmal der Wirksamkeit. Dies wird dadurch gestützt, dass ergänzend noch die Formulierung von

1103 Daneben ging es in den Streitfällen wegen der Veröffentlichung von Umgehungsbefehlen in diversen Foren oder Plattformen um hier nicht darzustellende Zurechnungsfragen. In diesem Zusammenhang lehnte des OLG Köln etwa die Haftung von Eyeo für Einträge in einem fremden Forum („forums.lanik.us“) ab, OLG Köln, Beschluss vom 17.12.2015 - 6 W 128/15, (unveröffentlicht). 
Filterbefehlen und die Einfügung dieser in die Blacklist des Werbeblockers notwendig sind.

Weiterer Prüfungspunkt war die Notwendigkeit, dass die technische Maßnahme dem Unterbinden urheberrechtlich relevanter Nutzungshandlungen dienen muss. Dies bejahte die Kammer unter Hinweis auf die Vervielfältigung der auf der Webseite enthaltenen geschützten Lichtbilder und Texte im Arbeitsspeicher des Nutzergeräts. Dies gehe über den urheberrechtlich nicht zu untersagbaren reinen Werkegenuss hinaus. Diskutabel war bei diesem Aspekt ein technisches Detail: Die Sperre wirkt beim erstmaligen Aufruf von Bild.de erst nach einer Dauer von einigen Sekunden. Dies ist die Dauer, in welcher der Adblocker-Detektor seine Arbeit verrichtet und bei erfolgreicher Detektion den Sperrbildschirm einblendet. Man kann also technisch davon sprechen, dass die Vervielfältigung im Arbeitsspeicher bereits abgeschlossen ist und es deshalb tatsächlich nur noch um den reinen Werkgenuss geht. Eine Unterbindung urheberrechtlich relevanter Nutzungshandlungen wäre dann nicht mehr anzunehmen. Außerdem berief sich Eyeo auf $\$ 44$ a UrhG, also die Schranke für vorübergehende Vervielfältigungen. Dem hielt das LG Hamburg entgegen, dass die konkrete Sperre tatsächlich verhindere, dass im Gerätearbeitsspeicher bereits geladene Elemente in den Browser-Cache verschoben werden. Dies stelle aber eine eigene und neue Vervielfältigung eines Werkes dar, da ein Werk aus dem „unsichtbaren“ Arbeitsspeicher hierdurch erstmals als Bildschirmkopie sichtbar wird ${ }^{1104}$. Eine Anwendung von $\$ 44$ a UrhG lehnte die Kammer $a b$, da diese Norm nicht in $\$ 95 b$ UrhG aufgeführt ist und demnach ein systematischer Vorrang der technischen Maßnahme vor der Schrankenregelung bestehe.

Zuletzt bejahte das LG Hamburg eine Umgehungshandlung gemäß $\$ 95$ a Abs. 3 Nr. 3 UrhG in dem Verbreiten von Softwarecode zur Umgehung. Dies gelte sowohl für die Einfügung in eine Blacklist als auch dem Bewerben solchen Codes in Internetforen.

Ganz ähnlich entschied die 10. Zivilkammer des LG Hamburg in ihrem Urteil vom 21.12.2016 ${ }^{1105}$. Sie hielt die mit dem Aufrufen and Anzeigenlassen der Internetseite verbundene Vervielfältigung von geschützten Fotos und Texten für ausreichend, um das Erfordernis von $\$ 95$ a Abs. 2 UrhG zu erfüllen. Ebenfalls führte es aus, dass $\$ 44$ a UrhG mangels Nennung in $\$ 95$ b UrhG nicht anwendbar sei. Die Wirksamkeit der technischen

1104 Verweis auf EuGH, Urteil vom 4.10.2011, C-403/08 und C-429/08, GRUR Int 2011, 1063.

1105 LG Hamburg, Urteil vom 21.12.2016 - 310 O 129/16, juris. 
Maßnahme begründete die Kammer damit, dass eine Zugangskontrolle stattfinde. Eine Verschlüsselung sei nicht erforderlich. Die Zugangskontrolle anhand der Prüfung der Nutzung eines Werbeblockers sei deshalb wirksam und ausreichend, weil der durchschnittliche Werbeblockernutzer die voreingestellten Filterlisten nicht modifiziere, sondern unverändert lasse. Außerdem könne dieser durchschnittliche Nutzer mangels hinreichender Programmierkenntnisse keinen Code lesen und verstehen. Es mangele Nutzern regelmäßig an der Kenntnis, wie Filterlisten ergänzt werden müssen. Dass diese Kenntnisse durch Recherche im Internet in Spezialforen zugänglich seien, verfange nicht, weil eine solche Recherche nur durch besonders technikaffine Nutzer erfolge, nicht aber durch den durchschnittlichen Nutzer. Zudem ergebe sich aus dem Umstand, dass Umgehungsmöglichkeiten mehr oder weniger ausführlich veröffentlicht worden sind, dass die Schutzmaßnahme nicht für jedermann leicht zu überwinden sei.

\section{b) Kritik in der Literatur}

Diese Rechtsprechung fand teils Zustimmung und teils Kritik in der Literatur. Mahnende Worte fand Peifer unmittelbar nach der Entscheidung im einstweiligen Verfahren zwischen Axel Springer und Eyeo. Wenngleich er keine ausführliche Prüfung vornahm, äußerte er seine Gedanken zu dieser nächsten Eskalationsstufe im Werbeblockerstreit. Obwohl er die Entscheidung des LG Hamburg als konsequent bezeichnet, weil ein Webseitenbetreiber, der technische Wehrmaßnahmen ergriffen hat, gegen Werbeblocker auch entsprechenden Schutz erhielt, gibt er zu erinnern, dass $\$ 95$ a UrhG nur dann anwendbar sei, wenn gesetzliche Befugnisse von Rechteinhabern verletzt werden. Die Verbindung von Werbung und Inhalt falle nicht darunter. Aus $\$ 95$ a UrhG dürfe keine bloße Kopplung von Werbung und Inhalt folgen ${ }^{1106}$. Zudem suggestieren Nink ${ }^{1107}$ und Witte ${ }^{1108}$, dass technische Maßnahmen nach $\$ 95$ a UrhG vor allem wirksam sein müssen, also nicht einfach und mit geringem Aufwand ausgeschaltet werden können. Während Nink sich einem Urteil enthält, lehnt Witte die notwendige Wirksamkeit ab, weil Überwindungswerkzeuge im Internet

1106 Peifer, AfP 2016, 5, 10; vgl. auch die pseudonyme Kritik unter https://www.dat enschutzbeauftragter-info.de/bildsmart-fragwuerdiges-urteil-des-lg-hamburg-zu r-adblock-sperre/, zuletzt abgerufen am 31.5.2019.

1107 Nink, CR 2017, 103, 111.

1108 Witte, ITRB 2018, 34, 38. 
leich zu finden seien. Außerdem weist er wie Peifer auf eine fehlende Erreichung urheberrechtlicher Schutzziele der Zugangssperre hin. Demnach käme kein Komplettverbot von Umgehungswerkzeugen in Betracht, da damit auch die nicht urheberrechtlich geschützte Gestaltung der Webseite bzw. der Anzeige von nicht geschützten Werbeelementen erfasst würden. \$95a UrhG würde dann durch überschießende Anwendung erlaubtes Verhalten untersagen.

Zustimmend äußert sich hingegen Runkel und stellt die Bild.de-Sperre auf dieselbe Stufe mit einer Passwortabfrage bei zugangsgeschützten Webseiten. Außerdem geht er davon aus, dass kostenpflichtige Inhalte, auf die man nur mit Passwort zugreifen kann, mit den werbefinanzierten aber kostenlosen Inhalten gleichzusetzen seien. Wirtschaftlich sei dies vergleichbar und die Werberezeption stelle die Gegenleistung für die Zugänglichmachung der Inhalte dar. Dies mache die Prüfung, ob die Finanzierungsgrundlage im konkreten Fall durch fehlenden Einsatz von Werbeblockern gesichert sei, akzeptabel. Deshalb bestehe kein Grund die Sicherungsmaßnahmen bei Bezahlmodellen anders zu behandeln als die Sicherung des werbefinanzierten Modells ${ }^{1109}$.

Eine ausgesprochen ausführliche Auseinandersetzung - insbesondere in technischer Hinsicht - liefern Kiersch und Kassel1110. In sorgfältiger Prüfung und Subsumtion des $\$ 95$ a UrhG wird zunächst geprüft, ob eine technische Maßnahme iSv $\mathbb{\$} 95$ Abs. 2 S. 1 UrhG vorliegt. In dieser Prüfung differenzieren die Autoren danach, ob durch die jeweilige technische Maßnahme eine Vervielfältigung von geschützten Werken verhindert wird. Dies verneinen sie für die erstmalige Vervielfältigung von Artikeltexten, die bereits mit dem HTML-Dokument in den Arbeitsspeicher der Nutzergeräts gelangen. Ob weitere Vervielfältigungen im Rahmen des Rendering durch den Browser, z.B. Überführung von Texten aus dem Arbeitsspeicher oder Nachladen von Lichtbildern, verhindert werden, hänge von der Programmierung des Adblocker-Detektors und der verbundenen Sperre ab. Ist dieser Zeitpunkt früh genug und verhindere tatsächlich die weitere Arbeit des Browsers am HTML-Dokument so könne durchaus eine ausreichende technische Maßnahme vorliegen, die den Zugriff auf geschützte Werke verhindere. Wirke die Sperre aber erst nach vollständigem Laden und Ausführen, so sei dies zu verneinen. An dieser Stelle widersprechen die Autoren auch behutsam der Ansicht des LG Hamburg, das unter Verweis

1109 Runkel, IPRB 2016, 81, 84.

1110 Kiersch/Kassel, CR 2017, 242. 
auf die Rechtsprechung des EuGH die Verbringung vom Arbeitsspeicher in Browser-Cache als ausreichende neue Vervielfältigung ansah.

Im sich anschließenden Prüfungspunkt der Wirksamkeit eben jener technischen Maßnahme setzen sich die Autoren mit der Möglichkeit des generellen Verzichts eines Nutzers auf JavaScript durch entsprechende Einstellung im Browser auseinander. Wenn JavaScript-Programme nicht ausgeführt werden, funktioniere demnach auch die Sperre bei Bild.de nicht richtig. Im Ergebnis bekomme der Nutzer Zugriff auf die Webseite, wenn auch unter verringerter Funktionalität, da auch andere JavaScriptAnwendungen nicht ausgeführt werden. Dies führt Kiersch und Kassel dazu, dass dann praktisch nur die Rezeption der Werke durch die Sperre verhindert werde, nicht aber deren urheberrechtlich relevante Nutzung. Dann bestehe aber auch keine wirksame Schutzmaßnahme. Hingegen wäre eine Sperre in jedem Fall wirksam, wenn sie die Inhalte der Webseite vor Prüfung der Werbeblockernutzung verschlüsselt oder gar nicht zum Download zulässt. Zwar scheint die Autoren das Argument nicht zu überzeugen, dass der durchschnittliche Internetnutzer selbst praktisch keine eigene Umgehung bewerkstelligen könnte, sie erkennen aber diese Realität an und konstatieren, dass dies ein Grund für die Wirksamkeit darstellen könne.

Bei der Prüfung, ob eine Umgehung im Sinne des $₫ 95$ a UrhG vorliegt, differenzieren die Autoren wiederum. So soll die Wahl eines Browsers, der generell JavaScript nicht ausführt, oder die Wahl einer Funktion, kein JavaScript auszuführen, jedenfalls nicht zu einer Umgehung führen. Dasselbe gelte beim Einsatz von Scriptblockern wie etwa NoScript. Eine direkte Manipulation der Zugangssperre etwa durch die Greasemonkey und Anti-Adblock-Killer Lösung halten sie dagegen für eine Umgehung. Wenn hingegen keine unmittelbare Ausschaltung der Zugangssperre vorliegt, sondern vielmehr dem dazu gehörigen Adblocker-Detektor technisch vorgegaukelt wird, dass das Köderelement vom Nutzergerät geladen und angezeigt wird, möge zu unterscheiden sein, ob die Fallgestaltung auf einer Ausschaltung von JavaScript generell beruht oder eine gewollte Umgehung darstellt. Im ersten Fall müsse zur Wahrung der Konsistenz mit der ersten dargestellten Fallgruppe eine Umgehung ausscheiden, im zweiten Fall läge hingegen eine Umgehung vor.

Im Ergebnis versuchen Kiersch und Kassel den Ausgleich zwischen der Freiheit der Nutzer, JavaScript-Anwendungen zu meiden, und den direkten Umgehungsversuchen bei Bild.de zu finden. Die vorgenommene differenzierende Betrachtung steckt dafür einen sinnvollen Rahmen. 
c) Stellungnahme

Auf dieser Grundlage soll nachfolgend Stellung genommen werden, wobei nicht allein auf die Bild.de-Sperre einzugehen ist, sondern das Thema Umgehung von Zugangssperren auf Webseiten abstrakt betrachtet werden soll. Dazu bedarf es einer genauen Beachtung der rechtlichen Anforderungen und der technischen Gegebenheiten. Eine rein wirtschaftliche Betrachtung wie Runkel sie vornimmt, wird der Komplexität in jedem Falle nicht gerecht. Auch die von Peifer und Witte geäußerten Zweifel vor dem Hintergrund des Schutzzwecks scheinen zu pauschal. Kiersch und Kassel bereiten das Thema sorgsam auf, jedoch ist ihren Ergebnissen nicht in allen Punkten zuzustimmen.

\$95a Abs. 1 UrhG enthält ein Umgehungsverbot für wirksame technische Maßnahmen zum Schutz eines nach dem UrhG geschützten Werkes oder Schutzgegenstandes. $\$ 95$ a Abs. 2 UrhG enthält die anwendbaren Definitionen für die technische Maßnahme und für deren Wirksamkeit. Sowohl im Text des Umgehungsverbots als auch bei den Definitionen ist der Schutz von Werken oder sonstigen Schutzgegenständen des UrhG ausdrücklich genannt. Dies zeigt deutlich, dass es unbedingte Grundlage der Anwendung von $\$ 95$ a UrhG ist, dass die Zugangssperre auf die Verhinderung von urheberrechtlich relevanten Nutzungshandlungen abzielt. Wie oben ausführlich herausgearbeitet, ist der Besuch einer Webseite insgesamt nicht urheberrechtlich relevant ${ }^{1111}$. Deshalb kann eine Zugangssperre nicht schon deshalb den Schutz von $\$ 95$ a UrhG auslösen, weil sie die bloße Rezeption von Webseiten - mit oder ohne Werbung - verhindern soll. Richtigerweise stellt das LG Hamburg deshalb auf den gleichwohl existierenden urheberrechtlichen Schutz von einzelnen Elementen einer Webseite ab. Journalistische Texte, Fotos und Videos sind für sich gesehen selbstredend schutzfähige Werke oder zumindest durch Leistungsschutzrechte erfasste Gegenstände.

Allerdings ergibt sich hier eine gewisse Diskrepanz zwischen dem Ziel der Zugangssperre und den eigentlich von $\$ 95$ a UrhG geschützten Werken und Schutzgegenständen. Bei oberflächlicher Betrachtung geht es nämlich nicht um einen Schutz vor Raubkopien von journalistischen Texten, Fotos oder Videos, auf den $\$ 95$ a UrhG eigentlich zugeschnitten ist. Vielmehr versuchen Webseitenbetreiber durch die Einführung von Selbsthilfemaßnahmen einen überschießenden Schutz zu erreichen, was

1111 Siehe oben Ziffer C. I. 4. a) bb). 
ein durchaus kritisiertes Problem bei der Anwendung der Norm ist ${ }^{1112}$. Gleichwohl führt an diesem überschießenden Schutz wohl kein Weg vorbei. Nur wenn die Umgehungslösung tatsächlich teilbar ist, kann ein Gericht lediglich ein Teilverbot aussprechen, etwa wenn ein Werbeblocker nur eine gewisse abgrenzbare Funktion aufwiese, die die Umgehung bewerkstelligt. In Fallkonstellationen wie sie dem LG Hamburg vorlagen kommt nur ein Komplettverbot der Umgehung in Betracht.

Wenn nicht über das Merkmal des Werks oder Schutzgegenstands differenziert werden kann, muss die urheberrechtliche Nutzungshandlung untersucht werden. Da bei der Nutzung von Webseiten (bzw. deren Elementen) die Vervielfältigung maßgeblich ist, muss untersucht werden, ob eine Vervielfältigung der maßgeblichen Texte und Fotos durch die $\mathrm{Zu}$ gangssperre verhindert wird. Dies kann ganz unterschiedlich ausgestaltet sein. Die Parteien im Streitfall des LG Hamburg im Verfahren $308 \mathrm{O}$ 375/15 stritten auf Grundlage von Sachverständigengutachten zur technischen Wirkung, ob die Vervielfältigung der Werke bereits unterbunden wird, bevor die Elemente der Internetseite vollständig in den Speicher des Betriebssystems des Nutzers kopiert werden oder erst dann, wenn die Elemente vom Speicher des Betriebssystems in einen anderen Teil des Arbeitsspeichers, den Browser-Cache, verschoben werden ${ }^{1113}$. Bei anderen Webseiten ist beim Besuch ganz deutlich, dass die gesamte Startseite einer Webseite vollständig geladen und auf dem Gerät bereits angezeigt wird, bevor die Zugangssperre zu wirken beginnt und auf einen Sperrbildschirm weiterleitet. Demnach hängt die Beurteilung der Rechtswidrigkeit einer Umgehung grundsätzlich davon ab, ob die Zugangssperre eine Vervielfältigung verhindert oder lediglich nach bereits erfolgter Vervielfältigung den „Werkgenuss“ vermeidet. Im ersten Fall ist rechtlich, technisch und wertungsmäßig der Schutz des Webseitenbetreibers geboten. Der zweite Fall genügt hingegen auf den ersten Blick nicht den rechtlichen Anforderungen, weil keine von $\$ 95$ a Abs. 2 UrhG geforderte Technologie vorliegt, die im normalen Betrieb dazu bestimmt ist, Werke oder Schutzgegenstände betreffende ungenehmigt Handlungen zu verhindern oder einzuschränken. Praktisch sind solche Technologien, die jede Vervielfältigung zunächst unterbinden, bis die Adblockernutzung geklärt wurde, durchaus möglich. Deshalb könnte auf den ersten Blick ein Webseitenbetreiber, der eine solche technisch unvollkommene Sperre einsetzt auch nicht schutzbedürftig sein.

1112 Vgl. Wandtke/Ohst, in: Wandtke/Bullinger, UrhG, $\$ 95 a$, Rn. 3.

1113 ZUM 2016, 892, 897. 
Allerdings werden durch die nach Laden einer Startseite der Landing Page nachträglich einsetzende Sperre weitere Vervielfältigungshandlungen unterbunden. Beim normalem Browsen durch das Internet werden nicht nur Startseiten, sondern auch darauf verlinkte Unterseiten, z.B. die ausführlichen Beiträge einer Nachrichtenseite, besucht. Wenn man nun aus dem schlichten Umstand, dass die Startseite bereits einmal im Arbeitsspeicher vervielfältigt worden ist, die gesamte Umgehung einer Zugangssperre erlauben würde, könnte der Nutzer auch auf alle Unterseiten zugreifen. Und deren erstmalige Vervielfältigung wird durch die Zugangssperre zweifelsohne wirksam unterbunden, weil der Nutzer durch den Sperrbildschirm daran gehindert wird, weiter auf der Webseite zu browsen. Bei einer Gesamtbetrachtung der Nutzung von Webseiten kommt es deshalb wohl gar nicht - wie beim LG Hamburg im Verfahren 308 O 375/15 behandelt - darauf an, ob man zwischen Cachekopien und Bildschirmkopien unterscheidet. Der Schwerpunkt der Zugangsperre liegt auf der Verhinderung der Erreichung anderer Seiten als der Startseite. Hierin sind weitere wertvolle Werke und Schutzgegenstände der Contentanbieter enthalten. Ein vollständiger Zugriff des Nutzers auf die Webseite nach Umgehung einer Zugangssperre ist deshalb grob unbillig und nicht gerechtfertigt.

Im Übrigen ist dem Nutzer mit einer auf Startseiten begrenzten zulässigen Umgehung nicht geholfen, weil die Umgehungsmaßnahmen nicht differenzieren. Entweder die Zugangssperre wird mit Wirkung für alle Seiten umgangen oder eben gar nicht. Wenn dem umgehenden Nutzer ein Artikel auf der „zu Recht“ freigeschalteten Startseite gut gefällt, würde er bei fortgesetzter Umgehung der Zugangssperre zu den noch nicht vervielfältigten Texten, Fotos und/oder Videos der Unterseite gelangen und somit gegen $\$ 95$ a UrhG verstoßen. Deshalb wird man wohl generell Umgehungsmaßnahmen im Web an $\$ 95$ a UrhG messen müssen. Eine partielle Zulässigkeit der Umgehung für Startseiten und Deep-Links ist praktisch nicht umzusetzen.

Als Zwischenergebnis ist demnach festzuhalten, dass durch Zugangssperren auf Webseiten urheberrechtlich relevante Vervielfältigungshandlungen verhindert werden, spätestens auf Unterseiten. Sie sind demnach als technische Maßnahmen gemäß $\$ 95 a$ Abs. 2 S. 1 UrhG anzusehen, die grundsätzlich dem Umgehungsschutz zugänglich sind.

Ergänzend muss aber noch die Wirksamkeit der technichen Maßnahme nach $\$ 95$ a Abs. 2 S. 2 UrhG gegeben sein, damit eine Umgehung verboten ist. Dies ist der Fall, wenn die oben identifizierten Vervielfältigungen durch „eine Zugangskontrolle, einen Schutzmechanismus wie Verschlüsselung, Verzerrung oder sonstige Umwandlung oder einen Mechanismus zur Kontrolle 
der Vervielfältigung, die die Erreichung des Schutzziels sicherstellen, unter Kontrolle gehalten" werden. Ob die Zugangssperre nun als Zugangskontrolle oder Schutzmechanismus einzuordnen ist, ist nicht entscheidend. Dies ist vielmehr das Merkmal des „Unter-Kontrolle-Haltens“ von Vervielfältigungen im Nutzergerät. Zu Recht geht das LG Hamburg davon aus, dass Wirksamkeit nicht bedeutet, dass jegliche Umgehungsmöglichkeit tatsächlich ausgeschlossen ist. Das Schutzniveau muss vielmehr gegenüber dem Kreis der potentiellen Angreifer ausreichend hoch angesetzt worden sein, wobei auch mit Recht vom durchschnittlichen Internetnutzer und nicht von Hackern oder besonders technikaffinen Nutzern ausgegangen werden darf ${ }^{1114}$.

Setzt man diesen Maßstab an, ist auch absolut richtig, dass der Großteil der Internetnutzer keinen Schimmer von der Gestaltung des Codes von Webseiten hat und somit selbst keine Umgehung programmieren kann. Der Umstand, dass im Internet Umgehungshilfen angeboten werden, bestätige insoweit, dass die Zugangssperre nicht einfach umgangen werden könne, so das LG Hamburg ${ }^{1115}$. Aber kommt es wirklich darauf an, dass ein Nutzer selbst und eigenverantwortlich die Sperre umgeht? Oder reicht es nicht aus, dass der Nutzer im Internet von entsprechend befähigten Programmierern die Anleitung erhalten kann, um die Sperre zu umgehen? Mit anderen Worten: wenn es praktisch nicht schwierig ist, eine Anleitung mit vorformulierten Codes oder Anwendungen zu finden und anzuwenden, ist die Sperre dann wirksam? Dabei gilt zu beachten, dass die Verwehrung solcher externen Hilfe zu einer Diskrepanz zwischen der Stufe des Werbeblockens und der Stufe der Erwehrung gegen Zugangssperren führen könnte. Auf der ersten Stufe kann nämlich nicht geleugnet werden, dass kaum ein Nutzer ohne Einbindung der entsprechenden Software und Filterbefehle effektiv Werbung blocken könnte. Genauso nimmt der durchschnittliche Nutzer, wenn er sich durch Zugangssperren gestört fühlt, verfügbare Hilfe in Anspruch. Dies umso mehr, wenn diese Hilfe durch für jedermann mögliche Schritte wie eine Google-Suche verfügbar ist.

Der BGH führte in Werbeblocker II aus, dass die Inanspruchnahme von technischer Hilfe auch dann nicht unzulässig ist, wenn sie zu einem Ergebnis führt, dass der Nutzer nicht alleine hätte bewirken können ${ }^{1116}$. Wenn die Nutzung von Hilfe bei der Werbeblockade demnach erlaubt

1114 LG Hamburg, Urteil vom 21.12.2016 - 310 O 129/16, juris.

1115 LG Hamburg, Urteil vom 21.12.2016 - 310 O 129/16, juris.

1116 BGH, Urteil vom 19.4.2018 - I ZR 154/16, WRP 2018, 1322 - Werbeblocker II. 
ist, kann man durchaus hinterfragen, ob dies bei der Ausschaltung der $\mathrm{Zu}$ gangssperre wirklich die Wirksamkeit der technischen Maßnahme begründen kann. Doch lässt sich das im Rahmen von $₫ 4$ Nr. 4 UWG geäußerte Argument des BGH in Werbeblocker II wohl nicht auf die Interessenlage von $\$ 95$ a UrhG übertragen. Die Werbung im Internet ist ein isoliertes Element innerhalb einer nicht schutzfähigen Webseite und nicht etwa eine technische Maßnahme iSv $\$ 95 a$ Abs. 2 S. 1 UrhG. Deshalb ist die Blockade dieser Elemente etwas vollkommen anderes als die Umgehung der Zugangssperre. Also liegt tatsächlich kein unmittelbarer Widerspruch vor. Der Gedanke des BGH kann aber insoweit Geltung erlangen, dass er bei der Bestimmung der von den durchschnittlichen Internetnutzern zu erwartenden Anstrengungen zur Umgehung einer solchen Zugangssperre herangezogen wird. Insoweit sind einfache Lösungen, wie die Installation eines Browser-Add-ons, durchaus realistischerweise von Nutzern zu erwarten, die eine Zugangssperre unwirksam machen wollen. Es kommt gerade nicht darauf an, ob ein Nutzer Programmierkenntnisse hat und eine Umgehungslösung selbst programmieren kann. Entscheidend ist, ob er sich mit einfachsten Mitteln behelfen kann. Dies kann bei einer Verbreitung von Umgehungsanleitungen im Web bejaht werden.

Auf einem anderen Blatt steht, ob diese Hilfe für einen Nutzer im Einzelfall leicht auffindbar und umsetzbar ist. Dies kann bei der oben beschriebenen Anti-Adblock-Killer Lösung durchaus verneint werden, weil hier zunächst eine neue Software wie Greasemonkey geladen werden muss, in welchem dann wiederum das Tool Anti-Adblock-Killer integriert werden muss. Zwar ist die Information über diese Umgehungslösung durch eine Google-Suche relativ leicht zu finden, für den durchschnittlichen Nutzer könnte diese jedoch (noch) zu kompliziert sein. Hierauf zielen die Ausführungen der 10. Kammer des LG Hamburg ab, die unter anderem ausdrücklich darauf hinweisen, dass der durchschnittliche Nutzer nicht wisse, wie man JavaScript im Browser deaktiviere. Dies hat die Kammer aus eigener Kenntnis beurteilt, weil sie sich zu den durchschnittlichen Nutzern gezählt haben ${ }^{1117}$. Jedoch ist zu beachten, dass mit dem Fortschritt von „digital literacy“ in der Gesellschaft, d.h. der Zunahme von Kenntnissen über Vorgänge und Möglichkeiten im digitalen Bereich, auf lange Sicht nicht mehr vom „ahnungslosen“ Internetnutzer ausgegangen werden kann. Der Maßstab des durchschnittlichen Internetnutzers ist nach hier vertretener Ansicht im Fluss vom „flüchtigen“ hin zum „verständigen "Internetnutzer. Diesem dürften dann auch nicht allzu schwere Aktio-

1117 LG Hamburg, Urteil vom 21.12.2016 - 310 O 129/16, juris. 
nen wie die Änderungen von Browsereinstellungen zur Deaktivierung von JavaScript zugetraut werden.

Die Wirksamkeit der Zugangssperren auf Webseiten wird man also in jedem Einzelfall neu bewerten müssen. Dass das LG Hamburg die Bild.deSperre als wirksam angesehen hat, ist dabei vor dem Hintergrund der konkret behandelten eher komplizierten Anpassung der Filterliste innerhalb von Adblock Plus verständlich und verdient Zustimmung. Dies kann aber sicherlich nicht als allgemeine Regel für jede Art von Umgehungsmaßnahme gegen jede Zugangsperre gelten. Auch hier ist das weitere Wettrüsten der verfeindeten Lager abzuwarten ${ }^{1118}$.

Die Ausschaltung eines Vorgangs, der das Vorhandensein von Werbeblockern beim Nutzer prüft, ist auch eine Umgehung im Sinne von $\$ 95$ a Abs. 1 UrhG. Der Begriff der Umgehung ist sehr weit und erfasst alle Handlungen, die zu einer Verwertung im Sinne des Urheberrechts führen ${ }^{1119}$. Dieses Merkmal haben Kiersch und Kassel in ihrem Beitrag weitgehend überzeugend geprüf ${ }^{1120}$. Insbesondere ist die verbreitete „Anti-Adblock-Killer"-Lösung eine klare Umgehung. Wird die Zugangssperre hingegen nur beiläufig von Scriptblockern, durch Ausschaltung von JavaScript im Browser oder die Wahl rein textbasierter Browser ausgehebelt, ist dies keine Umgehung, sondern eine Schwäche der Schutzmaßnahme. Interessant ist die Frage, ob eine Maßnahme, die dem Adblocker-Detektor „vorgaukelt“ den Köder geschluckt zu haben, eine Umgehung darstellt. Nach der zuvorgenannten abstrakten Definition, wonach allerlei Manipulationsvorgänge zu fassen sind, wenn damit eine Vervielfältigung eigentlich geschützter Werke verbunden ist, muss auch diese Art der Umgehung erfasst sein. Eine zweckmäßige Abgrenzung erfolgt dann über das Merkmal der Wirksamkeit. Wenn ein Webseitenbetreiber nur einen einzigen Köder legt, der auch leicht zu identifizieren ist, sollte keine Wirksame technische Maßnahme vorliegen. Wenn hingegen eine ausgeklügelte technische Maßnahme mit mehreren Köderelementen genutzt wird, sollte von einer wirksamen Maßnahme ausgegangen werden, die durch eine Manipulation umgangen wird.

Insgesamt ist die Umgehung einer Zugangssperre zu einer Webseite also in den folgenden Fällen unter $₫ 95$ a UrhG zu subsumieren und verboten:

- Wenn die Umgehung profunde Programmierkenntnisse benötigt und die Umgehungslösung nicht leicht im Internet auffindbar und/oder

1118 Vgl. zum Gedanken des Wettrüstens etwa Witte, ITRB 2018, 34, 39.

1119 Wandtke/Ohst, in: Wandtke/Bullinger, UrhG, $\mathbb{\$} 95 \mathrm{a}, \mathrm{Rn} .53$.

1120 Kiersch/Kassel, CR 2017, 242. 
leicht im Nutzergerät umsetzbar sind. Hierunter lassen sich die Bild.deFälle vor dem LG Hamburg subsumieren.

- Wenn die Umgehung wie beim „Anti-Adblock-Killer“ die Installation mehrerer Add-ons benötigt und die Lösung unmittelbar dazu dient, die Zugangssperre zu umgehen und Inhalte ohne Werbung zu genießen, die im Normalfall der Internetnutzung nicht ohne Werbung zur Verfügung stehen.

- Wenn die Umgehung auf einer Manipulation der Adblocker-Detektion beruht, die vorgaukelt, dass eine ausgeklügelte und quantitativ und/ oder qualitativ komlexe Köderlogik im Nutzergerät angezeigt wird.

Keine verbotene Umgehung liegt hingegen vor, wenn

- Die Umgehungslösung für jeden Nutzer, der in der Lage ist einen Werbeblocker zu installieren, derart leicht im Internet zu finden und im eigenen Gerät umzusetzen ist, dass die Zugangssperre als unwirksam zu bewerten ist. Dies wäre etwa der Fall, wenn ein Nutzer durch eine einfache Google-Suche eine brauchbare Umgehungslösung findet, die nur wenige Klicks zur effektiven Implementierung im Nutzergerät benötigt.

- Wenn die Nutzung von Skriptblockern oder die Auswahl einer Browsereinstellung dazu führt, dass die Zugangssperre (oder ein Teil davon) nicht ausgefüht wird. Allerdings muss hier einschränkend gelten, dass eine differenzierende Wirkung solcher Anwendungen und Einstellungen nicht akzeptabel ist, wenn sie alle für den Nutzer „vorteilhaften“ JavaScript-Anwendungen zulässt und nur unliebsame JavaScript-Anwendungen blockiert (sozusagen ein JavaScript-Whitelisting).

- Wenn die Umgehung auf einer Manipulation der Adblocker-Detektion beruht, die vorgaukelt, dass technisch banale Köder im Nutzergerät angezeigt werden.

\section{Umgehung von Zwangswerbung}

Keine Rechtsprechung existiert dagegen für die Umgehung von Lösungen, die den Nutzern Zwangswerbung ausspielen. Deshalb soll an dieser Stelle geprüft werden, inwiefern die obigen Gedanken übertragbar sind. Außerdem soll bewertet werden, ob eine Anwendung wie „Anti-Adblock Killer“ eine zulässige Reaktion auf Zwangswerbung ist.

Diese Bewertung hängt ebenso wie die Prüfung der Zugangssperren davon ab, ob die Zwangswerbung als wirksame technische Maßnahme gemäß \$95a UrhG bewerten werden kann. Dies ist nach den vorgehenden 
abstrakten Beschreibungen jedoch schnell beantwortet: Zwangswerbung fällt nicht unter $\$ 95$ a UrhG. Dies liegt daran, dass hier keine Vervielfältigung von urheberrechtlich geschützten Werken und nach dem UhrG geschützten Gegenständen verhindert wird. Der Zugang zur Seite und ihren Inhalten bleibt ja gerade mölich. Die Verknüpfung von Werbung und Content hingegen ist nicht urheberrechtlich geschützt. Deshalb liegt ohne Zweifel keine technische Maßnahme iSv $\$ 95 a$ Abs. 2 S. 1 UrhG vor.

$\mathrm{Da}$ oben bereits festgestellt worden ist, dass die Zwangswerbung eine unzumutbare Belästigung der Nutzer darstellt ${ }^{1121}$ ist eine solche Reaktion von Webseitenbetreibern auch nicht aus anderen Gründen schutzwürdig. Die Ausspielung von Zwangswerbung darf von Nutzern demnach allein schon aus Gründen des Selbstschutzes vor einer verbotenen Handlung umgangen werden.

Dies führt allerdings zur brisanten Frage, wie Nutzer diese Umgehung bewerkstelligen können. Während generell unblockierbare Werbung - wie die Beschreibung schon deutlich macht - nicht durch Werbeblockertechnologien zu verhindern sind, bleibt hier wohl nur die rechtliche Wehr. Anders bei der Austauschwerbung nach erkannter Werbeblockernutzung. Hier kann die Wirkung des Adblocker-Detektors umgangen werden. Wie im Zusammenhang mit Zugangssperren schon beschrieben kann dem Detektor vorgegaukelt werden, dass die ausgelegten Köder im Nutzergerät geladen worden sind. Daneben würden findige Programmierer nach Studium der Wirkweise konkreter Austauschwerbungslösung sicher weitere Umgehungen entwickeln können.

Eine weitere Lösung ist der bereits mehrfach genannte „Anti-Adblock Killer“. Dieser führt zu einer Verhinderung JavaScript-basierter AdblockerDetektoren. Bei Zwangswerbung in Form der Austauschwerbung ist diese Lösung ein probates Mittel zur Ausschaltung. Allerdings wurde im Zusammenhang mit Zugangssperren das Ergebnis gefunden, dass diese Lösung eine nicht zulässige Umgehung nach $\$ 95$ a UhrG darstellt. Für einen legalen Einsatz dieser Lösung müsste also sichergestellt sein, dass der "Anti-Adblock Killer“ nur die Seiten mit Zwangswerbung tangiert, nicht aber die den Webseitenbeteibern vorbehaltenen Zugangssperren. Dies könnte theoretisch über Whitelists umgesetzt werden. Auf dieser differenzierenden Basis wäre der Einsatz dieser Lösung demnach zulässig. Es bleibt abzuwarten, ob hier in zukunft ggf. konkrete Hilfemaßnahmen für

1121 Siehe oben Ziffer E. II. 2. a). 
Nutzer angeboten werden, die die Austauschwerbung verhindern. Rechtlich sind diese jedenfalls zu billigen ${ }^{1122}$.

1122 Gegen den Vorwurf einer gezielten Behinderung von Webseitenbetreibern oder Anbietern von Zwangswerbungslösungen wie „AdDefend“ lässt sich vorbringen, dass diese sich selbst nicht im wettbewerbsrechtlich rechtmäßigen Rahmen bewegen. Eine Reaktion auf diese rechtmäßige Handlung wäre dann wohl im Rahmen einer Interessenabwägung als zulässig zu erachten. 


\section{F. Kurzer Blick ins Ausland}

Adblocker sind ein global anzutreffendes Phänomen. Gleichwohl hat sich der weltweite Konflikt zwischen werbefinanzierten Inhalteanbietern und Werbeblockern nur in Deutschland derart offiziell manifestiert, sodass Gerichte entscheiden mussten. Dies drängt die Frage auf, ob die Diskussion auch im Ausland juristisch ausgetragen wird. Nachfolgend wird die rechtliche Situation in ausgewählten Staaten außerhalb Deutschlands kurz skizziert. Sodann wird versucht, eine Antwort auf die Frage zu geben, warum in Deutschland eine wahre Klagewelle zu beobachten war, während dies in anderen Staaten offensichtlich nicht geschehen ist.

\section{Darstellung der Situation im ausgewäblten Ausland}

Insgesamt ist das juristische Echo außerhalb von Deutschland leise. Nennenswerte offizielle oder akademische Auseinandersetzungen waren in den USA, in China sowie in Österreich zu beobachten.

\section{Situation in den USA}

In den Vereinigten Staaten wurde der Kampf gegen Werbeblocker in einem Aufmerksamkeit erregenden Schritt begonnen. Die Newspaper Association of America, eine „Non-Profit Organisation“, die nach eigenen Angaben die Interessen von ca. 2.000 Publisher in den USA und Kanada und ca. 90\% der täglichen Zeitungsauflagen in den USA sowie weiterer Wochenzeitungen, Nachrichtenwebseiten und mobilen Apps vertritt, reichte im Mai 2016 eine förmliche Beschwerde bei der Federal Trade Commission („FTC“) der USA ein ${ }^{1123}$. Mit der Beschwerde verbunden war der Antrag an die FTC, verschiedene unlautere Adblocking Praktiken zu

1123 Die Beschwerde ist im Web abrufbar unter: http://www.newsmediaalliance.o rg/wp-content/uploads/2016/05/NAA-FTC-Complaint_5-25-16.pdf, zuletzt abgerufen am 31.5.2019. Die nachfolgenden Aussagen sind aus dem englischen Dokument entnommen und durch den Bearbeiter frei ins Deutsche übersetzt. 


\section{F. Kurzer Blick ins Ausland}

untersuchen. Die Beschwerde nennt dabei die folgenden Praktiken und beschreibt diese näher:

- kommerzielles Whitelisting (wie von Adblock Plus praktiziert),

- der Austausch von Anzeigen auf Webseiten (wie bei Brave),

- kostenpflichtige Abonnements bei Adblockern, die versprechen mit den Zahlungen die Einnahmenverluste bei Publishern auszugleichen („alternative Refinanzierungsangebote“), und

- die Umgehung von beschränkt-kostenlosen Angeboten unter Einsatz eines Zählers (etwa zehn kostenlose Aufrufe in einem bestimmten Zeitraum) und Bezahlschranken.

$\mathrm{Zu}$ allen diesen Praktiken kommt die Beschwerde zum Ergebnis, dass ein Verstoß gegen Section 5 des Federal Trade Commission Act, 15 U.S.C. $\$ 45$ vorliege. Diese Norm verbietet unfaire Methoden sowie unfaire und unlautere Handlungen oder Praktiken im kommerziellen Wettbewerb. Außerdem wird durch diese Norm die FTC dazu aufgefordert, solche Handlungsweisen im Wettbewerb zu verhindern. Unlautere Handlungen liegen demnach insbesondere dann vor, wenn eine Aussage, Handlung oder Unterlassung einen Verbraucher irreführt. Dabei ist auf den vernünftigen Verbraucher abzustellen. Im Ergebnis muss eine Beeinflussing des Verbraucherhandelns oder der geschäftlichen Entscheidung des Verbrauchers wahrscheinlich sein.

Beim kommerziellen Whitelisting liege diese Unlauterkeit darin, dass fälschlicherweise versprochen werde, dass entweder Verbraucher nur solche Anzeigen erhalten, die einen objektiven Qualitätsstandard aufweisen oder dass sie gar keine Anzeigen erhalten. Auf dieser Grundlage würden Verbraucher davon ausgehen, dass nicht nur akzeptable Anzeigen von zahlenden Anbietern durch die Blockade geschleust würden. Die Aufklärung darüber sei in den Tiefen der Adblock Plus Webseite versteckt und sei für Verbraucher nur schwer auffindbar. Als zweites Argument führt die Beschwerde an, dass Eyeo kleine und große Werbeanbieter unterschiedlich behandele und den Verkehr darüber täusche. Einen überzeugenden Beweis bleibt die Beschwerde aber schuldig.

Den Austausch von Anzeigen auf Webseiten moniert die Newspaper Association of America als unlautere Praxis, weil dadurch dem Verbraucher der Eindruck vermittelt werde, dies gehöre zur „editorialen Stimme“ der jeweiligen Webseitenredaktion. Außerdem wird der Umstand, dass der jeweilige Webseitenbetreiber diesem Austausch nicht zugestimmt habe, besonders herausgehoben. Durch die Beschwerde der Newspaper Association wird in diesem Kontext der Eindruck vermittelt, Webseitenbetreiber 
übernähmen eine gewisse Qualitätskontrolle für die Werbung, die neben ihren Inhalten veröffentlicht wird.

Bei den alternative Refinanzierungsangeboten werden zwei Beispiele aufgeführt. Zum einen „Optimal“, ein Werbeblockerdienst der für monatlich \$ 5,99 verspricht, die Publisher anhand des generierten Traffics zu vergüten. Zum anderen „Flattr Plus“, ein von Eyeo betriebener Mikropayment-Dienst, mit denen bestimmten Publishern unmittelbar eine Zahlung zugesandt werden kann - wobei Flattr 10\% der Transaktionsgebühr für sich beanspruche. Ein vergleichbares System sehe auch der Brave Browser vor. Die Unlauterkeit dieser Lösungen ergebe sich daraus, dass Verbrauchern der falsche Eindruck vermittelt werde, durch die Zahlungen würden vom Werbeblocken ausgehende Schäden wieder gut gemacht. Diese Dienste gäben ein „moral incentive“, wobei tatsächlich keine effektive Wiedergutmachung von erlittenen Verlusten der Webseitenbetreiber vorliege.

Bei den zuletzt angegriffenen Umgehungen der Zählsysteme von beschränkt-kostenlosen Angeboten und Bezahlschranken läge eine direkte Schädigung von Publishern und Vebrauchern vor. Dies verstoße gegen die öffentliche Ordnung, die den kartellrechtlichen Vorschriften zu Grunde liegen. Denn durch diese Umgehung würde die Fähigkeit der Medien beeinträchtigt, die Verbrauchererwartungen zu erfüllen, weil die durch das Werbeblocken notwendige (Ersatz-) Einnahmequelle der Bezahlschranke beeinträchtigt werde.

Schlussendlich fordert die Beschwerde von der FTC, dass kommerzielles Whitelisting entweder untersagt werden soll, oder die Betreiber zumindest die irreführende Darstellung ihres Geschäftsmodells unterlassen sollen. Praktiken zur Austauschwerbung sollten untersagt werden. Bei Modellen, die eine alternative Finanzierung versprechen, sollte die Beendigung der irreführenden Aussagen herbeigeführt werden. Umgehungsmaßnahmen betreffenden Zählsysteme und Bezahlschranken sollten untersagt werden.

Eine Antwort der FTC ist allerdings nicht verfügbar. Die FTC hat weder die Beschwerde förmlich angenommen, noch Ermittlungen begonnen. Sie ist keinem der Verbotsanträge nachgekommen ${ }^{1124}$.

Die Beschwerde kennzeichnet einige Probleme, die im Laufe dieser Bearbeitung bereits unter deutschem Recht geprüft worden sind. Die für den Vollzug des Lauterkeitsrechts in den USA zuständige Behörde haben diese Phänomene offenbar nicht zum Eingreifen bewogen. Dies zeigt nach hiesigem Dafürhalten eine liberale Grundhaltung der Behörde, die sich

1124 Miller, Washington \& Lee Public Legal Studies Research Paper Series, Accepted Paper No. 2017 - 15, Fußnote 1 a.E.. 


\section{F. Kurzer Blick ins Ausland}

aus den wettbewerblichen Vorgängen am digitalen Werbemarkt herauszuhalten scheint. Außerdem lässt sich vermuten, dass die FTC bei initialer Betrachtung der Vorwürfe zu gleichen Ergebnissen gekommen ist wie sie in dieser Arbeit unter deutschem Recht gefunden worden sind. Wenn die Behörde nämlich offensichtlichen Rechtsverstöße vermutet hätte, wäre wohl zumindest ein Verfahren eröffnet worden.

Neben diesem offiziellen Antrag wurde das Thema Werbeblocker auch in der US-amerikanischen Rechtsliteratur behandelt. In einer nicht abschließenden Aufzählung sind drei Bearbeitungen aus dem Jahr 2017 hervorzuheben. Russell A. Miller setzte sich in seiner Bearbeitung „Liberation, Not Extortion: The Fate of Internet Ad-Blocking in German and American Law"1125 auf der Grundlage und nach Beschreibung der deutschen Rechtsstreitigkeiten mit der US-Rechtslage auseinander. Außerdem bewertete Jon T. Abrahamsen die Rechtslage in den Vereinigten Staaten in seiner Bearbeitung „Adblockers, Convenience or Trespass? Click here to find out!"1126. Tyler Barbacovi untersuchte sodann in seinem Beitrag „Blocking Ad Blockers"1127 die Frage, wie sich Webseitenbetreiber den Werbeblockern erwehren können. Damit sind wie in dieser Bearbeitung die verschiedenen Stufen des Kampfs um die Werbung im Internet grundsätzlich auch bereits in der US-Rechtsliteratur behandelt worden.

Miller kommt zu dem Ergebnis, dass Rechtsstreitigkeiten in den USA zwischen Webseitenbetreibern und Werbeblockerbetreibern denselben Ausgang haben werden wie in Deutschland. Deutsches und US-Recht beruhen nach seiner Ausarbeitung auf denselben Werten und Grundzügen, die zu denselben Ergebnissen führen. So sei in beiden Rechtsordnungen der Werbeblockerbetreiber nicht unmittelbar verantwortlich. Auch sei in beiden Ländern beachtlich, dass Werbeblocken Ausdruck individueller Autonomie und der Flucht vor aggressiver Werbung ist und mit sozialen Vorzügen verbunden ist wie etwa erhöhter Privatsphäre im Internet. Werbeblocken sei auch nach US-Recht nicht als Erpressung der von Werbung abhängigen Medien anzusehen. Vielmehr müsse der digitale Medienmarkt den Wettbewerb annehmen und dagegen bestehen ${ }^{1128}$. Miller prüfte dabei vier zivilrechtliche Tatbestände, die er vor dem Hintergrund des komplexen Zusammenspiels von US-Bundesrecht und dem Recht der einzelnen

1125 Miller, Washington \& Lee Public Legal Studies Research Paper Series, Accepted Paper No. 2017 - 15.

1126 Abrahamsen, Journal of Law, Technology \& Policy Vol. 2017, 477.

1127 Barbacovi, 16th John Marshall Review of Intellectual Property Law, 2017, 272.

1128 Miller, S. 79f. 
Bundesstaaten sowie von „statutory“ und „common law“ für am wahrscheinlichsten hielt, aber gleichwohl ablehnt:

- "tortious interference"1129, vergleichbar mit der deutschen Fallgruppe des Verleitens zum Vertragsbruch innerhalb von $\$ 4$ Nr. 4 UWG,

- "misappropriation"1130, am ehesten vergleichbar mit einer produktbezogenen Behinderung nach $\$ 4$ Nr. 4 UWG,

- "initial interest confusion"1131, einer Art Verwechslungsgefahr wie wir sie im deutschen Markenrecht und in $₫ 4 \mathrm{Nr} .3$ UWG kennen, und

- "copyright infringement", also dem Pendant zur deutschen Urheberrechtsverletzung ${ }^{1132}$.

US-Verfassungsrecht hält er für nicht einschlägig ${ }^{1133}$. Insgesamt sieht Miller also einen Gleichlauf der Ergebnisse zwischen deutschem und US-Recht. Auf Grundlage einer eher adblocker-freundlichen Auslegung hält er Werbeblocken in den USA damit für legal.

Kritischer sieht Abrahamsen die Zulässigkeit von Werbeblockersoftware unter der US-Rechtslage. Er verweist ausdrücklich auf das oben mehrfach referenzierte Urteil des OLG Köln in Sachen Axel Springer gegen Eyeo und führt aus, dass vergleichbares Recht zu $\$ 4$ a UWG in den USA nicht existiere. Deshalb sei das Urteil auf die Rechtslage in den USA nicht übertragbar ${ }^{1134}$. Er prüft Werbeblocker stattdessen unter dem Tatbestand "trespass to chattel“ aus dem „Restatement Second of Torts“ $\$ \$ 217$, $218^{1135}$. Wird dieser Tatbestand in die digitale Welt übertragen müssten demnach maßgeblich zwei Voraussetzungen vorliegen: erstens der vorsätzliche und ungenehmigte Eingriff in Besitzrechte an Computersystemen und zweitens die Herbeiführung eines Schadens ${ }^{1136}$. Er zitiert dazu drei „precedents“, in welchen es maßgeblich um Webcrawler ging. In der Entscheidung des United States Court of Appeals for the Ninth Circuit im Rechtsstreit „eBay, Inc. v. Bidder's Edge, Inc.“ aus dem Jahr 2000 gewährte das Gericht eine einstweilige Unterlassungsverfügung für eBay gegen Bidder's Edge gegen das ungenehmigte Crawlen der Auktionsplattform auf Grundlage eines „trespass to chattel“. In einem gleichgelagerten Fall aus dem Jahr 2001 in „Ticketmaster v. Tickets.com“ lehnte dasselbe Ge-

1129 Miller, S. 57ff..

1130 Miller, S. 66ff..

1131 Miller, S. 71ff..

1132 Miller, S. 75ff.

1133 Miller, S. 56f..

1134 Abrahamsen, Journal of Law, Technology \& Policy Vol. 2017, 500.

1135 Abrahamsen, Journal of Law, Technology \& Policy Vol. 2017, 498f..

1136 Abrahamsen, Journal of Law, Technology \& Policy Vol. 2017, 499. 


\section{F. Kurzer Blick ins Ausland}

richt allerdings den Tatbestand für den Webcrawler von Tickets.com auf der größeren Plattform Ticketmaster ab. Im Jahr 2004 nahm der Second Circuit dann aber im Fall „Register.com v. Verio“ die Verwirklichung eines „trespass to chattel“ beim Crawlen der WHOIS-Datenbank eines Domainregisters mit dem Argument an, dass eine Gestattung des Crawlens andere Marktteilnehmer derart ermutigen könne, dass die Computersysteme des Domainregisters überfordert würden und dadurch ein Schaden entsteht ${ }^{1137}$. Diese Heranziehung von „precedents“ ist deshalb interessant, weil auch in den deutschen Rechtsstreiten die Parallele zwischen Webcrawler bzw. Screen Scraping-Fällen und Werbeblockern gezogen worden ist. Nach deutschem Recht sind Webcrawler jedoch erlaubt, soweit keine technischen Schutzmaßnahmen umgangen werden ${ }^{1138}$. Nicht zuletzt diese Bearbeitung sieht das BGH Urteil Werbeblocker II in direkter Nachfolge zu dieser Webcrawler-Rechtsprechung ${ }^{1139}$.

Abrahamsen hingegen folgert aus den zuvor zitierten Urteilen, dass Werbeblocker nicht rechtmäßig sein könnten. Denn Werbeblocken im engeren Sinne und Element Hiding sollen nach seiner Rechtsansicht nicht vom Umfang der üblicherweise bei Seitennutzung eingeräumten Einwilligung gedeckt sein. Dies sei eindeutig der Fall, wenn die Nutzungsbedingungen der Webseite den Einsatz von Werbeblocker ausdrücklich untersagten. Wenn eine solche Klausel fehle, würden trotzdem Computersysteme in erheblichem Maße beeinflusst, vor allem Adserver. Dies erfolge ohne Einwilligung. Bei der Bewertung des Schadens könne beim eigentlichen Filterblocken wohl nur auf einen rein finanziellen Schaden durch Einnahmeverluste zurückgegriffen werden, der nicht unbedingt ausreichend sei. Vielmehr müsse ein Schaden im Sinne einer unnützen Ressourcennutzung vorliegen. Dies sei beim Element Hiding gegeben ${ }^{1140}$.

Insgesamt ist die Bearbeitung von Abrahamsen ein bemerkenswerter Perspektivenwechsel. Der geprüfte Tatbestand errinnert eher an deutsche Besitzschutzansprüche. Jedoch muss Abrahamsen vorgehalten werden, dass seine Ausführungen technisch pauschal sind und er im Übrigen die Interessen der Nutzer komplett außer Acht lässt. Deshalb scheint es auf juristischer „common sense“ Basis zweifelhaft, ob seine Argumente tatsächlich

1137 Abrahamsen, Journal of Law, Technology \& Policy Vol. 2017, 500ff..

1138 Vor allem die Webcrawler-Fälle des BGH in Flugvermittlung im Internet (Urteil vom 30.04.14 - I ZR 224/12, WRP 2014, 839) und Automobilbörse Online (Urteil vom 22.06.11 - I ZR 159/10, WRP 2011, 1469).

1139 Siehe oben Ziffer C. I. 4. b) bb).

1140 Abrahamsen, Journal of Law, Technology \& Policy Vol. 2017, 503ff. 
eine Gefahr für das Adblocking in den USA sein können. Die fehlende praktische Geltendmachung von Ansprüchen betroffener Marktteilnehmer spricht ebenfalls dagegen.

Zuletzt erläutert Barbacovi das amerikanische Pendant zu $\$ 95$ a UrhG. Ein Umgehungsschutz für technische Schutzmaßnahmen wurde in den USA durch das „Digital Millennium Copyright Act“ eingeführt und findet sich in 17 U.S.C. $\$ 1201(\mathrm{a}-\mathrm{b})$. Nach dieser Norm soll auch ein Werbeblockeranbieter für das Vorhalten einer Umgehungsmaßnahme unmittelbar haften ${ }^{1141}$. Interessanterweise soll nach Barbacovi in den USA der Quellcode einer Webseite an sich urheberrechtlich geschützt sein und beim US Copyright Office registriert werden können, der Urheberrechtschutz kann trotzdem im Einzelfall problematisch sein ${ }^{1142}$. Nach Prüfung der einzelnen Tatbestandsmerkmale des Umgehungsschutzes, die der deutschen bzw. europäischen Regelung ähnlich sind, kommt Barbacovi zum Ergebnis, dass die Umgehung einer Zugangssperre die Verbotsnorm erfüllt. Umgehungslösungen für Zugangssperren seien deshalb in den USA effektiv gerichtlich zu bekämpfbar ${ }^{1143}$.

Dieser letzte Beitrag zeigt genauso wie der zuerst zitierte Beitrag von Miller, dass an den maßgeblichen rechtlichen Stellen das europäische Recht nicht allzu sehr von den Wertungen im US-Recht abweicht. Im Fall der Umgehungsmaßnahmen kommt dabei noch hinzu, dass das „statutory law" sozusagen harmonisiert ist. Daraus lässt sich allerdings auch folgern, dass die in dieser Arbeit vorgenommene Prüfung und die gerichtliche Bewertung in Deutschland keine maßgeblichen Erwägungen übersehen hat. Die deutsche Bewertung kann deshalb wertungsmäßig als Blaupause für potentielle gerichtliche Fälle in den USA dienen.

\section{Situation in China}

Völlig verschieden sind hingegen Nachrichten, die im Jahr 2016 aus China $\mathrm{zu}$ vernehmen waren. Aufgrund diverser Probleme im Werbeumfeld in der Volksrepublik wurden die „Internet Advertising Interim Rules“ eingeführt. Diese enthalten insbesondere Rahmenbedingungen zum Schutz der Internetznutzer gegen falsche oder irreführende Werbung, Verbote

1141 Barbacovi, 16th John Marshall Review of Intellectual Property Law, 2017, 277.

1142 Barbacovi, 16th John Marshall Review of Intellectual Property Law, 2017, 280., 282.

1143 Barbacovi, 16th John Marshall Review of Intellectual Property Law, 2017, 288. 


\section{F. Kurzer Blick ins Ausland}

betreffend Werbung für verschreibungspflichtige Medikamente und Tabak sowie Beschränkungen des Werbeanteils auf bestimmsten Webseiten ${ }^{1144}$. Doch diese Regelungen enthalten auch einen Artikel 16, der gewisse Praktiken verbietet: „(i) das Bereitstellen oder Benutzen von Applikationen, Hardware oder Werbung Dritter, die die Anzeige von Display-Werbung blocken, filtern, verdecken, weiterleiten oder beschränken; (ii) den Einsatz von Netzwerkzugängen, -equipment, -applikationen oder anderen Maßnahmen, welche die normale Übertragung von Werbedaten stören, berechtigte Anzeigen blockieren oder unautorisierte Anzeigen laden"1145.

Der Wortlaut scheint ein Verbot von Werbeblockern zu stützen. Deshalb hat das Urteil zu erheblicher Verunsicherung im Lager der Werbeblockerbetreiber geführt ${ }^{1146}$. Sechs Monate nach Einführung der Regularien wurde ein nach dem Wortlaut mögliches Verbot von Werbeblockern allerdings nicht von chinesischen Behörden durchgesetzt und die hohe Verbreitung des bekanntermaßen werbeblockenden UC Mobile Browsers des chinesischen Internetriesen Alibaba und den Pendants von QQ und Baidu blieb unverändert. Der Großteil der chinesischen Nutzer von mobilen Geräten blockte also weiterhin Werbeanzeigen im Internet ${ }^{1147}$. Gerichtliche oder behördliche Verfahren in China zum Thema Werbeblocken sind ebenfalls nicht erkennbar. Insgesamt scheinen also Werbeblocker in der Volksrepublik China zumindest geduldet zu sein.

\section{Kartellverfahren in Österreich}

Eine letzte Anekdote stammt noch aus Österreich. Dort erhob der ORF im Jahr 2013 eine Beschwerde gegen Adblock Plus bei der Bundeswettbewerbsbehörde wegen Marktmachtmissbrauchs. Gründe waren scheinbar eine Ungleichbehandlung bzw. Diskriminierung bestimmter Medien -

1144 Vgl. https://adguard.com/en/blog/china-blocks-ad-blocking/, zuletzt abgerufen am 31.5.2019.

1145 Freie Übersetzung nach http://blockadblock.com.s221779.gridserver.com/ad blocking/six-months-since-china-banned-ad-blockers/, zuletzt abgerufen am 31.5.2019. Ähnlich https://adguard.com/en/blog/china-blocks-ad-blocking/, zuletzt abgerufen am 31.5.2019.

1146 Vgl. https://adblockplus.org/blog/the-lonely-bully-china-issues-edict-to-ban-ad -blockers, zuletzt abgerufen am 31.5.2019.; https://adguard.com/en/blog/china -blocks-ad-blocking/, zuletzt abgerufen am 31.5.2019.

1147 Vgl. http://blockadblock.com.s221779.gridserver.com/adblocking/six-months-s ince-china-banned-ad-blockers/, zuletzt abgerufen am 31.5.2019. 
ganz konkret die Bevorzugung Googles gegenüber dem ORF im Rahmen des kommerziellen Whitelistings und der Acceptable Ads Kriterien ${ }^{1148}$. Das daraufhin eröffnete Verfahre wurden im Januar 2019 allerdings eingestellt, weil die Behörde keinen Verstoß gegen Kartellrecht erkannt hat. Gleichwohl wurden gewisse vertragliche Regelungen in den Vereinbarungen zwischen Eyeo und Google geändert, um letzte kartellrechtliche Zweifel auszuräumen ${ }^{1149}$. Damit besteht ein Gleichlauf zwischen der behördlichen Praxis in Deutschland ${ }^{1150}$ und Österreich. Im Übrigen sind in Österreich keine zivilrechtlichen Streitigkeiten bekannt geworden. Dem Werbeblocken steht damit auch in der Alpenrepublik nichts im Wege.

\section{Gründe für den Schwerpunkt des Kampfs in Deutschland}

Das vorstehende Ergebnis zu den Auseinandersetzungen um Adblocker im Ausland drängt die Frage auf, wieso nur in Deutschland der Streit derart eskalierte, dass es zu diversen gerichtlichen Verfahren gekommen ist. Dafür lassen sich einige Gründe finden, die nachfolgend beschrieben werden sollen.

Zunächst ist der Hauptgrund, dass Eyeo $\mathrm{GmbH}$, also der Betreiber des weitest verbreiteten Werbeblockers Adblock Plus, ein deutsches Unternehmen mit Sitz in Köln ist. Damit lässt sich nicht nur unproblematisch ein Gerichtsstand herleiten, vielmehr ließe sich ein erwirktes Urteil auch nach den zuverlässigen deutschen Regeln vollstrecken. Bei anderen Anbietern, insbesondere solchen aus den USA oder dem sonstigen außereuropäischen Ausland, wäre die Vollziehung erwirkter Verfügungen oder Urteile in jedem Fall unsicherer und ökonomisch oft wenig sinnvoll. Der erste Grund für den Schwerpunkt der Auseinandersetzung in Deutschland ist also ein rein pragmatischer: die Rechtssicherheit des Gerichtsstandorts.

Ein weiterer Grund ist die Existenz des UWG, die Regelungstechnik der einzelnen Klauseln durch Generalklauseln und die Durchsetzungsbefugnis von Mitbewerbern. Die offene Formulierung des Gesetzes führt dazu, dass aus einer „ex-ante“-Sicht eine Vielzahl von Verhaltensweisen potentiell

1148 https:/futurezone.at/b2b/orf-wehrt-sich-gegen-google-und-internet-werbefilter/ 30.000.652, zuletzt abgerufen am 31.5.2019.

1149 https://futurezone.at/netzpolitik/wettbewerbsbehoerde-stellt-verfahren-gegen-g oogle-und-adblock-plus-ein/400384109, zuletzt abgerufen am 31.5.2019.

1150 https:/www.bundeskartellamt.de/SharedDocs/Meldung/DE/Pressemitteilunge n/2019/21_01_2019_Eyeo_Google.html, zuletzt abgerufen am 31.5.2019. 


\section{F. Kurzer Blick ins Ausland}

einem lauterkeitsrechtlichen Verbot unterfallen könnten. Wenn potentiell aktivlegitimierte Wirtschaftsunternehmen aktiv steuern können, ob ein wirtschaftlich bedrohliches Verhalten gerichtlich überprüft wird, liegt es nahe, dass ein Fall mit nicht eindeutiger Aussicht auf Erfolg vor Gericht gebracht wird. Dabei ist das deutsche Lauterkeitsrecht durch die sehr weite Auslegung des Mitbewerberbegriffs, der nicht zuletzt durch die Werbeblocker I ${ }^{1151}$ Entscheidung des BGH geprägt worden ist, für Behinderungsfälle wie vorliegend überaus vorteilhaft. Während in anderen Jurisdiktionen die Durchsetzung des Wettbewerbsrecht schon generell staatlichen Stellen vorbehalten ist, eröffnet das deutsche System eine weitgehende horizontale Durchsetzung des Lauterkeitsrechts. Hinzu kommt, dass im Zusammenhang mit der „Fernsehfee“ bereits das oben zitierte höchstinstanzliche Urteil Werbeblocker I zu Fernsehwerbeblockern vorlag. Weil die Internetwerbeblocker, vor allem durch das kommerzielle Whitelisting, allerdings einen durchaus aggressiveren Eindruck vermitteln als das niemals erfolgreiche „Fernsehfee“-Gerät, konnten die Webseitenbetreiber im Ausgangspunkt hoffen, dass Gerichte bei Adblock Plus anders als in Werbeblocker I eine Unlauterkeit bejahen würden. Wirtschaftlich betrachtet stellte sich also für die klagenden Webseitenbetreiber eine Gefahr dar, die bei ungehindertem Fortgang enorme Einnahmeneinbußen versprach. Durch die Rechtsstreite hatten diese Kläger zumindest eine Chance, diese Gefahr abzuwehren. Auf der anderen Seite war das Kostenrisiko der Prozesse angesichts der erhofften Untersagung des erfolgreichen Werbeblockertools auf dem Markt wohl verkraftbar. Der zweite Grund für den Schwerpunkt des Kampf in Deutschland ist also die deutsche Rechtslage.

Ein dritter Grund könnte darin gesehen werden, dass in Deutschland im zweiten Jahrzehnt des 21. Jahrhunderts bei Digitalisierungsthemen in vielen Teilen der Gesellschaft und damit auch der Wirtschaft und Justiz schlicht rückständige Ansichten verbreitet waren. Dieser persönliche Eindruck des Bearbeiters folgt nicht nur aus allgemeinen Phänomenen wie etwa unzureichender IT-Infrastrukturen, z.B. „schnelles Internet“, in Deutschland ${ }^{1152}$. Er folgt aus einem weit verbreiteten fehlenden Verständnis für technische Zusammenhänge in der durch Internet und Software getriebenen Welt der Digitalisierung. So zeigt auch diese Arbeit, dass es einer ausführlichen Beschreibung der technischen Grundlagen bedarf. Viele Zusammenhänge, die sich aus der Funktionsweise von Internet und

1151 BGH, Urteil vom 24.6.2004 - I ZR 26/02, GRUR 2004, 877 - Werbeblocker I.

1152 Vgl. beispielhaft https:/www.zdf.de/nachrichten/heute/groko-und-die-digitalis ierung-100.html, zuletzt abgerufen am 31.5.2019. 
der Gestaltung von Software - gleich ob Webseiten oder Computerprogramme im Sinne von $\$ 69$ a UrhG - sind weder in der breiten Bevölkerung noch im juristischen Milieu verbreitet. Dies ist nicht verwunderlich, wenn man bedenkt, dass weder in schulischer noch in universitärer Ausbildung Pflichtstoff zu diesen Themen gelehrt wird. Doch ist dieses auf analogen Zusammenhängen basierte Denken die Grundlage für eklatante Fehleinschätzungen. Damit ist auch zu erklären, dass Webseitenbetreiber zu Beginn der Auseinandersetzung verbal die Messer wätzten und Werbeblocker als „Wegelagerer" oder „Erpresser" bezeichneten. Wie die technischen Grundlagen des World Wide Web zeigen, haben Filterwerbeblocker aber vor allem eine offene Flanke des Adserver-Werbesystems genutzt und damit ein von vielen Nutzern sehr erwünschtes Ergebnis herbeigeführt.

Es ist ein außerordentlicher Verdienst der Beklagten der Werbeblockerstreitigkeiten - und deren Prozessvertreter -, dass sie den Gerichten diese Grundlagen schriftsätzlich vermitteln konnten. Wenn die Rechtsstreitigkeiten nämlich weniger auf technischer, sondern auf ethischer oder emotionaler Basis geführt worden wären, hätte das Ergebnis durchaus anders ausfallen können. Gerade an dieser Stelle scheint auch ein Unterschied zu den USA zu bestehen. Gerade wegen der Aufsehen erregenden Schadensersatzprozesse in den USA, die auf Grundlage emotionaler Argumentation oft horrende Strafschadensersatzzahlungen begründen ${ }^{1153}$, hätte es eigentlich nahe gelegen, dort mit einer emotionalen Argumentation zu klagen. Allerdings haben Betroffene von Internetwerbeblockern wie etwa Google offenbar Verträge mit Eyeo abgeschlossen, statt gerichtlich ein Verbot zu verfolgen. Dies mag damit zusammen hängen, dass in den USA, insbesondere im Silicon Valley, Heimat von Google, Facebook \& Co., die Toleranz für digitale Disruption höher ist.

Insgesamt war Deutschland also wegen Rechtsstandort, Rechtslage und verbreitetem Unverständnis für digitale Zusammenhänge ein geeignetes Schlachtfeld für den Kampf um die Werbung im Internet. Die große Schlacht um die Zulässigkeit von Internetwerbeblockern - sozusagen die Schlacht von Karlsruhe - konnten die Werbeblocker für sich entscheiden ${ }^{1154}$. Wie die vereinzelten Teilerfolge der „Werbeindustrie“ bei den

1153 Vgl. nur das jüngste Beispiel der Schadensersatzklagen gegen Monsanto bzw. Bayer, https:/www.tagesspiegel.de/wirtschaft/dritte-niederlage-in-glyphosat-p rozess-us-jury-verurteilt-bayer-zu-milliardenzahlung/24337578.html, zuletzt abgerufen am 31.5.2019.

1154 BGH, Urteil vom 19.4.2018 - I ZR 154/16, WRP 2018, 1322 - Werbeblocker II. 
technischen Schutzmaßnahmen ${ }^{1155}$ und beim Overblocking ${ }^{1156}$ aber zeigen, hat sich eine differenzierte Rechtslage entwickelt, die eine fortwährende Koexistenz ermöglichen.

1155 LG Hamburg, Urteil vom 3.12.2015 - 308 O 375/15, ZUM 2016, 892; Urteil vom 21.12.2016 - 310 O 129/16, juris.

1156 LG Hamburg, Urteil vom 26.9.2016, 308 O 244/16 (unveröffentlicht); a.A. in dieser Arbeit, siehe oben Ziffer D. I. 6.. 


\section{G. Thesen zum Abschluss}

Abschließend werden die folgenden Thesen als Fazit dieser Arbeit festgehalten:

1. Werbung im Internet ist zu großen Teilen rechtlich nicht zu beanstanden. Allerdings gibt es bestimmte Werbeformen, die die Aufmerksamkeit des Nutzers aggressiv erzwingen. Dies ist der Fall bei Pop-ups, Pre-Rolls oder Interstitials - also der Ausgestaltungen von Unterbrechungs- und Störungswerbung im Zeitalter des Internets. Diese Werbeformen bedürfen einer besonderen rechtlichen Beurteilung und können durchaus eine unzumutbare Belästigung nach $\$ 7$ UWG darstellen ${ }^{1157}$. Dabei sind im Rahmen der Generalklausel in $\$ 7$ UWG drei essentielle Regeln zu beachten, die für alle aktuell gebräuchlichen Display-Anzeigen eine interessengerechte Lösung bieten.

- Regel 1: Einfache Anzeigen, die in die Webseite eingefasst sind und nur einen Teil des Fensters beanspruchen, sind zulässig. Das Interesse des Nutzers, nicht mit Werbung konfrontiert zu werden, wird von den Interessen der Webseitenbetreiber und der Werbenden eindeutig überwogen.

- Regel 2: Werbung, die auf das Prinzip Störung setzt, ist grundsätzlich zulässig. Sie wird aber dann zur unzumutbaren Belästigung, sobald die Freiheit des Nutzers, sich der aufgedrängten Werbung zu entziehen, beschränkt wird. Die Interessen der Nutzer sind vor allem vor dem Hintergrund zeitlicher Bindung an aufgedrängte Inhalte zu schützen. Die an sich berechtigte und notwendige Refinanzierung der kostenfreien Inhalte durch die Webseitenbetreiber darf nicht um den Preis des faktischen Zwangs erreicht werden. Auch ist für einzelne Internetportale eine den Nutzer potentiell unzumutbar belästigende Summenwirkung von Zwangswerbung zu beachten.

- Regel 3: Je wertvoller der Content ist, desto höher ist das hehre Refinanzierungsinteresse. Bei der Zurverfügungstellung von Videos, Spielen und besonderen Plattformen ist dem Betreiber spiegelbildlich zu seiner besonderen Leistung, die Schaltung von länger andauernder und im Vordergrund stehender Werbung gestattet. Dies

1157 Siehe hierzu die Einzelheiten unter Ziffer B. IV. 1.. 
darf aber lediglich dazu führen, dass zeitintensive Werbeformen wie Pre-Roll-Videos nur für eine kurze Zeit verpflichtend sind und dann durch einfachen Klick beendet werden können. In keinem Fall darf der Werbende oder Webseitenbetreiber die zeitliche Bindung einseitig derart festlegen, dass der Nutzer für eine erhebliche Zeit die Werbung rezipieren muss.

2. Contentwerbung ist eine Werbeform, die von den meisten Werbeblockern nicht erreicht wird. Mit dieser Werbeform gehen aber andere Probleme einher, die ein erhöhtes Konfliktpotential aufweisen, z.B. Influencer-Marketing ${ }^{1158}$.

Im Übrigen wird zur Vermeidung von Wiederholungen auf die oben beschriebenen zusammenfassenden Thesen zum Werbemarkt in Ziffer B. V. verwiesen.

3. Internetwerbeblocker sind zulässige Werkzeuge der Nutzer. Sie können weder auf lauterkeitsrechtlicher, noch auf urheberrechtlicher, noch auf kartellrechtlicher Grundlage ${ }^{1159}$ verboten werden. Die zugrundelegenden Erwägungen werden oben in Ziffer C. I. 4. Ausführlich dargelegt; eine Zusammenfassung ist in Ziffer C. I. 4. a) dd) zu finden.

4. Nicht nur für Webseitenbetreiber gilt: wer sein Angebot im Internet schützt, der wird durch das Recht geschützt. Wer dies unterlässt, bewegt sich in unsicheren Gefilden und muss invasives Wettbewerbshandeln dulden. Insoweit sind die folgenden Leitlinien für disruptive Geschäftsmodelle im Internet folgern ${ }^{1160}$ :

- Vertragliche Bedingungen im Verhältnis Nutzer und Leistungsanbieter wirken als Schutzmaßnahme und dürfen durch Leistungen, Anwendungen oder Produkte Dritter nicht unterwandert werden.

- Technische Schutzmaßnahmen, selbst wenn sie leicht zu umgehen sind, müssen respektiert werden. Die Umgehung von technischen Schutzmaßnahmen führt wohl im Regelfall zur Annahme einer gezielten Behinderung des umgehenden Geschäftsmodells.

- Wenn Leistungen hingegen schutzlos angeboten werden und für jedermann frei verfügbar sind, sind eigene darauf aufbauende wettbewerbliche Leistungen regelmäßig nicht zu beanstanden.

1158 Siehe hierzu Ziffer B. I. 3. a) bb) (vi) und B. IV. 3.

1159 Dies gilt zumindest aktuell und mag zu überdenken sein, wenn Werbeblockeranbieter marktbeherrschend im Sinne des GWB sind.

1160 Siehe auch Ziffer C. I. 4. e). 
- In Dreipersonenverhältnissen wie bei Werbeblockern kommt der Nutzerautonomie eine herausragende Stellung zu, da ohne den Einsatz durch den Nutzer keine Verletzung eintreten würde. Die Nutzerautonomie kann hingegen nicht die zuvor beschriebene Umgehung von technischen oder vertraglichen Schutzmechanismen rechtfertigen.

- Grundrechte schützen Leistungsanbieter nicht vor innovativem Wettbewerb. Insbesondere können sie nicht den Schutz eines zuvor praktizierten Geschäftsmodells bewirken, wenn keinerlei Anstrengung zum Schutz des Geschäftsmodells durch bekannte technische oder vertragliche Schutzmaßnahmen zu erkennen ist.

5. Kommerzielles Whitelisting mag auf den ersten Blick ethisch unvertretbar sein. Bei Analyse der technischen und wirtschaftlichen Vorgänge ist kommerzielles Whitelisting allerdings ein akzeptabler Interessenausgleich von Refinanzierungs- und Gewinninteressen ${ }^{1161}$.

6. Eine gesetzliche Regulierung von Werbeblockern ist nicht geboten ${ }^{1162}$. Ein gesetzliches Verbot von Werbeblockern wäre eindeutige Klientelpolitik zugunsten der Wirtschaft, das die greifbaren Interessen von Verbrauchern bewusst ignorieren würde.

7. Webseitenbetreibern steht es zu, den Zugang für Nutzer mit aktiviertem Werbeblocker zu sperren. Diese Sperren dürfen von Werbeblockeranbietern oder deren Sympathisanten nicht derart umgangen werden, dass sie Umgehungslösungen verbreiten ${ }^{1163}$.

8. Die Schaltung von Zwangswerbung, die auch Nutzern mit aktiviertem Werbeblocker unblockierbare Anzeigen ausspielt, ist lauterkeitsrechtlich unzulässig 1164 .

9. Deutschland war vor allem wegen der Besonderheiten der Rechtslage und der Ansässigkeit des Betreibers von Adblock Plus der Hauptort des Kampfs zwischen „Werbeindustrie“ und Werbeblockern. In anderen Ländern haben keine vergleichbaren Streitigkeiten stattgefunden. Damit ist auch zukünftig nicht zu rechnen ${ }^{1165}$.

10. Das deutsche bzw. europäisch geprägte Lauterkeitsrecht ist schon im aktuellen Stand geeignet, innovative disruptive Geschäftsmodelle, wie

1161 Siehe zu den tatsächlichen Grundlagen Ziffer C. I. 2. und zur rechtlichen Bewertung Ziffer C. I. 4..

1162 Siehe zu den Bestrebungen in der Politik Ziffer C. I. 7. und zur Stellungnahme Ziffer C I. 7. c).

1163 Siehe hierzu Ziffer D. II. $1 .$.

1164 Siehe hierzu Ziffer D. II. 2 ..

1165 Siehe hierzu die Ausführungen unter F.. 
etwa ein Werbeblocker mit kommerzieller Whitelistfunktion, rechtlich differenzierend zu bewerten. Wie die Vielzahl von Rechtsprechungsfundstellen im Kontext der Internetwerbeblocker zeigt, ist eine einzelfall- und interessengerechte Bewertung von neuartigen Fällen durch die generalklauselartigen Normen des Lauterkeitsrechts möglich. 


\section{Literaturverzeichnis}

Abrahamsen, Jon T.: Adblockers, Convenience or Trespass? Click here to find out!, Journal of Law, Technology \& Policy Vol. 2017, 477.

Ablberg, Hartwig/Götting, Horst-Peter (Hrsg.): BeckOK Urheberrecht, 22. Edition (Stand 15.10.2018), München, 2018 (abgekürzt: Bearbeiter, in: BeckOK UrhR, $\$ x$, Rn. $x)$.

Abrens, Hans-Jürgen: Influencer Marketing - Regulierungsrahmen und Konsequenzen seiner Anwendung (Teil 1), GRUR 2018, 1211.

Alexander, Christian: Anmerkung zu OLG Köln, Urteil vom 24.6.2016 - 6 U 149/15, GRUR 2016, 1089.

Alexander, Christian: Anmerkung zu OLG München, Urteil vom 17.8.2017 - U 2225/15 Kart, GRUR 2017, 1156.

Alexander, Christian: Werbeblocker und Medienfinanzierung, NJW 2018, 3620.

Auer-Reinsdorff, Astrid/Conrad, Isabell (Hrsg.): Handbuch IT- und Datenschutzrecht, 2. Auflage, München, 2016 (abgekürzt: Bearbeiter, in: Auer-Reinsdorff/Conrad, $\mathbb{S}$ $x$, Rn. $x$ ).

Bamberger, Heinz Georg; Roth, Herbert; Hau, Wolfgang; Poseck, Roman (Hrsg.): BeckOK BGB, 50. Edition (Stand 1.5.2019), München 2019 (abgekürzt: Bearbeiter, in: BeckOK BGB, $\mathbb{} x$, Rn. $x$ ).

Barbacovi, Tyler: Blocking Ad Blockers, 16th John Marshall Review of Intellectual Property Law, 2017, 272.

Barth, Günter: Wettbewerbsrechtliche Abmahnung von Verstößen gegen das neue Datenschutzrecht, WRP 2018, 790.

Barth, Günter: Kommentar zu BGH, Urteil vom 8.10.2019 - KZR 73/17, WRP 2019, 1578.

Baumgartner, Ulrich/Sitte, Konstantin: Abmahnungen von DS-GVO-Verstößen - Angekündigte Abmahnwelle wird wohl ausbleiben, ZD 2018, 555.

Beater, Axel: Die Finanzierung von Print- und privaten Telemedien aus rechtlicher Sicht, AfP 2017, 277.

Bechtold, Rainer/Bosch, Wolfgang: Gesetz gegen Wettbewerbsbeschränkungen, Kommentar, 9. Auflage, München, 2018.

Bechtolf, Hans Leo/Vogt, Niklas: Zur Zulässigkeit von AdBlock-Detektoren vor dem Hintergrund der E-Privacy-Richtlinie, K\&R 2016, 445.

Becker, Maximilian/Becker, Felix: Zur rechtlichen Zulässigkeit von AdBlockern, GRURPrax, 2015, 245.

Bettinger, Torsten/Leistner, Matthias (Hrsg.): Werbung und Vertrieb im Internet, Köln, 2003.

Boehme-Neßler, Volker: Das Ende der Anonymität - Wie Big Data das Datenschutzrecht verändert, DuD 2016, 419. 
Bornkamm, Joachim/Seichter, Dirk: Das Internet im Spiegel des UWG - Grenzwerte für die lautere Nutzung eines neuen Mediums, CR 2005, 747.

Brüggemann, Christina Julia: Die rechtliche Zulässigkeit von OnlineWerbeblockern unter besonderer Berücksichtigung der Pressefreiheit, Münster, Univ., Diss., 2018.

Burmeister, Julian: Belästigung als Wettbewerbsverstoß, München, Univ., Diss., 2006.

Büscher, Wolfgang: Neuere Entwicklungen im wettbewerbsrechtlichen Leistungsschutz, GRUR 2018, 1.

Czernik Ilja: Anmerkung zu KG, Urteil vom 18.10.2013 - 5 U 138/12, MMR 2014, 45.

Deutsch, Askan: Kein Wettbewerbsverstoß durch Werbeblocker, GRURPrax 2015, 357.

Dreier, Thomas/Schulze, Gernot/Specht, Louisa: Urheberrechtsgesetz - Verwertungsgesellschaftengesetz - Kunsturhebergesetz - Kommentar, 6. Auflage, München, 2018 (abgekürzt: Dreier/Schulze, UrhG, $\mathbb{S} x, \mathrm{Rn} . x$ ).

Dreyer, Gunda/Kotthoff, Jost/Meckel, Astrid/Hentsch, Christian-Henner: Urheberrecht - Urheberrechtsgesetz, Verwaltungsgesellschaftengesetz, Kunsturhebergesetz, 4. Auflage, Heidelberg, 2018 (abgekürzt: Bearbeiter, in: Dreyer/Kotthoff/Meckel/ Hentsch, UrhG, $\mathbb{S} x, \mathrm{Rn} . x$ ).

Engels, Stefan: AdBlocker auf dem Prüfstand, GRURPrax 2015, 338.

di Fabio, Udo: Werbeblocker im Lichte des Verfassungsrechts - Kollidierende Privatrechtsinteressen bei der Verwendung digitaler Werbeblocker, MMR-Beilage 2016, 1.

Fezer, Karl-Heinz/Büscher, Wolfgang/Obergfell, Eva Inés: Kommentar zum Gesetz gegen den unlauteren Wettbewerb, 3. Auflage, München, 2016 (abgekürzt: Bearbeiter, in: Fezer/Büscher/Obergfell, UWG, $\left.\mathbb{\int} x, \mathrm{Rn} . x\right)$.

Fritzsche, Jörg: Kommentar zu OLG Köln, Urteil vom 24.6.2016 - 6 U 149/15, WRP 2016, 1036.

Fritzsche, Jörg: Aggressive Geschäftspraktiken nach dem neuen $\ 4$ a UWG, WRP 2016, 1.

Fritzsche, Jörg: Überlegungen zum Referentenentwurf eines Zweiten Gesetzes zur Änderung des UWG, WRP 2014, 1392.

Fritzsche, Jörg: Anmerkung zu BGH, Urteil vom 24.6.2004 - I ZR 26/02, LMK 2004, 193.

Frosch-Wilke, Dirk/Raith, Christian (Hrsg.): Marketing-Kommunikation im Internet - Theorie, Methoden und Praxisbeispiele vom One-to-One bis zum Viral-Marketing, Braunschweig/Wiesbaden, 2002.

Fuchs, Thomas/Hahn, Caroline: Erkennbarkeit und Kennzeichnung von Werbung im Internet - Rechtliche Einordnung und Vorschläge für Werbefragen in sozialen Medien, MMR 2016, 503.

Gerecke, Martin: Kennzeichnung von werblichen Beiträgen im Online-Marketing, GRUR 2018, 153. 
Gersdorf, Hubertus/Paal, Boris (Hrsg.): BeckOK Informations- und Medienrecht, 23. Edition, Stand: 1.2.2019, München (abgekürzt: BeckOK InfoMedienR/Bearbeiter, Gesetz, $\mathbb{x} x$ Rn. $x)$.

Gierschmann, Sibylle: Positionsbestimmung der DSK zur Anwendbarkeit des TMG - Ist ein deutscher Sonderweg wirklich die Lösung?, ZD 2018, 297.

Glöckner, Jochen: Lauterkeitsrechtlicher Schutz von Geschäftsmodellen auf mehrseitigen Märkten - zugleich Anmerkung zu BGH, Urt. v. 19.4.2018 - I ZR 154/16 Werbeblocker II, ZUM 2018, 844.

Gola, Peter (Hrsg.): Datenschutzgrundverordnung VO (EU) 2016/679 - Kommentar, München, 2017 (abgekürzt: Bearbeiter, in: Gola, DSGVO, Art. $x$, Rn. $x$ ).

Gomille, Christian: Die Verteidigung gegen unerwünschte Werbung, GRUR 2017, 241.

Götting, Horst-Peter/Nordemann, Axel (Hrsg.): UWG - Handkommentar, 3. Auflage, Baden-Baden, 2016 (abgekürzt: Bearbeiter, in: Götting/Nordemann, UWG, $\mathbb{S}$, Rn. $x)$.

Grünig, Karla-Maria: Die Urheberrechtliche Einordnung von Websites unter Berücksichtigung der französischen Diskussion von Multimediawerken, Hamburg, Univ., Diss., 2008.

Grünwald, Andreas/Nüßing, Christoph: Machine To Machine (M2M)-Kommunikation - Regulatorische Fragen bei der Kommunikation im Internet der Dinge, MMR 2015, 378.

Hansen, Hauke: Werbeblocker mit kostenpflichtiger „Whitelist“-Funktion ist wettbewerbswidrig, GRUR-Prax 2016, 338.

Harte-Bavendamm, Henning/Henning-Bodewig, Frauke (Hrsg.): Gesetz gegen den unlauteren Wettbewerb, Kommentar, 4. Auflage, München, 2016 (abgekürzt: Bearbeiter, in: Harte-Bavendamm/Henning-Bodewig, UWG, $\mathbb{S} x$, Rn. $x$ ).

Härting, Niko: Internetrecht, 6. Auflage, Köln, 2017.

Härting, Niko: Datenschutz-Grundverordnung, 1. Auflage, Köln, 2016.

Hass, Berthold/Willbrandt, Klaus: Targeting von Online-Werbung - Grundlagen, Formen und Herausforderungen, Medienwirtschaft 2011, 12.

Hauck, Ronny: „Erzwungene“ Lizenzverträge - Kartellrechtliche Grenzen der Durchsetzung standardessenzieller Patente, NJW 2015, 2767.

Heermann, Peter W./Schlingloff, Jochen (Hrsg.): Münchener Kommentar zum Lauterkeitsrecht, 2. Auflage, München, 2014 (abgekürzt: Bearbeiter, in: MüKo Lauterkeitsrecht, $\mathbb{S} x, \operatorname{Rn} . x)$.

Herrmann, Volker/Lauotoumai, Sebastian: Wettbewerbsrechtliche Zulässigkeit von Internet-Werbeblockern, IPRB 2014, 272.

Herrmann, Volker/Schwarz, Christian: Riegel vor: Im Internet ohne Werbung surfen?, K\&R 2015, 622.

Henning-Bodewig, Frauke: Influencer-Marketing - der "Wilde Westen des Werbens"?, WRP 2017, 1415.

Hoche, Angelika/Polly, Julia: Werbeblocker auf dem Prüfstand - "Adblock Plus": Legitimes Geschätsmodell oder "Schutzgelderpressung", IPRB 2015, 231. 
Hoene, Verena: Neue Werbeformen - Native Advertising, IPRB 2016, 59.

Hoeren, Thomas/Sieber, Ulrich/Holznagel, Bernd (Hrsg.): Handbuch MultimediaRecht - Rechtsfragen des elektronischen Geschäftsverkehrs, Loseblattsammlung Stand: Juli 2017, München (abgekürzt: Bearbeiter, in: Hoeren/Sieber/Holznagel, Multimedia-Recht, Teil $x$, Rn. $x$ ).

Hoeren, Thomas: Virenscanning und Spamfilter - Rechtliche Möglichkeiten im Kampf gegen Viren, Spams \& Co., NJW 2004, 3513.

Hoeren, Thomas: Kurzkommentar zu BGH, Urteil vom 24.6.2004 - I ZR 26/02, EWiR 2004, 1193.

Hoeren, Thomas: Werberechtliche Grenzen des Einsatzes von Adblockern - am Beispiel von "Adblock Plus", K\&R 2013, 757.

Hoeren, Thomas/Brandenburg, Jan: Anmerkung zu BGH, Urteil vom 19.4.2018 - I ZR 154/16, MMR 2018, 821.

Holland, Heinrich: Dialogmarketing - Offline- und Online-Marketing, Mobile- und Social Media-Marketing, 4. Auflage, München, 2016.

Jandt, Silke: Spezifischer Datenschutz für Telemedien und die DS-GVO - Zwischen Rechtssetzung und Rechtsanwendung, ZD 2018, 405.

Immenga, Ulrich/Mestmäcker, Ernst-Joachim/Körber, Torsten (Hrsg.): Wettbewerbsrecht, 5. Auflage, München, 2014 (abgekürzt: Bearbeiter, in: Immenga/Mestmäcker, Wettbewerbsrecht, $\mathbb{\S} x, \mathrm{Rn} . x)$.

Ingerl, Reinhard/Rohnke, Christian: Markengesetz, 3. Aufl., München, 2010.

Jacob, Michael: Integriertes Online-Marketing - Strategie, Taktik und Implementierung, Wiesbaden, 2015.

Kaiser, Mathias: Briefkastenwerbung durch Postwurfsendungen trotz Sperrvermerks, NJW 1991, 2870.

Kammerzelt, Helmut/ Wimmer, Harald (Hrsg.): Online Marketing; Grundlagen Planung - Durchführung - Messung, Baden-Baden, 2016.

Kellenter, Wolfgang/Verhauwen, Axel: Systematik und Anwendung des kartellrechtlichen Zwangslizenzeinwands nach „Huawei/ZTE“ und „Orange-Book“, GRUR 2018, 761.

Kiersch, Philipp/ Kassel, Patrik: Anti-Adblock-Sperren als wirksame technische Maßnahmen gem. \$95a UrhG, CR 2017, 242.

Kiersch, Philipp: Adblocking im Internet und seine lauterkeitsrechtliche Bewertung, Köln, Univ., Diss., 2018.

Kiersch, Philipp: Disruptive Geschäftsmodelle im Internet nach der BGH-Entscheidung „Werbeblocker II“, GRUR-Prax 2018, 487.

Keßler, Esther/ Rabsch, Stefan/ Mandic, Mirko: Erfolgreiche Websites - SEO, SEM, Online-Marketing, Usability, 3. Auflage, Bonn, 2015.

Köhler, Helmut/Bornkamm, Joachim/ Feddersen, Jörn: Gesetz gegen den unlauteren Wettbewerb, 37. Auflage, München, 2019 (abgekürzt Köhler/Bornkamm/Feddersen, UWG, $\mathbb{} x, \mathrm{Rn} . x)$..

Köhler, Helmut: Internet-Werbeblocker als Geschäftsmodell, WRP 2014, 1017. 
Köhler, Helmut: Der Regierungsentwurf zur UWG-Novelle 2015: Nur Klarstellungen oder doch tiefgreifende Änderungen?, WRP 2015, 275.

Köhler, Helmut: Funktion und Anwendungsbereich des Mitbewerberbegriffs im UWG - Zugleich Besprechung der Entscheidung „Werbeblocker II“ des BGH, GRUR 2019, 123.

Köhler, Helmut: Die DS-GVO - eine neue Einnahmequelle für gewerbsmäßige Abmahner?, ZD 2018, 337.

Köhler, Helmut: Durchsetzung der DS-GVO mittels UWG und UKlaG?, WRP 2018, 1269.

Köhler, Markus: Der Schutz von Websites gemäß \$\$ 87 a ff. UrhG, ZUM 1999, 548.

Kreutz, Oliver: Online-Angebote und Werbeblockersoftware - Eine lauterkeits- und zivilrechtliche Untersuchung unter besonderer Berücksichtigung der rechtlich zulässigen und technisch möglichen Handlungsalternativen der Webseitenbetreiber, Göttingen, Univ., Diss., 2017.

Kreutz, Oliver: Technische Umgehung von Werbeblocker-Software durch Webseitenbetreiber - Rechtlich zulässige Abwehrreaktion oder wettbewerbsrechtlich bedenkliche Nutzerbevormundung?, MMR 2016, 364.

Kreutz, Oliver: Kommentar zu OLG Hamburg, Urteil vom 15.3.2018 - 5 U 152/15, WRP 2018, 621.

Kreutzer, Till: Werbeblocker und Urheberrecht - Urheberrechtliche Zulässigkeit der Verwendung und des Vertriebs von Adblockern, MMR 2018, 639.

Krüger, Christof: Adblock Plus - ein "Verleger-Sargnagel"?, GRUR-Prax 2016, 322.

Kuhlmann, Simone: Regulierungspflicht von Adblockern?, AfP 2016, 318.

Lammenett, Erwin: Praxiswissen Online Marketing - Affiliate- und E-Mail-Marketing, Suchmaschinenmarketing, Online-Werbung, Social Media, Facebook-Werbung, 6. Auflage, Wiesbaden, 2017.

Laoutoumai,Sebastian/Dabmen, Anna: Influencer Marketing - Neue Stars, alte Pflichten?!, K\&R 2017, 29.

Laoutoumai, Sebastian/Hoppe, Adrian: Setzt die DSGVO das UWG Schachmatt? Können Datenschutzverstöße auch weiterhin über das Recht des unlauteren Wettbewerbs verfolgt werden?, K\&R 2018, 533.

Lehmann, Philipp: Lauterkeitsrechtliche Risiken beim Influencer Marketing, WRP 2017, 772.

Leible, Stefan: Internet-Werbung (Online-Werbung), Festschrift für Helmut Köhler zum 70. Geburtstag, München, 2014 (abgekürzt: Leible, in: FS Köhler, S. $x$ ).

Lempe, Markus: Der Konflikt zwischen dem Vertrieb von Werbeblockern und der Werbefinanzierung elektronischer Medien, unter besonderer Berücksichtigung der Rundfunkordnung, des allgemeinen Persönlichkeitsrechts und der negativen Informationsfreiheit, Baden-Baden, 2006; zugl. Chemnitz, Univ., Diss., 2005.

Leupold, Andreas/Bräutigam, Peter/Pfeiffer, Markus: Von der Werbung zur kommerziellen Kommunikation - die Vermarkung von Waren und Dienstleistungen im Internet, WRP 2000, 575. 
Lettmann, Sabine: Schleichwerbung durch Influencer Marketing - Das Erscheinungsbild der Influencer; GRUR 2018, 1206.

Libertus, Michael: Rechtliche Aspekte des Einsatzes von Social Bots de lege lata und de lege ferenda, ZUM 2018, 20.

Lichtnecker, Florian: Die Werbung in sozialen Netzwerken und mögliche hierbei auftretende Probleme, GRUR 2013, 135.

Lober, Andreas: Spielend werben: Rechtliche Rahmenbedingungen des Ingame-Advertising, MMR 2006, 643.

Loschelder, Michael/Erdmann, Willi (Hrsg.): Handbuch des Wettbewerbsrechts, 4. Auflage, München, 2010 (abgekürzt: Bearbeiter, in: Gloy/Loschelder/Erdmann, $\mathbb{S}$ $x$, Rn. $x)$.

Loewenheim, Ulrich/Leistner, Matthias/Ohly, Ansgar (Hrsg.): Urheberrecht, 5. Auflage, München, 2017 (abgekürzt: Bearbeiter, in: Schricker/Loewenheim, UrhG, $\mathbb{S} x$, Rn. $x$ ).

Luckhaus, Ulrich: Keine Werbung bitte - zur Zulässigkeit von Werbeblockern, K\&R 2016, 313.

Luckhaus, Ulrich: Anmerkung zu LG Berlin v. 8.12.2015 - 16 O 449/15, IPRB 2016, 103.

Luckhaus, Ulrich: Anmerkung zu OLG München, Urteil vom 17.8.2017 - U 2225/15 Kart, MMR 2017, 756.

Mallick, Rani/Weller, David: Aktuelle Entwicklungen im Influencer Marketing Ein Blick aus der Praxis, WRP 2018, 155.

Marly, Jochen: Der Schutzgegenstand des urheberrechtlichen Softwareschutzes Zugleich Besprechung zu EuGH, Urt. v. 2. 5. 2012 - C-406/10 - SAS Institute, GRUR 2012, 773.

Marly, Jochen: Bildschirmkopien, Cache-Kopien und Streaming als urheberrechtliche Herausforderungen, EuZW 2014, 616.

Miller, Russell J.: Liberation, Not Extortion: The Fate of Internet Ad-Blocking in German and American Law, Washington \& Lee Public Legal Studies Research Paper Series, Accepted Paper No. 2017 - 15, 2017.

Müllejans, Gabi: Werbeblocker sind weiterhin zulässig, GWR 2015, 281.

Musielak, Hans-Joachim/Voit, Wolfgang (Hrsg.): Zivilprozessordnung mit Gerichtsverfassungsgesetz - Kommentar, 16. Auflage, München, 2019.

Nink, Judith: Werbeblocker - Geschäftsmodelle, Detektoren und das Recht; Rechtliche Aspekte aus Anbieterperspektive, CR 2017, 103.

Ohly, Ansgar/Sosnitza, Olaf: Gesetz gegen den unlauteren Wettbewerb mit Preisangabenverordnung, Kommentar, 7. Auflage, München, 2016 (abgekürzt: Ohly/Sosnita, UWG, $\mathbb{S} x$, Rn. $x$ ).

Paal, Boris P./Pauly, Daniel A. (Hrsg.): Datenschutzgrundverordnung, 2017, München (abgekürzt: Bearbeiter, in: Paal/Pauly, DSGVO, Art. $x$, Rn. $x$ ).

Palme, Inga: Facebook-Marketing, Bonn, 2015.

Peifer, Karl-Nikolaus: Wer ist Herr im Haus? - Adblocker, Framing, Linking und Signalintegritätsschutz, AfP 2016, 5. 
Peifer, Karl-Nikolaus: Influencer Marketing - Rechtlicher Rahmen und Regulierungsbedürfnis (Teil 2), GRUR 2018, 1218.

Podszun, Rupprecht/de Toma, Michael: Die Durchsetzung des Datenschutzes durch Verbraucherrecht, Lauterkeitsrecht und Kartellrecht, NJW 2016, 2987.

Podszun, Rupprecht/Schwalbe, Ulrich: Digitale Plattformen und GWB-Novelle: Überzeugende Regeln für die Internetökonomie?, NZKart 2017, 98.

Raithel, Stephanie: Werbeblocker im Internet, 1. Auflage, Berlin, 2017.

Raue, Benjamin: Kommentar zu OLG München, Urteil vom 17.8.2017 - U 2225/15 Kart, WRP 2017, 1363.

Rehart, Nikolaus Konstantin: Anmerkung zu BGH - I ZR 23/15, MMR 2016, 683.

Reinholz, Fabian/Schirmbacher, Martin: Anforderungen an die Kennzeichnung von Influencer-Werbung - Zugleich Kommentar zu OLG Celle, Urteil vom 8. 6. 2017 - 13 U 53/17, K\&R 2017, 753.

Runkel, Kai: Neue Werbeformen - Adblocking; Der Kampf um die Werbeeinahmen im Internet, IPRB 2016, 81.

Säcker, Franz Jürgen/Rixecker, Roland/Oetker, Hartmut/Limperg, Bettina (Hrsg.): Münchener Kommentar zum Bürgerlichen Gesetzbuch, Band 6, 8. Auflage, München 2019 (abgekürzt: Bearbeiter, in: MüKo/BGB, $\mathbb{x} x$, Rn. $x$ ).

Sahni, Diksha: The Ultimate Guide To Mobile Programmatic Media Buying, eBook, verfügbar unter: https://go.applift.com/mobile-programmatic-media -buying-guide.

Schapiro, Leo/Żdanowiecki, Konrad: Screen Scraping - Rechtlicher Status quo in Zeiten von Big Data, MMR 2015, 497.

Schantz, Peter/Wolff, Heinrich Amadeus: Das neue Datenschutzrecht - DatenschutzGrundverordnung und Bundesdatenschutzgesetz in der Praxis, 2017, München.

Scherer, Inge: Verbraucherentscheidung für Werbeblocker - eine aggressive geschäftliche Handlung der Anbieter?, WRP 2019, 1.

Scherer, Inge: Das Chamäleon der Belästigung - Unterschiedliche Bedeutungen eines Zentralbegriffs des UWG, WRP 2017, 891.

Scherer, Inge: Die Neuregelung der aggressiven geschäftlichen Handlungen in $\$ 4 \mathrm{a}$ UWG, GRUR 2016, 233.

Scherer, Inge: Wohin mit der "Insolvenzmasse"? - Grundsätzliches zum geplanten Wegfall von $₫ 4$ Nr. 1, Nr. 2 UWG $\ 4$ a UWG-RefE, WRP 2015, 148.

Scherer, Inge: Rezeption kommerzieller Kommunikation in sozialen Netzwerken durch minderjährige Nutzer, WRP 2019, 277.

Scheurle, Klaus-Dieter/Mayen, Thomas: Telekommunikationsgesetz - Kommentar, 3. Auflage, München, 2018 (abgekürzt: Bearbeiter, in: Scheurle/Mayen, TKG, $\mathbb{S} x$, Rn. $x)$.

Schleipfer, Stefan: Datenschutzkonformes Webtracking nach Wegfall des TMG Was bringen die DS-GVO und die ePrivacy-Verordnung?, ZD 2017, 460.

Schirmbacher, Martin: Online-Marketing- und Social-Media-Recht - Das umfassende Praxis-Handbuch für alle rechtlichen Fragen im Marketing, 2. Auflage, Frechen, 2017. 
Schirmbacher, Martin: Unzumutbare Belästigung durch Display-Werbung - wann ist nervig auch wettbewerbswidrig? - Zugleich Kommentar zu OLG Nürnberg, Urteil vom 15. 1. 2019 - 3 U 724/18, K\&R 2019, 229.

Schirmbacher, Martin: Online-Marketing nach der DSGVO - ein Annäherungsversuch - Datenschutzrechtliche Anforderungen an E-Mail-Marketing, Tracking und Targeting, ITRB 2016, 274.

Schippel, Robert: Zulässigkeit digitaler Werbeblocker - Zur Sachstandsdiskussion, AfP 2017, 185.

Schreiber, Marlene: Wettbewerbsrechtliche Abmahnung von Konkurrenten wegen Verstößen gegen DS-GVO, GRUR-Prax 2018, 371.

Smith, Thomas M./ Smith, Robert L.: Ökologie, 6. Auflage, München, 2009.

Sobottka, Corinna/Czernik, Ilja: Anmerkung zu OLG Celle - 13 U 53/17, MMR 2017, 769.

Solmecke, Christian/ Kocatepe, Sibel: Recht im Online Marketing - So schützen Sie sich vor Fallstricken und Abmahnungen, Bonn, 2016.

Sosnitza, Olaf: Lauterkeitsrecht gestern, heute und morgen, GRUR 2018, 255.

Spindler, Gerald/Schuster, Fabian (Hrsg.): Recht der elektronischen Medien - Kommentar, 3. Auflage, München, 2015 (abgekürzt: Bearbeiter, in: Spindler/Schuster, $\mathbb{S} x, \operatorname{Rn} . x)$.

Steinmetz, Patrick: Apps im Lauterkeitsrecht - Eine Untersuchung ausgewählter rechtlicher Problemfälle im Zusammenhang mit dem Vertrieb von mobilen Anwendungen, Freiburg, Univ., Diss., 2017.

Suwelack, Felix: Schleichwerbung als Boombranche?, MMR 2017, 661.

Teplitzky, Otto/Peifer, Karl-Nikolaus/Leistner, Matthias (Hrsg.): Großkommentar zum Gesetz gegen den unlauteren Wettbewerb mit Nebengesetzen, 2. Auflage, Berlin, 2013 (abgekürzt: Bearbeiter, in: Teplitzky/Peifer/Leistner, UWG, $\mathbb{S} x$, Rn. $x$ ).

Thomale, Philipp-Christian: Adblocker - und kein Ende?, MMR 2017, 789.

Troge, Thorsten: Herausforderung: Influencer-Marketing, GRUR-Prax 2018, 87.

Ullmann, Eike (Hrsg.): juris Praxis Kommentar UWG - Gesetz gegen den unlauteren Wettbewerb, 3. Auflage, Saarbrücken, 2013 (abgekürzt: Bearbeiter, in: jurisPK-UWG, $\mathbb{S} x$, Rn. $x$ ).

Ullmann, Eike: Anmerkung zu LG Hamburg, Urteil vom 21.4.2015 - 416 HKO 159/14, jurisPR-WettbR 11/2015 Anm. 4,

Ulmer-Eilfort, Constanze/Obergfell, Eva Ines (Hrsg.): Verlagsrecht - Kommentar, München, 2013 (abgekürzt: Bearbeiter, in: Ulmer-Eilfort/Obergfell, Verlagsrecht, Rn. $x$ ).

Vonau, Eva: Unzulässige Influencer-Werbung auf Instagram - Anmerkung zu LG Hagen - 23 O 30/17, GRUR-Prax 2017, 541.

Wandtke, Artur-Axel/Bullinger, Winfried: Praxiskommentar zum Urheberrecht, 4. Auflage, München, 2014 (abgekürzt: Bearbeiter, in: Wandtke/Bullinger, UrhG, $\mathbb{S}$ $x, \mathrm{Rn} . x)$

Weidert, Stefan/Klar, Manuel: Datenschutz und Werbung - gegenwärtige Rechtslage und Änderungen durch die Datenschutz-Grundverordnung, BB 2017, 1858. 
Weingarten, Paul: Werbeformen im Internet - eine wettbewerbsrechtliche Analyse, Wien, 2003; zugl. Wien, Univ., Diss., 2003.

Wiebe, Andreas/Kreutz, Oliver: Native Advertising - Alter Wein in neuen Schläuchen? (Teil 1), WRP 2015, 1053 und (Teil 2), WRP 2015, 1179.

Witte, Andreas: Der Kampf um die Zulässigkeit von Werbeblockern - Eine Bestandsaufnahme mit Ausblick, ITRB 2018, 34.

Wolff, Heinrich Amadeus/Brink, Stefan (Hrsg.): BeckOK Datenschutzrecht, 27. Edition, Stand: 1.2.2019, München (abgekürzt: Bearbeiter, in: BeckOK Datenschutzrecht, Art. $x$, Rn. $x$ ).

Wolf, Heinrich Amadeus: UWG und DS-GVO: Zwei separate Kreise? Qualifizierung von Datenschutzbestimmungen der DS-GVO als Marktverhaltensregelungen i.S.v. \$3a UWG, ZD 2018, 248.

Zenker, Stefan: Werbeblocker "Adblock Plus" keine wettbewerbswidrige Behinderung, GWR 2016, 81.

Ziebarth, Wolfgang: Nutzer von Werbeblockern als Adressaten gezielter Werbung? Eine Untersuchung unter Berücksichtigung von TMG, UWG und dem Entwurf einer e-Privacy Verordnung, VuR 2018, 257.

Ziegelmayer, David: Adblocking - Ein Zankapfel auf dem Weg zum BGH, CR 2017, 668.

Zimprich, Stephan/Jeschke, Fabian: Ad Injections - Zulässiges Geschäftsmodell oder unlauterer Wettbewerb? Rechtliche Überlegungen zur Überblendung oder Ersetzung von Werbeflächen auf Webseiten durch Dritte, MMR 2016, 300. 
